
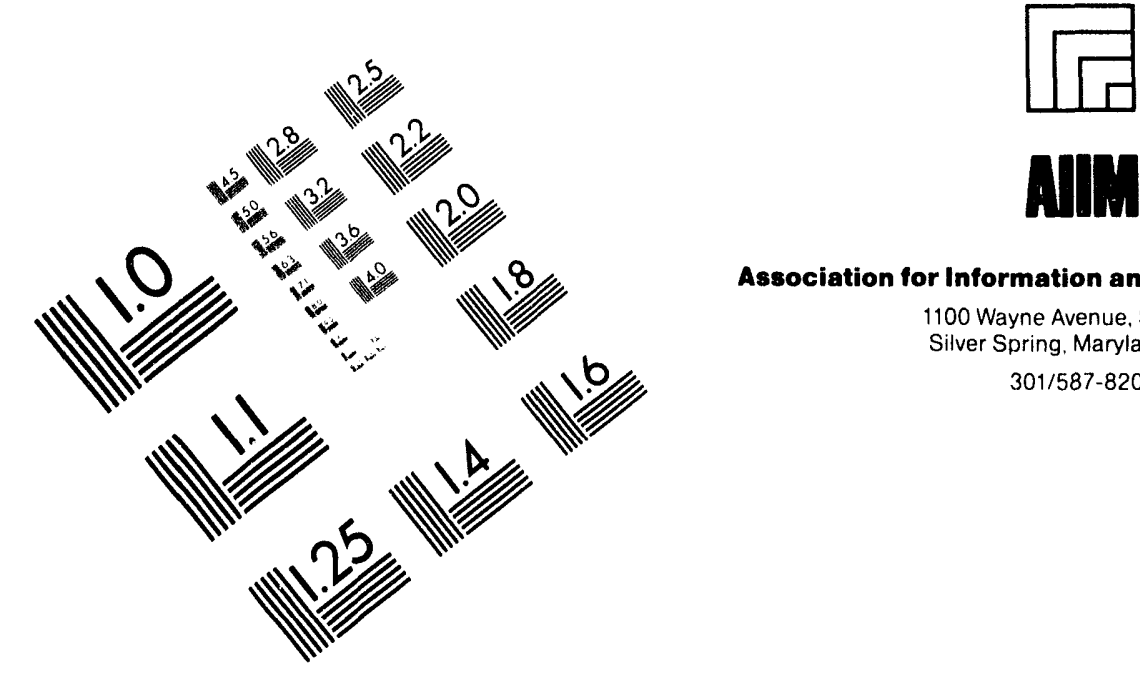

Association for Information and Image Management

1100 Wayne Avenue, Suite 1100

Silver Spring, Maryland 20910

301/587-8202

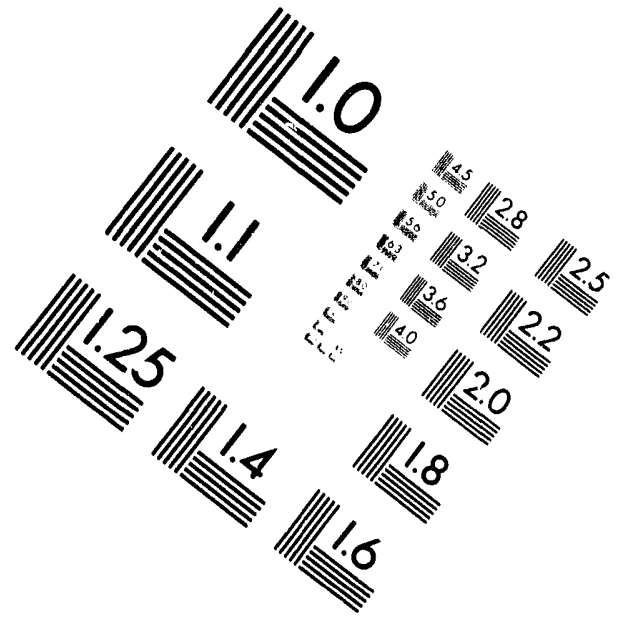

\title{
Centimeter
}

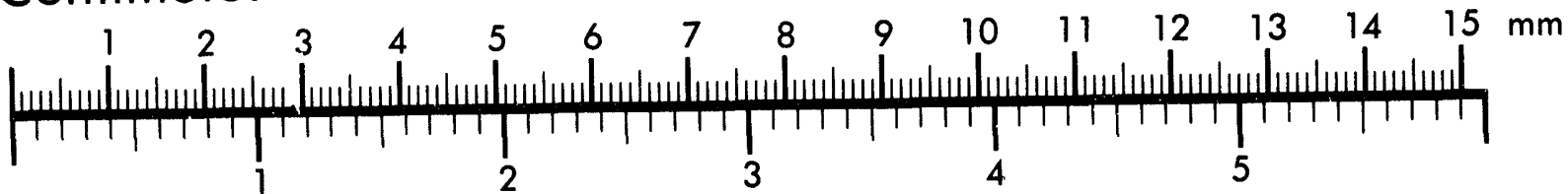
Inches
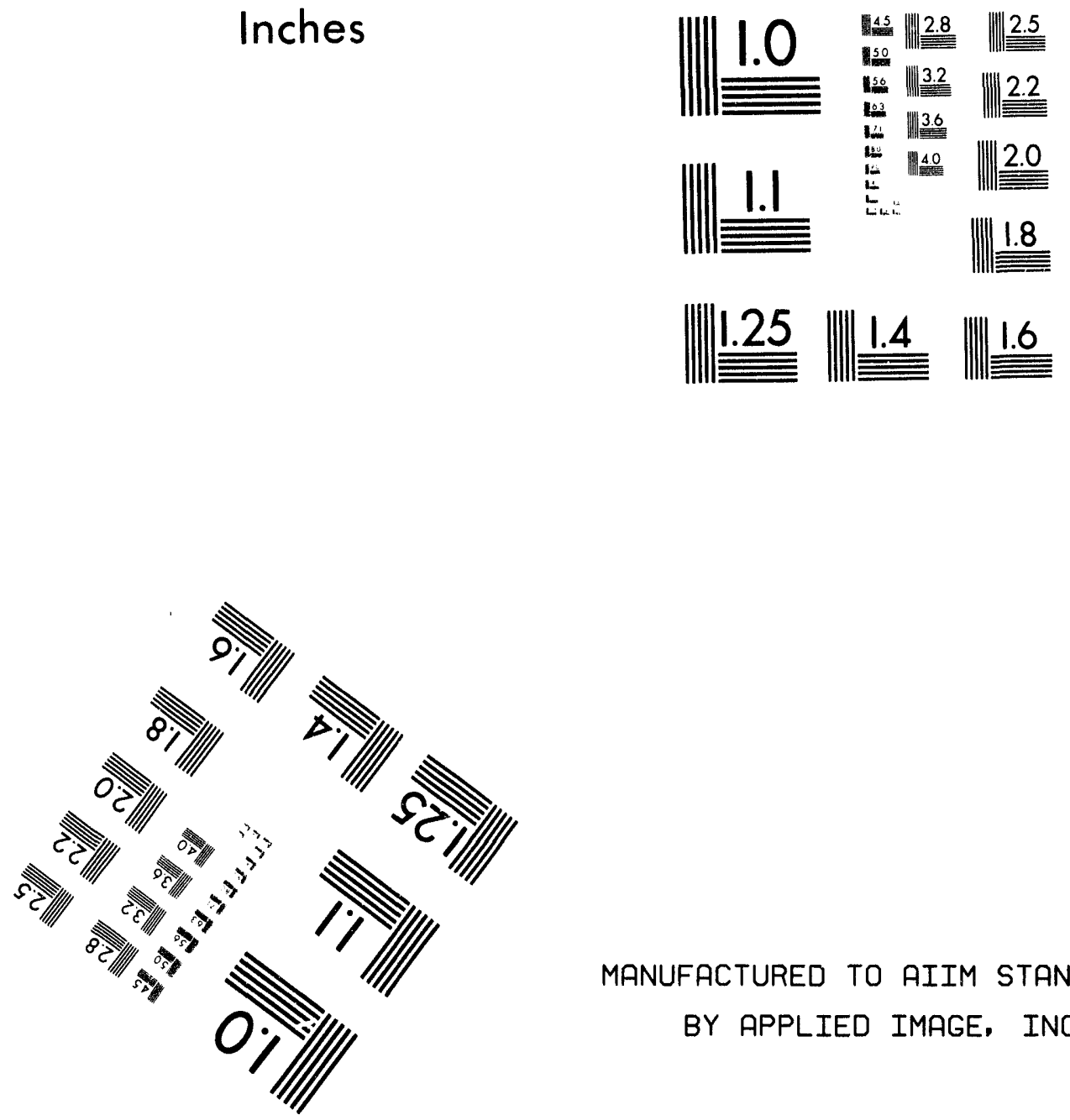

MANUFACTURED TO AIIM STANDARDS

BY APPLIED IMAGE, INC.

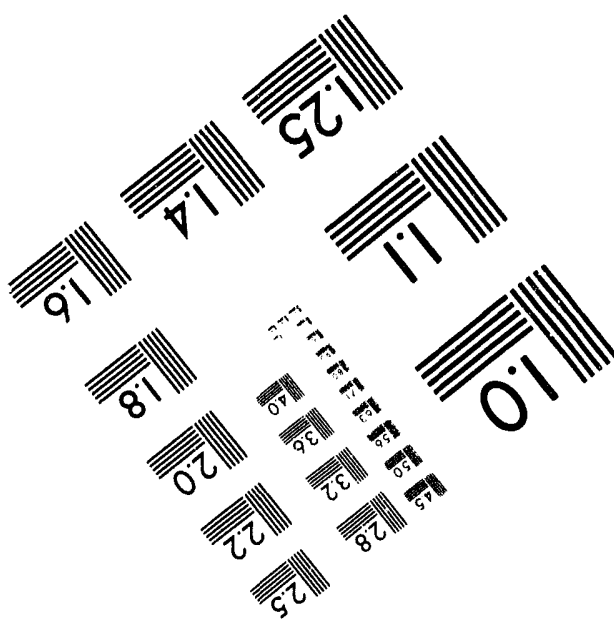



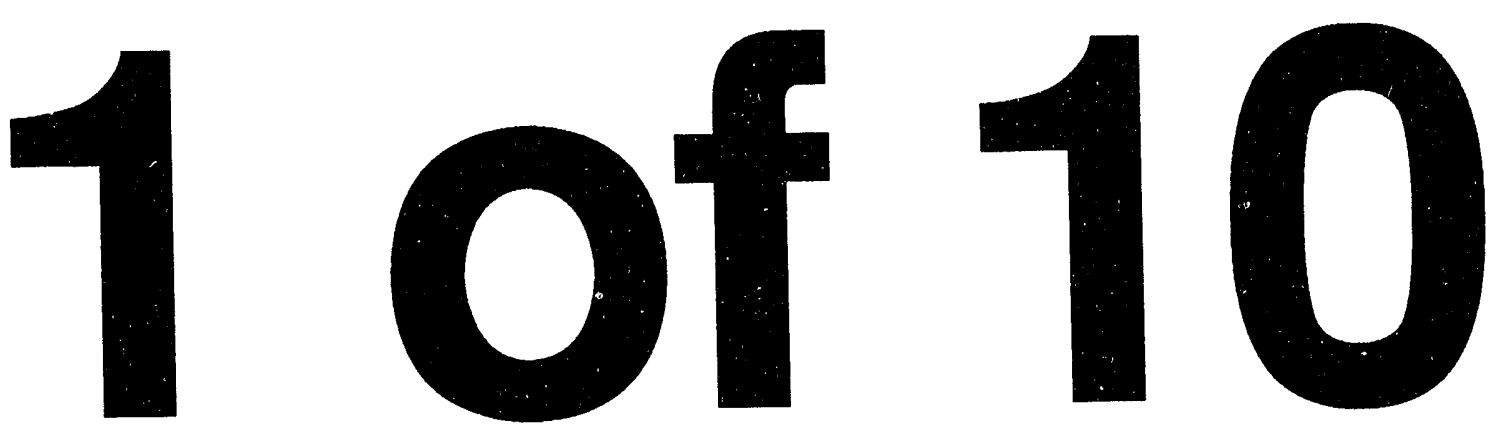


\section{BASIC DATA REPORT - DEFENSE WASTE PROCESSING FACILITY SLUDGE PLANT - SAVANNAH RIVER PLANT 200-S AREA (U)}

by

Amerine, D.B.

Westinghouse Savannah River Company

Savannah River Site

Aiken, South Carolina 29808

A document prepared for DOCUMENT RELEASE REQUEST

WEST VALLEY NUCLEAR SERVICES

DOE Contract No. DE-AC09-89SR18035

This paper was prepared in connection with work done under the above contract number with the U. S.

Department of Energy. By acceptance of this paper, the publisher and/or recipient acknowledges the U. S. Government's right to retain a nonexclusive, royalty-free license in and to any copyright covering this paper, along with the right to reproduce and to authorize others to reproduce all or part of the copyrighted paper. 
DPSP 80-1033

September 1982, Rev 9

Copy

92

TS RECORD GePT:-

BASIC DATA REPORT

DEFENSE WASTE PROCESSING FACILITY

SLUDGE PLANT

SAVANNAH RIVER PLANT 200-S AREA

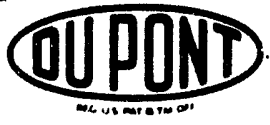

E. I. du Pont de Nemours \& Company

Savannah River Plant 


\section{DISCLAIMER}

This report was prepared as an account of work sponsored by an agency of the United States Government. Neither the United States Government nor any agency thereof, nor any of their employees, makes any warranty, express or implied, or assumes any legal liability or responsibility for the accuracy. completeness, or usefulness of any information, apparatus, product, or process disclosed, or represents that its use would not infringe privately owned rights. Reference herein to any specific commercial product, process, or service by trade name, trademark, manufacturer, or otherwise does not necessarily constitute or imply its endorsement, recommendation, or favoring by the United States Government or any agency thereof. The views and opinions of authors expressed herein do not necessarily state or reflect those of the United States Government or any ageniy thereof.

This report has been reproduced directly from the best available copy.

Available to DOE and DOE contractors from the Office of Scientific and Technical Information. P. O. Box 62, Oak Ridge. TN 37831; prices available from (615) $576-8401$.

Available to the public from the National Technical Information Service, U. S. Deparment of Commerce, 5285 Port Royal Rd., Springfield. VA 22161 
August 10, 1983

TO: PC Record Copy, 703-A

FROM: PUBLICATIONS DIVISION

\title{
DWPF BASIC DATA REPORT REVISIONS
}

You are officially charged with ropy 92 (a QA-controlled document) of this report. To keep your book up-to-date, you are responsible for substituting new items for old items on an item-by-item basis, for deleting the material, and for destroying the old pages. Revision 10 is a complete revision. You should destroy the text in your revision 9.

For Quality Assurance purposes, copies of this Basic Data Report assigned to certain individuals have been designated as controlled copies. To ensure that these documents are maintained in a current status, recipients so designated are requested to sign the attached receipt and return it as soon as the revision has been completed. Please return the receipt to:

$$
\begin{aligned}
& \text { R. M. Shulko } \\
& \text { Savannah River Plant } \\
& \text { Building } 773-28 \mathrm{~A} \\
& \text { Alken, SC } 29808
\end{aligned}
$$

PLEASE NOTE: Revised material in this document is denoted by underscore and double asterisks before and after the material.

\author{
ATTACHENT \\ DPSP $80-1033$ \\ Basic Data Report \\ Defense Waste Processing Fac1lity \\ Sludge Plant, Savamah River Plant 200-S Area \\ Revision 10, 1206 pages \\ (Volume I, $510 \mathrm{pp}$, and volume II, $696 \mathrm{pp}$ )
}

\section{QUALITY ASSURANCE CERTIFICATE}

I certify that I have received Revision 10, Volumes I and II, of the Basic Duta Report, Defense Waste Processing Facility, Sludge Plant, Savannah RIver Plent 200-S Area, DPSP 80-1033.
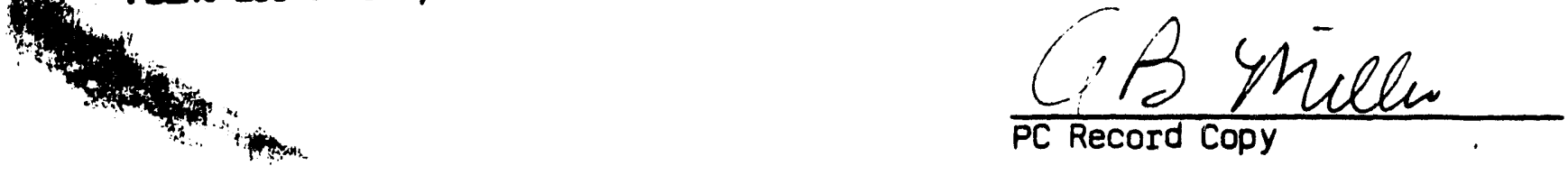
BASIC DATA REPORT

TABLE OF CONTENTS

SUMMARY

LIAISON GROUP

Purpose

Responsibilities

Personne1

WMP-DWPF Liaison Group Design Area

Responsibility List

Correspondence

Communication

OBJECTIVES

Genera1 Project Objectives

Production Capacity

Objective Startup -- Total Facility

SITE CONSIDERATIONS

General Site Requirements

Specific Siting Requirements

- S-Area Faciliries

- Interarea Facilities

Roads, Railroads, Parking, Fencing, etc

History

Geology -- Topography

Geologic Formations Beneath the Savannah

River Plant

Hydrology and Surface Water

Hydrology and Ground Water

Water from the Tuscaloosa Formation

Water from the Ellenton Formation

Water from the McBean and Congaree Formations

Water from the Barnwell Formation

Hydrology of the Chemical Separations Areas

Temperature, Humidity, and Precipitation

Wind

Tornadoes

Seismicity

Radioactivity Contamination History

GENERAL REQUIREMENTS AND SCOPING BASIS

Site - Dismantling and Relocation

Site Preparation by Plant

Anticipated Funding Schedule

Summary Description of Production Processes

Future Expansion Requirements

Security Requirements -- Considerations

Earthquake and Tornado Design Criteria $\frac{\text { Page }}{1}$

Part Item $\begin{gathered}\text { Latest } \\ \text { Revision }\end{gathered}$

1

$1 \quad 100 \quad 5-81$

$1 \quad 110 \quad 9-82$

$1 \quad 120 \quad 9-82$

$1 \quad 130 \quad 9-82$

$1 \quad 140 \quad 9-82$

$1 \quad 160 \quad 9-82$

2

2

2

2

100

9-82

$105 \quad 9-82$

$110 \quad 5-82$

3

3

$100 \quad 6-80$

$120 \quad 9-82$

$130 \quad 11-80$

$140 \quad 9-82$

$200 \quad 6-80$

$205 \quad 6-80$

$210 \quad 6-80$

$300 \quad 6-80$

$302 \quad 6-80$

$305 \quad 6-80$

$310 \quad 6-80$

$315 \quad 6-80$

$320 \quad 6-80$

$325 \quad 1-82$

$400 \quad 6-80$

$420 \quad 6-80$

$450 \quad 6-80$

$500 \quad 6-80$

$900 \quad 9-82$

3

110

5-81

$120 \quad 9-82$

$180 \quad 9-82$

$200 \quad 9-82$

$220 \quad 9-82$

$400 \quad 1-82$

$700 \cdot 9-82$ 
Summary Block Diagram

Interarea Transfer Piping

Pump Pits and Diversion Boxes

Pump Pit and Diversion Box Ventilation

Raw Materials Receipt and Storage Requirements

Cryogenic and Compressed Gas Requirements

Bulk Cold Feed Materials -- Preparation and Handling

Vitrification Building Cold Feed Facilities

Sludge Slurry Receipt, Adjustment, and

Evaporation

Mercury Purification and Storage

Melter Feed

Glass Melting

Off-Gas Treatment

Canister and Overpack Components -- Receipt and Preparation

Canister Handling

Canister Filling

Inner Canister Closure

**Canister Inspection/Glass Removal -- Me1t Ce11**

Canister Decontamination

Canister Smear Test (Decontamination Cell)

Canister Welding - Outer Closure

(Weld Test Ce11)

Canister Weld Repair (Weld Test Cell)

Canister Inspection (Weld Test Cell)

Canister Overpacking

In-Cell Canister Storage

Process Cooling Water

Melter Cooling Water

Process Steam System

Regulated Chilled Water Refrigeration System

Process Vessel Vent System

Cold Feed Tank Vent System

Sump Collection System

Radioactive Contaminated Liquid Wastes

Radioactive Contaminated Solid Wastes

Chemical and Industrial Wastes

INSTRUMENTATION AND PROCESS CONTROL

General Control Requirements

Main Process Cell General Instrument

Requirements

S-Area Process Control

Interarea Transfer Instrumentation and Contro!

Utilities Control

Ventilation Systems Control

$\begin{array}{ll}105 & 9-82 \\ 170 & 9-82 \\ 180 & 9-82 \\ 185 & 1-82 \\ 200 & 9-82 \\ 205 & 1-82\end{array}$

5

5

5

5
5

5 
SAMPLING AND ANALYTICAL CONTROL

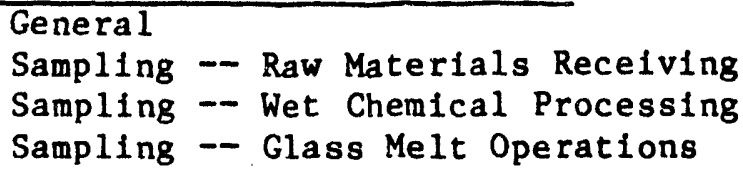

REGULATORY AND ENVIRONMENTAL CONSIDERATIONS

$$
\begin{aligned}
& \text { Licensing } \\
& \text { DWPF Status -- Regulatory } \\
& \text { Construction and Operating } \\
& \text { Radiation Releases -- Gase } \\
& \text { Non-radioactive Plant Ef fl } \\
& \text { Radiation Exposure Limits } \\
& \text { Radiation Contamination L1 } \\
& \text { or Shipment } \\
& \text { * Noise Leve1 Limits** } \\
& \text { Plant Decommissioning }
\end{aligned}
$$$$
\text { DWPF Status -- Regulatory Guldes }
$$$$
\text { Construction and Operating Permits }
$$$$
\text { Radiation Releases -- Gaseous/Aqueous/Solids }
$$$$
\text { Non-radioactive Plant Effluents }
$$$$
\text { Radiation Contamination Limits for Storage }
$$

7

7

7

7

7

8

8

8

8

8

8

8

8

QUALITY ASSURANCE AND PROCESS HAZARDS

QA Assessment Requirements

Basis for Consequence Calculations

PLANT POPULATION

Total Plant Population

100

120

150

200

220

300

350

400

500

$9-82$

$9-82$

9-82

9

9

9

120

140

9-82

$9-82$

10

100

9-82

BUILDING REQUIREMENTS

11

Main Processing Building

Process Building

- General Design Criteria

- Ventilation Requi rements

- Radiation Shielding Requirements

- Elevators -- Stairs

- Clean and Regulated Change Room Requirements

- Lighting

- Floor, Wall, Ceiling Finishes

- Interior, Exterior, and Shielding Doors Administration Building

- General

- Miscellaneous Space Requirements

- Medical Facility

- Cafeteria Requirements

- Offices, Auditorium, and Meeting Room Requi rements

- Heating, Ventilation, and Alr Conditioning

- Maintenance and Services Facilities

- Floor, Wall, Ceiling Finlshes

Gatehouse and Patrol Headquarters

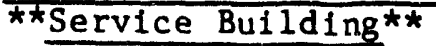

- General Requirements

- Space Requirements

- Heating, Ventilation, and Air Conditioning

- Floor, Wall, Celling Finishes

$11 \quad 330 \quad 9-82$


Glass Waste Interim Storage Building

- General Design Requirements

- Ventilation Requirements

- Maintenance and Access Kequirements

- Furniture, Fixtures, and Auxiliary Equipment

- Radiation Shielding Thickness Requirements

Sand Filter

Fan House For Zone 1 Exhausters

Exhaust Stacks

Fan House For Zone 2 Exhausters

Control Room Space

- General

- Design Criteria

- Space and Services Requirements

Miscellaneous Weather Protection and Control Buildings

HEALTH PROTECTION AND RADIATION MONITORING

(See also: Part 18, Safety - Fire Protection)

Facilities Requirement

Installed Radiation Monitoring Instruments

Installed Air Monitoring Instruments

Installed Liquid Monitoring Instruments

Environmental Monitoring Wells

$\begin{array}{lll}11 & 400 & 9-82 \\ 11 & 405 & 9-82 \\ 11 & 415 & 9-82 \\ 11 & 420 & 9-82 \\ 11 & 425 & 9-82 \\ 11 & 430 & 9-82 \\ 11 & 450 & 9-82 \\ 11 & 470 & 9-82 \\ 11 & 490 & 9-82 \\ 11 & 500 & 9-82 \\ & & \\ 11 & 600 & 5-81 \\ 11 & 605 & 5-81 \\ 11 & 610 & 5-81 \\ & & \\ 11 & 900 & 5-81\end{array}$

12

UTILITIES

Availability from Present Sources -- All Utilities
Electrical Power

Steam -- Design Basis and Criteria

Water Systems

Water Supply and Storage

Water Treatment

Cooling Tower

Electrical Power Supply

Electrical Distribution Facilities

Emergency Eiectrical Power - Design Basis Criteria

Central Refrigeration Facilities

Compressed Air -- **plant, Instrument and Breathing**

Sanitary Waste Treatment/Sewers/Disposal

MAINTENANCE REQUIREMENTS -- SHOPS

Equipment Receiving and Inspection

Process Equipment Decontamination Cells

Process Equipment Repalr Shop

Regulated Machine Shop

Regulated Electrical and Instrument Shops

Clean Maintenance Shop

Clean Electrical and Instrument Shops

Regulated Crane Maintenance and Decontamination Area

**Manipulator Repair Shop**

$T \& \mathrm{~T}$ Equipment/Vehicle Maintenance
12

12

12

12

12

13

13

$\begin{array}{rr}100 & 9-82 \\ 110 & 9-82 \\ 120 & 9-82 \\ 130 & 5-81 \\ 135 & 5-81 \\ & \\ & \\ 100 & 1-82 \\ 110 & 6-80 \\ 120 & 1-82 \\ 130 & 9-82 \\ 300 & 11-80 \\ 310 & 9-82 \\ 320 & 9-82 \\ 500 & 5-81 \\ 550 & 5-81 \\ 560 & 9-82 \\ 600 & 11-80 \\ & \\ 650 & 9-82 \\ 700 & 7-81\end{array}$

14

$14 \quad 100 \quad 2-81$

$14200 \quad 9-82$

$14250 \quad 9-82$

$14300 \quad 9-82$

$14350 \quad 9-82$

$14 \quad 400 \quad 9-82$

$14 \quad 450 \quad 9-82$

$14 \quad 550 \quad 9-82$

$14 \quad 580 \cdot 9-82$

$14600 \quad 6-80$ 
SPARE EQUIPMENT

Installed Spare Equipment -- Pollcy

**Extra Machinery Allowance**

15

15

15

100

200

6-80

$9-82$

AED PARTICIPATION IN PROJECT

Portable Equipment Procurement

16

Responsibility and Costs for Computer Programming

Canister Procurement

COMMUNICATIONS -- ALARM SYSTEMS

Bell Telephone System -- Plant Telephone System

Area and Plantwide Alarm Systems

Public Address System -- Areawide

Public Address and Intercom Systems In and

Between Bulldings

Teletype, Data Transmission Capabilities,

Requirements

SAFETY -- FIRE PROTECTION

Criticality

Radiation Hazards -- All Areas

Controlled Access-Survelllance Monitoring

Chemical Hazards -- All Areas

Fire Protection -- General

Fire Protection -- 200S Area

SPECIAL EQUIPMENT -- DESIGN BASIS/CRITERIA

Canister Components (As Recelved)

Overpack Components (As Received)

Radiation-Shielded Windows

**Manipulators**

Process Cel1 Crane

** In-Cell Cranes**

CCTV Systems - Crane and Cell Viewing

Process Equipment Repalr Shop Crane

Equipment Lifting Yokes

Cell Tanks, Vessels, and Specialized

Auxiliary Equipment

In-Cell Piping and Nozzles

Evaporators, Batch and Continuous

Glass Melter

Off-Gas Treatment Equipment

Mercury Recovery Equipment

Canister Decontamination Station

Canister Smear Test (Decontamination Cel1)

Canister Welding Equipment (Outer Closure)

**Overpack Welding Equipment**

Canister Final Smear-Test and Inspection

Equipment

Canister Transfer To Interim Storage
16

16

16

17

17

17

17

17

17

18

$\begin{array}{rr}50 & 5-81 \\ 200 & 11-80 \\ 300 & 7-81\end{array}$

100

150

$9-82$

200

11-80

6-80

250

$9-82$

300

5-81

18

18

18

18

18

18

100

110

120

200

600

620

$1-82$

$1-82$

7-81

9-82

1-82

9-82

20

20

20

20

20

20

20

20

20

20

50

9-82

60

1-82

150

9-82

160

9-82

180

7-81

181

182

9-82

5-81

185

1-82

187

9-82

20

200

9-82

20

205

210

230

250

255

260

265

270

271

9-82

9-82

9-82

9-82

1-82

9-82

9-82

9-82

9-82

$20 \quad 275$

9-82

20 . 
SPECIAL EQUIPMENT -- DESIGN BASIS/CRITERIA, COnE'd. 20

Process Vessel Vent System

Process Cell Pumps 20

Interarea Transfer Pumps

Special Process Cell Pumps

Process Cell Agitators

Design of Covered Burial Containers

MISCELLANEOUS PROCESS DATA

** Sludge Feed Composition**

$* *$ Salt Plant Product Composition**

Slurry Properties

Stoichiometry

Physical Property Data

Glass Frit Characteristics

Properties of DWPF Waste Glass

$\begin{array}{lll}21 & 100 & 9-82 \\ 21 & 150 & 9-82 \\ 21 & 200 & 5-81 \\ 21 & 250 & 9-82 \\ 21 & 300 & 9-82 \\ 21 & 350 & 5-81 \\ 21 & 400 & 9-82\end{array}$

\section{APPENDICES}

APPENDIX A

Table 3-1 -- Area Lighting Requirement

Table 3-2 -- Properties of Ground Water for Different Aquifers in the SRP Area

Table 3-3 -- Elevations of High Level Liquid Waste Tanks

Table 3-4 -- Temperature and Relative Humidity in Augusta, GA

Table 3-5 -- Observed Temperature Extremes

Table 3-6 -- Winter Weather in Augusta

Table 3-7 -- Savannah River Plant Precipitation Summary

Table 3-8 -- Frequency of Wind Speed at Various Elevations

Table 3-9 -- Prevalling Wind Direction at Augusta

Table 3-10 -- Dally Shift of Prevaliing Wind Direction in Augusta (1957)

Table 3-11 -- **Basis for Radiation Shielding -photon Source Terms from Waste Glass for Supernate Sludge Glass**

Table 3-12 -- Water Well Drawdown Data

Table 4-1 -- Classification of Structures, Systems, and Components

Table 5-1 -- Inventory Standard Bases

Table 5-2 -- ** Inventory Requirements**

Table 5-3 -- Design Requirements -- Cold Feed Vessels inside Building 211-s

Table 5-4 -- Component Quality Examinations

Table 5-5 -- Design Requirements -- Canyon 
Table 6-1 -- Instrumentation 9-82

Table 6-2 -- Controls 9-82

Table 8-1 -- Guide for Offsite Exposure 6-80

Table 8-2 -- Radioactive Release Guides (CY-78) 6-80

Table 8-3 -- Nonradioactive Discharge Limits 6-80

Table 10-1 -- Work Assignments

Table 10-2 -- Summary of Offices, Lockers, and Rest Room Requirements

$9-82$

Table 12-1 -- Permanently Installed Health Protection Monitors

$9-82$

$9-82$

Table 16-1 -- AED Allowance Request

$9-82$

Table 18-1 -- Estimated CombustiblesVitrification Facility

Table 18-2 -- Recommended Fire Protection Systems--Vitrification Facility 9-82

Table 20-1 -- Component Requirements

APPENDIX B

Figure 2-1 - Location of SRP Relative to Surrounding Population Centers

Figure 2-2 -- The Savannah River Plant Site

$6-80$

Figure 2-3 -- F-Area

$6-80$

Figure 2-4 -- H-Area

Figure 3-1 -- Geologic Provinces of Southeastern

$6-80$ United States

Figure 3-2 -- Coastal Terraces on the Savannah River Plant

$6-80$

Figure 3-3 -- Profile of Geologic Formation Beneath the Savannah River Plant

$6-80$

Figure 3-4 -- Relative Locations of Separations Areas and Associated Waste Handling Facilities

Figure 3-5 -- Prevalling Elevation of the Water Table at the Tank Farms and Burial Ground Contours Shown in Feet Above Sea Level

Figure 3-6 -- Depth to High Water Table (March 1965) at the Tank Farms and Burial Ground (Contours Shown in Feet Below Grade)

Figure 3-7 -- The Savannah River Plant Site

Figure 3-8 -- Hydrostatic Head in Ground Water Near H-Area

Figure 3-9 -- Flow in Tuscaloosa Aquifer

Figure 3-10 -- Summary of Temperatures at SRP from 1961 to 1972

Figure 3-11 -- Total Rainfall at Different Locations on SRP for 1971 and 1972

Figure 3-12 -- Wind Direction Frequency Near SRP at 300 Feet

Figure 3-13 -- Seismic Activity in Southern 


\begin{tabular}{|c|c|c|c|}
\hline Figure & $5-1$ & -- **DWPF Sludge Plant - Process & \\
\hline & & Block Flow Diagram** & $9-82$ \\
\hline Figure & $5-2$ & 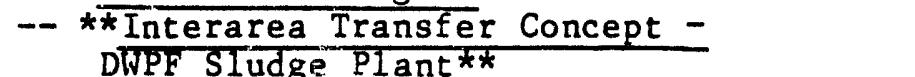 & \\
\hline Figure & $5-3$ & -- Containerization Process & $\begin{array}{l}9-82 \\
9-82\end{array}$ \\
\hline Figure & $5-4$ & $\begin{array}{l}\text {-- Canister Plug and Overpack Cover } \\
\text { Recelpt, Inspection and Storage }\end{array}$ & $7-81$ \\
\hline Figure & $5-5$ & $\begin{array}{l}\text {-- Canister and Overpack Receipt, } \\
\text { Inspection and Storage }\end{array}$ & $7-81$ \\
\hline Figure & $5-6$ & -- Decontamination Process & $1-82$ \\
\hline Figure & $5-7$ & -- Welding Process & $9-82$ \\
\hline Figure & $5-8$ & $\begin{array}{l}\text {-- Canister Inspection and Final } \\
\text { Smear Test }\end{array}$ & $9-82$ \\
\hline Figure & $5-9$ & -- Overpack Process & $9-82$ \\
\hline Figure & $11-1$ & $\begin{array}{l}\text {-- Proposed Serving Line S-Area } \\
\text { Cafeteria }\end{array}$ & $11-80$ \\
\hline Figure & $13-1$ & -- Water System & $9-82$ \\
\hline Figure & $13-2$ & $\begin{array}{l}\text {-- Water Utility Distribution and } \\
\text { Makeup Systems }\end{array}$ & $9 \cdot 82$ \\
\hline Figure & $20-1$ & $\begin{array}{l}\text {-- Procedure for Welding Tubes to } \\
\text { Tube Sheets in Heat Exchangers }\end{array}$ & $5-81$ \\
\hline **Figure & $20-2$ & -- Melter Off-Gas Bypass System** & $9-32$ \\
\hline APPENDIX & $\mathrm{C}--$ & Du Pont and DOE References & $9-82$ \\
\hline APPENDIX & $D--$ & Miscellaneous Technical References & $6-80$ \\
\hline APPENDIX & E-- & National Codes and Standards References & $6-80$ \\
\hline APPENDIX & F - & Federal and State Regulatory References & $6-80$ \\
\hline APPENDIX & G-- & NRC Regulatory Guides **APPENDIX DELETED** & $9-82$ \\
\hline APFENDIX & $\mathrm{H}$ & & \\
\hline Table & $21-1$ & -- $* \star$ Sludge Feed Composition (Dry Basis)** & $9-82$ \\
\hline Table: & $21-2$ & $--\star \star \overline{\text { Salt Plant Product Composition }}{ }^{*}$ & $9-82$ \\
\hline Table & $21-3$ & -- slurry Properties & $9-82$ \\
\hline Table & $21-4$ & -- Stoichiometry & $1-82$ \\
\hline Table & $21-5$ & -- $\star \star$ Physical Properties Data ${ }^{\star \star}$ & $9-82$ \\
\hline Table & $21-6$ & -- Glass Frit Characteristics & $5-81$ \\
\hline Table & $21-7$ & $\begin{array}{l}\text {-- Heat Capacities for DWPF Waste } \\
\text { Glass with Frit } 131\end{array}$ & $5-81$ \\
\hline Table & $21-8$ & $\begin{array}{l}\text { - Densities of DWPF Waste Glasses } \\
\text { with Frit } 131\end{array}$ & $5-81$ \\
\hline Table & $21-9$ & $\begin{array}{l}\text {-- Index of Refraction for DWPF Glass } \\
\text { with Frit } 131\end{array}$ & $5-81$ \\
\hline Table & $21-10$ & - $\mathrm{K}_{\mathrm{rad}}$ and $K_{\mathrm{eff}}$ for DWPF Glass & $5-81$ \\
\hline
\end{tabular}


APPENDIX H, Cont'd.

Table 21-11 - Resistivity of DWPF Glass with Frit 131

Table 21-12 -- DWPF Reference Canister, Heat Generation (Watts) **TABLE DELETED** 5-81

Table 21-13 -- Surface Temperature for DWPF Waste Glass (TDS-3A and Frit 131)

Table 21-14 - **Radiation from Reference DWPF Canister 5 Year old Sludge Plus 15 Year Old Supernate** **Table 21-15-- Material Balance Table - Sludge

**Table 21-16 - Material Balance - Supernate Sludge Material Balance $\star \star$

**Table 21-17 - Sludge Only Curie Balance**

$* *$ Table 21-18 - - Supernate Sludge Curie Balance**

**Table 21-19-- Isotopic Content of 5-Year In-Tank Waste $\star \star$

* Table 21-20 - Radionuclide Content of 5-Year In-Tank Waste**

$* *$ Table 21-21 -- Isotopic Concent of Sludge Feed**

$9-82$

9-82

$* *$ Table 21-22 - Radionuclide Content of Sludge Feed**

$9-82$

**Table 21-23 - Radionuclide Content of Feed to the Sludge plant from Salt Plant**

9-82

**Table 21-24 - Radionuclide Content of Sludge Only Glass**

** Table 21-25 - Radionuclide Content of Supernate Sludge Glass**

**Table 21-26 -- Estimated Annual Atmospheric Releases to the Enviroument -Sludge Only Operation**

**Table 21-27 - Estimated Annual Atmospheric Releases, Sludge Plus Supernate Operation**

Figure 21-1 - **Experimental Thermal Expansion $\begin{array}{ll}\text { Data for Simulated SRP Waste Glass** } & 9-82\end{array}$

**Figure 21-2 -- Process Sumary Diagram - Melter Feed Preparation**

**Figure 21-3 -- Process Summary Diagram Vitrification and off-Gas Treatment** 9-82

**Figure 21-4 -- Process Summary Diagram - Mercury Purification and Packaging**

**Figure 21-5 - Process Summary Diagram Decontamination and Miscellaneous Waste Stream Treatment**

**Figure 21-6 - Process Summary Diagram Canister Decontamination Closure and Inspection*t

**Figure 21-7 - sludge Only Glass Canister Decay Heat $\star * x$

**Figure 21-8 - Sludge Supernate Glass Canister 


\section{History Copy}

BASIC DATA REPORT STAGE 1

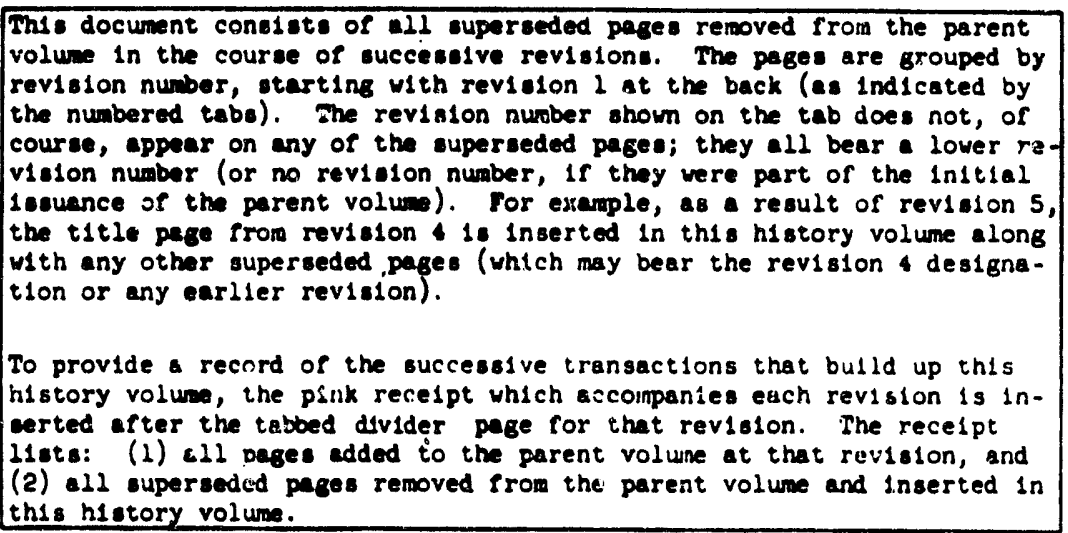

This document contains information relating $t(1)$ the activities of the United States Department. of Energy. Not to bi reproduced or released without prior approval.

E. I. du Pont de Nemours and Company 
This Basic Data Report for the Defense Waste Processing Facility (DWPF) Sludge Plant was prepared to supplement the Technical Data Summary. Jointly, the two reports were intended to form the basis for the design and construction of the DWPF. To the extent that conflicting information may appear, the Basic Data Report takes precec nce over the Technical Data Summary. It describes project objectives and design requirements. Pertinent data on the geology, hydrology, and climate of the site are included. Functions and requirements of the major structures are described to provide guidance in the design of the facilities.

Revision 9 of the Basic Data Report was prepared to eliminate inconsistencies between the Technical Data Summary, Basic Data Report and Scopes of Work which were used to prepare the September, 1982 updated CAB. Concurrently, pertinent data (material balance, curie balance, etc.) have also been placed in the Basic Data Report. It is intended that these balances be used as a basis for the continuing design of the DWPF even though minor revisions may be made in these balances in future revisions to the Technical Data Summary. 
PAR'T TITLE: LIAISON GROUP

ITEM TITLE: Purpose

The design and construction of any project of the magnitude of the waste processing facility requires prompt, orderly, and accurate interaction between all individuals involved. These individuals share a common goal: to provide, on time, minimum essential facilities which will operate safely and economically to produce a specified quantity and quality of product.

The liaison group generally consists of representatives with process, mechanical, instrument and electrical backgrounds. They coordinate activities with plant personnel, Savannah River Laboratory, research and development, and the Design Division of the Engineering Department.

The requirement that the Defense Waste Processing Facility be designed and constructed to comply with DOE requirements necessitates that knowledgeable personnel specify the process and design and construct the facility.

The purpose of this section is to define the responsibilities of the liaison group, identify the personnel involved, establish methods of communication and documentation of decisions regarding the design and construction of the defense waste processing facility. 
PART TITLE: LIAISON GROUP

ITEM TITLE: Responsibilities

Defense Waste Processing Facility (DWPF) Liaison

The primary responsibilities of the Waste Management Program DWPF Lialson Group are (1) to verify that any recommended process can be efficiently and safely operated and malntalned and (2) to see that all required facilities are provided.

The lialson group reviews process recommendations and process changes by SRL from an operating and maintaining viewpoint. Functions, objectives, requirements, and equipment for all process and nonprocess buildings are specified by the liaison group. Prints, scopes of work, and design criteria are reviewed for conformance with project objectives. Replies of SRP-SRL reviewers are coordinated and prepared for the Design Division. Requests for additional or clarifying information are answered along with print comments and technical data in transmittals. Information affecting the scope of the project, funding or project schedulies are transmitted by the group to the Projects Management Office of the Manufacturing Division for review.

A representative of the liaison group is expected to attend all pertinent plant design meetings between the Engineering Department Design Division specialists and SRL-SRP Engineers.

Departmental Engineer office

The Departmental Engineer Office provides general guidance to SRL, SRP, and Engg Design Division in the definition of project objectives, evaluation of the acceptability of conceptual design, and financial planning. This office reviews SRL-SRP recommendations and attends meetings between the Engg Design Division and SRL-SRP.

SRL Defense Waste Processing Section (DWPS)

Various SRL groups perform the research and development work for new processes. The SRL-DWPS group coordinates this effort and serves as liaison between SRL and the plant in cooperation with other SRL-SRP groups, the DWPS group specifies the process, process requirements, control methods, environmental considerations, safety, etc. This information has been compiled and published in the Technical Data Summary which is revised and updated as significant developments are made. As required, programs for the development of additional experimental data will be developed. This group is also responsible for coordinating the SRL review of all Engg Department Design Division prints, scopes of work, etc., and communicating these reviews to the liaison group. 
PART TITLE: LIAISON GROUP

ITEM TITLE: Personne1

Listed below are personnel in the Departmental Engineer office, DWPF Liaison and SRL with assignments related to the DWPF.

A. MANUFACTURING DIVISION - PROJECTS MANAGEMENT OFFICE

A. M. Lander AED Dept Engineer (ext 6246)

C. C. McBride Defense Waste Lialson Engineering Manager (ext 4312)

B. MANUFACTURING DIVISION - SAVANNAH RIVER PLANT OPERATIONS SRP Waste Management Programs

R. Maher Program Manager (725-3575)

C. DWPF LIAISON - SAN FRANCISCO OFFICE

J. B. Mellen

J. A. Gentilucci

H. K. Bethmann

J. C. Eargle

R. M. Galloway

J. R. Glasscock

D. B. Jet $t$

J. E. Koonce

T. T. Thompson

H. R. Huxford

M. C. Schroder

H. H. Elder

D. R. Boyd

D. E. Wood
Liaison Leader (882-3179)

$(882-3178)$

(768-6899)

(882-2449)

(882-2674)

(882-2643)

(882-2592)

(882-2673)

(882-2448)

(882-2447)

Reporting Systems

(882-2672)

(882-2450)

(882-2668) 
DPSP $80-1033$

PART 1

ITEM 120

PAGE 2 of 4

DATE 9-82; Rev 9

PART TITLE: LIAISON GROUP

ITEM TITLE: Personne1

D. DWPF LIAISON - SRP OFFICE

B. G. K1tchen Superintendent (725-2527)

E. L. Graf

$(725-1185)$

J. E. Callan

(725-1241)

A. J. Lethco

(725-1239)

R. M. Shu1ko

(725-1003)

B. R. Moultrie

$(725-1364)$

W. A. Murdaugh

(725-1010)
A. A. Schmidt
(725-3953)
J. J. Slovic
(725-1106)

D. C. Nichols

Superintendent (725-2136)
R. F. Rogers
(725-1324)
R. G. Baxter
(725-1187)
C. B. Goodlett
(725-3901)
R. R. Herries
(725-1238)
J. P. Moseley
(W11m - 366-2082)
R. N. Ransom
(725-3950)
R. W. Zeyfang
(725-2002) 
PART TITLE: LIAISON GROUP

ITEM TITLE: Personne1

E. TECHNICAL DIVISION - SAVANNAH RIVER LABORATORIES

S. Mirshak Director of Research (ext 3422)

1. Defense Waste Processing

J. A. Kel1y

J. F. Ortaldo

W. R. Stevens

R. M. Wallace

2. Solid Processes

D. C. Witt

T. L. Allen

D. L. Pellarin

C. L. Selby

H. L. Hull

K. R. Routt

J. W. Kelker, Jr.

C. R. Ward

G. T. Wright

3. Liquid Processes

M. D. Boersma

L. F. Landon

E. J. Weber

F. M. Heckendorn

P. L. Graf

D. S. Janes
Section Director (ext 2410)

Research Manager (ext 3578)

Research Manager (ext 1120)

Research Fellow (ext 2104)
Supervisor (ext 9173)

Nelter Process Development (ext 9195)

Sol1d Process Control, Glass Cracking (ext 9179)

Canister Decontamination (ext 9172)

PNL Liaison (ext 9181)

Vitrification Equipment Development (ext 9160)

Containerization (ext 9209)

Containerization (ext 9176)

Off-gas Scrubbing (ext 9193)

4. Full Scale Vitrification

F. H. Brown

M. B. Cosper

H. C. Wolf

J. L. Kessler

W. P. Colven

C. T. Randa11

G. A. Griffin

C. R. Pound

D. P. Lewis

D. M. Sabatino
Supervisor (ext 9139)

TDS (ext 9203)

Gravity Settling, Filtration, Aluminum Dissolving, (ext 9162)

Process Control (ext 9206)

Erosion Assessment (ext 9164)

SME, Filtration (ext 9230)

Supervisor (ext 9146)

Continuous Melter and Melter Physical Models (ext 9192)

In-Can Melter, Off-gas Analytical Systems (ext 9180)

Large Slurry-Fed Melter (ext 9191)

Mech. Systems for off-gas (ext 9170)

CM Off-Gas (ext 9169)

Instrumentation \& Control Maintenance (ext 9100)

Slurry Feed Systems (ext 9153)

Slurry Feed Systems (ext 9229)

Slurry Feed Systems (ext 9244) 
PART TITLE: LIAISON GROUP

ITEM TITLE: Personnel

\section{Glass Technology}

M. J. Plodinec

N. E. Bibler

W. N. Rankin

G. G. Wicks

T. J. Bird

D. C. Iverson

P. D. Soper

6. Process Technology

W. V. Wright

L. L. Kilpatrick

L. M. Lee

R. E. Elbling

D. D. Walker

J. R. Fowler

B. A. Hamm
Supervisor (ext 2170)

Radiation Chemistry, Glass Characterization (ext 2313)

Canister Decon, Materials Testing (ext 2363)

Glass Leac'ilng (ext 3190)

Liaison for Analyses of SRP Samples (ext 2313)

Small Scale Glass Melter (ext 1236)

off-gas, Glass Chemistry (ext 2313)

7. Waste Faru Processing

R. B. Ferguson

Supervisor (ext 9183)

P. D. D'entremont

M. A. Shmitz

Supervisor (ext 2947)

Full Height Ion Exchange Tracer Facilitles (ext 2777)

High Level Caves Ion Exchange (ext 2777)

Sludge Processing (ext 2369)

Ion Exchange Resins (ext 1237)

Waste Composition (ext 2363)

In-Tank Processing (ext 2369)

A. W. Wiggins

Supernate Precipitation Pump (ext 9180)

Supernate Precipitation Filter (ext 9207)

Supernate Precipitation Mixing (ext 9163)

8. Environmental Analysis and Planning

T. V. Crawford

W. L. Marter

J. S. Murdock

W. G. Holmes

J. W. Morris
Research Manager (ext 2767)

Enviromental Radioactive (ext 2775)

Preliminary Safety Analysis (ext 2457)

Environmental Information Document Regulatory

(ext 2434)

Environmental Impact Statement (ext 1226)

9. Analytical Development

W. E. Stewart

Ana1yt1cal Development (ext 3438)

10. Actinide Technology
W. S. Durant
W. C. Perkins
J. C. Huang

Safety Analysis (ext 1358)

Safety Analysis (ext 1361)

Safety Analysis (ext 1362) 
PART TITLE: LIAISON GROUP

ITEM TITLE: WMP DWPF Liaison Group Design Area Responsibility List VITRIFICATION BUILDING AND ASSOCIATED PROCESSING FACILITIES

Design

Area

$S-100$

$s-210$

$S-221$

S-291

S-292

S-294

$s-320$

Vitrification Equipment Exit Decontamination Facilities

S-324 Vitrification Bullding Hot Maintenance, Regulated and Special Shops

S-325 Shield Windows, M-S Manipulators and Auxiliary Facilities - Vitrification Bullding

S-326 Vitrification Buflding Cell Cranes and Auxiliaries

S-329 Glass Frit, Misc. Feeds and Common Service Facilities - Vitrification Building

S-350 Glass Melt and Off-Gas Treatment Facility

$-1 \quad$ Feed Receipt and Ad justing

-2 Melting

-3 of $f$-Gas

-4 Acid Hydrolysis

\begin{tabular}{|c|c|}
\hline \multicolumn{2}{|c|}{ AED Liaison } \\
\hline SF & SRP \\
\hline Jett & Murdaugh \\
\hline Eargle & Ca11an \\
\hline Bethmann & Zeyfang \\
\hline Jet $t$ & Zeyfang \\
\hline Jett & Zeyfang \\
\hline Jett & Zeyfang \\
\hline Koonce & Zeyfang \\
\hline Wood & Slovic \\
\hline Wood & Lethco \\
\hline Wood & Slovic \\
\hline Galloway & Shulko \\
\hline Koonce & Zeyfang \\
\hline Glasscock & $\begin{array}{l}\text { Baxter } \\
\text { Moseley }\end{array}$ \\
\hline Glasscock & $\begin{array}{l}\text { Baxter } \\
\text { Moseley }\end{array}$ \\
\hline Bethmann & Goodlett \\
\hline
\end{tabular}


PART TITLE: LIAISON GROUP

ITEM TITLE: WMP LIPF Lialson Group Design Area Responsibility List VITRIFICATION BUILDING AND ASSOCIATED PROCESSING FACILITIFS

Design

Area

$\mathrm{s}-360$
Title

Canister Weld, Test anil Decontamination Fac1lity

-1. Temporary Seal

-2 Canister Decon

-3 Canister We1d and Test

S-375 Central Vitrification Control and Data

Processing Facilities

S-376 Healih Protection and Monitoring Facilities Vitrification

S-378 Sample Collection and Analytical Test Fajllities

S-380 Embedded Piping Facilities - Vitrification B1dg.

S-381 In-Ce11 Interconnect \& Service Jumper Fac1lities

S-383 Process, Service, Gang Valve \& Misc. Header

Piping - Vitrification

S-390 Vitrification Bldg - Alr Supply System, H\&V \& Auxillary Facility

S-391 Vitrification B1dg. Exhaust Afr System, Fans, \& Auxillary Facility

S-395 Vitrification B1dg. Vessel Vent, Sump Collection \& In-Cell Common Fac1lity

S-422 Vitrification Fac1lity - Bulk Frit \& M1 eed Storage Facility

S-511 Pump P1t/Diversion Box Facilitles

S-550 Interarea Transfer Lines - Vitrification (End-to-End).

S-704 Central Adminlstration \& Control Bldg. Vitrification

\begin{tabular}{|c|c|}
\hline \multicolumn{2}{|c|}{ AED Liaison } \\
\hline SF & SRP \\
\hline Elder & Herries \\
\hline Eider & Herries \\
\hline Boyd & Herries \\
\hline & \\
\hline$-\cdots$ & Schmidt \\
\hline Koonce & Zeyfang \\
\hline Koonce & Lethco \\
\hline Bethmann & Zeyfang \\
\hline Bethmann & Zeyfang \\
\hline Bethmann & Zeyfang \\
\hline Jett & Zeyfang \\
\hline Jett & Zeyfang \\
\hline Galloway & Zeyfang \\
\hline Eargle & Shulko \\
\hline Eargle & Ransom \\
\hline Eargle & Ransom \\
\hline Eargle & Lethco \\
\hline
\end{tabular}


PART TITLE: LIAISON GROUP

ITEM TITLE: WMP DWPF Lialson Group Design Area Responsibility List VITRIFICATION BUILDING AND ASSOCIATED PROCESSING FACILITIES

Design

Area

$S-956$

$S-986$

$S-999$
Title

Emergency Electrical Generation Facility Vitrification

Compressed Air Facilities

Extra Machinery - Vitrification

\section{Glass Waste Storage Facllities}

S-250 Glass Waste Lag Storage B1dg.

S-450 Glass Waste Storage \& Transfer Handling

Facilities

$\begin{array}{ll}\frac{\text { AED Liaison }}{\text { SF }} & \frac{\text { SRP }}{-} \text { Schmidt } \\ \text { Boyd } & \text { Slovic } \\ \text { Wood } & \text { Slovic }\end{array}$

Galloway

Callan

Galloway

Callan

Power, General, and Service Facilities

S-600 Site, Roads, Walks, Fence, Parking, \& Rallroad

Facilities - Vitrification

Boyd

Lethco

S-698 Landscap1ng \& Erosion Control Fac1lities Vitrification

Boyd

Lethco

S-701 Gatehouse \& Patrol Headquarters Bldg •

Boyd

Lethco

S-802 Outside Overhead (OSOH) Process, Power \& Service Piping Facilities - Vitrification

Ransom

S-803 Outside Underground (OSUG) Process, Power \& Service Piping Facilities - Vitrification

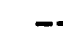

Ransom

S-821 Storm Sewer Fac1lities - Vitrification

Boyd

Shulko

S-831 Sanitary Sewer Facilities - Vitrification

Boyd

Shulko

S-901

Fire Protection Facilities - Vitrification

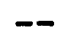

Lethco

S-905

Water Wells 1 and 2 \& Auxiliary Facilities

Boyd

Shulko 
PART TITLE: LIAISON GROUP

ITEM TITLE: WMP DWPF Lialson Group Design Area Responsibility List VITRIFICATION BUILDING AND ASSOCIATED PROCESSING FACILITIES

Design Area

S-951

S-953

S-958

System - Vitrification

S-980 Primary Water Treatment, Water Storage \& Chemical Waste Treatment Facilities

S-981 Service Cooling Tower \& Auxiliary Fac1litles

$s-995$

Title

Alert, \& Fire Alarm

\begin{tabular}{cc}
\multicolumn{2}{c}{ AED Lialson } \\
\hline- & $\frac{\text { SRP }}{\text { SF }}$ \\
-- & Moultrie \\
-- & Moultrie \\
Boyd & Shulko \\
Boyd & Shulko \\
Boyd & Slovic \\
& \\
-- & Goodlett \\
-- & Goodlett
\end{tabular}

Thompson Lethco

Thompson Lethco

Quality Assurance

Permits

SAR

Basic Data Report

Pump Task Force

CCTV Task Force

Melter Task Force

Canis:er Decon Task Force

Tolerances s Review
Technetium Removal 


\section{PART TITLE: LIAISON GROUP}

ITEM TITLE: Correspondence

\section{a. General}

1) Correspondence to SF DWPF Liaison group issued by the Engineering Department should be addressed as shown in Design Procedure DPE-3507 and mailed to:

J. B. Mellen

2) Correspondence to SRP DWPF Liaison group should be mailed to:

B. G. Kitchen

P. O. Box 757

Jackson, SC 29831

Copies of correspondence Items 1) and 2) will be made and distributed to ' WPF Liaison group as required. One copy will be reserved for the DWPF Records Information Management System. Additional copies are to be made for other groups as appropriate.

3) Transmittal letters and prints are to be addressed to:

J. A. Gentilucci, SF, with a carbon copy to A. J. Lethco, P. O. Box 757 , Jackson, SC 29831.

These transmittals and prints are to be distributed to the resporisible engineers. A copy of each print and transmittal will be maintained in an area file office. Transmittals will be logged in and a print out of each weeks receipts will be issued weekly to DWPF Lialson and SRL.

4) Correspondence from the DWPF Liaison to Design Division should be assigned a document number and routed as shown in DPE-3507, Design Procedure DWPF Part 3, Item 101, Page 4. A file code is to be assigned to each letter. 
PART TITLE : LIAISON GROUP

ITEM TITLE: Communication

\section{Telephone}

Design specialists may contact any SRL-SRP engineer concerning additional or clarifying information on a specific subject. However, SRL-SRP engineers are not authorized to issue any verbal instructions that will alter the scope of the project. These instructions must be forwarded in writing through the DWPF Liaison group.

\section{Electronic Mail}

Electronic mail can be scheduled by Lynn Ferguson, 773-29A, ext. 725-2506. The data phone number is extension 725-1107. The data phone is located in $773-29 A-2$.

3. Telecommunications

Teleconferencing by phone or slow scan TV may be scheduled by contacting $\mathrm{J}$. Arbogast, 773-28A, ext. 1028.

The phone numbers for teleconferencing are:

$$
\begin{aligned}
& \text { Ext. 725-1441 - Teleconferencing Phone } \\
& \text { Ext. 725-1438 - Data Phone } \\
& \text { Ext. 725-1442 - Trouble Shooting Phone }
\end{aligned}
$$

All phones are located in 773-29A-8.

\section{Whisper Writer}

Messages for the whisper writer are to be sent and received by $J$. Arbogast, 773-28A-8, ext. 1028. The Whisper Writer phone number is extension 2425. Al1 messages that are received will be delivered to the addressee with carbon copies as directed. All messages with ID numbers will be filed in the area correspondence file. 


\section{PART TITLE: OBJECTIVES}

\section{ITEM TITLE: General Project Objectives}

\section{Background}

The Savannah River Plant (SRP) occuples an approximately circular area of 300 square miles ( 192,000 acres) in South Carolina, 25 miles southeast of Augusta, GA (Figure 2-1, Appendix B). The site borders the Savannah River for approximately 17 miles. The plantsite has an elevation between 90 and $400 \mathrm{ft}$ above mean sea level. The plantsite is closed to the public except for guided tours, controlled deer hunts, controlled through traffic along South Carolina Highway 125 (SRP Road A) and along the Seaboard Coastline Rallroad, traffic on U.S. Highway 278 along the north edge of the site (Figure 2-2, Appendix B), and authorized environmental studies.

SRP was constructed during the 1950's to produce the basic materials, primarily $239 \mathrm{Pu}$ and tritium, used in the fabrication of nuclear weapons. ** The plant facilities (Figure 2-2, Appendix B) consist of three operating nuclear production reactors (in $P, K$, and $C$ Areas), two nuclear production reactors in standby condition (in $R$ and $L$ Areas), a small test reactor in standby condition (in U Area), two separations areas ( $F$ and H Areas) for processing irradiated materials, a heavy water recovery plant (in D Area), a fuel and target fabrication facility (in M Area) containing two test reactors, the Savannah R1ver Laboratory (SRL; a process development laboratory to support production operations), idministration facilities (in A Area), and the many non-nuclear facilities necessary for plant operations. ${ }^{*}$

The storage areas for high level liquid waste are adjacent to the separations areas and consist of two tank farms linked to the separations areas and to each other by pipelines with secondary containment. In addition, a 195-acre burial ground area located between $F$ and $H$ separations areas is used for controlled storage of solid radioactive wastes. The waste storage areas are at least 6 miles from the nearest plant boundary.

The wastes produced in the F- and H-Area canyons are neutralized to an alkaline $\mathrm{pH}$ and transf $\epsilon$ :red to the waste tank farms. After aging for 2 to 3 years, during which the insoluble hydroxides settle, the supernatant liquid is evaporated in a bent tube evaporator. The evaporator bottoms are transferred to another waste tank and allowed to cool, thereby depositing a wet salt cake. Excess 1iquid above the salt cake is recycled back to the evaporator system. The F- and H-Area waste tank farms each have two bent tube evaporators. 


\section{PART TITLE: OBJECTIVES}

\section{ITEM TTTLE: General Project Objectives}

At present, SRP has 37 large subsurface tanks for the 8 torage of aqueous radioactive wastes as sludge, supernatant liquid of various salt concentrations, and salt cake. (Tank 23, one of the 37 , has been reserved as a hold tank for resin regeneration wastes from the fuel storage basin.) Nineteen of these tanks are adjacent to one separations plant (H Area) and 18 are adjacent to the other ( $F$ Area). Fourteen additional tanks are either under construction or planned. Figures 2-3 and 2-4, Appendix B show the two separations areas with adjacent waste tanks.

SRP waste storage tanks are of four basic designs. As a result of tank upgrading and retirement programs, 23 tanks will be retired and all waste tanks in use in 1987 (with the exception of type IV tank 23 for RBOF service) will be of type III or IIIA construction. Type III and IIIA tanks are 1.3 million-gal tanks with double-steel bottom and sidewall construction.

\section{General Project Objectives}

The general project objectives for the Defense Waste Processing Facility (DWPF) are to:

1. **Process the liquid high-level radioactive wastes from the separations areas into solid matrices to reduce the mobility of the radionuclides. Insoluble radioactive waste (sludge) and radionuclides removed from decontaminated soluble waste (salt) will be immobilized in glass. The function of facilities described in this document is to immobilize the highly radioactive sludge. The facility will receive sludge which has been treated with caustic to reduce the volume of insoluble aluminum and washed to remove soluble sodium salts. The washed sludge will be incorporated into leach-resistant glass in sealed containers which will be stored onsite until a federal repository is available. ${ }^{* *}$

2. Design, construct, and operate the fncilities for processing and storing the solidified waste in a manner that will keep the radiation exposure of plant personnel and the general public to as low a value as practical.

3. Provide facilities to ensure that any liquid or gaseous effluent from the plant meets applicable federal and state regulations.

4. Minimize the cost of the facilities insofar as is consistent with the objectives stated herein. The design of DWPF should include provisions to make the construction and operation of later possible additions more convenient or less costly only to the extent that these provisions do not significantly increase the cost of the present project. 
PART TITLE: OBJECTIVES

ITEM TITLE: Production Capacity

In 1988, about 4 million gallons of sludge slurry will be available for processing. The capacity of DWPF should be sufficient to reduce stored waste to a current inventory within about 20 years after startup. A current inventory of waste sludge is that aged less than five years. An instantaneous glass production rate of about $225 \mathrm{lb} / \mathrm{hr}$ at an overall attainment of greater than $75 \%$ will meet the work off period objective. 
PART TITLE: OBJECTIVES

ITEM TITLE: Objective Start-Up -- Total Facility

** Sludge Plant Project Timing**

1. Turnover of the processing building should be based on anticipated project authorization and assuming a normal 40-hour construction work week. All other turnover dates are referenced to the turnover date for the processing building and assume a 12 -month period for checkout of process equipment, tank calibration, cold chemical runs, etc.

2. The turnover date for the sand filter, fan house, and exhaust stack should lead the turnover date for the process bullding.

3. ** The turnover date for the receiving and service building and cold feed facilities should lead the turnover date for the process building. The facilities will be required during the water, acid, and caustic checkout runs of process building equipment. The office area of the service building should be completed as early as possibe to provide office space for construction checking personne ${ }^{* *}$

4. The turnover date of the interim glass waste storage facility should not be later than 3 months after the turnover date of the process bullding. For functional checkout, the storage area will receive the first storage containers filled with glass from simulated waste during the first year of cold chemical operations.

5. Maintenance and Electrical \& Instrument shops should be turned over to operations about 1 month before the process building turnover. If a separate area shop building is provided, offices, lunch rooms, etc. should he completed as soon as possible after project authorization. These facilities will be used by Works Engineering personnel during contruction checking.

6. Facilities and some equipment for Patrolmen will be required as soon as the construction area is enclosed within a fence. The Patrol **headquarters** should be completed as soon as possible after project authorization. Until the bullding is completed, temporary buildings for Patrolmen plus some equipment will be required at all entrances into the construction area.

7. The turnover date for interarea transfer facilities should be at least 3 months before turnover of the processing building.

8. The turnover date for facilities required for comfort conditioning of various area buildings should be based on the earliest anticipated facility turnover. 


\section{PART TITLE: OBJECTIVES}

ITEM TITLE: Objective Start-Up - Total Facility

9. Generally, the vehicles or mobile equipment to be purchased by AED will not be required until turnover of the faclilty. However, the vehicles assigned to Safety and Security Department for patrol purposes should be procured at the time the construction area is enclosed by a fence.

10. It is desirable that the turnover date for the Administration Bullding should be as soon as possible after project authorlzation to house operations personnel assigned to construction checking. If the Administration Bullding is not avallable, AED will provide temporary housing (possibly trallers) to be located as conveniently as possible to the construction site.

**Assuming that the patrol headquarters and administration bulldings a re combined, it may be desirable that the sections of the building be turned over to operation separately to achleve an early occupancy. ${ }^{\star \star}$ 
DPSP $80-1033$

PART 3

ITEM 100

PAGE 1

DATE $6-80$

\section{PART TITLE: SITE CONSIDERATIONS}

\section{ITEM TITLE: General Site Requirements}

The following factors are to be considered in choosing a site location. The factors are listed in decreasing order of importance and are to be used only insofar as the soil conditions, terrain, etc. of the chosen site are consistent with good economics and engineering standards of construction.

1. The waste processing facility should be in close proximity to $F$ and $H$ separations areas and the rank farm areas to minimize the distance of transfer of radioactive liquids through pipelines.

2. The facility should be as far as possible from plant boundaries to minimize the potential impact of any routine or accidental stack releases to offplant population.

3. The facility should be as far as possible from rivers, creeks, and flowing streams to reduce the risk of any radioactive liquids being accidently released to the stream.

4. In choosing a site, the economic advantages and disadvantages of utilizing existing plant facilities such as paved roads, railroads, laundry, fire protection, employee travel, etc., shall be considered. 
PART TITLE: SITE CONSIDERATIONS

ITEM TITLE: Specific Siting Requirements -- S-Area Facilities

The following factors shall be considered in determining the location of specific bulldings in the area.

1. Consideration shall be given to potential accidental releases of gaseous effluents that might involve the main area entrance, employee parking lot, and building alr intakes.

2. Railroad entrances to the area and buildings should be at a location that w111 minimize interference with vehicular traffic patterns.

3. Where possible, pipelines carrying radioactive liquids should avoid railroads and frequently used roadways to reduce the potential for damage to the pipelines and subsequent exposure of personnel to radiation or release of contamination to the environment.

4. Parking lots and bulldings, especlally those with the most workers, should be located to minimize walking times and avold crossing of vehicle and pedestrian traffic as much as practical.

5. Whenever it is consistent with safety, security, and process operations, energy conservation shall be considered in all designs. The bulldings should be designed using the latest energy conservation techniques.

6. Provide space for expansion of the vitrification process building, the glass storage bullding, the sand filter and other facilities as stated in Part 4, Item 220.

7. Locate buildings to the extent practical to minimize the length of seismic resistant exhaust air tunnels. See Part 11, Item 490 for restrictions on siting the main air exhaust stacks.

8. **The Service and Interim Storage Buildings should be located to minimize handling of full and empty canisters within and between buildings.** 
PART TITLE: SITE CONSIDERATIONS

ITEM TITLE: Specific Siting Requirements -- Inter-Area Facilities

The following factors shall be considered in determining the location of pump pits, diversion boxes, and transfer lines.

1. Consideration shall be given to potential accidental release of radioactive liquid, especially from diversion boxes and pump pits. There is also potential for release of airborne radioactive dust from these facilities.

2. Where possible, pipelines carrying radioactive liquids should avoid railroads and frequently used roadways to reduce the potential for damage to the pipelines and subsequent exposure of personnel to radiation or release of contamination to the environment.

3. A pump pit shall be sited so that all transfer lines are Eree draining.

4. Pump pits should be located as near as practical to existing or new sources of utilities such as steam, plant and instrument air, electrical service, and cooling water.

5. Transfer lines for radioactive materials must be adequately shielded and above the water table. 


\section{PART TITLE: SITE CONSIDERATIONS}

ITEM TITLE: Roads, Railroads, Parking, Fencing, etc.

1. Railroad access will be required to receive cold chemicals and empty glass canisters .

2. Combined rail-truck access to the main process building is required with direct access to the process cell to permit loading the largest piece of building equipment from the process cell directly intu a covered burial container on a railroad car or truck bed within the shielded and confined area of the process building.

3. **Truck loading docks will be required at the main process building, the service building and at other areas and buildings for occasional unloading of supplies. ${ }^{\star \star}$

4. An employee private vehicle parking lot should be provided for 105 cars based on an average of 1.9 employees per car and an estimated work force of 122 day employees and 29 employees on each rotating shift plus an allowance of $10 \%$ excess. Use du Pont Civil Engineering Standard C7R for detailed design criteria for parking lots. Provide a three-sided metal shelter at the employee parking lot for employees waiting for carpools.

5. Access to S-Area should be from both Roads 4 and F via a continuous road between Roads 4 and $F$.

6. Fencing around the perimeter of the area should prevent unauthorized personnel from wandering into hazardous work areas. For permanent fences use No 11 AWG or heavier wire fabric topped by three strands of barbed wire to make a minimum overall height of eight (8) feet. Equip unattended openings of more than $96 \mathrm{sq}$. in. or over $6 \mathrm{in}$. in the smallest dimension with wire mesh (maximum 2-in. mesh with No 11 AWG wire or expanded metal) or 1/2-in. metal bars on not more than 6 in. centers and with cross bars to prevent spreading. Use heavy duty hardware; peen, braze or spot weld any hardware accessible from the outside.

7. Perimeter fencing should be at least $50 \mathrm{ft}$ and not more than $500 \mathrm{ft}$ from buildings as specified in Reference $C-4$, Appendix $C$. There should be a cleared area of at least $20 \mathrm{ft}$ outside the perimeter fence.

8. General area lighting should be provided for the gate house and gate area, parking lots, perimeter fences and other locations requiring outdoor lighting for general safety and security. See Table 3-1, Appendix A for lighting requirements. Whenever possible, consider using energy-saving, low-maintenance lighting systems and fixtures (such as high pressure sodium lamps) to minimize energy requirements. 


\section{PART TITLE: SITE CONSIDERATIONS}

ITEM TITLE: History

Information on the Savannah River Plant site and Waste Management Operations at the Savannah River Plant has been compiled and previously published (References $C-1, C-2$, and $C-2$ ). Pertinent information from these references has been excerpted and is reproduced here in subsequent Items 205 through 500 of Part 3. This information is intended only as general background information until a Preliminary Safery Analysis is published. The Preliminary Safety Analysis will provide more specific and detailed infurmation on site characteristics. 


\section{PART TITLE: SITE CONSIDERATIONS}

ITEM TITLE: Geology -- TOpography

The plant is located in the Coastal Plain geologic province as shown in figure $3-1$. This province is characterized by flat, mostly unconsolidated sediment of Cretaceous age or younger. About 20 miles northwest of the plantsite is the lower edge of the Piedmont Plateau; (the other main geologic province in South Carolina).

On the site, two distinct physiographic subregions are represented (figure 3-2): the Pleistocene Coastal Terraces (below $270 \mathrm{ft}$ in elevation) and the Aiken Plateau (above $270 \mathrm{ft}$ and rising $10400 \mathrm{ft}$ on the northwest boundary).

At least three terraces are recognizable within the coastal terraces subregion (figure 3-2). The lowest terrace (Wicomico, $100 \mathrm{ft}$ ) is the very broad floodplain of the Savannah River; it is largely covered with a dense swamp forest. The higher terraces (Sunderland, $170 \mathrm{ft}$, and Brandywine, $270 \mathrm{ft}$ ) have a level-to-gently-rolling topography. Before the establishment of SRP, the areas where soils and drainage were favorable were extensively cultivated.

The Aiken Plateau was once a relatively smooth, gently sloping area with a regional slope to the southeast. However, the plateau has been deeply eroded by numerous drainage tributaries. Those interstream areas underlain exclusively by Cretaceous sediments are characterized by gently rolling hills and few, if any, undrained areas. Those interstream areas with a thin cover of Tertiary sediments are characterized by plateaus with steep ravines and numerous undrained "sinks" or "Carolina bays." 


\section{PART TITLE: SITE CONSIDERATIONS}

\section{ITEM TITLE: Geologic Formations Beneath The Savannah River Plant}

SRP is underlain by a sequence of unconsolidated and semiconsolidated upper Cretaceous, Teritiary, and Quarternary sedimentsa deposited on an eroded basement of Precambrian and/or Palezoic igneous and metamorphic rocks (figure 3-3). These basement rocks consist of gneiss and schist, and are at a depth of about $900 \mathrm{ft}$ at SRP. They are part of the crystalline rock formations, which outcrop at the Fall Line, and separate the Piadmont Plateau and the Coastal Plain, and dip $36 \mathrm{ft} / \mathrm{mile}$ to the sourheast underneath the Coastal Plain sediments.

The sediments form a wedge ranging in thickness from a few feet at the Fall Line to more than $1,200 \mathrm{ft}$ on the southeastern or downdip side of the plantsite. They strike in an average direction of N600E and dip from 6 to 36 $\mathrm{ft} / \mathrm{mile}$ to the southeast. The sediments are unbroken by large displacement faults or severe unconformities.

A large Triassic deposit in a basin of the crystalline rock underlies one-third of the plant area and is located in the southeastern section of the site. This deposit consists of sedimentary material formed into sandstones, siltstones, and mudstones.

The geologic formation that immediately overlies the basement rock is called the Tuscaloosa formation and is 500 to $600 \mathrm{ft}$ thick. This formation consists of sand and clay and contains several prolific water-bearing beds, which supply over 1,000 gal of water per minute to each of several plant wells.

Overlying the Tuscaloosa formation are several formations of the Tertiary Period that range in age from about 10 million to about 50 million years. These formations have a combined thickness of about $350 \mathrm{ft}$ in the central part of the plant. They consist predominantly of compact clayey sand and sandy clay with a few beds of sand and few beds of hard clay. At depths ranging from about 100 to $180 \mathrm{ft}$, there is a zone in which the sandy deposits include calcareous cement, small lenses of limestone, and some shells. At scattered discontinous localities, slowly circulating ground water has removed this calcareous material and left these lenses less consolidated than the sedimentary rork surrounding them.

a Terjtjary sediments include the Paleocene, Eocene, 01 igocene, Miocene, and Pliocene epochs. Quarternary sediments include the recent Pleistocene epoch. 
DPSP $80-1033$

PART 3

ITEM 210

PAGE 2

DATE $6-80$

PART TITLE: SITE CONSIDERATIONS

ITEM TIILE: Geologic Formations Beneath the Savannah River Plant

At some places on the plant, the rocks of the Tertiary Period are overlain by more recent terrace deposits of alluviun. These deposits are usually thin in the upland areas, but are of significant thickness in the valleys of the Savannah River and some of its 1 arger tributaries. 


\section{PART TITLE: SITE CONSIDERATIONS}

\section{ITEM TITLE: Hydrology and Surface Water}

Almost all of the plantsite is drained by tributaries of the Savannah River. Only one small stream in the northeastern sector of the site drains to the Salkehatchie River to the east. Each of the tributaries is fed by small streams; therefore, no location on the site is very far from a continuously flowing stream.

In addition to the floving streams surface water is held in over 50 artificial impoundmerts covering a total of over 3,000 acres. The largest of these impoundments, Par Pond, has an area of 2,640 acres. Water is held intermittently in marshes and over 200 natural basins or Carolina Bays. The large swamp bordering the Savannah River is crossed by several of the streams.

The five main streams on the plantsite are Savannah River tributaries. They arise on the Aiken Plateau and descend 100 to $200 \mathrm{ft}$ before discharging to the river. On the plateau, the streams are clear except during periods of high water. Rainfall soaks into the ground, and seepage from the sandy soil furnishes the streams with a rather constant supply of water throughout the year.

The five tributaries are Upper Three Runs, Four Mile Creek, Pen Branch, Steel Creek, and Lower Three Runs (figure 2-2). Two of these streams, Upper Three Runs and Four Mile Creek, are close to the F and $H$ separations areas.

Surface water on the plant is very low in dissolved solids (less than 50 ppm) and iron and is very soft. All streams have pH values between 6 and 7 .

Upper Three Runs, the longest of the plant streams, differs from the other four streams in two respects: it is the only one with headwaters arising outside the plantsite, and $i t$ is the only one that has never received heated discharges of cooling water from the production reactors.

Upper Three Runs drains an area of about 190 square miles. Its significant tributaries are Tinker Creek and Tims Branch. Tinker Creek is a rather lengthy headwaters branch. Tims Branch receives industrial wastes from the iuel fabrication facilities in $M$ Area and from SRL; it flows through an impoundment, Steeds Pond. The M-Area effluent flow averages about 1 cfs. In July 1972, Tims Branch flowed at $1.6 \mathrm{cfs}$ below steeds Pond and $4 \mathrm{cfs}$ just before discharge into Upper Three Runs. 
DPSP $80-1033$

PART 3

ITEM 300

PACE 2

DATE $6-80$

PART TITLE: SITE CONSIDERATIONS

ITEM TITLE: Hydrology and Surface Water

The flow and temperature of Opper Three Runs have been ronitored at the highway 125 crossing. Fourteen flow measurements between 1960 and 1966 ranged from 193 to $529 \mathrm{cfs}$ and averaged $265 \mathrm{cfs}$. Flows measured in June and July 1972 were 345 and $195 \mathrm{cfs}$, respectively.

The average temperature for 1959 so 1966 was $16.90 \mathrm{C}$, with a maximum monthly average of $23.00 \mathrm{C}$ in July.

Upper Three Runs is designated as a national hydrologic benchmark stream by the United States Geological Survey (USGS). In benchmark streams, the water quality, temperature, and flow are measured monthly to provide hydrologic data for a river basin in which the hydrologic regimen will likely be governed solely by natural conditions. The thermal effects laboratory has been established on Upper Three Runs Creek just downstream frow F Area; the creek water flow is used in the research done there.

Four Mile Creek followe a generally southwesterly path to the Savannah River for a distance of about 15 miles. In the swamp along the river, the creek flow partially empties into Beaver Dam Creek which is a wuch shorter stream that discharges into the river. The remainder of the Four Mile Creek flow discharges through an opening in the levee between the swamp and the river, seeps through the levee into the river, or flows down the swamp and mixes with Steel Creek and Pen Branch.

Four Mile Creek and Beaver Dan Creek together drain about 35 square miles and receive discharges frow four plant areas. Four Mile Creek receives effluents from $F$ and $A$ separations areas and the reactor cooling water discharge from the C-Area reactor. The average flow upstream of any plant discharge is less than $0.5 \mathrm{cfs}$ and is increased by $F$ and $H$ Area effluents and drainage to about $20 \mathrm{cfs}$ just above the confluence with the reactor discharge. After the junction with the reactor cooling water, the creek flows about 7 miles before entering the river swamp. Beaver Dam Creek receives 65 to 130 cfs of effluent from the heavy water production process and the associated power plant in D Area. 
PART TITLE: SITE CONSIDERATIONS

ITEM TITLE: Hydrology and Ground Water

Water for domestic and process use will be obtained from deep wells in the vicinity of the processing facility because of the distance from the river.

The normal water table has not been well defined north of Upper Three Runs Creek. The highest recorded elevation south of Upper Three Runs is $286 \mathrm{ft}$ above mean sea level recorded near $H$ Area on March 30, 1965. Along the Savannah River at the southeast corner of the plant, the elevation is about 80 ft above mean sea level.a Local levels in the water table are modified by elevations of the drainage courses and variation in the permeability of the subsoil. In some areas, the water table and creek flow are sustained both by artesian water rising from the Tuscaloosa formation and by rainfall.

The ground water from all aquifers in the area has a chemical composition within Iimits for potable water defined by the U.S. Public Health Service. However, some samples have very high concentrations of iron. The temperature of ground water from all aquifers is between 65.5 and $710^{\circ}$. Table 3-2 compares the chemical compositions of characteristic ground water samples from different aquifers.

a At SRP, the nominal level of the river varies from about 84 ft above mean sea level near the upper plant boundary to about $80 \mathrm{ft}$ at the lower boundary. 


\section{PART TITLE: SITE CONSIDERATIONS}

ITEM TITLE: Water From the Tuscaloosa Formation

The Tuscaloosa formation is the principal aquifer in the SRP area and is under artesian pressure over much of the area. The aquifer is recharged predominantly through the Tertiary cover in the high areas around Aiken. Water movement in the aquifer at the plantsite is toward the piezometric low along the Savannah River downstream from Augusta.

Water from the Tuscaloosa formation is generally soft, acidic, and low in dissolved solids. The concentration of alkali. ions (sodium and potassium) is about equal to that of the alkaline earths (calcium and magnesium), and the number of sulfate, chloride, and nitrate ions exceeds the number of bicarbonate ions. Although little fluoride ion is found, it does occur in some locations in concentrations up to $0.1 \mathrm{ppm}$. Water from the Tuscaloosa formation is corrosive to most metal surfaces because of the very low concentration of dissolved solids and low $\mathrm{pH}$. This is especially true where the water contains appreciable amounts of dissolved oxygen and carbon dioxide. Such water causes iron pipe to deteriorate rapidly and to discolor the water flowing through it. 
PART TITLE: SITE CONSIDERATIONS

ITEM TITLE: Water From The Ellenton Formation

Wells screened in the Ellenton formation generally do not have the capacity to yield as much water as the permeable materials in the underlying Tuscaloosa formation. Because there is no continuous bed of clay separating the two formations, they act as one aquifer.

Water from the Ellenton formation generally has a low concentration of dissolved solids, a low hardness, a high content of iron, and a comparatively high proportion of sulfate among the ions. The ratio of sulfate ion concentration to rotal anion concentration ranges from 35 to $65 \%$. The dissolved silica is a relatively constant 22 to $28 \%$ of total dissolved solids. The concentration of calcium ions is in excess of the concentration of bicarbonate ions; this may be caused by scattered crystals of gypsum (calcium sulfate) in the Ellenton formation. 


\section{PART TITLE: SITE CONSIDERATIONS}

\section{ITEM TITLE: Water From The McBean and Congaree Formations}

The McBean and Congaree formations consist of (1) fine-tomedium sand, (2) green glauconitric marl and clayey sand, (3) laminated beds of red-brown or yellow semiplastic to nonplastic clay, (4) impure beds of soft fossilliferous limestone or marl, and (5) lenses of silicified limestone.

The fine-to-medium sand sections and the limestone section are water bearing and yield moderate-to-sizable quantities of water to industrial and municipa] wells in the area near SRP. Next to the Tuscaloosa formation, the McBean and Congaree formations are the most prolific aquifers in the area.

These formations are recharged in the topographically higher regions of SRP and discharge into the major drainageways on the plantsite such as Upper Three Runs, Four Mile Creek, and Steel Creek. Some water also discharges to the Savannah River and some migrates downdip to discharge by upward vertical leakage to overlying formations. Artesian conditions prevail over the greater part of the extent of the aquifer, and wells in the southern and southeastern part of the plantsite flow quite freely from the calcareous beds of the formation.

Water from the sandy parts of the McBean and Congaree aquifers is similar in chemical composition to that from the Tuscaloosa formation. In general, the water is acidic and low in dissolved solids. Water circulating through 1 imestone beds in the McBean formation contains alkaline earth metals in excess of the alkali metals, and the bicarbonate ion is in excess of the total concentration of other anionic constituents. This composition is comonly found in waters circulating through deposits made up predominantly of calcium carbonate. This water also contains higher concentrations of silica than water from any other formation at SRP. 
PART TITLE: SITE CONCENTRATIONS

ITEM TITLE: Water From The Barnwell Formation

The Barnwell formation of Eocene age is a deep-red fine-to-coarse clayey sand and compact sandy clay. Parts of the formation contain mottled-gray or greenish-gray sandy $c l$ ay and ledges of ferruginous sandstone. Small quantities of water are obtained from the Barnwell formation at some locations, but ordinarily, large supplies of water are not to be expected. 
ITEM TITLE: Hydrology of the Chemical Separations Areas

F and H-Areas are both located on relatively high ground between Upper Three Runs and Four Mile Creek. The locations of the F-and H-Area tank farms and the interarea waste transfer lines are indicated in Figure 3-4, Appendix $B$. The surface drainage from both $F$ and $H$ Area flows toward both Four Mile Creek and Upper Three Runs. Because of the water table contours, drainage from the $F$-Area tank farm into the ground divides with some flowing toward Upper Three Runs and some flowing toward Four Mile Creek (Figure 3-5, Appendix B). Drainage from $H$ Area into the ground flows toward Upper Three Runs. Fi gure $3-6$, Appendix $B$ shows the depth below the surface of the maximum water table that occurred in March 1965. The location of the proposed waste processing facility is shown in Figure 3-7, Appendix B.

The tank arrangements in each area are shown in Figures 2-3 and 2-4, Appendix B. For each group of completed tanks, Table 3-3, Appendix A lists the tank type; elevations of the ground surface, tank top, and tank bottom; and high and low recorded water table.

The results of detailed studies on the plantsite reveal how the geology and hydrology of the site affects ground water movement. Differences in the piezometric head (water pressure) measurements show the direction that ground water flow will take. Figure 3-8, Appendix $B$ shows the vertical distribution of hydrostatic head in ground water near $H$ Area, measured with six piezometers near the H-Area waste tank farm and four other piezometers outside $H$ Area. Downward percolation of water from the water table is indicated by decline to minimum head in the Congaree formation. In the two piezometers (ID and IE of Figure 3-8, Appendix $B$ ) above the $t$ an clay, the decline is probably fairly uniform with depth. Across the tan clay (ID to $1 \mathrm{C}$ ), the decline is relatively abrupt (about $12 \mathrm{ft}$ of head decline in $18 \mathrm{ft}$ of depth). The tan clay, maximum $12 \mathrm{ft}$ thick, is sufficiently impermeable to divert some of the water laterally (1) creeks, the nearest being several thousand feet away.

Within the fairly permeable sands of the McBean formation, the head declines only $2 \mathrm{ft}$ in approximately $50 \mathrm{ft}$ of geologic material (1C to $1 \mathrm{~B}$ ). The green clay shown on Figure 3-8, Appendix $B$ is one of the more significant hydrologic units in the region; it is only 6 to $10 \mathrm{ft}$ thick in H Area (al though somewhat thicker elsewhere), and its importance is easily nissed if only drilling information is available. The $80-\mathrm{ft}$ decline in piezometric head ( $1 B$ to $3 B, 1 A$ ) across the green clay indicates that the clay is continuous over a large area and has low permeability. Thus the green clay also diverts water laterally to creeks that have eroded down into the McBean formation. These points of discharge are farther from $H$ Area than the discharges from the Barnwell formation. 
PART TITLE: SITE CONSIDERATIONS

I'TEM TITLE: Hydrology of The Chemical Separations Areas

Ground water in the Congaree zone below the green clay also discharges into Upper Three Runs. This formation has the lowest hydrostatic head. The Ellenton formation has a head approximately $7 \mathrm{ft}$ higher than the Congaree, thus indicating that the El lenton is not receiving water from the Congaree formation.

Head is uniform in the three Tuscaloosa piezometers ( $P 3 C, P 3 B, P 3 A$ ), lower than that in the Ellenton formation (DRBTWW), but higher than that in the Congaree. Both the recharge and discharge regions of the Tuscaloosa formation ar': princ: ally off the plantsite, and they control its water level within the plantsite.

Piezometric contours for the Tuscaloosa formation (Figure 3-9, Appendix B) indicate that the Tuscaloosa water flows from the Aiken Plateau in a curved path to the Savannah River valley. This lateral flow through the very permeable formation supports the Tuscaloosa water level on the plantsite. Re :harge by vertical percolation from above probably does not occur at SRP. The Tuscaloosa aquifer underneath a portion of southeastern Georgia also flows toward and outcrops in the Savannah River valley as shown in Figure 3-9, Appendix B.

* The water table elevations of $\mathrm{H}$-Area wells range from 107 to 120 feet be low grade with drawdown ranging from 26 to 39 feet after pumping at 1000 gpm for 24 hours. See Table 3-12, Appendix A for detailed information. ${ }^{\prime}:$ 
PART TITLE: SITE CONSIDERATIONS

ITEM TITLE: Temperature, Humidity, and Precipitationa

The average Augusta winter temperature is $480 \mathrm{~F}$, the average summer temperature is $800 \mathrm{~F}$, and the annual average is $650 \mathrm{~F}$. The average daily temperature variation is about $200 \mathrm{~F}$. Additional temperature data covering a 77-year period are given in table 3-4 along with relative humidity data. The average relative humidity for Augusta is $70 \%$.

The highest, lowest, average high, average low, and average temperature at SRP for the years 1961 through 1972 are given in figure 3-10. Observed temperature extremes measured at Augusta and SRP are listed in table 3-5.

The average minimum remperature and the total time that the temperature is less than 320F in Augusta are listed in table 3-6 for the years 1966 through 1972.

The average annual rainfall at SRP was 47 in. for the years 1952 through 1972. Total annual rainfall measured at SRP for 1952 to 1972 is given in table 3-7. The recorded maximum annual precipitation in Augusta occurred in 1929 (73.82 in.); the recorded minimum, 1933 (28.05 in.).

The observed rainfall for 1971 and 1972 at different locations on the $\mathrm{plant}$ and in Augusta is given in figure 3-11. Precipitation is higher at all locations onplant than in Augusta with considerable variability among the si.tes at SRP.

On the average, rainfall is greatest in March and least in November (table 3-7). Hourly observations in Augusta indicate that the intensity of rainfall is usually less than $0.5 \mathrm{in}$. per hour, although the rate may reach $2.0 \mathrm{in}$. per hour in the summer.

Snowfall and freezing rain, which are infrequent during the winter months in the SRP area, does not cover the ground for more than a few days.

a Meteorological data for Augusta cited in this report were obtained from a series of annual reports entitled "Local Climatological Data Annual Summary with Comparative Data, Augusta, Georgia," published by the U. S. Department of Commerce. 
PART TITLE: SITE CONSIDERATIONS

ITEM TITLE: Wind

Wind data are obtained from two locations in the vicinity of SRP: the National Weather Service in Augusta and an instrument television tower within 15 miles of the center of SRP. Differences in the data are expected due to differences in height above ground level from which the data were obtained and topographical differences. The National Weather Service instruments are located ar the Bush Field Airport which is in the Savannah River valley at an altitude of about $130 \mathrm{ft}$ above mean sea level. Wind channeling effects in the valley could cause some bias from the northeast direction. The television tower at Beech Island is at a higher altitude (380 ft) and, therefore, should be relatively free of directional bias due to local ropography.

There are also surface effects with respect to measured wind velocity. The velocity generally increases as a logarithmic function of height near the ground surface. Departures from the logarithmic function occur due to variations in atmospheric stability.

The average hourly wind velocity for Augusta was $6.4 \mathrm{mph}$ (measured at a height of $20 \mathrm{ft}$ ) for the years 1950 to 1955 .

The frequency of wind speed as a function of height on the television transmission tower near SRP is given in table 3-8. These data show that at 120 ft above the ground, speeds of less than $2 \mathrm{~m}$ per second (approximately $4 \mathrm{mph}$ ) occur 15\% of the time with frequency decreasing with elevation. That this is so much less than indicated for Augusta is due to two reasons: more sensitive instruments on the television tower and greater height above the ground. The most frequent wind speed at $120 \mathrm{ft}$ above the ground is 2 to $5 \mathrm{~m}$ per second.

The occurrence of a hurricane along the coastal region does not generally mean that SRP will be subjected to winds of hurricane force. SRP is $100 \mathrm{miles}$ inland, and the high winds associated with hurricanes tend to diminish as the storms move over land. Winds of $75 \mathrm{mph}$ were measured by anemometers mounted at $200 \mathrm{ft}$ only once during the history of SRP -- during the passage of hurricane Gracie to the north of the plantside on September 29, 1959. 


\section{PART TITLE: SITE CONSIDERATIONS}

ITEM IITLE: Wind

The prevailing wind direction, by month, is given in table 3-9 based on a 9-year record at Auguers. Wind direction frequency near SRP is shown in figure 3-12 as the percent of time the wind was blowing from different directions. This figure represents data obrained at an elevation of $300 \mathrm{ft}$ (supplemented with data from elevations of 120 and $450 \mathrm{ft}$ ) from the instrumented celevision tower near SRP over a 2-year period (1966-1968). For the period measured, there was a preferance for winds frow the southwestern quadrant with a secondary maximun for winds from the northeastern quadrant.

The daily shift of prevailing wind at Augueta, as shown in table 3-10 is as much as 1800 from day to day throughout the year. The 1957 monthly average of day-to-day shifts in prevailing wind direction ranged from 42 to 80 per day. In addition, hourly observations at Augusta show that the wind direction was not often constant for 24 hours during the year 1957. In most cases, the wind shifted frow one hour to the next. 


\section{PART TITLE: SITE CONSIDERATIONS}

\section{ITEM TITLE: Tornados}

$S R P$ is in an area where occasional tornadoes are to be expected. National Weather Service records from 1916 to 1975 show that at least 300 rornadoes have occurred in South Carolina. In 1975, 12 tornadoes struck South Carolina and 22 struck Georgia. More accurate records of wind speeds and damage area have been kept since 1959. The Fugita-Pearson scale for assessing tornado wind speed and damage has been in use by the National Weather Service since 1971 . Most rornadoes occur in South Carolina and Georgia during the period February through June and August to September and travel in a southwest to north east direction. The combined area of Georgia and South Carolina is struck by an average of 24.6 rornadoes per year.

Tornado data from 1969 to 1975 show that Georgia and South Carolina may have extreme tornadoes with a maximum wind speed up to $260 \mathrm{mph}$. Tornadoes with winds up to $318 \mathrm{mph}$ have been observed in the midwest but not in the southeast. The probability of a tornado with winds in excess of $250 \mathrm{mph}$ striking a point within the SRP is estimated to be less than 10-5 per year. During the 24-year history of SRP, there has been no tornado damage to any production facility. On two occasions, light damage has occurred (displacement of light sheet metal roofing, window breakage, tree breakage, etc.). Several other rornado funnels have been sighted in unpopulated areas on the plantsite but investigations showed no damage; thus, the sighted funnels did not touch the ground. Investigation of tornadoes occurring near SRP in 1975-1976 showed damage from tornadic wind speeds varying from 100 to $175 \mathrm{mph}$. 


\section{PART IITLE: SITE CONSIDERATIONS}

ITEM TITLE: Seismicity

SRP is located in an area where moderate damage may occur from earthqualces, based on earthquake risk predictions by the U.S. Coast and Geodetic Survey. The spatial distribution of South Carolina earthquakes, with respect to southern Appalachian seismicity, is shown in figure 3-13. On the bas is of three centuries of recorded history of earthquakes, an earthquake above an intensity of VII on the modified Mercalli (MM) scale would not be expected at the Savannah River Plant. Average acceleration for intensity VII corresponds to $0.13 \mathrm{~g}$. During the past 100 years, the area within a $100-\mathrm{mil}$ e radius of SRP has experienced one shock of intensity $X$, one shock of intensity VIII, two shocks of intensity VII, and 12 shocks of intensity V, MM. Seismic monitors, which were installed in SRP reactor buildings between 1952 and 1955 , are set to alarm at 0.0028 (intensity $[I$ ) and have never indicated an earthquake shock of this intensity since their installation.

The shock of intensity $X M$ was the Charleston earthquake of August 31 , 1886. This earthquake was felt 800 to 1,000 miles away. An area of about $2,000,000$ square miles was affected.

The Charleston earthquake caused only minor superficial changes to the ground surface. The epicentral region was broken by many fissures through which water issued, but the fissures seldom attained a width of more than 1 in. The earthquake was probably caused by a fault movement in basement rock beneath a half-mile thickness of unconsolidated sediments. There is evidence that the intensity at and near the Fall Line was slightly greater than that nearer to the epicenter of the 1886 Charleston earthquake. This presumably is due to the fact that the sands and clays of the coastal plain sediments provide greater attenuation to seismic waves than do the underlying basement rock. The effect may also be due to reasonance of the soil column near the Fall Line.

Damage was greater at Augusta, GA, and Columbia, SC, on the Fall Line, than at intermediate locations. Reports on the effects of the 1886 Charleston earthquake from towns in the vicinity of SRP were used to estimate earthquake intensities.

Since the 1886 earthquake, Charleston has been the focus of continued seismic activity indicating that the earthquakes are associated with a rectonic structure even though it is obscured by the overlying Coastal Plain sediments. 


\section{PART TITLE: SITE CONSIDERATIONS}

\section{ITEM IITLE: Seismicity}

Earthquakes associated with the Piedmont Province do not seem to be associated with tectonic structures and could thus be assumed to occur anywhere within the province. The maximum earthquake occurred in Uniot, County on January 1, 1913. It occurred about 95 miles from SRP, and its intensity at SRP was about III MM. Since these earthquakes are not associated with a known tectonic structure, they can reasonably be assumed to occur anywhere in their tectonic province, which could be as close as 20 miles from waste management facilities at SRP. If an intensity VI-VII MM earthquake were to occur at this distance, the intensity at SRP would be V-VI MM. At the VI level the acceleration would be approximately $0.07 \mathrm{~g}$. Using a similar logic, the maximum earthquake in the Blue Ridge province and Valley and Ridge provinces would result in an intensity of I-II M and the acceleration would be less than 0.028 .

Intensified geologic studies have revealed a fault (Belair) northwest of Augusta along the Fall Line, in which crystalline metamorphic rocks are faulted up against sediments of the Tuscaloosa formation and in one area, against sediments that were reworked from the Tuscaloosa formation. Based on a study of the Belair fault by the U.S. Geological Survey, the Nuclear Regulatory Commission states:

The Belai.r fault zone is located about $16 \mathrm{~km}$ west of Augusta, GA. It is actually a number of faults, each 1.1 to $4.7 \mathrm{~km}$ in length, which when taken together comprise a zone at least $21 \mathrm{~km}$ long trending approximately north-northeast.

The conclusion of the latest report by the U. S. Geological Survey indicates that the age of the oldest unfaulted stratigraphic unit is rhought to be between 2,000 and approximately 23,000 years old. The age of the youngest faulted unit is approximately 65 million years old. To dare, no intermediate age strata have been found which would provide a more definitive date of last movement on the fault. Thus, although the study does not absolutely demonstrate lack of movement in the 1 ast 35,000 years, it does provide a high level of confidence that the last movement is not as recent as previously believed. With the absence of any correlation of macroseismicity with this fault zone, we have concluded that this fault is nor capable within the meaning of Appendix A to 10 CFR Part 100, "Seismic and Geologic Siting Criteria for Nuclear Power Plants". We will continue to monitor research activities which could lead us to modify this finding. 


\section{PART TITLE: SITE CONSIDERATIONS}

ITEM TITLE: Radioactivity Contamination History

** Two locations within S-Area were contaminated in 1958. This contamination was removed in June, 1982. ${ }^{\star \star}$

In the first incident, which occurred in April 1958, uranium solution and contaminated solvent leaked from a tank car loading apron in Building 211-H to a storm sewer. An estimated 1 curie of activity was leaked. The storm sewer drained east of Building 294-H. The drainage ditch was backfilled to fix the contamination. $* *$ The contaminated area at HP $\# 10$ is defined by coordinates (a) $N 72124, E 64672$; (b) N72132,E64790; (c) N71967, E64684; (d) N71961, E64810; (e) N71859, E64692; and (f) N71865, E64860.**

In the second incident, which occurred in November 1958, a recycle sump in Building 211-H overflowed carrying contaminated water and solvent via a storm sewer to an area northeast of Building $211-\mathrm{H}$ to HP Outfall 非9. Less than 1 curie of activity was leaked. A dam was built to retain the contaminated water. Subsequently, the retention pond and ditch were backfilled. The contaminated area at HP 559 is defined by coordinates (a) N73916, E63647; (b) N73916, E63950; (c) N73690, E63600; (d) N73690, E63903; (e) N73451, E63550; and (f) N73451, E63855.

**Health Protection Department has core drilled in these two areas to determine the level of radioactivity remaining in the soil and the extent of any migration that may have occurred. Data from the core sampling program were evaluated and the soil removed based on these data. ${ }^{\star \star}$ 
PART TITLE: GENERAL REQUIREMENTS AND SCOPING BASIS

ITEM TITLE: Site -- Dismant ling and Relocation

The site chosen for the waste processing facility is a gently rolling wooded area. There are no existing facilities in the area.

The DWPF project should fully fund any cost associated with site clearance, crossing existing roads, and new tank farm facilities such as *waste transfer lines, ** pump pits, etc. that are specifically for $S$ Area use.

Existing diversion boxes, tank farm area evaporators, etc. may require modifications to accomodate the DWPF waste streams. These modificarions will be provided by the Interim Waste Operations program.

See Part 5, Item 170 for coordinates of the tie-in point for nWPF pipelines to existing tank farm area facilities.

All construction work will be under non-regulated conditions. 
DPSP $80-1033$

PART 4

ITEM 120

PAGE 1 of 1

DATE 9-82; Rev. 9

PART TITLE: GENERAL REQUIREMENTS AND SCOPING BASIS ITEM

TITLE: Site Preparation by Plant

**The radioactivity contamination history at $S$-Area site was discussed in Part 3, Item 900. The contaminated soil has been removed.

Usable timber is being cut under the supervision of the U. S. Forestry Service. ${ }^{* x}$

Some H\&V cooling water discharged through the northeast H-Area storm water outfall causes a small swamp which would be included within S-Area. The water or the outfall run off will be diverted away from that area prior to the start of project construction.

The costs of completing the above items will not be part of the project. 
DPSP $80-1033$

PART 4

ITEM 180

PAGE 1 of 1

DATE 9-82; Rev. 9

PART TITLE: GENERAL REQUIREMENTS AND SCOPING BASIS ITEM

TITLE: Anticipated Funding Schedule

Profect schedule should be based on the following assumptions:

Design only project authorized - FY 82

Construction project authorized - FY 83

Construction period - $1983-1988$ 
PART TITLE: GENERAL REQUIREMENTS AND SCOPING BASIS ITEM

\section{TITLE: Sumary Description of Production Processes}

Prior waste handling operations in the $F$ and $H$ Area waste tank farms will have separated the process waste into a clear supernate or salt solution and a washed settled sludge from which most of the salt solution and aluminum have been removed.

Project objective are to be met by two stages of construction and operation. The first, Sludge Processing, will provide a vitrification facility to incorporate the insoluble sludge portion of the waste together with the long lived rationuclides contained in the sludge into a borosilicate glass sealed in canisters and stored onsite until shipped to a Federal repository. The second stage will provide a facility to decontaminate waste salt solution and transferring the recovered radionuclides to the vitrification facility.

When Salt Processing begins, the recovered radionuclides (primarily isotopes of $\mathrm{Cs}, \mathrm{Sr}$, and $\mathrm{Pu}$ ) will be incorporated into the sludge feed of the vitrification facility for immobilization in the borosilicate glass. Facilities to make the recovered radionucide feed compatible with sludge processing are part of the Salt Plant Project. 
PART TITLE: GENERAL REQUIREMENTS \& SCOPING BASIS

ITEM TITLE: Future Expansion Requirements

1. Sufficient contiguous area should be reserved for future incremental expansions of the interim glass storage building to a storage capacity up to the total number of canisters specified in Part 11, Item 405. Assume that the interim storage bullding will be expanded in continuous increments identical in size with the first unit.

2. Sufficient area should be reserved to build a replacement sand filter adjacent to and to tie into the air tunnels of the original sand filter.

3. ** Sufficient area should be reserved for supporting faclitiles (cold feed, administration bullding, etc.) to accommodate any expansion requirements that are necessitated by the Salt Plant construction. $\star \star$

4. Sufficient area should be reserved adjacent to the vitrification processing building to accommodate up to a $100 \%$ expansion of that building if necessitated by the selection of a waste form other than borosilicate glass. Assume the expansion to take place toward the north (assuming a north-south major axis for the main processing building). Allow a service alley (about $30 \mathrm{ft}$ ) for piping and electrical services between the building and the expansion area.

5. **Allow space to the extent feasible to increase the size or capacity of the following facilities to accommodate Salt plant at some future date without increasing capital investment in the Sludge plant:

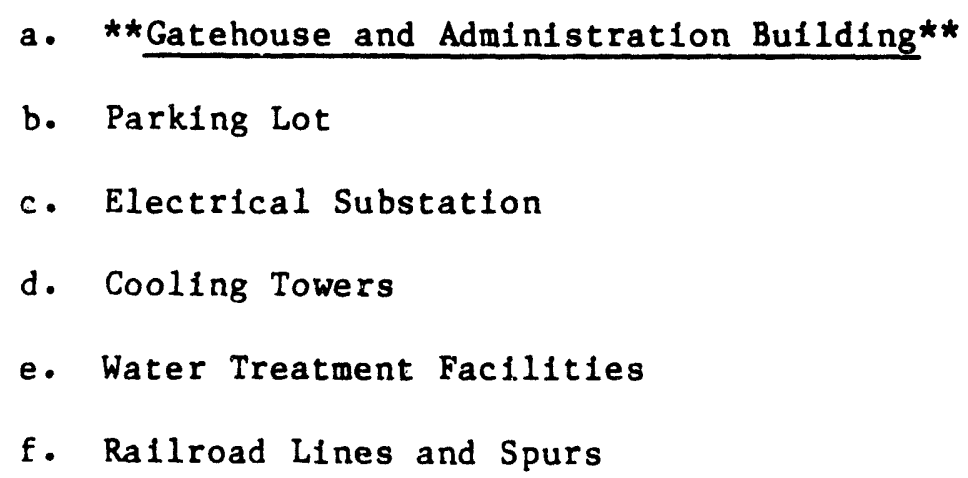

6. $* \star$ Plan excavations required so that future expansions as described above can be made while all existing factlities are operating.

7. Allow space, accessible by rall and truck for shipplng facilities. This space should be as close to the north end of 221-S and 250-S as practical. ** 
PART TITLE: GENERAL REQUIREMENTS AND SCOPING BASIS ITEM

ITEM TITLE: Security Requirements -- Considerations

The security requirements for S-Area are discussed below:

a. Patrol personnel will be assigned to the area for the protection of government property by controlling vehicular and pedestrian traffic entering and leaving the area. The entire area should be enclosed by a chain-link security fence with controlled entry.

b. The patrol gatehouse facility or area in which patrolmen are housed is to be hardened against possible terrorist attack in accordance with DOE requirements for all new facilities (Reference $C_{-4}$, Part 4, Section D.) see Part 11, Item 275 for specific areas to be hardened. There will be no requirements for safeguards (i.e. doorway and gate monitors, closed circuit television monitors, etc.). The guard area should have good visibility of approaching roads and the employee parking lot.

c. Safeguarding of special nuclear materials is not a consideration in the design of S-Area buildings. Protection of expensive, highly vunerable government property from sabotage is the main consideration.

d. The physical facilities for a patrol gatehouse headquarters may be either a separate facility located at the area gate or it may be combined with the administration building based on economics and site layout. If a separate patrol gatehouse building is provided, it should be complete with offices, lunchroom, change room, gun room, etc., as described in *'Part 11 , Item $275 . * *$ 
PART TITLE: GENERAL REQUIREMENTS AND SCOPING BASIS ITEM

\section{ITEM TITLE: Earthquake and Tornado Design Criteria}

DOE Order 6430 (Reference C-11, Appendix C) provides general design criteria for DOE facilities and specific design criteria for certain facilities (i.e. plutonium, etc.) but does not provide specific criteria for waste processing plants.

In the absence of specific design criteria for a waste processing plant, DWFF design requirements are based on an interpretation of the above document and are detailed in Reference C-17. SRP requirements and the bases for these requirements are discussed below:

\section{A. Design Basis Earthquake (DBE)}

\section{Background}

The term Safe Shutdown Earthquake (SSE) is used in various regulations and Design Basis Earthquake (DBE) in Reference $C-11$. The two terms are synonymous. Since the DWPF is a DOE facility, the term DBE will be used to describe the DWPF requirements.

**Site investigations as presented in Section 4.2 .5 of Reference $c-17$ defines the peak horizontal ground acceleration for the design basis earthquake at SRP as $0.208^{\star \star}$

Reference C-11, Chapter XXI, 3.e and Chapter XXI, 7.a specifies the seismic requirements for plutonium facilities. It specifies that critical structures and systems important to safety shall be designed to withstand the DBE. These structures and systems are those necessary to assure the capability to:

a) As necessary to safely shutdown operations, maintain the plant in a safe shutdown condition, and maintain integrity of the final confinement barrier of plutonium.

b) To prevent or mitigate the consequences of accidents which could result in potential offsite exposures determined in accordance with 10 CFR 100.

**It should be recognized that the DWPF Sludge Plant is not a plutonium processing facility and, therefore, the above criteria do not apply as such, but rather are used to formulate a conservative

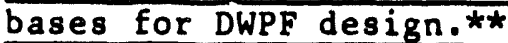


PART TITLE: GENERAL REQUIREMENTS AND SCOPING BASIS

ITEM TITLE: Earthquake and Tornado Design Criteria

2. SRP Requirements and Bases for DWPE Design

** Seismic design requirements for the DWPF should be based on Reference $\mathrm{C}-17 . * \star$

If a DBE should occur, it is assumed that the DWPF would no longer be useable as a production facility. However, the DWPF should:

a) contain the radioactive materials to the maximum extent practical and not to exceed limits specified in 10CFR100.

b) achieve a safe shutdown for all process operations.

c) cope with the consequences of any accident resulting from the earthquake.

d) confine any spilled radioactive materials while the necessary resources are obtained to cope with the problem.

To accomplish the above objectives, recommended construction criteria for the principal DWPF structures and systems are shown in Table 4-1, Appendix A.

B. Investment Protection Earthquake (IPE)

1. Background

The specific criteria for plutonium facilities contained in Reference $\mathrm{C}-11$, (Chapter XXI, 3.1) defines an operating basis earthquake (OBE) as equivalent to one-half of the DBE and as the earthquake for which the facility is designed to remain operable or readily restorable to operating condition. Chapter XXI, 7.a of Reference C-11 states that critical areas shall be capable of full operability and critical items (ventilation, electrical, fire protection, etc.) should be capable of continued operation after an OBE. It is also stated that an analysis shall be made on a case-by-case basis of other than critical items to determine if operability should be retained for an OBE.

It is assumed that the requirements for the OBE were developed by the nuclear power industry so that electrical generation could be restored relatively quickly, whereas the rationale for the DOE position is that providing some protection to be able to maintain a high cost production facility in a productive state is justified while willing to risk the loss of less expensive supporting facilities. It is also presumed that if DOE prepared criteria for a waste processing facility, a similar criteria would be invoked. These assumptions are used as a bases for the SRP requirements below for an investment protection earthquake (IPE). 
PART TITLE: GENERAL REQUIREMENTS AND SCOPING BASIS

ITEM TITLE: Earthquake and Tornado Design Criteria

2. SRP Requirements and Bases for DWPF Design

SRP requirements for an IPE are as follows:

a) **IPE design criteria for horizontal ground motion for the DWPF should be based on Reference C-17. $\star *$

b) Structures and facilities designed according to the IPE design criteria must be capable of resuming operations after repair and/or replacement of damaged equipment. The repair and/or replacement of equipment must be limited to that equipment which is normally designed for this purpose.

Examples of this philosophy are:

- Crane should be retrievable to crane maintenance for repair

- Embedded piping should be useable

- Trunnion guides, sleepers, etc. should not be misaligned

- Critical elements of ventilation systems, fire protection systems, and emergency electrical systems should be operable as necessary to protect critical structures and items

- In-cell process vessels, jumpers, etc. should be replaceable as necessary

- Operating area equipment should be repairable or replaceable as necessary

- Supporting facilities (administration building, cold feed, etc.) should be repairable or replaceable as necessary.

c) Table 4-1, Appendix A presents an analysis on a case-by-case basis of the items for which full operability is to be maintained. The rationale for this classification is that structures and equipment essential to safety must remain operable and all equipment which is not normally repairable must remain useable. 
DPSP $80-1033$

PART 4

ITEM 700

PAGE 4 of 4

DATE 9-82; Rev. 9

PART TITLE: GENERAL REQUIREMENTS AND SCOPING BASIS

ITEM TITLE: Earthquake and Tornado Design Criteria

C. Tornado

1. Background

Section 4.2.2 of Reference C-17 presents historical data on tornadoes in South Carolina. The Design Basis Tornado (DBT) is defined as having a rotational speed of $230 \mathrm{mph}$ at a radius of $230 \mathrm{ft}$ and a maximum translational speed of $50 \mathrm{mph}$, also having a total pressure drop of $1.5 \mathrm{psig}$ at a maximum rate of $0.5 \mathrm{psi} / \mathrm{sec}$.

2. SRP Requirements and Basis for DWPF Design

Recommended tornado construction criteria for DWPF structures and systems are defined in Table 4-1, Appendix $A$ and should meet the DBT requirements set forth in Reference $\mathrm{C}-17$.

\section{Standard Construction}

1. Background

Reference C-11, Chapter IV, 9.b states that except where otherwise designated in these criteria, earthquake loads shall be accordance with the applicable section of the Uniform Building Code.

Reference $C-17$ specifies standard construction criteria for the DWPF.

2. SRP Requirements and Basis for DWPF Design

Standard construction facilities are to be designed in accordance with Re ference $\mathrm{C}-17$. 


\section{PART TITLE: PROCESS FACILLITIES BASIS}

ITEM TITLE: SUmmary Block Diagram

**A simplified process flow diagram for DWPF Sludge Plant is given in Figure 5-1, Appendix $B_{0 *}$ All vessels required to operate the process are located within one main process cell in the vitrification building. The main process cell may be divided into sub-cells to segregate some portions of the process such as the glass melting and mechanical handling operations for better ventilation and contamination control. All vessels estimated to be required to operate the process are 1 isted in Table 5-5, Appendix A; included are some of the required vessel design features.

**The facilities are to be designed for processing 5-year cooled sludge from the waste farm. Waste from the vitrification plant returning to the waste farm is to be segregated from the 15-year cooled salt solution that will be processed in the salt processing facilities.**

All radioactive waste solution generated in the vitrification building is neutralized if necessary and transferred to the waste farm through the Recycle Collection Tank. 


\section{PART TITLE: PROCESSING FACILITIES BASIS}

\section{ITEM TITLE: Interarea Transfer Piping}

Underground interarea transfer 1 ines will be required to transport sludge feed and recycle waste between $S$ and $H$ Areas. A third 1 ine is required as a common spare. All lines must drain by gravity to a low point pump tank. To accomplish transfers, maximum use should be made of existing lines and diversion boxes. **The transfer piping provided for the sludge Plant should be planned with consideration for the future requirements for salt processing. Provide four process lines between outside 221-S and the chemical process cell. ${ }^{* t}$ Additional design requirements follow:

Piping Origination -- For this design effort, the sludge feed, recycle waste, and spare line should all originate at coordinates N71200, E61830. Tie-ins will be made under clean (non-regulated) work conditions. The elevation of the lines at this point is to be adjusted to provide free drainage.

Construction -- The three interarea lines require jacketing. A double core-single jacket and a single core with jacket are required. The sludge feed (slurry) and spare lines are to be paired in one jacket. Leak detection and hydrostatic test provisions for the jacket are to be included. These lines must undergo a flexibility analysis. All transfer lines are to have an unidirectional minimum slope of $0.5 \%$. Refer to Part 3 , Item 130 for 1 ine siting information.

Shielding -- Provide sufficient shielding for all lines to reduce the radiation level at the shielding surface to $1.0 \mathrm{mr} / \mathrm{hr}$. This is the shielding requirement in areas outside inhabited working facilities and where personnel movements are no:" controlled. Shielding may be provided by burying the lines, earth mounding, 0 : use of high density materials. **Radionuclide concentratio... for the shielding calculations are found in Appendix $H$, Tables $21-19$ and $21-20.5$

Shielding boxes may be required above grade at the processing building entry point for the interarea lines.

Operating Conditions -- Although most transfers through the interarea lines will be at ambient conditions, occasionally warm fluid may be transferred through these lines. The following operating conditions apply:

\begin{tabular}{|c|c|c|c|}
\hline Transfer Line & Temperature Cycle & $\begin{array}{l}\text { Cycles } \\
\text { per yr }\end{array}$ & $\begin{array}{l}\text { Lifetime } \\
\text { Cycles }\end{array}$ \\
\hline Sludge & $\begin{array}{l}\text { Ambient to } 50^{\circ} \mathrm{C} \\
\text { Ambient to } 75^{\circ} \mathrm{C}\end{array}$ & $\begin{array}{l}100 \\
\text { Varies }\end{array}$ & $\begin{array}{l}3,000 \\
1,000\end{array}$ \\
\hline Recycle Waste & $\begin{array}{l}\text { Ambient to } 50^{\circ} \mathrm{C} \\
\text { Ambient to } 75^{\circ} \mathrm{C}\end{array}$ & $\begin{array}{l}350 \\
\text { Varies }\end{array}$ & $\begin{array}{r}10,000 \\
1,000\end{array}$ \\
\hline
\end{tabular}

See Part 6, Item 300 for instrumentation and control.

Rheological data for sludge slurries are presented in Table 21-3, Appendix H. 


\section{PART TITLE: PROCESSING FACILITIES BASIS}

\section{ITEM TITLE: Canister Decontamination}

Canister decontamination is accomplished by wet blasting using glass frit as an abrasive. The process steps are shown in Figures 5-3, 5-6, and 5-9, Appendix B. Prior to decontamination, it must be confirmed that the surface temperature of the canister is less than $100^{\circ} \mathrm{C}$, to prevent formation of steam in the decontamination chamber. The glass frit is conveyed from the cold feed area to the Process Building where it is mixed with water and formic acid to form a slurry. In the decontamination cell, canisters are cleaned on all surfaces using a low pressure slurry blast, rinsed with high pressure water, dried, and removed to the smear station. **Those canisters requiring additional cleaning (2nd cycle) are indexed to permit cleaning only the indicated areas, then are cleaned with a high pressure water and slurry blast*, rinsed, dried, and removed, ${ }^{*}$. The spent frit and water (used only once) are collected for transfer to glass melting process.

Conditions to be used for decontamination are as follows:

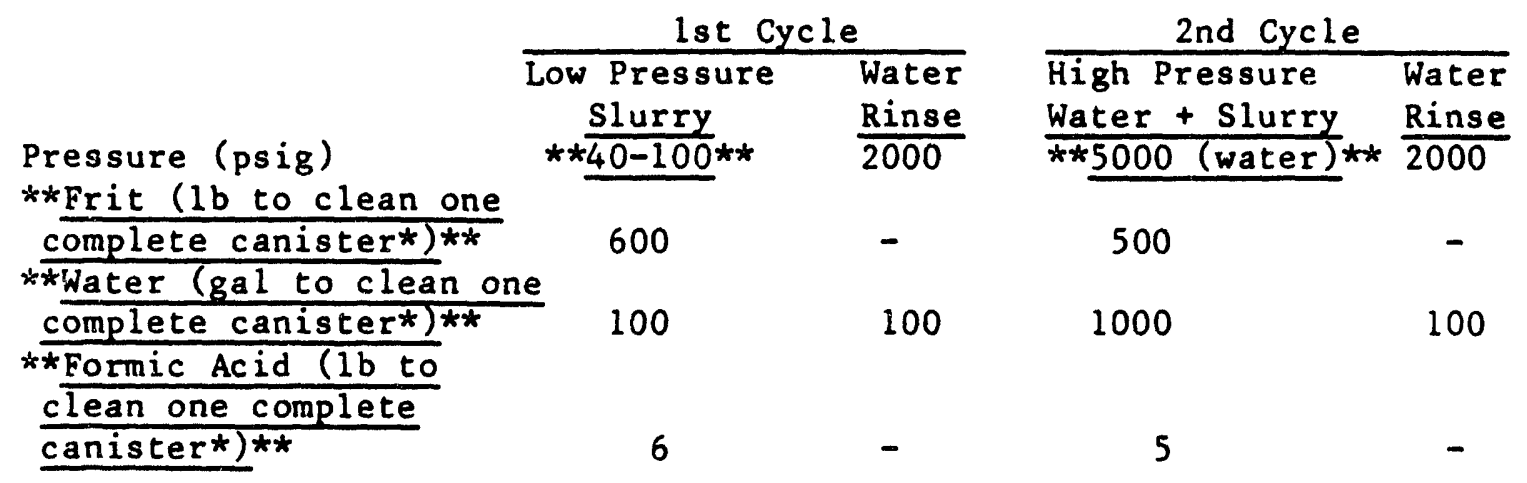

It is assumed that only $20 \%$ of the canisters require 2 nd cycle cleaning and on only $50 \%$ of their surface areas. Rinsing of the entire surface is assumed. Thus usage for average flow sheet conditions is assumed to be $650 \mathrm{lb}$ of frit, $6.5 \mathrm{lb}$ of formic acid and $320 \mathrm{gal}$ of water per canister processed through the cell. Of these totals $200 \mathrm{gal}$ of water is as part of the frit/water slurry and $120 \mathrm{gal}$ is rinse water.

** Overpacked canisters are decontaminated in the same equipment as the canisters but might require only the water rinse. ${ }^{\star x}$

The decontamination equipment requirements are given in Part 20 , Item 2611.

Frit used for decontamination, the same as that fed to the glass melter, is described in Part 5, Item 255 and Table 21-6, Appendix $H$.

*For high pressure blast, the water enters the blast nozzle at 5000 psi and the slurry is a separate feed to the nozzle where it is educted and propelled by the water biast. 


\section{PART TITLE: PROCESSING FACILITIES BASIS}

ITEM TITLE: Canister Smear Test (Decontamination Cel1)

**Decontaminated canisters or overpacked canisters are to be smear tested after leaving the Decontamination Cell but before entering the Weld Test Cel1.** Those with contamination levels below the limits set forth in Part 8 , Item 350 are transferred to the Weld Test Cell. Those exceeding the acceptance limit are to be recycled for further decontamination. Canisters and overpacks are also visually examined for residual oxide, glass on the surface, and to read the identifying numbers. The sequence of operations is shown in Figure 5-3, Appendix B.

Requirements for the smear test station equipment are set forth in Part 20 , Item 265 . 
PART TITLE: PROCESS FACILITIES BASIS

ITEM TITLE: Canister Welding - Outer Closure (Weld Test Cell)

Final closure of the canister is to be accomplished by welding the outer plug into the throat of the canister using an upset-resistance welder. ** Requirements developed to date are based on tests at SRP and SRL.**

Filled canisters are received from the canister decontamination cell or from in-process storage within the Weld Test Cell. **The surface to be welded is visually examined and an oversize plug, with a beveled leading edge, is placed over the nozzle bore. The canister is positioned vertically in the welder, supported by its upper flange which rests squarely upon horizontal grounding plates. A vertical ram is lowered onto the plug and a force is exerted to achieve the desired resistance for the electrical circuit through the ram, the plug, the canister flange, and the grounding plates ${ }^{* *}$

Resistance of the circuit is measured to assure adequate continuity before the actual weld. With the ram force maintained, the weld current is then applied. As the metal at the plug-canister interface heats, plastic deformation occurs and the plug is forced about $1 / 2$ inch into the nozzle and a solid state weld is formed. The ram is retracted and the canister is removed from the welder and transferred to the inspection/smear operations.

A block flow diagram of the welding process is shown in Figure 5-7, Appendix B.

The weld area is visually examined, before and after the plug is inserted, to ensure that there is no interference with insertion of the plug or achievement of a satisfactory weld. Examinationa covers:

- Presence of foreign material on nozzle

- Gross deformation of nozzle (hole) or flange bottom surface

- Discoloration of nozzle (hole) or flange bottom

- Fit of plug in hole

- Reading canister number

a **There are no acceptance/rejection criteria for these examinations. The information will be used to rectify indicated problems. $* *$ 
DPSP $80-1033$

PART 5

ITEM 280

PAGE 2 of 2

DATE 9-82; Rev. 9

PART TITLE: PROCESS FACILITIES BASIS

ITEM TITLE: Canister Welding - Outer Closure (Weld Test Cel1)

Adequate welds can be made with different combinations of weld current, weld duration, and ram force. Welding development is continuing at TNX to letermine optimum cond cions. Shown below, as a guide, are those conditions now used for a 5 inch diameter weld and those of which the welder must be sapable. Requirements for the welder are given in Part 20, Item 270.

**TNX WE LDER

$\frac{250,000}{1.3}$

Weld current (amps)

Weld duration (sec.)

Ram force (pounds)
DWPF Design Basis (max)

Provisions are required for delivery of plugs from the service building to the welder.*t In-process storage requirements for canisters are given in part 5, Item 295. 
PART TITLE: PROCESSING FACILITIES BASIS

ITEM TITLE: Canister Weld Repair (Weld Test Cell)

Canister assemblies with defective upset resistance welds must be reworked to provide complete containment. $\star *$ A design goal shall be to perform the weld repair in work stations that are used for normal canister processing (for example, in the canister inspection station or the overpack weld station). $* *$ The preferred method involves welding a cap to the canister flange to cover the defective plug weld. The sequence of operations that take place in the weld test cell is shown in Figure 5-8, Appendix B.

Requirements for the repair cap are set forth in Table 20-1, Appendix A.

The closure must be designed for TIG or MIG welding of the repair cap to the canister flange. **The goal is to provide a $3 / 8$ inch minimum corrosion barrier around the glass. ${ }^{\star \star}$

Weld quality is to be inspected visually.

The closure design must not interfere with grappling or handling of the canister.

The repair cap must incorporate a helium capsule meeting the same requirements as the capsule on the canister plug (set forth in Part 20, Item 50) unless the capsule on the canister plug can be used to leak test.

The welding operation is to be remote. Welding equipment set up, adjustment, disassembly, and maintenance should be hands-on. 
PART TITLE: PROCESSING FACILITIES BASIS

ITEM TITLE: Canister Inspection (Weld Test Cell)

Canisters are to be inspected and characterized prior to interim storage. The process steps, also shown in Figure 5-3, 5-8, and 5-9, Appendix B, are:

- Measure gamma radiation level*

- Measure canister surface temperature

- Visually examine weld and canister surfaces

- Measure surface defects

- Smear canister surfaces for contamination measurement

- Read canister number

$* *$ These operations are to be performed in the Weld Test Cell, except as noted below. $* *$

Equipment requirements for inspection/smear operations are given in Part 20, Irem 275 .

The processing sequence may be varied; however, the smear test must be ti.e last operation before the canister leaves the weld test cell. *x* Processing cf canisters with overpacks is the same as for canisters. ${ }^{* *}$

After glass fill and closure have been effected, the canister dimensions and shape may not conform with original shape and dimensions.

$* *$ There are no acceptance or rejection criteria for radiation levels, temperature, or surface defects. ${ }^{* *}$ This information will be used to monitor process performance, adjust process conditions, and to characterize product to be shipped off-site at some future date. Limits for contamination are given in Part 8, Item 350. If canisters fail these limits they are spot decontaminated in the Canister Decontamination Cell.

Completed welds are to be visually examined to verify their integrity. A videotape record is required. Examination is to include:

- Symmetry of weld extrusion (full circumference)

- Height of plug above flange

- Presence of spots (from arcing) on bottom of grounding flange

* The gamma radiation level may be measured in the transfer tunnel between the WTC and loadout port. 


\section{PART TITLE: PROCESSING FACILITIES BASIS}

\section{ITEM TITLE: Canister Overpacking}

A small number of filled canister assemblies that are unsuitable for transfer to the Interim Storage Building must be sealed in overpacks. * Examples are canisters that were overfilled, have glass on the exterior surfaces that cannot be removed, or have been severely damaged and the wall thinned or penetrated. $\star *$

The sequence and location of each operation for overpacking is shown in Figure 5-9, Appendix $B$. The requirements for overpack component design are set forth in Part 20, Item 60.

A design goal shall be to perform overpacking operations in work station; that are used for normal canister processing. Provisions for placing canisters into overpacks are required in the melt cell. Similar provisions are also desired in the weld test cell provided it can be accomplished with minimal modifications to an existing work station. Welding of all overpacks will be done in the weld test cell.

Overpack components will be transported to the assembly station, preferably as an assembly and handled similarly to canisters. The overpack is to be opened, the canister inserted, and the overpack closed. Closure is to be verified (visual verification is acceptable) to ensure water tightness. Overpack assemblies are to be decontaminated and smear tested in the decontamination cell as set forth in Part 5, Items 275 and 276 . **Assemblie: are to be transported to the weld test cell and welded. Requirements for thi? welding equipment are set forth in Part 20, Item 271. We.lded assemblies are inspected the same as canisters (Part 5, Item 290).

Overpack welds will be visually inspected, and non-destructively tested. Ultrasonic testing is preferred. The goal for overpacking is to provide a 38 inch minimum corrosion barrier around the canister.

Inspected canisters are transported to the Interim Storage Building. Welds failing the inspection will be repaired.** 


\section{PART TITLE: PROCESS FACILITIES BASIS}

\section{ITEM TITLE: In-Cell Canister Storage}

Facilities must be provided to store canisters and overpacked canisters when not in a process station in the Melt Cell, Canister Decontamination Cell and Weld Test Cell. In-process storage sequence is shown in Figures 5-3, 5-h, 5-7, and 5-9, Appendix $B$. Following is the minimum number of canister storage positions considered necessary for operability. Additional positions are desirable to provide operating flexibility assuming they require no additional increase in building size or are required as a result of the attainment studies.

\section{$\underline{\text { Ce11 }}$}

Melt

Canister Decontamination

Weld Test Cell
Number of

Positions

4

3

1

1

2 Awaiting welding

1 Awaiting SCT

1

\section{Expected Use}

Empty canisters Filled canisters, cooling Spare

Cleaned canister Spare

** In determining the number of positions, it is assumed that inspected canisters are available in the service building and that transfer into the Melt Cell and out of the Weld Test Cell can be carried out on a 24-hour basis, if required.**

Requirements for storage facilities are:

- At least one position in each cell should be capable of receiving an overpack.

- Remove decay heat, if necessary, so glass centerline temperature does not exceed $500^{\circ} \mathrm{C}$.

- In order that personnel can enter the Weld Test Cell for maintenance, shielded storage positions are preferred, or the ability to shield these locations should be provided. Guidelines for attenuation of dowe rates are set forth in Part 11, Item 115. Intermittent occupancy is as sumed.

- Dimensions of canisters and overpacks are given in Part 20, Items 50 and 60 , respectively. 


\section{PART TITLE: PROCESS FACILITIES BASIS}

\section{LTEM TITLE: In-Cell Canister Storage}

- The designs should incorporate features to minimize damage to canisters. Examples of such features are:

- Avoid sharp corners or edges

- Adequate viewing

- The designs should minimize contamination of canisters by the storage facilities (e.g. minimum contact area, proximity to high activity sources, provision for decontamination, etc.)

- Materials of construction should be compatible with decontamination solutions. (See Part 14, Item 200.) 
PART TITLE: PROCESSING FACILITIES BASIS

\section{ITEM TITLE: Process Cooling Water}

Cooling water must be provided to various tanks and other equipment containing radioactive process solutions to remove radioactive decay heat, cool thermally heated solutions, and to maintain temperatures of various processing solutions in required ranges. The cooling load should be based on removing heat from radioactive decay of 5 year old sludge or 15 year old salt or both combined and from heated solutions to cool the solutions down to a maximum of $50^{\circ} \mathrm{C}$ or a lower temperature if required by the process. Cooling coils will not be required where vessels or equipment are not expected to self heat or be heated above $50^{\circ} \mathrm{C}$ or specified process maximums.

The cooling water for vessel cooling coils should be supplied from a closed-loop circulating process cooling water system to ensure confinement of radioactivity in the event of a cooling coil leak. A positive pressure must be maintained on the cooling water coils at all times so that if any leaks occur, cooling water will leak into the tank rather than the tank contents into the cooling coils. For vessels requiring both cooling and heating, use two sets of coils - one set for water cooling and one set for steam heating (see Part 5, Item 405 for steam coils).

Water for the closed loop may be treated with corrosion inhibitors or biocides to prevent algae growth provided that they do not contain or degrade to form free chloride ion. Chloride must be excluded to prevent chloride stress corrosion of stainless steel components.

The capacity and number of heat exchangers, pumps and other hardware for the circulating system should be adequate to allow normal maintenance without shutting down the circulating system. The reliability of utility systems should be high enough to avoid influencing process attainment studies; these studies assume utility systems are almost always available. Cooling water for the heat exchangers should be provided from the cooling tower circulating system (Part 13, Item 320). Water pressure in the cooling tower side of the heat exchangers should be maintained higher than that in the circulating process cooling water side. The heat exchangers should be protected during a DBE to prevent damage which might allow leakage of potentially contaminated cooling water from the circulating processing cooling water side into the circulating cooling tower water side.

The water from process vessel coils should be routed through a process cooling water return header where it must be continuously monitored and periodically sampled before returning to the circulating pumps and heat exchangers for cooling and reuse. The water return line from each process vessel coil should be equipped with a valved sample tap (but no sampling device). If contamination or extensive loss of water is detected in the process cooling water system, circulation will be stopped by closing the water control valves; however, pressure must be maintained in all coils while the liquid level in each vessel containing coils is observed to see which vessel shows an increase in level. The level increase will confirm which coil is leaking. The sample taps will be used primarily to verify the absence of radioactivity inside a coil prior to returning a vessel to service after a loss of coil pressure while the coil was covered with solution containing radioactivity. 


\section{PART TITLE: PROCESSING FACILITIES BASIS}

\section{ITEM TITLE: Process Cooling Water}

Radioactive contamination will be purged from the process cooling water system by displacing the contaminated water with fresh makeup water and discarding the contaminated water to a delay tank or tanks. Either an intermittent or a continuous purge system is acceptable. If purges of the water system are intermittent, one 10,000 gallon tank will be sufficient. If purges are continuous, at least two tanks will be required. When a tank is full, a sample will be taken and analyzed offline to verify that tank contents are within standards for discharge. About 12 full volume flushes of the system are anticipated to be required to dilute and remove any contamination from the loop by a factor of $10^{4}$. Assuming a flush rate of 50 to $100 \mathrm{gpm}$ and an analytical turn-around time of 5 hours, continuous flushing would appear to require tanks that are too large (over 10,000 gallons each); intermittent flushing should be selected if it appears more economical.

The delay tank(s) may be located inside or outside of the process building. **Equip the delay tank(s) with seal-less pumps to prevent leakage, agitators, cold feed type samplers and vent to the cold feed vent system Tart 5, Item 425) through a HEPA filter. ${ }^{\star *}$ Piping and equipment should be provided for transferring the potentially contaminated delay tank effluent to the H-Area drainage system and for manually diverting any contaminated water from the H-Area drainage system to the existing Building 281-8H elastomer-lined retention basin, or to the recycle collection tank in the vitrification building. Purges to eliminate spent biocides or corrosion inhibitors if used may be discarded via the chemical waste treatment facility (Part 5, Item 460) after analysis has verified no radioactive contamination.

Provide in-line monitoring for radioactivity with a local alarm and recorder plus alarms in the Health Protection area and appropriate central control room.

All operations and maintenance will be conducted in a direct hands-on mode. Components of this system requiring emergency power are listed in Part 13, Item 560 . 


\section{PART TITLE: PROCESSING FACILITIES BASIS}

\section{ITEM TITLE: Melter Cooling Water}

Cooling water is required for the melter and the melter off-gas system to minimize corrosion of melter refractory, reduce the temperature of the outside surface of the melter to a maximum of $50^{\circ} \mathrm{C}$, condense water from the off gas and cool non-condensable of $f$ gas.

The cooling water should be supplied by a circulating water system having the same features regarding coil pressurization, heat exchangers, pumps, samplers, radioactivity monitoring, earthquake protection, purge facilities, biocides, corrosion inhibitors, etc., as described for the Process cooling Water, Part 5, Item 400. This cooling system must also meet the following requirements:

1. Remain operable during **purchased power failure.**

2. Have an alternative source of cooling water independent of the circulating cooling tower water

3. Be sufficiently clean and pure to have low electrical conductivity if the water must be used to cool energized electrical bus bars or other electrical jumpers

The process cooling water may be used for the melter cooling system if the additional emergency power, alternative water supply and applicable water quality criteria can be met.

$* *$ Components of this system requiring emergency power are listed in Part 13, Item $560 .^{\text {*x* }}$ 


\section{PART TITLE: PROCESSING IPACILITIES BASIS}

\section{ITEM TITLE: Process Steam System}

The process steam system serves in cell equipment and therefore is subject to contamination. It should be a once through system because the low steam requirements do not justify a closed-1oop steam system. Steam condensate from the process vessels should be directed to process steam condensate delay (or purge) tanks. The tanks may be located outside the process building seisinic structure. When a tank is full, a sample will be taken and analyzed offline to verify that tank contents are within standards for use as process water or for discharge as described below. Allow 6 hours for obtaining, delivering to the laboratory, and analyzing the sample in addition to the time required for emptying the tank in determining the tank capacity. **Equip condensate collection delay tank(s) with seal-less pumps to prevent leakage, agitators, cold feed type samplers and vent to cold feed vent system (Part 5, Item 425) through a HEPA filter. **

Provide in-line monitoring for radioactivity in the steam condensate with a local alarm and recorder plus alarms in the Health Protec:ion area and appropriate central control room.

A positive pressure must be maintained automatically in the steam coils of process vessels at all times so that if any leaks occur, leakage will be into the tank from the coils. Compressed air or steam condensate may be used as the backup method of pressurization.

The steam pressure should be 1 imited to a maximum of 195 psig.

Condensate from process equipment should be collected and analyzed and, based on the analyses, disposed of as follows:

- No radioactive contamination - use as process water. (See Part 13, It em 130)

- Contaminated with radioactivity - discard to Recycle Collection Tank or, alternatively in emergencies only, to the H-Area retention basin for disposal or cleanup.

See Part 6, Item 400 and Tables 6-1 and 6-2, Appendix $A$ for instrumentation and control. 
PART TITLE: PROCESSING FACILITIES BASIS

ITEM TITLE: Regulated Chilled Water Refrigeration System

A refrigeration system may be required in the processing building to provide chilled water to the glass melter off-gas wand mercury recovery vent*** systems. The chilled water should be a circulating system having the same features regarding coil pressurization, pumps, sampling points, radioactivity monitoring, purge facilities, biocides and corrosion inhibitors as described for the Process Cooling Water, Part 5, Item 400. *Additional makeup and purge disposal facilities may be required if an antifreeze is required in the circulating coolant.

Components of this system requiring emergency power are listed in Part 13 , Item 560 .

The basis for sizing this system is set forth in Part 5, Item 260. $* *$ 
PART TITLE: PROCESSING FACILITIES BASIS

ITEM TITLE: Process Vessel Vent System

The purpose of the process vessel vent system is to limit leakage of vapors into the cell. Technical studies indicate that it is also necessary to cool vapors exiting tanks containing mercury and formic acid solutions to limit emissions to the atmosphere. For segregation of fumes, two vent headers are required; one for vapors from nitric acid and alkaline containing vessels, the second for formic-mercury containing vessels. The vent header for the formic-mercury system should have a condenser to remove the mercury and formic acid vapors; the condenser is to vent to the vessel vent header for the nitric-alkaline system. For flexibility for future connections and the ability to segregate formic acid and nitric acid fumes/1iquids, each vessel position (excluding Weld Test Cell and Equipment Decon Cells) should have the capability of connecting to either header.

Design criteria for the vessel vent system are as follows:

SRP experience shows that vapor leakage can be controlled by a nominal 50 scfm air flow through unsparged tanks. Although some air inleakage may occur at vessel shaft openings, for design purposes assume that all vent air enters through the overflow pipe. The vessel vent system design is also to assure an air sweep through vessels with air sparging; the sparge rate is expected to be $0.6 \mathrm{scfm}$ per $\mathrm{ft}^{2}$ of liquid surface on loss of agitation. The vessel vent design is to provide for exhausting two vessels at the maximum sparge rate with all other spargers at the minimum rate. Sealed vessels (evaporators) are to operate at negative pressure with minimal air inleakage.

The preferred vessel vent system design should establish the desired flow by properly sizing the headers, vent jumpers, and overflow lines and not include orifices or valves at individual vessel positions. If it becomes necessary to accomodate a range of static pressure conditions, consideration may be given to locating orifices in the connectors on certain vent line jumpers.

During process vessel repair and replacement work, it should not be necessary to provide for adjustment of air flow from that vessel into the vent header. If it does become necessary to reduce header inflow because of an extended vessel outage, a blank connector can be used for isolation of the header.

When the vessel vent system is not functioning, process operations will be controlled to limit vapor flow out of the vessels or the process will be shut down.

Vessel vent positions are required in the canlster decontamination cell for equipment venting. Two vent positions are to be provided in the melter cell for future connections. Vessels in the mercury purification cell are to be vented to the vessel vent system. The glass melter and its off-gas system are to be separate from the vessel vent system except for provision of emergency ventilation of the melter pour spout. 


\section{PART TITLE: PROCESSING FACILITIES BASIS}

\section{ITEM TITLE: Process Vessel Vent System}

Individual vessel vent lines and the vent headers should be sloped to permit total drainage. Make provision to collect drainage from the headers in vessels in matching service. If necessary, the headers may drain to a floor sump rather than directly to a vessel. Provide liquid level detection in the vent headers. Access to the headers is not required, but access to each header drain line is required as SRP experience has shown that header drains can be expected to plug with deposits from the vent system.

The combined air from the two vent headers must be routed through an in-line heater and a dry, remotable filter system. Exhaust must be provided by remotable, redundant exhaust fans located in the cell. Automatically functioning valves are required on the suction side of the vessel vent fans to provide operations continuity in the event of a fan failure. The filtered air is discharged to the cell exhaust air tunnel. The $1 \mathrm{n}-1$ ine air heater must be insulated as necessary to limit thermal drafts associated with hot equipment.

Since little liquid will collect in the vessel vent filter, include capability to drain liquid to the floor. The filter design, air heater, and exhaust fans are discussed in Part 20, Item 320.

Alr sampling requirements are discussed in Part 12, Item 120. See Tables 6-1 and 6-2, Appendix $A$ for instrumentation and controls. Recycle of fan discharge for control or whatever purpose is not desirable; the fans should function satisfactorily over a nominal flow and static pressure range that may be expected to be established by system instrumentation and flow control. 


\section{PART TITLE: PROCESSING FACILITIES BASIS}

ITEM TITLE: Cold Feed Tank Vent Systems

** Three cold feed tank ventilation systems are required to limit discharges of chemical vapors from cold feed make-up and head tanks, one in the main processing building and two in the miscellaneous cold feed storage facility. ${ }^{*}$ Vessels receiving pneumatically conveyed frit are not to be connected to these vent systems.

1. Processing Building System

The cold feed vent system is also to provide venting of liquid waste collection tanks located in the operating area of the main processing building. $* \star$ Cold feed and drain catch tanks in formic acid service are vented through a condenser to condense formic acid fumes. This condenser vents to the cold feed vent system and drains to the formic acid catch tank. ${ }^{\star \star}$

Air flow through this vent system is established as follows:

- A nominal $50 \mathrm{cfm}$ is to be pulled through any open overflow line on vessels connected to the cold feed tank vent header. It is noted that the overflow line on some vessels is connected to an enclosed drain system (Part 5, Item 215) and will not be an air source.

- Where make-up tanks are provided with dry chemical charging chutes, the vent system should provide for greater than $100 \mathrm{fpm}$ air flow through an open chute to limit dusting from the operation. Assume two chutes are open at any time.

- Air inleakage at other vessel openings is to be ignored in designing the system.

Filter requirements for this vent system are:

- Any tank possibly receiving contaminated liquid must have the tank vent line equipped with a replaceable HEPA filter.

- Tanks equipped with chutes for solid chemical additions are to be provided with a dust collection filter in the tank vent line.

$0 \quad * *$ Air from the cold feed vent header is to be routed through a filter to remove particulates. This filter should have a Group III ASHRAE/52-68 rating (see Chapter 3 of Reference C-13, Appendix C). ** This filter installation will not require shielding. Although radioactivity is not expected to be present, sampling capability should be provided per Part 12, Item 120.

Exhaust fans for this system are to be commerclal units provided for acid/caustic fume service. An installed spare is required. All parts of the vent systems will be repaired by hands-on maintenance. 


\section{PART TITLE: PROCESSING FACILITIES BASIS}

ITEM TITLE: Cold Feed Tank Vent Systems

Air from this system is to be continuously monitored for radioactivity before discharging to the atmosphere because it possibly may contain radioactive particles. If this system discharges through the building zone 2 exhaust system, the stack effluent monitor will satisfy this requirement.

Tables 6-1 and 6-2, Appendix A, note instrumentation for the system.

2. $* \star$ Miscellaneous Cold Feed Systems

Two systems are required for miscellaneous cold feed storage. Tanks in formic or oxalic acid service are vented through the organic acid vent system. Other tanks are vented through a separate system.

Air flow through these vent systems are established as follows:**

- A nominal $50 \mathrm{cfm}$ is to be pulled through any open overflow line on vessels connected to the cold feed tank vent header.

- Where make-up tanks are provided with dry chemical charging chutes, the vent system should provide greater than $100 \mathrm{fpm}$ air flow through an open chute to limit dusting from the operation. Assume two chutes are open at any time.

- **Air inleakage at other vessel openings is to be ignored in designing the systems.

A dust collection filter is to be provided only for the organic acid vent system.

Single exhaust fans are required for each system. Commercial units will be satisfactory. The fans should discharge through a stack to avoid contact with people. ${ }^{* *}$

Tables 6-1 and 6-2, Appendix A, note instrumentation for these systems. 


\section{PART TITLE: PROCESSING FACILITIES BASIS}

\section{ITEM TITLE: Sump Collection Systems}

Sumps are to be provided throughout the area to collect process leaks and spills and floor flushes. The number, location, type, etc. of sumps will depend on factlity designs.

Sump liquids are to be collected in systems for contaminated liquid or in a system for slightly contaminated/clean 1iquid. Sumps expected to be wet or active should have liquid level detectors and pumpout facilities. Those expected to be dry should have a conductivity type detector and access to permit liquid removal. The systems are described further below.

\section{Contaminated Liquid Collection}

Contaminated liquid in the remotely operated processing area is to be collected in two completely segregated systems to separate nitric acid and formic acid streams with separate headers for each. Liquid collected in sumps in the vitrification building exhaust system should be returned to the header for formic acid streams. Liquid waste with high levels of radioactivity which is generated during decontamination of equipment is to be returned to the header for nitric acid wastes. Formic acid waste streams are routed to the recycle collection tank; nitric acid waste to the decon waste treatment tank.

A third collection header, discharging to the decon waste treatment tank, should be provided for liquid originating in vitrification building regulated operating areas not designed for or not expected to have high levels of contamination. This liquid is expected to contain considerably less radioactivity than liquid originating in the remote processing cells; the third header is to assure that grossly contaminated liquid does not back-up into inhabited work areas.

Collection branches may be utilized and tied into the cell headers, with the design to preclude air flow and liquid flow from the header into sumps tied into the header. The cell header need not be part of the process cell pipe rack. Flushing capability is to be provided for headers expected to handle solids.

Pumps used to empty sumps are to be in remotable piping in the remote cell areas. Pumps serving sumps in inhabited areas are to be designed for hands-on maintenance. The branch connections to the collection header should be such that dummy connectors are not required to prevent discharge from adjacent connection points.

The process cell floor is expected to be flushed twice a year with 10 gallons of water per $15 \mathrm{ft}^{2}$ of floor. The sump collection system must be capable $\mathrm{f}$ handling a varlety of materials ranging from water to sludge and sluds rit slurries. 


\section{PART TITLE: PROCESSING FACILITIES BASIS}

\section{ITEM TITLE: Sump Collection Systems}

The only sump solution expected to be sampled are those in the exhaust ventilation faclittles, including any in the fan house plenums. Liquid level dip tubes in these sumps will be utilized for sampling when necessary; permanently installed sampling facilities are not required. See Part 11, Items 450,470 , and 490 for the piping requirements for the transfer of sump liquids from the exhaust ventilation facilities to the vitrification bullding.

2. Slightly Contaminated/Clean Liquid Collection

\section{A. Vitrification Bullding}

Operating corridors within the vitrification building, both regulated and clean, will require either floor drains or a sump system to handle slightly contaminated/clean liquid from these corridors. The sump collection system in this part of the vitrification building is to discharge to the floor drain header catch tank. See Part 5, Item 215 and Part 11, Item 105 for additional information on floor drains.

Sampling facllities for these sumps are not required.

B. Glass Waste Storage Building

A sump should be provided in each vault compartment of the glass waste storage bullding. Each sump should be equipped with a conductivity probe for detection of liquids. Access to permit sampling and to empty the sumps to a portable container should be provided; permanently installed equipment is not required.

C. Service Bullding

Floor drains and/or a sump system are required to handle liquids in the chemical storage and make-up areas of this bullding. Liquids from this system are to be discharged to the chemical and Industrial waste treatment facilities (part 5, Item 460). Sampling equipment is not required in this system.

Floor drains with a collection system will be required for collecting potentially contaminated fire water from the regulated areas of the service building ( $1 . e$. Health Protection, change rooms, etc.). 
PART TITLE: PROCESS DESCRIPTION

ITEM TITLE: *Radioactive** Contaminated Liquid Wastes

$*$ Radioactive*'t contaminated process wastes and solutions from sumps and drains in the process cells should be accumulated in the Recycle Collection Tank for return to the tank farn (see Part 5, Item 430).

*Wastes collected through $*$ floor drains from regulated areas of the processing building should $* * b e$ directed to the floor drain catch tank and then to either*'* the Recycle Collection Tank for return to the tank farm or to the chemical waste treatment facility (Part 5, Item 460) depending on analyses. See Part 5, Item 215 for regulated floor drain requirements.

Sanitary sewage from any toilets located in the regulated areas should be combined with sewage from clean areas for treatment. 


\section{PART TITLE: PROCESSING FACILITIES BASIS}

ITEM TITLE: Radioactive Contaminated Solid Wastes

\section{General}

Radioactive contaminated solid waste generated in S-Area will consist of waste generated in the regulated operating areas of he buildings in th: area and failed process equipment. This solid waste will be both combustible and noncombustible. For control purposes it will be divided into two types; (1) job control waste and (2) process cell or radiation danger zone waste.

Job control waste will be composed of material generated in the regulated operating areas of the building, such as paper materials, plastics, gloves, scrap materials, and used cleaning materials.

Process cell waste will consist of failed or obsolete equipment (i.e. process vessels, jumpers, pumps, etc.). If necessary, large items will be decontaminated in the decon cells prior to packaging for disposal.

Waste will be separated into two catergories for disposal.

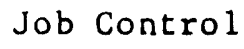

High level - greater than 300 mrad or 50 mrem at $18^{\prime \prime}$

All wastes will be identified, packaged, and transported under properly authorized procedures to prevent spread of contamination or undue exposure to personnel. Facility design should give consideration to routes for waste removal from buildings in relation to minimum distance of travel and through lesser populated areas. Waste removal routes are to be through regulated areas.

\section{Facilities Required}

1. A covered box storage area, approximately $15 \mathrm{ft} \times 10 \mathrm{ft}$, for low level waste with truck access at each waste location. One load lugger is to be spotted at pad near the regulated loading dock entrance. The other load lugger is to be located near exit point of the shielded transport carrier. This one is to be used for scheduled filter changes at other area sites as required.

2. A $15 \mathrm{ft} \times 15 \mathrm{ft}$ concrete loading pad for waste dumpster with truck access at each waste disposal location listed in No. 1 above.

3. Enclosed beta gamma waste dumpsters, per SRP Standard Design. Regulated load lugger, Heil Mfg. Co., Series 4096, Model DSB-12, $12 \mathrm{cu}$ yds, painted yellow. Load luggers are 1 isted in Table 16.1, Appendix A. 


\section{PÁRT TITLE: PROCESSING FACILITIES BASIS}

\section{I'IEM TITLE: Radioactive Contaminated Solid Wastes}

4. Carts for transporting high level radiation waste to dumpster at loading pad. A shielded waste buggy is to be used for high level waste. Carts and buggy are listed in Table 16-1, Appendix A. Design of this buggy will be provided later by SRP.

5. Access to and method of removal (truck or rail) for the largest process vesse 1 to be installed in the process building with provision for adding local shielding.

6. Air locks (Part 11 , Item 110) are required at shipping points to control air flow direction.

Volumes of Waste

Low level or job control waste is estimated to be approximately $* * 40,000 * *$ $\mathrm{cu} f \mathrm{f} / \mathrm{yr}$. Weight will depend on type of material, job control will be lighter than process cell waste and mostly combustible.

Process cell waste is estimated to be approximately $2,000 \mathrm{cu} f t / y r$. This will be heavier than job control waste and primarily uncombustible except for plastic packaging. Examples are jumpers, process vessels, process scrap, and even the largest process vessel. Shielding requirements for vessels including a failed melter are stated in Part 20, Item 380. 


\section{PART TITLE: PROCESSING FACILITIES BASIS}

\section{ITEM TITLE: Chemical and Industrial Wastes}

Facilities will be required to provide for disposal of non-radioactive solid waste and for treatment capabilities to clarify and/or purify non-radioactive chemically contaminated waste waters from chemical spills in cold feed and process areas, truck unloading pad effluents, cooling tower blowdown, etc. Limits for release of treated wastes are given in Part 8, Item 220 .

\section{Liquid Wastes}

Separate collection facilities and hold up tanks should be provided for caustic and acid waste systems with a two week capacity. Facilities should permit controlled blending for self-neutralization of wastes or separate treatment with other agents to render waste streams disposable to the environment. Administrative, procedural controls will be required to avoid or control mixing of normally incompatible chemicals. Treatment tanks should be equipped with agitators and samplers and should be designed to allow periodic removal of sediments for disposal to a landfill. The tanks and working area should be protected from rain and be ventilated to remove any gases that may evolve from the liquids or from treatment reactions.

Chemicals and mixtures thereof which will require disposal include the following:

\author{
Nitric Acid \\ Sodium Hydroxide \\ Potassium permanganate \\ Sodium hypochlorite \\ **Sodium bisulfite** \\ Glass Frit
}

\author{
Biocides (if required by design) \\ Corrosion inhibitors (if required by tesign) \\ Oxalic acid \\ Formic acid \\ Detergents \\ Acid-stable surfactant
}

Treated solutions should be filtered if necessary, analyzed and discharged to Four Mile Creek by pump and pipe line interconnecting with existing H-Area facilities. This may be a multipurpose line from other waste water sources in the DWPF, such as process cooling water purges. If so, the line should have a separate diversion permitting discharge either to the retention basin or to Four Mile Creek. The sludge from treatment operations should be dried and removed to a landfill area.

The volumes and amounts of chemicals to be processed through the waste treatment facility may be based on the following criteria:

- A volume equivalent to one-half the volume of a make-up batch will be dumped once every 100 makeups. Assume acid and caustic makeups equally subject to error.

- Overflow of a volume equivalent to the volume of one tank full of each make-up and receipt tank once every 500 fillings or makeups 


\section{PART TITLE: PROCESSING FACILITIES BASIS}

ITEM TITLE: Chemical and Industrial Wastes

- A flush of $0.15 \mathrm{gal} / \mathrm{ft}^{2}$ of diked, curbed or otherwise allocated floor area :

a) each time a tank is made up for makeup tanks

b) once each week for tanks used only for receipt and transfer (no makeup)

c) once each month for other operating areas but not including control rooms, is lectrical equipment rooms and clean areas generally

- Spillage of $1 \%$ of the contents of a makeup tank during each makeup

- Assume all floor flushes are discarded via the waste chemical treatment facility even though occasional contaminated flushes may be discarded via the Recycle Collection Tank.

- Assume the maximum amount of floor flushing which may occur at one time to be equal to $1 / 5$ of the total possible flushes.

- The capacities of drain header and floor drain catch tanks are specified in Part 5, Item 215, page 1. Other tank sizes should be optimized based on process needs.

\section{Solid Wastes}

Clean, combustible and non-combustible solid wastes will be handled according to present plant practices. Three clean, front load compactor dumpsters will be required under this project and are listed in Table 16-1, Appendix A. Existing plant equipment will be used to service the dumpsters. 
PART TITLE: INSTRUMENTATION AND PROCESS CONTROL

\section{ITEM TITLE: General Control Requlrements}

** The Technical Data Summary spectfles process parameters requiring monitoring and/or control for the various process equipment. ${ }^{* \hbar}$ The process control system must be designed to provide safe and efficient operation of all buflding facilities. In addition, a safe shutdown and standby condition must be achievable under emergency conditions. To accomplish these objectives, the following items should be considered in system design.

- A central control room (CCR) and field operating stations (FOS) are required for normal operations.

$0 * *$ The central control room area houses the following 3 consoles: supervisor's console; process console; and power console. All process operations are carried out from the process console by the operator. The power console allows the operator to monitor the operation of al1 electrical, heating, ventilating and alr-conditioning, other utilities and services for S-Area.** Limited controls are available at the location for the power operator to control some emergency equipment. Normal operation of most utility and major electrical equipment is done locally at the equipment.

* The supervisor's console acts as a back-up to the process operator's console. ${ }^{\star \star}$ During normal operations, control of the equipment is inhibited at the supervisor's console.

- Control facilities must allow operator or automatic control of individual pieces of equipment and/or closely coupled groups (CCG). CCG's are groups of equipment in which it is desirable to interlock or sequence operations through a common or integrated process control 1oop.

- The operator must be able to start and stop equipment, adjust process control points, and perform other operations required for safe, efficient process control.

- The operator must be able, at any time, to take over control of a loop unless the loop is designed to prevent takeover for safety reasons.

- Continued normal operation of each process control loop should not be affected by fallure of other control loops.

- Facilities to integrate control of two or more loops should be irovided if feasible and desirable.

- In the automatic mode, all operations should be performed accorling to programmed operating parameters without operator assistance. 
PART TIMLE: INSTRUMENTATION AND PROCESS CONTROL

\section{ITEM TITLE: General Control Requirements}

- A variety of visual displays must be obtainable in the CCR. Displays may be sequential and should include process variables, setpoints, alarm points, and other required operating information. Audible alarms should a iso be provided where needed.

- Failure of the automatic mode must atill allow operator control from either the CCR or from local facilities.

- Design should ensure the automatic transfer to a controlled safe standby condition at particular setpoints and the capability to accomplish a controlled safe shutdown in the event of equipment or component failure.

- Tre receiving tank level information and/or interlocks must be provided at: all locations where the transfer can be initiated.

- The system should perform automatic diagnostic tests on all loops, provide malfunction alarms, and identify location and type of mel function.

- Provide restricted access (key-operated or similar) for certain fluctions such as alarm setting changes and setpoint changes where rtquired.

"Provide redundant sensors, processors, controllers, electrical equipment, transmission lines, computers, and other operating facilities as required for safety and/or operating efficiency.

- Hard wire all system interlocks required for safety of personnel, ecuipment, or the environment, with the exception of the process cell crane if a wireless control and/or viewing transmission system is used.

- Facilities should be provided to perform data acquisition and storage of all measured process variables including sample data from the 772-F laboratory and calculated variables. Current values of all variables and sample data will be stored for rccall for at least 24 hours. Some current values, averages, sample data or calculated variables will be stored for recall for at least 30 days. All alarms will be logged and stored for recall for at least 24 hours. Some alarms will be stored for recall for at least 30 days.

- Facilities should be provided to print large volumes of reports, statistics and other operator requests, as well as routine reports.

- Facilities to provide records of selected data for at least 50 years should be furnished. Selection of the record keeping system should be based on small volume and reliable retention. No record storage facilities will be required in S-Area. 

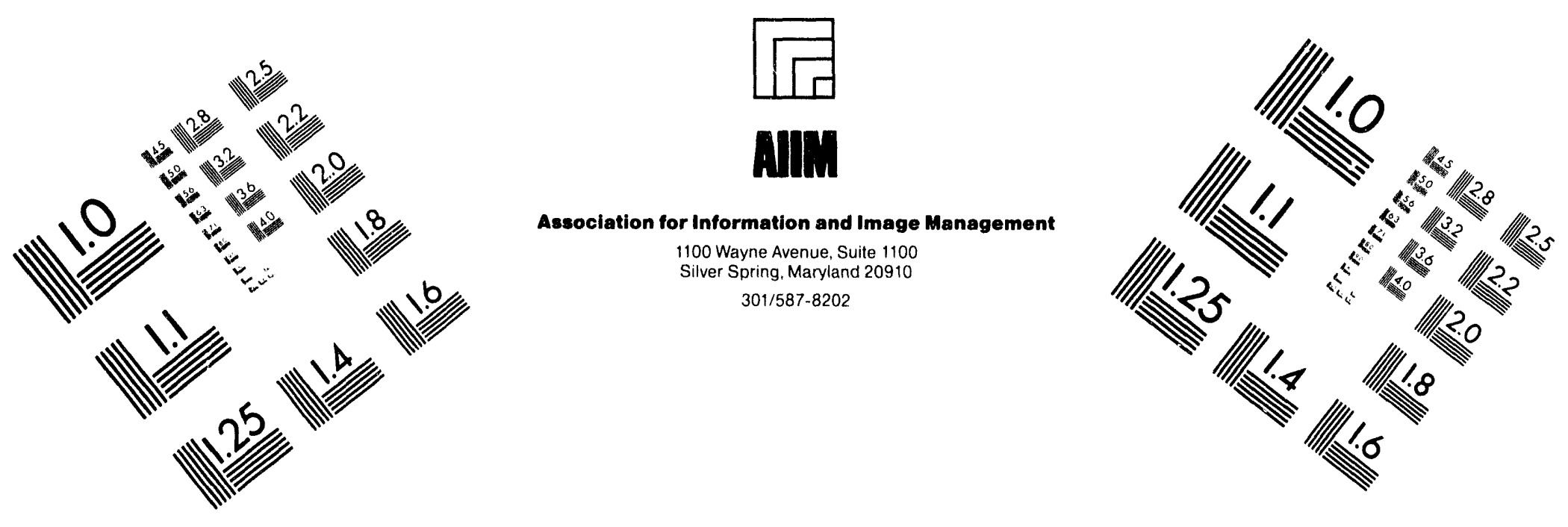

Centimeter

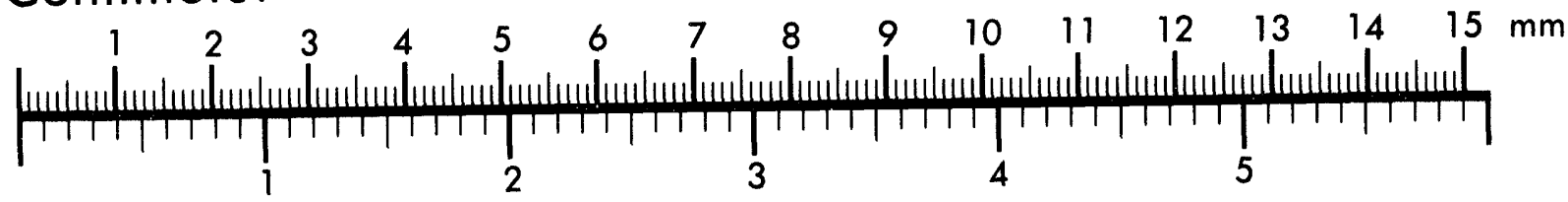
Inches
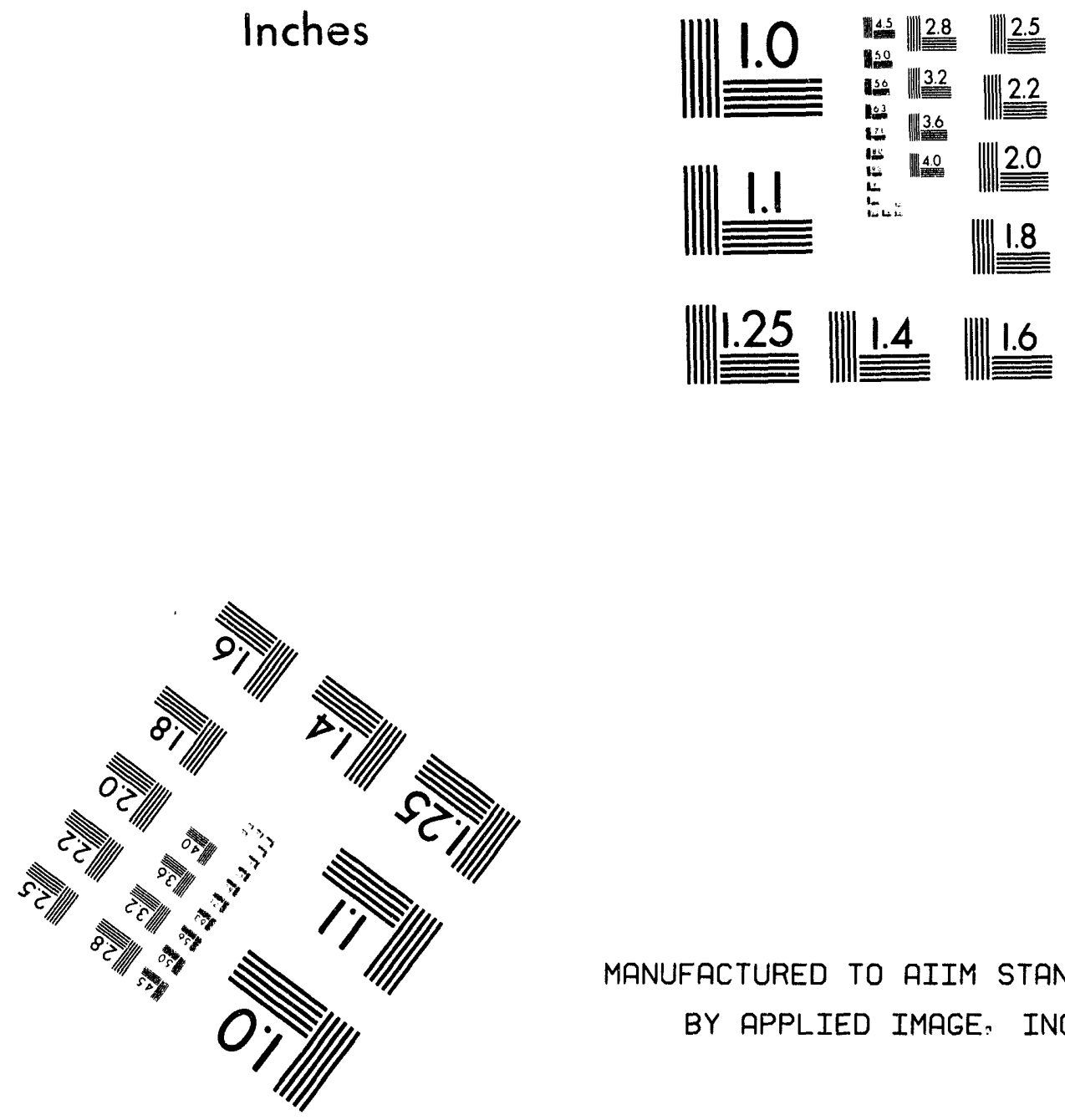

MANUFACTURED TO AIIM STANDARDS

BY APPLIED IMAGE: INC.

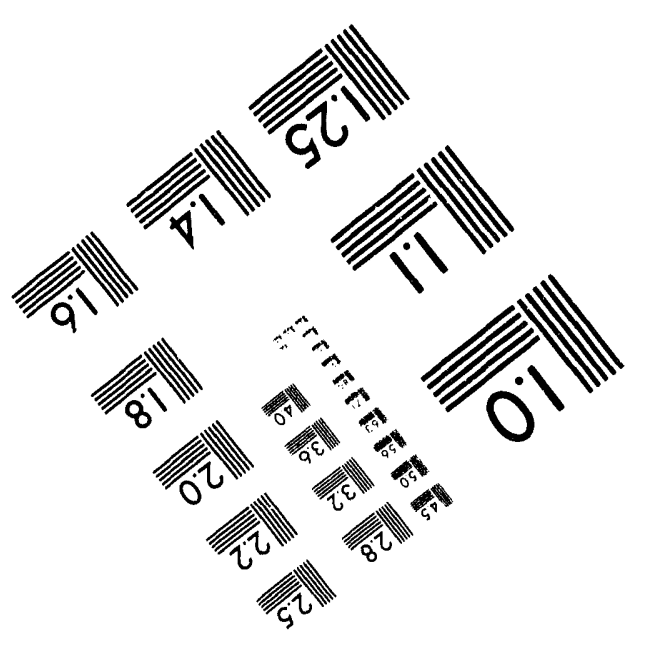



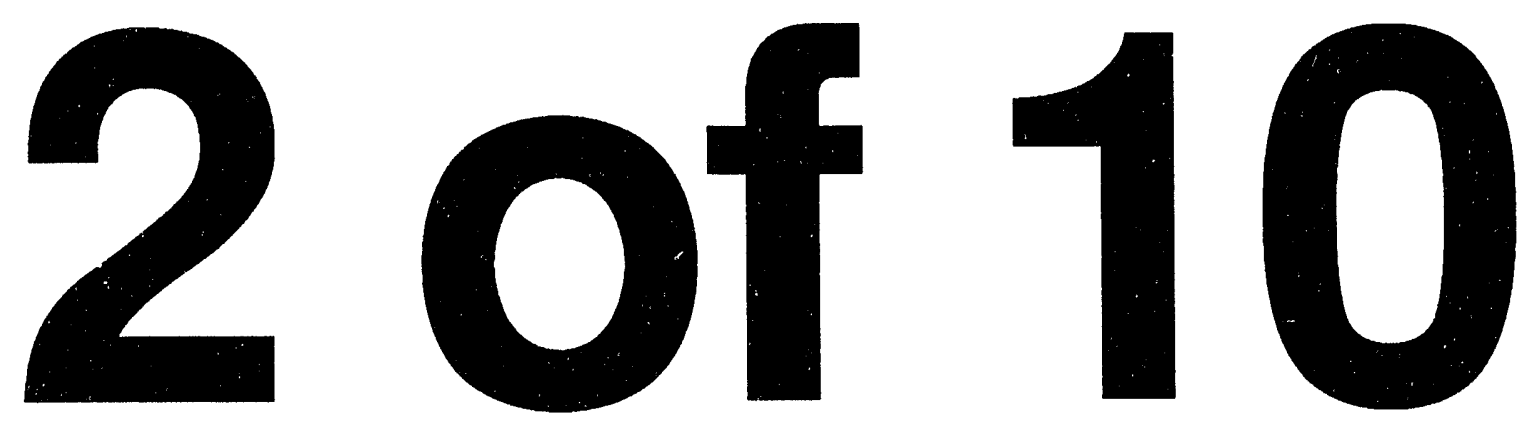


\section{PART TITLE: INSTRUMENTATION AND PROCESS CONTROL}

\section{ITEM TITLE: General Control Requirements}

- Process control devices should not be located in damp or corrosive areas or in other environments that can adversely affect their accurecy or create excessive maintenance problems.

- Modular design permitting rapid replacement should be incorporated as much as possible.

- Maximum practical standardization should be used in equipment choice.

- Provide redundant instrumentation and emergency or uninterruptable power where continuous service and control are essential.

- Install equipment in other buildings as required to have needeo information and control functions available in the CCR and at the FOS's.

- Electrical or electronic sensing and transmission should be used whenever possible to be compatible with computer systems.

- Data Highways will be required from all S-Area Process and Service Facilities, 772-F Laboratory, H-Area Tank Farm Control Room, ard FOS's to the CCR.

- Safety system requirements should be assessed by the criteria as specified in Part 9, Item 120. Some examples of items that should be considered as part of the safety system are fire detectors, HP monitors, ventilation controls, seismic monitors, multitemperature monitors, etc. All safety-related measurements should be sensed by two separate devices, preferably using different sensing principles. Identical redundant sensors, separately mounted and connected, can be used where only one sensing principle is available.

- For specific instrument requirements see Tables 6-1 and 6-2, Appendix A. These tables list the conceptual variables to be measured and control locations. 
PART TITLE: INSTRUMENTATION AND PROCESS CONTROL

ITEM TITLE: **Main Process Cell General Instrument Requirements**

- To the extent possible, sensors, electronic components, anil similar devices must be located out of the main process cell where they can be readily maintained.

o When sensors or other such components must be located in the main process cell, provisions should be made for checking their resfonse and calibration from convenient out-of-cell locations.

- All sensors or other such components located in the main process cell must be remotable. When possible, they should be slide-in type for ease $c$ f replacement and maintenance.

- Electrical or electronic lines used tc transfer signal energy from the main process cell will terminate in a Regulated Area. Beyond th is point, equipment will be located in nonregulated areas when practical. 
PART TITLE: INSTRUMENTATION AND PROCESS CONTROL

ITEM TITLE: S-Area Process Control

Specific design requirements for $S$ Area facilities are listed below:

** Chemical Process Cel1 ${ }^{* *}$

o Provide facilities to allow emergency operation of equipment required for safety of personnel, equipment, or the environment, from local control units.

o **Field operating stations (FOS) for equipment required to be located in a tornado and seismic resistant structure (See Part 4, Item $70 \mathrm{C}$.) are also to be housed in that structure. ${ }^{\star *}$

o Normal operation of the process should be from a central control room.

Melter Cell

- **Two independent canister glass level detection systems are required with capability to establish the final glass level to $\pm 1 / 2$ inch. One of these systems must have the capability to detect stalagmite formation. Neutron transmission and detection of waste glass radioactivity are recommended as glass level detection systems.

- A glass weight measurement system with an accuracy of \pm 15 lbs is required to monitor the pour rate. ${ }^{* *}$

Canister Decontamination Cell

**Because of the nature of the operations in the canister decontanination cell, control of the operations will differ from that in the chemical process cell. Most operations will be controlled locally from Fos in the operating area and near the viewing windows. $* *$

o For instrumentation and control requirements of specific equiprant in the canister decontamination cell, refer to Part 20, Items 260 and 265.

Weld Test Cell

**Because of the nature of the operations in the weld test cell, =ontrol of the operations will differ from that in the chemical process cell. $* *$ Most operations will be controlled locally from FOS in the operating area and near the viewing windows.

Data from in-cell instrumentation should be displayed and/or recoeded at local FOS. Some data may also be entered directly into the CCR computir; other data may be entered by operators from local terminals. The central process monitor may also be used to query local operators status, action to bis taken, etc. The welder will be controlled locally and key QA data will be seit back to the central computer. 
PART TI ILE: INSTRUMENTATION AND PROCESS CONTROL

ITEM TIILE: S-Area Process Control

- For instrumentation and control requirements of specific items in the wisld test cell, refer to Part 20, Items 270 and 275.

Cold Feid Prep

- Basic composition of mixing or blending will be verified by analysis.

- All pumps delivering solutions to Process Building should have both $r$ mote switches in the CCR and field switches. Flow measurements on these streams should be available both in the field and the CCR.

- T) prevent line drainage from the main process building back to cold fized prep, provide valves at the pump discharge in the cold feed $t$ cansfer lines to shut of $f$ when the cold feed transfer pumps shut down. 
DPSP $80-1033$

PART 6

ITEM 300

PAGE 1 of 1

DATE $5-81$; Rev. $t$

PART TITLE: INSTRUMENTATION AND PROCESS CONTROL

ITEM TITLE: Interarea Transfer Instrumentation and Control

$*$ Specific design requirements for control of transfers between $H$ and $S$ Areas are $l$ isted below:**

- Control of transfers of sludge slurry from the H-Area tank farm to $S$-Area **and of transfers of recycle waste solution from S-Ar?a to the H-Area tank farm will be required.

- Normally the point of control of these transfers should be at the point of origin after permission has been given by the receiver to initiate the transfer.

- The receiving station is to have voice communication with the transferring station to report any malfunction at the receiving station. $* \cdots$

- The existing H-Area waste farm control building will require enlargement to house the instrumentation required for the interarea system as instrumentation planned for current projects will fill the existing building. 
PART TITLE: INSTRUMENTATION AND PROCESS CONTROL

ITEM TITLE: Utilities Control

Since a powerhouse will not be required, instruments and controls as listed in Tables $6-1$ and $6-2$, Appendix A should be installed to have needed information and controls in the CCR for all utilities and services.

- **Provide facilities to allow emergency operation of equipment required for safety of personnel, equipment, or the environment, from field operating stations (FOS).

- FOS for equipment required to be located in a tornado and seismic resistant structure (See Part 4, Item 700.) are also to be housed in that structure.**

- See Part 13, Item 560 for emergency power requirements. 
DPSP $80-1033$

PART 6

ITEM 500

PAGE 1 of 1

DATE 5-81; Rev. 6

PART TITLE: INSTRUMENTATION AND PROCESS CONTROL

ITEM TITLE: Ventilation Systems Control

*xprocess Building**

The ventilation supply and exhaust fan rooms will normally not be occupied except for walkthrough inspections. Design considerations for ventilation system control are:

- Failure of ventilation equipment should immediately activate backup equipment and alarms in the central control room on the power operators panel and at the location of the failed equipment (locallv).

- Failure of a single fan in any exhaust system should not shut down production operations. Provide emergency power sufficient to maintain minimum air flow **upon failure of normal power** (see part 13, Item 560).

- Process building air supply fans should be interlocked to the exhaust fan as appropriate to automatically reduce the air supply in the event of exhaust fail.re.

$* *$ Glass Waste Interim Storage Building

- Instrumentation for pressure differential (vault vs. outdnors and above-vault operating area) and air flow through stack is required.

- Alarms for pressure differential, diversion to filtration, and failure of diversion system are required in the operating areas, the storage building office and the processing building control room.

- Changeover from normal convection cooling to fan-powered cooling and filtration of tre ventilation air will be manually controlled.

- See Part 13, Item 560 for emergency power requirements.** 
PART TITLE: SAMPLING AND ANALYTICAL CONTROL

ITEM TITLE: General

General

An analytical laboratory for process control in the vitrification facility will not be provided. Samples will be taken in sample cells or at sampling locations and transferred to an existing laboratory for analysis. w*the amount of time necessary to sample and transport the samples is to be included in the sample turn around time and will not exceed times that are now listed in Part 5, Item 230.**

It is assumed that during the tank retirement program, the Interim Waste Operations program will prepare the sludge (aluminum dissolution and sludce washing) to meet the specifications of the feed requirements for the vitrification facility. **Savannah River Laboratory will provide analytical service for this interim program. $* * *$

Requirements for characterization of the glass product are not well defined at the time. Current control philosophy envisions that the quality of the glass product will be controlled by stringent parameters in glass melter operations and that routine characterization of the glass product by destructive analyses will not be required. However, it $c$ an be assumed that some limited sampling of the glass product will be required to verifv that the process control parameters are being met. It is assumed that any required analysis of the glass samples can be obtained by use of existing facilities at SRL. $* *$ A description of these sample requirements is 1 isted in part 7 , Item 400.

A description of requirements for the** non-destructive examination of the filled glass canister $* *$ is included in Part 5, Item 290 and Part 20, Itom $275 . \div-*$

During the construction of the supernate processing facility, addition. vessels may be required in the vitrification facility. Design of the sampling cells should consider the potential requirements for the addition of additional samplers.

$* *$ An AED allowance for purchase of laboratory equipment is 1 isted in Table 16-1, Appendix A. Installation of equipment is to be by AED or a construction cross order funded by AED. *** 
PART TITLE: SAMPLING AND ANALYTICAL CONTROL

ITEM TITLE: Sampling -- Raw Materials Receiving

Raw Materials used in the vitrification facility will be analyzed on receipt. These materials will be received in bulk quantities, both solid and liquid, by truck and railway shipment. (See Table 5-2, Appendix A.)

Chemical solutions prepared from the raw materials will be analyzed betore being used in the process.

Provision must be made for sampling shipments of raw materials and prepared chemical solutions in small containers and transfer of these containers to the Analytical Laboratory for the required analyses.

Raw materials used in the process are not to be used until the essential materials analyses are complete. If the material has been unloaded prior to acceptance and the material does not meet specifications, provision for reloading and shipment back to the vendor must be included.

Exposure to and inhalation of hazardous chemicals to personnel during sampling must be considered.

Current SRP policy for sampling, analyzing and unloading raw materials are outlined below for guidance in designing required facilities.

- Bulk chemicals including glass frit received by rail car are sampled from the rail car. After laboratory verification that the material meets specifications, the contents of the rail car are transferred to the receiving vessel.

- Bulk chemicals received by truc's are sampled from the truck **before*** the truck is unloaded into a receiving tank. If laboratory analyses indicate that the material is unacceptable, **the material will be returned to the vendor.***

- Chemicals received in drums, carboys, bags, etc. are unloaded into a holding area. A statistically representative number of the containers in the shipment are samplud for analyses. Following completion of the laboratory analyses, the material is released for process use.

- Chemical cold feed solutions are prepared from the bulk chemicals in makeup tanks. Prior to process use, each makeup is sampled and analyzed prior to process use to verify proper makeup.

- Sample size is dictated ty analytical requirements but is normally about 200-500 mL.

- Sampler used for sampling bulk chemical vessels and process chemical vessels (cold feed solutions) is shown on W148193 and D1 16567. 
PART TITLE: SAMPLING AND ANALY'TICAL CONTROL

\section{ITEM TITLE: Sampling-Glass Melt Operations}

Small samples of the glass product will be occasionally required for analyses to determine product quality. The required analyses will be performed in the high level caves at SRL. **Sampling of the melt stream will provide information of vitrification, chemical composition, radionuclide distribution and physical properties. These results may influence operating parameters, but are not intended for daily process control. ***

Design should provide for obtaining a representative 1 liter sample of the molten glass as it is poured into the canister. Equipment for removing the sample from the glass melt cell and transporting to SRL will be required. This includes a shielded shipping container which must meet canister smear requirements and be compatible to handling facilities at both sites. Facilities at SRL are now being scoped and drawing numbers will be made available as soon as they are complete. 
PART TITLE: REGULATORY AND ENVIRONMENTAL CONSIDERATIONS

ITEM TITLE: Licensing

DOE waste processing facilities are exempt from licensing by the Nuclear Regulatory Commission (NRC). 
PART TITLE: REGULATORY AND ENVIRONMENTAL CONSIDERATIONS

ITEM TITLE: DWPF Status - Regulatory Guides

The design and construction of the facility should be in accordance with the requirements of DOE as set forth in applicable portions of the DOE Manual. Reference C-11, Appendix C provides design requirements for DOE facilities.

The DWPF should be designed and constructed in such a manner as to provide a degree of protection to the work force and to the genecal public that is no less than that provided for facllities constructed in conformance with accepted industrial standards and requirements. Regulatory guides have been issued by NRC for various nuclear factlities. These guides, which are applicable to power plants and to elements of the commercial fuel cycle, may be used to supplement the DOE guides. 
PART TITLE: REGULATORY AND ENVIROIMENTAL CONSIDERATIONS

ITEM TITLE: Construction and Operating Permits

\section{General}

A permit to construct and operate the DWPF per se is not required. However, permits will be required for various portions of the DWPF. DOE will obtain these permits from the appropriate agency. Prior to granting the permit, the agency requires a review of the design of the facility for which the permit is requested. In general, the request for a permit should be accompanied by sufficient drawings, flow rates, estimated releases and any other information that may be necessary for the agency to independently verify the estimated releases to the environment.

Requests for permits should be prepared and submitted to SRP for transmittal to DOE and thence to the appropriate agency. Generally, 30 days will be required for review of the permit application by DOE and 180 days for the agency review. Thus, the design should be complete at least 210 days prior to the date that construction is expected to begin.

The following discusses the permits, plans, actions, etc. that will be required.

\section{Erosion Control Plan During Construction}

A plan to prevent or mitigate erosion during construction will be required. A permit from the state will not be required for the erosion and control plan; however, the plan will be submitted to the State for informational purposes. The plan should be submitted at least 60 days prior to construction activity to allow for DOE and State review.

The erosion control plan should show the method of controlling erosion (sedimentation basins, ripracking, etc.), number and location of discharge points. Monitoring of the discharge should not be required. Consideration should be given to the potential for making the sedimentation basins permanent structures for potential mitigation of the disturbance of the existing wetland in S-Area.

\section{Site Dewatering Wells}

Wells may be required for dewatering the construction site prior to deep excavation for construction of the building. Number, location and discharge points for these wells should be shown on the Erosion Control Plan.

It should be assumed that the South Carolina Department of Health and Environmental Control (SC-DHEC) will not require that ground water discharged to streams during site dewatering be treated to meet NPDES requirements 8 , Item 220), but will require notification of the quantity and source of the wiatex. 
PART TITLE: REGULATORY AND ENVIRONMENTAL CONSIDERATIONS

ITEM TITLE: Construction and Operating Permits

Ground Water Wells

DOE will obtain a "Permit to Construct Ground Water Wells" from the South Carolina Department of Health and Environmental Control (SC-DHEC) Water Supply Division (WSD). This requirement will apply to ground wells constructed for supplying water for industrial and domestic usage. The request for a permit should contain the number and location of the wells plus drawings and specifications for the wells.

Surface Runoff

A permit to construct storm sewers will not be required. However, storm water discharge to the streams will require revision of the existing NPDES permit. This revision will require showing the number, location, area served, etc. for each discharge point. Design of the storm sewer system must assure that no discharges other than rainfall reach the storm sewers. The revision should be submitted 210 days prior to completion of the storm sewer system.

Concrete Batch Plant

The concrete batch plant used during construction will require a "Permit to Construct" and a "Permit to Operate" from the Bureau of Air Quality Control (BAQC) of SC-DHEC.

This requirement can be assumed to apply to any batch plant constructed on-site by either Du Pont Construction or a sub contractor, but would not apply to an existing off-site batch plant. The State will inspect the batch plant after construction completion and issue an operating permit.

\section{Domestic Water System}

A "Permit to Construct" the domestic water treatment and distribution system will be required from WSD of SC-DHEC. The request for a permit should contain the drawings and specifications for the domestic water system.

Chemical and Industrial Waste Treatment Facility

A "Permit to Construct" the chemical and industrial waste treatment facility will be required from Industrial and Agricultural Waste Water Division (IAWD) of SC-DHEC.

The request for a permit should contain the method of treatment, sources and expected concentrations of feed to the waste treatment facility, flow rates, quality of effluent from the treatment facility, location of discharge points, provisions for sampling and monitoring, etc. The facility should be designed to meet the effluent limits specified in Part 8, Item 220. 


\section{PART TITLE: REGULATORY AND ENVIRONMENTAL CONSIDERATIONS}

ITEM TITLE: Construction and Operating Permits

Prior to placing the facility into operation, the NPDES permit will be modified to include this facility as a discharge point. This permit modification will be submitted about 180 days prior to placing the facility into operation.

\section{Sanitary Waste Water Treatment}

A "Permit to Construct" the sanitary treatment facilities will be required from the IAWD of SC-DHEC.

For planning purposes, assume that the request for a permit must be submitted 210 days prior to construction of the treatment facilities. However, SC-DHEC has granted conditional approval within 60 days for some SRP treatment facilities when assured that the planned treatment facility was essentially identical to purchased package units already in existence at SRP. This conditional approval was granted on the basis of report showing vendor's information. Full approval normally requires the 180 days. After construction completion, the State will inspect the facility and grant a permit to operate.

**It is planned to discharge the effluent to the streams; therefore, the NPDES permit will require modification. Limits for discharge to streams are shown in Part 8, Item 220. Revision to the NPDES Permit will be submitted about 180 days prior to placing the facility into operation. ${ }^{*} \%$

Diesel Generators

A "Permit to Construct" the diesel generators must be obtained from BAQC of SC-DHEC for any diese 1 generator with a $150 \mathrm{kw}$ or greater capacity. This requirement will apply to emergency diesel generators and to direct drive diesels used with the well water system. The request for a permit should show the expected emissions to the atmosphere from the diesel operation.

A "Permit to Operate" the diesel generators will be required from the same agency.

\section{Exhaust Stack}

A permit to construct and a permit to operate the exhaust stack for the vitrification building will be required. The permit is required because the stack is a source of $\mathrm{NO}_{x}$ emissions to the atmosphere. 
DPSP $80-1033$

PART 8

ITEM 150

PAGE 4 of 4

DATE 1-82; Rev. 8

PART TITLE: REGULATORY AND ENVIRONMENTAL CONSIDERATIONS

ITEM TITLE: Construction and Operating Permits

The permit request should contain location, height, drawings, specifications, etc. of the stack plus flow rate and concentrations of non-radioactive emissions.

If the exhaust stack exceeds $200 \mathrm{ft}$ in height, the FAA must be notified.

\section{Storage of Materials}

A Spill Prevention Control and Countermeasures plan (SPCC) must be submitted to IAWD of SC-DHEC for oil storage facility of greater than 660 gallon capacity. Construction will be responsible for preparing the plan for construction and operations will prepare the plan for operations.

Process Cell Crane and CCTV Viewing

If a wireless system is used, permits must be obtained from the Federal Communications Comnission. 
PART TITLE: REGULATORY AND ENVIRONMENTAL CONSIDERATIONS

ITEM TITLE: Radiation Releases -- Gaseous/Aqueous/Solids

General goals for waste management, operating criteria, and design criteria have been published in SRO-TWM-77-1, Integrated Radioactive Defense Waste Management Plan, July, 1977. Excerpts from this reference that are applicable to the DWPF are reproduced here. These criteria must be incorporated into the design of the DWPF.

\section{General Goals for Waste Management}

The primary objective of Savannah River's radioactive waste management program is to manage the waste in such a manner as to minimize the radiation exposure and associated risk to man and his environment over the lifetime of the radionuclides. To realize this objective, the Savannah River Plant applies a defense-in-depth approach to the design, construction, operation, and maintenance of waste management facilities. Defense-in-depth approach provides for multiple barriers, both physical and procedural, to minimize the incidence of abnormal events and to 1 imit the adverse consequences of events that may occur. This policy has been implemented by the formulation and observance of the following goals:

- All waste management operations must be consistent with the policies set forth by DOE Manual, Chapter 0511.

- Releases of radionuclides to the biosphere must be within standards set forth in Reference C-10, Appendix $\mathrm{C}$; in addition, releases should be limited to as low as reasonably achievable.

- All waste materials in storage should be retrievable.

- High level liquid wastes will be converted into a relatively stable solid form suitable for packaging and storage in a retrievable mode.

\section{Specific Requirements}

\section{- Operating Criteria}

Aqueous Wastes

- Liquid radioactive wastes should be subdivided into two fractions: one (high level waste) containing concentrations of radionuclides that require confinement and one (low level waste) that may be discharged to the environment pursuant to Reference $\mathrm{C}-10$, Appendix $\mathrm{C}$. 
PART TITLE: REGULATORY AND ENVIRONMENTAL CONSIDERATIONS

ITEM TITLE: Radiation Releases -- Gaseous/Aqueous/Solids

- High level liquid wastes should be converted into suitable physical and chemical forms and confined in a manner that will provide high assurance of isolation from the environment.

- Liquid wastes will be stored in carefully engineered systems equipped with provisions for leak detection and control.

- Adequate diversion systems must be provided to ensure that normally releasable streams from the SRP operations are promptly or automatically diverted to controlled holding areas if they become contaminated to levels that exceed established standards for release cited in Reference C-10, Appendix $C$.

- A system of monitoring wells within and about the radioactive waste storage sites is required to monitor possible migration of radionuclides from their storage location.

Airborne Radioactive Effluents

- Gaseous and other airborne radioactive effluents must be controlled at the lowest levels reasonably achievable and below limits specified in Reference $\mathrm{C}-10$, Appendix $\mathrm{C}$.

- Monitoring and surveillance systems are required to assess the integrity of containment systems and to inventory the quantity of radioactivity discharged to the atmosphere.

b. Design Criteria

These criteria apply to all new facilities:

- Storage sites for solid and liquid wastes must be selected to take advantage of natural barriers that could minimize the release of radioactivity to the environment even if the man made containment barriers fail.

- Storage facilities should be as far as practical from plant boundaries and water sources.

- Containment systems must be designed to withstand or cope with specified natural forces and design basis accidents without releasing excessive radioactivity or other pollutants offsite.

- Liquid waste storage facilities should be as near as practical to the point where the waste is discharged. 
PART TITLE: REGULATORY AND ENVIRONMENTAL CONSIDERATIONS

ITEM TITLE: Radiation Releases -- Gaseous/Aqueous/Solids

- Primary barriers or transfer systems that are, or may be expected to be, in direct contact with radioactive waste must be designed and tested to be leak-free under expected normal operating conditions.

- Secondary barriers must be provided that enclose each primary barrier to ensure the concept of double confinement. For radioactive liquid wastes, this container will be designed to contain the entire contents of the primary container without leakage.

- Aqueous waste transfer systems should be installed in each of the primary and secondary containers and be ready for emptying the liquid contents immediately if required.

- Ventilation systems must be provided to prevent accumulation of flammable gases above 1 iquid wastes in storage and process vessels.

- Ventilation systems must be designed to limit radioactivity releases to the atmosphere during normal operation to concentrations that are as low as is reasonably achievable.

- Design of confinement facilities and equipment must be such that radiation exposure to operating personnel meets the criteria specified in Reference $\mathrm{C}-10$, Appendix $\mathrm{C}$.

- An independent backup source of electrical power should be installed to maintain the integrity of barriers. Redundant electrical supply lines from the backup source are not required.

- Monitoring and surveillance systems must be provided to assess the integrity of primary barriers so that the condition of the barriers can be determined at any time and the extent of any leakage can be evaluated.

- The capability should be provided to assess the integrity of secondary containers so that double confinement of liquid and solid waste can be assured and the extent of iny leakage can be evaluated.

- Monitoring systems, instrumentation, and procedural controls must be included to ensure that waste facilities operate within operating guidelines and technical standards. 
DPSP $80-1033$

PART 8

ITEM 200

PAGE 4 of 4

DATE 9-82; Rev. 9

PART TITLE : REGULATORY AND ENVIRONMENTAL CONSIDERATIONS

ITEM TITLE: Radiation Releases -- Gaseous/Aqueous/Solids

- Waste management facilities should be designed such that the facilities can be operated with as little reliance as possible on people and instruments. Loss of power, cooling water, or possible facility evacuation should not result in conditions that immediately threaten the integrity of physical barriers.

- Monitoring systems must be provided to detect and evaluate the quantity and distribution of any radioactivity released to the atmosphere or ground water.

3. Other Design Considerations

- All facilities should be designed for the safe confinement under all credible conditions of all radioactive waste handled, processed, and stored.

- Any equipment in any system which governs the protection of personnel onsite or offsite should be designed so that in case of failure alternate equipment will automatically come online.

- Liquid and gaseous effluents shall be decontaminated to meet SRP standards before release to the environment. SRP currently operates on the basis of Technical Standard DPST-RH-W-0.1 for release of radioactivity from the plantsite. This standard does not specify the amount of individual radionuclide that may be released but limits the total maximum exposure of an offsite individual from all SRP releases to that shown in Table 8-1, Appendix A. These 1 imits are lower than those imposed by DOE Manual, Chapter 0511 and Reference $C-10$, Appendix $C$, but are considered those reasonably achievable. Since the technical standards limits apply to the summation of all releases from the plantsite, guides for individual production facilities have been developed based on operating experience. These guides are summarized in Table 8-2, Appendix A. Any release from the DWPF will have to be low enough that the plant does not exceed the technical standard.

- Storm water drainage from areas of high contamination potential outside of buildings (i.e., pump pits, or comparable regulated areas) is potentially contaminated. These facilities must be protected from rain or the storm run-off water collected and monitored for radioactivity with the capability of diverting the runoff to the existing Building 281-H retention basin. This in not to be interpreted as applying to outdoor cold feed areas or to reas outside of airlock doors to regulated areas such so. - - ilway tunnel to Building 221-S, the fan house and glass wasce storage building, HEPA servicing entrances or the sand filter airlock entrance. 
PART TITLE: REGULATORY AND ENV IRONMEN'TAL CONSIDERATIONS

ITEM TITLE: Non-radioactive Plant Effluents

\section{A. Genera 1}

Currently, nonradioactive 1 iquid releases from SRP are controlled in accordance with NPDES permits SC0023710 (sanitary sewerage) and SC0000175 (industrial waste). The permits expire in 1980 and 1981 , respectively. The requirements of these permits are discussed below in divisions $B$ and $C$. The Environmental Protection Agency is currently transferring administrative and enforcement responsibilities for the permits to the State of South Carolina. Future revisions of the permits, in 1980 and 1981 , are expected to impose more restrictive limits on metals (i.e., chromium, nickel, and cadmium) and on accidental spills of chemicals.

Federal facilities must comply with all federal: state, and local regulations. Any facilities provided on this project must comply with applicable federal regulations on water pollution and air pollution. In addition, South Carolina regulations must be met. For example, South Carolina Air Pollution Control Regulations and Standards require both constructon and operating permits for facilities with liquid and/or gaseous effluents. The permit applications are normally prepared by Du Pont for DOE-SR to submit to state authorities.

B. NPDES Permit SC0023710

This permit requires secondary treatment, monitoring, and reporting of sanitary waste water discharges to tributaries of the Savannah River.

$* *$ The permit requires flow measurement and specifies monitoring and 1 imits for the following parameters: ${ }^{*}$ t'

Concentration

Suspended solids, Ppm

BOD, $\mathrm{pPm}$

Fecal coliform, colonies/100 m 1

$\mathrm{pH}$
Monthly average less than 30

Monthly average

less than 30

Monthly geometric average less than 200

Between 6 and 9
Monthly maxinum less than 45

Monthly maximum less than 45

Monthly maximum less than 400 
PART TITLE: REGULATORY AND ENVIRONMENTAL CONSIDERATIONS

ITEM TITLE: Non-radioactive Plant Effluents

In addicion, a loading limit which is obtained by multiplying the concentration by the flow is specified.

SRP policy for sanitary waste water discharges from the secondary treatment plants *xhas been** to eliminate discharges to streams by use of spray irrigation on the land surface in a manner that avoids runoff. Spray irrigation equipment is now installed in $A, D$, and $H$ Areas. However, recent plant experience has shown that spray irrigation has not been entirely satisfactory. The current policy $* *$ is discharge the effluent to plant streams and dispose of accumulated sludge to existing SRP land fill area. ${ }^{\text {kf }}$

C. NPDES Permit SC0000175

This permit specifies limits for discarding nonradioactive industrial effluents to streams on the plantsite.

The permit specifies limits for various types of discharges. The 1 imits are summarized in Table 8-3, Appendix $A$ and are applicable to each waste stream of a particular type. In addition to the limits, flow measurement is required for each of the discharges. Sampling and flow measurement must be at the source and prior to mixing with any other waste stream.

The permit also specifies limits for effluents from the following facilities: (a) vehicle and equipment cleaning facilities, (b) painting and corrosion control facilities, (c) vehicle and equipment maintenance areas, (d) petroleum, oil, and lubricant storage and handling areas, and (e) photographic laboratories.

200-S Area will have nonradioactive effluent streams of one or more of these types and those shown in Table 8-3, Appendix A. If the waste stream is discharged directly to the environment, it must meet the water quality limits specified and provisions for sampling and flow measurement of each stream must be provided. If several waste streams are combined for treatment to improve the water quality, then only the effluent from the treatment facility will require monitoring for compliance with the discharge permit. Limits for this treated effluent will be specified by federal and state authorities. However, it can be assumed that this treated effluent will require monitoring for all of the parameters specified in Table 8-3, Appendix $A$ and that the most restrictive limits will apply. 
PART TITLE: REGULATORY AND ENVIRONMENTAL CONSIDERATIONS

ITEM TITLE: Radiation Exposure Limits

**Reference $\mathrm{C}-10$, Appendix $\mathrm{C}^{* *}$ prescribes 1 imits for worker radiation exposure. It also stipulates that the exposure should be as low as technically and economically feasible and that worker exposures of less than 1000 $\mathrm{mren} /$ year should be a design objective.

To meet the above objective, SRP policy (Technical Standard DPSTS-RH-0.02, proposed revision $4 / 74$ ) states that shielding shall be provided to limit the exposure to less than $0.5 \mathrm{mrem} / \mathrm{hr}$ in continuously occupied areas and less than $5 \mathrm{mrem} / \mathrm{hr}$ in intermittently occupied areas. 
PART TITLE: REGULATORY AND ENVIRONMENTAL CONSIDERATIONS

ITEM TITLE: Radiation Contamination Limits for Storage or Shipment

The limit for transferable contamination on the canister is 220 $\mathrm{d} / \mathrm{min} / \mathrm{dm}^{2}$ al pha and $2200 \mathrm{~d} / \mathrm{min} / \mathrm{dm}^{2}$ beta-gamma. 
PART TITLE: REGULATORY AND ENVIRONMENTAL CONSIDERATIONS

ITEM TITLE: NOISE LEVEL LIMITS

The maximum permissible noise level for personnel for an 8-hour working day is $90 \mathrm{DBA}$. All practical engineering and design efforts should be made to reduce noise to personnel to a level below this requirement. Areas exceeding 90 DBA are to be posted and ear protection supplied for personnel working in the area. J2C.

Design must be in accordance with Du Pont Engineering Stancards J2B and 
PART TITLE: REGULATORY AND ENVIRONMENTAL CONSIDERATIONS

ITEM TITLE: Plant Decommissioning

General

** The decommissioning of the Sludge Plant can be facilitated by incorporating in the design features which will assist in this effort. DOE factlities general design criterla requires that design features be considered which will facilitate decommissioning Reference C-11, Appendix $\mathrm{C}_{0}{ }^{\star \star}$ These features may be utflized in any one of the four general modes of decommissioning as described in published literature.

(1) Layaway

(2) Protect1ve storage

(3) Entombment

(4) Dismunt lement

**The decommissioning plan for the Sludge Plant is based on the following assumptions: ${ }^{\star \star}$

- Dismantlement is the ultimate objective of any decommissioning effort

- Techniques and methods of decontamination and decommission w111 probably change during the lifetime of the facility.

- The intent of the regulations is to anticipate the most likely method to accomplish decommissioning

- **Due to the purpose of the Sludge Plant, it will be one of the last facilities at SRP to be decommissioned.*

- The criteria selected to assist in decommissioning will not represent a significant increase in cost

Plan

**A general plan for a method of decommissioning sludge processing fac1lities will Involve: ${ }^{\star \star}$

(1) Flushing of lines and vessels

(2) Evaporation of liquid waste in the Eank farm evaporator or providing an evaporator for this task 


\section{PART TITLE: REGULATORY AND ENVIRONMENTAL CONSIDERATION}

ITEM TITLE: Plant Decommissioning

(3) Solidification of liquid waste

(4) Conversion of certain areas to a facility suitable for volume reduction and packaging of process equipment

(5) Decontamination of process cell interior surfaces

(6) Isolation of decontaminated areas to prevent recontamination

(7) Demolition

It is assumed that the weld test cell portion of the process cell will be modified and used for a volume reduction and packaging facility because of the remote handling, viewing and transportation handling capabilities. This area of the process building will probably be the last one to be decontaminated. Design of the process cell should facilitate this approach.

Decommissioning is planned in four phases.

a. Chemical Decontamination

This phase will involve rinsing and chemically cleaning the internal surfaces of process lines, vessels, and equipment. The contamination will be removed by a series of flushes designed to reduce the level to as low a value as practical. The external surfaces of process equipment will be sprayed remotely with a series of decontamination solutions or steam. Spent cleaning solutions will be evaporated and solidified.

\section{b. Removal of Contaminated Equipment}

This phase will involve disconnecting and removing all process equipment to the decontamination cells for further decontamination and preparation for burial. The process equipment will be reduced in volume by cutting, sawing, etc., and packaging for transportation to a waste disposal facility. 


\section{PART TITLE: REGULATORY AND ENVIRONMENTAL CONSIDERATIONS}

ITEM TITLE: Plant Decommissioning

\section{c. Decontamination of structures}

This phase will include decontamination of all contaminated surfaces of the process cells. These surfaces will be remotely sprayed with a series of decontamination solutions and steam to reduce tbe radiation levels. Spent cleaning solutions will be evaporated. Residual contamination of structural surfaces will be removed using state-of-the-art methods at the time of decommissioning. This might include such techniques as chipping, grinding, etc. All contaminated material will be packaged for transportation to a waste disposal facility.

\section{d. Demolition and Restoration}

**This phase will include demolition of all above grade portions of the Sludge Plant facilities using conventional methods such as explosives and impact balls. The site will then be graded and planted with vegetation to near prefacility conditions. The DWPF site will be released for unrestricted use. ${ }^{*}$

\section{Design Criteria}

Although major investment in decommissioning requirements should be avoided it is desirable to inrlude design features wherever possible to facilitate any decommissioning method that may be selected. **Based on the general procedure just given, the following design criteria for decommissioning the DWPF facilities were developed.** Several of these criteria are required for process operation. Others are criteria to be included to the extent that no significant additional cost is incurred.

Items 1 through 6 are included in general design criteria for the main processing building Part 11, Item 105. These are considered necessary for process operations and will assist in decommissioning. Items 8 through 17 are included to provide design criteria sepcifically for decommissioning if they can be included in the design without increasing construction costs. 


\section{PART TITLE: REGULATORY AND ENVIRONMENTAL CONSIDERATIONS}

\section{ITLM TITLE: Plant Decommissioning}

\section{Maintenance}

Provide the capability to introduce, loosen, take apart, disconnect, locate, relocate, and remove all equipment. The process cell will require remote maintenance. In selected locations, hands-on maintenance will be acceptable provided that the capability for removing or placing in shielded storage in-process materials is available.

\section{Compartmentalization of Process Functions}

Where practical, process functions should be divided into different compartments. Division of the glass melt cell and the weld test cells is an example of this concept.

\section{Access to Process Equipment}

Provide ready remote access to all contaminated process equipment. Provide process cells with removable covers and do not stack process vessels except where absolutely necessary. Keep the number of jumpers on top of jumpers and piping services that cause obstructions to a minimum.

4. Cell Sumps and Jets

Provide a sump and a jet for each decon cell, process cell, and for removal of liquid. In any cell where liquids are not routinely handled during normal operation, include only the sump with provision for later addition of the jet.

\section{Protective Coatings}

Protective coating should be applied to concrete surfaces subject to chemical or radioactive spill. The protective coatings will reduce the amount of radioactive contamination absorbed into the concrete. If stainless steel linings are not used, a protective coating recommended to resist deterioration caused by radiation and process and decontamination chemicals should be tested, approved, and applied according to standards. See Reference F-2, Appendix $F$ on selection and application of protective coatings. 
DPSP $80-1033$

PART 8

ITEM 500

PAGE 5 of 6

DATE 9-82; Rev. 9

PART TITLE: REGULATORY AND ENVIRONMENTAL CONSIDERATIONS

ITEM TITLE: Plant Decommissioning

6. Openings, Wall Penetrations, and Service Piping

**Keep the number of wall penetrations in other design areas to an absolute minimum. Consider providing wall penetrations with a flange or 1 ip which will give a surface to weld covers over each opening if required. ${ }^{\star \star}$

7. Provision for Chemical Decontamination

Provide capability of modifying piping and services to allow effective chemical decontamination of canyon surfaces. Provide for addition of spray rings or decontamination lances to any process cell section. Provide spray rings or decontamination features in the decontamination cells.

8. $* *$ Liquid Waste Disposal

Provide a means to transfer liquid waste from sump collection tanks and cell washdown to the Waste Tank Farm.**

9. Isolation of Sections of Ventilation System

Consider providing a method of ventilation control which will permit air flow from selected process cell sections to be selectively reduced or eliminated at the exhaust entrance to the air tunnel. This capability is not required during normal operations, but provision for installation during decommissioning is desirable.

10. Control Room Location

If feasible, the control room should be located so that controls for the continued operation of the weld test cell will be available during dismant lement.

\section{Electrical Substations}

If practical, the location of substations should be chosen to facilitate the continued operation of the weld test cell. 
PART TITLE: REGULATORY AND ENVIRONMENTAL CONSIDERATIONS

ITEM TITLE: Plant Decommissioning

\section{Capability for Mechanical Decontamination}

Following chemical decontamination of canyon surfaces, it may be necessary to remove residual contamination by grinding or other methods. Design should facilitate the spalling of the concrete surface.

\section{Coating of Exhaust Tunnels}

**The exhaust air tunnels from the Sludge Plant process cells should be coated in the same manner as exposed canyon walls.**

14. Access to Sand Filter

Provide air lock access to the top of the filter to permit entry for sand removal and decontamination.

15. Secondary Filtration at Sand Filter

Consider provisions for passing air from the sand filter through HEPA filters before discharge to the stack during decomissioning. $\star \star$ This can be accomplished by providing any knockout plugs, etc., that might be required to divert the sand filter exhaust to the air tunnel from the operating area of the Sludge Plant building to the HEPA filtration system for that air. ${ }^{* *}$ As an alternative, reserve sufficient space between the sand filter and the stack to install a HEPA system during decommissioning.

\section{Air Flow Patterns}

**Air flow patterns should be from clean areas to regulated areas to process cells. Flow should be directed from weld test cell to process cell to sand filter.*ᄎ

17. Volume Reduction of Waste

Volume reduction, treating, and packaging of solid waste is a desirable feature. This capability is not required during normal operations, but provisions for installation during decomissioning should be considered, at least in a limited scope, during final design. 


\section{PART TITLE: QUALITY ASSURANCE}

ITEM TITLE: QA Assessment Basis

\section{General}

**Quality assurance requirements for Savannah River activities are outlined in DOE Order SR-5700.6A.** DU Pont interprets and satisfies these requirements through the Savannah River Quality Assurance Policy, DPW-76-111-1, Revision 1 and a series of six Savannah River Quality Assurance Manuals, DPW-78-111-2, plus detailed instructions for each organization. For the DWPF project, the program is slightly modified to accommodate the change in Du Pont work activities because an outside company is employed as the engineering contractor.

\section{Quality Assurance Assessement Process}

An assessment process is employed to determine whether all or part of the QA program is to be applied to a project, facility, or portion thereof.

In implementing the QA Program for DWPF, a QA assessment process will be employed to classify all items and services into one of two categories, $Q$ or $S$, as defined under definitions. The reasons for these classifications are based on group judgment of knowledgeable people and are documented. The formal QA Program is implemented for those items and services that are classified as $Q$.

Quality Assurance Assessment Criteria

**The Quality Assurance Assessment criteria for DWPF are given below: **

\section{Radioactive Material Releases}

Release of radioactive materials to the environment, from normal operations or credible accidents, must not exceed the following annual doses at the site boundary.

Type of Exposure Whole body, gonads, or bone marrow Other organs

\begin{tabular}{cr}
$\frac{\text { Exposure, mrems }}{\text { Maximum }}$ & \multicolumn{1}{c}{ Average $^{\text {Ave }}$} \\
\cline { 1 - 1 } 500 & 170 \\
1500 & 500
\end{tabular}

$a_{\text {Based }}$ on dose to individuals at points of maximum probable exposure. based on average dose to suitable sample of exposed population. 


\section{PART TITLE: QUALITY ASSURANCE}

ITEM TITLE: QA Assessment Bas is

\section{Nonradioactive Hazardous Gas Releases}

Release of nonradioactive hazardous gases to the environment, from normal operations or credible accidents must not exceed the following concentration levels at the site boundary.

\begin{tabular}{|c|c|}
\hline Gas & Hazard Leve 1, ppm \\
\hline Chlorine & Over 15 \\
\hline Sulfur dioxide & $\begin{array}{l}\text { Over } 100 \text {, or } \\
\text { between } 50 \& 100 \\
\text { for over } 2 \text { hours } \\
\text { over } 40\end{array}$ \\
\hline
\end{tabular}

3. Unexpected Costs

Unexpected costs, such as damage and/or cleanup expenses, to facilities or processes must not exceed 10 miilion dollars per event.

4. Loss of Production

Loss of production of an acceptable product in a single production process must not exceed a 6 -month period.

5. Unplanned Nuclear Criticality

Unplanned nuclear criticality must not occur in any facility or process.

6. Process Hazards

Unplanned reactions in, or upsets to, manufacturing processes that could cause explosion, fire, release of toxic material, eruption from overpressurization, or radiation exceeding 300 rems, resulting in fatality or total and permanent disability, must be prevented or mitigated.

Supporting services (electricity, steam, air, water, material handling, modes of transportation, etc.) and failure of hardware (rupture disks, pressure relief valves, gaskets, valve packing, seals, breathing-air equipment, etc.) are typically not considered under this QA assessment criterion.

7. Others

Department Superintendents with the concurrence of the site QA coordinator, may elect to assess projec $s$ or facilities for application of the QA program beyond the scope of the preceding criteria in order to achieve other important project objectives. 
PART TITLE: QUALITY ASSURANCE

ITEM TITLE: QA Assessment Basis

Applicability of Criteria

For the DWPF, QA Assessment Criteria No.'s 1, 3, 4 and 6 (radioactive material releases, unexpected costs, loss of production and process hazards) are considered applicable. Criticality is not considered feasible in the DWPF and therefore criterion No. 5 is not applicable. Hazardous gases are not expected to be utilized in the DWPF in sufficient quantities that would exceed the release limits specified in Criterion No. 2; therefore this criterion is not considered applicable. The four applicable criteria, No.'s $1,3,4$ and 6 , are designated the "DWPF QA Assessment Criteria."

\section{Qualifications}

The following qualifications apply to the four DWPF QA Assessment Criteria:

1. The following clarifications apply to the process hazards criterion:

- It is concerned with high consequence (death or total disability) accidents only. It does not apply to those hazards which would normally be covered by standard industrial design practices and safety programs.

- It applies only to accidents that result from a manufacturing process operation. As a result, it will only be applied to the following design areas. However, the results of the assessment process may have an impact on other design areas.

$\begin{array}{ll}221 & 378 \\ 250 & 383 \\ 329 & 395 \\ 350 & 450 \\ 360 & 511 \\ 376 & 550\end{array}$

The basis for selection of these design areas is given below:

- The process hazards criterion will be applied to design areas in which there is a manufacturing process operation and/or potential hazard for a radiation dose to an individual employee exceeding 300 rems.

- The manufacturing process is considered to begin with the origin of the waste transfer line, as defined in Part 5, Item 170, and end with the storage of the filled canister in the glass storage building.

- The boundaries of the process are given below.

- Includes the off-gas treatment, mercury recovery-recyclé collection and mercury purification-containerization systems. 


\section{PART TITLE: QUALITY ASSURANCE}

\section{ITEM TITLE: QA Assessment Basis}

- Includes chemical feed systems that directly feed the process, but does not include bulk storage of dry or liquid chemicals or the preparation of chemical solutions.

- Includes sample collection and handing.

- Does not include the 221-s exhaust system.

- By its definition, this criterion seeks to identify potential process accidents that are not obvious and are more difficult to identify. Therefore, appropriate expertise must be applied to the identification process.

2. The radioactive material release criterion is applicable to all incidents, including natural phenomena such as earthquake, tornado, flood, etc. This holds true up to the design basis of each phenomenon (e.8. DBE, DBT).

3. The following clarifications apply to the radioactive material release criterion:

- The word exposure, as used in the introductory sentence and in the heading above the limits, means dose.

- Subscript b. means a sample of exposed population within a radial distance of $50 \mathrm{miles}$ from the center of the release.

4. The unexpected costs and 1088 of production criteria are not applicable when they result from any natural phenomena, such as earthquake, tornado, flood, etc.

5. In estimating the unexpected costs, the estimate will be based on the cost at the time the assessment is performed and will not be escalated.

6. Decomissioning will not be considered in the QA assessment.

7. Reasons for classifying an item or service as $Q$ or $S$ are to be documented.

8. For any item or service classified as $Q$, an action plan (QAAP) is to be developed and implemented. The action plan is to be combensurate with the importance of the item or system. The QA action plan is to cover the design, procurement, construction, inspection, and operation of the DWPF. In addition, other groups (AES, LDL, Construction, etc.) may have their own action plans, but none of these are to supercede or diminish the requirements established by the formally approved QAAP. 


\section{PART TITLE: QUALITY ASSURANCE}

\section{ITEM TITLE: QA Assessment Basis}

9. A set of rules for selecting and evaluating credible accident scenarios and for the effect of redundancy in classifying segments or components $Q$ or $S$ is given below.

- Generally, assume single failures as initiating events with nis credit taken for items which can mitigate the consequences of events, unless these mitigators are $Q$.

- A credible exception is multiple failures with operator error as the second failure.

- If consequences are severe or probabilities are high, use multiple barriers and/or whatever else might be needed, based on judgment.

- Redundancy of actions or constraints to prevent or mitigate the consequences of a $Q$ event are not used as the basis for voiding the $Q$ classification of the major segments. Horever, redundancy or other design actions can reduce the need for $Q$ classification of the components.

\section{DEFINITIONS}

For the QA Program on DWPF, the following definitions are employed:

Q - Designator for any item or service that is assessed to have characteristics whose quality requirements must be validated by 1 formal QA program to reduce the consequences of a postulated everit to less than the 1 imits established by the DWPF QA Assessment Criteria.

$S$ - Designator for any item or service that is not $Q$ as determined tirrough the QA assessment process. Standard Du Pont practices apply. S items need no QAAPS and the formal QA program is not applied.

QAAP - Quality assurance action plan. 


\section{PART TITLE: QUALITY ASSURANCE}

\section{ITEM TITLE: Bases for Consequence Calculations}

The objective of this item is to assure that the same consequences for a given accident will be calculated at Savannah River and by the organization performing the QA assessment. This objective is to be accomplished by using the same methodology for consequence calculations that has been used at SRL for the Preliminary Safety Analysis. The following describes the bases used by SRL for performing the calculations for the Preliminary Safety Analysis.

\section{Form of Material Releases}

- Spills are assumed to be low energy events - liquid on the cell floor with potential of liquid being released to the ground surface.

- Subsurface releases have been shown to have negligible consequences.

- Evaporation results in radioactivity in the vapor phase condensing to a liquid aerosol.

- Violent reactions within a 1 iquid-containing vessel are assumed to disperse liquid directly into cell atmosphere as an aerosol. The residual liquid is subject to surface run off.

- Explosion of melter or canister rupture will disperse activity into cell atmosphere as a particulate aerosol. Re-entrainment contributes only a small fraction to the initial amount released and is not to be considered. Surface run off is not to be considered.

Volume or Mass of Material Released

Maximum vessel contents were assumed to be applicable for calculations for the safety analysis for liquid systems. Vessel sizes should be obtained from the current, approved flow sheet.

Isotopic Distribution

Isotopic distributions for the contents of each of the vessels have been determined from information contained in Tables 6, 7,8, and 9 of DPST 81-379.

Partition Factors for Specific Isotopes

Partition factors for the evaporation of liquids are as follows:

- 1.0 for tritium and iodine

0.01 for selenium, technitium, and ruthenium 


\section{PART TITLE: QUALITY ASSURANCE}

ITEM TITLE: Bases for Consequence Calculations

- 0.0001 for non-volatile radionuclides

In cases where the liquid is dispersed directly into the cell air as a result of a violent reaction, a partition factor of 1.0 is applied to all radionuc lides.

\section{Duration of Release}

Operating experience indicates that 1 iquid releases are flushed and returned to a process vessel within 8 hours. Therefore, all accidents (except natural phenomena) are assumed to have a duration of 8 hours for the release and transport of radioactive materials.

\section{Method for Calculating Amount of Liquid Vaporized During a Spill}

If a spill of process liquid were to occur in the DWPF, the amount of radioactive materials that would be transferred from the spill pool to the exhaust filter is a function of the parameters shown in the following table:

\section{Parameter}

$$
\begin{aligned}
& \text { Decay heat generation in } \\
& \text { process liquid } \\
& \text { Time before cleanup } \\
& \text { Gamma radiation } 1088 \\
& \text { from liquid } \\
& \text { Liquid temperature } \\
& \text { Heat of vaporization } \\
& \text { Heat capacity } \\
& \text { Air flow over liquid } \\
& \text { Relative humidity of air } \\
& \text { Conduction into the } \\
& \text { concrete }
\end{aligned}
$$

Increase in Parameter Increases or Decreases Amount Vaporized?

Increases

Increases

Decreases

Increases

Decreases

Decreases

Increases

Decreases

Decreases
Parameter to be Considered in Consequence Calculations?

Yes

Yes

No

Yes

Yes

Yes

No

No

No 
DPSP $80-1033$

PART 9

ITEM 140

PAGE 3 of 7

DATE 9-82; Rev. 9

PART TITLE: QUALITY ASSURANCE

ITEM TITLE: Bases for Consequence Calculations

Parameter

Pool surface area

Partition factor between 1 iquid and vapor for specific isotope

Condensation between liquid pool and exhaust filter
Increase in Parameter Increases or Decreases Amount Vaporized?

Increases

Increases

Decreases
Parameter to be Considered in Consequence Calculations?

No

Yes

No

A precise determination of material transport would involve a complex transient mass - heat transfer calculation. Such a calculation is not deemed cost effective because of the time required to develop the calculational procedure, because the consequences of evaporation from a pool are several orders of magnitude less than the medium-to-high energy events postulated, and because the factors omitted in the simpler determination are generally self-compensating.

**For the purposes of this sample calculation, the decay heat generation rates for the specific compositions under consideration were taken from the Preliminary Technical Data Summary for the DWPE, DPSTD-80-38. The time before cleanup was based on consultation with plant personnel and assigned a value of eight hours. Because most of the material that is vaporized would be water, $540 \mathrm{pcu} / \mathrm{pound}$ was used as the heat of vaporization. Partition factors for the specific isotopes are listed and justified in the Preliminary Safety Analysis, DWPF, DPST-81-421. For future calculations, the latest (most current) references should be used. The current heat generation notes are in Appendix $\mathrm{H}$, Tables 21-17 through 21-25.**

For an example, assume a spill from the melter feed tank of 5375 gallons. This corresponds to the conditions of the stream from the Slurry Mix Evaporator to the Melter Feed Tank and has the following values:

Temperature

Heat capacity

Specific gravity

Heat generation rate

Cleanup time

Flush water* $38^{\circ} \mathrm{C}$

$0.683 \mathrm{pcu} / 1 \mathrm{~b}-{ }^{\circ} \mathrm{C}$

1.28

0.485 watts/gallon

8 hrs.

$20001 \mathrm{~b}$.

*The effect of flush water on the calculation of the amount of liquid vaporized during a spill is negligible and may be neglected. 
DPSP $80-1033$

PART 9

ITEM 140

PAGE 4 of 7

DATE 9-82; Rev. 9

PART TITLE: QUALITY ASSURANCE

ITEM TITLE: Bases for Consequence Calculations

Mass of material spilled:

$5375 \mathrm{gal} \times \frac{8.33 \mathrm{lbs}}{\mathrm{gal} \text { water }} \times 1.28(\mathrm{sp} . \mathrm{g.})=57310$ lbs sludge

Average heat capacity:

57310 lbs sludge $\times 0.683 \mathrm{pcu} / 1 \mathrm{~b}-{ }^{\circ} \mathrm{C}+2000$ lbs water $\times 1.0 \mathrm{pcu} / 1 \mathrm{~b}-{ }^{\circ} \mathrm{C}$ 57310 lbs sludge +200016 s water

$=0.694 \mathrm{pcu} / 1 \mathrm{~b}-{ }^{\circ} \mathrm{C}$

Heat required to vaporize one pound of water:

$540 \mathrm{pcu} / 1 \mathrm{~b}+\left(100^{\circ} \mathrm{C}-38^{\circ} \mathrm{C}\right)\left(0.694 \mathrm{pcu} / 1 \mathrm{~b}-{ }^{\circ} \mathrm{C}\right)=583 \mathrm{pcu} / 1 \mathrm{~b}$

Heat generation rate in pcu:

$(0.485$ watts $/ \mathrm{gal})(0.05692 \mathrm{Btu} / \mathrm{min}$-watt) (lpcu/1.8 Btu)

$(60 \mathrm{~min} / \mathrm{hr})(8 \mathrm{hr})(5375 \mathrm{gal})=39570 \mathrm{pcu}$

Mass vaporized:

$39570 \mathrm{pcu} / 583 \mathrm{pcu} / 1 \mathrm{~b}=67.91 \mathrm{bs}$

Fraction vaporized:

$67.9 \mathrm{lbs} / 57312 \mathrm{lbs}=1.18 \times 10^{-3}$

Curies of Ru 106 vaporized given an initial concentration of 2.083 curies/gallon and a partition factor of $1 \times 10^{-2}$ :

(5375 gallons) $\left(2.083\right.$ curies/gallon) $\left(1.18 \times 10^{-3}\right)\left(1 \times 10^{-2}\right)$

$=0.132$ curies

These calculations are consistent with Subsection 9.4 .2 of the DWPF preliminary safety alalysis. 
PART TITLE: QUALITY ASSURANCE

ITEM TITLE: Bases for Consequence Calculations

Mechanism for Transport of Radioactive

Materials to the Filtration System

Airborne material escaping the canyon cell in which the accident occurred will be transported in the exhaust air stream to a deep bed sand filter. Tritium (as tritiated water), iodine, and ruthenium will condense to some extent on cold surfaces; however, they will resuspend in time. It is, therefore, conservative to assume that $100 \%$ of the airborne material reaches the sand filter.

\section{Filtration System Efficiency}

The efficiency of sand filters used at the Savannah River Plant has been measured on numerous occasions. A correlation of these data shows that $97 \%$ of the time the penetration factor ( 1 - efficiency) is $4.9 \times 10^{-3}$ or less and $50 \%$ of the time the penetration factor is $3 \times 10^{-4}$ or 1 ess. The $97 \%$ value is used for safety analysis calculations and the $50 \%$ value for environmental effects calculations. The efficiencies are greater where burst-type releases occur, but the more conservative values are used.

Elevation of Release Point to the Environment

Accidents in which nozmal ventilation is maintained result in a release from the 140- $\mathrm{ft}$ ventilation stack. Where the ventilation system is inoperable, a release height of 10 meters is assumed to be equivalent to a ground level release.

Dilution Factors During Transport ( $\mathrm{X} / \mathrm{Q}$ Values)

**Dilution factors were calculated by the NRC 145 computer code according to NRC Regulatory Guide 1.145 and can be found in Tables, 3, 4 and 5 of DPST 81-379, Memorandum Durant, W. S. and J. C. Huang to H. D. Harmon, DWPF QA Assessments - Items Requiring Coordination, Bechtel, May 11, 1981. **

\section{Population Distribution}

Population distributions are based on the 1970 census records and can be found in Tables 1 and 2 of DPST 81-379.

\section{Radial Distance for Population Dose}

Dose calculations are made out to a radial distance of 50 miles from Building 221-s. 
PART TITLE: QUALITY ASSURANCE

ITEM TITLE: Bases for Consequence Calculations

Dose Conversion Factors for Specific Isotopes

Dose conversion factors are available for each of the applicable radionuclides in NUREG-0172, Age-Specific Radiation Dose Commitment Factors for a One-Year Chronic Intake, G. R. Hoenes and J. K. Soldat, Batelle Pacific Northwest Laboratories, Richland, Washington, November, 1977. The dose conversion factors for tritium should be increased by a factor of 2.6 over the value specified in NUREG-0172.

Evacuation Time and Distance

Evacuation is not considered in consequence calculations for SRP separations and waste processing facilities primarily because of the low consequences of accidents associated with these facilities. However, if evacuation is to be considered, it is suggested that three days to evacuate out to a distance of 25 miles would be appropriate for an offsite population.

\section{Inhalation Rates}

Dose calculations for the DWPF are made using the GASPAR computer code. This code considers four distinct age groups: infant, child, teenager, and adult. Respiration rates in units of $\mathrm{m}^{3} / \mathrm{yr}$ for these groups are as follows for population dose calculations:

$\begin{array}{ll}\text { Infant: } & 1400 \\ \text { Child: } & 3700 \\ \text { Teenager: } & 8000 \\ \text { Adult: } & 8000\end{array}$

Maximum individual inhalation rates are 1.5 times the above values. 


\section{PART TITLE: QUALITY ASSURANCE}

ITEM TITLE: Bases for Consequence Calculations

Liquid Release Outside of Processing Building

Part of the waterborne release will stay in the ground water and part will flow to the surface water. The ground water migrates slowly, and takes tens of years to reach Four Mile Creek or Upper Three Runs Creek. Contamination of the ground water by an accident is limited to onsite and makes little or no contribution to the offsite dose. It is conservatively assumed, however, that all waterborne radionuclide releases reach the river; this assumption yields an upper limit for the dose. The maximum individual doses included only the potable water pathway. Daily water consumption by an individual was taken as 2 liters. The minimum Savannah River flow $\left(6000 \mathrm{ft}^{3} / \mathrm{sec}\right)$ was assumed for calculation of waterborne radionuclide concentrations.

The computer code LADTAP was used to calculate doses. This code, developed by USNRC, is based on USNRC Regulatory Guide 1.109, "Calculation of Annual Doses to Man from Routine Releases of Reactor Effluents for the Purpose of Evaluating Compliance with 10 CFR Part 50, Appendix I." 
PART TITLE: PLANT POPULATION

ITEM TITLE: Total Plant Population

General

**The Sludge Plant population is estimated to be a total of 238 persons. This plant population is divided into the following categories:**

- Wilmington Salary 74

- Local roll hourly 125

- Local roll weekly 39

The total of the above assigned to days will be 122 .

The total of the above assigned to shifts will be 116.

The total estimated to be present in the area at one time is 151 .

Personnel

A summary of the personnel to be assigned to $S$ Area is listed in Table 10-1, Appendix A. A 1 ist of of fice locations, number of lockers and location, and a sumary of sanitary facilities for both male and female are included in Table 10-2, Appendix A. 


\section{PART TITLE: BUILDING REQUIREMENTS}

\section{ITEM TITLE: Processing Building}

The main processing building is to house a glass melter and all associated equipment required to vitrify washed sludge from the waste farm. All process operations should be performed in a cell which includes segregated melter, canister decontamination, and **weld test cells** to control thermal currents and cross-contamination. Sludge from the waste farm will be processed to a retrievable, relatively nonleachable, radioactive glass form product which will be stored in an interim onplant storage facility. The processing building should house process cooling water systems, process equipment decontamination facilities, local control units for emergency operations, Health Protection facilities, and supporting $E \& I$ and maintenance shops and $a$ few of fices for essential personnel.

Processing areas must be located in a building of earthquake and tornado resistant construction in accord with Part 4, Item 700. Process equipment must be located in remotely operated cells. Process equipment will be ** remotely installed and removed for maintenance** except in certain locations where contact maintenance will be permitted. All cell equipment and piping must be located relative to fixed reference points. Containment of radioactivity is essential. Decontamination capability for cell equipment is also essential and design of equipment should facilitate decontamination. $*$ Remotely removable equipment is to** exit through a decontamination area in the cell before it is transferred to the repair shops or is removed from the building.

**If space is not available in the seismic portion of the building, $* *$ clean area facilities such as control rooms, locker rooms, cold feeds, $\mathrm{H} \& \mathrm{~V}$ equipment rooms, electrical substations, etc., should be located in a contiguous or nearby building. There are no laboratory facilities required in S-Area, but process sampling capability will be required.

Ventilation supply fans may be housed on the roof of the process structure.

Air compressor equipment required for emergency instrument air service is to be located within the seismic resistant structure.

Emergency diesel-generator sets, if provided to serve Processing Building facilities exclusively, should be housed within the seismic structure of the process building. The critical electrical switch gear should also be housed within this structure. 
PART TITLE: BUILDING REQUIREMENTS

ITEM TITLE: Process Building -- General Design Criteria

Design considerations for the processing building are as follows:

1. Process Cell Criteria

- The following definitions will be used in discussing the design criteria and should be applied to the design of the facilities.

- Remote Process Cell (RPC) -- A concrete-shielded, remotely operated area for processing radioactive waste. Generally rectangular in shape, the RPC includes areas which are open or closed as specified below..

- Chemical Process Cell (CPC) -- The open area within the RPC which contains tanks and equipment related to melter feed preparation, waste handing, vessel vent and melter off-gas facilities.

- Remote Equipment Decontamination Cell -- The enclosed area within the RPC, separated by cell covers, for remote decontamination of equipment in preparation for repair or removal from the RPC.

- Contact Equipment Decontamination Cell -- The enclosed area within the RPC, separated by cell covers and air locks, for direct decontamination and limited repair of equiprent by operating personnel.

- Melter Cell -- A covered area within the RPC, isolated by cell covers and transfer tunnels, housing the glass melter and a cool down station for filled canisters.

- Canister Decontamination Cell -- A covered area within the RPC isolated by cell covers and transfer tunnels, housing canister decontamination equipment.

- Weld Test Cell -- An area within the processing building possibly within the confines of the process cell, isolated by air locks and transfer tunnels, housing facilities to seal and monitor the canisters.

- Railroad Well and Air Lock -- The enclosed area within the RPC, separated by cell covers and ventilation control door, which serves as the air lock for transfer of equipment between the remote process cell and the outside of the vitrification building.

- These cells are to be designed to service a specific equipment arrangement. A modular cell configuration is not required, but is desirable if available at no additional cost. 


\section{PART TITLE: BUILDING REQUIREMENTS}

ITEM TITLE: Process Building -- General Design Criteria

- Provide about $10 \%$ spare penetrations through the cell shielding wall at each equipment location (including spare equipent modules), with a minimum of one spare penetration for each type of service where inclusion of spare penetration does not increase the building length.

- At spare equipment modules, provide penetrations per Appendix A, Table 5-5.

- To control the spread of contamination by thermal currents, insulate or water cool thermally hot major equipment pieces to the extent practical. Although some flanges, bails, connectors, and other protrusions cannot be readily covered, it is desirable to reduce heat loss to the cells by insulating essentially all thermally hot piping and vessel surfaces. Steam jumpers and associated piping are excluded from insulation considerations.

- A protective coating resistant to deterioration by radiation, process chemicals, and moisture is to be applied to areas inside the remote process cell to reduce the amount of radioactive contamination absorbed into the concrete. This coating is also to be applied to interior surfaces of the concrete exhaust air plenums from the process cells.

- Cell datum grid sleepers or equipment positioning floor pads, and positioning trunnion guides must permit precise positioning and remote installation of all equipment.

- Cell covers over spaces requiring occasional personnel access must provide shielding against radiation. Covers over unoccupied areas are for ventilation control. All of these covers may be constructed of concrete or carbon steel. All covers should be designed to fit without the aid of dowel pins. Shielding covers must be stepped to provide protection against radiation streaming (leakage).

- Cell covers are to be designed for temporary jumper or yoke scorage but not for cell equipment storage. Provide an equipment storage or laydown space for storing heavy equipment.

- Provision must be made for stacking or storing all of the cell covers that are involved in movement of a piece of equipment.

- All permanent process cell piping, trunnions and guides, structural parts, kick plates, identification plates, etc., should be 304L stainless steel per spec 4498. Special materials are to be substituted as required when service exposure conditions render $304 \mathrm{~L}$ stainless steel unacceptable. 
PART TITLE: BUILDING REQUIREMENTS

\section{ITEM TITLE: Process Building -- General Design Criteria}

- Jumpers may be designed to allow transfers from one vessel to other vessels or equipment without entering the wall piping system. Such transfers may be necessary in some cases because of the need to transfer slurries at low flow rates through small-size pipe.

- Provide clear overhead access to all process equipment, avoiding stacking of process vessels.

- Process cell jumpers should be designed to minimize crossing over other jumpers so that one can be removed without removing other jumpers.

- Piping may be located in replaceable horizontal stacks or vertical arrays. Piping for which replacement is most probable should be located at the top of the stacks or vertical arrays.

- Permanently installed piping should be protected against mechanical damage by embedding in concrete or mounting in a steel structure ("cage"). The piping should have smooth large radius bends to maintain the integrity of the shield wall.

- The flat faces of embedded nozzles must all be established in a series of parallel vertical (or horizontal) planes.

- Embedded piping should be designed for structural flexibility and protected against chloride attack. Embedded piping through which frit or slurry-frit mixtures are transferred should be replaceable or have remotely renewable liners.

- Embedded electrical pipe and connectors should have replaceable wiring and connectors. Embedded electrical pipe should penetrate the shield wall by the shortest route possible and should have smooth large radius bends to maintain the integrity of the shield wall.

- Permanent and embedded piping should be limited to a few standard sizes. Recommended hole size in standard connectors are 3 -inch, 2-inch, four 1/2-inch, and sample connectors. For a limited and specific use, a nonstandard connector would be considered.

- Nondraining low points or expansion loops should be avoided because of the solids expected to be present in most of the process solutions. Piping for transfer of slurries should be designed as far as practical to be free draining and without traps. The existing in-line connector design for pipe jumpers is considered to satisfy this criterion.

- Slope process cell floors and floors in all transfer tunnels to drain to sumps. Refer to Part 5, Item 430 for additional sump system information. 
PART TITLE: BUILDING REQUIREMENTS

ITEM TITLE: Process Building -- General Design Criteria

- Provide floor sprays for general flushing of the cell floor.

- Provide in-cell storage space for lifting yokes. Refer to Part 20, Item 187 for yoke information. Consider a portable (movable by crane) yoke storage rack, large enough to hold needed yokes but small enough not to interfere with equipment moves in the cell.

- Provide remote and contact decontamination cells within the process cell. See Part 14, Item 200 for detail on the decontamination cells.

\section{Melter Cell Criteria}

This space is required within the process cell to house the glass melter operation and control spread of contamination from this operation.

- Canisters are to enter and leave this cell through air locks.

- Covers are provided over this cell for ventilation control only; see Part 11, Item 110.

- The cell is to be sized for operations described in Part 5, Items 255, $270,273,293$, and 295.

- All process operations are accomplished with the cell covers in place. The covers are to be removed primarily for equipment or jumper replacement.

- Slope cell floor to drain to a sump. This sump is to be connected with the process cell sump system, Part 5, Item 430 .

- Provide floor sprays for general flushing of the cell floor.

- Walls separating the melter cell from other cells are for ventilation control and structural purposes only and not for radiation stielding.

- The cell should be provided with viewing windows for critical operations; see Part 20, Item 150.

\section{Canister Decontamination Cell}

A cell space adjacent to the Melter Cell is required to house canister decontamination operation. This isolation is intended to limit spread of radioactive particles from the operation.

- Canisters are to enter and leave this cell through air locks. 
PART TITLE: BUILDING REQUIREMENTS

ITEM TITLE: Process Building -- General Design Criteria

- The cell is to be sized for operations described in Part 5, Items 275, 276 , and 295.

- Walls separating the canister decontamination cell from other cells are for structural and ventilation control purposes only ant nn: for radiation shielding.

- Covers are provided over this cell for ventilation control only; see Part 11, Item 110.

- All process operations are accomplished with the cell covers in place. These covers are to be removed primarily for equipment or jumper replacement.

- Slope cell floor to drain to a sump. This sump is to be connected with the process cell sump system, Part 5, Item 430. The design is not to preclude making it possible to connect this sump transfer system to the frit collection tank in this cell.

- Provide floor sprays for general floor flushing.

- The cell should be provided with windows for viewing the critical operations described in Part 5, Items 275 and 276.

\section{Weld Test Cell Criteria}

An isolated space is required within or outside of the process cell to house operations with filled glass canisters The isolation is provided to maintain canister surface and equipment cleanliness following canister decontamination. Cell design must provide for remotely controlled process operations with equipment that is expected to be designed for hands on maintenance.

- Canisters are to enter and leave this cell through air locks.

- The cell is to be sized for operations described in Part 5, Items 280, $285,290,293$, and 295.

- Walls and roof separating the weld test cell from other cells must be sized for personnel shielding, providing for intermittent occupancy ( 5 $\mathrm{mR} / \mathrm{hr}$ at the shield surface).

- Slope cell floor to drain to a sump. This sump is to be connected with the process cell sump system, Part 5, Item 430.

- Provide floor sprays for general floor flushing. 


\section{PART TITLE: BUILDING REQUIREMENTS}

\section{ITEM TITLE: Process Bullding -- General Design Criteria}

- The cell should be provided with windows for viewing the critlcal operations described in Part 5, Items 280 and 290.

- A shlelded doorway with alr lock 18 required for cell entrance.

- Radiation level outside this shlelded doorway is to be less than 0.5 $\mathrm{mR} / \mathrm{hr}$.

- Shielding for canisters as specifled in Part 5, Item 295.

5. Other Process Bullding Criterla

- Provide office space as noted in Table 10-1, Append1x A.

- If required gang valves should be located at an elevation sufficient to avold suckback of solutions from the process cell. Shield or embed in concrete all lines between the process vessel and the gang valves for at least $34 \mathrm{ft}$ above the maximum liquid level in the vessels.

- Gang valve venting system must prevent vapor flow from the process cell.

- Alr supply to or exhaust from operating areas must not contaminate large sections of personnel Inhablted areas if one part becomes contaminated. Provide partitions in areas of high contamination potential to minimize spread of contamination.

- Use 304L stalnless steel per spec. 4498 for any 11 nes that are inaccessible in areas where hands-on maintenance will result in high radiation exposure to personnel. Special materials are to be substituted as required when service exposure conditions render $304 \mathrm{~L}$. stainless steel unacceptable.

- Locate sample cells to minimize sample $11 \mathrm{ft}$ requlrements. Sample plping configurations must prevent syphoning.

- Master-slave man1pulator-operated sampling cells for obtaining samples from multiple locations are preferred, if feasible. See Part 7, Item 300 for additional detall on sampling requirements and Part 11, Item 110 for ventilation control in the sampling cells.

- Where applicable, design sample systems to accomodate 1n-11ne analytical instruments.

- Do not locate passageways, p1pes, condult, etc. under any portion of the remote process cell, except the weld test cell. 
PART TITLE: BUILDING REQUIREMENTS

\section{ITEM TITLE: Process Building -- General Design Criteria}

- Provide floor drain system to dispose of leakage or was lown liquids. Collection systems for overflow and drainage from chemical makeup and head tanks is required. See Part 5, Item 215 and 430 for additional information.

- All lines for radioactive solutions which are routed through personnel occupied areas should be jacketed, equipped for leak detection, shielded or shieldable, easily replaced (unless embedded in building structure), and equipped for flushing, draining, and rodding, if necessary, to a suitable tank for containment and controlled disposal. The formic acid, acid, and floor drain headers are excluded. Embedded piping for transfer of radioactive process solutions into and out of the building through shielding walls is also excluded. However, all Zone 2 exhaust plenums (Part 11 , Item 110) are to be protected against in-leakage from embedded piping.

- Locate freight elevators on outside walls to facilitate material flow to and from the building. Make passageways to elevators wide enough to transport largest equipment on a given level. Freight elevators should be equipped with an emergency telephone (Type I telephone). See Part 17, Item 100.

- Personnel movement between clean and regulated areas of the building must be controlled to eliminate potential contamination of clean areas. There should be one main entrance into the clean areas of the building and one main entrance into the regulated areas. Air locks are to be provided for personnel movement between different confinement zones.

- Avoid locating personnel areas under process piping containing radioactive solutions.

- Locate noncritical services (locker rooms, clothing storage, offices, shops, etc.) outside of the earthquake and tornado resistant building structure in standard construction facilities wherever possible to minimize building cost.

- Locate a process equipment repair shop so that it is accessible from an air lock for equipment transfer between the shop and process cell. The shop must have crane to handle decontaminated and new equipment. This shop should be of standard construction. See Part 14, Item 250 for additional detail on the Process Equipment repair shop and Part 20, Item 185 for detail on the shop crane. 


\section{PART TITLE: BUILDING REQUIREMENTS}

\section{ITEM TITLE: Process Building -- General Design Criteria}

- Provide a room of about $150 \mathrm{ft}^{2}$ for decontamination of tools and small equipment. The following services and facilities are necessary:

- Process water supply.

- Liquid discharge to the Recycle Waste Collection Tank through the highly contaminated sump system. (See Part 5, Item 430.)

- Sink and hood facilities.

- At nominal 100-foot intervals, provide sealed access ports from the operating corridor into the process cell (Zone 1) exhaust air plenum. The access ports are to be sized for entry by personnel wearing protective suits. These ports are expected to be used very infrequently and all necessary support facilities (air locks, breathing air, steps) will be provided by operating personnel. Equipment locations in the operating corridors are to have priority, with the port locations adjusted as necessary.

- The remotely operated process cell crane (Part 20, Item 180) will be primarily for installation and removal of piping and equipment and will normally remain in a crane maintenance area. With the open cell operating concept, crane decontamination may be required prior to hands-on maintenance. The crane maintenance area (Part 14, Item 550) is to be separated from the process cell by a shielding door.

- Experience at SRP indicates a minimum $3 / 8$ inch stainless steel floor covering is required for the crane maintenance area to prevent severe contamination of the building concrete and for impact resistance. The recommended material for the liner is $304 \mathrm{~L}$ stainless steel per Spec. 4498.

- Rails provided for the process cell crane are to be the heaviest duty available as these rails are expected to be inaccessible for maintenance.

- Bus bars providing power to the process cell crane must be accessible for inspection and repair while process operations continue. This maintenance work will require a breathing air supply and the maximum air hose length permitted ( $150 \mathrm{feet}$ ) establishes the number of access points to the bus bar installation. Provide air locks where necessary at the access points.

- Crane rails must accomodate the shielding door at the crane maintenance area. 


\section{PART TITLE: BUILDING REQUIREMENTS}

\section{ITEM TITLE: Process Building -- General Design Criteria}

- Building clearance for operation of the remote crane must provide access to all cell equipment. The crane maintenance shielding door may be opened to provide crane access to the section of the process cell adjacent to the decontamination room.

- Floor elevation in the crane maintenance area is to accommodate the in-cell canister handling devices (Part 5, Item 266) when suspended on the process cell crane.

- Provide capability to remove WTC in-cell crane trolley in event of double crane failure in the WTC.

- Provide truck and rail access to the process cell for direct load-out of failed equipment; see Part 3, Item 140. This direct rail access is through the Process Equipment Repair Shop which also provides for equipment movement between this repair shop and the process cell. Equipment movements will be made using existing SRP transportation equipment and the special equipment in Part 20, Item 380 .

- Maintenance and decontamination of the Shielded Canister Transporter (SCT) should be performed in 221-S building in an area with adequate air filtration and contaminated liquid disposal facilities.

- Transfer tunnels and equipment should have the following features:

\begin{tabular}{|c|c|c|c|c|c|c|}
\hline Tunne 1 & $\begin{array}{l}\text { Personne } 1 \\
\text { Access } \\
\end{array}$ & $\begin{array}{l}\text { Trolley } \\
\text { Hatches } \\
\text { Both Ends }\end{array}$ & $\begin{array}{l}\text { Remote } \\
\text { Canister } \\
\text { Removal } \\
\end{array}$ & $\begin{array}{l}\text { Remote } \\
\text { Trolley } \\
\text { Removal } \\
\end{array}$ & $\begin{array}{l}\text { Ful1 } \\
\text { Remote } \\
\text { Maintenance }\end{array}$ & $\begin{array}{l}\text { Drag } \\
\text { Trolley } \\
\text { To } \\
\end{array}$ \\
\hline Warehouse-MC & $\mathrm{x}$ & $x$ & & & & (Not Needed) \\
\hline$M C-C D C$ & $x$ & $\mathrm{x}$ & $x$ & $x$ & $x$ & MC End \\
\hline CDC-WTC & $x$ & $\mathrm{x}$ & $\mathrm{x}$ & $\mathrm{x}$ & & CDC End \\
\hline WTC-SCT & $x$ & $\mathrm{x}$ & $\mathrm{x}$ & & & WTC End \\
\hline
\end{tabular}

The transfer tunnel between the $M C$ and the $C D C$ must be designed with remote maintenance capability for use should the tunnel become excessively contaminated (e.g. replacement of drag bar, motors, etc.)

6. Safety Systems

- See Part 13, Item 560 for emergency power requirements for the Process Building.

- Automatic sprinkler and/or Halon 1301 fire protection systems should be provided where applicable in personnel area; see Part 18, Item 620.

- Permanently installed radiation and air monitoring equipment should be provided in the main process building; see Part 12, Items 110 and 120. 


\section{PART TITLE: BUILDING REQUIREMENTS}

ITEM TITLE: Process Building -- Ventilation Requirements

\section{A. General}

Ventilation requirements for the process building are based on these general concepts.

- The building should be divided into zones for ventilation and contamination control.

- A combination of parallel and series ventilation systems should be used to provide protection for personnel and control of contamination at minimum investment and operating cost.

- In a ventilation system, air flow is to be from zones of low contamination potential toward zones of greater contamination potential.

- Air recirculation from a zone of higher contamination back to a zone of lesser contamination is prohibited.

- Motive force for the exhaust air system should be provided by multiple fans downstream of the filters. Operation of standby fans is to be initiated by abnorinal pressures in the ventilation system.

B. Ventilation System Zoning

The building must have a layout that physically separates the processing zones with high contamination potential from personnel zones with lesser contamination potential. The ventilation zones described here are based on the definitions provided in Reference C-13, Appendix C.

Zone 1: $\star *$ The process cell area and immediately adjacent crane service areas with high contamination and/or high radiation level are to have a separate ventilation system with air supply and exhaust independent from surrounding zones.** A single deep-bed sand filter $(99.95 \%$ efficient) provides a reliable fire-proof filtration system of the exhaust as demonstrated by SRP operating experience. However, some specific Zone 1 areas are to be exhausted through the Zone 2 exhaust system as detailed later.

When radiation levels permit, entry into some sections of zone 1 is permitted with full-body protective clothing and respirators or full-face gas masks.

Zone 2: Normally occupied regulated operating areas with potential for contamination are in this ventilation zone. Air supply to zone 2 is from zone 3 (clean areas) or outside air if the series air flow from zone 3 is insufficient for zone 2 needs. All zone 2 air should exhaust through single--stage HEPA filters. Zone 2 air is not to be routed to zone 1 except for infiltration through air locks separating these zones and for flows established from subdivisions $2 a$ and $2 b$. 


\section{PART TITLE: BUILDING REQUIREMENTS}

ITEM TITLE: Process Buflding -- Vent1lation Requirements

Zone 2a describes a major subdivision of zone 2, a space contiguous to zone 1 through a large air lock required for entry into and removal of equipment from the process cell. Zone $2 a$ must be maintalned at positive pressure relative to zone 1. A portion of the zone $2 a$ exhaust exits through the equipment air lock and the remainder combines with normal zone 2 exhaust.

**Zone $2 \mathrm{~b}$, a subdivision of zone 2 , describes operating space between zone 2 and small, 1 solated zone 1 areas (sample and mercury recovery cells) established within zone 2 space. ${ }^{\star \star}$ Alr flow is to be from zone 2 to zone $2 b$ to zone 1 ; zone $2 b$ must be maintained at positive pressure relative to zone 1 .

Zone 3: Offices, control rooms, and all other clean areas in the process bullding comprise this zone. Fresh alr is supplied to zone 3, which then exhausts to zone 2. However, recirculation may be established within zone 3 to reduce air conditioning cost.

Recirculaton of air in zone 3 is not necessary for isolation of essential personnel from toxic fumes. In the event of an air reversal or loss of alr, personnel can don respiratory equipment and implement a safe and orderly shutdown and evacuation of the facility.

C. Zone 1 Criteria

The basic design criteria for process cell ventilation are: 1) removal of process heat and 2) contamination control

Process heat removal is necessary to:

- 11mit the cell operating temperature to $40^{\circ} \mathrm{C}$, the maximum permitted for electrical motors and other temperature sensitive electrical and Instrument components.

- minimize thermal currents which carry particulate contamination up to the cell crane.

Contamination control is attained by:

- ** providing covers over the cells.

- establishing alr flow from the top to the bottom of the cell space, thus reducing the effect of the rmal currents.

- establishing alr flow from areas of low contamination to areas of greater contamination. ${ }^{\star \star}$ 
PART TITLE: BUILDING REQUIREMENTS

ITEM TITLE: Process Building -- Ventilation Requirements

The following are to be used in implementing the basic criteria:

- **When removing covers from cells housing process operations, a minimum alr velocity of $50 \mathrm{fpm} \mathrm{is} \mathrm{required} \mathrm{for} \mathrm{up} \mathrm{to} 400$ square feet openings. Cover openings this size are expected to be sufficlent for most remote crane operations.

- Equipment decontamination cells do not require air velocitles of $50 \mathrm{fpm}$ through cover openings.

- Cover openings resulting in alr velocitles of less than $50 \mathrm{fpm}$ w111 require process shut down and reduction of equipment temperature. ${ }^{\star \star}$

- A minimum velocity of 400 feet per minute is required through spaces between cell covers to ensure unidirectlonal flow of alr through the covers during operations.

- **A1r is to flow down through covers over the cells housing operations resulting in the presence of large quantities of loose radioact.vity, and up through covers over cells which are to be maintalned as clean as possible. For example, flow should be down into the melter and chemical processing cells and into the remote equipment decon cell where spraying operations are expected; flow should be up from the canister decon and

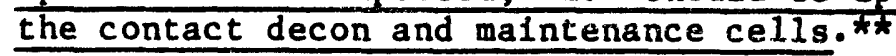

- Cell covers over the air lock separating the process equipment repair shop and the process cell are to be sealed to limit outflow in the event of a tornado.

- **Air supply for the contact decon and maintenance cell shall be separate from the process cell supply for safety of personnel working in the cel1. ${ }^{\star \star}$

- Alr supply for the weld test cell shall be separate from the process cell supply to preclude backflow of alrborne contamination from the process cell. As the weld test cell is a direct maintenance area within Zone 1 that is to be maintained as clean as possible, this cell is to exhaust through the Zone 2 exhaust system. The cell will be Inhabited for malntenance work and the ventilation system should provide about six air changes per hour. As there is potential for severe contamination of the weld test cell, the exhaust from the cell is to pass through a HEPA filter prior to entering the Zone 2 exhaust system. The preferred location of the weld test cell HEPA f1lters is in a shielded room outside of rather than in the weld test cell; **th1s location will permit changing the filters without personnel exposure to background radiation which may exist in the weld test cell. Twelve inches of concrete will provide sufficient shielding for the filters (which may be contaminated to 150 mrem/hr in the event of a severe lncident) as the radloactive source will be removed upon fllter replacement. ${ }^{*}$ 


\section{PART TITLE: BUILDING REQUIREMENTS}

\section{ITEM TITLE: Process Building -- Ventilation Requirements}

- Alr flow pattern in the canister decontamination cell should be from the inspection area toward the canister inlet end.

- The Zone 1 exhaust system is to be constructed according to the requirements outlined in Part 4, Item 700 and Table 4-1, Appendix A.

\section{Zone 2 and Zone 3 Criteria}

A primary objective for zone 2 and 3 ventilation is contamination control. The following design criteria apply:

- Alr flow direction should be from clean areas (Zone 3) to contaminated areas (Zone 2). Thus, air pressure in offices in clean areas should be positive in relation to that of the regulated operating areas and shops which in turn are to be positive in relation to the equipment decontamination cells and the process cell.

- Zone 2 alr is not to be cascaded from one zone 2 space to another with the exception that Zone 2 will supply air to the zone $2 b$ space.

- Zone 2 areas with higher potential for becoming contaminated are to be isolated from adjacent Zone 2 areas.

- To control concentrations of airborne contamination, the following minimum hourly turnover rates are to be applied:

Zone 3, all clean, non-regulated areas

Zone 2 , areas of high contamination potential, such as regulated shops, etc.

Zone $2 a$, equipment repair shop

Zone $2 b$, area surrounding sample and mercury recovery cells

Zone 2, all other areas
- 6 room air changes

- 8 room air changes

- 8 ruom alr changes

- 8 room alr changes

- 6 room alr changes

Exhaust from Zone 2 areas may be routed through stancard construction facilities. This air is exhausting primarily from operating areas where personnel will not usually be required to wear respiratory protection and the amount of radioactive materlal expected in the exhaust system should be minor. Occasional radloactive releases can be expected in Zone 2 areas (contaminated samples, contaminated equipment repair, etc.) resulting in some contamination on the HEPA filters in the exhaust system. The amount of radloactivity expected to be deposited on the filters is much less than the annual release gulde for an SRP separations plant. Therefore, the radiological risk for release from the DWPF HEPA filters for an earthquake-caused incident is very small. The HEPA filter housing and exhaust fans are to be located to provide optimum operating efficiency and maximum cost savings. **A separate stack may be used for this exhaust system and if so, this stream 18 to be monitored for radioactivity (see Part 12, Item 120). $* \star$ 


\section{PART TITLE: BUILDING REQUIREMENTS}

ITEM TITLE: Process Buflding -- Ventilation Requirements

** The Shielded Canister Transporter (SCT) malntenance and decontamination facility $1 \mathrm{~s}$ to be exhausted to the zone 2 system to control possible contamination and exhaust fumes from this faclilty. The alr supply is to be cooled to minimize the alr volume flowing through this faclilty to the zone 2 HEPA f1lters. ${ }^{* \star}$

E. Sample Cells, Mercury Recovery Cell

Several small cells (zone 1 areas) contalning radioactive materials are expected to be located within regulated operating areas (zone 2 ). These criteria shall apply to ventilation of these cells. **Note that these zone 1 areas may be supplied from a zone 2 space and exhausted through the sand fllter. $^{\star}{ }^{*}$ See Part 7, Item 300 for additional sample cell Information.

- Areas immedlately surrounding the cells shall be considered zone $2 b$ with high contamination potential. **Th1s envelope around the cell 18 to be partitloned from the zone 2 space. An alr lock is not required for entry into the envelope from the zone 2 area. ${ }^{\star \star \hbar}$

- Air flow entering the cells from zone $2 b$ shall pass through a HEPA filter to provide protection in the event of backflow from the cells.

- Provide a minimum alr flow of $150 \mathrm{fpm}$ through ports or access openings in glove boxes or hoods servicing these cells.

- **Cell exhaust shall pass through a concrete plenum directly to the zone 1 exhaust tunnel to limit exposure of personnel to radioactive contamination.

- Cell exhaust shall be at least $10 \%$ of cell volume per minute as recommended in Section 2.2 .1 of Reference C-13, Append1x C. However, cell exhaust should be a minimum of $500 \mathrm{cfm}$.

- Hoods servicing these cells shall exhaust through HEPA filters and then be comblned with zone 2 exhaust alr, thus passing through a second stage of HEPA f11tering. ${ }^{\star \star}$

F. Alr Locks

Alr locks are required at all entrance/exit portals to the main processing bullding and normal passage points between ventilation zones. The following criteria shall apply.

- An alr lock maintains confinement of contamination by maintaining alr flow through the alr lock to zones of high contamination at all times. **This flow 18 attained by differential pressure between the zones.**

- Exclusively emergency exits from zone 2 and zone 3 areas may be established without alr locks. 
PART 11

ITEM 110

PAGE 6 of 8

DATE 9-82; Rev. 9

\section{PART TITLE: BUILDING REQUIREMENTS}

\section{ITEM TITLE: Process Bullding -- Ventilation Requirements}

- **The stairwells are to be considered as air locks.**

- Alr locks at entrance/exit portals between zone 3 and the environment do not require a separate air supply.

- Equipment entry and removal from the process cell (zone 1) shall be through a large alr lock contlguous to the process equipment repalr shop (zone 2a). This alr lock is not to have a separate alr supply, but is to be supplied from zone 2a. A large volume flow shall be directed through this air lock to provide a minimum air velocity of $50 \mathrm{fpm}$ when the alr lock opening to the process cell is 400 square feet.

- Air locks are required at all entry points between zone $2 a$ and zones 1 , 2 , or 3 .

- An alr lock is required for rail car/truck access to the process equipment repair shop (Zone $2 a$ ) from the outside. **SRP experience with this type of air lock indicates that flow should be established by differential pressure between the shop and the environment. ${ }^{* \star}$

\section{G. Canister Transfer Tunnels}

Alr flow through open ports into all canister transfer tunnels is to comply with the general concept of flow from zones of low contamination potential toward zones of greater contamination potential. The two openings Into the transfer tunnels of greatest interest are 1) at the entry point for unfilled canisters and 2) at the entry of filled canisters into the weld test cell. Alr flow into the transfer tunnel with the port open is to be a minimum of $150 \mathrm{fpm}$ at these two points. This flow is to provide protection for personnel handling the unfilled canisters at the entry point and to limit contamination movement from the transfer tunnel into the cleaner weld test cell. **If it is not practical to establish this rate at these two points, consider use of an air lock to provide the necessary control of alr movement.**

H. Dampers

Dampers are to be provided as required to control and balance air flows in the bullding. Dampers must be accessible for operation and repalr. Backflow dampers are required in supply ducts where contamination from process cell backflows would increase personnel exposures.

Tornado dampers are to be provided in alr ducts at the tornado resistent bullding envelope to prevent alrborne releases to the environment. Ventilation system design should minimize the number of alr duct entrances requiring tornado dampers and ducts are not to penetrate the roof directly into the process cell.

Also, a tornado damper should be provided in the alr exhaust from the process equipment repalr shop and/or the equipment alr lock tunnel where these enter the tornado resistant bullding envelope. 


\section{PART TITLE: BUILDING REQUIREMENTS}

ITEM TITLE: Process Building -- Ventilation Requirements

\section{Filters}

Provide filters on air supply systems ( 50 to $65 \%$ ASHRAE efficlency) in accordance with Section 2.3.3 of Reference C-13, Appendix C.

The HEPA filtration system for zone $2,2 a$, and $2 b$ exhaust should meet the intent of NRC Reg. Guide 3.32, c., 4, a. for only criterla of (a) leakage, (b) replacement, (c) DOP testing, (d) Instrumentation, and (e) 1solation valves. No heat removal or other fire protection system is required for these filters which are expected to retain only minimal activity from zone 2 releases. The only roughing filters required in the exhaust system are to be located in the HEPA filter installation, at least 36 inches up stream of the HEPA filters per Section 9.5.2 of Reference 13, Append1x C.

\section{J. Construction and Testing}

Design and construction is to provide for convenient inspection, maintenance, decontamination, or replacement of critical components such as filters, fans, sensors, and controls with minfmum exposure to personnel and minimum release of contaminants.

All air supply systems are to be equipped with installed spare fans to provide for normal ventilation during routine fan maintenance. All fans are to be of standard materials of construction; ventilation supply ducts are to be galvanized steel or concrete. $* \star A l l$ alr supply fans may be located in unhoused groupings, with proper weather protection for the motors and alr handling units. Provision should be made for determining the presence of and removing liquid from the supply ducts. ${ }^{\star \star}$

Fallure of a single fan in any exhaust system should not shut down production operations. Provide multiple fans for each type of service. Provide emergency power to maintain minimum air flow requirements during normal power fallures (see Part 13, Item 560). **A11 exhausters are to be of standard materlals of construction except those servicing the sample and mercury cell hoods which are to be stalnless steel. Exhausters for the zone 1 area are to be located In a fan house described in Part 11, Item 470 . The zone 2 exhausters may be located in an unhoused facility.

Metal exhaust ducts from normally occuppled areas (zone 2) are standard materials of construction. However, duct work from potentlally contaminated areas (sample and mercury purification cell hoods, etc.) are to be fabricated with 304L stainless steel per Spec. 4498 or be concrete plenums. ${ }^{\star \star}$

Concrete plenums and ducts are discussed in the building general design criteria, Part 11, Item 105. Exhaust port openings near the process cell and melter cell floors must be designed and positioned to prevent any liquid which may be draining down the cell walls, or liquid on the cell floor, from entering the exhaust air plenum. 
PART TITLE: BUILDING REQUIREIENTS

ITEM TITLE: Process Building -- Ventilation Requirements

Reliability of the ventilation confinement system depends on a program of initial and periodic testing and inspection. Design should provide for periodic testing without incurring excessive personnel exposure or release of contaminants. Surveillance capability is to include:

- measurement of air flow in exhaust ducts

- testing performance of filters

- testing, under conditions as near to design as practicable, the operating sequence that would start up ventilation systems, including the transfer to alternative power sources

Additional detail concerning acceptance and periodic testing is specified in Chapter 8 of Reference C-13, Appendix C.

R. Climate Control

Criteria for climate control are presented in Reference C-12, Appendix C.

Office areas, change rooms, shops, and other occupied working areas are to be comfort conitioned.

Computer rooms are to be temperature and humidity controlled.

The Process Equipment Repair Shop is to be temperature controlled to the degree necessary for photogrametry work. However, it is acceptable to limit the controlled temperature zone to the actual work space near floor level.

\section{Controls and Instrumentation}

The appropriate devices are required to indicate pressure differentials between zones, thus providing indication of proper ventilation within the process building. Additional instrumentation requirements are discussed in Part 6, Item 500 . 
PART TITLE: BUILDING REQUIREMENTS

ITEM TITLE: Process Building -- Radiation Shielding Requirements

Radiation shielding for personnel is to be provided by the process cell walls and roof and the melter, canister decon, and weld test cell walls. The shield thickness required should limit the maximum total exposure of facility personnel to a value of less than $1 \mathrm{rem} / \mathrm{yr} / \mathrm{person}$. This requirement can be met if the average whole body dose rate in normally occupied areas is 0.5 $\mathrm{mrem} / \mathrm{hr}$ or less (assuming about 2000 hours of occupancy per year per person). Design dose rates greater than $0.5 \mathrm{mrem} / \mathrm{hr}$ in intermittently occupied areas are acceptable if it can be shown that the total exposure for an employee is not likely to exceed $1 \mathrm{rem} / \mathrm{yr} / \mathrm{person}$. In all cases except emergency escape routes, design exposure rates should not exceed $5.0 \mathrm{mrem} / \mathrm{hr}$.

The bases for the shielding calculations are:

- $* *$ Radionuclide concentrations given in Appendix $H$, Tables 21-17 and $21-18 . * \star$

- All process vessels filled to maximum operating levels, about $90 \%$ full in most cases.

- Shielding calculations are to be based on processing 5-year-old sludge and 15-year-old supernate or 5-year-old sludge, whichever is limiting.

- The personnel runway provided for access to the crane bus bars should be shielded to limit personnel exposure to $5 \mathrm{mrem} / \mathrm{hr}$, the maximum for intermittent occupancy.

- Normally occupied areas are those in which personnel are continuously exposed to radiation for the 8 hour work shift.

- Intermittent occupancy defines areas inhabited less than an average $10 \%$ of the time. 


\section{PART TITLE: BUILDING REQUIREMENTS}

\section{ITEM TITLE: Process Bullding -- Elevators-Sta1rs}

**At least one frelght passenger/elevator will be required in the vitrif lcation bullding *t Th1s elevator should be In the regulated area on an outside wall, and service all levels, Including the roof. Bullding design should provide for equipment installation and removal via this elevator. Access to the bullding roof is required to service the ventilation equipment. Elevator capacity should be slzed for the largest integral load expected. **An equipment $11 \mathrm{ft} / \mathrm{elevator} 11 \mathrm{ft}$ is required for for moving samples from the sample cells to the loading dock, and moving mantpulators to the repalr shop. $^{\star \hbar}$ Emergency power requirements are l1sted In Part 13, Item 560.

** Stal rways are to be located so that personnel are never more than 100 feet from a stalrwell [(National Fire Protection Association Code 101 - Life Safety Code) Pressurized stalrwells will not be necessary in 221-s building because of the low personnel density, the number of stalrwells and the resultant low residence time in the stalrwells. ${ }^{\text {th }}$ Any emergency exits frow stalrwells at grade level are not to open lnto adjolning bulldings, but are to be direct to the outside (through 1solated passageways, if necessary).

** If ventilation equipment is located on the bullding roof, a stalrwell and frelght/passenger elevator access will be required. $\star \star$ Access to the clean ventilation equipment on the roof 18 not to be provided through the regulated bullding -- except as an emergency escape route. 


\section{PART TITLE: BUILDING REQUIREMENTS}

\section{ITEM TITLE: Process Building -- Clean and Regulated Change Room Requirements}

A central change room and locker facility should be provided. The total change room and locker facility should be in the standard construction facility to minimize, where feasible, space requirements within the seismic structure. The specific number of lockers and change facilities required for the predicted plant population are shown in Appendix A, table 10-2.

Space for laundry bags for used clothing and overshoes will be required in the regulated change room. Additional space for storage of several bags of both clean and used clothing (received from laundry and being returned to laundry) will be required. $\star *$ Used clothing is not to pass through clean areas of the building, and is to leave the area from the truck loading dock. ${ }^{\star \star}$

The **normal** movement of personnel between regulated and clean areas (ventilation zones 2 and 3 ) is through the regulated locker room and the major clothing handling requirements are in this location. In addition, space is required for contaminated clothing hampers and personnel monitoring instruments at transfer points between ventilation zones 1 and 2 , such as the crane maintenance entrance and the contact decontamination cell entrance, **and at the normal transition between zones 2 and $2 a$ or $2 b, * *$ Monitoring and clothing stations are not required at emergency exits. 
DPSP $80-1033$

PART 11

ITEM 130

PAGE 1 of 2

DATE 7-81; Rev. 7

PART TITLE: BUILDING REQUIREMENTS

ITEM TITLE: Process Building -- Lighting

Normal Requirements

Provide standard fluorescent 1 ighting in all work and operating areas, control rooms, hallways, and offices. Lighting fixtures in regulated work areas should be designed for ease of relamping and be recessed to facilitate decontamination. Include provisions for reducing lighting in intermittently occupied areas.

Provide the capability of reducing lighting in operating areas containing shielded viewing windows.

Whenever possible, especially in remote locations or high bay areas, consider using energy-saving, low-maintenance lighting systems and fixtures (such as high pressure sodium lamps) to minimize energy requirements.

\section{Special Requirements}

a. Process Cell

Lighting for crane work should be provided by lights mounted on the crane bridge. The illumination level is to be compatible with the remote television viewing requirements. No other 1 ighting is required in the process cell area.

b. Melter and Canister Decon Cells

In-cell lighting is required to view handling of the glass canisters and other operations. The lighting is to be remotely maintained, preferably by a technique not requiring removal of the cell covers for routine bulb/fixture replacement nor removal of the fixtures through the shielding wall into the operating corridor. The lighting intensity is to be adjustable and compatible with television viewing as well as direct viewing through cell wall windows.

c. **Weld Test Cell**

In-cell lighting is required to view handling of the glass canisters and other operations. If possible, design should provide for remote replacement of light bulbs; all other lighting system repairs will be by direct maintenance. The lighting intensity is to be adjustable and compatible with television viewing as well as direct viewing through cell wall windows.

d. Equipment Decontamination Cells

See Part 14, Item 200

e. Sample Cells and Mercury Recovery Cell

Provide remotely replaceable lights in these cells. 
DPSP $80-1033$

PART 11

ITEM 130

PAGE 2 of 2

DATE 7-81; ReV. 7

PART TITLE: BULETWG REQUIREMEETS

ITEM TITLE: Prores: Building -- Lighting

f. Grane and CCIV Control Raom

Ceiling lighting shall have switching and dimming provisions for control of the console illumination level.

\section{Emergency Requirements}

A minimum amount of righting tor pergonnel safecy mast be provided in all personnel areas of the building upon failure of the normal electrical distribution system.

Melter and **weld test cell lighting required for safe process operation must be provided with emergency pawer to be able to continue these functions; see Part 13, Item 560 . 


\section{PART TITLE: BUILDING REQUIREMENTS}

ITEM TITLE: Process Bullding -- Floor, Wall, Celling Finishes

Clean Areas - Ventilation Zone 3

- Control room, office, and hallway floors are to be t1le-covered and walls are to be fire-resistant construction. Standard painting is to be used throughout this area.

- Equipment area floors within this zone are to be smooth, unpainted concrete.

Operating Areas - Ventilation Zones 2, 2a, and 2b.

- Any offices or change rooms in this area are to have smooth, easily decontaminated floors and walls with painted finishes using standard paints for the surfaces.

- The walls, floors, and cellings of operating areas with risk of contamination are to be finished with epoxy coating.

- Equipment areas with low risk of contamination are to have smooth floors and walls with painted finishes using standard paints.

Ce11 Areas - Ventilation Zone 1

- The following surfaces are to be covered with a coating resistant to deterioration by radiation, process chemicals, and moisture.

- The flonr in the process cell and the walls up to five feet above the cell rovers (Part 11, Item 105).

- The $f^{\prime}$ ors and walls in the melter, canister decontamination, and weld test ells.

- The floors and walls of the canister transfer tunnels.

- All cell covers.

- **The crane maintenance area walls and celling and any portion of the floor area not covered with stainless steel.

- The decontamization portion of the crane maintenance area floor is to have a stainless steel lining (see Part 11, Item 105 and Part 14, Item 550).**

- The floors and walls of the remote and contact decontamination cells are to be stainless steel lined (see Part 14, Item 200). 
PART TITLE: BUILDING REQUIREMENTS

ITEM TITLE: Process Bullding -- Interior, Exterior, and Shielding Doors

Interior Doors

All doors are to be nonflamable construction. View windows for safety are required on personnel passage doors.

Exterior Doors

All exterior doorways must be of tornado resistant construction. A labyrinth type entrance affording mfssile protection and an easily opened and easily malntalned door providing pressure protection 18 preferred for all bullding entrances.

Equipment entrances and normal personnel access/egress passages must be through an afrlock or equivalent to control spread of contaminated material. Shielding Doors

**A shielding door will be required to separate the process cell and the crane maintenance area. This shielding should limit personnel exposure to $5 \mathrm{mrem} / \mathrm{hr}$ based on intermittent occupancy of the crane maintenance area. ${ }^{k \hbar}$

A shielding door will be required at the entrance to the process cell equipment access tunnel. As the radiation level within the tunnel is to be reduced to the intermittent occupancy rate $(5 \mathrm{mrem} / \mathrm{hr})$ by shlelding at the process cell, the metal door at the tunnel entrance need only to be thick enough to reduce the radiation level to $0.5 \mathrm{mrem} / \mathrm{hr}$. An alternative 18 to provide sufficient process cell shielding to reduce the radiation level to 0.5 mrem/hr within this access tunnel, thus eliminating the need for a shielding door at the tunnel entrance. Radioactive equipment will not be stored or parked in this access tunnel; the tunnel door need not provide shielding for the transition period when radioactive equipment is moving through the tunnel.

The entrance to the weld test cell must provide shlelding to reduce the radiation level on the outside to the normal occupancy requirement, 0.5 $\mathrm{mrem} / \mathrm{hr}$.

Shielding for all canister transfer tunnels is to reduce radiation levels to the intermittent occupancy level, $5 \mathrm{mrem} / \mathrm{hr}$.

Refer to Part 11, Item 115 for additional detalls for shielding calculations. 
PART TITLE: BUILDING REQUIREMENTS

ITEM TITLE: Administration Building -- General

**A facility to house the administrative and support personnel for the vitrification facility will be required. ${ }^{\star}$

The administration and patrol building should consist of:

- Office space, See Part 11, Item 225

- Receptionist area, See Part 11, Item 210

- Cafeteria, See Part 11, Item 220

- Records management center/file room, See Part 11, Item 235

- Conference room, See Part 11, Item 225

- Reproduction room, See Part 11, Item 235

- Mail room, See Part 11, Item 235

- Parking area for pool cars, See Part 11, Item 235

- Sanitary facilities, See Part 11, Item 235

- Janitors closet, See Part 11, Item 235

- Supply storage, See Part 11, Item 235

- Heating and ventilation room, See Part 11, Item 235

- Clean waste pad with dumpster, See Part 11, Item 235 
DPSP $80-1033$

PART 11

ITEM 200

PAGE 2 of 2

DATE 9-82; Rev 9

PART TITLE: BUILDING REQUIREMENTS

ITEM TITLE: Adainistration Building - General

The Administration Buflding should be standard construction.

Provisions for the physically handicapped should be provided in the bullding.

The building should be located to accomplish the following objectives:

- The cafeteria should be conventently accessible to personnel from all buildings without passing through the administration area.

- Clerks in the area file room are to serve as Credit Union representatives. The file room should be located where it is accessible to all area personnel. 
6

DATE 5-81; Rev.

PART TITLE: BUILDING REQUIREMENTS

ITEM TITLE: Administration Building -- **Misc. Space Requirements**

$* *$ Reception Area**

Provide a combined office for a receptionist and employee counseler with the counseler's office separated for privacy. This office should be easily accessible to personnel.

The receptionist office should include an alcove (4- $x 6 \mathrm{ft}$ ) for luggage storage. The receptionist should have access to area page facilities. Suitable furniture should be provided for visitors to wait for escorts or appointments. A phone should be provided for visitors. 
DPSP $80-1033$

PART 11

ITEM 215

PAGE 1 of 1

DATE 5-81; Rev. 6

PART TITLE: BUILDING REQUIREMENTS

ITEM TITLE: Administration Building -- Medical Facility

**Medical facilities will not be required in the administration building during the construction of the DWPF. ${ }^{\star \star}$ Medical services will be provided in H-Area for the S-Area personnel. 
PART 11

ITEM 220

PAGE 1 of 2

DATE 5-81, Rev. 6

PART TITLE: BUILDING REQUIREMENTS

ITEM TITLE: Administration Building -- Cafeteria Requirements

a. Provide space and equipment for serving and seating 40 people. Except for some short orders, food service will be primarily catered from the main cafeteria. The food line will normally consist of salads, desserts, prepared sandwiches, one soup, two entrees, three vegetables, hot and cold drinks, and frozen desserts. Figure $11-1$ is a suggested serving line plan.

b. Provide space for storage of prepared cold and hot foods.

c. ** Provide a dishwashing area.**

d. Provide an area for unloading a small truck with catered food supplies *ikat a loading dock.**

e. Provide a $* * 60 \mathrm{ft} 2 * *$ area for snacks, drink machine and empty bottles in or near the cafeteria.

All cafeteria serving line equipment is to be stainless steel. Cafeteria equipment requirements are tabulated **below. A suggested installation for these items is shown in Figure 11-1.

Cafeteria Area

Item numbers correspond to those shown in Figure $11-1$.

Item Identification

\begin{tabular}{|c|c|}
\hline 1 & 1 Reach-in storage cabinet \\
\hline$\overline{2}$ & l Holden electric heat unit, $220-\mathrm{V}$ \\
\hline$\overline{3}$ & I Microwave oven \\
\hline$\overline{4}$ & I SS worktable \\
\hline$\overline{5}$ & 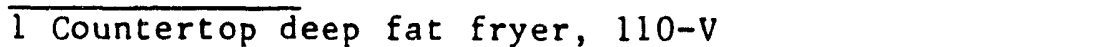 \\
\hline$\overline{6}$ & l Countertop electric grill, $220-\mathrm{V}$ \\
\hline$\overline{7}$ & I SS holding table with three undershelf drawers \\
\hline$\overline{8}$ & I SS deep sink with undershelf storage \\
\hline$\overline{9}$ & I SS worktable with storage underneath \\
\hline $1 \overline{0}$ & I Three-door, reach-in refrigerator, $110-\mathrm{V}$ \\
\hline 11 & 1 Delta 300 Cash register \\
\hline 12 & 1 Undercounter storage drawer \\
\hline 13 & I Sneeze-guard glass with 12 -in top, ss \\
\hline 14 & I Standrad SS electric four-hole cafe line, $220-\mathrm{V}$ \\
\hline$\overline{15}$ & I Two-door, slide-under storage area \\
\hline$\overline{16}$ & l sS coffee pot, 5-gal \\
\hline 17 & I SS tea decanter, 5-gal \\
\hline 18 & I Self-serve ice dispenser, $80-1 \mathrm{~b}, 220-\mathrm{V}$ \\
\hline$\overline{19}$ & I Four-unit fruit beverage dispenser, electric, $110-\mathrm{V}$ \\
\hline 20 & In-line, two hole deep freezer, 110-V \\
\hline$\overline{21}$ & In-line, cold salad counter \\
\hline
\end{tabular}


DPSP $80-1033$

PART 11

ITEM 220

PAGE 2 of 2

DATE 5-81; Rev. 6

PART TITLE: BUILDING REQUIREMENTS

ITEM TITLE: Administration Building -- Cafeteria Requirements

$\underline{\text { Item }}$

\begin{tabular}{l}
$\frac{22}{23}$ \\
$\frac{24}{25}$ \\
$\frac{26}{27}$ \\
$\frac{28}{29}$ \\
$\frac{30}{31}$ \\
$\frac{32}{33}$ \\
$\frac{34}{35}$ \\
\hline 36 \\
\hline 37 \\
\hline
\end{tabular}
Identification

1 Dessert display, two-shelf

I In-line serving ware cart holder

I Shelf storage napkins

ISS shelf tray storage, two-stack

1 SS undershelf with door, Stor -6

I SS worktable

ITree-rail tray slide

1 Beverage cup station

1 SS holding table with 4-in lip

1 Garbage disposal unit, 220-V/110-V

1 Dishwashing machine, 220-V

1 Exhaust hood, electric, 220-V (with filters and automatic fire protection as required by state law)

Two-shelf storage undercounter between items 15 and 25

Bin storage ice machine, $110-V$

Two-door slide-under storage refrigerator

4 Cafeteria tables with swing-out seatsti 
DPSP $80-1033$

PART 11

ITEM 225

PAGE 1 of 1

DATE 5-81; Rev. 6

PART TITLE: BUILDING REQUIREMENTS

ITEM TITLE: Administration Building -- Offices, Auditorium and Meeting Room Requirements

a. Offices

Provide offices as specified in **Table 10-2, Appendix $A$, ** for the personnel located in the administration building area.

\section{b. Conference Rooms}

One conference room is required. This conference room should be large enough to seat 30 people. It should be designed so that it can be divided for small groups. The divider is to be as sound proof as practical. *wFurniture and audiovisual equipment for this conference room are listed in Table $16-1_{1}$ Appendix A. ${ }^{* *}$ 
PART TITLE: BUILDING REQUIREMENTS

ITEM TITLE: Administration Building - Heating, Ventilation and Air Conditioning

**Heating, ventilation and air conditioning of the administration building will be according to energy conversation requirements listed in Reference C-12, Appendix $C$.

The offices, cafeteria and miscellaneous service rooms are to be full comfort air conditioned only on the day shift.

The lunch room, change room, control room and conference room are to be confort conditioned 24 hrs a day, 7 days a week.

The men's and women's change rooms on the regulated side are to be an isolated system with HEPA filtration.

Controls and equipment should be located with easy access for repair or replacement.** 
DPSP $80-1033$

PART 11

ITEM 235

PAGE 1 of 1

DATE 5-81; Rev. 6

PART TITLE: BUILDING REQUIREMENTS

ITEM TITLE: Administration Building -- Maintenance Service Facilities

File Room (Record Center)

clerk.

Provide a file room of approximately $400 \mathrm{ft}^{2}$ with desk space for one

Reproduction Room

Provide a central area for reproduction equipment such as Xerox copier, print reproduction, and duplicating machines, etc. This room should also have a storage area for supplies for the reproduction equipment. Locate this room adjacent to the file room. (If it is not adjacent to the file room, then provide space for print reproduction equipment in the file room.)

Mailroom

Provide approximately $130 \mathrm{ft} 2$ for a mailroom.

Janitor's Closet

Provide approximately $40 \mathrm{ft}^{2}$ for a storage area for janitorial supplies.

Restrooms

Provide men's and women's rest rooms as specified in Appendix A, Table 10-2. Locate as close to cafeteria entrance as possible.

Equipment Room

Provide space for heating and air-conditioning equipment, electrical distribution panels, hot water tanks, etc.

Miscellaneous

Provide a visitor parking area for four vehicles in front of the building. provide a service entrance and parking area for a small truck carrying cafeteria supplies and building supplies.

Provide a bulletin board area on the wall at the entrance to the administration building.

Provide a parking area behind the building for eight pool vehicles.

$\because *$ Provide a room $130 \mathrm{ft}^{2}$ with shelves for supply storage.

Provide a dumpster pad near a rear entrance for clean waste dumpster listed in Table 16-1, Appendix A.** 
PART TITLE: BUILDING REQUIREMENTS

ITEM TITLE: Administration Building -- Floor, Wall, Ceiling Finishes

Floors in all areas should be covered with vinyl tile with the exception of restrooms (ceramic tile), conference rooms (carpet), and equipment rooms (smooth concrete).

Provide standard fluorescent lighting for all areas. Lighting in conference room should be on at lesst two circuits (front and back) and controlled by a variable dimmer switch.

Provide standard painting for all areas. 


\section{PART TITLE: BUILDING REQUIREMENTS}

\section{ITEM TITLE: Gatehouse and Patrol Headquarters}

The gatehouse and patrol headquarters should be designed to meet the following criteria:

a. **The patrol office and guard area, lieutenants office and communications room portion of $* *$ the building should be hardened against terrorist attack as specified in Part 4, of Re ference $C-4$, Appendix $C$. **This space should be isolated in one corner of the building and the outer perimeter of this space is to be hardened. It will not be necessary to provide hardening for the lunchroom, workshop, mechanical room or change rooms.**

b. The building should be located to control pedestrian and vehicular traffic into and out of the area. The building should provide good visibility of approaching roads and the employee parking lot.

c. The building shall have full comfort air conditioning according to Reference $\mathrm{C}-12$, Appendix $\mathrm{C}$.

d. Provide space for a **patrol office and guard area*k located between the pedestrian passageway and the vehicle gate. ${ }^{*}$ Temporary badges and emergency alarms will be located in this area. All walls, doors and windows bounding the pedestrian passageway, patrol of fice and guard area shall be hardened. All doors are to be operated remotely from the guard station.** It should also provide good visibility of approaching roads and the employee parking lot. It should provide ready access to the vehicle gate for badge inspections. The vehicle gate should consist of a barricade automatically raised and lowered from the guard station with a manually closed rolling vehicular backup gate of the chain-link fence type.

e. Provide a weather-enclosed pedestrian passageway located between the guard station and a patrol headquarters. The passageway should be unobstructed and large enough to accommodate two lines of traffic. The S-Area side of the passageway should have a minimum of 18 linear feet of wall space to accommodate Health Protection badge racks -- preferably on opposite walls of the passageway to facilitate personnel movement.

f. Provide **an administrative** office area just inside the guard headquarters large enough for **one desk** and a safe. ** This office area is an isolated office for the lieutenant. $* *$

8. Provide a lunchroom sized to seat six people. Provide space for sink, hotplate, microwave oven, refrigerator, icemaker, and vending machines.

h. Provide men's change room sized to accommodate 15 male employees. Maximum utilization in any 8-hour shift should not exceed five employees. Lockers should be sized to accommodate clothes on hangers. Sanitary facilities including showers are required. 
PART TITLE: BUILDING REQUIREMENTS

ITEM TITLE: Gatehouse and Patrol Headquarters

i. Provide women's change room sized to accommodate 5 employees. Maximum utilization in any 8-hour shift should not exceed two employees. Provide clothes lockers identical to men's. Sanitary facilities including showers are required.

j. Provide an approximately $12 \times 12 \mathrm{ft}$ storage room for uniforlus, dirty laundry, and cleaning and storage of weapons. This room should be equipped with a wooden workbench and gun cabinet.

k. Provide janitor's closet with a mop sink.

1. Provide telephone equipment room sized to house the S-Area telephone system.

$m$. Provide an area sized for six footlockers for storage of health Protection emergency equipment. These lockers may be stacked to conserve floor space.

n. Provide parking space for two patrol vehicles in close proximity to the patrol area.

o. Provide wall space for timecard boxes, store order bin, and bulletin boards in the pedestrian passageway.

p. Provide space for a small three-sided metal shelter at the entrance road for employees waiting for carpools.

q. Office space is to be provided for patrol personnel as set forth in Table 10-2, Appendix A.

\section{Auxiliary Equipment}

- Fixed radio station, channels 1 and 3

- Set, walkie-talkie, dual channel, with duress capability

- Mop sink in janitor's closet

- 20 clothing lockers

- Two fire alarm detection systems (one for pull boxes and one for building fire detection systems)

- Safety alarm systems (including area paging system and emergency alarm systems)

- Counter top storage area along entrance and exit gates. 


\section{PART TITLE: BUILDING REQUIREMENTS}

ITEM TITLE: **Service Building -- General Requirements

The service bullding provides space for receipt, storage, and preparation of raw materials for the vitrification process and may also house other service faclifties (e.g., compressors, malntenance shops, change rooms, offices, control room, computer room, etc.). General storage areas for raw materials are: $\star \star$

\begin{tabular}{ll}
\multicolumn{1}{c}{ Area } & Location \\
\hline Bulk storage (frit) & Outside \\
$\star^{*}$ Liquid Cold feed storage** & Outside \\
Cold feed make-up & $\star \star$ Outside** \\
Dry chemical storage & Inside \\
Component storage and preparation & Inside
\end{tabular}

General

- ${ }^{*}$ The service bullding is to be of standard construction.**

- Provision must be made to prevent inadvertent chemical splils from reaching the environment.

- Isolation between acid, caustic, oxidizing, and reducing agents must be provided.

- Those make-up operations which use dry chemicals should be located within the warehouse. The unloading dock areas should have protection from inclement weather.

- The layout of bulk chemical storage, the receiving and storage warehouse, and the cold feed area should facilitate movement of supplies, chemicals, and canisters through the facilities and to the process cells.

- Because of safety considerations and the possible need for rapid evacuations, no provision for the physically handicapped is required.

- Materials of construction for tanks and lines is to be compatible with the material being handled.

-Pumps for critical streams to Building $221-5$ should have installed spares.

- Requirements for sumps in chemical solution areas are set forth in Part 5 , It.em 430.

- Requirements for vessel vent systems are set forth in Part 5, Item 425.

- Instrumentation and control requirements are set forth in Part 6, Item 200 . 
PART TITLE: BUILDING REQUIREMENTS

ITEM TITLE: **Service Building -- Space Requirements**

Space is required for the inventory items specified in Part 5, Item 200, and the preparation facilities outlined in Part 5, Items 210 and 265. In addition, space should be provided for:

- Rallroad and truck unloading docks for chemicals and canister and overpack components.

- Laydown a rea for unpacking and recelving inspection of canisters and overpacks. $* *$ (This may be on unloading dock area.)**

- Storage of miscellaneous chemicals equivalent to $10 \%$ of the specifically identifled chemicals storage area.

- ** Storage of small items in a $10 \times 10-\mathrm{ft}$ area.**

- Recelpt of Incoming materials before laboratory release equivalent to the largest incoming dry chemical shipments. (See Part 5, Item 200)

- An Inspection area for canlster and overpack components (see Part 5, Item 265) containing:

$0 * *$ A canister inspection station (about $8 \mathrm{ft} \times 8 \mathrm{ft}$ ) with dimensional gages and helium leak test connection. The station should be suitable for either audit or in-process inspection. The station should be capable of handling one overpack and 2 or 3 canlsters at a time. $^{\star \star}$

- Three canister storage positions and one overpack position. Canister and overpack sizes are given in Part 20, Item 50 and Item 60.

- A canister and overpack weld $x$-ray area about $8 \mathrm{ft} \times 8 \mathrm{ft}$ with additional space for ofl cooler and $x$-ray control room (about $4 \mathrm{ft} x$ $4 \mathrm{ft}$ ). X-ray area requires about $2 \mathrm{ft}$ of concrete shielding

- Two work benches (each 8-ft long $x$ 2-1/2-ft wide) and two storage cabinets (each abou = 6-ft wide $x$ 24-in. deep)

- Vacuum pump system to evacuate canisters, overpacks, and helfum capsules, and backfill with helium.

o Hellum leak tester

o Helium cylinder storage rack for 6 cylinders (or equivalent supply)

- A local control room for local panels related to cold feed area storage and make-up operations 


\section{PART TITLE: BUILDING REQUIREMENTS}

ITEM TITLE: **Service Bullding -- Space Requirements**

- Safety showers and eyewash stations in the chemical storage and cold feed preparation areas

- **Battery charging station for forklift trucks will be located on the loading dock**

- Storage of reject chemicals and containers

- Lunchroom, restrooms, and change rooms if not combined with other areas. Lunchroom should include space for sink, hotplate, microwave oven, refrigerator, Icemaker, and vending machines. Occupancy requirements for these areas are dependent upon the facilities combined with the warehouse operations.

- Office requirements as set forth in Table 10-2, Appendix A

- Shops and maintenance space have been incorporated with requil rements outlined in Part 14, Item 400

- Provide approximately $40 \mathrm{ft}^{2}$ for a storage area for jantiorial supplies and mop sink

- Provide a dumpster pad near rear entrance for a clean waste dumpster.

$=* *$ Mechanical equipment room to house the Building S-221 compressors.

- Electrical equipment room needed for $S-210$ services and some services for S-221.

- Central control room for the $5-221$ building as given in Part 11 , Items 600,605 , and 610 .

$=$ Computer room for the S-221 bullding as given in Part 11, Items 605 and 610.

= E\&I Shops with requirements outlined in Part 14, item 450 for Shops 4 and 5. Shop 4 should be close to the computer and control rooms.

= Conference room large enough for 25 people.** 
PART TITLE: BUILDING REQUIREMENTS

ITEM TITLE: **Service Building -- Heating, Ventilation and Air Conditioning

Control of radioactive contamination is a concern in the regulated change rooms. Airlocks and air flows must prevent spread of contamination to the clean areas. Offices, lunchroom, change rooms, restrooms, central control room, and component inspection area should be comfort conditioned. ${ }^{\star *}$

Some chemicals will degrade at extreme temperatures. Liquids should be protected from freezing. A minimum temperature of $550 \mathrm{~F}$ should be satisfactory for these areas.

The canister and overpack component storage and inspection area should be protected from any movement of dust and/or chemicals from the chemical storage area.

Outside installations will require freeze protection compatible with the solutions being handled.

The ventilation system shall meet the requirements set forth in Reference C-12, Appendix $C$.

The basis for occupancy and for operating schedule for HVAC equipment is set forth in Part 5, Item 200. 
PART TITLE: BUILDING REQUIREMENTS

ITEM TITLE: **Service Building -- Floor, Wall, Ceiling Finishes, and Lighting ${ }^{\star \star}$

Floors in offices and the lunchroom should be vinyl tiled. Ceramic tile should be provided on floors in restrooms and the janitor's closet. All other floors are to be smooth concrete. Tank areas are to be curbed or diked and isolation provided between acidic, caustic, and oxidizing solutions.

Provide standard lighting in all offices, change rooms, and warehouse areas. Lighting in container inspection area should be equivalent of office lighting for visibility while reading gages. Lighting for operating areas should be controlled by switches at all entrances.

Provide standard painting for all areas and equipment.

Suspended acoustical ceilings are required in the local control room, lunchroom, change rooms, restrooms, and offices. 
PART TITLE: BUILDING REQUIREMENTS

ITEM TITLE: Glass Waste Interim Storage Building

The function of this building is to serve as a storage location for containers of vitrified waste on an interim basis. Facilities are required to:

- Receive and store canisters filled with the vitrified glass-form waste. The canisters have previously been sealed, decontaminated, and characterized.

- Remove the radioactive decay heat generated from the canisters.

- **Provide natural and forced air ventilation.

- Provide HEPA filtration of forced air ventilation.

- House electrical power supply components required for the building and its equipment.

- Provide one regulated HP office and one clean operating office, one regulated and one clean change room, and and one clean janitor closet. $* *$ 
PART TITLE: BUILDING REQUIREMENTS

ITEM TITLE: Glass Waste Interim Storage Building -- General Design Requirements General design considerations for the building are:

- Provide for storage of glass-form waste.

- ** Storage capacity of the building shall be sufficient to accommodate two years production of canisters (about 1025).

- During normal operation, remove radioactive decay heat by natural convection of air. The heat generation rate for glass-form waste is in Figure 21-7 and 21-8, Appendix $\mathrm{H}_{0}{ }^{*}$ The maximum allowable centerline temperature for the glass-form waste in storage is $500^{\circ} \mathrm{C}$.

- Provide biological shielding for personnel assuming all vault storage spaces are filled with a canister of waste.

- ** Contain air-borne contamination except in the event of a design basis tornado or an investment protection or design basis earthquake * *

- Canisters must be retrievable for future shipment to a federal repository.

- Provide space for future expansions up to a 10,000 canister capacity. Subsurface preparation shall be sufficient to prevent future excavations for expansion from jeopardizing the seismic and tornado resistance of the initial building.

- Each addition (or expansion) of the building should provide for separate entrance of the vehicle used for transporting the canister. Ideally, the first and future buildings would have a duplicate design and layout for reasons of economy.

- As a basis for design, it is assumed that each building expansion increment will operate independently. Building-to-building access for personnel or for the SCT vehicle (Ref. Part 20, Item 290) is not required, and ventilation systems for each building added will operate completely independent of the systems provided on the original project.

- The design of the vault enclosure and/or contiguous steel portions of Building 250-s must be such that vault is not breached by missiles or collapsing steel structural members over or adjacent to the vault structure during a design basis tornado or earthquake.

- At least 12 spaces in the building should be capable of storing canisters in overpacks. Overpack sices are given in Part 20, Item 60. 
DPSP $80-1033$

PART 11

ITEM 405

PAGE 2 of 2

DATE 9-82; Rev. 9

PART TITLE: BUILDING REQUIREMENTS

ITEM TITLE: Glass W te Storage Building -- General Design Requirements

- Since neither general or remote maintenance capabilities are practical, materials of construction for the vault section should be based on a 50-year useful life.

Part of the storage building must resist the design basis earthquake and tornado; part is of standard construction as set forth in Part 4, Item 700 . 


\section{PART TITLE: BUILDING REQUIREMENTS}

\section{ITEM TITLE: Glass Waste Interim Storage Bullding -- Ventilation Requirements}

\section{**Vault Area**}

Design of the vault ventilation system is to be based on natural convection circulation for the removal of the decay heat load. Under normal operating conditions filtration of exhaust alr is not required.

** Provision is to be made to divert the exhaust air from the vault area to HEPA filters in the event alrborne contamination exceeds acceptable levels. Provide for DOP testing of the HEPA filters. Above grade portions of the alr inlet to the vault, air exhaust from the vault and HEPA filtration system should be standard construction. Tornado dampers are not required on the air inlet or exhaust.**

To minimize the spread of contamination and the volume of alr diverted to filtration should a canister be damaged during handilng, the vault is to be divided into compartments (partitions required for ventilation only) with the ability to filter air from individual compartments.

Provide ducts to permit mult1-compartment use of HEPA system for vault chambers where feasible. The system for air diversion and filtering should be provided with emergency power.

At no time shall air be permitted to flow from the vault to the adjacent operating areas. When plugs are removed (as for insertion of canister) a minimum afr flow into the vault of 150 linear feet per minute is required through the opening. Consider using the emergency HEPA filter exhaust system to create this if the natural draft of the chimney falls to do so.

The vault ventilation air should be discharged a minimum of twelve feet above the roof line of the bullding in order to meet minimum recommendations set forth in Reference $\mathrm{C}-13$, Appendix $C$, and in order to meet acceptable concentrations for air-borne radioactivity at ground level.

Requirements for radiation and air monitoring are shown in Part 12, Items 110 and 120. Requirements for instrumentation and control are set forth in Part 6, Item 500. $* \star$ As shown in Table 4-1, the air monitoring instrumentation should be of standard construction.

Office Area

The office area is to be air conditioned per Reference C-11, Appendix C.

The regulated change room and HP office and counting room are potentially contaminated. Exhaust alr from this area is not to be recirculated, but does not require HEPA filtration prior to discharge. Exhaust alr from the clean operations office can be recirculated depending on economics.

Above Vault Area

Provide for heat removal and fume removal from the above vault operating area. Although this area is potentially contaminated, the exhaust alr does not require HEPA filtration. ${ }^{\star \star}$ 
PART TITLE: BUILDING REQUIREMENTS

ITEM TITLE: Glass Waste Storage Bldg. -- Maintenance and Access Requirements

The design is to preclude the need for maintenance inside the vault. Maintenance in any operating area outside the vault will be hands-on, with air suits or controlled access procedures as necessary to limit radiation exposure.

Access is required for changing HEPA filters, for maintenance of ventilation system, and for maintenance of the air flow and radiation monitoring instrumentation. 


\section{PART TITLE: BUILDING REQUIREMENTS}

ITEM TITLE: Glass Waste Storage Bullding -- Furniture, Fixtures, and Aux1liary Equipment

$\underline{\text { Space }}$

Personnel will normally not occupy the above vault deck space or the personnel and maintenance spaces of the storage bullding. Operating and Health Protection personnel, assigned to the process bullding, will periodically enter the building to place canisters in the vault and to perform maintenance on building equipment. Doors providing access to the operating area above the vault should be equipped with intrusion alarms to notify the CCR when entry is made.

**A clean change room with six lockers and clean protective clothing stórage (no showers, etc.) 1 s required. A regulated change room with space for bag storage of used clothing is required. ${ }^{*}$ Location of the change room should consider access from those areas of potential contamination (HEPA f1lter malntenance and vault deck).

Room Finishing and Lighting

Floors in the office should be covered with vinyl tile. All other floors are to be smooth concrete. Paint walls, floors, and cellings of the office, toilet, change room and shop area for ease of decontamination.

Provide for standard lighting in office and shange room/restroom. Lighting in the storage bullding operating area should be adequate for an operator to operate the SCT and to remove and replace shield plugs. Include provisions for reducing lighting in unoccupied areas of the building. A.

Furniture required for the office area is included in Table 16-1, Appendix

Miscellaneous requirements are:

$-\star \star 2$ Mop sinks**

- A desk top data input station (for the central computer) is required in the storage building office for record and inventory purposes.

- A public address system is required in the office and in other occupled areas.

$\Sigma *$ Hand and foot counters

$=$ HP counting equipment** $^{* *}$ 
PART TITLE: BUILDING REQUIREMENTS

ITEM TITLE: Glass Waste Interim Storage Building -- Radiation Shielding Thickness Requirements

**Radionuclide concentrations are in Tables $21-17$ and $21-18$, Appendix $H_{0} * \star$ Guidelines for attenuation of dose rates are set forth in Part 11, Item 115. For purposes of determining the required shielding thickness, assume the office and personnel areas, the operating areas above and around the vault are intermittently occupied. However, use of earth (as with a below grade vault) is desirable to further limit the radiation rate around the vault.

The design is to provide for expansion of the storage capecity of the building in an incremental fashion without construction personnel being exposed to radiation levels exceeding those for continuous occupancy and without jeopardizing the structural integrity of the storage building vault or foundation. 


\section{PART TITLE: BUILDING REQUIREMENTS}

ITEM TITLE: Sand Filter

The function of this building is to serve as the medium for removal of radioactive particulates from the process cell exhaust air, and final filtration of vessel vent system and melter off-gas air. Included in this section is a discussion of the air tunnel system. The sand filter and tunnels are to be constructed according to the requirements outlined in part 4, Item 700 and Table 4-1, Appendix A.

The sand filter will consist of an air inlet and distribution system, a bypass system, the filter bed and an air exit system. The air inlet and distribution system must be corrosion resistant. The bypass is to route processing building exhaust air around the sand filter until hot startup of the processing building. **The bypass will be temporary construction.** Design of the bypass must ensure that unfiltered air cannot bypasy the filter after hot startup. The filter bed must consist of graded layers of rock and sand designed to remove a minimum of $99.95 \%$ of the radioactive particulates at an air velocity of $5 \mathrm{ft} / \mathrm{minute}$. The filtered air must meet the limits specified in Reference $C-10$, Appendix C. The air exit system should discharge the filtered air to the exhaust stack.

The sand bed is to be supported with grating of $304 \mathrm{~L}$ stainless steel per Spec. 4498 and the corners of the distribution trenches are to be covered with stainless steel to provide resistance to corrosion. Specifications for the content, sampling, testing, transporting, and placement, along with size tolerances and depth tolerances, of the filter material are presented in Du Pont Spec. 6795. Generally:

1. A layer of supporting tile or material satisfactory for earthquake requirements

2. A 12-in. layer of $1-1 / 4$ to 3 in. rock (A layer)

3. A 12-in. layer of $5 / 8$ to $1-1 / 2$ in. rock (B layer)

4. A 12-in. layer of $1 / 4$ to $5 / 8$ in. gravel (C layer)

5. A 6-in. layer of No. $8 \mathrm{U}$. S. mesh to No. $4 \mathrm{U}$. S. mesh sand (E layer)

6. A 12-in. layer of No. $20 \mathrm{U}$. S. mesh to No. $8 \mathrm{U}$. S. mesh sand (F layer)

7. A 36-in. layer of No. $50 \mathrm{U}$. S. mesh to No. $20 \mathrm{U}$. S. mesh sand (G layer)

8. An 8-in. layer of No. 50 U. S. mesh to No. 40 U. S. mesh/No. 30 U.S. mesh sand (H layer)

The size of the sand filter will depend on the size of the Zone 1 areas in the processing building and the quantity of ventilation air from those zones. Space should be reserved for expansion of the sand filter.

Sumps should be provided for collection of condensate and any water entering the sand filter or the air tunnel system. $\star \star$ Provide facilities for transferring the liquid to the main processing building through underground, stainless steel lines that are protected against galvanic corrosion. ${ }^{\star}$ A containment jacket is not required on these lines. 


\section{PART TITLE: BUILDING REQUIREMENTS}

\section{ITEM TITLE: Sand Filter}

Provide an air lock for access to the sand filter for periodic inspection. Provide permanent lighting, with switches at the air lock entrance, with sufficient intensity for safe movement of personnel within the sand filter.

The interior surfaces of the sand filter and the air tunnels are treated as follows:

a. Protective coating resistant to deterioration by radiation, process chemicals, vapors, and moisture

- Tunnel from the processing building to the sand filter

- Floor and troughs of the sand filter

- Interior walls up to sand surface

b. Dust-proofing surface sealer

- Tunnel from the sand filter to the fan house

- Sand filter bypass tunnel

- Filter interior above the sand surface

c. No treatment

- Tunnel from the fan house to the stack

All air tunnels are to be the minimum length necessitated by area layout and seismic requirements. The tunnel between the sand filter and fan house may be eliminated if seismic design permits the exhaust fan installation to be adjacent to the sand filter.

An emergency blowout port, which is to be seismic and tornado resistant, is required in the tunnel between the fan house and the stack. This tunnel, the length of which is established by air sampling needs, is to be seismic and tornado resistant up to and including the blowout port but not beyond. This port must be located to preclude the stack structure falling on it and it is to open automatically if the stack becomes blocked.

Monitor tubes for occasional radiation profile measurements through the filter beds are required. A set of 6 -inch tubes spaced 30 feet apart along the filter is required about $1 / 3$ of the way across the filter bed and a second set of 6-inch tubes also spaced 30 feet apart is required about $2 / 3$ of the way across the filter bed. The two sets of monitoring tubes should be offset about 15 feet.

Provisions should also be made for injecting DOP into the incoming air supply and sampling upstream and downstream of the filter to perinit determination of filter efficiency.

See Table 6-1, Appendix A, for instrument requirements.

Part 12, Item 120 and Table 12-1, Appendix A specify Health Protection requirements associated with the sand filter. 

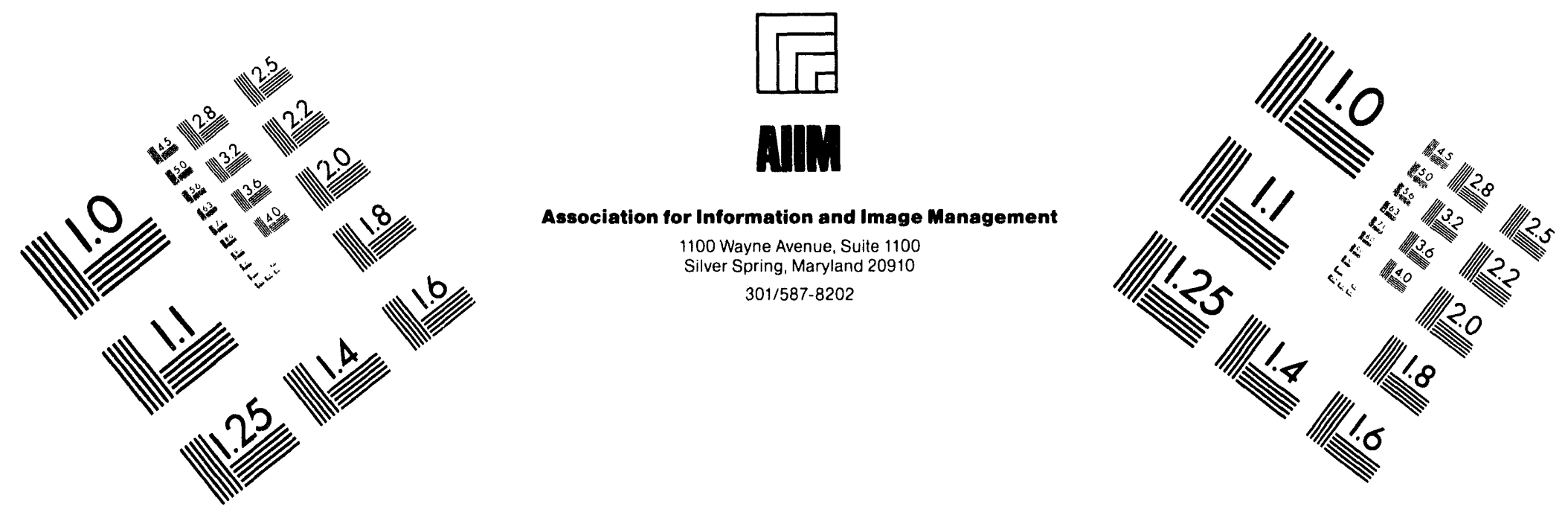

\section{Centimeter}

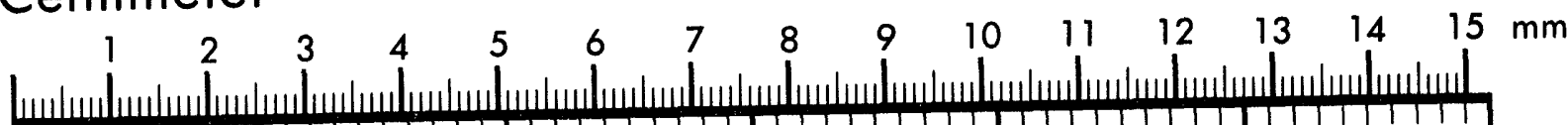
$\prod_{1}$ Inches
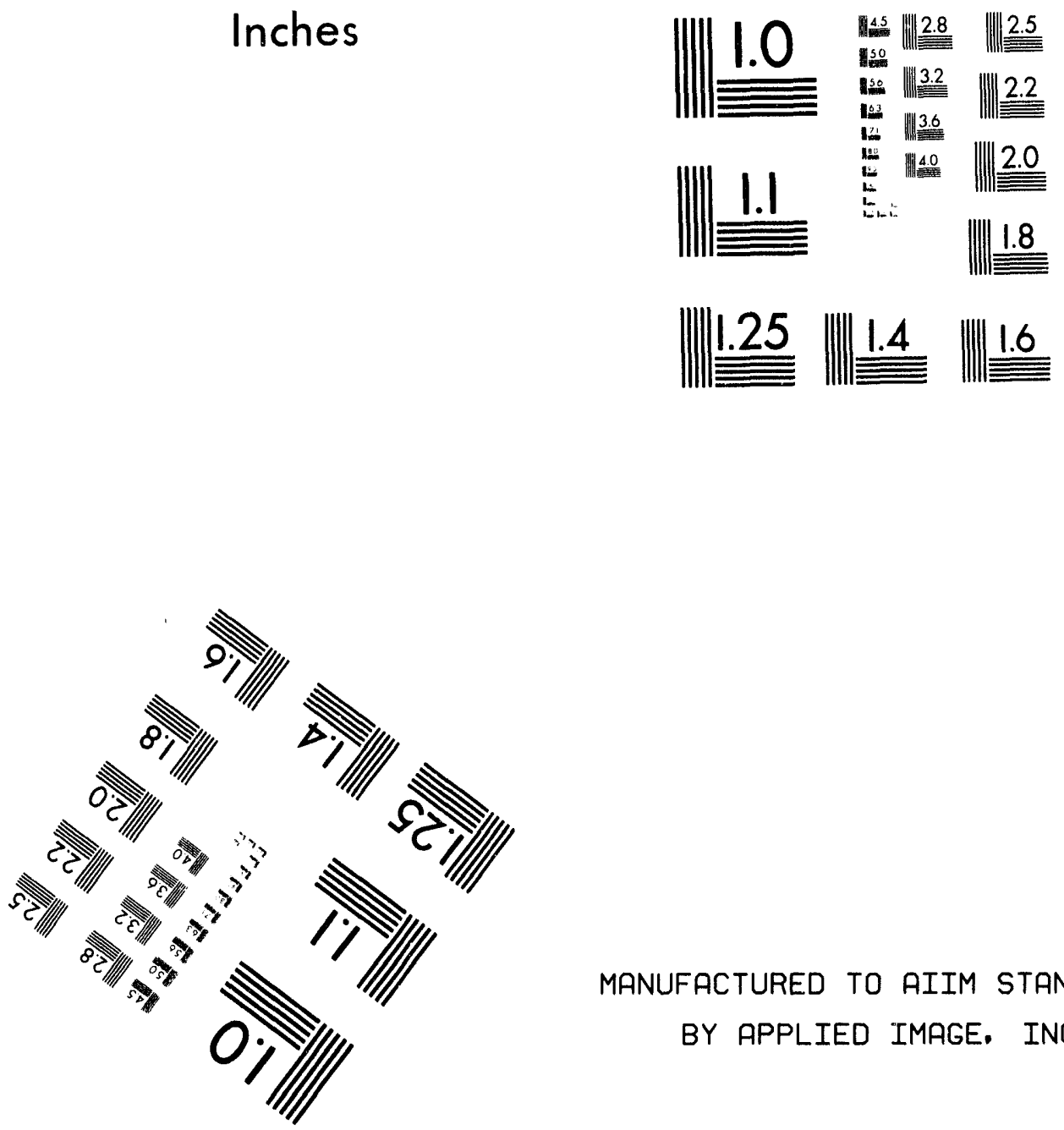

MANUFACTURED TO AIIM STANDARDS BY APPLIED IMAGE, INC.

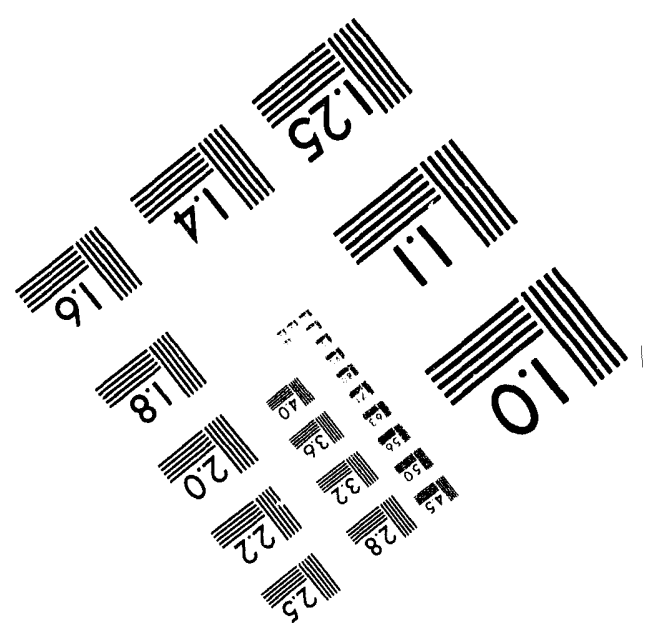




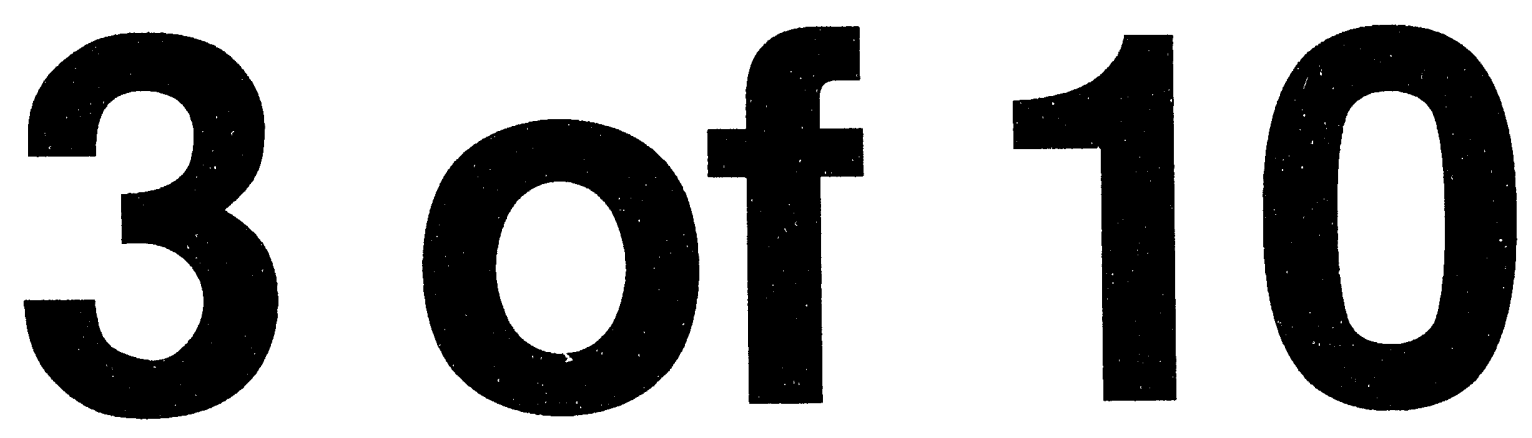


DPSP $80-1033$

\section{PART TITLE: BUILDING REQUIREMENTS}

ITEM TITLE: Fan House for Zone 1 Exhausters

This building is to contain exhaust fans and associated electrical equipment to exhaust the operating cells within the processing building. The fan house is to be constructed according to the requirements outlined in part 4, Item 700 and Table 4-1, Appendix A.

Design considerations for the fan house are:

- Provide a condensate collection system and sump in the plenums beneath the fan house if these do not drain to the connecting air tunnels (Part 11 , Item 450). **Condensate is to be returned to the processing building; any underground piping is to be stainless steel line with galvanic corrosion protection. ${ }^{\star \star}$

- The surfaces of air plenums beneath the fans are to be treated as follows :

- Fan inlet plenums are to have a dust-proofing surface sealer

- Fan discharge plenums require no treatment.

- **Provide for building ventilation to remove motor heat loads. Climate control is not required.**

- Provide space for electrical motor centers associated with normal fan operation.

- Provide space for diesel generator(s) to supply emergency electrical power to the exhaust fans and monitoring system.

- Provide adequate space for manually operated monorails and hoists for removal and installation of heavy equipment. Permanently installed monorails and hoists are preferred over portable equipment.

- All maintenance work will be performed in a direct hands-on mode. However, adequate provisions should be provided in space layout for construction of plastic huts around potentially contaminated equipment during repair work.

- Personnel will not be permanently assigned to this building.

- Floors should have a smooth concrete finish.

- Painting is not required. 
DPSP $80-1033$

PART 11

ITEM 470

PAGE 2 of 2

DATE 9-82; Rev. 9

PART TITLE: BUILDING REQUIREMENTS

ITEM TITLE: Fan House for Zone 1 Exhausters

- Lighting should be standard for work locations. Lighting should be controlled by switches at building entrances.

- ** Provide a portable eye wash facility in the vicinity of the battery charge station. ${ }^{\star \star}$ 


\section{PART TITLE: BUILDING REQUIREMENTS}

\section{ITEM TITLE: Exhaust Stacks}

The function of the exhaust stacks is to disperse filtered air from the processing building to the atmosphere. Design of the stack (height, location, etc.) should consider the variables discussed in References C-13, Appendix C, and $D-1$ and $D-2$, Appendix $D$.

Design considerations for the stacks are:

- The stacks should be standard construction; earthquake and tornado resistant stacks are not required.

- Provide a stack sized for the quantity of air to be exhausted from the process cell (Zone 1) and a stack for the quantity of air to be exhausted from the operating areas (Zone 2 ) of the processing building.

- The primary design criterion is to provide a stack that assures dispersion of exhaust air such that concentration of airborne radioactivity from the design basis accident does not exceed allowable limits at the air intake for any area bulldings or at SRP boundaries. At area bullding alr intakes, the maximum concentration for unidentified alpha is $2 \times 10^{-12} \mathrm{uci} / \mathrm{cc}$ and for unidentifled beta-gamma is $1 \times 10^{-9}$ uci/cc. For allowable limits on airborne radioactivity at the SRP boundaries, see Reference C-10, Appendix C. See Part 9, Item 140 and Reference $\mathrm{C}-18$, Appendix $\mathrm{C}$ for further information on design calculations.

- The stacks should be at least 2-1/2 times the height of buildings within 500 feet to obtaln the maximum dispersion of any released radioactivity or chemicals.

- Locate the stack to permit or facilitate expansion of the sand filter and at least one stack-length from the blowout port or any other safety related structures.

- Provide aircraft warning lights if required by height of the stack.

- ** Provide condensate collection systems with facilities for transfering the condensate back to the processing building. Any underground piping is to be stainless steel line with galvanic corrosion protection. ${ }^{*}$

- Paint the stacks inside and outside with a chemical fume resistant paint.

- ** The zone 2 exhaust air should be discharged a minimum of 12 feet above the highest point of the 221-S building in order to meet minimum recommendations set forth in Reference $\mathrm{C}-13$, Append1x $\mathrm{C}^{* \star}$ 
PART 5

ITEM 180

PAGE 1 of 3

DATE $9-82 ; \operatorname{Rev} .9$

PART TITLE: PROCESSING FACILITIES BASIS

ITEM TITLE: Pump Pits and Diversion Boxes

Pits are to be provided for pump tanks and auxiliary equipment for transfers between the H-Area waste farm and S-Area. Diversion boxes will be required for flow direction control at the pump pits. Valve installations are acceptable in diversion boxes where necessary but not in pump pits.

A pump pit will be required at the low point between $S$ and $H$ Areas to provide drainage for the interarea recycle waste 1 ine and sludge 1 ine. **The diversion box associated with this pump pit should include piping for the recycle waste line, the sludge feed line, and the common spare line for the Sludge plant plus four spare embedded lines for future connections.**

Multiple pump tanks, probably two, will be required to deliver sludge from $\mathrm{H}$-Area to the vitrification plant in S-Area. One of these pump tanks should be located at the low point pump pit (above), thus sharing a ventilation system and diversion box with the recycle waste pump tank. The auxiliary pump pit(s) in the sludge transfer system will require only a single tank. The diversion box at the auxiliary pump pit(s) must include piping for the common spare line; the recycle waste line may by-pass this diversion box. The diversion box at the auxiliary pump pit(s) must provide for continual sloping piping for the spare interarea line to preclude holdup in a low point in this spare line. Diversion boxes associated with auxiliary pump pits should have at least one spare pair of nozzles for future 1 ines. **A pump pit and interarea transfer concept for DWPF-Sludge Plant is shown in Figure 5-2, Appendix B.**

Capability for transfer in either direction through the sludge feed line and recycle waste transfer line is required; however, as reverse flow is expected only occasionally, piping changes within the diversion boxes will be acceptable to make this feasible. Sludge properties are presented in Table 21-3, Appendix H.

Covers should be provided to direct rainwater from the pump pits, diversion boxes, and working pads. Crane access is needed for these facilities. Facility design must include sloping floors with a sump, sunp level detection, cell liners, underliner leak detection, and water sprays for pit decontamination. Underliner leak detection systems at multiple pump pit-diversion box installations must be segregated to identify the leaking liner. **Sump solutions will be transferred with pumps; if possible, these pumps should be replaceable by remote operation.** At the low point pump pit, the diversion box sump is to drain to the recycle waste tank pit sump; at the auxiliary pump pit(s), the diversion box sump is to drain into the pump pit sump. 


\section{PART TITLE: PROCESSING FACILITIES BASIS}

\section{ITEM TITLE: Pump Pits and Diversion Boxes}

SRP experience with equipment handling in pump pits and diversion boxes indicates a minimum thickness $3 / 8$ "stainless steel lining is required on floors for impact resistance and a lighter 11 gauge sheet on the walls. The heavier liner should extend 18" up the walls. All inside stainless steel liner plates are to be $304 \mathrm{~L}$ corrosion evaluated per specification 4498; this liner will ensure against leakage to the environment.

**A shielded cab crane is being purchased (Project 9S-1747, purchase order No AXC 2103-W) for use at SRP to make connections and handle jumpers within pump pits and diversion boxes. The DWPF pump pit and diversion box designs must allow use of the new shielded cab crane when servicing these facilities. $* * *$

Each pump tank must be sized and instrumented to preclude overflow when receiving a transfer and subsequent pipe drainage from the preceeding tank. The pump tanks shall include an installed spare pump to make it possible to empty the tank if the in-service pump fails. A spray nozzle fixed to the end of a tank jumper should be provided for tank internal decontamination. Removal of highly radioactive material from a pump tank, and flushing of the system prior to work in a pump pit reduces personnel exposure significantly. The pump design should exclude use of water as a bearing coolant/lubricant to avoid extra water in the process. Agitation is required in all pump tanks to preclude solids buildup in the tanks and to facilitate equipment decontamination. The sludge slurry pump tank should include redundant liquid level instrumentation. Each pump tank should include two spare nozzles and corresponding spare nozzles should be incorporated in the pit wall with 1 ines leading to the diversion box. In addition, a spare electrical nozzle is to be provided in each pump pit.

Tank positioning trunnion guides are required to provide precise positioning for remote replacement of equipment. The wall nozzle arrangement should be standardized for all pump pits to provide modularity. Pump tank fabrication is to make it possible to replace any of the pump pit tanks with a common spare tank without providing new jumpers to service the tank. However, it is unnecessary to provide for interchangeability of jumpers between pump pits or between diversion boxes.

Ambient temperature slurries/solutions will be transferred through the interarea system. The sludge feed system will operate on a batch basis providing a feed batch as required by the process which is expected to be on a four day cycle. The recycle waste system will operate on a batch basis as required, probably once daily. **Fission product decay heat must not be permitted to increase solution temperature in the pump tanks to (1) create a vapor or humidity problem in the tank vent system, (2) overconcentrate the sludge slurry feed to greater than 19 wt \% sludge, or (3) raise the solution temperature to the point where these pumps will not function. If cooling is not required in the pump tanks, coils will not be required in the tanks. Append $x H$, Tables $21-22$ and $21-23$ provide decay heat information. ${ }^{* *}$ 


\section{PART TITLE: PROCESSING FACILITIES BASIS}

ITEM TITLE: Pump Pits and Diversion Boxes

A safety shower is to be located at the low point pump pit and at the auxiliary pump pit for personnel use if contacted by caustic process solution or decontamination chemicals.

Instrument requirements for the pump pit/diversion box complexes are discussed further in Part 6, Item 300 and Tables 6-1 and 6-2, Appendix A. Radiation monitoring requirements are presented in Part 12, Item 110. Electrical and instrument services are to be field mounted with weather protection. 


\section{TITLE: PROCESSING FACILITIES BASIS}

\section{I'TEM TITLE: Pump Pit and Diversion Box Ventilation}

Pump pit diversion box ventilation systems very similar to existing installations are described here along with the design bases.

Pump pits -- Ventilation is required to limit escape of radioactive dust, control the atmosphere within process vessels, and limit radioactive particulate escape in event of pit overpressuring. The latter is attained by use of gaskets beneath the pump pit covers and a HEPA filter on the air inlet duct to the pump pit.

Diversion Boxes -- Ventilation is required primarily to limit escape of radioactive dust to the environment. This control is established by exhausting $150 \mathrm{cfm}$ through a high efficiency particulate filter, allowing for air inleakage around the diversion box covers.

Diversion Box-Pump Pit Combinations -- Diversion boxes associated with pump pits may be ventilated through the pump pits to eliminate a separate filter and fan system. When ventilating a diversion box through a pump pit, diversion box covers are to be sealed similarly to the pump pit covers and the diversion box air inlet, which in this case supplies the pump pits, is to be provided with a HEPA filser.

Generally, air flow in the pump pit complex housing the sludge slurry feed tank and the recycle waste tank should be as follows: (a) from the diversion box through a wall opening to the recycle waste tank pit, (b) from the recycie waste tank pit through a wall opening to the sludge tank pit, (c) up through the overflow pipes on both tanks, and (d) out through the vent jumpers on th, tanks.

Plant experience has demonstrated that an air flow of $75 \mathrm{cfm}$ from each tank in a pump pit, with a single stage HEPA filter on the system, provides satisfactory pit ventilation. Satisfactory control of radioactivity within these vent systems at SRP has been demonstrated only when a **demister-condenser reheater $* *$ system has been included upstream of the HEP, filter. The DWPF pump pit ventilation system is to be designed to preclude condensation or moisture fall-out in the filter, exhaust fan and duct work. $* *$ Demister and reheater are required, plus space for future installation of 7 condenser.**

Parallel HEPA filters with isolation valves are required in the exhaust systems to permit filter changes without system shutdown. These filters require shielding, eight inches of concrete based on SRP experience with similar installations, and should be remotely changeable to reduce personnel radiation exposure.

A single exhaust $f$ an is satisfactory in this service. The fan should discharge through a nominal stack (minimum height $12^{\prime}$ ) to avoid direct contat with personnel. 
PART TITLE: PROCESSING FACILITIES BASIS

ITEM TITLE: Pump Pit and Diversion Box Ventilation

Solution temperature in the sludge feed and recycle waste pump tanks will normally range from ambient to that attained by the sludge during the nominal residence cycle for the batch transfer. However, the basis for humidity and condensation control in the tank ventilation system is to be saturated air at $75^{\circ} \mathrm{C}$ which is the maximum temperature of solution permitted by the design basis for transfers through the interarea lines.

Instrument requirements are shown in the Tables $6-1$ and $6-2$, Appendix $A$; radiation monitoring requirements are shown in Table 12-1, Appendix $A$, and discussed in Part 12, Item 120. 
PART TITLE: PROCESSING FACILITIES BASIS

ITEM TITLE: Raw Materisls Receipt and Storage Requirements

\section{General}

The function of this facility is to:

- Receive, inspect, store, and dispense glass product storage container components (canisters, overpacks, plugs, etc.).

- Receive, sample, store, and dispense bags and drums of dry and liquid cold feed chemicals.

- Receive, sample, unload, store, and transfer chemicals purchased in bulk quantities.

- Prepare, sample, and feed chemical solutions to the consuming points.

\section{Process}

The following operations will be performed on day shift, Monday through Friday:

- Receipt and sampling of bulk, bag, and drum chemicals.

- Receipt, and inspection of canister and overpack components.

- Preparation and sampling of cold feed solutions.

Transfer of chemicals (such as glass frit and cold feed solutions) and canister components to the process building will be performed continuously on $A, B, C$, and $D$ shifts. The office, lunchroom, and change room area will be used 24 hours per day. **All movements between the service building and the process building will be made by operating personnel. ${ }^{* *}$

Receipt of glass frit, bulk chemicals, canister components etc. and preparation and/or dispensing of these materials will be performed by the same work group. These facilities should be located in close proximity to each other for maximum operating efficiency and to minimize transportation facilities.

Capacity of vessels feeding into the process cells must be at least equal to a $j$-day consumption requirement. $\star \star$ Where ccld feed solutions are made up in large quantities, make-up is to be accomplished outside. Where quantities are small, the operations will take place at the vitrification building cold feed facilities.**

The inventory standard bases for these facilities are shown in Table 5-1, Appendix A. Storage requirements are shown in Table 5-2, Appendix A.

Cold feed materials preparation and handling requirements are set forth in Part 5, Item 210. Canister and overpack component requirements are set forth in Part 5, Item 265 and in Table 5-4, Appendix A

Canister and overpack procurement is covered in Part 16, Item 300. 
FART TITLE: PROCESSING FACILITIES BASIS

ITEM TITLE: Cryogenic and Compressed Gas Requirements

Maintenance and Power compressed gas requirements will be provided by distribution from 700 area central receiving. Dedicated plant locations at the use points will be required for storage of full, empty and active cylinders. Expected requirements include cylinders of:

\section{Cy $1 /$ Yr}

Oxygen

Acetylene

Argon

Freon

Instrument calibration gases

$\mathrm{Ni}$ trogen

Breathing air

** He 1 ium
120

50

25

a

b

75

200

$\underline{35}$

$\underline{\mathrm{SCF} / \mathrm{Cy} \mathrm{I}}$

244

250

24

a

b

81

300

$236 * *$

a 1400 lbs. per year, all types

${ }^{b}$ As sume four different types of gases at one cylinder per month each. 


\section{PART TITLE: PROCESSING FACILITIES BASIS}

ITEM TITLE: Bulk Cold Feed Materials -- Preparation and Handling

$* *$ Bulk chemicals will be received and stored in the cold feed area. $* *$ These chemicals will be used directly or used in the preparation of chemical solutions for use in the process and/or equipment decontamination. Facilities will be required for make-up of the cold chemical process solutions as follows:

\section{Formic Acid System}

Design considerations are:

- A tank truck unloading station is required.

- Two $90 \%$ formic acid storage tanks are required. These tanks are vented to the atmosphere through conservation breathers.

- A formic acid dilution tank and a dilute formic acid feed tank are required. Vent from these tanks should be treated to minimize the corrosive effects of formic acid vapors on the remaining portion of the cold feed vent system.

- Connect drains and overflows from all formic acid tanks to the organic acid drain system.

- Provide samplers similar to those described in Part 7, Item 100, except replace air jet with a self-priming pump.

- See Part 6, Item 100 and Tables 6-1 and 6-2, Appendix A for instrumentation and controls.

- The formic acid system should be located in a separate diked area that drains to a sump. The sump should discharge to the Chemical and Industrial Waste Treatment Facilities.

- Freeze protection required for outside storage.

\section{Frit (See Figure 5-10, Appendix B)}

Design considerations are:

- **Air supply for the frit unloading and transfer system is to be from. dedicated compressor for this purpose only. Air will be dried to a maximum dew point of $2^{\circ} \mathrm{F}\left(18^{\circ} \mathrm{F}\right.$ below SRP minimum design temperature - see Engineering Standard $\mathrm{H} 6$.**

- Facilities are required for sampling frit (Part 7, Item 100).

- Provide facilities for removing out-of-specification material from the storage silos and returning it to the hopper car. 
PART TITLE: PROCESSING FACILITIES BASIS

[TEM TITLE: Bulk Cold Feed Materials -- Preparation and Handling

Nitric Acid System (See Figure 5-12, Appendix B)

Design considerations are:

- Storage tanks for $50 \%$ nitric acid are not required. A portable tank will be used for storage. (See drawing S5-6-594. Material of construction to be $304 \mathrm{~L}$ stainless steel. Heater is not required.) Provide space for one portable tank.

- Provide mixing, cooling, and sampling for the $\mathrm{HNO}_{3}-\mathrm{KMnO}_{4}$ makeup tank.

- Connect drain and overflow lines to an acid drain system. The acid drain system should discharge to Chemical and Industrial Waste Treatment Facilities.

- Use cold feed sampler similiar to that described in Part 7, Item 100.

- Vent tank to cold feed vent system. (See Part 5, Item 425.)

- Refer to Part 6, Item 200 and Tables 6-1 and 6-2, Appendix A for instrumentation and controls.

Oxalic Acid System

Design considerations are:

- Oxalic acid will be received in $50 \mathrm{lb}$. bags, 32 bags per pallet.

- ** Provide an oxalic acid makeup tank. Vent the tank to the cold feed vent system. Provide mixing and heating for this tank. ${ }^{\star *}$

- Drain and overflow lines should discharge to the Chemical and Industrial Waste Treatment Facilities.

- Use cold feed sampler similar to that described in Part 7, Item 100.

- Refer to Tables 6-1 and 6-2, Appendix A for instrumentation and controls. 


\section{PART TITLE: PROCESSING FACILITIES BASIS}

ITEM TITLE: Bulk Cold Feed Materials -- Preparation and Handing

Caustic System (See Figure 5-11, Appendix B)

Design considerations are:

- Storage tanks for $50 \%$ caustic are not required. A portable tank will be used for storage. (See drawing 55-6-594.) Provide space for one portable tank.

- Connect drain and overflow lines to an alkaline drain system. Alkaline drain system should discharge to chemical and industrial waste treatment facilities.

- Vent tank to atmosphere.

- Refer to Part 6, Item 200 and Tables 6-1 and 6-2, Appendix A for instrumentation and controls.

- Freeze protection must be provided for outside storage. 


\section{PART TITLE: PROCESSING FACILITIES BASIS}

\section{ITEM TITLE: Vitrification Building Cold Feed Facilities}

**Bulk chemicals and prepared solutions from the cold feed makeup facilities will be transferred into the vitrification process building where the chemicals will be either used directly in the process or will supply other tanks which in turn transfer to the process. ${ }^{* *}$

Special decontamination solutions and small volume solutions for mercury recovery will be prepared in tanks inside the building. Larger volume cold feeds and decontamination solutions for crane and equipment decontamination will be prepared outside the building and transferred by pipeline into tanks in the building (see Part 5, Item 210).

Cold feed tanks inside the building and their design requirements are summarized in Table 5-3, Appendix A. ** These tanks should be equipped with seal-less pumps to prevent leakage and to avoid exposure of personnel to chemical or radioactive hazards. ${ }^{*}$ For any tank requiring access for addition of chemicals, provide appropriate mechanical means of adding the chemicals and room for any forklift trucks required. Based on SRP operating experience the working capacity of the decontamination solution feed and makeup tanks inside the building should be 250 gallons each, and the acid, formic acid and floor drain catch tanks should have a capacity of 1000 gallons each. The sizes of other cold feed tanks should be optimized based on process needs.

Some cold feed tanks located inside the building will handle formic acid. Vents from these tanks should be treated to minimize the corrosive effects of formic acid vapors on concrete exhaust plenums. All other cold feed tanks inside the building should be vented to the cold feed vent system (Part 5 , Item 425) and be equipped with overflow and drain lines connected to the appropriate drain headers as described below. The vent line from the floor drain catch tank (see next paragraph) must be equipped with a HEPA filter to protect the rest of the cold feed vent system (Part 5, Item 425) from contamination when and if the tank must handle radioactive material. Overflow and drain line on frit handling tanks and floor areas adjacent to frit handling facilities should be designed to avoid or minimize the introduction of frit into drain headers and floor drains.

Provide an acid drain header, a formic acid drain header and a combined alkaline drain and floor drain header terminating in acid, formic acid and floor drain header catch tanks, respectively. **These tanks should be equipped with seal-less pumps to prevent leakage and to avoid exposure of personnel to chemical or radioactive hazards. ${ }^{*} *$ The acid and formic acid drain header catch tanks should discharge to chemical and industrial waste treatment facilities (Part 5, Item 460). Solutions in the floor drain catch tank are to be sampled and analyzed for radioactivity. If the solution is radioactive, it should be discharged to the suinp collection system and thence to the Recycle Collection Tank (Part 5, Item 430). If the solution is not radioactive, it should be discharged to the chemical and industrial waste 
"ART TITLE: PROCESSING FACILITIES BASIS

TEM TITLE: Vitrification Building Cold Feed Facilities

treatment facilities (Part 5, Item 460). Tanks which alternately handle both - lkaline and acidic solutions must be equipped with agitators and suitable valving to permit drainage and overflow to the proper drain header depending in the tank contents. Occasionally, other chemicals may be used for special iurposes; administrative procedural controls will be required to avoid or ontrol mixing of normally incompatible chemicals.

Agitators and cold feed samplers, similar to those described on W148193 ind D116567, should be provided on all tanks used for makeup of chemical :olutions or for collection of material which must be analyzed for disposal. The referenced drawings describe typical equipment that has been used ixtensively at SRP and has given excellent service.

All tanks should be connected to a process water supply for flushing.

** The following cold chemicals and solutions are normally prepared or stored in the cold chemical area and are transferred to cold feed tanks inside the building for subsequent addition to the process or decontamination cells $:^{\star *}$

- Decontamination Solutions

- 0.75 wt\% potassium permanganate in 12 wt\% nitric acid

- $10 w t \%$ oxalic acid

- **Potassium Permanganate, $5 \% * *$

- Nitric Acid, 50 wt\%

- Sodium hydroxide, $50 \%$ wt\%

- Glass Frit, solid

- Formic acid, $90 w t \%$

- ** Dilute Formic Acid, $1.5 \% * *$

Formic acid is pumped from outside storage tanks to the frit slurry makeup tanks inside the building prior to adding the frit slurry to the process cells for melter feed makeup or canister decontamination.

A nitric acid solution is made up from 50 wt\% nitric acid solution inside the building in small quantities for use as column wash solution : the mercury purification cell inside the building. 


\section{PART TITLE: PROCESSING FACILITIES BASIS}

ITEM TITLE: Sludge Slurry Receipt, Adjustment, and Evaporation

\section{Process Description}

Washed sludge slurry from the H-Area waste tank farm will be pumped through interarea piping and pump pits (Part 5, Items 170 and 180) to the Sludge Recelpt and Adjustment Tank (SRAT) in the main process cell, cooled if necessary, and sampled after sufficlent agitation to ensure adequate mixing. Occasionally, small quantities of liquid mercury may be received from the mercury collection sump in the Slurry Mix Evaporator (SME). Based on sample results (wt \% solids), the batch will be adjusted by adding formic acid solution and boiling under total reflux to reduce mercury to the elemental, liquid state. Formic acid also provides the reductant in the glass melter feed. The liquid mercury will settle and collect in a sump in the bottom of the tank. Periodically, the mercury will be transferred to the Mercury Water Wash Tank (MWWT). After cooling, the adjusted sludge slurry will be transferred to the Slurry Mix Evaporator where fresh frit and spent frit (from canister decontamination; Part 5, Item 280) in water slurries will be added. Water will be evaporated from the composite slurry to a calculated endpoint based on the analyses and otherwise known compositions of the added components. The evaporated batch will be sampled, analyzed and then transferred to the Melter Feed Tank. **Condensate from the Slurry Mix Evaporator will flow by gravity into the Slurry Mix Evaporator Condensate Ta:ak and then will be transferred to the Recycle Collection Tank.** Additional mercury which may accumulate in the SME condensate tank will be transferred to the Mercury Water Wash Tank.

\section{Design Data}

Genera1

- The composition of the washed sludge surry from the tank farm is given in Table 21-1, Appendix H.

- Physical properties of all sludge and sludge frit slurries are given ir Table 21-3, Appendix H.

- Vessels should be sized to provide lowest capital investment and permil operation of the process to meet objective operating rates (Part 2, Itt $n$ 105). In addition, consider the following:

a) minimum number of tank farm to S-Area transfers

b) **Inclusion of concentrated cesium waste from salt processing in the Slurry Receipt and Adjustment Tank. ${ }^{\star \star}$ 
PART TITLE: PROCESSING FACILITIES BASIS

ITEM TITLE: Sludge Slurry Receipt, Adjustment, and Evaporation

- Sludge Slurry Receipt and Adjustment

- **The maximum concentration of washed sludge from the tank farm is 19 wt \% solids and ranging from $13 \%$ to $19 \%$. Concentration may be increased up to $25 \%$ in the SRAT. $* *$

- The formic acid should be added as $90 \%$ by weight and $10 \%$ in excess of the stoichiometric amount required by the equations given in Table 21-4, Appendix H. **Assume six hours at boiling under total reflux and at a boil-up rate of 500 lbs per hour. ${ }^{* *}$

- Assume $99 \%$ of the mercury $i$ is reduced and pumped out of the SRAT along with 0.1 gallon of feed slurry per gallon of mercury to the Mercury Water Wash Tank.

- The deentrainment section of the SRAT should provide a DF of at least $10^{4}$ for entrained bottoms where

$$
D F=\frac{\text { Concentration in SRAT Concentrate }}{\text { Concentration in SRAT Condensate }}
$$

Slurry Mix Evaporation

- Assume fresh and spent frit additions to the SME give $65 \pm 7$ lbs of dry frit per 35 lbs of other solids in the SRAT batches. Assume the control and delivery system can add fresh frit as a slurry containing $60 \pm 2.5$ wt\% of frit.

- All frit slurry additions should be adjusted with 0.01 lb formic acid per lb of frit.

- The mercury from the SME condensate is transferred periodically to the Mercury Water Wash Tank. **Condensate is transferred to the Recycle Collection Tank. **

- The evaporated batch is nominally 40 wt \% solids with a maximum of 47 wt\%.

- The contents of the Slurry Mix Evaporator Condensate Tank must be maintained or capable of being cooled to below $50^{\circ} \mathrm{C}$.

- The deentrainment section of the SME should provide a DF of at least 104 for entrained bottoms where

$$
D F=\frac{\text { Concentration in SME Concentrate }}{\text { Concentration in SME Condensate }}
$$




\section{PART TITLE: PROCESSING FACILITIES BASIS}

ITEM TITLE: Sludge Slurry Receipt, Adjustment, and Evaporation

- $\quad * *$ Formic Acid Vent Condenser System

The formic acid vent condenser should operate at $15^{\circ} \mathrm{C} . \star \star$

- Operating Cycles

The following cycles assume three tanks, the Sludge Recelpt and Adjustment Tank (SRAT), the Slurry Mix Evaporator (SME) and the SME Condensate Tank (SMECT).

- Sludge Recelpt and Ad justment Tank (SRAT): a

- Receive batch of washed sludge slurry.

- Con 1

- Agitate

- Sample and analyze (6 hours)

- $* \star$ Concentrated cesium waste additions**

- Add formic acid solution

- Heat

- $* \star$ Boil six hours under total reflux**

- Cool

- Sample and analyze ( 4 hours)

- Transfer adjusted sludge slurry

- Perlodically transfer mercury to the Mercury Water Wash Tank.

- Slurry Mix Evaporator (SME):

- Recelve sludge slurry batch

- Recelve spent frit slurry batch

- Recelve fresh frit slurry batch

- Heat

- Evaporate excess water

- Cool

- Sample and analyze (6 hrs)

- Transfer batch

- Periodically transfer mercury to SRAT **(Provide pump flange, sump and services; pump will be installed as necessary) ${ }^{\star \star}$

- SME Condensate Tank (SMECT):

- Receive condensate continuously (during evaporation)

- Sample periodically

- Transfer batches as tank fills

- Perlodically transfer mercury to the Mercury Water Wash Tank. ** (Provide pump flange, sump and services; pump will be installe 1 as necessary. $)^{\star \star}$

The operating cycles may be revised as necessary to allow for preliminary evaporation of sludge slurry to $19 \mathrm{wt} \%$ in the SRAT before formic acid adjustment if the sludge slurry from the tank farm is dilute. The SRAT condenser therefore must be capable of diverting the condensate for removal or reflux. Removed condensate is routed to the SMECT.

a All vessels must be agitated continuously when they contain frit or frit and sludge slurry. 
PART TITLE: PROCESS FACILITIES

ITEM TITLE: Mercury Purification and Storage

Process Description

**Periodically, llquid mercury will be transferred from the Sludge Recelpt and Ad justment Tank to a Mercury Water Wash Tank in the process cell. Recovered mercury will be washed with water to remove entrained sludge slurry, formic acid and other contaminants accompanying the mercury. Mercury is transferred to the Mercury Purification Cell and washed with nitric acid to dissolve amalgamated metals. ${ }^{\star \star}$ A final scrub is provided by passing mercury countercurrently through packed columns with nitric acid and water scrub streams. Washed mercury is vacuum distilled, loaded into containers and stored before shipment to 200-H Area. Wash solutions are neutralized and disposed of to the waste slurry process.

Design Data

- General

Vessels should be sized to provide lowest capital cost and permit operation of the process to meet objective operating rates in Part 2, Item 105.

\section{- Mercury Transfer}

Assume that for each transfer of mercury 0.1 gallon of solution environment accompanies each gallon of mercury. Assume that each contaminant component accompanying mercury retains its chemical identity throughout the mercury purification process with the exception of formic acid and those contaminants that amalgamate with mercury.

The frequency of mercury transfers must be compatible with the capacity of the mercury collection sections in the Slurry Receipt and Adjustment Tank and the Slurry Mix Evaporator Condensate Tank.

- Operating Cycles

1. $\star *$ Mercury Water Was's Tank $* \star$

- Recelve mercury from the Slurry Receipt and Adjustment Tank and/or from the Slurry Mix Evaporator Condensate Tank.

- Add 3 gallons of water per gallon of mercury.

- **Mix for 2 hours with an air sparge of 1.3 scfm per $\mathrm{ft}^{2}$ of liquid surface. ${ }^{* *}$

- Settle for 30 minutes to separate phases. 
PART TITLE: PROCESS FACILITIES

ITEM TITLE: Mercury Purification and Storage

- Decant water wash and transfer to the Slurzy Receipt and Ad jus tment Tank.

- Transfer mercury to Mercury Acid Wash Tank in Mercury Purification Cell.

2. Mercury Acid Wash

- Receive water washed mercury from Mercury Water Wash Tank (MWWT).

- Wash mercury in the Mercury Acid Wash Tank by adding one part $12 \%$ nitric acid from the Mercury Acid Scrub Column to one part mercury by volume.

- Mix for 60 minutes.

- Settle for 30 minutes to separate phases.

- Decant acid wash and transfer to the Spent Wash Tank.

- Transfer mercury to the Mercury Feed Tank No. 1.

3. Mercury Acid Scrub

- Start $12 \%$ nitric acid flow from Acid Feed Tank to Mercury Acid Scrub Column. Spent acid discharges to the Mercury Acid Wash Tank.

- Start mercury feed from Mercury Feed Tank No. 1 to Mercury Acid Scrub Column. Use volume flow ratio of one part mercury to one part acid. Mercury discharges from the column to the Mercury Feed Tank No. 2.

- When mercury feed is complete, stop acid flow to Mercury Acid Scrub Column.

4. Mercury Water Wash

- Sample mercury in Mercury Feed Tank No. 2 to assure low contamination level for transfer from cell to hood area for the distillation and packaging operations.

- Start water flow from the Water Wash Feed Tank to the Mercury Water Wash Column. Spent water discharges to the Spent Wash Tank. 


\section{PART TITLE: PROCESS FACILITIES}

ITEM TITLE: Mercury Purification and Storage

- Start mercury flow from Mercury Feed Tank No. 2 to the Mercury Water Wash Column. Use a volume flow ratio of one part mercury to one part water. Mercury discharges to the Mercury Hold Tank.

- When mercury feed is complete, stop water flow to the Mercury Water Wash Column.

\section{Vacuum Distillation}

- Start vacuum still and feed mercury from the Mercury Hold Tank to the still.

- Condensed mercury will flow into mercury storage bottles. Periodically sample and analyze distillate to assure purity.

- When mercury feed has been completed, shutdown still. A portion of mercury feed will remain in the Mercury Feed Tank with contaminants.

6. Flushing Vacuum Still Bottoms

- Wash mercury remaining in the Mercury Feed Tank by adding one part $12 \%$ nitric acid to one part mercury by volume.

- Mix for 60 minutes.

- Settle for 30 minutes.

- Decant acid wash and transfer to the Spent Wash Tank.

- Rinse mercury by adding three parts water to one part mercury by volume.

- Mix 60 minutes.

- Settle for 30 minutes to separate phases.

- Decant water rinse and transfer to the Spent Wash Tank.

- Transfer mercury from the Mercury Feed Tank to the Mercury Feed Tank No. 1 for reprocessing.

7. Spent Wash Treatment

- Collect spent washes from the various wash and rinsing operations. 
DPSP $80-1033$

PART 5

ITEM 235

PAGE 4 of 4

DATE 9-82; Rev. 9

PART TITLE: PROCESS FACILITIES

ITEM TITLE: Mercury Purification and Storage

- Neutralize collected washes by adding 50\% sodium hydroxide.

- Agitate for 30 minutes.

- Sample and analyze for pH to assure neutralization.

- Transfer neutralized solution to the Slurry Mix Evaporator for processing with waste slurry.

3. Recovered Mercury Storage

- As mercury containers are filled, remove to storage area in process building. Provide storage area for 100 bottles.

- Periofically transfer filled containers to mercury storage building in 200-H Area. 
PART TITLE: PROCESSING FACILITIES BASIS

ITEM TITLE: Melter Feed

**Sections of DPSP 80-1033, Appendix H which apply to Melter Feed are listed below:

DWPF Sludge Feed Composition Salt Plant Product Composition Slurry Properties

Frit Characteristics Sludge Only Glass Canister Decay Heat Sludge Supernate Glass Canister Decay Heat
Table 21-1, Appendix $\mathrm{H}$ Table 21-2, Appendix $H$ Table 21-3, Appendix $\mathrm{H}$ Table 21-6, Appendix $\mathrm{H}$ Figure 21-7, Appendix $H$ Figure 21-8, Appendix $H^{*} *$

Process Description

The Melter Feed Tank (MFT) will receive the composite slurry from the Slurry Mix Evaporator. Agitation is required to keep the solids in suspension. Instrumentation for sampling, specific gravity, temperature, liquid level and high and low level alarms are also required. ** Sampling is required in the MFT to provide an accurate description of the chemical and radionuclide content of material going into the glass waste form. ${ }^{*} *$ This analysis will become a permanent part of each canister record. (See Part 6, Item 200.)

Provide two independent continuous feed ports located at opposite sides of the melter to simultaneously introduce the feed slurry close to the melt surface at low velocity. **The intent is to introduce feed as symmetrically as possible to avoid irregular cold cap buildup as demonstrated during PNL and SRL tests.** The feed loops will require continuous circulation to keep the solids in suspension with a take off to the feed ports. Flow through each line should be adjustable to prevent assymetrical cold cap buildup. (See Part 20, Item 230.)

Each feed loop should be able to provide the full flow rate in the event one loop is down.

A minimum velocity of $3 \mathrm{fps}$ is required to avoid solids settling.

**The feed lines should be flushable with pressurized water. During idling, water will be pumped through the feed lines to remove line deposits. Mechanical means for unplugging the feed lines may be required. Tests are planned to verify this.

For purposes of continuing design, provide for a water fog nozzle in the melter vapor space to cool the glass surface during idling. Flow rate is equal to norma! water feed rate. $* *$ 
PART TITLE: PROCESSING FACILITIES BASIS

ITEM TITLE: Melter Feed

Provide a transfer pump and piping to transfer out-of-specification inaterial back to the slurry mix evaporator. Permanent piping, rather than a jumper change, is preferred as occasional adjustments will be required due to difficulties in obtaining consistent samples in the slurry mix evaporator and melter feed tank.

**Abrasion resistant materials of construction are required for recirculation and transfer piping. Design of the recirculating feed loop should be of the heaviest wall pipe that can be fitted to standard connector components.

Provide for direct addition of frit slurry to the melter to permit periodic flushing of the melt volume. ${ }^{* \star}$ 
PART TITLE: PROCESSING FACILITIES BASIS

ITEM TITLE: Glass Melting

** Sections of Appendix $H$ which apply to Glass Melting are listed below.**

Vitrification Stoichiometry

Frit Characteristics
Table 21-4, Append ix $\mathrm{H}$ Table 21-6, Append IX H

The objective of the glass melting step is to use a liquid fed joule-heated melter to evaporate water from a slurry feed, melt borosilicate glass frit, and combine the melt with waste to form a homogeneous molten glass to be poured into canisters.

Design considerations for glass melting are:

- An instantaneous melting rate of at least $8 \mathrm{lbs} /(\mathrm{hr})\left(\mathrm{ft}^{2}\right)$ of melt surface. ${ }^{*}$ Lid heating may be required to obtain this rate.

- A nominal instantaneous melting rate of $2281 \mathrm{bs} / \mathrm{hr} . * *$

o A slurry contalning sludge and frit adjusted to a pH less than 7 is fed directly to the melter. The slurry contains approximately $40 \%$ total solids by weight.

- Design basis is Frit 131. Composition of the frit is shown in Table 21-6, Appendix $\mathrm{H}$. The recommended particle size range is greater than 325 to less than 80 mesh (44-177 microns).

o Assume that 1.0 wt\% of the feed components and frit are entrained in the melter off-gas.

- The off-gas temperature is to be controlled to $375 \pm 25^{\circ} \mathrm{C}$ at the of $f$-gas outlet from the melter by use of a water, steam or air injection.

- The melter bulk glass temperature is controlled to $1150^{\circ} \mathrm{C} \pm 20^{\circ} \mathrm{C}$ with a minimum glass temperature within the melter of $1050^{\circ} \mathrm{C}$.

o Special equipment design basis criteria for the melter is discussed in Part 20, Item 230. 
PART TITLE: PROCESSING FACILITIES BASIS

ITEM TITLE: Glass Melting

Semi-Volatiles Production

Component

- Ruthenium

- Cesium

- Chloridel Fluoride

- Boron

- Mercury

- Iodine

- Group $A^{a}$
100

$\underline{100}$

\section{$\%$ (Elemental)}

10

5

100

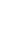

0.5 5
Reaction

$* *$ Volatilizes as $\mathrm{RuO}_{4}(v)$ and decomposes to $\mathrm{RuO}_{2}$ and $\mathrm{O}_{2}$ prior to the quencher. ${ }^{* *}$

Volatilizes as $\mathrm{Cs}_{2} \mathrm{O}(\mathrm{v})$ and reacts with $\mathrm{NaCl}$ to form CsCl prior to the quencher. $\mathrm{Cs}_{2} \mathrm{O}+$ $2 \mathrm{NaCl}=2 \mathrm{CsCl}+\mathrm{Na}_{2} \mathrm{O}$

Volatilize as sodium salts. $25 \%$ of the sodium fluoride hydrolyzes. $2 \mathrm{NaF}+\mathrm{H}_{2} \mathrm{O}=2 \mathrm{HF}+\mathrm{Na}_{2} \mathrm{O}$

Volatilizes as sodium metaborate $\mathrm{B}_{2} \mathrm{O}_{3}+\mathrm{Na}_{2} \mathrm{O}=2 \mathrm{NaBO}_{2}$ and polymerizes to $\mathrm{Na}_{2} \mathrm{~B}_{4} \mathrm{O}_{7}$. $4 \mathrm{NaBO}_{2}=\mathrm{Na}_{2} \mathrm{~B}_{4} \mathrm{O}_{7}+\mathrm{Na}_{2} \mathrm{O}$

Volatilizes as elemental mercury vapor. For material balance purposes, assume the $\mathrm{Hg}$ to oxidize completely to $\mathrm{HgO}$ prior to the quencher.

Volatilizes as NaI vapor. For material balance, assume $1 \%$ of $\mathrm{NaI}$ disassociates as $\mathrm{I}_{2}$ and leaves the melter in the off-gas.

Volatilize as oxide vapors and scrubbed as particulates.

${ }^{a}$ See Table 21-1, Appendix $\mathrm{H}$ for definition. 


\section{PART TITLE: PROCESSING FACILITIES BASIS}

\section{ITEM TITLE: Off-Gas Treatment}

The purpose of off-gas treatment is to reduce the radionuclide content of the melter of $f$-gas to a level which meets local, state and federal standards, and which is compatible with current cumulative releases from existing SRP facilities. The off-gas system consists of a series of equipment pieces designed to clean the melter off-gas. The principal unit operations consists of quenching the hot gas, removing entrained particles by filtration, condensing adsorbed water, heating, adsorbing ruthenium and iodine, cooling, and exhausting to a sand filter followed by stack discharge.

The formic acid treatment of the melter feed produces an oxygen deficient atmosphere. The of $f$-gas consists of non-condensables, particulates, and condensibles. One percent (1.0\%) of the feed components and frit are entrained in the melter off-gas, and are carried to the quencher.

Reactions assumed in the melter for the purpose of completing the material balances are outlined in Part 5, Item 255 and in Table 21-4, Appendix $H$. Volatilization characteristics of ruthenium, cesium, mercury, halides, sodium, and boron are summarized in Part 5, Item 255.

\section{Off-Gas Treatment}

- The melter off-gas temperature is to be controlled between $400^{\circ} \mathrm{C}$ at the melter exit and not to drop below $290^{\circ} \mathrm{C}$ at the quencher.

- The melter off-gas is cooled between $350-400^{\circ} \mathrm{C}$ at the exit point from the melter to minimize deposition in the off-gas plpe between the melter and quencher.

- The vapor temperature is reduced below the dew point to condense water vapor and coalesce semi-volatiles. The condensate is sent to the Recycle Collection Tank.

- The particulates are removed by two washed deep bed filters each consisting of two stages and are purged to the Recycle Collection Tank.

- The scrubbed vapor stream is heated above its dew point and passed through a silica gel bed to adsorb ruthenium.

- The vapor is heated further and passed through a silver mordenite bed to adsorb lodine.

- The exiting vapor stream is cooled to the required temperature for the off-gas exhauster, passed through a HEPA filter, the exhausters, then discharged to the sand filter. 


\section{PART TITLE: PROCESSING FACILITIES BASIS}

ITEM TITLE: off-Gas Treatment

\section{General Criteria}

Overall DF of Wet Scrubbing System (excluding adsorber beds \& HEPA filter)

- Particulates (from entrainment) - 106

- Semi-volatile reaction/condensing products - 104

\section{Cooling \& Quenching}

- Melter off-gas water spray is to reduce melter vapor temperature to 350 to $4000^{\circ} \mathrm{C}$. For flow sheet purposes, it is assumed that the temperature of the off-gas leaving the melter is $520{ }^{\circ} \mathrm{C}$ and that a water spray reduces the off-gas temperature to $3750^{\circ} \mathrm{C}$.

- Provide for elther air, water, steam, frit blasting or mechanically scraping to remove deposits in off-gas line. Quencher should be located as close as practical to the melter to minimize the length of line requiring cleanout. Off-gas line should exit the melter vertically to minimize entrainment.

- Quencher -- reduce of $E$-gas vapor temperature below the vapor dew point

- Off-Gas Condenser -- The maximum allowable temperature of the vapor leaving the off-Gas Condenser of the off-gas treatment system is $280^{\circ}$.

\section{Dilution Air}

- Minimum flow set to assure the carbon monoxide and hydrogen concentration in the melter of $f-g$ as beyond the quencher-scrubber is less than $70 \%$ of the lower explosive limit at $3 \mathrm{X}$ nominal melter of $f$-gas generation rate. No credit taken for melter or canister air inleakage. The lower explosive limit for $C O$ in alr is 12.5 vol \% C atmospheric pressure. The normal point of operation will be less than 25\% of the LEL. The lower explosive limit for $\mathrm{H}_{2}$ in air is 4 vol \%. Control air is added upstream of the off-gas quencher; dilution air is added at the discharge of the off-gas quencher.

- The melter pressure control system should be capable of handling periodic melter off-gas excursions up to seven times the average melter off-gas flow rate lasting a maximum period of 8 minutes*. Relief system should handle a $12 X$ surge in steam generation rate for 2.5 secs. without exceeding the seal pot setting of $1^{\prime \prime}$ W.C.

* $7 \mathrm{X}$ of $\mathrm{f}$-gas $\mathrm{f}$ low excluding air inleakage and purges. Duration at greater than or equal to $35 \%$ of peak helght $(2.5 \mathrm{X})$ is 1 minute. Total duration is 8 minutes. Data based on LSFM-5 and Frit 131 . 


\section{PART TITLE: PROCESSING FACILITIES BASIS}

ITEM TITLE: Off-Gas Treatment

- Assume an air inleakage of $20 \mathrm{lbs} / \mathrm{hr}$ to the melter, $401 \mathrm{bs} / \mathrm{hr}$ alr inleakage at the canlster vent, $40 \mathrm{lbs} / \mathrm{hr}$ air inleakage at the drain canister vent, a seal pot purge of $201 \mathrm{bs} / \mathrm{hr}$, and a TV camera lens purge of $20 \mathrm{lbs} / \mathrm{hr}$ for each camera. Additional control air is introduced upstream of the off-gas quencher. Air leakage plus control air will determine the amount of dilution air added to meet the $70 \%$ lower explosive 1 imit requirement.

\section{By-Pass System}

Since the off-gas treatment equipment is in series, replacement of off-gas equipment would eliminate the ability to exhaust the melter off-gas. Additional equipment is required to continue exhausting gases from the idling melter while equipment replacement in the main off-gas line is in progress. The by-pass system should permit the following repalrs or replacement while the melter is in the idilng mode:

- Quencher

- Equipment associated with the off-gas condensate tank or primary washed deep bed filter.

- The secondary washed deep bed filter, the filter pump tank, ruthenium adsorber preheater, ruthenlum adsorber, lodine adsorber preheater, lodine adsorber and of $f$-gas cooler. 


\section{PART TITLE: PROCESSING FACILITIES BASIS}

\section{ITEM TITLE: Canister and Overpack Components - Recelpt And Preparation}

The operations involved in receiving, storing, and inspecting canisters, inner and outer plugs, overpacks and overpack covers are shown in the Figures $5-3,5-4$, and 5-5, Appendix B.

\section{Receiving}

**Components are delivered to the service bullding either by truck or

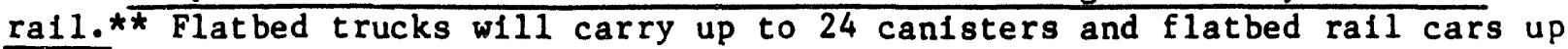
to 72 . Each canister will be fastened in a wooden shipping cradle about $3 \mathrm{ft} x$ $3 \mathrm{ft} \times 10 \mathrm{ft}$. Plugs will be received in boxes on pallets. On the loading dock canisters will be removed from the cradles, and protective covers will be removed from the nozzles. Each canister receives a cursory visual inspection for damage incurred during shipment or handling. Overpacks will be handled similar to the canisters. Depending on final design, overpack covers might be handled similar to plugs.

\section{Inspection and Storage}

All quality examinations for canisters and plugs are shown in Table 5-4, Appendix A. Included are tests and inspections to be performed by S-Area ** service bullding** personnel as well as, for information purposes, those performed by the vendor and by SRP laboratories. Recelved prior to each shipment will be a sample of metal from each melt and/or fabrication lot for laboratory analysis.

About $5 \%$ of the components from each shipment will be transferred directly to the inspection area for an audit of the vendor's certification. Following the audit inspections these components are transferred to storage. The remainder ( $95 \%$ of shipment) are transferred directly from the receiving inspection to storage. When a given lot has been released (based on the results of laboratory examinations and the audit inspection) components are removed from storage as needed. At the in-process inspection all components are inspected (see Table 5-4, Appendix A) for:

- cleanliness

- damage incurred in handling or storage and

- those specifications critical to operations in the process cells (alignment at the melter, welding, etc.).

At in-process inspection, solled components are hand cleaned. Those with minor surface damage are dressed, using hand tools, to meet specifications. Each canister and each overpack will be hand stamped with an Identifying number (in addition to the vendor's lot number) to provide a sequential number for SRP processing.

Outer plugs and overpack covers will have helium capsules attached for leak testing of the final canister or overpack closure just prior to shipping to a federal repository. No facilities for helium leak testing for final closures are to be provided on this project. The capsules are to be filled with helium, sealed, weighed, and leak tested to verify helium content just prior to use in the vitrification process. 


\section{PART TITLE: PROCESSING FACILITIES BASIS}

ITEM TITLE: Canister and Overpack Components - Receipt And Preparation

Plugs and overpack covers have no receiving inspection. They are given an audit inspection and stored. All components are examined at the in-process inspection prior to use.

Requirements for canisters and plugs are set forth in Part 20, Item 50. Those for overpacks and covers are in Part 20, Item 60.

Acceptance/rejection criteria for leak testing as-received canisters and overpacks is a leak rate of $1 \times 10^{-6} \mathrm{~atm}-\mathrm{cm}^{3} / \mathrm{sec}$ helium.

Rejected canisters and overpacks will be returned to the vendor, packaged as they were received.

Rejected plugs or overpack covers might be returned to the vendor or might be discarded as scrap, depending on quantities and/or reject cause.

Space requirements for component testing and storage are set forth in Part 11 , Item 305. 
PART TITLE: PROCESS FACILITIES BASIS

ITEM TITLE: Canister Handling

Facilities must be provided to transport canisters into and through the receiving, the filling and the containerization processes. These transfers are generally grouped as follows:

A) $* *$ Service Building - From receiving to inspection, storage, and then to the melt cell in the Process Building* $\star *$

B) Melt Cell - To storage, melter (both pour spout and freeze valve), cooling station, plug (inner) insertion, in-cell storage, and then to the canister decontamination cell

C) Canister Decontamination Cell - **To storage, temperature measurement, decontamination station $\# 1$ and \#2, smear station, and then to the weld test cell.**

D) Weld Test Cell - **To storage, welder, inspection/smear station, in-cell storage, radiation survey, and load-out area**

The sequence of operations is set forth in Figures 5-3 through 5-9, Appendix B.

Requirements for the transport systems are:

\section{General}

- Keep filled canisters in the vertical position until welded to avoid spilling contents.

- Normally, canisters will be processed, but provide capability for handling the larger size overpacks (needed on very infrequent occasions to enclose damaged or breeched canisters). Sizes of canisters and overpacks are set forth in Part 20, Items 50 and 60.

- Use of the canister transport systems for handing glass samples is acceptable. (Ref. Part 7, Item 400)

- Minimize contamination of canisters by the transport systems (e.g. minimum contact area, replaceable pads, decontamination of transporters, etc.)

- The design should incorporate features to minimize damage to the canisters. Examples of such features are:

- Minimizing the number of times a canister is grappled, handled, etc.

- Provide viewing for each operation where a canister is raised, lowered, or moved by remotely operated crane, except within the decontamination chamber. 
PART TITLE: PROCESS FACILITIES BASIS

ITEM TITLE: Canister Handling

- Minimizing potential for dropping, toppling, impact with equipment or structures, etc.

Operation

- Transport systems are to be controlled from the operating area (not the CCR )

- Methods are required for retrieval of canisters and/or carriers located inside cells or transfer tunnels in case of transport system malfunction. $* *$ (See Part 11, Item 105 for operation of transfer tunnels.)** A back-up system is required in the weld test cell to remove canisters to shielded storage should the primary transport system fail.

- Each system should be capable of returning canisters from any station or cell to the preceding station or cell.

Maintenance

- **Methods must be provided for maintenance or replacement of $t$ ransport system components located inside cells. (See Part 11, Item 105 for maintenance in transfer tunnels.) $\star \star *$ Materials of construction must be compatible with decontamination solutions. (See Part 14, Item 200)

- Where practical, drives for transport systems should be located in areas with acess to permit contact maintenance.

**Canister Grapple

A grapple for carrying canisters should meet the following goals:

$=$ Be the same for each cell ( $M C, C D C$, WTC).

$=$ Have minimum moving parts.

= Have no motors.

$=$ Have positive locking of the load.

$=$ Have easy visual verification of locking.

$=$ Be easily replaceable for other uses of the crane hook or other tools on the crane hook.

$=$ Work through minimum size openings transfer tunnels or decon chamber.

$=$ Minimize damage to canister grounding flange. (Consider soft grapple surface, e.g. Cu or bronze insert to prevent welding surface damage.) $^{\star \star}$ 
PART TITLE: PROCESSING FACILITIES BASIS

\section{ITEM TITLE: Canister Filling}

After melting of the frit and homogenization of the sludge oxides with the melted frit, the molten glass flows through the riser and pour spout. The glass temperature is kept between $1050-1170^{\circ} \mathrm{C}$ by means of riser and pour spout heaters. Pouring into a metal canister is accomplished by lowering the pour spout pressure with respect to the melter vapor space pressure. Normal melter vapor space pressure is approximately $745 \mathrm{~mm} \mathrm{Hg}$. The canister filling step describes the design criteria for pouring glass into a metal canister followed by ambient air cooling.

- The inside surface of the canister neck is to be protected from glass spills and condensation of volatile products from the molten glass stream. Protection is needed to facilitate insertion of the canister inner plug and to ensure a relatively clean surface for upset resistance welding of the final canister closure.

- For good glass flow within the canister, viscosity of the glass should be less than 500 poise. In order to achieve a smooth, uniform, relatively crack-free monolith, the glass is poured rapidly into the canister to ensure flow to the canister perimeter. The instantaneous glass production rate of greater than $228 \mathrm{lb} / \mathrm{hr}$ should ensure a perimeter viscosity of 490 poise which is equivalent to a temperature of $650^{\circ} \mathrm{C}$ for reference TDS composite sludge mixed with Frit 131.

- During the f 111 cycle and the first $1 / 2$ hour of cooling, the canister is vented to the off-gas system. After filling, the canister is allowed to cool for $1 / 2$ hour beneath the pour spout while still connected to the of $f$-gas system. Venting is required to contain the release of volatile radionuclides such as $137 \mathrm{Cs}$. The canister is then rotated from beneath the melter pour spout or drain valve on a turntable and loose fitting cover is placed on the canister nozzle. The canister is cooled by normal cell ventilation until the top surface center glass temperature is below the softening point of $5500^{\circ}$. This time period is 13 hours from the end of pour. The temperature of $550^{\circ} \mathrm{C}$ is the softening point of waste glass; in the unlikely event that the filled canister were to fall on its side, no glass would flow out. During further cooling to $550^{\circ} \mathrm{C}$, venting is to the cell atmosphere through the loose fitting cover. A tight fitting plug is inserted either while the canister is on the turntable or in the cooling rack.

- The partially cooled canister is then lifted from the turntable by the in-cell crane and placed in the cooling rack. The canister continues to slowly cool to cell temperature. The cooling process will require about 31 hours from the end of pour to $\mathrm{cool}$ the canlster surface to $100^{\circ} \mathrm{C}$. 


\section{PART TITLE: PROCESSING FACILITIES BASIS}

\section{ITEM TITLE: Canister Filling}

Samp11ng

The melt stream will require perlodic sampling. A sample volume of approximately 1 liter is required, filled at the instantaneous pour rate. (See Part 7, Item 400.) At a pour rate of $245 \mathrm{lbs} / \mathrm{hr}$ (See section below on Pour Rate.), the 1 liter sample will fill in $1.3 \mathrm{~min}$ and welgh 5.21 bs. For design purposes, assume a sample frequency of $1 \%$; $1 . e .5$ sample contalners per year.

Heat Load - The calculated thermal heat load per canister is approximately $20,000 \mathrm{pcu} / \mathrm{hr}$ over the cool-down cycle. If this heat load upsets ventilation when all covers are removed, an insulated shroud should be provided for each thermally hot canister.

Inner Plug Insertion - An Inner plug can be inserted Into canister neck any time after completion of the pour.

\section{Cantster Weight}

A glass welght measurement system with an accuracy of +15 ib is required to monitor the pour rate ani provide an independent means of establishing the glass level. Continuous welght monitoring is required at both the pour spout and drain valve locations. Alarm indicators are required just prior to fill, at $f 111$, and $1 f$ an overfill develops due to a process upset.

\section{Canister Glass Leve1}

Two Independent canister glass level detection systems are required with capability to establish the full canister glass level to $+1 / 2 \mathrm{in}$. One of these systems must have the capability to detect stalagmite formation. Fast neutron transmission and detection of waste glass radioactivity are recommended as candidate glass level detection systems. Specific requirements are as follows:

- Fill level is $91+1 / 2 \mathrm{ln}$. or $3260+15$ lbs. whichever occurs first.

- Two level detection systems are required at both the pour spout and drain valve locations.

- Both level detection systems should indicate start of fill, progression of f111, pref111, f111 and overfill if 1 t occurs. A sultable system for the pour spout and drain valve could be: 
PART TITLE: PROCESSING FACILITIES BASIS

ITEM TITLE: Canister F1lling

Level, in

3

15

30

45

60

75

90

91

Overf 111
Neutron Transm1s810n

$\mathrm{x}$

$\begin{array}{ll}x & \mathrm{x} \\ \mathrm{X} & \mathrm{x} \\ \mathrm{x} & \mathrm{x}\end{array}$

$x$

\section{Pour Rate}

The glass pour rate is dependent upon the canister change out time, as well as the glass production rate. For a canister filled with 3,26016 of glass at a rate of $228 \mathrm{lb} / \mathrm{hr}$, a total of 14.3 hours is required. However, assuming the canister change out time is 1.0 hours, a 13.3 hour fill cycle results in an average instantaneous glass pour rate of $245 \mathrm{lb} / \mathrm{hr}$.

\section{Canister Cooling}

The general philosophy in canister cooling is to cool as rapidly as practical from the pouring temperature down to $500^{\circ} \mathrm{C}$ to minimize devitrification, then cool to equilibrium temperature as slowly as practical to minimize cracking. Coolling studies are in progress at SRL. Until requi rements are determined, no special cooling equipment is required. SRL experimental data are shown in DPSTD-80-38-2, Part 10 , Items 320 and 325 for filling and in Items 330 and 335 for cooldown. 


\section{PART TITLE: PROCESS FACILITIES BASIS}

\section{ITEM TITLE: Inner Canister Closure (Melter Ce11)}

Filled cantoters are sealed with an inner closure to:

- prevent slurry or water from entering the canister during subsequent decontamination.

- contaln activity within the canister to minimize contamination of the Canlster Decontamination Cell and the Weld Test Cell.

Criteria for the Inner closure design and components are given in Part 20, Item 50 and Table 20-1, Append1x A. The sequence of operations is shown in Figure 5-3, Appendix $B$.

After canisters are filled and before they are sealed, it is necessary to verify that they will accept the inner canister closure and outer plug (1.e. the canister has not been overfllled to a helght that prevents the subsequent operations). Use of the two glass level detection systems will be acceptable provided their accuracy is adequate. An example of an alternative method would be a 80-no-go gage handled by manipulator or 1n-cell crane.

Following glass level verification, the canister nozzle is sealed to contaln volatiles. Seallng of the inner closure may be accomplished either on the turntable or at a separate station after the canister has cooled. Verification is required to ensure that the seal was properly accomplished. Examples of verification go-no-go gage, visual examination of plug position or configuration, etc.

As a basis for continuing design, a test (more positive than the verification method) is needed to determine that the seal is water tight before and after decontamination. A method is required to remove water from those canisters where the seal did leak. 
PART TITLE: PROCESS FACILITIES BASIS

ITEM TITLE: Canister Inspection/Glass Removal - Melt Cell

As a basis for continuing design, facilities are required to visually inspect canisters for adhering 8 lass and to remove the glass before the canisters leave the Melt Cell. 
PART TITLE: BUILDING REQUIREMENTS

ITEM TITLE: Fan House for Zone 2 Exhausters

Standard construction facilities are satisfactory for the exhausters for the Zone 2 operating areas within the process bullding. (See Part 11, Item 110.) The exhausters may be located outside if motors are properly weather protected, etc. 
PART TITLE: BUILDING REQUIREMENTS

ITEM TITLE: Control **Room Space - General

The function of this building space is to house the control operating mechanisms for the process cell. This space may be located in a standard construction building or in a seismic-tornado resistant building in order of priority established in Table 4-1, Appendix $A$. Neither the control room space nor its contents need survive a seismic or high wind event. It is preferable that this space be in a non regulated area. If it is located outside, local control options are to be provided inside the process building. The process building is not to be enlarged to accomodate control room space.

The control room space will be utilized on a four-shift, seven day per week basis. Personnel assigned to the control room space are listed in Tables $10-1$ and $10-2$, Appendix A.** 
DPSP $80-1033$

PART 11

ITEM 605

PAGE 1 of 1

DATE $5-81$; Rev. 6

PART TITLE: BUILDING REQUIREMENTS

ITEM TITLE: Control **Room Space --Design Criteria

The control room space is to be temperature and humidity controlled where computers and hardware are located. Rooms separate from the computers are to be comfort conditioned as specified in Reference $c-12$, Appendix $C$. Energy conservation should be considered.

Floors are to be vinyl sheet or tile except for the conference room. The conference room should be carpeted. The computer floor is to be raised for services.

Ceiling is to be suspended acoustical panels with fluorescent lighting with emergency lights for continuity of operation.

Fire detection and supression is specified in Table 18-2, Appendix A. ** 
PART TITLE: BUILDING REQUIREMENTS

ITEM TITLE: **Control Room Space -- Space and Services Requirements**

Provide space for **the following: **

- Central computer and data processing hardware

- Central control console

- w*Supervisory control console

- Power control console

- Remote crane control console

- **Health Protection computer room

- $10^{\top} \times 10^{\prime}$ lockable fireproof storage room

- Office or segregated space for supervisory personnel and clerk as specified in Table $10-1$, Appendix A

- Rest room requirements as shown in Table 10-2, Appendix A

- Conference room to seat 20 people - audiovisual aids and furniture are isted in Table 16-1, Appendix A

- Lunchroom sized to seat 30 people - equipment is listed in Table 16-1, Appendix A

- Janitors closet

- EdI shop as stated in Part 14, Item 450

- A combined reproduction room and supply room** 


\section{PART TITLE: BUILDING REQUIREMENTS}

ITEM TITLE: Miscellaneous Weather Protection and Control Buildings

Provide $*$ space at scattered locations for storing supplies and for occasional use as office space by roving operators. These facilities are not to be air conditioned. $* *$

Depending on the site plot plan, the S-Area functions that may require weather protection include, but are not limited to, the following:

- **Local instrument control stations**

- Chemical treatment facilities for S-Area water supply

- **Industrial waste treatment facilities**

- Health Protection monitoring instrumentation installed in water lines

- Shelter at employee parking lot

- Rain water protection facilities as required at cold feed preparation areas

- **Electrical substation facilities**

In general, these buildings should be consistent with the intended purpose of the building. Some buildings may require freeze protection but comfort conditioning is not required. Lighting should be controlled locally. 
PART TITLE: HEALTH PROTECTION AND RADIATION MONITORING

ITEM TITLE: Facilities Requirements

\section{General}

Monitoring of employee and public exposure to radiation, and radioactivity releases should be provided by an adequate system of monitoring (a) employees for personnel contamination, (b) monitoring radiation in employees work area and (c) monitoring of airborne and aqueous radioactivity releases, (d) additional personnel monitoring for hazards associated.with industrial hygiene as determined by procedures.

This item defines the space requirements for the Health Protection employee monitoring program. Requirements for installed radiation and radioactivity monitoring are discussed in other items.

\section{Facility Requirements Criteria}

Provide a Health Protection Monitoring Area close to the regulated change rooms and the main building entrance to the vitrification facility. The Health Protection monitoring area should consist of the following:

- **A computerized data processing center is required with dual CRT's and printers, disk storage, a microfilm station for record documentation, selectable recorders ( $5 \%$ of total continuously monitored sites), dedicated exhaust stack activity recorders, and discard water activity recorders, and an audio/visual alarm panel. Should the main frame computer location be away from the HP facility, a CRT, recorder and disk storage should be provided at the main frame. The system should have uninterruptable power supply. ${ }^{\star \star}$

- A personnel decontamination room, approximately 9- x $12 \mathrm{ft}$, equipped with a shower, and a sink. The shower and sink drains should go to the floor drain catch tank in the process building and not to sanitary sewage.

- An instrument decontamination and storage room, approximately $9 \times 12 \mathrm{ft}$, equipped with a hood, sink with hot and cold domestic water. Sink and hood drains should go to the floor drain catch tank in the process building. The room should contain lab benches and shelves. The hood will require $1501 \mathrm{fm}$ air flow face velocity at full face opening.

- A laboratory, approximately $9 \times 12 \mathrm{ft}$, equipped with a hood; sink with hot and cold domestic water, distilled water and drain to floor drain catch tank. This laboratory will be used for the preparation of samples for analysis. The hood will require 150 ifm air flow face velocity at full face opening. 
PART TITLE: HEALTH PROTECTION AND RADIATION MONITORING

\section{ITEM TITLE: Facilities Requirements}

- A counting room, approximately $20 \times 20 \mathrm{ft}$, equipped with instrumentation for counting health Protection samples. This room should be located so that the background radiation does not exceed $0.02 \mathrm{mr} / \mathrm{hr}$ and may require shielding walls to achieve this level of background radiation. Provide a source of stable electrical power without interference from equipment.

- Offices for Health Protection personnel as shown in Tables 10-1 and 10-2, Appendix A.

- All regulated Health Protection facilities are to have:

a. Recessed fluorescent lighting except in Health Protection counting room provide incandescent 1 ighting

b. Sheet vinyl or equivalent floors with sanitary corners and joints sealed.

c. Smooth walls that are easily decontaminated

d. Sufficient electrical outlets for portable laboratory instruments and equipment with instrument power. Emergency power for each area will be required to maintain $25 \%$ of operating equipment.

In addition to the above space requirements, floor space will be required at the change room entrance exit for Health Protection hand and foot counters and at exits from selected work areas for location of Health Protection personnel survey instruments. 
PART TITLE: HEALTH PROTECTION AND RADIATION MONITORING

ITEM TITLE: **Installed Health Protection Radiation Monitoring Instruments**

Beta-garma dose rate monitors should be installed at selected locations in the processing building to provide warning of radiation level. Specific locations and numbers will be defined by SRP after layout of the processing facility. Table 12-1, Appendix A provides general guidelines for purpose of estimating number of instruments required.

All of these installed instruments should be interfaced to the Health Protection Monitoring Console in addition to providing visible and audible local alarms. 


\section{PART TITLE: HEALTH PROTECTION AND RADIATION MONITORING}

ITEM TITLE: Installed Air Monitoring Instruments

**Air sampling and monitoring instrumentation must be installed in many work locations and gaseous release locations to (a) determine the quality of air that employees breathe, (b) quantity and type of radionuclides released to the environment and (c) the source of airborne radioactivity. ${ }^{\star \star}$ Specific locations and numbers of installed monitoring instruments will be determined by SRP after layout of the processing facility. General guidelines for the purpose of estimating the required instrumentation are provided in Table 12-1, Appendix A. Additional guidelines are given below:

1. **For the processing building exhaust stacks, provide a redundant representative air sampling system. ${ }^{*}$ Continuous monitoring systems for both alpha and beta-gamma activity are required to determine the type and quantity of radionuclide released. * In addition, sampling and monitoring systems for iodine- 129 and tritium are required. ${ }^{\star \star}$ Redundancy in the sensing instrumentation is not required. Sampling equipment must be on emergency power, see Part 13, Item 560 . Samples will be analyzed in 221-s Health Protection counting room described in Part 12, Item 100.

2. A method of sampling the air in certain process areas is desirable. Conceptually, this would consist of a sample tap, and a portable sampler on a cart. The air, after sampling, should be discharged to the original air space. These sampling locations would be used to locate specific sources of high air activity when installed monitors indicate a problem. Suggested locations for this type installation are as follows:
a. **Four samplers are required in the chemical process cell.**
b. In weld test cell.
c. $\star \star$ After each HEPA filter associated with samples and mercury cells.
d. Before and after filter in vessel vent system.**
e. In the remote and contact decon cells.
f. In melter cell.
g. Canister decontamination cell. 
PART TITLE: HEALTH PROTECTION AND RADIATION MONITORING

ITEM TITLE: Installed Air Monitoring Instruments

3. ** Sampling and monitoring is required for exhaust air from each of the two divisions of the vault storage area, ${ }^{\star \star}$. If radioactivity is detected, the air should be diverted to a HEPA filtration system. If filtered air from the HEPA system bypasses the regular exhaust stack from interim storage, then a representative sampling and monitoring stream must be provided downstream of the HEPA filters. Sampling of air around a canister prior to removal is required. The monitoring system must ensure that current RCG valves as set forth in Reference C-10, Appendix $C$ are not exceeded.

4. For representative sampling of exhaust streams, see ANSI N. 13.1 American National Standard Guide to Sampling Airborne Radioactive Materials in Nuclear Facilities.

The above monitoring instruments should be interfaced to the Health Protection monitoring console. Local alarms will be required in operating areas. The Health Protection wiring/cable from outlying locations is to meet wiring codes, but does not have to withstand earthquake and tornado design criteria. 
PART TITLE: HEALTH PROTECTION AND RADIATION MONITORING

ITEM TITLE: Installed Liquid Monitoring Instruments

Radioactivity monitoring instruments will be required in various aqueous streams that are normally free of radioactivity but potentially may become contaminated.

Aqueous monitoring instruments should be provided as required to provide early detection of releases.

Aqueous monitoring instruments will be required in the following locations:

1. Storm sewer effluent from the vicinity of potentially contaminated outside areas (i.e. pump pits) if the facility is not protected from rainwater.

2. Process cooling water system (circulating closed loop)(Part 5, Item 400).

3. Melter cooling water system (Part 5, Item 402).

4. Process steam system steam condensate from process vessels (Part 5, Item 405).

5. Regulated chilled water refrigeration system (Part 5, Item 410).

6. Effluent from the $*$ sanitary** sewerage cleanup if release is on continuous basis.

The above instruments should be interfaced to the Health Protection monitoring console in addition to providing local alarms. 


\section{PART TITLE: HEALTH PROTECTION AND RADIATION MONITORING}

ITEM TITLE: Environmental Monitoring Wells

Wells must be provided for obtaining water samples for detecting and monitoring any inadvertent releases of radioactivity from the various confinement structures to the ground. Criteria for locating and constructing the wells are specified below:

1. Provide a pair of wells at each end of each construction joint in the vitrification building ( 4 wells per construction joint).

2. The wells should be located as close as practical to the walls of the building (about 10 feet). *tsince outer perimeter buildings may be covering area at the process building construction joint, design these buildings to allow access to the wells for sampling. ${ }^{\star \star}$

3. Each pair of wells should contain a shallow well and a deep well.

4. The shallow well should penetrate to the top of the foundation mat for the vitrification building. It should be screened for 10 feet above the foundation mat.

5. The deep well should penetrate to the water table and be screened for 20 feet. The midpoint of the screen should be located at the midpoint of the water table fluctuation.

6. A single deep well should be provided at each pump pit. The well should be as close as practical to the pump pit and should be similar to the deep well of the vitrification building.

7. Four-inch O.D. schedule 40 PVC is recommended for casing the well. Slotted schedule 40 PVC screen can be used for the well screen.

8. The annular space around the casing should be filled with gravel to a point just above the well screen. Annular space above the gravel should be filled with grout to prevent surface drainage into the well.

9. The well should be capped. No installed instrumentation or sampling equipment is required. 
PART 13

ITEM 100

PAGE 1 of 1

DATE 1-82; Rev. 8

PART TITLE: UTILITIES

ITEM TITLE: Availability From Present Sources -- All Utilities

** Steam will be available from the plant system via a new pipeline from Hto S-Areas. ${ }^{* \star}$ New facilities are required to provide electricity, water, compressed air, refrigeration and sewage treatment. 


\section{PART TITLE: UTILITIES}

ITEM TITLE: Electrical Power

Provide electrical power to S-Area by construction at necessary lines, substations, etc. and connecting to the existing SRP electrical system. 


\section{PART TITLE: UTILITIES}

ITEM TITLE: Steam - Design Basis and Criteria

Steam is required for building and process heating and operation of auxiliary equipment.

* Steam will be supplied by pipeline from H-Area. The demand is currently estimated to be $36,000 \mathrm{lbs} / \mathrm{hr}$ of 300 psig steam.** The tie-in point for the S-Area steam supply 1 ine may be at coordinates N71835 and E62617.

Steam reducing valves will be required at various locations to reduce the steam pressure for the user location. At any location where a steam outage may significantly impact on the production throughput (attainment) consider providing parallel reducing stations. Reducing stations should be protected from the weather as necessary to minimize freezing problems.

Within the vitrification processing building, steam lines will be required to deliver steam to the various process operations. Where feasible and economical to do so, the steam supply lines should be "looped" to minimize outages from repair work.

Condensate from $H \& V$ systems will be used as process water (See Part 13, Item 130) for cold chemical makeup and other process uses. Excess condensate may be discarded to the storm sewer.

Condensate from process equipment should be collected, analyzed and disposed of as described in Part 5, Item 405. 
PART TITLE: UTILITIES

ITEM TITLE: Water Systems needed:

The following water systems (see Figure 13-1 and 13-2, Appendix B) w111 be

Raw Well Water

Neutrallzed Well Water

Fire Water

Domestic Water

Process Water

Melter Cooling Water

Process Cooling Water

Regulated Chilled Water

Cooling Tower Water

Chilled Water

Raw Well Water

Raw well water will be from deep wells (see Part 13, Item 300) and w111 be the primary source of water for all the water systems except the process water system. It serves as exergency cooling water for the cooling tower side of the melter, process and regulated chilled cooling water systems, for air compressors and for the computer room alr conditioner condenser. The well water pumps should be driven by comblnation of electric and diesel drives.

\section{Neutrallzed Well Water}

Neutralized well water will be degassed and $\mathrm{pH}$ adjusted raw well water and will supply water to all other water systems and it will serve as a backup supply for the process water system. Neutrallzed well water w111 serve as dilution water in chemical makeup for water treatment. Neutralized well water should be supplied from a portion of the neutralized well and fire water tank. One of the neutrallzed water pumps should be on emergency power.

\section{Fire Water}

Fire water will be neutralized well water and will share the same storage tank with neutrallzed water. Flre water storage should provide a two hour supply of water for the largest fire anticlpated. The neutralized water pump should not be able to reach the fire water reserve. DOE requires that a second fire water source tank with sufficient capacity to supply water for an additional one-half hour be. provided in addition to this primary tank (See Part 18, Item 620). Th1s secondary f1re water should be supplied from the most: cost effective system (elther from H-Area or from a shared domestic water tank). Fire water pumps should be driven by combination electric and diesel drives. 
PART TITLE: UTILITIES

ITEM TITLE: Water Systems

\section{Domest1c Water}

Domestic water will be chlorinated neutralized well water and should be ifmited to drinking and sanitary purposes. Do not connect domestic water to the process or any potential source of contamination. Domestic water should provide washdown water through hose connactions in non-regulated areas of the main processing bullding and in all areas of other area buldings. One of the domestic water pumps should be on emergency power.

\section{Process Hater}

Process water will be primarily steam condensate from heating and ventilating and nonradloactive process users. Steam condensate from process equipment handling radioactive materials may be used as process water after laboratory analysis has verifled that the condensate is not contaminated with radioactivity (see Part 5" Item 405). Process water will be used for all cold chemical and cell chemical makeup for process uses, make up to the closed loop cooling system and as washdown water in regulated areas of the main processing building.

Melter, Process, \& Regulated Water

Melter cooling water 18 used to cool the melter and part of its off-gas system (Part 5, Item 402).

Process coollng water is used to cool all process vessels containing radioactive materlals (Part 5, Item 400),

Regulated chilled water is used to cool parts of the melter off-gas system (Part 5, Item 410).

Central refrigeration facilitles for heating and ventilating systems (Part 13, Item 600).

The above closed loop water clrculating systems will be made up from process water; disposal of purged water is described in Part 5, Item 400 .

\section{Cooling Tower Water}

Cooling tower water 18 made up when necessary from neutralized water. It will be chlorinated after it is added to the circulating system. Purged water must be treated to destroy chlorine before discard to the environment. 
DPSP $80-1033$

PART TITLE: UTILITIES

ITEM TITLE: Water Systems

Chilled Water

Chilled water is used for cooling non-process equipment (mostly heating and ventilating) to temperatures lower than those attainable with cooling tower water.

\section{Regulated Chilled Water}

Regulated chilled water is used for cooling process equipment (mainly condensers) to temperature lower than those attalnable with cooling tower water.

See Part 13, Item 560 for emergency electrical power requirements. 
DP'SP $80-1033$

PART 13

ITEM 300

PAGE 1

DATE 11-80; ReV 4

PART TITLE : UTILITIES

ITEM TITLE: Water Supply and Storage

Water should be supplied from at least two deep wells by well pumps with combination electric and diesel drives. The pumps should discharge to a common header to water treatment facilities and the various water systems or system storage tanks. See block diagram, figure 13-1 and Part 13, Item 130. 
PART TITLE: UTILITIES

\section{ITEM TITLE: Water Treatment}

A water treatment bullding with facllitles for water analyses and the necessary chemical treatment equipment should be located near the water storage tanks or basins.

** Raw well water will be degassifled to reduce the $\mathrm{CO}_{2}$ content to less that $5 \mathrm{ppm}$ and then adjusted with sodium hydroxide to a $\mathrm{pH}$ of about 7 to yleld neutrallzed well water. This water will be used as make up to the cooling towers and will be the primary flre water supply.

Neutralized well water used for domestic water should be chlorinated to a residual chlorine content of 0.5 to $1.5 \mathrm{ppm}$ and then stored in a domestic water tank. **

If sufficient steam condensate is not avallable for process water needs, neutrallzed well water should be supplied as a backup supply of process water.

Sodium hypochlorite should be used as the source of chlorine for all water treatment systems.

Water treatment systems should be provided to feed:

1. sodium hydroxide solution to degassed well water.

2. sodium hypochlorite to neutrallzed well water and to the cooling tower basin water,

3. **sodium blsulfite to purged coollng tower basin water prior to disposal.

Sodium hypochlorite and sodium bisulfite will be supplied from drums with at least one dedicated metering pump for each treatment point and one Installed spare pump. ${ }^{\star \star}$ 


\section{PART TITLE: UTILITIES}

ITEM TITLE: Cooling Tower

**Two cooling towers with circulating water systems will be required, one to provide cooling for the process, and another for air compressors, refrigeration equipment and other non-process equipment. ${ }^{\text {t }}$

Process cooling will be via the heat exchangers in the closed-loop process cooling water system. Water circulating through the cooling tower will be isolated by the heat exchangers from water circulating through process equipment. See Part 5, Item 400.

Studies were undertaken recently at SRP to find ways to save energy in plant cooling tower systems. The following recommendations were made and are planned to be followed by the plant:

1. Cooling tower fans should be capable of operating at zero, half or full speed and be automatically controlled by water supply line temperature for minimum fan energy usage.

2. The tower water supply and return pumps should be automatically controlled, based on changes in supply line pressure to minimize the number of pumps running and the average line pressure pumped against.

Unless other more energy efficient and cost effective designs can be conceived, these recommendations should be applied to DWPF design. 


\section{PART TITLE: UTILITIES}

ITEM TITLE: Electrical Power Supply

A primary substation should be supplied with dual feeders from the plant $115 \mathrm{kV}$ transmission system on the primary side and dual $13.8 \mathrm{kV}$ distribution on the secondary side. The substation should be capable of supplying all of the normal load and switching that allows either transformer or supply line to be taken out of service for maintenance without curtailing production.

The primary substation should be connected to the plant supervisory control system **and include remote controls/indications at the 751-A dispatcher office, 221-S CCR and local controls/indications at the primary substation as shown in Tables $6-1$ and $6-2$, Appendix $A_{.}{ }^{* *}$

Secondary substations should be supplied primary electrical power at $13.8 \mathrm{kV}$ from the primary substation. Each substation should be dual feed from two $13.8 \mathrm{kV}$ supply feeders, one for the normal and one for alternate supply. Each feeder must have the capacity to carry the complete substation load. Appropriate breakers, switches and protective devices should be supplied.

Three-pole structures should be used at turns in the $115 \mathrm{kV}$ transmission system. Underground distribution lines are preferred if economically feasible. 
DPSP $80-1033$

'PART 13

ITEM 550

PAGE 1 of 1

DATE 5-81; Rev. 6

PART TITLE: UTILITIES

ITEM TITLE: Electrical Distribution Facilities

A dual $13.8 \mathrm{kv}$ distribution bus should be supplied with the main and alternate feeds for a substation, $* \star$ feeder 8 to be routed in separate raceways if installed overhead.**

**Provide a minimum of $25 \%$ spare duct banks for each voltage level if installed underground *** 
PART TITLE: UTILITIES

ITEM TITLE: Emergency Electrical Power - Design Basis Criteria

The general philosophy 18 to provide emergency electrical power to systems which must operate during a power fallure. The requirement may be for personnel protection, equipment protection, or protection of the environment.

The following 18 a list of critical loads which are to be connected to emergency power:

- Emergency lighting

- Elevators

- Instrumentation and control power, regulated voltage

- Central control computer system

- Process coollng water pump

- **Neutrallzed water pump

- Domest 1c water pump**

- All cell cranes

- Cell crane lighting

- TV monftoring system on the process cell crane

- **TV monitoring system in remote cel1**

- Regulated chilled water pumps and associated refrigeration machine

- Cooling water pumps serving melter

- **Coollng water delay tank pumps ${ }^{* *}$

- Off gas system exhausters - melter

- Process vessel vent system exhausters

- Off-gas system quencher pump - melter

- Melter dump - canister handling system

- Melter spout vacuum jet pump

- Slurry recelpt \& adjustment tank agitator

- Process frit slurry feed tank agltator 
DPSP 80-1033

PART 13

ITEM 560

PAGE 2 of 3

DATE 9-82; Rev. 9

PART TITLE: UTILITIES

ITEM TITLE: Emergency Electrical Power - Design Basis Criteria

- Slurry mix evaporator tank agitator

- Melter feed tank agttator

- Decon frit slurry feed tank agitator

- **Decon chamber ggitation system**

- Spent frit hold tank agitator

- Main electrodes - weiter

- Exhaust fans, sample and mercury recovery cells

- $\star \star$ Exhaust fans, weld test cell ${ }^{* \star}$

- HEPA filter exhaust fans, glass storage

- ** Pour spout r1ser, and drain valve heater - melter ${ }^{*}$

- Battery chargers (total)

- Diesel generator auxiliaries

- Emergency condensing unit for HP computer

- Emergency alr-handling unit for HP computer

- Electrical and Instrument control area (vitrification building) supply fans

- Electrical and Instrument control area (vitrification building) exhaust fans

- Sand f1lter exhaust fans, See Part 6, Item 500 for emergency power criteria

- HEPA f1lter exhaust fans, See Part 6, Item 500 for emergency power criteria

- Computer room equipment:

- Supply fans

- Return fans

- ChIller

- Pump

- $25 \%$ of the 120V AC outlets in the Health Protection lab and counting room 
PART TITLE: UTILITIES

ITEM TITLE: Emergency Electrical Power - Des1gn Basis Criterla

- **Instrumentation and Health Protection monitors at pump pits and diversion boxes.

- Health Protection computer and monftoring system

- Communications and alarm systems

- Patrol headquarters

- Perimeter fence lighting

- Lights at guard station

- Primary Filters Pump (Off-gas System)

- Secondary F1lters Pump (Off-gas System)

- ** Instrument/Plant air compressors.** 
PART TITLE: UTILITIES

ITEM TITLE: Central Refrigeration Facilities

Central Refrigeration Facilities should provide refrigeration and chilled water to supply buildings that can be economically served by a central installation rather than individual systems. This item only deals with heating and ventilating refrigeration.

Provide the number and size of water chillers necessary to allow conservation of energy by minimizing the number of units on line and the volume of circulating chilled water during periods of low chilled water demand. 
PART TITLE: UTILITIES

ITEM TITLE: **Compressed Air -- Instrument, Plant and Breathing

Compressed air will be required for instrument/plant uses and personnel breathing air.

All compressors must be heavy duty, non-lubricated, electric motor driven units. $\star \star$ Emergency backup must be provided for breathing and instrument/plant air systems. Air compressors may be located in standard construction facilities except for the emergency backup instrument air system which must be located within the seismic structure. ${ }^{\text {th }}$

Specific design features of the air systems are as follows:

Breathing Air

Compressors used for breathing air must be non-lubricated with intakes located to avoid entry of air containing hazardous contaminants and with a discharge pressure to provide a supply pressure of 100 to 120 psig at the stations. The system muat be separate from all other compressed air systems. The air must meet the requirements for Grade E breathing air as described in Compressed Gas Association Commodity Specification G-7.1-1966 as follows:
Oxygen
Carbon dioxide
Carbon monoxide
Hydrocarbon vapors
Odor

- 19 to $23 \%$

- 500 ppm maximum

- 10 ppm maximum

- $5 \mathrm{mg} / \mathrm{m}^{3}$ maximum

- none

Additional SRP requirements are:

$\begin{array}{ll}\text { Moisture } & -0.5 \% \text { maximum } \\ \text { Other gases - inert } & -1 \% \text { maximum } \\ & - \text { none } \\ \text { Particulate matter } & - \text { none }\end{array}$

The system should be sized to accomodate 8 persons at one time with each person having $20 \mathrm{scfm}$ available.

Each breathing air station consists of a distribution manifold equipped with a filter, pressure gage and individual valves at each outlet hose connection. Breathing air stations and the required number of outlets at each are to be in clean areas located adjacent to the following areas: 
PART 13

ITEM 650

PAGE 2 of 3

DATE 9-82; Rev. 9

PART TITLE: UTILITIES

ITEM TITLE: **Compressed Air -- Instrument, Plant and Breathing**

Station

- Contact decontamination cell

- Process equipment repair shop

- Regulated Machine Shop/Regulated E\&I Shop \#1

- Weld test cell entrance

- Crane maintenance area

- Both sides of process cell on second level

- Air locks at each in-cell caniater transfer tunnel ( 4 locations)

- Entrances to crane bus bar runway (est 3 locations) $\frac{\text { outlets }}{3}$

5

2

3

4

3 each

2 each

2 each

As required by design, provide a means to route breathing air hoses through doorways without crimping the hose (See Project S-1748).

Alarms indicating loss of breathing air supply should be visible or audible to the persons using the air, or some other means of warning must be provided.

Breathing air for other locations in the vitrification building and other area locations such as the fan house, sand filter, glass storage building, etc. may be serviced by portable cylinder carts or a portable compressor if necessary.

The breathing air compressor should be backed up by sufficient $300 \mathrm{ft}^{3}$ compressed breathing air cylinders to provide a 10 minute supply of air for escape. These cylinders must be located within the seismic structure.

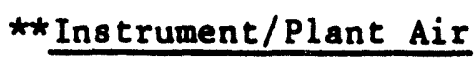

The instrument/plant air will be supplied by three identical water-cooled 750 scfm compressors. These compressors will be located in the seismic structure, cooled with emergency well water, and will be supplied with emergency power (see Part 13, Item 560). Other requirements are as below.** 


\section{PART TITLE: UTILITIES}

ITEM TITLE: **Compressed Air -- Instrument, Plant and Breathing**

Instrument Air

Instrument air should be provided at about 100 psig at the compressor. The air should be as oil free as possible, but not to exceed $1 \mathrm{ppm}$ oil. The required maximum dew point is $20 \mathrm{~F}$ as specified by Standards RIOON and H6P. A lower dew point is acceptable providing there is no cost penalty. A dessicant dryer will be required. The system capacity should be at least $10 \%$ greater than the anticipated total connected load.

$\star *$ Plant Air

The plant air system will be supplied at 100 psig. The system capacity will accommodate sparging $30 \%$ of the vessels that have air spargers at 50 scfm/sparger at any one time. ${ }^{\star \star}$ 
DPSP $80-1033$

PART 13

ITEM 700

PAGE 1 of 1

DATE 7-81; Rev. 7

PART TITLE: UTILITIES

ITEM TITLE: Sanitary Waste Treatment/Sewers/Disposal

A. Sanitary Sewers

Function

To provide for secondary treatment of sanitary waste.

Process

Secondary treatment for the biological and chemical treatment of sanitary waste should be provided by a packaged extended aeration waste treatment plant sized to serve the expected area population (See Part 10, Item 100). Assume a load of $* * 50 * *$ gallons per person per day. $* * A$ Clow Treatment Plant should be specified because there are presently 8 units on plant with 5 more on order. The same personnel and spare parts will serve all units. Design for $25 \%$ expansion over the expected area population and round off to the next higher 1000 gpd unit. $x^{*} x$ An influent surge basin with an 8 -hour capacity should be provided to allow for uniform loading of the treatment plant.

Accumulated sludge should be removed $* *$ by off-plant contractors and disposed of on the SRP site in existing land fill areas. ${ }^{* *}$ Liquid effluents must be chlorinated with sodium hypochlorite before disposal $* *$ to Four Mile Creek via the existing line from H-Area to Four Mile Creek. ***

All discharges must be monitored and sampled as required by the NPDES permit. A small building should be provided for chemical treatment equipment, sample analyses, and instrumentation. See Part 8 , Item 220 for discharge limits.

B. Storm Sewers

Function

To provide a system for collection and disposal of runof $f$ storm water.

Process

Systems will be required to handle storm water that is uncontaminated. $* *$ The uncontaminated water may be discharged directly to the environment.

Radioactively or chemically contaminated areas should be protected from rainfall with suitable walls and roofs so that runoff requires no treatment prior to disposal. Any rainwater which should happen to enter contaminated areas must be discarded in the same manner as other potentially contaminated solution from those areas. Disposal would be through the Recycle Collection Tank (Part 5, Item 445) or the Chemical and Industrial Waste Facility (Part 5, Item 460).*** 


\section{PART TITLE: MAINTENANCE REQUIREMENTS - SHOPS}

ITEM TITLE: Equipment Receiving and Inspection

Equipment purchased for initial installation in the processing cell of the processing building should be purchased to specifications which will provide reasonable assurance of proper fit in the process cell. Temporary equipment must be provided to inspect and verify that equipment received at SRP from a vendor has been fabricated to the required tolerances, specifications, macerials, etc., and to measure "as built" dimensions. These records are required for field fabrication of jumpers and subsequent replacement of failed process equipment. Final checkout of this remotely installed equipment and piping should be performed in the main process building during installation. 


\section{PART TITLE: MAINTENANCE REQUIREMENT - SHOPS}

\section{ITEM TITLE: **Process Equipment Decontamination and Maintenance Cells**}

Failed process equipment must be decontaminated prior to removal to the process equipment repair shop. $\star *$ Cells for remote and contact decontamination plus an air lock entry into the contact decontamination and maintenance cell will be required.

The function of the two cells is to provide a location for decontamination and repair of highly contaminated failed process equipment. ${ }^{\star *}$ The interior of the equipment will be cleaned by circulating decontamination chemicals through the equipment. Exterior surfaces will be sprayed to remove contamination. The cells should be located in the tornado and earthquake resistant sections of the processing building and should be large enough to accommodate the largest piece of process equipment. Equipment to be decontaminated will be moved into and out of the cells using the process cell crane. Both cells should have easy access to the railroad air lock for removal of equipment.

**Design requirements common to both the remote and contact decontamination and maintenance cells are as follows: $* *$

- Cell lighting which is waterproof and easily relamped

- **Cel1 junction boxes, receptacles, conduit, etc. are to be 304L SS corrosion release per Spec. $4498 .^{\star \star}$

- Embedded sleeves to accomodate removable radiation measuring instruments; the sleeves should terminate at steel plate spray shields on the inside of the cell walls near the location of the vessels when being decontaminated.

- Holding frames for pumps, agitators, and motors

- Impact resistant stainless steel liner, at least $3 / 8$ inch thick on floors and 18 inches up the walls and a lighter gage 1 iner from 18 inches above the floor to the bottom of the cell covers. Liners are to be corrosion released $304 \mathrm{~L}$ stainless steel per Spec. 4498 .

- Wall nozzles (one per service per cell unless stated otherwise)to provide utilities and services as follows:

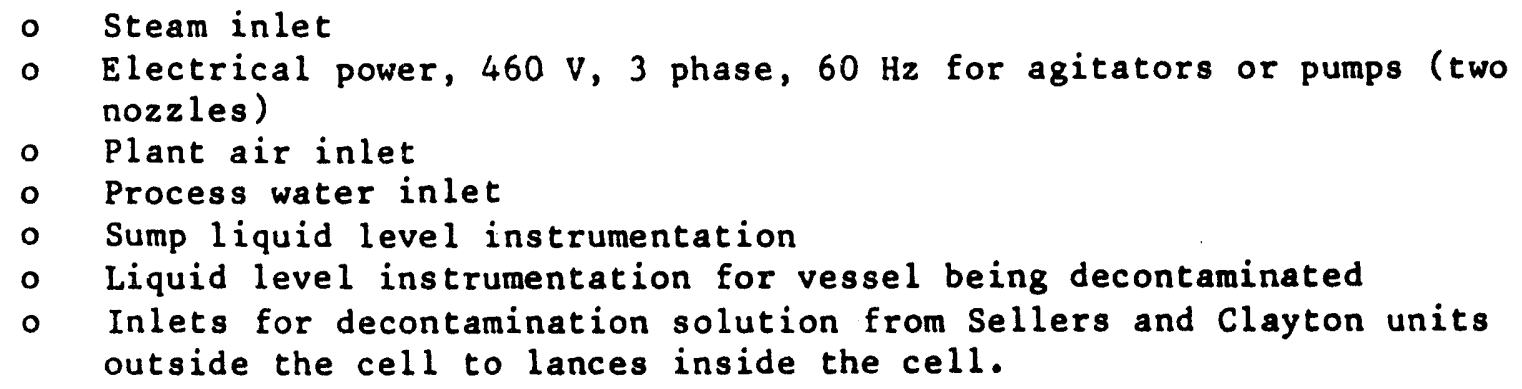




\section{PART TITLE: MAINTENANCE REQUIREMEN'S - SHOPS}

ITEM TITLE: **Process Equipment Decontamination and Maintenance Cells**

- Inlet for bulk decontamination solution to vessels

- **Outlet for sump pump discharge to sump collection system to the Decontamination Waste Treatment Tank

- Sloped floors to drain freely to sumps

- No trunnion guides**

- A freely rotating hook which can be held by the non-rotating overhead process cell crane hook to permit rotation of vessels inside the decontamination cells.

**Design requirements specific to the remote decontamination and malntenance ce11: ${ }^{\star \star}$

- Sufficient clearance around the vessel being decontaminated to permit easy access by manipulator held lances dispensing pressurized decontamination solutions.

- Electromechanical manipulators to handle lances for spraying decontamination solution and assisting orientation of vessels in the cell during placement by the process cell crane.

- Shlelded viewing window(s) at the bullding second level operating area with decontamination solution controls and manipulator operating controls.

Design requirements specific to the contact decontamination cell:

- Shlelded viewing window(s) at the bullding first level operating area with decontamination solution controls and manipulator operating controls.

- Shlelding cell covers and shielding walls between the contact decontamination cell and the remote decontamination and process cells to give $0.5 \mathrm{mrem} / \mathrm{hr}$ in the cell. Assume a melter, full of glass, in position in the remote decontamination cell.

- Stand or rack to hold electromechanical manipulators for decontamination, repair and testing.

- Plugged spaces for possible Installation of master/slave manipulators at the viewing window(s) or electromechanical manipulators if process equipment design features require or allow some remote disassembly for additional decontamination or repalr. 
PART TITLE: MAINTENANCE REQUIREMENT - SHOPS

ITEM TITLE: **Process Equipment Decontamination and Maintenance Cells**

- Personnel entry from an air lock. **Provide a safety shower with eyewash, safety light, and floor drain with water seal draining into the contact decontamination and maintenance cell.

- Stainless steel set of drawers with divided sections $4^{\prime} \mathrm{w} \times \mathrm{l}^{\prime} \mathrm{d} \times 6^{\mathrm{h}} \mathrm{h}$ for storage of small power and hand tools ${ }^{* \star}$

- Jib cranes or equivalent equipment with a capacity of 2 tons for handling small or disassembled equipment.

- Welding and burning equipment as follows:

- **Supply of oxygen, nitrogen, acetylene and argon with controls inside the cell and the compound gas cylinders outside the cell.

- Two 400 amp high frequency welder with the machine outside the cell and with the welder receptacles and all phase controls and polarity switches inside the cell. ${ }^{\star \star}$

- See Project S-1748 for typical welder and gas facilities that have been used extensively at SRP with excellent results.

Design requirements for the air lock to the contact decon cell:

- **Breathing air manifold with hoses. The hoses should be routed through the air lock without crimping. (See design used for Project S-1748.)**

- Space for clothing hampers, waste containers and personnel monitoring equipment.

- Viewing window or other suitable means for maintaining visual contact between personnel in the air lock and the cell.

- Method of communicating with personnel wearing protective plastic suits in the cell.

Chemicals normally used for decontamination of equipment (Part 5, Items 210 and 215) will be supplied through Sellers and clayton units on feed tanks outside the cells to lances inside the cells. **A Clayton cleaner dilutes solutions with steam by about $25 \%$ by volume. The decon solution routes through a Sellers jet can be varied between $0-10 \%$ of the total flow. Use $7 \%$ as an average. The remaining $3 \%$ is the steam and water supplied to the jet. $\star \star$ 


\section{PART TITLE: MAINTENANCE REQUIREMENTS - SHOPS}

ITEM TITLE: Process Equipment Repair Shop

A process equipment repair shop will be required for the repair of process equipment which has been decontaminated in the equipment decontamination cells. This shop may be located in a standard construction structure contiguous to the process building.

Design requirements for this shop are:

- Access to the equipment decontamination cells via a rail and truck access air lock to isolate the shop from the building process cell.

- A grade level rail and truck approach through a standard structure air lock to the shop and connecting with the rail and truck access air lock (described above). See Part 11, Items 105 and 110.

- Access to the Regulated Machine Shop (See Part 14, Item 300) for movement of equipment and parts to and from the machine shop for repair.

- An overhead crane; see Part 20, Item 185.

- Two approximately $20 \mathrm{ft} \times 30 \mathrm{ft}$ spaces to allow simultaneous maintenance on two vessels from the process, melter or weld test cells; the floors in at least one of these spaces should serve as a datum plane for precise equipment measurements. Provide jib cranes or equivalent equipment with a capacity of 2 tons for handling small or disassembled equipment over these spaces.

- Equipment to verify (e.g. by photogrametry) that vessels have been repaired to required dimensions and tolerances; this is part of required repair work and should be done in the same maintenance spaces described above.

- A tank or tanks and associated instrumentation to run-in repaired pumps, agitators, etc.

- Two 300 amp high frequency welders and a curtained area about $12 \mathrm{ft} \times 12$ $f t$ including a workbench for welding smaller parts.

- Compressed oxygen, acetylene and argon from cylinders mounted outside the shop to supply the work space 3 and welding areas.

- Smooth walls and floors for easy decontamination. **See Part 11, Item 135 for details on wall and floor finishes. $* *$

- Four workbenches, $60 \times 34$ inches, and about 144 sq ft of caged tool storage space including storage shelves and bins.

- ** Sump and pump to the decontamination waste treatment tank. $* *$ 
PART TITLE: MAINTENANCE REQUIREMENTS - SHOPS

ITEM TITLE: Process Equipment Repair Shop

- Utilities and services as follows:
- Plant air
- Instrument air
- Process water
- Domestic water
- Breathing air
- Steam

- Electrical outlets for portable power tools and process pumps and agitators.

- Supplementary ventilation with HEPA filters to discharge to the building air (Zone 2) exhaust plenum at all locations where welding, cutting, grinding or metal removal operations take place; additional fans or blowers may be required. See Part 11, Item 110 for general ventilation requirements. 
PART TITLE: MAINTENANCE REQUIREMENTS -- SHOPS

ITEM TITLE: Regulated Machine Shop

A regulated machine shop is required to provide space for repair of failed components of process equipment after decontamination. This shop may be located in a standard construction structure.

Design requirements for this shop are:

- Access to the process equipment repair shop (see Part 14, Item 250) for movement of equipment and parts between the two shops.

- A tool crib of approximately $300 \mathrm{ft}^{2}$ equipped with standard tool storage bins.

- Smooth walls and floors to facilitate decontamination.

- Supplementary ventilation with HEPA filters to discharge to the building air (Zone 2) exhaust plenum at all locations where welding, cutting, grinding or metal removal operations take place; additional fans or blinwers may be required. See Part 11 , Item 110 for general ventilation requirements.

- Utilities and services as follows:

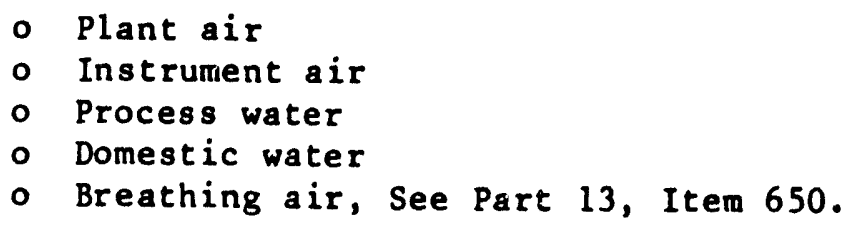

- Electrical outlets for portable and fixed power tools.

- Monorail with 2-ton capacity to service the machine shop and process equipment repair shop.

- ** Sump and pump to the decontamination waste treatment tank. ${ }^{\star *}$

- Compressed oxygen, acetylene and argon from cylinders mounted outside the shop to supply the work areas.

- Maintenance shop area equipped as follows:

- Lathe, 20 in. swing, 75 in. bed

- Hydraulic press, 50-ton air operated

- Radial drill, $3 \mathrm{ft}$. with adjustable table

- Welding booth, $10 \times 10 \mathrm{ft} . ; 300$-amp high frequency welder

- Drill press, 20 in. floor model, variable speed 
PART TITLE: MAINTEMANCE REQUIREMENTS -- SHOPS

ITEM TITLE: Regulated Machine Shop

- Grinder, 15 in. pedestal with dust collector

- Arbor press, with stand similar to Do All Model 789-000619

- Saw, band, 20 in. variable speed

- Horizontal cut-off saw, 10 in. wet

- Pipe threading machine, portable, 2 in. pipe capacity

- Four workbenches, $72 \times 34$ inches, and three storage cabinets, 84 inches high, 18 inches deep and 48 inches wide with swing doors.

- E I shop area as described in Part 14, Item 350, Shop 1.

- **A one-man office for the Maintenance foreman adjacent to or near the shop (See Table 10-1, Appendix A). 
PART TITLE: MAINTENANCE REQUIREMENTS - SHOPS

ITEM TITLE: Regulated Electrical and Instrument Shops

Shops and offices as described are for $\mathrm{E}$ \& I groups for repair of regulated area electrical equipment and instrumentation. Where possible, offices should be adjacent to shops.

Shop 1-

Location: Adjacent to Process Equipment Repair Shop on $18 t$ level of 221-s

Shop Size: approximately $600 \mathrm{sq} \mathrm{ft}$

office size: approximately 100 sq $\mathrm{ft}$

Shop function: This shop will be used for the repair of electrical

and inatrument process equipment, which has been

decontaminated in the equipment decontamination cells.

Utility Requirements: - 120 Volt 60 Hertz, single phase, AC Electrical Service

- 240 Volt 60 Hertz, single phase, AC Electrical Service

- 480 Volt 60 Hertz, 3 phase, AC Electrical Service

- Instrument Air

- Plant Air

- Breathing Air, See Part 13, Item 650

- See Part 11, Item 110 for ventilation requirements

Shop Equipment: A two ton monorail and hoist

See Table 16-1, Appendix A for additional equipment requirements. 
DPSP $80-1033$

PART 14

ITEM 350

PAGE 2 of 3

DATE 9-82; Rev. 9

- PART titLe: maintenance requirements - SHOPS

ITEM TITLE: Regulated Electrical and Instrument Shops

Shop 2-

Location: East side 2nd level 221-s

Shop Size: approximately 600 sq $\mathrm{ft}$

Office Size: approximately 100 oq $\mathrm{ft}$

Shop Punction: This shop will be used for the repair of electrical

and instrument process, H. P. and Laboratory equipment

which has been decontaminated.

Utility Requirements: - 120 Volt, 60 Hertz, single phase, AC Electrical Service

- 240 Volt, 60 Hertz, single phase, AC Electrical Service

- 480 Volt, 60 Hertz, 3 phase, AC Electrical Service

- Instrument Air

- Plant Air

- See Part II, Item 110 for ventilation requirements

Shop Bquipment:

See Table 16-1, Appendix A for equipment requirements. 
PART TITLE: MAINTENANCE REQUIREMENTS - SHOPS

ITEM TITLE: Regulated Electrical and Instrument Shops

Shop 3-

Location: 3rd level $221-\mathrm{s}$, adjacent to crane maintenance area Shop Size: approximately 1000 sq $\mathrm{ft}$ office Size: approximately $100 \mathrm{sq} \mathrm{ft}$

Shop Function: *tThis shop will be used for the repair of all Process Crane electrical and instrument equipment. ${ }^{* \star}$

Utility Requirements: - 120 Volt, 60 Hertz, single phase, AC Electrical Service

- 240 Volt, 60 Hertz, single phase, AC Electrical Service

- 480 Volt, 60 Hertz, 3 phase, AC Electrical Service

- Instrument Air

- Plant Air

- See Part 11, Item 110 for ventilation requirements

Shop Equipment - In addition to the items listed in Table 16-1, Appendix A, this shop should include facilities designed for test and repair of individual components in the shop and to exercise the crane viewing and control system in place. 


\section{PART TITLE: MAINTENANCE REQUIREMENTS -- SHOPS}

ITEM TITLE: Clean Maintenance Shop

A clean maintenance shop for the repair of clean equipment such as fans, refrigeration equipment, etc. should be provided. The shop should contain sufficient floor space to accomodate the following facilities, and equipment:

- Tool crib of approximately $700 \mathrm{ft}^{2}$ with tool storage cabinets.

- Three-fourth inch drill press

- Twelve-inch pedestal grinder

- Twenty-five-ton hydraulic press

- Portable pipe threading machine -- up to 2 in.

- Pipe bending machine -- up to 2 in.

- Reciprocating hacksaw, 10 in. wet

- Bandsaw, 20 in. variable speed

- Welding machine -- 300 amp. high frequency

- Welding machine, gasoline powered and trailer mounted, 300 amp., high frequency

- Welding gas manifold

- Four workbenches, $60 \times 34$ inches

- **Include one man $100-120 \mathrm{ft}^{2}$ office space in total area**

- Portable welding machine, electric, 300 amp

- Ventilation exhauster for welding booth

- Welding and burning table, $48 \times 24$ inches

- Monorail, one ton capacity

- Material storage rack about $7 \mathrm{ft}$ high to accomodate $20 \mathrm{ft}$ lengths of pipe and stock. The rack may be located outdoors but as close to the shop as practicable.

- Fabrication area of approximately $600 \mathrm{ft}^{2}$ (about $20 \times 30 \mathrm{ft}$ ) 


\section{PART TITLE: MAINTENANCE REQUIREMENTS -- SHOPS}

ITEM TITLE: Clean Elcctrical and Instrument Shops

Shops and offices as described are for E \& I groups for repalr of clean area electrical equipment and instrumentation. Where possible, of fices should be adjacent to shops.

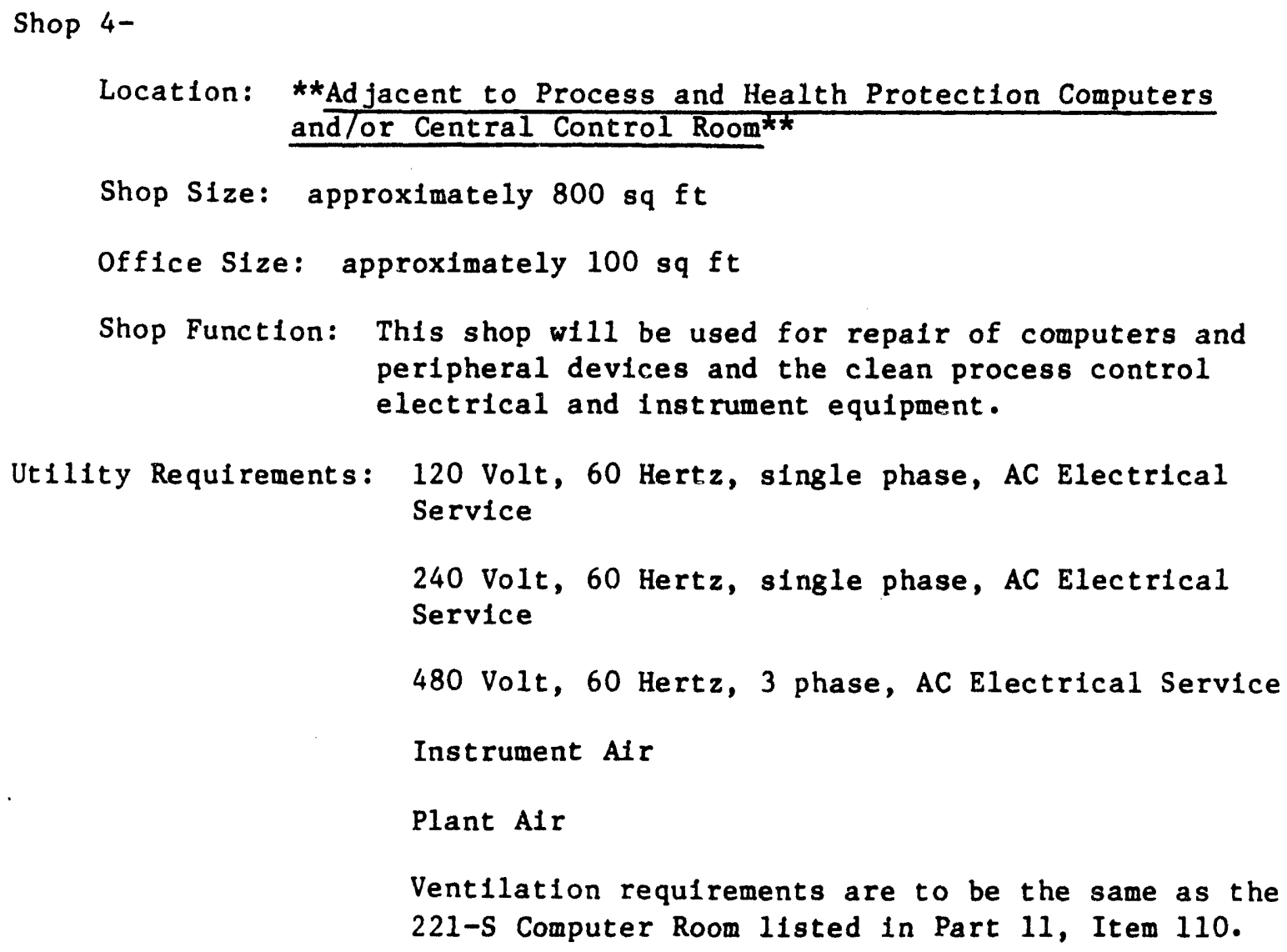

Shop Equipment:

See Table 16-1, Appendix A for equipment requirements. 
PART TITLE: MAINTENANCE REQUIREMENTS -- SHOPS

ITEM TITLE: Clean Electrical and Instrument Shops

Shop 5-

Location: **Th1s shop should located in a central part of S-Area.**

Shop S1ze: approximately $1600 \mathrm{sq} \mathrm{ft}$

Office S1ze: aproximately $100 \mathrm{sq} \mathrm{ft}$

Shop Function: This shop will be used for the repair of all clean electrical and instrument equipment not located in 221-S.

Ut1lity Requirements: 120 Volt, 60 Hertz, single phase, AC Electrical Service

240 Volt, 60 Hertz, single phase, AC Electrical Service

480 Volt, 60 Hertz, 3 phase, AC Electrical Service

Instrument A1r

Plant Air

See Part 11, Item 110 for ventilation requirements.

Shop Equipment:

See Table 16-1, Appendix A for equipment requirements. 
PART TITLE: MAINTENANCE REQUIREMENTS -- SHOPS

ITEM TITLE: Regulated Crane Maintenance Area

The process cell crane will require periodic decontamination, maintenance and repair. An area must be provided that will permit isolation of the crane from the process cell area and permit access by personnel. The area must be shielded from the process cells area by a shielding door.

Design requirements for the area are:

- Facilities for wet decontamination using hand held wands or lances.

- Portable or fixed facilities or both to permit access to crane with lances dispensing decontamination solutions.

- Services to hose or other connectors to provide:

- decontamination solution

- process water

- plant air

- Communication, between crane maintenance area and area outside viewing window for personnel wearing protective plastic suits.

- Waterproof high intensity lighting.

- The floor is lined with an impact resistant $304 \mathrm{~L}$ stainless steel at least $3 / 8$ inch thick on the floor and 18 inches up the walls.

- Adequately sloped and trenched floor to direct spent decontamination solution to a floor drain sump for drainage or discharge to the Decontaination Waste Treatment Tank.

- Clearances and rail supports to accomodate any in-cell crane carried into the area by the main process cell crane for decontamination, repair and run in after repair.

- Breathing air (see Part 13, Item 650).

- Sufficient space for access to all crane components using permanent or portable, or both, stainless steel scaffolding.

- Monorail system with a capacity of 2 tons to move crane parts to adjacent maintenance and $\mathrm{E} \&$ I facilities (see below). 


\section{PART TITLE: MAINIENANCE REQUIREMENTS -- SHOPS}

ITEM TITLE: Regulated Crane Maintenance Area

- Means and sufficient head room above the crane for hoisting any piece of equipment (motors, gearboxes, wheel assemblies, etc.) from the crane and lowering it to the floor.

- One workbench, $60 \times 34$ inches, metal topped and one tool storage cabinet, 84 inches high, 18 inches deep and 48 inches wide with swing door.

- Access to freight elevator to move repair parts and waste to and from the maintenance area.

- Windows are required to observe and direct maintenance activities from adjacent areas.

A regulated maintenance work and shop area should be provided adjacent to the crane area and be equipped as follows:

- Welder, $300 \mathrm{amp}$, high frequency, portable for use in both the crane area and adjacent area.

- Oxygen, acetylene and argon from compressed gas cylinders located in a clean area (to avoid contamination of cylinders).

- Two workbenches $60 \times 34$ inches, metal topped and three tool storage cabinets, 84 inches high, 18 inches deep, and 48 inches wide with swing doors. 
PART TITLE: MAINTENANCE REQUIREMENTS -- SHOPS

ITEM TITLE: Master-Slave Manipulator Repair Shop

A facility will be required for repair of master-slave manipulators. Design requirements for this facility are:

- Glove box for slave end disassembly of one manipulator at a time.

- Glove box for decontamination of slave end components.

- Glove box construction per Spec. 7187.

- Workbench, $30 \mathrm{ft} \times 3 \mathrm{ft}$ with access from both sides for reassembly, run-in, and checkout of repaired manipulators.

- Storage area with access from one side and including overhead racks for storage of up to eight failed or repaired manipulators.

- Storage wall about $20 \mathrm{ft}$ long by $6 \mathrm{ft}$ high with bins or drawers for new manipulator parts.

- Four, wall-mounted storage racks about $25 \mathrm{ft}$ long for storage of new cables and tubes.

- Four, $5 \times 3 \mathrm{ft}$ workbenches in a $400 \mathrm{ft}^{2}$ area for disassembly and assembly of manipulator components.

- High intensity 1 ighting.

- **One man office (see Appendix A, Table 10-1) $\left(100-120 \mathrm{ft}_{2}\right) . * *$

The shop should be located in a regulated area close to the locations where manipulators are used; however, it is not necessary that the shop be in the seismic-tornado resistant portion of the building. 
PART TITLE: MAINTENANCE REQUIREMENTS - SHOPS

ITEM TITLE: T \& T Equipment/Vehicle Maintenance

Existing vehicle maintenance shops will be used for repair and servicing of $\mathrm{T} \& \mathrm{~T}$ equipment and vehicles. No maintenance faciliites are required on this project unless design of the equipment for transporting the canister to the interim storage building necessitates some type of vehicle maintenance facility. 
PART TITLE: SPARE EQUIPMENT

ITEM TITLE: Installed Spare Equipment -- Policy

Installed spare equipment will be the minimum consistent with contamination control, personnel safety and major equipment protection. 
DATE 9-82, Rev. 9

PART TITLE: SPARE EQUIPMENT

ITEM TITLE: **Extra Machinery Allowance**

These extra machinery items should be estimated as one complete spare melter including all components, frames and melter to frame connections plus $\star * 0.75 \% * *$ of tota project cost. 
DPSP $80-1033$

PART 16

ITEM 50

PAGE 1 of 1

DATE 5-81; Rev. 6

\section{PART TITLE: AED PARTICIPATION IN PROJECT}

ITEM TITLE: Portable Equipment Procurement

Miscellaneous portable tools, instruments, office furniture and special allowances are listed in table 16-1. This equipment is to have an AED allowance for SRP procurement by the Project Department. **The items estimated in section $A$ of this table have not been escalated from FY 81 $\operatorname{costs.} * *$ 


\section{PART TITLE: AED PARTICIPATION IN PROJECT}

ITEM TITLE: Responsibility and Costs for Computer Programming

The responsibility for developing the necessary computer programs for operation of the process control and Health Protection computer programs has not been defined. The following SRP-DOE policy should be use as a guide for estimating costs.

- Costs for computer programs purchased from a vendor as part of a computer procurement should be capitalized as part of the project cost.

- Costs for computer programs developed or modified by SRP Du Pont personnel will be funded from operating costs and will not be capitalized.

- Costs for computer programs developed by Design Division or Engineering Service Division personnel will probably not be capitalized as part of the project.

- Procurement of automatic data processing equipment requires submission to DOE of an implementation plan and again of a procurement plan. 
DPSP $80-1033$

PART 16

ITEM 300

PAGE 1 of 1

DATE 7-81; Rev. 7 ,

PAR'T TITLE: AED PARTICIPATION IN PROJECT

ITEM TITLE: Canister **\& Overpack** Procurement

There will be no canisters **or overpacks* purchased on this project. 


\section{PART TITLE: COMMUNICATIONS-ALARM SYSTEMS}

ITEM TITLE: Be1l Telephone System -- Plant Telephone System

There will be four types of Bell Telephone systems required in S Area.

Type 1 - Intra-area only, four d1g1t number, switching 1n local area swit chboard.

Type 2 - Intra-area and $3 / 700$ Area, four digit number, switching in local area switchboard, w1ll use type 1 phone with switch on phone to select type 2. Only telephones that are essential to operation will have this capability.

Type 3 - Inter-area and offplant, four diglt number, switching in local area and 3/700-Area switchboard.

Type 4 - Same as type 3 except 1 t w111 be considered as nonessential and may be disconnected by local area control during plant emergencies.

In addition, the Bell Telephone System should provide the following:

1. A Patrol emergency telephone -- an additional telephone located in Patrol Headquarters to be used for emergencles -- type 3.

2. A fire emergency telephone -- an additional telephone located In Patrol Headquarters to be used only to report a fire -- type 3 .

3. An SSI telephone providing direct communications with all other Area Patrol Headquarters central control room, and the EOC (Emergency Operating Center). All SSI telephones can be on line at the same time.

Communication systems should be provided with emergency power from a generator and a standby storage battery system. 
PART TITLE: COMMUNICATIONS-ALARM SYSTEMS

ITEM TITLE: Bell Telephone System -- Plant Telephone System

Prellminary estimates of the telephone requirements are shown below:

Location

S-221, Fre1ght elevator

S-221, Sample elevator

S-292, Fan house

S-951, Primary substation

S-704, Patrol headquarters and

S-704, Administration building

S-221, Vitrification bullding

S-210, Service bullding

S-511, Pump pits

S-250, Interim storage

S-981, Cooling tower

S-980, Water treatment

S-831, Sewage treatment

S-422, Bulk Frit \& Cold Chem
Type 1 Type 2 Type 3 Type 4 SS1

$\begin{array}{ccccc}1 & - & - & - & - \\ 1 & - & - & - & - \\ 3 & - & - & - & - \\ - & 1 & - & - & - \\ - & - & 4 a & 1 & 1 \\ 6 & - & 24 & 18 & - \\ 24 & 5 & 16 & 4 & - \\ 6 & - & 24 & 14 & - \\ 1^{b} & - & - & - & - \\ 3 & - & 1 & - & - \\ 1 & - & - & - & - \\ 1 & - & - & - & - \\ 1 & - & - & - & - \\ 1 & - & - & - & -\end{array}$

a Includes dedicated fire and patrol emergency telephones.

b Provide a telephone for each enclosure at each pump pit. 
PART TITLE: COMMUNICATIONS-ALARM SYSTEMS

\section{ITEM TITLE: Area and Plantwide Alarm Systems}

An Areawide fire alarm system should be provided to activate alarms in the CCR, Patrol Headquarters and the F-Area fire station. The system must be compatible with the American District Telegraph System presently being installed plantwide on Project S 1840 and be coded to identify the S-Area location of the alarm for quick response by F-Area fire station.

A tie-in to the H Area "Nuclear Incident Monitoring System" (NIMS) should be provided to ensure the alerting of $S$ Area personnel of incidents that may affect them. No sensors associated with the NIM System are required, however, within S-Area. The alarms should be located in Patrol Headquarters and in the CCR Building.

Installed radiation monitoring, air monitoring, liquid effluent and monitoring essential ventilation equipment, etc., should be appropriately alarmed at the immediate site and in the CCR Building. 

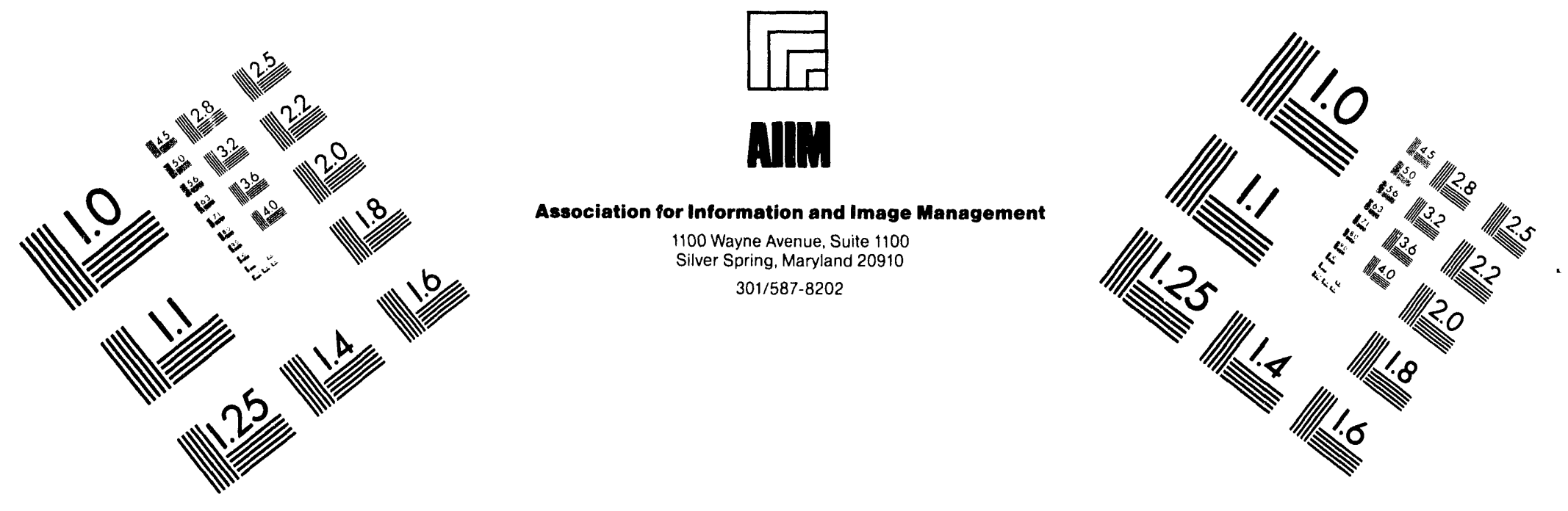

\section{Centimeter}

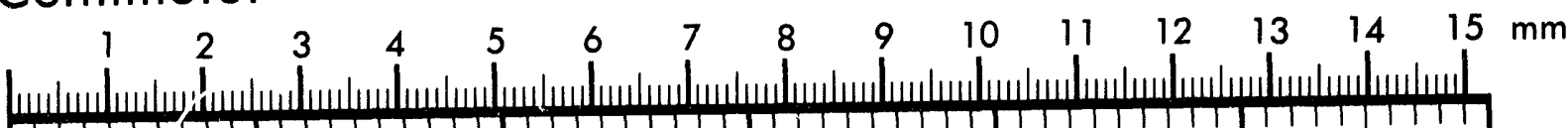
गITIT| Inches
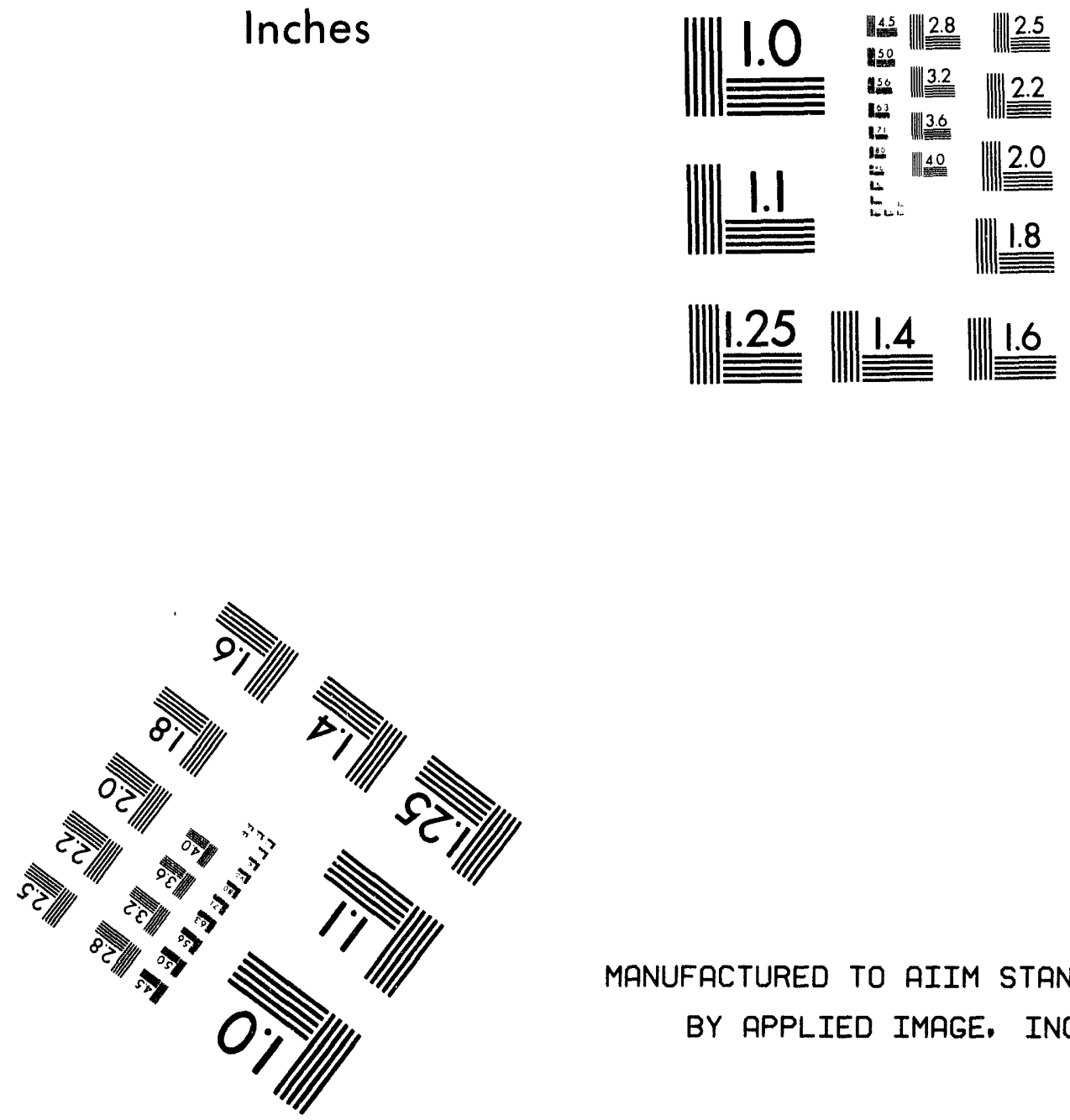

MANUFACTURED TO AIIM STANDARDS BY APPLIED IMAGE. INC.

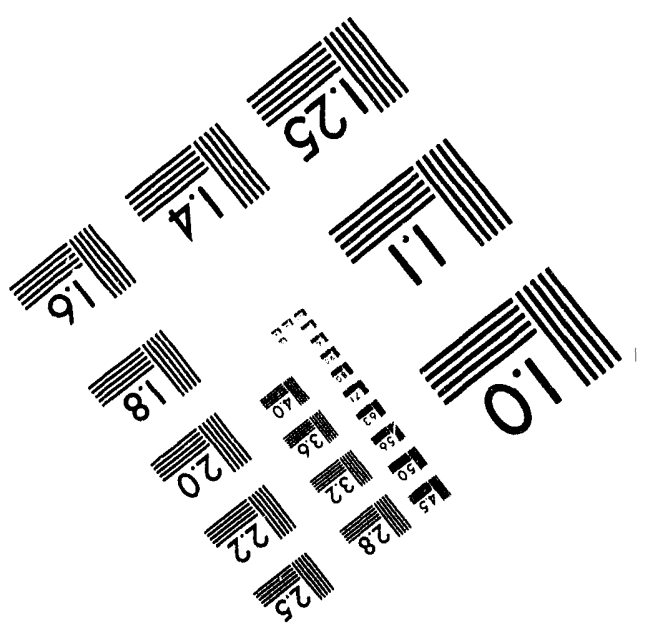



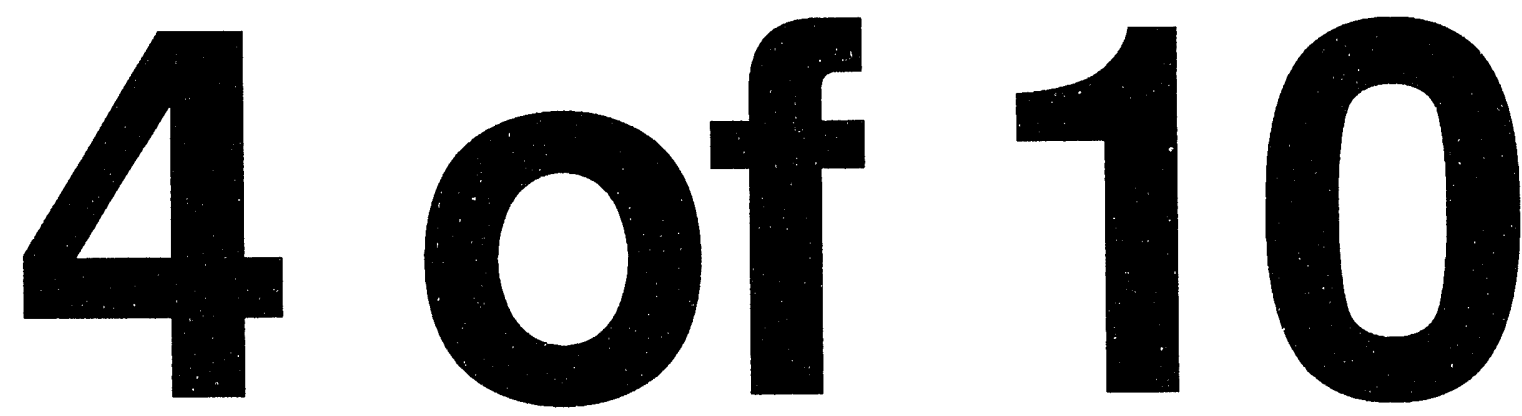


\section{PART TITLE: COMMUNICATIONS-ALARM SYSTEMS}

ITEM TITLE: Public Address System -- Areawide

An areawide public address system should be provided to assure that information vital for operation and safety reaches all personnel. Initiation of the public address system should be available from any of the four type telephones with a master override of the system being located in Patrol Headquarters. 
PART TITLE: COMMUNICATIONS-ALARM SYSTEMS

ITEM TITLE: Public Address and Intercom Systems in and Between Buildings

Building or sub-area public address and/or intercom systems should be provided at various locations as required.

In addition to the areawide public address system discussed in Part 17, Item 200, public address systems covering limited areas and/or buildings are required. These systems should also be accessible from the Bell telephones as discussed in Item 200. The subsystems and locations covered are as follows:

- process building (vitrification)

- interim storage building

- **service building-outside cold feed area**

- all remaining outside work areas (i.e. water treatment, sewage treatment, pump pits, etc.) 
DP SP $80-1033$

\author{
PART 17 \\ ITEM 300 \\ PAGE 1 of 1 \\ DATE 5-81; Rev. 6
}

\title{
PART TITLE: COMMUNICATIONS-ALARM SYSTEMS
}

ITEM TITLE: Teletype, Data Transmission Capabilities, Requirements.

The teletype and automatic data processing links of the plant should be expanded to include $S$ Area.

Data transmission capabilities shculd be provided between interim storage, CCR, 772-F Laboratory and all processing Buildings with the S-Area central computer. Provisions should be provided for tie-in of additional data transmission systems for future expansion.

**Two, 100 watt base station radio-control centers are to be established in S-Area, one located in Patrol Headquarters and one in the 221-s Central Control Room. The base station systems must use Motorola Digital Voice Protection equipment to be consistent with the existing SRP system. Four transmitting channels are required at frequencies of $164.225 \mathrm{MHz}, 164.750 \mathrm{MHz}$, $164.325 \mathrm{MHz}$ and $165.2625 \mathrm{MHz}$. Two receiving channels are required at frequencies of $164.225 \mathrm{MHz}$ and $164.325 \mathrm{MHz} *^{* *}$ 
PART TITLE: SAFETY -- FIRE PROTECTION

ITEM TITLE: Criticality

Design considerations for buildings and equipment where nuclear criticality is a possibility must be in compliance with DOE requirements as addressed in $* *$ Reference $C-10$, Appendix $C_{0} * *$ A detailed evaluation of the potential for criticality is being made by SRL. At present, there are no known criticality hazards in the process, however, the basic data will be revised as necessary when the evaluation by SRL is completed. The impact on design effort and cost to meet DOE requirements if criticality hazards are found is e pected to be small being limited to detection, alarm and recording instrumentation. 


\section{PART TITLE: SAFETY -- FIRE PROTECT ION}

ITEM TITLE: Radiation Hazards -- Al 1 Areas

Protection from radiation hazards must be adequate to insure compliance with DOE standards in **Reference $C-10$, Appendix C.** Radiation hazards exist in waste process streams and equipment in the process, weld test, decontamination and repair cells of the main processing building, in solidified waste in the storage building and in air and liquid effluents from the main processing building. Exposure to direct radiation is to be controlled by shielding walls in the main processing building (Part 11, Item 115, Page 1) and in the glass storage building (Part 11, Item 430, Page 1). Radioactive contamination in ventilation air is to be controlled by the ventilation requirements in Part 11, Item 110, Pages 1-7.

Additional protection against exposure to radiation is to be provided by monitoring air and 1 iquid streams to detect radiation from air reversals, process liquid leaks, process equipment failure, etc. (Part 12, Items 100, $110,120,130)$. Protective clothing, restricted access, regular monitoring of personnel and body fluids provide further protection from radiation exposure (Part 12, Item 140).

Examples of radiation hazards include:

- Entry into weld test cell, contact decontamination cell, crane maintenance, ventilation fan room, etc.

- Reversal of ventilation air flow

- Leaks of process 1 iquids

- Accumulation of activity in replaceable filters

- Removal of contaminated equipment from process area

- Inadvertant spread of contamination by personnel from contaminated areas to clean areas. 


\section{ITEM TITLE: Controlled Access -- Surveillance Monitoring}

Facilities and equipment must be provided to permit movement of personnel between areas of differing contamination and radiation levels to perform operation and maintenance functions. Typical arrangements provided for movement between areas of different contamination levels generally include an airlock for control of air flow, clothing change facilities and personnel radiation monitoring instruments. Clothing change facilities required depend upon the difference in level of contamination between two areas and may very from the use of a lab coat and shoe covers over street clothing to a complete change of clothing into protective clothing including use of respiratory or fresh air breathing equipment.

Personnel monitoring equipment must be provided for use when moving from a high radiation/contamination potential area to one with a lower radiation/contamination level. Monitoring equipment requirements may vary from complete monitoring by Health Protection personnel when leaving an area of high radiation/contamination, to a self admisistered hand and foot count before entering a "clean" area.

Some examples of controlled access requirements are:

- Between clean areas, eg., outside, offices, control room and process building operating areas (Part 11, Item 125)

- Between process building operating areas where radiation or contamination levels might be quite different. An example might be between a local process control area and a sampling area.

- Between process building operating area and the ${ }^{*}$ weld test cell ${ }^{* *}$ or the contact decontamination cell.

- Between outside and sand filter, stack or building housing ventilation fans.

- Between outside and glass storage building. 


\section{PART TITLE: SAFETY -- FIRE PROTECTION}

\section{ITEM TITLE: Controlled Access -- Surveillance Monitoring}

Surveillance monitoring of radiation in the process building and in the air and liquid streams is discussing in Part 12, Items 110,120 , and 130 .

In addition to the general employee work area surveillance, monitoring of employees in the preceeding discussion concerning controlled access, a detailed program for monitoring each employees radiation exposure is maintained. SRP policy and requirements are summarized below:

- Each employee who enters a radiation area is required to wear a Health Protection TLD badge. Employees assigned to the processing building plus employees assigned to clean buildings but whose duties require periodic visits to the process facilities will be assigned permanent Health Protection badges. Badge racks must be provided at the area patrol headquarters where all employees will leave badges overnight. Space must also be provided for storage of visitors badges. Periodically (once/month or once/quarter) the employee radiation exposure will be determined by reading the dosimeter in existing Health Protection facilities to provide a historical record of employee exposure.

- Employees entering high radiation areas such as crane maintenance, contact decon cell, etc. will be required to wear self reading dosimeters. These dosimeters will provide a daily estimate of employee exposure and the estimate is recorded on the employee radiation exposure card. The dosimeters will be kept in the Health Protection complex and returned to Health Protection for recharging at the end of each shift.

- Employee's exposure to radiation by inhalation or ingestion is monitored by a Health Protection bioassay program. Periodically, employees assigned to regulated area work are required to leave bioassay samples. Change rooms should be equipped with a small rack for storage of bioassay sample bottles. The se samples will be analyzed in existing facilities. 


\section{PART TITLE: SAFETY -- FIRE PROTECTION}

\section{ITEM TITLE: Chemical Hazards -- All Areas}

A number of chemicals as liquids or gases are used in the process and include:

- Nitric acid

- Sodium hydroxide

- Potassium permanganate

- Hydroxylamine sulfate

- Oxygen

- Acetylene

- Sodium hypochlorite

- Caustic waste

- Sulfuric acid

- **Sodium bisulfite**

- Formic acid

- Oxalic Acid

Design Safety Considerations

In addition to proper unloading, storage and containment requirements, provision must be made for personnel protection in the event of contact with chemical agents. Although protective clothing and equipment is prescribed when handling chemicals, design should include eyewash stations and safety showers in all locations where chemicals are used. **These locations include the dry chemical storage, liquid cold chemical storage and makeup area, pump pits, fan house and all locations within the main process building when contact with chemicals is likely. These stations are to meet Du Pont Standard S1E, a design guide for new facilities. If permanent, plumbed facilities are not practical, use of portable eyewash containers is acceptable if the requirements of Standard S1E are met.

The heavy (approximately 1,000 1b) canisters and lids represent potentially serious safety hazards during all transporting, inspecting, and storage operations. Equipment design should consider the following requirements :

1 All loads should be securely fastened during transport, inspection and storage.

2 Operations should not require employee to place extremities of body in potential pinch point areas.

Sodium hydroxide and nitric acid have a strong local corrosive action. Avoid contact with or exposure to these corrosive chemicals.

Potassium permanganate is a strong oxidizing agent. It should be kept away from combustible and organic materials. 
DPSP $80-1033$

PART 18

ITEM 200

PAGE 2 of 2

DATE 9-82; Rev. 9

\section{PART TITLE: SAFETY -- FIRE PROTECTION}

ITEM TITLE: Chemical Hazards -- All Areas

Hydroxylamine sulfate is a highly toxic compound. When heated to approximately $350^{\circ} \mathrm{F}$, it begins to decompose forming free hydroxylamine and toxic oxides of sulfur. The hydroxylamine may decompose explosively.

Sodium hypochlorite is corrosive and an irritant via ingestion and inhalation. Anhydrous salt is highly explosive, and can cause violent reactions with amines, cellulose, ethylene imine and ammonium acetate, carbonate, nitrate, oxalate and phosphate.

Sodium sulfite is moderately toxic through ingestion. Aqueous solutions are toxic and corrosive.

Formic acid is moderately toxic through ingestion and is an irritant to skin, eyes and mucous membranes. It is a moderate fire hazard when exposed to heat or flame. It is an explosive hazard with furfural alcohol, hydrogen, peroxide, $\mathrm{Tl}\left(\mathrm{NO}_{3}\right)_{3} \cdot{ }^{3} \mathrm{H}_{2} \mathrm{O}$. Fire fight with carbon dioxide, dry chemical or alcohol foam.

Oxalic acid is highly toxic when ingested and can cause death rapidly. Inhalation of dust or vapor can cause chronic irritation of the upper respiratory tract, gastrointestinal disturbances, albuminura, gradual loss of weight, increasing weakness and nervous system complaints. Oxalic acid has a caustic action on the skin and may cause dermititis.

Storage, transfer, and makeup of corrosive chemicals represent potential hazards to operating and maintenance personnel. All lines should be sloped for drainage. Pumps should be located to minizize potential sprays from leaks at flanges, etc. All operating equipment, such as pumps, etc., must be capable of being locked out and lines must be capable of being drained before repair. Provide safety showers in close proximity to all locations where corrosive chemicals are handled. 


\section{PART TITLE: SAFETY -- FIRE PROTECTION}

\section{ITEM TITLE: Fire Protection -- General}

Fire protection systems must be in compliance with DOE policy and objectives defined in **Reference $C-10$, Appendix $C * *$ which are that fires will not result in injury to personnel, radioactive or other hazardous exposure of the public (including failures of critical safety systems and loss of primary confinement integrity), unacceptable impairment of DOE programs and excessive damage to or loss of Government property. Criteria covering the fire protection requirements applicable to buildings and facilities are included in $* *$ Reference $\mathrm{C}-11$, Appendix $\mathrm{C} . * *$

In general, fire protection equivalent to an "improved risk" as accepted by the fire insurance industry is required. Exceptions are where large or unusual fire potential exists, or where radioactive contamination of plant or public environment could occur, a level of protection exceeding the "improved risk" level is required. Such improved protection generally consists of special precautions to prevent fires, multiple types of fire extinguishment, inerting, rapid detection of incipient fires, increased fire rating of construction materials, rapid response of fire departments, etc.

Particular attention should be given to the fire protection water supply and distribution system for compliance with the general design criteria for DOE facilities as specified in **Reference $\mathrm{C}-11$, Appendix $\mathrm{C} *^{* *}$ Among other things, this section specifies recommendations for looped water systems, sprinkler flow of $15 \mathrm{gpm}$ for each sprinkler head expected to operate in a fire with a reserve of $500 \mathrm{gpm}$ for hydrant use, and a fire water flow for at least two hours and perhaps longer for certain fires. 


\section{PART TITLE: SAFETY -- FIRE PROTECTION}

\section{ITEM TITLE: Fire Protection -- 200S Area}

** Provide a fire alarm system for the area which is activated from manual stations and by fl.re detectors located in unattended areas such as the process cell in the main processing bullding, service bullding, etc. ${ }^{*}$ Alarms connected to the area system should sound in the affected bullding, central control room, area guard headquarters and the $200 \mathrm{~F}$ fire station. **This fire system should be compatible with the low voltage Gamewel1 Flex III* chassis and the ADT Autoterms ${ }^{\star}$ and Hoffman ${ }^{\star}$ enclosures in the existing SRP system. Prints of the existing system have been supplied. ${ }^{\star \star}$ Fire detection and local alarm systems using detectors such as heat and smoke types may be used for early detection of fires but should not be used in lieu of automatic suppression systems for general bullding protection except under certaln conditions.

Automatic fire suppression systems should be installed for general building protection. Two types are considered adequate for most applications. Water sprinkler systems can be used for most occupled areas and warehouse facilities. $* \star$ Halon systems should be used for areas where the re are concentrations of electronic equipment, e.g., computer equipment, and for some restricted areas such as sample cells in the main processing building. Motor control centers and electrical load centers will be segregated from areas with automatic fire suppression system by flre walls with a minimum one (1) hour rating and will be equipped with fire detection and portable fire extinguishers. ${ }^{\star \star}$

Fire hose stations and/or portable extinguishers should be provided in all facilities accessible to personnel including appropriate outside areas whether or not automatic extinguishment is provided. Additional extinguishers for special hazards should be provided as required.

An area wide fire water supply, storage, and distribution system must be provided and must be operable in the event of electrical power fallure. Water supplies for fire protection shall be adequate in pressure and volume to provide not less than $15 \mathrm{gpm}$ for each sprinkler head expected to operate in the largest probable fire, with at least $500 \mathrm{gpm}$ reserved from hydrant use. Fire water flows shall be continuously avallable for a period of at least two hours, except that for very large buildings, buildings with special public or plant hazard potential, multiple building sites or groups of combustible bulldings a minimum four-hour reserve is required.

The fire protection water supply must assure avallability regardless of process and domestic usage and may be provided by a separate fire protection water supply system, multiple or combined supplies with reserve fire supply or by connection to an effectively inexhaustible supply (such as a small plant supplied from a large city distribution system). ** The back-up fire water storage should be provided by a minimum cost system.**

*Register demark 


\section{PART TITLE: SAFETY -- FIRE PROTECTION}

ITEM TITLE: Fire Protection - 200 S Area

A looped or two-way flow system should be provided with sectional valving arranged to provide alternate flow paths in the event of breaks, shutdowns for future connections, or other impairments. Fire supply valves should be capable of being locked open to assure availability of supply.

An estimate of combustible materials that will be contained in the vitrification facilities is shown in Table 18-1, Appendix A. This should be used as a guide for determining fire potential and areas requiring automatic suppression systen.

Based on the DOE criteria and the estimated quantities of combustible materials, recommended fire protection systems are listed in Table 18-2, Appendix A. 


\section{PART TITLE: SPECIAL EQUIPMENT -- DESIGN BASIS/CRITERIA}

ITEM TITLE: Canister Components (As-Recelved)

A set of canister components consists of a canister, an inner plug, and an outer plug (with a hellum capsule attached). Repalr caps are used to cover defective welds.

Design requirements for components are shown in Table 20-1, Appendix A.

Component receiving, storage, and inspection requirements are set forth in Part 5, Item 265. Component processing is shown in Figures 5-3 through 5-8, Appendix B, and described in appropriate Items of Parts 5 and 20.

The design of canisters should incorporate features for fall safe lifting by cranes and grapplers. Ideally, the design and methods for both canisters and overpacks should be the same; however, this is not a requirement because of the very low frequency for handling overpacks.

Design of all components should incorporate features to facllitate decontamination of the approprlate portions (e.g., no crevices, radiuses should be greater than 0.06 in., etc.).

ASME boller codes for pressure vessels apply to design of canisters, except that pressure proof tests are not required.

The design of the inner canister closure shall:

- prevent exchange of a1r between cell and canister and entry of water or frit slurry into the canister during decontamination (see Part 5, Item 275 and Part 20, Item 260).

- facilitate decontamination of all exposed external surfaces.

- minimize accumulation of frit and water above the nozzle seal.

- contain contamination inside the canister before and until after welding of the outer plug.

o not interfere with welding of the outer plug.

- accommodate a helium capsule, for later release and helium leak testing.

o permit helium, when released, to fill the entire canister vold space.

- not create an electrical path that short circuits the outer plug weld. 
PART TITLE: SPECIAL EQUIPMENT -- DESIGN BASIS/CRITERIA

ITEM TITLE: Canister Components (As-Recelved)

- not contaln materials or produce materials that will cause degradation of the canister (molsture, acids, chlorides, etc.).

- provide a method to verify that the closure was properly installed (e.g. go-no-go gage, etc.).

- withstand decontamination conditions.

Outer plugs shall have capsules attached that are pressurized with sufficient helium to provide a minimum of $50 \%$ helium concentration in the entire vold space of glass filled canisters (both above and below the inner sea1). The capsules shall be designed to be filled and seeled and to retain the hellum for release and leak testing of the canister closure just prior to shipping to a federal repository. The design shall incorporate features to contain the hellum, to permit its release and to canfirm release at the desired time. An acceptable release mechanism would be a ruptured disc, with rupture triggered by heating the gas in the capsule. 


\section{PART TITLE: SPECIAL EQUI PMENT -- DESIGN BASIS/CRITERIA}

ITEM TITLE: Overpack Components (As-Received)

A set of overpack components consists of an overpack, a cover with a helium capsule attached, and possibly other miscellaneous parts as determined by design.

Design requirements for components are shown in Table 20-1, Appendix A.

Component receiving, storage, and inspection requirements are set forth in Part 5, Item 265. The overpack process is shown in Figure 5-9, Appendix B, and described in Part 5, Item 293.

The design of overpacks should incorporate features for fail safe lifting by cranes and grapplers. Ideally, the design and methods for both canisters (see Part 20, Items 50) and overpacks should be the same; however, this is not a requirement because of the very low frequency for handling overpacks.

Design of all components should incorporate features to facilitate decontamination of the appropriate portions (e.g., no crevices, radiuses should be greater than 0.06 in., etc.).

**To exclude water during decontamination, the overpack components should be designed with a water tight seal that is subsequently welded. If gaskets are used they must not contain chlorides, or produce chlorides under radiation, that cause stress corrosion cracking of stainless stee $1 .{ }^{*} *$

ASME boiler codes for pressure vessels apply to the design of overpack components, except that the pressure proof tests are not required.

The overpack covers shall have capsules attached that are pressurized with sufficient helium to provide a minimum of $50 \%$ helium concentration in the void space in the overpack. The capsules shall be designed to be filled and sealed and to retain the helium for release and leak testing of the overpack closure just prior to shipping to a federal repository. The design shall incorporate features to contain the helium, to permit its release and to confirm release at the desired time. 


\section{PART TITLE: SPECIAL EQUIPMENT -- DESIGN BASIS/CRITERIA}

\section{ITEM TITLE: Radiation Shielded Windows}

Radiation shielded windows will be required for viewing of equipment and operations in the following areas:

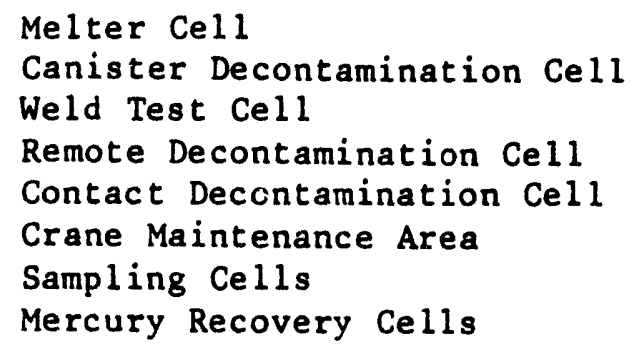

These windows are to provide shielding equivalent to the cell walls. They are to be non-fogging, low browning, and have a separate protective glass cov: ring on the hot side. Installation and removal equipment will be required. Removal for replacement or repair shall be from the cold side of the cell walls. A shielded barrier plug should be provided for placement inside the melter cell and canister decontamination cell when the windows are removed.

The type, size, mounting height, and specifications for each window location will be determined when layout plans are complete and location of in-cell equipment is known.

Shielded windows will be used to observe:

- All functions of the process cell crane and the remote operation of the crane while it is in the crane maintanance area. If $E$ \& I Shop 非 and the Maintenance Shop are on opposite sides, viewing will be required from both sides.

- Vessel and equipment decontamination in the remote decontamination cell.

- Equipment and personnel in the contact decontamination cell.

- Inner plug insertion and canister inspection in the melt cell.

- Smearing of canister in the canister decontamination cell.

- Weld inspection and smearing of canister in the weld test cell.

- Sampling, sample flow, and in-cell equipment in the sampling cells.

- Mercury purification equipment and in-cell equipment in the mercury purification cell. 
DPSP $80-1033$

PART TITLE: SPECIAL EQUIPMENT -- DESIGN BASIS/CRITERIA

ITEM TITLE: Radiation Shielded Windows

- Melter operation and maintenance including:

- Observation of pour spout bellow replacement.

- Observation of makeup of canister to melter bellows flange.

- **observation of glass sampling of melter.

- In addition to the above specific requirements, it is desirable to generally view the cell to facilitate placement of the canister vent shroud, replace the turntable drive motor and observe the melter and the canister being filled. $\star *$ If the viewing windows can be located to supplement TV observation of equipment replacement by crane in the melter $1 \mathrm{id}$, this aspect should also be considered. The lid equipment includes thermowells, TV camera, feed tubes, conductivity probe, bubbler, oxygen analyzer or light.

Additional viewing requirements such as identifying canister numbers, in-cell grappling and material transfer in the melt cell, canister decontamination cell, and weld test cell may be resolved with CCTV or windows depending on equipment placement and line of sight interferences.

**Window shielding should be comparable to wall shielding. The window's cell side should be protected with a removable guard. For continuing design, some means of window cleaning should be provided. $* *$ 


\section{PART TITLE: SPECIAL EQUIPMENT DESIGN BASIS/CRITERIA}

\section{ITEM TITLE: Manipulators}

At least two master-slave (M-S) manipulators will be required in each sample cell and the mercury purffication cell for the vitrification facility. The manipulator should be capable of $101 \mathrm{~b}$ handling capacity with fingers and a $50 \mathrm{lb}$ vertical lift capacity. All M-S manipuators will be thru wall mounted in penetrations above the cell window. These manipulators should be positioned so that complete coverage of the working area will be obtalned. All manipulators are to have SRL stainless steel tongs, standard $X, Y$, and $Z$ motion with booting and gauntlet for containment.

Additional manipulators may be required in the equipment decontamination cells, melter cell, canister decontamination cell and the weld test cell. These manipulators may be either $M-S$ thru wall mounted or electromechanical (E $M$ ) depending on the operation to be performed or the design of $1 n$-cell equipment. Type, size, function and specifications should be determined as equipment and cell design progresses. Remote operations which cannot be performed by the in cell crane are candidates for either $M-S$ manipulators or $E-M$ manipulators.

At each shielded window location, provide two master-slave manipulator port holes. At shielded window locations where M-S manipulators are not provided on the profect, shielded plugs for the port holes are required.

Each E-M manipulator shoud be capable of belng controlled from a shielded window. Each E-M manipulator shoud be capable of being remotely removed and installed in its cell via the process cell crane. Staggered helght dowels should be provided for locating these manipulators in remote cells. 


\section{PART TITLE: SPECIAL EQUIPMENT -- DESIGN BASIS/CRITERIA}

\section{ITEM TITLE: Process Cell Crane}

A remotely operated crane will be required to install and remove equipment and piping in the process cell. Design considerations for this crane are noted here.

\section{A. Crane Service}

- The crane is to be capable of these operations:

- Lift the heaviest cell equipment, including cell covers.

o Lift 10 tons with an auxiliary hoist.

- Reach one wall with an electrically operated impact wrench that is carried routinely on a 1 ton hoist suspended from a trolley; include an auxiliary 1 ton hoist on this trolley.

- Reach the opposite wall with an electrically operated impact wrench that is carried routinely on a 1 ton hoist suspended from a second trolley; include an auxiliary 1 ton hoist on this trolley also.

- Electrical connections and parts and all mechanical parts must be able to withstand crane washdown without failure. **Warm water under pressure**, detergent solution, and steam will be used for crane decontamination. General crane decontamination is likely to be required once a quarter, and decontamination of localized areas to permit maintenance is likely to occur monthly.

- The crane is to be operated using a closed circuit TV viewing system, see Part 20, Item 182, with remote control. No on-board operating controls or cab is required.

- Although remotely operable, maintenance and repair will be a direct "hands on" operation.

- The crane will operate in a $13-40^{\circ} \mathrm{C}$ environment, without humidity control. The intermittent radiation levels are expected to vary between 100 to $300 \mathrm{rads} / \mathrm{hr}$. However, the maximum short period rate may reach $1100 \mathrm{rads} / \mathrm{hr}$ as when the crane is operating directly over certain equipment. A period of $100 \mathrm{hrs}$ per year at $1100 \mathrm{rads} / \mathrm{hr}$ in addition to a constant rate of $300 \mathrm{rads} / \mathrm{hr}$ shall be used for the design. The crane must be available $90 \%$ of the time to perform cell maintenance tasks based on a 25 year radiation exposure period.

B. Crane Structural Components

- The girders, end trucks, and trolley shall be structural steel materials; stainless steel is not required.

- A 304L stainless steel checkered plate footwalk running the length of the bridge shali be supplied on each side of the bridge. 
PART TITLE: SPECIAL EQUIPMENT -- DESIGN BASIS/CRITERIA

ITEM TITLE: Process Cell Crane

C. Mechanical Components

- Cable cutters are required on the main and auxiliary hoists to dispose of a suspended load in an extreme emergency requiring this step. Cable cutters are not required on auxiliary hoists that carry loads of less than 3 tons.

- Provide for retrieval of the crane from the process cell in the event of failure of the main drive system or any other system which would prevent return of the crane to the maintenance area under normal operating procedures. Retrieval must provide for removing hoist loads.

- The main bridge trolley must be remotely retrievable (movable) under single mode failure conditions.

- The main bridge drive must be equipped with auxiliary wheels which can be remotely jacked into place to completely take the load of $f$ of main drive wheels so as to allow retrieval of the crane under emergency conditions. The auxiliary wheels are to be actuated/operated separately.

Crane lubrication points are to be accessible from the crane mounted platforms or the crane maintenance area platforms.

- Crane hooks are not to swivel.

D. Seismic Considerations

- In an **Investment Protection Earthquake (IPE)** situation, the crane shall stay on the runway rails and be retrievable to the maintenance area for any necessary repair prior to its use. The bridge trolley must remain on the bridge structure.

- Structural components are to be designed so as to suffer no permanent structural distortion that would disrupt or prevent crane operation as a result of loads imposed by an **IPE**.

- The crane is not required to be operable or retrievable during or after a Design Basis Earthquake (DBE). 
PART TITLE: SPECIAL EQUIPMENT -- DESIGN BASIS/CRITERIA

ITEM TITLE: Process Cell Crane

E. Electrical Design

- Supply voltage to the crane is to be 460 volt, 3 Phase, 3 wire 60 Hertz AC.

- A redundant bus bar power supply is preferred. The bus bars must be accessible for inspection and repair.

- Dual power pickup shoes or contacts are required on each set of bus bars.

- Electric motors shall be totally enclosed, non-ventilated, type NEMA design $B$ temperature rise with Class $H$ insulations Motors shall be rated for 60 minute crane duty service.

- Component cabinets requiring ventilation are to have HEPA filters on inlet and outlet air openings. Cabinet doors are to be sealed against water inleakage from decontamination spraying. Other openings are to be located and/or configured to exclude spray water from inside the cabinets. Cabinets are to be fabricated of $304 \mathrm{~L}$ stainless steel.

- Crane is to have controllable accelleration and decelleration on the main crane drive and the main trolley drive.

- Crane is to have stepped speed control on all functions per the following table:

\begin{tabular}{lrrr} 
& Min. & Max. & $\frac{\text { Steps }}{5}$ \\
\cline { 2 - 4 } Bridge & 3FPM & 100FPM & 5 \\
Trolley & 3 FPM & 7 FFM & 5 \\
Main Hoist & $3 F P M$ & $14 F P M$ & 5 \\
Auxiliary Hoist & $3 F P M$ & $21 F P M$ & 2 \\
Girder Monorail Trolley & 2FPM & $6 F P M$ & 2 \\
Girder Monorail Hoist & 12FPM & $47 F P M$ &
\end{tabular}

- Brakes on main bridge trolley hoists are to be redundant.

- Operator controllable variable braking action is required on the main crane drive. The brake control lever or pedal is to be spring returned to the off position when the operator releases the lever or pedal.

- Brakes on all crane drive functions are to be set when power is interrupted. 
PART TITLE: SPECIAL EQUIPMENT -- DESIGN BASIS/CRITERIA

ITEM TITLE: Process Cell Crane

- Brakes on all crane drive functions except the main crane drive are to set when the motion control is returned to the neutral (off) position.

- Brakes on all crane drive functions must be remotely operable under single mode failure conditions.

- The main and auxiliary trolley hoist shall have separate, redundant gear train drive systems to prevent an uncontrolled load drop should a gear fail.

- For fire protection requirements, see Part 18, Items 600 and 620.

\section{F. Crane Operating Criteria}

- The remote operator's console should be designed so that all normal controls can be reached from one operating position.

= For additional maintenance control console, see Part 14, Item 350.

- The crane control system must be operable over the full length of the crane travel (rail length).

- Control system components requiring maintenance or subject to failure cannot be located in an inaccessible position in the process cell.

- Permits, where and as necessary must be obtained from the FCC for operation of a wireless control system. A festooned cable assembly may be an option for crane control wiring. The CCTV's control is described in Part 20, Item 182.

\section{Crane Lighicing}

- The main process cell shall be equipped with lighting sufficient to accomodate operational viewing by means of closed circuit television viewing; see Part 20, Item 182 . This is to be interpreted as lighting which provides a minimum illumination intensity of 200 foot candles over an area equal to the span and the width of the crane measured at a plane located a minimum of 60 feet below the crane rail elevation. 
PART TITLE: SPECIAL EQUIPMENT -- DESIGN BASIS/CRITERIA

ITEM TITLE: In-Ce11 Cranes

Four remotely operated cranes will be required: one each in the Melt Cell (MC) and Canister Decontamination Cell (CDC), and two in the Weld Test Cell (WTC).

This item outlines general design criteria. Close coordination of shielded window, in-cell CCTV viewing, and in-cell lighting designs with this design is required to assure proper crane operation. Placement systems are to be located on all electrical connections and parts and all mechanical parts must be able to withstand crane washdown without failure. Warm water under pressure, detergent solution, and steam will be used for crane decontamination. Each crane will have a 5-ton hoist with a non-swivel hook.

The following are general requirements for the cranes:
- No TV equipment on cranes
- No lights on cranes
- No manipulators mounted on cranes
- Manual movement all directions " $X "$ ", "Y", " $Z$ "
- Each crane equipped with two (2) motions
1. Hook
2. Impact Wrench

(An electro-magnet will not be installed)

- All drives, $X, Y, Z, Z$ in emergency mode to be driven by impact wrench

- Standardize cranes if possible

- Cable cutter on both $\mathrm{Z,Z}$ motions

- Add maintenance functions to crane in addition to operating functions, extent to be determined without enlarging building size

- CCTV's in all cells require removal by cranes

MC and CDC Cranes

These cranes will be remotely removed by the main process crane (MPC) for maintenance in the crane maintenance area. The electrical connections should be of the Hanford Jesign. 
DPSP 80-1033

PART 20

ITEM 181

PAGE 2 of 2

DATE 9-82; Rev. 9

PART TITLE: SPECIAL EQUIPMENT -- DESIGN BASIS/CRITERIA

ITEM TITLE: In-Cell Cranes

WTC Cranes

"Hands-on" malntenance will be perforwed on WTC cranes after all canisters have been removed from the cell or placed in shielded storage. To assure this capability, a refundant crane system 18 required. One crane must be operable at all times. Crane controls inside and outside the cell are required.

- After an Investment Protection Earthquake (IPE), the crane shall stay on the runway ralls and remain operable. The bridge trolley must remain on the bridge structure.

- Structural components are to be designed so as to suffer no permanent structural distortion that would disrupt or prevent crane operation as a result of loads imposed by an IPE.

- These cranes are not required to be operable or retrlevable during or after a Design Bas1s Earthquake (DBE).

These cranes w111 not normally be removed by the Main Process Crane (MPC) for malntenance in the crane maintenance area. However, in the very unlikely event that both WTC in-cell cranes fall simultaneously, the capability of removing the in-cell crane drive system must be capable of being removed to the crane maintenance area via the process cell crane and a plug in the floor of crane maintenance.

The electrical connections shud be of the Hanford design. 


\section{PART TITLE: SPECIAL EQUIPMENT -- DESIGN BASIS/CRITERIA}

ITEM TITLE: CCTV Systems - Crane and Cell Viewing

Remote operations in the processing cell will require a viewing system. The system should be a remotely operated TV viewing system mounted on the process cell crane (See Part 20, Item 180) and maintained in the crane maintenance area.

\section{A. General}

- Permits, where and as necessary must be obtained from the FCC for operations of a wireless system. A coaxial cable reel **or festooned cablex* assembly may be options if size and reliability are not a problem.

- The viewing system should be designed so that an operator can work comfortably for long periods.

- The operator's console should be designed so that all normal controls can be reached from one operating position.

- *rCCTV control or signal circuitry located on the crane should be hard wired. $*$ *

B. Viewing Range and Resolution

- **High revolution TV cameras should be used for maximum visual clarity and for possible use in conjunction with photogrammetry and/or in cell photography.***

- While the crane bridge is being moved, the width of the process cell, with some overscan, must be visible at cell cover height.

- In process cells, magnification and resolution must be adequate to perform a variety of jobs such as removal and installation of vesseis and jumpers. Vision must be adequate to properly position tools and to detect small leaks.

- Placement of TV cameras must be separated on the crane bridge structure so as to improve apparent depth perception to the extent practical.

- **All CCTV cameras** should have zoom magnification **and camera pan/tilt capability.**.

C. Design and Maintenance

- Commercially available components are to be used where practical. 


\section{PART TITLE: SPECIAL EQUIPMENT -- DESIGN BASIS/CRITERIA}

ITEM TITLE: CCTV Systems - Crane and Cell Viewing

- The system enclosures must be able to withstand wet decontamination without failure. Cranes may become contaminated to levels where it is necessary to clean the ${ }^{* *}$ crane** using high pressure ( 300 psig) streams of laundry detergent solution, warm water and saturated steam.

- The system must permit removal and replacement of CCTV cameras, pan-tilt mechanisms or other operating components within a time span of four hours or less to limit personnel radiation exposure.

- A usable viewing system must be available following failure of any **single** component or module.

- Tre CCTV control system must be operable over the full length of the crane travel (rail length).

- Control system components requiring maintenance or subject to failure cannot be located in an unaccessible position in the process cell.

- Auxiliary video and audio recording equipment is required to record crane operations. Voice dubbing is required for the videotape system.

- A supervisory viewing station is to be provided with monitors and **monitor** switching capabilities duplicating those of the operator's console.

- The operator's console is to be located in a sound *treated room to meet PNC 40 curve. $* \star^{\circ}$

- The remote operator's console should be part of the crane operating console and be designed so that all controls can be reached from one operating position **with the operator in a seated position. ${ }^{* * *}$

$=* *$ CCTV and associated transmission components located on the crane slall meet the temperature and radiation conditions as stated in Part 20, Item 180 .

$=$ The CCTV system shall be considered as part of the crane to meet the availability and life expectancy requirements as stated in part 20, Item 180.

$=$ For additional maintenance control console, see Part 14, Item $350 .{ }^{* *}$ 
PART TITLE: SPECIAL EQUI PMENT -- DESIGN BASIS/CRITERIA

ITEM TITLE: Process Equipment Repair Shop Crane

A crane will be required in the process equipment repair shop to provide services for process cell equipment repairs.

A. Crane Service

- * The crane may be a modified standard, commercial crane.**

- The crane is to be remotely operated by radio or cable from the shop floor with a portable control system. On-board operating controls and $c a b$ are not required.

- Crane maintenance and repair will be a "hands-on" operation as with any commercial crane.

- The crane is to be equipped as follows;

- Duplicate the $* *$ lifting capacity of the large hoist** and the 10 ton auxiliary hoist on the process cell crane.

- Provide a single monorail with a trolley from which is suspended two 1-ton hoists, one to carry an electrically operated impact wrench and one for miscellaneous service.

- The crane will operate in a $13-40^{\circ} \mathrm{C}$ environment without humidity control. The radiation level in this shop will not be a factor in crane design.

B. Crane Structural Components

- All parts of the crane are to be standard materials of construction.

C. Mechanical Components

- Crane lubrication points are to be accessible from the crane mounted platforms or the maintenance area platforms.

- Crane hooks are not to swivel.

D. Seismic Consideration

- This crane is not required to survive an operating basis earthquake. 
DPSP $80-1033$

PART 20

ITEM 185

PAGE 2 of 2

DATE 1-82; Rev. 8

PART TITLE: SPECIAL EQUIPMENT -- DESIGN BASIS/CRITERIA

ITEM TITLE: Process Equipment Repair Shop Crane

E. Electrical Design

- Supply voltage to the crane is to be 460 volt, 3 phase, 3 wire 60 Hertz AC.

- Power supply bus bars will be accessible at all times and redundancy in the power supply is not required.

- **Electric motors shall be totally enclosed, non-ventilated, type NEMA design B temperature rise with Class H insulation. Motors shall be rated for 60 minute crane duty service. $* \cdot x$

- For fire protection requirements, see Part 18, Items 600 and 620.

- Any cabinets provided for climate control for electrical components are to have HEPA filters on the inlets to avoid long term accumulation of radioactive particulates in the cabinets. These cabinets do not renuire waterproofing.

- Provide lighting on the crane to increase shop floor illumination during load manipulations.

- Crane is to have variable speed control on all functions identical to the process cell crane, Part 20, Item 180.

- Brakes on main bridge trolley hoists are to be redundant.

- Brakes on all crane drive functions are to be set when power is interrupted.

- Brakes on all crane drive functions are to be set when the motion control is returned to the neutral (off) position.

- The main and auxiliary trolley hoist shall have separate, redundant gear train drive systems to prevent an uncontrolled load drop should a gear fail.

- Permits, as necessary, must be obtained from the FCC for operation of a wireless system. 


\section{PART TITLE: SPECIAL EQUIPMENT -- DESIGN BASIS/CRITERIA}

\section{ITEM TITLE: Equipment Lifting Yokes}

Each prece of equipment installed in the process cell must be hand led remotely using efther a hook on the cell crane or a combination of the crane hook and a yoke matched to the equipment plece. To minimize the number of yokes required in the cell, lifting balls and trunnions on similar equipment (weight, size, function) arc to be matched to mate with a single yoke. For example, single yokes could be provided each of the following equipment groups:

- all cell covers, both sheilding and ventilation covers

- all pumps and agitators

- large diameter and wide equipment

o small diameter and narrow equipment

Provision of additional bracing for balls or trunnions and oversized lifting trunnions is desirable to reduce the multiplicity of lifting yokes. All yokes in process cell service are to be carbon steel and painted. These yokes will not be removed for use elsewhere and storage must be provided in the cell. All equipment movements will be accomplished within the process cell with the one set of lifting yokes

A second set of lifting yokes is required in the process equipment repalr shop to handle new and decontaminated equipment. These yokes are to be carbon steel and painted. Use of adjustable lifting yokes adaptable to lifting trunnions on various equipment pleces would significantly reduce the number of yokes required in the shop and result in significant cost and space savings. Adjustable yokes have been demonstrated satisfactorily at SRP.

A set of lifting yokes is required to handle the tanks and equipment in the interarea line pump tank pits.

**All carbon steel lifting yokes are to be Inspected and stress relleved by:

o U1trasonically inspecting plate material to be used for hooks and eyes prior to cutting so that defects (laminations, cracks, etc.) will not be present in the final assembly.

- Inspecting all welds (visual and dye-penetrant) before and after stress relieving. No defects permitted.

- Stress relieving completed yoke in accordance with Section VIII, Division I, Paragraph UCC 56 of the ASME Boiler and Pressure Vessel Code.

을 pot permitting heating of stress relleved assembly.

Specifications for the fabrication of stainless steel yokes should 1nclude the above 1tems, except they should not be stress relleved." $* \star$ 


\section{PART TITLE: SPECIAL EQUIPMENT -- DESIGN BASIS/CRITERIA}

ITEM TITLE: Cell Tanks, Vessels, and Specialized Auxiliary Equipment

Equipment in the process, melter, canister decontamination, and remote and contact decontamination cells must be remotely removable by the overhead maintenance crane. This includes the in-cell cranes, if any, and canister transporter in the melter and canister decontamination cells. Equipment pieces or major components from these cells will be removed to the remote decontamination cell or crane maintenance area for decontamination and then to shops for repair.

All in-cell vessels should be designed in accordance with the following criteria.

Load and Service Conditions

- Internal or external pressure as defined by ASME Boiler and Pressure Vessel Code, Section VIII, Division 1, Part UG 21.

- Weight of the vessel and normal contents under operating or test conditions.

- Superimposed loads, such as counterweights, agitators, pumps, piping, other vessels, and heating and cooling coils.

- Localized stresses resulting from attachment or mounting of trunnions, supports, agitators, pumps, skirts, rings, legs, etc.

- Localized stresses through equipment lift trunnions which cause deformation to a vessel sufficient to affect the tolerances during normal handing after completion of fabrication at the fabricator or after handling at the Savannah River Plant.

- Stresses generated during shipment from the fabricator's shop to the Savannah River Plant and into and out of the process building.

\section{Surface Finishes}

- Plate material for vessel walls are to be supplied as hot-rolled and annealed (or heat treated), then blast cleaned (or pickled), which is the condition and finish commonly preferred for corrosion resisting applications. This is essentially a No. 1 Finish that is used for existing SRP remotely handled equipment. This finish has been found adequate for effective decontamination prior to any maintenance work.

- All gouges, crevices, and pits greater than $0.012-i n$. deep must be backfilled with weld metal, then ground smooth. 


\section{PART TITLE: SPECIAL EQUIPMENT -- DESIGN BASIS/CRITERIA}

ITEM TITLE: Cell Tanks, Vessels, and Specialized Auxiliary Equipment

\section{Flange Surface Finishes}

- Ungasketed surfaces, such as cell tank agitator or pump mounting flanges, should have a 125 RMS or AA equivalent finish.

- Gasketed surfaces, such as vessel nozzles or evaporator, reboiler and main body flanges, should have a 63 RMS or AA equivalent finish.

\section{Vessel Coils}

- All pipe coils inside a vessel shall be seamless schedule 40 pipe (preferred) or welded schedule 80.

- Weld shall not be located in the vapor space, but preferably as close to the coil as possible. Experience has shown that welds located in the vessel vapor space are most subject to failure.

- Coil dimensions be held to a tolerance of $+/-1 / 16$ in. to make certain they provide no obstructions below tank nozzles.

- Support frames are fabricated from rolled bars.

- All exposed edges of the bars and bottom support plate are sealed by fusion welding these exposed edges with $1 / 16-i n$. thick weld metal (for end grain corrosion protection).

Heat Exchanger Tube Bundles

- Only welded tube bundles are acceptable and must use a special, three-pass tube-to-tube sheet weld which has exhibited better life than other weld designs. See Figure 20-1, Appendix B.

- All tubing shall be inspected by the method described in ASTM A655 Section 17 -- "RZ Ultrasonic Inspection" or Section 16 -- RY Radiographic examination. In addition, short end samples of tubing will be taken, polished, and examined. Evidence of interior carburization in excess of 0.005 in. will be cause for rejection.

Corrosion Allowance

No corrosion allowance is required for process cell equipment. Erosion allowances may be required pending results of ongoing research. 


\section{PART TITLE: SPECIAL EQUIPMENT -- DESIGN BASIS/CRITERIA}

ITEM TITLE: Cell Tanks, Vessels, and Specialized Auxiliary Equipment

\section{Crevice and End Grain Corrosion}

- Crevices, corners, pockets, and gouges must be avoided to prevent entrapment of contaminated material and to minimize crevice corrosion. All bubble tray risers, if any, and nozzles should be seal-welded on both sides of the tray or vessel shell, and all heat exchanger tube-to-tube sheet joints exposed to process solutions should be seal-welded to eliminate crevices.

- All internal and external attachment pads must be welded all the way around to avoid pockets. The use of weld backup strips should be avoided. If used, the strips should be completely seal-welded in all areas contacting process solutions or vapors.

- The faces of all cut surfaces in contact with process or decontamination solutions must be buttered to avoid end-grain corrosion.

\section{Stress Corrosion Cracking of 300 Series Stainless Steel Parts}

During fabrication and installation, the total chloride level for any material in long term contact ( 3 months or more) with stainless steel must be limited to 250 ppa per SRP Specification 5992. Controls must be exercised to minimize exposure of stainless steel to chlorides and/or other contaminators which cause stress corrosion cracking, or to remove chloride bearing materials by thorough cleaning if contact is unavoidable. Chloride-bearing items which have caused stress corrosion cracking of 300 series stainless steel at SRP include cutting fluids, welding flux, neoprene gaskets, plastic and painted labels, caulking compounds, marking pencils, thermal insulation, and PVC tape. The guidelines for minimizing stress-corrosion cracking sutlined in specification 5992 must be followed.

\section{Vessel Arrangements and Details}

- Insofar as practical, the top head arrangement should be standardized regarding the size of agitator openings, size of pump openings, and the nozzle circle in the interest of standardizing jumper, pump, and agitator designs to the minimum number of configurations.

- The arrangement shall be such that the space below all nozzles and other openings are free of obstruction from coils, coil support, or other internal items which would interfere with insertion of pumps, agitators, dip tubes, etc. 


\section{PART TITLE: SPECIAL EQUIPMENT -- DESIGN BASIS/CRITERIA}

ITEM TITLE: Cell Tanks, Vesse1s, and Specialized Auxiliary Equipment

- Provide for complete pumpout of vessels as nearly as possible. Avoid bottom outlets.

- Make all remote connections and lifting lugs sufficiently visible through the crane viewing system to permit removal and installation of all piping and equipment.

- Designs should be kept as simple as possible consistent with the intended purpose, to minimize the degree of skill required for operation and maintenance. On more complicated equipment consider subassemblies which can be removed remotely to facilitate decontamination, repair or replacement.

- To the extent that it can be economically justified, in-cell vessels should be limited to a minimum number of standard sizes and be as large as practical to gain full advantage of utilizing standard accessories (jumpers, pumps, agitators, etc.).

- All equipment normally operating at elevated temperatures should be insulated or cooled or both so that outside surface temperatures are $50^{\circ} \mathrm{C}$ or less.

- All coils in vessels must be kept pressurized automatically by air, water, or condensate to keep coil pressure higher than vessel pressure whenever cooling or heating of the vessels is not required.

- Each vessel except those connected to the melter off-gas system must have an overflow at the top of the tank and a nozzle for a connection to the vessel vent system. The overflow should be piped to discharge near the cell floor. $\star \star V e s s e l s$ serving as evaporators or operating on total reflux should have their vent and overflow points downstream of the condenser and deentrainment and stripping columns (if any) or may have conservation vents on the vessels. ${ }^{\star \star t}$

- Openings in vessels at entry points for agitator shafts, pumps, etc. should be kept sufficiently small so that the controlling pressure drop for limiting air flow into a vessel is through the overflow (see Part 5, Item 420).

Acme Studs and Nuts

Acme studs and nuts are used to bolt equipment to vessels and for bolting main body flanges on gasketed surfaces. Design and material requirements for the $2-i n$. studs to be used is shown in D118033. Studs are attached to equipment flanges with two No. 9 taper $p$ as and a $1 / 4-i n$. fillet weld at the bottom as shown in D137949. The length of the stud shank is equal to the thickness of the equipment flange plus $1 / 4 \mathrm{in}$. When space will not permit use of taper pins, the alternate weld fastening shown on D138653 Section "V-V" is acceptable. 
PART TITLE: SPECIAL EQUIPMENT -- DESIGN BASIS/CRITERIA

ITEM TITLE: Cell Tanks, Vesse1s, and Specialized Auxiliary Equipment

The overall length of an Acme Stud is based on the requirement of the impact wrench that there be a length of $6-7 / 8$ in. from the top of the stud to the bottom of its mating nut after impaction.

Acme studs shall be located to have their ccaterline a nominal 2 in. from the edge of a flange. This is necessary to permit the shank of the impact wrench to rest against the flange edge and to provide the necessary resistance for impacting. If rotation of the wrench must be limited to a predetermined orientation to prevent damage to nearby equipment, lugs shall be welded to the edge of the flange.

From a test of a stud/nut assembly, loads in the range of 40,000 to $50,000 \mathrm{lb}$ were developed after 10 to 12 seconds of impacting. The time-load curve flattens after 12 seconds so that further impacting does not increase the load proportionately. Using the values obtained, the torque developed at the pitch line of the threads will be (assumed coef. of friction - 0.1):

$T=\frac{1.806 \mathrm{in} . P_{.} \text {. }_{1}}{2} \times \tan (2.30$ thread angle +4.70 friction angle) $\times 40,000$ to $53,0001 \mathrm{~b}=5,100$ to $6,750 \mathrm{lb}$ in.

This torque applied to the double pitch Acme threads on the studs will develop a pull of (assumed coef. of friction $=0.1$ ):

$\mathbf{P}=$ 5,100 to $6,750 \mathrm{lb}$ in. torque $\frac{1.8754 \text { in. P.D. }}{2} \times \tan \left(4.8^{\circ}\right.$ thread angle $+2 \times 5.7^{\circ}$ friction angle $)$

$=19,000$ to $25,0001 \mathrm{~b}$

Since these values are based on assumed friction coefficients, limits of 20,000 to $30,000 \mathrm{lb}$ were used as the basis for design of the flanges and stud fastening.

When using studs on equipment which will not permit the shank of the impact wrench to clear in the vertical dimension, use a Dutchman as shown on Detail 2 and 7 of D-137901.

The bolt holes of mating flanges through which the Acme studs pass shall have nut retainer rings $3-11 / 16$ in. inside diameter $\times 3-5 / 16$ in. outside by $1-1 / 2$ in $h i g h, a 11+/-1 / 16$ in. placed around them. The rings are welded to the back (top) side of the rating flange by a 1/8-in. fillet on the outside diameter.

The design and material requirements for a 1-in. Acme nut are shown on D-136208. 
PART 20

ITEM 200

PAGE 6 of 7

DATE 9-82; Rev. 9

\section{PART TITLE: SPECIAL EQUIPMENT -- DESIGN BASIS/CRITERIA}

ITEM TITL: Cell Tanks, Vessels, and Specialized Auxiliary Equipment Equipment Locating Dowel Pins

Two-in. diameter dowel pins are used for locating and orienting equipment attached to other equipment. Two dowels are normally required to locate an equipment item; these must be of different lengths to enable a crane operator to first engage the longer dowel and then to move slowly to engage the short dowel. Drawing $D-118032$ shows the details and material of construction for a 2-in-diameter dowel.

Trunnions and Trunnion Guides

Each major in-cell equipment space is provided with a pair of permanent trunnion guides to precisely locate the equipment. Design and material requirements for a trunnion guide are shown on D127519B and D127520B; W146665 shows a typical arrangenent of a vessel equipped with its trunnions and supports.

Trunnion guides shall be installed to retain their orientation for earthquakes less than the DBE (see Part 4, Item 700). **The installation requirements should incorporate how the tiunnion guide $\pm 1 / 32$ tolerance should be systematically maintained during construction via designs comparable to $D-127719, W-146424$, and $W-706916$. The trunnion guide layout should be referenced to the permanent building bench mark. $\star \star$

Material of Construction and Corrosion Evaluation

The material of construction silected for piping and equipment must be compatible with process chemicals at the concentration given in the flowsheet.

All materials purchased for fabrication of process equipment and piping must be corrosion evaluated in accordance with Du Pont Standards SW $800 \mathrm{M}$ or Specification 4498 for $304 \mathrm{~L}$ stainless steel. Additional testing specifications may be required after final selection of the materials of construction.

Most of the design drawing references cited in this part and elsewhere specify 304L which is the material used at SRP. These may need to change after flowsheet compositions and concentrations are confirmed.

Fabrication Tolerances

High Maintenance Equipment

(Pumps Agitators)

$+/-1 / 16$

Melter Frame, Wall and Vessel

Nozzles ( $X, Y$ and $Z$ )

Spec. SG2S 
PART TITLE: SPECIAL EQUIPMENT -- DESIGN BASIS/CRITERIA

ITEM TITLE: Cell Tanks, Vessels, and Specialized Auxiliary Equipment

$\begin{array}{ll}\text { Melter Frame, Wall and Vessel } & 0.0025 \text { ins per in } \\ \text { Nozzles (Tilt) } & \\ \begin{array}{l}\text { Trunnions, Trunnion Supports and } \\ \text { Equipment Positioning Guides }\end{array} & +/-1 / 16 \\ \text { Vessel Support Feet (Levelness) } & +/-1 / 16 \\ \text { Rack Piping (Permanent Sections) } & +/-1 / 16 \\ \text { Jumpers (X, Y and } Z \text { ) } & \\ \begin{array}{l}\text { Cell Floor Sleepers (Levelness of those } \\ \text { common to one vessel) }\end{array} & +/-0.005 \text { ins }\end{array}$

Fabrication Cleaning and Shipping Requirements

All canyon vessels shall be fabricated in accordance with the ASME Boiler and Pressure Vessel Code Section VIII, Division 1; but only those vessels which fall within the scope of Section $D-1$ shall require a code and national board stamp.

All welding is to be done in accordance with techniques recormended by Du Pont Standards for the selected material of construction.

All welds in contact with process solutions require $100 \%$ radiographic inspection with acceptance criteria per Paragraph UW-51, Sectrion VIII of the ASME Boiler Code. Liquid penetrant inspection of the root and final weld pass is required for all containment welds which cannot be inspected by radiography. (For welds in vessels requiring a Code Stamp, Boiler Code procedures predominate.)

To assure that the dimensional tolerances are met, only those fabricators should be chosen:

- Who can fully demonstrate the capability to manufacture the complete unit.

o Who are code-qualified fabricators for the shell and coil and then ship the unfinished unit to a specialized fabricator with demonstrated ability to meet the tolerances.

- Who are code-qualified fabricators for the shell and coil and then ship the unfinished unit to SRP for completion of the tolerance i tems.

Cleaning of vessels is required by the fabricator to remove all oils, grease, weld splatter, dirt and other soils. 
PART TITLE: SPECIAL EQUIPMENT -- DESIGN BASIS AND CRITERIA

ITEM TITLE: In-Cell Piping and Nozzles

Transfer of chemicals to the process cell, process solutions between cells, and transmission of power and instrument signal to, from, and between cells is accomplished through piping and conduit embedded in the concrete shielding or dividing walls of the cells. Transfers and transmissions to, from, and between vessels and equipment in the cells is made using pipe and electrical jumpers. Each jumper is an individual length of pipe with connector blocks and connector assemblies at each end. The block fits into a remotely operated connector assembly which mates the block with flanged nozzles on walls, vessels, or other jumpers. **Jumper length and complexity should be minimized consistent with equipment and building arrangement requirements. ${ }^{\star \star}$

Pipe Jumpers

There are two basic sizes of blank connector blocks shown on D138570 used for liquid or gas jumpers at SRP. There are:

- A 5-1/2 in. (nominal) diameter x 4.50-in. high block and

- A 5-1/2 in. (nominal) diameter $\times$ 5.50-in. high block.

These two blank sizes are drilled to provide the variety of multiport connector blocks shown on D138602 to D138609 and D138618. These blocks are designed specifically for use with gaskets retained by a snap ring which prevents the gasket from rotating during impaction. Gasket location is particularly important for multiport blocks.

Changes required to the above basic blocks to permit the use of an unretained "lampshade" gasket are shown on D138708. The specific change is a decrease of approximately $18 \mathrm{mils}$ in raised face to compensate for the metal thickness of the gasket holder shown on D111716, Detail 1. These two blanks are drilled to provide the variety of blocks shown on D138617 and D138618.

Drawing Dl 38584 is a special block design used to support resistance temperature devices (RDT) at the vessel nozzles. The appropriate thermowell (shown on D138562) is added to the special block.

Cell pipe jumpers are attached to their mating wall or vessel nozzles by using the appropriate connector assembly selected from W234777. The assembly selected depends only on the orientation and size of the block and is independent of the type of gasket (snap ring or lampshade) used. However, assemblies with lampshade gaskets are identified by painting the upper surface of the jaw guide with red paint. 


\section{PART TITLE: SPECIAL EQUIPMENT -- DESIGN BASIS AND CRITERIA}

\section{ITEM TITL: In-Cell Piping and Nozzles}

A special connector assembly shown on W232452, "General Agreement for Tube Pulled Nozzle," is used when the services required by a piece of canyon equipment exceeds the number of embedded pipe nozzles readily available. A bundle of 8 ix tubes, 1/2-in. OD $x .065-i n$. thick wall is pulled through a free 3-in. diameter embedded pipe.

Drawing W133996 is an arrangement of an in-line connector used for rack piping when the hold up resulting from rack expansion loops can not be tolerated.

These arrangements, now used at SRP, should also be used in the DWPF. All of the types described may not be required and some new types may need to be designed for special DWPF equipment. Deviations from designs in use should be kept to a minimum.

\section{Electrical Jumpers}

Instead of the connector blocks described under pipe jumpers, electrical jumpers terminate in an assembly called "upper holder" which mates with a "lower holder" instead of a flanged nozzle. Three types of lower and two types of upper electrical holders are in use at SRP.

Each lower holder has three strike plates (or kick plates) separated radially by $120^{\circ}$ with which the clamping jaws of the upper connector are aligned and make initial contact when connecting. The alignment of the kick plates and clamping jaws has a secondary function: namely, when removing a jumper, the jaws lower onto the kick plates and push the rest of the body of the upper holder upwards and thus break any pressure seal that may have formed with the gasket. Each has six electrical studs on $60^{\circ}$ spacing and $30^{\circ}$ spacing off the center line of the kick plates.

Each is equipped for a conduit entrance. Details are shown on drawings D138234, D138278, and D138235. Uses of lower holders are shown on W234207.

Each upper holder has three clamping jaws separated radially by $120^{\circ}$. A 2-in. conduit entrance is provided midway between two of the clamping jaws and diametrically opposite the third jaw. Each has three skirt sections between adjacent jaws which serve the double function of shedding moisture away from the contact points and acting as a guide when being installed on a lower connector. Details are shown on drawings D138261, D138279, and W234198. 


\section{PART TITLE: SPECIAL EQUIPMENT -- DESIGN BASIS AND CRITERIA}

ITEM TITLE: In-Cell Piping and Nozzles

For the DWPF many canyon vessels will require electrical power to two or more pumps on a vessel. To minimize the number of electrical connections at the wall, it is preferred that one wall connection service two pumps requiring a lower holder on the vessel, which in turn connects to a lower holder at each of two pumps. Where in the past the lower holders and conduit was bolted to the vessel, it is now preferable to make this a remotable electrical "harness." Drawing W233718 shows an arrangement of three such harnesses serving six different users on a bicylindrical tank used at SRP.

Improved electrical and electronic transmission connectors will be required for the DWPF for thermocouple, CCTV, and other low-level signals. Development works on design of such connectors is in progress at SRP. Also the wiring and terminal blocks in embedded SRP electrical piping cannot be replaced. Wiring and terminal blocks in DWPF design must allow removal and replacement of wires and terminal blocks including all electrical contacts.

\section{Wall and Vessel Nozzles}

All nozzle gasket faces must be designed to be $3-5 / 8$ in. $+/-1 / 8$ in. from a kick plate on the nozzles to permit the connector jaws to break the seal between the connector gasket and the nozzle flange. On vessels the top head may serve as the kick plate. Kick plates should be at least 1/4-in. thick and be rigidly supported to minimize dislocation of the nozzle.

Drawing D138620 shows the designs of special butt-welded nozzles used on embedded piping to connect with jumper connector assemblies at SRP.

Drawing D138553 shows a blank flange which can be drilled to give the variety of configurations shown on D138597 through D138600. Multihole flanges on D138599A and D138599B are the only ones normally used. The others were used for special projects.

Drawing D138599A is used for embedded sample piping and D138599B is used for lubrication lines, pneumatic instrument lines and for embedded condensate piping.

\section{Corrosion and Erosion Allowances}

No corrosion allowance is required for cell piping. Erosion allowance of special linings may be required pending result of on-going research. It is anticipated that frit-containing slurries will be abrasive; therefore, frit-containing slurry transfers should be routed only through replaceable piping. **Where this is impossible (such as in some embedded piping) use replaceable liners to protect the piping. 


\section{PART TITLE: SPECIAL EQUIPMENT DESIGN BASIS/CRITERIA}

\section{ITEM TITLE: Evaporators, Batch and Continuous}

All evaporators in the operating cells must be remotely replaced by the overhead maintenance crane. Major components such as condensers, tube bundles, columns, agitators, pumps, etc., should be separately removatle for decontamination and repair or replacement. All evaporators in the cells must be insulated or cooled or both to limit external temperatures to a maximum of $50^{\circ} \mathrm{C}$; however, the insulation must not interfere with the remote handling features described above.

Evaporators located outside the operating cells may be of more conventional design because remote removal and maintenance are not required; however, most other design features given in Part 20, Item 200 are generally applicable, particularly those in Part 6, Item 301 of the Canyon Design Guide. Since all evaporators, in or out of the cells, normally will contain various levels of radioactive material it is required that the ease of maintenance is a necessary design feature to reduce the radiation exposure of maintenance personnel.

All evaporators, continuous or batch, should be capable of being emptied as completely as possible.

** Steam and cooling water should be provided in separate remoteable coils in the evaporator pots. ${ }^{\star *}$ Steam pressure to evaporators inside canyon cells where steam must enter through embeded pipe should be limited to a maximum of 195 psig. Steam to evaporators outside the cells are limited only by available supply pressure.

Agitators should be provided on evaporators expected to contain significant amounts of undisolved solids.

All coils must be kept pressurized automatically by air, water or condensate to keep coil pressure higher than vessel pressure whenever the unit is shut down.

**The evaporators should be designed to operate at a negative pressure of about two inches of water relative to the operating cell. ** 


\section{PART TITLE: SPECIAL EQUIPMENT -- DESIGN BASIS AND CRITERIA}

\section{ITEM TITLE: Glass Melter}

The glass melter located in the vitrification section of the DWPF is a liquid-fed melter designed to evaporate water from a process waste-frit slurry and melt the mixture at temperature of $1150^{\circ} \mathrm{C}$ so the molten glass can be poured into metal canisters.

Design bases and specific criteria are outlined below.

\section{General Requirements}

- Melter should be capable of remote removal and replacement.

- All melter components with an anticipated life of less than 2 years should be designed for remote replacement by either overhead crane, in-cell crane, master-slave, or electromechanical manipulator. Removal of a minimum amount of piping is acceptable to obtain access to melter components. Candidates for remote replacement are the thermocouple clusters, pour spout bellows, TV cameras, feed tubes, conductivity probe, bubbler, and other lid instrumentation.

- Melter size should be based upon a glass minimum melting rate of 8 $\mathrm{lb} /(\mathrm{hr}) /\left(\mathrm{ft}^{2}\right)$ of melt surface, for a glass melting rate of $228 \mathrm{lb} / \mathrm{hr}$.

- Provide auxiliary overhead lid heat to: (1) supplement melt joule heating, and (2) provide a method of melter startup. Amount of lid heat supplied must satisfy the $8 \mathrm{lb} /(\mathrm{hr}) /\left(\mathrm{ft}^{2}\right)$ melting rate criteria. Melter interior must be at least $650^{\circ} \mathrm{C}$ before joule heating is established.

- Provide two independent continuous feed ports located at opposite sides of the melter to simultaneously introduce the feed slurry close to the melt surface at low velocity. The intent is to introduce the feed in such a manner as to minimize penetration below the glass melt surface, thereby minimizing the possibility of a steam eruption. Feed lines at the melter should be cooled sufficiently to prevent boiling and plugging in the line. Cooling of the feed lines will be required during replacement to prevent cracking due to thermal shock.

- Melter feed is a slurry containing 40 wt. \% total solids.

- Provide for venting the pour spout and drain valve to the off-gas system during pouring or draining. At the completion of pouring (and after $1 / 2 \mathrm{hr}$ of cooling in place) or draining, the canisters may be vented to the melter cell atmosphere through a loose fitting cap. 
PART TITLE: SPECIAL EQUIPMENT -- DESIGN BASIS AND GRITERIA

ITEM TITLE: Glass Melter

- A bottom drain valve should be provided. Valve should be able to cycle at least enough times to empty melter contents into standard canisters filled to 3260 lbs each. SRL 13 planning to test various drain valve designs. Weight and level instrumentation should be provided to verify canister contents.

- Pouring can be either by differential pressure or by tilting. Differential pressure is preferred if a means can be developed to avoid canister overfill in the event melter is overpressurized with respect to pour spout.

- Melter external body surface temperature should be $50{ }^{\circ} \mathrm{C}$ maximum, to minimize cell updrafts when the cell covers are removed for melter repalr. When working on melter, power will be off, and cooling water flow reduced.

- Provide catch pans beneath melter to contain spilled glass in the event of canister overfill or melter fallure. Catch pans should be large enough to contain the amount of glass calculated to be displaced in the event of melter pressurization. This quantity will be determined by the off-gas dynamic study. The pans should have interconnecting overflow weirs and lifting lugs. Pans should be removable from beneath the melter for placement into burial boxes for eventual long-term disposal. A splash shield should be provided to protect the canister turntable mechanism.

- Components which contact the glass will be electrically hot. Jumpers for these components must be electrically isolated.

- Provide ground fault interrupters to minimize electrical hazard.

- For emergency power requirements, see Part 13, Item 560.

- Design basis frit is 131. See Table 21-6, Appendix H.

Specific Requirements

Glass Contact Materials

Glass containment refractory

Electrode material

Monofrax K3

Incone 1690

Upper S1dewalls and L1d

Vertical distance from normal melt level to the nearest upper sidewall penetration: 
PART TITLE: SPECIAL EQUIPMENT -- DESIGN BASIS AND CRITERIA

ITEM TITLE: Glass Melter

Monofrax $\mathrm{K} 3$ height above melt line:

9 in. min.

Monofrax K3 corrosiona

allowance on sidewall

above melt line:

$3 \mathrm{mlls} / \mathrm{day}$

No horizontal joints within $5 \mathrm{in}$. of melt 11 ne.

Freeboard: For disengagement space calculations, assume 1\% carryover of feed component particles. Measurements of particle size and distribution are being accumulated by SRL.

\section{Sidewalls Below Melt Line}

Monofrax $\mathrm{K} 3$ corrosion allowance

on sidewall:a

a) 2-4" below melt line

b) greater than $4^{\prime \prime}$ below melt line

$7.5 \mathrm{mils} / \mathrm{day}$

$5.4 \mathrm{mils} / \mathrm{day}$

Backup refractory materials:

(less than $800^{\circ} \mathrm{C}$ )

Zirmul, Alfrax

RAM Cement, Monof rax-M

Overall heat transfer coefficlent based on inside

$U_{\text {wall }}$ less than wall area or equal to $1.5 \mathrm{BTU} /(\mathrm{hr})$ $\left(f t^{2}\right)\left({ }^{\circ} F\right)$

\section{Melter Bottom}

Monofrax K3 corrosion allowance

on bottoma :

$3 \mathrm{mils} / \mathrm{day}$

Refractory hot side minimum

$1050^{\circ} \mathrm{C}$ temperature

asee note on Page 7. 
PART TITLE: SPECIAL EQUIPMENT -- DESIGN BASIS AND CRITERIA

ITEM TITLE: Glass Melter

\section{Melt Chamber}
Feedpile coverage:
$80-90 \%$ a
Glass temperature:
$1050-1170^{\circ} \mathrm{C}$
Residence time:
12 hrs. minimum

a $80 \%$ minimum coverage is to enhance melt rate and reduce radionuclide volatilization; $90 \%$ maximum is to avoid feed pile bridging.

\section{Melt Chamber Electrodes}

Material

Thickness

Corrosion rate ${ }^{a}$ :
Inconel 690

2 yr life min.

$1.3 \mathrm{mils} /$ day

$1.8 \mathrm{mils} /$ day

$1.6 \mathrm{mils} / \mathrm{day}$

c) 6" below melt line

Current flux

5 amps/in ${ }^{2} \max$.

DC component

less than $50^{\mathrm{b}} \mathrm{milliamps}$

Power skew ratio

$0.7-1.3$ times nominal

Internal bus bars

Inconel 690

For electrode penetrations below melt line, provide secondary containment seal to prevent glass leakage.

Throat

Throat angle

Throat cooling $10^{\circ}$ from horizontal min.

Optional(Min. glass temp. = $\left.1050^{\circ} \mathrm{C}\right)$

asee note on Page 7.

bIf silicon controlled rectifiers are placed on the transformer secondary, a DC elimination circuit will be required to keep the DC component to a minimum. 
PART TITLE: SPECIAL EQUIPMENT -- DESIGN BASIS AND CRITERIA

ITEM TITLE: Glass Melter

Throat (Cont'd.)

Glass velocity

a) Material

Upward weara

Horizontal weara (total, both sides)

or
b) Material
Corrosion ratea

Riser

Material

Corrosion rate

Glass temperature

Riser Electrodes

Material

Thickness

Corrosion ratea

Current flux

Internal bus bars

Pour Spout

Direct pour spout downward into canister nozzle

Pour spout temperature
20 in. $/ \mathrm{hr}$. $\max . *$

Monofrax K3

$12 \mathrm{mils} /$ day

$4 \mathrm{mils} / \mathrm{day}$

Incone 1690

$1.8 \mathrm{mils} / \mathrm{day}$

Monofrax $\mathrm{K} 3$

$5 \mathrm{mils} / \mathrm{day}$

$1050^{\circ} \mathrm{C}-1170^{\circ} \mathrm{C}$

Inconel 690

2 yr life min.

$1.8 \mathrm{mils} /$ day

5 amps/in 2 max.

Inconel 690

\footnotetext{
a See note on Page 7.

*For continuing design. CAB design has a glass velocity of about $100 \mathrm{in} / \mathrm{hr}$ in the throat.
} 
PART TITLE: SPECIAL EQUIPMENT -- DESIGN BASIS AND CRITERIA

ITEM TITLE: Glass Melter

\section{Me1ter Instrumentation}

- Provide for glass melt temperature measurement at three depths in two locations. Depths at each location should be different with respect to each other. Instrument range $100-1500^{\circ} \mathrm{C}$. Power to the glass is controlled by the $81 x$ melt temperature thermocouples.

- Provide for vapor space temperature measurement at one depth in one location. The well will contain from 3-7 sensors.

- Provide for refractory cold face measurement $6 \mathrm{in}$. below the melt line at two locations.

- Provide remote vlewing of the glass melt surface by means of TV. It is desired to have the capability of seeing all of the surface all of the t1me, therefore two cameras with wide angle lens are acceptable. The viewing area should at least include the two feed entry points, the feedpile between one feed point and the nearest sidewall, and a portion of the sidewall. The CCTV cameras proposed for the melter require cooling at all times, including installation and removal. Provision should be made in the design to meet this requirement.

- Provide method of determining foam and/or feedplle depth and radial distribution.

- Provide glass level measurement to reflect three operating levels:

Start of pour

Midway through pour

At completion of pouring

- Melter pressure rellef should be by seal pot. Design should minimize glass pouring when the melter equilibrates to seal pot pressure.

Seal pot pressure setting: One inch of $\mathrm{H}_{2} \mathrm{O}$. To reduce entrance, Iine and exit losses, pot should be close coupled to melter and ducts should be as large as practical. Assume off-gas line is unplugged with normal flow.

The seal pot is vented to the cell atmosphere in the CAB design. For continuing design, the seal pot should be vented to vessel vent system or of $f$-gas system to avold contamination of melter cell. 
PART TITLE: SPECIAL EQUIPMENT -- DESIGN BASIS AND CRITERIA

\section{ITEM TI."LE: Glass Melter}

- The melter pressure control system should be capable of handling periodic steam excursions of seven times the nominal melter off-gas flowrate lasting for a period of 8 minutes*. In addition, the rellef system should be large enough to handle an excursion of 12 times the steam generation rate for a perlod of $2.5 \mathrm{secs}$. Without pressurizing the melter to one $\mathrm{in}$. $\mathrm{H}_{2} \mathrm{O}$ above atmospheric. The relief system must also handle the normal alr leakage flow as well as rellef line and TV camera purges. Assume that control alr is shut off when the melter vapor space is pressurized. A velocity of $0.2 \mathrm{ft} / \mathrm{sec}$. Is recommended by Bechtel for the melter relief line, and $2.5 \mathrm{ft} / \mathrm{sec}$. for the camera port. The intent 18 to minimize the amount of glass pushed out of the melter in the event of abnormal vapor space pressurization.

- Melter off-gas temperature is controlled to $375 \pm 25^{\circ} \mathrm{C}$ at the melter exit port. Cooling of the gas stream to the specified temperature can be by water spray nozzle, steam, or by a dilution air nozzle. Water or steam spray should avoid refractory contact, by use of an Inconel liner through the refractory.

- Provide water sprays to cool the melt surface during idling to reduce radionuclide volatility.

- Provide Instrumentation to measure $\mathrm{CO}$ and $\mathrm{H}_{2}$ concentration downstream of quencher for combustibility determination.

*Seven times ( $7 \mathrm{X}$ ) off-gas flow excluding air 1nleakage and purges. Duration at $35 \%$ or more of peak height $(2.5 \mathrm{X})$ is one minute. Total duration is 8 minutes. continuous powder feed at $4.7 \mathrm{lb} / \mathrm{hr} / \mathrm{ft}^{2}$ of melt surface, electrodes uncooled, and melt depth of 10 inches. 


\section{PART TITLE: SPECIAL EQUIPMENT -- DESIGN BASIS/CRITERIA}

ITEM TITLE: Off-Gas Treatment Equipment

General criteria for the off-gas treatment is described in Part 5, Item 260 and DPSTD-80-38-2, Part 10, Item 250.

Design considerations for the off-gas treatment system are:

- off-gas blowers should have motor-driven butterfly valves in the suction and impact wrench operation in the discharge piping. The suction valves should also have mechanical closure capability using the crane impact wrench.

- Valves to control air bleed to the off-gas system should be located in the operating area of the building because of the anticipated frequency of maintenance. Considerations should be given to locating the valves in the mercury purification cell or the exhaust entry/exit hood of the cell. A jumper mounted filter in the melt cell and a block valve in the operating area may be required to isolate the control valve.

- As a basis for continuing design, the line between the pour spout and ejector should be heated to $800^{\circ} \mathrm{C}$ up to the point of control air addition to prevent condensation in the line. The control air addition should be located as close as practical to the melter. The entire line should be remotely replaceable.

- Provide for caustic, nitric acid, and water flush addition to the off-Gas Condensate Tank and Filter Pump Tank.

- Melter off-gas, after treatment, should be sampled for ${ }^{137} \mathrm{Cs},{ }^{90} \mathrm{Sr}$, ${ }^{106} \mathrm{Ru},{ }^{129} \mathrm{I}$, and mercury at a sample point downstream of the exhausters. Grab samples will be taken periodically.

- The recommended material of construction from melter exit to scrubber inlet should be "Inconel" 600 series, "Hastelloy" or similar alloy selected to resist corrosion from off-gas products.

- The two off-gas exhausters should be remotely replaceable.

- Water cooling systems require an independent pressurization source for individual coils or heat exchangers to minimize the potential for process backup into the service facilities.

- The ruthenium absorber and preheater and the $I_{2}$ absorber and preheater should be sized to last 6 years before replacement is required. 


\section{PART TITLE: SPECIAL EQUIPMENT -- DESIGN BASIS/CRITERIA}

ITEM TITLE: Off-Gas Treatment Equipment

- Intermittent gas samples are required downstream of the ruthenium and iodine absorber beds to detect breakthrough of either bed.

- A particulate sampler should be provided before the ruthenium absorber to measure efficiency of the scrubbing system. The sample will be taken periodically.

\section{Equipment Specifications}

\section{Quencher}

The function of the Quencher is to cool the melter off-gas below the dewpoint to achieve condensation, solids formation, and coalescing. Design for a vapor inlet temperature of 290 to $400^{\circ} \mathrm{C}$, and contacting of the vapor stream with a cooled circulating quench stream. Condensables and noncondensables discharge into the off-Gas Condensate Tank. The section of line through ventilation barrier connecting the Quencher to the off-Gas Condensate Tank need not be remoteable, since the Quencher is expected to remove residual solids from the gas stream.

Off-Gas Condensate Tank

The off-Gas Condensate Tank provides a collection reservoir for the condensables and the source of scrub solution for the Primary Deep Bed Filter and Quencher. Agitation should be provided that will suspend all solids. off-Gas Condensate Tank solution is purged to the Recycle Collection Tank.

The tank requires instrumentation to monitor temperature, specific gravity, and liquid level. A sampler is also required. (See Part 6, Item 100).

Pump-Quencher

Part of the contents of the Off-Gas Condensate Tank is circulated to the quencher. The pump is on emergency power. Monitor discharge pressure and flow.

Pump-Primary Deep Bed Filter

This pump circulates a portion of the contents of the off-Gas Condensate Tank through the spray nozzles to each stage in the Primary Deep Bed Filter housing.

\section{Cooling Coils}

The function of the cooling coils is to cool liquid circulating through the off-Gas Condensate Tank. Cooling water flow to be automatically controlled to maintain the quench stream entering the Quencher at the desired temperature. 
PART TITLE: SPECIAL EQUIPMENT -- DESIGN BASIS/CRITERIA

ITEM TITLE: Off-Gas Treatment Equipment

\section{Primary Deep Bed Filtera}

The function of the two stage Primary Deep Bed Filter is to scrub the majority of particulates from the vapor stream; the filter discharges into a two stage Secondary Deep Bed Filter. An acid-stable surfactant at a concentration of $10^{-3}$ wtz is used with the scrub stream to prevent plugging of the filters.

Filter Pump Tanka

The Filter Pump Tank provides a source of scrub solution for the two stage Secondary Deep Bed Filter. Scrub solution is pumped from the Filter Pump Tank to the off-Gas Condensate Tank on an overflow basis. Pumping is controlled by a level sensor that activates the pump on higher level and turns it of $f$ when the level is reduced to a practical minimum. The temperature of the vapor exiting the second stage of the Secondary Deep Bed Filter and the temperature of the scrub should be monitored. Liquid level measurement is also required.

Secondary Deep Bed Filter

The two stage Secondary Deep Bed Filter provides final scrubbing of the melter off-gas and discharges into the vapor space of the Filter Pump Tank.

\section{Pump - Filter Pump Tank}

This pump circulates a portion of the Filter Pump Tank contents through the two stage Secondary Deep Bed Filter spray nozzles.

\section{Off-Gas Condenser}

The off-Gas Condenser cools the vapor stream from the Filter Pump Tank to a temperature of $28^{\circ} \mathrm{C}$.

\section{Quencher}

A quencher is provided on the Filter Pump Tank to be used only when the of $f$-Gas Condensate Tank system is shutdown for repair. The bypass piping also permits bypassing the Filter Pump Tank through the adsorber beds and HEPA filters located on the exhausters inlet. When the bypass off-gas system is used, the melter is put into the idling mode. As a basis for continuing design, water is sprayed into the melter to reduce volatilization of particulates.

\footnotetext{
alternate scrubber arrangements are acceptable if they meet the DF requirements of Part 5, Item 260.
} 
DPSP $80-1033$

PART 20

ITEM 250

PAGE 4 of 6

DATE 9-82; Rev. 9

PART TITLE: SPECIAL EQUIPMENT -- DESIGN BASIS/CRITERIA

ITEM TITLE: Off-Gas Treatment Equipment

Ruthenlum Adsorber Preheater

The Ruthenlum Adsorber Preheater ralses the temperature of the vapor stream to $80^{\circ} \mathrm{C}$ by controlling electrical power to the heater.

Ruthenium Adsorber

The function of the Ruthenium Adsorber 18 to adsorb volatile ruthenium from the vapor stream. The recommended design parameters are:

- Adsorbent: Davidson Chemicals grade 40 -- sillca gel, 6 to 12 mesh

- Adsorbent capac1ty: 136 g ruthenium/ft ${ }^{3}$

- Bed depth: 52 in.

- Superficial face velocity: $0.4 \mathrm{ft} / \mathrm{sec}$ (maximum)

- Pressure drop: $0.6 \mathrm{ln}$. $\mathrm{H}_{2} \mathrm{O} / \mathrm{In}$. of bed at design face veloc1ty

- Efficlency: $99 \%$ for volat1le ruthenlum; $50 \%$ for particulates

The pressure drop across the bed should be monitored and the concentration of $106_{\mathrm{Ru}}$ should be intermittently monitored in the effluent to detect bed breakthrough. The temperature of the adsorbent should also be monitored throughout the bed. It may be necessary to concentrate a portion of the gas stream on a small adsorption bed located in the operating area and to monitor the radiation from this bed.

\section{Iodine Adsorber Preheater}

The Iodine Adsorber Preheater ralses the temperature of the vapor stream to $150^{\circ} \mathrm{C}$. Vapor temperature is controlled by adjusting electrical power to the heater.

Iodine Adsort 冉

The function of the Iodine Adsorber 18 to adsorb $I_{2}$ from the off-gas stream. The recomended design parameters are:

- Temperature: $1500 \mathrm{C}$

- Superficlal velocity: $0.82 \mathrm{ft} / \mathrm{sec}$

- Adsorbent: AgOZ (silver-exchanged mordenite) 
PART TITLE: SPECIAL EQUIPMENT -- DESIGN BASIS/CRITERIA

ITEM TITLE: Off-Gas Treatment Equipment

- Capac1ty: $100 \mathrm{mg} \mathrm{I}_{2} / 8$ of adsorbent

- Bulk density: $49.21 \mathrm{~b} / \mathrm{ft}^{3}$

- Collection efficiency: $99 \%$ for $I_{2}$

- Pressure drop: $0.5 \mathrm{ln}$. $\mathrm{H}_{2} \mathrm{O} / \mathrm{in}$. bed

- Gas residence time: greater than 2 seconds

- Insulation: Insulate adsorber to reduce thermal updrafts in cell.

- Active 11fe: 6 years

It may be necessary to concentrate a portion of the gas stream on a small adsorption bed located in the operating area and to analyze this bed off-line.

Off-Gas Cooler

The Off-Gas Cooler reduces the temperature of the vapor leaving the Iodine Adsorber to a level selected to prevent exhausters from overheating.

HEPA Filters

Two HEPA filters are connected in parallel to the exhauster inlet. One filter is on-line continuously; the second filter is used when off-gas equipment replacement is required.

Off-Gas Exhausters

The off-Gas Exhausters keep the melter under vacuum and pull the gases generated in the system through the Off-Gas Condensate Tank, F1lter Pump Tank and the process adsorbers.

The exhauster should be spared and on emergency power, so the spare comes online automatically if the other exhauster falls. Failure of either exhauster should automatically shut off feed to the melter.

Instrumentation to monitor vapor temperature and pressure at both the inlet and outlet of the exhauster are required. 
PART 20

ITEM 250

PAGE 6 of 6

DATE 9-82; Rev. 9

\section{PART TITLE: SPECIAL EQUIPMENT -- DESIGN BASIS/CRITERIA}

ITEM TITLE: Off-Gas Treatment Equipment

\section{Bypass System}

As discussed in Part 5, Item 260, a bypass system is required to continue exhausting melter gases while the melter is in the 1dling mode. The bypass system described below is one concept designed to meet this objective. See Appendix B, Figure 20-2 for detalls.

- Repalr or replace equipment assoclated with the off-Gas Condensate Tank (OGCT) or Primary Washed Deep Bed Filter (PWDBF):

Provide an alternative off-gas exit line with a quencher connecting between the melter-seal pot line and the Filter Pump Tank (FPT). Use of the by-pass line is controlled by a valve $(A)$ on the quencher inlet line. The alternate quencher on the FPT serves the same function as the quencher on the OGCT.

- Repalr or replace equipment assoclated with the FPT or Secondary Washed Deep Bed Filter (SWDBF):

Provide a line connecting between the PWDBF-FPT and the inlet to the Ruthenium Adsorber Preheater. A three way valve $(B, C)$ is required on each end of the by-pass line.

- Repair or replace equipment assoclated with the Ruthenium Adsorber Preheater (RAP), Ruthenium Adsorber (RA), Iodine Adsorber Preheater (IAP) or Iodine Adsorber (IA):

Provide a line between the FPT Condenser-Ruthenium Adsorber Preheater and the inlet to the HEPA filters. The line should contain a heater performing a similar function as the RAP and IAP. Three way valves are required in positions $C$ and $D$. 
PART TITLE: SPECIAL EQUI PMENT -- DESIGN BASIS/CRITERIA

ITEM TITLE: Mercury Purification Equipment

\section{General}

About $1.8 \mathrm{lb} / \mathrm{hr}$ of mercury will be recovered in the DWPF process. Mercury reduced to the metal in the Slurry Receipt and Adjustment Tank and in the Slurry Mix Evaporator is transferred to the Mercury Water Wash Tank in the Process Cell for washing. After water washing, mercury is sent from the Process Cell to the Mercury Purification Cell for further batch washing with acid and countercurrent washing with acid anc water in packed columns. Final purification is accomplished in a ventilated hood facility by vacuum distillation and mercury is packaged into storage bottles. Packaged mercury is stored in a ventilated storage area until transfer to the mercury storage building in 200-H Area.

\section{Design Criteria}

Equipment must be designed to process on a batch basis the mercury recovered from the waste sludge slurry.

A decontamination factor from radioactivity of at least $10^{6}$ must be provided by the purification facilities.

Each batch of mercury must be sampled and analyzed after the acid scrub and after distillation to verify effectiveness of purification operations.

Tanks in which mercury is to be handled must provide for collection, measurement and transfer of both mercury and aqueous solutions. Where batch washing of mercury is specified, an effective means of mixing mercury and aqueous solutions must be provided.

For the countercurrent washing steps specified, scrub columns must provide for effective dispersion of mercury and adequate contact time for washing. Spray, plate, packing or other type dispersion media should be considered.

A vacuum still is required to meet operating conditions below.

$$
\begin{array}{ll}
\text { Temperature } & -195^{\circ} \mathrm{C} \\
\text { Pressure } & -5 \times 10^{-2} \mathrm{~mm} \mathrm{Hg} \\
\text { Distillate Temperature } & -38^{\circ} \mathrm{C}
\end{array}
$$

Performance of the still should provide 100 lbs mercury distillate per lb of mercury bottoms, and a decontamination factor from radioactive fission products of $1 \times 10^{3}$ or greater. 
DPSP $80-1033$

PART 20

ITEM 255

PAGE 2 of 2

DATE 1-82; Rev. 8

PART TITLE: SPECIAL EQUI PMENT -- DESIGN BASIS/CRITERIA

ITEM TITLE: Mercury Purification Equipment

Ventilation of the still, storage bottle filling station and storage area must be adequate to protect operating personnel from mercury vapor.

An interim storage area accommodating 100 storage bottles of recovered mercury should be provided. 


\section{PART TITLE: SPECIAL EQUIPMENT - DESIGN BASIS/CRITERIA}

\section{ITEM TITLE: Canister Decontamination Station}

Two 1dentical decontamination stations are required. Either can be used for low pressure (overall) canister blasting or for high pressure (spot) blasting, thus permitting greater operating flexibility and permitting interchangeability of equipment.

Processing of canisters is described in Part 5, Item 275, and Figures 5-3, 5-6, and 5-9, Appendix B.

Following are criteria for the decontamination equipment:

\section{General}

- **The design must be capable of decontaminating all surfaces of the canisters (Including exposed Inner surface of the nozzle and exposed portion of inner plug).**

- Residual slurry or water are not to remain in the canister nozzle above the interim closure.

- The system must contain contaminated slurry, water, vapors, and frit to prevent spread of contamination throughout the cell and especially to the smear station.

$0 * \star$ The equipment must accommodate any glass that might be removed from canister surfaces. A method must be provided for removal and disposition of the glass. ${ }^{\star \star}$

- Slurries will contain frit, water and formic acld as set forth in Part 5, Item 275.

- The equipment must be designed for remote operation and maintenance or replacement.

- The equipment must also accommodate canister in overpacks. Overpack sizes are given in Part 20, Item 60.

Decontamination Chambers - shall

- be sealed from cell atmosphere and shall not, when open, permit liquid, mist, or frit to drip or be expelled to cell

- have means to flush contamination from all interior surfaces and to purge mist, water, slurry, and frit with chamber closed. **Air purge shall be at least $50 \mathrm{cfm}$ and exhausted through the formic acid vent system. $^{\star \star}$ 
PART TITLE: SPECIAL EQUIPMENT - DESIGN BASIS/CRITERIA

ITEM TITLE: Canister Decontamination Station

- have no bottom openings

- have erosion resistant surfaces (inside)

Spray nozzles - shall be

- **positioned about 2 to 18 inches from surface to be cleaned**

- directed at surface with an angle between 30 and 900

- $* \star$ individually removable by remote means in the CDC if possible, if not then by means of contact maintenance in the equipment decontamination cel1s**

- made of boron carbide or material with equal or better wear resistance

- flushable

Water and slurry source, pumps, tanks, and auxiliaries - shall provide

- frit slurry supply tank and spent frit hold tank sufficient for handling frit and water for six canisters, minimum.

- a source of variable high pressure water

o venting through vessel vent system

- a means to prevent backflow should the pressure of one component entering any common nozzle exceed that of the other component

- variable pressure for each mode of operation

- a source of variable low pressure air

Instrumentation and controls - provide

- temperature check to assure canister surface is below $100^{\circ} \mathrm{C}$ before decontamination begins

- canister position indexing and feedback ability to permit cleaning selected areas or bands

- liquid level indicator and alarms for each vessel

- cycle control with variable timing

- interlock for pumps with vessel cover closure

- pressure and flow rate instrumentation for water and for slurry 
PART TITLE: SPECIAL EQUIPMENT - DESIGN BASIS/CRITERIA

ITEM TITLE: Canister Decontamination Station

Canister pickup and handling - provide

- confirmation of canister grappler engagement

- **canister movement inside the vessel decon chamber independent of in-cell crane. Crane to be used only for insertion and removal of canister.

- means of removing canister in case canister grapple or handling mechanisms fail.

Working elements inside chambers (nozzle clusters, headers, etc.) - shall

o be removable

- have variable canister surface traversing speeds from $1 / 4$ to 4 inches/sec

- have sealed lifetime lubricated bearings

- have minimum moving parts exposed to decontamination chamber atmosphere 
PART TITLE: SPECIAL EQUIPMENT - DESIGN BASIS/CRITERIA

ITEM TITLE: Canister Smear Test (Decontamination Cel1)

**Requirements for smear testing after decontamination are set forth in Part 5, Item 276.** The sequence of operations is shown in Figure 5-3, Appendix B.

Requirements for the equipment are as follows.

\section{General}

- **A system is required to introduce clean smear papers to the smear test station and to return them to a shielded counting area (hood) outside the cell. $\star *$ Equipment is also required for counting smear paper activity. This system could share common parts with that for the final smear station in the weld test cell (see Part 20, Item 275).

- A method is required to smear those parts of the smear station that come into contact with, or are in close proximity to, the canisters to ensure that they have not become excessively contaminated. Methods are required to decontaminate or replace those parts.

- Materials of construction should, wherever practical, be compatible with decontamination solutions (see Part 14, Item 200).

- Facilities are to provide capability for visually examining the entire canister or overpack surface for residual oxide (not removed in decontamination), glass on the outer surface, and reading the identifying numbers.

- **A method is required for periodic cleaning of smear test area.**

Canister and Overpack Positioning

- The equipment must be capable of positioning the canister or overpack and/or implements to permit smearing of any place on the exposed surfaces of the canister, including the canister bottom, inside the nozzle, the lower surfaces of flanges, or patterns on the cylindrical surfaces.

- A system of indexing is required so that retesting of recleaned areas is possible.

- The positioning features are to be independent of in-cell handling equipment once the canister has been moved into position.

\section{Maintenance}

**The smear test station shall be designed for hands-on maintenance or replacement. ${ }^{\star \star}$ 
PART TITLE: SPECIAL EQUIPMENT-DESIGN BASIS/CRITERIA

ITEM TITLE: Canister Welding Equipment (Outer Closure)

The welding process is described in Part 5, Item 280, and shown in Figure 5-7, Appendix B.

Requirements for the DWPF welder are as follows:

- General

1. **Produce a weldment of 5 to 6 in. diameter.

2. Provide electrode force up to $150,000 \mathrm{lb}$ acting through a distance of $1 / 2$ inch minimum within a 2 second period and able to sustain force as long as weld current is on.

3. Provide ability to sustain an AC or DC current up to 300,000 amp, at about 11 volts, for up to 3.3 seconds. **

4. Electrode downstroke power is to be dry high pressure gas which may be lubricated if necessary. Hydraulic oils are not acceptable.

5. Equipment must be capable of performing a weld at least every 30 minutes without overheating of transformers.

6. Remote maintenance and/or replacement is not required. However, a method is required for remote removal of a canister from the welder, to shielded storage, should the equipment malfunction. **Welder must be designed so that replacement parts are sized for entry through an air lock from operating area. ${ }^{* \star}$

7. Materials of construction shall be compatible with decontamination solutions (refer to Part 14, Item 200), where practical, or the parts must be easily replaceable.

- Instrumentation

1. Provide measurement and digital displays for the following weld parameters :

a. In-line weld force (for example, using a load cell such as Strainsert model FL1500U-3SP)

b. Distance of electrode travel during weld (for example, by eddy current device such as Kaman Sciences Corp -- Multi-Vit)

c. Pressure in cylinder supplying force to electrode (for example, by strain gage transducer) 
PART TITLE: SPECIAL EQUIPMENT-DESIGN BASIS/CRITERIA

ITEM TITLE: Canister Welding Equipment (Outer Closure)

d. **Weld current (measurement at weld preferred but may be measured on busses).**

e. Pre-weld resistance measurement of welder secondary circuits (go-no-go measurement)

f. Current and voltage for transformer primary parameters

g. Time of weld duration

2. Provide dynamic recording with trace identification for all the above parameters during the weld.

3. Provide a printout of the static values of the above parameters with each identified on the printout.

- Control

1. Provide an automatic sequence control system (for example, using the Pertron PWC 300) for press, weld, hold, and off-timing.

The sequence is shown in Figure 5-3, Appendix B.

The sequence controller is to be operable in either a "weld" or "no-weld" mode. In the "no-weld" mode, the operation is to be automatically sequenced but the weld is not to be made.

Panel lights are to be provided to indicate "weld" or "no-weld" mode as well as the sequence step in progress.

2. Weld period is to be adjustable from 0 to $3.3 \mathrm{sec}$ (or 200 cycles of $60 \mathrm{~Hz}$ ).

$3 . \star *$ Provide an override weld timer. ${ }^{\star *}$

4. An adjustable amperage control is to be provided having a range of $40 \%$ to $100 \%$ of full cycle conduction.

5. Provide a controller to interrupt current if preset electrode force is not sustained through full weld time cycle.

6. $* *$ Electrode force is to be adjustable between 30,000 and 150,000 $1 b^{*}{ }^{\star \star *}$ 
PART TITLE: SPECIAL EQUIPMENT-DESIGN BASIS/CRITERIA

ITEM TITLE: Canister Welding Equipment (Outer Closure)

- Safety

Safety considerations are:

1. Transmission of high power to the welder

2. Use of high pressure gas

3. Application of high force to a loosely held work piece with potential for ejecting a projectile.

4. Application of insufficient force during the weld cycle with potential for splatter of molten metal. 
PART TITLE: SPECIAL EQUIPMENT-DESIGN BASIS/CRITERIA

ITEM TITLE: Overpack Welding Equipment

Requirements for welding overpacks are set forth in Part 5, Item 293. Requirements for the equipment are as follows:

- A gas tungsten arc (GTA) with helium/argon purge gas mixture is preferred.

- Multiple weld passes should make one continuous weld (no interruption between passes).

- The work piece should be rotated past a fixed torch to facilitate viewing of the welding.

- The weld should be made on a horizontal surface (i.e. down hand position).

- The equipment should be fully automatic, computer guided and controlled, including automatic weld and torch movement from pass to pass. Adjustments must be remote.

- The canister fixture should locate the torch squarely and accurately in relocation to the weld groove.

- The equipment must be capable of rewelding unacceptable welds.

- Maintenance of the welding equipment will be hands-on, after the canister is removed remotely. 
PART TITLE: SPECIAL EQUIPMRT -- DESIGN BASIS/CRITERIA

ITEM TITLE: Canister Final Smear-Test and Inspection Equipment

The requirements for examining canisters or canisters in overpack prior to Interim Storage are described in Part 5, Item 290 and shown in Figure 5-3, F-8, and 5-9, Appendix B.

Requirements for instruments and equipment to carry out these tests are given below.

General

- **A system shall be provided to introduce clean smear papers to the weld test cell smear-test location and to return them to a counting area (hood) outside the cell. ${ }^{\star \star}$ Equipment is also required for counting smear paper activity.

- Components and materials of construction should, wherever practical, be compatible with decontamination solutions. (See Part 14, Item 200.)

\section{Canister Positioning/Control}

- The equipment must be capable of positioning the canister and/or instruments for the following operations and tests:

- A minimum of two gross gamma radiation level measurements are required. The measurements should be made at a distance greater or equal to $22.75 \mathrm{ft}$ from the canister centerline (so that the canister acts as a point source) and from directions $180^{\circ}$ apart. The measurement must be made in an environment where the background correction is less than $5 \%$.

- Temperature measurements on canister surface at 3 elevations (22, 45 and 68 inches from the bottom) in any one circumferential position.

- Smearing of any place on the canister surface, including canister bottom, weld area, lower surfaces of flanges, any area observed to have residual oxide or selected bands on cylindrical surfaces.

- Visual examination-all surfaces of canister (including full weld circumference, canister bottom, etc.)

- Measure surface defects-depth and size of any damaged area.

- The system shall be programmable for each repetitive mode of operation (eg-smearing bands).

- Operator control shall be provided for non-repetitive operations (eg-smearing area with oxide). 


\section{PART TITLE: SPECIAL EQUIPMENT DESIGN BASIS/CRITERIA}

ITEM TITLE: Canister Final Smear-Test and Inspection Equipment

- The equipment must be capable of being indexed to a desired location along the length of the canisters for retesting.

- The smear test and inspection equipment is to operate independent of the in-cell handling equipment once the canister has been moved into position.

\section{Instruments}

- An air ionization chamber with an operating range from $10^{-2}$ to $10^{3}$ $\mathrm{R} / \mathrm{hr}$ would be suitable for gamma radiation measurement. Radiation levels expected are given in Part 11 , Item 430.

- Surface temperatures to be measured are expected to range from 300 to $150^{\circ} \mathrm{C}$. Spring loaded type $\mathrm{K}$ thermocouples would be suitable.

- Limits for contamination are given in Part 8, Item 350.

- Facilities are to provide capability for visually inspecting the entire canister surfaces to determine the integrity and to read identifying numbers. In addition, canister surfaces are to be visually examined for residual oxide (not removed at decontamination). Weld symmetry (full circumference), height of plug above flange, and presence of spots on bottom of grounding flange are to be examined.

- Defect measurement capability is to be provided to measure the width, length, and depth of surface defects as small as $1 / 8$ in by $1 / 8$ in by $1 / 8$ in deep.

\section{Data Collection}

- **Facilities are required to videotape the visual examinations.**

- Provide local readout at operator station. Data entry to central computer will be both direct and from operator teminal. See Part 6, Item 200 for record data input requirements to the computer.

\section{Maintenance}

- The smear-test and inspection station equipment need not be designed for remote maintenance or replacement. 
PART TITLE: SPECIAL EQUIPMENT -- DESIGN BASIS/CRITERIA

ITEM TITLE: Canister Transfer to Interim Storage

Equipment is required to transport filled canisters from the $221 \mathrm{-S}$ Building load-out cell to the 250-S Interim Storage Building. The method selected by the Design Division is a shielded transfer handing car. This section provides requirements for such a method, however alternative transport me thods would be acceptable.

The sequence of operations to be performed by the shielded canister transporter (SCT) in the present concept is as follows:

- SCT enters 221-s and positions over the load-out station

- Cell shield plug is removed

- Canister is transferred from the cell into the SCT shield chamber

- SCT chamber shield is closed

- Cell plug is replaced

- SCT travels to Interim Storage Building and positions at designated storage position

- Vault deck shield-plug is removed

- SCT Chamber shield is opened

- Canister is transferred to storage position

- Vault deck shield plug is replaced (Note: Sequence of removing shield plugs and positioning of SCT may change depending on design concept for Interim Storage Building and SCT)

Requirements for the SCT are:

\section{General}

- Shield cask shall be continuously capable of providing shielding on sides, top and bottom at all times (e.8., should the car be overturned or involved in an accident with a canister inside). The system shall also provide shielding at all times over open holes at loadout or storage.

- Shielding on the SCT vehicle shall reduce the exposure rate in the operator's cab to $0.5 \mathrm{mrem} / \mathrm{hr}$ and the exposure at all other locations on and around the SCT to $5 \mathrm{mrem} / \mathrm{hr}$ when shield plugs are removed or canisters are being handled or transported. The SCT vehicle will always move under traffic and HP escort.

- Requirements for earthquake and tornado resistance are contained in Part 4, It em 700. 
DPSP $80-1033$

PART 20

ITEM 290

PAGE 2 of 3

DATE $1-82 ; \operatorname{ReV} .8$

PART TITLE: SPECIAL EQUI PMENT -- DESIGN BASIS/CRITERIA

ITEM TITLE: Canister Transfer To Interim Storage

- SCT shall be an all weather vehicle with head, warning, obstruction, and equipment illumination lights. Roads are to be shared with other traffic. Maximum speed of SCT is to be $5 \mathrm{mph}$.

- Design shall facilitate decontamination of the equipment, specifically, plug and canister chamber interiors should be lined with stainiess steel.

\section{Specific}

- Lift grappler engagement and lock with the canister is to be confirmed before the canister is moved.

- A means shall be provided to confirm canister location when being raised, lowered or held in the chamber.

- Provision shall be made to prevent dropping of the canister in the event of power loss, and for auxiliary drives for raising or lowering of canister and operation of shield gates.

- Provide interlock or positive protection to prevent damage to canisters due to abnormal circumstances or equipment malfunction when canisters are being handled or when shield gates are being closed.

- If the vehicle is diesel driven it is to be refueled by an existing mobile tank truck.

- Instruments for monitoring radiation and airborne contamination to be provided for use during SCT operations are listed in Part 12, Items 110 and 120 .

- Minimum dimensions of the shielded cask chamber shall be sufficient to accommodate an overpacked canister. See Part 20, Item 60 for overpack size.

- The SCT shall be capable of removal of canisters from the vault for transfer to other storage positions. 
PART TITLE: SPECIAL EQUI PMENT -- DESIGN BASIS/CRITERIA

ITEM TITLE: Canister Transfer to Interim Storage

- **Maintenance and decontamination shall be performed in the 221-S Building. See Part 11, Item 110 for further information. **

- Operational cycles for the SCT vehicle and design capacity is to be based on movement of 24 hour output from the Building 221-s to Building 250-s each eight hour shift. The transfer operations will be carried out on a multi-shift basis during early start-up and training, but normal operation assumes that this might become a 40 hour a week daytime operation.

- Operator of the SCT shall have 2 way radio communication with the CCR in 221-S Building. 
PART TITLE: SPECIAL EQUIPMENT -- DESIGN BASIS/CRITERIA

ITEM TITLE: Process Vessel Vent System

Exhaust Fans

- A fan unit will consist of the motor, fan, couplings, and base **which are assembled as a single unit for remote handling. ${ }^{* *}$ An installed spare unit is required.

- The exhausters and motors are to be designed for long life, with the capability for remote addition of lubricating oil where required. Upon failure, the motor-fan unit will probably be discarded because the contamination level is expected to make it impossible to satisfactorily decontaminate the unit to permit repairs.

- An inertia base is required in addition to the mounting base; it may hold both **fan units. ** 


\section{PART TITLE: SPECIAL EQUIPMENT -- DESIGN BASIS/CRITERIA}

ITEM TITLE: Process Vessel Vent System

This equipment consists of an in-line air heater, a high efficiency filter, and redundant fans installed in the process cell. The installation is to be very similar to that provided for SRP under Project S9-2149, but sized for the DWPF ventilation requirements. Filcer design is to be very similar $L u$ that shown on Du Pont engineering drawing $D-116600$. All equipment must be made of $* * 304 \mathrm{~L}$ corrosion released $* *$ stainless steel where possible as it will be subjected to nitric acid fumes.

The major equipment must be remotely installed as units and joined together with gas line jumpers. The jumpers are to contain motur-driven butterfly vaives to provide isolation for automatic switching to a spare exhauster. The butterfly valves are to have mechanical drive capability also using the crane impact wrench. Electrical and instrument jumpers are to provide service for this equipment as needed. Design criteria for the system are:

In-line Air Heater

- **Process vessel vent conditions

- Inlet air to all vessels assumed to be at ambient conditions within the process cell.

- Outlet air from all vessels assumed to be saturated air at vessel operating temperature. ${ }^{* *}$

- This heater is to **increase** vent header air **temperature $10^{\circ} \mathrm{C} . * *$

- The heater is to be incorporated in the tilter inlet jumper.

- See Part 5, Item 405 for steam and condensate requirements.

Filter

- The existing SRP filter design provides for $25 \mathrm{fpm}$ air flow to attain the desired efficiency (greater than $99.9 \%$ )** for particulates. Volatiles are not removed. $*$ \%

- The high efficiency packing layer must be sealed around the edges to ensure ${ }^{*}$ efficiency.

o The filter will not be DOP tested atter installation.

을 A single filter is required.** 
PART TITLE: SPECIAL EQUIPMENT - DESIGN BASIS/ORITERIA ITEM

\section{ITEM TITLE: Process Cell Pumps}

Vertical, submerged centrifugal pumps without shaft seals and which can be installed in and removed from process vessels by the remotely operated process cell crane (Part 20, Item 180) are required. Pumps may be fitted with water jet primers.

Design features are as follows:

- No submerged bearings.

- Sealed bearings (no orovision for lubrication required).

- Standardized mountings, bearings, shafts, etc., wherever possible is allow interchange of motors and pumps.

- Corrosion resistant materials of construction.

- Automatic DC or regenerative braking of motors if the plimp cperate. above critical speed.

- Hardened or special alloys for impellers and casings where necessary to minimize erosion.

- Continuous service at maxinum ambient uperating temperature of $400^{\circ}$, the temperature of vessel contents may reach $100-110^{\circ} \mathrm{C}$ for pericds of time, but pumps will not be required to pump fluids above $50^{\circ} \mathrm{C}$.

- Maximum pump heels should be equivaleni to $1 ; 2$ inch of 1 iquid at thnominal tank diameter.

- Some pumped streams will require flow rate cortrol; a means for varying the speed of the pump mctors must be available for the pumps in those services.

- Air flow at the point of pump shaf atstry to the vessel must be into the vessel; however, the ilow must be sufficiently restricted so that most of the air entering a vesse $i$ is in..ougl: the ve:sel sierflow pipe.

- Lead or steel shielding where practical to minimize exposure of insulation or other organic materials to radiation.

Pumps and mountings will handle highly radioactive solutions and slurries and must be designed for free drainage and without crevices and inaccessible areas to facilitate decontamination and minimize exposure to maintenance personnel. 
DPSP $80-1033$

PART 20

ITEM 330

PAGE 2 of 2

DATE 9-82; Rev. 9

PART TITLE: SPECIAL EQUIPMENT - DESIGN BASIS/CRITERIA ITEM

ITEM TITLE: Process Cell Pumps

Motors should be totally enclosd, fan cooled (with metal fans) type NEMA design $B$ temperature rise with class $\mathrm{H}$ insulation. Motors may be subjected to sprays from process leaks and from high-pressure lances during decontamination prior to maintenance.

The number of different size pumps should be minimized to reduce spare part requirements and facilitate interchangeability. See Canyon Design Guide, DPE 3573, Part 7 for background and pump development information.

Rheology of solutions and slurries to be pumped is contained in Table 21-3, Appendix $H$. 
PAKT TITLE: SPECIAL EQUIPMENT -- DESIGN BASIS/CRITERIA

ITEM TITLE: Inter Area Transfer Pumps

The design features set forth in Part 20, Item 330 for process cell pumps apply to these pump tank pumps. However, the allowable heel in pump pit tanks is six inches. The basic design data for transferring sludge slurry through the inter-area piping and pump tanks are presented in $* *$ Table $21-3$, Appendix H.*** The sludge slurry is a Bingham plastic which is transferred at laminar flow conditions. The suggested rate is $3 \mathrm{fps}(70 \mathrm{gpm})$ through $3-\mathrm{in}$. pipe. Pump requirements are further established by flow loss and head changes in the inter area transfer system.

* Where possible, pump assemblies are to be identical to make for interchangeability of pumps with minimum replacement of connecting jumpers. However, $\frac{i}{n-x}$ the pumps in recycle waste transfer service may differ from those in slurry transfer service if different capacities or discharge heads are required. 


\section{PART TITLE: SPECIAL EQUIPMENT -- DESIGN BASIS/CRITERIA}

\section{ITEM TITLE: Special Process Cell Pumps}

Special pumps for sampling process slurries and solutions and for transferring mercury are required. The sample pumps should be small, all one size, fit through a typical 3-inch vessel nozzle, if possible, and capable of transferring slurries or solutions from a vessel to a sampling station without changing the composition of the material.

Mercury, collected from the process, must be pumped to a recovery facility. This may require a positive displacement pump with means for draining the discharge piping prior to removal of the pump or piping for maintenance.

Design requirements are as follows:

- Sealed bearings (no provision for lubrication **allowed**). No submerged bearings.

- Corrosion resistant materials of construction.

- Hardened or special alloys, where necessary, for parts subject to erosion.

- Lead or steel shielding where practical to minimize exposure of insulation or other organic materials to radiation.

- Continuous service at maximum ambient operating temperature of $40^{\circ} \mathrm{C}$. The temperature of vessel content may reach $100-110^{\circ} \mathrm{C}$ for periods of time, but pumps will not be required to pump fluids abcive $50^{\circ} \mathrm{C}$.

Rheology of solutions and slurries to be pumped is contained in ** Table $21-3$, Append ix $\mathrm{H}^{*} * *$

Sample pumps may be sealed and submerged provided they meet performance requirements and are sufficiently radiation resistant to handle process solutions and slurries. 


\section{PART TITLE: SPECIAL EQUIPMENT -- DESIGN BASIS/CRITERIA}

\section{ITEM TITLE: Process Cell Agitators}

Agitators of sufficient horsepower to satisfactorily mix DWPF slurries are required. Ideally one size will fit all process vessels. The agitator assembly must be capable of being installed in and removed from the cell by the remotely operated process cell crane (Part 20, Item 180).

Design features are as follows:

- No submerged bearings

- Sealed bearings (no provision for lubrication required)

- Standardized mountings, bearings, shafts, gear boxes, etc., wherever possible to allow interchange of motors and parts.

- Remotely separable drive arrangement containing the drive motor, bearings and reduction gears, if possible.

- Corrosion resistant materials of construction.

- Automatic DC or regenerative braking of motors if the agitator operates above critical speed.

- Hardened or special alloys for agitator blades and shafts where necessary to minimize erosion.

- Continuous service at maximum ambient temperature of $40^{\circ} \mathrm{C}$ and solution and slurry temperatures **up to $110^{\circ} \mathrm{C}$.**

- Air flow at the point of shaft entry to the vessel must be into the vessel; however, the flow must be sufficiently restricted so that most of the air entering a vessel is through the vessel overflow pipe.

Agitators and mountings will be exposed to highly radioactive solutions and slurries and must be designed for free drainage and without crevices and inaccessible areas to facilitate decontamination and minimize exposure to maintenance personnel.

Motors should be totally enclosed, fan cooled with (metal fans) **type NEMA design $B$ temperature rise with Class $H$ insulation. ${ }^{* *}$ Agitator motors may be subjected to sprays from process leaks and from high-pressure lances during decontamination prior to maintenance. 


\section{PART TITLE: SPECIAL EQUIPMENT - DESIGN BASIS/CRITERIA}

\section{ITEM TITLE: Design of Covered Burial Containers}

Provide the design for covered burial containers for final disposal of contaminated process cell equipment that has become obsolete or is unrepairable. Fabrication will be completed on an as needed basis. Assume all equipment, except the glass melter, has been sufficiently decontaminated so that no shielding is required beyond that afforded by the covered burial container.

**A shielded rail car capable of transporting a failed glass melter from the process building to burial is required. Design of the car should accomodate the weight of a full failed melter plus the shielding as stipulated in the following paragraph. Failed process cell equipment may be transported on this same car. ${ }^{* *}$

For the glass melter, assume a full charge of radioactive glass remains in the melter, and provide sufficient shielding in the burial container to reduce the radiation level to one $\mathrm{R} / \mathrm{hr}$ at one meter around the burial container. The exposure rate to the operator of the rail cab must be 1 imited to $50 \mathrm{mR} / \mathrm{hr}$. Protection of the operator may be accomplished by additional shielding of the burial container, maintaining sufficient distance between the burial container and the operator to reduce exposure, or providing shielding on the truck or rail cab. See Table 3-11 for a basis for shielding. 
DPSP $80-1033$

PART 21

ITEM 100

PAGE 1 of 1

DATE 9-82; ReV 9

PART TITLE: MISCELlane OUS PROCESS DATA

ITEM TITLE: Sludge Feed Composition

The composition of the Sludge Feed Stream is shown in Table 21-1, Appendix $H$. 
PART TITLE: MISCELLANEOUS PROCESS DATA

ITEM TITLE: Salt Plant Product Composition

The compositions of product streams that are blended with sludge plant feed during coupled operation are shown in Table 21-2, Appendix $H$. 
PART TITLE: MISCELLANEOUS PROCESS DATA

ITEM TITLE: Slurry Properties

Slurry properties are shown in Table 21-3, Appendix $H$.

**NEW ITEM** 
PART TITLE: MISCELLANEOUS PROCESS DATA

ITEM TITLE: Stoichiometry

The process reactions to be assumed for preparing material balances are 1 ist 1 in Table 21-4, Appendix H. Reactions 80 to completion unless otherwise noted. 
PART TITLE: MISCELLANEOUS PROCESS DATA

ITEM TITLE: Physical Property Data

Physical property data for process stream components are shown in Table 21-5, Appendix $\mathrm{H}$. 
PART TITLE: MISCELLANEOUS PROCESS DATA

ITEM TITLE: Glass Frit Characteristics

The chemical composition and characteristics of Frit 131 are 1 isted in Table $21-6$, Appendix H. 
PART TITLE: MISCELLANEOUS PROCESS DATA

ITEM TITLE: Properties of DWPF Waste Glass

The following physical properties of simulated DWPF waste glass using frit 131 are tabulated in Tables 21-7 through 21-14, and Figure 21-1, Appendix $H$.

Table

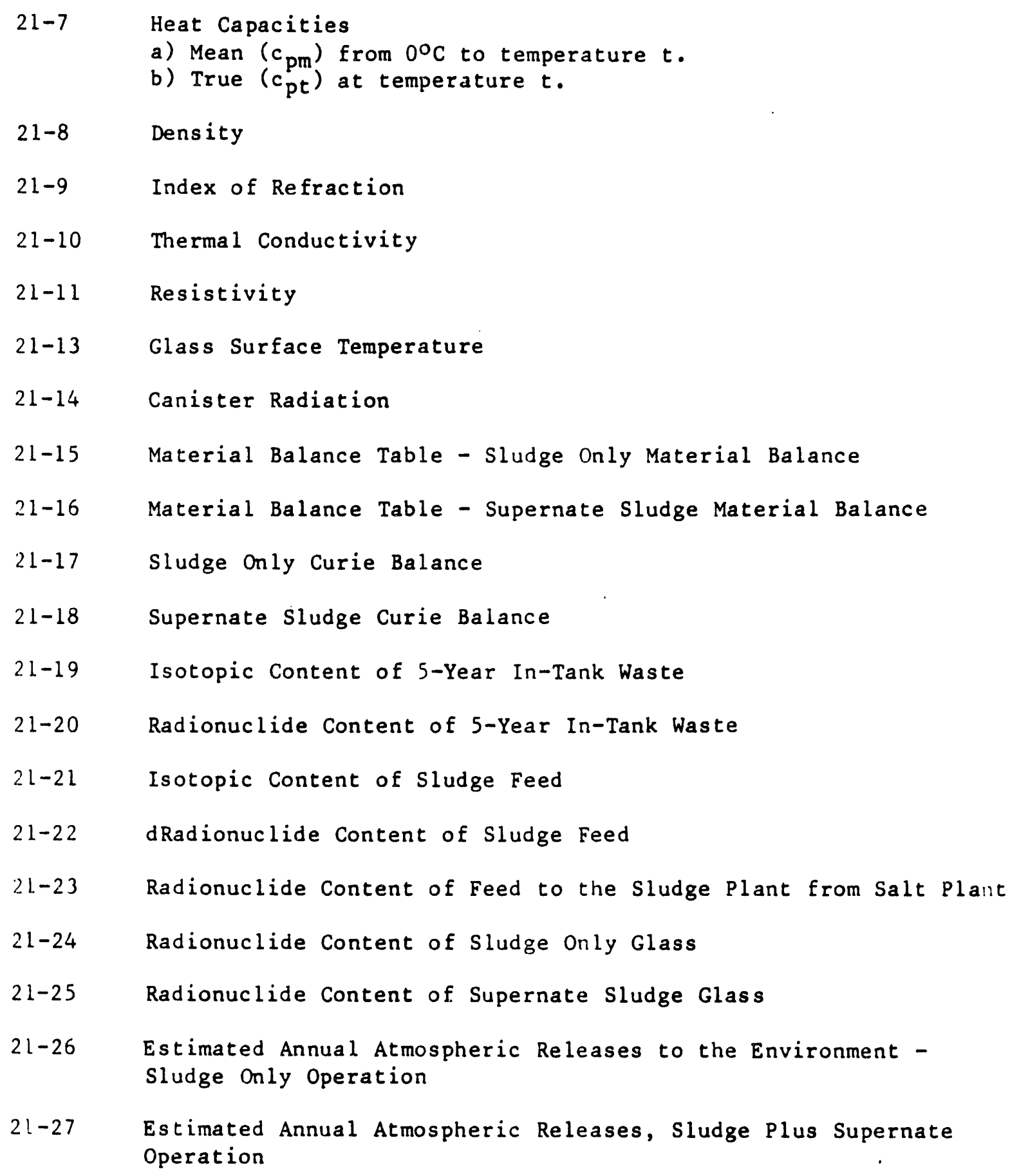


DPSP $80-1033$

PART 21

ITEM 400

PAGE 2 ot 2

DATE $9-82 ; P$. . Y

PART TITLE: MISCELLANEOUS PROCESS DATA

ITEM TITLE: Properties of DWPF Waste Glass

Figure

21-1 Thermal Expansion

21-2 Process Sumary Diagram - Melter Feed Preparation

21-3 Process Summary Diagram - Vitrification and off-Gas Treatment

21-4 Process Summary Diagram - Mercury Purification and Packaging

21-5 Process Summary Diagram - Decontamination and Miscellaneous Waste Stream Treatment

21-6 Process Summary Diagram - Canister Decontamination Closure and Inspection

21-7 Sludge Only Glass Canister Decay Heat

21-8 Sludge Supernate Glass Canister Decay Heat 
APPENDIX A

DPSP 80-1033

TABLE 3-1

PAGE 1 of 1

DATE 6-80

TABLE 3-1

AREA LIGHTING REQUIREMENT

\begin{tabular}{|c|c|c|c|c|c|c|c|c|}
\hline \multirow{2}{*}{ Area } & \multirow{2}{*}{$\begin{array}{l}\text { Footcandle } \\
\text { Illiumination }\end{array}$} & \multicolumn{4}{|c|}{ Luminaire } & \multicolumn{3}{|c|}{ Location of Luminatres, ieet } \\
\hline & & Type & Beam & $\begin{array}{l}\text { Lamp } \\
\text { Size }\end{array}$ & Number & $\begin{array}{l}\text { Inside } \\
\text { Boundary }\end{array}$ & Height & Spacing \\
\hline \multirow{2}{*}{$\begin{array}{l}\text { Nonisolated } \\
\frac{\text { Fenced Boundaries }}{120 \text { feet inside }} \\
\text { to } 40 \text { feet outside } \\
\text { fence line) }\end{array}$} & 0.04 & Streetlight & $\begin{array}{l}\text { Medium Wide } \\
\text { Asymmetric }\end{array}$ & $10,000 \mathrm{~L}$ & 1 & 20 & 30 & $\therefore 15$ \\
\hline & $\begin{array}{l}0.04 \\
0.04\end{array}$ & $\begin{array}{l}\text { Streetlight } \\
\text { Streetlight }\end{array}$ & $\begin{array}{l}\text { Medium Wide } \\
\text { Medium Wide }\end{array}$ & $\begin{array}{l}6,000 \mathrm{~L} \\
4,000 \mathrm{~L}\end{array}$ & 1 & $\begin{array}{l}20 \\
20\end{array}$ & $\begin{array}{l}25 \\
25\end{array}$ & $\vdots \begin{array}{l}35 \\
: 65\end{array}$ \\
\hline \multirow{2}{*}{$\begin{array}{l}\frac{\text { Pedestrian }}{\text { Entrances }} \\
\text { (25 feet inside to } \\
25 \text { feet outside } \\
\text { boundary gate) }\end{array}$} & 2 & Streetlight & $\begin{array}{c}\text { Wide } \\
\text { Asymetric }\end{array}$ & $15,000 \mathrm{~L}$ & 4 & & 30 & $: 2.5$ \\
\hline & $\begin{array}{l}2 \\
2 \\
2\end{array}$ & $\begin{array}{l}\text { Floodlight } \\
\text { Floodlight } \\
\text { Floodlight }\end{array}$ & $\begin{array}{l}\text { Very Wide } \\
\text { Very Wide } \\
\text { Medium Wide }\end{array}$ & $\begin{array}{l}750 \mathrm{~W} \\
500 \mathrm{~W} \\
150 \mathrm{~W}\end{array}$ & $\begin{array}{r}3 \\
4 \\
15\end{array}$ & $\begin{array}{l}5 \text { at each } \\
\text { of } 3 \text { loca- } \\
\text { tions }\end{array}$ & $\begin{array}{l}25 \\
25 \\
25\end{array}$ & $\begin{array}{l}25 \\
\vdots 2.5 \\
50\end{array}$ \\
\hline \multirow{3}{*}{$\begin{array}{l}\text { Venicular } \\
\text { Entrances } \\
50 \text { feet inside } \\
\text { to } 50 \text { feet } \\
\text { outside boundary } \\
\text { gate) }\end{array}$} & 1 & Streetlight & $\begin{array}{c}\text { Wide } \\
\text { Asymetric }\end{array}$ & $15,000 \mathrm{~L}$ & 4 & & 30 & 25 \\
\hline & 1 & Floodlight & Very Wide & $750 \mathrm{~W}$ & 3 & & 25 & $\equiv 0$ \\
\hline & 1 & Floodlight & Very Wide & $500 W$ & 4 & & 25 & -5 \\
\hline \multirow{3}{*}{$\begin{array}{l}\frac{\text { industrial }}{\text { Thoroughfares }} \\
\text { 30 feet wide not } \\
\text { jordered by } \\
\text { buildings) }\end{array}$} & 0.05 & Streetlight & $\begin{array}{l}\text { Two-way } \\
\text { Four-Way }\end{array}$ & $6,000 \mathrm{~L}$ & 1 & \multirow{3}{*}{$\begin{array}{l}\text { Overhang to } \\
\text { center of } \\
\text { road } \\
\text { Overhang } \\
\text { side of road } \\
2 \text { feet }\end{array}$} & 25 & 225 \\
\hline & $\begin{array}{l}0.05 \\
0.05\end{array}$ & $\begin{array}{l}\text { Streetlight } \\
\text { Streetlight }\end{array}$ & $\begin{array}{l}\text { Four-way } \\
\text { Narrow } \\
\text { Asymetric }\end{array}$ & $\begin{array}{l}4.000 \mathrm{~L} \\
6.000 \mathrm{~L}\end{array}$ & 1 & & $\begin{array}{l}25 \\
25\end{array}$ & $\begin{array}{l}i \geqslant 0 \\
1 \geqslant 0\end{array}$ \\
\hline & 0.05 & Streetlight & Narrow & $4,000 \mathrm{~L}$ & 1 & & 25 & 100 \\
\hline \multirow{2}{*}{$\begin{array}{l}\text { Open Yards } \\
\text { PStorage and } \\
\text { parking areas) }\end{array}$} & & & & & & & & \\
\hline & $\begin{array}{l}0.10 \\
0.10 \\
0.10 \\
0.10\end{array}$ & $\begin{array}{l}\text { Floodlight } \\
\text { Floodlight } \\
\text { Floodlight } \\
\text { Floodlight }\end{array}$ & $\begin{array}{l}\text { Wide } \\
\text { Wide } \\
\text { Very Wide } \\
\text { Very Wide }\end{array}$ & $\begin{array}{r}1.000 \mathrm{~W} \\
750 \mathrm{~W} \\
500 \mathrm{~W} \\
300 \mathrm{~W}\end{array}$ & $\begin{array}{l}4 \\
4 \\
4 \\
4\end{array}$ & & $\begin{array}{l}60 \\
60 \\
40 \\
40\end{array}$ & $\begin{array}{r}125 \\
1: 3 \\
25 \\
: 8\end{array}$ \\
\hline
\end{tabular}

$L=$ Lumens $W=$ Watts 
TABLE 3-2

PROPERTYES OF GROUNO WATER FOR

OIFFERENT AQUIFERS IN THE SRP AREA

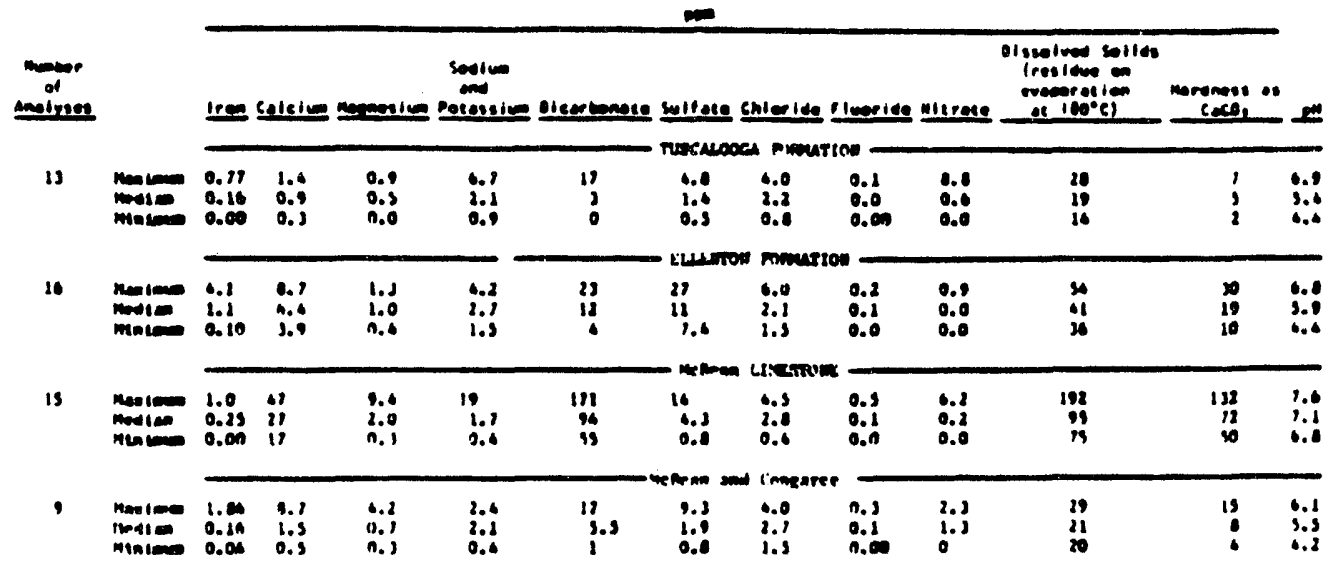

TABLE 3-3

ELEVATIONS OF HIGH LEVEL LIQUID HASTE TANKS

\begin{tabular}{|c|c|c|c|c|c|c|c|}
\hline \multirow[b]{2}{*}{ Area } & \multirow[b]{2}{*}{ Tonk } & \multicolumn{6}{|c|}{ Elevation. feet above mean sea level } \\
\hline & & $\begin{array}{l}\text { Tank } \\
\text { Type }\end{array}$ & $\begin{array}{l}\text { Grade } \\
\text { Level }\end{array}$ & $\begin{array}{l}\text { Tank Topa } \\
(\min )\end{array}$ & $\begin{array}{l}\text { Tark Bottom } \\
\text { (min) }\end{array}$ & $\begin{array}{l}\text { High Water } \\
\text { Tabze }\end{array}$ & $\begin{array}{l}\text { Low Water } \\
\text { Table }\end{array}$ \\
\hline $\mathbf{F}$ & $\begin{array}{l}1-4 \\
5-8 \\
17-20 \\
25-28 \\
33-34\end{array}$ & $\begin{array}{l}\text { I } \\
\text { I } \\
\text { IV } \\
\text { IIIA } \\
\text { III }\end{array}$ & $\begin{array}{l}280 \\
278 \\
268 \\
285 \\
284\end{array}$ & $\begin{array}{l}270 \\
267 \\
274 \\
286 \\
285\end{array}$ & $\begin{array}{l}243 \\
240 \\
229 \\
249 \\
248\end{array}$ & $\begin{array}{l}234 \\
234 \\
234 \\
234 \\
234\end{array}$ & $\begin{array}{l}228 \\
228 \\
228 \\
228 \\
228\end{array}$ \\
\hline H & $\begin{array}{l}9-12 \\
13-16 \\
21-24 \\
29-32 \\
35 \\
36-37\end{array}$ & $\begin{array}{l}\text { I } \\
\text { II } \\
\text { IV } \\
\text { III } \\
\text { III } \\
\text { IIIA }\end{array}$ & $\begin{array}{l}280 c \\
304 \\
322 \\
321 \\
323 \\
323\end{array}$ & $\begin{array}{l}270 \\
305 \\
328 \\
321 \\
324 \\
324\end{array}$ & $\begin{array}{l}243 \\
274 \\
284 \\
284 \\
287 \\
287\end{array}$ & $\begin{array}{l}282 \\
282 \\
282 \\
282 \\
282 \\
282\end{array}$ & $\begin{array}{l}274 \\
274 \\
274 \\
274 \\
274 \\
274\end{array}$ \\
\hline
\end{tabular}

a. Top surface of concrete roof of lowest tank in group. Access riser lips are about 8 in. higher than roof surface in Type II and III tanks, and several ft higher (i.e., about $1 \mathrm{ft}$ above grade) in Type I tanks. Elevations given for Type IV tank tops are for apex of domed roof; Type IV roof periphery is about $4 \mathrm{ft}$ below final grade.

b. Elevation of bottom steei of primary rank.

c. When the water table in the H-Area tank farm rises above the present grade level at Tanks 9-12, water seeps from the surrounding embankments and drains to the storm sewer. 


\begin{tabular}{|c|c|c|c|c|c|c|c|c|c|}
\hline \multirow[b]{2}{*}{ Month } & \multirow{2}{*}{$\begin{array}{l}\text { Average } \\
\text { Daily } \\
\text { Maximum }\end{array}$} & \multicolumn{2}{|c|}{ Temperature, ${ }^{\circ} \mathrm{F}$} & Extreme $T$ & $\mathrm{np},{ }^{\circ} \mathrm{F}$ & iverage & \multirow{2}{*}{\multicolumn{2}{|c|}{ ive Humidity, }} & \multirow{2}{*}{$\%$} \\
\hline & & $\begin{array}{l}\text { Daily } \\
\text { Minimum }\end{array}$ & $\begin{array}{l}\text { Monthly } \\
\text { Average }\end{array}$ & $\begin{array}{l}\text { Record } \\
\text { Maximum }\end{array}$ & $\begin{array}{l}\text { Record } \\
\text { Minimum }\end{array}$ & $\frac{\operatorname{Relat}}{1 \mathrm{am}}$ & & & \\
\hline January & 57.4 & 38.5 & 47.9 & 84 & 1 & 75 & 84 & 59 & 69 \\
\hline February & 59.8 & 39.9 & 49.9 & 84 & 3 & 72 & 82 & 56 & 63 \\
\hline March & 67.3 & 46.7 & 56.7 & 93 & 14 & 72 & 80 & 57 & 59 \\
\hline April & 75.2 & 53.1 & 64.1 & 94 & 29 & 74 & 77 & 48 & 56 \\
\hline May & 83.4 & 61.7 & 72.6 & 100 & 40 & 78 & 77 & 48 & 59 \\
\hline June & 89.4 & 68.9 & 79.3 & 105 & 46 & 82 & 79 & 51 & 64 \\
\hline July & 90.9 & 71.9 & 81.5 & 105 & 55 & 86 & 83 & 55 & 69 \\
\hline August & 89.7 & 71.2 & 80.5 & 105 & 58 & 87 & 87 & 56 & 71 \\
\hline September & 85.5 & 66.5 & 76.0 & 106 & 41 & 84 & 85 & 55 & 71 \\
\hline October & 76.2 & 55.0 & 65.5 & 94 & 29 & 79 & 84 & 50 & 70 \\
\hline November & 65.8 & 44.3 & 55.0 & 86 & 11 & 77 & 84 & 53 & 67 \\
\hline December & 57.9 & 38.6 & 48.3 & 81 & 5 & 77 & 84 & 58 & 70 \\
\hline
\end{tabular}


TABLE 3-5

OBSERVED TEMPERATURE EXTREMES

\begin{tabular}{|c|c|c|}
\hline & Temperature ${ }^{\circ} \mathrm{F}$ & $\begin{array}{l}\text { Observation } \\
\text { Date }\end{array}$ \\
\hline Lowest SRP & 1 & January 1982 \\
\hline Lowest Augusta & 1 & January 1982 \\
\hline Highest SRP & 105 & June 1970 \\
\hline Highest Augusta & 106 & July 1952 \\
\hline
\end{tabular}


TABLE 3-6

WINTER WEATHER IN AUGUSTA

\begin{tabular}{lc} 
Year & Time at less than $32^{\circ}$ \\
\hline $1966-1967$ & 212 \\
$1967-1968$ & 268 \\
$1968-1969$ & 278 \\
$1969-1970$ & 497 \\
$1970-1971$ & 422 \\
$1971-1972$ & 133 \\
$1972-1973$ & 353
\end{tabular}

\begin{tabular}{c}
$\begin{array}{c}\text { Average Minimum } \\
\text { Temperature, }\end{array}$ \\
\hline 28.2 \\
29.1 \\
29.3 \\
26.4 \\
26.2 \\
27.2 \\
25.7
\end{tabular}

Average Minimum 28.2 25.7 
TABLE 3-7

SAYAMMAH RIVER PLANT PRECIPIIATION SUMMARY

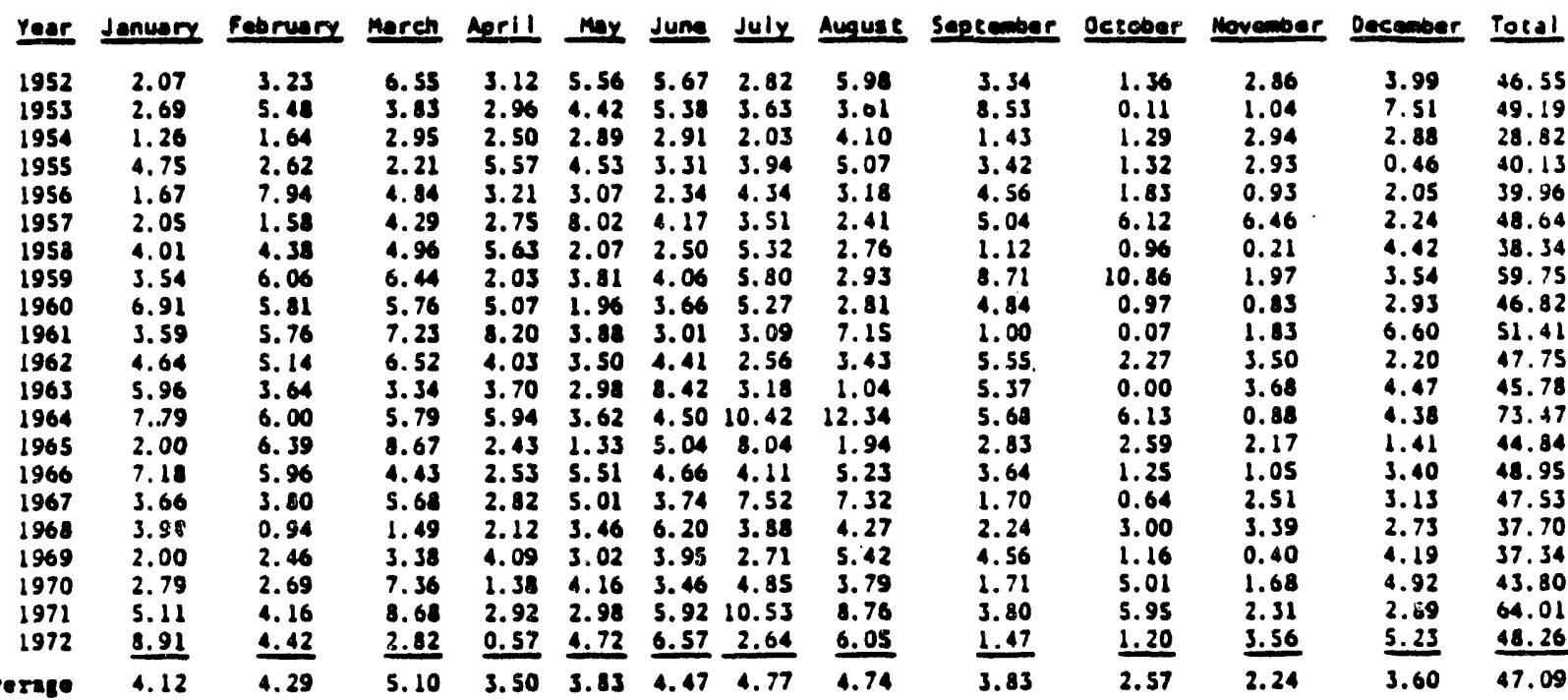

TABLE 3-8 loU FREQUENCY OF WIMO SPEED AT VARIOUS ELEVATIONS

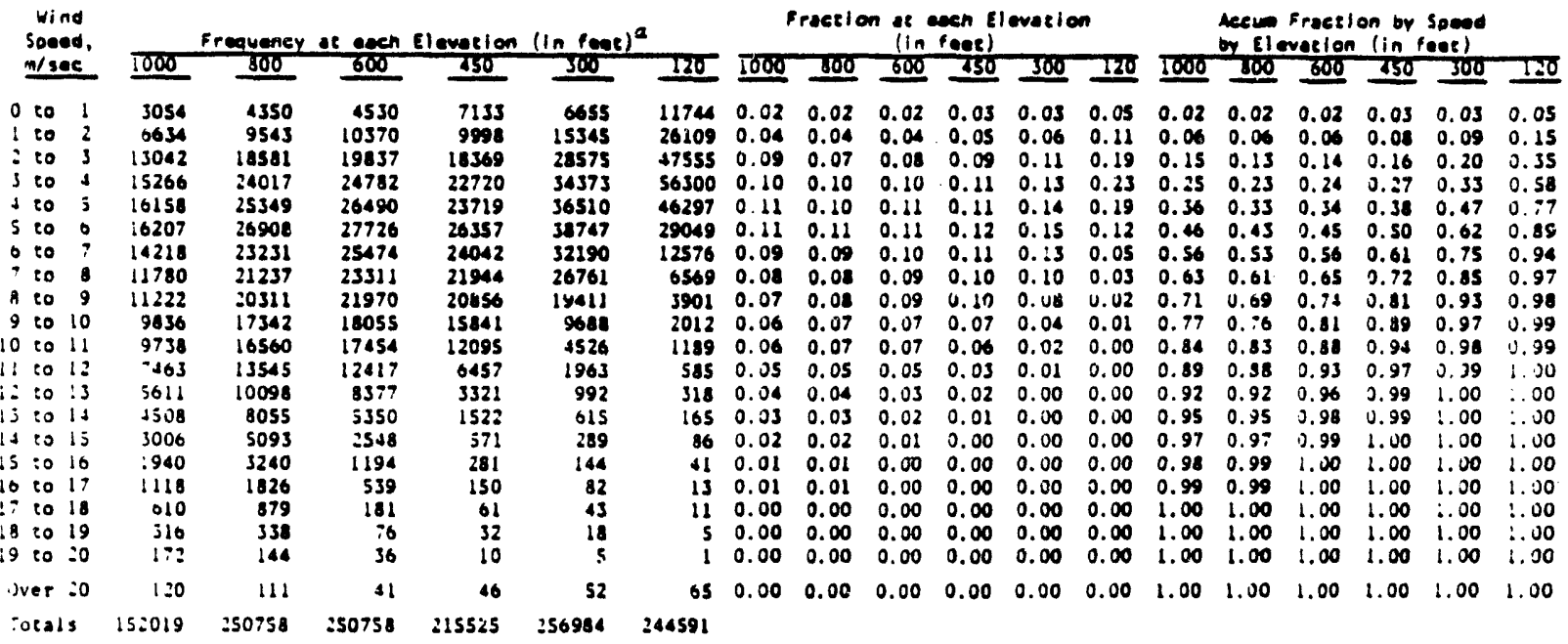


TABLE 3-9

PREVAILIMG WIMO DIRECTIOM AT AUGUSTA

\begin{tabular}{|c|c|c|}
\hline Month & $\begin{array}{l}\text { Prevailing } \\
\text { Wind }\end{array}$ & $\begin{array}{c}\text { Time at } \\
\text { Given Direction, } \\
\end{array}$ \\
\hline $\begin{array}{l}\text { January } \\
\text { Pabruary } \\
\text { March } \\
\text { April } \\
\text { May } \\
\text { June } \\
\text { July } \\
\text { August } \\
\text { Septeaber } \\
\text { October } \\
\text { November } \\
\text { Deceaber }\end{array}$ & $\begin{array}{l}\text { Northwest } \\
\text { Norehwest } \\
\text { Nort hwest } \\
\text { Norehwest } \\
\text { Norehwest } \\
\text { South } \\
\text { South } \\
\text { South } \\
\text { East } \\
\text { Nort hwest } \\
\text { Northwest } \\
\text { Northwest }\end{array}$ & $\begin{array}{l}26 \\
26 \\
25 \\
19 \\
17 \\
21 \\
26 \\
23 \\
20 \\
21 \\
28 \\
22\end{array}$ \\
\hline
\end{tabular}

TABLE 3-10

OAILY SHIFT OF PREVAILING WIND DIRECTION IN AUGUSTA (1957)

Shift, degrees ${ }^{a}$

\begin{tabular}{|c|c|c|c|c|c|c|c|c|c|c|c|c|}
\hline Date & January & February & Mreh & April & May & June & July & Auqust & September & Dctober & November & December \\
\hline 1 & NRW & SSW & $W$ & ESE & $\mathbf{E}$ & $\mathrm{NE}$ & NH & SW & NH & $\mathrm{NE}$ & NW & $W$ \\
\hline 2 & 15 & 150 & 30 & 120 & 30 & 75 & 90 & 75 & 180 & 0 & 90 & 45 \\
\hline 3 & 0 & 120 & 165 & 105 & 75 & 0 & 90 & 0 & 105 & 15 & 105 & 15 \\
\hline 4 & 165 & 0 & 0 & 0 & 0 & 30 & 45 & 60 & 15 & 60 & 15 & 90 \\
\hline 5 & 120 & 180 & 0 & 45 & $n$ & 135 & 135 & 165 & 75 & 0 & 0 & 15 \\
\hline 6 & 180 & 45 & 0 & 90 & 90 & 15 & 180 & 0 & 30 & 45 & 90 & 135 \\
\hline 7 & 180 & 45 & 75 & 60 & 165 & 30 & 135 & 90 & 0 & 0 & 90 & 0 \\
\hline 8 & 135 & 120 & 150 & 0 & 120 & 30 & 60 & 135 & 45 & 60 & 0 & 0 \\
\hline 9 & 75 & 90 & 30 & 105 & 150 & 180 & 15 & 135 & 15 & 0 & 165 & 135 \\
\hline 10 & 30 & 15 & 15 & 75 & 15 & 45 & 165 & 75 & 30 & 45 & 60 & 45 \\
\hline 11 & 180 & 135 & 16.5 & 120 & 0 & 135 & 0 & 75 & 15 & 105 & 60 & 30 \\
\hline 12 & 15 & 30 & 120 & 150 & 75 & 0 & 30 & 105 & 15 & 15 & 15 & 30 \\
\hline 13 & 135 & 75 & 60 & 30 & 75 & 150 & 90 & 150 & 0 & 45 & 0 & 90 \\
\hline 14 & 30 & 15 & 30 & 105 & 15 & 120 & 0 & 120 & 0 & 30 & 90 & 60 \\
\hline 15 & 165 & 180 & 90 & 0 & 60 & 75 & 120 & 45 & 30 & 120 & 45 & 30 \\
\hline 16 & 45 & 180 & 90 & 75 & 0 & 45 & 30 & 105 & 0 & 0 & 60 & 0 \\
\hline 17 & 60 & 0 & 45 & 0 & 90 & 135 & 105 & 0 & 30 & 45 & 30 & 135 \\
\hline 18 & 0 & 180 & 180 & 0 & 60 & 180 & 45 & 75 & 180 & 135 & 60 & 0 \\
\hline 19 & 150 & 180 & 135 & 15 & 120 & 135 & 30 & 15 & 60 & 30 & 120 & 45 \\
\hline 20 & 135 & 105 & 30 & 15 & 90 & 30 & 90 & 30 & 60 & 15 & 30 & 60 \\
\hline 21 & 15 & 0 & 30 & 30 & 105 & 15 & 15 & 60 & 30 & 15 & 120 & 150 \\
\hline 22 & 180 & 15 & 0 & 0 & 0 & 0 & $\rightarrow 5$ & 0 & 60 & 30 & 150 & 60 \\
\hline 23 & 120 & 75 & 165 & 0 & 0 & 15 & 45 & 15 & 165 & 60 & 15 & 30 \\
\hline 24 & 135 & 165 & 75 & 0 & 105 & 30 & 0 & 45 & 90 & 0 & 90 & 0 \\
\hline 25 & 0 & 0 & 180 & 15 & 105 & 0 & 165 & 135 & 135 & 120 & 180 & 90 \\
\hline 26 & 0 & 60 & 15 & 15 & 45 & 90 & 15 & 90 & 45 & 60 & 135 & 150 \\
\hline 27 & 180 & 30 & 75 & 30 & 60 & 90 & 15 & 75 & 90 & 15 & 60 & 130 \\
\hline 28 & 0 & 90 & 30 & 0 & 165 & 60 & 15 & 120 & 0 & 0 & 00 & 0 \\
\hline 29 & 0 & 0 & 45 & 15 & 15 & 60 & 45 & 30 & e & 0 & 105 & 180 \\
\hline 30 & 90 & 0 & 5 & 13 & 15 & 00 & 43 & 30 & 45 & 45 & 45 & 120 \\
\hline 31 & 105 & 0 & 43 & 15 & 0 & 30 & 150 & 120 & 0 & 60 & 90 & 30 \\
\hline נו & 105 & 0 & 150 & 0 & 15 & 0 & 150 & 90 & 0 & 150 & 0 & 30 \\
\hline Average & 83 & 84 & 74 & 42 & 62 & 67 & 71 & 75 & 54 & 45 & 73 & 60 \\
\hline
\end{tabular}

a. The change was taken as the smaller angular rotation from the previous day's prevailing wind. Iite actual change could be greater than indicated if the snift occurred through the larger angular rotation. 
Mean Energy
$(\mathrm{KeV})$

100

125

225

375

575

850

1250

1750

2250

2750

3500
Photons $/ \mathrm{cm}^{3} / \mathrm{sec}$

2.449E07

9.533E07

6.305 E06

$1.994 \mathrm{E} 07$

$2.129 \mathrm{E} 09$

$3.973 E 07$

4.827E07

$9.746 \mathrm{E} 05$

$4.343 E 06$

$1.491 \mathrm{E} 04$

$2.088 \mathrm{E0} 3$

*Includes $\mathrm{Cs}, \mathrm{Sr}$ and $\mathrm{Pu}$ separated from supernate during salt processing. Curie balance used for these calculations is in Appendix $H$, Table 21-18. 
TABLE $\quad 3-12$

WATER WELL DRAWDOWN DATA

Well No.

Location

Water Elevation

(Feet below ground)

Feet of Drawdowna
$45 \mathrm{H}$

N 70600

E 63100

107

26
$48 \mathrm{H}$

N 71200

E 62950

109

35
120

$88 \mathrm{H}$

N 71400

E 63150

33

a Measured after 24 hours of pumping at $1000 \mathrm{gpm}$. 
TABLE $4-1$

CLASSIFICATION OF STRUCTURES, SYSTEMS, AND COMPONENTS

Tornado DBE IPE

Resist. Resist. Resist. Standard Remarks

Waste Transfer Facilities

Pump Pits/Diversion

Boxes

Transfer Lines

Process Equipment, Piping Service Auxiliarys

Vitrification Building Structure

Vitrification Bldg

(including building

outer wall, floors,

crane maintenance

area, and process

cells enclosure, etc.)

Vitrification Bldg Air

Supply Fan House

Vitrification Bldg

Railroad Airlock

Vitrification Bldg

Railroad Tunnel

(access to process

cell enclosure)

$\mathbf{x}$

Vitrification Building SCT Loading Area

Process Equipment Repair Shop Space

Shop Space

Central Instrument Control

Room Space

Local Control Units Space $\mathrm{x}$ $\mathbf{x}$

$\mathbf{x}$

$\mathbf{x}$

$\mathbf{x}$

(1) 
TABLE 4-1

CLASSIFICATION OF STRUCTURES, SYSTEMS, AND COMPONENTS

$\begin{array}{lccc}\text { Tornado } & \text { DBE } & \text { IPE } & \\ \text { Resist. } & \text { Resist. } & \text { Resist. } & \text { Standard } \\ \end{array}$

Space for Emergency Instrument Air Compressor and Bottled Breathing Air Storage

Offices, Change Rooms, etc.

Equipment Located in or Servicing Vitrification Bldg

Vitrification Bldg Air Supply Equipment

Cranes

- Process Cell Crane

- Melt Cell and Canister Decon Cell In-Cell

Cranes

$x$

- Weld Test Cell In-Cell Cranes

- Process Equipment

Repair Shop Crane

Process and Equipment Decon

Cell Equipment:

- Fixed Non-Remotable Equipment such as Embedded piping, trunnions, sleepers, dowels, etc.

- Removable Equipment (vessels, melter, jumpers, rack piping, etc.)

Melter and Process Cooling

Water HX System Components

Maintenance and $E$ \& I

Shop Equipment 

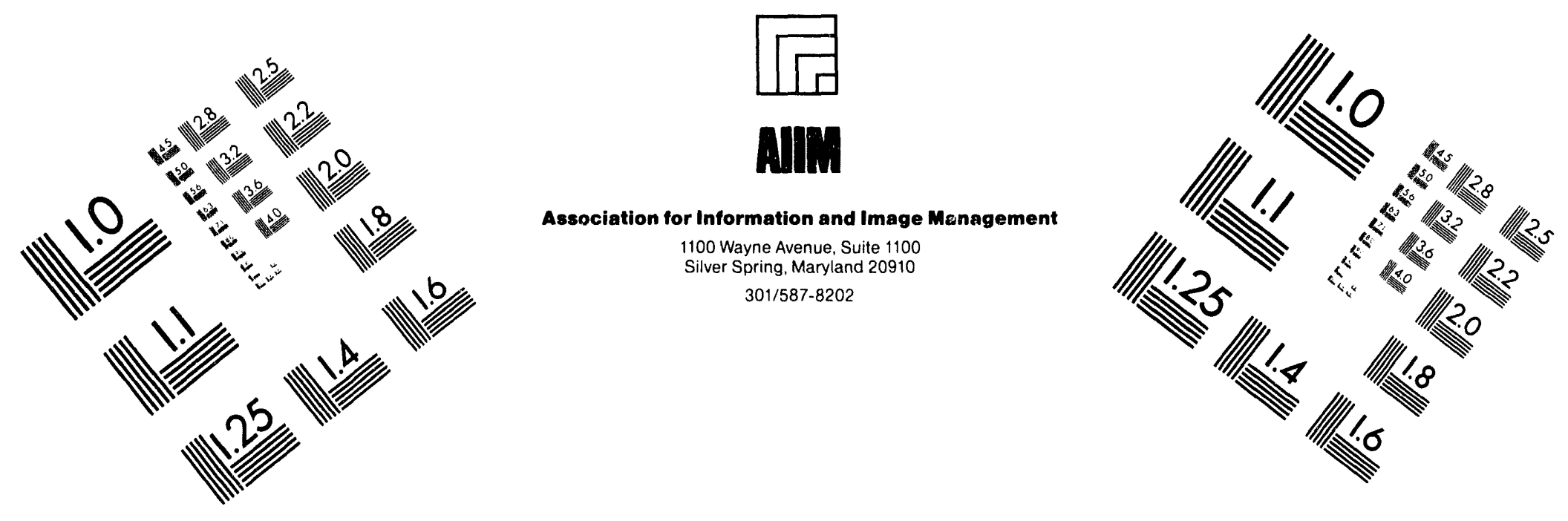

Centimeter

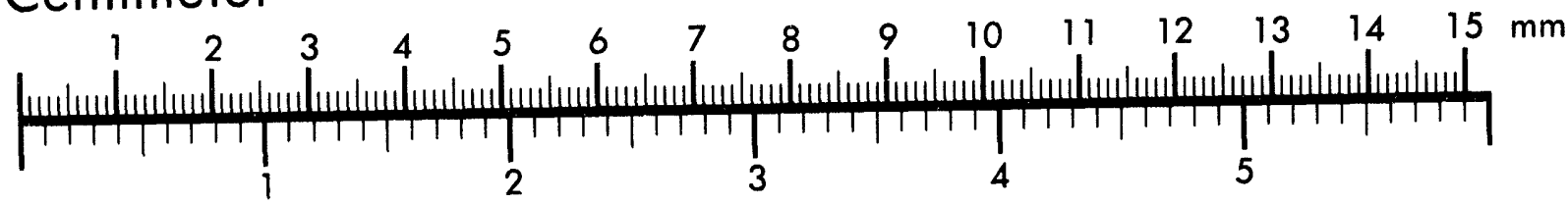
Inches
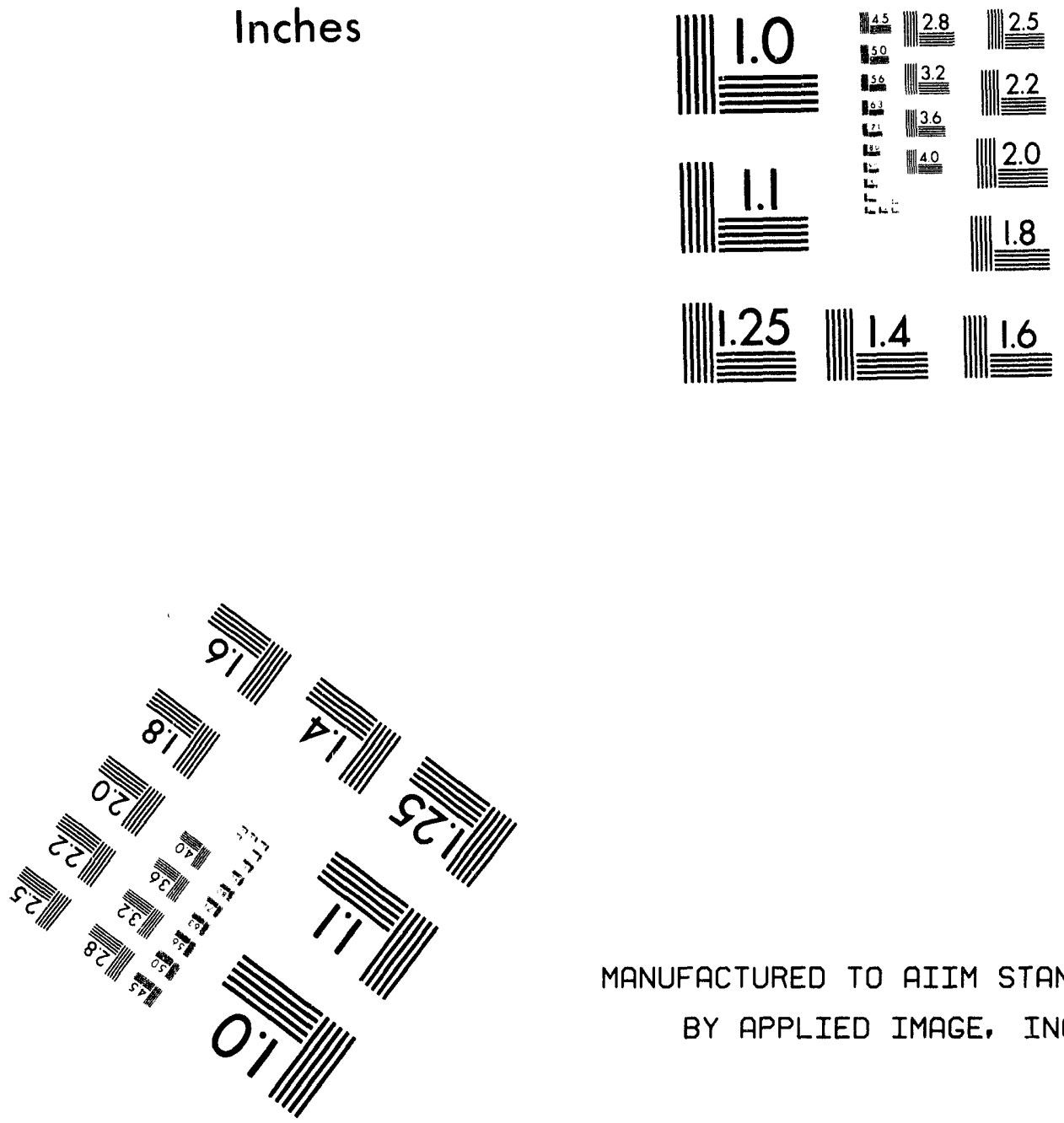

MANUFACTURED TO AIIM STANDARDS

BY APPLIED IMAGE, INC.

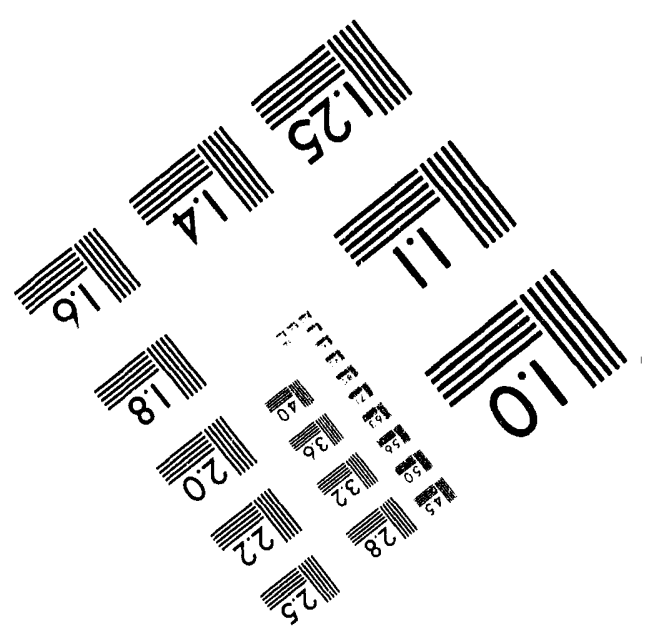



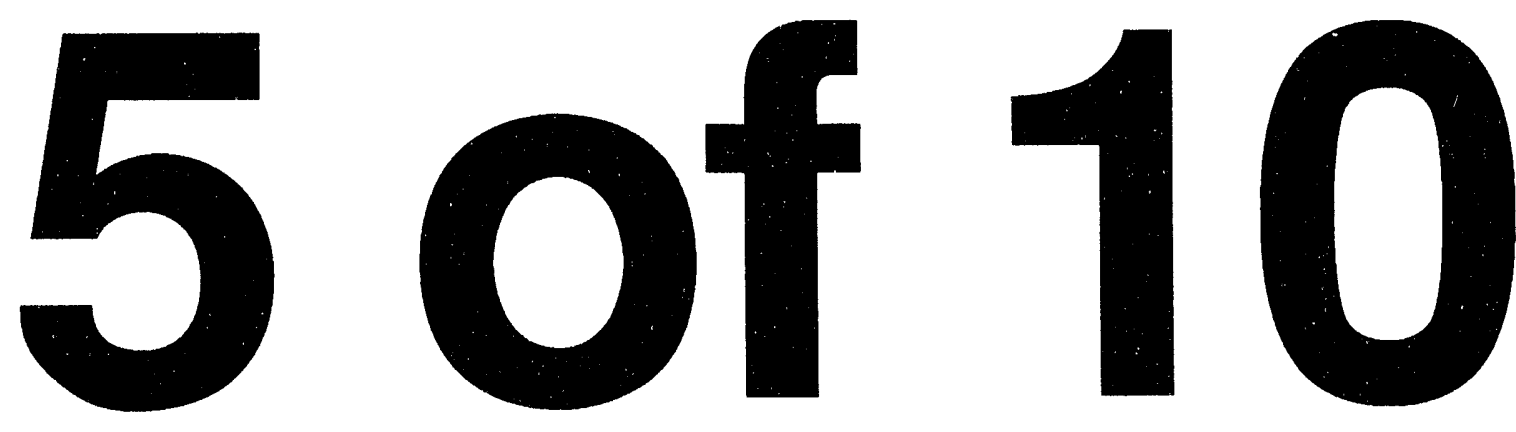
TABLE 4-1

CLASSIFICATION OF STRUCTURES, SYSTEMS, AND COMPONENTS

Resist. Resist. Resist. Standard Remarks

Process Steam System Components

Other Process Equipment Outside Process Cell

Central Control Room Computer

Local Instrument Control Units (emergency units for process shutdown)

Health Protection Facilities:

- Vitrification Building Air Effluent Monitor

- HP Computer $\mathbf{x}$

$\mathbf{x}$

$\mathbf{x}$

$\mathbf{x}$

h

$\mathbf{x}$

$\mathbf{x}$

$\mathbf{x}$

$\mathbf{x}$ $1, d, j$ g<smiles></smiles>

Interim Storage Building Structure

Vault Storage Area

Vault Supply Afr Structure (above grade)

Vault Exhaust Afr Structure, including space for emergency ventilation and air monitoring equipment (above grade)

Canister Support Rack/ Storage Grid with below grade air ducting structure

Storage Bldg above Vault, Operating Area, Office, \& Shop $\mathbf{x}$

$\mathbf{x}$

$\mathbf{x}$

$\mathbf{x}$

x

x

x

x 
TABLE 4-1

CLASSIFICATION OF STRUCTURES, SYSTEMS, AND COMPONENTS

$\begin{array}{lccc}\text { Tornado } & \text { DBE } & \text { IPE } & \\ \text { Resist. } & \text { Resist. } & \text { Resist. } & \text { Standard } \\ \end{array}$

Equipment Located in or Servicing Interim Storage Building

Shielded Canister Transport Vehicle

Emergency Ventilation

Equipment including filters, electrical

components, etc.

Interim Storage Building Air Effluent Monitor

Other Facilities - Servicing the Confinement Functions of Vitrification and/or Interim Storage Building

Vitrification Building Sand Filter - Concrete Structure

Sand Filter (integrity of media against breakthrough/ bypass )

Sand Filter Instrumentation $\mathbf{x}$ $\mathbf{x}$ $\mathbf{x}$

Fan House - Structure housing Zone 1 exhaust fans $\mathbf{x}$ $\mathbf{x}$ $\mathbf{x}$

Zone 2 and 3 exhaust fans

Fan House - HEPA Filters for Operating Area of Vitrification Building

Fan House - Exhaust Fans for Vitrification Bldg (all ventilation zones) 
TABLE 4-1

CLASSIFICATION OF STRUCTURES, SYSTEMS, AND COMPONENTS

Tornado DBE IPE

Resist. Resist. Resist. Standard Remarks

Fan House - Maintenance

Equipment (monorail, etc.)

Exhaust Stack

Air Tunnels (Vitrification Bldg to Blowout Port)

$\mathbf{x}$

$\mathbf{x}$

$\mathbf{x}$

Sand Filter Bypass Tunnel

Air Tunnels (Blowout Port

to Stack)

Space for Emergency

Electrical Generation

Equipment and Associated

Switch Gear

$\mathbf{x}$

$\mathbf{x}$

$\mathbf{x}$

Emergency Electrical

Generation System

(including supply to

usage points)

$\mathbf{x}$

Air Compressors

$\mathbf{x}$

Fire Protection Systems

$\mathbf{x}$

Service Facilities

Receiving and Storage Area

$\mathbf{x}$

Cold Feed Area Structures

$\mathbf{x}$

Chemical and Industrial

waste Treatment

Administration Building

$\mathbf{x}$

Patrol Building

$\mathbf{x}$

Water Treatment Facilities

$\mathbf{x}$ 
APPENDIX A

TABLE 4-1

PAGE 6 of 8

DATE 9-82; Rev. 9

TABLE 4-1

CLASSIFICATION OF STRUCTURES, SYSTEMS, AND COMFONENTS

\begin{tabular}{lccc} 
Tornado & DBE & IPE & \\
Resist. & Resist. & Resist. & Standard \\
\hline
\end{tabular}

Electrical Substations

(Primary \& Secondary)

Sewage Treatment Facilities

$\mathbf{x}$

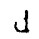

Central Refrigeration

Facilities

Steam Supply Line

Other Power, General and Service Facilities not

Tabulated $\mathbf{x}$

$\mathbf{x}$

$\mathbf{x}$

$\mathbf{x}$ 
TABLE 4-1

CLASSIFICATION OF STRUCTURES, SYSTEMS, AND COMPONENTS

\section{Footnotes}

(a) Design of pump pits, diversion box and waste transfer line is to be based on the criteria as used for existing waste tank farm facilities, namely to meet earth loads and radiation shielding requirements.

(b) The portion of the railroad tunnel which provides access to the process cell is to be useable after an IPE at least to the extent that the tunnel is not permanently blocked by the IPE and that the tunnel can be restored to full operation.

(c) The SCT must provide earthquake and tornado protection to the canister during transfer from the vitrification building to interim storage to the extent that the canister cannot be ruptured by an accident, missile, tipping over, etc. The SCT loading area of the vitrification bullding must resist the IPE to the extent that the loading area is not permanently blocked by an IPE.

(d) If any space is available within the seismic resistant portion of the vitrification building after locating essential functions (process cells, crane areas, sample cells, cold feed tanks, piping galleries, etc.), the space should be utilized for other supporting services. Services to be considered for location in the vitrification building are; HP computer, secondary subrtation, central instrument control; HP facilities; shops, and offices. The decision for locating in the selsmic portion of the building should be based on space avallability, function, operating convenience, etc. Some facilities such as shops should be located close to the facilities serviced and preferred locations are specified in items in this BDR describing these factlities.

(e) ** Process cell crane and weld test cell in-cell crane are to be operational following an IPE at least to the extent that the crane can be retrieved to crane maintenance area and repaired as necessary. This requirement implies that the crane shielding doors must resist the IPE or be repairable. ${ }^{\star *}$

(f) Provided its fallure will not compromise the DBE or IPE resistant structures equipment. For example, the heavy melter and its frame may require special consideration to the extent that any "rocking motion" does not impair the alignment integrity of fixed positioning components and wall nozzles.

(g) Service equipment outside the cell enclosure must not fall in a manner that compromises the DBE or IPE structure. Process cooling water and steam systems should survive a DBE or IPE event to the extent that damage does not result in unacceptable levels of leakage of potentially contaminated cooling water from the circulating process water side to the circulating cooling tower side and potentially contaminated steam condensate to the delay tanks. 
TABLE 4-1

CLASSIFICATION OF STRUCTURES, SYSTEMS, AND COMPONENTS

Footnotes (Cont'd)

(h) Instrumentation for local control units must always remain operable to the extent necessary to achieve and maintain a safe shutdown of the process operations.

(i) Effluents released to the environment must be monitored at all times. The effluent monitor and the computer must provide the capability or a seismic and tornado resistant sampling system must provide for continuous sampling of the exhaust air stream during natural phenomena for off-line analyses in an existing portable Health Protection trailer containing analytical equipment.

(j) If the HP computer is located in the seismic structure, it should be placed on a "soft-mount" so that it will survive the IPE.

(k) **Temporary structure to be used before $221-S$ receives waste. To be sealed when the DWPW Sludge Plant starts up. $\star \star$

General Note

If standard construction steel structure or components collapse or fail as a result of a DBE, IPE or a DBT event, they are not to penetrate a seismic structure or compromise the containment integrity or facility function of a seismic structure. 


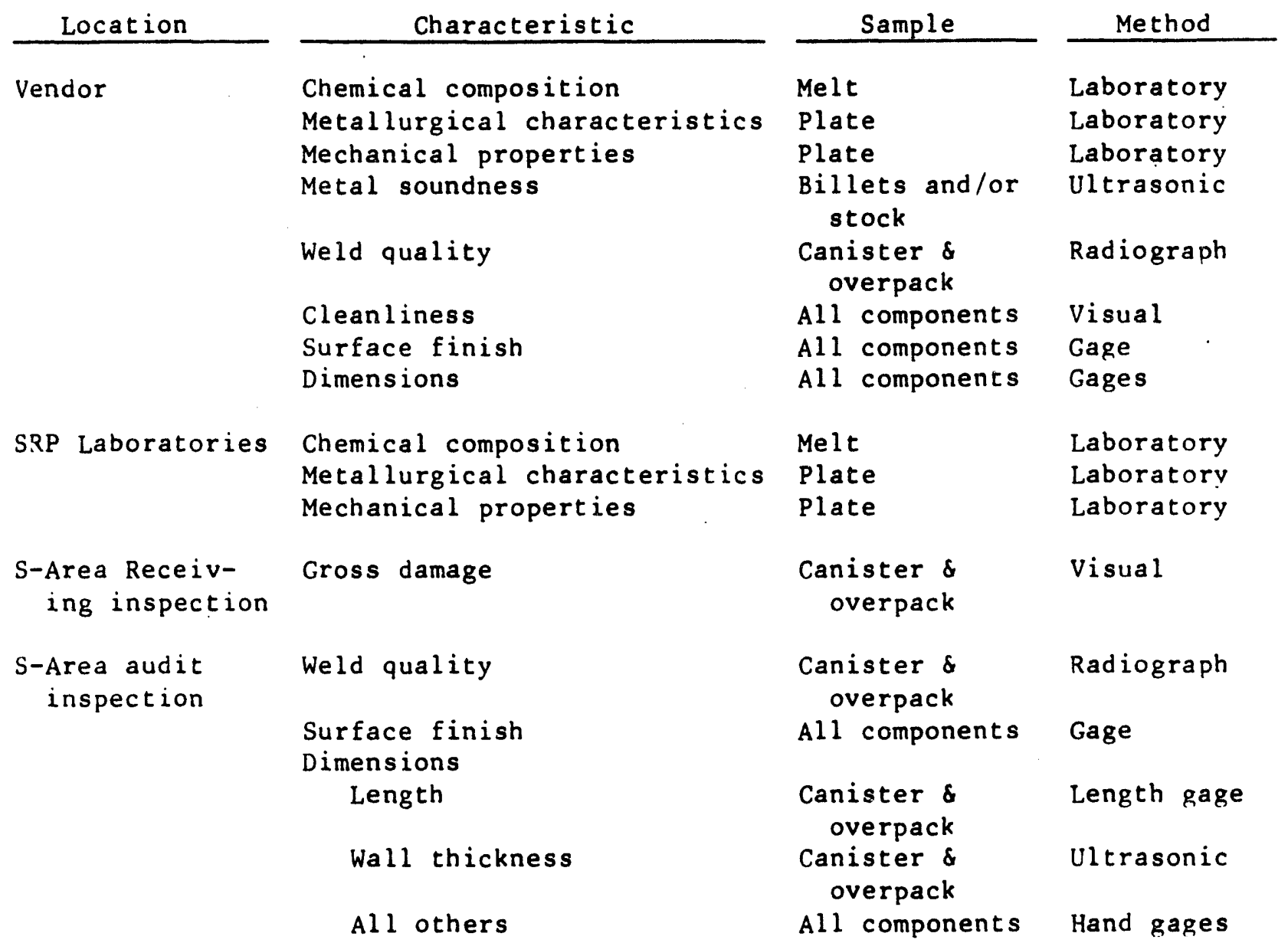


TABLE 5-4

\section{COMPONENT QUALITY EXAMINATIONS}

\begin{tabular}{|c|c|c|c|}
\hline Location & Characteristic & Sample & Method \\
\hline \multirow{11}{*}{$\begin{array}{l}\text { S-Area Inprocess } \\
\text { inspectionc }\end{array}$} & Cleanliness & All components & Visual \\
\hline & $\begin{array}{l}\text { Surface mars } \\
\text { Throat ID \& OD } \\
\text { Flange OD }\end{array}$ & $\begin{array}{l}\text { All components } \\
\text { Canister } \\
\text { Canister }\end{array}$ & $\begin{array}{l}\text { Depth gage } \\
\text { Go,nc-go gage } \\
\text { Go,no-go gage }\end{array}$ \\
\hline & Outer diameter & $\begin{array}{r}\text { Canister \& } \\
\text { overpack }\end{array}$ & $\begin{array}{l}\text { Go, no-go gage } \\
\text { Go, no-go gage }\end{array}$ \\
\hline & Inner diameter & Ove rpack & Go, no-go gage \\
\hline & Leng th & $\begin{array}{r}\text { Canister \& } \\
\text { overpack }\end{array}$ & Go, no-go gage \\
\hline & $\begin{array}{l}\text { Parallelism -- flange to } \\
\text { bottom }\end{array}$ & Canister & Go, no-go gage \\
\hline & $\begin{array}{l}\text { Concentricity -- throat to } \\
\text { canister }\end{array}$ & Canister & Go, no-go gage \\
\hline & Weight & Canister & Load cell \\
\hline & Helium leak test & $\begin{array}{r}\text { Canister } \delta \\
\text { overpack }\end{array}$ & Mass spec \\
\hline & $O D$ & Pluga & Go, no-go gage \\
\hline & ID & Plug $b$ & Go, no-go gage \\
\hline $\begin{array}{l}\text { aBoth inner plug } \\
\text { bInner plug only }\end{array}$ & and outer plug & & \\
\hline $\begin{array}{l}\mathrm{c}^{\mathrm{C}} \text { omplete list of } \\
\text { overpack covers }\end{array}$ & $\begin{array}{l}\text { critical dimensions t } \\
\text { o be determined pend }\end{array}$ & ted for & $s$ and \\
\hline
\end{tabular}


TABLE 5-1

INVE NTORY STANDARD BASES

Requirements for raw materials receipt and storage are based on the standards outlined below.

Bulk chemical storage gross tank capacities must be equivalent to a 2 -month supply and there must be at least two tanks for each comodity.

**Inventory requirements are based on: ***

1) For normal-type chemicals:

Minimum inventory -- 1-month supply

Normal inventory -- 2 -month supply

Maximum inventory -- 2-1/2-month supply

2) For special-type chemicals:

Minimum inventory -- 2-month supply

Normal inventory -- 4 -month supply

Maximum inventory -- 5-month supply

3) For items requiring periodic replacement more than two times per year: Minimum inventory -- equivalent to two replacements

Normal inventory -- equivalent to three replacements

Maximum inventory -- equivalent to four replacements

4) For items requiring periodic replacement (two or less times per year): Minimum inventory -- equivalent to one bed or line replacement

Normal inventory -- equivalent to two replacements

Maximum inventory -- equivalent to three replacements

5) Canister components (including six sets of overpack components) storage gross capacity will be equivalent to a 2 -month supply.

6) $* *$ Silver mordenite and silica gel - one bed change. ${ }^{* *}$ 
TABLE 5-2

INVE NTORY REQUIREMENTS

The estimated consumption, inventory requirements, and receipt sources are shown below.

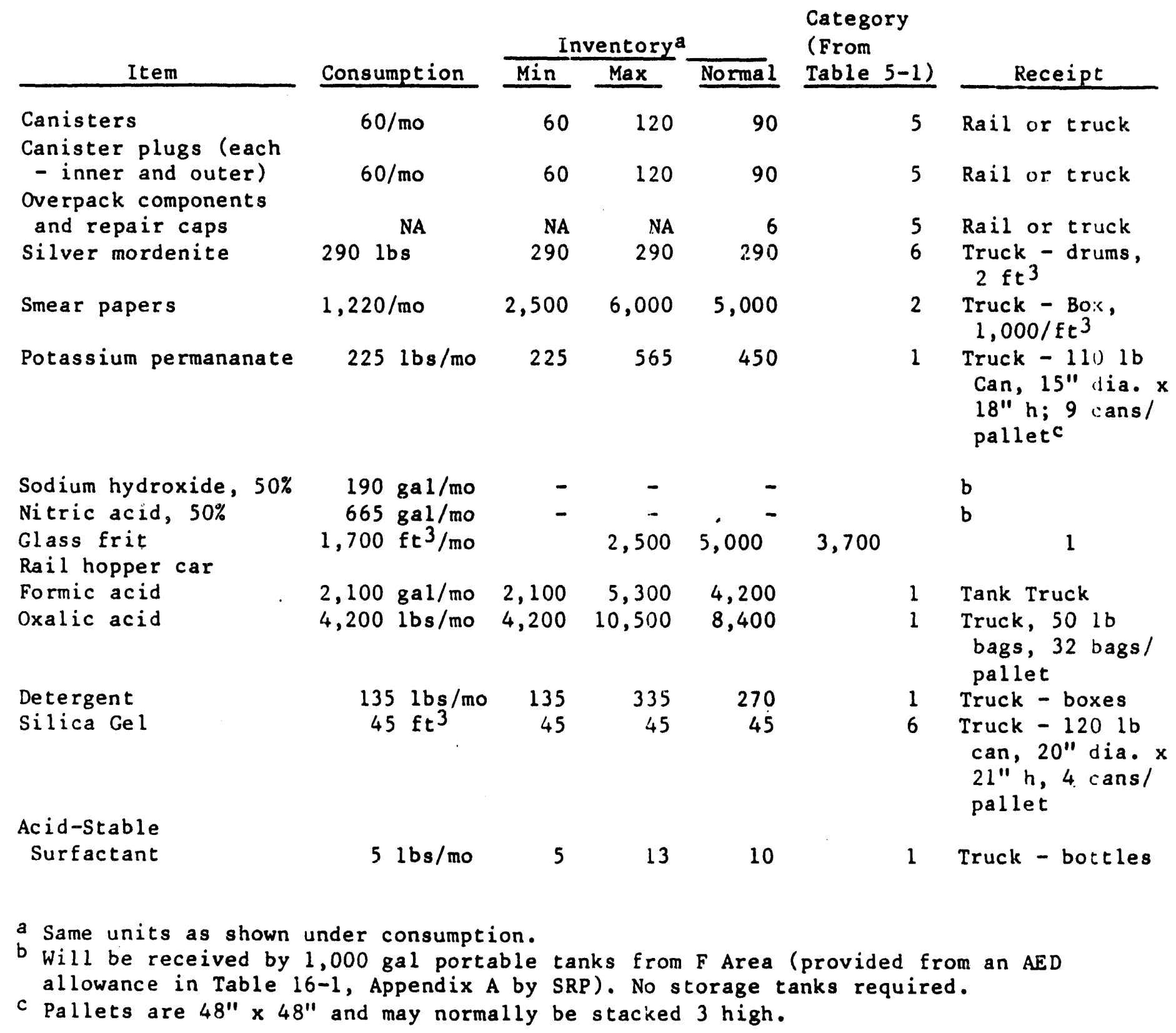

NOTE: Chemicals for water treatment will be received and stored at those facilities. 
TABLE 5-3

DESIGN REQUIREMENTS - - COLD FEED VESSELS INSIDE BUILDING 221-S

Agi- Air Heat-Cool- Sampler

tator Sparge ing ing (cold) Vent Pumps Function Special Equipment

Nitric Acid

Dilution Tank

(Mercury

Purif.)

$\mathbf{x}-\quad-\quad \mathrm{CW} \quad \mathrm{x} \quad \mathrm{CF}-\mathrm{MF}$

Remote Decon

Nitric Acid

Feed Tank

Remote Decon

Oxalic Acid

Feed Tank

$\mathbf{x}$

$\times \quad-\quad H$

HW -

CF -

F Lance \& jet oper controls

Contact Decon

Nitric Acid

Feed Tank

Contact Decon

Oxalic Acid

Feed Tank

HW

CF

$\mathbf{F}$

Lance \& jet oper controls

Crane Decon

Nitric Acid

Feed Tank

Crane Decon

Oxalic Acid

Feed Tank

$\mathbf{x}$

Lance \& jet oper controls

Decon Soln

Makeup Tank

$\mathbf{x}$

x - $\quad \mathrm{HW} \quad \mathrm{CW}$

$\times \quad \mathrm{CF} \quad 1$

M

Process Frit

Weigh Bin

Process Frit

Slurry Feed

Tank

.

$\begin{array}{lll}- & C F^{a} & \times\end{array}$ 
TABLE 5-3

DESIGN REQUIREMENTS -- COLD FEED VESSELS INSIDE BUILDING 221-S

$$
\begin{aligned}
& \text { Ag1- Air Heat- Cool- Sampler } \\
& \text { tator Sparge Ing ing (cold) Vent Pumps Function Special Equipment }
\end{aligned}
$$

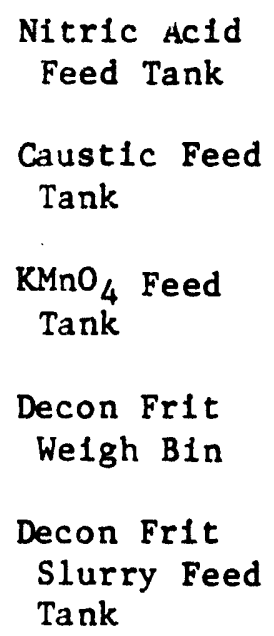

$\mathbf{F}$ Special interlock to prevent overflow

Process Condensate Tanks $b$

$\begin{array}{llllllll} & - & - & C W & x & C F & 1 & C\end{array}$


TABLE 5-3

DESIGN REQUIREMENTS -- COLD FEED VESSELS INSIDE BUILDING 221-S

Agi- Air Heat-Cool-Sampler

tator Sparge ing ing (cold) Vent Pumps Function Special Equipment

CW Delay

Tanksb

$\mathbf{x}$

$\mathbf{x} \quad$ CF 1

C

\footnotetext{
(x) - Service Required

(A) - Separate outside vent if air from frit transport would overload CF vent system.

(-) - Service not required

(M) - Makeup tank

(CW) - Cooling water

(HW) - Hot water preferred, but steam is acceptable

(F) - Feed or batch addition tank (c) - Collection tank for chemicals, etc. for
disposal.

(CF) - Cold Feed vent system

${ }^{a}$ Will require a condenser to isolate formic acid fumes from the rest of the vent system.

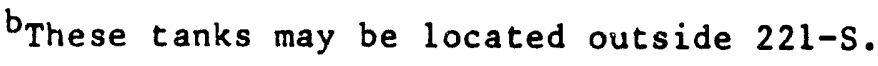




$$
\text { Agi- Cooling Chilled Transfer Cold }
$$

Tank or Vessel tator Steam Water Water
Sampler Vent Pumps

Feeds*
Special

\section{Spare}

Equipment

Modules

$x$

Sludge Recelpt

$\&$ Adj Tank

$\begin{array}{lll}\mathbf{x} & \mathbf{x} & \mathbf{x} \\ \mathbf{x} & \mathbf{x} & \mathbf{x}\end{array}$

Sludge Receipt

$\&$ Adj Tank

Column

Sludge Receipt $\&$ Ad f Tank Condenser

Slurry Mix Evap

$\mathbf{x} \quad \mathrm{x}$
Slurry Mix Evap Col
Slurry Mix Evap Cond'r
Slurry Mix Evap Cond Tank.
Formic Acid Vent Cond'r
Mercury Water Wash Tank

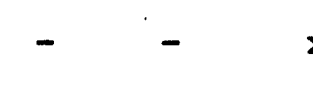

$\mathbf{x}$

$\mathrm{x}$

$\mathbf{x}$

$\mathbf{x}$

$\mathbf{x}$

x - -

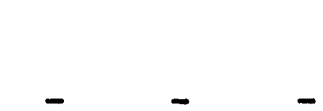

\section{Equipment}

Alr Sparge

Mercury

Formic Pump, Acid

Air

Sparge

PW

Flush

Frit, Mercury

Slurry Pump, (F)

$\&$

Formic Air

Acid

Sparge

PW

Flush

Mercury

Pump (F)

$\mathrm{AV}$
1

$-$

PW
Mercury

Pump, (F)

Alr

Sparge 
TABLE 5-5

DESIGN REQUIREMENTS -- IN-CELL VESSELS

Ag 1- Coollng Chilled

Tank or Vessel tator Steam Water

Melter Feed

Tiank

Of $\mathrm{f}-\mathrm{Ga}$ s

Condensate

Tank

ilter

Pump Tank

Quencher

Off-Gas

Condenser

Ru Adsorber Preheater

Ru

Adsorber

I 2 Adsorber Preheater

I 2 Adsorber

Of $f-G a s$ Cooler $\mathbf{x}$ Water $\mathbf{x}$

$\mathbf{x}$

$\mathbf{x}$

$\mathbf{x}$

$$
-
$$
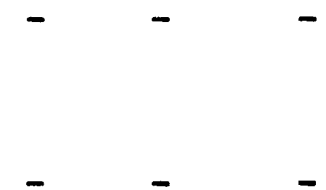

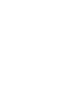$$
\text { ( }
$$

Transfer Cold Sampler Vent Pumps Feeds*

Frit

( Temp Jumper ) Formic Acid

OG

$\mathbf{x}$

OG

3 
TABLE 5-5

DESIGN REQUIREMENTS -- IN-CELL VESSELS

\begin{tabular}{|c|c|c|c|c|c|c|c|c|c|}
\hline Tank or Vessel & $\begin{array}{l}\text { Ag 1- } \\
\text { tator } \\
\end{array}$ & $\underline{\text { Steam }}$ & $\begin{array}{l}\text { Cooling } \\
\text { Water }\end{array}$ & $\begin{array}{l}\text { Chilled } \\
\text { Water } \\
\end{array}$ & Samp1er. & Vent & $\begin{array}{l}\text { Transfer } \\
\text { Pumps } \\
\end{array}$ & $\begin{array}{l}\text { Cold } \\
\text { Feeds* }\end{array}$ & $\begin{array}{l}\text { Special } \\
\text { Equipment }\end{array}$ \\
\hline $\begin{array}{l}\text { Primery Deep } \\
\text { Bed Filters }\end{array}$ & - & - & - & - & - & OG & - & - & - \\
\hline $\begin{array}{l}\text { Secondary Deep } \\
\text { Bed Filters }\end{array}$ & - & - & - & - & - & OG & - & - & - \\
\hline $\begin{array}{r}\text { Spent Frit } \\
\text { Hold Tank }\end{array}$ & $\mathbf{x}$ & - & - & - & $\mathrm{x}$ & $\mathbf{v}$ & 1 & - & $\begin{array}{l}\text { Alr } \\
\text { Sparge }\end{array}$ \\
\hline $\begin{array}{l}\text { Decontami- } \\
\text { nation } \\
\text { Chambers }\end{array}$ & - & - & - & - & - & $\mathbf{v}$ & 2 & $\begin{array}{l}\text { Frit } \\
\text { Slurry }\end{array}$ & $\begin{array}{l}\text { Air } \\
\text { Sparge }\end{array}$ \\
\hline $\begin{array}{l}\text { Recycle Coll } \\
\text { Tank }\end{array}$ & $\mathbf{x}$ & - & $\mathrm{x}$ & - & $\mathbf{x}$ & $\mathbf{A V}$ & 1 & $\begin{array}{l}50 \% \\
\mathrm{NaOH}\end{array}$ & - \\
\hline $\begin{array}{l}\text { Vessel Vent } \\
\text { Preheater }\end{array}$ & - & $\mathbf{x}$ & - & - & - & $\mathbf{v}$ & - & - & - \\
\hline $\begin{array}{l}\text { Vessel Vent } \\
\text { Filter }\end{array}$ & - & $\mathbf{x}$ & - & - & $x$ & $\mathbf{V}$ & - & - & - \\
\hline $\begin{array}{l}\text { Decontamina- } \\
\text { tion Waste } \\
\text { Treatment } \\
\text { Tank }\end{array}$ & $\mathbf{x}$ & $\mathrm{x}$ & $\mathbf{x}$ & - & $\mathbf{x}$ & - & $1-$ & $\begin{array}{l}50 \% \\
\mathrm{NaOH}, \\
50 \% \\
\mathrm{HNO}_{3}, \\
\mathrm{KMnO}_{4} \\
\mathrm{Sol}^{4} \mathrm{n}\end{array}$ & \\
\hline AWNT Column & - & - & - & - & - & - & $-\quad-$ & $\begin{array}{l}\text { PW } \\
\text { Flush }\end{array}$ & - \\
\hline $\begin{array}{l}\text { AWNT } \\
\text { Condenser }\end{array}$ & - & - & $\mathbf{x}$ & - & - & $\mathbf{V}$ & - & - & - \\
\hline Abbreviations: & $\begin{array}{l}A V- \\
V- \\
x- \\
O G- \\
- \\
P W- \\
F-\end{array}$ & $\begin{array}{l}\text { - Formic } \\
\text { - Vessel } \\
\text { - Servic } \\
\text { - Me1ter } \\
\text { - Service } \\
\text { - Proces } \\
\text { Future }\end{array}$ & $\begin{array}{l}\text { Acid Ver } \\
\text { Vent } \\
\text { :e Require } \\
\text { Off-Gas } \\
\text { e Not Reg } \\
\text { s Water } \\
\text { (Provide }\end{array}$ & $\begin{array}{l}\text { nt Conde } \\
\text { ed } \\
\text { System } \\
\text { quired } \\
\text { e servic }\end{array}$ & es, pump & to $b$ & be Install & led as re & u(red.) \\
\hline
\end{tabular}


TABLE 6-1

INSTRUME NTATION

\section{General}

This table reflects the following instrumentation schemes:

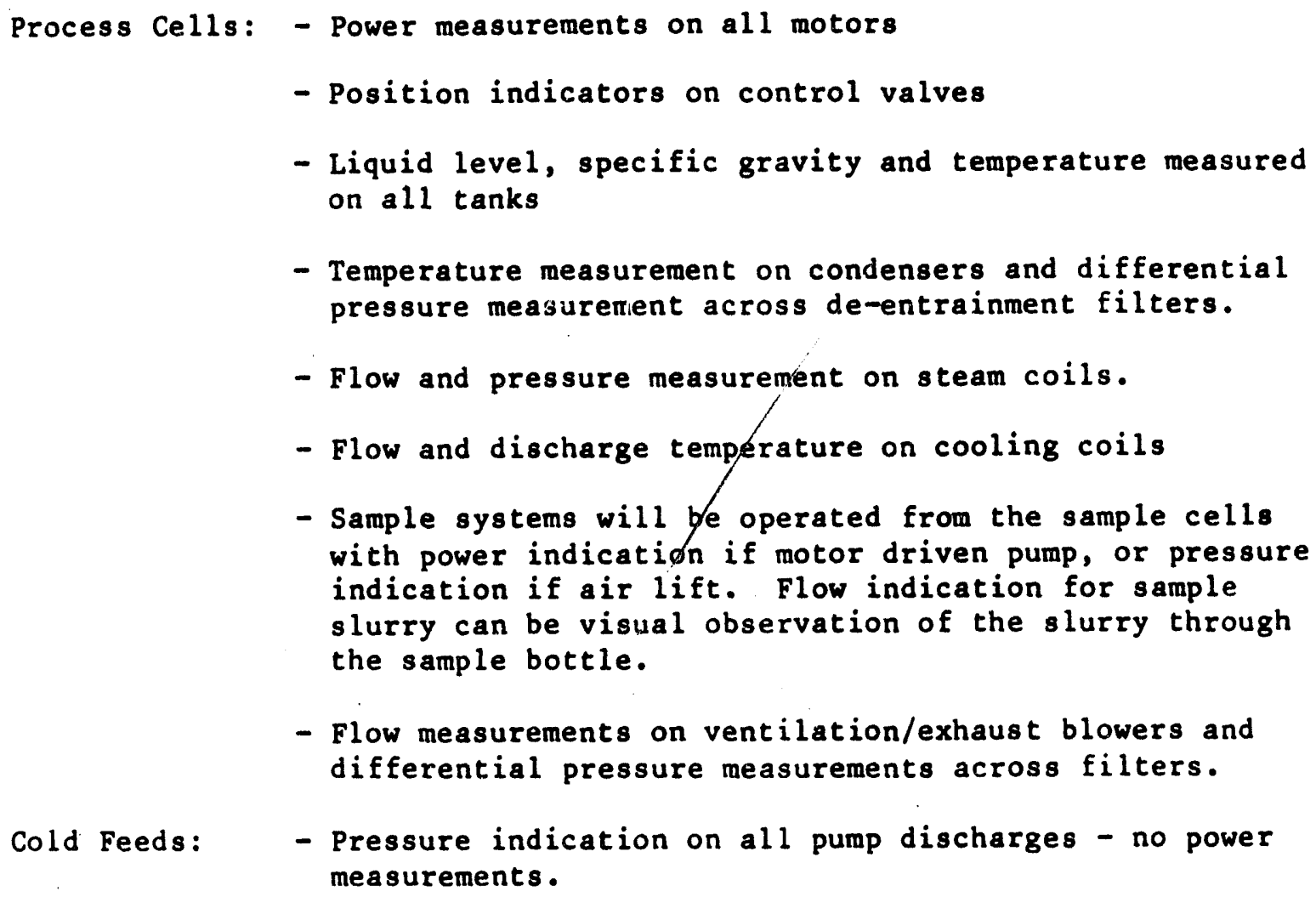

- Liquid level, specific gravity and temperature measured on all tanks

- Temperature measurement on condensers and differential pressure measurement across de-entrainment filters.

- Flow and pressure measurement on steam coils.

- Flow and discharge temperature on cooling coils

- Sample systems will be operated from the sample cells with power indication if motor driven pump, or pressure indication if air lift. Flow indication for sample slurry can be visual observation of the slurry through the sample bottle.

- Flow measurements on ventilation/exhaust blowers and differential pressure measurements across filters.

Cold Feeds: - Pressure indication on all pump discharges - no power measurements.

This table does not describe every instrument. It shows typical instrument requirements for the major process, cold feed, and utility systems. Instruments with standard package systems (e.g. refrigeration units, clayton and Sellers jets, etc.) are not shown. 
The following key identifies the readout location:

A - Central Control Room Process Console with emergency operation at Field Operating Stations.

B - Central Control Room Power Console - Roving operator - with emergency backup at field operating station.

C - Process Field Operating Station - Operator normally present - CCR surveilance

D - Process Field Operating Station - Roving operator - CCR surveilance

E - Power Field Operating Station - Roving operator - CCR surveilance

F - Crane Console - Operator present when crane is being operated Supervisory viewing room surveilance

G - Crane Console - E \& I Shop Crane Maintenance

H - H-Area Waste Tank Farm Control Room - CCR surveilance

I - 751-A Power Dispatcher

K - Power Field Operating Station at substation

0 - Local indication only

2 - Combination of $D \& H$, defined above

3 - Combination of I\&k, defined above 


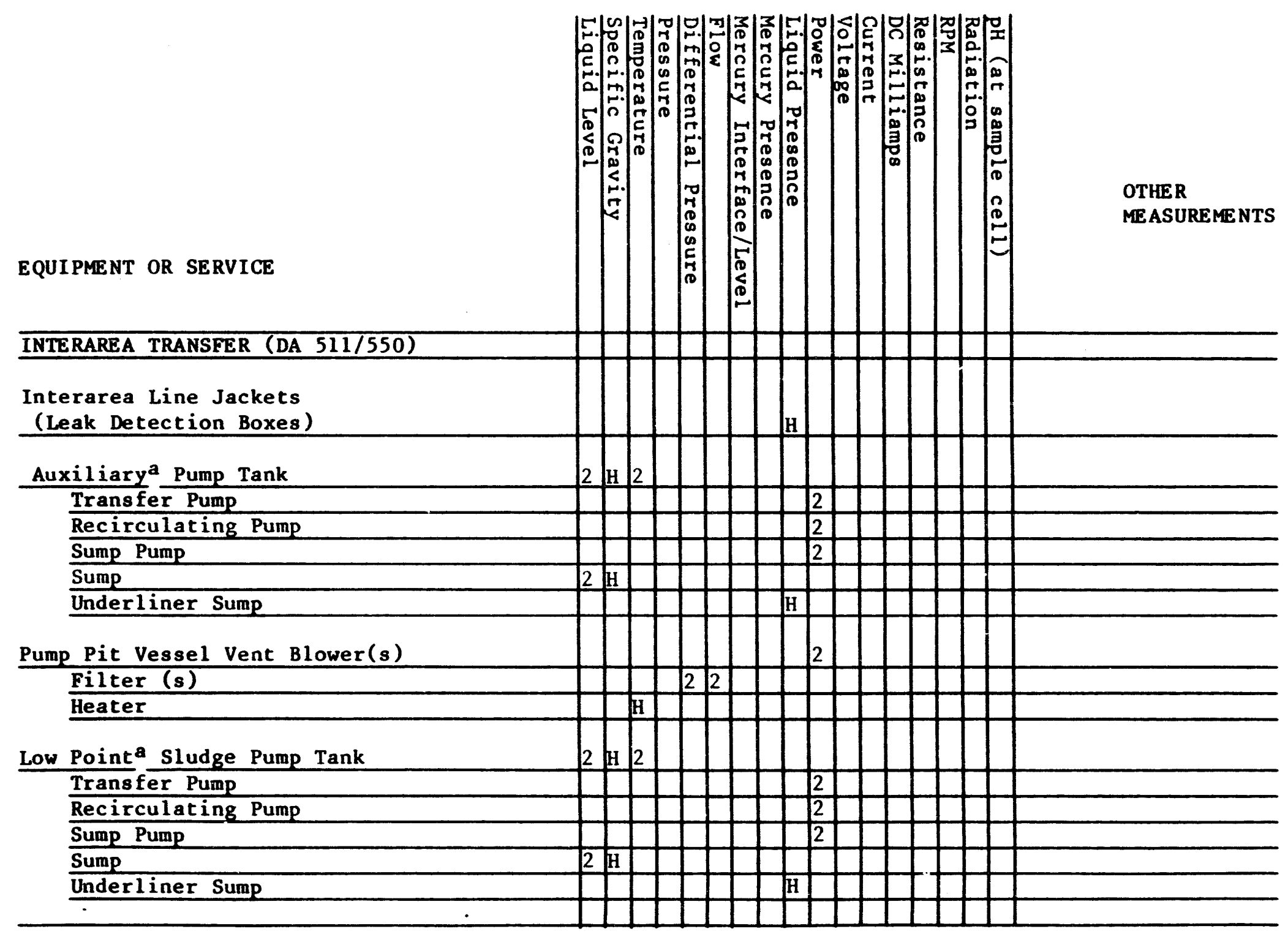

a Requires redundant $\mathrm{LL}$ and SpG 


\section{EQUIPMENT OR SERVICE}

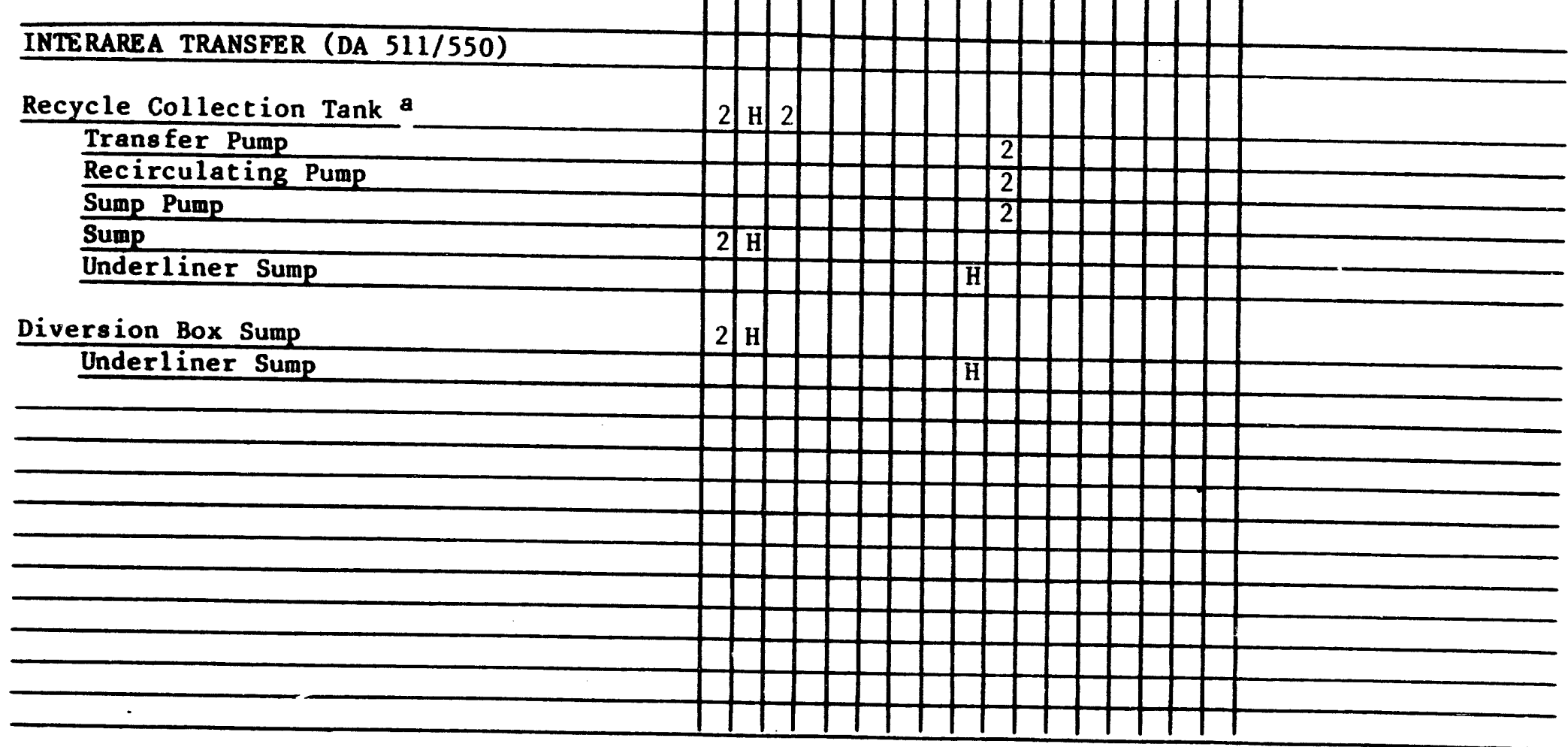




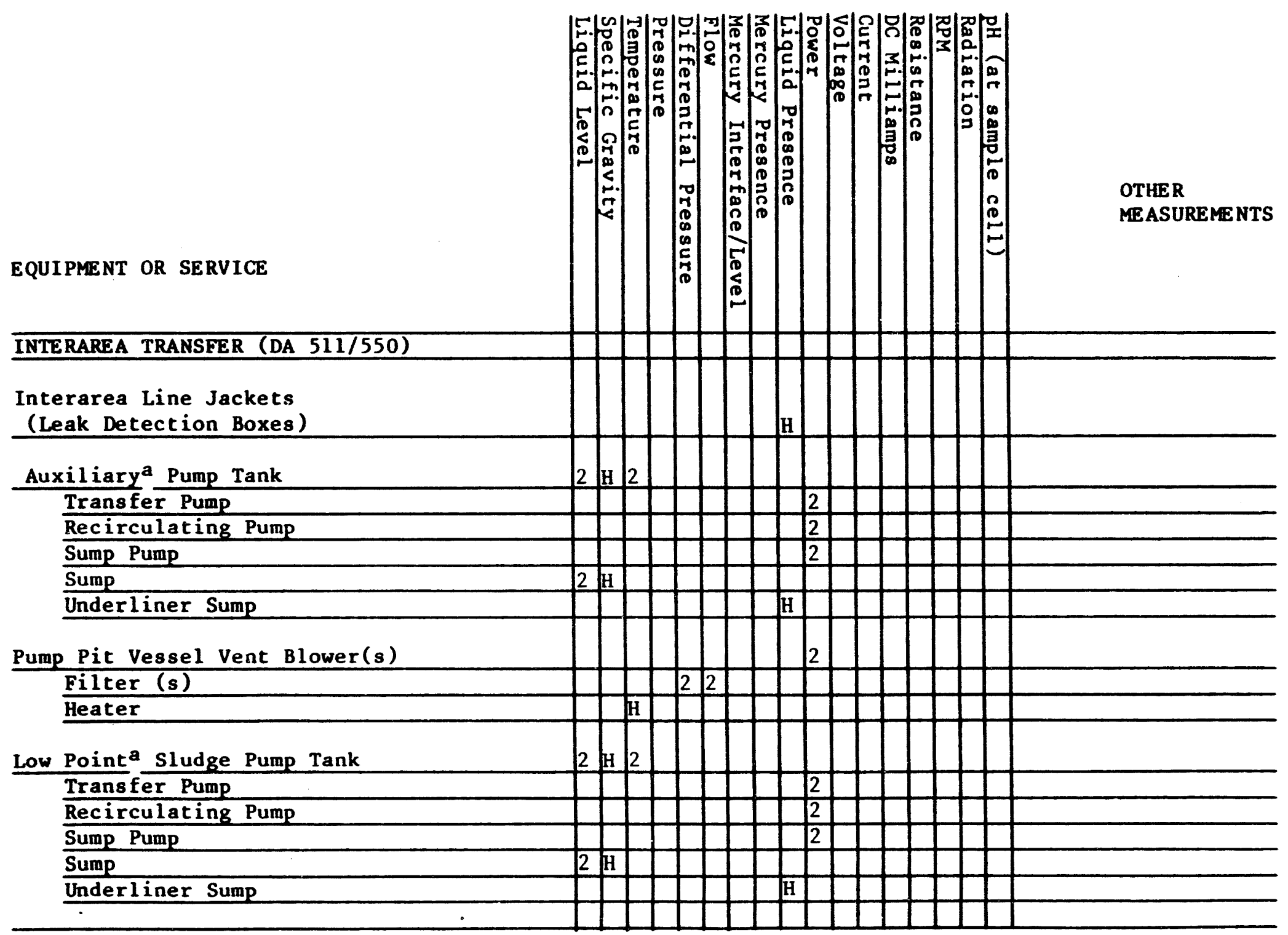

a Requires redundant LL and SpG 


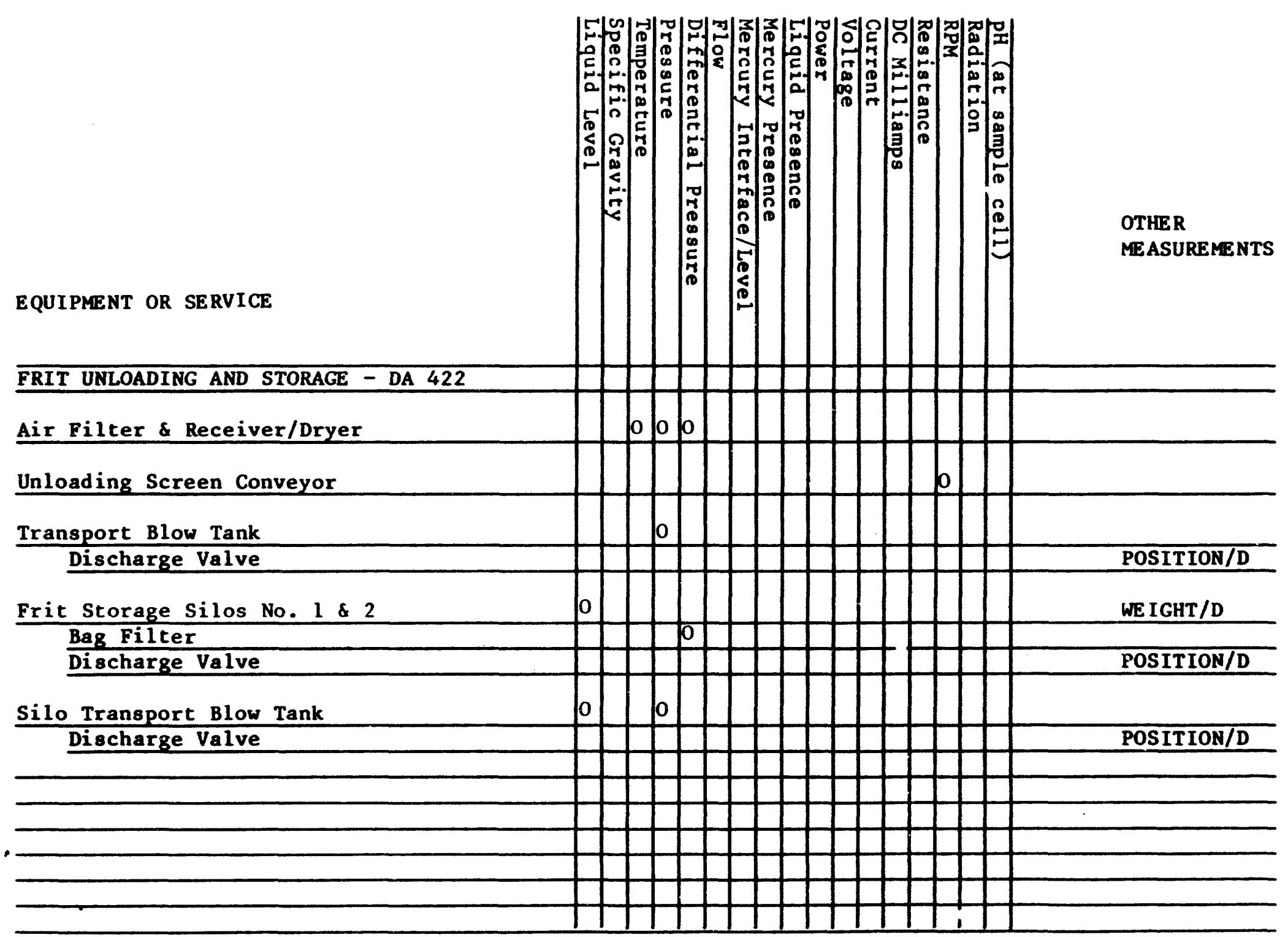


VARIABLES TO BE MEASURED AND READOUT LOCATIONS

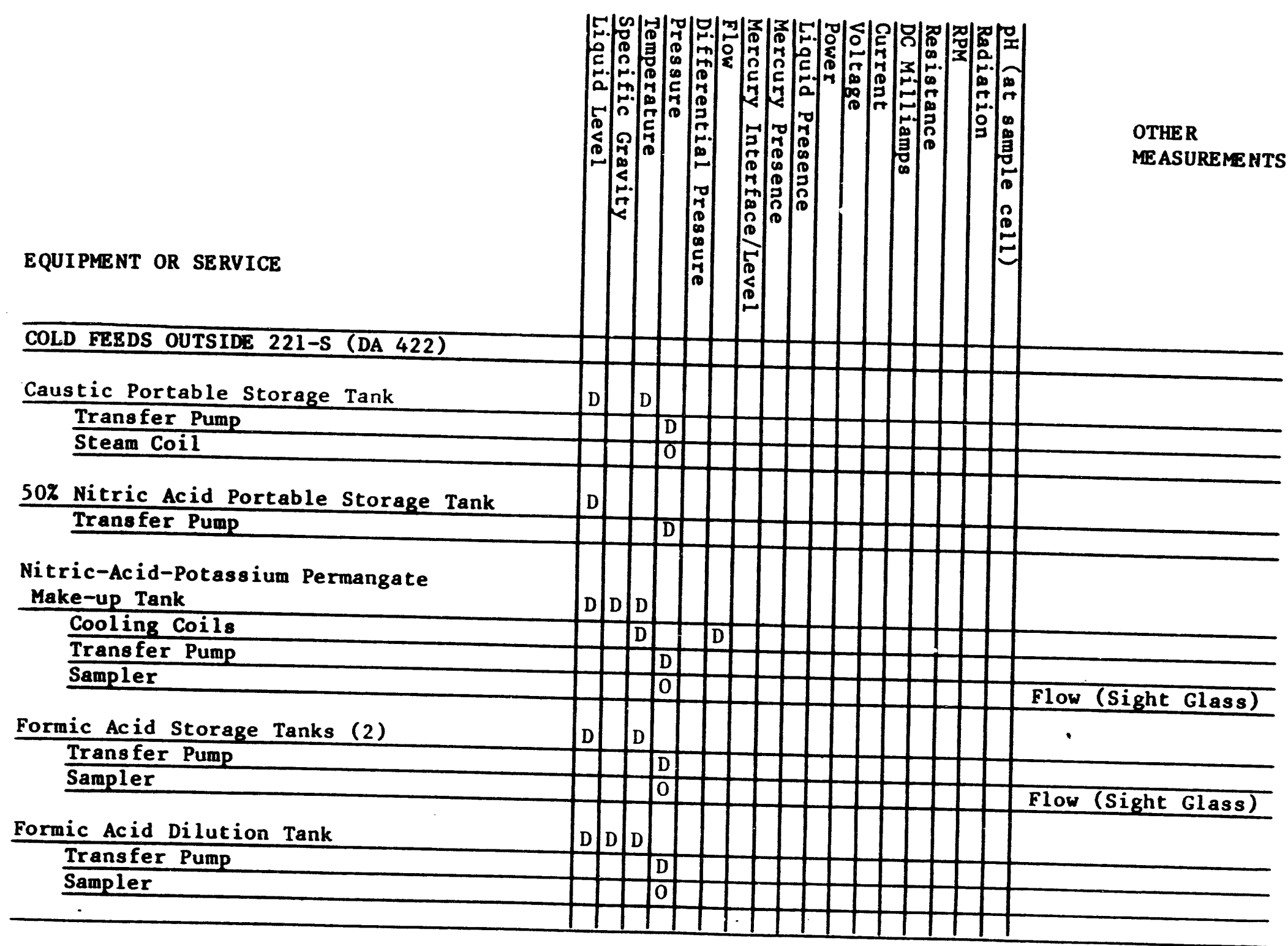


pH (at sample cell)

Radiation

$$
\text { RPM }
$$

Resistance

DC Milliamps

Current

Voltage

Power

Liquid Presence

Mercury Presence

Mercury Interface/Level

Flow

Differential Pressure

Pressure

Temperature

Specific Gravity

Liquid Level

잉

a)

olao

10

10

a

a 10

a

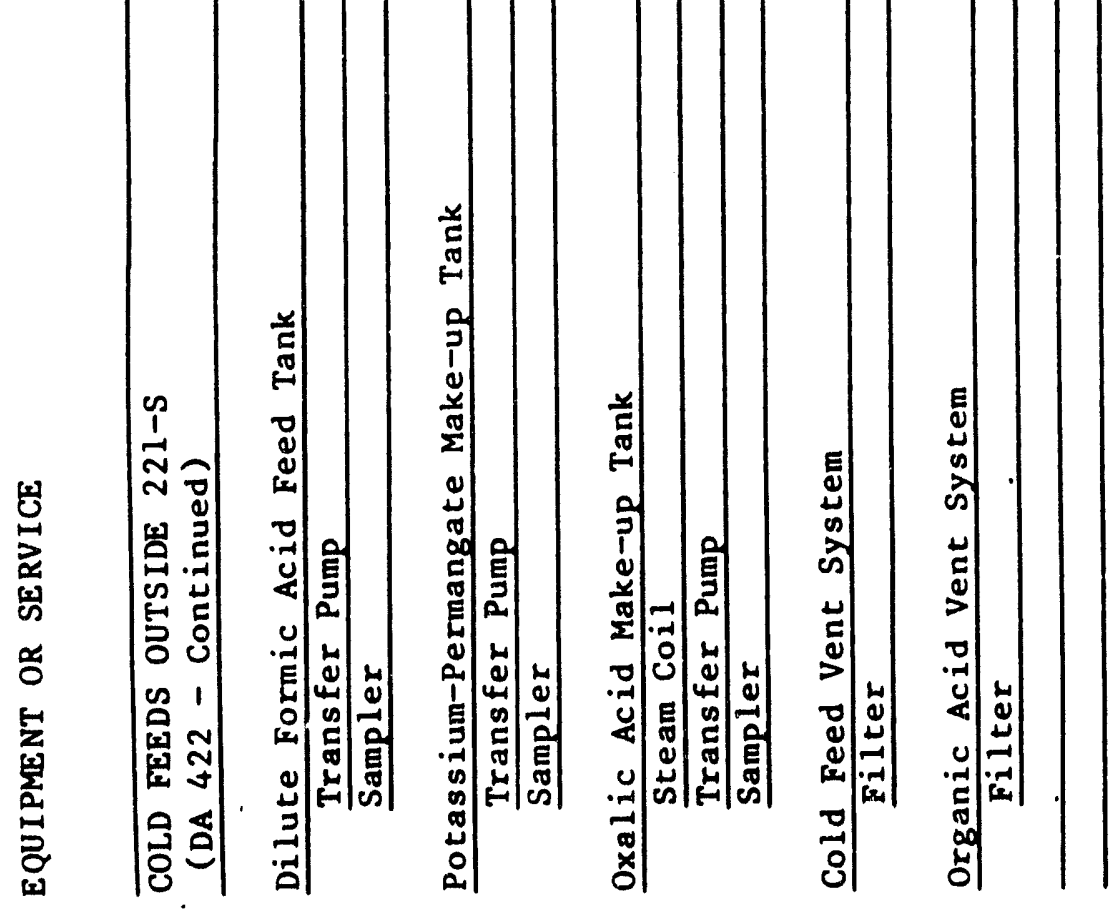




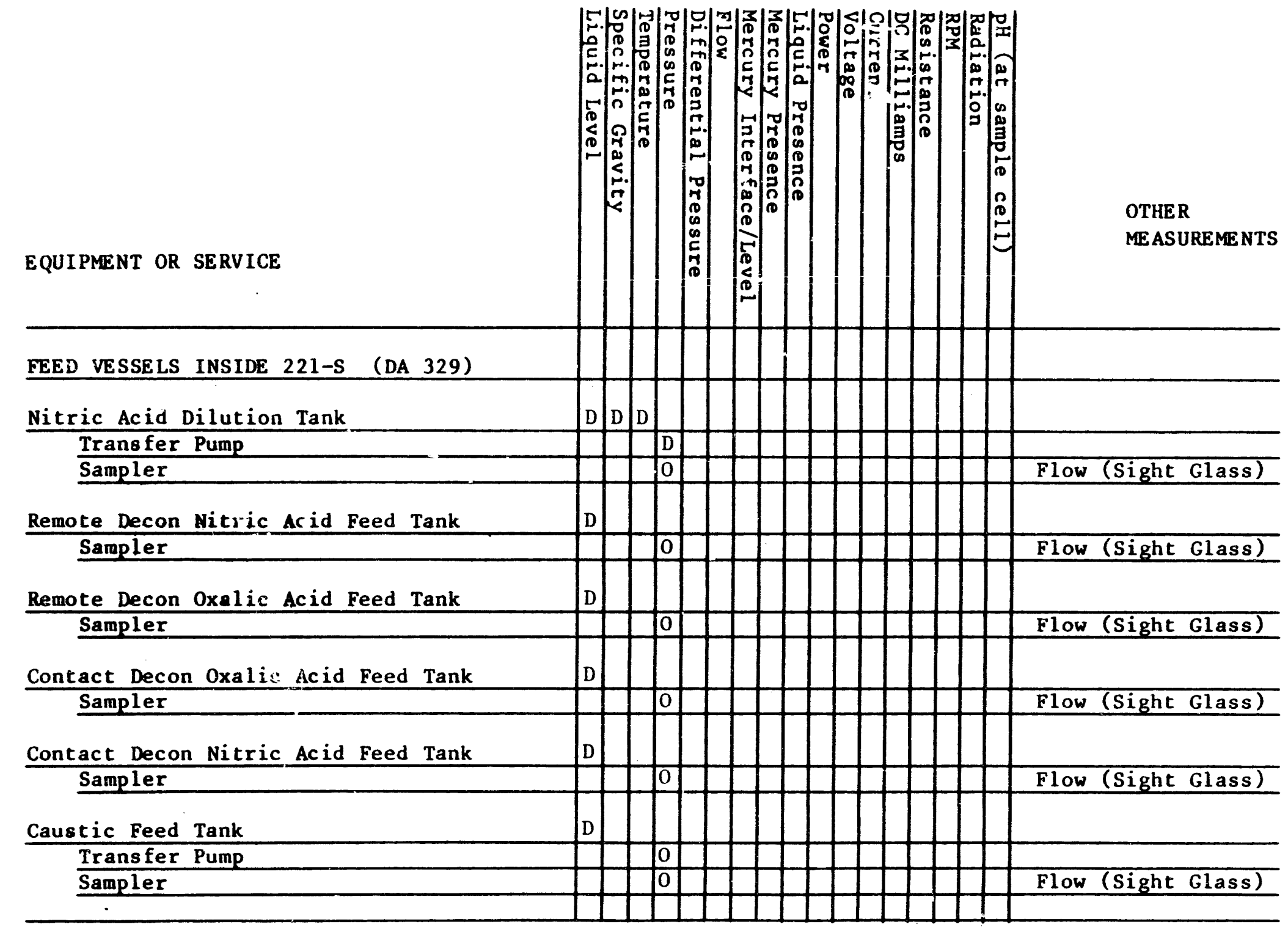


VARIABLES TO BE MEASURED AND READOUT LOCATIONS

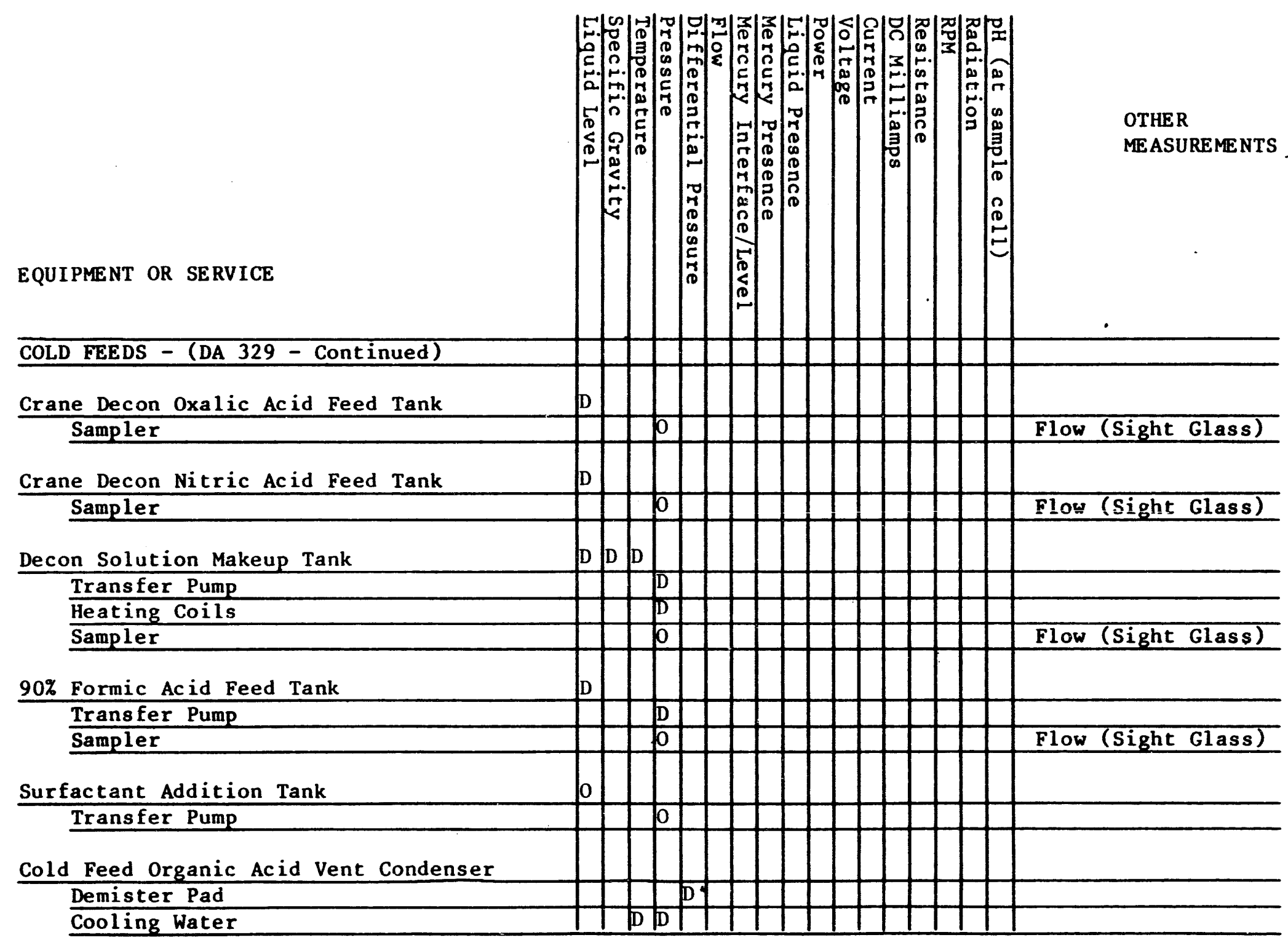


VARIABLES TO BE MEASURED AND READOUT LOCATIONS

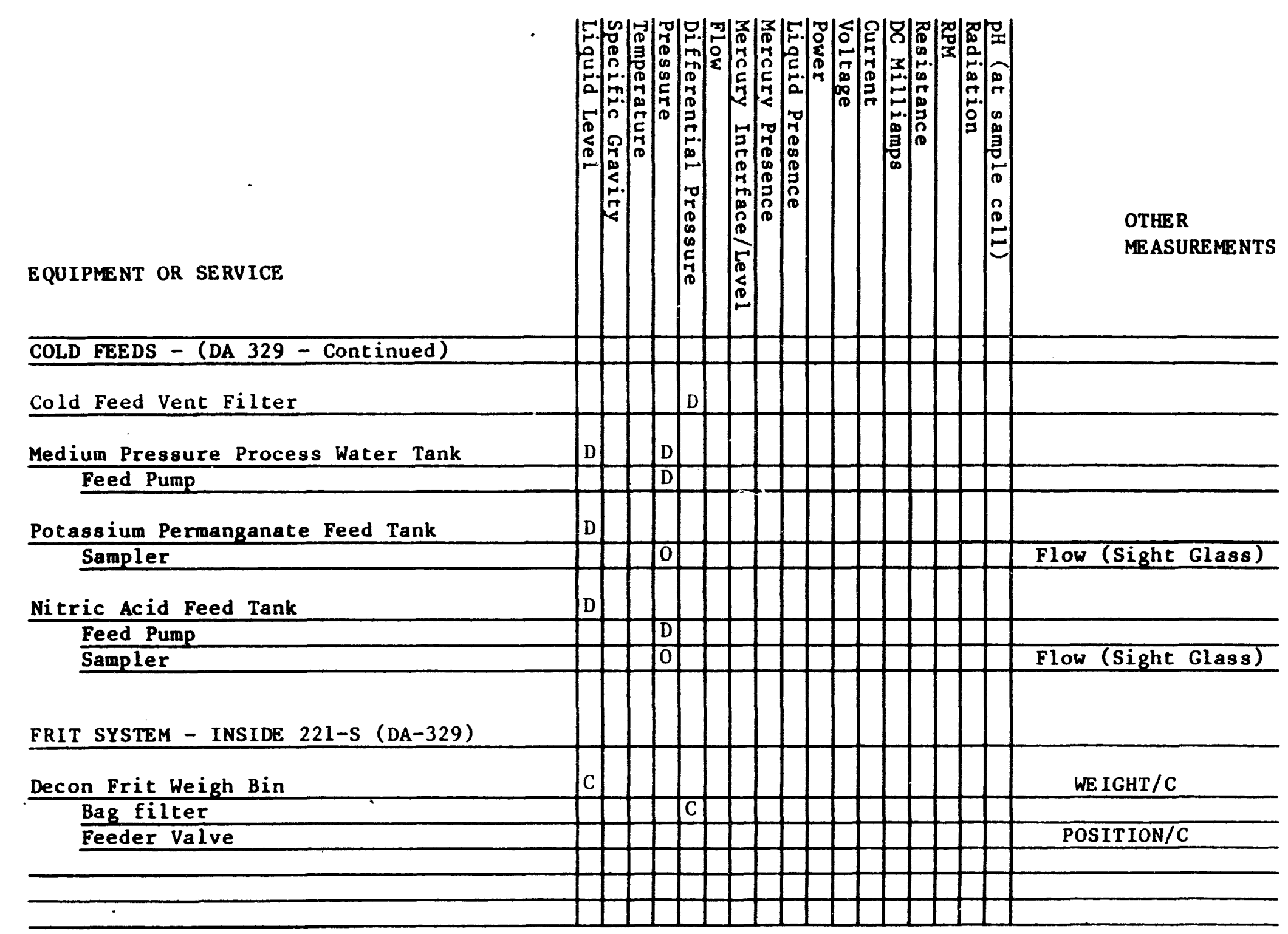




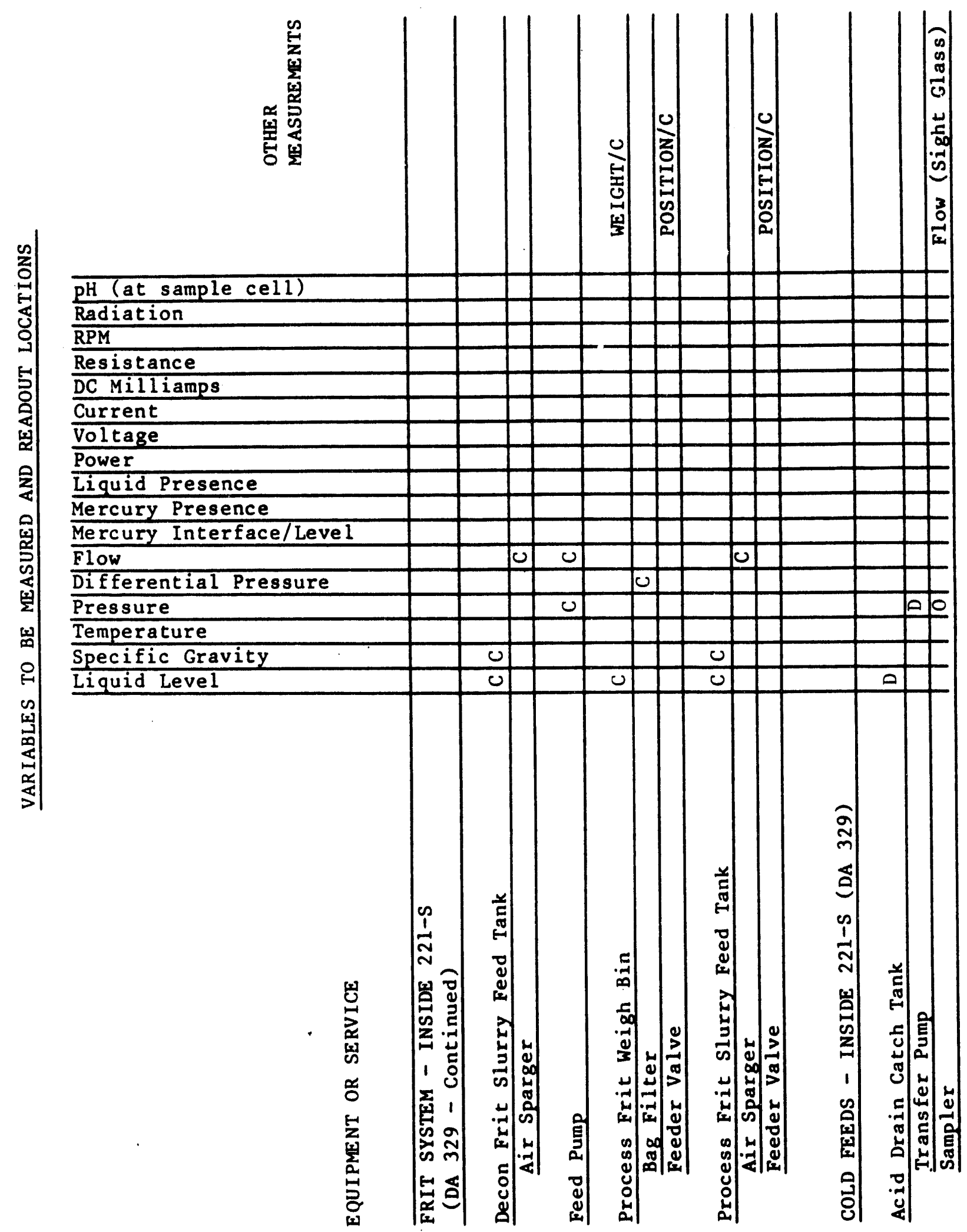




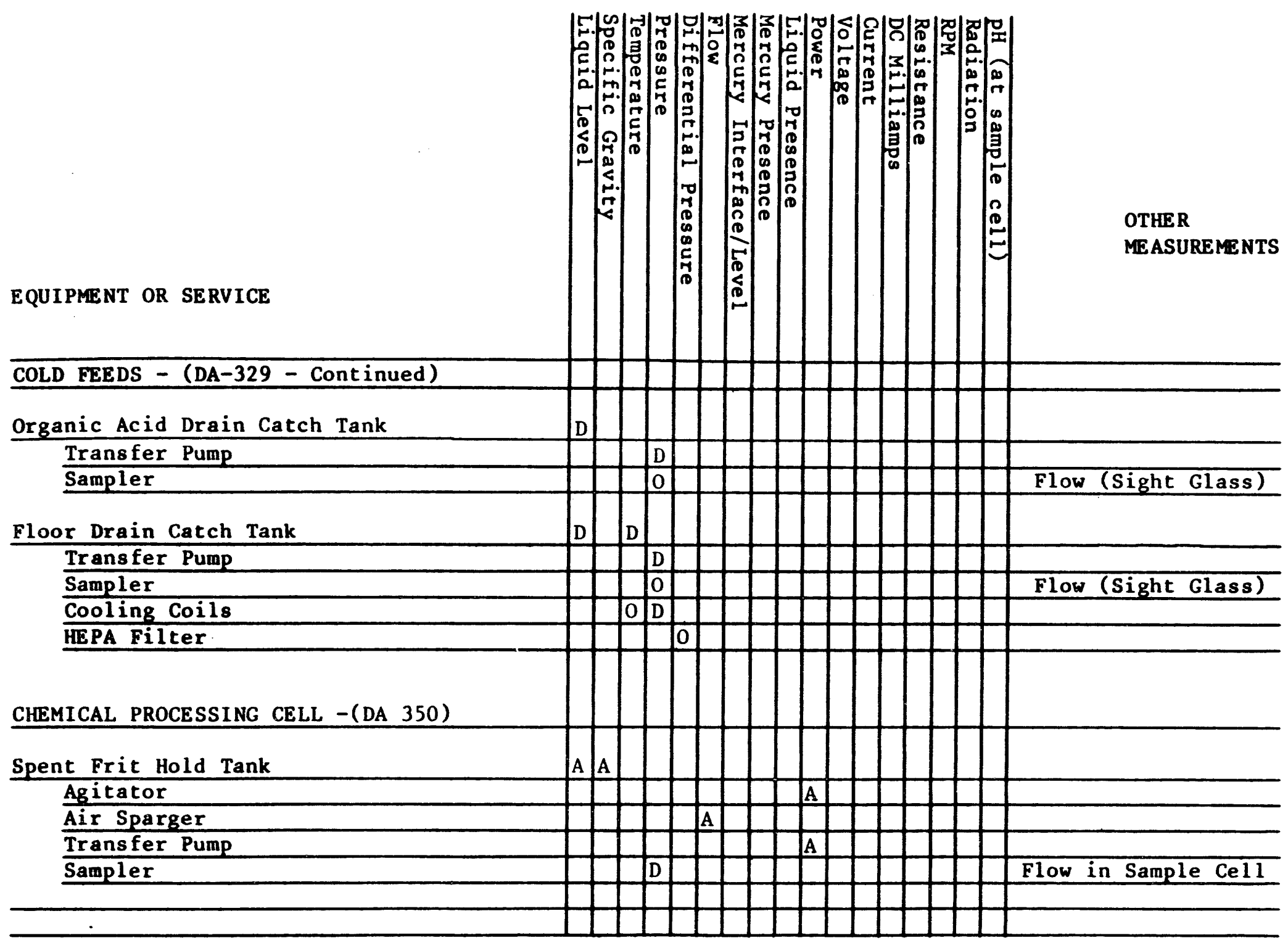


EQUIPMENT OR SERVICE

CHEMICAL PROCESSING CELL

(DA 350 - Continued)

Sludge Receipt and Adjustment Tank

Agitator

Air Sparger

Transfer Pump

Sample Pump

Mercury Sump

Mercury Transfer Pump

De-entrainment Filter

Condenser

Steam Coils

Cooling Water Coils

Process Cell Sumps

Sump Pumps

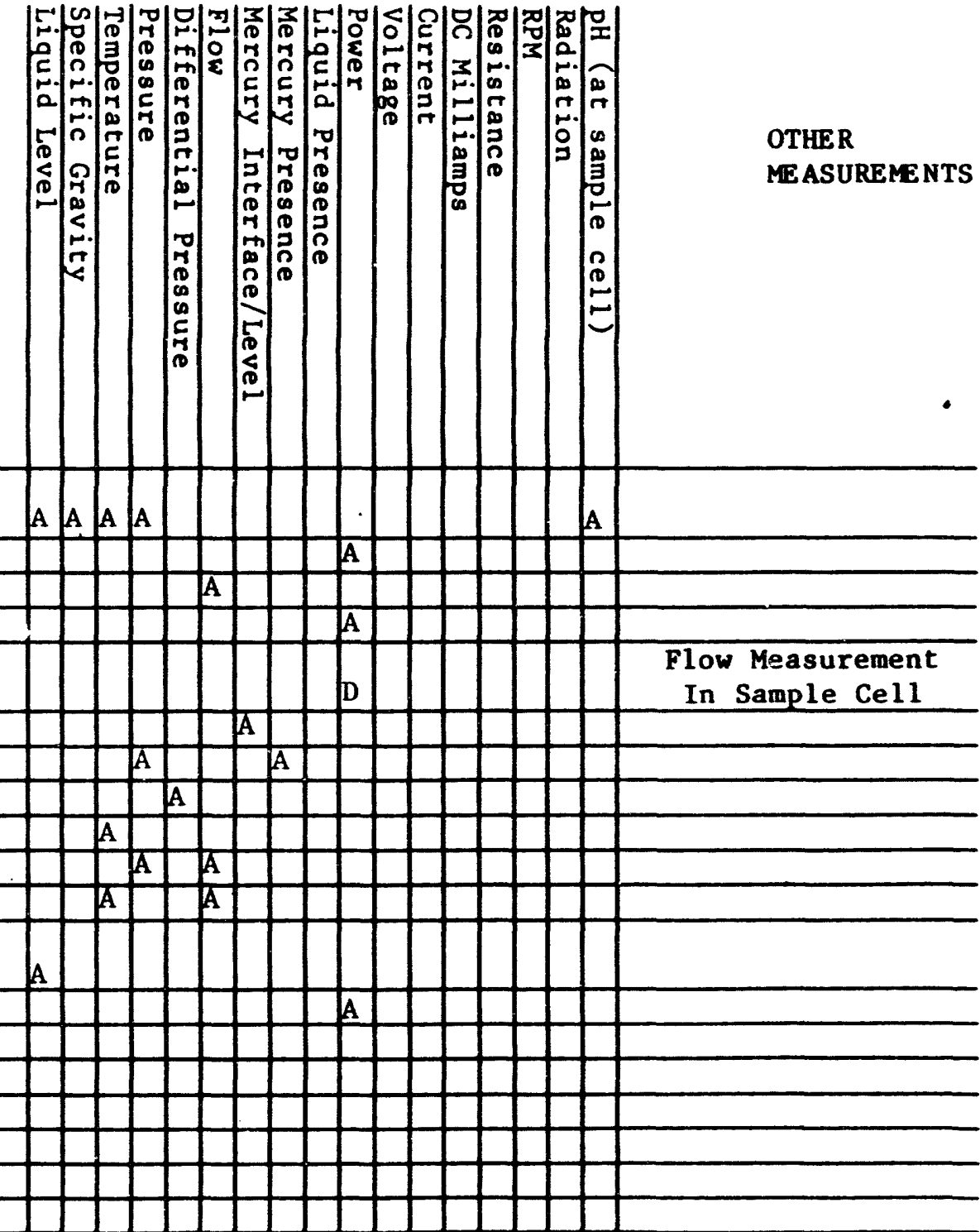


EQUIPMENT OR SERVICE

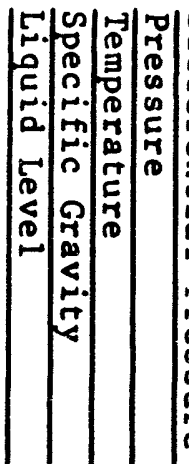

CHEMICAL PROCESSING CELL

(DA 350 - Continued)

Slurry Mix Evaporator

Agitator

Air Sparger

Transfer Pump

Sample Pump

Mercury Sump

De-entrainment Filter

Condenser

Steam Coils

Cooling Water Coils
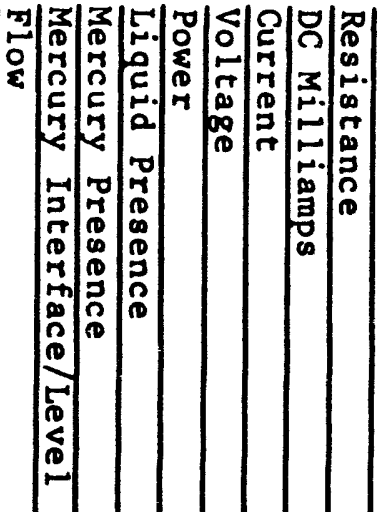

OTHER

MEASUREMENTS

SHE - Condensate Tank

Air Sparger

Transfer Pump

Sample Pump 
on

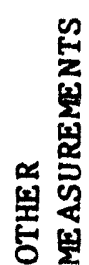

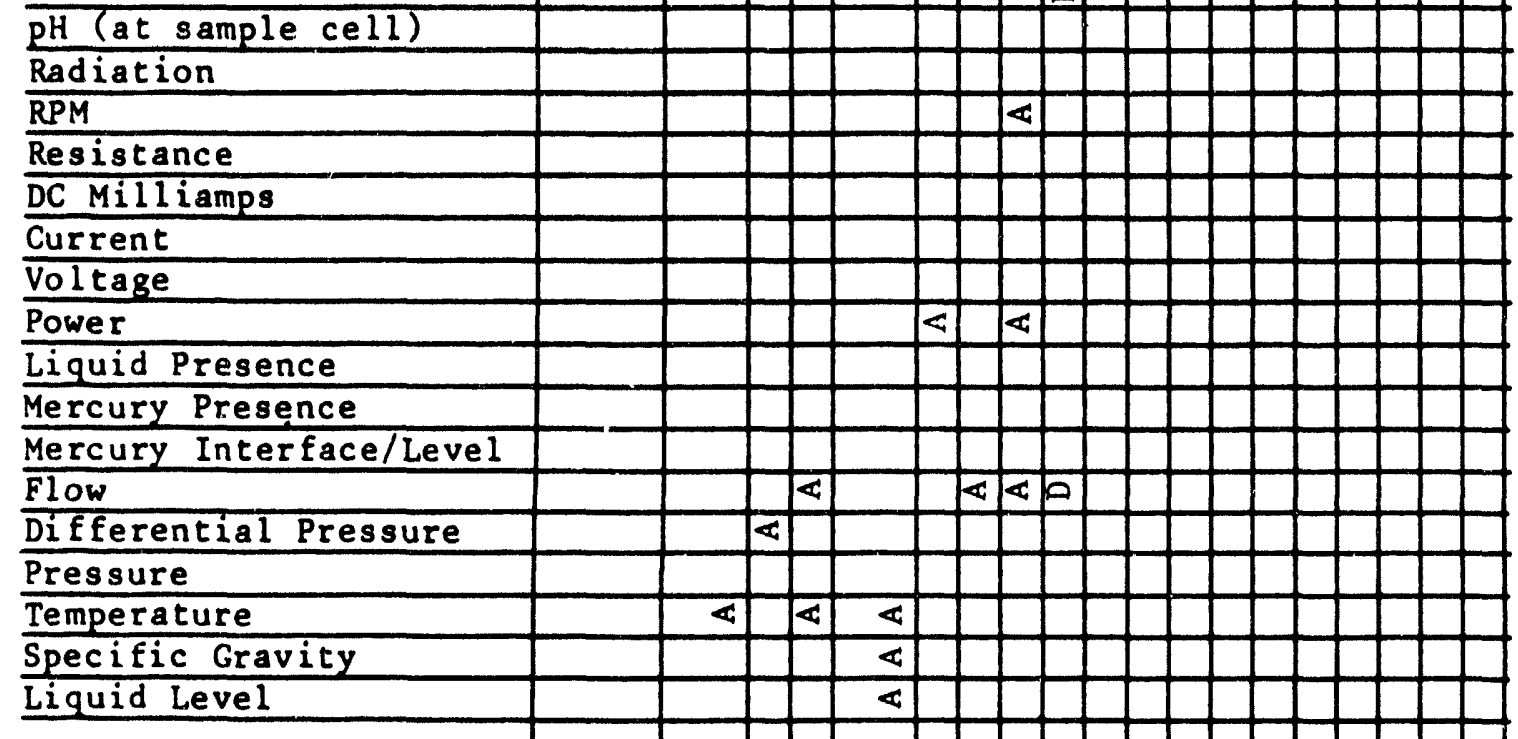

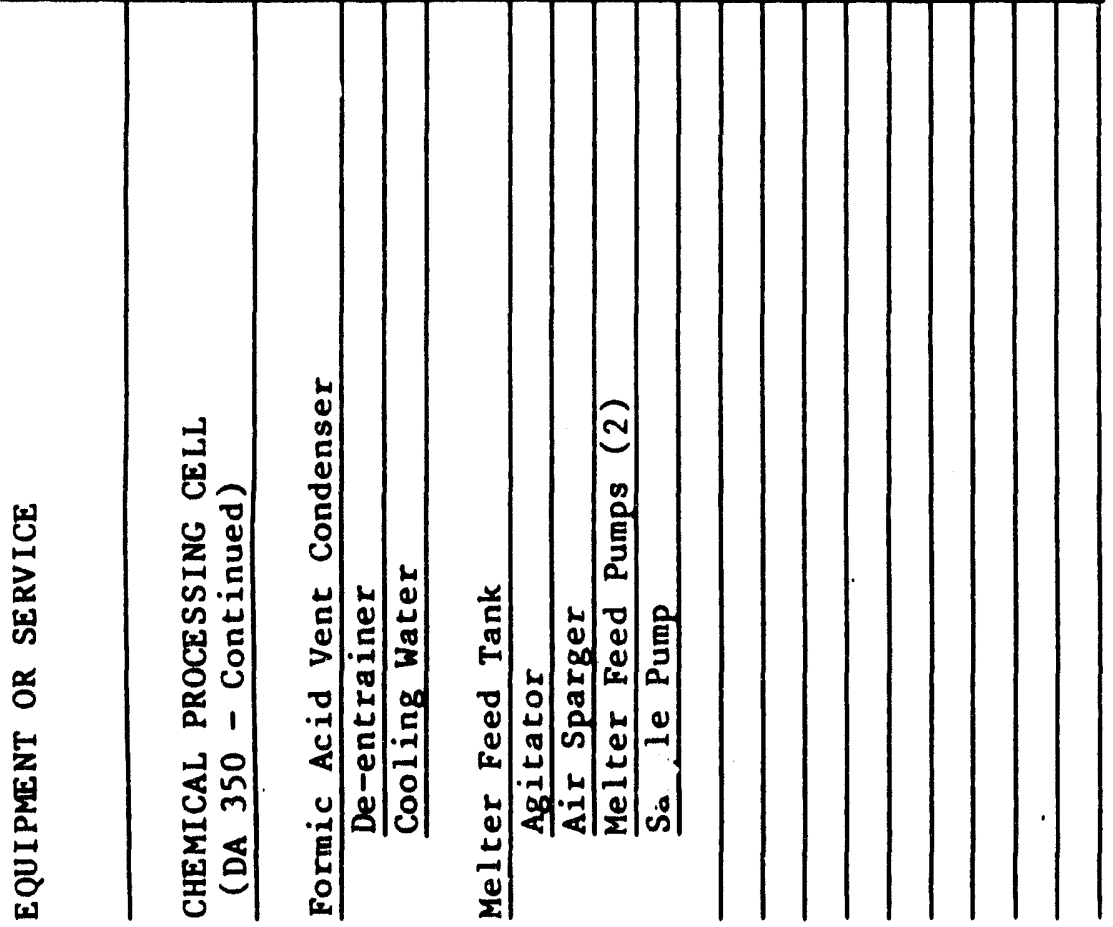


VARIABLES TO BE MEASURED AND READOUT LOCATIONS

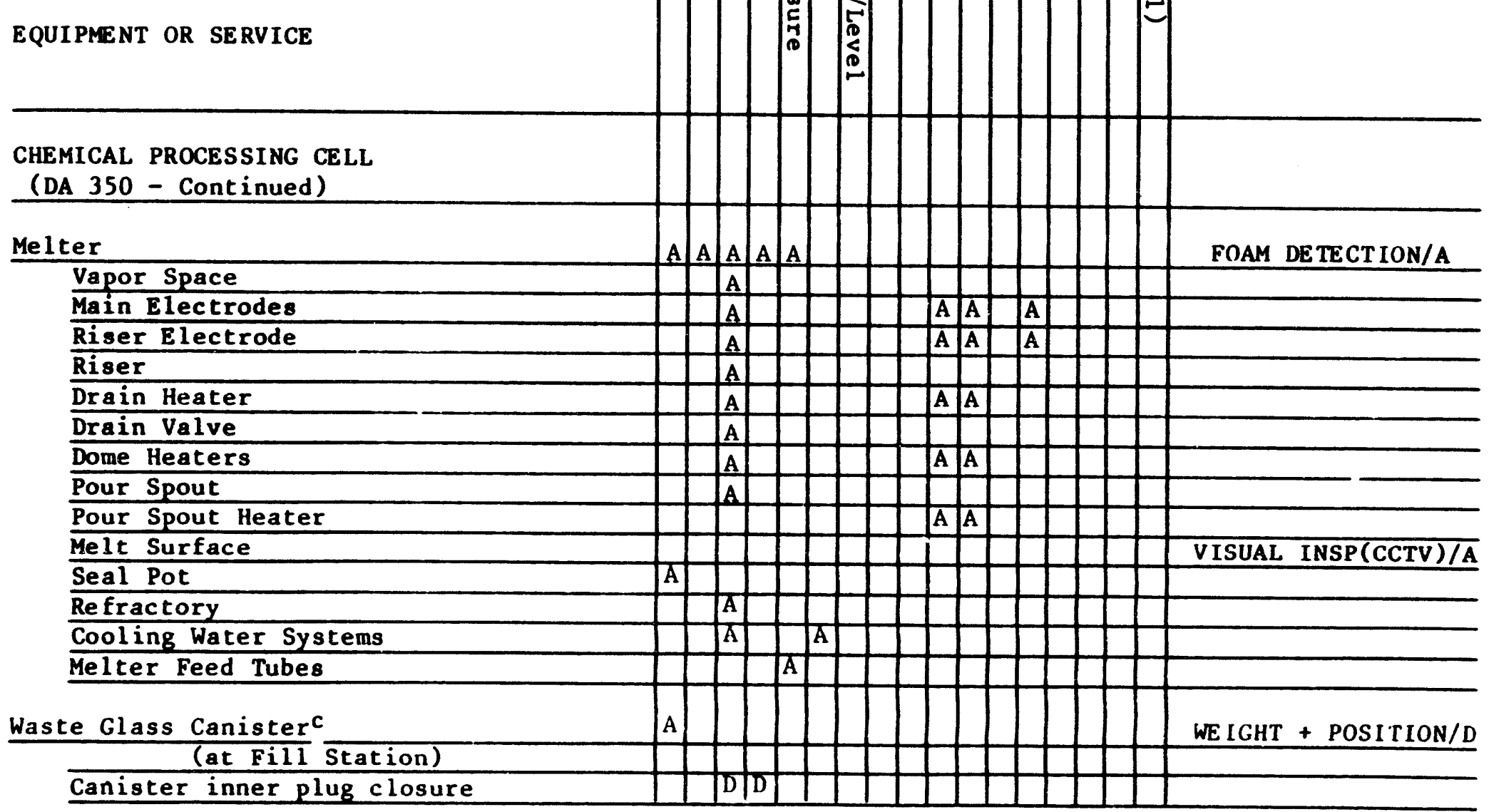

OTHER

MEASUREMENTS 


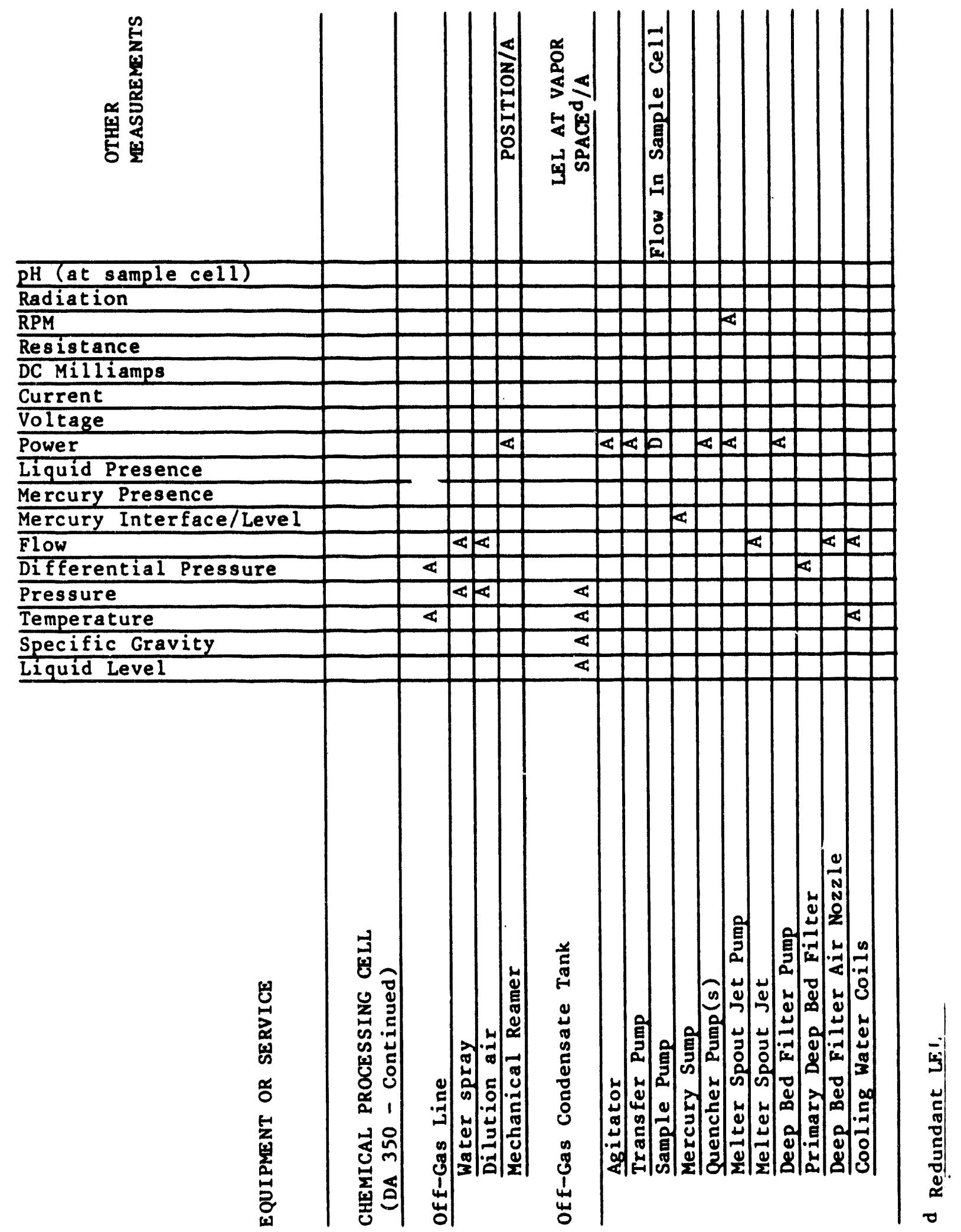




\section{EQUIPMENT OR SERVICE}

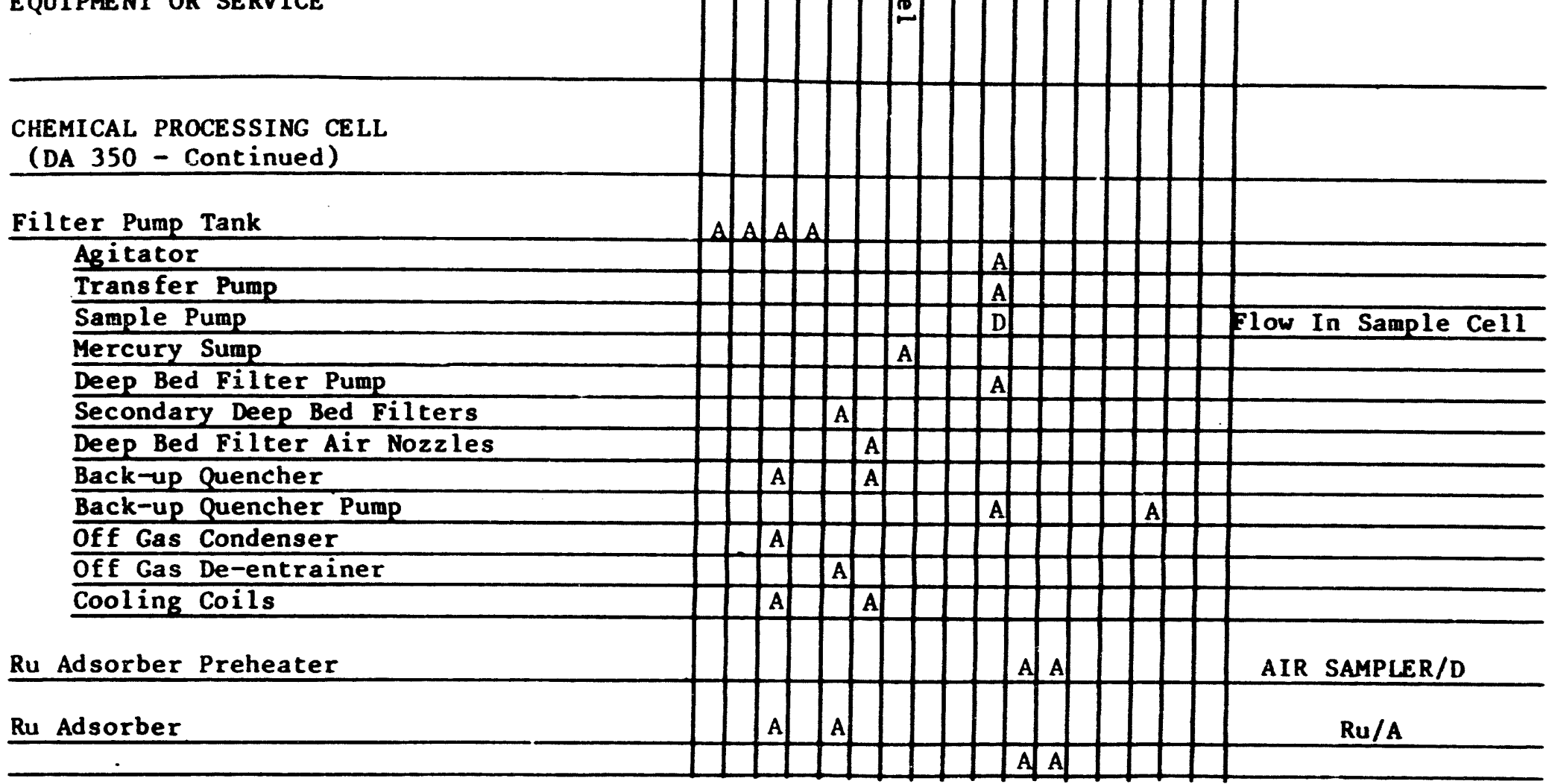

OTHE R

MEASUREMENTS 


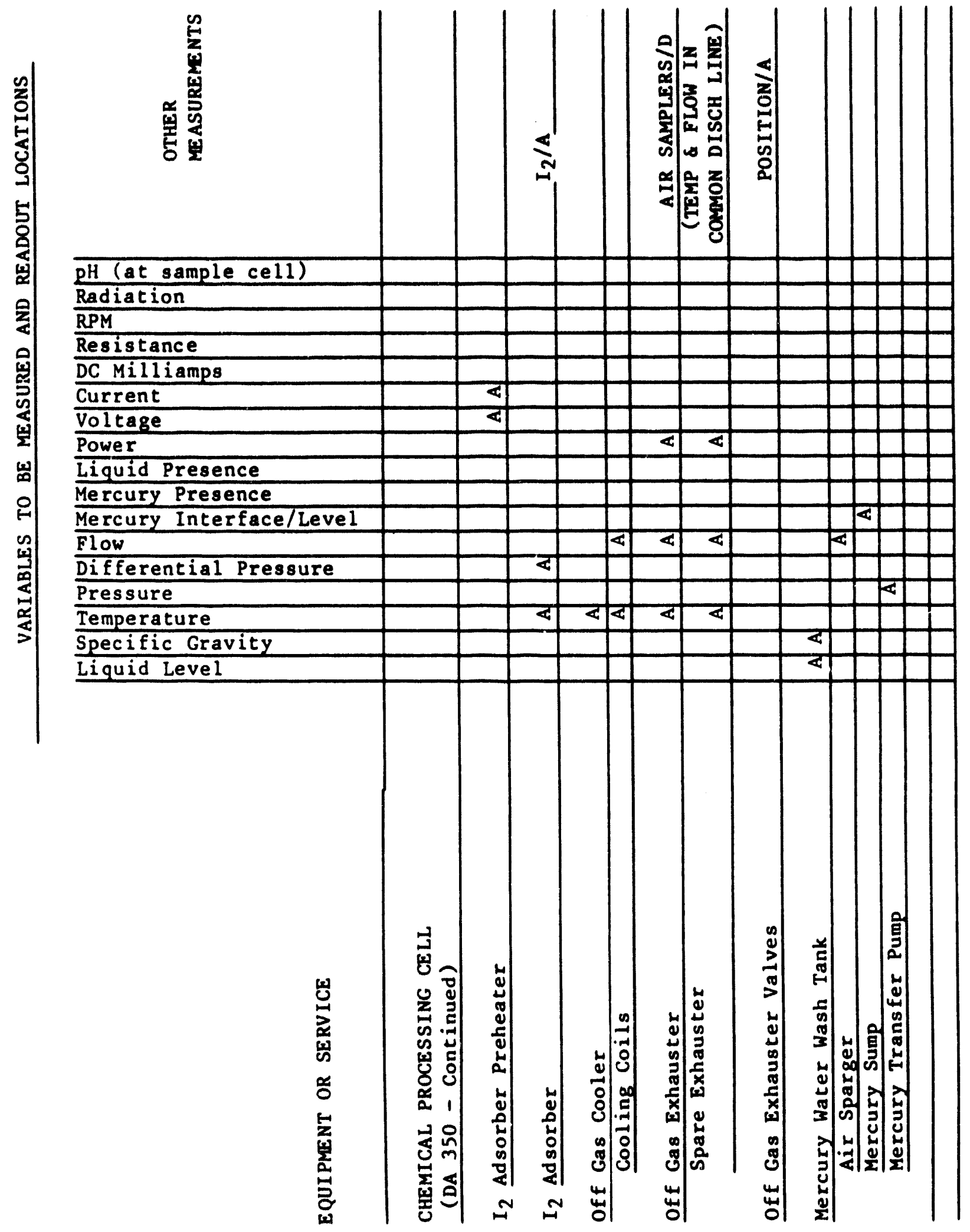




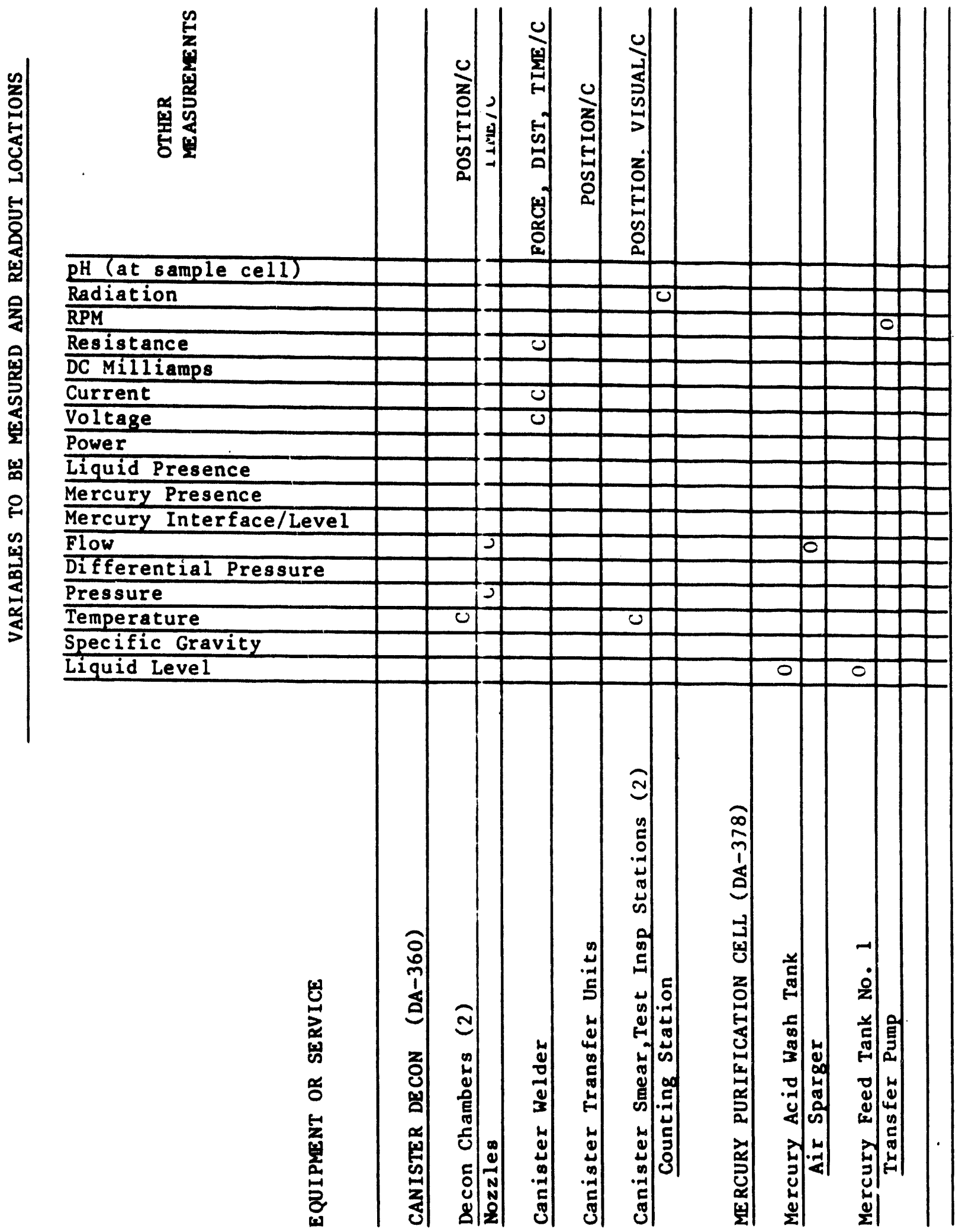




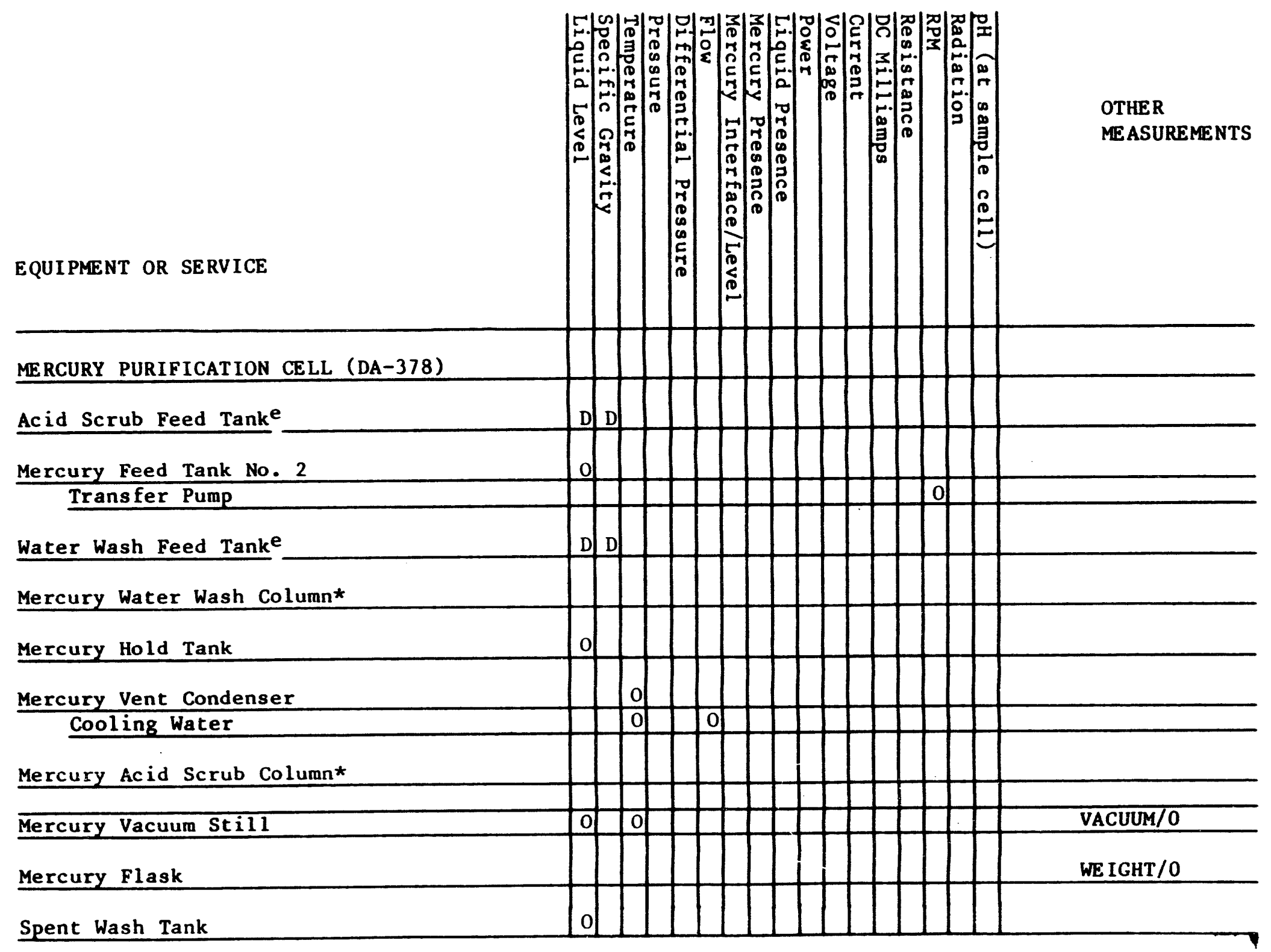

e May be located outside of purification cell

* No instrumentation required if equipment is constructed of glass. 
EQUIPMENT OR SERVICE

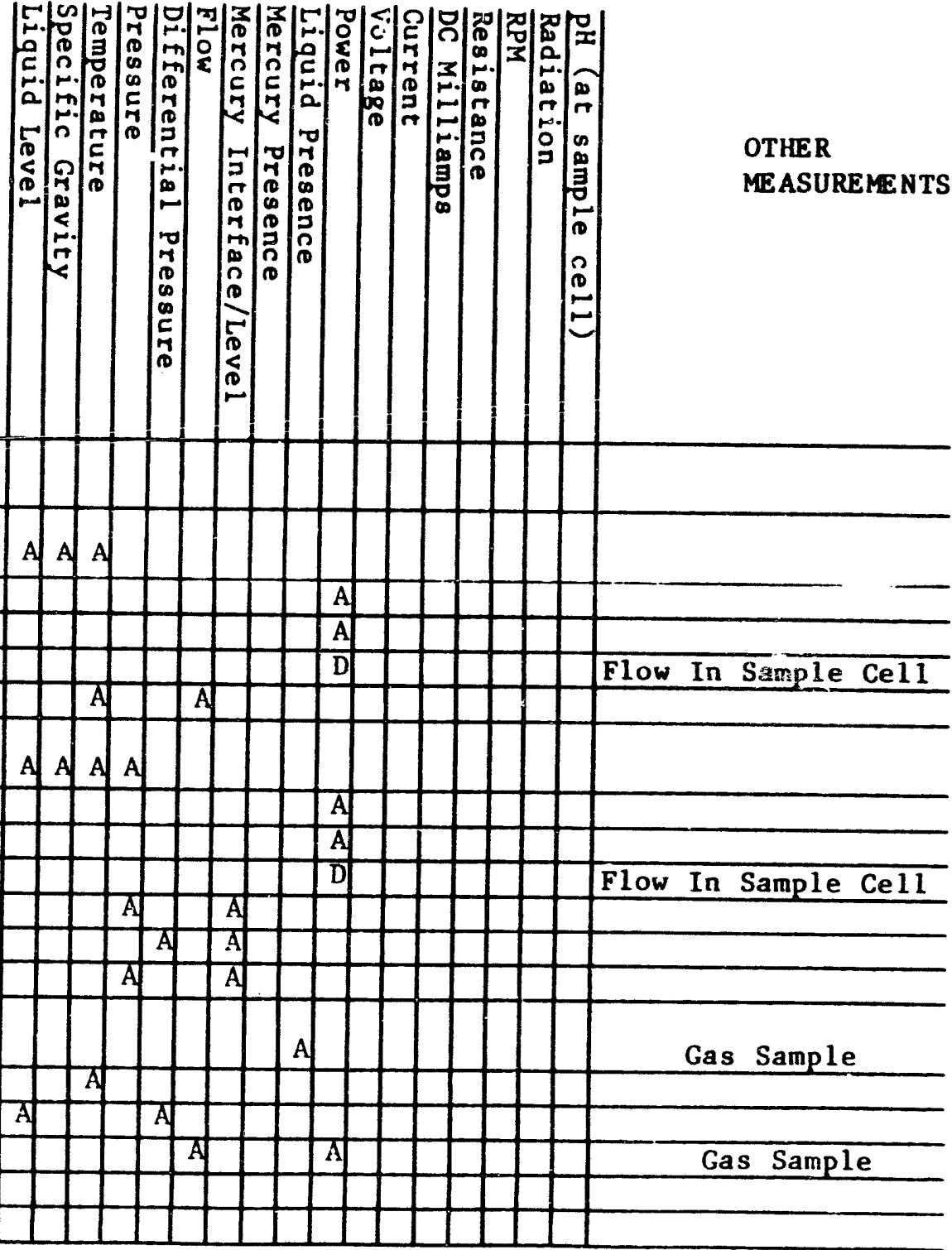

CHEMICAL PROCESSING CELL - (DA 395)

Recycle Collection Tank

Agitator

Transfer Pump

Sample Pump

Cooling Coils

Decon Waste Treatment Tank

Agitator

Trans fer Pump

Sample Pump

Cooling Coils

Steam Coils

Reflux Condenser \& Cooling Coils

Vessel Vent Header

Preheater

Filter (s)

Blowers (2) 
VARIABLES TO BE MEASURED AND READOUT LOCATIONS




VARIABLES TO BE MEASURED AND READOUT LOCATIONS

EQUIPMENT OR SERVICE

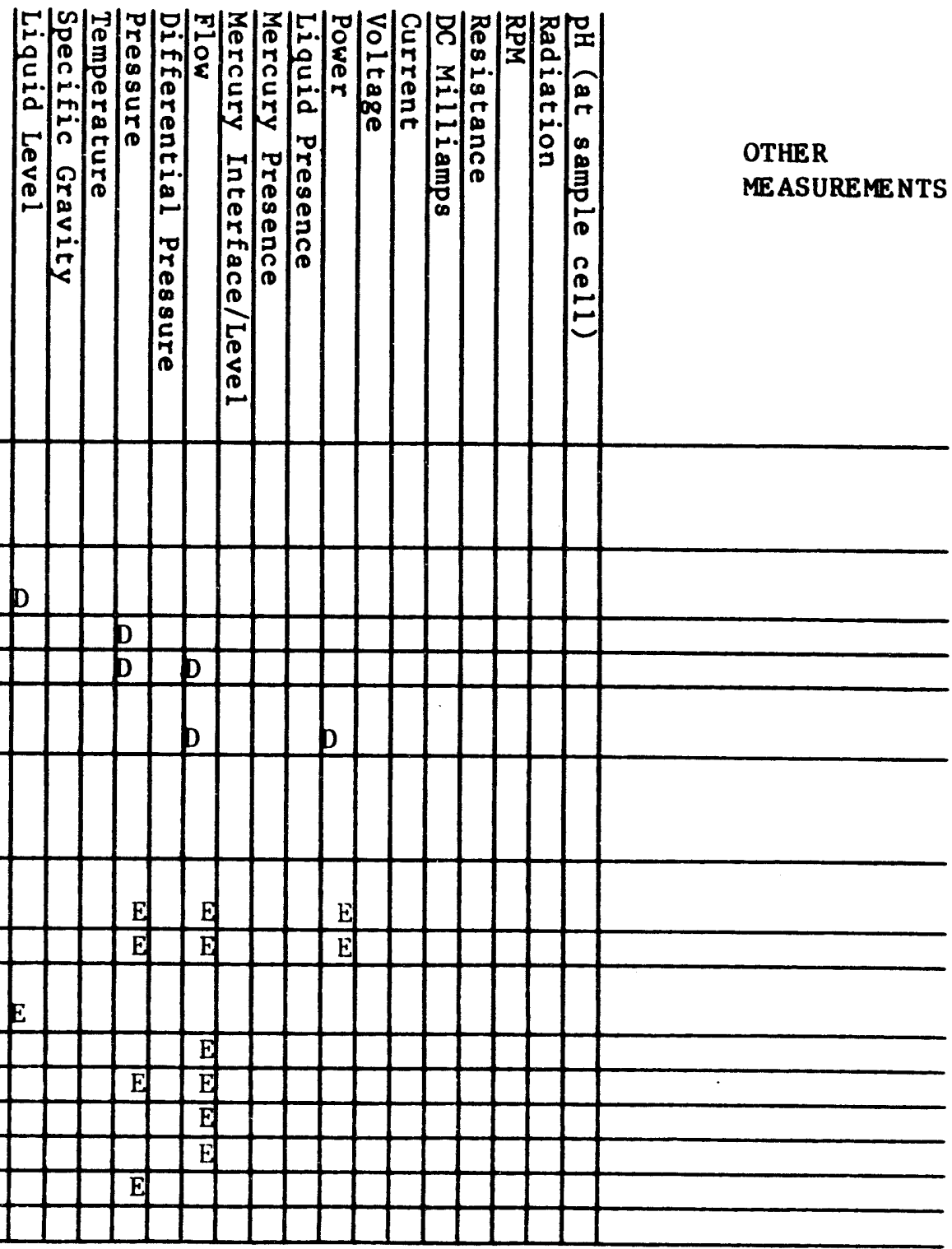

\section{WASTE TREATMENT SYSTEM}

(DA 980 - Continued)

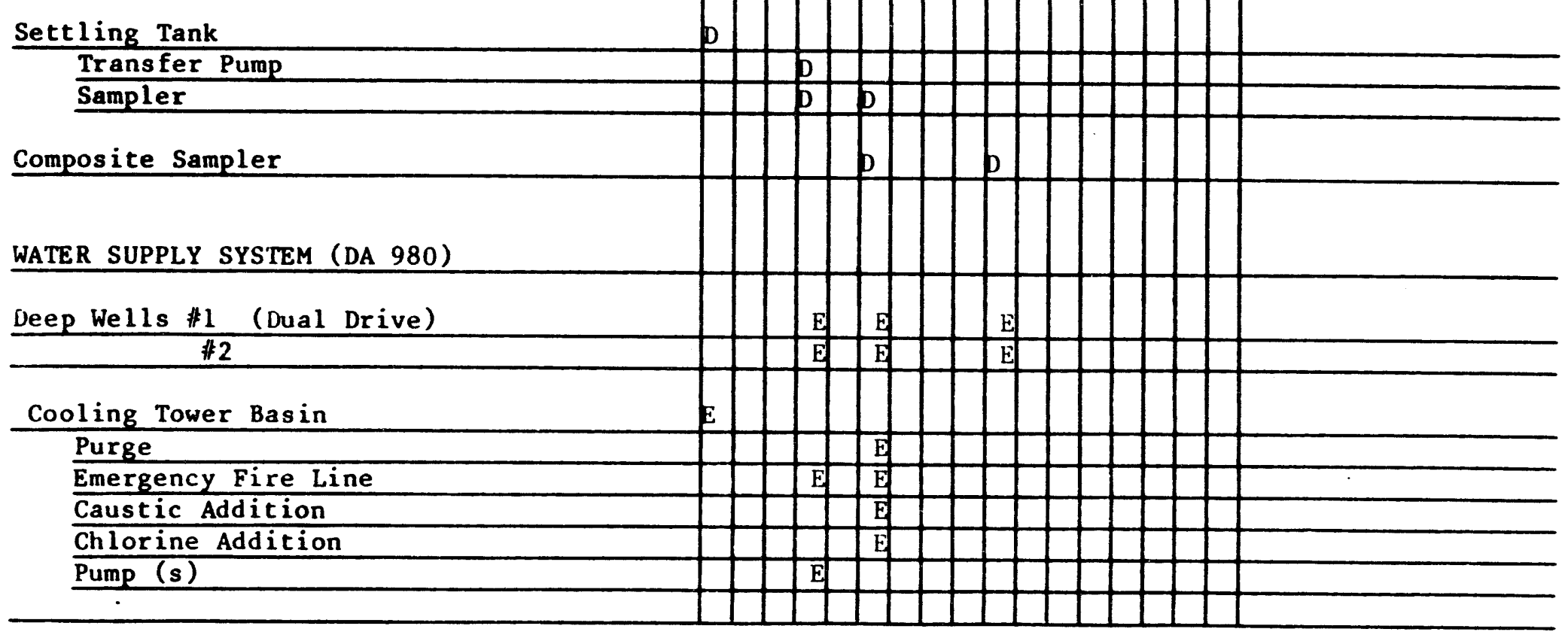




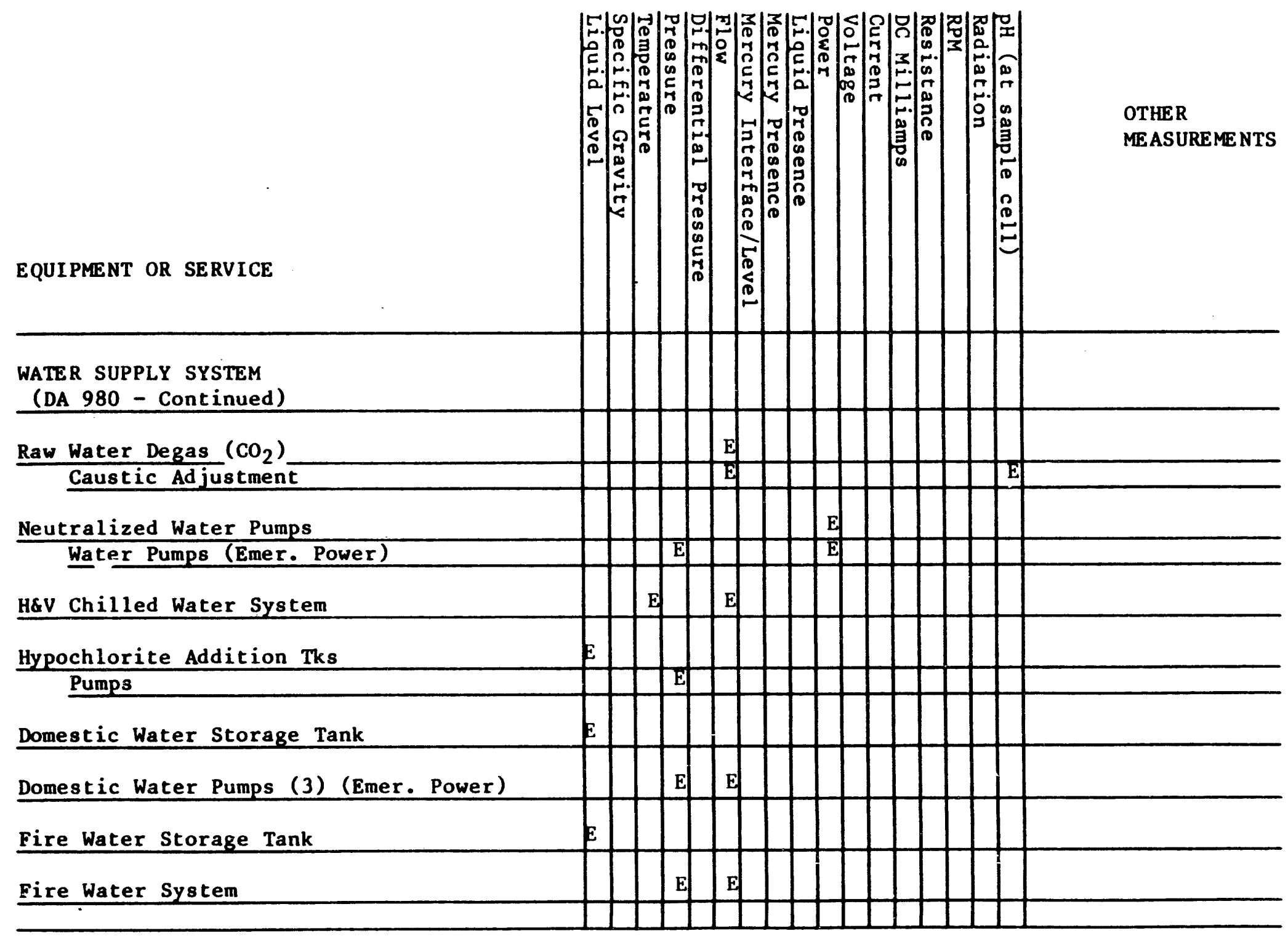




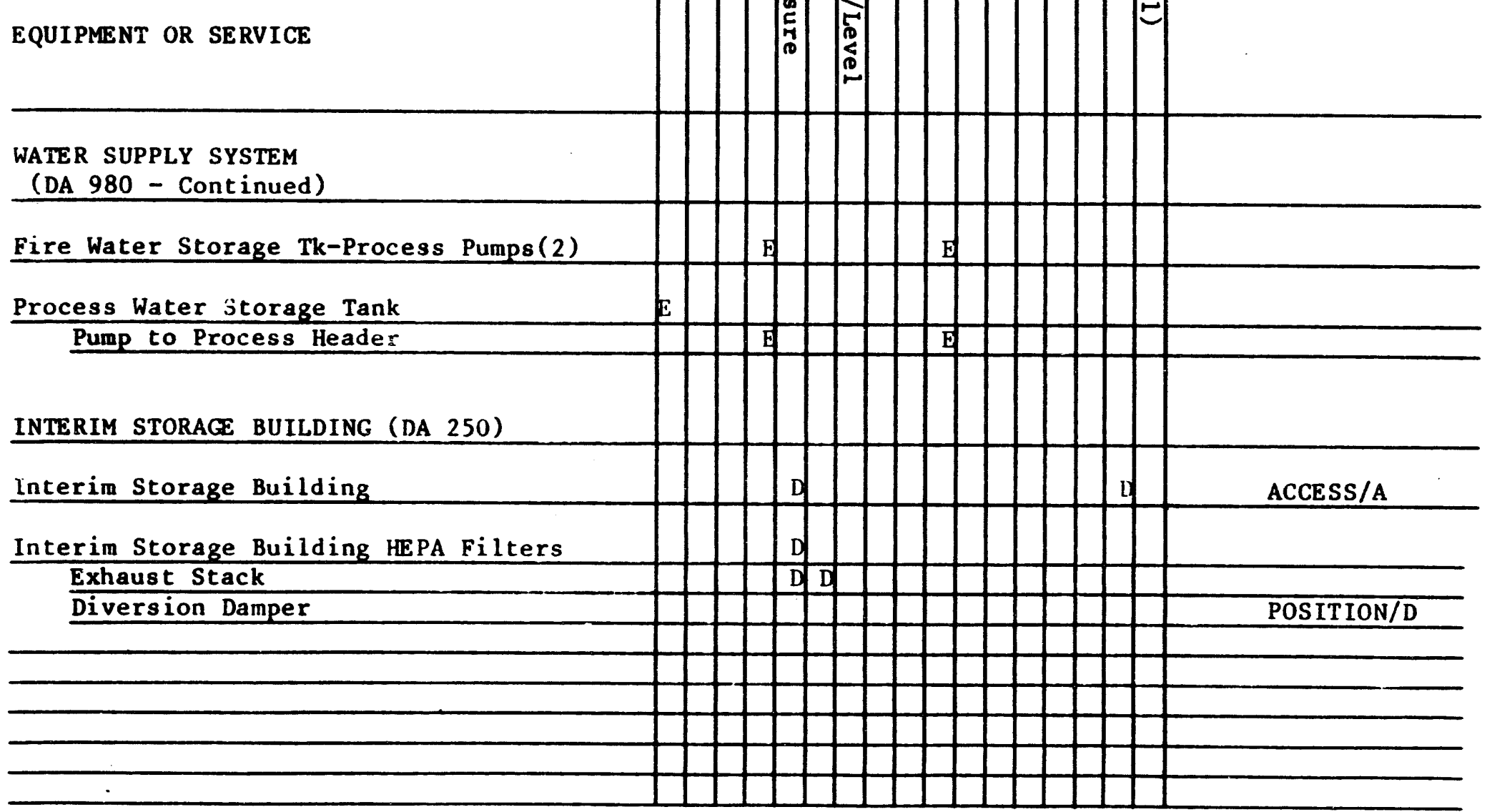




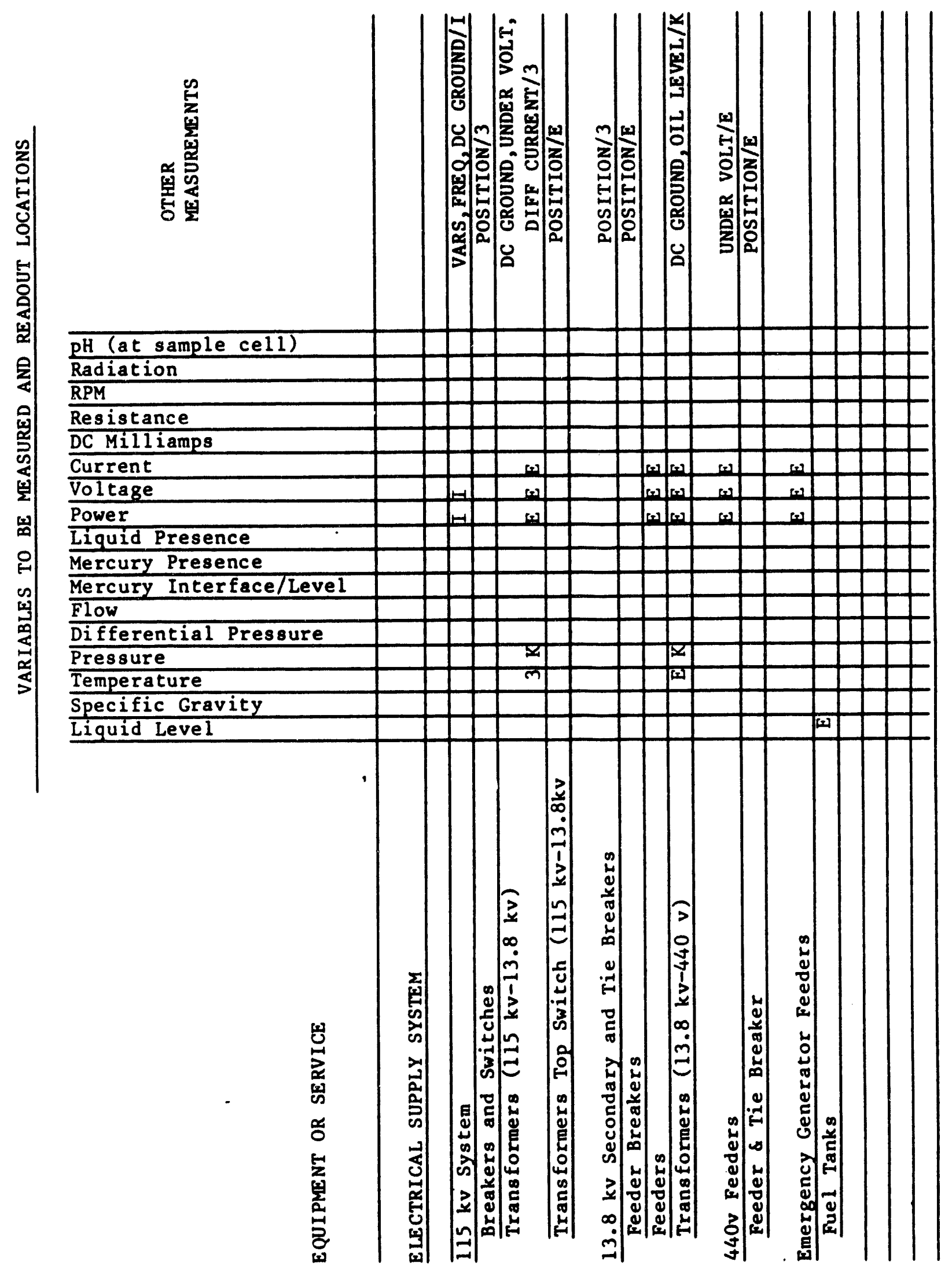


VARIABLES TO BE MEASURED AND READOUT LOCATIONS

EQUIPIENT OR SERVICE

\section{AIR SYSTEMS}

221-s Zone 1 Air Supply Fans

Air

Air Exhaust Ducte

Sand Filter

Air Exhaust Pans

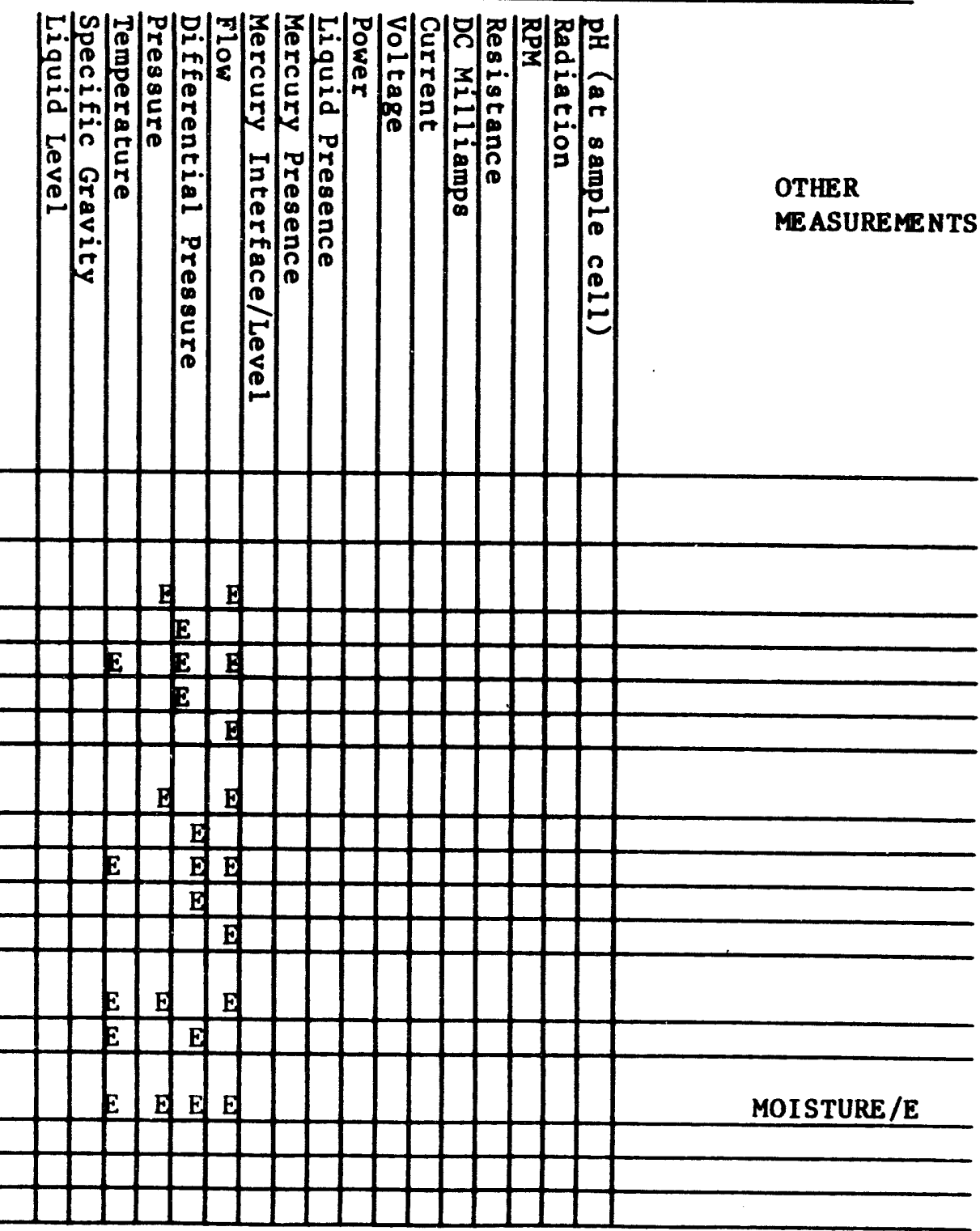

221-S Zone $2 \& 2 A$ Air Supply Fans

Air

Air Exhaust Ducts

HEPA Filters

- Air Exhaust Fans

221-S Zone 3 Air Supply Ducts Air

H\&V Systems Non-Regulated

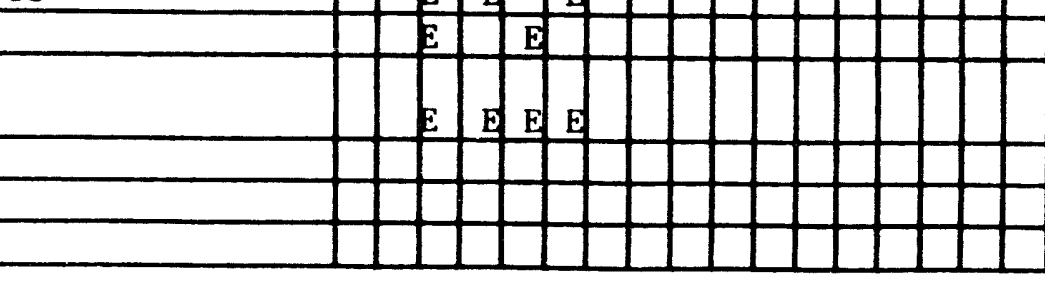




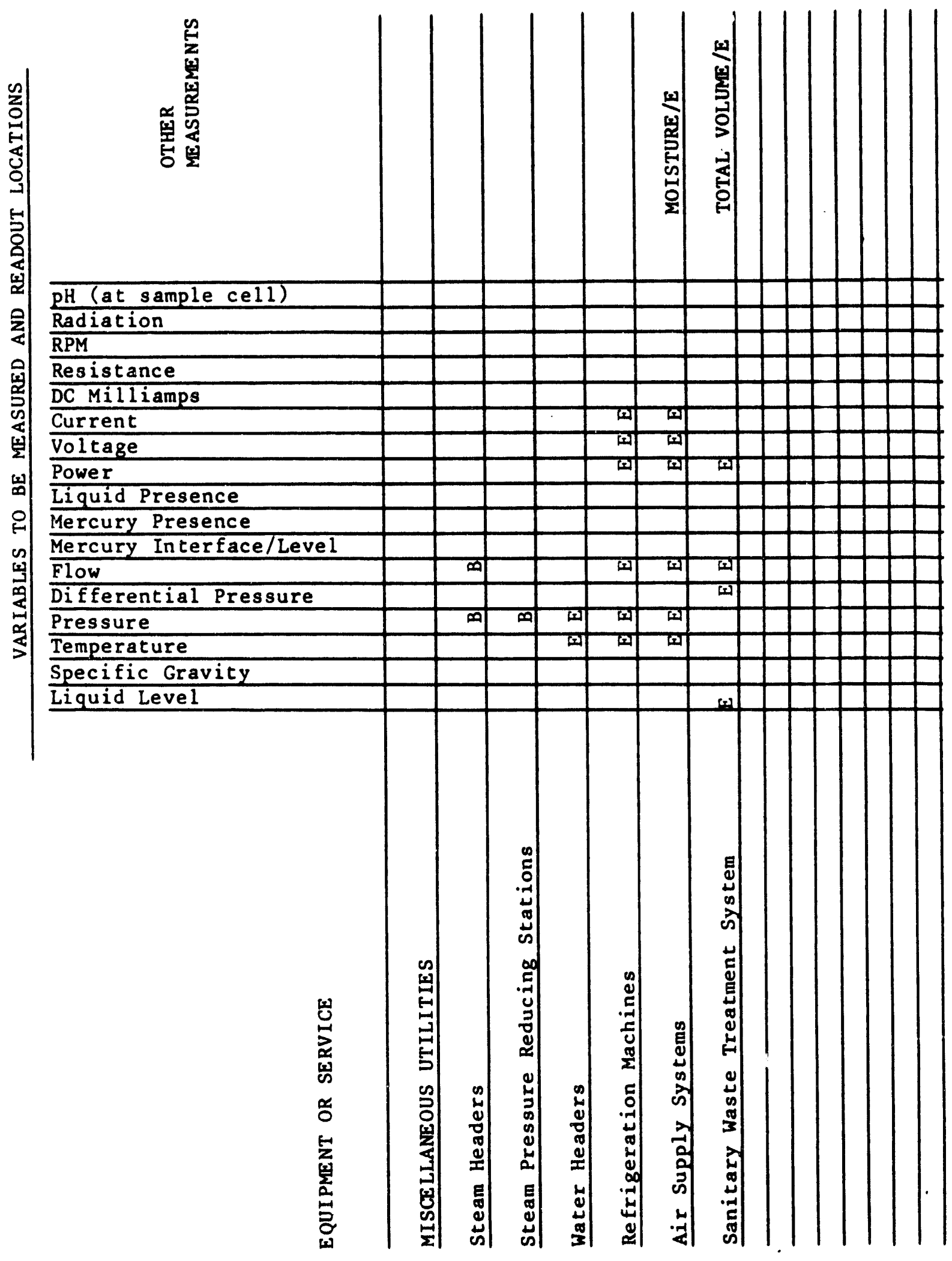


TABLE 6-2

CONTROLS

\section{General}

All motors for agitators, pumps and blowers should have remote off-on controls located at the control area responsible for their operation (i.e. H-Area

Control Room, 221-S Central Control Room or 751-A Power Dispatcher). Additionally, off-on control should be available at the Field Operating Station (FOS) for operation and/or emergency shutdown.

Process Cell sampling systems should be controlled from the sample cells.

The following key identifies the readout location:
A - Central Control Room Process Console with emergency operation at Field Operating Stations.
B - Central Control Room Power Console - Roving operator - with emergency backup at field operating station.
C - Process Field Operating Station - Operator normally present - CCR surveilance
D - Process Field Operating Station - Roving operator - CCR surveilance
E - Power Field Operating Station - Roving operator - CCR surveilance
F - Crane Console - Operator present when crane is being operated - Supervisory viewing room surveilance
G - Crane Console - E \& I Shop Crane Maintenance
H - H-Area Waste Tank Farm Control Room - CCR surveilance
I - 751-A Power Dispatcher
K - Power Field Operating Station at substation
0 - Local indication only 
Interarea Transfer (DA 511/550)

Pump \& Fan Motors

Pump Pit Sump Pumps

Pump Pit Vessel Heaters

Cold Feeds Outside 221-S (DA 422)

Air Filter \& Receiver/Dryer

Unloading Screen Conveyor

Transport Blow Tank(s)

Caustic Portable Storage Tank

Nitric-Acid-Potassium Permanganate Make-Up Tank

Formic Acid Dilution Tank

Oxalic Acid Make-Up Tank

Cold Feeds Inside _:-1-S (DA 329)

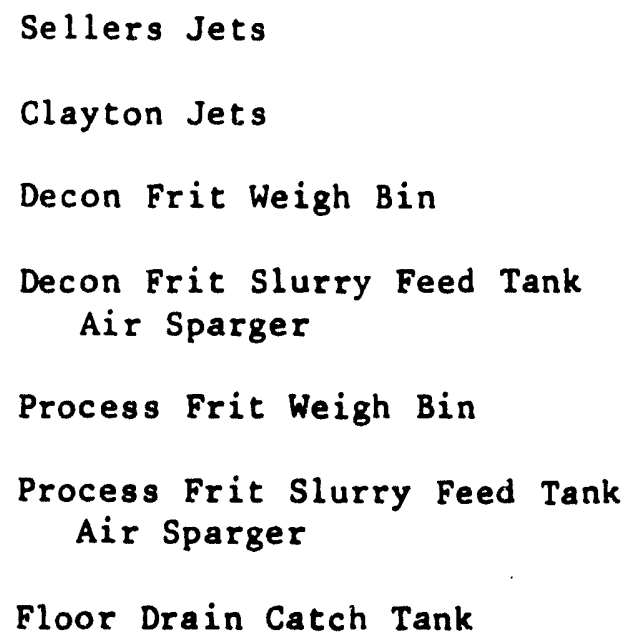

\author{
Off $-O n / D \& H$ \\ off - On $/ D$ \\ Temperature/H
}

Temperature, Flow/D

of $f-0 n / C$

of $f-0 n / C$

Temperature/C

Liquid Level (Batch Sequence Controller), Temperature/C

Liquid Level (Batch Sequence Controller)/C

Temperature/C

Flow, Pressure, Temperature/C

Flow, Pressure, Temperature/C

Weight/C

Air Flow/C

Weight/C

Air Flow/C

Temperature/D 
Cold Feeds Inside 221-S (DA 329)

Nitric Acid Dilution Tank

Cold Feed Organic Acid Vent Condenser

Medium Pressure Process Water Tank

Decon Solution Make-up Tank

Floor Drain Catch Tank

Chemical Processing Cell (DA 350)

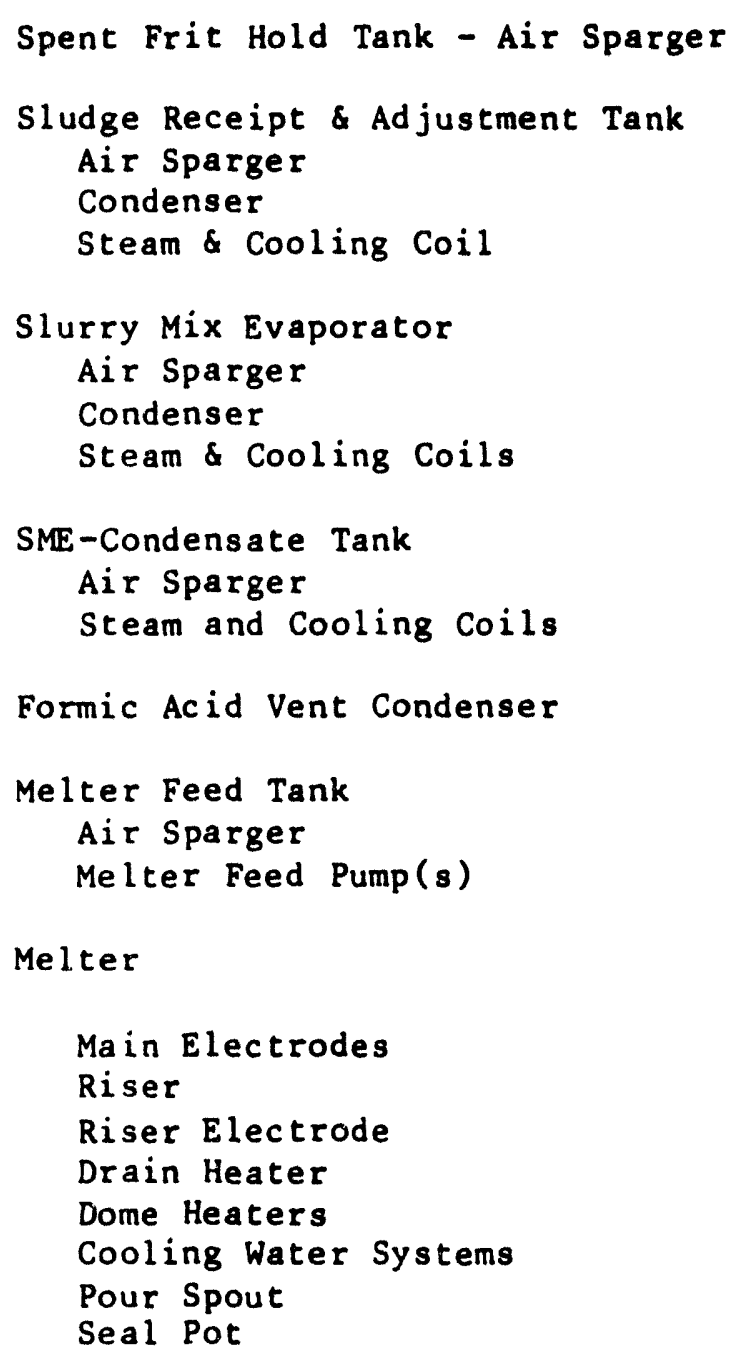

Liquid Level (Local Sequence Controller)

Temperature/A

Pressure, Liquid Levelin

Liquid Level (Sequence

Controller)/A

Temperature/A

Air Flow/A

Temperature/A

Air Flow/A

Temperature/A

Flow/A

Temperature/A

Air Flow/A

Temperature/A

Flow/A

Liquid Level, Temperature/A

Air Flow/A

Flow/A

Temperature/A

Air Flow/A

Flow/A

Temperature, Pressure \&

Differential Pressure/A

Temperature/A

Temperature/A

Temperature/A

Temperature/A

Temperature/A

Flow/A

Differential Pressure/A Liquid Level/A 
APPENDIX A

TABLE 6-2

PAGE 4 of 6

DATE 9-82; Rev. 9

Chemical Processing Cell (DA 350), Cont'd.)

Of f-Gas Line

Off-Gas Condensate Tank

Air Flow to Deep Bed Nozzles

Filter Pump Tank

Air Flow to Deep Bed Nozzles

off-Gas Condenser

Ru Adsorber Preheater

I 2 Adsorber Preheater

Of f-Gas Cooler

Off-Gas Exhausters

Mercury Water Wash Tank

Air Sparger

Chemical Processing Cell (DA 395)

Recycle Collection Tank

Decon Waste Treatment Tank

Reflux Condenser

Vessel Vent Header-Preheater

Mercury Purification Cell (DA 378)

Mercury Acid Wash Tank

Air Sparger

Mercury Ve.rt Condenser

Mercury Vacuum Still

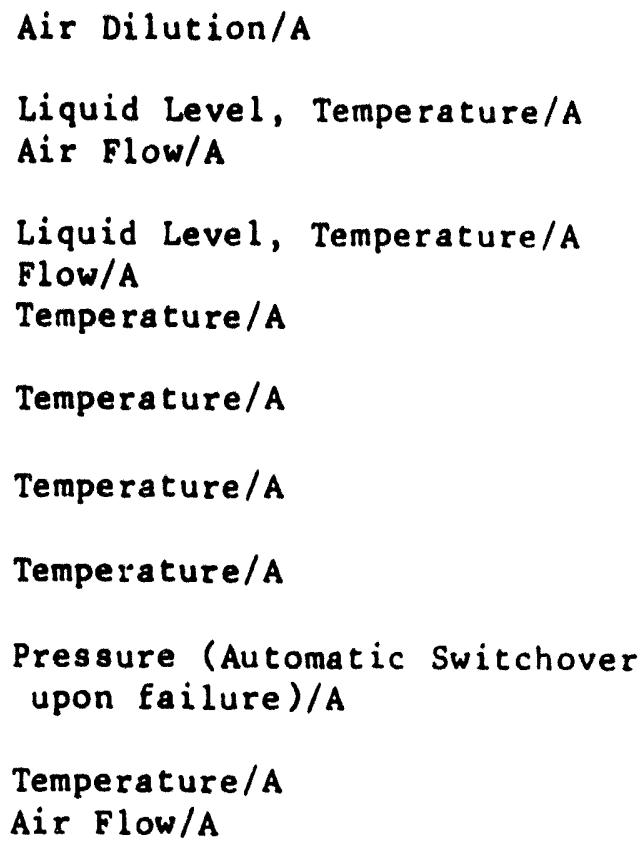

Temperature/A

Temperature/A

Temperature/A

Differential Temperature/A 
Canister Decon (DA 360)

Decon Chambers

Spray Nozzles

Canister Welder

Canister Decon Stations

Liquid Level/C

Flow/C

Force, Sequence, Current
Time/c

Position/C

Canister Smear Test Inspection Stations

Position/C

Waste Treatment System (DA 980)

Acid Waste Hold Tanks

Liquid Level/D

Organic Acid Waste Neutralization Tanks

Liquid Level/D

Caustic Waste Neutralization Tanks

Liquid Level/D

Sodium Sulfide Addition Tank

Liquid Level/D

Water Systems

We $11 \mathrm{~s}$

Flow/D

Storage Tanks

Liquid Leve1/D

Interim Storage Building (DA 250)

No Automatic-Remote Manual On-off for Forced Air Ventilation/B

\section{Electrical Supply System}

$115 \mathrm{KV}$ Breakers and Switches

On-Off/E\&I

$115 \mathrm{KV}-13.8 \mathrm{KV}$ Transformer Tap Switch

Position/B

13.8 KV Secondary and Tie Breakers

On-Off/E\&I

13.8 KV Feeder Breakers

On-OEE/B\&E

440 Volt Feeder and Tie Breaker

On-Off/E

Emergency Generator Breaker

On-Off/B\&E

H\&V System Non-Regulated

On-of $f / E$ 
Air Systems

Other Utilities

Steam Headers

Refrigeration Machines

Air Supply Systems
Flow, Pressure/D

Temperature, Flow/D

Flow, Pressure/D 
TABLE 8-i

GUIOE FOR OFFSITE EXPOSURE

(Revised March 1972)

\section{A. APPI.ICABILITY}

This gulde applies co the release of radioactive macerlals in gaseous and liquid effluents from the Savannah River Plane and Laboracory.

\section{B. OSJECTIVE}

The objective for prescribing the dose-liaits in chis gulde is to keep exposures to the public in the vicinity of the Savannah Rivar Plant as iov as pracelcable.

\section{c. LIMITS}

The annual eaposure in an Individual in the of lation caused speciffcally by release of radioactivity froe the Savannah fiver Plant and Laboratory shall not exceed the following linics:

\begin{tabular}{lc} 
Type of Exposure & Dose Lisit, arem/yr \\
\hline Whole body & 10 \\
Conads & 10 \\
Bone marrow & 10 \\
Cascroincestinal crace & 30 \\
Bone & 30 \\
Thyrold & 30 \\
Nl other individual organs & 30
\end{tabular}

\section{BASES}

The bases for this guide are operating experience, recomendations of the International Cormiseion on Radiological Prorection (ICRP), the National Councli on Radiation Protection and Measurewents (NCRP), the Federal Radiation Council (FRC), and the guidelines of the Energy Research and Development adwinistration.

This guide does not in any way modlfy the guides recomended by the ICRP. NCRP, and FRC for control of population exposure. The nuevical. 1 init recomended by these guides-setting organtrations of 170 mrea/yr for the average dose to the whole population remains as che basic radiation protection criterion for concrol of public exposure. The Savannah River plane's objective is to keep offsite exposures as far below chis cricerion as practicable. 
TABLE 8-2

RADIOACTIVE RELEASE GUIDES $(C Y-78)$

\section{a. Release Guides for Liquid Radioactive Releases to Streams and Basins}

The quantity of each radionuclide entering Plant streams or basins from reactor area facilities shall not exceed the following guides.

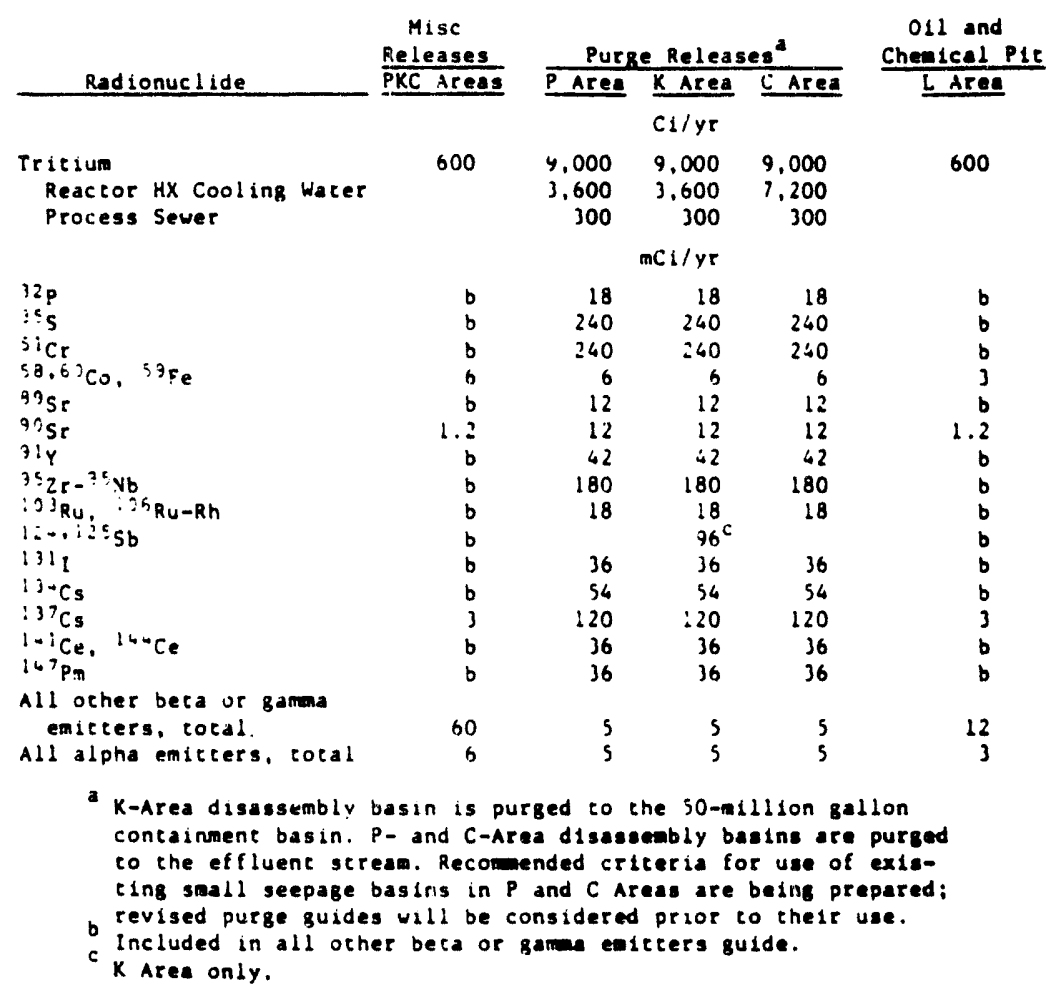

\section{b. Release Guides for Atmospheric Radioactivity Releases}

The quantity of each radionuclide entering the atmosphere from reactor area facilities shall not exceed the following guides.

\begin{tabular}{|c|c|c|c|}
\hline Redionuctide & P Aree & xares & C Aree \\
\hline & & $\mathrm{C} 1 / \mathrm{ye}$ & \\
\hline \multirow[t]{2}{*}{ 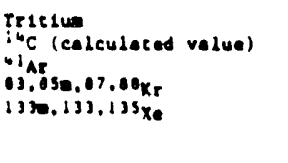 } & $\begin{array}{r}60.000 \\
20 \\
36.000 \\
1.620 \\
2.700\end{array}$ & $\begin{array}{r}60.000 \\
20 \\
36.000 \\
1.620 \\
2.100\end{array}$ & $\begin{array}{r}60.000 \\
20 \\
36.000 \\
1.620 \\
2.700\end{array}$ \\
\hline & & $-c 1 / r r$ & \\
\hline \\
\hline Stack & $\begin{array}{l}1.2 \\
4.8\end{array}$ & 1.2 & $\begin{array}{l}1.2 \\
4.8\end{array}$ \\
\hline \multirow[t]{2}{*}{$\begin{array}{l}\text { Ald other beca or gams } \\
\text { entitere, tocel }\end{array}$} & $i$ & 1 & 1 \\
\hline & & $w C 1 / y r$ & \\
\hline All alphe caltets, toc & - & 6 & \\
\hline
\end{tabular}


a. Release Guides for Liquid Radioactivity Releases to Streams and Basins

The quantity of eacil radionuclide entering Plant streams or basins from separations areas facilities shall not exceed the following guides.

(1) Seepage Basin

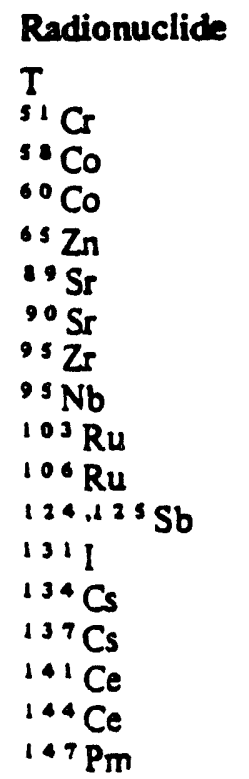

All other beta or gamma emitters, total All alpha emitters, total

\begin{tabular}{cc}
\multicolumn{2}{c}{ Ci/year } \\
F Area & H Area \\
15,000 & 24,000 \\
& 10.0 \\
& 1.0 \\
& 1.0 \\
0.2 & 1.0 \\
0.2 & 0.5 \\
4.0 & 0.6 \\
4.0 & 1.0 \\
2.0 & 2.0 \\
10.0 & 2.0 \\
1.0 & 0.2 \\
1.0 & 0.5 \\
0.4 & 1.0 \\
4.0 & 6.0 \\
0.1 & 0.5 \\
0.5 & 1.5 \\
1.0 & 1.5 \\
0.5 & 0.8 \\
0.5 & 0.2
\end{tabular}

- Included in all other beta or gamma emitters guide.

[2] Plant Streams

(Combined $\mathrm{F}$ and $\mathrm{H}$ Areas)

Radionuclide

$T$ $09.90 \mathrm{Sr}$ $134.137 \mathrm{Cs}$

All other beta or gamma emitters. total All alpha emitters. total

$\begin{array}{cc}\mathrm{mCi} / \text { year } & \mathrm{Ci} / \text { year } \\ & 150 \\ 25 & \\ 50 & \\ 125 & \\ 10 & \end{array}$


b. Release Guides for Atmospheric Radioactivity Releases

The quantity of each radionuclide entering the atmosphere from separations areas facilities shall not exceed the following guides (combined $F$ and $H$ Areas).

\section{Radionuclide}

$T$

${ }^{4} \mathrm{C}$ (Calculated value)

is $\mathrm{Kr}$ (Calculated value)

$89.90 \mathrm{Sr}$

$95 \mathrm{Zr}$

$95 \mathrm{Nb}$

$103 \mathrm{Ru}$

$106 \mathrm{Ru}$

1291 (Calculated value)

1311

$131 \mathrm{~m}, 132 \mathrm{Xe}$ (Calculated value)

$134 \mathrm{Cs}$

$137 \mathrm{Cs}$

$141 \mathrm{Ce}$

$144 \mathrm{Ce}$

$235.238 \mathrm{U}$

$238.239 \mathrm{Pu}$

All other beta or gamma emitters, total

All other alpha emitters, total

$\begin{array}{ccc}\mathrm{mCi} / \text { year } & \mathrm{Ci} / \text { year } & \mathrm{kCi} / \text { year } \\ & 50 & 275 \\ & & 950\end{array}$

10

50

75

75

500

250

500

0.5

3

2

30

10

10

5 
300-M AREA

a. Release Guides for Liquid Releases to Streams and Basins

The quantity of each radionuclide entering plant streams and basins from 300-Area facilities shall not exceed the following guides.

$\begin{array}{lc}\text { Radionuclide } & \mathrm{mC} / \text { year } \\ 235,230 \mathrm{U} \text { to streams } & 100 \\ 233,230 \mathrm{U} \text { to basins } & 400\end{array}$

b. Release Guides for Atmospheric Radioactivity Releases

The quantity of each radionuclide entering the atmosphere from 300-Area facilities shall not exceed the following guides.

$\begin{array}{rlcc} & \text { Radionuclide } & \mu \mathrm{Ci} / \text { year } & \mathrm{Ci} / \text { year } \\ 313-\mathrm{M} & 238 \mathrm{U} & 25 & \\ 321-\mathrm{M} & \text { Total alpha } & 25 & \\ -322-\mathrm{M} & \mathrm{T} & 25 & 100 \\ 322-\mathrm{M} & \text { Total alpha } & 25 & \end{array}$

\section{0-D AREA}

a. Release Guides for Liquid Releases to Streams and Basins

The quantity of each radionuclide entering plant streams from 400-Area facilities shall not exceed the following guides.

$\begin{array}{lcc}\text { Radionuclide } & \text { mCi/year } & \text { Ci/year } \\ \text { T } & & 3000 \\ 89.90 \mathrm{Sr} & 5 & \\ 134,13^{79} \mathrm{Cs} & 5 & \\ \text { All other beta or gamma emitters. total } & 50 & \\ \text { All alpha emitters, total } & 1\end{array}$

b. Release Guides tor Atmospheric Radioactivity Releases The quantity of
exceed the following guide
Radionuclide
$\mathrm{Ci} /$ year
$\mathrm{T}$
5000 
DPSP $80-1033$

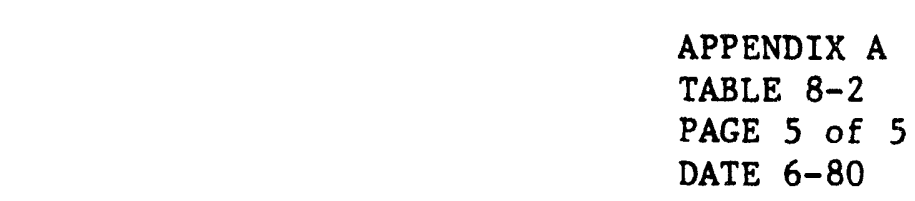

TABLE 8-2 (contd)

RADIOACTIVE RELEASE GUIDES (CY -78)

\section{TECHNICAL AREAS}

a. Release Guides for Liquid Radioactive Releases to Streams and Basins

The quantity of each radionuclide entering Plant streams or basins from technical area facilities shall not exceed the following guides.

[1] Building 773-A Seepage Basins

$\begin{array}{lrc}\text { Radionuclide } & \text { mCi/year } & \text { Ci/year } \\ \mathrm{T} & 2 & 15 \\ 89,90 \mathrm{Sr} & 1 & \\ 134,137 \mathrm{Cs} & 10 \\ \text { All other beta or gamma emitters, total } & 4 \\ 235,238 \mathrm{U}, \mathrm{Pu} & 10 & \\ \text { All other alpha emitters, total } & \end{array}$

(2) Plant Streams

\section{Radionuclide}

All beta or gamma emitters, total

All alpha emitters. total

$\mathrm{mCi} /$ year

8

4

(3) CMX-TNX Seepage Basins

Radionuclide

$233.238 \mathrm{U}$

$\mathrm{mCi} /$ year

2.5

b. Release Guides for Atmospheric Radioactivity Releases

The quantity of each radionuclide entering the atmosphere from technical area facilities shall not exceed the following guides.

(1) Building 773-A

Radionuclide

T

${ }^{60} \mathrm{Co}$

1311

All other beta or gamma emitters. total

All alpha emitters. cotal
$\mathrm{mCi} /$ year

Ci/year

30

0.5

0.2 
Trous 8-3

Movaptoactive OIScun:se LIAITS

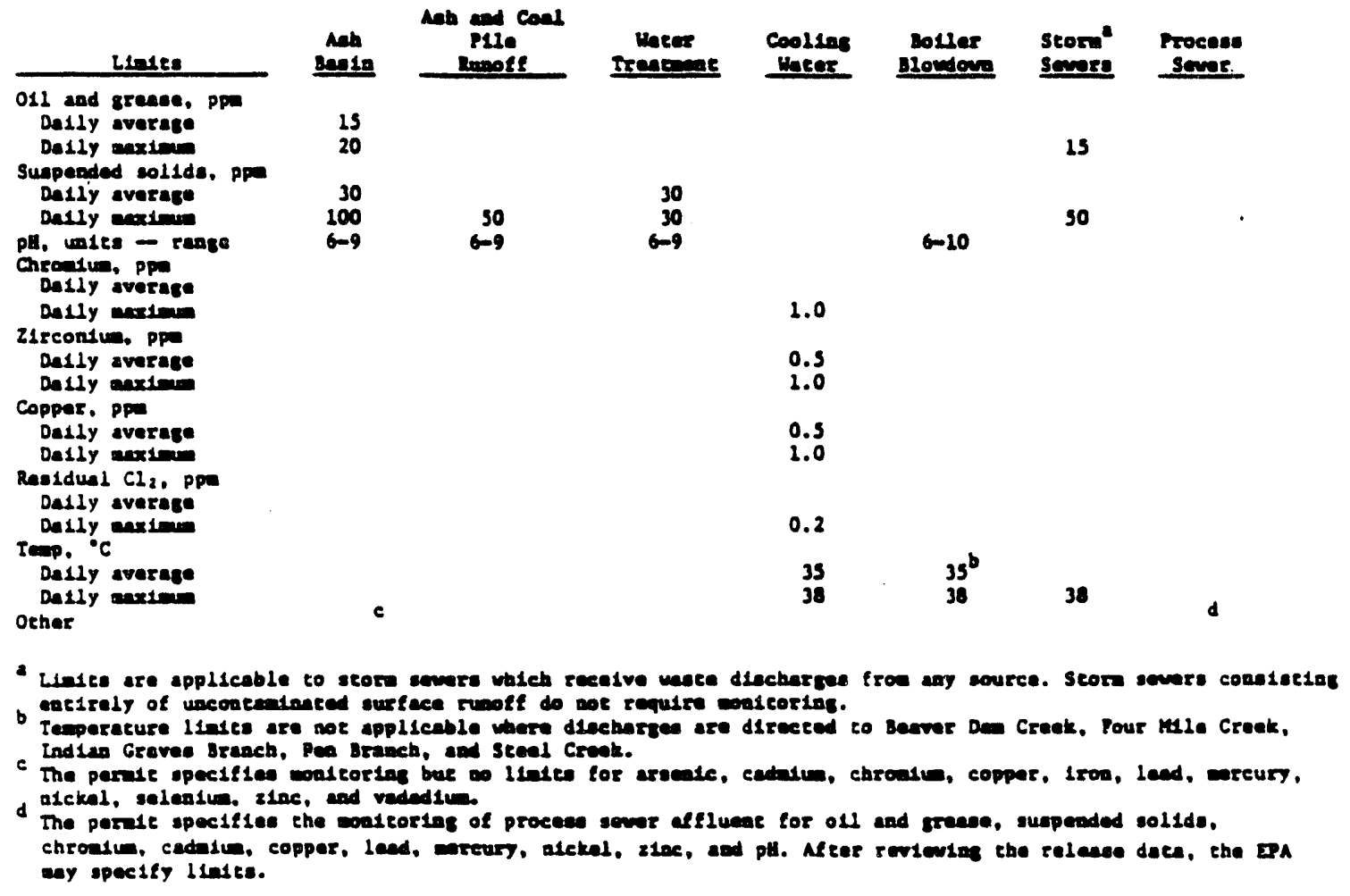


TABLE $10-1$

WORK ASSIGMMENTS -- SUPERVISION

\begin{tabular}{|c|c|c|c|c|c|c|c|}
\hline Dept & Position & No & Day 8 & $\mathrm{ABCD}$ & Offices & Location & Remarks \\
\hline \multirow{3}{*}{$\begin{array}{l}\text { Health } \\
\text { Protection }\end{array}$} & Sr Supvr & 1 & $\mathbf{x}$ & & 1 & Adm Bldg & 1 man office \\
\hline & $\begin{array}{l}\text { Rad Survey } \\
\text { Supvr }\end{array}$ & 1 & $\mathbf{x}$ & & 1 & Service Bldg & $\begin{array}{l}1 \text { man Office } \\
\text { Near HP Area }\end{array}$ \\
\hline & Rad Survey & 4 & & $\mathbf{x}$ & 1 & $\begin{array}{l}\text { Service Bldg } \\
\text { Counting Rm }\end{array}$ & $\begin{array}{l}4 \text { man Office } \\
\text { Near HP Area }\end{array}$ \\
\hline \multirow{3}{*}{$\begin{array}{l}\text { Waste } \\
\text { Management } \\
\text { Technology }\end{array}$} & Chief Supvr & 1 & $\mathbf{x}$ & & 1 & Adm Bldg & 1 man office \\
\hline & Area Supvr & 1 & $\mathbf{x}$ & & 1 & Adm B1dg & 1 man office \\
\hline & Eng I neers & 5 & $\mathbf{x}$ & & 3 & Service B1dg & 2 man office \\
\hline \multirow{14}{*}{$\begin{array}{l}\text { Waste } \\
\text { Management } \\
\text { Operations }\end{array}$} & Area Supt & 1 & $\mathbf{x}$ & & 1 & Adm B1dg & 1 man office \\
\hline & Area Supvr & 1 & $\mathbf{x}$ & & 1 & Adm Bldg & 1 man office \\
\hline & Sr Supvr & 4 & & $\mathbf{x}$ & 1 & Service B1dg & 4 man office \\
\hline & $\begin{array}{l}\text { Shift } \\
\text { Supvr }\end{array}$ & 4 & & $\mathbf{x}$ & 1 & Service B1dg & 4 man of $f$ ice \\
\hline & Foreman & 8 & & $\mathrm{x}$ & 2 & Service B1dg & 4 man of $f$ ice \\
\hline & $\begin{array}{l}\text { Relief } \\
\text { Supvr }\end{array}$ & 4 & $\mathbf{x}$ & & 2 & Service Bldg & 2 man offices \\
\hline & Sr Supvr & 1 & $\mathbf{x}$ & & 1 & Service B1dg & 1 man office \\
\hline & Foreman & 4 & $\mathbf{x}$ & & 2 & Service Bldg & 2 man offices \\
\hline & Sr Supvr & 1 & $\mathbf{x}$ & & 1 & Cold Feed & 1 man of $f$ ice \\
\hline & Foreman & 2 & $\mathbf{x}$ & & 1 & $\begin{array}{l}\text { Cold Feed } \\
\text { (Control Rm) }\end{array}$ & 2 man office \\
\hline & Foreman & 1 & $x$ & & 1 & $\begin{array}{l}\text { Service B1dg } \\
\text { (Canister Insp) }\end{array}$ & 1 man office \\
\hline & Shift Supvr & 1 & $\mathbf{x}$ & & 1 & Service Bldg & 1 man of 1 ice \\
\hline & Shift Supvr & 2 & $\mathbf{x}$ & & 1 & Adm B1dg & 2 man office \\
\hline & & & & *REVIS & ED TABLE* & & \\
\hline
\end{tabular}


DPSP $80-1033$

APPENDIX A

TABLE 10-1

PAGE 2 of 4

DATE 9-82; Rev. 9

WORK ASSIGNMENTS -- SUPERVISION

Department

Position

No Days

$A B C D$

0ffices

Location

Remarks

Maintenance Area Engr

$1 \mathrm{x}$

$1 \quad$ Adm B1dg

1 man office

Department

$E \& I$

Department
$T \& T$

Department

Safety \& Security

Project Dept

Personnel

Engineer
Foreman

Foreman

Foreman

Foreman

Area Engr

Foreman

$1 \mathrm{x}$

Foreman

$1 \mathrm{x}$

Foreman

Foreman

Foreman

\section{$1 \mathrm{x}$}

$1 x$

$1 \mathrm{x}$

$1 \quad \mathbf{x}$

$1 \quad x$

1

Foreman

Lieutenant

Safety Eng

Area Eng

Mech Eng

Electrical

Eng I neers

Employee Counsler

$1 \mathrm{x}$
$2 x$
$1 x$

1 Adm B1dg

1 man office

1 Service Bldg 1 man office in shop

1 Process Area 1 man office Reg.Mach.Shop

1

Process Area 1 man office Crane Maint

1 Process Area 1 man office Manip Repair

$1 \quad$ Adm B1dg

1 man office

1 Service Bldg

(Near

Computer $\mathrm{Rm}$ ) Shop $\# 4$

1 Crane Maint Shop \#3

2 Process Area Shop $\# 2$

1 Service B1dg Shop \#5

x 1 Process Area Shop \#1

1 Service Bldg 1 man office

$x \quad 1$ Adm Bldg 1 man office

1 Adm B1dg 1 man of fice

1 Adm B1dg 1 man close

to files

1 Adm Bldg 2 man office

1 Adm Bldg 2 man office

1 Adm B1dg 1 man office 
WORK ASSIGNMENTS -- LOCAL ROLL

\begin{tabular}{|c|c|c|c|c|c|c|c|}
\hline Department & Position & No & Days & $\mathrm{ABCD}$ & Off 1 ces & Location & Remarks \\
\hline \multirow{3}{*}{$\begin{array}{l}\text { Health } \\
\text { Protection }\end{array}$} & Clerk & 1 & $x$ & & $1 / 2$ & Adm B1dg & Near HP office \\
\hline & Inspector & 1 & $\mathbf{x}$ & & & & \\
\hline & Inspector & 8 & & $\mathbf{x}$ & & & \\
\hline $\begin{array}{l}\text { Waste } \\
\text { Mgt Tech }\end{array}$ & Clerk & 1 & $\mathbf{x}$ & & $1 / 2$ & Adm Bldg & \\
\hline \multirow{5}{*}{$\begin{array}{l}\text { Waste } \\
\text { Management } \\
\text { Operations }\end{array}$} & Secretary & 2 & $\mathbf{x}$ & & 1 & Adm Bldg & 1 man office \\
\hline & Operators & 48 & & $\mathbf{x}$ & & & \\
\hline & Clerk & 1 & $\mathbf{x}$ & & 1 & $\begin{array}{l}\text { Service B1dg } \\
\text { Control } \mathrm{Rm}\end{array}$ & $\begin{array}{l}1 \mathrm{man} \text { office } \\
\text { with files }\end{array}$ \\
\hline & Operators & 15 & $\mathbf{x}$ & & & & \\
\hline & Clerk & 1 & $\mathbf{x}$ & & $1 / 2$ & Cold Feed & \\
\hline \multirow[t]{4}{*}{ MaIntenance } & Clerk & 1 & $\mathbf{x}$ & & $1 / 2$ & Adm B1dg & \\
\hline & $\begin{array}{l}\text { Project } \\
\text { Ass' } t\end{array}$ & 1 & $\mathbf{x}$ & & $1 / 2$ & Adm Bldg & \\
\hline & Mech's & 17 & $\mathbf{x}$ & & & & \\
\hline & Mech's & 8 & & $x$ & & & \\
\hline \multirow[t]{4}{*}{$E \& I$} & Clerk & 1 & $\mathbf{x}^{\prime}$ & & $1 / 2$ & Adm B1d 8 & \\
\hline & $\begin{array}{l}\text { Project } \\
\text { Ass't }\end{array}$ & 1 & $\mathbf{x}$ & & $1 / 2$ & Adm B1dg & \\
\hline & Mech's & 19 & $\mathbf{x}$ & & & & \\
\hline & Mech's & 8 & & $\mathbf{x}$ & & & \\
\hline$T \& T$ & RIggers & 3 & $\mathbf{x}$ & & & & \\
\hline \multirow[t]{2}{*}{$\begin{array}{l}\text { Safety } 8 \\
\text { Security }\end{array}$} & Patrolmen & 3 & $\mathbf{x}$ & & & & \\
\hline & Patrolmen & 12 & & $\mathbf{x}$ & & & \\
\hline
\end{tabular}


DPSP $80-1033$

APPE NDIX A

TABLE 10-1

PAGE 4 of 4

DATE 5-81; Rev. 6

WORK ASSIGNMENTS -- LOCAL ROLL

Department

Position

No Days $A B C D$ Offices

Location

Remarks

Cafeteria Food

Servers $2 x$

Info

Systems

File Clerk $1 \times$

$1 \quad$ Adm Bldg

File Room

Project

Dept

Draftsman $1 x$

$1 \quad$ Adm Bldg

Close to

Dept

Eng Ass't 1 x

1/2 Adm B1dg

Clerk

$1 \times$

1/2 Adm Bldg

Power

Operators

4

$\mathrm{x}$

Service

Janitors

$3 x$

Total

238

51 
TABLE $10-2$

SUMMARY OF OFFICES, LOCKERS, AND REST ROOM REQUIREMENTS

Office Locat lons

\begin{tabular}{|c|c|c|c|c|c|c|}
\hline Type & $\begin{array}{l}\text { Control } \\
\text { Room Space } \\
\end{array}$ & $\begin{array}{l}\text { Process } \\
\text { Area } \\
\end{array}$ & Adm B1dg & $\begin{array}{l}\text { Service } \\
\text { Bldg } \\
\end{array}$ & Patrol & $\begin{array}{l}\text { Cold } \\
\text { Feed } \\
\end{array}$ \\
\hline 1 man & - & 6 & 14 & 12 & $-\quad-$ & 2 \\
\hline $2 \operatorname{man}$ & - & - & 7 & 5 & ‘ 1 & 1 \\
\hline 4 man & - & - & - & 7 & - & - \\
\hline File Room & - & - & 1 & - & - & - \\
\hline Control Rm & - & - & - & 1 & - & 1 \\
\hline Total & - & 6 & 22 & 24 & 1 & 4 \\
\hline
\end{tabular}

Locker Requirements

\begin{tabular}{lcc} 
Location & Service B1dg & Patrol \\
\cline { 2 - 3 } & 141 & 15 \\
Female & 42 & 5 \\
Total & 183 & 20
\end{tabular}

Female lockers based on $23 \%$ of total

Allow additional space for 10 male and 5 female

Lockers in service bldg to accomodate personnel changes

Rest Room Requirements

\begin{tabular}{|c|c|c|c|}
\hline Locat1on & Service Bldg & $\begin{array}{l}\text { Patrol } \\
\text { Gatehouse }\end{array}$ & Adm B1dg \\
\hline Male & 71 & 5 & 26 \\
\hline Female & 25 & 5 & 9 \\
\hline Total & 96 & 10 & 35 \\
\hline
\end{tabular}

Female facilities based on $25 \%$ except for Adminlstration which was increased due to Clerical.

Showers are not to be included in Administration Bullding. 
PERMANENTLY INSTALLED HEALTH PROTECTION MONITORS

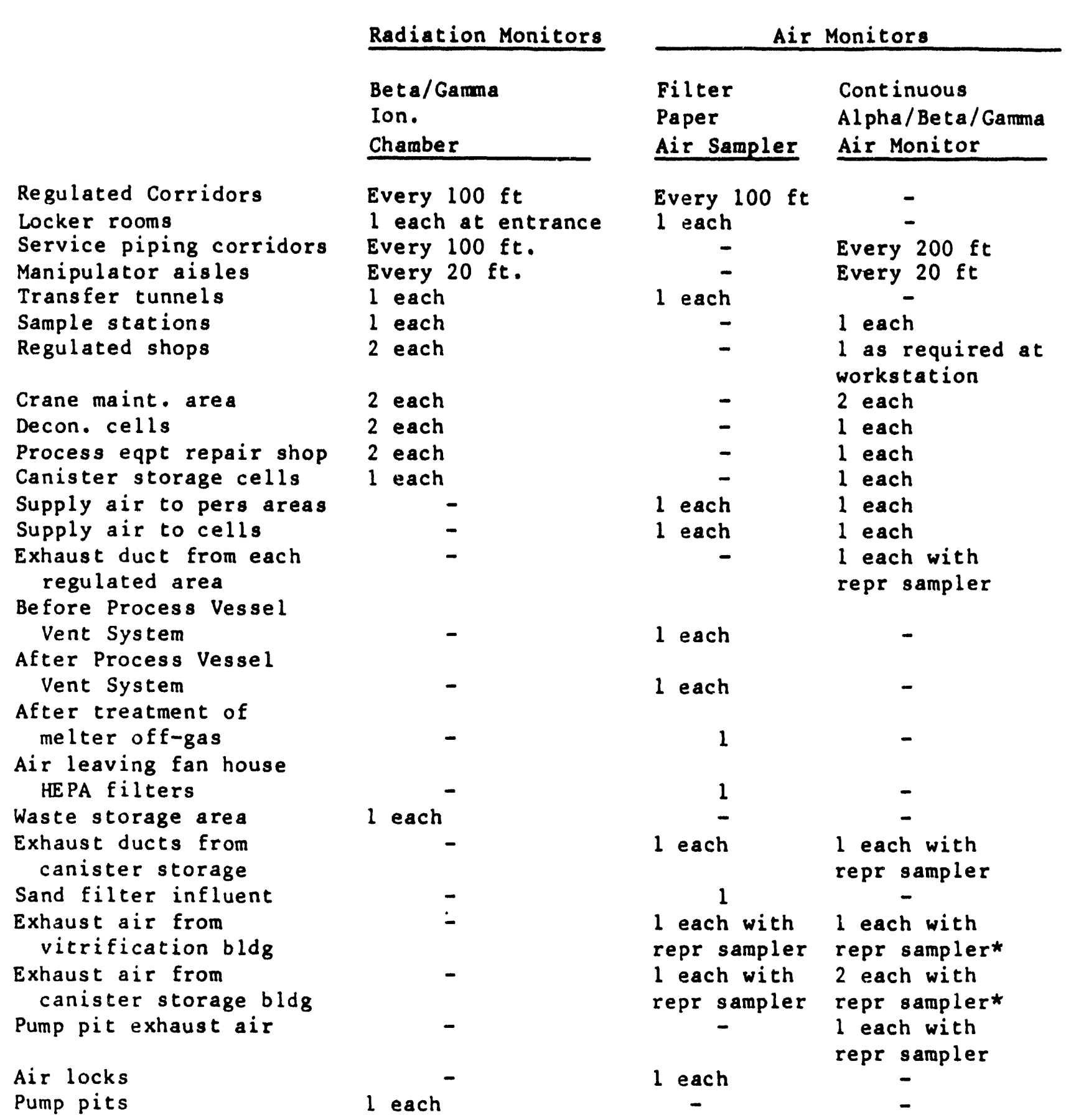

*Note: 2 stacks 


\section{AED ALLOWANCE REQUEST}

The Following Items Will Require An AED Allowance For Purchase By The SRP Project Department

Item

Portable laboratory equipment

\section{Maintenance Tools}

Tool crib tools, ladder

tool chests and carts

\section{E \& I Tools}

Tool crib tools, ladder

tool chests, and carts

A. Items that have been estimated.

Furniture, Office Equipment, Accessories

\section{Furniture}

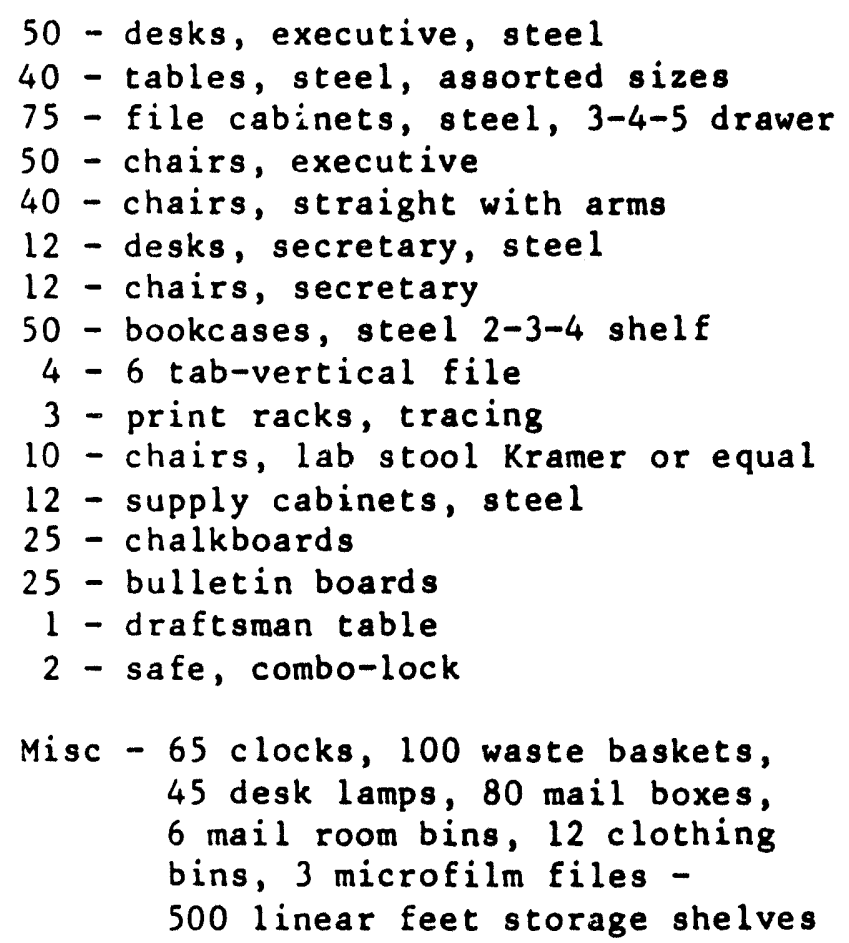


Conference Room Equipment

$\begin{array}{rr}6 \text { - conference room tables } & 4,590 \\ 50 \text { - conference room chairs } & 3,500 \\ 4 \text { - projector screens, overhead } & 1,200 \\ 3 \text { - TV monitor sets } & 7,500 \\ 3 \text { - TV tape players } & 450 \\ 3 \text { - Vu graph projectors } & 320 \\ 4 \text { - speakers stands } & 1,000 \\ 1 \text { - movie projector } & 300 \\ 1 \text { - slide projector } 35 \mathrm{~mm} & \end{array}$

\section{Office Equipment}

15 - typewriters IBM Selectric or equal

40 - calculators

1 - reader printer

2 - copiers with collator Xerox or equal

1 - microfiche reader

1 - 1 blueprint printer-copier

$\$ 18,000$

6,000

700

900

280

2,000

\section{Janitors Items}

4 - janitors carts

2 - supply carts

$\$ 1,000$

500

200

- furniture mover

200

1 - pallet mover

5,360

8 - vacuum cleaners

3,200

2 - buffers

4 - supply cabinets

2 - Load Luggers - as specified in Part 5, Item 450

3 - clean dumpsters, isnnt-load compactor, 8 cubic yd, white

1,000

10,500

H. P. Items

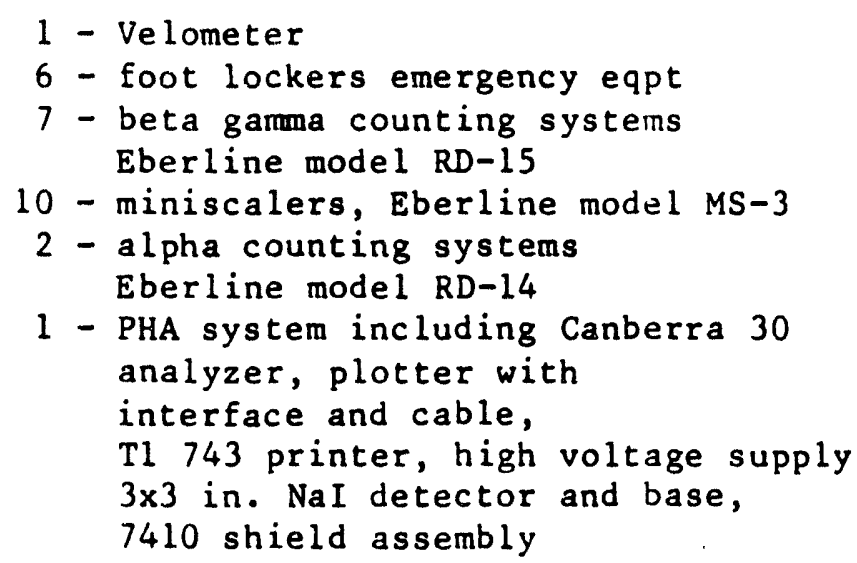


H. P. Items, Continued

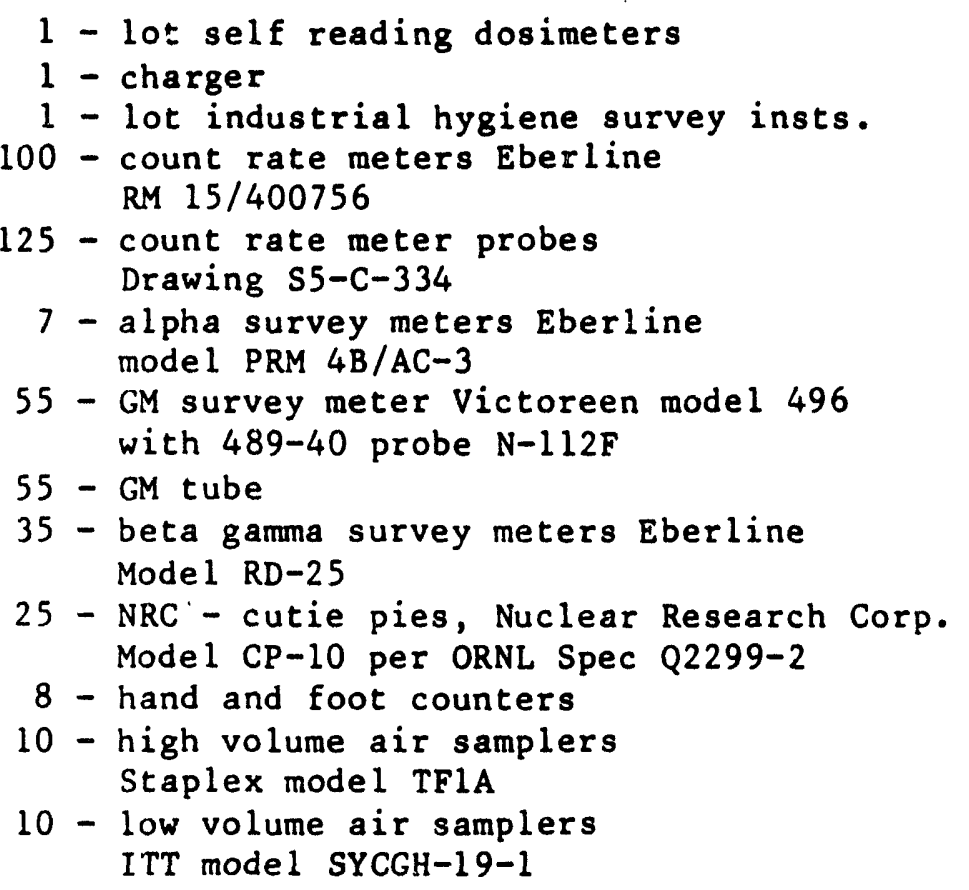

$\$ \quad 78$

107

25,000

60,000

55,625

8,400

1,102

29,260

25,000

112,000

2,150

2,150

Carts - Materials Handling

$$
\begin{aligned}
3 \text { - gas cylinder carts } \\
1 \text { - shielded waste buggy } \\
12 \text { - sample carts } \\
4 \text { - supply carts - aluminum Nutting } \\
\quad \text { or equal }
\end{aligned}
$$

Vehicles, Special Handling-Equipment

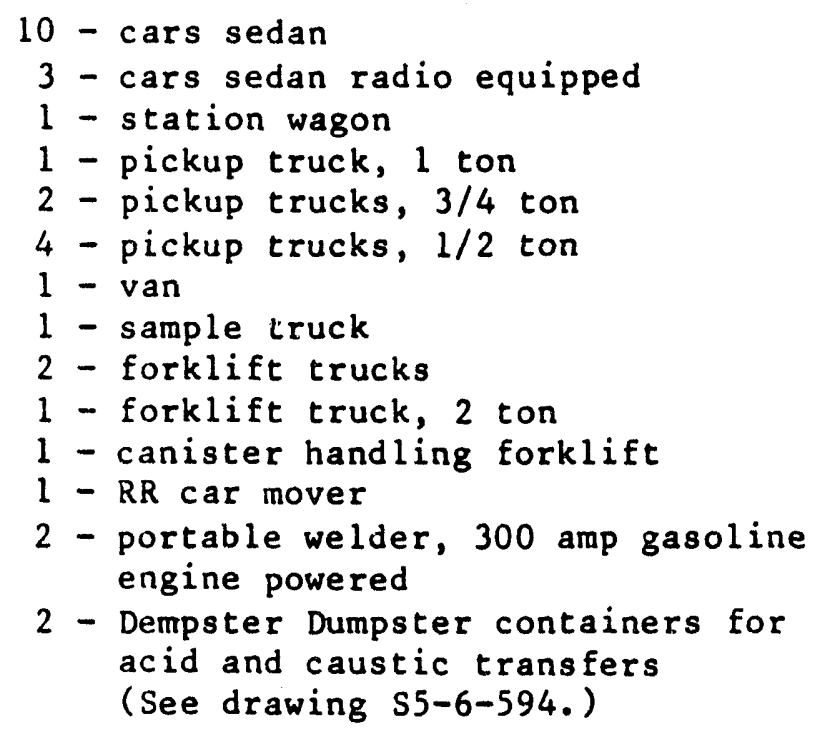


Fire and Safety Items

$$
\begin{aligned}
12 & \text { - Scott air packs } \\
4 & \text { - walkie talkie radios } \\
126 & \text { - fire extinguishers }
\end{aligned}
$$

\section{Security Equipment}

1 - gun cabinet

1 - work bench wooden top

1 - storage shelves 40 linear feet

6 - footlockers

1 - safe, combo-lock

Cafeteria and Lunch Room Equipment

(Serving Line Equipment not Includ..d)

3 - grills, single

1 - grill, double

4 - microwave ovens

3 - hot plates, 2-4 eye

3 - sinks

3 - icemakers

3 - refrigerators

28 - tables - 4 person

112 - chairs for tables

\section{E\&I Shop Equipment}

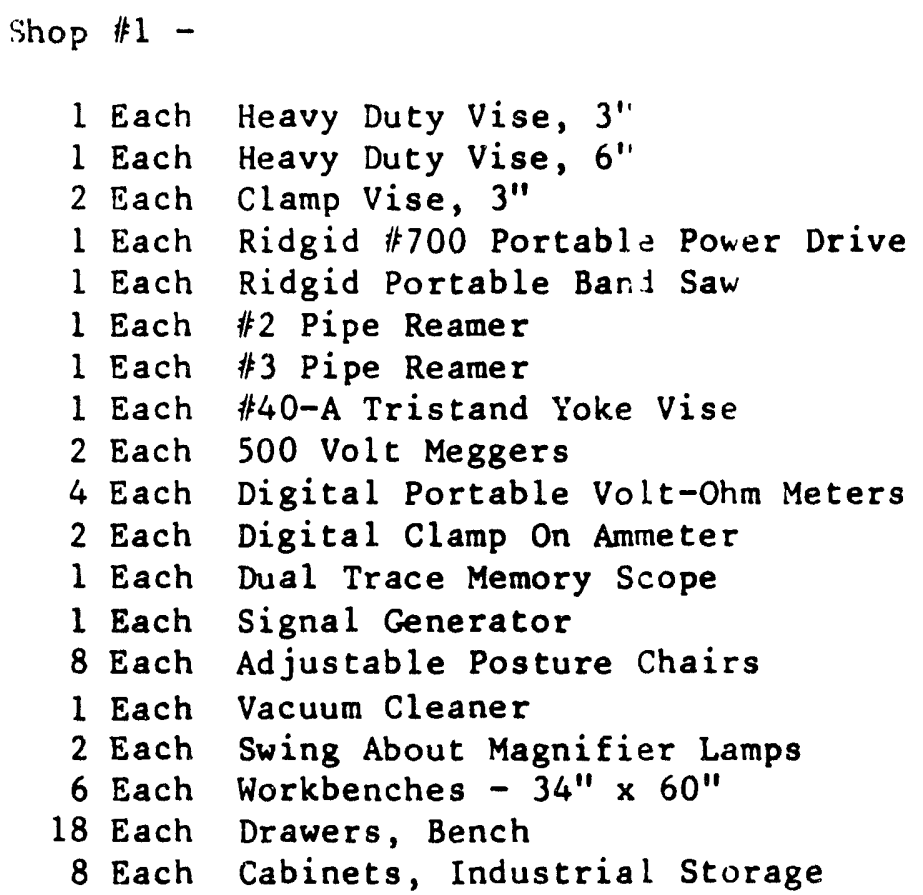

6 Each

Digital Clamp On Ammeter Dual Trace Memory Scope Signal Generator Adjustable Posture Chairs Vacuum Cleaner

$\$ 2,400$

2,000

14,645

$\$ 1,200$

1,000

1,000

1,590

221

$\$ 1,650$

700

2,000

3,000

2,100

9,360

5,100

1,400

1,624

\$ 40

80

400

2,300

165

1,100

760

400

800

220

1,080

670

210

1,800

1,170

4,184 
E\&I Shop Equipment, Continued

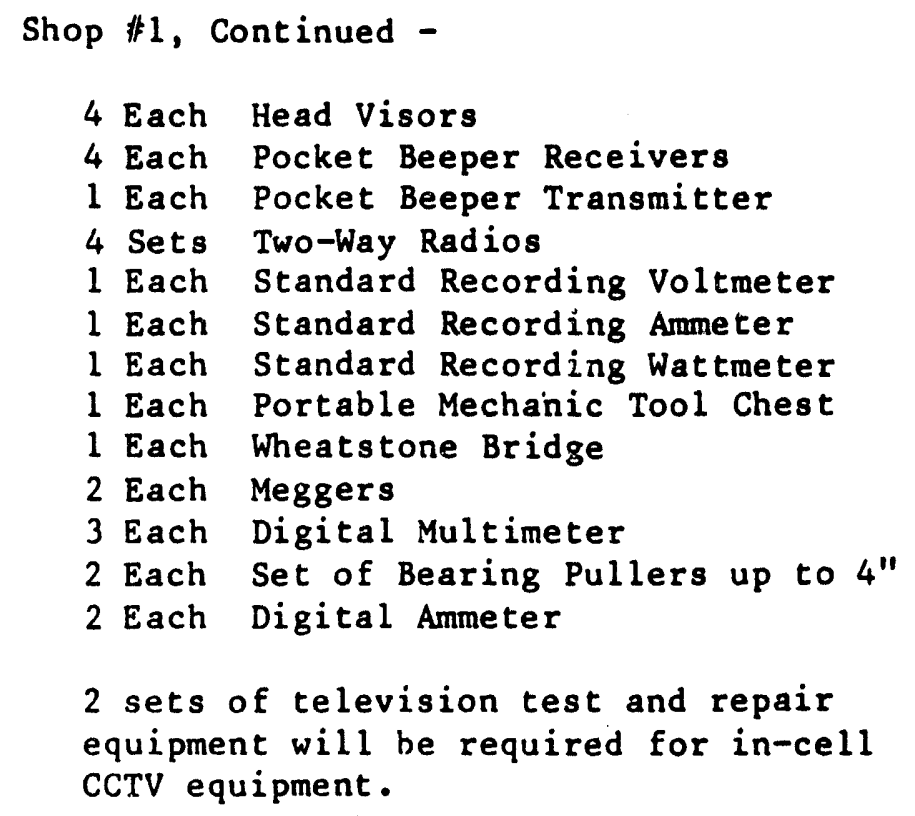

1 Each

1 Each

2 Each

1 Each

1 Each

1 Each

1 Each

1 Each

2 Each

4 Each

2 Each

8 Each

1 Each

2 Each

6 Each

18 Each

8 Each

4 Each

4 Each

1 Each

2 Each

2 Each

3 Each

1 Each
Heavy Duty Vise, 3"

Heavy Duty Vise, 6"

Clamp Vise, $3^{\prime \prime}$

Ridgid \#700 Portable Power Drive

Ridgid Portable Band Saw

非 2 Pipe Reamer

\#3 Pipe Reamer

\#40-A Tristand Yoke Vise

500 Volt Meggers

Digital Portable Volt-Ohm Meters

Digital Clamp On Ammeter

Adjustable Posture Chairs

Vacuum Cleaner

Swing About Magnifier Lamps

Workbenches - 34" $\times 60^{\prime \prime}$

Drawers, Bench

Cabinets, Industrial Storage

Head Visors

Pocket Beeper Receivers

Pocket Beeper Transmitter

Dual Trace Memory Scope

Standard Digital Potentiometer

Standard Digital Pneumatic

Pressure Indicator

Standard Frequency Generator

and Counter
$\$ 400$

600

150

6,000

190

355

190

17

1,500

1,000

375

1,200

400

2,300

165

1,000

760

400

1,080

670

210

1,800

1,170

4,184

400

600

150

1,600

1,600

120

170 
E\&I Shop Equipment, Continued

Shop $\# 2$, Continued -

$\begin{array}{lrr}2 \text { Each Standard Pulse Generator } & 300 \\ 2 \text { Each Power Supplies D. C. } & 1,720 \\ 3 \text { Each Digital Multimeters } & 375 \\ 3 \text { Each Digital Ohmmeters } & 735 \\ 2 \text { Each IC Tester } & 900 \\ 1 \text { Each Differential Voltmeter } & 300 \\ \text { l Each Capacitance Meter } & 25 \\ 2 \text { Each 4 to 20 MA Current Recorder } & 360 \\ \text { l Each Chicago Conduit Bender } & 1,200 \\ \text { l Each Pipe Threading Machine } & 1,850 \\ 2 \text { Each Transister Tester } & 120 \\ 3 \text { Each Multimeter } & 420 \\ 1 \text { Set Pneumatic Valve Tool } & 200 \\ \text { Z Sets Logic Pulsers } & 300 \\ 4 \text { Each Standard Digital Temp. Indicator } & 2,400\end{array}$

Shop 非 3

1 Each Heavy Duty Vise, 3"
1 Each Heavy Duty Vise, 6"
2 Each Clamp Vise, 3"
1 Each Ridgid \#700 Portable Power Drive
1 Each Ridgid Portable Band Saw
1 Each \#2 Pipe Reamer
1 Each \#3 Pipe Reamer
1 Each 非40-A Tristand Yoke Vise
2 Each 500 Volt Meggers
4 Each Digital Portable Volt-Ohm Meters
2 Each Digital Clamp On Ammeter
1 Each Dual Trace Memory Scope
1 Each Signal Generator
8 Each Adjustable Posture Chairs
1 Each Vacuum Cleaner
2 Each Swing About Magnifier Lamps
6 Each Workbenches - 34" x 60"
18 Each Drawers, Bench
8 Each Cabinets, Industrial Storage
4 Each Head Visors
4 Each Pocket Beeper Receivers
1 Each Pocket Beeper Transmitter
2 Each Dual Trace Memory Scope
3 Each Standard Digital Potentiometer
3 Each Standard Digital Pneumatic
1 Each Standard Frequency


E\&I Shop Equipment, Continued

Shop \#3, Continued -

2 Each Standard Pulse Generator

2 Each Power Supplies D. C.

3 Each Digital Multimeters

3 Each Digital Ohmmeters

2 Each

1 Each

1 Each

3 Each

3 Each

1 Each

1 Each

4 Each

6 Each

3 Sets

1 Each

1 Each

2 Each

1 Each

1 Each

2 Each

3 Sets

1 Each

1 Each

1 Each

4 Each

1 Each

1 Each

IC Testers

Differential Voltmeter

Capacitance Meter

4 to 20 MA Current Recorder

Meggers

Chicago Conduit Bender

Pipe Threading Machine

Transistor Tester

Multimeter

Logic Pulsers

TV Signal Generator

TV Sweep Generator

Portable Mechanic Tool Chest

Wheatstone Bridge

Set of Bearing Pullers Up to 4"

Digital Armeter

Two-Way Radios

Standard Recording Voltmeter

Standard Recording Armeter

Standard Recording Wattmeter

Standard Digital Temp. Indicator

$\$$

1,720

375

735

900

300

25

540

1,500

1,200

1,850

240

840

450

500

500

34

1,500

600

400

4,500

190

355

190

2,400

400

200

1 Each Console cabinet to house

monitors and crane control panel

1 Each Crane control unit to exercise

1,500

all functions of the crane

1 Each

Set of cables for console and

camera test unit

2,000

1,500

2 sets of radio control test equipment

will be required if the crane is remotely

controlled by radio.

Shop \# 4

2 Each 500 Volt Meggers

4 Each Digital Portable Volt-Ohm Meters

$\$ 1,000$

760

400

2 Each Digital Clamp On Ammeter

1,600

Dual Trace Memory Scope

1 Each Signal Generator

8 Each Adjustable Posture Chairs

1,080 
E\&I Shop Equipment, Continued

$\begin{array}{rlr}\text { Shop } \# 4, \text { Continued - } & \\ 1 \text { Each Vacuum Cleaner } & 670 \\ 2 \text { Each Swing About Magnifier Lamps } & 210 \\ 6 \text { Each Workbenches 34" x 60" } & 1,800 \\ 18 \text { Each Drawers, Bench } & 1,170 \\ 8 \text { Each Cabinets, Industrial Storage } & 4,184 \\ 4 \text { Each Head Visors } & 400 \\ 4 \text { Each Pocket Beeper Receivers } & 600 \\ 1 \text { Each Pocket Beeper Transmitter } & 150 \\ 2 \text { Each Standard Digital Potentiometer } & 1,600 \\ 1 \text { Each Standard Digital Pneumatic } & \\ & & \\ 1 \text { Each Sress Indicator } & 40 \\ 1 \text { Each Standard Digital Frequency } & 170 \\ 1 \text { Each Power Supply D. C. } & 150 \\ 1 \text { Each IC Tester } & 860 \\ 1 \text { Each Capacitance Meter } & 450 \\ 1 \text { Each 4-20 MA Current Recorder } & 25 \\ 2 \text { Each Standard Digital Temp. Indicator } & 180 \\ 1 \text { Each Wheatstone Bridge } & 1,200 \\ 1 \text { Each Electrical Cord Tester } & 1,500 \\ 1 \text { Each Differential Voltmeter } & 100 \\ 2 \text { Each Transistor Tester } & 300 \\ 4 \text { Each Multimeter } & 120 \\ 2 \text { Each Logic Pulser } & 560 \\ 1 \text { Each Precision Ohmeter } & 300 \\ & \text { to 5ecimal Place } & 400\end{array}$

Shop 非 -

2 Each Standard Digital Potentiometer

2 Each Standard Digital Pneumatic

Press. Ind.

$\$ 1,600$

1 Each Standard Frequency Generator and Counter

1 Each

Power Supply D. C.

170

860

450

I. C. Tester

25

Capacitance Meter

180

4-20 MA Current Recorder

1,200

Chicago Conduit Bender

1,850

Pipe Threading Machine

Transistor Tester

1 Each

2 Each

Multimeter

60

280

1 Each

Logic Pulser

150

2 Each Standard Digital Temp. Indicator

2 Sets Two-Way Radios with Ear

Communication

1,200

3,000 
E\&I Shop Equipment, Continued

$\begin{array}{lr}\text { Shop \#5, Continued - } & \\ 1 \text { Each Standard Recording Voltmeter } & 190 \\ 1 \text { Each Standard Recording Ammeter } & 355 \\ 1 \text { Each Standard Recording Wattmeter } & 190 \\ 1 \text { Each Wheatstone Bridge } & 1,500 \\ 2 \text { Each Digital Strobotac } & 940 \\ 1 \text { Each Heavy Duty Vise, 3" } & 40 \\ 1 \text { Each Heavy Duty Vise, 6" } & 80 \\ 2 \text { Each Clamp Vise, 3" } & 400 \\ 1 \text { Each Ridgid \#700 Portable Power Drive } & 600 \\ 1 \text { Each Ridgid Portable Band Saw } & 1,300 \\ 1 \text { Each \#2 Pipe Reamer } & 200 \\ 1 \text { Each \#3 Pipe Reamer } & 200 \\ 1 \text { Each \#40-A Tristand Yoke Vise } & 165 \\ 2 \text { Each 500 Volt Meggers } & 1,000 \\ 4 \text { Each Digital Portable Volt-Ohm Meters } & 760 \\ 2 \text { Each Digital Clamp On Ammeter } & 400 \\ 1 \text { Each Dual Trace Memory Scope } & 800 \\ 1 \text { Each Signal Generator } & 220 \\ 8 \text { Each Adjustable Posture Chairs } & 1,080 \\ 1 \text { Each Vacuum Cleaner } & 670 \\ 2 \text { Each Swing About Magnifier Lamps } & 210 \\ 6 \text { Each Workbenches - 34" x 60" } & 1,800 \\ 18 \text { Each Drawers, Bench } & 1,170 \\ 8 \text { Each Cabinets, Industrial Storage } & 4,184 \\ 4 \text { Each Head Visors } & 400 \\ 4 \text { Each Pocket Beeper Receivers } & 600 \\ 1 \text { Each Pocket Beeper Transmitter } & 150\end{array}$

TOTAL $2 Q 80=\$ 1,387,554$

Add $8 \%$ for contingency items and SRP

project costs for purchase

$\$ 1,498,583$ 
TABLE 18-1

EST IMATED COMBUSTIBLES-VITRIFICATION FACILITY

Material

Material
Gil
Grease
Clothing
Clothing
Supplies (paper, gloves,
plastics, etc)
Paper
Wood(pallets, canister
packing)
Diesel Fuel
Electrical Insulation
Solid waste

Quantity

50 gallon

$201 \mathrm{bs}$

4 bags - $601 \mathrm{bs}$ ea

15 bags - 60 lbs ea

2,000 cu ft

Approximately

$10-15,0001 \mathrm{~b}$

$200 \mathrm{cu} \mathrm{ft}$

Day Tank

5,000 cu ft

$0-225 \mathrm{cu} f t$

4 cylinders on line

4 cylinders on standby

8 cylinders in storage

2 cylinders on cart

\section{Location}

E \& I, Maintenance shops

E I, Maintenance shops

Work locations

Change rooms

Supply storage rooms (Adm, process bldg, control $\mathrm{rm}$ )

Approximately 200-300 1b/office

Service Bldg

Emergency diesels

Motor Control Center, Control room wiring, etc.

Loading dock

Maintenance shops 
TABLE 18-2

RE COMMENDED FIRE PROTECTION SYSTEMS -- VITRIFICATION FACILITY

Area

Computer Areas (HP and CCR)

** Central Control Room**

Electrical Substations

Electrical Control Room (Motor Control Centers)

Sample Cells

Emergency generators

Cafeteria Exhaust duct

Process Cell, Weld Test Cell,

Equipment Decon cells

Maintenance and E \& I Shop Areas

**Service Bldg

Lunchroom, Conference rooms

offices, $24 \mathrm{hr}$ occupancy

offices, straight day occupancy

Boxed waste storage area

Records Room

Cooling Tower.

Ha 11 ways

Cold Feed

Area
Fire Protection

Halon-1301

Halon-1301

**Fire Detection -

Portable Extinguisher**

**Fire Detection -

Portable Extinguisher**

Halon-1301

**Fire Detection Portable Extinguisher**

Halon-1301

Fire detector

Fire detector

Fire detector

Fire detector

Sprinklers

Sprinklers

Sprinklers

Sprinklers

Sprinklers

Hose Boxes

Hose Boxes

Fire hydrants, pull boxes 
TABLE 20-1

COMPONENT REQUIREMENTS

\begin{tabular}{|c|c|c|c|c|c|c|}
\hline Item & Canister & $\begin{array}{l}\text { Outer } \\
\text { Plug }\end{array}$ & $\begin{array}{l}\text { Inner } \\
\text { Plug } \\
\end{array}$ & Overpack & $\begin{array}{l}\text { Overpack } \\
\text { Cover }\end{array}$ & $\begin{array}{l}\text { Repair } \\
\text { Cap }\end{array}$ \\
\hline Material & $304 \mathrm{~L}-\mathrm{SS}$ & $304 \mathrm{~L}-\mathrm{SS}$ & $\mathbf{a}$ & $304 L-S S$ & $304 L-S S$ & $304 \mathrm{~L}-\mathrm{SS}$ \\
\hline Length or height ( $f t$, in.) & $9^{\prime} 10^{\prime \prime}$ & $\mathbf{a}$ & $\mathbf{a}$ & $\mathbf{a}$ & $\mathbf{a}$ & $\mathbf{a}$ \\
\hline Outer diameter (in.) & 24.0 & 5.070 & $\mathbf{a}$ & $\mathbf{a}$ & $\mathbf{a}$ & $\mathbf{a}$ \\
\hline Inner diameter (in.) & - & - & $\mathbf{a}$ & $\begin{array}{l}27.5 \\
(\min )\end{array}$ & $\mathbf{a}$ & $\mathbf{a}$ \\
\hline Wall thickness (in.) & $\begin{array}{l}3 / 8 \\
(\text { nom })\end{array}$ & - & a & $\begin{array}{l}3 / 8 \\
\text { (nom) }\end{array}$ & $\begin{array}{l}3 / 8 \\
(\text { nom })\end{array}$ & $\begin{array}{l}3 / \varepsilon \\
\text { (nom) }\end{array}$ \\
\hline Nozzle ID (in.) & 4.995 & - & - & - & - & - \\
\hline $\begin{array}{l}\text { Minimum Weld flange } \\
\text { contact area (in. }{ }^{2} \text { ) }\end{array}$ & 13 & - & - & - & - & - \\
\hline Volume total $\left(\mathrm{ft}^{3}\right)$ & 25.7 & - & - & a & $\mathbf{a}$ & - \\
\hline Unmachined surface finish & $2 B$ & a & $2 B$ & No. 4 & No. 4 & $\mathbf{a}$ \\
\hline
\end{tabular}




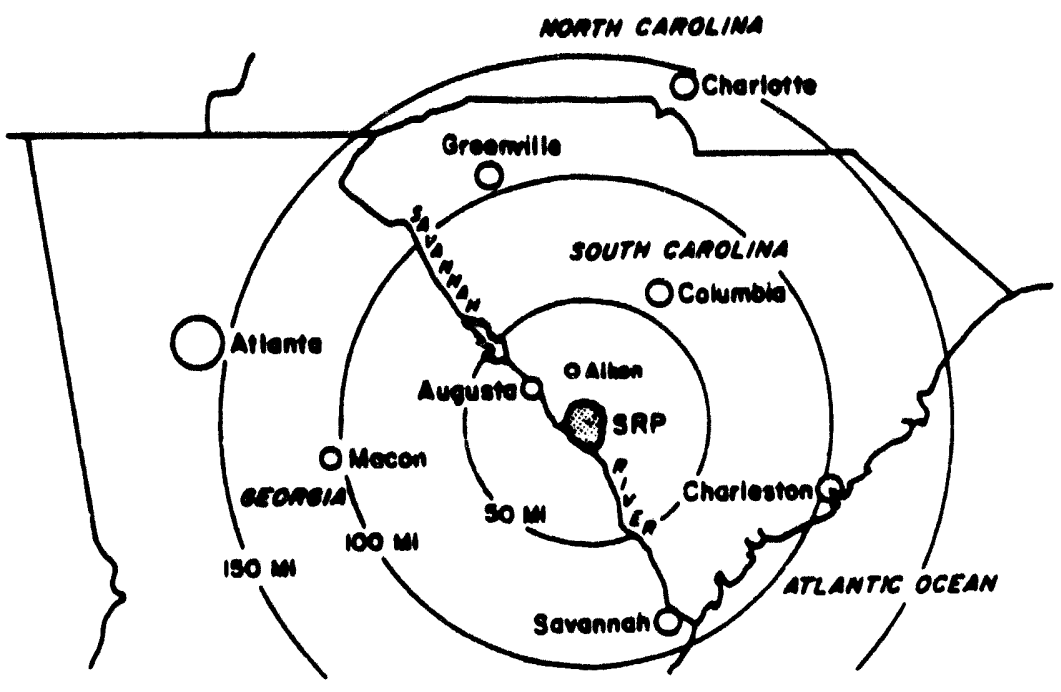

FIGURE 2.1. LOCATION OF SRP RELATIVE TO SURROUNDING FOPULATION CENTERS 


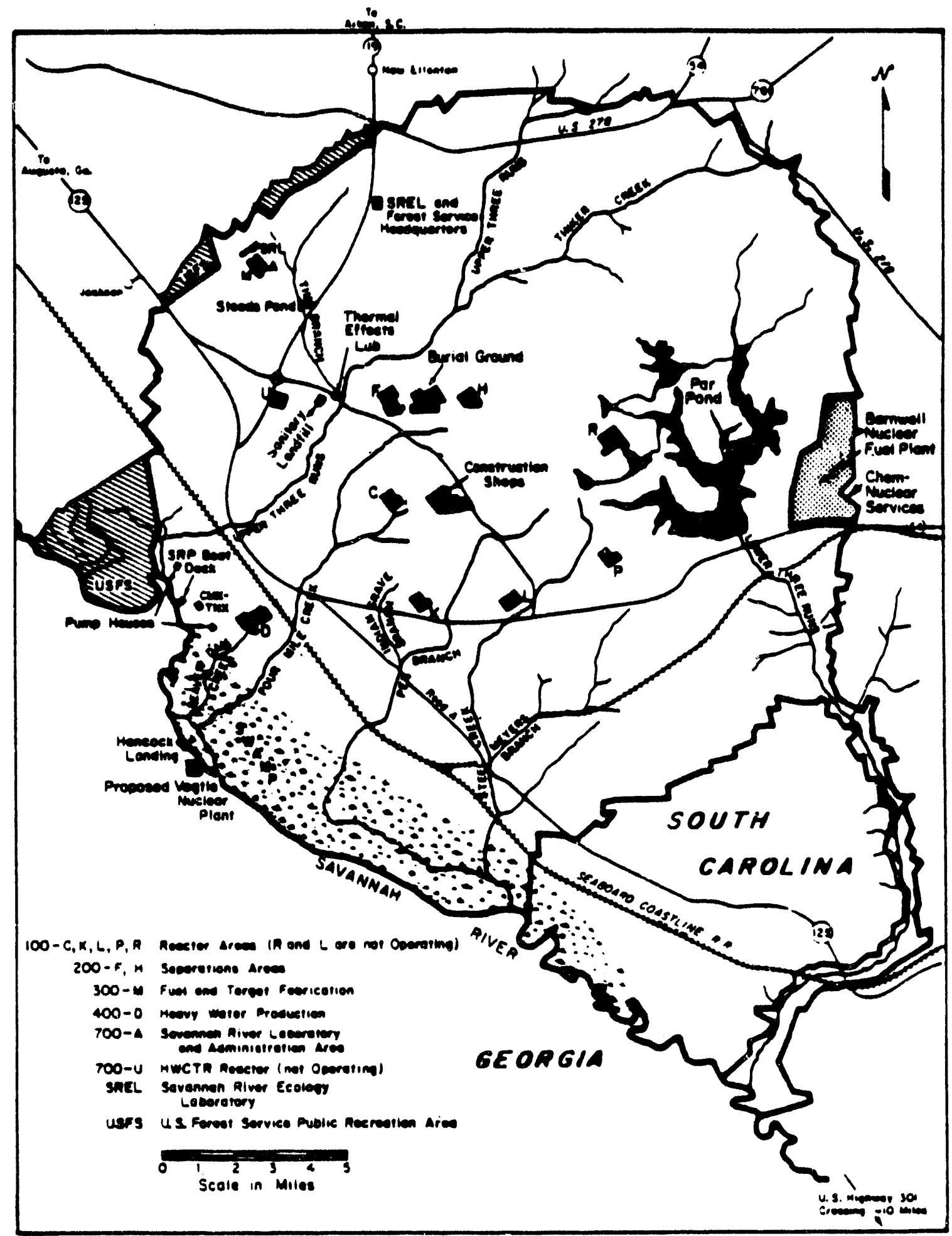

FIGURE 2.2. THE SAVANNAH RIVER PLANT SITE 


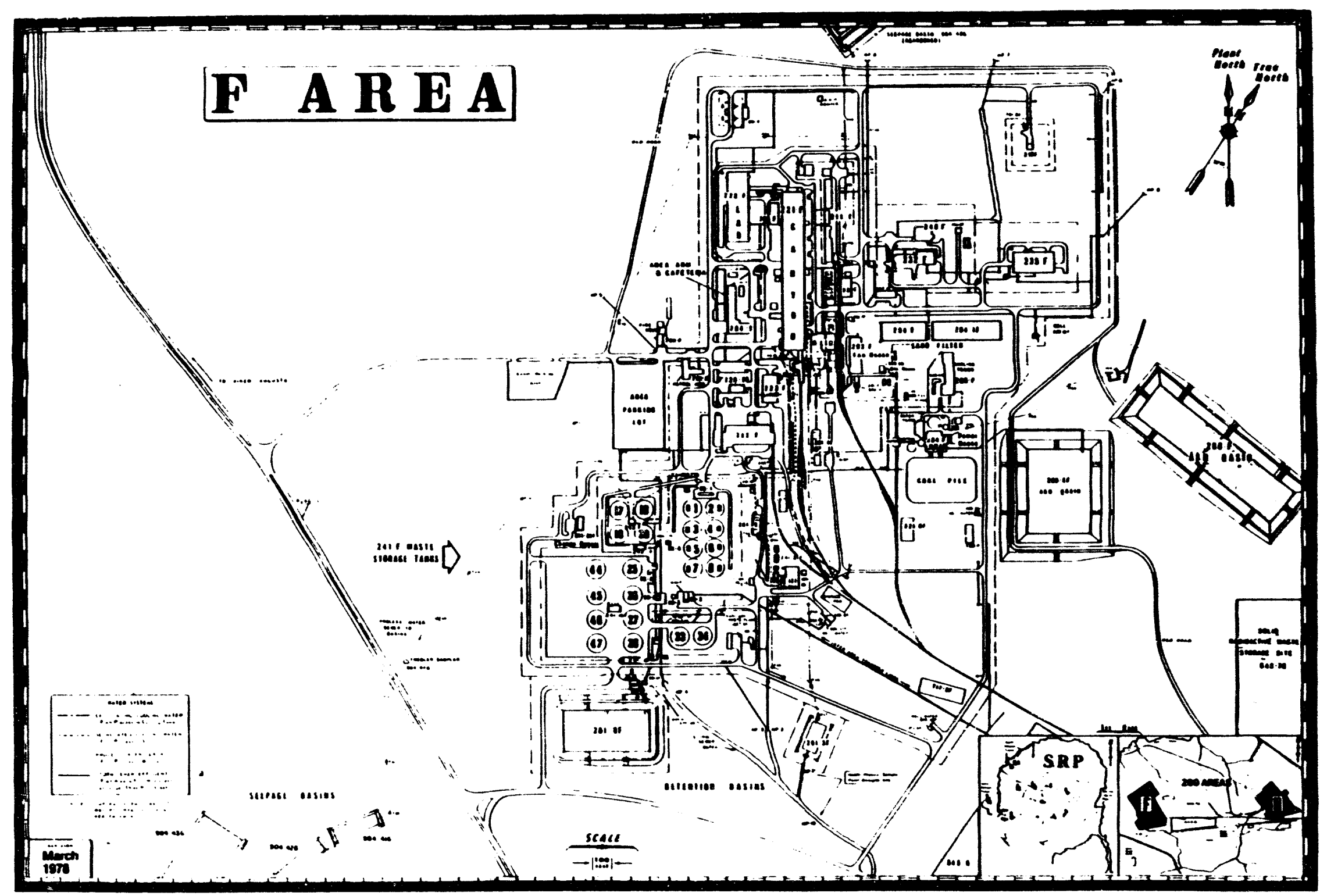

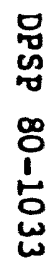

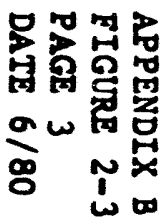




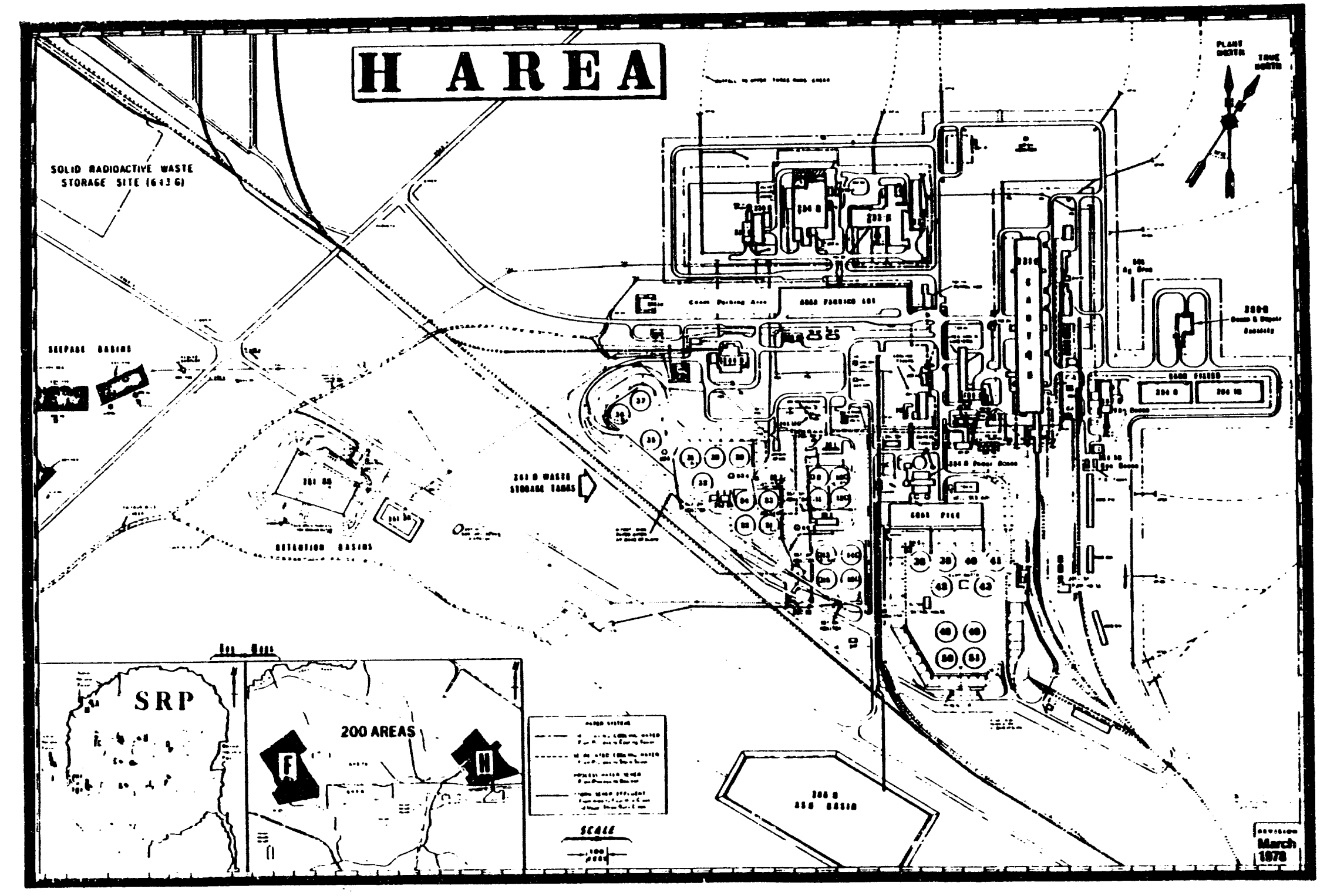

0
0
0
$o$
1
$\vdots$
0
$\omega$

FIGURE 2.4. H AREA

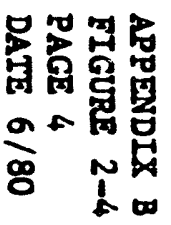




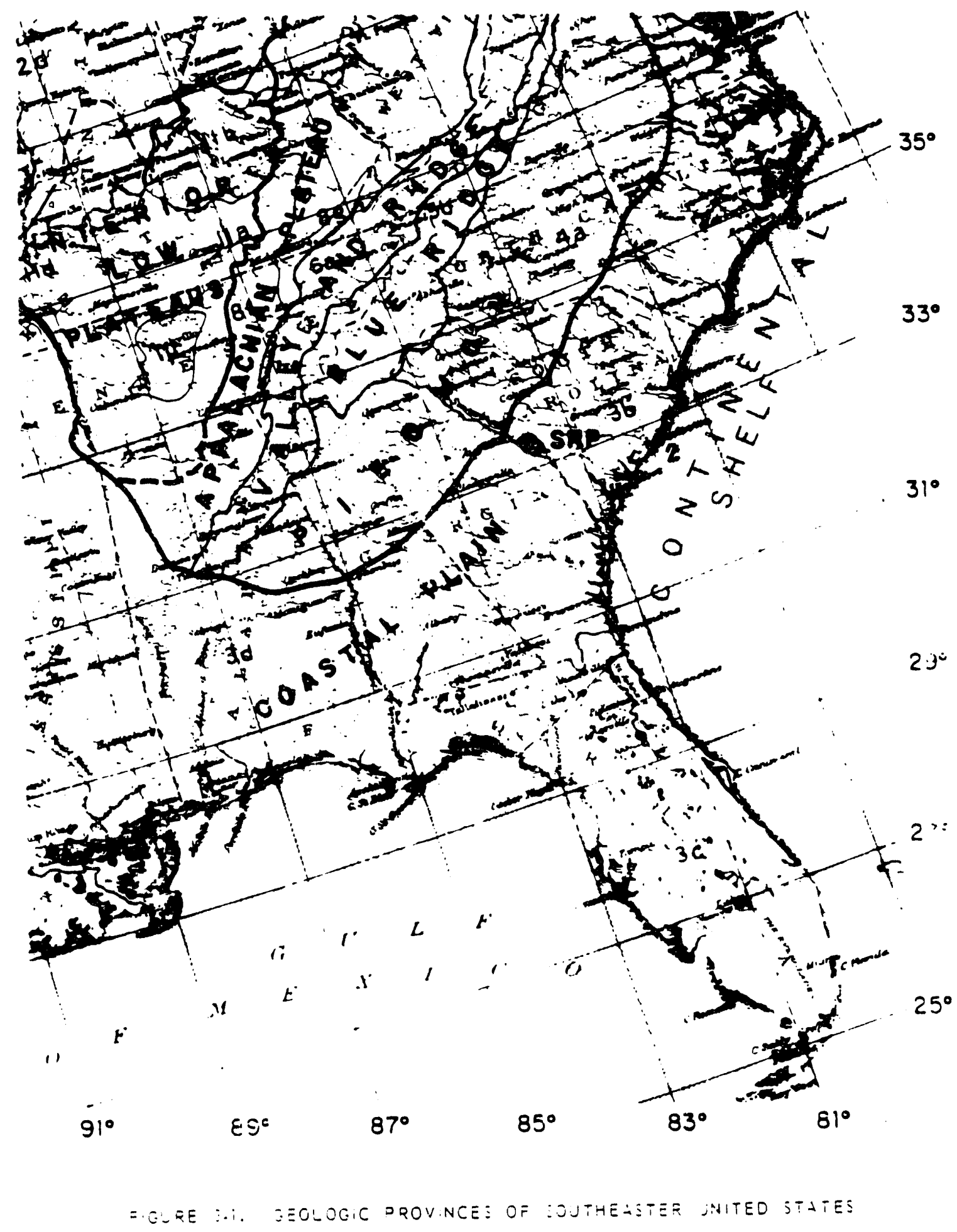




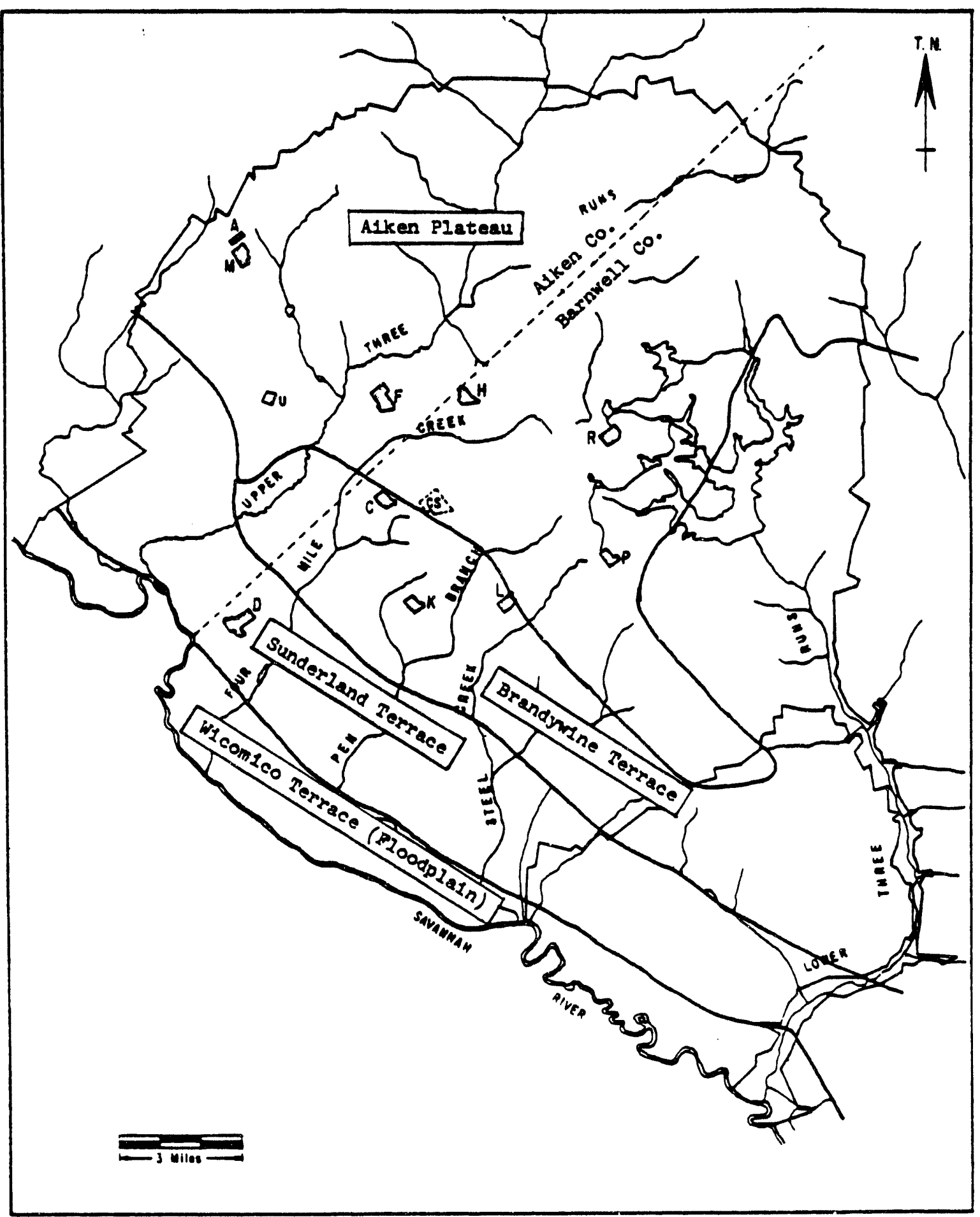

gigure 3.2. coAstal terRaces on the savannah RIVER PLANT 


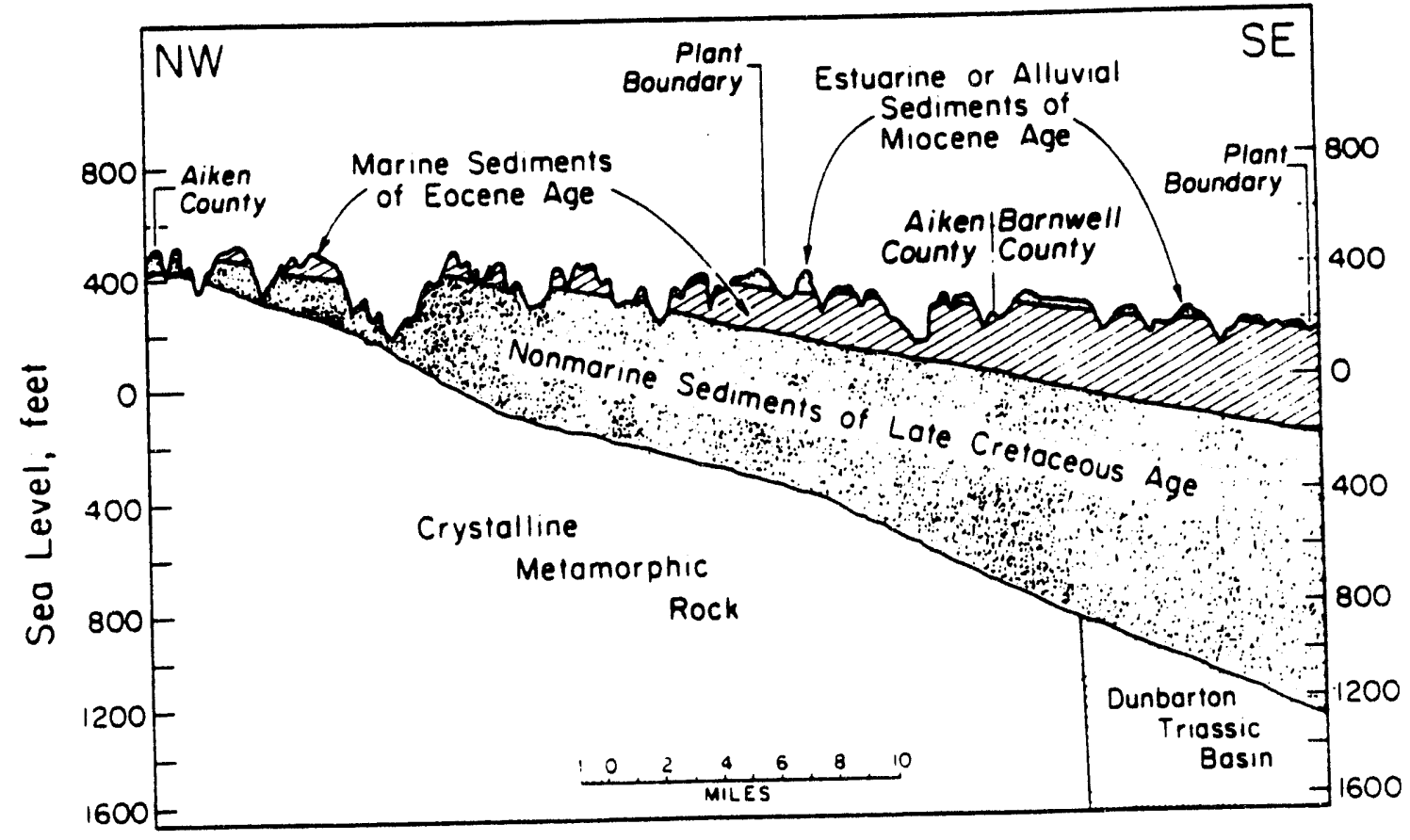

FIGURE 3.3. PROFILE OF GEOLOGIC FORMATION. BENEATH THE SAVANNAH RIVER PLANT 


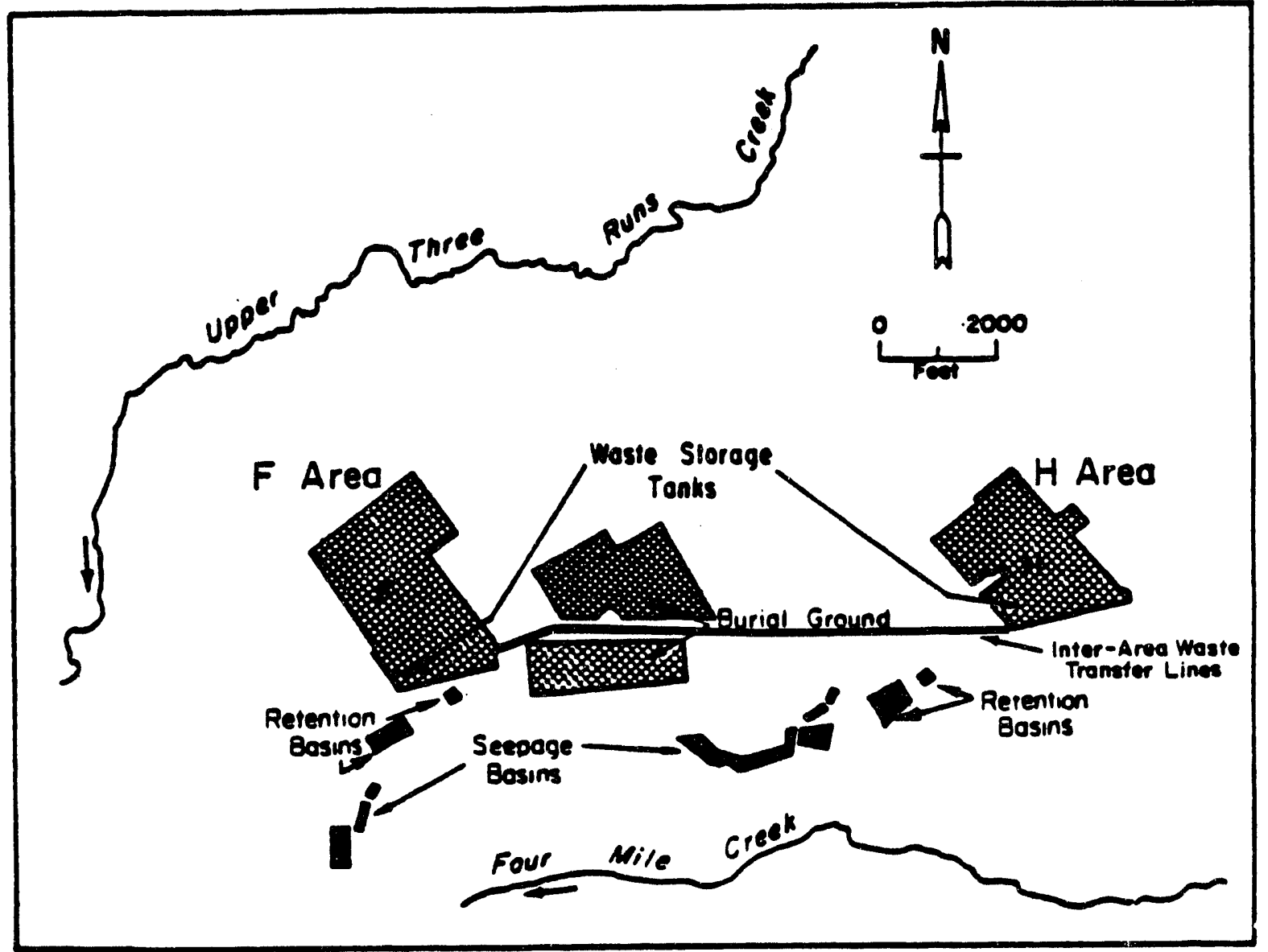

FIGURE 3.4. RELATHVE LOCATIONS OF SEPARATIONS AREAS ANO ASSOCIATED WASTE HANDLING FACILITIES 


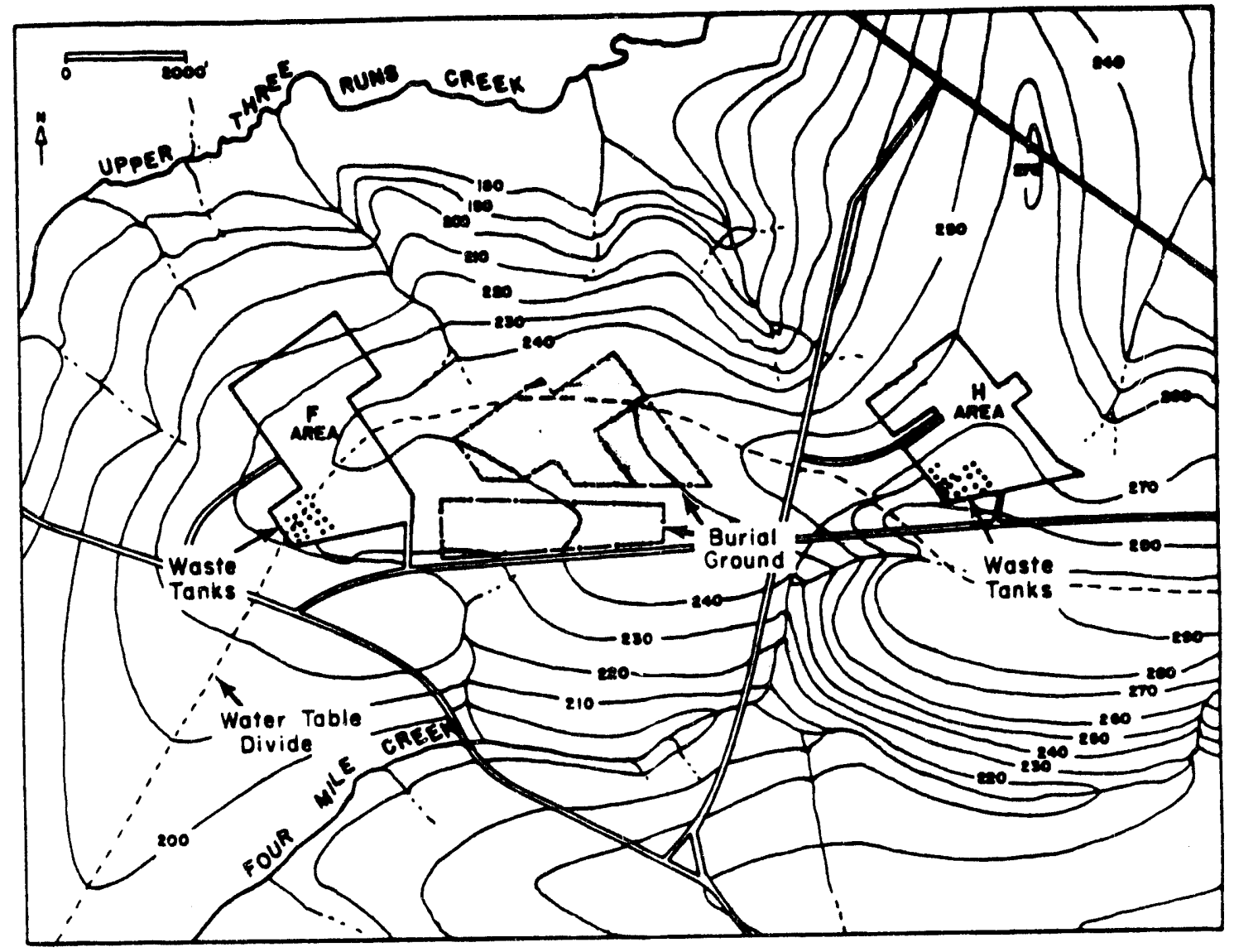

FIGURE 3.5. PREVAILING ELEVATION OF THE WATER TABLE AT THE TANK FARMS AND BURIAL GROUND CONTOURS SHOWN IN FEET ABOVE SEA LEVEL 


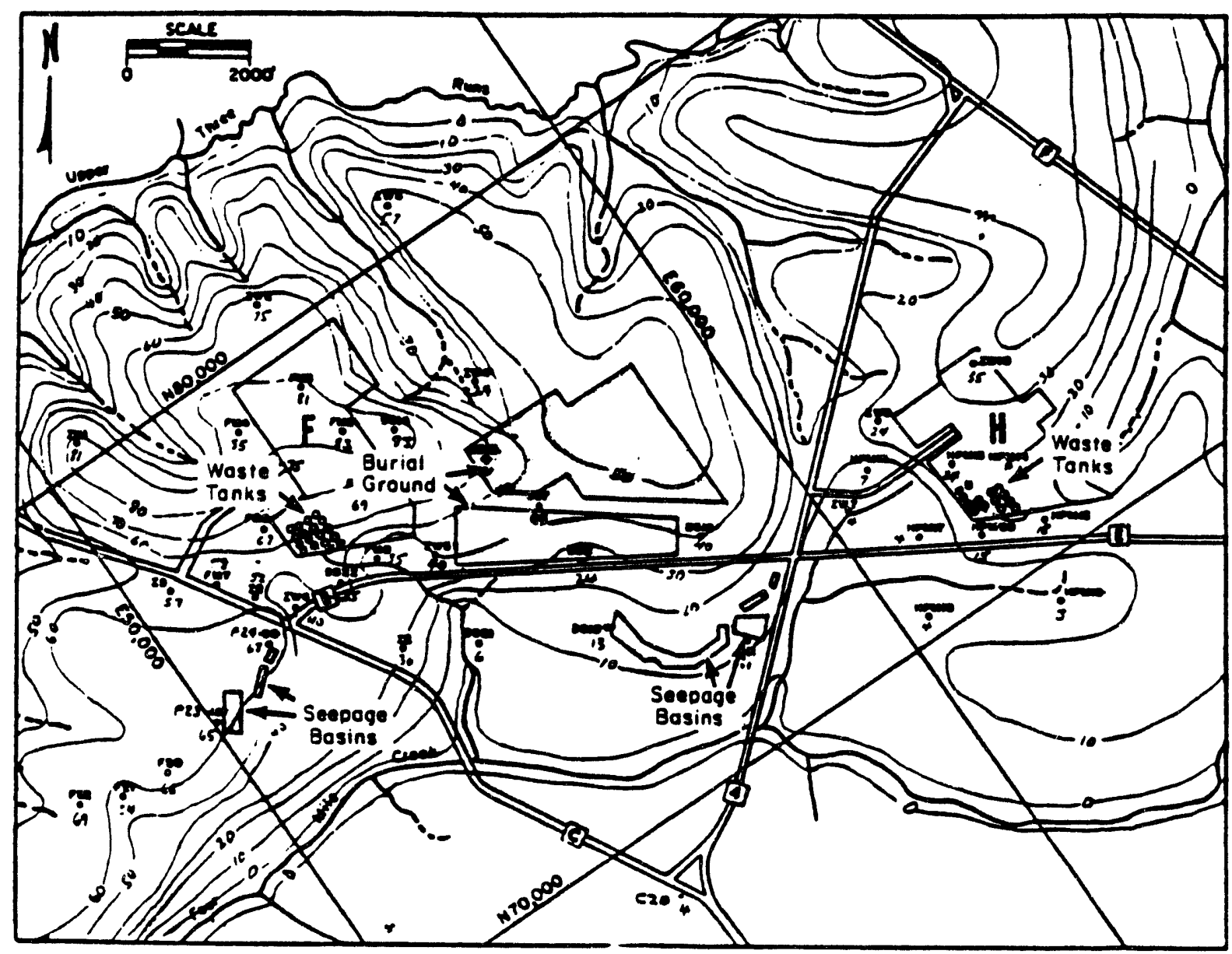

FIGURE 3.6. DEPTH TO HIGH WATER TABLE (MARCH 1965) AT THE TANK FARMS AND BURIAL GROUND (CONTOURS SHOWN IN FEET BELOW GRADE) 


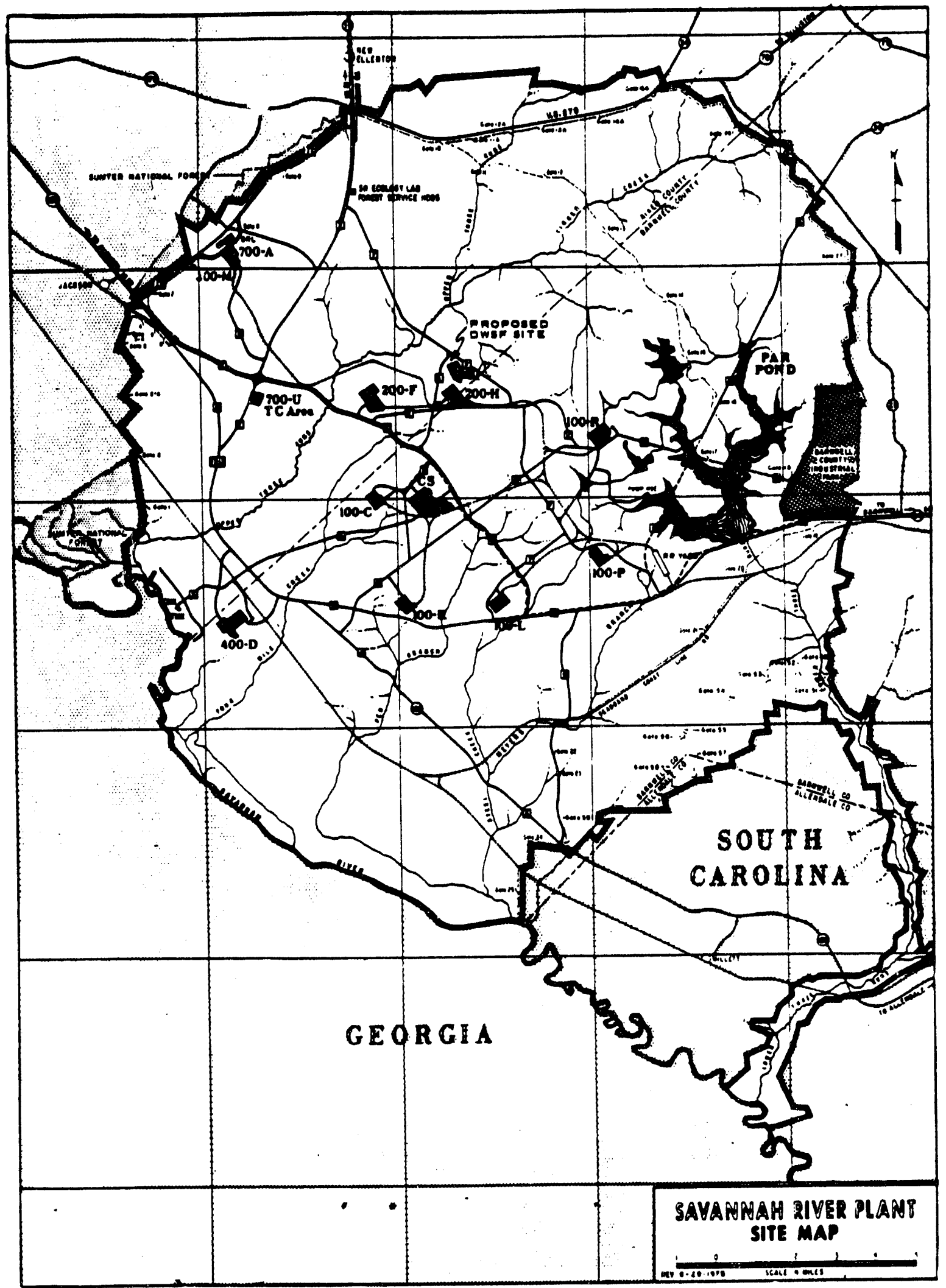

figure 3.7. The savannah river plant site 


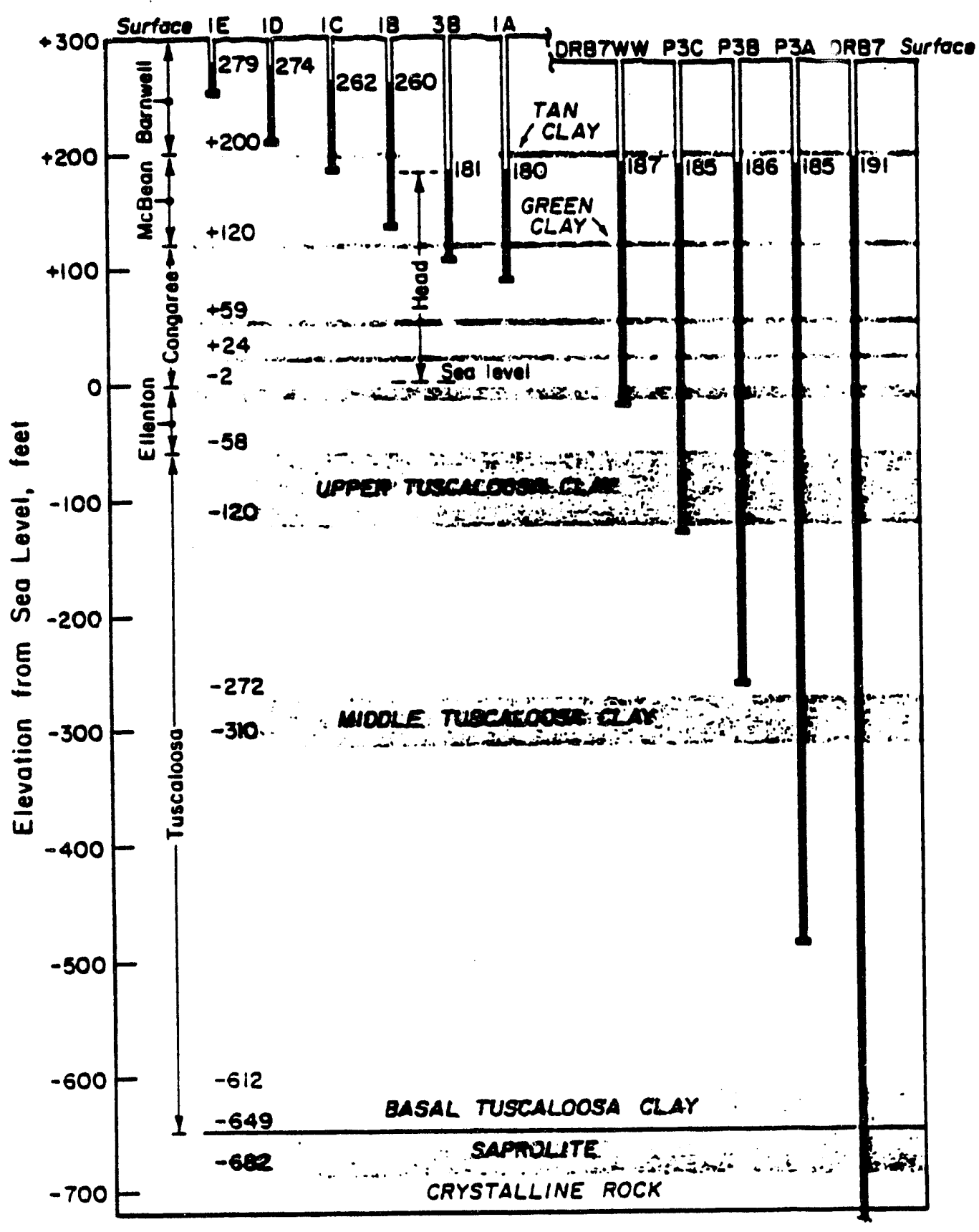

FIGURE 3.8. HYOROSTATIC HEAD IN GROUND HATER NEAR H AREA 


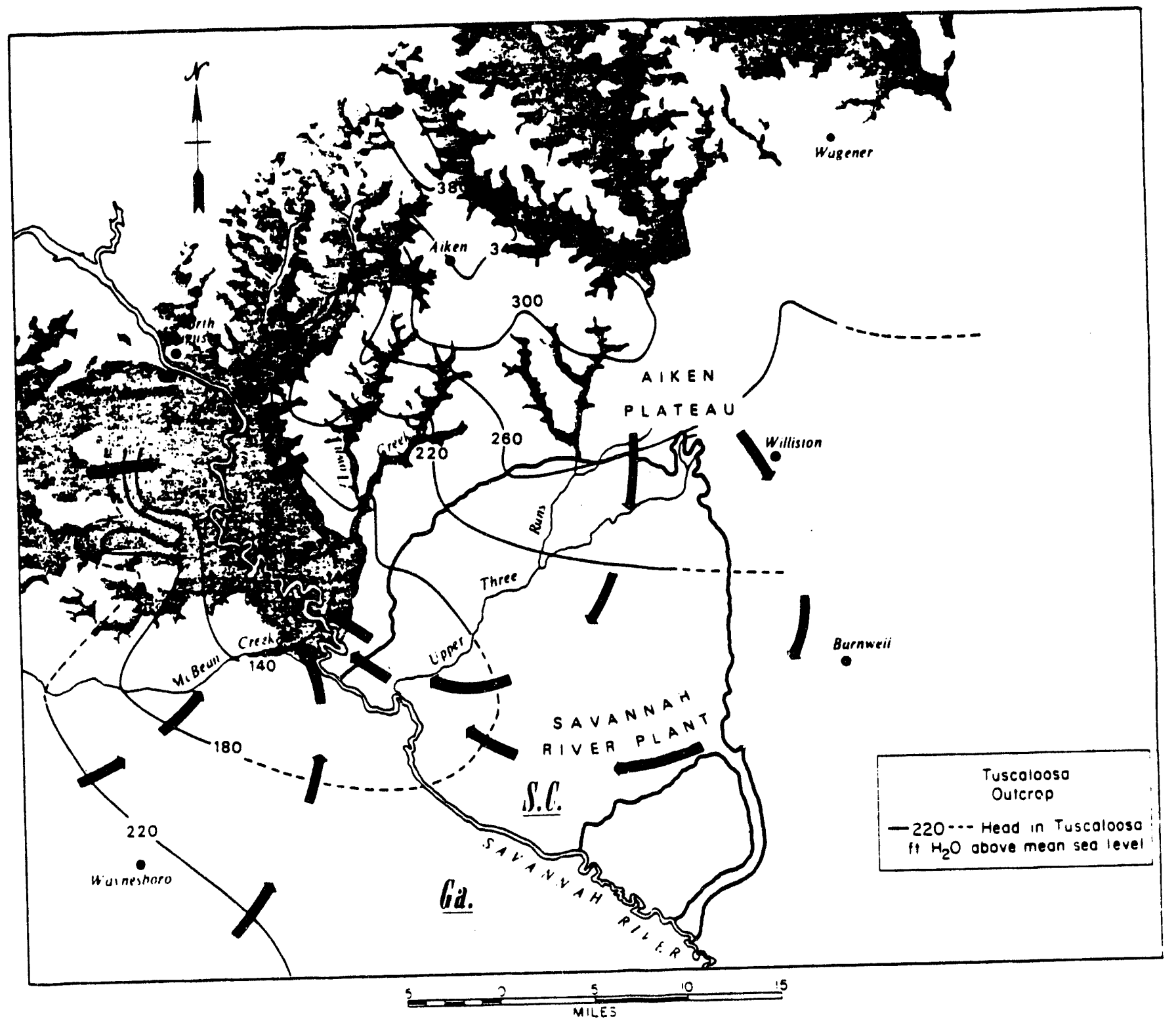

FIGURE 3.9. FLOW IN TUSCALOOSA AQUIFER 


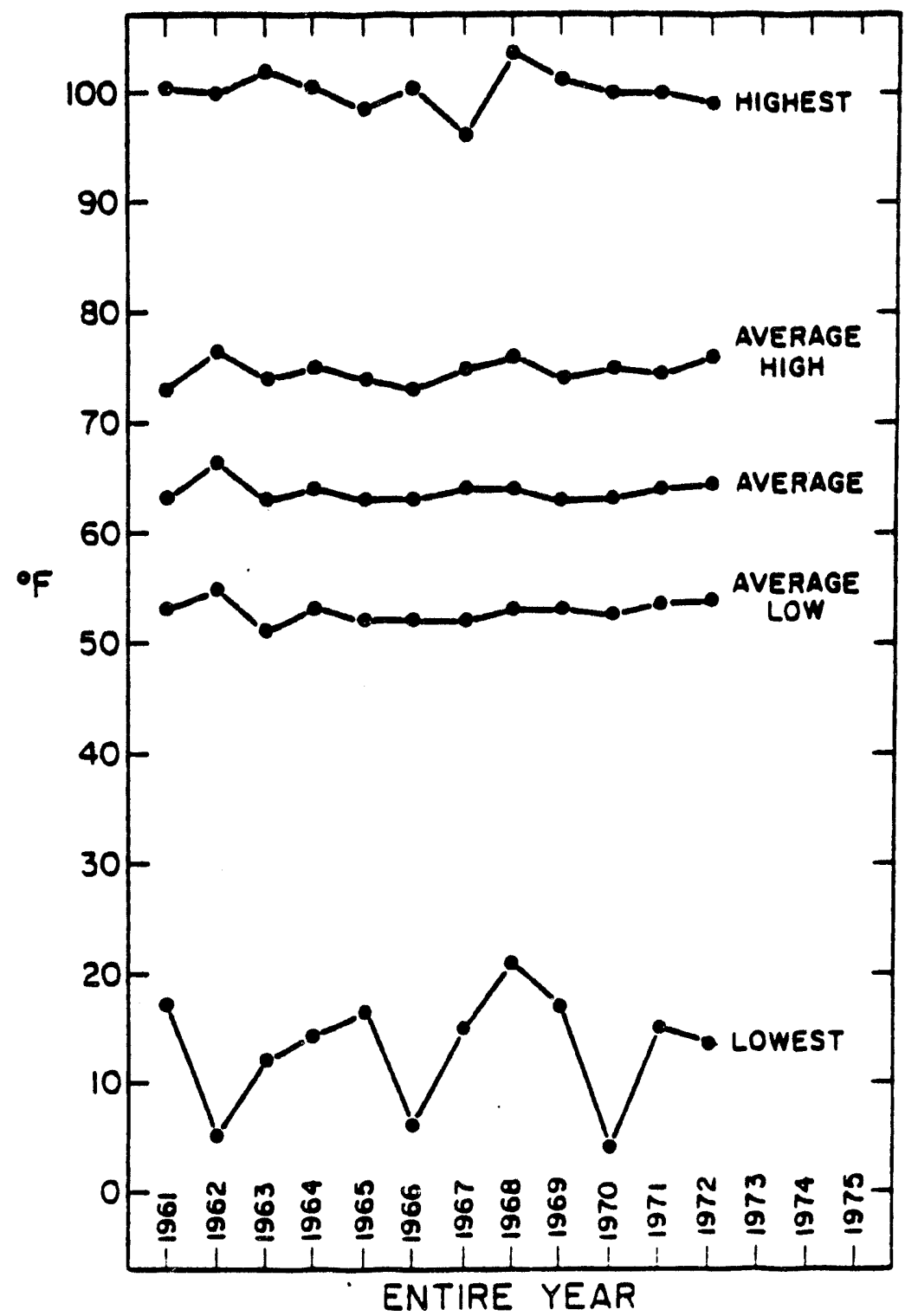

FIGURE 3.10. SUMMARY OF TEMPERATURES AT SRP FROM 1961 TO 1972 


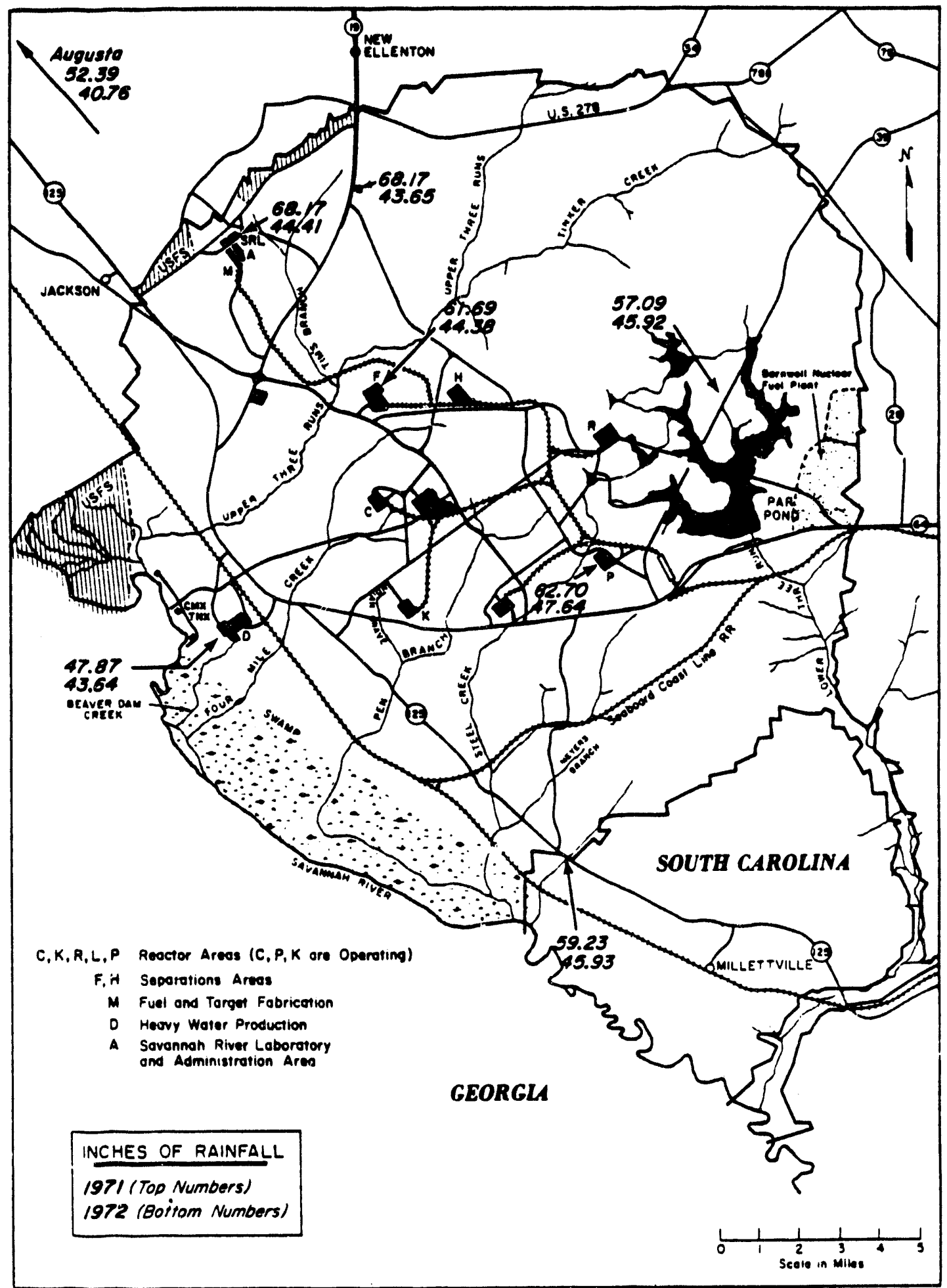

FIGURE 3.11. TOTAL RAINFALL AT DIFFERENT LOCATIONS ON SRP FOR 1971 AND 1972 


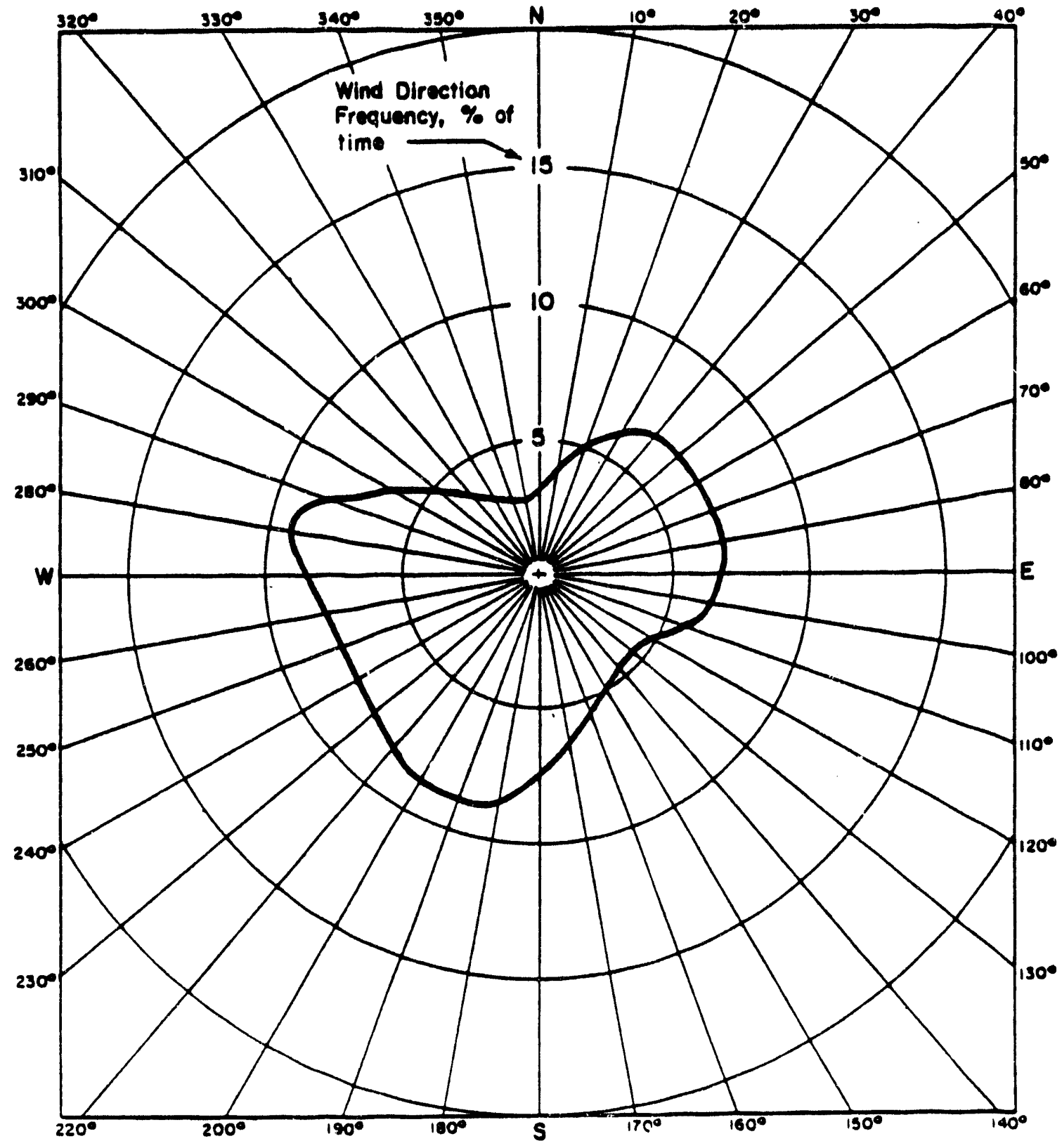

FIGURE 3.12. WIND DIRECTION FREQUENCY NEAR SRP AT 300 FEET 


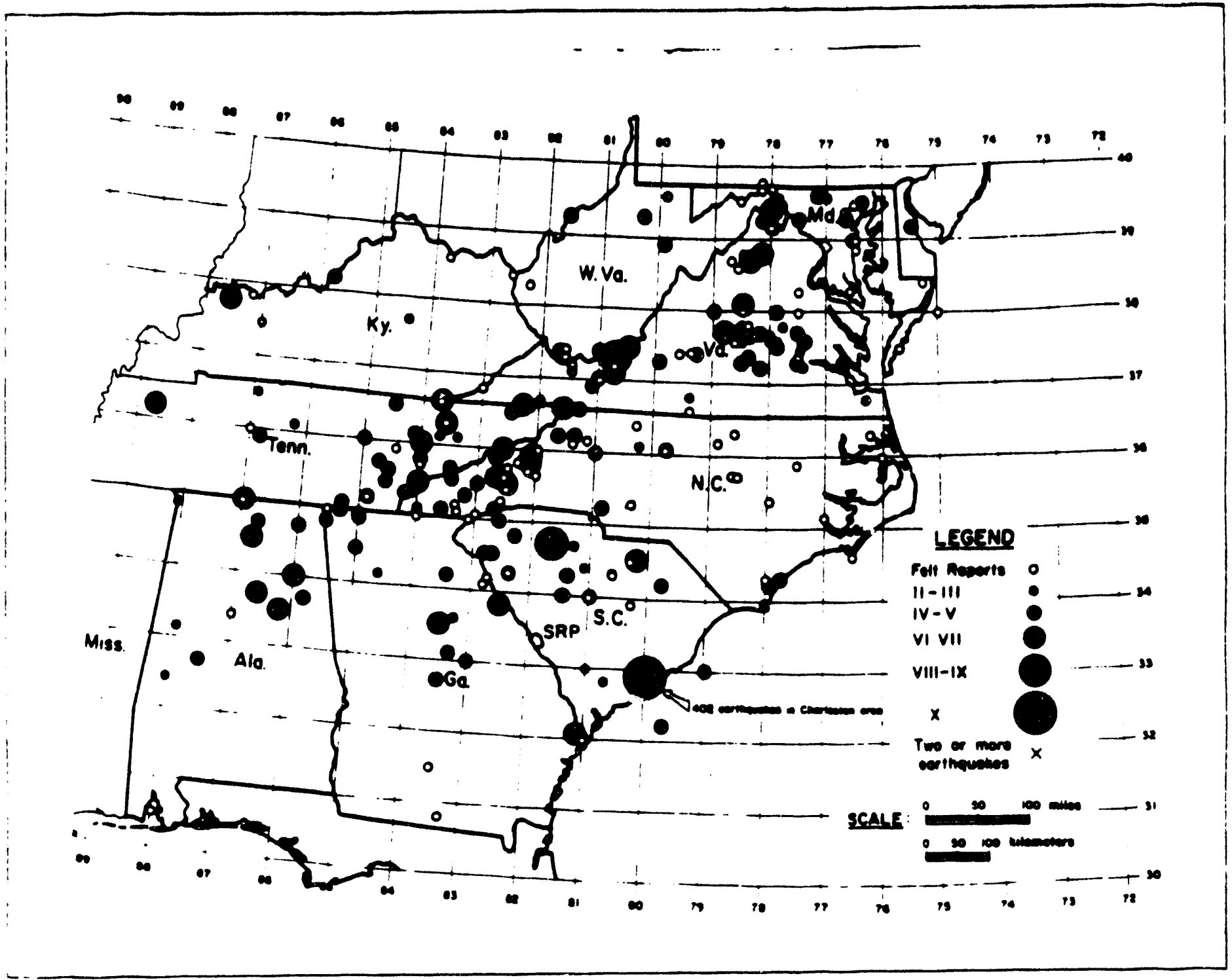

FIGURE 3-13. SEISMIC ACTIVITY IN SOUTHERN APPALACHIAN AREA BETWEEN 1754 AND 1970 

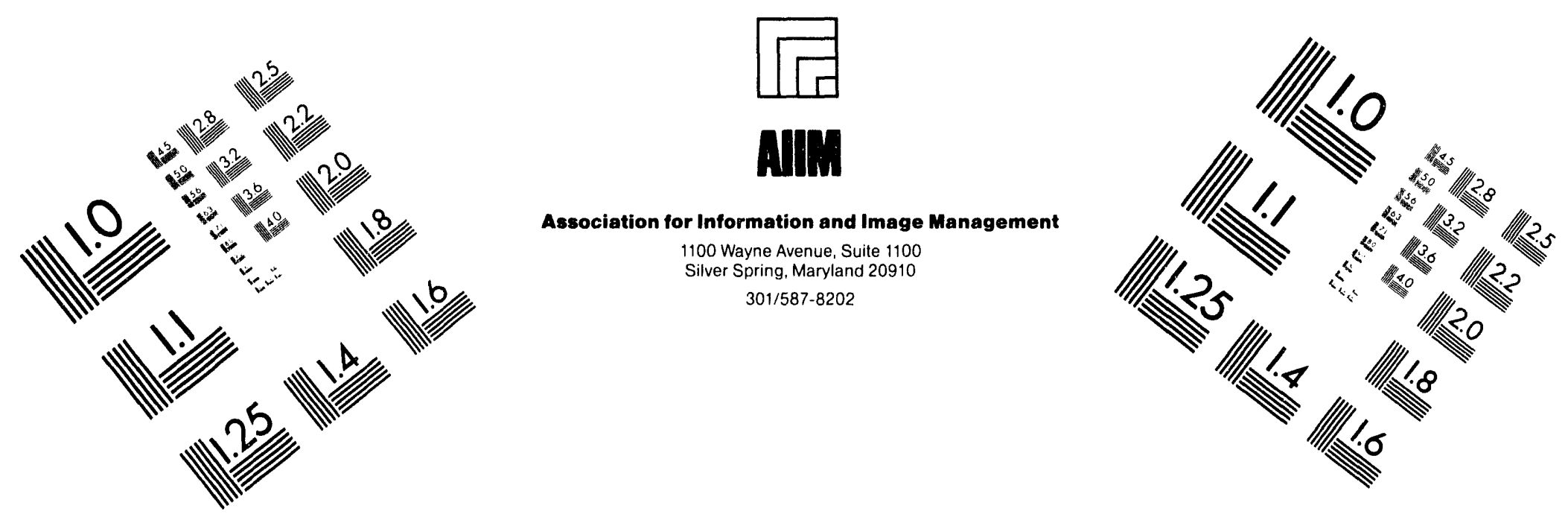

\section{Centimeter}

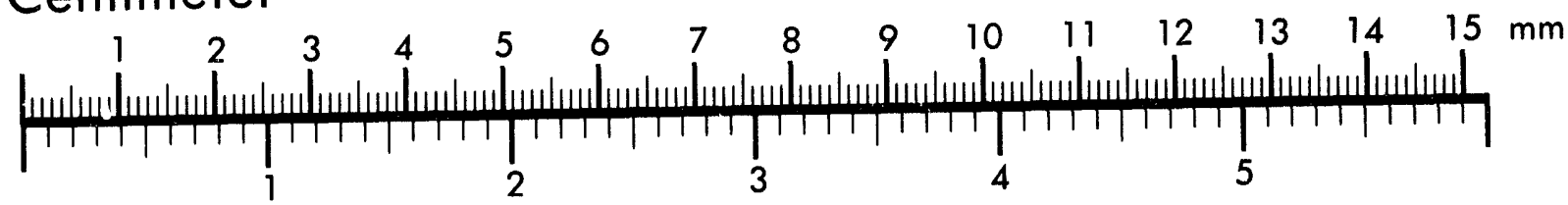
Inches
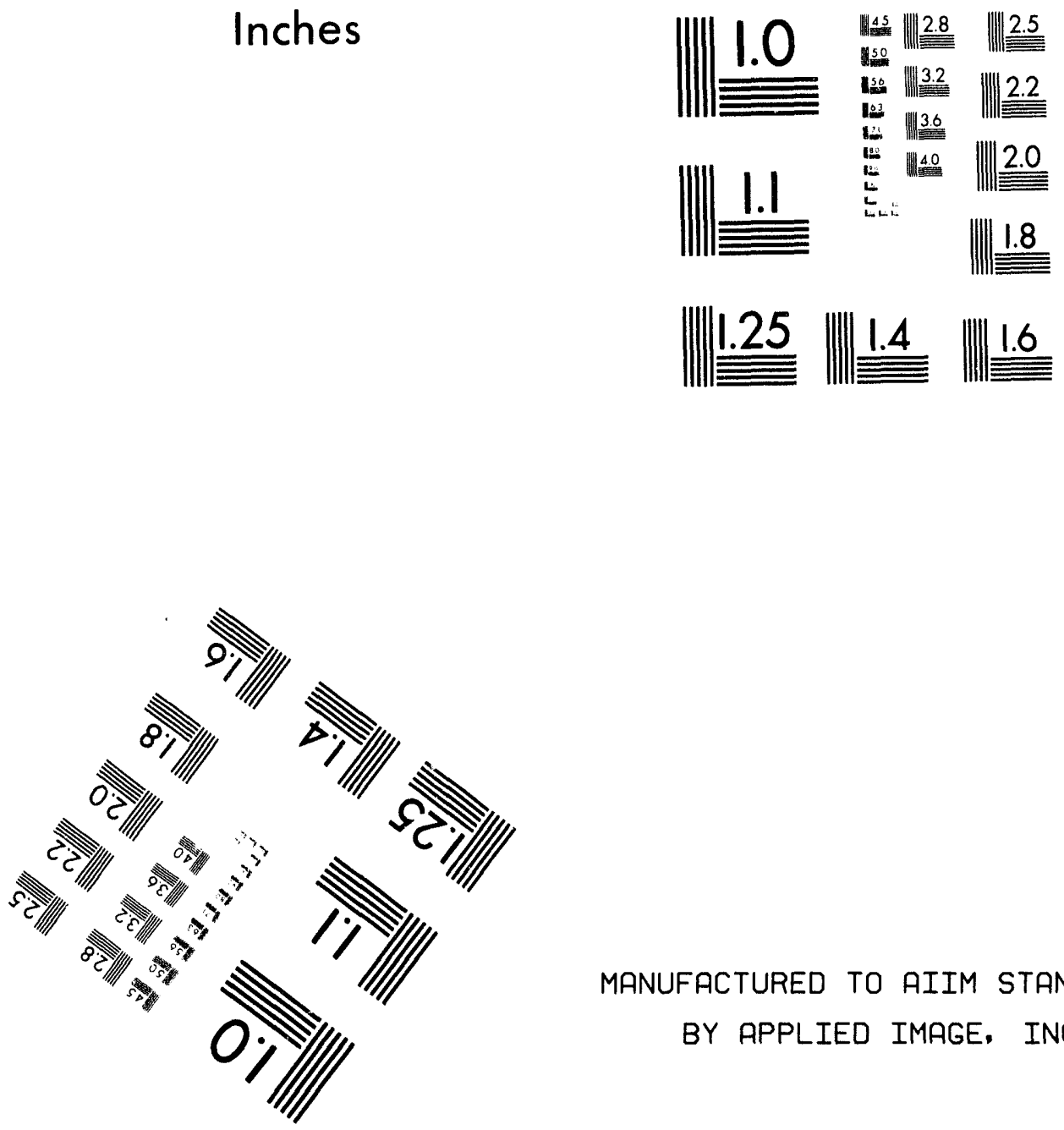

MANUFACTURED TO AIIM STANDARDS BY RPPLIED IMAGE, INC.

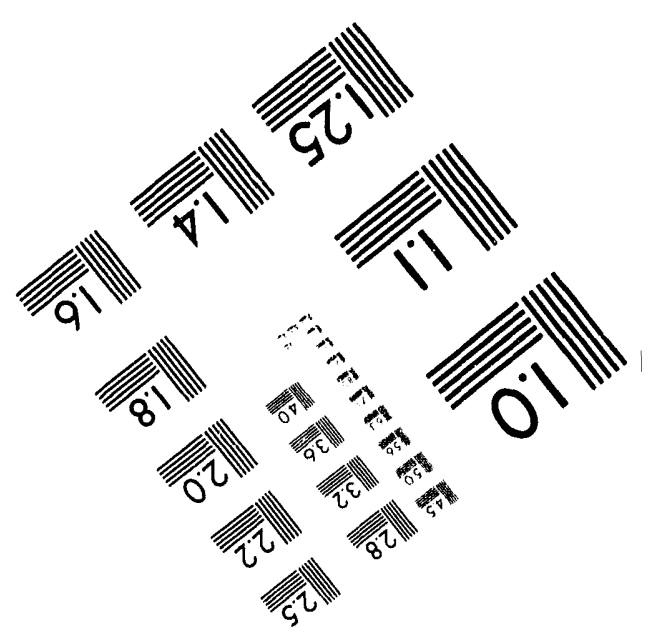



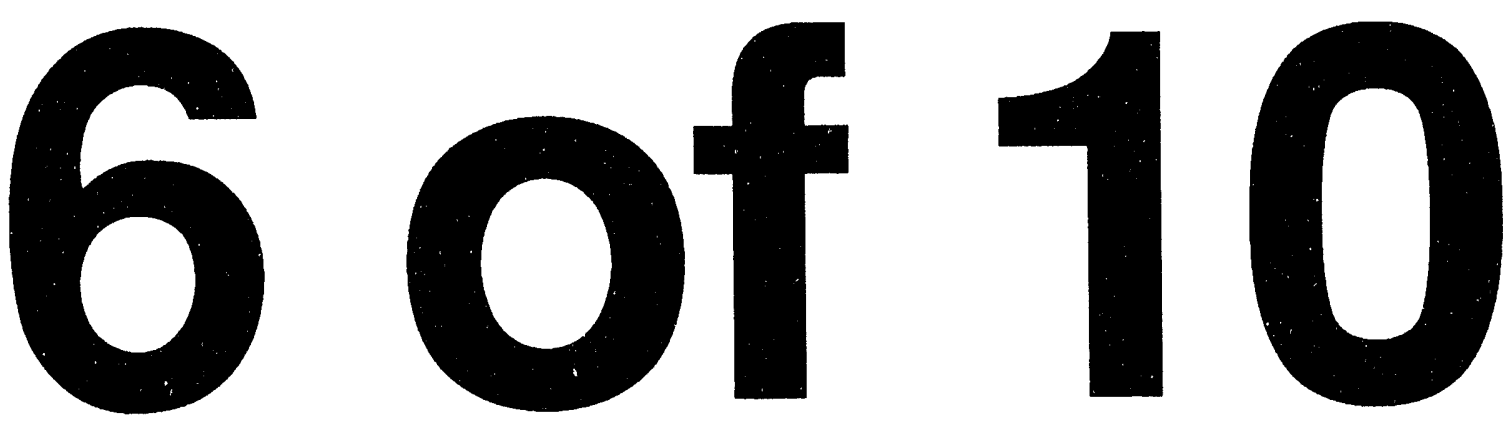
Washed

Sludge Slurry

from

Waste Tank Farm

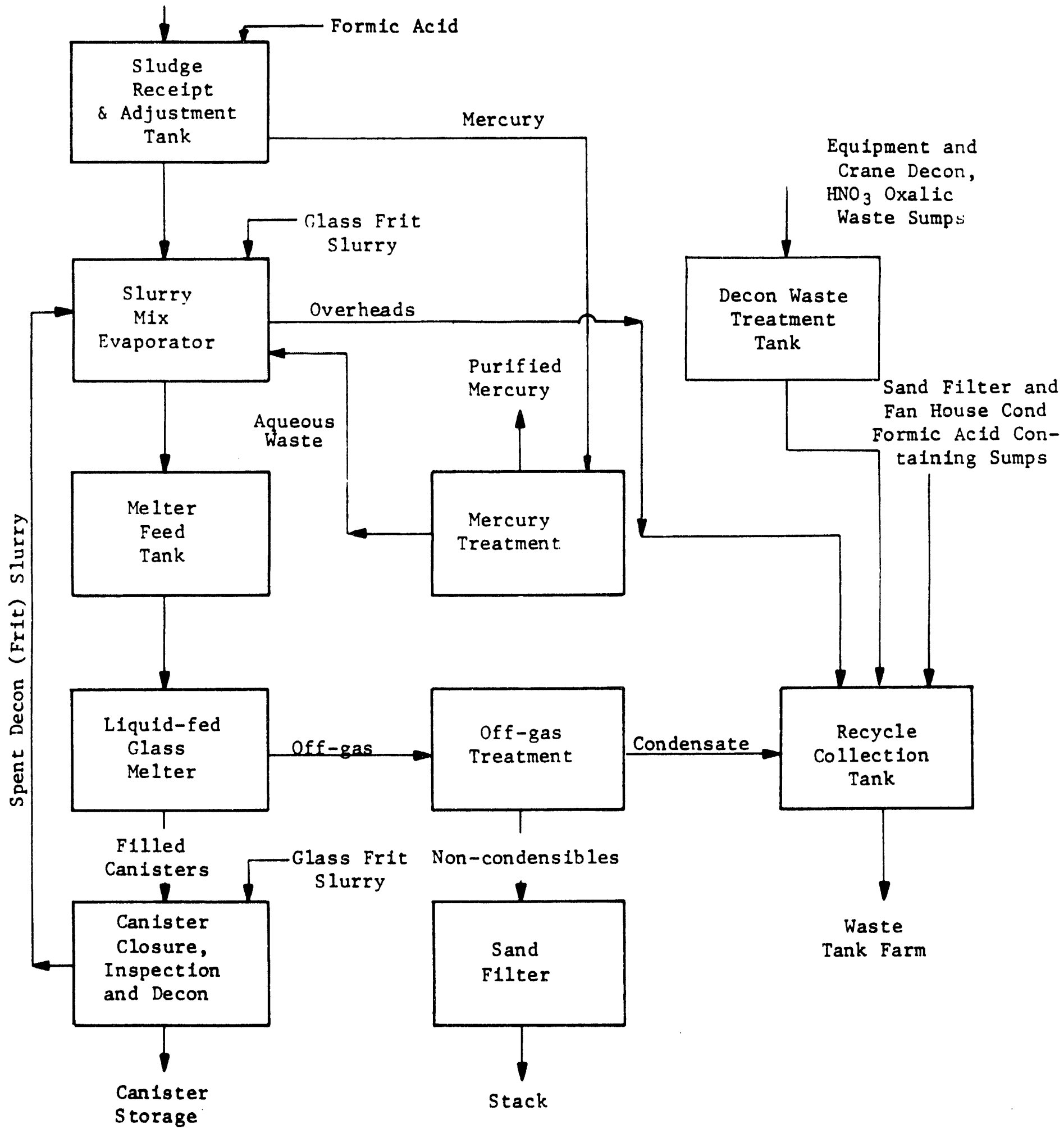

FIGURE 5-1. DWPF PROCESS BLOCK FLOW DIAGRAM 


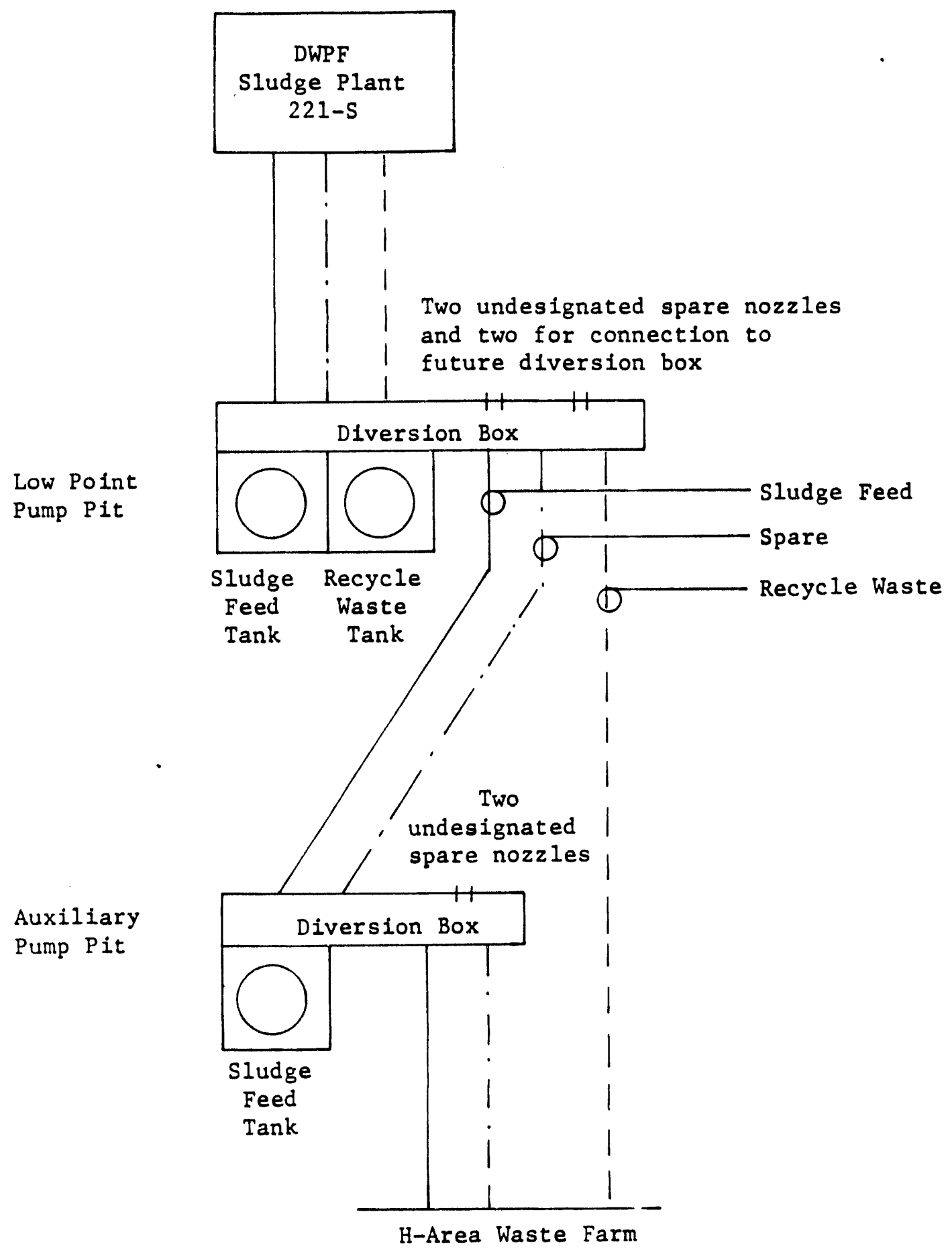

FIGURE 5-2. INTERAREA TRANSFER CONCEPT - DWPF SLUDGE PLANT 
Components
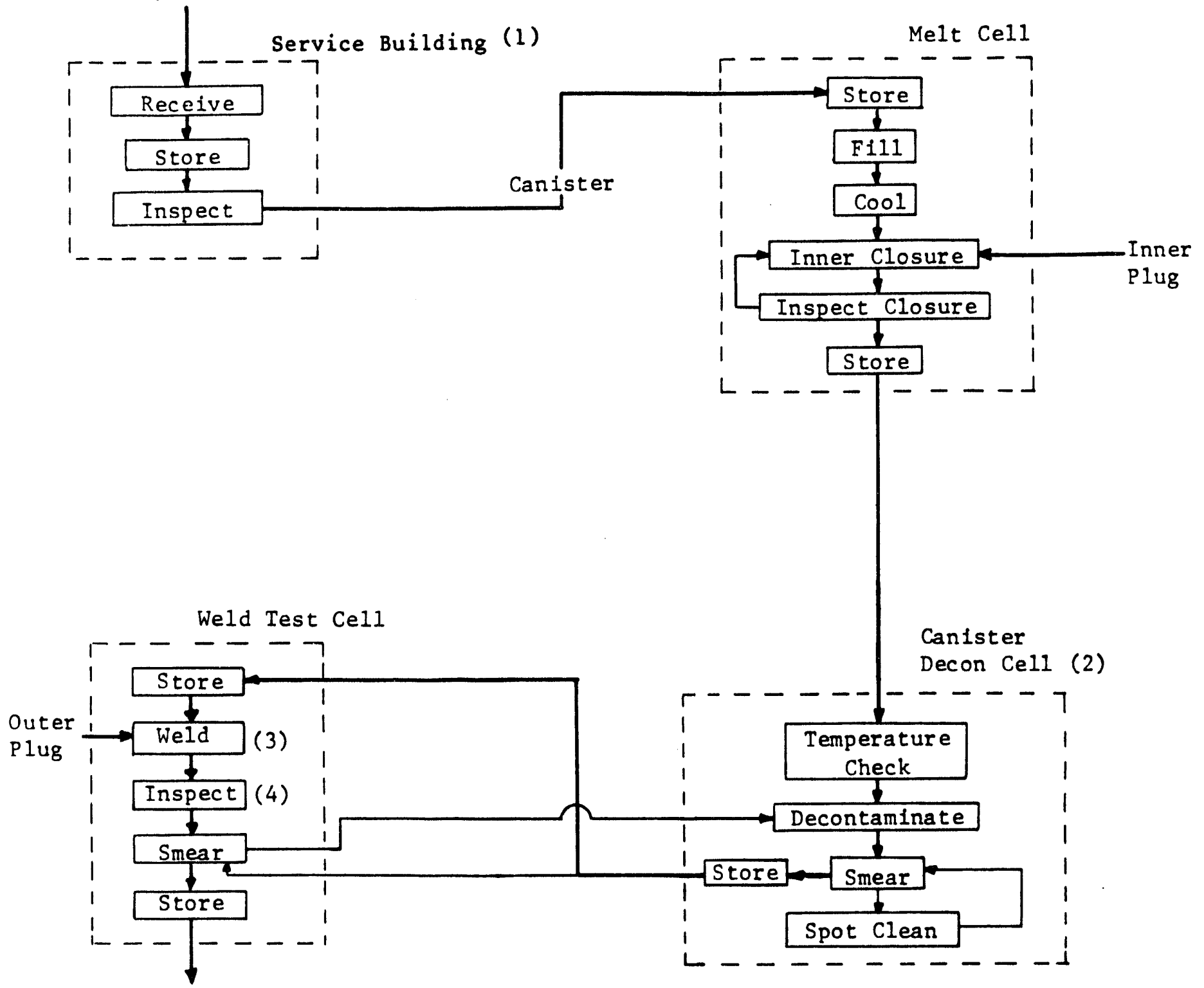

To Interim Storage Building

FIGURE 5-3. CONTAINERIZATION PROCESS

\section{Legend}

(1) Detalls in Figures 5-4 \& 5-5

(2) Detalls in Figure 5-6

(3) Detalls in Figure 5-7

(4) Details in Figure 5-8

\section{$=$ Accept}

- Recycle 


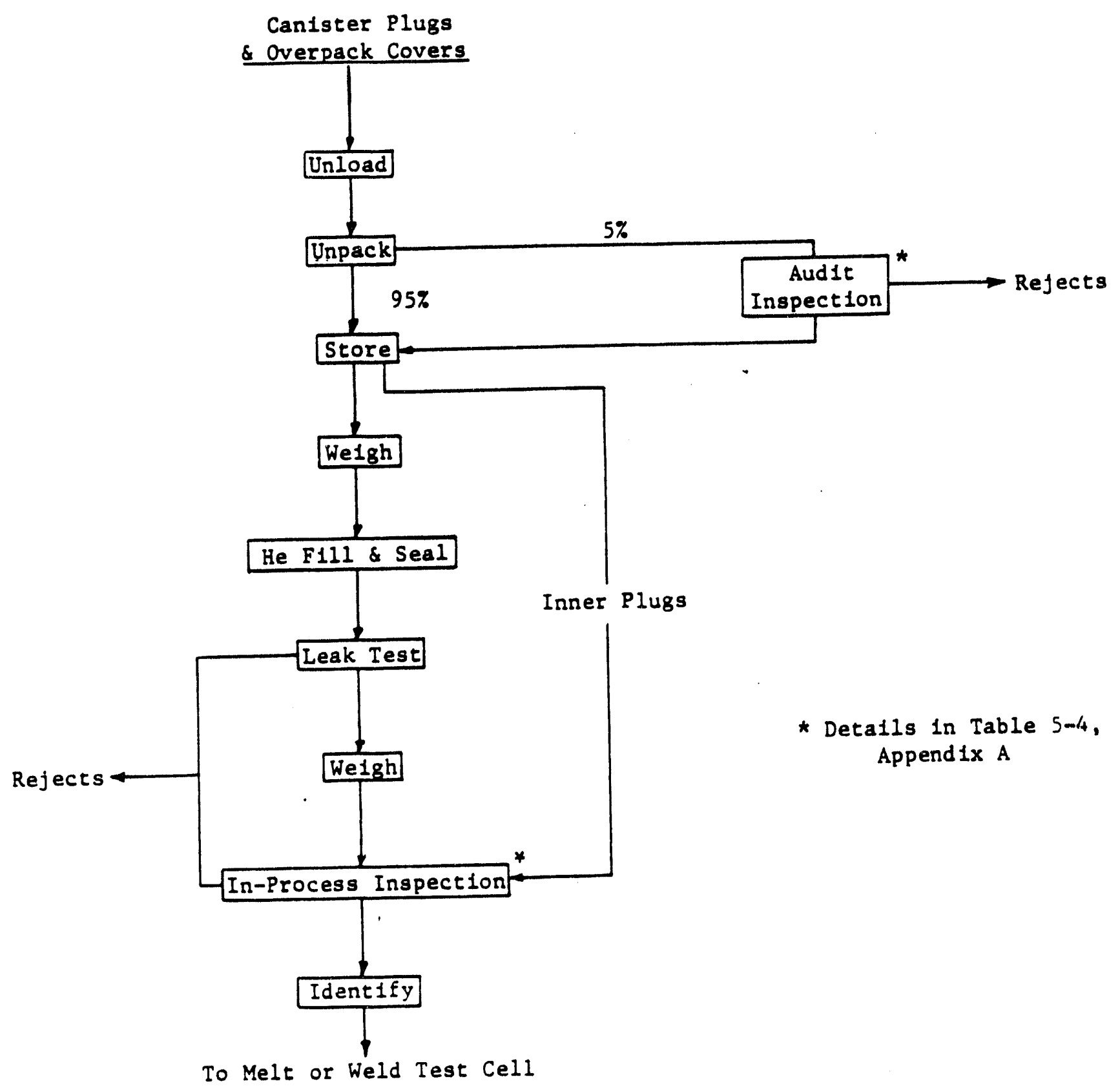

FIGURE 5-4. CANISTER PLUG AND OVERPACK COVER

RECEIPT, INSPECTION AND STORAGE 


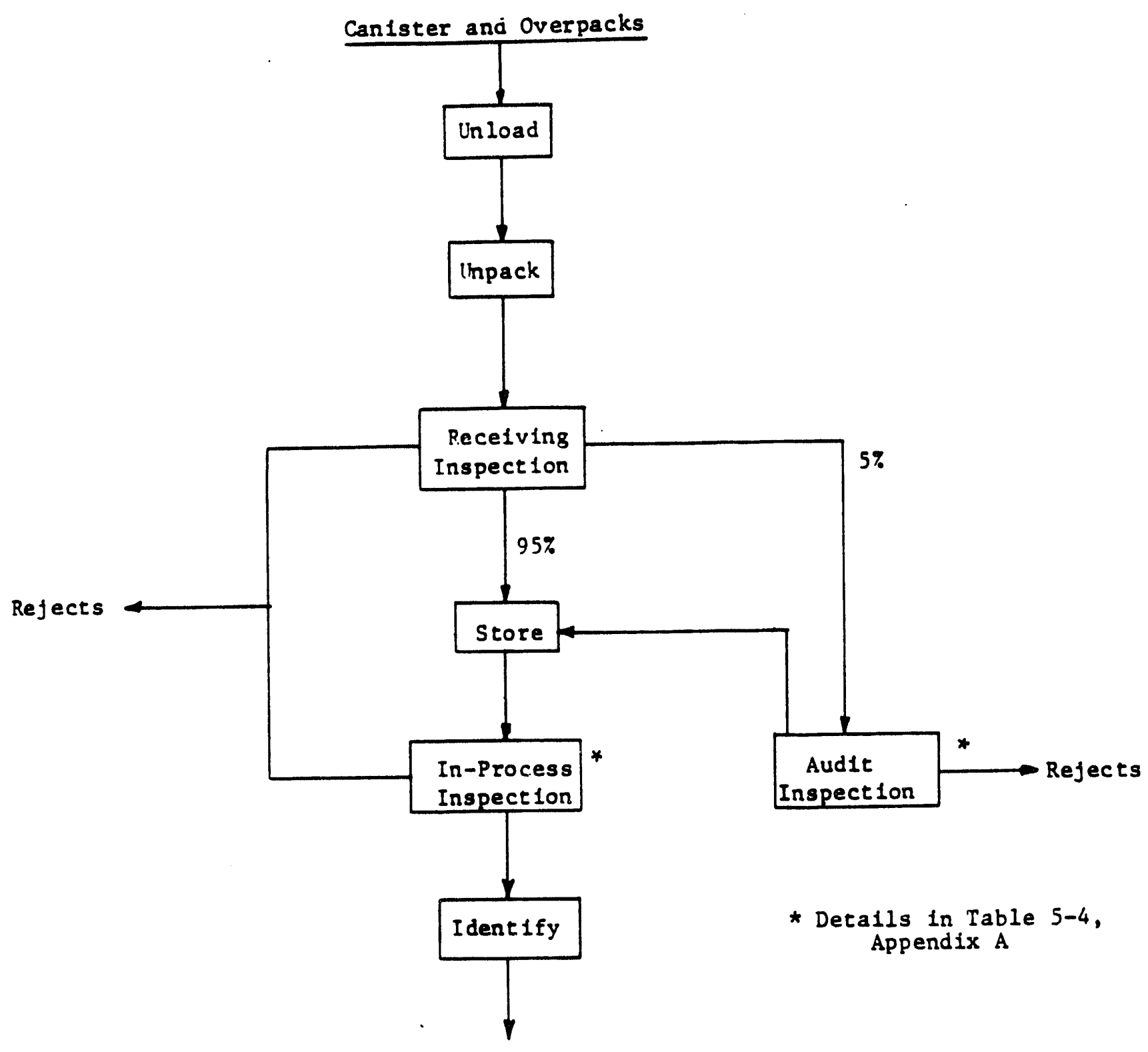

To Melt or Weld Test Cell

FIGURE 5-5. CANISTER AND OVERPACK RECEIPT, INSPECTION AND STORAGE 


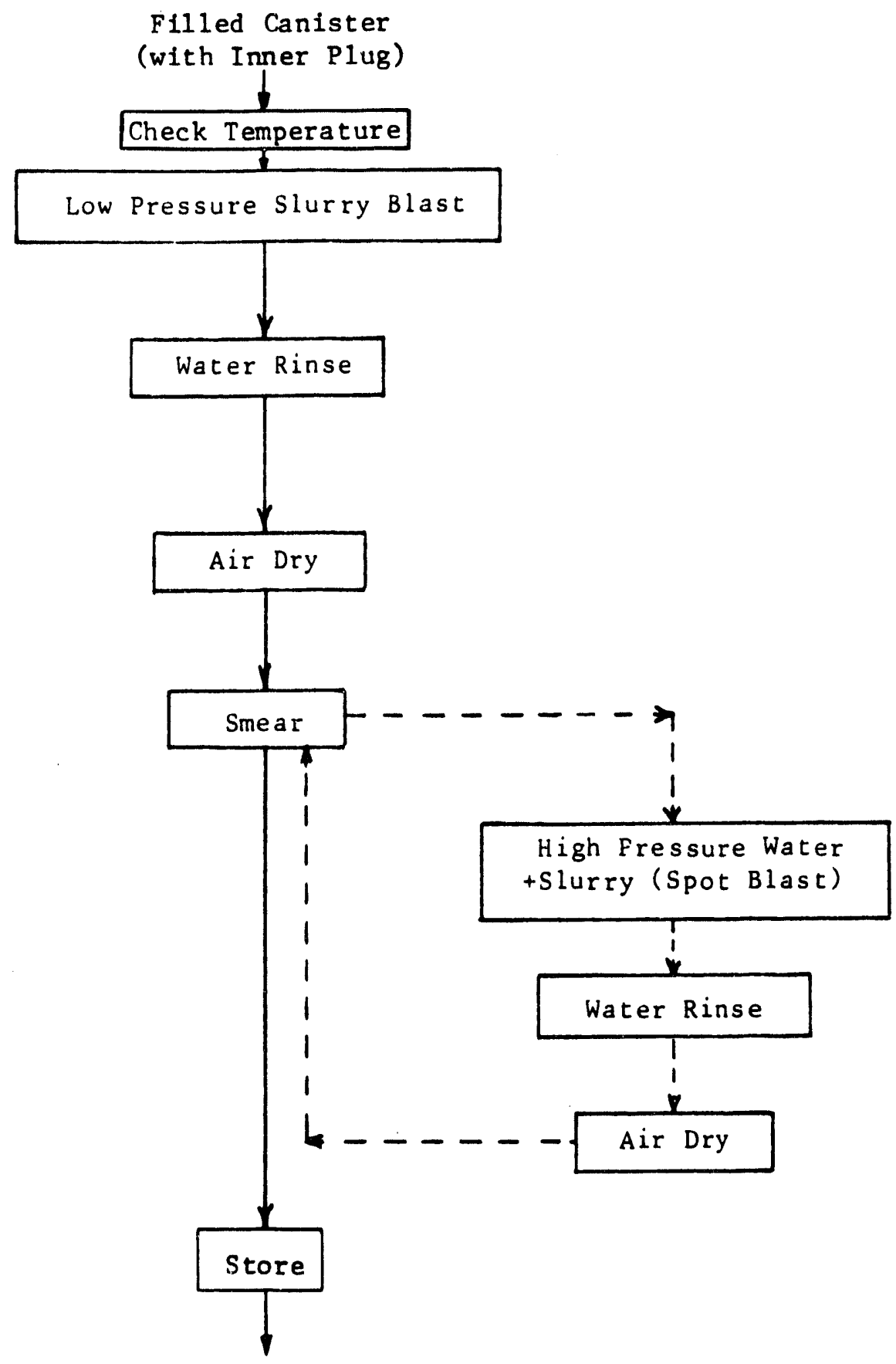

To Weld Test Cell

FIGURE 5-6. DECONTAMINATION PROCESS 


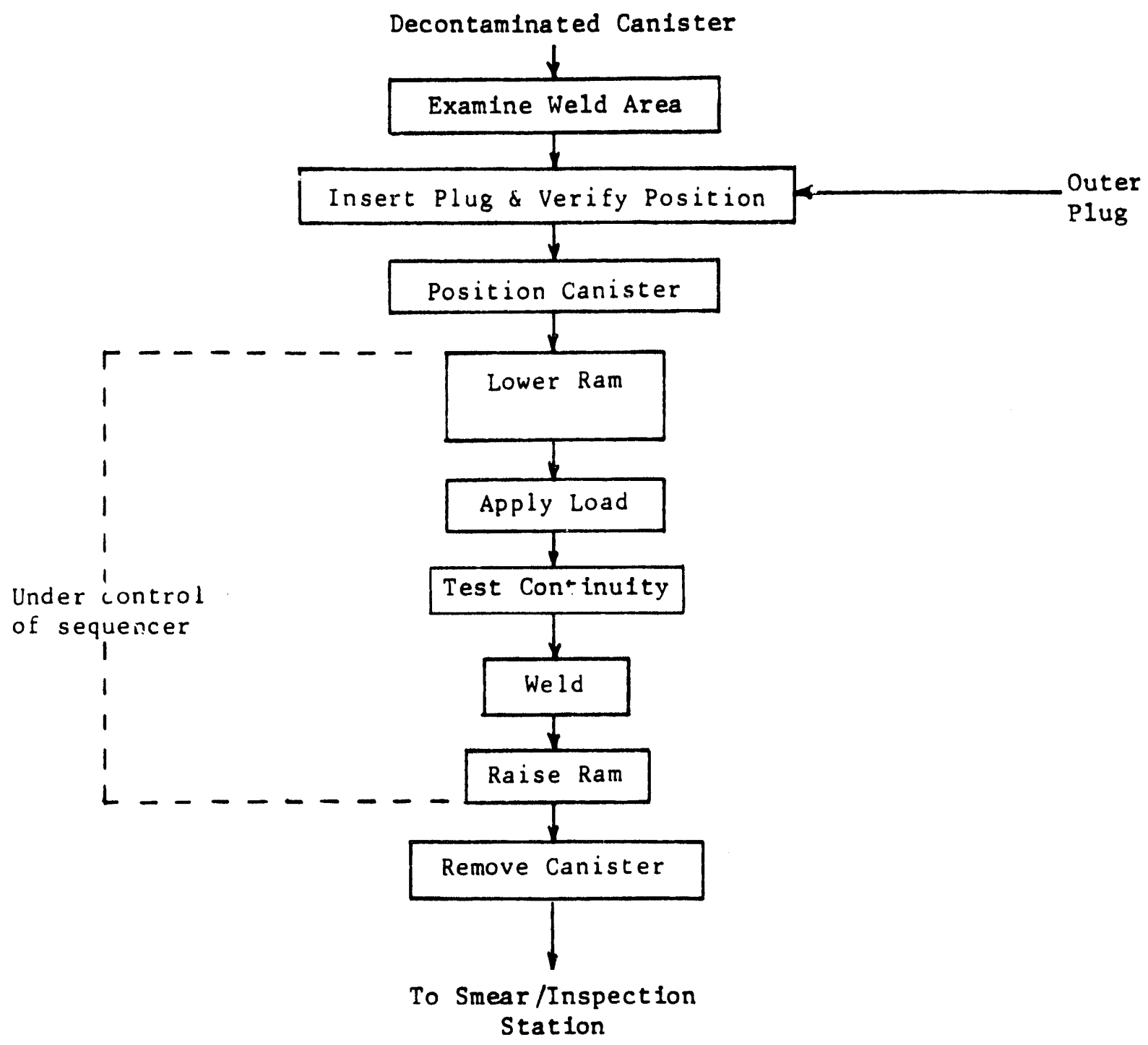

FIGURE 5-7. WELDING PROCESS 
Welded or Overpacked Canister

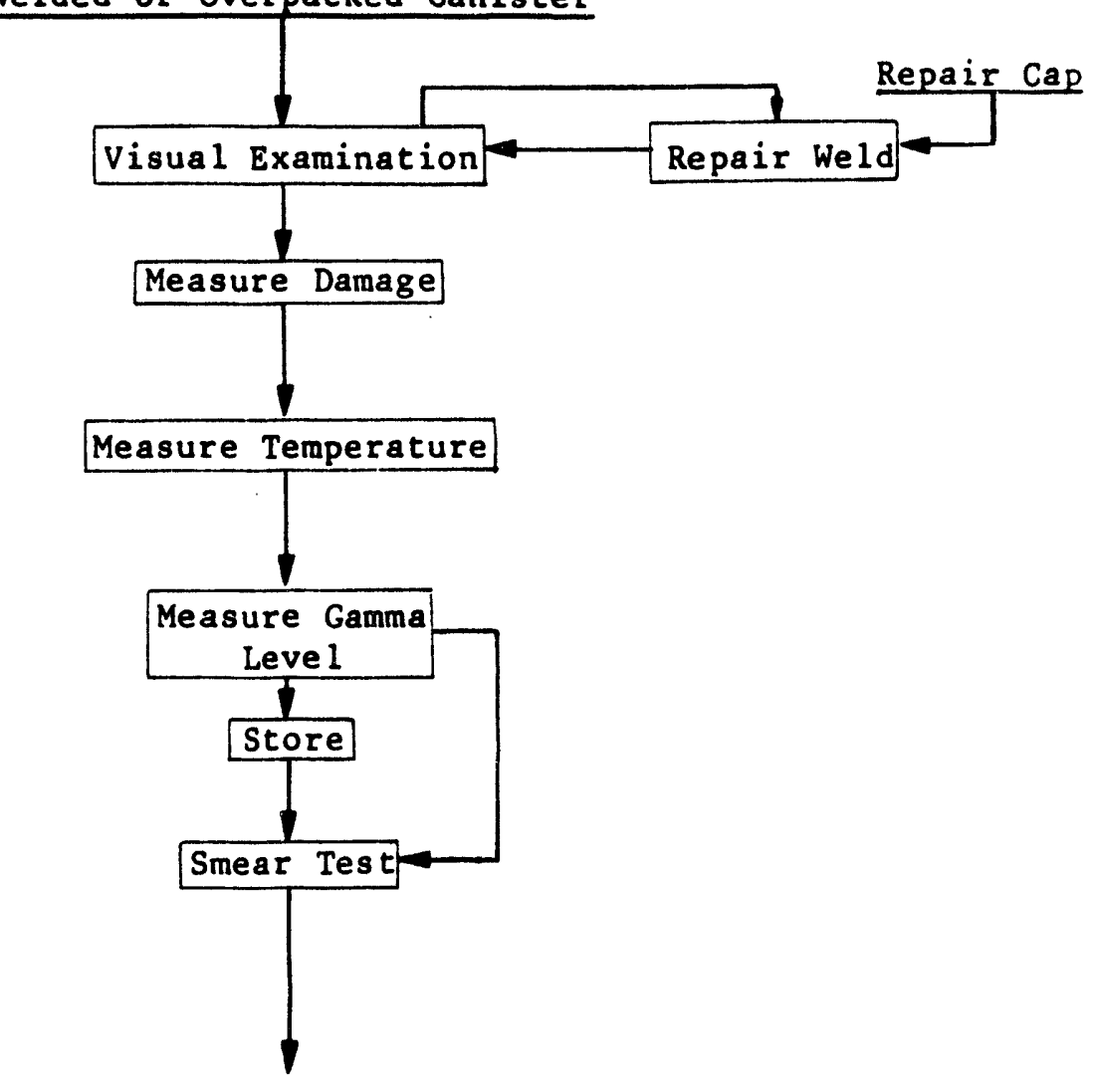

To Interim Storage Building

Note: Sequence may vary; however, smear must be last operation just before canister leaves WTC. Gamma measurement may be made outside WTC.

FIGURE 5-8. CANISTER INSPECTION AND FINAL SMEAR TEST 


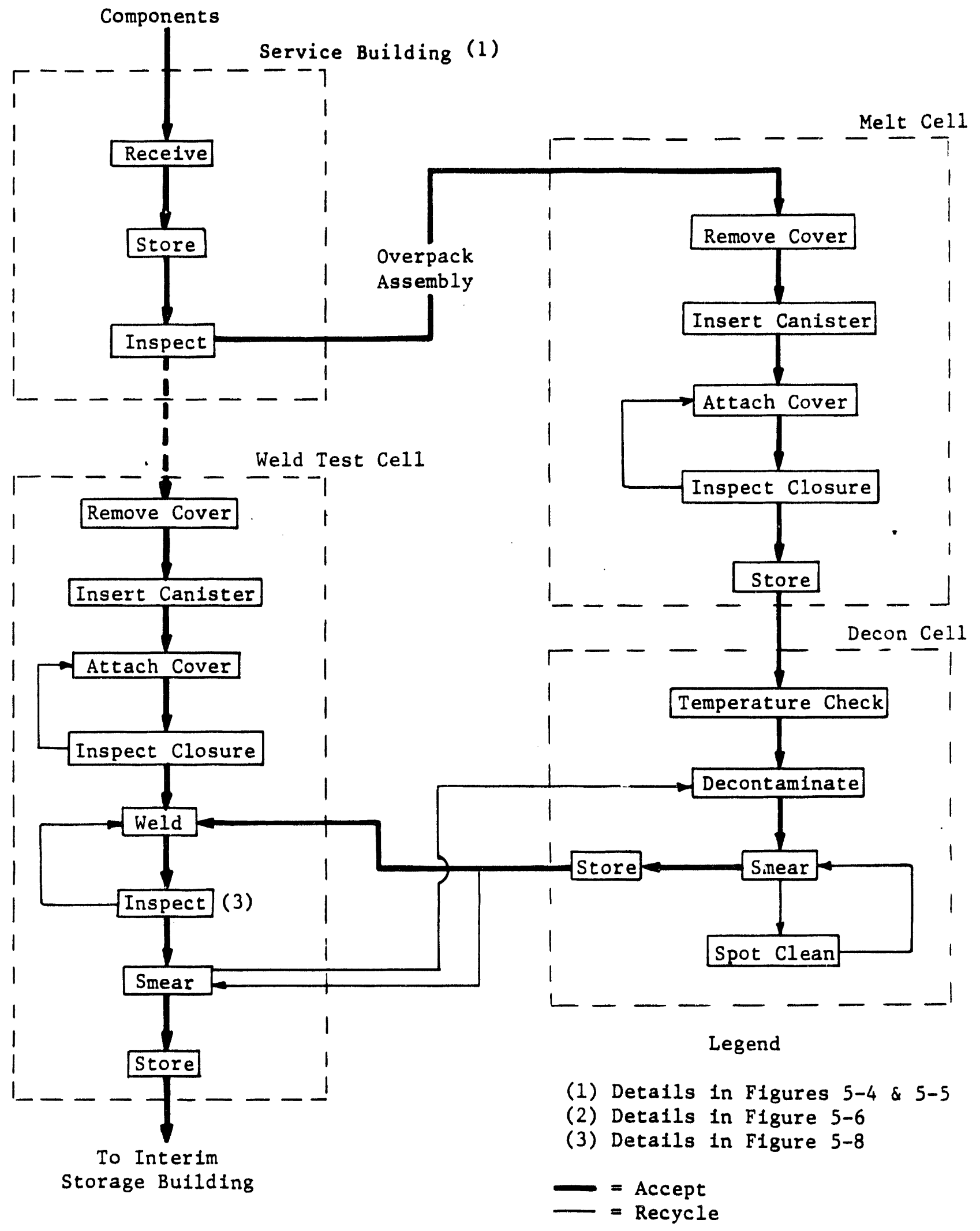

FIGURE 5-9. OVERPACK PROCESS 
33

\begin{tabular}{|l|}
\hline 33 \\
\hline 32 \\
\hline 31 \\
\hline 30 \\
\hline
\end{tabular}

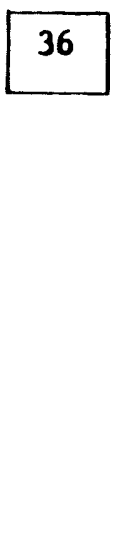

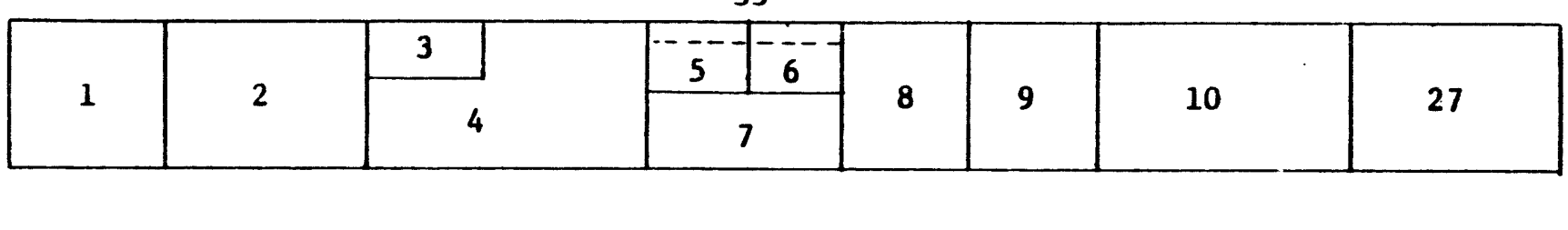

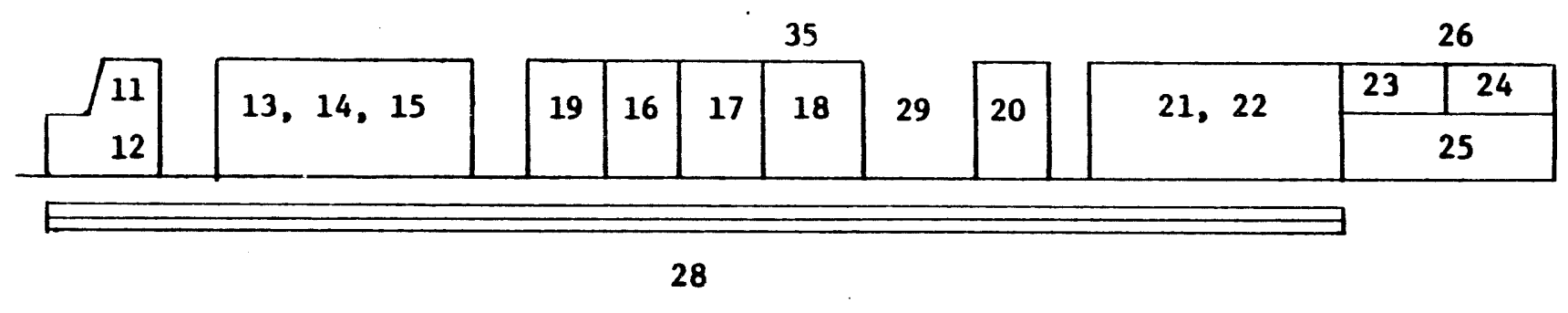

37

29

Legend: See cafeteria equipment list for identification of equipment.

FIGURE II.I. PROPOSED SERVING LINE S.AREA CAFETERIA

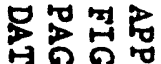

因界写罗

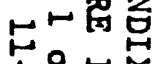

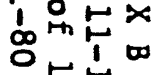






FIGURE 13-1. WATER SYSTEM 


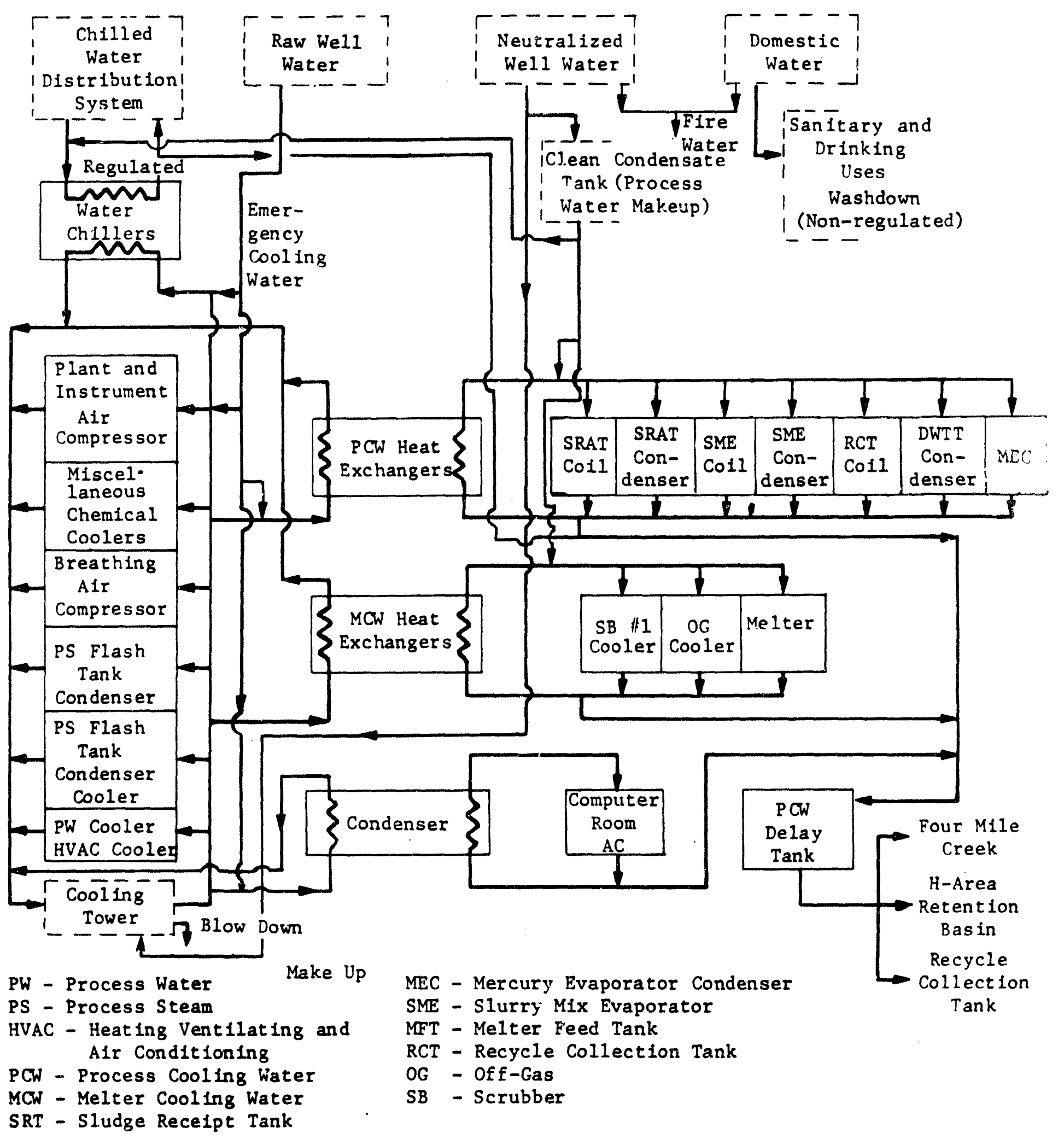

FIGURE 13-2. WATER UTILITY DISTRIBUTION AND MAKEUP SYSTEMS 
[NOTE: The first pass is to be made without filler materlal. The second and third passes shall be made with the addition of filler material. The second pass shall not burn through the first, and the third not through the second. These passes shall result in covering the end of the tube with $1 / 4^{\prime \prime}$ minimum thickness of weld metal. Welding shall be done with an inert gas shield process.]

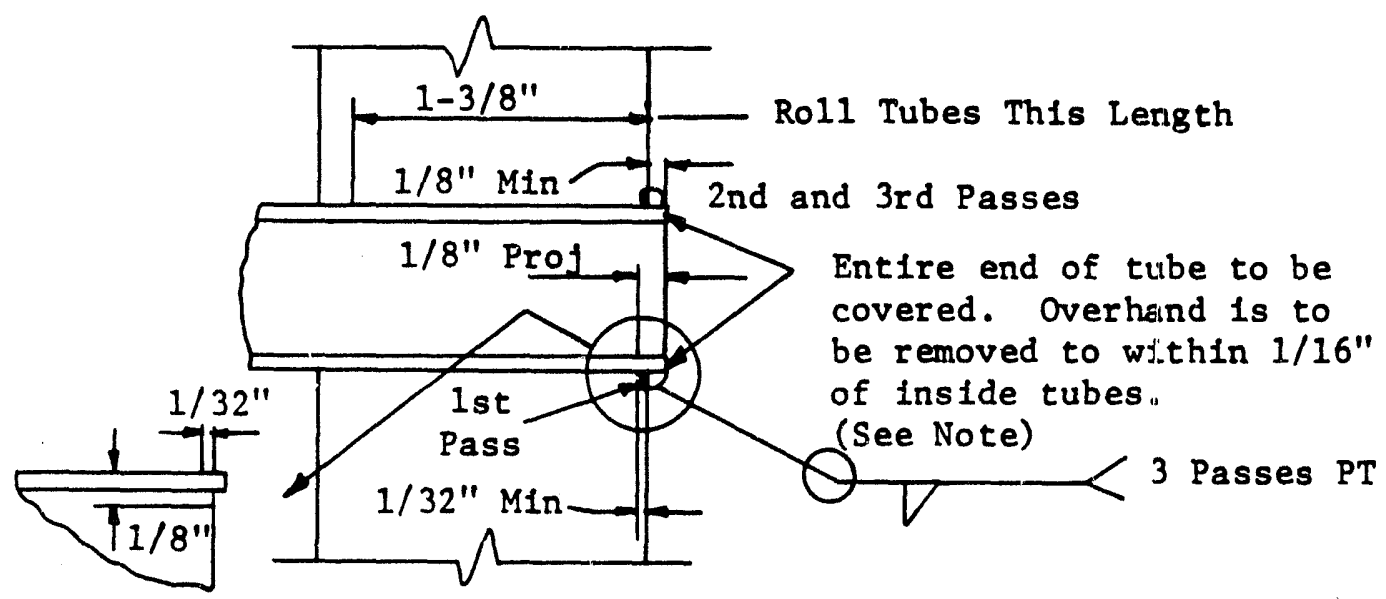

Det TS Bevel Detail Tube Attachment

(Typ Both Ends)

FIGURE 20-1. PROCEDURE FOR WELDING TUBES TO TUBE SHEETS IN HEAT EXCHANGERS 


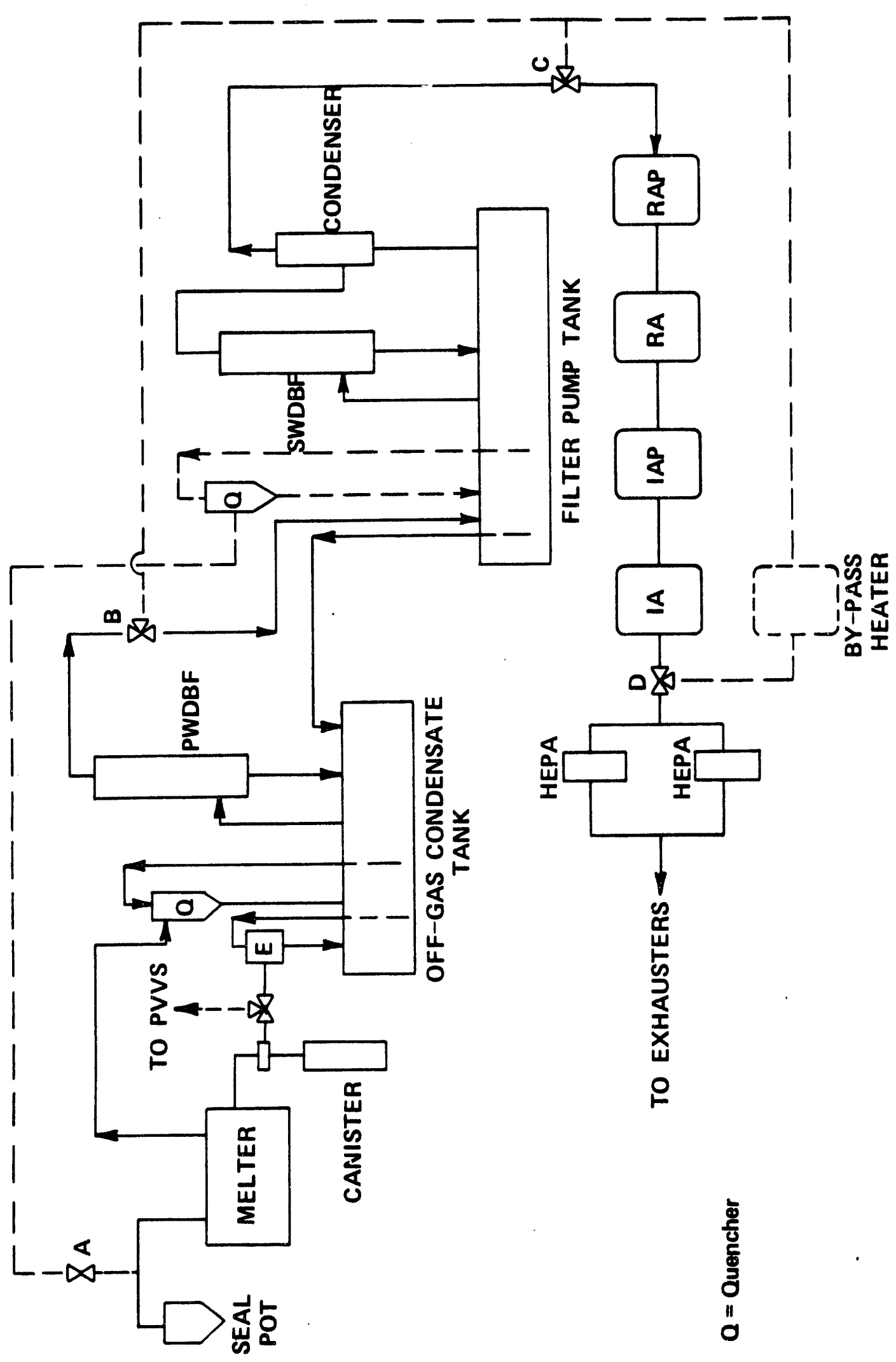


DU PONT AND DOE REFERENCES

1. DOE-EIS-0023, Final Environmental Impact Statement, Long-Term Management of Defense High-Level Radioactive Waste (Research and Development Report for Immobilization). Savannah River Plant, Aiken, SC, November, 1979.

2. Final Environmental Statement, Waste Management Operations, Savannah River Plant, Aiken, SC, ERDA 1537, 1977. Energy Research and Development Administration.

3. Langley, T. M., and W. L. Marter, The S ivannah River Plant Site. USAEC Report DP-1323, 1973. E. I. du Pont de lemours \& Co., Savannah River Laboratory, Aiken, SC 29801.

4. DOE Manual, Appendix 2401.

5. **Technical Data Summary for the Defens ' Waste Processing Facility, DPSTD-80-38-2.**

6. Preliminary Technical Data Sumnary No. for the Defense Waste Processing Facility, DPSTD-77-13-3, May 1980.

7. Deleted

8. Deleted

9. Deleted

10. DOE Order 5480.1, "Environmental Protec ion, Safety, and Health Protection Program for DOE Operations."

11. DOE Order 6430, "General Design Criteri. Manual."

12. Deleted

13. ERDA 76-21, Nuclear Air Cleaning Handbor.k.

14. Deleted

15. Deleted

16. Deleted

17. **Preliminary Safety Analysis, Defense laste Processing Facility, DPST-82-675.**

18. Recommended Stack Height for DWPF-Stage 1 Design, DPST-80-647, November 3 , 1980. 


\section{MISCELLANEOUS TECHNICAL REFERENCES}

1. G. A. Brigss, Estimation of Downwash Effects, chapter 6, Power Generation: Air Pollution Monitoring and Control. Edited by K. E. Null and W. T. Davis, Ann Arbor Science Publishers, Ann Arbor, Michi.gan, 1976.

2. G. Nonhebel, Process for Air Pollution Control, p 632. CRC Press, 1972. 
PAGE 1

- DATE 6-80

NATIONAL CODES AND STANDARDS REFERENCES

1. ANSI N.300 American National Standard for Decommissioning at Nuclear Fuel Reprocessing Plants. 


\section{FEDERAL AND STATE REGULATORY REFERENCES}

1. NUREG-0278, Technology, Safety and Costs of Decommissioning a Reference Nuclear Fuel Reprocessing Plant. Battele Pacific Northwest Laboratory, October 1977 .

2. NRC Regulatory Guide 3.30, Selection, Application and Inspection of Protective Coatings (Paints) to Fuel Reprocessing Plants. 
**DWPF SLUDGE FEED COMPOSITION (DRY BASIS)**

Soluble Solids

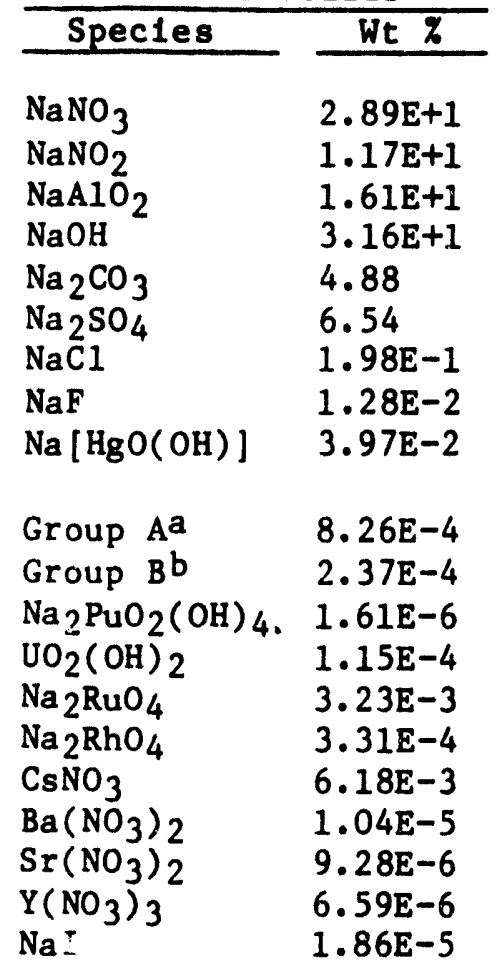

Insolukle Solids

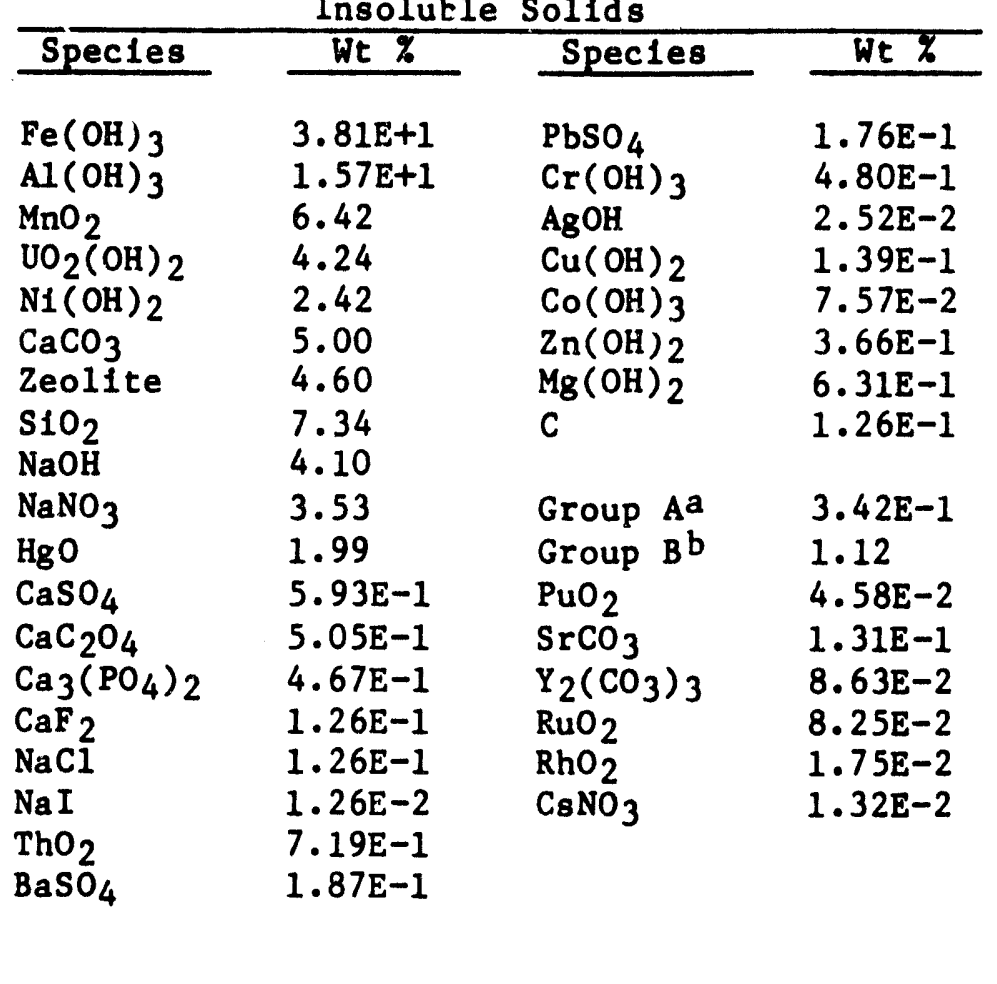

a $T c$, Se, $T e, R b$, Mo

b Ag, Cd, Cr, Pd, Th, La, Ce, Pr, Pm, Nd, Sm, Tb, Sn, Sb, Co, Zr, Nb, Eu, Np, Am, Cm 
*

Ion Exchange Eluate

Spec1e8

$\mathrm{H}_{2} \mathrm{O}$

$\mathrm{NaCOOH}$

$\mathrm{HCOOH}$

4. 058E+1

4.487

$5.493 \mathrm{E}+1$
Waste F1lter Media

Spec1es

$\mathrm{H}_{2} \mathrm{O} \quad 8.369 \mathrm{E}+1$

$\mathrm{NaOH} \quad 3.315$

C. 2.365

$\mathrm{SiO}_{2} \quad 1.063 \mathrm{E}+1$

a 8.66E-2 1b NaCOOH in eluite per $1 \mathrm{~b}$ Insoluble solids in Stagt: 1 feed.

**NOTE: This table is based on the Ion Excliange Process for the Salt Plant. It has been retalned for materlal alance purposes only. ${ }^{*}$ 


\section{SLURRY PROPERTIES}

\begin{tabular}{|c|c|c|c|c|c|c|}
\hline & \multicolumn{2}{|c|}{ Washeda } & \multirow{2}{*}{\multicolumn{2}{|c|}{$\begin{array}{l}\text { SRATb } \\
\text { Slurry }\end{array}$}} & \multirow{2}{*}{\multicolumn{2}{|c|}{$\begin{array}{l}\text { Melterc, e } \\
\text { Feed Slurry }\end{array}$}} \\
\hline & \multirow{2}{*}{$\begin{array}{c}\text { Sludge } \\
\text { Max } \\
\end{array}$} & \multirow{2}{*}{$\begin{array}{c}\text { Slurry } \\
\text { Min } \\
\end{array}$} & & & & \\
\hline & & & Max & M1n & Max & Min \\
\hline Y1eld Stress, dynes $/ \mathrm{cm}^{2}$ & 100 & 25 & 50 & 15 & 150 & 25 \\
\hline Consistency, $C_{p}$ & 12 & 4 & 12 & 5 & 40 & 10 \\
\hline Density, $g / c c$ & 1.17 & 1.09 & 1.23 & 1.21 & 1.45 & 1.33 \\
\hline Transfer Velocity, ft/sec & 5 & 3 & 5 & 3 & 5 & $3 d$ \\
\hline Solids content, weight \% & 19 & 13 & 25 & 21 & 50 & 40 \\
\hline
\end{tabular}

${ }^{a}$ Aluminum dissolved and washed

bormic acid added

${ }^{c}$ Formic acid and frit added

dExcept for feed dropline to melter where tubing or plpe 18 to have a 0.30 " minimum inside diameter

eproperties of 250 dynes $/ \mathrm{cm}^{2}$ and $60 \mathrm{cp}$ should be expected and agitation to dilute must be provided.

Pumps in all 3 services must be capable of pumping water to flush systems.

The data presented in this table are a mixture of experimental and theoretical values. Research is st1ll active to determine properties of slurries, and more definite data w1ll be supplied as it becomes avallable.

If slurries are encountered with higher solids contents than shown in the table, they may be diluted to the value desired. 
DPSP $80-1033$

APPENDIX $\mathrm{H}$

TABLE 21-4

PAGE 1 of 4

DATE $1-82 ; \operatorname{ReV} 8$

STOICH IOME TRY

Each reaction goes to completion unless otherwise noted.

A. Mercury Reduction (In Slurry Receipt Ad justment Tank)

Reactant 8

$2 \mathrm{NaNO}+3 \mathrm{HCOOH}$
$\mathrm{Na} 2 \mathrm{CO}_{3}+2 \mathrm{HCOOH}$
$\mathrm{MnO}_{2}+3 \mathrm{HCOOH}$
$\mathrm{Ni}(\mathrm{OH})_{2}+2 \mathrm{HCOOH}$
$\mathrm{UO}_{2}(\mathrm{OH})_{2}+2 \mathrm{HCOOH}$
$\mathrm{CaCO}_{3}+2 \mathrm{HCOOH}$
$\mathrm{Mn}(\mathrm{OH})_{2}+2 \mathrm{HCOOH}$
$\mathrm{HgO}+\mathrm{HCOOH}$
$\mathrm{NaOH}+\mathrm{HCOOH}$
$2 \mathrm{AgOH}+\mathrm{HCOOH}$
$2 \mathrm{Cu}(\mathrm{OH})_{2}+2 \mathrm{HCOOH}$
$2 \mathrm{CO}(\mathrm{OH})_{3}+5 \mathrm{HCOOH}$
$\mathrm{Zn}(\mathrm{OH})_{2}+2 \mathrm{HCOOH}$
$\mathrm{Mg}(\mathrm{OH})_{2}+2 \mathrm{HCOOH}$
$\mathrm{SrCO}$
$\mathrm{Y}(\mathrm{CO}$
$\mathrm{Y}$
2

Products

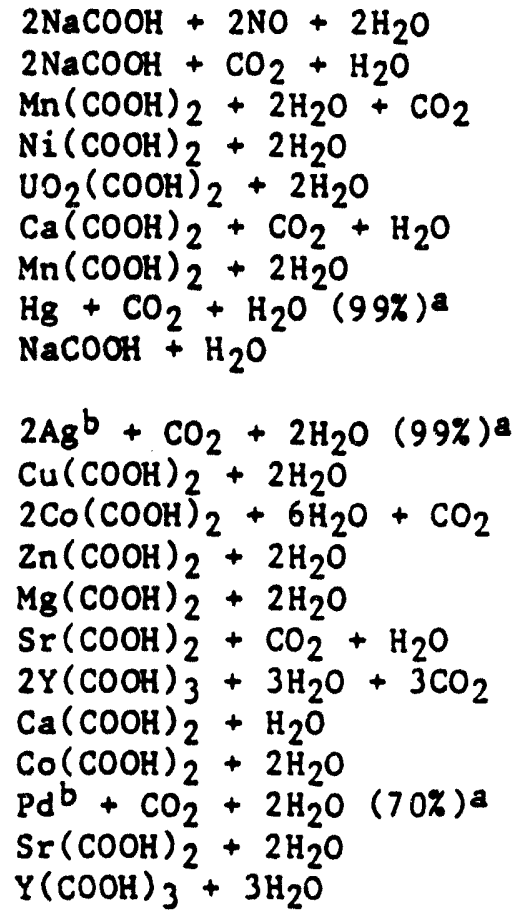

a The remaining $\mathrm{HgO}, \mathrm{AgOH}$, and $\mathrm{Pd}(\mathrm{OH})_{2}$ are transferred to the SME.

b Amalgamates with mercury. 


\section{B. Vitrification}

Reactants

$4 \mathrm{KNO}_{3}+6 \mathrm{NaCOOH}$
$4 \mathrm{NaNO} 3_{3}+6 \mathrm{NaCOOH}$
$2 \mathrm{Na}_{2} \mathrm{SO}_{4}+2 \mathrm{NaCOOH}$
$4 \mathrm{CaNO} \mathrm{NO}_{3}+6 \mathrm{NaCOOH}$
$2 \mathrm{Ba}\left(\mathrm{NO}_{3}\right)_{2}+6 \mathrm{NaCOOH}$
$2 \mathrm{Sr}\left(\mathrm{NO}_{3}\right)_{2}+6 \mathrm{NaCOOH}$
$4 \mathrm{Y}\left(\mathrm{NO}_{3}\right)_{3}+18 \mathrm{NaCOOH}$
$2 \mathrm{CaSO}+2 \mathrm{NaCOOH}$
$2 \mathrm{BaSO}_{4}+2 \mathrm{NaCOOH}$
$2 \mathrm{PbSO}_{4}+2 \mathrm{NaCOOH}$
$\mathrm{HCOOH}$
$4 \mathrm{Fe}(\mathrm{OH})_{3}+2 \mathrm{NaCOOH}$
$2 \mathrm{Fe}(\mathrm{OH})_{3}$
$2 \mathrm{NaCOOH}$

$\mathrm{Mn}(\mathrm{COOH})_{2}$

$\mathrm{Ni}(\mathrm{COOH})_{2}$

$\mathrm{Ca}(\mathrm{COOH})_{2}$

$\mathrm{UO}_{2}(\mathrm{COOH})_{2}$

$2 \mathrm{C}+\mathrm{O}_{2}$

$2 \mathrm{CuCOOH}$

$\mathrm{Co}(\mathrm{COOH})_{2}$

$\mathrm{Zn}(\mathrm{COOH})_{2}$

$\mathrm{Mg}(\mathrm{COOH})_{2}$

$\mathrm{Sr}(\mathrm{COOH})_{2}$

$2 \mathrm{Y}(\mathrm{COOH})_{3}$

$\mathrm{CaC}_{2} \mathrm{O}_{4}$

$2 \mathrm{NaAlO}_{2}$

$\mathrm{NaCl}$

$\mathrm{NaF}$

$2 \mathrm{Na}[\mathrm{HgO}(\mathrm{OH})]$

$2 \mathrm{Na}_{2} \mathrm{PuO}_{2}(\mathrm{OH})_{4}$

$2 \mathrm{Na}_{2} \mathrm{RuO}_{4}$

$2 \mathrm{Na}_{2} \mathrm{RhO}_{4}$

$\mathrm{NaI}$

$2 \mathrm{Al}(\mathrm{OH})_{3}$

$\mathrm{Hg}$

$\mathrm{CaF}_{2}+\mathrm{Na}_{2} \mathrm{O}$

$2 \mathrm{Cr}(\mathrm{OH})_{3}$

$2 \mathrm{CsCOOH}$

$\mathrm{Pu}(\mathrm{COOH})_{4}$

$2 \mathrm{Pd}+\mathrm{O}_{2}$

$\mathrm{H}_{2} \mathrm{O}+\mathrm{CO}$

$\mathrm{Pd}(\mathrm{OH})_{2}$

$2 \mathrm{AgOH}$

$\mathrm{Na}_{2} \mathrm{C}_{2} \mathrm{O}_{4}$
STOICH IOME TRY

PAGE 2 Of 4

DATE 1-82; Rev $s$
Products

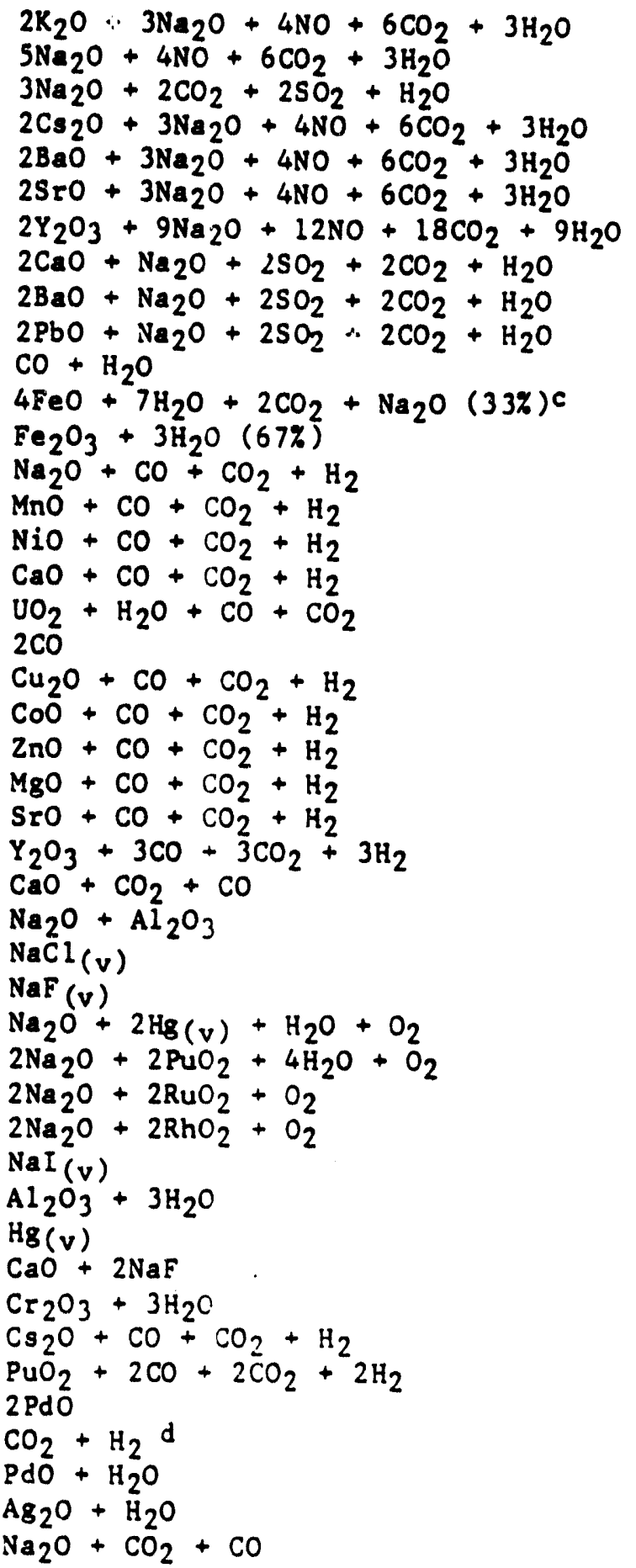

cMaximum percentage of $\mathrm{Fe}(\mathrm{OH})_{3}$ to be reduced. If insufficient $\mathrm{NaCOOH}$ available, the unreduced $\mathrm{Fe}(\mathrm{OH})_{3}$ is decomposed to $\mathrm{Fe}_{2} \mathrm{O}_{3}$ and $\mathrm{H}_{2} \mathrm{O}$.

dsee DPSTD-80-38-2, Part 6, Item 610 for equilibrium constants. 


\section{STO:CH IOME TRY}

B. Vitrification (Contd)

Reactants
$\mathrm{Cs}_{2} \mathrm{O}$
$\mathrm{B}_{2} \mathrm{O}_{3}+\mathrm{Na}_{2} \mathrm{O}$
$\mathrm{GrOup} \mathrm{A}^{\mathrm{RuO}_{2}+\mathrm{O}_{2}}$
$4 \mathrm{Ag}_{2}+\mathrm{O}_{2}$
$2 \mathrm{HgO}$
$\mathrm{CsCl}$

\begin{tabular}{|c|}
\hline Products \\
\hline $\begin{array}{l}\mathrm{Cs}_{2} \mathrm{O}(\mathrm{v}) \quad(5 \%) \\
2 \mathrm{NaBO}_{2}(0.5 \%) \\
\text { Group A }(5.0 \%)\end{array}$ \\
\hline $\begin{array}{l}\mathrm{RuO}_{4}(\mathrm{v})(10 \%) \\
2 \mathrm{Ag}_{2} \mathrm{O} \\
2 \mathrm{Hg}(\mathrm{v})+\mathrm{O}_{2} \\
\mathrm{CsCl}_{(\mathrm{v})}\end{array}$ \\
\hline
\end{tabular}

Unreacted Melter Feed Components

\begin{tabular}{|c|c|c|c|}
\hline $\begin{array}{l}\mathrm{SiO}_{2} \text { f } \\
\mathrm{Group} \mathrm{Be}^{\mathrm{e}} \\
\text { Zeolite }\end{array}$ & $\begin{array}{l}\mathrm{Ca}_{3}\left(\mathrm{PO}_{4}\right)_{2} \mathrm{e} \\
\mathrm{ThO}_{2} \mathrm{e}^{-} \\
\mathrm{PuO}_{2} \mathrm{e}\end{array}$ & $\begin{array}{l}\mathrm{ZrO}_{2}{ }^{8} \\
\mathrm{La}_{2} \mathrm{O}_{3} \mathrm{~g}^{\mathrm{B}} \\
\mathrm{TiO}_{2} \mathrm{~S}^{8}\end{array}$ & $\begin{array}{l}\mathrm{MgOF}^{\mathrm{F}} \\
\mathrm{Li}_{2} \mathrm{O}\end{array}$ \\
\hline $\begin{array}{l}\text { Source } \\
\text { f Source } \\
8 \text { Source }\end{array}$ & d and Frit & & \\
\hline
\end{tabular}

C. Off-Gas Treatment

\begin{tabular}{|c|c|}
\hline Reactants & Products \\
\hline $4 \mathrm{NaI}+\mathrm{O}_{2}$ & $2 \mathrm{I}_{2}+2 \mathrm{Na}_{2} \mathrm{O}(1 \%)$ \\
\hline $\begin{array}{l}2 \mathrm{Hg}+\mathrm{O}_{2} \\
2 \mathrm{NaF}+\mathrm{H}_{2} \mathrm{O}\end{array}$ & $\begin{array}{l}2 \mathrm{HgO} \\
2 \mathrm{HF}+\mathrm{Na}_{2} \mathrm{O}(25 \%)\end{array}$ \\
\hline $\begin{array}{l}\mathrm{Cs}_{2} \mathrm{O}+2 \mathrm{NaCl} \\
4 \mathrm{NaBO}_{2}\end{array}$ & $\begin{array}{l}2 \mathrm{CsCl}+\mathrm{Na}_{2} \mathrm{O} \\
\mathrm{Na}_{2} \mathrm{~B}_{4} \mathrm{O}_{7}+\mathrm{Na}_{2} \mathrm{O}\end{array}$ \\
\hline $\begin{array}{l}\mathrm{RuO}_{4} \\
2 \mathrm{NO}^{2} \mathrm{O}_{2}\end{array}$ & $\begin{array}{l}\mathrm{RuO}_{2}+\mathrm{O}_{2} \\
2 \mathrm{NO} \quad(10 \%)\end{array}$ \\
\hline
\end{tabular}

D. Quenching

$\begin{array}{ll}\text { Reactants } & \text { Products } \\ \mathrm{HF}+\mathrm{Na}_{2} \mathrm{O} & \mathrm{H}_{2} \mathrm{O}+2 \mathrm{NaF}\end{array}$




\section{STOICH IOME TRY}

E. Process Waste Treatment

\section{Oxalic Acid Destruction}

Reactants

$2 \mathrm{KMNO}_{4}+6 \mathrm{HNO}_{3}+5 \mathrm{H}_{2} \mathrm{C}_{2} \mathrm{O}_{4}$

$3 \mathrm{H}_{2} \mathrm{C}_{2} \mathrm{O}_{4}+2 \mathrm{HNO}_{3}$

$$
\begin{gathered}
\text { Products } \\
2 \mathrm{Mn}\left(\mathrm{NO}_{3}\right)_{2}+10 \mathrm{CO}_{2}+8 \mathrm{H}_{2} \mathrm{O}+2 \mathrm{KNO}_{3} \\
6 \mathrm{CO}_{2}+2 \mathrm{NO}+4 \mathrm{H}_{2} \mathrm{O}(99 \%)
\end{gathered}
$$

Caustic Ad justment

Reactants

$\mathrm{HNO}_{3}+\mathrm{NaOH}$

$\mathrm{Mn}\left(\mathrm{NO}_{3}\right)_{2}+2 \mathrm{NaOH}$

$\mathrm{H}_{2} \mathrm{C}_{2} \mathrm{O}_{4}+2 \mathrm{NaOH}$

\author{
Products \\ $\mathrm{NaNO}_{3}+\mathrm{H}_{2} \mathrm{O}$ \\ $\mathrm{Mn}(\mathrm{OH})_{2}+2 \mathrm{NaNO}_{3}$ \\ $\mathrm{Na}_{2} \mathrm{C}_{2} \mathrm{O}_{4}+2 \mathrm{H}_{2} \mathrm{O}$
}

F. Recycle Collection

Stoichiometry (components not 1 isted are unreacted)

Reactants

$\mathrm{HCOOH}+\mathrm{NaOH}$

$\mathrm{Mn}(\mathrm{COOH})_{2}+2 \mathrm{NaOH}$

$\mathrm{Ni}(\mathrm{COOH})_{2}+2 \mathrm{NaOH}$

$\mathrm{UO}_{2}(\mathrm{COOH})_{2}+2 \mathrm{NaOH}$

$\mathrm{Ca}(\mathrm{COOH})_{2}+2 \mathrm{NaOH}$

$\mathrm{Cu}(\mathrm{COOH})_{2}+2 \mathrm{NaOH}$

$\mathrm{Co}(\mathrm{COOH})_{2}+2 \mathrm{NaOH}$

$\mathrm{Zn}(\mathrm{COOH})_{2}+2 \mathrm{NaOH}$

$\mathrm{Mg}(\mathrm{COOH})_{2}+2 \mathrm{NaOH}$

$\mathrm{Sr}(\mathrm{COOH}) 2+2 \mathrm{NaOH}$

$\mathrm{Y}(\mathrm{COOH})_{3}+3 \mathrm{NaOH}$

$\mathrm{Pu}(\mathrm{COOH})_{4}+4 \mathrm{NaOH}$
Products

$\mathrm{NaCOOH}+\mathrm{H}_{2} \mathrm{O}$

$\mathrm{Mn}(\mathrm{OH})_{2}+2 \mathrm{NaCOOH}$

$\mathrm{Ni}(\mathrm{OH})_{2}+2 \mathrm{NaCOOH}$

$\mathrm{UO}_{2}(\mathrm{OH})_{2}+2 \mathrm{NaCOOH}$

$\mathrm{Ca}(\mathrm{OH})_{2}+2 \mathrm{NaCOOH}$

$\mathrm{Cu}(\mathrm{OH})_{2}+2 \mathrm{NaCOOH}$

$\mathrm{Co}(\mathrm{OH})_{2}+2 \mathrm{NaCOOH}$

$2 \mathrm{n}(\mathrm{OH})_{2}+2 \mathrm{NaCOOH}$

$\mathrm{Mg}(\mathrm{OH})_{2}+2 \mathrm{NaCOOH}$

$\mathrm{Sr}(\mathrm{OH})_{2}+2 \mathrm{NaCOOH}$

$\mathrm{Y}(\mathrm{OH})_{3}+3 \mathrm{NaCOOH}$

$\mathrm{PuO}_{2}+4 \mathrm{NaCOOH}+2 \mathrm{H}_{2} \mathrm{O}$

G. Mercury Purification

\footnotetext{
Reactants

$\mathrm{Hg}+4 \mathrm{HNO}_{3}$

$\mathrm{Pd}+4 \mathrm{HNO}_{3}$

$\mathrm{Ag}+2 \mathrm{HNO}_{3}$

$2 \mathrm{HNO}_{3}+\mathrm{HCOOH}$
}

\section{Produats}

$$
\begin{aligned}
& \mathrm{Hg}\left(\mathrm{NO}_{3}\right)_{2}+2 \mathrm{H}_{2} \mathrm{O}+2 \mathrm{NO}_{2} \\
& \mathrm{Pd}\left(\mathrm{NO}_{3}\right)_{2}+2 \mathrm{H}_{2} \mathrm{O}+2 \mathrm{NO}_{2} \\
& \mathrm{AgNO}+\mathrm{H}_{2} \mathrm{O}+\mathrm{NO}_{2} \\
& 2 \mathrm{H}_{2} \mathrm{O}+\mathrm{CC}_{2}+2 \mathrm{NO}_{2}
\end{aligned}
$$

Spent Wash Neutralization

Reactants

$\mathrm{HNO}_{3}+\mathrm{NaOH}$

$\mathrm{Hg}\left(\mathrm{NO}_{3}\right)_{2}+2 \mathrm{NaOH}$

$\mathrm{AgNO}_{3}+\mathrm{NaOH}$

$\mathrm{Pd}\left(\mathrm{NO}_{3}\right)_{2}+2 \mathrm{NaOH}$
Products

$\mathrm{NaNO}+\mathrm{H}_{2} \mathrm{O}$

$\mathrm{HoO}+2 \mathrm{NaNO}_{3}+\mathrm{H}_{2} \mathrm{O}$

$\mathrm{AgOH}+\mathrm{NaNO}_{3}$

$\mathrm{PC}(\mathrm{OH})_{2}+2 \mathrm{NaNO}_{3}$ 


\section{PHYSICAL PROPERTY DATA}

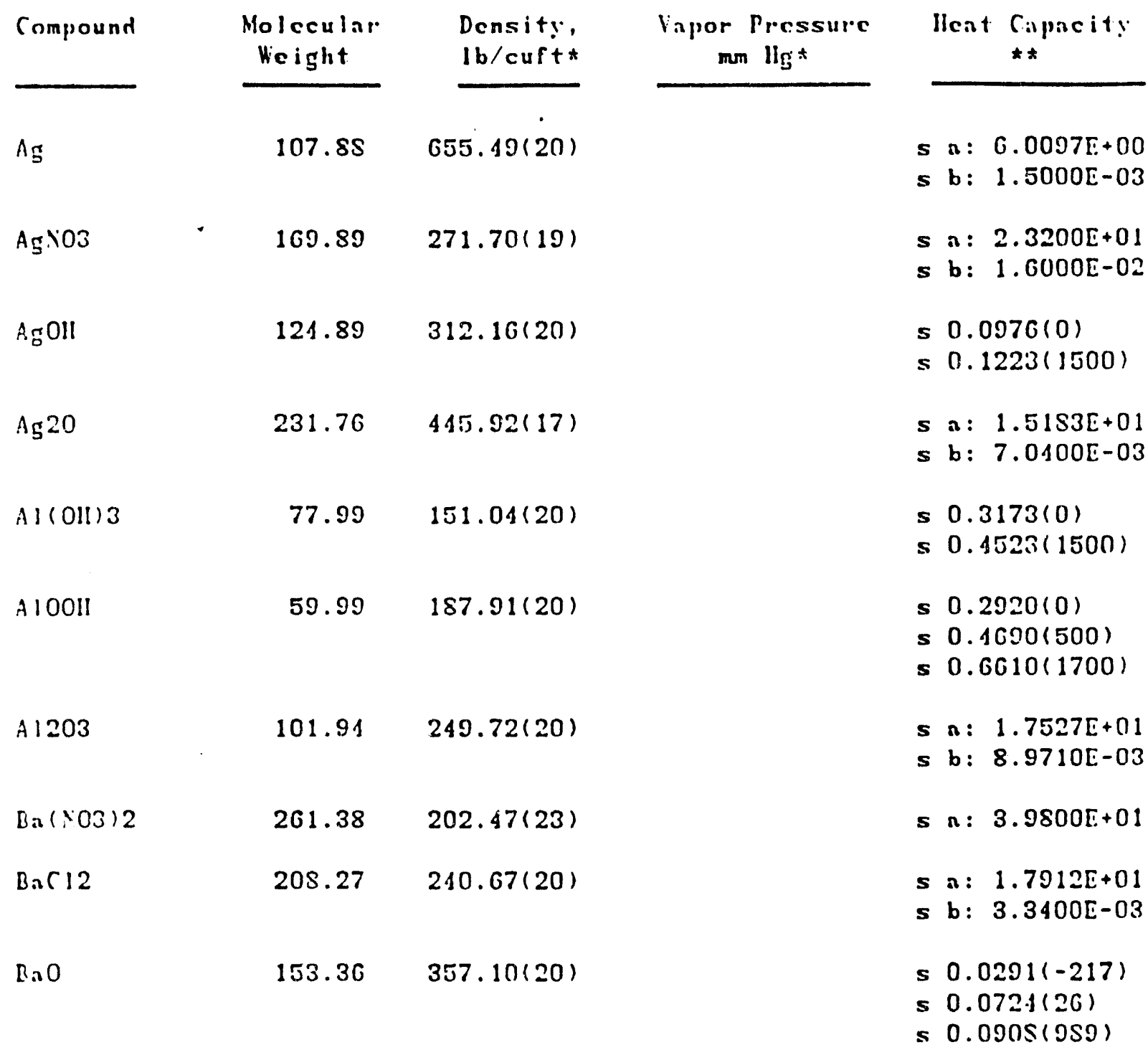

* - Temperitures in degrees (shown in parcutheses

* - lloal capacity data provided in two formits: for data followed by a parentlicsis, heat capacity is giver in PCl' M-degrec-c at temperature in parentlicsis: for data preceded by "a", "b", or. "c", hent capacity in P(l: lb-nule-degrec-s is ieternined by the relationship" "lll $(a p=a+b t+e t t "$, "here $t$ is in degrecs 6 and the non-zero constants "a", "b", nnd "c" are listed 


\section{PHYSICAL PROPERTY DATA}

\begin{tabular}{|c|c|c|c|c|}
\hline Compound & $\begin{array}{l}\text { Molecular } \\
\text { Height }\end{array}$ & $\begin{array}{l}\text { Density, } \\
\text { llo/cuft* }\end{array}$ & $\begin{array}{c}\text { Vappor Pressure } \\
\text { mm } l_{\mathfrak{g}} *\end{array}$ & lleat Capacity $_{* *}$ \\
\hline B. SO.4 & 233.12 & $280.87(15)$ & & $\begin{array}{l}s \text { a: } 2.5201 \mathrm{ti}+01 \\
s \text { b: } 1.4100 \mathrm{0}-02\end{array}$ \\
\hline B203 & 69.64 & $115.49(20)$ & & $\begin{array}{l}\text { s a: } 1.35 s 1 E+01 \\
\text { s b: } 3.2000 E-02\end{array}$ \\
\hline C:I $($ cooll $) 2$ & 130.12 & $125.70(20)$ & & $\begin{array}{l}\text { s } 0.2137(0) \\
\text { s } 0.3729(1500)\end{array}$ \\
\hline $\mathrm{Ca}(\mathrm{OII}) 2$ & 74.10 & $137.35(20)$ & & s a: $2.1400 E+01$ \\
\hline Carbon & 12.01 & $141.09(20)$ & & $\begin{array}{l}s \text { a: } 1.8210 \mathrm{~L}+00 \\
s \text { b: } 2.6170 \mathrm{E}-03\end{array}$ \\
\hline $\mathrm{CaCO}$ & 100.09 & $182.87(20)$ & & $\begin{array}{ll}\text { s } n: 1.8505 E+01 \\
\text { s b: } 1.1590[-02\end{array}$ \\
\hline CaC201 & 128.10 & $137.31(4)$ & & $\begin{array}{l}\text { s } 0.1636(0) \\
s 0.3159(1500)\end{array}$ \\
\hline$C: \sqrt{2}$ & 78.08 & $198.48(20)$ & & $\begin{array}{l}\text { s } n: 1.573 S E+01 \\
\text { s b: } 3.8000 E-03\end{array}$ \\
\hline $\mathrm{C} n \mathrm{O}$ & 56.08 & $207.21(20)$ & & $\begin{array}{l}\text { s a: } 9.8715 E+00 \\
\text { s b: } 4.8 \cdot 100 E-03\end{array}$ \\
\hline $\mathrm{CaSO}$ & 136.14 & $184.75(20)$ & & $\begin{array}{l}\text { s a: } 2.2420 E+01 \\
\text { s b: } 2.1970 E-02\end{array}$ \\
\hline $\cos 3(p)+1) 2$ & 310.20 & $195.98(20)$ & & $\begin{array}{l}\text { s } 0.1690(0) \\
\text { s } 0.3265(1500)\end{array}$ \\
\hline
\end{tabular}

* - Temperintures in degroes $r$ shown in parentheses

* - Heat capacity data provided in two formats: for data followed by a parenthesis, hent capircity is given in PCli, lb-degree-c at temperature in parenthesis; for data preceded by "a", "b", or "c", hent capacity in PClilb-nole-degrec-s is determined by the relationship "llt (ap = a + bt + ctt", where t is in degrees ( and the non-zero constants "a", "b", and "c" are listed 
PHYSICAL PROPERTY DATA

\begin{tabular}{|c|c|c|c|c|}
\hline Compound & $\begin{array}{l}\text { Molecular } \\
\text { Height }\end{array}$ & $\begin{array}{l}\text { Density, } \\
\text { lb/cuftt }\end{array}$ & $\begin{array}{c}\text { lapor Pressure } \\
\text { mm } \|_{p} * *\end{array}$ & llent Capicity \\
\hline Coment & 70.00 & $190.00(20)$ & & $\begin{array}{l}\text { s } 0.1860(0) \\
\text { s } 0.1860(100)\end{array}$ \\
\hline $\mathrm{Co}(\mathrm{coOH}) 2$ & $14 \delta .98$ & $132.91(22)$ & & $\begin{array}{l}s 0.1816(0) \\
s 0.3317(1500)\end{array}$ \\
\hline $\mathrm{Co}(\mathrm{Oll}) 2$ & 92.95 & $221.56(15)$ & & $\begin{array}{l}s 0.1990(0) \\
=0.3127(1500)\end{array}$ \\
\hline $\mathrm{Co}(011) 3$ & 109.90 & $278.43(20)$ & & $\begin{array}{l}s 0.22(53(0) \\
s 0.340 .1(1500)\end{array}$ \\
\hline $\mathrm{CoO}$ & 74.91 & $351.51(20)$ & & $\begin{array}{l}\text { s a: } 1.0101 E+01 \\
\text { s b: } 2.2000 E-03\end{array}$ \\
\hline $\mathrm{Cr}(011) 3$ & 103.03 & $230.90(20)$ & & $\begin{array}{l}\text { s } 0.2368(0) \\
s 0.3359 ! 1500)\end{array}$ \\
\hline Cr203 & 152.02 & $325.1 S(20)$ & & $\begin{array}{l}\text { s } n: 2.7003 E+01 \\
\text { s b: } 4.0000 E-03\end{array}$ \\
\hline Cscil & 168.30 & $248.96(20)$ & & $\begin{array}{l}s \text { n: } 1.251 \cdot 1 E+01 \\
s \text { b: } 3.0900 E-03\end{array}$ \\
\hline C.si'0011 & 177.93 & $187.29(20)$ & & $\begin{array}{l}\text { s } 0.1890(0) \\
=0.2110(1500)\end{array}$ \\
\hline Csios & 19.1 .92 & $230.15(25)$ & & $\begin{array}{l}s 0.1007(0) \\
s 0.1259(1500)\end{array}$ \\
\hline$C \leq: 0$ & $2 S 1.81$ & $265.32(20)$ & & $\begin{array}{l}s a: 1.7975 E+01 \\
s \text { b: } 5.4000 E-03\end{array}$ \\
\hline $\begin{array}{l}\text { * - Tempe } \\
\text { * - Heit } \\
\text { paren } \\
\text { teripe } \\
\text { hent } \\
\text { relat } \\
\text { then }\end{array}$ & $\begin{array}{l}\text { res in degre } \\
\text { city data pl } \\
\text { is, hent rn } \\
\text { re in parcn } \\
\text { city in pri } \\
\text { hip "llt Cnp } \\
\text { cro constant }\end{array}$ & 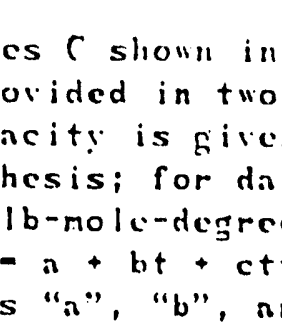 & 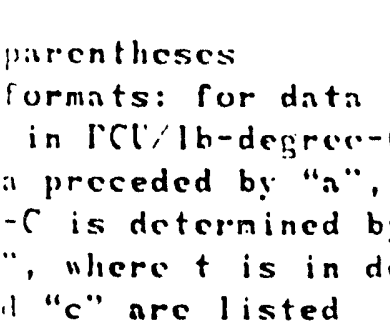 & $\begin{array}{l}\text { followed by" a } \\
\text { c nt } \\
\text { "b"., or "c", } \\
\text { the } \\
\text { degrees } C \text { andl }\end{array}$ \\
\hline
\end{tabular}


PHYSICAL PROPERTY DATA

\begin{tabular}{|c|c|c|c|c|}
\hline Compound & $\begin{array}{l}\text { Molecular } \\
\text { Heiglit }\end{array}$ & $\begin{array}{l}\text { Density, } \\
\text { lusuftt }\end{array}$ & $\begin{array}{c}\text { Vapor Pressure } \\
\text { mm llg* }\end{array}$ & Heat Cipacit! \\
\hline $\mathrm{Cu}(\mathrm{COOH}) 2$ & 153.61 & $114.31(20)$ & & s $0.1079(25)$ \\
\hline $\mathrm{Cu}(011) 2$ & 97.59 & $210.20(20)$ & & $\begin{array}{l}\text { s } 0.150 .1(1)) \\
\text { s } 0.25 .11(15001\end{array}$ \\
\hline $\mathrm{CuO}$ & 70.57 & $399.55(20)$ & & $\begin{array}{l}\text { s a : } 0.5253 E+1 \\
\text { s b: } 3.5760 E-1\end{array}$ \\
\hline co & 28.01 & $50.82(-195)$ & $\begin{array}{r}1.00(-222) \\
760.00(-191) \\
7600(-161)\end{array}$ & $\begin{array}{ll}\because & a: 6.927 S E+() \\
\because & b: 1.20(10 E-1.3 \\
1 & 0.5132(-204) \\
1 & 0.519 S(-190) \\
s & 0.1410(0) \\
\text { s } & 0.20 S 0(1000)\end{array}$ \\
\hline $\mathrm{CO} 2$ & 44.01 & $68.71(-37)$ & $\begin{array}{c}1.00(-134) \\
760.00(-78) \\
7600(-10)\end{array}$ & $\begin{array}{ll}v & a: 8.4652 E+(0) \\
v & b: 2.7100 E-0: 3 \\
1 & 0.4160(-55) \\
1 & 0.1030(-15) \\
1 & 0.7500(20)\end{array}$ \\
\hline $\mathrm{Fe}(\mathrm{OII}) 3$ & 106.87 & $243.45(20)$ & & $\begin{array}{l}\text { s } 0.0551(0) \\
\text { s } 0.3512(1500)\end{array}$ \\
\hline $\mathrm{F} \times \mathrm{O}$ & 71.55 & $355.85(20)$ & & $\begin{array}{l}\text { s } 0.1221(0) \\
\text { s } 0.2520(1500)\end{array}$ \\
\hline re203 & 150.70 & $327.12(20)$ & & $\begin{array}{l}\text { s a : } 2.3427 E+01 \\
\text { s b: } 1.6010 E-02\end{array}$ \\
\hline Groupl (n) & 98.30 & $401 . S S(20)$ & & $\begin{array}{l}s 0.0000(0) \\
s 0.07 .10(300)\end{array}$ \\
\hline
\end{tabular}

* Temperatures in depreces C shuwn in pirentheses

* - lleal capacity data provided in two formats: for data followed by a parentlicsis, heat capacit! is giver in PCl Ho-degrecer at temperature in parentliesis; for data preceded by "a", "b", or "c", heat capacity in PCl,lb-mole-degrecec is deternincd by the relationship "llt (ap - a + bt + ctt", "liere t is in degrees 6 and the non-zero constants " $n "$ " " $b "$, nrd "c" are listed

a $-Y_{0}, R b, S c, T c, T c$ 
PHYSICA], PROPERTY DATA

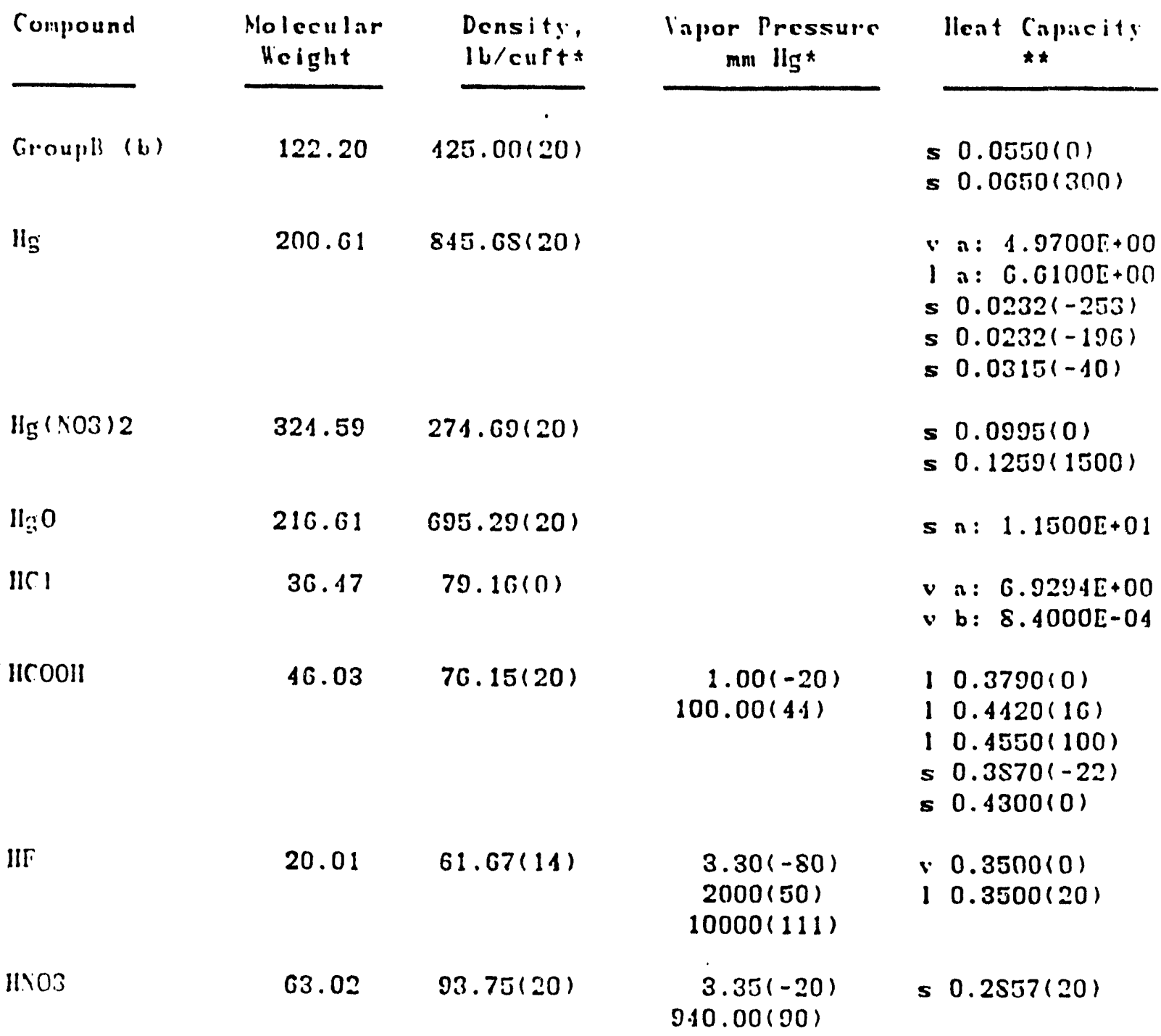

* Temperatures in degrecs $C$ shoun in parcutlieses

* - lleat capacity data provided in two formats: for data followed by a parenthesis, hent capicity is given in prlilu-degrerec at temperature in parentlicsis; for data preceded by "a" "b", or. "c", heat copacity in PCl" lb-role-degree-l is doterinined by the rolationship "llt Cap - + +bt + ctt". "horet is in degroes and the non-zero constints "a", "b", nnd "c" are listed

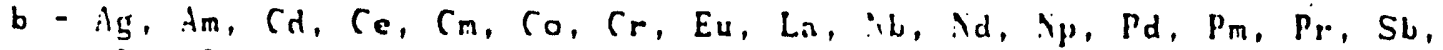
$S_{m}, S_{11}, T b, T I, Z_{r}$ 


\section{PHYSICAL PROPERTY DATA}

\begin{tabular}{|c|c|c|c|c|}
\hline Compound & $\begin{array}{l}\text { Molecular } \\
\text { Height }\end{array}$ & $\begin{array}{l}\text { Density, } \\
\text { lb/cuft* }\end{array}$ & $\begin{array}{c}\text { linpor l'ressure } \\
\mathrm{mm} \mathrm{llg}^{*}\end{array}$ & Heat $\operatorname{lap}^{\text {Habity }}$ \\
\hline 112 & 2.02 & $4.13 !-2531$ & $\begin{array}{r}1.00(-263) \\
760.00(-253) \\
7600(-2.12)\end{array}$ & $\begin{array}{l}v \text { a }: 6.81131:+00 \\
v \text { b: S. } 1000 L-0.1\end{array}$ \\
\hline $112 C 20.1$ & 90.03 & $103.20(19)$ & & $\begin{array}{l}\text { s } 0.1070(-200) \\
\text { s } 0.2970(50)\end{array}$ \\
\hline 1120 & 15.02 & $62.13(1)$ & $\begin{array}{r}1.00(-17) \\
760.00(100) \\
7600(181)\end{array}$ & 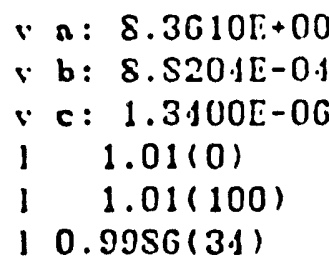 \\
\hline 11202 & 31.02 & $89.75(20)$ & $\begin{array}{c}1.70(20) \\
115.00(100) \\
760.00(150)\end{array}$ & $\begin{array}{l}10.5780(0) \\
\text { s } 0.1710(-25)\end{array}$ \\
\hline 12 & 253.81 & $307.77(20)$ & $\begin{array}{c}1.00(39) \\
100.00(117)\end{array}$ & $\checkmark$ a: $9.0000 E+00$ \\
\hline $\mathrm{K} / \mathrm{ln} 0.1$ & $15 \$ .03$ & $168.71(20)$ & & $s a: 2.8000 E+01$ \\
\hline KNO3 & 101.10 & $131.73(11)$ & & $\begin{array}{l}s \text { a: } 2.0807 E+01 \\
s \text { b: } 5.3000 E-02\end{array}$ \\
\hline K20 & 04.10 & $144.8 \cdot 1(20)$ & & $\begin{array}{l}\text { s a: } 1.76 .15 E+01 \\
\text { s b: } 0.4000 E-013\end{array}$ \\
\hline $\operatorname{Ln} 203$ & 325.82 & $400.41(15)$ & & $\begin{array}{l}s \text { a: } 2.5311 E+01 \\
s \text { b: } 3.0760 L-03\end{array}$ \\
\hline
\end{tabular}

* Temperatures in degrees $C$ shown in parentheses

* - lleat capacity data provided in tus furrats: fur data followcel by a parenthesis, heat capacity is given in PClilb-degrec-c at temperature in parentliesis; for data preceded hy "a", "b", or "c", hent capacity in FCl: ib-mole-drgrec-C is determined by the -rolntionship. "llt $(n p-a+b t+c t t$ ", "herct is in degrecs $C$ and the non-zero constants "a", "b", nnd "c" arec listed 


\section{PHYSICAL PROPERTY DATA}

\begin{tabular}{|c|c|c|c|c|}
\hline Conpound & $\begin{array}{l}\text { Molecular } \\
\text { Heiglit }\end{array}$ & $\begin{array}{l}\text { Density, } \\
\text { lb/cuft* }\end{array}$ & $\begin{array}{c}\text { Vinpor Pressure } \\
\mathrm{mm} \|_{\mathrm{g}}{ }^{*}\end{array}$ & $\begin{array}{c}\text { llent Capacity } \\
\star *\end{array}$ \\
\hline $\operatorname{Li20}$ & 20.85 & $125.64(25)$ & & $\begin{array}{l}\text { s n: } 1.2575 E+01 \\
\text { s b: } 5.1000 E-03\end{array}$ \\
\hline $\operatorname{Mgg}(\mathrm{COOII}) 2$ & 114.35 & $85.65(20)$ & & $\begin{array}{l}\text { s } 0.2402(0) \\
\text { s } 0.10 S 5(1500)\end{array}$ \\
\hline $\mathrm{Mg}(011) 2$ & $5 S .31$ & $117.33(20)$ & & $s n: 1.5200 E+01$ \\
\hline $\mathrm{NgO}$ & 40.32 & $227.81(20)$ & & $\begin{array}{l}s \text { n: } \\
s .389 S E+00 \\
s \text { b: } 1.1970 E-03\end{array}$ \\
\hline $\mathrm{M}_{11}(\mathrm{COO} 11) 2$ & $144.9 \mathrm{~s}$ & $121.93(20)$ & & $\begin{array}{l}\text { s } 0.1013(0) \\
\text { s } 0.3363(1500)\end{array}$ \\
\hline$M \ln (.03) 2$ & 178.37 & $113.62(20)$ & & $\begin{array}{l}\text { s } 0.171 .1(0) \\
\text { s } 0.2579(1500)\end{array}$ \\
\hline$M n(O I 1) 2$ & 85.95 & $203.40(13)$ & & $\begin{array}{l}\text { s } 0.2112(0) \\
\text { s } 0.3193(1500)\end{array}$ \\
\hline $\operatorname{MnO}$ & 70.93 & $310.86(20)$ & & $\begin{array}{l}s \text { n: } 1.2180 E+01 \\
\text { s b: } 1.6102 E-02 \\
\text { s c }-3.6200 E-06\end{array}$ \\
\hline $\mathrm{MnO2}$ & 86.93 & $313.69(20)$ & & $\begin{array}{l}\text { s a: } 1.2560 E+01 \\
\text { s b: } 3.0575 E-02 \\
\text { s c: }-2.9700 E-05\end{array}$ \\
\hline $\mathrm{A}:\left(\mathrm{IIg}_{\mathrm{g}} \mathrm{O}(\mathrm{O} / 1)\right)$ & 256.59 & $412.97(20)$ & & $\begin{array}{l}s 0.0 S 75(0) \\
s 0.126 S(1500)\end{array}$ \\
\hline
\end{tabular}

* Tomperatures in degrecs C sliown in parentheses

* - llont capacity data provided in tuo furmats: for data followed lig a parcuthesis, heat cipacity is giron in PCl lb-degrec-s at temperature in paronthesis; for data proceled by "a". "b", or "c". heat capacity in PClilb-nole-degroc-C is determined by the relationslip "llt Cap - n+ hit+ett", "licret is in degrecs $C$ and the non-zero constints "n", "b", and "c" are listed 


\section{PHYSICAL PROPERTY DATA}

\begin{tabular}{|c|c|c|c|c|}
\hline Compound & $\begin{array}{l}\text { Molecular } \\
\text { Height }\end{array}$ & $\begin{array}{l}\text { Densily, } \\
\text { lb/curt* }\end{array}$ & $\begin{array}{c}\text { Vinpor Pressurc } \\
\text { mm } \|_{g}\end{array}$ & Hent Capacity \\
\hline$\therefore a \wedge 102$ & 81.97 & $153.83(20)$ & & $\begin{array}{l}\text { s } 0.0253(-22(1) \\
s 0.1074(-149) \\
=0.2137(25)\end{array}$ \\
\hline $\mathrm{NaBO2}$ & 65.51 & $153.52(20)$ & & $\begin{array}{l}\text { s a: } 1.5836 E+01 \\
s \text { b: } 1.9000 E-02\end{array}$ \\
\hline$N_{a r}(1$ & $5 S .15$ & $135.04(20)$ & & $\begin{array}{l}\text { s a: } 1.1937 E+01 \\
\text { s b: } 4.20010 E-03\end{array}$ \\
\hline$\lambda_{a}$ rooll & GS.01 & $110.77(20)$ & & $\begin{array}{l}\text { s } 0.2557(0) \\
\text { s } 0.4673(1500)\end{array}$ \\
\hline$\therefore: 5$ & 42.00 & $171.18(20)$ & & $\begin{array}{l}\text { s a: } 1.1189 E+01 \\
\text { s b: } 2.8900 E-03\end{array}$ \\
\hline Nin I & 119.92 & $228.87(0)$ & & $\begin{array}{l}\text { s a : } 1.2013 E+01 \\
\text { s b: } 1.0200 n-03\end{array}$ \\
\hline $\mathrm{NaN02}$ & 69.01 & $135.35(0)$ & & $\begin{array}{l}\text { s } 0.2301(0) \\
\text { s } 0.3772(1500)\end{array}$ \\
\hline $\mathrm{NaNO}$ & 85.01 & $140.87(20)$ & & $\begin{array}{l}s n: 2.0103 E+01 \\
s \text { b: } 5.5000 E-02\end{array}$ \\
\hline 1.OII & 40.00 & $132.91(20)$ & & $\begin{array}{l}\text { s } 0.3230(0) \\
s 0.5101(1500)\end{array}$ \\
\hline $\operatorname{Na2B.107}$ & 201.27 & $1.17 .73(20)$ & & $s n: 4.7900 E+01$ \\
\hline $1: 2503$ & 106.00 & $155.00(20)$ & & s a: $2.8 n 005+01$ \\
\hline
\end{tabular}

* - Temperatures in degreas $C$ slionn in parentlieses

* * lleat capacity data provided in two formats: for data followed by a parentlesis, heat capacity is given in PClifb-degrecer at temperature in pircentlesis; for data preceded b! "al, "b", or "c", leat capacity ill PCl /b-mole-degrec-C is deternined by the relationship "llt Cap - $a+b t+c t t "$, "here $t$ is in degreces $C$ and the non-zero constants "a", "b", and "c" are listed 


\section{PHYSICAL PROPERTY DATA}

\begin{tabular}{|c|c|c|c|c|}
\hline Compound & $\begin{array}{l}\text { Mulecular } \\
\text { Height }\end{array}$ & $\begin{array}{l}\text { Density, } \\
\text { lb/cuft* }\end{array}$ & $\underset{\text { Mm lig }}{\text { Pinpor Pressure }}$ & Llent \\
\hline$x_{12} 2 C 201$ & 131.01 & $116.09(20)$ & & $\begin{array}{l}=0.2055(0) \\
=0.4142(1500)\end{array}$ \\
\hline$N_{i} 20$ & 61.90 & $141.68(20)$ & & $\begin{array}{l}s \text { a } 1.7175 E+01 \\
s \text { b: } 5.1000 E-03\end{array}$ \\
\hline$N_{2} 2 p_{4} 02(011) 4$ & 355.01 & $369.96(20)$ & & $\begin{array}{l}s 0.1312(0) \\
s 0.2053(1500)\end{array}$ \\
\hline $\mathrm{Na} 2 \mathrm{RH}_{1} 04$ & $212 . s S$ & $187.29(20)$ & & $\begin{array}{l}=0.1447(0) \\
=0.2 .94(1500)\end{array}$ \\
\hline $\mathrm{N} \approx 2 R_{u} 04$ & 211.05 & $187.29(20)$ & & $\begin{array}{l}=0.1111(0) \\
=0.2151(1500)\end{array}$ \\
\hline $\mathrm{Na} 2501$ & 142.05 & $165.39(20)$ & & $s n: 3.2800 E+01$ \\
\hline $\mathrm{Ni}(\mathrm{COOll}) 2$ & 148.72 & $131.47(20)$ & & $\begin{array}{l}\text { s } 0.1555(0) \\
\text { s } 0.3605(1500)\end{array}$ \\
\hline $\mathrm{Ni}(011) 2$ & 92.71 & $272.19(20)$ & & $\begin{array}{l}=0.2011(0) \\
=0.35 S s(1500)\end{array}$ \\
\hline $\mathrm{NiO}$ & 74.69 & $464.98(20)$ & & $\begin{array}{l}\text { s a: } 1.1857 E+01 \\
\text { s b: } 2.1500 E-03\end{array}$ \\
\hline 10 & 30.01 & $70.22(-150)$ & $\begin{array}{r}1.00(-185) \\
760.00(-152) \\
7000(-127)\end{array}$ & $\begin{array}{l}\because 0.2130(27) \\
\because 0.3070(4727)\end{array}$ \\
\hline 102 & 46.01 & $90.35(20)$ & $\begin{array}{l}1.00(-50) \\
100.00(7)\end{array}$ & $\begin{array}{ll}* & 0.2090(50) \\
* & 0.2500(150) \\
v & 0.2790(550) \\
1 & 0.3503(-7) \\
1 & 0.3727(32)\end{array}$ \\
\hline
\end{tabular}

* - Temperatures in degrecs $C$ sliown in parentlieses

* - llent capacity data provided in two formats: for data followed by a parentlicsis, hent capicity is given in PCl /h-degrec-s at temperature in parenthesis; for data preceded by " $n$ ". "b". or "c", hent capacity in PCl//b-nole-degree-C is determined by the relationship "llt Cap - a + bt + ctt". "here $t$ is in degrees 6 and the non-zero constants " $a$ ". " $b "$ " and "c" are listed 
PHYSICAL PROPERTY DATA

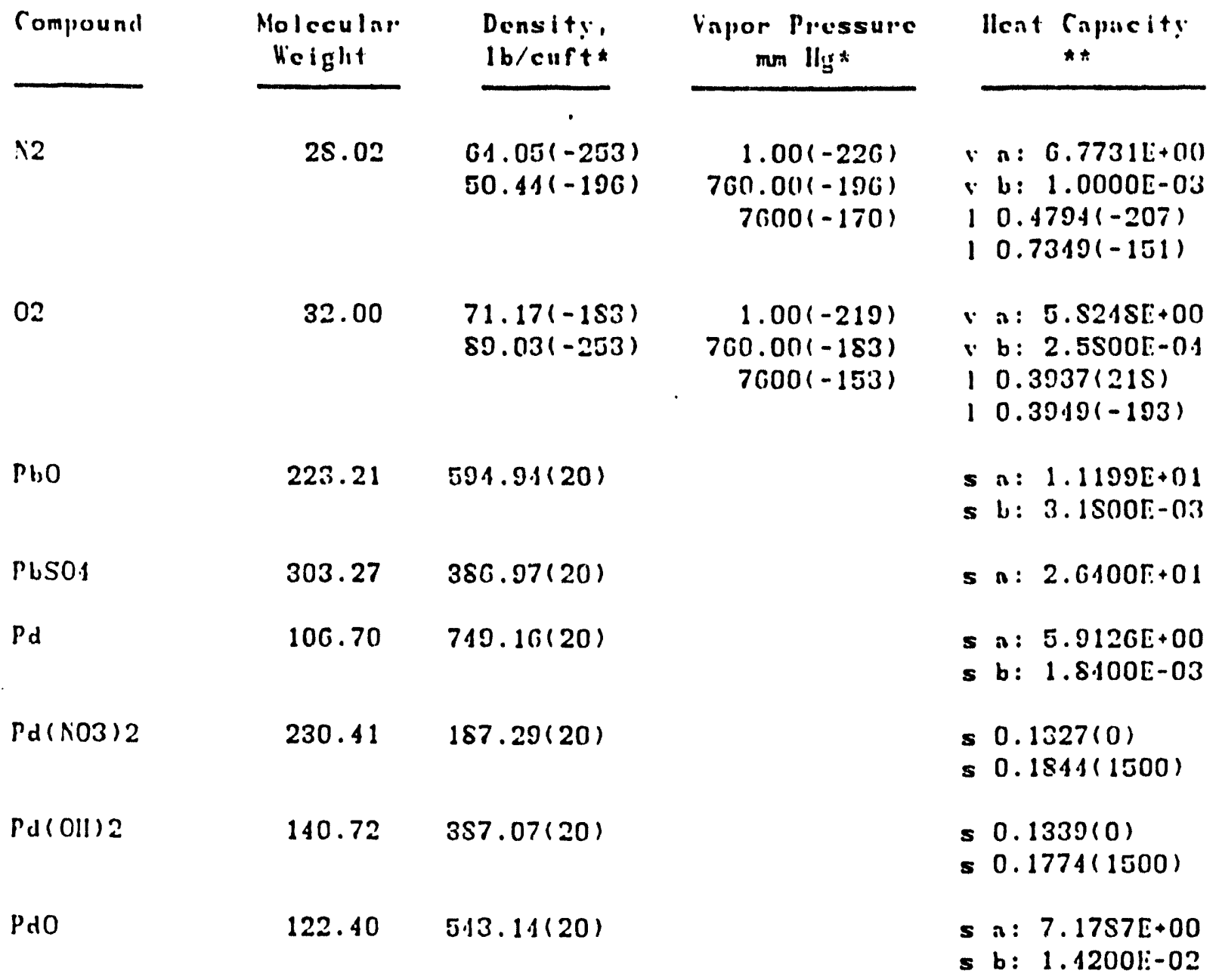

Polylectrolyte $71.05 \quad 38.00(16)$

Pozzolith $\quad 102.00 \quad 71.79(20)$

* Temperatures in denpeces shown in parentheses

* - llent capacity data procided in two formats: rese data followed by a parenthesis, heat capicit! is given in lli,ll-dergren-e at terperafure in parenthesis; for data preceded by "a", "b", or "c", hent capacity in PCl lh-mole-degrea-c is deternined by the relationship "llt $(n p=n+b t+e t t "$, "hare $t$ is in degrees $r$ and the non-zero constants "a", "b", and "c" are listed 


\begin{tabular}{|c|c|c|c|c|c|}
\hline Compound & $\begin{array}{l}\text { Molecular } \\
\text { Neiglit }\end{array}$ & $\begin{array}{l}\text { Density, } \\
\text { lb/cuft* }\end{array}$ & $\begin{array}{c}\text { Inpor Pressure } \\
\mathrm{mm} \mathrm{II}^{*}\end{array}$ & llent & Capneity \\
\hline$P_{u}($ cooll $) 4$ & 410.13 & $37.1 .58(20)$ & & $\begin{array}{l}=0.11 \\
s 0.20\end{array}$ & $\begin{array}{l}179(0) \\
0.15(1500)\end{array}$ \\
\hline $\mathrm{PuO2}$ & 274.00 & $715.12(20)$ & & $\begin{array}{l}\text { s } 0.05 \\
\text { s } 0.07\end{array}$ & $\begin{array}{l}530(0) \\
700(500)\end{array}$ \\
\hline RhO2 & 13.90 & $435.12(20)$ & & $\begin{array}{l}\text { s } 0.08 \\
\text { s } 0.13\end{array}$ & $\begin{array}{l}876(0) \\
331(1500)\end{array}$ \\
\hline$R_{1102}$ & 133.07 & $435.12(20)$ & & $\begin{array}{l}s \text { n: } 1 \\
=b: 0\end{array}$ & $\begin{array}{l}1.3039 E+01 \\
6.0000 E-03\end{array}$ \\
\hline RuO. & 165.70 & $360.22(100)$ & & $=n: 2$ & $2.0000 E+01$ \\
\hline $\mathrm{SiO} 2$ & 60.00 & $143.55(20)$ & & $\begin{array}{lll}s & a: & 9 \\
s & b & 8\end{array}$ & $\begin{array}{l}9.81111:+00 \\
8.2000 \mathrm{i}-03\end{array}$ \\
\hline $5 r(c 0011) 2$ & 177.66 & $168.08(20)$ & & $\begin{array}{l}s 0.15 \\
=0.25\end{array}$ & $\begin{array}{l}552(0) \\
539(1500)\end{array}$ \\
\hline $\operatorname{Sr}\left(N_{03}\right) 2$ & 211.65 & $180.42(20)$ & & $\begin{array}{ll}\text { s } & 0.15 \\
s & 0.23 \\
s & 0.12\end{array}$ & $\begin{array}{l}588(-153) \\
392(25) \\
243(627)\end{array}$ \\
\hline $\mathrm{Sr}(011) 2$ & 121.65 & $220.31(20)$ & & $\begin{array}{l}\text { s } 0.15 \\
\text { s } 0.20\end{array}$ & $\begin{array}{l}532(0) \\
035(1500)\end{array}$ \\
\hline $\mathrm{srcos}$ & 147.61 & $230.93(20)$ & & $\begin{array}{l}s \quad 0.10 \\
s \quad 0.10 \\
s \quad 0.21\end{array}$ & $\begin{array}{l}009(-111) \\
603(152) \\
122(913)\end{array}$ \\
\hline
\end{tabular}

* - Terupratures in degrees $C$ shown in parentheses

*: - lleat capicity data provided ill two furmats: for data folloned ly, a parenthesis, heat capacity is given in PClilb-degree-c nt teriperature in parenthesis; fur data preceded by " $n$ ", "b", or "c", heat capacity in PCl, lb-mole-degrec-s is defermined by the relationship "llt Cap - + bt + ett", where $t$ is in degrecs $C$ and the non-zero constants "n", "b", nud "c" nre listed 


\section{PHYSICAL PROPERTY DATA}

\begin{tabular}{|c|c|c|c|c|c|}
\hline Componind & $\begin{array}{l}\text { Mulecular } \\
\text { Heiglit }\end{array}$ & $\begin{array}{l}\text { Density, } \\
\text { lb/cuft: }\end{array}$ & $\underset{m m}{\text { Pinpor Pressure }}$ & llont & Cnpacity \\
\hline S.0 & 103.63 & $293.35(20)$ & & $\begin{array}{l}\text { s } n: \\
\text { s } \text { b: }\end{array}$ & $\begin{array}{l}1.0225 \mathrm{~T}+01 \\
1.1200 \mathrm{E}-03\end{array}$ \\
\hline Sureractant & & $00.80(20)$ & & & \\
\hline s02 & 0.1 .00 & $80.66(20)$ & $\begin{array}{c}1.00(-96) \\
760.00(-10) \\
7600(56)\end{array}$ & $\begin{array}{ll}v & n: \\
v & b: \\
v & c:-8 \\
1 & 0.25 \\
1 & 0.25\end{array}$ & $\begin{array}{l}9.0555 E+00 \\
4.8160 E-03 \\
8.3000 L-07 \\
910(-20) \\
5 S 0(-100)\end{array}$ \\
\hline THO2 & 264.12 & $601.79(20)$ & & $\begin{array}{l}s \quad n: \\
=b:\end{array}$ & $\begin{array}{l}1.5955 \mathrm{~T}+01 \\
5.0700 \mathrm{E}-03\end{array}$ \\
\hline $\mathrm{TiO} 02$ & 79.90 & $262.21(20)$ & & $\begin{array}{l}\text { en: } \\
\text { s b: }\end{array}$ & $\begin{array}{l}1.330 S E+01 \\
7.5100 E-03\end{array}$ \\
\hline Iritium & 3.02 & $62.43(1)$ & $\begin{array}{r}1.00(-17) \\
760.00(100) \\
7600(181)\end{array}$ & $\begin{array}{rr}1 & 1 \\
1 & 1 \\
1 & 0.99\end{array}$ & $\begin{array}{l}.01(0) \\
.01(100) \\
0 S 6(34)\end{array}$ \\
\hline 102 & 270.07 & $650.31(20)$ & & $\begin{array}{l}=n: 1 \\
s \quad b: 1\end{array}$ & $\begin{array}{l}1.4339 E+01 \\
1.6200 E-03\end{array}$ \\
\hline $1102(c 0011) 2$ & 360.06 & $230.37(19)$ & & $\begin{array}{l}=0.09 \\
=0.17\end{array}$ & $\begin{array}{l}944(0) \\
763(1500)\end{array}$ \\
\hline $102(011) 2$ & 301.01 & $369.96(20)$ & & $\begin{array}{l}=0.08 \\
s 0.14\end{array}$ & $\begin{array}{l}823(0) \\
418(1500)\end{array}$ \\
\hline yiconil)s & 223.96 & $157.29(20)$ & & $\begin{array}{l}s 0.17 \\
s 0.20\end{array}$ & $\begin{array}{l}72.1(0) \\
0(17(1500)\end{array}$ \\
\hline
\end{tabular}

* - Temperatures in degrecs C sliown in parentleses

* - lleat capacity data provided in two formits: fur data followed by n parentliesis, hent capicity is given in l'llibu-degree-e at temperature in parentlesis; fur data preceded by " $a$ ", "b", or "c", , hent capacity in PCl, lb-mole-degrecer is determilled by the roliationship "llt Cap - n + bt + ctt", where t is in degroes r nud the non-zero constants " $n$ ", "b", nnd "c" nre listed 
PHYSICAL PROPERTY DATA

\begin{tabular}{|c|c|c|c|c|}
\hline Compound & $\begin{array}{l}\text { Moleculno } \\
\text { He ight }\end{array}$ & $\begin{array}{l}\text { Density, } \\
\text { lW/cuft* }\end{array}$ & $\begin{array}{c}\text { Pinpor Pressiure } \\
\text { mm } \|_{g^{*}}\end{array}$ & lleat Capacit! \\
\hline I(N03)3 & 274.92 & $167.14(20)$ & & $\begin{array}{l}\text { s } 0.1557(0) \\
s 0.2214(1500)\end{array}$ \\
\hline$y(011) 3$ & 139.93 & $218.51(20)$ & & $\begin{array}{l}=0.1800(0) \\
s 0.2472(1500)\end{array}$ \\
\hline $12(r 03) 3$ & 357.57 & $218.51(20)$ & & $\begin{array}{l}\text { s } 0.1209(0) \\
s 0.2111(1500)\end{array}$ \\
\hline 1203 & 225.81 & $312.70(20)$ & & $\begin{array}{l}=0.1120(0) \\
=0.1120(500)\end{array}$ \\
\hline Zeolite & 600.20 & $43.00(20)$ & & $=0.2050(1000)$ \\
\hline $2 n($ cooll $) 2$ & 155.42 & $147.83(20)$ & & $\begin{array}{l}\text { s } 0.1777(0) \\
\text { s } 0.3003(1500)\end{array}$ \\
\hline $\ln (011) 2$ & 99.40 & $190.59(20)$ & & $\begin{array}{l}\text { s } 0.1878(0) \\
=0.2649(1500)\end{array}$ \\
\hline $\mathrm{ZnO}$ & 81.38 & $311.40(20)$ & & $\begin{array}{l}\text { s } 0.1150(0) \\
\text { s } 0.1070(1300)\end{array}$ \\
\hline $\mathrm{Zr02}$ & 123.22 & $357.63(20)$ & & $\begin{array}{l}s \quad n: 1.2005[+01 \\
s \text { b: } 1.0 \cdot 160 E-02\end{array}$ \\
\hline
\end{tabular}

* - Temperatures in degrees C shown in parentlieses

* - lleat capacity data provided in two formals: fur data followed by n parenthesis, heat capicity is given in PCli/h-degree-C at temperature in parenthesis; for data preceded by " $n$ ", "b", or "c", heat capacity in $\mathrm{PCl} / / \mathrm{b}-m u l c-d e g r e c-C$ is determined by the relationship "llt (ap - + + bt + ctt", where t is in degrees $C$ nnd the non-zero cunstints " $n "$ " "l,", and "c" nre listed 
GLASS FRIT CHARACTERISTICS

(FRIT 131)

A. Composition

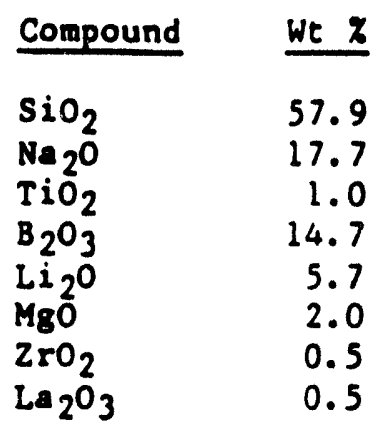

B. Physical Properties

Particle size: $-80,+325$ mesh

Bulk density: 70 to $94 \mathrm{lb} / \mathrm{ft}^{3}$

Specific density: $152 \mathrm{lb} / \mathrm{ft}^{3}$

Angle of repose: 30 to 430 
HEAT CAPACITIES FOR DWPF WASTE GLASS WITH FRIT 131

\begin{tabular}{|c|c|c|}
\hline \multirow{2}{*}{ Temperature, } & \multicolumn{2}{|c|}{ Composite TDS-3A } \\
\hline & $\overline{c_{p m} \frac{C_{a l}}{g^{\circ} \bar{c}}}$ & $C_{p t} \frac{C a l}{g^{\circ}}$ \\
\hline 0 & 0.186 & 0.186 \\
\hline 100 & 0.213 & 0.237 \\
\hline 200 & 0.234 & 0.271 \\
\hline 300 & 0.252 & 0.296 \\
\hline 400 & 0.264 & 0.314 \\
\hline 500 & 0.276 & 0.328 \\
\hline 600 & 0.285 & 0.338 \\
\hline 700 & 0.293 & 0.346 \\
\hline 800 & 0.300 & 0.353 \\
\hline 900 & 0.307 & 0.359 \\
\hline 950 & 0.309 & 0.361 \\
\hline 1,000 & 0.312 & 0.363 \\
\hline 1,025 & 0.313 & 0.364 \\
\hline 1,050 & 0.315 & 0.365 \\
\hline 1,075 & 0.316 & 0.366 \\
\hline 1,100 & 0.317 & 0.367 \\
\hline 1,125 & 0.318 & 0.368 \\
\hline 1,150 & 0.319 & 0.369 \\
\hline 1,175 & 0.320 & 0.369 \\
\hline 1,200 & 0.321 & 0.370 \\
\hline 1,250 & 0.323 & 0.372 \\
\hline 1,300 & 0.325 & 0.373 \\
\hline
\end{tabular}


DENSITIES OF DWPF WASTE GALSSES WITH FRIT 131

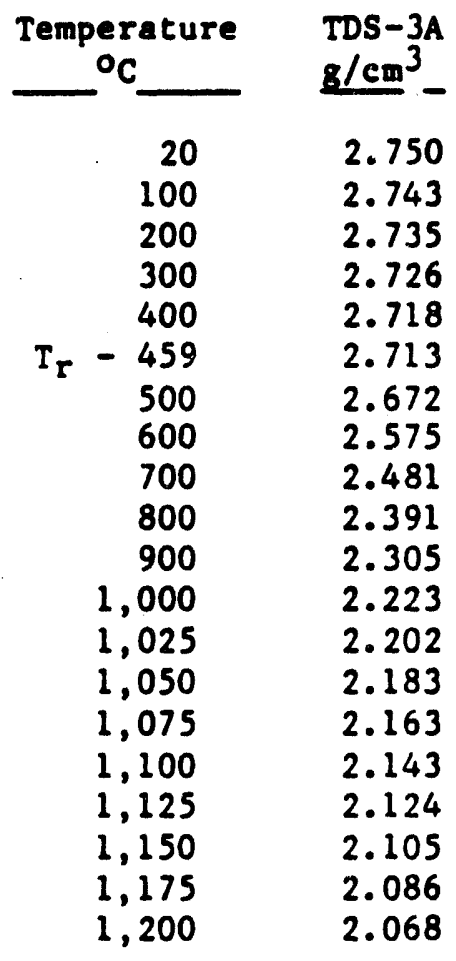


APPENDIX $\mathrm{H}$

TABLE 21-9

PACE 1 of 1

DATE 5-81; Rev 6

INDEX OF REFRACTION FOR DWPF GLASS WITH FRIT 131

$$
N=1.662 \text { at Lambda }=4,860 \text { angstroms }
$$


$\underline{K}_{r a d}$ AND Keff FOR DWPF GLASS WITH FRIT 131

\begin{tabular}{|c|c|c|}
\hline \multirow{2}{*}{$\begin{array}{c}\text { Temperature } \\
{ }^{\circ} \mathrm{C} \\
\end{array}$} & \multicolumn{2}{|c|}{ Composite Waste } \\
\hline & $\underline{K}_{\mathrm{rad}}$ & $\underline{K} \in f E$ \\
\hline 0 & 0 & 0.4893 \\
\hline 100 & 0 & 0.5616 \\
\hline 200 & 0 & 0.6339 \\
\hline 300 & 0 & 0.7062 \\
\hline 400 & 0 & 0.7785 \\
\hline 500 & 0 & 0.8508 \\
\hline 600 & 0 & 0.9231 \\
\hline 670 & 3.5 & 0.9737 \\
\hline 685 & & 1.0105 \\
\hline 700 & $4.83 E-2$ & 1.044 \\
\hline 800 & $2.45 E-1$ & 1.313 \\
\hline 900 & $5.20 \mathrm{E}-1$ & 1.660 \\
\hline 1,000 & $8.73 \mathrm{E}-1$ & 2.085 \\
\hline 1,025 & 9.72 E-1 & 2.200 \\
\hline 1,050 & 1.08 & 2.33 \\
\hline 1,075 & 1.18 & 2.45 \\
\hline 1,100 & 1.30 & 2.58 \\
\hline 1,125 & 1.41 & 2.71 \\
\hline 1,150 & 1.53 & 2.85 \\
\hline 1,175 & 1.65 & 2.99 \\
\hline 1,200 & 1.78 & 3.14 \\
\hline
\end{tabular}




\section{RESISTIVITY OF DWPF GLASS WITH FRIT 131}

\begin{tabular}{|c|c|}
\hline $\begin{array}{c}\text { Temperature } \\
\left({ }^{\circ} \mathrm{C}\right)\end{array}$ & $\begin{array}{l}\text { Resistivity } \\
\text { (ohm-cm) }\end{array}$ \\
\hline $\begin{array}{r}800 \\
900 \\
1,000 \\
1,100 \\
1,200\end{array}$ & $\begin{array}{l}9.2 \\
5.4 \\
3.8 \\
2.7 \\
1.8\end{array}$ \\
\hline
\end{tabular}


SURFACE TEMPERATURE FOR DWPF WASTE GLASS

(TDS-3A and Frit 131)

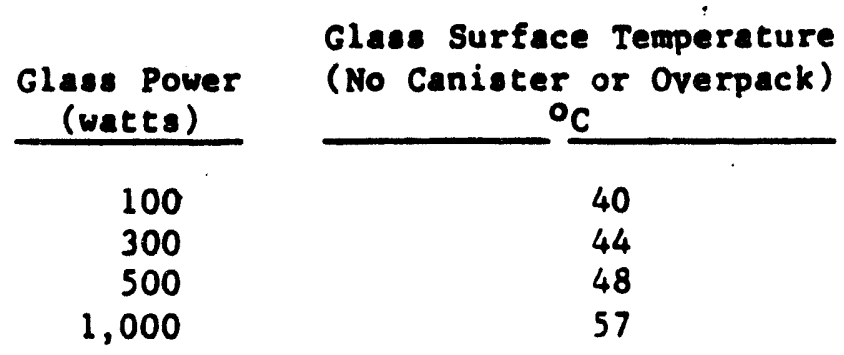

Reference DWPF waste form ( $2 \mathrm{ft} \times 7 \mathrm{ft} 7 \mathrm{in.}$ ).

$165 \mathrm{gal}$ of waste glass containing $35 x$ sludge oxides.

Air temperature: $38^{\circ} \mathrm{C}$.

Natural convection heat transfer coefficient $=1.0 \mathrm{pcu} /(\mathrm{hr})\left(\mathrm{ft} \mathrm{t}^{2}\right)\left({ }^{\circ} \mathrm{C}\right)$. 


\section{RADIATION FROM REFERENCE}

DWPF CANISTER

5 YEAR OLD SLUDGE PLUS

15 YEAR OLD SUPERNATE

(STAGE I + STAGE II)

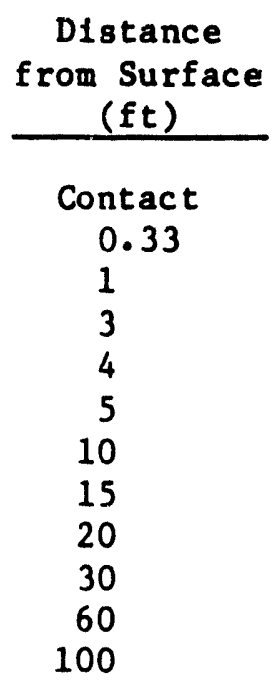

Radiation

Level

rems/hr

5565
3835
1745
570
400
295
97
45
26
12
3
1.1

Basis of Calculations

- Geometry

$$
\begin{aligned}
& 2^{\prime} \text { OD } \times 10^{\prime} \text { Length } \\
& 0.375^{\prime \prime} \mathrm{S} / \mathrm{S} \text { Walls } \\
& 7.59^{\prime} \mathrm{F} 11 \mathrm{l} \text { He1ght }
\end{aligned}
$$

- Glass Density $2.75 \mathrm{~g} / \mathrm{cm}^{3}$

- The Source Term is given in Appendix A, Table 3-11.

- Source Model

Cylinder volume source with self-adsorption

- Data Base: ORNL DOE/TIC-11026, 1981.

- Code: SDC, Shielding-Design Calculation Code for Fuel-Hand1ing Fac1lities, ORNL-3041, March 1966. 
DPSP $80-1088$

MATERIAL BALANCE TABLES

SLUDGE-ONLY FEED

INDEX
Appendix $\mathrm{H}$

Toble 21-15

Page 001 of 173

Date 09/30/82 Rev 09

\begin{tabular}{|c|c|c|c|c|c|c|c|c|c|c|c|c|c|c|c|c|c|c|c|}
\hline \multirow{3}{*}{\multicolumn{2}{|c|}{$\begin{array}{l}\text { STREAM NUMBERS } \\
\text { STREAM NUMBERS }\end{array}$}} & \multicolumn{2}{|c|}{ DESCRIPTION } & \multirow[b]{2}{*}{3} & \multirow[b]{2}{*}{4} & \multirow[b]{2}{*}{ - } & & & & & & & \multirow{2}{*}{\multicolumn{3}{|c|}{ - • • }} & \multirow{2}{*}{ - $\frac{\text { PACE }}{2}$} \\
\hline & & 1 , & 2 , & & & & & & & & & & & & & & & & \\
\hline & & & 6. & 7. & 8 & - & . • & & $\cdot$ & $\cdot$ & $\bullet$ & - & - & - & . . & - . & - & - & \\
\hline STREAM & NUMBERS & 9 & 10 . & 11. & 12 & - & - • & • • & - & - & - & - & - & - & . & - • & . & • & . 10 \\
\hline STREAM & NUMBERS & 13 , & 14. & 15 . & 16 & - & • • & & & & - & - & - & - & . & • • & - & - & \\
\hline STREAM & NUMBERS & 17. & 18, & 19, & 20 & & - & & • & & - & • & • & - & . & - • & - & • & \\
\hline STREAM & NUMBERS & 21. & 22, & 23 & 24 & & - & & - & & - & • & • & - & - & - & - & • & \\
\hline STREAM & NUMBERS & 25 , & 26. & 27 , & 28 & - & - & • & - & • & - & • & - & - & • & - & . & • & \\
\hline STREAM & NUMBERS & 29. & 80, & 31 , & 82 & - & - & - & - & - & - & • & - & • & - & - & . & • & \\
\hline STREAM & NUMBERS & 33, & 84, & 85 , & 86 & - & • & - & - & - & - & • & - & - & - & - & . & • & \\
\hline STREAM & NUMBERS & 37 . & 88 , & 89 , & 40 & - & - & - & - & - & - & • & - & . & - & - & • & • & \\
\hline STREAM & NUMBERS & 41, & 42 , & 43. & 44 & - & - & • & - & - & - & - & - & - & - & - & - & • & \\
\hline STREAM & NUMBERS & 45 , & 46, & 47. & 48 & - & - & - & - & - & - & • & - & - & - & - & • & • & \\
\hline STREAM & NUMBERS & 49 , & 50, & 51. & 52 & 。 & - & - & - & - & - & • & - & - & - & - & - & • & \\
\hline STREAM & NUMBERS & 53, & 54, & 55. & 56 & - & - & - & - & - & - & - & • & - & - & - & - & - & \\
\hline STREAM & NUMBERS & 57. & 68, & 59, & 60 & - & - & - & - & • & - & - & • & • & • & - & • & - & \\
\hline STREAM & NUMBERS & 61, & 62. & 63, & 64 & - & - & - & - & - & • & - & - & • & • & - & • & - & 62 \\
\hline STREAM & ERS & 65 , & 66, & 67. & 68 & - & - & - & - & • & - & • & - & • & • & - & - & . & 00 \\
\hline$A M$ & NUMBERS & 69, & 71, & 72, & 78 & - & - & - & - & • & - & - & - & - & • & - & • & - & \\
\hline STREAM & NUMBERS & 74. & 75, & 76. & 78 & - & - & - & - & - & - & - & - & • & - & - & • & - & \\
\hline REAM & NUMBERS & 79 & 80 , & 81. & 82 & - & • & - & - & - & - & • & - & - & - & - & - & - & \\
\hline REAM & NUMBERS & 83 , & 84, & 85. & 86 & - & • & - & - & - & - & • & - & - & - & - & - & - & \\
\hline TREAM & NUMBERS & & 88 , & 89, & 90 & ${ }^{\circ}$ & - & • & • & • & • & • & • & - & & • & • & • & \\
\hline STREAM & NUMBERS & & 92. & 93, & 94 & • & • & . & . & 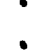 & $*$ & 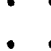 & . & $\bullet^{\circ}$ & . & . & . & $\dot{0}$ & \\
\hline STREAM & NUMBERS & 96 & 98, & 99 , & 100 & - & & & & & & & & & & & & & - \\
\hline STREAM & NLMBERS & 102 , & 103 & 104. & 105 & - & - & - & - & - & - & - & - & - & - & - & - & - & \\
\hline STREAM & NUMBERS & 106 , & 107. & 108 , & 109 & - & - & - & - & - & - & • & - & - & - & - . & • & - & 102 \\
\hline STREAM & NUMBERS & 110, & 111. & 112. & 113 & - & - & - & - & - & - & - & - & - & - & • & • & - & 06 \\
\hline STREAM & NUMBERS & 114, & 115 & 117. & 118 & - & - & - & - & - & - & & - & - & - & • & - & - & 110 \\
\hline STREAM & NUMBERS & 119. & 120, & 121. & 122 & $\bullet$ & . & - & - & - & - & & - & - & - & •. & - & - & 114 \\
\hline STREAM & NUMBERS & 123. & 124, & 125 & 126 & - & - & - & - & - & - & & - & - & - & - & - & - & .118 \\
\hline STREAM & NUMBERS & 127. & 128 & 129 & 180 & - & - & - & - & - & - & & - & • & - & - • & • & - & .122 \\
\hline STREAM & NUMBERS & 181. & 182. & 183 & 184 & - & - & - & - & - & - & & - & • & - $\cdot$ & - & - & - & .12 \\
\hline STREAM & NUMBERS & 185, & 186, & 187. & 188 & $\bullet$ & - & - & - & - & - & & - & - & - • & - & - & - & .18 \\
\hline STREAM & NUMBERS & 189, & 140 & 141. & 142 & - & . & - & . & • & - & & - & - & - & - & - & - & 13 \\
\hline STREAM & NUMBERS & 148, & 144, & 145, & 146 & - & . & - & - & & & & - & . & . & - & - & . & 13 \\
\hline STREAM & NUMBERS & 147, & 148 & 149 & 160 & $\bullet$ & - & & & & & & - & & . & - & . & & .14 \\
\hline STREAM & NUMBERS & 151 , & 152, & 153 , & 154 & & & & & & & & & & & & & & .14 \\
\hline STREAM & NUMBERS & 155 , & 156 & 157 , & 158 & - & & $\bullet$ & - & - & $\bullet$ & & - & - & & - & - & - & .150 \\
\hline STREAM & NUMBERS & 159, & 160. & 161. & 162 & & - & - & • & • & • & & & - & & - & - & - & .154 \\
\hline STREAM & NUMBERS & 163. & 165 & 167. & 168 & - & . & $\bullet^{\circ}$ & 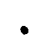 & $\bullet$ & $\bullet$ & & & - & & . & . & - & .15 \\
\hline STREAM & NUMBERS & 169, & 170 , & 171, & 172 & - & - & $\bullet$ & & $\bullet$ & $\bullet$ & & & • & & & - & & .162 \\
\hline STREAM & NUMBERS & 173. & 174. & 176 & 176 & - & $\bullet$ & & & $\bullet$ & 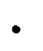 & & & • & & • & • & & .166 \\
\hline STREAM & NUMBERS & 177 & - . & & & • & & & & $\bullet$ & & & & • & - & - • & $\dot{\varphi}$ & & .170 \\
\hline
\end{tabular}


MATERIAL BALANCE TABLES

SLUDGE-ONLY FEED

STREAM NUMBERS -

STREAN NAME

$\begin{array}{ccc}1 & 2 & 8 \\ \text { Wshed Sludge } & 90^{2} \text { wt } & \text { Supenate } \\ \text { fr Tank Farm Formic Acid } & \text { Concontrate }\end{array}$

COMPONENT FLOV'S, LB/HR

fr Tank Farm Formic Acid Concentrate SME

\begin{tabular}{|c|c|c|c|c|c|}
\hline 1 & 1120 & 885.3 & 2.841 & .0000 & $.8656 E-05$ \\
\hline 45 & Ag & .0000 & .0000 & .0000 & $.9693 \mathrm{E}-04$ \\
\hline 116 & $\mathrm{Ag} 20$ & .0000 & .0000 & .0000 & .0000 \\
\hline 134 & AgNO3 & .0000 & .0000 & .0000 & .0000 \\
\hline 51 & $\mathrm{AgOH}$ & $.2236 \mathrm{E}-01$ & .0000 & .0000 & .0000 \\
\hline 74 & AI $(O H) 3$ & 18.98 & .0000 & .0000 & $.1892 E-06$ \\
\hline 77 & A1203 & .0000 & .0000 & .0000 & .0000 \\
\hline 75 & A 100II & .0000 & .0000 & .0000 & .0000 \\
\hline 106 & B203 & .0000 & .0000 & .0000 & .2895E-06 \\
\hline 9 & $\mathrm{Ba}(\mathrm{N} 03) 2$ & $.1843 E-06$ & .0000 & .0000 & $.1829 \mathrm{E}-14$ \\
\hline 95 & $\mathrm{BaCl2}$ & .0000 & .0000 & .0000 & .0000 \\
\hline 15 & $\mathrm{BnO}$ & .0000 & .0000 & .0000 & .0000 \\
\hline 24 & $\mathrm{BaS04}$ & .1659 & .0000 & .0000 & . 1653E-08 \\
\hline 66 & $\mathrm{CO}$ & .0000 & .0000 & .0000 & $.2440 \mathrm{E}-32$ \\
\hline 37 & $\mathrm{CO} 2$ & .0000 & .0000 & .0000 & $.1073 E-16$ \\
\hline 142 & $\operatorname{co2}(\mathrm{C} 14)$ & .0000 & .0000 & .0000 & $.8052 E-28$ \\
\hline 63 & $\mathrm{Ca}(\mathrm{COOH}) 2$ & .0000 & .0000 & .0000 & $.5734 E-07$ \\
\hline 120 & $\mathrm{Ca}(\mathrm{OII}) 2$ & .0000 & .0000 & .0000 & .0000 \\
\hline 113 & $\mathrm{Ca} 3(\mathrm{PO} 4) 2$ & .4185 & .0000 & .0000 & $.4119 \mathrm{E}-08$ \\
\hline 20 & $\mathrm{CaC2O4}$ & .4472 & .0000 & .0000 & $.4455 \mathrm{E}-08$ \\
\hline 18 & $\mathrm{CaCO} 3$ & 4.428 & .0000 & .0000 & .0000 \\
\hline 78 & CaF2 & .1118 & .0000 & .0000 & $.1114 E-08$ \\
\hline 41 & $\mathrm{CnO}$ & .0000 & .0000 & .0000 & .0000 \\
\hline 19 & $\mathrm{CaSO} 4$ & .5253 & .0000 & .0000 & $.5233 E-08$ \\
\hline 29 & Carbon & .1118 & .0000 & .0000 & $.1114 E-08$ \\
\hline 26 & Co(COOHI $) 2$ & .0000 & .0000 & .0000 & $.9054 E-09$ \\
\hline 121 & $\mathrm{Co}(\mathrm{OII}) 2$ & .0000 & .0000 & .0000 & .0000 \\
\hline 53 & $\mathrm{Co}(\mathrm{OH}) \mathrm{3}$ & $.6708 \mathrm{E}-01$ & .0000 & .0000 & .0000 \\
\hline 59 & $\mathrm{CoO}$ & .0000 & .0000 & .0000 & .0000 \\
\hline 99 & $\mathrm{Cr}(\mathrm{Oll}) 3$ & .4250 & .0000 & .0000 & $.4284 \mathrm{E}-08$ \\
\hline 98 & Cr203 & .0000 & .0000 & .0000 & .0000 \\
\hline 42 & Cs20 & .0000 & .0000 & .0000 & $.1669 \mathrm{E}-18$ \\
\hline 137 & Cs20 Semi Vol & .0000 & .0000 & .0000 & .0000 \\
\hline 90 & Cscooll & .0000 & .0000 & .0000 & .0000 \\
\hline 96 & $\mathrm{CsCl}$ & .0000 & .0000 & .0000 & $.1074 E-13$ \\
\hline 136 & CsCl Semi Vol & .0000 & .0000 & .0000 & .0000 \\
\hline 8 & CsNO3 & $.1182 \mathrm{E}-01$ & .0000 & .0000 & $.1173 E-09$ \\
\hline 88 & CsResin & .0000 & .0000 & .0000 & .0000 \\
\hline 122 & $\mathrm{Cu}(\mathrm{COOHI}) 2$ & .0000 & .0000 & .0000 & $.1984 \mathrm{E}-08$ \\
\hline 52 & $\mathrm{Cu}(\mathrm{OHI}) 2$ & .1233 & .0000 & .0000 & .0000 \\
\hline 58 & $\mathrm{Cu} 20$ & .0000 & .0000 & .0000 & .0000 \\
\hline 64 & CuCoOIl & .0000 & .0000 & .0000 & .0000 \\
\hline 130 & CuO & .0000 & .0000 & .0000 & .0000 \\
\hline 18 & Fe(OH) & 83.72 & .0000 & .0000 & $.8370 \mathrm{E}-06$ \\
\hline 80 & Fe203 & .0000 & .0000 & .0000 & $.0000^{\circ}$ \\
\hline
\end{tabular}


MATERIAL BALANCE TABLES

SLUDGE-ONLX FEED

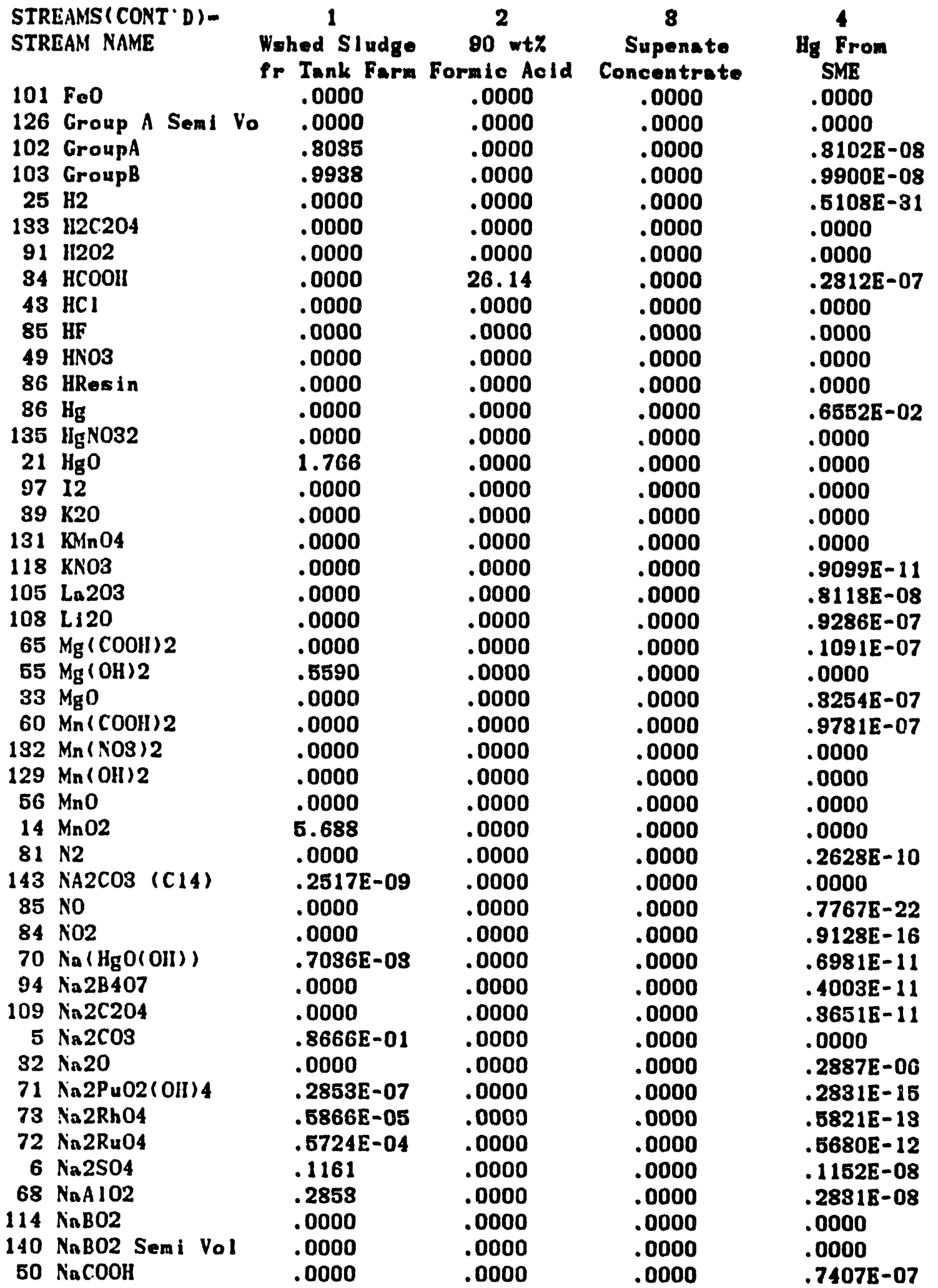


DPSP $80-1039$

MATERIAL BALANCE TABLES

SLUDGE-ONLY FEED

STREAMS (CONT'D )STREAM NAME

$7 \mathrm{NaCl}$

$188 \mathrm{NaCl}$ Semi Vol

$69 \mathrm{NaF}$

189 NaF Semi Vol

$12 \mathrm{NaI}$

125 Nal Semi Vol

3 NaN02

$2 \mathrm{NaN08}$

$4 \mathrm{NaOH}$

87 NaResin

$61 \mathrm{Ni}(\mathrm{COOH}) 2$

$17 \mathrm{Ni}(\mathrm{OH}) 2$

$40 \mathrm{NiO}$

8202

$67 \mathrm{PbO}$

$28 \mathrm{PbSO} 4$

$124 \mathrm{Pd}$

$123 \mathrm{Pd}(\mathrm{OII}) 2$

112 PdN082

110 PdO

$117 \mathrm{Pu}(\mathrm{COOH}) 4$

$76 \mathrm{Pu} 02$

$22 \mathrm{RhO2}$

$79 \mathrm{RuO2}$

23 Ru02 Semi Vol

83 RuO4

$88 \mathrm{SO2}$

$111 \mathrm{SiO2}$

115 Silica Gel

$48 \mathrm{Sr}(\mathrm{COOH}) 2$

$10 \mathrm{Sr}(\mathrm{NO3}) 2$

$127 \mathrm{Sr}(\mathrm{OH}) 2$

$80 \mathrm{SrCO}$

$46 \mathrm{Sr} 0$

89 SrRESIN

141 Surfactant

92 Th02

107 Ti02

119 Tritium

$93 \mathrm{U} 02$

$62 \mathrm{VO2}(\mathrm{COOH}) 2$

$16 \mathrm{U02}(\mathrm{Oll}) 2$

$27 \mathrm{Y}(\mathrm{COOH}) \mathrm{S}$

$11 \mathrm{Y}(\mathrm{N}$. 08$) 8$

$128 Y(\mathrm{OH}) \mathrm{S}$

$81 Y 2(\mathrm{CO}) 3$
Append ix II

Tnble 21-15

Pago 004 of 173

Dnte 09/30/\$2 Rev 09

\begin{tabular}{|c|c|c|c|}
\hline 1 & 2 & 8 & 4 \\
\hline $\begin{array}{l}\text { Wrhed Sludgo } \\
\text { fr Tank Fnrm }\end{array}$ & $\begin{array}{l}\text { So wt\% } \\
\text { Formic Acid }\end{array}$ & $\begin{array}{c}\text { Supenato } \\
\text { Concentrat }\end{array}$ & $\begin{array}{l}\text { IIg From } \\
\text { SYE }\end{array}$ \\
\hline .1153 & .0000 & .0000 & $.114 S E-93$ \\
\hline .0000 & .0000 & .0000 & .0060 \\
\hline $.2268 \mathrm{E}-03$ & .0000 & .0000 & $.6006 E-11$ \\
\hline .0000 & .0000 & .0000 & .0000 \\
\hline $.1118 \mathrm{E}-01$ & .0000 & .0000 & $.1112 \pi-09$ \\
\hline .0000 & .0000 & .0000 & .0000 \\
\hline .2073 & .0000 & .0000 & .0000 \\
\hline 8.635 & .0000 & .0000 & $.8622 \mathrm{E}-07$ \\
\hline 4.189 & .0000 & .0000 & .0000 \\
\hline .0000 & .0000 & .0000 & .0000 \\
\hline .0000 & .0000 & .0000 & $.3431 E-07$ \\
\hline 2.147 & .0000 & .0000 & .0000 \\
\hline .0000 & .0000 & .0000 & .0000 \\
\hline .0000 & .0000 & .0000 & $.1470 \mathrm{E}-10$ \\
\hline .0000 & .0000 & .0000 & .0000 \\
\hline .1562 & .0000 & .0000 & . $1556 \mathrm{E}-08$ \\
\hline .0000 & .0000 & .0000 & .0000 \\
\hline .0000 & .0000 & .0000 & .0000 \\
\hline .0000 & .0000 & .0000 & .0000 \\
\hline .0000 & .0000 & .0000 & .0000 \\
\hline .0000 & .0000 & .0000 & .0000 \\
\hline $.4064 \mathrm{E}-01$ & .0000 & .0000 & $.4048 \mathrm{E}-09$ \\
\hline . 1553E-01 & .0000 & .0000 & $.1547 \mathrm{E}-09$ \\
\hline $.7320 \mathrm{E}-01$ & .0000 & .0000 & $.7577 E-09$ \\
\hline .0000 & .0000 & .0000 & .0000 \\
\hline .0000 & .0000 & .0000 & .0000 \\
\hline .0000 & .0000 & .0000 & $.1760 \mathrm{E}-31$ \\
\hline 6.504 & .0000 & .0000 & $.1008 \mathrm{E}-05$ \\
\hline .0000 & .0000 & .0000 & .0000 \\
\hline .0000 & .0000 & .0000 & . 1393E-OS \\
\hline $.1645 E-06$ & .0000 & .0000 & $.1632 \mathrm{E}-14$ \\
\hline .0000 & .0000 & .0000 & .0000 \\
\hline .1162 & .0000 & .0000 & .0000 \\
\hline .0000 & .0000 & .0000 & .0000 \\
\hline .0000 & .0000 & .0000 & .0000 \\
\hline .0000 & .0000 & .0000 & .0000 \\
\hline .6371 & .0000 & .0000 & $.6347 \mathrm{E}-08$ \\
\hline .0000 & .0000 & .0000 & . 1623E-07 \\
\hline .7300E-09 & .0000 & .0000 & $.4007 \mathrm{E}-17$ \\
\hline .0000 & .0000 & .0000 & .0000 \\
\hline .0000 & .0000 & .0000 & . 4488E-07 \\
\hline 8.762 & .0000 & .0000 & .0000 \\
\hline .0000 & .0000 & .0000 & $.9548 \mathrm{E}-09$ \\
\hline $.1168 \mathrm{E}-06$ & .0000 & .0000 & $.1159 \mathrm{E}-14$ \\
\hline .0000 & .0000 & .0000 & .0000 \\
\hline $.7657 \mathrm{E}-01$ & .0000 & .0000 & .0000 \\
\hline
\end{tabular}


MATERIAL BALANCE TABLES

Date 09/80/82 Rev 09

\section{SLUDGE-ONLY FEED}

STREAMS (CONT'D)-

STREAM NAME

$\begin{array}{rl}47 & Y 203 \\ 100 & \mathrm{Z} 001 \text { l to } \\ 44 & \mathrm{Zn}(\mathrm{COOH}) 2 \\ 54 & \mathrm{Zn}(\mathrm{OII}) 2 \\ 57 & \mathrm{ZnO} \\ 104 & \mathrm{ZrO}\end{array}$

TOTAL FLOW, LB/IIR

VAPOR FLOW, CFM

LIQUID FLOH, GPM

DESIGN FLOH,

DENSITY, LBS/FT3

TEMPERATLRE, DEG C

PRESSURE, ATM

PI:ESSURE, PSIG

PRESSCRE, MM HG

PIIISE

EXTHALPY, PCV/HR

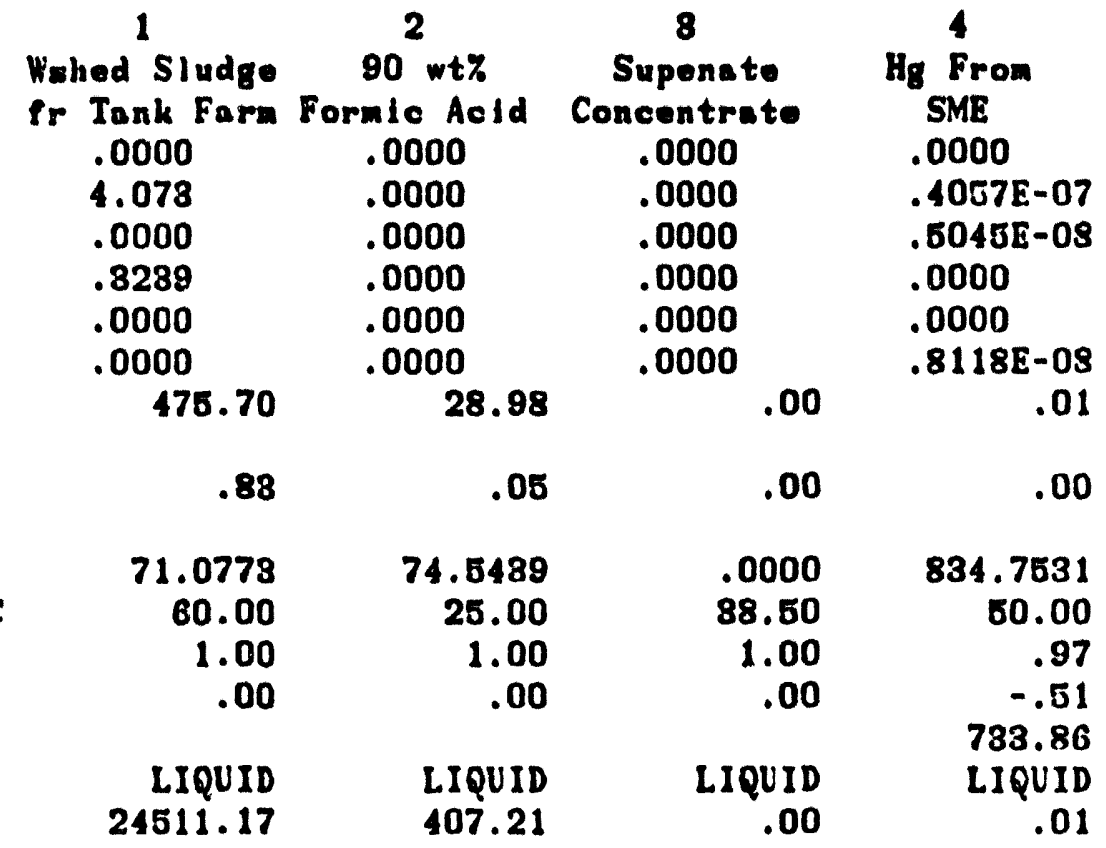


MATERIAL BALANCE TABLES

Date 09/80/82 Rev 09

SLUDCI:-ONLY FEED

STREAM NUMBERS -

STREAM NAME

COMPONENT F:.OWS, LB/HR

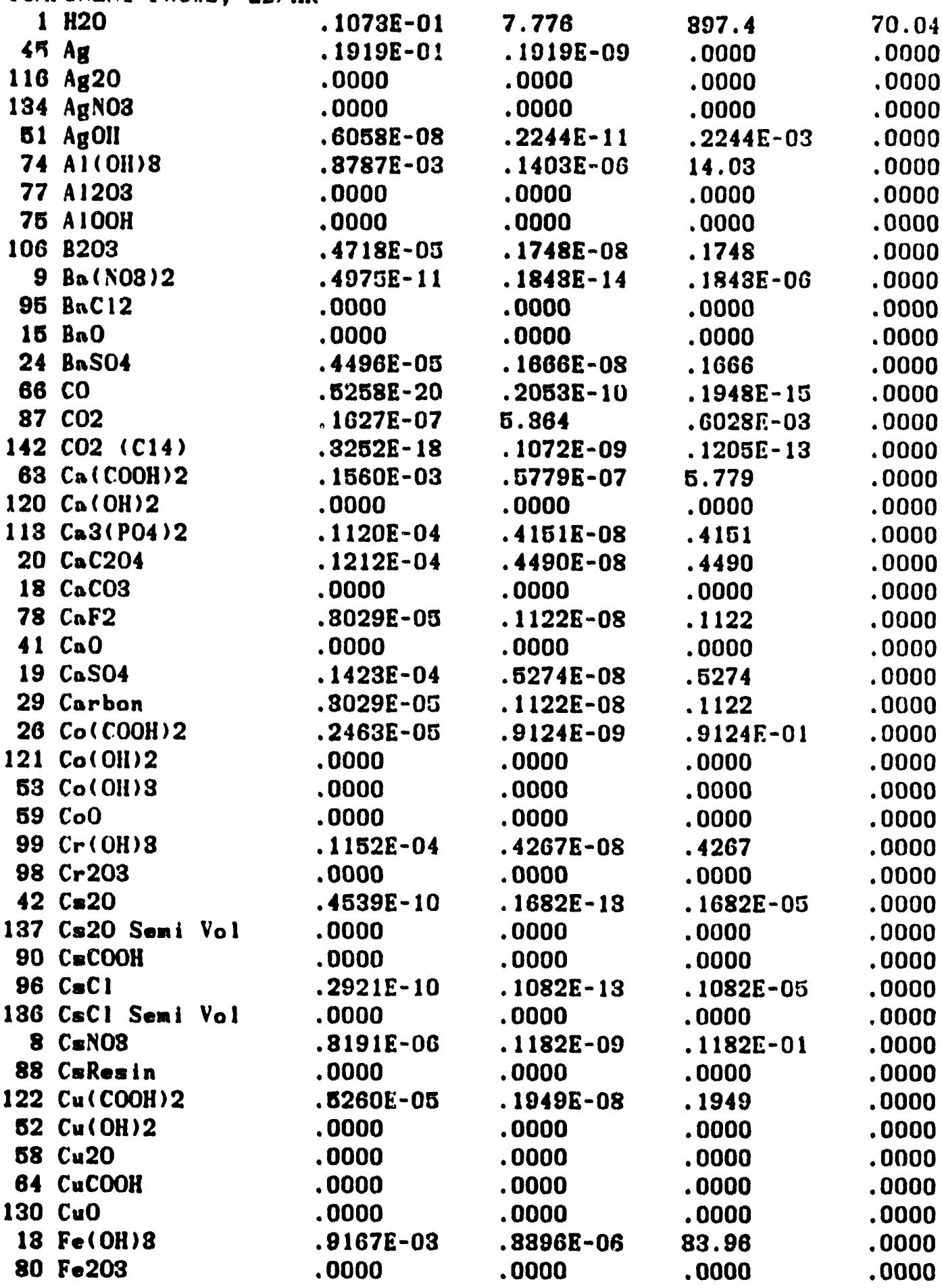


MATIRIAL BALANCE TABLES

Date 09/30/82 Rev 09

\section{SLLDGE-ONLY FEED}

STREAMS ( CONT'D)STREAM NAME

$101 \mathrm{FeO}$

126 Group A Semi Vo

102 GroupA

103 Group B

25112

133 H2C.2O4

$91 \mathrm{H2O2}$

34 IICOOII

$43 \mathrm{HCl}$

$85 \mathrm{HF}$

49 HNO3

86 HRes in

$36 \mathrm{Hg}$

$135 \mathrm{HgNO} 2$

$21 \mathrm{HgO}$

$\begin{array}{lll}97 & 12\end{array}$

$39 K 20$

$131 \mathrm{KMnO4}$

$118 \mathrm{KNO3}$

$105 \operatorname{Ln} 203$

$108 \mathrm{Li} 20$

$65 \mathrm{Mg}(\mathrm{COOII}) 2$

$55 \mathrm{Mg}(\mathrm{OH}) 2$

$33 \mathrm{MgO}$

$60 \mathrm{Mn}(\mathrm{COOH}) 2$

$132 \mathrm{Mn}(\mathrm{NO3}) 2$

$129 \mathrm{Mn}(\mathrm{OII}) 2$

$56 \mathrm{MnO}$

$14 \mathrm{MnO2}$

81 N2

143 NA2CO3 (C14)

35 NO

$84 \mathrm{N02}$

$70 \mathrm{ia}(\mathrm{HgO}(\mathrm{OH}))$

94 in $2 B 407$

$109 \mathrm{Na} 2 \mathrm{C2O4}$

$5 \mathrm{Na} 2 \mathrm{CO}$

$32 \mathrm{Na} 20$

$71 \mathrm{in} 2 \mathrm{Pu} 02(\mathrm{OH}) 4$

$73 \mathrm{Na} 2 \mathrm{RhO4}$

$72 \mathrm{Na} 2 \mathrm{Ru} 04$

$6 \mathrm{Na} 2 \mathrm{SO} 4$

$68 \mathrm{NaAlO2}$

$114 \mathrm{NinBO2}$

140 NaBO2 Semi Vol

$50 \mathrm{NnCOOH}$
6

Hg from SRAT Cond

SRAT to MWWT Vent to FAVC .0000

.0000

$.8437 E-05$

$.2693 E-04$

$.8976 E-19$

.0000

.0000

$.6732 \mathrm{E}-04$

.0000

.0000

.0000

.0000

1.622

.0000

$.4774 E-06$

.0000

.0000

.0000

$.2475 \mathrm{E}-07$

$.8687 \mathrm{E}-07$

$.1824 \mathrm{E}-05$

.2969E-04

.0000

$.5394 \mathrm{E}-06$

.2647E-03

.0000

.0000

.0000

.0000

.2944E-08

.0000

$.4317 \mathrm{E}-10$

. 3573E-10

. 1899E-07

$.1089 \mathrm{E}-07$

$.9930 \mathrm{E}-08$

.0000

$.6722 \mathrm{E}-05$

$.7701 E-12$

. 1583E-09

. 1545E-08

$.3133 E-05$

.7701E-05

.0000

.0000

.2015E-03
.0000

.0000

$.8126 \mathrm{E}-08$

$.9977 \mathrm{E}-08$

.3091E-09

.0000

.0000

$.4386 \mathrm{E}-01$

.0000

.0000

.0000

$.1835 \mathrm{E}-07$

.0000

$.1769 E-09$

.0000

.0000

.0000

$.9170 \mathrm{E}-11$

$.3219 \mathrm{E}-10$

$.6757 \mathrm{E}-09$

$.1100 E-07$

.0000

$.1999 \mathrm{E}-09$

$.9807 E-07$

.0000

.0000

.0000

.0000

64.93

.0000

$.9017 \mathrm{E}-01$

$.8550 E-04$

$.7036 \mathrm{E}-11$

$.4034 \mathrm{E}-11$

$.3679 E-11$

.0000

$.2490 \mathrm{E}-08$

$.2853 E-15$

$.5866 \mathrm{E}-13$

$.5724 \mathrm{E}-12$

$.1161 \mathrm{E}-08$

.2853E-08

.0000

.0000

$.7465 E-07$
.0000
7

SRAT Trans Rinso Hiater

fer to SME to Can Decon

.0000

.0000

.8126

.9977

$.8326 \mathrm{E}-14$

.0000

.0000

2.494

.0000

.0000

.0000

.0000

.0000

.0000

$.1769 \mathrm{E}-01$

.0000

.0000

.0000

$.9170 \mathrm{E}-03$

.8219E-02

$.6757 \mathrm{E}-01$

1.100

.0000

.1998E-01

8.807

.0000

.0000

.0000

.0000

$.1091 \mathrm{E}-03$

.0000

$.1600 \mathrm{E}-05$

$.1324 \mathrm{E}-05$

$.7036 \mathrm{E}-03$

$.4034 \mathrm{E}-03$

.3679E-03

.0000

.2490

.2853E-07

.5866E-05

.5724E-04

.1161

.2853

.0000

.0000

7.464
.0000

.0000

.0000

.0000

.0000

.0000

.0000

.0000

.0000

.0000

.0000

.0000

.0000

.0000

.0000

.0000

.0000

.0000

.0000

.0000

.0000

.0000

.0000

.0000

.0000

.0000

.0000

.0000

.0000

.0000

.0000

.0000

.0000

.0000

.0000

.0000

.0000

.0000

.0000

.0000

.0000

.0000

.0000

.0000

.0000
.0000 
DPSP $80-1038$

MATERIAL BALANCE TABLES SLUDGE - ONLY FEED

STREAMS (CONT'D)STREAM NAME

$7 \mathrm{NaCl}$

$138 \mathrm{NaCl}$ Semi Vol

$69 \mathrm{NaF}$

$139 \mathrm{NaF}$ Semi Vol

$12 \mathrm{NaI}$

$125 \mathrm{NaI}$ Semi Vol

$8 \mathrm{NaNO2}$

$2 \mathrm{NaNO3}$

$4 \mathrm{NaOH}$

87 NaResin

$61 \mathrm{Ni}(\mathrm{COOHI}) 2$

$17 \mathrm{Ni}(\mathrm{OII}) 2$

$40 \mathrm{NiO}$

8202

$67 \mathrm{PbO}$

$28 \mathrm{PbSO4}$

$124 \mathrm{Pd}$

$123 \mathrm{Pd}(\mathrm{OH}) 2$

112 PdNO32

110 PdO

$117 \mathrm{Pu}(\mathrm{COOII}) 4$

$76 \mathrm{Pu} 02$

$22 \mathrm{Rh} 02$

$79 \mathrm{RuO2}$

23 Ru02 Semi Vol

$83 \mathrm{Ru} 04$

$88 \mathrm{SO} 2$

$111 \mathrm{SiO2}$

$115 \mathrm{Silica}$ Gel

$48 \mathrm{Sr}(\mathrm{COOH}) 2$

$10 \mathrm{Sr}(\mathrm{NO}) 2$

$127 \mathrm{Sr}(\mathrm{OH}) 2$

$30 \mathrm{SrCO}$

$46 \mathrm{Sr} 0$

89 SrRESIN

141 Surfactant

$92 \mathrm{ThO2}$

$107 \mathrm{TiO2}$

119 Tritium

$93 \quad \mathrm{V02}$

$62 \mathrm{VO} 2(\mathrm{COOH}) 2$

$16 \mathrm{VO}(\mathrm{OII}) 2$

$27 \mathrm{Y}(\mathrm{COOH}) 3$

$11 \mathrm{Y}(\mathrm{N} 03) 8$

$128 \mathrm{Y}(\mathrm{OHI}) \mathrm{3}$

$81 \mathrm{Y} 2(\mathrm{CO}) 3$
Appendix $\mathrm{H}$

Table 21-15

Page 008 of 173

Date 09/30/82 Rev 09

\begin{tabular}{|c|c|c|c|}
\hline 5 & 6 & 7 & 8 \\
\hline Hg from & SRAT Cond & SRAT Trans & Rinse Hinter \\
\hline SRAT to MWNT & Vent to FAVC & fer to SWE & to Cin Decon \\
\hline $.3123 E-05$ & $.1157 E-08$ & .1157 & .0000 \\
\hline .0000 & .0000 & .0000 & .0000 \\
\hline $.1634 \mathrm{E}-07$ & $.6053 \mathrm{E}-11$ & $.6052 E-05$ & .0000 \\
\hline .0000 & .0000 & .0000 & .0000 \\
\hline $.3025 E-06$ & $.1121 E-09$ & $.1121 \mathrm{E}-01$ & .0000 \\
\hline .0000 & .0000 & .0000 & .0000 \\
\hline .0000 & .0000 & .0000 & .0000 \\
\hline $.9852 E-04$ & $.3650 \mathrm{E}-07$ & 3.650 & .0000 \\
\hline .0000 & .0000 & .0000 & .0000 \\
\hline .0000 & .0000 & .0000 & .0000 \\
\hline $.9383 E-04$ & $.3458 E-07$ & 3.458 & .0000 \\
\hline .0000 & .0000 & .0000 & .0000 \\
\hline .0000 & .0000 & .0000 & .0000 \\
\hline $.1600 \mathrm{E}-08$ & 19.61 & $.5929 \mathrm{E}-04$ & .0000 \\
\hline .0000 & .0000 & .0000 & .0000 \\
\hline $.4232 E-05$ & $.1568 E-08$ & .1568 & .0000 \\
\hline .0000 & .0000 & .0000 & .0000 \\
\hline .0000 & .0000 & .0000 & .0000 \\
\hline .0000 & .0000 & .0000 & .0000 \\
\hline .0000 & .0000 & .0000 & .0000 \\
\hline .0000 & .0000 & .0000 & .0000 \\
\hline $.1101 E-05$ & $.4080 \mathrm{E}-09$ & $.4080 \mathrm{E}-01$ & .0000 \\
\hline $.4207 E-06$ & $.1559 \mathrm{E}-09$ & . 1559E-01 & .0000 \\
\hline $.2061 E-05$ & $.7636 \mathrm{E}-09$ & $.7636 E-01$ & .0000 \\
\hline .0000 & .0000 & .0000 & .0000 \\
\hline .0000 & .0000 & .0000 & .0000 \\
\hline $.6705 E-20$ & $.1185 \mathrm{E}-10$ & $.2484 E-15$ & .0000 \\
\hline $.1954 \mathrm{E}-03$ & $.7240 \mathrm{E}-07$ & 7.240 & .0000 \\
\hline .0000 & .0000 & .0000 & .0000 \\
\hline $.3790 E-05$ & $.1404 E-08$ & .1404 & .0000 \\
\hline $.4439 E-11$ & $.1645 E-14$ & $.1645 E-06$ & .0000 \\
\hline .0000 & .0000 & .0000 & .0000 \\
\hline .0000 & .0000 & .0000 & .0000 \\
\hline .0000 & .0000 & .0000 & .0000 \\
\hline .0000 & .0000 & .0000 & .0000 \\
\hline .0000 & .0000 & .0000 & .0000 \\
\hline . 1726E-04 & $.6396 E-08$ & .6396 & .0000 \\
\hline $.1676 \mathrm{E}-06$ & $.6210 \mathrm{E}-10$ & $.6210 E-02$ & .0000 \\
\hline $.1942 E-18$ & $.1405 \mathrm{E}-10$ & $.7197 E-09$ & .0000 \\
\hline .0000 & .0000 & .0000 & .0000 \\
\hline $.1207 \mathrm{E}-08$ & .4473E-07 & 4.473 & .0000 \\
\hline .0000 & .0000 & .0000 & .0000 \\
\hline $.2597 E-05$ & $.9622 E-09$ & $.9622 E-01$ & .0000 \\
\hline $.8152 E-11$ & $.1168 E-14$ & $.1168 \mathrm{E}-06$ & .0000 \\
\hline .0000 & .0000 & .0000 & .0000 \\
\hline .0000 & .0000 & .0000 & .0000 \\
\hline
\end{tabular}


MATERIAL BALANCE TABLES

Date 09/30/82 Rev 09

SLUDGE-ONLY FEED

STREAMS (CONT'D)-

STREAM NAME

47 Y203

100 Zeolite

$44 \mathrm{Zn}(\mathrm{COOH}) 2$

$54 \mathrm{Zn}(\mathrm{OH}) 2$

$57 \mathrm{ZnO}$

$104 \mathrm{ZrO}$

TOTAL FLON, LB/HR

VAPOR FLOH, CFM

LIOUID FLOW, GPM

DESIGN FLOW,

DENSITY, LBS/FT3

TEMPERATURE, DEG C

PRESSURE, ATM

PRESSURE; PSIG

5

Hg from SRAT Cond

SRAT to MWWT Vent to FAVC

.0000

.0000

$.1104 \mathrm{E}-03$

4089E- 07

.1372E-04

.0000

. 5084E-08

.0000

.0000

.0000

7

SRAT Trans Rinse Water

fer to SME to Cnn Decon

.0000

4.089

.0000

.5084

.0000

.0000

.0000

.0000

.0000

$.8687 \mathrm{E}-07$

$.8219 \mathrm{E}-10$

1.65

97.81

.00

25.51

773.8155

50.00

1.00

PRESSURE, MM HG

.00

$.8219 \mathrm{E}-02$

.0000

.0000

PIIASE

ENTILALPY, PCU/HR

LIQUID

8.81

$$
\begin{array}{r}
.0639 \\
50.00 \\
.97 \\
-.51 \\
733.86 \\
\text { VAPOR } \\
215.33
\end{array}
$$

.88

70.04

.14

70.8346

62.4300

50.00

30.00

1.00

137.09

1999.98

LIQUID

21130.03

LIQUID

2133.73 
DPSP 80-1033

MATERIAL BALANCE TABLES

SLUDGE-ONLY FEED

STREAM NUMBERS -

STREAM NAME

COMPONENT FLOHS, LB/HR

\section{$1 \mathrm{H} 20$}

$45 \mathrm{Ag}$

116 Ag20

$184 \mathrm{AgNO}$

$51 \mathrm{AgOH}$

$74 \mathrm{Al}(\mathrm{OH}) \mathrm{S}$

77 A 1203

$75 \mathrm{AlOOH}$

106 B203

$9 \mathrm{Ba}(\mathrm{NO3}) 2$

$95 \mathrm{BaCl} 2$

$15 \mathrm{BaO}$

$24 \mathrm{BaSO} 4$

$66 \mathrm{CO}$

$87 \mathrm{CO} 2$

$142 \mathrm{CO2}$ ( $\mathrm{C14})$

$63 \mathrm{Ca}(\mathrm{COOH}) 2$

$120 \mathrm{Ca}(\mathrm{OH}) 2$

$113 \mathrm{Ca} 3(\mathrm{PO}) 2$

$20 \mathrm{CaC204}$

$18 \mathrm{CaCO} 3$

$78 \mathrm{CaF2}$

$41 \mathrm{CaO}$

$19 \mathrm{CaSO} 4$

29 Carbon

$26 \mathrm{Co}(\mathrm{COOH}) 2$

$121 \mathrm{Co}(\mathrm{OH}) 2$

$53 \mathrm{Co}(\mathrm{OH}) 3$

$59 \mathrm{CoO}$

$99 \mathrm{Cr}(\mathrm{OH}) 3$

$98 \mathrm{Cr} 203$

$42 \mathrm{Cs} 20$

137 Cs20 Semi Vol

$90 \mathrm{CsCOOH}$

$96 \mathrm{CsCl}$

$136 \mathrm{CsCl}$ Seml Vol

$8 \mathrm{CsNO3}$

88 CsResin

$122 \mathrm{Cu}(\mathrm{COOH}) 2$

$52 \mathrm{Cu}(\mathrm{OII}) 2$

$58 \mathrm{Cu} 20$

$64 \mathrm{CuCOOH}$

$180 \mathrm{CuO}$

$13 \mathrm{Fe}(\mathrm{OII}) \mathrm{3}$

$80 \mathrm{Fe} 203$
116.8

.0000

.0000

.0000

.0000

.0000

.0000

.0000

6.616

.0000

.0000

.0000

.0000

.0000

.0000

.0000

.0000

.0000

.0000

.0000

.0000

.0000

.0000

.0000

.0000

.0000

.0000

.0000

.0000

.0000

.0000

.0000

.0000

.0000

.0000

.0000

.0000

.0000

.0000

.0000

.0000

.0000

.0000

.0000

.0000
Appendix $\mathrm{H}$

Table 21-15

Page 010 of 173

Date 09/30/82 Rey 09

10

FCT Vent to FAVC

\subsection{3}

.0000

.0000

.0000

.0000

.0000

.0000

.0000

$.1757 E-05$

.0000

.0000

.0000

.0000

.0000

.0000

.0000

.0000

.0000

.0000

.0000

.0000

.0000

.0000

.0000

.0000

.0000

.0000

.0000

.0000

.0000

.0000

.0000

.0000

.0000

.0000

.0000

.0000

.0000

.0000

.0000

.0000

.0000

.0000

.0000

.0000
11

SFIIT Vent Decon Frit to FAVC Slrry to SIIE

\subsection{7}

.0000

.0000

.0000

.0000

.0000

.0000

.0000

$.8911 \mathrm{E}-06$

.0000

.0000

.0000

.0000

.0000

.0000

.0000

.0000

.0000

.0000

.0000

.0000

.0000

.0000

.0000

.0000

.0000

.0000

.0000

.0000

.0000

.0000

.0000

.0000

.0000

.0000

.0000

.0000

.0000

.0000

.0000

.0000

.0000

.0000

.0000

.0000
178.3

.0000

.0000

.0000

.0000

.0000

.0000

.0000

6.616

.0000

.0000

.0000

.0000

.0000

.0000

.0000

.0000

.0000

.0000

.0000

.0000

.0000

.0000

.0000

.0000

.0000

.0000

.0000

.0000

.0000

.0000

.0000

.0000

.0000

.0000

.0000

.0000

.0000

.0000

.0000

.0000

.0000

.0000

.0000

$.0000^{\circ}$ 
MATERIAL BHLANCE TABLES

Date 09/80/82 Rev 09

SLUDGE-ONLY FEED

STREAMS (CONT'D)-

STREAM NAME

$101 \mathrm{FeO}$

$\frac{9}{\text { Frit Slurry }}$
to Can Decon

.0000

126 Group a Semi Vo

.0000

102 GroupA

.0000

103 GroupB

.0000

$25 \mathrm{II} 2$

$133 \mathrm{H2C2O4}$

.0000

.0000

9111202

$34 \mathrm{HCOOH}$

.0000

$43 \mathrm{HCl}$

$85 \mathrm{HF}$

49 IINO3

86 HResin

$36 \mathrm{Hg}$

135 llgN032

.4504

.0000

.0000

.0000

.0000

.0000

.0000

$21 \mathrm{HgO}$

$97 \quad 12$

$39 \mathrm{~K} 20$

$131 \mathrm{KMnO4}$

$118 \mathrm{KNO3}$

105 La203

108 Li 20

$65 \mathrm{Mg}(\mathrm{COOH}) 2$

.0000

.0000

.0000

.0000

.0000

.2250

2.566

.0000

$55 \mathrm{Mg}(\mathrm{OH}) 2$

.0000

$33 \mathrm{MgO}$

.9002

$60 \mathrm{Mn}(\mathrm{COOH}) 2$

.0000

$132 \mathrm{Mn}(\mathrm{NO}) 2$

.0000

$129 \mathrm{Mn}(\mathrm{OII}) 2$

$56 \mathrm{MnO}$

$14 \mathrm{MnO2}$

$81 \mathrm{~N} 2$

143 NA2CO3 (C14)

.0000

.0000

.0000

.0000

.0000

$35 \mathrm{NO}$

84 NO2

.0000

.0000

$70 \mathrm{Na}(\mathrm{HgO}(\mathrm{OHI}))$

.0000

$94 \quad \mathrm{~N} 2 \mathrm{~B} 407$

$109 \mathrm{Na} 2 C_{204}$

$5 \mathrm{Na} 2 \mathrm{CO3}$

$82 \mathrm{~N} 220$

.0000

.0000

.0000

$71 \mathrm{Na2Pu02(OH)4}$

7.967

.0000

.0000

.0000

$72 \mathrm{Na2RuO4}$

.0000

$6 \mathrm{Na2SO4}$

$68 \mathrm{NaAlO2}$

.0000

.0000

114 NaB02

.0000

$140 \mathrm{NaBO2}$ Semi Vol

.0000

10
FCT Vent
to FAVC
.0000
.0000
.0000
.0000
.0000
.0000
.0000
$.2977 E-01$
.0000
.0000
.0000
.0000
.0000
.0000
.0000
.0000
.0000
.0000
.0000
$.5976 E-07$
$.6812 E-06$
.0000
.0000
$.2390 E-06$
.0000
.0000
.0000
.0000
.0000
875.9
.0000
.0000
.0000
.0000
.0000
.0000
.0000
$.2115 E-05$
.0000
.0000
.0000
.0000
.0000
.0000
.0000
.0000

11
SFHT Vent
to FAVC

.0000

.0000

.0000

.0000

.0000

.0000

.0000

$.1460 \mathrm{E}-01$

.0000

.0000

.0000

.0000

.0000

.0000

.0000

.0000

.0000

.0000

.0000

$.8031 E-07$

.8455E-06

.0000

.0000

$.1212 E-0 G$

.0000

.0000

.0000

.0000

.0000

188.0

.0000

.0000

.0000

.0000

.0000

.0000

.0000

$.1073 E-05$

.0000

.0000

.0000

.0000

.0000

.0000

.0000

.0000
12

Decon Frit

Sirry to SME

.0000

.0000

.0000

.0000

.0000

.0000

.0000

.4060

.0000

.0000

.0000

.0000

.0000

.0000

.0000

.0000

.0000

.0000

.0000

.2250

2.566

.0000

.0000

.9002

.0000

.0000

.0000

.0000

.0000

$.2780 \mathrm{E}-02$

.0000

.0000

.0000

.0000

.0000

.0000

.0000

7.967

.0000

.0000

.0000

.0000

.0000

.0000

.0000

.0000 
DPSP $80-1088$

MATERIAL BALANCE TABLES

SLUDGE-ONLY FEED

STREAMS (CONT'D)STREAM NAME

$7 \mathrm{NnCl}$

$138 \mathrm{NaCl}$ Seni Vol

$69 \mathrm{NaF}$

$139 \mathrm{NaF}$ Semi Vol

$12 \mathrm{NaI}$

$125 \mathrm{NaI}$ Semi Vol

$3 \mathrm{NaNO2}$

$2 \mathrm{NaNO3}$

$4 \mathrm{NaOH}$

87 NaResin

$61 \mathrm{Ni}(\mathrm{COOH}) 2$

$17 \mathrm{Ni}(\mathrm{OH}) 2$

$40 \mathrm{NiO}$

8202

$67 \mathrm{PbO}$

$28 \mathrm{PbSO} 04$

$124 \mathrm{Pd}$

$128 \mathrm{Pd}(\mathrm{OH}) 2$

112 PdNO32

$110 \mathrm{PdO}$

$117 \mathrm{Pu}(\mathrm{COOH}) 4$

$76 \mathrm{Pu}_{\mathrm{u}} \mathrm{2}$

$22 \mathrm{RhO2}$

$79 \mathrm{Ru} 02$

28 Ru02 Semi Vol

$83 \mathrm{RuO4}$

$88 \mathrm{SO2}$

$111 \mathrm{SiO} 2$

115 Silica Gel

$48 \mathrm{Sr}(\mathrm{COOII}) 2$

$10 \mathrm{Sr}(\mathrm{N} 03) 2$

$127 \mathrm{Sr}(\mathrm{OH}) 2$

$80 \mathrm{SrCO}$

46 Sro

89 SrRESIN

141 Surfectant

$92 \mathrm{Th} 02$

$107 \mathrm{Ti02}$

119 Tritium

$93 \mathrm{V02}$

$62 \mathrm{VO} 2(\mathrm{COOH}) 2$

$16 \mathrm{VO} 2(\mathrm{OH}) 2$

$27 \mathrm{Y}(\mathrm{COOH}) 3$

$11 Y(N O 3) 3$

$128 \mathrm{Y}(\mathrm{OH}) \mathrm{S}$

$81 Y 2(\cos ) 8$
9

Frit Slurry

to Can Decon .0000

.0000

.0000

.0000

.0000

.0000

.0000

.0000

.0000

.0000

.0000

.0000

.0000

.0000

.0000

.0000

.0000

.0000

.0000

.0000

.0000

.0000

.0000

.0000

.0000

.0000

.0000

26.06

.0000

.0000

.0000

.0000

.0000

.0000

.0000

.0000

.0000

.4501

.0000

.0000

.0000

.0000

.0000

.0000

.0000

.0000
Appendix $\mathrm{H}$

Table 21-15

Page 012 of 173

Date 09/30/82 Rev 09 
MATERIAL BALAYCE TABLES

Date 09/30/82 Rev 09

SLUDGE-ONLY FEED

STREAMS (CONT'D) -

STREAM NAME

$47 \Upsilon 203$

100 Zeolite

$44 \mathrm{Zn}(\mathrm{COOH}) 2$

$54 \mathrm{Zn}(\mathrm{Oll}) 2$

$57 \mathrm{ZnO}$

$104 \mathrm{Zr} 02$

TOTAL FLOH, LB/HR

VAPOR FLOH: CFM

$\begin{array}{cc}9 & 10 \\ \text { Frit Slurry } & \text { FCT Vent } \\ \text { to Cnn Decon } & \text { to FAVC } \\ .0000 & .0000 \\ .0000 & .0000 \\ .0000 & .0000 \\ .0000 & .0000 \\ .0000 & .0000 \\ .2250 & .5976 E-07 \\ 162.25 & 503.44 \\ & 121.94 \\ .27 & \end{array}$

$\begin{array}{cc}11 & 12 \\ \text { SFIIT Vent } & \begin{array}{c}\text { Decon Frit } \\ \text { to FAVC }\end{array} \\ \text { SIrry to SME } \\ .0000 & .0000 \\ .0000 & .0000 \\ .0000 & .0000 \\ .0000 & .0000 \\ .0000 & .0000 \\ .8031 \mathrm{E}-07 & .2250 \\ 251.74 & 223.69 \\ 60.98 & \\ & \end{array}$

DESIGN FLOW,

DEXSITI, LES/FTZ

TEMPERATURE, DEG C

73.7839

.0688

29.99

80.00

PRESSLRE, ATM

PRESSURE, PSIG

PRESSURE, MM HG

PHASE

5.08

59.96

.97

$-.51$

733.86

ENTHALPY, PCU/HR

LIQUID

VAPOR

.0688

29.99

.97

$-.51$

733.86

604.57

$-22733.39$

VAPOR

70.2707

80.00

.97

$-.51$

738.86

LIQUID

$-11368.04$

5934.74 
DPSP $80-1033$

MATERIAL BALANCE TABLES

SLUDGE-ONLY FEED

STREAM NUMBERS STREAM NAME

COMPONENT FLOHS, LB/HR

\begin{tabular}{|c|c|c|c|}
\hline 1 & H2O & .0000 & 78.70 \\
\hline 45 & Ag & .0000 & .0000 \\
\hline 116 & Ag20 & .0000 & .0000 \\
\hline 184 & AgNiOs & .0000 & .0000 \\
\hline 51 & AgOH & .0000 & .0000 \\
\hline 74 & Ai(OII) 3 & .0000 & .0000 \\
\hline 77 & $A 1208$ & .0000 & .0000 \\
\hline 75 & AlOOH & .0000 & .0000 \\
\hline 106 & B203 & .0000 & 17.34 \\
\hline 9 & $\mathrm{Ba}(\mathrm{N} 03) 2$ & .0000 & .0000 \\
\hline 95 & $\mathrm{BaCl2}$ & .0000 & .0000 \\
\hline 15 & $\mathrm{BaO}$ & .0000 & .0000 \\
\hline 24 & $\mathrm{BaSO} 4$ & .0000 & .0000 \\
\hline 66 & CO & .0000 & .0000 \\
\hline 87 & $\mathrm{CO} 2$ & .0000 & .0000 \\
\hline 142 & $\operatorname{co2}(\mathrm{C} 14)$ & .0000 & .0000 \\
\hline 63 & $\mathrm{Ce}(\mathrm{COOH}) 2$ & .0000 & .0000 \\
\hline 120 & $\mathrm{Ca}(\mathrm{OH}) 2$ & .0000 & .0000 \\
\hline 113 & $\mathrm{C} \approx 8(\mathrm{P} 04) 2$ & .0000 & .0000 \\
\hline 20 & $\mathrm{CaC2O4}$ & .0000 & .0000 \\
\hline 18 & $\mathrm{CaCOS}$ & .0000 & .0000 \\
\hline 78 & $\mathrm{CaF2}$ & .0000 & .0000 \\
\hline 41 & $\mathrm{Ca} 0$ & .0000 & .0000 \\
\hline 19 & CaSO4 & .0000 & .0000 \\
\hline 29 & Carbon & .0000 & .0000 \\
\hline 26 & $\mathrm{Co}(\mathrm{COOH}) 2$ & .0000 & .0000 \\
\hline 121 & $\mathrm{Co}(\mathrm{OH}) 2$ & .0000 & .0000 \\
\hline 58 & $\mathrm{Co}(\mathrm{OH}) 8$ & .0000 & .0000 \\
\hline 59 & $\mathrm{CoO}$ & .0000 & .0000 \\
\hline 99 & $\mathrm{Cr}(\mathrm{OHI}) 3$ & .0000 & .0000 \\
\hline 98 & Cr203 & .0000 & .0000 \\
\hline 42 & Cs20 & .0000 & .0000 \\
\hline 187 & Cs20 Semi Vol & .0000 & .0000 \\
\hline 90 & $\mathrm{Cs} \mathrm{COOH}$ & .0000 & .0000 \\
\hline 96 & $\mathrm{Cs} C l$ & .0000 & .0000 \\
\hline 186 & Cscl Semi Vol & .0000 & .0000 \\
\hline & CsNO3 & .0000 & .0000 \\
\hline 88 & CsResin & .0000 & .0000 \\
\hline 122 & $\mathrm{Cu}(\mathrm{COOH}) 2$ & .0000 & .0000 \\
\hline 52 & $\mathrm{Cu}(\mathrm{OH}) 2$ & .0000 & .0000 \\
\hline 58 & Cu2O & .0000 & .0000 \\
\hline 64 & $\mathrm{CuCOOH}$ & .0000 & .0000 \\
\hline 130 & CuO & .0000 & .0000 \\
\hline 18 & Fe(OlI) 3 & .0000 & .0000 \\
\hline 80 & Fe203 & .0000 & .000 \\
\hline
\end{tabular}

Appendix H

Table 21-15

Page 014 of 173

Date $09 / 30 / 82$ Rev 09
$1314 \quad 15 \quad 16$

Waste Sand Fresh Frit SME Condens SME Cndnsate Sirry to SME ate to SMECT to RCT

78.70

\section{2}

$.1166 E-07 \quad .0000$

$.0000 \quad .0000$

$.0000 \quad .0000$

$.0000 \quad .6882 \mathrm{E}-09$

$.8439 E-03 \quad .8445 E-03$

.0000

.0000

$.1451 E-02$

$.1108 \mathrm{E}-10$

.0000

.0000

$.1002 \mathrm{E}-04$

$.1948 \mathrm{E}-15$

$.4235 \mathrm{E}-02$

$.1205 \mathrm{E}-13$

$.3475 \mathrm{E}-03$

.0000

$.2497 E-0.4$

.2700E-04

.0000

$.6750 \mathrm{E}-05$

.0000

$.3172 E-04$

$.6750 \mathrm{E}-05$

$.5487 \mathrm{E}-05$

.0000

.0000

.0000

$.2566 \mathrm{E}-04$

.0000

$.1012 \mathrm{E}-09$

.0000

.0000

$.6508 \mathrm{E}-10$

.0000

$.7110 \mathrm{E}-\mathrm{OC}$

.0000

$.1172 \mathrm{E}-04$

.0000

.0000

.0000

.0000

.2043E-02

.0000
.0000

.0000

$.145 \cdot 4 E-02$

$.1109 E-10$

.0000

.0000

$.1003 E-04$

$.1013 E-14$

.3081E-05

$.1129 \mathrm{E}-16$

.3478E-03

$.1593 \mathrm{E}-09$

.2498E-04

$.2702 E-04$

.0000

$.6755 E-05$

.0000

$.3174 E-01$

$.6755 \mathrm{E}-05$

$.5491 \mathrm{E}-05$

$.2756 \mathrm{E}-11$

.0000

.0000

$.2568 \mathrm{E}-04$

.0000

$.1012 \mathrm{E}-09$

.0000

.0000

$.6799 \mathrm{E}-10$

.0000

$.7115 \mathrm{E}-06$

.0000

$.1173 E-04$

. $5995 \mathrm{E}-11$

.0000

.0000

.0000

.2044E-02

.0000 
DPSP $80-1033$

MATERIAL BALANCE TABLES

SLUDGE-ONLY FEED

STREAMS (CONT'D) -

STREAM NAME

$101 \mathrm{FeO}$

126 Group A Semi Vo

102 GroupA

103 Group B

$25 \mathrm{H} 2$

$133 \mathrm{H} 2 \mathrm{C} 204$

$91 \mathrm{H2O2}$

$84 \mathrm{IICOOH}$

$43 \mathrm{HCl}$

85 HF

49 HNO3

86 HResin

$36 \mathrm{Hg}$

$135 \mathrm{HgN032}$

$21 \mathrm{HgO}$

9712

$39 \mathrm{~K} 20$

$131 \mathrm{kNin} 04$

$118 \mathrm{KNO3}$

105 La203

$108 \mathrm{Li} 20$

$65 \mathrm{Mg}(\mathrm{COOH}) 2$

$55 \mathrm{Mg}(\mathrm{OHI}) 2$

$83 \mathrm{MgO}$

$60 \mathrm{Mn}(\mathrm{COOH}) 2$

$132 \mathrm{Mn}(\mathrm{NO3}) 2$

$129 \mathrm{Mn}(\mathrm{Oll}) 2$

$56 \mathrm{MnO}$

$14 \mathrm{MnO2}$

81 N2

143 NA2CO3 (C14)

$35 \mathrm{NO}$

$84 \mathrm{NO} 2$

$\left.70 \mathrm{Na}\left(\mathrm{HgO}_{\mathrm{g}} \mathrm{OH}\right)\right)$

$94 \mathrm{Nn} 2 \mathrm{~B} 407$

$109 \mathrm{Na} 2 \mathrm{C} 204$

$5 \mathrm{Na} 2 \mathrm{CO} 3$

$82 \mathrm{Na} 20$

$71 \mathrm{Na} 2 \mathrm{Pu} 02$ (OII) 4

$73 \mathrm{Nn} 2 \mathrm{RhO4}$

$72 \mathrm{Na} 2 \mathrm{Ru} 04$

$6 \mathrm{Na} 2 \mathrm{SO}_{4}$

$68 \mathrm{NaAlO2}$

$114 \mathrm{NaBO2}$

140 NaB02 Semi Vol

$50 \mathrm{~N} 2 \mathrm{COOH}$
18

Waste Sand

.0000

.0000

.0000

.0000

.0000

.0000

.0000

.0000

.0000

.0000

.0000

.0000

.0000

.0000

.0000

.0000

.0000

.0000

.0000

.0000

.0000

.0000

.0000

.0000

.0000

.0000

.0000

.0000

.0000

.0000

.0000

.0000

.0000

.0000

.0000

.0000

.0000

.0000

.0000

.0000

.0000

.0000

.0000

.0000

.0000

.0000
Appendix H

Table 21-15

Page 015 of 173

Date 09/30/82 Rev 09 
DPSP $80-1038$

MATERIAL BALANCE TABLES

SLLDGE-ONLY FEED

STREAMS (CONT'D)-

STREAM NAME

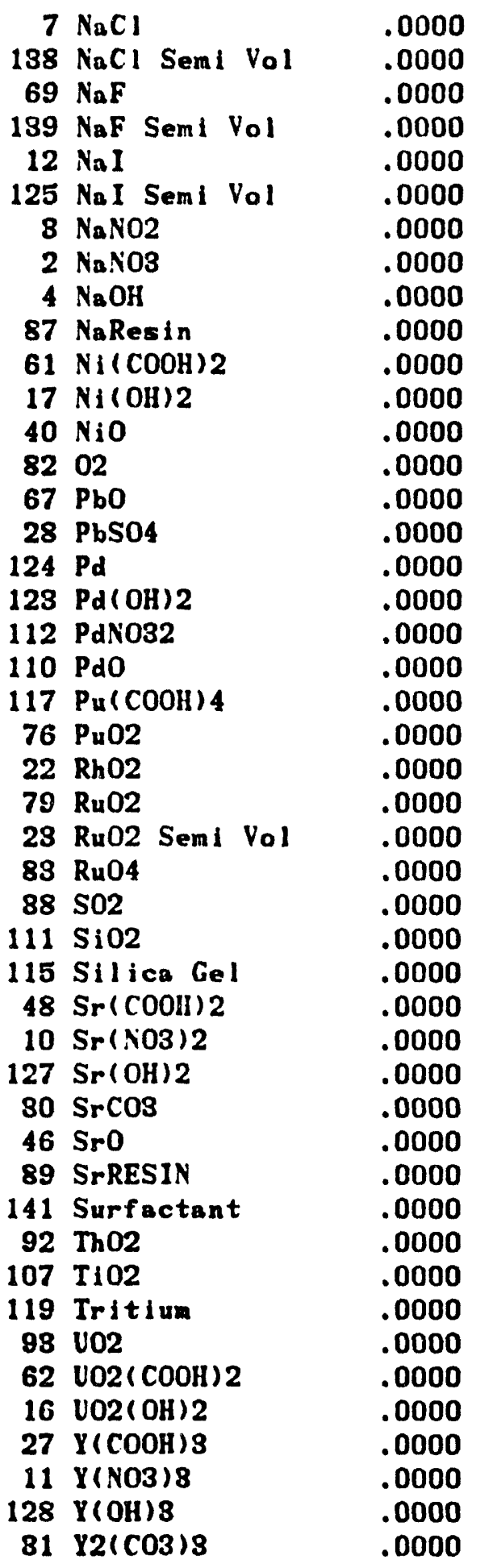

13

Waste Sand
Appendix H

Table 21-15

Page 016 of 173

Date 09/30/82 Rev 09 Sirry

14 Frit SNE

Fresh Frit SWE Condens SME Cndnsiote

.0000

.0000

.0000

.0000

.0000

.0000

.0000

.0000

.0000

.0000

.0000

.0000

.0000

.0000

.0000

.0000

.0000

.0000

.0000

.0000

.0000

.0000

.0000

.0000

.0000

.0000

.0000

68.31

.0000

.0000

.0000

.0000

.0000

.0000

.0000

.0000

.0000

1.180

.0000

.0000

.0000

.0000

.0000

.0000

.0000

.0000
$15 \quad 16$

$.6960 \mathrm{E}-05 \quad .6966 \mathrm{E}-0 \mathrm{5}$

$.0000 \quad .0000$

$.8640 E-07 \quad .8743 E-07$

$.0000 \quad .0000$

$.6740 \mathrm{E}-06 \quad .6745 \mathrm{E}-06$

$.0000 \quad .0000$

$.0000 \quad .0000$

$.2195 \mathrm{E}-03 \quad .2197 \mathrm{E}-03$

$.0000 \quad .0000$

$.0000 \quad .0000$

$.2080 E-03 \quad .2081 E-03$

$.0000 \quad .1044 \mathrm{E}-09$

$.0000 \quad .0000$

$5.159 \quad .2361 \mathrm{E}-02$

$.0000 \quad .0000$

$.9429 \mathrm{E}-05 \quad .9435 \mathrm{E}-05$

$.0000 \quad .0000$

$.0000 \quad .0000$

$.0000 \quad .0000$

$.0000 \quad .0000$

$.0000 \quad .0000$

$.2454 \mathrm{E}-05 \quad .2455 \mathrm{E}-05$

.9375E-06 .9382E-06

$.4592 \mathrm{E}-05 \quad .4595 \mathrm{E}-05$

$.0000 \quad .0000$

$.0000 \quad .0000$

$.2484 E-15 \quad .230 .4 E-14$

$.6111 \mathrm{E}-02 \quad .6120 \mathrm{E}-02$

.0000

$.8445 \mathrm{E}-05$

$.9891 \mathrm{E}-11$

.0000

.0000

.0000

.0000

.0000

$.8847 \mathrm{E}-04$

$.9840 \mathrm{E}-04$

.2914E-09

, 0000

.2690E-03

.0000

$.5787 \mathrm{E}-05$

$.7024 \mathrm{E}-11$

.0000

.0000 to SMECT to RCT
.0000

$.8451 \mathrm{E}-05$

$.9898 \mathrm{E}-11$

$.4656 E-11$

.0000

.0000

.0000

.0000

. 3849E-04

$.9854 \mathrm{E}-04$

. 3094E-09

.0000

.2692E-03

. 1829E-09

.5791E-05

$.7029 \mathrm{E}-11$

.2911E-11

$.0000^{\circ}$ 
DPSP $80-1033$

MATER:AL BALANCE TABLES SLUDGE-ONLY FEED

STREAMS (CONT'D)STREAM NAME

$47 \quad Y 203$

100 Zeollte

$44 \mathrm{Zn}(\mathrm{COOH}) 2$

$54 \mathrm{Zn}(\mathrm{Oll}) 2$

$57 \mathrm{ZnO}$

101 2r02

TOTAL FLOW, LB/IIR

VAPOR FLOH, CFM

LIQUID FLOW, GPM

DESICN FLOW,

DENSITY, LBS/FT3

TEMPERATURE, DEG C

PRESSURE, ATM

PRESSURE, PSIG

PRESSURE, MM HG

PHASE

ENTHALPY, PCU/HR
18

Waste Sand

.0000

.0000

.0000

.0000

.0000

.0000

.00

.00

.0000

88.00

1.00

.00

LIQUID

.00
Append IX H

Table 21-15

Page 017 of 178

Date 09/80/82 Rev 09 
DPSP $80-1088$

MATERIAL BALANCE TABLES

SLUDGE-ONLY FEED

STREAM NUMBERS -

STREAM NAME

COMPONENT FLOWS, LB/HR

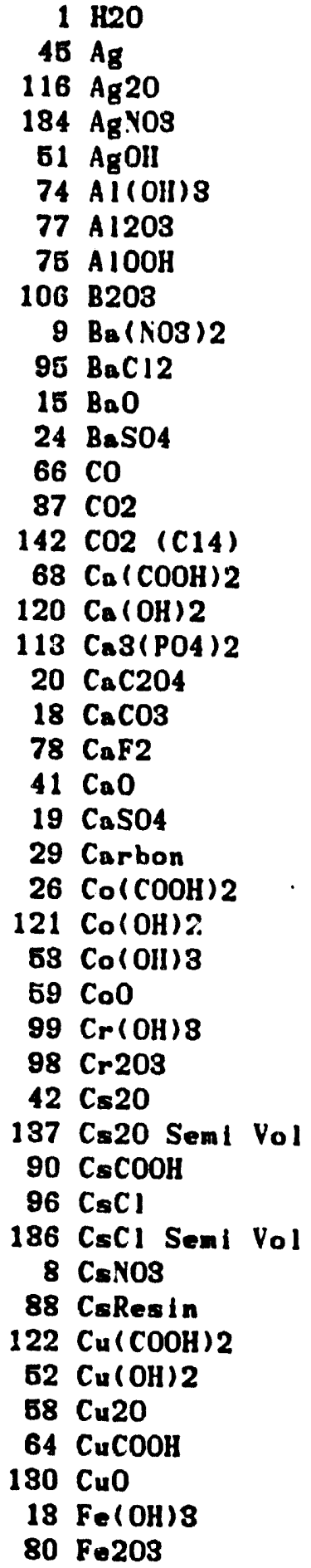

Append IX H

Table 21-15

Page 018 of 173

Date 09/30/82 Rev 09
.2507E-04

.2682E-07

.0000

.0000

$.4667 \mathrm{E}-16$

$.6176 \mathrm{E}-10$

.0000

.0000

$.1063 \mathrm{E}-09$

$.8112 \mathrm{E}-18$

.0000

.0000

$.7331 \mathrm{E}-12$

$.7407 \mathrm{E}-22$

.2253E-12

$.8256 \mathrm{E}-24$

$.2548 E-10$

$.1165 E-16$

$.1827 E-11$

$.1976 E-11$

.0000

$.4940 \mathrm{E}-12$

.0000

$.2321 \mathrm{E}-11$

$.4940 E-12$

$.4016 \mathrm{E}-12$

.2016E-18

.0000

.0000

$.1878 E-11$

.0000

$.7404 E-17$

.0000

.0000

$.4972 E-17$

.0000

$.6203 \mathrm{E}-13$

.0000

$.8578 \mathrm{E}-12$

$.4384 E-18$

.0000

.0000

.0000

$.1495 E-09$

.0000
18

SME Concent

rate to MFT

$$
\begin{aligned}
& 869.8 \\
& .9693 E-04 \\
& .0000 \\
& .0000 \\
& .2233 E-01 \\
& 14.03
\end{aligned}
$$

.0000

.0000

24.13

.1848E-06

.0000

.0000

.1666

$.2459 E-24$

.1081E-08

$.8076 \mathrm{E}-20$

5.778

.0000

.4151

.4489

.0000

.1122

.0000

.5273

.1122

$.9124 \mathrm{E}-01$

.0000

.0000

.0000

.4267

.0000

$.1682 \mathrm{E}-05$

.0000

.0000

$.1082 E-05$

.0000

$.1182 \mathrm{E}-01$

.0000

.1949

.0000

.0000

.0000

.0000

83.96

.0000 $\begin{array}{cc}19 & 20 \\ \text { Melter } & \text { Melter Seil } \\ \text { Feed } & \text { Pot Purge }\end{array}$

$852.3 \quad .8304$

$.9693 E-04 \quad .0000$

$.0000 \quad .0000$

$.0000 \quad .0000$

$.2283 E-01 \quad .0000$

$14.08 \quad .0000$

$.0000 \quad .0000$

$.0000 \quad .0000$

$24.13 \quad .0000$

$.1843 E-06 \quad .0000$

$.0000 \quad .0000$

$.0000 \quad .0000$

$.1666 \quad .0000$

$.6964 \mathrm{E}-29 \quad .0000$

$.7696 \mathrm{E}-12 \quad .0000$

$.2189 \mathrm{E}-23 \quad .0000$

$5.778 \quad .0000$

$.0000 \quad .0000$

$.4151 \quad .0000$

$.4489 \quad .0000$

$.0000 \quad .0000$

$.1122 \quad .0000$

$.0000 \quad .0000$

$.5278 \quad .0000$

$.1122 \quad .0000$

$.9124 \mathrm{E}-01 \quad .0000$

$.0000 \quad .0000$

$.0000 \quad .0000$

$.0000 \quad .0000$

$.4267 \quad .0000$

$.0000 \quad .0000$

$.1682 \mathrm{E}-05 \quad .0000$

$.0000 \quad .0000$

$.0000 \quad .0000$

$.1082 E-05 \quad .0000$

$.0000 \quad .0000$

$.1182 \mathrm{E}-01 \quad .0000$

$.0000 \quad .0000$

$.1949 \quad .0000$

$.0000 \quad .0000$

$.0000 \quad .0000$

$.0000 \quad .0000$

$.0000 \quad .0000$

$83.96 \quad .0000$

$.0000 \quad .0000$. 


\section{SLUDGE-ONLY FEED}

\section{STREAMS (CONT'D)- STREAM NAME}

$101 \mathrm{FcO}$

126 Group A Semi Vo

102 GroupA

103 GroupB

25112

133 HIC204

91 H2O2

84 HCOOH

43 IIC. I

$85 \mathrm{HF}$

49 HNO3

80 HResin

$86 \mathrm{Hg}$

$135 \mathrm{lg} N 032$

$21 \mathrm{HgO}$

9712

$89 \mathrm{~K} 20$

$131 \mathrm{KMnO4}$

$118 \mathrm{KNO3}$

$105 \operatorname{Ln} 203$

108 Li20

$65 \mathrm{Mg}(\mathrm{COOH}) 2$

$55 \mathrm{Mg}(\mathrm{O} ! 1) 2$

$33 \mathrm{MgO}$

$60 \mathrm{Mn}(\mathrm{COOH}) 2$

$132 \mathrm{Mn}(\mathrm{NO}) 2$

$129 \mathrm{Mn}(\mathrm{OH}) 2$

$56 \mathrm{MnO}$

$14 \mathrm{MnO2}$

81 N2

$143 \mathrm{~N} / 2 \mathrm{CO} \quad(\mathrm{C} 14)$

$35 \mathrm{NO}$

84 102

$70 \mathrm{Na}(\mathrm{HgO}(\mathrm{OH}))$

94 Na 2B407

$109 \mathrm{Na}_{2} \mathrm{C204}$

$5 \mathrm{Na} 2 \mathrm{CO} 3$

$32 \mathrm{Na} 20$

$71 \mathrm{Na} 2 \mathrm{Pu}_{\mathrm{O}} \mathrm{O2}$ (OII) 4

73 Nn2Rh04

$72 \mathrm{Na} 2 \mathrm{RuO4}_{4}$

$6 \mathrm{Na} 2 \mathrm{SO}_{4}$

$68 \mathrm{NaAlO2}$

$114 \mathrm{NaBO2}$

140 NaBO2 Semi Vol

$50 \mathrm{NiCOOH}$

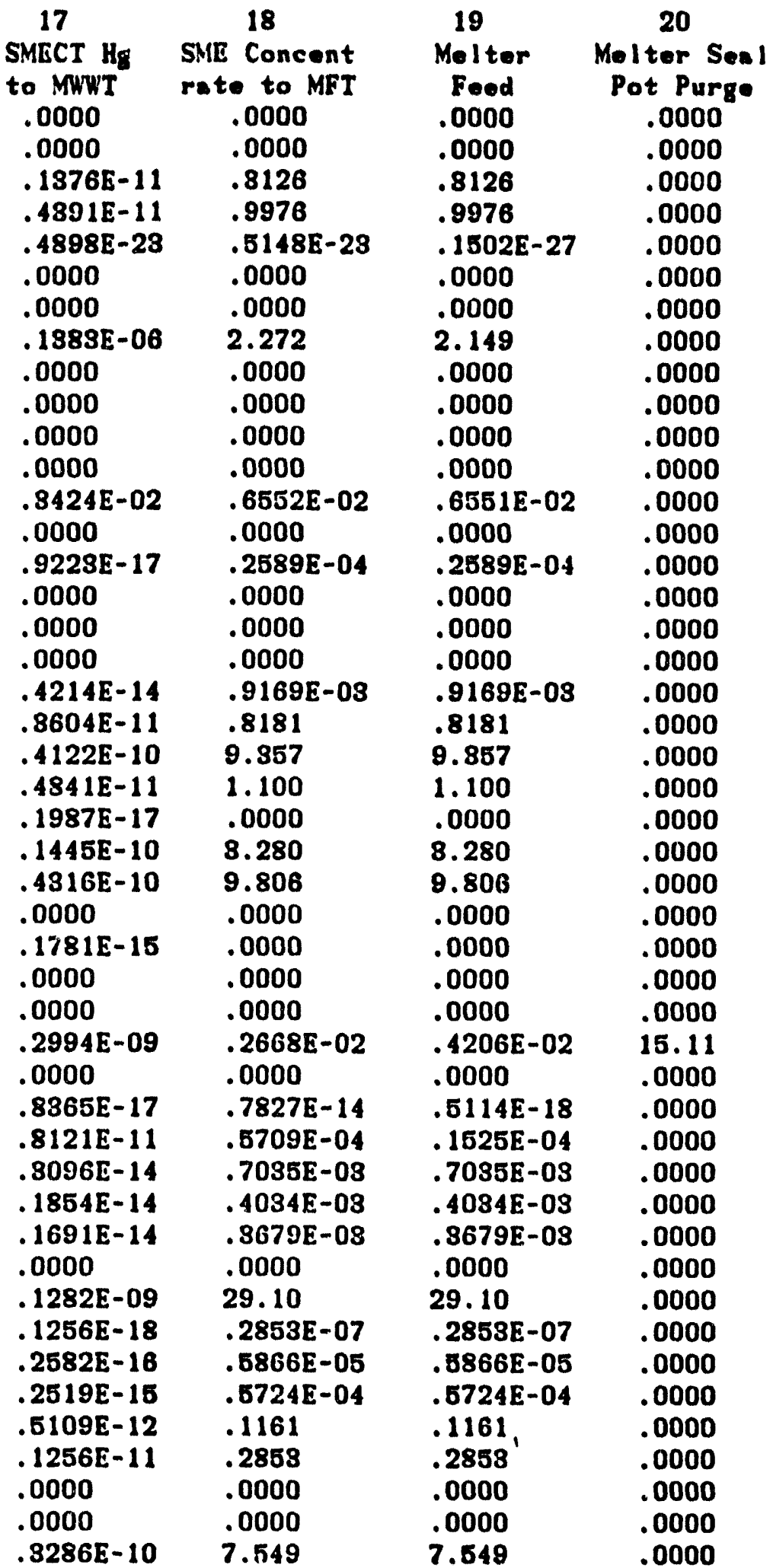


DPSP $80-1088$

MATERIAL BALANCE TABLES

SLUDGE-ONLY FEED

STREAMS $(C O N T$ 'D) STREAM NAME

$7 \mathrm{NaCl}$

$188 \mathrm{NaCl}$ Semi Vol

$69 \mathrm{NaF}$

139 NaF Semi Vol

$12 \mathrm{NaI}$

$125 \mathrm{NaI}$ Semi Vol

$8 \mathrm{NaNO} 2$

2 NaNOS

$4 \mathrm{NaOH}$

87 NaResin

$61 \mathrm{Ni}(\mathrm{COOH}) 2$

$17 \mathrm{Ni}(\mathrm{OH}) 2$

$40 \mathrm{NiO}$

8202

$67 \mathrm{PbO}$

$28 \mathrm{PbSO} 4$

$124 \mathrm{Pd}$

$128 \mathrm{Pd}(\mathrm{OH}) 2$

112 PdNO32

110 PdO

$117 \mathrm{Pu}(\mathrm{COOH}) 4$

$76 \mathrm{Pu}_{\mathrm{u}} \mathrm{2}$

$22 \mathrm{Rh} 02$

$79 \mathrm{Ru} 02$

23 Ru02 Semi Vol

$88 \mathrm{Ru} 04$

$88 \mathrm{SO2}$

$111 \mathrm{Si} 02$

115 Silica Gel

$48 \mathrm{Sr}(\mathrm{COOH}) 2$

$10 \mathrm{Sr}(\mathrm{NO}) 2$

$127 \mathrm{Sr}(\mathrm{OH}) 2$

$80 \mathrm{SrCOS}$

$46 \mathrm{SrO}$

89 SrRESIN

141 Surfactant

$92 \mathrm{Th} 02$

107 TiO2

119 Tritium

$98 \mathrm{~V} 02$

$62 \mathrm{VO} 2(\mathrm{COOH}) 2$

$16 \mathrm{VO2}(\mathrm{OH}) 2$

$27 \mathrm{Y}(\mathrm{COOH}) \mathrm{S}$

$11 \mathrm{Y}(\mathrm{NOS}) 8$

$128 \mathrm{Y}(\mathrm{OH}) 8$

$81 Y 2(\mathrm{COS}) 3$
17

SMECT $\mathrm{Hg}$ SME Concent

to MWWT

.5094E-12

.0000

$.2737 E-14$

.0000

$.4938 E-13$

.0000

.0000

$.1607 \mathrm{E}-10$

.0000

.0000

$.1622 \mathrm{E}-10$

$.7633 \mathrm{E}-17$

.0000

$.1727 \mathrm{E}-09$

.0000

$.6900 \mathrm{E}-12$

.0000

.0000

.0000

.0000

.0000

$.1796 \mathrm{E}-12$

$.6861 \mathrm{E}-13$

$.3961 \mathrm{E}-12$

.0000

.0000

$.1685 E-21$

$.4475 E-09$

.0000

$.6180 \mathrm{E}-12$

$.7238 \mathrm{E}-18$

$.8405 \mathrm{E}-18$

.0000

.0000

.0000

.0000

$.2815 \mathrm{E}-11$

$.7207 \mathrm{E}-11$

$.2262 E-16$

.0000

$.1969 \mathrm{E}-10$

$.1887 \mathrm{E}-16$

$.4235 \mathrm{E}-12$

. $5140 \mathrm{E}-18$

$.2129 \mathrm{E}-18$

.0000
Appendix $\mathrm{H}$

Tuble 21-15

Page 020 of 173

Date 09/30/82 Rev 09 
MATERIAL BALANCE TABLES

Dute 09/30/82 Rev 09

\section{SLUDGE-ONLY FEED}

STREAMS (CONT'D)-

STREAM NAME

47 Y203

100 Zeollte

$44 \mathrm{Zn}(\mathrm{COOH}) 2$

$54 \mathrm{Zn}(\mathrm{Oll}) 2$

$57 \mathrm{Zn} 0$

$104 \mathrm{ZrO2}$

TOTAL FLON, LB/HR

VAPOR FLOK, CFM

LIOUID FLOH, GPM

DESIGN FLOW,

DENSITY, LBS/FT3

TEMPERATURE, DEG C

PRESSURE, ATM

PRESSURE, PSIG

PRESSURE, MM HG

PHISE

E.TTHALPY, PCU/IIR
17

SMECT Hg

to MWWT

.0000

. 1800E- 10

.2237E-11

$.1151 \mathrm{E}-17$

.0000

$.3604 \mathrm{E}-11$

.00

.00

774.7016

50.00

.97

$-.61$

783.86

LIQUID

.01
18

SME Concent

rate to MFT

.0000

4.089

.5084

.0000

.0000

.8181

636.81

.97

81.6111

49.96

1.00

.00

LIQUID

22699.77
19

Molter

Feed

.0000

4.089

.6084

.0000

.0000

.8181

619.20

.94

82.8263

60.00

.97

$-.51$

733.86

LIQUID

21821.00
20

Molter Seal

Pot Purge

.0000

.0000

.0000

.0000

.0000

.0000

20.0 n

4.72

.0706

85. CO

1.00

.00

VAPOR

$-1029.96$ 
DPSP $80-1033$

MATERIAL BALANCE TABLES

SLLDGE-ONLY FEED

STREAM NUMBERS -

STREAM NAME

COMPONEYT FLOHS, LB/HR

\begin{tabular}{|c|c|c|}
\hline 1 & H2O & .6609 \\
\hline 45 & $\mathrm{Ag}$ & .0000 \\
\hline 16 & Ag20 & .0000 \\
\hline & AgNO3 & .0000 \\
\hline 1 & $\mathrm{AgOH}$ & .0000 \\
\hline 4 & AI $(\mathrm{OH}) \mathrm{B}$ & .0000 \\
\hline 7 & A1203 & .000 \\
\hline 75 & A $100 \mathrm{H}$ & .0000 \\
\hline & B203 & .000 \\
\hline 9 & $\mathrm{Ba}(\mathrm{N} 03) 2$ & .000 \\
\hline 95 & $\mathrm{BaCl} 2$ & .0000 \\
\hline 15 & $\mathrm{Ba} O$ & .0000 \\
\hline 4 & $\mathrm{BaSO4}$ & .0000 \\
\hline 6 & $\mathrm{CO}$ & .0000 \\
\hline & $\mathrm{CO2}$ & .0000 \\
\hline & $\operatorname{co2}(\mathrm{C} 14)$ & .0000 \\
\hline & $\mathrm{Ca}(\mathrm{COOH}) 2$ & .0000 \\
\hline & $\mathrm{C}_{\mathrm{B}}(\mathrm{OH}) 2$ & .000 \\
\hline & $\mathrm{Ca}_{2}(\mathrm{P} 04) 2$ & .000 \\
\hline 0 & $\mathrm{CaC2O4}$ & .0000 \\
\hline 18 & $\mathrm{CaC03}$ & .0000 \\
\hline 8 & $\mathrm{CaF} 2$ & .0000 \\
\hline & $\mathrm{CaO}$ & .0000 \\
\hline 9 & CaSO4 & .0000 \\
\hline 9 & Carbon & .0000 \\
\hline 6 & $\mathrm{Co}(\mathrm{COOH} ; 2$ & .0000 \\
\hline & $\mathrm{Co}(\mathrm{OH}) 2$ & .0000 \\
\hline & $\mathrm{Co}(\mathrm{OH}) 3$ & .0000 \\
\hline & $\mathrm{CoO}$ & .0000 \\
\hline 9 & $\mathrm{Cr}(\mathrm{OH}) 3$ & .0000 \\
\hline 8 & Cr203 & .0000 \\
\hline & Cs20 & .0000 \\
\hline & Cs20 Semi Vol & .000 \\
\hline & $\mathrm{CsCOOH}$ & .000 \\
\hline & $\mathrm{CsCl}$ & .0000 \\
\hline & CsCl Semi Vol & .000 \\
\hline & CsNu3 & .0000 \\
\hline 88 & CsResin & .0000 \\
\hline & $\mathrm{Cu}(\mathrm{COOH}) 2$ & .000 \\
\hline & $\mathrm{Cu}(\mathrm{OH}) 2$ & .000 \\
\hline & Cu20 & .000 \\
\hline & $\mathrm{CuCOOH}$ & .000 \\
\hline & $\mathrm{CuO}$ & .000 \\
\hline & $\mathrm{Fe}(\mathrm{OH}) 8$ & .000 \\
\hline & & .00 \\
\hline
\end{tabular}

Appendix $\mathrm{H}$

Table 21-15

Page 022 of 178

Date 09/30/82 Rev 09
21

Melter CCTV Melter Air

In Leakage

.3804

.0000

.0000

.0000

.0000

.0000

.0000

.0000

.0000

.0000

.0000

.0000

.0000

.0000

.0000

.0000

.0000

.0000

.0000

.0000

.0000

.0000

.0000

.0000

.0000

.0000

.0000

.0000

.0000

.0000

.0000

.0000

.0000

.0000

.0000

.0000

.0000

.0000

.0000

.0000

.0000

.0000

.0000

.0000

.0000
23

Melter

Off-Gas

368.5

.0000

.0000

.0000

.2233E-03

.1403

.0000

.0000

.2413

. 1843E-08

.0000

.0000

. 1666E-02

5.598

13.09

.2189E-23

.5778E-01

.0000

$.4151 \mathrm{E}-02$

.448SE-02

.0000

.1122E-02

.0000

$.5273 \mathrm{E}-02$

. 1122E-02

$.9124 \mathrm{E}-03$

.0000

.0000

.0000

$.4267 E-02$

.0000

$.1682 \mathrm{E}-07$

.0000

.0000

$.1082 E-07$

$.5066 \mathrm{E}-03$

$.1182 \mathrm{E}-03$

.0000

$.1949 \mathrm{E}-02$

.0000

.0000

.0000

.0000

.8396

.0000
24

Haste

Glass

.0000

.0000

$.2052 E-01$

.0000

.0000

.0000

9.254

.0000

23.77

.0000

.0000

.1053

.0000

.0000

.0000

.0000

.0000

.0000

.4109

.0000

.0000

.0000

2.955

.0000

.0000

.0000

.0000

.0000

$.4544 E-01$

.0000

.8108

$.8039 \mathrm{E}-02$

.0000

.0000

.0000

.0000

.0000

.0000

.0000

.0000

.0000

.0000

$.9994 \mathrm{E}-01$

.0000

18.93 
MATERIAL BALANCE TABLES

Date 09/30/82 Rev 09

SLCDCIE-ONLY FEED

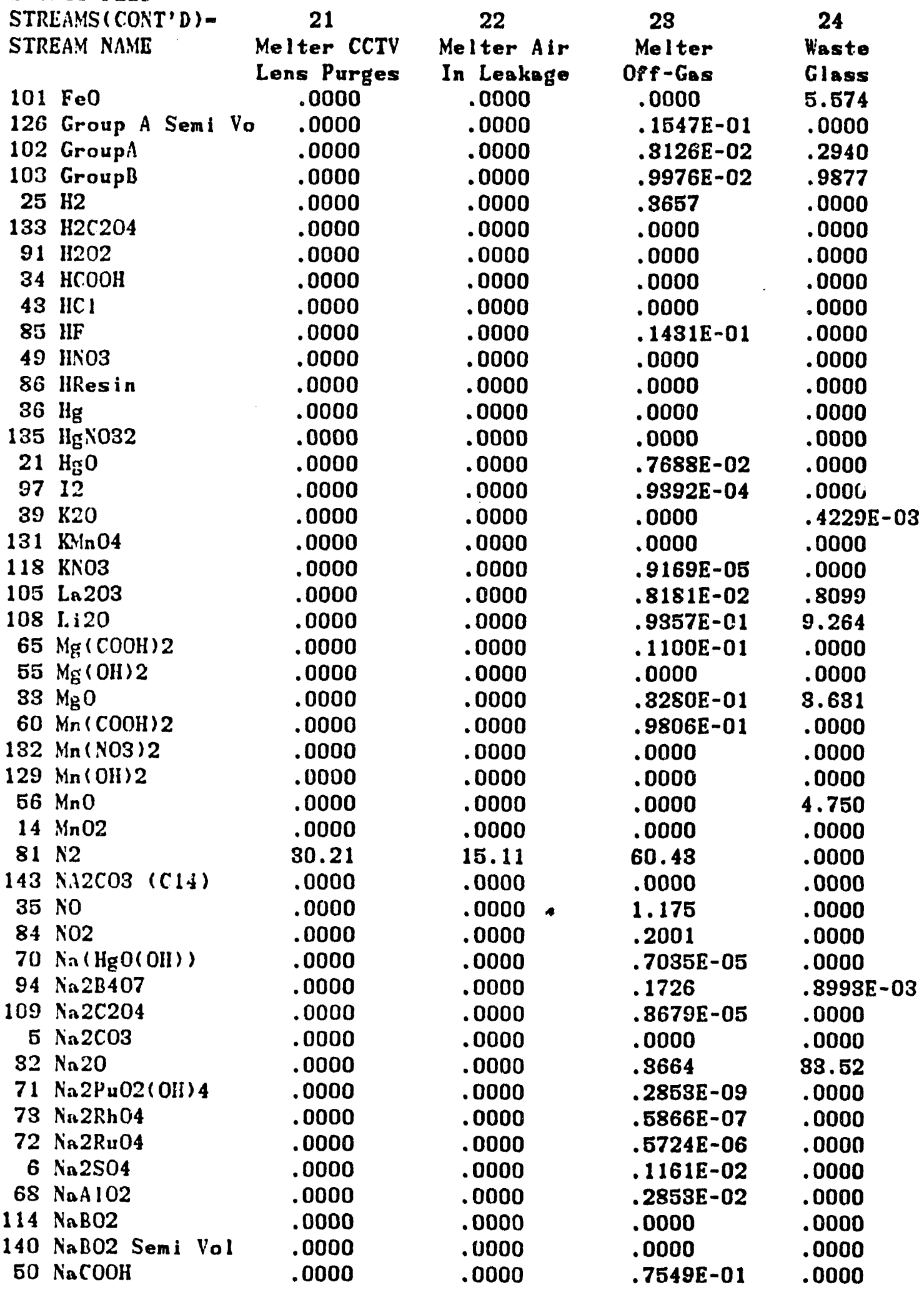


DPSP $80-1038$

MATERIAL BALANCE TABLES SLUDGE-ONLY FEED STREAMS ( CONT'D)STREAM NAME

$7 \mathrm{NaCl}$

$188 \mathrm{NaCl}$ Semi Vol

$69 \mathrm{NaF}$

$139 \mathrm{NaF}$ Semi Vol

$12 \mathrm{NaI}$

$125 \mathrm{NaI}$ Semi Vol

$8 \mathrm{NaNO} 2$

$2 \mathrm{NaNO3}$

$4 \mathrm{NaOH}$

87 NaResin

$61 \mathrm{Ni}(\mathrm{COOH}) 2$

$17 \mathrm{Ni}(\mathrm{OH}) 2$

$40 \mathrm{NiO}$

8202

$67 \mathrm{PbO}$

$28 \mathrm{PbSO} 4$

$124 \mathrm{Pd}$

$123 \mathrm{Pd}(\mathrm{OII}) 2$

112 PdNO32

$110 \mathrm{PdO}$

$117 \mathrm{Pu}(\mathrm{COOH}) 4$

$76 \mathrm{Pu} 02$

$22 \mathrm{RhO2}$

$79 \mathrm{Ru} 02$

23 Ru02 Semi Vol

$83 \mathrm{Ru} 04$

$88 \mathrm{~S} 02$

111 SiO2

115 Silica Gel

$48 \mathrm{Sr}(\mathrm{COOH}) 2$

$10 \mathrm{Sr}(\mathrm{NO3}) 2$

$127 \mathrm{Sr}(\mathrm{OH}) 2$

$80 \mathrm{SrCOS}$

$46 \mathrm{Sr} 0$

89 SrRESIN

141 Surfactant

92 Th02

$107 \mathrm{Ti02}$

119 Tritium

$93 \mathrm{VO2}$

$62 \mathrm{VO} 2(\mathrm{COOH}) 2$

$16 \mathrm{VO2}(\mathrm{OH}) 2$

$27 \mathrm{Y}(\mathrm{COOH}) \mathrm{S}$

$11 \mathrm{Y}(\mathrm{NOS}) \mathrm{B}$

$128 \mathrm{Y}(\mathrm{OH}) \mathrm{S}$

$81 \mathrm{Y} 2(\mathrm{CO} 3) 3$
Appendix $\mathrm{H}$

Table 21-15

Page 024 of 173

Date $09 / 30 / 82$ Rev 09

\begin{tabular}{|c|c|c|c|}
\hline 21 & 22 & 23 & 24 \\
\hline $\begin{array}{l}\text { Melter CCTV } \\
\text { Lens Purges }\end{array}$ & $\begin{array}{l}\text { Molter Alr } \\
\text { In Leakage }\end{array}$ & $\begin{array}{l}\text { Melter } \\
\text { Off-Gas }\end{array}$ & $\begin{array}{l}\text { Viaste } \\
\text { Glass }\end{array}$ \\
\hline .0000 & .0000 & $.1157 \mathrm{E}-02$ & .0000 \\
\hline .0000 & .0000 & .1144 & .0000 \\
\hline .0000 & .0000 & $.6052 E-05$ & .0000 \\
\hline .0000 & .0000 & $.9010 \mathrm{E}-01$ & .0000 \\
\hline .0000 & .0000 & $.1121 \mathrm{E}-03$ & .0000 \\
\hline .0000 & .0000 & . 1098E-01 & .0000 \\
\hline .0000 & .0000 & .0000 & .0000 \\
\hline .0000 & .0000 & $.3728 E-01$ & .0000 \\
\hline .0000 & .0000 & .0000 & .0000 \\
\hline .0000 & .0000 & .0000 & .0000 \\
\hline .0000 & .0000 & $.8458 \mathrm{E}-01$ & .0000 \\
\hline .0000 & .0000 & .0000 & .0000 \\
\hline .0000 & .0000 & .0000 & 1.719 \\
\hline 9.127 & 4.563 & 18.19 & .0000 \\
\hline .0000 & .0000 & .0000 & .1142 \\
\hline .0000 & .0000 & . 1568E-02 & .0000 \\
\hline .0000 & .0000 & .0000 & .0000 \\
\hline .0000 & .0000 & .0000 & .0000 \\
\hline .0000 & .0000 & .0000 & .0000 \\
\hline .0000 & .0000 & .0000 & .0000 \\
\hline .0000 & .0000 & .0000 & .0000 \\
\hline .0000 & .0000 & $.4080 \mathrm{E}-03$ & $.4039 E-01$ \\
\hline .0000 & .0000 & $.1559 \mathrm{E}-03$ & $.1544 E-01$ \\
\hline .0000 & .0000 & $.7635 E-03$ & $.6806 \mathrm{E}-01$ \\
\hline .0000 & .0000 & $.7563 E-02$ & .0000 \\
\hline .0000 & .0000 & .0000 & .0000 \\
\hline .0000 & .0000 & .8755 & .0000 \\
\hline .0000 & .0000 & 1.016 & 100.6 \\
\hline .0000 & .0000 & .0000 & .0000 \\
\hline .0000 & .0000 & $.1404 \mathrm{E}-02$ & .0000 \\
\hline .0000 & .0000 & $.1645 E-08$ & .0000 \\
\hline .0000 & .0000 & .0000 & .0000 \\
\hline .0000 & .0000 & .0000 & .0000 \\
\hline .0000 & .0000 & .0000 & $.8109 E-01$ \\
\hline .0000 & .0000 & .0000 & .0000 \\
\hline .0000 & .0000 & .0000 & .0000 \\
\hline .0000 & .0000 & $.6896 \mathrm{E}-02$ & .6332 \\
\hline .0000 & .0000 & $.1636 \mathrm{E}-01$ & 1.620 \\
\hline .0000 & .0000 & $.8805 E-09$ & .0000 \\
\hline .0000 & .0000 & $.00 n 0$ & 8.321 \\
\hline .0000 & .0000 & $.4478 E-01$ & .0000 \\
\hline .0000 & .0000 & .0000 & .0000 \\
\hline .0000 & .0000 & $.9621 \mathrm{E}-03$ & .0000 \\
\hline .0000 & .0000 & $.1168 \mathrm{E}-08$ & .0000 \\
\hline .0000 & .0000 & .0000 & .0000 \\
\hline .0000 & .0000 & .0000 & .0000 \\
\hline
\end{tabular}


MATERIAL BALANCE TABLES

SLUDGE-ONLY FEED STREAMS (CONT'D)STREAM NAME

\author{
$47 \quad Y 203$ \\ 100 Zeolite \\ $44 \mathrm{Zn}(\mathrm{COOH}) 2$ \\ $54 \mathrm{Zn}(\mathrm{OH}) 2$ \\ $57 \mathrm{ZnO}$ \\ $104 \mathrm{Zr} 02$ \\ TOTAL FLOH, LB/HR \\ VAPOR FLON, CFM \\ LIQUID FLOW, GPM \\ DESIGN FLOH, \\ DENSITY, LBS/FT3 \\ TEMPERATURE, DEG C \\ PRESSURE, ATM \\ PRESSURE, PSIG \\ PRESSURE, MM HG \\ PHASE \\ ENTHALPY, PCU/IIR
}

\begin{tabular}{|c|c|c|c|}
\hline 21 & 22 & 28 & 24 \\
\hline $\begin{array}{c}\text { Molter CCTV } \\
\text { Lens Purges } \\
\text { Dono }\end{array}$ & $\begin{array}{l}\text { Melter Air } \\
\text { In Leakage } \\
\text { 0000 }\end{array}$ & $\begin{array}{l}\text { Melter } \\
\text { Off-Ges } \\
0000\end{array}$ & $\begin{array}{l}\text { Waste } \\
\text { Glass } \\
4802 \mathrm{E}-01\end{array}$ \\
\hline .0000 & .0000 & $.4089 \mathrm{E}-01$ & 4.048 \\
\hline .0000 & .0000 & $.5084 \mathrm{E}-02$ & .0000 \\
\hline .0000 & .0000 & .0000 & .0000 \\
\hline .0000 & .0000 & .0000 & .2635 \\
\hline .0000 & .0000 & $.8181 E-02$ & .8099 \\
\hline $\begin{array}{r}40.00 \\
9.45\end{array}$ & $\begin{array}{r}20.00 \\
4.72\end{array}$ & $\begin{array}{l}471.10 \\
420.55\end{array}$ & 228.11 \\
\hline & & & .19 \\
\hline .0706 & .0706 & .0187 & 152.6455 \\
\hline 85.00 & 85.00 & 520.00 & 1050.00 \\
\hline 1.00 & 1.00 & .99 & .99 \\
\hline .00 & .00 & -.18 & -.18 \\
\hline & & 750.88 & 750.88 \\
\hline VAPOR & VAPOR & VAPOR & LIQUID \\
\hline-2059.93 & -1029.96 & 327421.58 & 77096.27 \\
\hline
\end{tabular}

$-1029.96$

327421.58

LIQUID
77096.27 
DPSP $80-1088$

MATERIAL BALANCE TABLES

SLUDGE-ONLY FEED

STREAM NUMBERS -

STREAM NAME

COMPONENT FLOWS, LB/HR

$1 \mathrm{H} 2 \mathrm{O}$

$45 \mathrm{Ag}$

$116 \mathrm{Ag} 20$

134 AgNO3

61 AgOH

74 Al $(\mathrm{OH}) 3$

77 A 1203

$75 \mathrm{AlOOH}$

106 B203

$9 \mathrm{Ba}(\mathrm{NOS}) 2$

$95 \mathrm{BaC} 12$

$15 \mathrm{BaO}$

$24 \mathrm{BaSO4}$

$66 \mathrm{CO}$

$87 \mathrm{CO} 2$

$142 \mathrm{CO}$ (C14)

$63 \mathrm{Ca}(\mathrm{COOH}) 2$

$120 \mathrm{Ca}(\mathrm{OH}) 2$

$118 \mathrm{Ca}$ ( $\left(\mathrm{PO}^{2}\right) 2$

$20 \mathrm{CaC2O4}$

$18 \mathrm{CaCO}$

$78 \mathrm{CaF2}$

$41 \mathrm{CaO}$

$19 \mathrm{CaSO} 4$

29 Carbon

$26 \mathrm{Co}(\mathrm{COOH}) 2$

$121 \mathrm{Co}(\mathrm{OH}) 2$

$63 \mathrm{Co}(\mathrm{OH}) 3$

$69 \mathrm{CoO}$

$99 \mathrm{Cr}(\mathrm{OH}) 3$

98 Cr203

42 Cs20

187 Cs20 Semi Vol

$90 \mathrm{CsCOOH}$

$96 \mathrm{CsCl}$

$136 \mathrm{CsCl}$ Semi Vol

8 CsNO3

88 CsResin

$122 \mathrm{Cu}(\mathrm{COOH}) 2$

$62 \mathrm{Cu}(\mathrm{OH}) 2$

$58 \mathrm{Cu} 20$

$64 \mathrm{CuCOOH}$

$180 \mathrm{CuO}$

$13 \mathrm{Fe}(\mathrm{OH}) \mathrm{S}$

$80 \mathrm{Fe} 203$

\section{5 \\ Off-Gas \\ Spray Weter}

44.08

.0000

.0000

.0000

.0000

.0000

.0000

.0000

.0000

.0000

.0000

.0000

.0000

.0000

.0000

.0000

.0000

.0000

.0000

.0000

.0000

.0000

.0000

.0000

.0000

.0000

.0000

.0000

.0000

.0000

.0000

.0000

.0000

.0000

.0000

.0000

.0000

.0000

.0000

.0000

.0000

.0000

.0000

.0000

.0000
Appendix $\mathrm{H}$

Table 21-15

Pnge 026 of 173

Date 09/30/82 Rev 09
26
Cooled
Off-Gas

412.6

.0000

.0000

.0000

.2233E-03

.1408

.0000

.0000

.2418

.1848E-08

.0000

.0000

$.1666 \mathrm{E}-02$

5.598

13.09

$.2189 \mathrm{E}-23$

$.5778 E-01$

.0000

$.4151 E-02$

$.4489 E-02$

.0000

$.1122 \mathrm{E}-02$

.0000

. 5279E-02

$.1122 \mathrm{E}-02$

$.9124 \mathrm{E}-03$

.0000

.0000

.0000

$.4267 \mathrm{E}-02$

.0000

$.1682 \mathrm{E}-07$

.0000

.0000

$.1082 E-07$

$.5066 \mathrm{E}-03$

$.1182 E-03$

.0000

.1949E-02

.0000

.0000

.0000

.0000

.8396

.0000

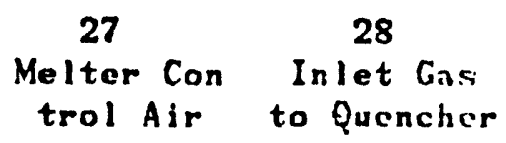

27

Melter Con Inlet Gas

trol Air to Quencher

2.612

415.2

.0000

.0000

.0000

.0000

.0000

.0000

.2233E-03

.0000

.1408

.0000

.0000

.0000

.0000

.0000

.0000

.0000

.0000

.0000

.0000

.0000

.0000

.0000

.0000

.0000

.0000

.0000

.0000

.0000

.0000

.0000

.0000

.0000

.0000

.0000

.0000

.0000

.0000

.0000

.0000

.0000

.0000

.0000

.0000

.0000

.0000

.0000

.0000

.0000

.0000
.0000

.2413

. 1843E-08

.0000

.0000

.1666E-02

5.598

13.09

$.2189 \mathrm{E}-23$

.5778E-01

.0000

$.4151 \mathrm{E}-02$

$.4489 \mathrm{E}-02$

.0000

. 1122E-02

.0000

. 5278E-02

. 1122E-02

$.9124 \mathrm{E}-03$

.0000

.0000

.0000

$.4267 \mathrm{E}-02$

.0000

$.1682 E-07$

.0000

.0000

$.1082 E-07$

. 5066E-03

$.1182 \mathrm{E}-03$

.0000

. 1949E-02

.0000

.0000

.0000

.0000

.8396

$.0000^{\circ}$ 
DPSP 80-1033

MATERIAL BALANCE TABLES

\section{SLUDGE-ONLY FEED}

STREAMS (CONT'D)-

STREAM NAME

$101 \mathrm{FeO}$

126 Group A SemI Vo

102 GroupA

103 Group $B$

$25 \mathrm{H} 2$

$133 \mathrm{H} 2 \mathrm{C} 204$

$91 \mathrm{H202}$

$84 \mathrm{HCOOH}$

$43 \mathrm{HCl}$

$85 \mathrm{HF}$

49 HNO3

86 HResin

$36 \mathrm{Hg}$

$135 \mathrm{HCSNO}_{\mathrm{S}} \mathrm{NO}$

$21 \mathrm{Hg} 0$

$97 \quad 12$

$39 \times 20$

$131 \mathrm{kN} / \mathrm{n} 04$

$118 \mathrm{KNOS}$

$105 \operatorname{Ln} 203$

$108 \mathrm{Li} 20$

$65 \mathrm{Mg}(\mathrm{COOH}) 2$

$55 \mathrm{Mg}(\mathrm{OH}) 2$

83 MgO

$60 \mathrm{Mn}(\mathrm{COOII}) 2$

$132 \mathrm{Mn}(\mathrm{NO}) 2$

$129 \mathrm{Mn}(\mathrm{OH}) 2$

$56 \mathrm{MnO}$

$14 \mathrm{MnO2}$

$81 \mathrm{N2}$

$143 \mathrm{NA2COS} \mathrm{(C14)}$

$35 \mathrm{NO}$

$84 \mathrm{NO2}$

$70 \mathrm{Na}(\mathrm{HgO}(\mathrm{OH}))$

$94 \mathrm{Na} 2 \mathrm{~B} 407$

$109 \mathrm{Na} 2 \mathrm{C} 204$

$5 \mathrm{Na} 2 \mathrm{CO} 3$

$32 \mathrm{Na} 20$

$71 \mathrm{Na} 2 \mathrm{Pu} 02$ (OH) 4

$73 \mathrm{Na} 2 \mathrm{RhO}_{04}$

$72 \mathrm{Na}_{2} \mathrm{RuO}_{4}$

$6 \mathrm{Na}_{2} \mathrm{SO}_{4}$

$68 \mathrm{NaAlO2}$

$114 \mathrm{NaBO2}$

$140 \mathrm{NaBO2}$ Semi Vol

$50 \mathrm{NaCOOH}$
25
Off-Gas
Spray Water

.0000

.0000

.0000

.0000

.0000

.0000

.0000

.0000

.0000

.0000

.0000

.0000

.0000

.0000

.0000

.0000

.0000

.0000

.0000

.0000

.0000

.0000

.0000

.0000

.0000

.0000

.0000

.0000

.0000

.0000

.0000

.0000

.0000

.0000

.0000

.0000

.0000

.0000

.0000

.0000

.0000

.0000

.0000

.0000

.0000

.0000
Append ix H

Table 21-15

Page 027 of $1: 3$

Date 09/80/82 Rev 09
26
Cooled
Off-Gas
.0000
$.1547 E-01$
$.3126 E-02$
$.997 G E-02$

.8657

.0000

.0000

.0000

.0000

.0000

.0000

.0000

.0000

.0000

$.7688 \mathrm{E}-02$

$.9392 \mathrm{E}-04$

.0000

.0000

$.9169 \mathrm{E}-05$

$.8181 \mathrm{E}-02$

$.9357 E-01$

$.1100 \mathrm{E}-01$

.0000

$.3280 \mathrm{E}-01$

$.9806 \mathrm{E}-01$

.0000

.0000

.0000

.0000

60.43

.0000

1.175

.2001

$.7035 \mathrm{E}-05$

.1726

$.3679 \mathrm{E}-05$

.0000

.8442

.2853E-09

. $5866 \mathrm{E}-07$

$.6724 \mathrm{E}-06$

.1161E-02

.2853E-02

.0000

.0000

$.7549 \mathrm{E}-01$

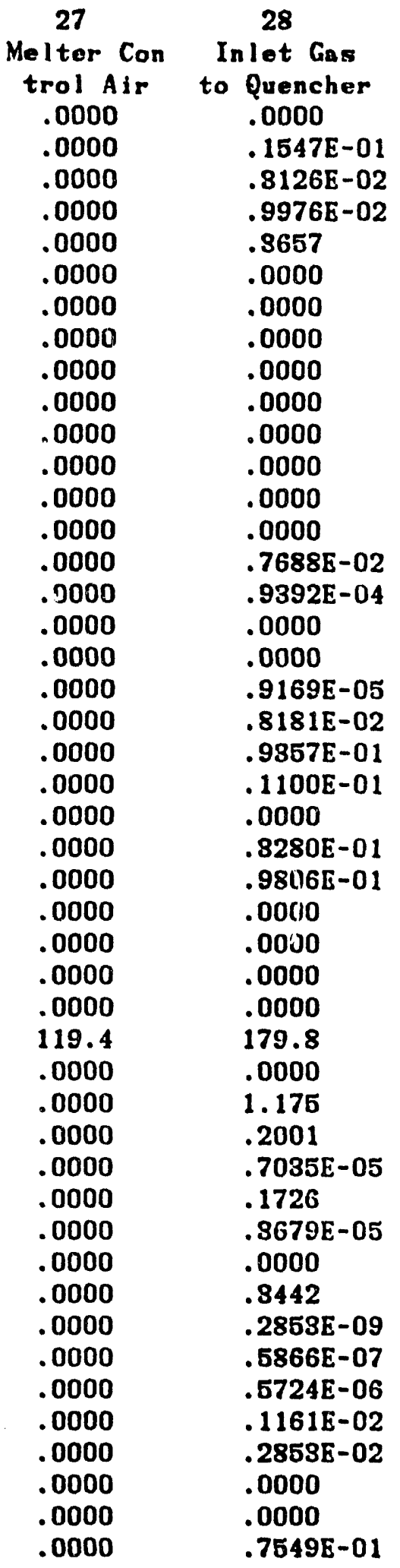


DPSP $80-1033$

MATERIAL BALANCE TABLES SLUDGE-ONLY FEED STREAMS (CON'T'D)STREAM NAME

\begin{tabular}{|c|c|c|c|c|c|}
\hline \multirow{2}{*}{\multicolumn{2}{|c|}{$\begin{array}{l}\text { STREAMS }\left(C O N T^{\prime} D\right)- \\
\text { STREAM NAME }\end{array}$}} & \multirow{3}{*}{$\begin{array}{c}25 \\
\text { Off-Gas } \\
\text { Spray Water } \\
.0000\end{array}$} & \multirow{3}{*}{$\begin{array}{c}26 \\
\text { Cooled } \\
\text { Off-Gas }\end{array}$} & \multirow{3}{*}{$\begin{array}{l}27 \\
\text { Melter Con } \\
\text { trol Air } \\
.0000\end{array}$} & \multirow{3}{*}{$\begin{array}{l}28 \\
\text { Inlet Gns } \\
\text { to Querclier } \\
.1157 \mathrm{E}-02\end{array}$} \\
\hline & & & & & \\
\hline 7 & $\mathrm{NaCl}$ & & & & \\
\hline 188 & $\mathrm{NaCl} \mathrm{Se}_{11} \mathrm{Vol}$ & .0000 & .1144 & .0000 & .1144 \\
\hline 69 & $\mathrm{NaF}$ & .0000 & $.3004 E-01$ & .0000 & $.8004 E-01$ \\
\hline 189 & NaF Sem: Vol & .0000 & $.9010 \mathrm{E}-01$ & .0000 & $.9010 E-01$ \\
\hline 12 & $\mathrm{NaI}$ & .0000 & $.1121 E-03$ & .0000 & $.1121 \mathrm{E}-03$ \\
\hline 125 & NaI Semi Vol & .0000 & $.10985-01$ & .0000 & $.10985-01$ \\
\hline 8 & $\mathrm{NaNO2}$ & .0000 & .0000 & .0000 & .0000 \\
\hline 2 & NaNOS & .0000 & $.3728 E-01$ & .0000 & $.8728 E-01$ \\
\hline 4 & $\mathrm{NaOH}$ & .0000 & .0000 & .0000 & .0000 \\
\hline 87 & NaResin & .0000 & .0000 & .0000 & .0000 \\
\hline 61 & $\mathrm{~N} i(\mathrm{COOH} ; 2$ & .0000 & $.8458 \mathrm{E}-01$ & .0000 & $.8458 E-01$ \\
\hline 17 & $\mathrm{~N} 1(\mathrm{OH}) 2$ & .0000 & .0000 & .0000 & .0000 \\
\hline 40 & N10 & .0000 & .0000 & .0000 & .0000 \\
\hline 82 & 02 & .0000 & 18.19 & 86.07 & 54.25 \\
\hline 67 & $\mathrm{PbO}$ & .0000 & .0000 & .0000 & .0000 \\
\hline 28 & $\mathrm{PbSO4}$ & .0000 & $.1568 \mathrm{E}-02$ & .0000 & $.1568 E-02$ \\
\hline 124 & Pd & .0000 & .0000 & .0000 & .0000 \\
\hline 123 & $\mathrm{Pd}(\mathrm{OH}) 2$ & .0000 & .0000 & .0000 & .0000 \\
\hline 112 & PdN032 & .0000 & .0000 & .0000 & .0000 \\
\hline 110 & PdO & .0000 & .0000 & .0000 & .0000 \\
\hline 117 & $\mathrm{Pu}(\mathrm{COOH}) 4$ & .0000 & .0000 & .0000 & .0000 \\
\hline 76 & Pu02 & .0000 & $.4080 \mathrm{E}-03$ & .0000 & $.4080 E-03$ \\
\hline 22 & $\mathrm{RhO2}$ & .0000 & $.1559 E-03$ & .0000 & $.1559 E-03$ \\
\hline 79 & $\mathrm{RuO2}$ & .0000 & $.7685 E-03$ & .0000 & $.7635 E-03$ \\
\hline 23 & Ru02 Seni Vol & .0000 & $.7568 E-02$ & .0000 & $.7568 \mathrm{E}-02$ \\
\hline 83 & Ru04 & .0000 & .0000 & .0000 & .0000 \\
\hline 88 & SO2 & .0000 & .8755 & .0000 & .8755 \\
\hline 111 & 5102 & .0000 & 1.016 & .0000 & 1.016 \\
\hline 115 & Sillica fiel & .0000 & .0000 & .0000 & .0000 \\
\hline 48 & $\mathrm{Sr}(\mathrm{COOH}) 2$ & .0000 & $.1404 E-02$ & .0000 & $.1404 \mathrm{E}-02$ \\
\hline 10 & $\operatorname{Sr}(\mathrm{NOS}) 2$ & .0000 & $.1645 E-08$ & .0000 & $.1645 E-08$ \\
\hline 127 & $\mathrm{Sr}(\mathrm{OH}) 2$ & .0000 & .0000 & .0000 & .0000 \\
\hline $\mathbf{8 0}$ & SrCO3 & .0000 & .0000 & .0000 & .0000 \\
\hline 46 & Sro & .0000 & .0000 & .0000 & .0000 \\
\hline 89 & SrRESIN & .0000 & .0000 & .0000 & .0000 \\
\hline 141 & Surfactant & .0000 & .0000 & .0000 & .0000 \\
\hline 92 & Th02 & .0000 & $.6896 \mathrm{E}-02$ & .0000 & $.6396 \mathrm{E}-02$ \\
\hline 107 & $\mathrm{~T} 102$ & .0000 & $.1686 \mathrm{E}-01$ & .0000 & $.1636 E-01$ \\
\hline 119 & Tritium & .0000 & $.8805 E-09$ & .0000 & $.8805 E-09$ \\
\hline 93 & U02 & .0000 & .0000 & .0000 & .0000 \\
\hline 62 & U02(c00II) 2 & .0000 & $.4473 E-01$ & .0000 & $.4478 E-01$ \\
\hline 16 & $\mathrm{VO2}(\mathrm{OH}) 2$ & .0000 & .0000 & .0000 & .0000 \\
\hline 27 & $\mathrm{Y}(\mathrm{COOH}) 3$ & .0000 & $.9621 E-08$ & .0000 & $.9621 E-03$ \\
\hline 11 & $Y(N 08) 8$ & .0000 & $.1168 \mathrm{E}-08$ & .0000 & $.1168 \mathrm{E}-08$ \\
\hline 128 & $Y(\mathrm{OH}) 8$ & .0000 & .0000 & .0000 & .0000 \\
\hline 81 & $Y 2(\cos ) 3$ & .0000 & .0000 & .0000 & .0000 \\
\hline
\end{tabular}

\begin{tabular}{|c|c|c|c|c|c|}
\hline \multirow{2}{*}{\multicolumn{2}{|c|}{$\begin{array}{l}\text { STREAMS }\left(C O N I^{\prime} D\right) \text { - } \\
\text { STREAM NAME }\end{array}$}} & \multirow{3}{*}{$\begin{array}{c}25 \\
\text { Off-Gas } \\
\text { Spray Water } \\
.0000\end{array}$} & \multirow{3}{*}{$\begin{array}{c}26 \\
\text { Cooled } \\
\text { Off-Gas }\end{array}$} & \multirow{3}{*}{$\begin{array}{l}27 \\
\text { Melter Con } \\
\text { trol Air } \\
.0000\end{array}$} & \multirow{3}{*}{$\begin{array}{c}28 \\
\text { Inlet Gns } \\
\text { to Querclier } \\
.1157 E-02\end{array}$} \\
\hline & & & & & \\
\hline 7 & $\mathrm{NaCl}$ & & & & \\
\hline 188 & $\mathrm{NaCl}$ Sell Vol & .0000 & .1144 & .0000 & .1144 \\
\hline 69 & $\mathrm{NaF}$ & .0000 & $.3004 E-01$ & .0000 & $.3004 E-01$ \\
\hline 189 & NaF Sem: Vol & .0000 & $.9010 \mathrm{E}-01$ & .0000 & $.9010 E-01$ \\
\hline 12 & $\mathrm{NaI}$ & .0000 & $.1121 E-03$ & .0000 & $.1121 \mathrm{E}-03$ \\
\hline 125 & NaI Semi Vol & .0000 & $.1098 \mathrm{E}-01$ & .0000 & $.10985-01$ \\
\hline 8 & $\mathrm{NaNO2}$ & .0000 & .0000 & .0000 & .0000 \\
\hline 2 & NaNOS & .0000 & $.3728 E-01$ & .0000 & $.8725 E-01$ \\
\hline 4 & $\mathrm{NaOH}$ & .0000 & .0000 & .0000 & .0000 \\
\hline 87 & NaResin & .0000 & .0000 & .0000 & .0000 \\
\hline 61 & $\mathrm{Ni}(\mathrm{COOH}) 2$ & .0000 & $.8458 \mathrm{E}-01$ & .0000 & $.8458 E-01$ \\
\hline 17 & $\mathrm{~N} 1(\mathrm{OH}) 2$ & .0000 & .0000 & .0000 & .0000 \\
\hline 40 & N10 & .0000 & .0000 & .0000 & .0000 \\
\hline 82 & 02 & .0000 & 18.19 & 86.07 & 54.25 \\
\hline 67 & $\mathrm{PbO}$ & .0000 & .0000 & .0000 & .0000 \\
\hline 28 & $\mathrm{PbSO4}$ & .0000 & $.1568 \mathrm{E}-02$ & .0000 & $.1568 \mathrm{E}-02$ \\
\hline 124 & Pd & .0000 & .0000 & .0000 & .0000 \\
\hline 123 & $\mathrm{Pd}(\mathrm{OH}) 2$ & .0000 & .0000 & .0000 & .0000 \\
\hline 112 & PdN032 & .0000 & .0000 & .0000 & .0000 \\
\hline 110 & PdO & .0000 & .0000 & .0000 & .0000 \\
\hline 117 & $\mathrm{Pu}(\mathrm{COOH}) 4$ & .0000 & .0000 & .0000 & .0000 \\
\hline 76 & $\mathrm{Pu} 02$ & .0000 & $.4080 \mathrm{E}-03$ & .0000 & $.4080 \mathrm{E}-03$ \\
\hline 22 & $\mathrm{RhO2}$ & .0000 & $.1559 E-03$ & .0000 & $.1559 E-03$ \\
\hline 79 & Ru02 & .0000 & $.7685 E-03$ & .0000 & $.7635 \mathrm{E}-03$ \\
\hline 23 & Ru02 Seml Vol & .0000 & $.7568 \mathrm{E}-02$ & .0000 & $.7568 \mathrm{E}-02$ \\
\hline 83 & $\mathrm{RuO4}$ & .0000 & .0000 & .0000 & .0000 \\
\hline 88 & SO2 & .0000 & .8755 & .0000 & .8755 \\
\hline 111 & S102 & .0000 & 1.016 & .0000 & 1.016 \\
\hline 115 & Silica fel & .0000 & .0000 & .0000 & .0000 \\
\hline 48 & $\mathrm{Sr}(\mathrm{COOH}) 2$ & .0000 & $.1404 E-02$ & .0000 & $.1404 \mathrm{E}-02$ \\
\hline 10 & $\operatorname{Sr}(\mathrm{NOS}) 2$ & .0000 & $.1645 E-08$ & .0000 & $.1645 E-08$ \\
\hline 127 & $\mathrm{Sr}(\mathrm{OH}) 2$ & .0000 & .0000 & .0000 & .0000 \\
\hline 80 & SrCO3 & .0000 & .0000 & .0000 & .0000 \\
\hline 46 & Sro & .0000 & .0000 & .0000 & .0000 \\
\hline 89 & SrRESIN & .0000 & .0000 & .0000 & .0000 \\
\hline 141 & Surfactant & .0000 & .0000 & .0000 & .0000 \\
\hline 92 & ThO2 & .0000 & $.6396 \mathrm{E}-02$ & .0000 & $.6396 \mathrm{E}-02$ \\
\hline 107 & Ti02 & .0000 & $.1686 \mathrm{E}-01$ & .0000 & $.1636 \mathrm{E}-01$ \\
\hline 119 & Tritium & .0000 & $.8805 E-09$ & .0000 & $.3805 E-09$ \\
\hline 93 & U02 & .0000 & .0000 & .0000 & .0000 \\
\hline 62 & v02(COOII) 2 & .0000 & $.4473 E-01$ & .0000 & $.4478 E-01$ \\
\hline 16 & $\mathrm{VO2}(\mathrm{OH}) 2$ & .0000 & .0000 & .0000 & .0000 \\
\hline 27 & $1(\mathrm{COOH}) 3$ & .0000 & $.9621 E-08$ & .0000 & $.9621 E-03$ \\
\hline 11 & $Y(N 08) 8$ & .0000 & $.1168 \mathrm{E}-08$ & .0000 & $.1168 \mathrm{E}-08$ \\
\hline 128 & $Y(\mathrm{OH}) 8$ & .0000 & .0000 & .0000 & .0000 \\
\hline 81 & $Y 2(\cos ) 3$ & .0000 & .0000 & .0000 & .0000 \\
\hline
\end{tabular}

Append IX $H$

Table 21-15

Page 028 of 173

Date 09/30/82 Rev 09 
M:TERIAL BALANCE TIBLES

SLLUGE-ONLY TEED

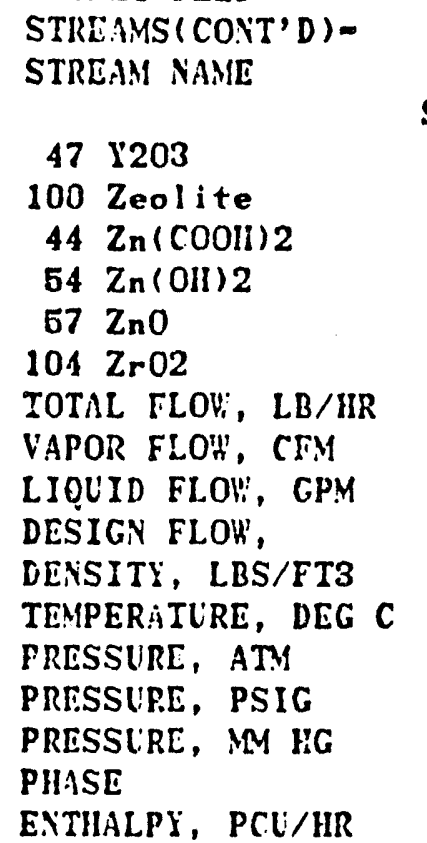

\begin{tabular}{|c|c|}
\hline \multirow{3}{*}{$\begin{array}{c}25 \\
\text { Off-Gas } \\
\text { Spray Hater }\end{array}$} & \multirow{2}{*}{$\begin{array}{c}26 \\
\text { Cooled }\end{array}$} \\
\hline & \\
\hline & Off-Gas \\
\hline .0000 & .0000 \\
\hline .0000 & $.4089 \mathrm{E}-01$ \\
\hline .0000 & $.5084 \mathrm{E}-02$ \\
\hline .0000 & .0000 \\
\hline .0000 & .0000 \\
\hline .0000 & $.8181 E-02$ \\
\hline 44.08 & 515.17 \\
\hline & \\
\hline
\end{tabular}

62.4300

40.00

1.84

5.00

LIOUID

1795.61

828924.96

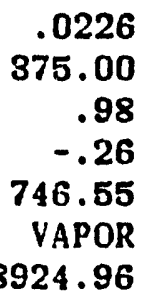

.0706

85.00

1.00

.00

VAPOR

$-8140.56$

$$
\begin{aligned}
& 28 \\
& \text { Inlet Gas } \\
& \text { to Quencher } \\
& .0000 \\
& .4089 E-01 \\
& .5084 \mathrm{E}-02 \\
& .0000 \\
& .0000 \\
& .81818-02 \\
& 675.25 \\
& 430.79 \\
& \\
& .0260 \\
& 829.79 \\
& .98 \\
& -.84 \\
& 7.42 .44 \\
& \text { VAPOR }
\end{aligned}
$$


DPSP $80-1038$

MATERIAL BALANCE. TABLES

SLLDGE-ONLY FEED

STREAM NUMR ZRS -

STREAM NAME

COMPONENT F'OHS, LH/HR

$1 \mathrm{H} 2 \mathrm{O}$

$45 \mathrm{Ag}$

$116 \mathrm{Ag} 20$

134 AgNO3

$51 \mathrm{AgOH}$

74 Al (OII) 3

77 A1208

$75 \mathrm{AlOOH}$

106 B203

$9 \mathrm{Ba}(\mathrm{NO3}) 2$

$95 \mathrm{BaCl} 2$

$15 \mathrm{BaO}$

$24 \mathrm{BaSO4}$

$66 \mathrm{CO}$

$87 \mathrm{CO2}$

$142 \mathrm{CO}$ ( $\mathrm{Cl}$ )

$68 \mathrm{Ca}(\mathrm{COOH}) 2$

$120 \mathrm{Ca}(\mathrm{OH}) 2$

$113 \mathrm{CaS}(\mathrm{PO}) 2$

$20 \mathrm{CaC} 204$

$18 \mathrm{CaCO3}$

$78 \mathrm{CaF2}$

$41 \mathrm{Ca} O$

19 CaSO4

29 Carbon

26 Col COOH 2

$121 \mathrm{Co}(\mathrm{OH}) 2$

$53 \mathrm{Co}(\mathrm{OH}) 3$

$59 \mathrm{CoO}$

$99 \mathrm{Cr}(\mathrm{OH}) 3$

98 Cr203

$42 \operatorname{Cs} 20$

137 Cs20 Seri Vol

$90 \mathrm{CsCOOII}$

$96 \mathrm{CsCl}$

$136 \mathrm{CsCl}$ Seni Vol

8 CsNOS

88 CsResin

$122 \mathrm{Cu}$ ( COOH: 2

$52 \mathrm{Cu}(\mathrm{OH}) 2$

58 Cu2O

$64 \mathrm{CuCOOH}$

$130 \mathrm{CuO}$

$13 \mathrm{Fe}(\mathrm{OHI}) \mathrm{s}$

80 Fe203

\section{9 \\ Liquid to \\ Quencher \\ 80 \\ Dilution \\ Air}

.27665405

.0000

.0000

.0000

$.6797 \mathrm{E}-02$

7.253

.0000

.0000

12.48

$.5696 \mathrm{E}-07$

.0000

.6000

.5140E-01

$.3156 \mathrm{E}-02$

.1700

.2842E-25

1.783

.0000

.1281

.1385

.0000

$.3463 E-01$

.0000

.1627

.8463E-01

.2815E-01

.0000

.0000

.0000

.1817

.0000

$.5246 \mathrm{E}-06$

$.1007 \mathrm{E}-03$

.0000

$.1962 E-06$

. 1780E-01

$.3654 E-02$

.0000

$.6014 E-01$

.0000

.0000

.0000

.0000

17.56

.0000
7.835

.0000

.0000

.0000

.0000

.0000

.0000

.0000

.0000

.0000

.0000

, 0000

.0000

.0000

.0000

.0000

.0000

.0000

.0000

.0000

.0000

.0000

.0000

.0000

.0000

.0000

.0000

.0000

.0000

.0000

.0000

.0000

.0000

.0000

.0000

.0000

.0000

.0000

.0000

.0000

.0000

.0000

.0000

.0000

.0000
Appendix $\mathrm{H}$

Table 21-15

Page 030 of 173

Date 03/3J/S2 Rev 03
81

Quencher Exit

82

Off-Gas to PUDUF

$\begin{array}{ll}.2908 E+0 J & 106.0 \\ .0000 & .0000 \\ .0000 & .0000 \\ .0000 & .0000 \\ .6806 \mathrm{E}-02 & .1861 \mathrm{E}-03 \\ 7.269 & .1169 \\ .0000 & .0000 \\ .0000 & .0000 \\ 12.50 & .2011 \\ .5704 \mathrm{E}-07 & .1536 \mathrm{E}-08 \\ .0000 & .0000 \\ .0000 & .0000 \\ .5147 \mathrm{E}-01 & .1388 \mathrm{E}-02\end{array}$

5.602

13.26

$.2217 \mathrm{E}-23$

1.786

.0000

.1283

.1387

.0000

$.3468 \mathrm{E}-01$

.0000

.1629

$.3468 \mathrm{E}-01$

$.2819 \mathrm{E}-01$

.0000

.0000

.0000

.1318

.0000

$.5254 \mathrm{E}-06$

$.1010 \mathrm{E}-03$

.0000

$.1962 E-00$

$.1775 \mathrm{E}-01$

$.3659 \mathrm{E}-02$

.0000

$.6022 \mathrm{E}-01$

.0000

.0000

.0000

.0000

17.59

.0000
ธ. 598

13.00

$.218 S E-23$

$.4816 \mathrm{E}-\mathrm{J} 1$

.0000

.3459E-02

.3741E-02

.0000

$.9353 E-03$

.0000

$.4394 \mathrm{E}-02$

$.9353 E-03$

$.7603 E-03$

.0000

.0000

.0000

$.8556 \mathrm{E}-\mathrm{-02}$

.0000

$.1401 E-07$

.0000

.0000

$.9018 \mathrm{E}-08$

.5066E-03

$.9851 \mathrm{E}-0.1$

.0000

$.1624 \mathrm{E}-\mathrm{C} 2$

.0000

.0000

.0000

.0000

.2830

.0000 
DPSP 80-1083

MATER.IAL BALANCE TABLES

SLLDCI:-ONLY FEED

STREAMIS (CONT'D)-

STREAM NAME

101 FeO

126 Group A Semi Vo

102 GroupA

103 GroupB

$25 \mathrm{H} 2$

133 H2C2O4

$01 \mathrm{H202}$

$34 \mathrm{HCOOH}$

$43 \mathrm{IICl}$

85 IIF

49 HNO3

86 HResin

$36 \mathrm{HIg}$

$135 \mathrm{HgNOS2}$

$21 \mathrm{HgO}$

$37 \quad 12$

39 K20

$131 \mathrm{KMnO4}$

$118 \mathrm{KNOO}$

105 La203

108 Li 20

$65 \mathrm{Mg}(\mathrm{COOH}) 2$

$55 \mathrm{Mg}(\mathrm{OH}) 2$

$33 \mathrm{MgO}$

$60 \mathrm{Mn}(\mathrm{COOH}) 2$

$132 \mathrm{Mn}(\mathrm{NO3}) 2$

$129 \mathrm{Mn}(\mathrm{OII}) 2$

$56 \operatorname{Min} 0$

$14 \mathrm{MnO2}$

81 '2

$143 \quad \mathrm{NA2CO3}$ (C14)

35 .10

$84 \mathrm{N02}$

$70 \mathrm{Na}(\mathrm{llg} 0(\mathrm{OHI}))$

$94 \mathrm{Na} 2 \mathrm{~B} 407$

$100 \mathrm{~N} 2 \mathrm{C204}$

$5 \mathrm{Na} 2 \mathrm{CO} 3$

32 Na20

$71 \mathrm{Na} 2 \mathrm{Pu}_{\mathrm{u}} \mathrm{O2}(\mathrm{OH}) 4$

$73 \mathrm{Na}_{2} \mathrm{Rh}_{2} \mathrm{O}$

$72 \mathrm{Na}_{2 \mathrm{Ru} 04}$

$6 \mathrm{Na} 2 \mathrm{SO}_{4}$

$68 \mathrm{NaAl} 102$

$114 \mathrm{NaBO} 2$

$140 \mathrm{NnBO2}$ Semi Vol

$50 \mathrm{NaCOOH}$

$\begin{array}{lc}29 & 80 \\ \text { Liquid to } & \text { Dilution } \\ \text { Quencher } & \text { Air } \\ .0000 & .0000 \\ .5924 & .0000 \\ .9570 E-01 & .0000 \\ .3079 & .0000 \\ .2147 \mathrm{E}-08 & .0000 \\ .0000 & .0000 \\ .0000 & .0000 \\ .0000 & .0000 \\ .0000 & .0000 \\ .0000 & .0000 \\ .0000 & .0000 \\ .0000 & .0000 \\ .0000 & .0000 \\ .0000 & .0000 \\ .2367 & .0000 \\ .0000 & .0000 \\ .0000 & .0000 \\ .0000 & .0000 \\ .2111 \mathrm{E}-03 & .0000 \\ .2525 & .0000 \\ 4.826 & .0000 \\ .8394 & .0000 \\ .0000 & .0000 \\ 1.487 & .0000 \\ 8.028 & .0000 \\ .0000 & .0000 \\ .0000 & .0000 \\ .0000 & .0000 \\ .0000 & .0000 \\ .2966 & .858 .2 \\ .0000 & .0000 \\ .1491 E-02 & .0000 \\ 1.016 & .0000 \\ .2175 E-03 & .0000 \\ 6.701 & .0000 \\ .8471 E-04 & .0000 \\ .0000 & .0000 \\ 17.80 & .0000 \\ .8819 E-08 & .0000 \\ .1813 E-05 & .0000 \\ .1769 E-04 & .0000 \\ .3588 E-01 & .0000 \\ .8819 E-01 & .0000 \\ .0000 & .0000 \\ .0000 & .0000 \\ 8.529 & .0000 \\ & \end{array}$

Append Ix H

Table 21-15

Page 031 of 1 . 3

Dnte 09/30/82 Rev 09 
DPSP $80-1038$

MATERIAL BALANCE TABLES SLUDGE-ONLY FEED STREAMS (CONT'D)STREAM NAME

\section{$7 \mathrm{NaCl}$}

$138 \mathrm{NaCl}$ Semi Vol

$69 \mathrm{NuF}$

$139 \mathrm{NaF}$ Semi Vol

$12 \mathrm{NaI}$

$125 \mathrm{NaI}$ Semi Vol

8 NaNO2

$2 \mathrm{NaN03}$

$4 \mathrm{NaOH}$

87 NaResin

$61 \mathrm{Ni}(\mathrm{COOH}) 2$

$17 \mathrm{Ni}(\mathrm{OH}) 2$

40 NiO

8202

$67 \mathrm{PbO}$

$28 \mathrm{PbSO} 04$

$124 \mathrm{Pd}$

$123 \mathrm{Pd}(\mathrm{OH}) 2$

112 PdNO32

$110 \mathrm{PdO}$

$117 \mathrm{Pu}(\mathrm{COOH}) 4$

$76 \mathrm{Pu} 02$

$22 \mathrm{RhO2}$

79 Ru02

23 Ru02 Semi Vol

$83 \mathrm{Ru} 04$

$38 \mathrm{SO2}$

$111 \mathrm{Si02}$

115 Silica Gel

$48 \mathrm{Sr}(\mathrm{COOH}) 2$

$10 \mathrm{Sr}(\mathrm{.03}) 2$

$127 \mathrm{Sr}(\mathrm{OII}) 2$

$80 \mathrm{SrCO} 3$

$46 \mathrm{Sr} 0$

89 SrRESIN

141 Surfactant

$92 \mathrm{ThO}$

$107 \mathrm{TiO}$

119 Tritium

93 V02

$62 \mathrm{U} 02$ (COOII) 2

$16 \mathrm{VO2}(\mathrm{OH}) 2$

$27 \mathrm{Y}(\mathrm{COOH}) 3$

$11 \mathrm{Y}(\mathrm{NO3}) \mathrm{S}$

$128 \mathrm{Y}(\mathrm{OII}) \mathrm{8}$

$31 Y 2(\mathrm{COB}) 3$

$\begin{array}{lc}29 & 80 \\ \text { Liqud to } & \text { Dilution } \\ \text { Quencher } & \text { Air } \\ .3575 E-01 & .0000 \\ 6.863 & .0000 \\ .9472 & .0000 \\ 4.996 & .0000 \\ .3461 E-02 & .0000 \\ .4288 & .0000 \\ .0000 & .0000 \\ 1.152 & .0000 \\ .0000 & .0000 \\ .0000 & .0000 \\ 1.067 & .0000 \\ .0000 & .0000 \\ .0000 & .0000 \\ .1699 & 108.2 \\ .0000 & .0000 \\ .4838 E-01 & .0000 \\ .0000 & .0000 \\ .0000 & .0000 \\ .0000 & .0000 \\ .0000 & .0000 \\ .0000 & .0000 \\ .1259 E-01 & .0000 \\ .4810 E-02 & .0000 \\ .2819 E-01 & .0000 \\ .2291 & .0000 \\ .0000 & .0000 \\ .6104 E-03 & .0000 \\ 62.53 & .0000 \\ .0000 & .0000 \\ .4333 E-01 & .0000 \\ .5083 E-07 & .0000 \\ .0000 & .0000 \\ .0000 & .0000 \\ .0000 & .0000 \\ .0000 & .0000 \\ .0000 & .0000 \\ .1974 & .0000 \\ .4912 & .0000 \\ .1092 E-07 & .0000 \\ .0000 & .0000 \\ 1.880 & .0000 \\ .0000 & .0000 \\ .2969 E-01 & .0000 \\ .8610 E-07 & .0000 \\ .0000 & .0000 \\ .0000 & .0000 \\ & \\ & \end{array}$

Appendix $H$

Table 21-15

Page 032 of 173

Date 09/30/82 Rev 00

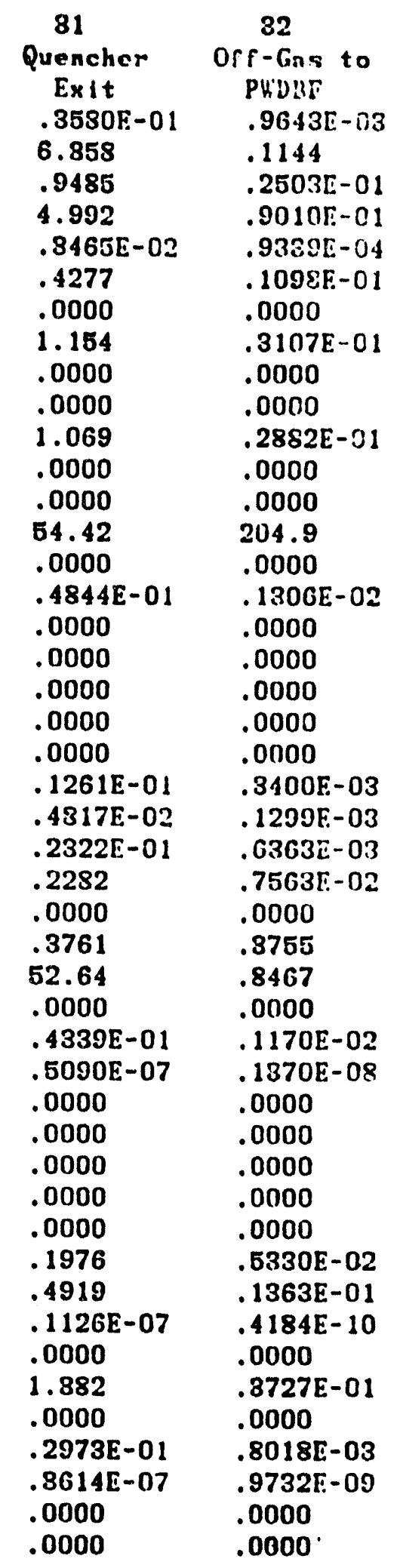


MATERIAL BALANCE TABLES

Date 09/30/82 Rev 09

SLUDCEE-ONLY FEED

STREAMS(CONT'D)STREAM NAME

$47 Y 203$

100 Zeolite

$44 \mathrm{Zn}(\mathrm{COOHI}) 2$

$54 \mathrm{Zn}(\mathrm{Oll}) 2$

$57 \mathrm{ZnO}$

$104 \mathrm{ZrO2}$

TOTAL FLOH', LB/HR

VAPOR FLOW, CFM

LIQ̣UID FLOW, CPM DESICY FLOW,

DENSITY, LBS/FT3

TEMPERATURE, DEG C

PRESSURE, ATM

PRESSURE, PSIG

PRESSURE, MA IIG

PIIASE

EXTHILPY, PCU/IIR
29

Liquid to

Quencher

.0000

1.262

.1569

.0000

.0000

.2525

27815.50

65.88

62.6253

55.00

8.72

89.97

LIQUID

1559676.19
80

Dilution

Air

.0000

.0000

.0000

.0000

.0000

.0000

474.22

112.02

.0706

35.00

1.00

.00

VAPOR

$-24421.69$
81

Quoncher

Ex1t

.0000

1.263

.1571

.0000

.0000

.2528

28485.92

66. 80

62.5314

64.37

.99

$-.14$

752.78

LIQUID

1879907.84
82

Off-GaE to 8WDBF

.0000

.8407 E- 01

.4236E-02

.0000

.0000

$.6818 \mathrm{E}-02$

1012.79

271.05

.0023

64.94

.99

$-.21$

748.90

VAYOR

15933.34 
DPSP $80-1033$

MATERIAL BALANCE TABLES

SLUDGE-ONLY FEED

STREAM NUNIBERS -

STREAM NAME

CONPONENT FLOHS, LB/IIR

$\begin{array}{rl}1 & \mathrm{H} 20 \\ 45 & \mathrm{Ag} \\ 116 & \mathrm{Ag} 20 \\ 134 & \mathrm{AgNO3} \\ 51 & \mathrm{AgOH} \\ 74 & \mathrm{Al}(\mathrm{OII}) 3 \\ 77 & \mathrm{~A} 1203 \\ 75 & \mathrm{~A} 100 \mathrm{II} \\ 10 \mathrm{~B} & \mathrm{~B} 203 \\ 9 & \mathrm{Bg}(\mathrm{Y} 03) 2\end{array}$

$9 \mathrm{Ba}(\mathrm{NO} 03) 2$

$95 \mathrm{BaCl} 2$

$15 \mathrm{BaO}$

$24 \mathrm{BaSO}$

$66 \mathrm{CO}$

$37 \mathrm{CO2}$

$142 \mathrm{CO}$ (C14)

$63 \mathrm{Ca}(\mathrm{COOH}) 2$

$120 \mathrm{Ca}(\mathrm{OH}) 2$

$113 \mathrm{Ca} 3(\mathrm{PO}) 2$

$20 \mathrm{CaC2}_{2}$

$18 \mathrm{CaCO} 3$

$78 \mathrm{CaF2}$

$41 \mathrm{CaO}$

$19 \mathrm{CaSO} 4$

29 Carbon

$26 \mathrm{Co}(\mathrm{COOH}) 2$

$121 \mathrm{Co}(\mathrm{OH}) 2$

$53 \mathrm{Co}(\mathrm{Oll}) 3$

$59 \mathrm{CoO}$

Q9 $\mathrm{Cr}(\mathrm{OH}) 3$

$98 \mathrm{Cr} 203$

$42 \mathrm{Cs} 20$

137 Cs20 Semi Vol

$90 \mathrm{CsCOOH}$

$96 \mathrm{CsCl}$

$186 \mathrm{CsCl}$ Semi Vol

8 CsNO3

88 CsResin

$122 \mathrm{Cu}(\mathrm{COOH}) 2$

$52 \mathrm{Cu}(\mathrm{OH}) 2$

$58 \mathrm{Cu} 20$

$64 \mathrm{CuCOOH}$

$130 \mathrm{CuO}$

$13 \mathrm{Fe}(\mathrm{Oll}) 3$

$80 \mathrm{Fe} 203$
88

Liq to PWDDF

Nozzles

8998.

.0000

.0000

.0000

$.9823 E-03$

1.048

.0000

.0000

1.808

$.8233 E-08$

.0000

.0000

$.7429 \mathrm{E}-02$

$.4561 \mathrm{E}-03$

$.2457 \mathrm{E}-01$

$.4108 \mathrm{E}-26$

.2577

.0000

$.1851 \mathrm{E}-01$

.2002E-01

.0000

$.6006 \mathrm{E}-02$

.0000

$.2352 E-01$

. 5006E-02

.4069E-02

.0000

.0000

.0000

$.1903 \mathrm{E}-01$

.0000

$.7583 \mathrm{E}-07$

$.1455 \mathrm{E}-04$

.0000

$.2836 \mathrm{E}-07$

$.2573 E-02$

$.5281 E-03$

.0000

.8692E-02

.0000

.0000

.0000

.0000

2.587

.0000
Appendix $\mathrm{H}$

Table 21-15

Page 034 of 173

Date U9/30/82 Rev 09
$84 \quad 35$

PUDBF \#1 PUDDF \#1

Atonzg Alr Exit Liquid

\subsection{8}

.0000

.0000

.0000

.0000

.0000

.0000

.0000

.0000

.0000

.0000

.0000

.0000

.0000

.0000

.0000

.0000

.0000

.0000

.0000

.0000

.0000

.0000

.0000

.0000

.0000

.0000

.0000

.0000

.0000

.0000

.0000

.0000

.0000

.0000

.0000

.0000

.0000

.0000

.0000

.0000

.0000

.0000

.0000

.0000
1993.

.0000

.0000

.0000

$.6714 \mathrm{E}-03$

.6374

.0000

.0000

1.096

$.5604 \mathrm{E}-08$

.0000

.0000

. 5059E-02

. 1972E-03

. 1091E-01

$.1824 \mathrm{E}-26$

.1755

.0000

. 1261E-01

$.1363 E-01$

.0000

.3409E-02

.0000

. 1601E-01

.3409E-02

.2771E-02

.0000

.0000

.0000

. 1296E-01

.0000

$.5148 \mathrm{E}-07$

$.7274 E-05$

.0000

.2291E-07

. 1742E-02

.8594E-03

.0000

.5919E-02

.0000

.0000

.0000

.0000

1.543

.0000
86

PVDEF I!?

Exit Gas

126.2

.0000

.0000

.0000

. 1861E-06

$.1169 \mathrm{E}-03$

.0000

.0000

.2011E-03

. 1536E-11

.0000

.0000

. 1388E-05

5.598

13.09

$.2189 \mathrm{E}-23$

.4S16E-04

.0000

$.34605-05$

$.3742 \mathrm{E}-05$

.0000

$.9355 E-0 G$

.0000

$.4395 \mathrm{E}-05$

$.9355 \mathrm{E}-0 \mathrm{C}$

$.7604 E-06$

.0000

.0000

.0000

.3556E-05

.0000

$.1402 \mathrm{E}-10$

.0000

.0000

$.9019 E-11$

.5060E-05

$.9853 \mathrm{E}-07$

.0000

$.1624 \mathrm{E}-05$

.0000

.0000

.0000

.0000

$.2831 E-03$

.0000 
DPSP $80-1033$

MATERIAL BaLANCE TABles

SLLDAE-ONLY TEED

STRLAAIS (CONT' D)STREAM NAME

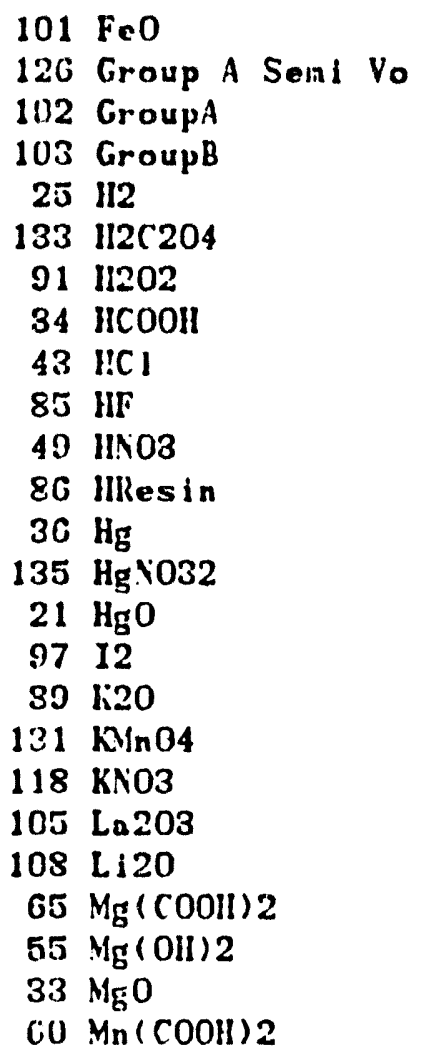

$132 \mathrm{Mn}(\mathrm{NOB}) 2$

$120 \mathrm{Mn}(\mathrm{OII}) 2$

$56 \mathrm{MnO}$

$14 \mathrm{MnO2}$

$81 \mathrm{N2}$

$143 \times 12503(0.14)$

$35 \mathrm{NO}$

84.102

$70 \mathrm{Na}\left(\mathrm{Hg}_{\mathrm{g}} \mathrm{O}(\mathrm{Oli})\right)$

9. $\mathrm{Na} 2 \mathrm{~B} 407$

$109 \mathrm{Na2C204}$

$5 \mathrm{Na} 2 \mathrm{CO}$

$82 \mathrm{Na}_{2} 2$

$71 \mathrm{Nu} 2 \mathrm{Pu} 02(\mathrm{OH}) 4$

$73 \mathrm{Na} 2 \mathrm{RhO4}$

$72 \mathrm{Nin} 2 \mathrm{Ru} 04$

$6 \mathrm{Na}_{2} \mathrm{SO}_{4}$

$68 \mathrm{Nanl} 02$

$114 \mathrm{NaBO2}$

1:0 NaBO2 Semi Vol

$50 \mathrm{NaCOOll}$

\begin{tabular}{|c|c|c|c|}
\hline 83 & 84 & 85 & 86 \\
\hline $\begin{array}{l}\text { iq to PWDBF } \\
\text { Nozzles }\end{array}$ & $\begin{array}{c}\text { PWDBF } \# 1 \\
\text { Atomzg Air }\end{array}$ & $\begin{array}{c}\text { PWDBF \#1 } \\
\text { Exit Liquid }\end{array}$ & $\begin{array}{l}\text { PWDBF \#2 } \\
\text { Ex it Gas }\end{array}$ \\
\hline .0000 & .0000 & .0000 & .0000 \\
\hline $.8561 E-01$ & .0000 & $.5673 E-01$ & $.1547 E-03$ \\
\hline $.1383 E-01$ & .0000 & $.9438 E-02$ & $.2605 E-05$ \\
\hline . 4449E-01 & .0000 & $.8030 E-01$ & $.8315 E-05$ \\
\hline $.3104 E-04$ & .0000 & $.1337 E-04$ & .8657 \\
\hline .0000 & .0000 & .0000 & .0000 \\
\hline .0000 & .0000 & .0000 & .0000 \\
\hline .0000 & .0000 & .0000 & .0000 \\
\hline .0000 & .0000 & .0000 & .0000 \\
\hline .0000 & .0000 & .0000 & .0000 \\
\hline .0000 & .0000 & .0000 & .0000 \\
\hline .0000 & .0000 & .0000 & .0000 \\
\hline .0000 & .0000 & .0000 & .0000 \\
\hline .0000 & .0000 & .0000 & .0000 \\
\hline .842 & .0000 & $.2402 E-01$ & $.7688 E-04$ \\
\hline .0000 & .0000 & .0000 & $.9392 E-04$ \\
\hline .0000 & .0000 & .0000 & .0000 \\
\hline .0000 & .0000 & .0000 & .0000 \\
\hline . 3051F-04 & .0000 & $.2266 E-04$ & $.7642 E-08$ \\
\hline $.8649 E-01$ & .0000 & $.2485 E-01$ & $.6819 \mathrm{E}-0 \overline{\mathrm{J}}$ \\
\hline .6975 & .0000 & .4242 & .7799E-04 \\
\hline $.4906 E-01$ & .0000 & $.8340 E-01$ & $.9168 \mathrm{E}-05$ \\
\hline .0000 & .0000 & .0000 & .0000 \\
\hline .2149 & .0000 & .1389 & $.2733 E-04$ \\
\hline .4377 & .0000 & .2980 & $.8173 E-04$ \\
\hline .0000 & .0000 & .0000 & .0000 \\
\hline .0000 & .0000 & .0000 & .0000 \\
\hline .0000 & .0000 & .0000 & .0000 \\
\hline .0000 & .0000 & .0000 & .0000 \\
\hline $.4287 E-01$ & 123.1 & $.2202 E-01$ & 924.7 \\
\hline .0000 & .0000 & .0000 & .0000 \\
\hline $.2155 E-03$ & .0000 & $.9384 E-04$ & 1.175 \\
\hline .1468 & .0000 & $.6961 \mathrm{E}-01$ & .1886 \\
\hline $.3143 E-04$ & .0000 & $.2139 E-04$ & $.5864 E-08$ \\
\hline .9685 & .0000 & .6235 & $.1439 \mathrm{E}-03$ \\
\hline $.1224 \mathrm{E}-04$ & .0000 & $.9090 E-05$ & $.8066 \mathrm{E}-0 \mathrm{~S}$ \\
\hline .0000 & .0000 & .0000 & .0000 \\
\hline 2.572 & .0000 & 1.564 & $.2869 E-03$ \\
\hline . 127EE-08 & .0000 & $.8675 E-09$ & $.2378 E-12$ \\
\hline . 2620E-06 & .0000 & $.1784 \mathrm{E}-06$ & $.4889 E-10$ \\
\hline $.2557 \mathrm{E}-05$ & .0000 & $.1740 E-05$ & $.4771 E-09$ \\
\hline $.5185 E-02$ & .0000 & $.8529 E-02$ & $.9675 \mathrm{E}-06$ \\
\hline $.1275 E-01$ & .0000 & $.8675 E-02$ & $.2378 E-05$ \\
\hline .0000 & .0000 & .0000 & .0000 \\
\hline .0000 & .0000 & .0000 & .0000 \\
\hline .5100 & .0000 & .8159 & $.6292 E-04$ \\
\hline
\end{tabular}

Appendix $\mathrm{H}$

Table 21-15

Page 085 of 173

Dote 09/30/82 Rev 09 
DPSP $80-1033$

MATERIAL BALANC: TABLES

SLLDGE-ONLY FEE.)

STREAMS $(C O$ T'D)-

STREAM NAM:

$7 \mathrm{NaCl}$

$138 \mathrm{NaCl}$ Siml Vol

$69 \mathrm{NaF}$

$139 \mathrm{NaF}$ Seni Vol

$12 \mathrm{NaI}$

$125 \mathrm{NaI}$ Seni Vol

$8 \mathrm{NaNO} 2$

$2 \mathrm{NaNO3}$

$4 \mathrm{NaOll}$

$87 \mathrm{NaResir}$

$61 \mathrm{Ni}(\mathrm{COOli}) 2$

$17 \mathrm{Ni}(\mathrm{OHI}) 2$

$40 \mathrm{NiO}$

8202

$67 \mathrm{PbO}$

$28 \mathrm{PbSO}$

$124 \mathrm{Pd}$

$123 \mathrm{Pd}(\mathrm{OH}) 2$

112 PdNO32

$110 \mathrm{PdO}$

$117 \mathrm{Pu}(\mathrm{COOH}) 4$

$76 \quad \mathrm{Pu} 02$

$22 \mathrm{RhO2}$

$79 \mathrm{Ru} 02$

23 Ru02 Seni Vol

$83 \mathrm{RuO} 4$

$38 \mathrm{SO2}$

$111 \mathrm{SiO} 2$

115 Silice fel

$48 \mathrm{Sr}(\mathrm{COOH}) 2$

$10 \mathrm{Sr}(\mathrm{N} 03) 2$

$127 \mathrm{Sr}(\mathrm{OH}) 2$

$30 \mathrm{SrCO}$

$46 \mathrm{Sr} 0$

89 SrRESIN

141 Surfactant

92 Th02

$107 \mathrm{TiO} 2$

119 Tritium

$98 \mathrm{VO2}$

$62 \mathrm{VO2}(\mathrm{COOII}) 2$

$16 \mathrm{VO2}(\mathrm{OH}) 2$

$27 \mathrm{Y}(\mathrm{COOH}) 3$

$11 \mathrm{Y}(\mathrm{NOS}) 3$

$128 \times(011) 3$

$31 \mathrm{Y}_{2(\mathrm{CO}) 3}$
Appendix $\mathrm{H}$

Table 21-15

Page 036 of 173

Dite 09/30/52 Rev 0J $\begin{array}{llll}33 & 84 & 85 & 86\end{array}$

Liq to PHDBF PHDBF \#1 PHDBF \#1 PIDE: \#2

No:zles

$.5167 \mathrm{E}-02$

.0196

.1369

.7220

$.5002 \mathrm{E}-03$

$.6197 \mathrm{E}-01$

.0000

.1665

.0000

.0000

.1542

.0000

.0000

$.2456 \mathrm{E}-01$

.0000

$.6992 E-02$

.0000

.0000

.0000

.0000

.0000

$.1820 \mathrm{E}-02$

$.6952 \mathrm{E}-03$

.5352E-02

. $3311 \mathrm{E}-01$

.0000

$.8823 \mathrm{E}-04$

7.592

.0000

$.6262 \mathrm{E}-02$

$.7346 \mathrm{E}-08$

.0000

.0000

.0000

.0000

.0000

$.2852 \mathrm{E}-01$

$.7100 E-01$

$.1579 \mathrm{E}-08$

.0000

.1995

.0000

.4291E-02

$.5217 E-08$

.0000

.0000
Atomzg Air

.0000

.0000

.0000

.0000

.0000

.0000

.0000

.0000

.0000

.0000

.0000

.0000

.0000

37.19

.0000

.0000

.0000

.0000

.0000

.0000

.0000

.0000

.0000

.0000

.0000

.0000

.0000

.0000

.0000

.0000

.0000

.0000

.0000

.0000

.0000

.0000

.0000

.0000

.0000

.0000

.0000

.0000

.0000

.0000

.0000

.0000
Esit Liquid

. 3517E-02

.5628

.8260 E-01

.4421

$.8405 \mathrm{E}-03$

$.4087 E-01$

.0000

.1133

.0000

.0000

.1050

.0000

.0000

$.1264 \mathrm{E}-\mathrm{G} 1$

.0000

$.4761 \mathrm{E}-02$

.0000

.0000

.0000

.0000

.0000

. 1239E-02

$.4734 \mathrm{E}-03$

.2292E-02

.2336E-01

.0000

.8854E-04

4.616

.0000

$.4264 \mathrm{E}-02$

$.5000 \mathrm{E}-03$

.0000

.0000

.0000

.0000

.0000

$.1942 E-01$

$.4870 E-01$

$.7860 \mathrm{E}-05$

.0000

.1358

.0000

.2922E-02

.3551E-08

.0000

.0000
Exit Cas

.9645:-06

$.11445-62$

$.25041:-0.4$

$.90101:-03$

$.9340 \mathrm{E}-07$

$.1098 \mathrm{E}-03$

.0000

.3105r-04

.0000

.0000

$.2882 \mathrm{E}-04$

.0000

.0000

279.3

.0000

$.13075-05$

.0000

.0000

.0000

.0000

.0000

$.34005-06$

$.12995-06$

.6364 E-06

$.7563 E-04$

.0000

.3755

.8465E-03

.0000

$.1170 \mathrm{E}-05$

$.1371 \mathrm{E}-11$

.0000

.0000

.0000

.0000

.0000

$.5331 E-05$

$.1364 \mathrm{E}-04$

$.4978 \mathrm{E}-10$

.0000

.3728E-04

.0000

$.8019 \mathrm{E}-06$

$.9734 \mathrm{E}-12$

.0000

$.0000^{\circ}$ 
MATERIAL BALANCE TABLES

Date 09/30/82 Rev 09 SLUDGE-ONLY FEED

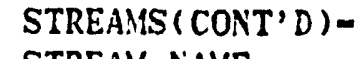

STREAM NAME

$\begin{array}{rl}47 & Y 203 \\ 100 & \mathrm{Zeol} \text { te } \\ 44 & \mathrm{Zn}(\mathrm{C} 0011) 2 \\ 54 & \mathrm{Zn}(0 \mathrm{H}) 2 \\ 57 & \mathrm{Zn} 0 \\ 104 & \mathrm{Zr} 02\end{array}$

TOTAL FLOW, LB/HR

VAPOR FLOW, CEM

LIQUID FLOH, GPM

DESIGN FLOW,

DEISITY, LBS/FT3

TEMPERATURE, DEG C PRESSURE, ATM

PRESSURE, PSIG

PRESSURE, MM IIG

PIIASE

EXTHALPY, PCU/HR

$\begin{array}{cccc}33 & 84 & 85 & 86 \\ \begin{array}{c}\text { Liq to PHDBF } \\ \text { Nozzles }\end{array} & \begin{array}{c}\text { PWDBF \#1 } \\ \text { Atomzg Air }\end{array} & \begin{array}{c}\text { PWDBF \#1 } \\ \text { Exit Liquid }\end{array} & \begin{array}{c}\text { PWDBF } \# 2 \\ \text { Exit Gas }\end{array} \\ .0000 & .0000 & .0000 & .0000 \\ .1823 & .0000 & .1242 & .8408 E-04 \\ .2267 E-01 & .0000 & .15442-01 & .4237 E-05 \\ .0000 & .0000 & .0000 & .0000 \\ .0000 & .0000 & .0000 & .0000 \\ .3649 E-01 & .0000 & .2485 E-01 & .6819 E-05 \\ 4020.14 & 162.98 & 2006.80 & 1350.09 \\ & 10.52 & & 370.08 \\ 8.00 & & & \end{array}$

62.6253

55.00

3.18

32.04

LIQUID

225417.85
.2588

40.00

8.72

89.97

VAPOR

$-8198.74$
62.6714

53.48

.97

$-.51$

733.70

LIQUID

109255.65
.0608

52.46

.95

$-.72$

722.76

VAPOR

8726.08 
IPSP $80-1033$

\section{MATERIAL BALANCE TABLES SEUDGE-ONLY FEED STREAM NUMBERS - STRLAM NAME}

COMPONENT FLOHS, LB/IIR

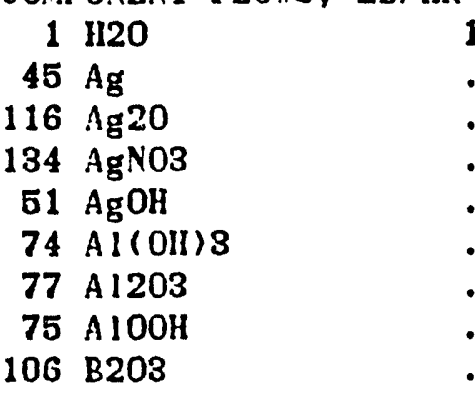

$9 \mathrm{Ba}(\mathrm{NOS}) 2$

$95 \mathrm{BnCl} 2$

$15 \mathrm{BaO}$

$24 \mathrm{BaSO} 4$

$66 \mathrm{CO}$

$37 \mathrm{CO} 2$

142 C.02 (C14)

$63 \mathrm{Ca}(\mathrm{COOH}) 2$

$120 \mathrm{Ca}(\mathrm{OHI}) 2$

113 Ca3 ( P04) 2

$20 \mathrm{CAC2O4}_{4}$

$18 \mathrm{CaCO} 3$

$78 \mathrm{CaF} 2$

$41 \mathrm{CaO}$

$19 \mathrm{CaSO}_{4}$

29 Carbon

$26 \mathrm{Co}(\mathrm{COOH}) 2$

$121 \mathrm{Co}(\mathrm{OII}) 2$

$53 \mathrm{Co}(\mathrm{OH}) \mathrm{3}$

$59 \mathrm{CoO}$

$99 \mathrm{Cr}(\mathrm{OH}) 3$

$98 \mathrm{Cr} 203$

$42 \operatorname{Cs} 20$

137 Cs20 Semi Vol

$90 \mathrm{CsCOOH}$

$96 \mathrm{CsCl}$

$136 \mathrm{CsCl}$ Semi Vol

8 CsNO3

88 CsResin

$122 \mathrm{Cu}(\mathrm{COOH}) 2$

$52 \mathrm{Cu}(\mathrm{OHI}) 2$

$58 \mathrm{Cu} 20$

$64 \mathrm{CuCOOH}$

$130 \mathrm{CuO}$

$18 \mathrm{Fe}(\mathrm{OH}) 3$

$80 \mathrm{Fe} 203$
Append ix 11

Table 21-15

Page 038 of 173

Date 09/30/:2 Rev 09

37

88

39

40

FPT Liquid Canister Air Inlet Air Liquid Feed to OGCT Inleakage to Ejector to Ejector

$103.8 \quad .6654$

1.331

.0000

.0000

.0000

.0000

.0000

.0000

.0000

.0000

.0000

.0000

.0000

.0000

.0000

.0000

.0000

.0000

.0000

.0000

.0000

.0000

.0000

.0000

.0000

.0000

.0000

.0000

.0000

.0000

.0000

.0000

.0000

.0000

.0000

.0000

.0000

.0000

.0000

.0000

.0000

.0000

.0000

.0000

.0000

.0000
$.885 C E+05$

.0000

.0000

.0000

.2174 E- 01

23.20

.0000

.0000

39.91

. 1822E-00

.0000

.0000

.1644

.1010 E-01

.5438

$.9093 \mathrm{E}-25$

5.704

.0000

.4098

.4432

.0000

.1108

.0000

.5206

.1108

$.9007 \mathrm{E}-01$

.0000

.0000

.0000

.4212

.0000

. 1678E-05

.3220E-03

.0000

$.6277 \mathrm{E}-06$

.5695E-01

. 1169E-01

.0000

.1924

.0000

.0000

.0000

.0000

56.17

.0000 
MATERIAL BALANCE TARLES

\section{SLUDGE-ONLY FEED}

\begin{tabular}{|c|c|c|c|c|c|}
\hline \multicolumn{2}{|c|}{$\begin{array}{l}\text { STREAMS (CONT'D)- } \\
\text { STREAM NAME }\end{array}$} & $\begin{array}{l}37 \\
\text { FPT Liquid } \\
\text { to OGCT }\end{array}$ & $\begin{array}{c}88 \\
\text { Canister Air } \\
\text { Inleakage }\end{array}$ & $\begin{array}{l}\quad 89 \\
\text { Inlet Air } \\
\text { to Ejector }\end{array}$ & $\begin{array}{l}40 \\
\text { Liquid Feed } \\
\text { to Eiector }\end{array}$ \\
\hline 101 & FeO & .0000 & $.0000^{\circ}$ & .0000 & .0000 \\
\hline 126 & Group A Semi Vo & $.1090 \mathrm{E}-03$ & .0000 & .0000 & 1.895 \\
\hline 102 & GroupA & $.1854 E-05$ & .0000 & .0000 & .8062 \\
\hline 103 & GroupB & $.5981 E-05$ & .0000 & .0000 & .9849 \\
\hline 25 & $\mathrm{H2}$ & $.4489 E-06$ & .0000 & .0000 & $.6870 \mathrm{E}-03$ \\
\hline 133 & $\mathrm{H} 2 \mathrm{C} 204$ & .0000 & .0000 & .0000 & .0000 \\
\hline 91 & H2O2 & .0000 & .0000 & .0000 & .0000 \\
\hline 84 & HCOOH & .0000 & .0000 & .0000 & .0000 \\
\hline 43 & $\mathrm{HCl}$ & .0000 & .0000 & .0000 & .0000 \\
\hline 85 & HF & .0000 & .0000 & .0000 & .0000 \\
\hline 49 & HNO3 & .0000 & .0000 & .0000 & .0000 \\
\hline 86 & IIITes in & .0000 & .0000 & .0000 & .0000 \\
\hline 36 & Hg & .0000 & .0000 & .0000 & .0000 \\
\hline 135 & $\operatorname{lig} N 032$ & .0000 & .0000 & .0000 & .0000 \\
\hline 21 & $\mathrm{Hg}_{\mathrm{g}} \mathrm{O}$ & $.5475 E-04$ & .0000 & .0000 & .7571 \\
\hline 97 & 12 & .0000 & .0000 & .0000 & .0000 \\
\hline 89 & $\mathrm{~K} 20$ & .0000 & .0000 & .0000 & .0000 \\
\hline 131 & $\mathrm{KMnO4}$ & .0000 & .0000 & .0000 & .0000 \\
\hline 118 & KNO3 & $.3546 \mathrm{E}-08$ & .0000 & .0000 & $.6754 \mathrm{E}-03$ \\
\hline 105 & $\operatorname{La} 203$ & $.4905 E-05$ & .0000 & .0000 & .8076 \\
\hline 108 & Li 20 & $.5606 \mathrm{E}-04$ & .0000 & .0000 & 15.44 \\
\hline 65 & $\mathrm{Mg}(\mathrm{COOH}) 2$ & $.6594 \mathrm{E}-05$ & .0000 & .0000 & 1.086 \\
\hline 55 & $\mathrm{Mg}(\mathrm{OH}) 2$ & .0000 & .0000 & .0000 & .0000 \\
\hline 33 & $\mathrm{MgO}$ & $.1964 \mathrm{E}-04$ & .0000 & .0000 & 4.757 \\
\hline 60 & $\operatorname{Mn}(\mathrm{COOII}) 2$ & $.5886 E-04$ & .0000 & .0000 & 9.688 \\
\hline 132 & $\operatorname{Mn}\left(\mathrm{N}_{03}\right) 2$ & .0000 & .0000 & .0000 & .0000 \\
\hline 129 & $\mathrm{Mn}(\mathrm{OII}) 2$ & .0000 & .0000 & .0000 & .0000 \\
\hline 56 & $\mathrm{MnO}$ & .0000 & .0000 & .0000 & .0000 \\
\hline 14 & $\mathrm{Mn} 02$ & .0000 & .0000 & .0000 & .0000 \\
\hline 81 & N2 & $.1219 E-02$ & 30.42 & 60.84 & .9490 \\
\hline 143 & $\mathrm{NA}_{2} \mathrm{CO}(\mathrm{C} 14)$ & .0000 & .0000 & .0000 & .0000 \\
\hline 35 & NO & $.3310 \mathrm{E}-05$ & .0000 & .0000 & $.4770 \mathrm{E}-02$ \\
\hline 84 & N02 & $.3508 E-02$ & .0000 & .0000 & 8.249 \\
\hline 70 & $\mathrm{Na}\left(\mathrm{HgO}_{\mathrm{g}}(\mathrm{OH})\right)$ & $.4226 \mathrm{E}-08$ & .0000 & .0000 & $.6956 \mathrm{E}-03$ \\
\hline 94 & $\operatorname{Na2B} 407$ & $.1037 E-03$ & .0000 & .0000 & 21.44 \\
\hline 109 & $\mathrm{Na2C204}$ & $.1423 E-08$ & .0000 & .0000 & $.2710 \mathrm{E}-03$ \\
\hline 5 & $\mathrm{Na} 2 \mathrm{CO}$ & .0000 & .0000 & .0000 & .0000 \\
\hline 32 & $\operatorname{Na20}$ & $.2067 E-03$ & .0000 & .0000 & 56.94 \\
\hline 71 & $\mathrm{Nn} 2 \mathrm{Pu}_{\mathrm{u}} \mathrm{2}(\mathrm{OHI}) 4$ & $.1714 \mathrm{E}-12$ & .0000 & .0000 & $.2821 E-07$ \\
\hline 73 & $\mathrm{Na}_{2} \mathrm{Rh}_{3} \mathrm{O4}$ & $.3524 E-10$ & .0000 & .0000 & $.5800 \mathrm{E}-05$ \\
\hline 72 & $\mathrm{Na2Ru04}$ & $.3439 E-09$ & .0000 & .0000 & $.5660 E-04$ \\
\hline 6 & $\mathrm{Na} 2 \mathrm{SO} 04$ & $.6973 E-06$ & .0000 & .0000 & .1148 \\
\hline 68 & InA 102 & $.1714 E-05$ & .0000 & .0000 & .2821 \\
\hline 114 & $\mathrm{NaBO} 2$ & .0000 & .0000 & .0000 & .0000 \\
\hline 140 & NaBO2 Semi Vol & .0000 & .0000 & .0000 & .0000 \\
\hline 50 & Nincooll & $.4530 \mathrm{E}-04$ & .0000 & .0000 & 11.29 \\
\hline
\end{tabular}


DPSP $80-1033$

MATERIAL BALANCE TABLES

SLUDGE-ONLY FEED

STREAMS (CONT'D)-

STREAM NAME

$7 \mathrm{NaCl}$

$138 \mathrm{NaCl}$ Semi Vol

$69 \mathrm{NaF}$

139 NaF Semi Vol

$12 \mathrm{NaI}$

125 NaI Semi Vol

$8 \mathrm{NaNO} 2$

$2 \mathrm{NiNO3}$

$4 \mathrm{NaOH}$

87 NaResin

$61 \mathrm{Ni}(\mathrm{COOH}) 2$

$17 \mathrm{Ni}(\mathrm{OH}) 2$

$40 \mathrm{NiO}$

8202

$67 \mathrm{PbO}$

$28 \mathrm{PbSO4}$

$124 \mathrm{Pd}$

$123 \mathrm{Pd}(\mathrm{OH}) 2$

112 PdN032

$110 \mathrm{PdO}$

$117 \mathrm{Pu}(\mathrm{COOH}) 4$

$76 \mathrm{PuO2}^{2}$

$22 \mathrm{Rh} 02$

$79 \mathrm{Ru} 02$

23 Ru02 Semi Vol

$83 \mathrm{Ru} 04$

$38 \mathrm{S02}$

$111 \mathrm{SiO} 02$

$115 \mathrm{Silica} G e l$

$48 \mathrm{Sr}(\mathrm{COOH}) 2$

$10 \mathrm{Sr}(\mathrm{NO3}) 2$

$127 \mathrm{Sr}(\mathrm{OH}) 2$

$80 \mathrm{SrCO3}$

$46 \mathrm{Sr} 0$

89 SrRESIN

141 Surfactant

$92 \mathrm{Th}^{02}$

$107 \mathrm{TiO}$

119 Tritium

$93 \mathrm{VO2}$

$62 \mathrm{V02}(\mathrm{COOHI}) 2$

$16 \mathrm{~V} 02(\mathrm{Oll}) 2$

$27 \mathrm{Y}(\mathrm{COOH}) 3$

$11 \mathrm{Y}(\mathrm{NOS}) \mathrm{S}$

$128 \mathrm{Y}(\mathrm{OH}) \mathrm{S}$

$31 \mathrm{Y} 2(\mathrm{CO}) 3$
87

FPT Liquid to OGCT

$.6940 \mathrm{E}-06$

$.8146 \mathrm{E}-03$

$.1798 \mathrm{E}-04$

$.6405 E-03$

$.6724 E-07$

$.7826 E-04$

.0000

.2237E-04

.0000

.0000

.2073E-04

.0000

.0000

$.7065 \mathrm{E}-03$

.0000

$.9399 \mathrm{E}-06$

.0000

.0000

.0000

.0000

.0000

.2446E-06

$.9345 \mathrm{E}-07$

.4487E-06

$.5278 E-04$

.0000

$.1880 \mathrm{E}-05$

$.6101 \mathrm{E}-03$

.0000

$.8418 \mathrm{E}-06$

$.9879 E-12$

.0000

.0000

.0000

.0000

.0000

$.3834 E-05$

.9808E-05

$.1628 \mathrm{E}-10$

.0000

.2681E-04

.0000

$.5768 \mathrm{E}-06$

$.7016 \mathrm{E}-12$

.0000

.0000
Appendix II

Tisble 21-15

Page 010 of 173

Date 09/30/82 Rey 09

88
Canister Air
Inleakage
.0000
.0000
.0000
.0000
.0000
.0000
.0000
.0000
.0000
.0000

39

40

Inlet Air Liquid Feed

to Ejector to Ejector

$.0000 \quad .1144$

$.0000 \quad 20.20$

$.0000 \quad 3.030$

$.0000 \quad 15.98$

$.0000 \quad \ldots 1107 E-0$ !

.0000

1.372

.0000

.0000

.0000

.0000

.0000

.0000

8.685

.0000

.0000

.0000

3.414

.0000

.0000

9.189

.0000

.0000

18.88

.0000

.0000

.0000

.0000

.5435

.0000

.0000

.0000

.0000

.0000

.0000

.0000

.0000

.0000

.0000

.0000

.0000

.0000

.0000

.0000

.0000

.0000

.0000

.0000

.0000

.0000

.0000

.1548

.0000

.0000

.0000

.0000

.0000

.0000

.0000

.0000

.0000

.0000

.0000

$.4027 \mathrm{E}-01$

. 1530E-01

$.7410 \mathrm{E}-01$

.0000

.7329

.0000

$.1953 \mathrm{E}-02$

168.0

.0000

.1386

.1626E-06

.0000

.0000

.0000

.0000

.0000

.6314

.0000

.0000

.0000

.0000

.0000

.0000

.0000

.0000

.0000

1.572

$.3494 E-07$

.0000

4.415

.0000

$.9498 \mathrm{E}-01$

$.1155 \mathrm{E}-0 \mathrm{C}$

.0000

.0000

.0000

.0000

.0000

.0000

.0000 
MaTERIAL BAIANCE THBLES Date $09 / 80 / 82$ Rev $0 J$

\section{SLUDGE-ONLY FEED \\ STREANSS (CONT'D)- \\ STRLAM NAME}

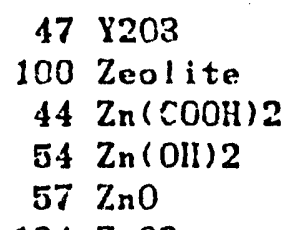

104 $\mathrm{Zr} 02$

TOTAL FLOW, LB/IIR

VAPOR FLOH, CFY

LIOUID FLOH, GPM

DESIGS FLOW,

DENSITI, LBS/FT3

TEMPERITLRE, DEG C

PRESSURE, ATM

PRESSLRE, PSIG

PRESSURE, MM HG

PHASE

EXTIHAPY, PCU/IIR

\begin{tabular}{|c|c|c|c|}
\hline 87 & 38 & 89 & 40 \\
\hline $\begin{array}{l}\text { FPT Liquid } \\
\text { to OGCT } \\
.0000\end{array}$ & $\begin{array}{c}\text { Canister Air } \\
\text { Inleakngo } \\
.0000\end{array}$ & $\begin{array}{l}\text { Inlet Air } \\
\text { to Ejector } \\
.0000\end{array}$ & $\begin{array}{c}\text { Liquid Feed } \\
\text { to Ejector } \\
.0000\end{array}$ \\
\hline $.2451 E-04$ & .0000 & .0000 & 4.036 \\
\hline $.8048 \mathrm{E}-05$ & .0000 & .0000 & .5019 \\
\hline .0000 & .0000 & .0000 & .0000 \\
\hline .0000 & .0000 & .0000 & .0000 \\
\hline . 4905E-05 & .0000 & .0000 & .8076 \\
\hline 103.85 & $\begin{array}{r}40.28 \\
9.88\end{array}$ & $\begin{array}{l}80.55 \\
20.70\end{array}$ & 88984.02 \\
\hline .21 & & & 177.15 \\
\hline $\begin{array}{r}62.4318 \\
46.47\end{array}$ & $\begin{array}{r}.0680 \\
35.00\end{array}$ & $\begin{array}{l}.0648 \\
84.98\end{array}$ & $\begin{array}{r}62.6253 \\
55.00\end{array}$ \\
\hline .99 & .96 & .92 & 3.72 \\
\hline-.21 & -.54 & -1.19 & 39.97 \\
\hline 748.90 & 732.03 & 698.44 & \\
\hline LIQUID & VAPOR & VAPOR & LIQUID \\
\hline 4924.28 & -2074.10 & -4148.21 & 4989529.19 \\
\hline
\end{tabular}


DPSP $80-1033$

MATERIAL BALANCE TABLES

SLUDGE-ONLY FEED
Appendix II

Trable 21-15

Page 042 of 173

Date 09/30/82 Rev 09

STREAM NUMBIRS -

STREAM NAME

41 COMPONENT F.OHS, LB/IIR

Ejector Ejector Liquid Spray Atomzg Al.

1 HI2O

$45 \mathrm{Ag}$

116 Ag20

134 AgNO3

$51 \mathrm{AgOH}$

$74 \mathrm{Al}(\mathrm{OH}) \mathrm{B}$

77 A 1203

75 AlOOH

106 B203

$9 \mathrm{Ba}(\mathrm{N} 03) 2$

$95 \mathrm{BaCl} 2$

$15 \mathrm{BaO}$

$24 \mathrm{BaSO4}$

$66 \mathrm{CO}$

$37 \mathrm{CO} 2$

$142 \mathrm{CO}$ (C14)

$63 \mathrm{Ca}(\mathrm{COOH}) 2$

$120 \mathrm{Ca}(\mathrm{OH}) 2$

$113 \mathrm{Ca3}(\mathrm{PO}) 2$

$20 \mathrm{CaC} 204$

$18 \mathrm{CaCO3}$

$78 \mathrm{CaF2}$

$41 \mathrm{CaO}$

$19 \mathrm{CaSO} 4$

9.053

.0000

.0000

.0000

.0000

.0000

.0000

.0000

.0000

.0000

.0000

.0000

.0000

$.9888 \mathrm{E}-02$

.8660

$.6120 \mathrm{E}-25$

.0000

.0000

.0000

.0000

.0000

.0000

.0000

.0000

29 Carbon

.0000

.0000

.0000

.0000

$121 \mathrm{Co}(\mathrm{OH}) 2$

.0000

.0000

.0000

.0000

.0000

.0000

.0000

.0000

.0000

.0000

.0000

.0000

.0000

.0000

.0000

.0000

.0000

$.8849 E 405$
.0000
.0000
.0000
$.2165 E-01$
23.18
.0000
.0000
89.87
$.1815 E-06$
.0000
.0000
.1638
$.2082 E-03$
.1778
$.2973 E-25$
5.681
.0000
.4081
.4414
.0000
.1103
.0000
.5185
.1103
$.8970 E-01$
.0000
.0000
.0000
.4195
.0000
$.1672 E-05$
$.3231 E-03$
.0000
$.6219 E-06$
$.5678 E-01$
$.1164 E-01$
.0000
.1916
.0000
.0000
.0000
.0000
56.11
.0000

2912.

3.913

$.0000 \quad .0000$

$.0000 \quad .0000$

$.0000 \quad .0000$

$.3671 \mathrm{E}-05 \quad .0000$

$.2363 E-02 \quad .0000$

$.0000 \quad .0000$

$.0000 \quad .0000$

.4064 E-02 .0000

$.3105 E-10 \quad .0000$

$.0000 \quad .0000$

$.0000 \quad .0000$

$.2800 \mathrm{E}-04 \quad .0000$

$.1885 E-03 \quad .0060$

$.1179 E-01 \quad .0000$

$.1971 \mathrm{E}-20 \quad .0000$

$.9715 \mathrm{E}-03 \quad .0000$

$.0000 \quad .0000$

$.6979 E-01 \quad .0000$

$.7548 E-04 \quad .0000$

$.0000 \quad .0000$

$.1887 E-04 \quad .0000$

$.0000 \quad .0000$

$.8866 \mathrm{E}-04 \quad .0000$

$.1887 \mathrm{E}-04 \quad .0000$

$.1535 \mathrm{E}-04 \quad .0000$

$.0000 \quad .0000$

$.0000 \quad .0000$

$.0000 \quad .0000$

$.7173 E-04 \quad .0000$

$.0000 \quad .0000$

$.2598 \mathrm{E}-09 \quad .0000$

$.0000 \quad .0000$

$.0000 \quad .0000$

$.8772 \mathrm{E}-10 \quad .0000$

$.1012 \mathrm{E}-03 \quad .0000$

$.1992 E-05 \quad .0000$

$.0000 \quad .0000$

$.3277 E-04 \quad .0000$

$.0000 \quad .0000$

$.0000 \quad .0000$

$.0000 \quad .0000$

$.0000 \quad .0000$

$.5719 \mathrm{E}-02 \quad .0000$

$.0000 \quad .0000$. 
MATREIAL BALANCE TALLES

Date 09/80/82 Rev 09

SLUDGE-ONLY FEED

STREAMS (CONT'D)-

STREAM NAME

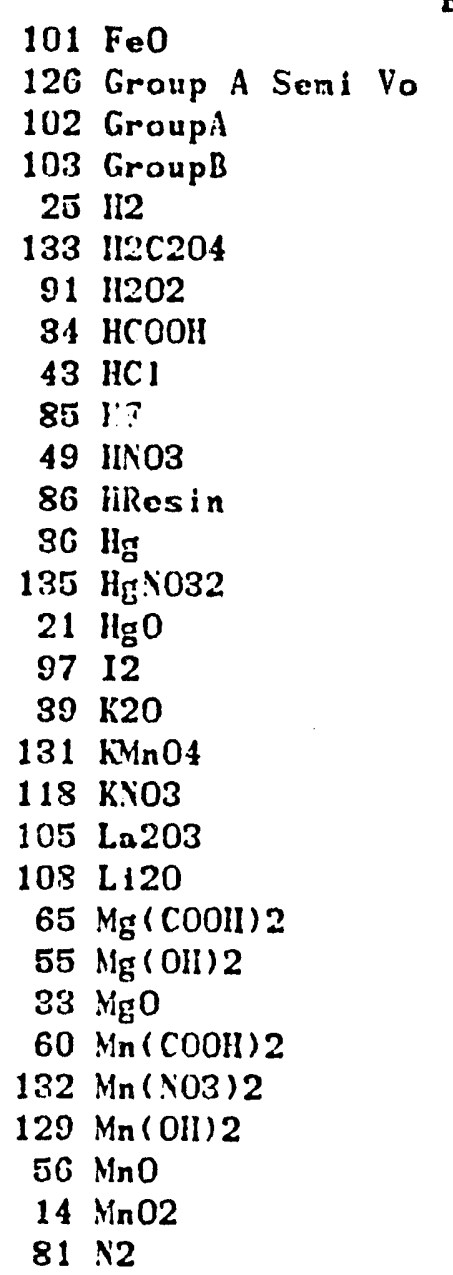

$143 \times 12003$ (C14)

35 10

$84 \quad \mathrm{N02}$

$70 \mathrm{Ni}\left(\mathrm{IIg}_{\mathrm{g}} \mathrm{O}(\mathrm{OIII})\right)$

94 $\mathrm{Na} 2 \mathrm{~B} 407$

109 in 2C204

$5 \mathrm{Na} 2 \mathrm{CO3}$

32 Na20

$71 \mathrm{Na} 2 \mathrm{PuO2}_{4}(\mathrm{OiI}) 4$

$73 \mathrm{Na2Rh04}$

$72 \mathrm{Na2Ru04}$

$6 \mathrm{Na} 2 \mathrm{SO} 4$

$68 \mathrm{NaAl} 102$

$114 \mathrm{NaBO} 2$

$140 \mathrm{NaBO2}$ Semi fol

$50 \mathrm{NaCOOH}$
41

Ejector

Exit Vapor

.0000

.0000

.0000

.0000

$.6722 \mathrm{E}-03$

.0000

.0000

.0000

.0000

.0000

.0000

.0000

.0000

.0000

.0000

.0000

.0000

.0000

.0000

.0000

.0000

.0000

.0000

.0000

.0000

.0000

.0000

.0000

.0000

60.80

.0000

.4554E-02

. 1507E-01

.0000

.0000

.0000

.0000

.0000

.0000

.0000

.0000

.0000

.0000

.0000

.0000

.0000
42

Ejector

Exit Liquid

.0000

1.890

.8049

.9809

. 1474E-04

.0000

.0000

.0000

.0000

.0000

.0000

.0000

.0000

.0000

.7540

.0000

.0000

.0000

$.6710 \mathrm{E}-03$

.8044

15.42

1.081

.0000

4.749

9.649

.0000

.0000

.0000

.0000

.9933

.0000

.2160E-03

3.234

$.6928 \mathrm{E}-03$

21.38

.2692E-03

.0000

56.88

.2810E-07

$.5777 \mathrm{E}-05$

.5637 E-04

.1143

.2810

.0000

.0000

11.27
43

Liquid Spray

to SUIDBF \#1

.0000

.3057E-02

.5200E-04

$.1677 \mathrm{E}-03$

$.1259 \mathrm{E}-04$

.0000

.0000

.0000

.0000

.0000

.0000

.0000

.0000

.0000

$.1535 \mathrm{E}-02$

.0000

.0000

.0000

$.9945 \mathrm{E}-07$

$.1375 \mathrm{E}-03$

. 1572E-02

$.1849 \mathrm{E}-03$

.0000

.5508:-03

. 1651E-02

.0000

.0000

.0000

.0000

$.3418 \mathrm{E}-01$

.0000

$.9281 \mathrm{E}-04$

$.9839 \mathrm{E}-01$

$.1185 \mathrm{E}-06$

.2907E-02

$.3900 E-07$

.0000

$.5796 \mathrm{E}-02$

$.4807 \mathrm{E}-11$

$.9882 \mathrm{E}-09$

. 9643E-08

. 1955E-04

$.4807 \mathrm{E}-04$

.0000

.0000

$.1270 E-02$
44

Atomig Alr SHIDBF \#1

.0000

.0000

.0000

.0000

.0000

.0000

.0000

.0000

.0000

.0000

.0000

.0000

.0000

.0000

.0000

.0000

.0000

.0000

.0000

.0000

.0000

.0000

.0000

.0000

.0000

.0000

.0000

.0000

.0000

178.9

.0000

.0000

.0000

.0000

.0000

.0000

.0000

.0000

.0000

.0000

.0000

.0000

.0000

.0000

.0000

.0000 
DPSP $80-1033$

MATERIAL BALANCE TABLES

SLUDGE-ONLY FEED

STREAMS (CONT'D) -

STREAM NAME

\begin{tabular}{|c|c|}
\hline 7 & $\mathrm{NaCl}$ \\
\hline 188 & NaCl Seni Vol \\
\hline 69 & $\mathrm{NaF}$ \\
\hline 139 & NaF Semi Vol \\
\hline 12 & $\mathrm{NaI}$ \\
\hline 125 & NaI Semi Vol \\
\hline 8 & $\mathrm{NaNO2}$ \\
\hline 2 & $\mathrm{NaNO3}$ \\
\hline 4 & $\mathrm{NaOH}$ \\
\hline 87 & NaResin \\
\hline 61 & $\mathrm{Ni}(\mathrm{COOH}) 2$ \\
\hline 17 & $\mathrm{Ni}(\mathrm{OH}) 2$ \\
\hline 40 & $\mathrm{NiO}$ \\
\hline 82 & 02 \\
\hline 67 & $\mathrm{PbO}$ \\
\hline 28 & PbSO4 \\
\hline 124 & Pd \\
\hline 123 & $\mathrm{Pd}(\mathrm{OH}) 2$ \\
\hline 112 & PdN032 \\
\hline 110 & PdO \\
\hline 117 & $\mathrm{Pu}(\mathrm{COOH}) 4$ \\
\hline 76 & Pu02 \\
\hline 22 & Rh02 \\
\hline 79 & Ru02 \\
\hline 23 & Ru02 Semi Vol \\
\hline 83 & $\mathrm{Ru04}$ \\
\hline 88 & SO2 \\
\hline 111 & SiO2 \\
\hline 115 & Silicn Gel \\
\hline 48 & $\mathrm{Sr}(\mathrm{COOH}) 2$ \\
\hline 10 & $\mathrm{Sr}(\mathrm{NO3}) 2$ \\
\hline 127 & Sr $(011) 2$ \\
\hline 30 & SrCO3 \\
\hline 46 & SrO \\
\hline 89 & SrRESIN \\
\hline 141 & Surfactant \\
\hline 92 & ThO2 \\
\hline 107 & Ti02 \\
\hline 119 & Tritium \\
\hline 93 & vo2 \\
\hline 62 & $\mathrm{UO2}(\mathrm{COOH}) 2$ \\
\hline 16 & V02(OH)2 \\
\hline 27 & $Y(\mathrm{COOH}) 8$ \\
\hline 11 & $Y(N 03) 8$ \\
\hline 128 & $Y(\mathrm{OH}) 8$ \\
\hline 31 & $\mathrm{Y} 2(\mathrm{CO}) 3$ \\
\hline
\end{tabular}

41

Ejector

Exit Vapor

.0000

.0000

.0000

.0000

.0000

.0000

.0000

.0000

.0000

.0000

.0000

.0000

.0000

18.85

.0000

.0000

.0000

.0000

.0000

.0000

.0000

.0000

.0000

.0000

.0000

.0000

. 1841E-02

.0000

.0000

.0000

.0000

.0000

.0000

.0000

.0000

.0000

.0000

.0000

$.8560 \mathrm{E}-11$

.0000

.0000

.0000

.0000

.0000

.0000

.0000
Appendix II

Table 21-15

Page 044 of 173

Date 09/30/82 Rev 03 
MATERIAL BALANCE TABLES

Date 09/30/82 Rev 09

SLUDGE-ORLY FEED

STREANSS(CONT'D)STREAII NAME

$47 \quad 1203$

100 Zeolite

$44 \mathrm{Zn}(\mathrm{COOII}) 2$

$54 \mathrm{Zn}_{\mathrm{n}}(\mathrm{OH}) 2$

$57 \mathrm{Zn}_{\mathrm{n} 0}$

$104 \mathrm{Zr} \cdot 02$

41

Ejector

Exit Vapor

.0000

.0000

.0000

.0000

.0000

.0000

TOTIL FLOW, LB/IIR

VAPOR FLOH, CFM

LIQUID FLOH, GPM

DESIGN FLOW,

DENSITY, LBS/ET3

TEMPERATURE, DEG C

PRESSLRE, ATMI

PRESSURE, PSIG

PRESSURE, MM UIG

PIIASE

ENTHALPI, PCU/IIR
88.60

23.68

.0624

54.95

.99

$-.21$

748.90

VAPOR

1071.84
42

Ejector

Exit Liquid

.0000

4.020

.4998

.0000

.0000

.8044

88975.45

177.18

62.6250

54.95

.99

$-.21$

748.90

LIQUID

4984302.56
43

Liquid Spray to SWDBF \#1

.0000

$.6874 \mathrm{E}-03$

$.8547 \mathrm{E}-04$

.0000

.0000

.1375E-03

2912.20

5.82

62.4318

46.47

3.18

32.04

LIQUID

138094.43

\section{4}

Atomzg Air SWDBF \#1

.0000

.0000

.0000

.0000

.0000

.0000

236.86

15.28

.2583

40.00

8.72

39.97

VAPOR

$-11915.22$ 
DPSP $80-1033$

MATERIAL BALANCE TABLES

SLUDGE-ONLY FEED

STREAM NAME

COMPONEYT FLOHS, LB/HR

$1 \mathrm{H2O}$

$45 \mathrm{Ag}$

116 Ag20

134 AgNO3

$51 \mathrm{AgOH}$

74 Al(OH) 3

77 A1203

$75 \mathrm{AlOOH}$

106 B203

$9 \mathrm{Ba}(\mathrm{NO3}) 2$

$95 \mathrm{BaC} 12$

$15 \mathrm{BaO}$

$24 \mathrm{BaSO} 4$

$66 \mathrm{CO}$

$87 \mathrm{CO} 2$

$142 \mathrm{CO}$ ( $\mathrm{C} 14$ )

$63 \mathrm{Ca}(\mathrm{COOH}) 2$

$120 \mathrm{Ca}$ (OII) 2

$113 \mathrm{Cn} 3(\mathrm{PO}) 2$

$20 \mathrm{CaC204}$

$18 \mathrm{CaCO3}$

$78 \mathrm{CaF2}$

$41 \mathrm{CnO}$

$19 \mathrm{CaSO}_{\mathrm{A}}$

29 Carbon

$26 \mathrm{Co}(\mathrm{COOH}) 2$

$121 \mathrm{Co}(\mathrm{OH}) 2$

$53 \mathrm{Co}(\mathrm{OII}) \mathrm{3}$

59 $\mathrm{CoO}$

$99 \mathrm{Cr}$ (OII) $\mathrm{s}$

$98 \mathrm{Cr} 203$

$42 \mathrm{Cs} 20$

137 Cs20 Seni Vol

$90 \mathrm{CsCOOH}$

$96 \mathrm{CsCl}$

$186 \mathrm{CsCl}$ Semi Vol

$8 \mathrm{CsNO3}$

88 CsResin

$122 \mathrm{Cu}(\mathrm{COOH}) 2$

$52 \mathrm{Cu}(\mathrm{OHI}) 2$

$58 \mathrm{Cu} 20$

$64 \mathrm{CuCOOH}$

$130 \mathrm{CuO}$

$13 \mathrm{Fe}(\mathrm{OH}) \mathrm{S}$

$80 \mathrm{Fe} 203$
45

SWDBF \#1

Exit Liquid

2917.

.0000

.0000

.0000

$.8851 \mathrm{E}-05$

.2476E-02

.0000

.0000

.4258E-02

$.3254 \mathrm{E}-10$

.0000

.0000

.2935E-04

.2021E-03

$.1237 \mathrm{E}-01$

$.2068 \mathrm{E}-26$

1018E-02

.0000

$.7314 \mathrm{E}-04$

$.7010 \mathrm{E}-04$

.0000

$.1978 \mathrm{E}-04$

.0000

$.9291 \mathrm{E}-04$

. 1978E-04

$.1609 \mathrm{E}-04$

.0000

.0000

.0000

.7518E-04

.0000

.2734E-09

.0000

.0000

$.9645 \mathrm{E}-10$

$.1058 \mathrm{E}-03$

.2087E-05

.0000

$.8434 \mathrm{E}-04$

.0000

.0000

.0000

.0000

.5993E-02

.0000
Appendix H

Table 21-15

Page 046 of 173

Date 09/30/82 Rev 09 $\begin{array}{lll}46 & 47 & 48\end{array}$

SWDBF \#1 Liquid Spray SWDBF $\# 2$

Exit Gas to SHDBF $\# 2$ Atomzg Air

126.9

.0000

.0000

.0000

$.5887 E-08$

$.3699 E-05$

.0000

.0000

$.6361 E-05$

$.4858 E-18$

.0000

.0000

$.4391 E-07$

5.598

18.09

$.2189 E-23$

$.1523 E-05$

.0000

$.1094 \mathrm{E}-06$

$.1183 \mathrm{E}-06$

.0000

.2958E-07

.0000

$.1390 \mathrm{E}-06$

$.2958 \mathrm{E}-07$

.2405E-07

.0000

.0000

.0000

$.1125 \mathrm{E}-06$

.0000

.4433E- 12

.0000

.0000

.2852E- 12

.5066E-06

.3116E-08

.0000

$.5137 \mathrm{E}-07$

.0000

.0000

.0000

.0000

$.8952 E-05$

.0000
2912.

.0000

.0000

.0000

$.8671 E-05$

.2363E-02

.0000

.0000

$.4064 \mathrm{E}-02$

$.8105 \mathrm{E}-10$

.0000

.0000

.2800E-04

. 1885E-03

$.1179 E-01$

$.1971 \mathrm{E}-26$

$.9715 E-03$

.0000

$.6979 \mathrm{E}-04$

$.7548 \mathrm{E}-04$

.0000

$.1887 \mathrm{E}-0$;

.0000

$.8866 E-04$

$.1887 E-04$

$.1535 \mathrm{E}-04$

.0000

.0000

.0000

$.7173 E-04$

.0000

.2598E-09

.0000

.0000

$.8772 \mathrm{E}-10$

$.1012 \mathrm{E}-03$

$.1992 E-05$

.0000

.3277E-04

.0000

.0000

.0000

.0000

$.5719 \mathrm{E}-02$ .0000
3.913

.0000

.0000

.0000

.0000

.0000

.0000

.0000

.0000

.0000

.0000

.0000

.0000

.0000

.0000

.0000

.0000

.0000

.0000

.0000

.0000

.0000

.0000

.0000

.0000

.0000

.0000

.0000

.0000

.0000

.0000

.0000

.0000

.0000

.0000

.0000

.0000

.0000

.0000

.0000

.0000

.0000

.0000

.0000

.0000 . 
DPSP $80-1033$

MATERIAL BALANCE TABLES

SLUDGE-ONLY FEED

STREAMS (CONT'D)-

STREAM NAME

$101 \mathrm{FeO}$

126 Group A Semi Vo

102 Grouph

103 GroupB

$25 \mathrm{H} 2$

133 H2C.2O4

$91 \mathrm{H} 2 \mathrm{O2}$

$34 \mathrm{IICOOH}$

43 IICl

$85 \mathrm{HF}$

49 IINO3

86 llkesin

$86 \mathrm{Hg}$

135 HgNO32

$21 \mathrm{HgO}$

97 I2

$39 k 20$

$131 \mathrm{KN} / \mathrm{n} 04$

$118 \mathrm{KNO3}$

$105 \operatorname{Ln} 203$

103 Li 20

$65 \mathrm{Mg}(\mathrm{COOH}) 2$

$65 \mathrm{Mg}(\mathrm{Oll}) 2$

$33 \mathrm{MgO}$

$60 \mathrm{Mn}(\mathrm{COOH}) 2$

$132 \mathrm{Mn}(\mathrm{N} 03) 2$

$129 \mathrm{Mn}(\mathrm{OIII}) 2$

$56 \mathrm{MnO}$

$14 \mathrm{MnO2}$

81 N2

$143 \mathrm{NA2CO3} \mathrm{(C14)}$

$85 \mathrm{NO}$

84 N02

$70 \mathrm{Na}(\mathrm{HgO}(\mathrm{OII}))$

$94 \quad \mathrm{Na} 2 \mathrm{~B} 407$

$109 \mathrm{Na} 2 \mathrm{C} 204$

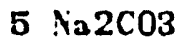

$32 \mathrm{Na} 20$

$71 \mathrm{Na} 2 \mathrm{Pu}_{\mathrm{u}} 02$ (OII) 4

$73 \mathrm{Na} 2 \mathrm{RhO} 04$

$72 \mathrm{Na} 2 \mathrm{Ru} 04$

$6 \mathrm{Na} 2 \mathrm{SO} 4$

$68 \mathrm{NaAlO2}$

$114 \mathrm{NaBO2}$

$140 \mathrm{NaBO2}$ Semi Vol

$50 \mathrm{NaCOOII}$
Appendix $H$

Table 21-15

Page 047 of 173

Date 09/80/82 Rev 09

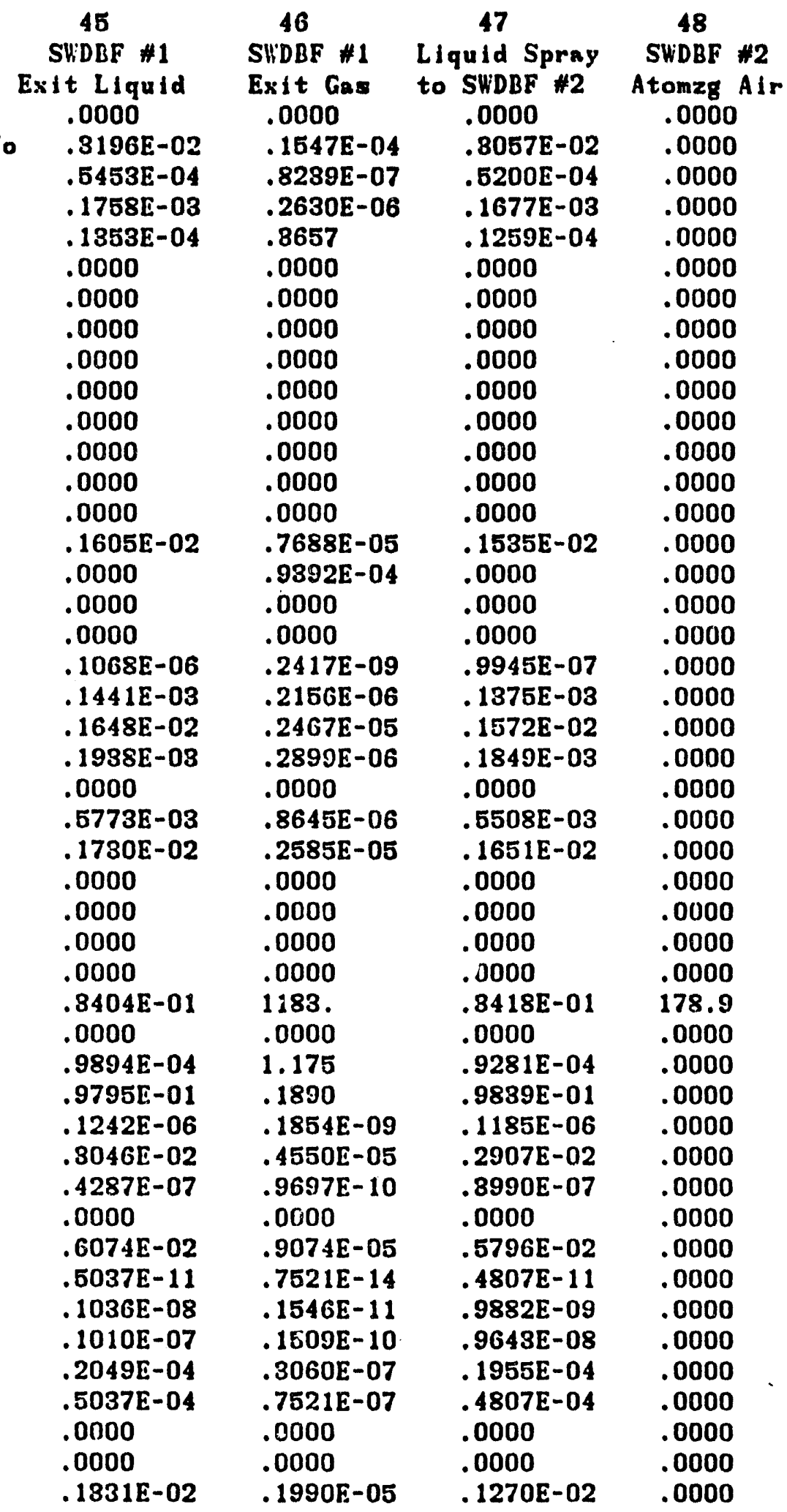


DPSP $30-1033$

MATERIAL BALANCE TABLES SLLDGE-ONLY FEED STREAMS (CONT'D)STREAM NAME

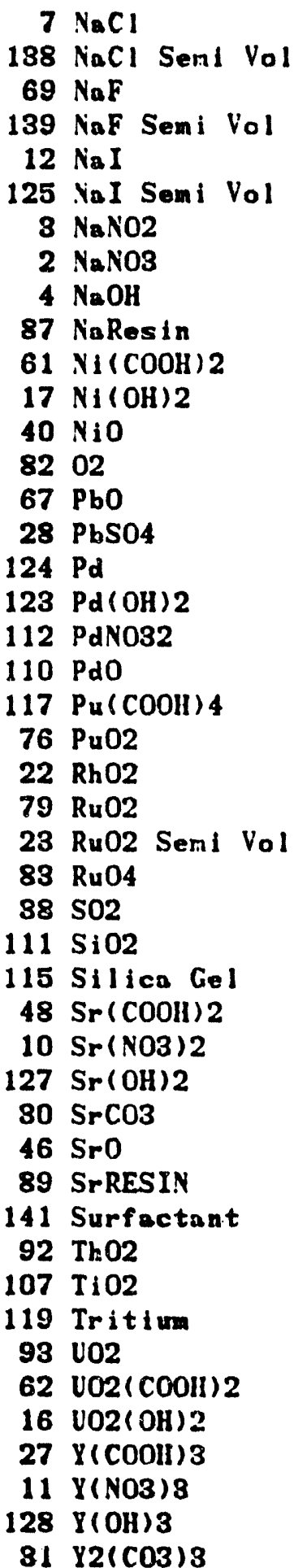

45

SWDBF \#1

Exit Liquid .2040E-0.4 .2387E-01 .5285E-03 $.1877 E-01$ $.1976 E-05$ .2294E-02 .0000 $.6574 \mathrm{E}-03$

.0000

.0000

$.6093 E-03$

.0000

.0000

$.1970 \mathrm{E}-01$

.0000

.2762E-04

.0000

.0000

.0000

.0000

.0000

$.7188 \mathrm{E}-05$

$.2747 E-05$

. 1320E-04

.1548E-02

.0000

$.4114 E-04$

$.1798 E-01$

.0000

$.2474 \mathrm{E}-04$

.2003E-10

.0000

.0000

.0000

.0000

.0000

$.1127 E-03$

$.2883 E-03$

$.4852 \mathrm{E}-09$

.0000

$.7881 E-03$

.0000

$.1695 \mathrm{E}-04$

.2062E- 10

.0000

.0000
Appendix H

Table 21-15

Page 048 of 173

Date 09/30/82 Rev 0.3 
MATERIAL BALANCE TABLES

Date 09/30/82 Rev 09

SLUDGE-ONLY FEED

STREAMS (CONT'D)-

STREAMI NAME

$47 Y 203$

100 Zeolite

$44 \mathrm{Zn}(\mathrm{COOII}) 2$

$54 \mathrm{Zn}(\mathrm{OH}) 2$

$57 \mathrm{ZnO}$

$104 \mathrm{ZrO2}$

TOTAL FLOW, LB/IIR

VAPOR FLOW, CFM

LIQUID FLOW, GPM DESIGN FLOW,

DENSITÏ, LES/FT3

TEMPERATURE, DEG C

PRESSLRE, ATM

PRESSURE, PSIG

PRESSURE, M HG

PIIASE
45

SWIDBF \#1

Exit Liquid

.0000

$.7204 \mathrm{E}-03$

$.8957 \mathrm{E}-04$

.0000

.0000

.1441E-08

2917.24

5.83

62.4318

47.71

.98

$-1.01$

707.56

LIQUID

142089.85
46

SWDBF \#1

Exit Gas

.0000

$.1078 \mathrm{E}-05$

$.1340 \mathrm{E}-06$

.0000

.0000

.2156E-06

1688.25

462.56

E.THALPY, PCL/IIR
.0608

47.74

.93

$-1.06$

705.05

VAPOR

$-12616.99$

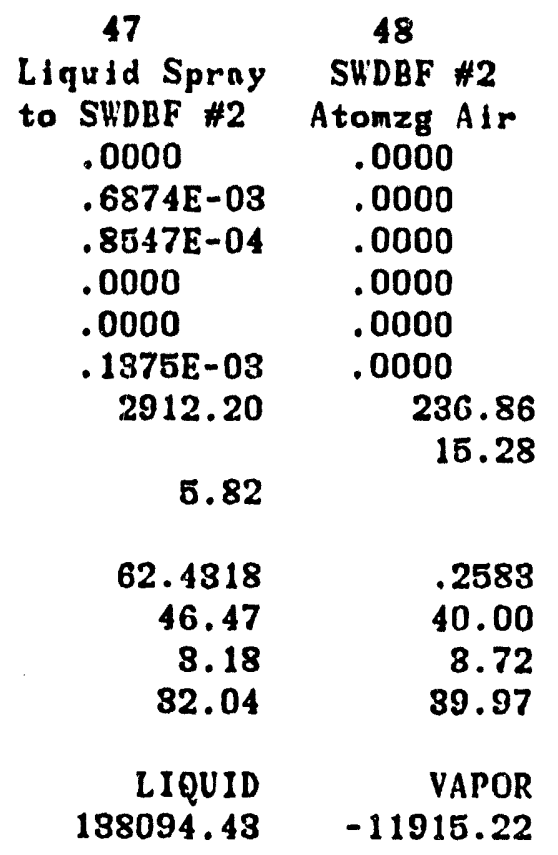



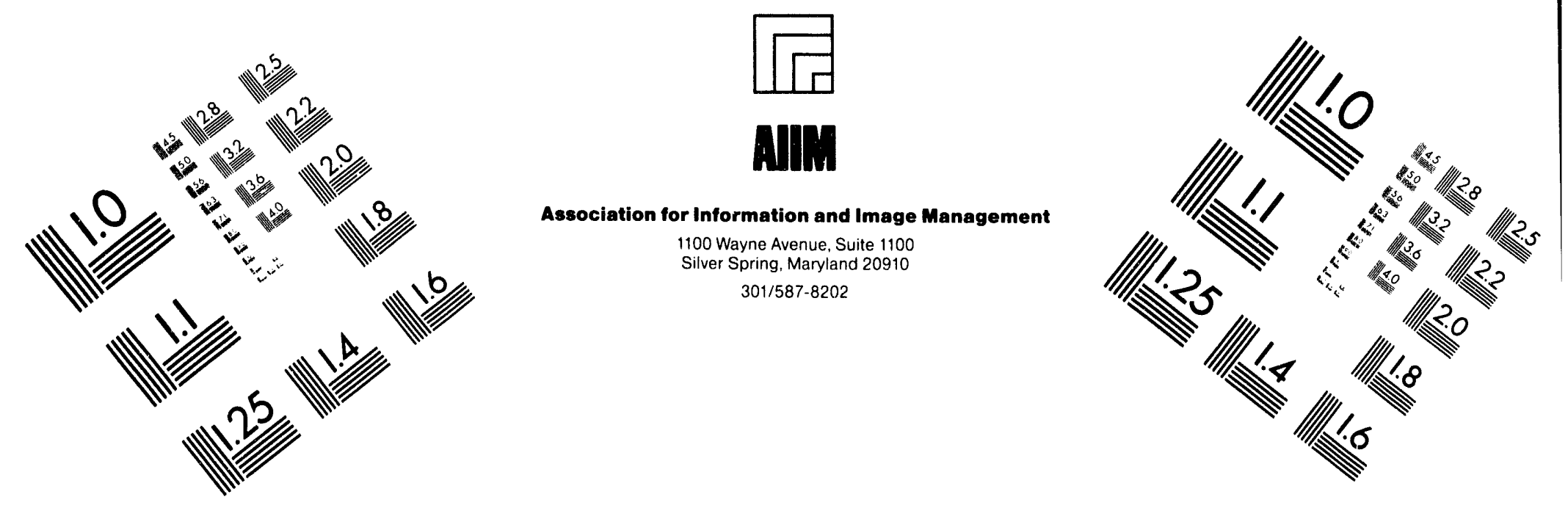

\section{Centimeter}

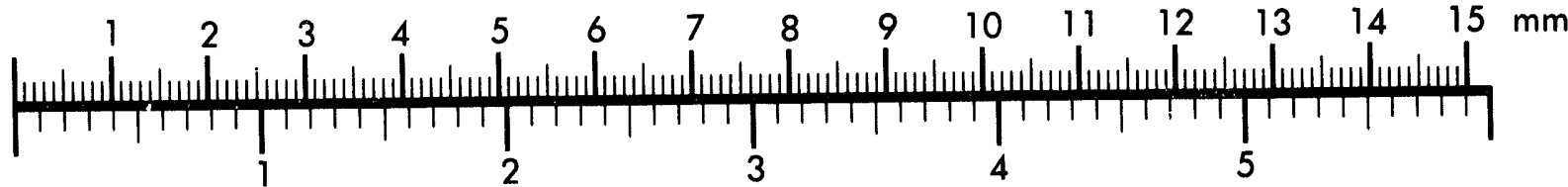
Inches
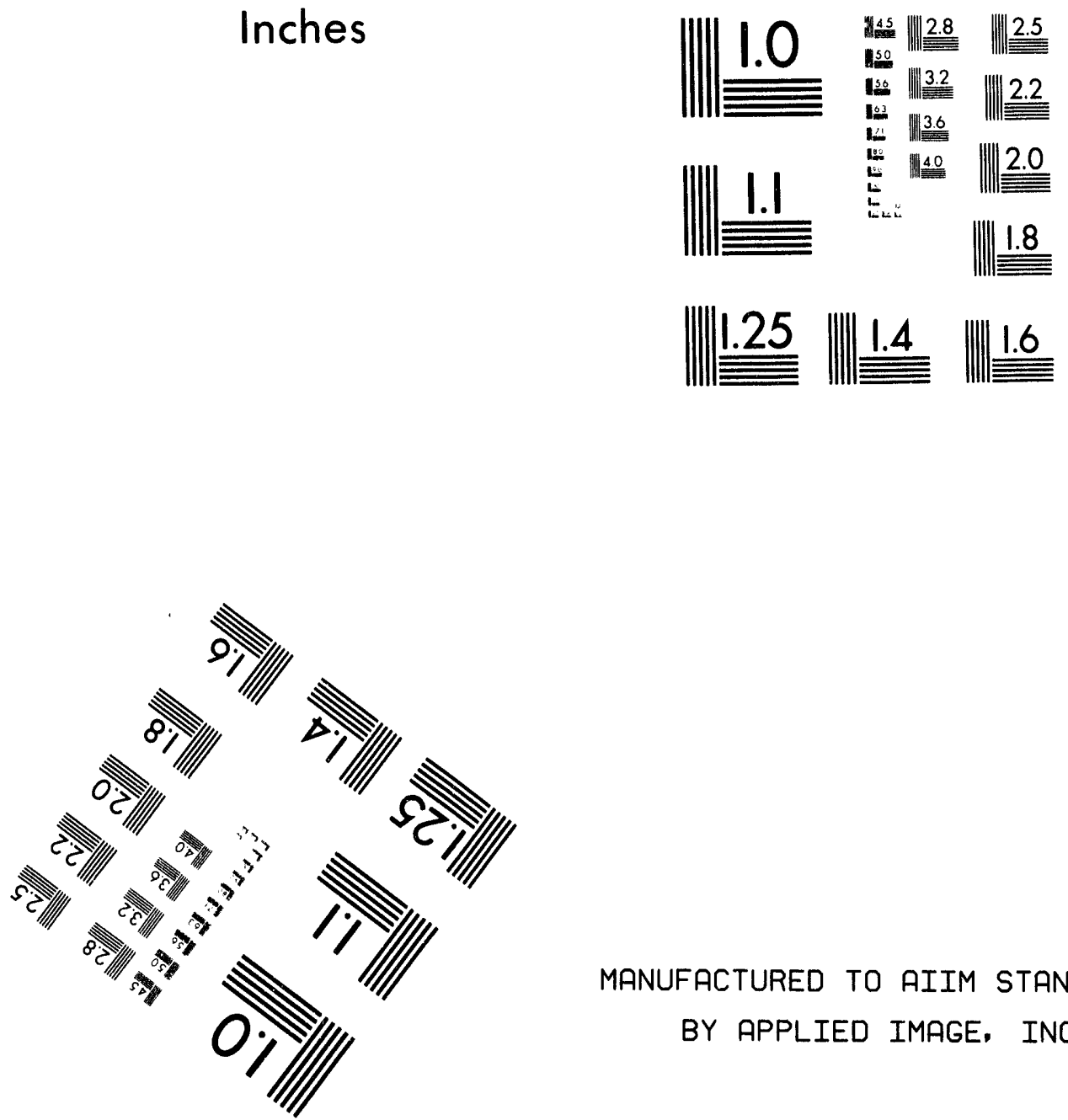

MANUFACTURED TO AIIM STANDARDS

BY APPLIED IMAGE, INC.

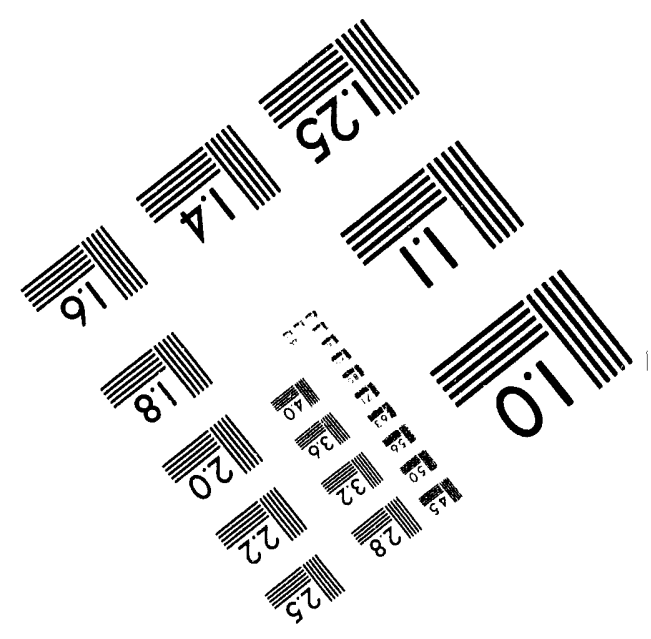



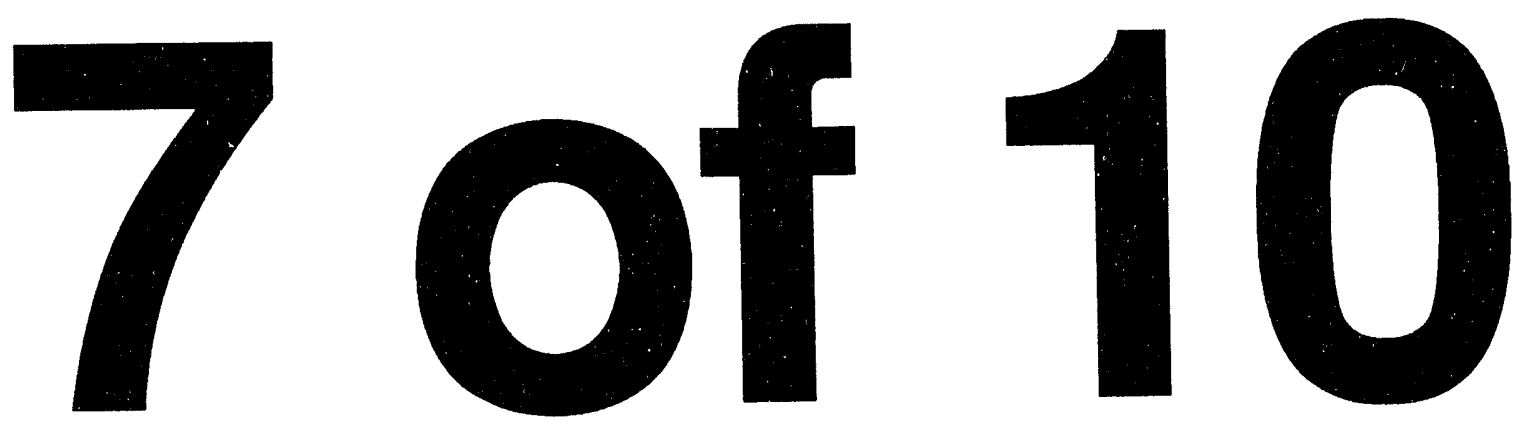
DPSP $80-1033$

MATERIAL BALANCE TABLES

SLUDGE-ONLX FEED

STREAM NUMBERS -

STREAM NAME

COMPONENT FLOWS, LB/IIR

$1 \mathrm{H} 20$

$45 \mathrm{Ag}$

116 Ag20

184 Ag:N03

$51 \mathrm{AgOH}$

74 Al (OII) 3

77 A1203

$75 \mathrm{~A} 100 \mathrm{H}$

$106 \mathrm{~B} 203$

$9 \mathrm{Ba}(\mathrm{NO3}) 2$

$95 \mathrm{BaCl} 2$

$15 \mathrm{BaO}$

$24 \mathrm{BaSO4}$

$66 \mathrm{CO}$

$37 \mathrm{CO2}$

$142 \mathrm{CO}$ ( $\mathrm{C} 14)$

$63 \mathrm{Ca}(\mathrm{COOH}) 2$

$120 \mathrm{Ca}(\mathrm{OH}) 2$

$113 \mathrm{Ca} 3(\mathrm{P} 04) 2$

$20 \mathrm{CaC2O4}$

$18 \mathrm{CaCO} 3$

$78 \mathrm{CaF2}$

$41 \mathrm{CaO}$

$19 \mathrm{CaSO}_{4}$

29 Carbon

$26 \mathrm{Co}(\mathrm{COOH}) 2$

$121 \mathrm{Co}(\mathrm{OH}) 2$

$53 \mathrm{Co}(\mathrm{OH}) 3$

$59 \mathrm{CoO}$

$99 \mathrm{Cr}(\mathrm{OH}) 3$

98 Cr203

$42 \operatorname{Cs} 20$

137 Cs20 Semi Vol

$90 \mathrm{Cs} C O O H$

$96 \mathrm{CsCl}$

$136 \mathrm{CsCl}$ Semi Vol

$8 \mathrm{CsNO3}$

88 CsResin

$122 \mathrm{Cu}(\mathrm{COOH}) 2$

$52 \mathrm{Cu}(\mathrm{OH}) 2$

$58 \mathrm{Cu} 20$

$64 \mathrm{CuCOOH}$

$180 \mathrm{CuO}$

$13 \mathrm{Fe}(\mathrm{OH}) \mathrm{s}$

80 Fe203
49

SWDBF \#2

Exit Liquid

2909.

.0000

.0000

.0000

$.3677 \mathrm{E}-05$

$.2366 \mathrm{E}-02$

.0000

.0000

$.4070 \mathrm{E}-02$

$.3110 \mathrm{E}-10$

.0000

.0000

$.2805 E-04$

$.1760 \mathrm{E}-03$

$.1112 \mathrm{E}-01$

$.1860 \mathrm{E}-2 \mathrm{G}$

$.9730 \mathrm{E}-03$

.0000

$.6989 \mathrm{E}-0.4$

$.7559 \mathrm{E}-0.4$

.0000

$.1890 \mathrm{E}-04$

.0000

$.8879 \mathrm{E}-04$

.1890E-04

$.1538 \mathrm{E}-04$

.0000

.0000

.0000

$.7184 \mathrm{E}-04$

.0000

.2603E-09

.0000

.0000

$.8799 \mathrm{E}-10$

$.1017 \mathrm{E}-03$

$.1995 \mathrm{E}-05$

.0000

$.3282 E-04$

.0000

.0000

.0000

.0000

$.5728 \mathrm{E}-02$

.0000
Appendix $H$

Table 21-15

Page 050 of 173

Dnte 09/30/82 Rev 09

50

SHDBF \#2

Exit Gas

51

52

Ru Adsorber 12 Adsorber

Gas Feed Prehter Feed

$$
\begin{aligned}
& 134.1 \\
& .0000 \\
& .0000 \\
& .0000 \\
& .1862 E-09 \\
& .1170 E-06 \\
& .0000 \\
& .0000 \\
& .2012 E-06 \\
& .1536 E-14 \\
& .0000 \\
& .0000 \\
& .1389 E-08 \\
& 5.598
\end{aligned}
$$

13.09

$.2189 \mathrm{E}-23$

$.4817 \mathrm{E}-07$

.0000

$.3460 \mathrm{E}-08$

$.3742 E-08$

.0000

$.9356 \mathrm{E}-09$

.0000

$.4396 \mathrm{E}-08$

$.9356 \mathrm{E}-09$

$.760 G E-09$

.0000

.0000

.0000

$.3557 \mathrm{E}-08$

.0000

$.1402 E-13$

.0000

.0000

$.9021 E-14$

$.5066 \mathrm{E}-07$

$.9855 \mathrm{E}-10$

.0000

$.1625 \mathrm{E}-08$

.0000

.0000

.0000

.0000

$.2831 E-06$

.0000

$$
\begin{aligned}
& 50 \\
& .000 \\
& .000 \\
& .000 \\
& .11 \\
& .000 \\
& .000 \\
& .1 \\
& .000 \\
& .000 \\
& 5 . \\
& 13 .
\end{aligned}
$$

50.0

.0000

.0000

.0000

$.1862 \mathrm{E}-03$

$.1170 \mathrm{E}-00$

.0000

.0000

.2012E-06

.0000

.0000

. 1389E-08

5.598

13.09

$.2189 \mathrm{E}-23$

$.4817 \mathrm{E}-07$

.0000

$.3460 \mathrm{E}-08$

$.3742 E-08$

.0000

$.9356 \mathrm{E}-09$

.0000

$.4396 \mathrm{E}-08$

$.9356 \mathrm{E}-09$

.0000

.0000

.0000

.0000

$.8557 \mathrm{E}-08$

.0000

$.1402 E-13$

.0000

.0000

.5066E-07

.0000

$.9855 \mathrm{E}-10$

.0000

$.1625 \mathrm{E}-08$

.0000

.0000

.0000

.0000

.2831E-06

.0000
$.1536 \mathrm{E}-14$
50.04

.0000

.0000

.0000

$.930 S E-10$

$.5348 E-07$

.0000

.0000

$.1006 E-06$

$.7682 E-15$

.0000

.0000

$.6943 E-09$

5.598

13.09

$.2189 \mathrm{k}-23$

.2409E-07

.0000

$.1730 E-08$

$.1871 \mathrm{E}-03$

.0000

$.4678 \mathrm{E}-02$

.0000

$.2198 \mathrm{E}-08$

$.4678 \mathrm{E}-00$

.0000

.0000

.0000

.0000

$.1778 \mathrm{E}-08$

.0000

$.7010 \mathrm{E}-14$

.0000

.0000

$.2533 \mathrm{E}-07$

.0000

$.4927 \mathrm{E}-10$

.0000

$.8123 E-09$

.0000

.0000

.0000

.0000

$.1416 \mathrm{E}-06$

.0000 
MATERIAL BALANCE TABLES

Date 09/30/82 Rev 09

SLIDGE-ONLY FEED

STREAMS (CONT'D)-

STREAM NAME

$101 \mathrm{Fe} 0$

49

SW:DBF \#2

Exit Liquid

126 Group A Seni Vo

102 Grouph

103 Group B

$25 \mathrm{H} 2$

133 112C204

$91 \mathrm{H} 202$

$34 \mathrm{IICOOH}$

$43 \mathrm{IICl}$

85 IIF

49 HNOB

86 HRes in

$36 \mathrm{Hg}$

$135 \mathrm{HgN} \times 32$

21 HgO

97 I2

$39 \mathrm{~K} 2 \mathrm{O}$

$131 \mathrm{~K} / \mathrm{n} 04$

$118 \mathrm{KNOB}$

$105 \quad$ L.203

108 Li20

65 $\mathrm{Mg}(\mathrm{COOII}) 2$

$55 \mathrm{Mg}(\mathrm{OH}) 2$

$33 \mathrm{kgO}$

CO $\mathrm{Mn}(\mathrm{COOII}) 2$

$132 \mathrm{Mn}(\mathrm{NO3}) 2$

$129 \mathrm{Mn}(\mathrm{OH}) 2$

$56 \mathrm{MnO}$

$14 \mathrm{MnO2}$

$81 \mathrm{N2}$

143 NA2COB (C14)

$35 \mathrm{NO}$

$84 \mathrm{NO2}$

$70 \mathrm{Na}(\mathrm{HgO}(\mathrm{OlI}))$

$94 \quad \mathrm{Na} 2 \mathrm{~B} 407$

$109 \mathrm{Na} 2 \mathrm{C2O4}$

$5 \mathrm{Na} 2 \mathrm{CO3}$

$32 \wedge \mathrm{Na} 20$

$71 \mathrm{Na} 2 \mathrm{Pu} 02$ (OII) 4

$73 \mathrm{Na2RhO4}$

$72 \mathrm{Na} 2 \mathrm{RuO4}_{4}$

$6 \mathrm{Na} 2 \mathrm{SO}$

$68 \mathrm{NaAl} 02$

$114 \mathrm{NaBO} 2$

140 NaB02 Semi Vol $50 \mathrm{NaCOOll}$
.0000

50

SHDBF \#2

Exit Gas

.0000

$.1547 \mathrm{E}-05$

$.2606 \mathrm{E}-08$

$.8317 E-08$

.3657

.0000

.0000

.0000

.0000

.0000

.0000

.0000

.0000

.0000

.0000

.1542E-02

.0000

.0000

.0000

$.9968 \mathrm{E}-07$

.1378E-03

$.1575 \mathrm{E}-02$

$.1852 \mathrm{E}-03$

.0000

.5516E-03

$.1653 \mathrm{E}-02$

.0000

.0000

.0000

.0000

.8435E-01

.0000

.8691E-04

$.9478 \mathrm{E}-01$

$.1187 \mathrm{E}-06$

.2911E-02

.4000E-07

.0000

.5805E-02

$.4814 \mathrm{E}-11$

.9897E-09

$.9658 \mathrm{E}-08$

$.1958 \mathrm{E}-04$

$.4814 \mathrm{E}-04$

.0000

.0000

$.1272 E-02$
$.7688 \mathrm{E}-06$

$.9392 \mathrm{E}-04$

.0000

.0000

$.7644 \mathrm{E}-11$

$.6820 \mathrm{E}-08$

$.7800 \mathrm{E}-07$

$.9169 E-08$

.0000

$.2734 \mathrm{E}-07$

$.8175 \mathrm{E}-07$

.0000

.0000

.0000

.0000

1862.

.0000

1.175

.1926

$.5865 \mathrm{E}-11$

$.1439 E-06$

$.3067 \mathrm{E}-11$

.0000

.2870E-06

$.2378 E-15$

$.4890 E-13$

$.4772 E-12$

$.9676 \mathrm{E}-09$

.2378E-08

.0000

.0000

$.6293 E-07$
51

Ru Adsorber I2 Adsorber

Gas Feed Prehter Feed

.0000

.0000

$.1550 E-05$

$.8317 \mathrm{E}-08$

.8657

.0000

.0000

.0000

.0000

.0000

.0000

.0000

.0000

.0000

$.7688 \mathrm{E}-06$

$.9392 \mathrm{E}-04$

.0000

.0000

$.7644 \mathrm{E}-11$

$.6820 \mathrm{E}-08$

$.7800 \mathrm{E}-07$

$.9169 \mathrm{E}-08$

.0000

$.2734 \mathrm{E}-07$

$.8175 \mathrm{E}-07$

.0000

.0000

.0000

.0000

1862.

.0000

1.175

.1850

$.6865 \mathrm{E}-11$

$.1439 \mathrm{E}-06$

$.3067 E-11$

.0000

.2870E-06

$.2378 \mathrm{E}-15$

$.4890 \mathrm{E}-18$

$.4772 E-12$

$.9676 \mathrm{E}-09$

$.2378 E-08$

.0000

.0000

$.6293 \mathrm{E}-07$
.0000

.0000

$.7749 E-06$

$.4158 \mathrm{E}-08$

.3657

.0000

.0000

.0000

.0000

.0000

.0000

.0000

.0000

.0000

$.3844 \mathrm{E}-06$

$.9392 E-04$

.0000

.0000

. 3822E- 11

$.3410 \mathrm{E}-08$

. 3900E-07

$.4585 \mathrm{E}-08$

.0000

$.1367 \mathrm{E}-07$

$.4087 \mathrm{E}-07$

.0000

.0000

.0000

.0000

1362.

.0000

1.175

.1850

.2932E-11

$.7195 \mathrm{E}-07$

$.1583 E-11$

.0000

$.1485 \mathrm{E}-06$

$.1189 \mathrm{E}-15$

$.2445 E-13$

.2386E- 12

$.4838 \mathrm{E}-09$

$.1189 \mathrm{E}-03$

.0000

.0000
.8146E-07 
DPSP $80-1033$

MATERIAL BALANCE TABLES SLUDGE-ONLY FEED

STREAMS (CONI'D)STREAM NAME

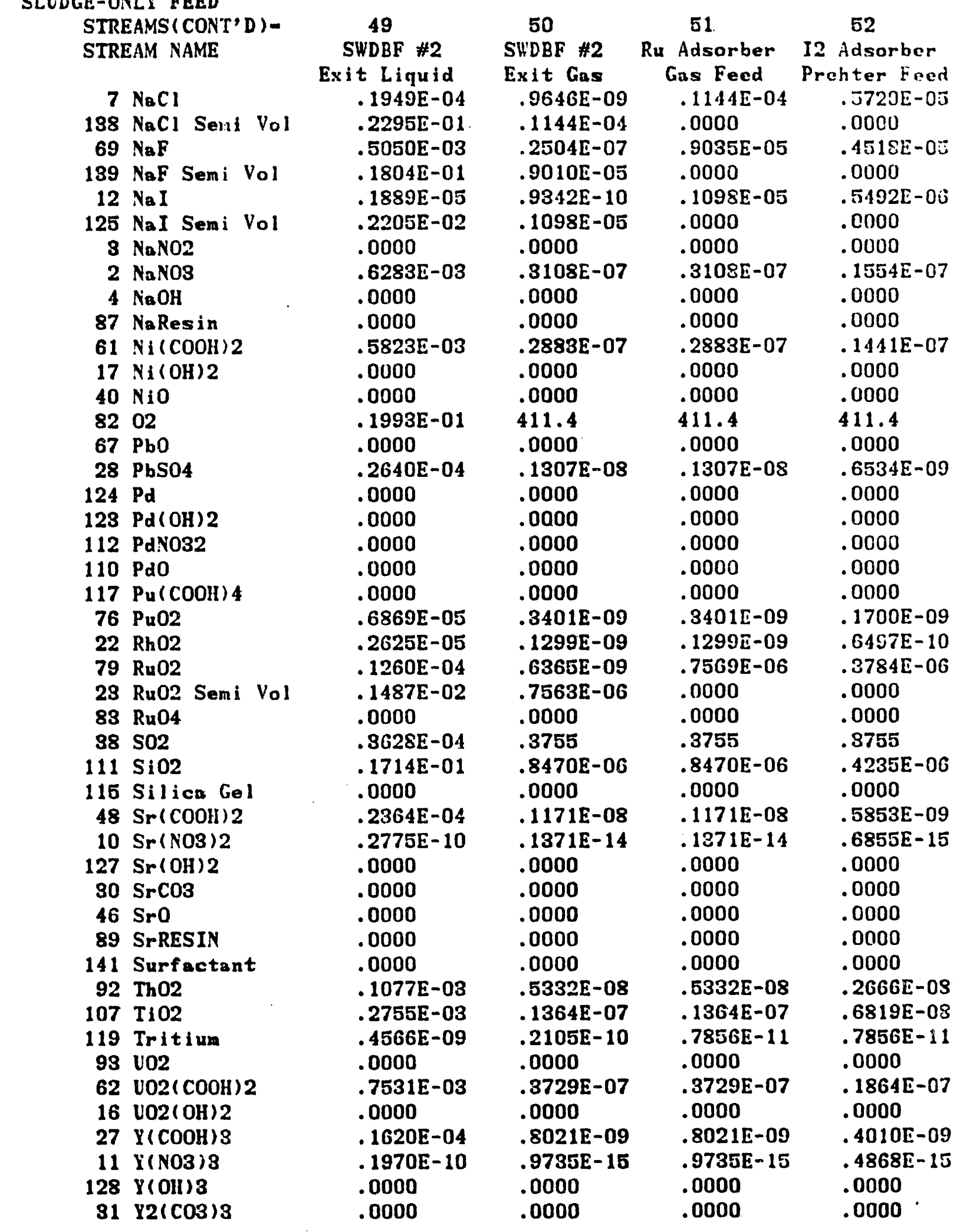

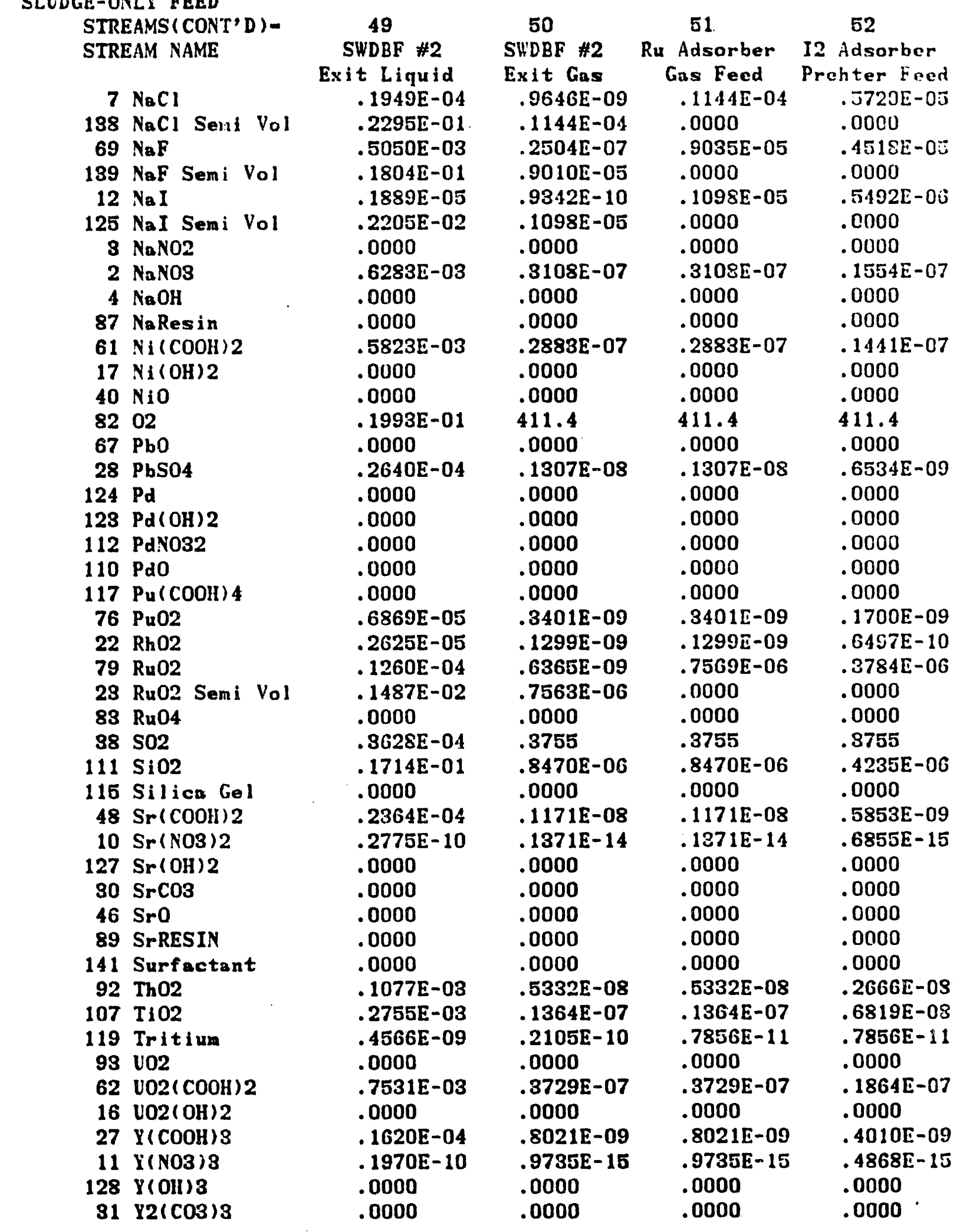

Appendix H

Table 21-15

Pnge 052 of 173

Date 09/30/82 Rev 09 
Append IX H

Table 21-15

Page 053 of 173

Date 09/30/82 Rev 09

MATERIAL BALANCE TABLES

SLIDGE-ONLY FEED

STREAMS (CONT'D)-

STREAU! NAME

47 Y 203

100 Zeolite

$44 \mathrm{Zn}(\mathrm{COOH}) 2$

$54 \mathrm{Zn}(\mathrm{OII}) 2$

$57 \mathrm{ZnO}$

$104 \mathrm{ZrO2}$

TOTAL. FL.OH, LB/IIR

VAPOR FLOW, CFM

LIOUID FLOW, GPM

DESIGN FLOH',

DENSITY, LBS/FT3

TEMPERATLRE, DEG C

PRESSURE, ATM

PRESSURE, PSIG

PRESSURE, MA HG

PHASE

49

SWDBF \#2

50

51

52

Exit Liquid

.0000

SWDBF \#2

Ru Adsorber

$.6884 \mathrm{E}-03$

Exit Gas

.0000

$.8560 \mathrm{E}-04$

$.3408 E-07$

$.4238 \mathrm{E}-08$

.0000

.0000

.0000

.0000

$.1378 \mathrm{E}-03$

2908.87

$.6820 \mathrm{E}-08$

1928.44

530.88

5.81

62.4318

45.97

.92

$-1.21$

697.45

LIOUUID

ENTIIALPY, PCU/HR

136453.47

.0487

80.00

.80

$-3.00$

604.66

VAPOR

$-22894.38 \quad-59622.31$

$-59622.31$ 
DPSP $80-1033$

MATERIAL BALANCE TABLES

SLUDGE-ONLY FEED

STREAM NUMBERS -

STREAM NAME

COMPONENT FLOHS, LB/HR

1 H2O

$45 \mathrm{Ag}$

116 Ag20

134 AgN03

51 AgOH

74 Al (OHI) 3

77 A1203

$75 \mathrm{AlOOH}$

$106 \mathrm{B203}$

$9 \mathrm{Ba}(\mathrm{NO3}) 2$

$95 \mathrm{BaCl} 2$

$15 \mathrm{BaO}$

$24 \mathrm{BaSO4}$

$66 \mathrm{CO}$

$87 \mathrm{CO} 2$

$142 \mathrm{CO}$ ( $\mathrm{C} 14)$

$63 \mathrm{Ca}(\mathrm{COOH}) 2$

$120 \mathrm{Ca}(\mathrm{OH}) 2$

$113 \mathrm{Ca} 3(\mathrm{PO} 4) 2$

$20 \mathrm{CaC2O4}$

$18 \mathrm{CaCO3}$

$78 \mathrm{CaF2}$

$41 \mathrm{CaO}$

$19 \mathrm{CaSO4}$

29 Carbon

$26 \mathrm{Co}(\mathrm{COOH}) 2$

$121 \mathrm{Co}(\mathrm{OH}) 2$

$53 \mathrm{Co}(\mathrm{OH}) 3$

$59 \mathrm{CoO}$

$99 \mathrm{Cr}(\mathrm{OH}) 3$

98 Cr203

$42 \operatorname{Cs} 20$

137 Cs20 Seni Vol

$90 \mathrm{CsCOOH}$

$96 \mathrm{CsCl}$

$136 \mathrm{CsCl}$ Semi Vol

8 CsNO3

88 CsResin

$122 \mathrm{Cu}(\mathrm{COOH}) 2$

$52 \mathrm{Cu}(\mathrm{OH}) 2$

$68 \mathrm{Cu} 20$

$64 \mathrm{CuCOOH}$

$180 \mathrm{CuO}$

$13 \mathrm{Fe}(\mathrm{OH}) 3$

$80 \mathrm{Fe} 203$
53

12 Adsorber Off-Gas Cool Gas Feed

50.04

.0000

.0000

.0000

$.9308 \mathrm{E}-10$

.5848E-07

.0000

.0000

$.1006 \mathrm{E}-06$

$.7682 E-15$

.0000

.0000

$.6943 \mathrm{E}-09$

5.598

13.09

$.2189 \mathrm{E}-23$

.2409E-07

.0000

$.1730 \mathrm{E}-08$

$.1871 \mathrm{E}-08$

.0000

$.4678 \mathrm{E}-09$

.0000

.2198E-08

$.4678 E-09$

.0000

.0000

.0000

.0000

$.1778 E-08$

.0000

$.7010 E-14$

.0000

.0000

$.2533 E-07$

.0000

$.4927 \mathrm{E}-10$

.0000

.8123E-09

.0000

.0000

.0000

.0000

$.1416 \mathrm{E}-06$

.0000 er Gas Feed

50.04

.0000

.0000

.0000

$.4654 \mathrm{E}-10$

.2924E-07

.0000

.0000

$.5029 \mathrm{E}-07$

.3841E- 15

.0000

.0000

.3471E-09

5.598

13.09

$.2189 \mathrm{E}-23$

$.1204 \mathrm{E}-07$

.0000

$.8651 \mathrm{E}-09$

$.9356 \mathrm{E}-09$

.0000

.2339E-09

.0000

. 1099E-08

.2339E-09

.0000

.0000

.0000

.0000

$.8892 \mathrm{E}-09$

.0000

$.3505 E-14$

.0000

.0000

$.1266 \mathrm{E}-07$

.0000

.2464E- 10

.0000

$.4062 \mathrm{E}-09$

.0000

.0000

.0000

.0000

$.7078 \mathrm{E}-07$

.0000
Appendi: $\mathrm{H}$

Table 21-15

Page 054 of 173

Date 09/30/82 Rev 09
55

HEPA

Gas Feed

50.04

.0000

.0000

.0000

$.4654 \mathrm{E}-10$

$.2924 \mathrm{E}-07$

.0000

.0000

$.5029 \mathrm{E}-07$

$.3841 \mathrm{E}-15$

.0000

.0000

$.3471 \mathrm{E}-09$

5.598

13.09

$.2189 \mathrm{E}-23$

$.1204 \mathrm{E}-07$

.0000

$.8651 \mathrm{E}-09$

$.9356 \mathrm{E}-09$

.0000

$.2339 \mathrm{E}-09$

.0000

$.1099 \mathrm{E}-09$

.2339E-09

.0000

.0000

.0000

.0000

$.8892 E-09$

.0000

$.3505 \mathrm{E}-14$

.0000

.0000

$.1266 \mathrm{E}-07$

.0000

.2464E-10

.0000

$.4062 \mathrm{E}-09$

.0000

.0000

.0000

.0000

$.7078 \mathrm{E}-07$

.0000
56

Off-Gis Exh

Exit Gas

50.04

.0000

.0000

.0000

$.4654 \mathrm{E}-13$

$.2924 \mathrm{E}-10$

.0000

.0000

$.5029 \mathrm{E}-\mathrm{i0}$

$.3841 \mathrm{E}-18$

.0000

.0000

.3471E-12

5.598

13.09

$.2189 \mathrm{E}-23$

$.1204 \mathrm{E}-10$

.0000

$.8651 \mathrm{E}-12$

$.9356 \mathrm{E}-12$

.0000

$.2339 \mathrm{E}-12$

.0000

$.1099 \mathrm{E}-11$

.2339E-12

.0000

.0000

.0000

.0000

$.8892 E-12$

.0000

$.3505 E-17$

.0000

.0000

$.1266 \mathrm{E}-10$

.0000

.2464E-13

.0000

$.4062 \mathrm{E}-12$

.0000

.0000

.0000

.0000

$.7078 \mathrm{E}-10$

.0000 
MATERIAL BALANCE TABLES

Date 09/30/82 Rev 09

\section{SLUDGE-ONLY FEED}

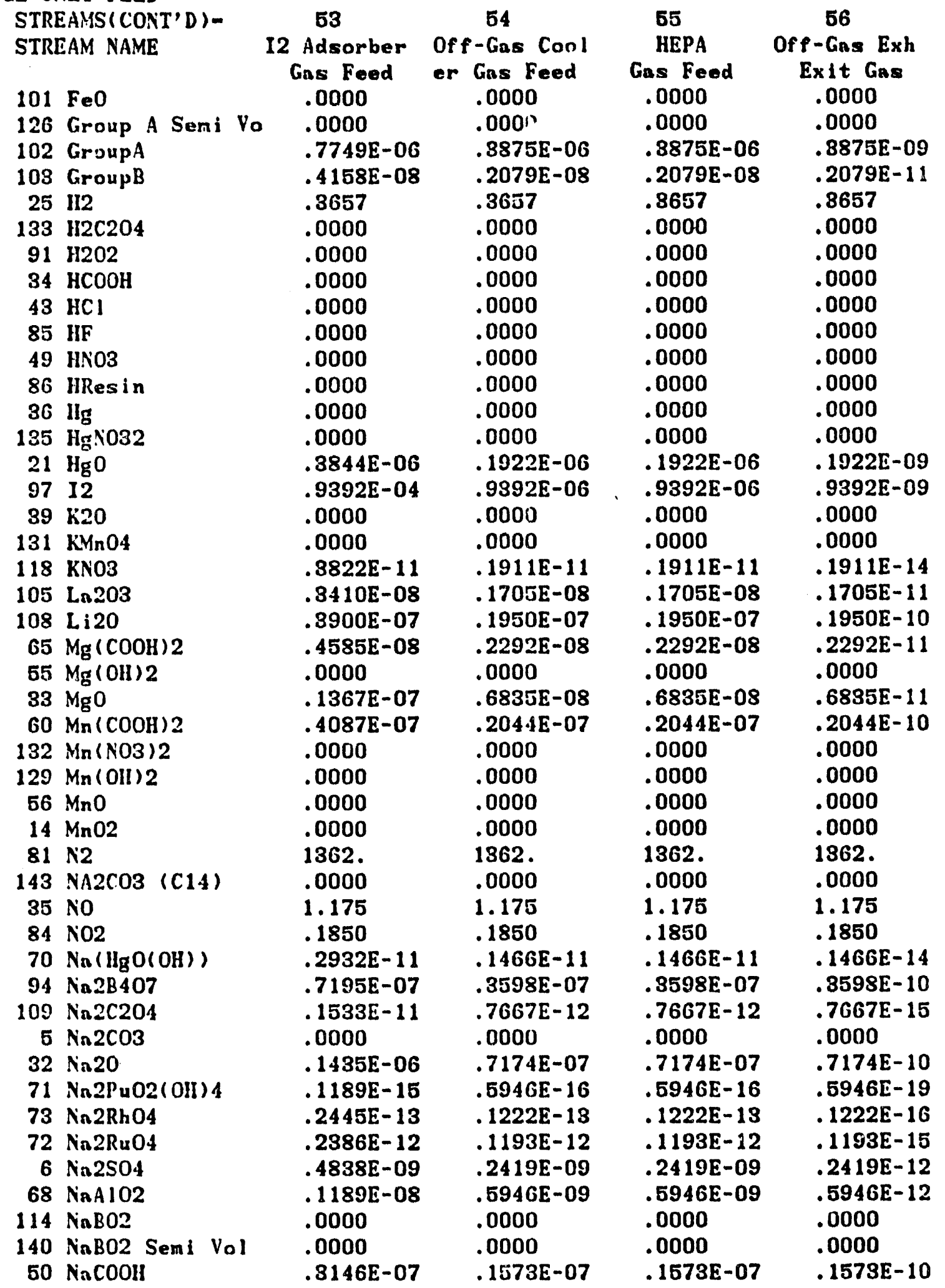


DPSP $80-1033$

MATERIAL BALANCE TABLES SLUDGE-ONLY FEED

STREAMS (CONT'D)STREAN NAME

$7 \mathrm{NaCl}$

$138 \mathrm{NaCl}$ Semi Vol

$69 \mathrm{NaF}$

$139 \mathrm{NaF}$ Semi Vol

$12 \mathrm{NaI}$

$125 \mathrm{NaI}$ Semi Vol

$8 \mathrm{NaNO} 2$

$2 \mathrm{NaNO3}$

$4 \mathrm{NaOH}$

87 NaResin

$61 \mathrm{Ni}(\mathrm{COOH}) 2$

$17 \mathrm{Ni}(\mathrm{OH}) 2$

$40 \mathrm{NiO}$

8202

$67 \mathrm{PbO}$

$28 \mathrm{PbSO4}$

$124 \mathrm{Pd}$

$123 \mathrm{Pd}(\mathrm{OH}) 2$

112 PdYO32

$110 \mathrm{PdO}$

$117 \mathrm{Pu}(\mathrm{COOH}) 4$

$76 \mathrm{Pu} 02$

$22 \mathrm{Rh} 02$

$79 \mathrm{Ru} 02$

23 Ru02 Semi Vol

83 Ru04

$38 \mathrm{SO2}$

$111 \mathrm{SiO} 2$

115 Silien Gel

$48 \mathrm{Sr}(\mathrm{COOH}) 2$

$10 \mathrm{Sr}(\mathrm{NO3}) 2$

$127 \mathrm{Sr}(\mathrm{OIII}) 2$

$30 \mathrm{SrCO}$

$46 \mathrm{Sr} 0$

89 SrRESIN

141 Surfactant

92 Th02

$107 \mathrm{TiO2}$

119 Tritiun

$93 \mathrm{~V} 02$

$62 \mathrm{VO2}(\mathrm{COOH}) 2$

$16 \mathrm{VO2}(\mathrm{OH}) 2$

$27 \mathrm{X}(\mathrm{COOH}) 3$

$11 \mathrm{Y}(\mathrm{NO3}) \mathrm{3}$

$128 \mathrm{Y}(\mathrm{OH}) 3$

$81 \mathrm{Y} 2(\mathrm{CO}) 3$
53

12 Adsorber Off-Gas Cool

Gas Feed

.5720E-05

.0000

$.4518 \mathrm{E}-05$

.0000

$.5492 E-06$

.0000

.0000

$.1554 \mathrm{E}-07$

.0000

.0000

.1441E-07

.0000

.0000

411.4

.0000

$.6534 \mathrm{E}-09$

.0000

.0000

.0000

.0000

.0000

$.1700 \mathrm{E}-09$

$.6497 \mathrm{E}-10$

.3784E-06

.0000

.0000

.8755

$.4235 \mathrm{E}-06$

.0000

.5853E-09

$.6855 \mathrm{E}-15$

.0000

.0000

.0000

.0000

.0000

$.2666 \mathrm{E}-08$

$.6819 \mathrm{E}-08$

$.7856 \mathrm{E}-11$

.0000

$.1864 E-07$

.0000

$.4010 \mathrm{E}-09$

$.4868 \mathrm{E}-15$

.0000

.0000
Appendix $\mathrm{H}$

Table 21-15

Page 056 of 173

Date $09 / 30 / 82$ Rev 03 
MATERIAL BALANCE TARLES SLUDGE-ONLY FEED

STREAMS ( CONT'D)STREAM NAME

$\begin{array}{rl}47 & \text { Y203 } \\ 100 & \mathrm{Zeol} \text { ite } \\ 44 & \mathrm{Zn}(\mathrm{COOH}) 2 \\ 54 & \mathrm{Zn}(\mathrm{OH}) 2 \\ 57 & \mathrm{ZnO} \\ 104 & \mathrm{Zr} 02\end{array}$

TOTAL FLOW, LB/HR VAPOR FLOW, CFM LIQUID FLOW, GPM DESIGN FLOW, DENSITY, LBS/FT3 TEMPERATURE, DEG C PRESSURE, ATM PRESSURE, PSIG PRESSURE, MI HG PIIASE

E.THALPY, PCU/HR

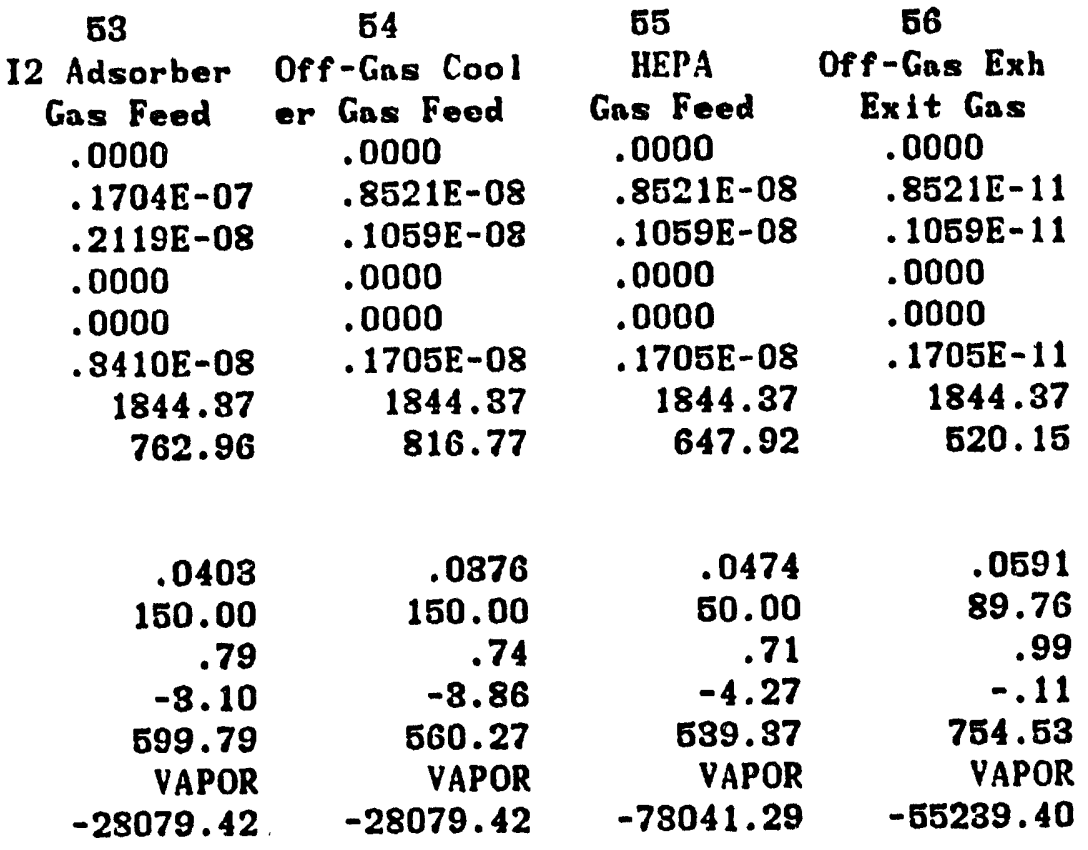


DPSP 80-1038

MATERIAL BALANCE TABLES

SLUDGE-ONLY FEED

STREAM NUME ERS STREAM NAME

COMPONENT F:OHS, LB/IHR

$1 \mathrm{H} 20$

$45 \mathrm{Ag}$

116 Ag20

184 AgNO3

$51 \mathrm{AgOH}$

74 Al (OH) 3

77 A1203

75 A $100 \mathrm{H}$

106 B203

$9 \mathrm{Ba}(\mathrm{NO3}) 2$

$95 \mathrm{BaCl} 2$

$15 \mathrm{BaO}$

$24 \mathrm{BaSO4}$

$66 \mathrm{CO}$

$87 \mathrm{CO} 2$

$142 \mathrm{CO}(\mathrm{Cl} 4)$

$63 \mathrm{Cn}(\mathrm{COOH}) 2$

$120 \mathrm{Ca}(\mathrm{OH}) 2$

$113 \mathrm{Ca} 3(\mathrm{PO} 04) 2$

$20 \mathrm{CaC}_{2} 04$

$18 \mathrm{CaCO}_{\mathrm{C}}$

$78 \mathrm{CaF2}$

$41 \mathrm{CaO}$

$19 \mathrm{CaSO4}$

29 Carbon

$26 \mathrm{Co}(\mathrm{COOII}) 2$

$121 \mathrm{Co}(\mathrm{OH}) 2$

$53 \mathrm{Co}(\mathrm{OHI}) 3$

$59 \mathrm{CoO}$

$99 \mathrm{Cr}(\mathrm{OH}) \mathrm{s}$

98 Cr203

$42 \operatorname{Cs} 20$

137 Cs20 Semi Vol

$90 \mathrm{CsCOH}$

$96 \mathrm{CsCl}$

$136 \mathrm{CsCl}$ Semi Vol

$8 \mathrm{CsNO3}$

88 CsResin

$122 \mathrm{Cu}(\mathrm{COOH}) 2$

$52 \mathrm{Cu}(\mathrm{OH}) 2$

$58 \mathrm{Cu} 20$

$64 \mathrm{CuCOOH}$

$130 \mathrm{CuO}$

$13 \mathrm{Fe}(\mathrm{OH}) 3$

$80 \mathrm{Fe} 203$
57

OGCT Liquid to RCT

409.2

.0000

.0000

.0000

$.1005 \mathrm{E}-03$

.1073

.0000

.0000

.1845

$.8427 E-09$

.0000

.0000

.7604E-03

$.4669 \mathrm{E}-04$

. 2515E-02

$.4205 \mathrm{E}-27$

.2638E-01

.0000

.1895E-02

.2049E-02

.0000

$.5124 E-03$

.0000

.2407E-02

$.5124 \mathrm{E}-03$

$.4165 \mathrm{E}-03$

.0000

.0000

.0000

$.1948 \mathrm{E}-02$

.0000

$.7761 \mathrm{E}-08$

$.1489 \mathrm{E}-05$

.0000

.2003E-08

$.2634 \mathrm{E}-03$

$.5405 E-04$

.0000

$.8897 E-03$

.0000

.0000

.0000

.0000

.2597

.0000
Appendix $\mathrm{H}$

Table 21-15

Page 058 of 173

Date 09/30/\&2 Rev 00

58

SMECT Vent

59

60

to FAVC

Total Vessel

Vent to PVVil

pyiritit

Gins

\subsection{0}

24.99

$.2084 \mathrm{E}-14$

.0000

.0000

$.4959 \mathrm{E}-16$

$.6562 \mathrm{E}-10$

.0000

.0000

$.1130 \mathrm{E}-09$

$.8619 \mathrm{E}-18$

.0000

.0000

$.7790 \mathrm{E}-12$

$.8675 E-10$

$.4446 E-02$

$.1629 \mathrm{E}-13$

.2702E-10

$.1238 E-16$

$.1941 E-11$

$.2100 E-11$

.0000

$.5249 E-12$

.0000

$.2466 \mathrm{E}-11$

$.5249 \mathrm{E}-12$

$.4267 E-12$

$.2142 E-18$

.0000

.0000

$.1995 E-11$

.0000

$.7867 \mathrm{E}-17$

.0000

.0000

$.5283 E-17$

.0000

.5529E- 18

.0000

.9114 E-12

$.4659 \mathrm{E}-18$

.0000

.0000

.0000

$.1588 \mathrm{E}-09$

.0000
$.1547 E-07$

.0000

$.2539 \mathrm{E}-07$

$.4848 \mathrm{E}-08$

$.5799 E-06$

.0000

.0000

.2201E-05

$.7609 E-14$

.0000

.0000

$.6877 \mathrm{E}-08$

$.4639 \mathrm{E}-04$

10.94

$.1072 \mathrm{E}-09$

.2383E-06

$.1600 \mathrm{E}-09$

$.1714 \mathrm{E}-07$

$.1854 \mathrm{E}-07$

.0000

$.4634 E-08$

.0000

$.2177 E-07$

$.4634 \mathrm{E}-08$

.3763E-08

$.2768 E-11$

.0000

.0000

$.1762 E-07$

.0000

$.9015 \mathrm{E}-13$

.0000

.0000

$.2919 \mathrm{E}-11$

.0000

$.4881 \mathrm{E}-09$

.0000

.8037E-08

$.6022 E-11$

.0000

.0000

.0000

$.1404 \mathrm{E}-05$

.0000
24.99

$.1547 \mathrm{E}-07$

.0000

.2539E-07

.484 SE- 08

$.5799 \mathrm{E}-00$

.0000

.0000

$.2201 E-05$

.7G00E- 14

.0000

.0000

.6877 [-08

$.4639 \mathrm{E}-04$

10.94

$.1072 \mathrm{E}-09$

$.2383 E-06$

$.1600 \mathrm{E}-09$

$.1714 \mathrm{E}-\mathrm{C}$ ?

$.1854 \mathrm{E}-07$

.0000

$.4634 E-08$

.0000

$.2177 E-07$

.4634E-OS

$.37635-03$

$.2768 \mathrm{E}-11$

.0000

.0000

.1762 E-07

.0000

$.9015 \mathrm{E}-12$

.0000

.0000

.2919E-11

.0000

$.4881 E-09$

.0000

$.8037 E-08$

$.6022 \mathrm{E}-11$

.0000

.0000

.0000

$.1404 E-05$

.0000 
MATERIAL BALANCE TABLES

Date 09/80/82 Rev 09

\section{SLUDGE-ONLY FEED}

STREAMS ( CONT'D)STREAM NAME

101 FoO
126 Group A Semi Vo
102 GroupA
103 GroupB
25 H2
133 H2C204
91 H2O2
84 HCOOH
43 HCI
85 HF
49 HNO3
86 HResin
36 Hg

135 HgNO32

$21 \mathrm{HgO}$

$97 \quad 12$

39 K20

$131 \mathrm{KMnO4}$

$118 \mathrm{KNO3}$

105 La203

$108 \mathrm{Li} 20$

$65 \mathrm{Mg}(\mathrm{COOHI}) 2$

$55 \mathrm{Mg}(\mathrm{OH}) 2$

$83 \mathrm{MgO}$

$60 \mathrm{Mn}(\mathrm{COOH}) 2$

132 $\mathrm{Mn}(\mathrm{NO}) 2$

$129 \mathrm{Mn}(\mathrm{OII}) 2$

$56 \mathrm{MnO}$

$14 \mathrm{MnO2}$

81 N2

143 NA2COB (C14)

35 NO

$84 \mathrm{~N} 02$

$70 \mathrm{Na}(\mathrm{HgO}(\mathrm{OII}))$

$94 \mathrm{Na} 2 \mathrm{~B} 407$

$109 \mathrm{Na} 2 \mathrm{C} 204$

$5 \mathrm{Nn} 2 \mathrm{COB}$

$32 \mathrm{Na} 20$

$71 \mathrm{Nn} 2 \mathrm{Pu} 02$ (OII) 4

$73 \mathrm{Nn} 2 \mathrm{RhO4}$

$72 \mathrm{Ni2Ru} 04$

$6 \mathrm{Na} 2 \mathrm{SO}_{4}$

68 NiA 102

$114 \mathrm{NaBO2}$

140 NaBO2 Semi Vol $50 \mathrm{NaCOOH}$
67

OGCT Liquid to RCT

.0000

.8763E-02

.1416E-02

$.4554 \mathrm{E}-02$

.8177E-05

.0000

.0000

.0000

.0000

.0000

.0000

.0000

.0000

.0000

$.8501 \mathrm{E}-02$

.0000

.0000

.0000

.8128E-05

.3735E-02

$.7139 E-01$

.5021E-02

.0000

.2200E-01

$.4480 \mathrm{E}-01$

.0000

.0000

.0000

.0000

$.4388 E-02$

.0000

.2206E-04

. 1502E-01

.3217E-05

$.9913 E-01$

. 1253E-05

.0000

.2633

. 1305E-09

.2682E-07

.2617E-06

.5307E-03

. 1305E-02

.0000

.0000

.5220E-01

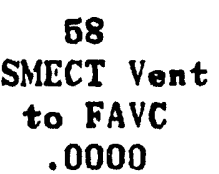

.0000

$.1462 \mathrm{E}-11$

$.4666 \mathrm{E}-11$

.2359E-11

.0000

.0000

.1118

.0000

.0000

.0000

.0000

.8725E-07

.0000

$.9800 \mathrm{E}-17$

.0000

.0000

.0000

$.4478 E-14$

$.8829 \mathrm{E}-11$

$.4880 \mathrm{E}-10$

.5144E-11

.2112E- 17

$.1535 E-10$

$.4586 \mathrm{E}-10$

.0000

$.1892 E-15$

.0000

.0000

188.0

.0000

$.1799 \mathrm{E}-05$

.3130E-08

$.8290 \mathrm{E}-14$

$.1970 \mathrm{E}-14$

$.1797 E-14$

.0000

.1362E-09

$.1834 \mathrm{E}-18$

$.2748 \mathrm{E}-16$

$.2677 \mathrm{E}-15$

$.5429 \mathrm{E}-12$

. 1334E-11

.0000

.0000

$.84916-10$
69

Total Vessel

Vent to PVVH

.0000

.0000

.1300E-07

$.4119 E-07$

$.8156 \mathrm{E}-05$

.0000

.0000

$.6663 \mathrm{E}-01$

.0000

.0000

.0000

.0000

$.8797 \mathrm{E}-03$

$.1589 \mathrm{E}-10$

.1312E-09

.0000

.0000

.0000

$.7204 \mathrm{E}-08$

$.7472 E-07$

$.8584 \mathrm{E}-06$

.4536 E- 07

.2729E-10

.2993E-06

$.4044 \mathrm{E}-06$

.0000

$.6598 \mathrm{E}-08$

.0000

.0000

1292.

.0000

1.259

$.1885 \mathrm{E}-01$

$.2905 E-10$

$.1088 \mathrm{E}-08$

$.2891 E-08$

.0000

.2652E-05

.1178E- 14

$.2422 \mathrm{E}-12$

$.2863 E-11$

$.4792 \mathrm{E}-08$

$.1178 E-07$

.0000

.0000

.8803E-06
60

PVVII Exit

Gas

.0000

.0000

$.1800 \mathrm{E}-07$

$.4119 \mathrm{E}-07$

$.8156 \mathrm{E}-05$

.0000

.0000

$.6663 \mathrm{E}-01$

.0000

.0000

.0000

.0000

$.8797 E-03$

$.1539 \mathrm{E}-10$

$.1812 \mathrm{E}-09$

.0000

.0000

.0000

$.7204 \mathrm{E}-08$

$.7472 \mathrm{E}-07$

$.8584 E-06$

$.4536 \mathrm{E}-07$

. 2729E-10

.2993E-06

.4044E-06

.0000

$.6598 \mathrm{E}-08$

.0000

.0000

1292.

.0000

1.259

$.1885 \mathrm{E}-01$

$.2905 \mathrm{E}-10$

$.1088 \mathrm{E}-08$

.2891E-08

.0000

.2652E-05

$.1178 \mathrm{E}-14$

.2422E-12

$.2363 \mathrm{E}-11$

.4792E-08

$.1178 \mathrm{E}-07$

.0000

.0000

.8803E-06 
DPSP $80-1033$

MATERIAL BALANCE TABLES SLUDCE-ONLY FEED STREAMS (CONT'D) STREAM NAME

\section{$7 \mathrm{NaCl}$}

$138 \mathrm{NaCl}$ Semi Vol $69 \mathrm{NaF}$

139 NaF Semi Vol $12 \mathrm{NaI}$

$125 \mathrm{NaI}$ Semi Vol

$8 \mathrm{NaNO2}$

$2 \mathrm{NaNO3}$

$4 \mathrm{NaOH}$

87 NaResin

$61 \mathrm{Ni}(\mathrm{COOH}) 2$

$17 \mathrm{Ni}(\mathrm{OH}) 2$

$40 \mathrm{NiO}$

8202

$67 \mathrm{PbO}$

$28 \mathrm{PbSO} 4$

$124 \mathrm{Pd}$

$123 \mathrm{Pd}(\mathrm{OH}) 2$

$112 \mathrm{PdNO32}$

110 PdO

$117 \mathrm{Pu}(\mathrm{COOH}) 4$

$76 \mathrm{Pu} 02$

$22 \mathrm{RhO2}$

$79 \mathrm{Ru} 02$

23 Ru02 Semi Vol

$83 \mathrm{Ru} 04$

$88 \mathrm{S02}$

1115102

115 Silica Gel

$48 \mathrm{Sr}(\mathrm{COOH}) 2$

$10 \mathrm{Sr}(\mathrm{NOS}) 2$

$127 \mathrm{Sr}(\mathrm{OH}) 2$

$80 \mathrm{SrCO3}$

$46 \mathrm{Sr} 0$

89 SrRESIN

141 Surfactant

$92 \mathrm{ThO2}$

107 Ti02

119 Tritium

$98 \mathrm{VO2}$

$62 \mathrm{VO} 2(\mathrm{COOH}) 2$

$16 \mathrm{VO} 2(\mathrm{OHI}) 2$

$27 \mathrm{Y}(\mathrm{COOH}) 3$

$11 \mathrm{Y}(\mathrm{NOS}) \mathrm{S}$

$128 Y(\mathrm{OH}) 8$

$81 Y 2(\cos ) 3$
67

OGCT Liquid to RCT

.5288E-03

$.9413 E-01$

$.1401 E-01$

$.7391 \mathrm{E}-01$

$.5119 \mathrm{E}-04$

$.6343 \mathrm{E}-02$

.0000

$.1704 \mathrm{E}-01$

.0000

.0000

$.1579 E-01$

.0000

.0000

.2513E-02

.0000

$.7157 E-03$

.0000

.0000

.0000

.0000

.0000

$.1862 \mathrm{E}-03$

$.7116 \mathrm{E}-04$

.3431E-03

.3389E-U2

.0000

$.9080 \mathrm{E}-05$

.7770

.0000

$.6410 \mathrm{E}-03$

$.7519 E-09$

.0000

.0000

.0000

.0000

.0000

.2920E-02

.7267E-02

$.1616 \mathrm{E}-09$

.0000

.2042E-01

.0000

$.4392 E-03$

. 5840E-09

.0000

.0000
Appendix 1

Table 21-15

Page 060 of 173

Date 09/30/82 Rev 09
58

SMECT Vent to FAVC

$.5413 \mathrm{E}-12$

.0000

$.2908 E-14$

.0000

$.5242 \mathrm{E}-13$

.0000

.0000

$.1707 \mathrm{E}-10$

.0000

.0000

$.1617 \mathrm{E}-10$

$.8111 \mathrm{E}-17$

.0000

66.78

.0000

$.7332 \mathrm{E}-12$

.0000

.0000

.0000

.0000

.0000

.1908E-12

$.7290 \mathrm{E}-13$

$.8571 \mathrm{E}-12$

.0000

.0000

.2799E- 10

$.4755 \mathrm{E}-09$

.0000

$.6567 \mathrm{E}-12$

$.7691 \mathrm{E}-18$

$.3618 \mathrm{E}-18$

.0000

.0000

.0000

.0000

$.2991 \mathrm{E}-11$

$.7658 \mathrm{E}-11$

$.1949 \mathrm{E}-10$

.0000

$.2092 \mathrm{E}-10$

$.1421 E-16$

$.4500 \mathrm{E}-12$

.5462E- 18

$.2262 \mathrm{E}-18$

.0000
59

Total Vessel Vent to PVVII

$.5372 \mathrm{E}-08$

.0000

$.1030 \mathrm{E}-08$

.0000

$.5338 \mathrm{E}-09$

.0000

.0000

$.3032 \mathrm{E}-06$

$.1200 \mathrm{E}-03$

.0000

$.1426 \mathrm{E}-06$

. 1048E-09

.0000

890.8

.0000

$.6473 \mathrm{E}-08$

.0000

.0000

.0000

.0000

.0000

$.1684 \mathrm{E}-08$

$.6436 \mathrm{E}-09$

$.3188 E-08$

.0000

.0000

$.8969 E-05$

$.8940 \mathrm{E}-05$

.0000

$.5791 E-08$

$.6790 \mathrm{E}-14$

$.4676 \mathrm{E}-11$

.0000

.0000

.0000

.0000

. 2641E-07

$.1494 \mathrm{E}-06$

$.5190 E-10$

.0000

$.1845 \mathrm{E}-0 \mathrm{G}$

$.1837 \mathrm{E}-09$

$.8968 \mathrm{E}-08$

$.4822 \mathrm{E}-14$

.2924E-11

.0000
60

PVIi: Esit

Gas

. $58725-03$

.0000

$.1030 \mathrm{E}-0 z$

.0000

.533SE-02

.0000

.0000

$.3032 E-00$

. 1200E-09

.0000

$.1426 \mathrm{E}-06$

$.1048 E-0 ?$

.0000

890.3

.0000

$.6473 E-08$

.0000

.0000

.0000

.0000

.0000

$.1684 \mathrm{E}-03$

$.6436 E-09$

$.3188 \mathrm{E}-0 \mathrm{~S}$

.0000

.0000

$.8969 E-05$

$.8940 \mathrm{E}-05$

.0000

.5.?1E-08

$.6790 \mathrm{E}-14$

$.4676 \mathrm{E}-11$

.0000

.0000

.0000

.0000

.2641E-07

$.1494 \mathrm{E}-06$

$.5190 \mathrm{E}-10$

.0000

$.1845 \mathrm{E}-06$

. 1837F-09

$.3968 \mathrm{E}-08$

$.4822 \mathrm{~F}-14$

.2924E-11

$.0000^{\circ}$ 
DPSP 80-1023

MATrRIAL BALANCE TABLES SLUDGE-ONLY FEED STREAMS (CONT'D)STREAM NAME

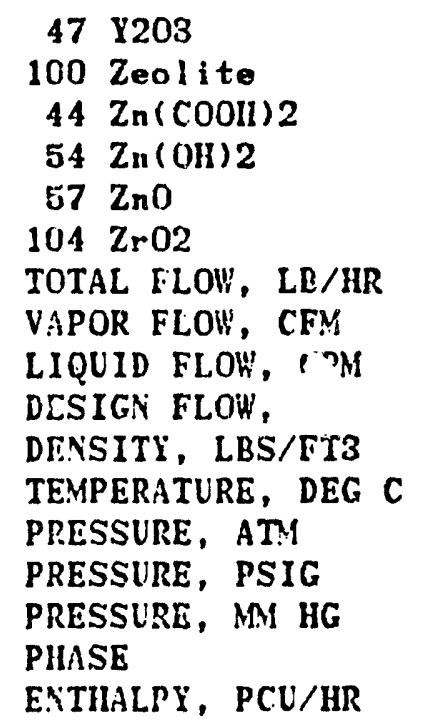

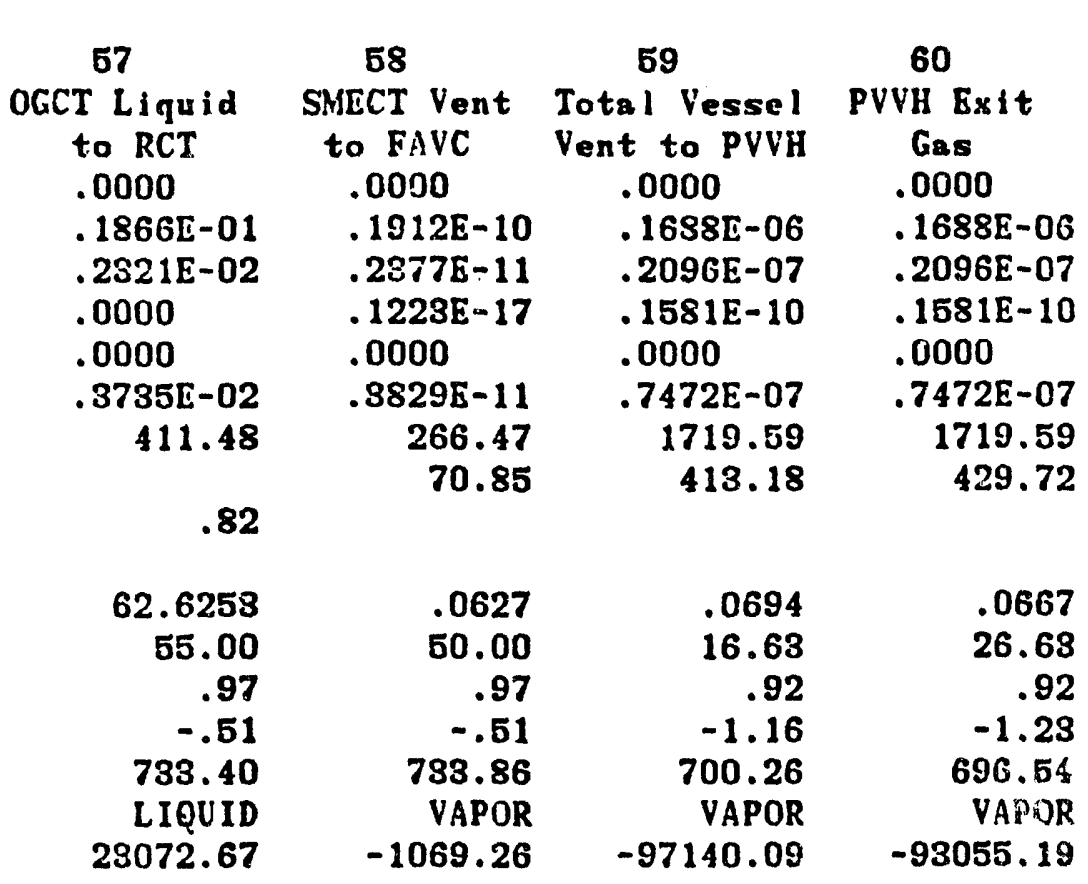

Append Ix II

Table 21-15

Page 061 of 173

Date 09/30/82 Rev 09 
DPSP 80-1039

MATERIAL BALANCE TABLES SLUDCL-ONLY FEED

STREAM NUMBERS STREAM NAME

COMPONENT FLOHS, LB/HR

\begin{tabular}{|c|c|}
\hline & H2O \\
\hline 45 & $\mathrm{Ag}$ \\
\hline 116 & $\mathrm{Ag} 20$ \\
\hline 184 & $\mathrm{AgN03}$ \\
\hline 51 & $\mathrm{AgOH}$ \\
\hline 74 & Al(OII) 8 \\
\hline 77 & A1208 \\
\hline 75 & $\mathrm{~A} 100 \mathrm{H}$ \\
\hline 106 & B203 \\
\hline 9 & $\mathrm{Ba}(\mathrm{NO} \mathrm{O}) 2$ \\
\hline 95 & $\mathrm{BaCl} 2$ \\
\hline 15 & $\mathrm{BaO}$ \\
\hline $\begin{array}{l}24 \\
66\end{array}$ & $\begin{array}{l}\mathrm{BaSO4} \\
\mathrm{CO}\end{array}$ \\
\hline 87 & $\mathrm{CO2}$ \\
\hline 142 & $\operatorname{Co2}(\mathrm{C} 14)$ \\
\hline 63 & $\mathrm{Ca}(\mathrm{COOH}) 2$ \\
\hline 120 & $\mathrm{Ca}(\mathrm{OHI}) 2$ \\
\hline 113 & $\mathrm{Cas}(\mathrm{PO} 4) 2$ \\
\hline 20 & $\mathrm{CaC2}_{2} \mathrm{O}$ \\
\hline 18 & $\mathrm{CaCO} 3$ \\
\hline 78 & $\mathrm{CaF} 2$ \\
\hline 41 & $\mathrm{CaO}$ \\
\hline 19 & $\mathrm{CaSO4}$ \\
\hline 29 & Carbon \\
\hline 26 & $\mathrm{Co}(\mathrm{COOHI}) 2$ \\
\hline 121 & $\mathrm{Co}(\mathrm{OH}) 2$ \\
\hline 53 & $\mathrm{Co}(\mathrm{OH}) 3$ \\
\hline 59 & $\mathrm{CoO}$ \\
\hline 99 & $\mathrm{Cr}(\mathrm{OH}) 3$ \\
\hline 98 & Cr203 \\
\hline 42 & $\mathrm{Cs} 20$ \\
\hline $\begin{array}{l}137 \\
90\end{array}$ & $\begin{array}{l}\text { Cs20 Semi } \\
\text { CsCOOH }\end{array}$ \\
\hline 96 & $\mathrm{CsCl}$ \\
\hline 180 & CsCl Semi \\
\hline $\begin{array}{r}8 \\
88\end{array}$ & CsNO3 \\
\hline 122 & CsResin \\
\hline 52 & $\mathrm{Cu}(\mathrm{OII}) 2$ \\
\hline 58 & Cu2O \\
\hline 64 & $\mathrm{CuCOOH}$ \\
\hline 180 & $\mathrm{CuO}$ \\
\hline $\begin{array}{l}13 \\
80\end{array}$ & $\begin{array}{l}\text { Fe }(\mathrm{OH}) 3 \\
\text { Fe203 }\end{array}$ \\
\hline
\end{tabular}

61

PVVF Exit Gins

24.99

$.1547 \mathrm{E}-10$

.0000

$.2539 \mathrm{E}-10$

$.4848 \mathrm{E}-11$

$.5799 \mathrm{E}-09$

.0000

.0000

$.2201 E-08$

$.7609 \mathrm{E}-17$

.0000

.0000

$.6877 \mathrm{E}-11$

$.4639 E-04$

10.94

$.1072 E-09$

.2383E-09

$.1600 \mathrm{E}-12$

$.1714 \mathrm{E}-10$

$.1854 \mathrm{E}-10$

.0000

$.4634 \mathrm{E}-11$

.0000

$.2177 \mathrm{E}-10$

$.4634 \mathrm{E}-11$

.3763E-08

$.2768 \mathrm{E}-14$

.0000

.0000

$.1762 \mathrm{E}-10$

.0000

$.9015 \mathrm{E}-16$

.0000

.0000

$.2919 \mathrm{E}-14$

.0000

$.4881 \mathrm{E}-12$

.0000

$.8037 \mathrm{E}-11$

$.6022 \mathrm{E}-14$

.0000

.0000

.0000

$.1404 E-08$

.0000
Appendix II

Table 21-15

Page 062 of 173

Date 09/30/S2 Rev 09
62

HN03 Rinse Water Rinse to MUS

.1014
.0000
.0000
.0000
.0000
.0000
.0000
.0000
.0000
.0000
.0000
.0000
.0000
.0000

.0000

.0000

.0000

.0000

.0000

.0000

.0000

.0000

.0000

.0000

.0000

.0000

.0000

.0000

.0000

.0000

.0000

.0000

.0000

.0000

.0000

.0000

.0000

.0000

.0000

.0000

.0000

.0000

.0000

.0000

.0000

\begin{tabular}{|c|c|}
\hline .8317 & .4330 \\
\hline .0000 & .0000 \\
\hline .0000 & .0000 \\
\hline .0000 & $.3007 E-05$ \\
\hline .0000 & $.4437 E-13$ \\
\hline .0000 & $.1248 E-10$ \\
\hline .0000 & .0000 \\
\hline .0000 & .0000 \\
\hline .0000 & $.1633 \mathrm{E}-1$. \\
\hline .0000 & $.1640 \mathrm{E}-18$ \\
\hline .0000 & .0000 \\
\hline .0000 & .0000 \\
\hline .0000 & $.14 \& 2 E-12$ \\
\hline .0000 & .0000 \\
\hline .0000 & $.2 S 26 E-32$ \\
\hline .0000 & .0000 \\
\hline .0000 & $.51+1 E-11$ \\
\hline .0000 & $.38395-24$ \\
\hline .0000 & $.3692 E-12$ \\
\hline .0000 & $.3994 E-12$ \\
\hline .0000 & .0000 \\
\hline .0000 & $.9985 E-13$ \\
\hline .0000 & .0000 \\
\hline .0000 & $.4691 \mathrm{E}-12$ \\
\hline .0000 & $.9985 E-13$ \\
\hline .0000 & $.8117 \mathrm{E}-10$ \\
\hline .0000 & $.6641 \mathrm{E}-20$ \\
\hline .0000 &.$c 000$ \\
\hline .0000 & .0000 \\
\hline .0000 & $.3796 E-12$ \\
\hline .0000 & .0000 \\
\hline .0000 & $.1490 \mathrm{E}-17$ \\
\hline .0000 & .0000 \\
\hline .0000 & .0000 \\
\hline .0000 & $.9627 E-1 S$ \\
\hline .0000 & .0000 \\
\hline .0000 & . $1052 E-13$ \\
\hline .0000 & .0000 \\
\hline .0000 & $.1734 \mathrm{E}-12$ \\
\hline .0000 & $.1444 \mathrm{E}-25$ \\
\hline .0000 & .0000 \\
\hline .0000 & .0000 \\
\hline .0000 & .0000 \\
\hline .0000 & $.3021 \mathrm{E}-10$ \\
\hline .0000 & .0000 \\
\hline
\end{tabular}

64 Nis Rinses to SHT 
MATLRIAL BALANCE TABLES

SLLDGE-ONLY FEED

STREANS (CONT'D)STREAM NAME

$101 \mathrm{FeO}$

126 Group A Semi Vo

102 GroupA

103 GroupB

25112

$133 \mathrm{H} 2 \mathrm{C} 204$

9111202

84 HCOOII

$43 \mathrm{IICl}$

85 IIF

49 HNOB

86 llRes in

$36 \mathrm{Hg}$

$135 \mathrm{Hg} N 032$

$21 \mathrm{HgO}$

$\begin{array}{lll}97 & 12\end{array}$

$39 \mathrm{~K} 20$

$131 \mathrm{KMnO4}$

11 KNO3

105 La203

$108 \mathrm{Li} 20$

$65 \mathrm{Mg}(\mathrm{COOH}) 2$

$55 \mathrm{Mg}(\mathrm{OII}) 2$

$33 \mathrm{MgO}$

$60 \mathrm{Mn}(\mathrm{COOHI}) 2$

$152 \mathrm{Mn}(\mathrm{NO}) 2$

$129 \mathrm{Mn}(\mathrm{Oll}) 2$

$56 \mathrm{MnO}$

$14 \mathrm{MnO2}$

\&1 N2

143 NA2CO3 (C14)

$85 \mathrm{NO}$

$84 \mathrm{N02}$

$70 \mathrm{Na}(\mathrm{HgO}(\mathrm{OH}))$

94 Na2B.407

$109 \mathrm{Na} 2 \mathrm{C204}$

$5 \mathrm{Na} 2 \mathrm{CO} 3$

$82 \mathrm{Na} 20$

$71 \mathrm{Na2Pu02(Oll)4}$

$73 \mathrm{Na} 2 \mathrm{Rh} 04$

$72 \mathrm{Na} 2 \mathrm{Ru} 04$

$6 \mathrm{Na2S04}$

$68 \mathrm{NaAlO2}$

$114 \mathrm{Nin} \mathrm{BO} 2$

140 NaB02 Semi Vol $50 \mathrm{NaCOOH}$
61

PVVF Exit

Gas

.0000

.0000

$.1800 \mathrm{E}-10$

$.4119 E-10$

.3156E-05

.0000

.0000

$.6663 \mathrm{E}-01$

.0000

.0000

.0000

.0000

. 3797E-03

$.1589 \mathrm{E}-18$

$.1312 \mathrm{E}-12$

.0000

.0000

.0000

$.7204 \mathrm{E}-11$

$.7472 E-10$

.8534E-09

$.4536 \mathrm{~T}-10$

.2729E-13

.2993E-09

.4044E-09

.0000

$.6598 \mathrm{E}-11$

.0000

.0000

1292.

.0000

1.259

$.1835 \mathrm{E}-01$

.2905E- 18

$.1088 \mathrm{E}-11$

$.2891 E-11$

.0000

.2652E-08

$.1178 \mathrm{E}-17$

$.2422 E-15$

.2363E- 14

$.4792 \mathrm{E}-11$

$.1178 \mathrm{E}-10$

.0000

.0000

.3803E-09
62

HN03 Rinse

to MVS

.0000

.0000

.0000

.0000

.0000

.0000

.0000

.0000

.0000

.0000

. 1882E-01

.0000

.0000

.0000

.0000

.0000

.0000

.0000

.0000

.0000

.0000

.0000

.0000

.0000

.0000

.0000

.0000

.0000

.0000

.0000

.0000

.0000

.0000

.0000

.0000

.0000

.0000

.0000

.0000

.0000

.0000

.0000

.0000

.0000

.0000

.0000
63

Water Rinse

to MVS

.0000

.0000

.0000

.0000

.0000

.0000

.0000

.0000

.0000

.0000

.0000

.0000

.0000

.0000

.0000

.0000

.0000

.0000

.0000

.0000

.0000

.0000

.0000

.0000

.0000

.0000

.0000

.0000

.0000

.0000

.0000

.0000

.0000

.0000

.0000

.0000

.0000

.0000

.0000

.0000

.0000

.0000

.0000

.0000

.0000

.0000
64

MVS Rinses

to SWT

.0000

.0000

$.2781 \mathrm{E}-12$

$.8875 \mathrm{E}-12$

.0000

.0000

.0000

.0000

.0000

.0000

$.1382 E-01$

.0000

.0000

$.1500 \mathrm{E}-05$

$.1578 \mathrm{E}-13$

.0000

.0000

.0000

$.8157 \mathrm{E}-15$

$.3130 \mathrm{E}-14$

$.6315 \mathrm{E}-18$

$.9785 E-12$

$.6547 E-25$

$.1884 \mathrm{E}-13$

$.8724 \mathrm{E}-11$

.0000

$.5868 \mathrm{E}-28$

.0000

.0000

$.9213 \mathrm{E}-17$

.0000

.0000

. 1239E-05

$.6259 \mathrm{E}-15$

$.8588 \mathrm{E}-15$

$.3273 E-15$

.0000

$.2810 \mathrm{E}-12$

$.2588 \mathrm{E}-19$

$.5218 E-17$

.5092E-16

. 1033E- 12

$.2588 \mathrm{E}-12$

.0000

.0000

$.6640 \mathrm{E}-11$ 
DPSP 80-1038

MATERIAL BALANCE TABLES

SLLDCE-ONLY FEED

STREAMS (CONT'D) -

STREAM NAME

$7 \mathrm{NaCl}$

$188 \mathrm{NaCl}$ Semi Vol

$69 \mathrm{NaF}$

189 NaF Semi Vol

$12 \mathrm{NaI}$

$125 \mathrm{NaI}$ Semi Vol

$8 \mathrm{NaNO} 2$

$2 \mathrm{NaNO3}$

$4 \mathrm{NaOH}$

87 NaResin

$61 \mathrm{Ni}(\mathrm{COOH}) 2$

$17 \mathrm{Ni}(\mathrm{OH}) 2$

$40 \mathrm{NiO}$

8202

$67 \mathrm{PbO}$

$28 \mathrm{PbS04}$

$124 \mathrm{Pd}$

$123 \mathrm{Pd}(\mathrm{OH}) 2$

112 PdiNO32

$110 \mathrm{PdO}$

$117 \mathrm{Pu}(\mathrm{COOH}) 4$

$76 \mathrm{Pu} 02$

$22 \mathrm{RhO2}$

$79 \mathrm{Ru} 02$

23 Ru02 Somi Vol

$83 \mathrm{Ru} 04$

$88 \mathrm{SO} 2$

$111 \mathrm{SiO2}$

115 Silica Gel

$48 \mathrm{Sr}(\mathrm{COOH}) 2$

$10 \mathrm{Sr}(\mathrm{NOS}) 2$

$127 \mathrm{Sr}(\mathrm{OH}) 2$

$80 \mathrm{SrCO}$

$40 \mathrm{Sr} 0$

89 SrRESIN

141 Surfactant

92 ThO2

$107 \mathrm{TiO}$

119 Tritium

$93 \mathrm{VO2}$

$62 \mathrm{VO}$ ( COOH) 2

$16 \mathrm{UO2}(\mathrm{OH}) 2$

$27 \mathrm{Y}(\mathrm{COOH}) 3$

$11 \mathrm{Y}(\mathrm{NO3}) 3$

$128 Y(\mathrm{OH}) 8$

$31 Y 2(\cos ) 8$
Appendix $\mathrm{H}$

Table 21-15

Page 064 of 173

Date 0 $8 / 30 / 82$ Res 09

61

PVVF Exit 62

Gas

$.5872 \mathrm{E}-11$

.0000

$.1080 \mathrm{E}-11$

.0000

.5338E- 12

.0000

.0000

.3032E-09

.1200E-12

.0000

1426E-09

$.1048 \mathrm{E}-12$

.0000

890.8

.0000

$.6473 E-11$

.0000

.0000

.0000

.0000

.0000

$.1684 \mathrm{E}-11$

$.6486 \mathrm{E}-12$

$.3188 E-11$

.0000

.0000

$.8969 \mathrm{E}-05$

$.8940 \mathrm{E}-08$

.0000

$.5791 \mathrm{E}-11$

$.6790 \mathrm{E}-17$

$.4676 \mathrm{E}-11$

.0000

.0000

.0000

.0000

$.2641 E-10$

$.1494 \mathrm{E}-03$

$.5190 \mathrm{E}-10$

.0000

$.1845 \mathrm{E}-09$

$.1837 \mathrm{E}-12$

$.3968 \mathrm{E}-11$

$.4822 \mathrm{E}-17$

$.2924 E-14$

.0000
UNO3 Rinse Winter Rinse

to MVS

.0000

.0000

.0000

.0000

.0000

.0000

.0000

.0000

.0000

.0000

.0000

.0000

.0000

.0000

.0000

.0000

.0000

.0000

.0000

.0000

.0000

.0000

.0000

.0000

.0000

.0000

.0000

.0000

.0000

.0000

.0000

.0000

.0000

.0000

.0000

.0000

.0000

.0000

.0000

.0000

.0000

.0000

.0000

.0000

.0000

.0000

\section{to MVS}

.0000

.0000

.0000

.0000

.0000

.0000

.0000

.0000

.0000

.0000

.0000

.0000

.0000

.0000

.0000

.0000

.0000

.0000

.0000

.0000

.0000

.0000

.0000

.0000

.0000

.0000

.0000

.0000

.0000

.0000

.0000

.0000

.0000

.0000

.0000

.0000

.0000

.0000

.0000

.0000

.0000

.0000

.0000

.0000

.0000

.0000
64

MVS Rinses

to $\mathrm{S}: \mathrm{T}$

$.10295-12$

.0000

$.5854 E-15$

.0000

$.9970 E-14$

.0000

.0000

$.8612 \mathrm{E}-11$

.0000

.0000

$.30765-11$

$.2515 E-2.1$

.0000

$.8979 E-17$

.0000

$.1395 \mathrm{E}-12$

.0000

.0000

.0000

.0000

.0000

$.3629 \mathrm{E}-13$

$.1887 E-13$

$.6793 \mathrm{E}-13$

.0000

.0000

.0000

$.6471 \mathrm{E}-11$

.0000

$.1249 \mathrm{E}-12$

$.1463 E-18$

$.1122 \mathrm{E}-25$

.0000

.0000

.0000

.0000

$.5690 \mathrm{E}-12$

$.6057 \mathrm{E}-14$

$.3011 \mathrm{E}-26$

.0000

$.8979 \mathrm{E}-11$

$.4406 \mathrm{E}-24$

$.8559 \mathrm{E}-13$

$.1039 \mathrm{E}-18$

$.7013 \mathrm{E}-26$

.0000 
DPSP SO-1033

Material balanice tables SLUDCE-ONLII FEED STREAMS (CONT'D)STRIMM NAME

47 Y2O3
$100 \mathrm{Zeolite}$
$44 \mathrm{Zn}($ COOH) 2
$54 \mathrm{Zn}(0 \mathrm{H}) 2$
$57 \mathrm{ZnO}$
$104 \mathrm{ZrO2}$
TOTAL FLOK, LB/HR
VAPOR FLOW, CFM
LIQUID FLOW, GPM
DESIGY FLOW,
DENSITY, LBS/FT3
IEMPERATURE, DLG C
PRESSURE, ATM
PRESSIRE, PSIG
PRESSURE, MI IIG
PHASE
ENTIALPY, PCU/IR

Appendix $H$ Table 21-15

Page 065 of 173

Date 09/30/82 Rev 09

\begin{tabular}{|c|c|c|c|}
\hline 61 & 62 & 63 & 64 \\
\hline PVVF Exit & HN03 Rinse & Vater Rinse & MVS Rinses \\
\hline Gas & to MVS & $\begin{array}{l}\text { to MVS } \\
0000\end{array}$ & to SWT \\
\hline $.1688 \mathrm{E}-09$ & .0000 & .0000 & $.3637 E-11$ \\
\hline $.2096 \mathrm{E}-10$ & .0000 & .0000 & $.4522 E-12$ \\
\hline $.1581 E-18$ & .0000 & .0000 & $.8793 E-25$ \\
\hline .0000 & .0000 & .0000 & .0000 \\
\hline $.7472 E-10$ & .0000 & .0000 & $.3180 \mathrm{E}-14$ \\
\hline \multirow{2}{*}{$\begin{array}{r}1719.59 \\
436.78\end{array}$} & .12 & .83 & .45 \\
\hline & .00 & .00 & .00 \\
\hline .0656 & 65.0373 & 62.4300 & 63.0822 \\
\hline 26.68 & 25.00 & 25.00 & 38.00 \\
\hline .90 & 1.00 & 1.00 & 1.00 \\
\hline-1.44 & .00 & .00 & .00 \\
\hline \multicolumn{4}{|l|}{685} \\
\hline VAPOR & LIQUID & LIQUID & LIQUID \\
\hline-93055.19 & 2.67 & 8.41 & 16.90 \\
\hline
\end{tabular}


DPSP $80-1033$

MATERIAL BALANCE TABLES

SLLDGE-ONLY FEED

STREAM NUMBERS -

STREAM NAME

COMPONENT FLOISS, LB/HR

$\begin{array}{rl}1 & \mathrm{H} 20 \\ 45 & \mathrm{Ag} \\ 116 & \mathrm{Ag} 20 \\ 184 & \mathrm{AgNO3}\end{array}$

$61 \mathrm{AgOH}$

74 Al(Oli) 3

77 A 1203

$75 \mathrm{~A} 100 \mathrm{H}$

106 B203

$9 \mathrm{Ba}(\mathrm{NOS}) 2$

$95 \mathrm{BaCl} 2$

$15 \mathrm{BaO}$

24 BaS04

$66 \mathrm{CO}$

$87 \mathrm{CO2}$

$142 \mathrm{CO}$ ( $\mathrm{C} 14)$

$63 \mathrm{Ca}(\mathrm{COOH}) 2$

$120 \mathrm{Ca}(\mathrm{OH}) 2$

$113 \mathrm{Ca} 3(\mathrm{P04}) 2$

$20 \mathrm{CaC2O4}$

$18 \mathrm{CaCO3}$

$78 \mathrm{CaF} 2$

$41 \mathrm{CaO}$

$19 \mathrm{CaSO4}$

29 Carbon

$26 \mathrm{Co}(\mathrm{COOH}) 2$

$121 \mathrm{Co}(\mathrm{OII}) 2$

$58 \mathrm{Co}(\mathrm{OH}) 3$

$59 \mathrm{CoO}$

$99 \mathrm{Cr}(\mathrm{OH}) 3$

$98 \mathrm{Cr} 203$

$42 \mathrm{Cs20}$

137 Cs20 Semi Vol

$90 \mathrm{CsCOOH}$

$96 \mathrm{CsCl}$

$186 \mathrm{CsCl}$ Semi Vol

8 CsNO3

88 Cskesin

$122 \mathrm{Cu}(\mathrm{COOH}) 2$

$52 \mathrm{Cu}(\mathrm{OH}) 2$

$58 \mathrm{Cu} 20$

$64 \mathrm{CuCOOH}$

$130 \mathrm{CuO}$

$13 \mathrm{Fe}(\mathrm{OH}) \mathrm{8}$

$80 \mathrm{Fe} 203$
65

MVS Bottoms to MAWT

$.9544 \mathrm{E}-04$

. 1927E-07

.0000

$.6629 \mathrm{E}-09$

$.9779 \mathrm{E}-17$

$.2751 \mathrm{E}-14$

.0000

.0000

$.3600 \mathrm{E}-16$

$.3614 \mathrm{E}-22$.

.0000

.0000

$.8266 \mathrm{E}-16$

.0000

$.6229 \mathrm{E}-36$

.0000

$.1133 E-14$

$.8462 E-28$

$.8139 E-16$

$.8803 \mathrm{E}-16$

.0000

$.2201 \mathrm{E}-16$

.0000

$.1084 \mathrm{E}-15$

$.2201 \mathrm{E}-16$

$.1789 \mathrm{E}-16$

$.1464 \mathrm{E}-29$

.0000

.0000

$.8366 \mathrm{E}-1 \mathrm{3}$

.0000

$.3298 \mathrm{E}-21$

.0000

.0000

$.2122 E-21$

.0000

$.2818 \mathrm{E}-17$

.0000

$.3821 \mathrm{E}-16$

$.3184 E-29$

.0000

.0000

.0000

$.6659 E-14$

.0000
Appendix II

Table 21-15

Page $0 G 0$ of 173

Date 09/30/52 Rev 09

66

MVC Vent

to PVVS

.2494

. 3003E-09

$.00 \mathrm{CO}$

$.2539 E-07$

$.4209 E-08$

.2141E-10

.0000

.0000

$.2801 \mathrm{E}-12$

.2812E-18

.0000

.0000

$.2542 \mathrm{E}-12$

$.4846 \mathrm{E}-27$

$.1782 \mathrm{E}-05$

$.7431 \mathrm{E}-24$

$.8817 E-11$

$.6585 \mathrm{E}-24$

$.6333 \mathrm{E}-12$

$.6850 E-12$

.0000

$.1712 E-12$

.0000

$.8046 \mathrm{E}-12$

$.1712 \mathrm{E}-12$

.1392E-12

$.1139 E-25$

.0000

.0000

$.6510 E-12$

.0000

$.2566 \mathrm{E}-17$

.0000

.0000

$.1651 E-17$

.0000

$.1804 E-13$

.0000

$.2974 \mathrm{E}-12$

.2478E-25

.0000

.0000

.0000

$.5182 E-10$

.0000
67

Mis Vent to MAllT IIg

Vacuum Pump to Uit il

.0000

.0000

.0000

.0000

.0000

.0000

.0000

.0000

.0000

.0000

.0000

.0000

.0000

.0000

.0000

.0000

.0000

.0000

.0000

.0000

.0000

.0000

.0000

.0000

.0000

.0000

.0000

.0000

.0000

.0000

.0000

.0000

.0000

.0000

.0000

.0000

.0000

.0000

.0000

.0000

.0000

.0000

.0000

.0000

.0000
$.1157 \mathrm{E}-01$

$.1929 \mathrm{E}-\mathrm{C} 3$

.0000

$.1724 E-02$

$.1902 E-10$

$.1190 \mathrm{E}-05$

.0000

.0000

$.15575-07$

$.1563 E-13$

.0000

.0000

$.1412 E-07$

$.5054 E-34$

$.5327 \mathrm{E}-11$

.2430E-20

$.48995-06$

.36ธ9อ- 19

. 35191:-07

. S306E-G7

.0000

$.9516 \mathrm{E}-0 \mathrm{~S}$

.0000

$.4171 E-07$

$.8516 E-08$

.7735E-0S

$.6329 E-21$

.0000

.0000

$.3617 E-C 7$

.0000

$.1426 \mathrm{E}-12$

.0000

.0000

$.9174 \mathrm{E}-13$

.0000

$.1002 E-08$

.0000

. 1652E-07

$.1377 \mathrm{E}-20$

.0000

.0000

.0000

$.2879 \mathrm{E}-05$

.0000 
DPSP $80-1033$

MATERIAL BALANCE TABLES

\section{SLLDCE-ONLY FEED}

STREAMS (CONI'D)STREAM NAME

$101 \mathrm{FeO}$

126 Group A Semi Vo

102 Grouph

103 Group B

$25 \mathrm{H} 2$

$133 \mathrm{H2C2O4}$

$91 \mathrm{H2O} 2$

34 IICOOII

$43 \mathrm{HCl}$

85 HF

49 HNO3

86 HResin

$56 \mathrm{Hg}$

$135 \mathrm{HgNO} 2$

$21 \mathrm{HgO}$

$97 \quad 12$

$89 k 20$

$131 \mathrm{kN} / \mathrm{n} 04$

$118 \mathrm{KNO3}$

$105 \quad$ l.203

108 Li20

$65 \mathrm{Mg}(\mathrm{COOH}) 2$

55 $\mathrm{Mg}(\mathrm{OII}) 2$

$33 \mathrm{MgO}$

$60 \mathrm{Mn}(\mathrm{COOH}) 2$

$152 \mathrm{Mn}\left(\mathrm{NO}_{03}\right) 2$

$129 \mathrm{Mn}(\mathrm{OII}) 2$

$56 \mathrm{MnO}$

$14 \mathrm{MnO} 2$

$81 \mathrm{N2}$

143 NA2CO3 (C14)

$85 \mathrm{No}$

$84 \quad \mathrm{NO2}$

$70 \mathrm{Na}\left(\mathrm{H}_{\S} \mathrm{O}(\mathrm{OII})\right)$

94 in $2 B 407$

$109 \mathrm{Na2C204}$

$5 \mathrm{Na} 2 \mathrm{CO} 3$

$32 \mathrm{Na} 20$

$71 \mathrm{Na} 2 \mathrm{Pu} 02(\mathrm{OH}) 4$

$73 \mathrm{Na} 2 \mathrm{RhO}_{4}$

$72 \mathrm{Na} 2 \mathrm{Ru} 04$

$6 \mathrm{Nin} 2 \mathrm{SO4}$

$68 \mathrm{NaAl} 102$

$114 \mathrm{NaBO2}$

140 NaBC2 Semi Vol

$50 \mathrm{NnCOOHI}$

Appendix H

Table 21-15

Page 067 of 173

Date 09/30/\$2 Rev 09

\section{5}

MVS Bottoms to MAW'

.0000

.0000

$.6129 \mathrm{E}-16$

$.1956 \mathrm{E}-15$

.0000

.0000

.0000

.0000

.0000

.0000

$.3045 E-05$

.0000

$.1325 \mathrm{E}-01$

.3307E-09

$.8478 E-17$

.0000

.0000

.0000

$.1798 \mathrm{E}-18$

$.6898 \mathrm{E}-18$

$.1892 \mathrm{E}-16$

$.2157 \mathrm{E}-15$

. 1443E-28

$.4153 \mathrm{E}-17$

. 1923E-14

.0000

$.1293 E-26$

.0000

.0000

.2031E-20

.0000

.0000

.2731 E-09

. $1380 \mathrm{E}-18$

$.7910 \mathrm{E}-19$

$.7214 \mathrm{E}-19$

.0000

$.5091 \mathrm{E}-16$

.5595E-28

$.1150 \mathrm{E}-20$

$.1122 \mathrm{E}-19$

.2276E-16

$.5595 E-16$

.0000

.0000

$.1464 \mathrm{E}-14$
66

MVC Vent

to PVVS

.0000

.0000

$.4769 \mathrm{E}-12$

$.1522 \mathrm{E}-11$

$.8403 E-26$

.0000

.0000

.0000

.0000

.0000

$.4663 \mathrm{E}-02$

.0000

.2327E-03

$.1589 \mathrm{E}-10$

$.4902 E-11$

.0000

.0000

.0000

$.1399 \mathrm{E}-14$

$.5368 \mathrm{E}-14$

. 1083E- 12

$.1678 \mathrm{E}-11$

$.1123 E-24$

$.8232 E-18$

$.1496 \mathrm{E}-10$

.0000

$.1006 \mathrm{E}-22$

.0000

.0000

17.16

.0000

$.9053 \mathrm{E}-17$

.8185E-02

$.1073 E-14$

$.6155 \mathrm{E}-15$

.5618E-15

.0000

$.3962 E-12$

.4353E-19

$.8950 \mathrm{E}-17$

$.8734 \mathrm{E}-16$

$.1771 \mathrm{E}-12$

$.4353 E-12$

.0000

.0000

$.1139 \mathrm{E}-10$
67

MVS Vent to

Vacuum Pump

.0000

.0000

.0000

.0000

.0000

.0000

.0000

.0000

.0000

.0000

.0000

.0000

.0000

.0000

.0000

.0000

.0000

.0000

.0000

.0000

.0000

.0000

.0000

.0000

.0000

.0000

.0000

.0000

.0000

.0000

.0000

.0000

.0000

.0000

.0000

.0000

.0000

.0000

.0000

.0000

.0000

.0000

.0000

.0000

.0000

.0000
68 MAWT $\mathrm{H}_{\mathbf{g}}$ to MFT il

.0000

.0000

.2650E-07

$.8458 E-07$

$.8777 \mathrm{E}-33$

.0000

.0000

.0000

.0000

.0000

$.1665 \mathrm{E}-03$

.0000

1.644

$.1074 \mathrm{E}-05$

$.1499 \mathrm{E}-08$

.0000

.0000

.0000

$.7774 \mathrm{E}-10$

. 2983E-09

$.6018 \mathrm{E}-08$

$.9326 \mathrm{E}-07$

$.6240 \mathrm{E}-20$

$.1796 \mathrm{E}-08$

$.8314 \mathrm{E}-06$

.0000

. $5592 E-18$

.0000

.0000

$.3015 E-06$

.0000

.281GE-23

$.1910 \mathrm{E}-04$

. 5965E-10

$.3420 \mathrm{E}-10$

$.8119 \mathrm{E}-10$

.0000

.2201E-07

$.2419 \mathrm{E}-14$

$.4973 E-12$

$.4853 \mathrm{E}-11$

$.9841 \mathrm{E}-08$

.2419E-07

.0000

.0000

$.6328 \mathrm{E}-06$ 
NPSP $80-1053$

MATERIAL BALANCE TABLES

SLUDGE-ONLY FEED

STREAMS (CONT'D)STREAM NAME

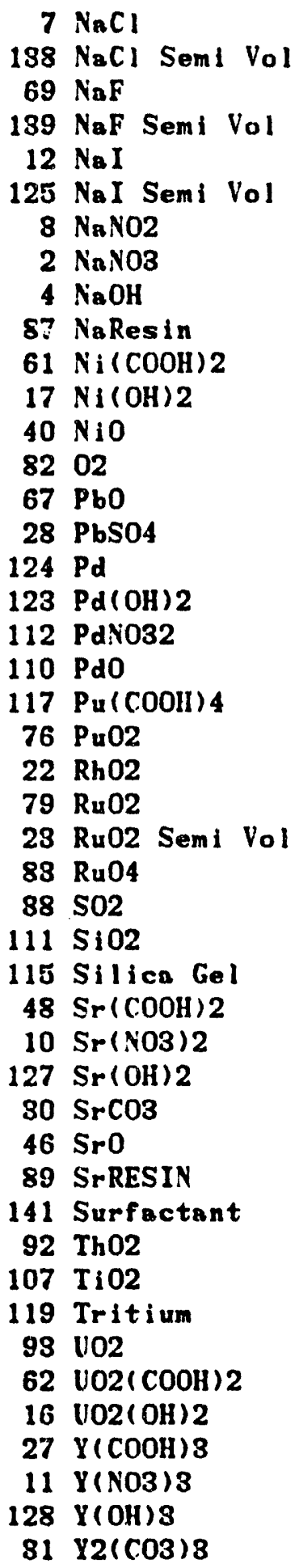

65

MY'S Bottoms to MANT

.2269E-16

.0000

$.1187 \mathrm{E}-18$

.0000

$.2197 E-17$

.0000

.0000

$.7962 E-15$

.0000

.0000

$.6780 \mathrm{E}-15$

$.5543 E-28$

.0000

$.1979 \mathrm{E}-20$

.0000

$.3074 E-16$

.0000

.0000

.0000

.0000

.0000

$.8000 \mathrm{E}-17$

$.3057 \mathrm{E}-17$

$.1497 \mathrm{E}-16$

.0000

.0000

.0000

$.1426 \mathrm{E}-14$

.0000

.2753E-16

$.3225 \mathrm{E}-22$

.2472E-29

.0000

.0000

.0000

.0000

$.1254 \mathrm{E}-15$

$.1335 \mathrm{E}-17$

$.6637 \mathrm{E}-30$

.0000

$.8770 \mathrm{E}-15$

$.9712 \mathrm{E}-28$

$.1887 \mathrm{E}-16$

$.2290 \mathrm{E}-22$

$.1546 \mathrm{E}-29$

.0000
Appendix H

Table 21-15

Page 063 of 173

Date 09/30/82 Rev 03 
M:TRRIAL BALANCE TARLES

Date 09/30/82 Rev 09

\section{SLUDGE-ONLY FEED}

STREAMS (CONT'D) -

STREAM TAME

$47 \quad 1203$

100 Zcolite

$44 \mathrm{Zn}(\mathrm{COOII}) 2$

$54 \mathrm{Zn}(\mathrm{OH}) 2$

$57 \mathrm{ZnO}$

104 Z.r02

65

NVS Bottoms

to MAWT

.0000

$.8017 \mathrm{E}-15$

$.9968 \mathrm{E}-16$

$.8361 \mathrm{E}-29$

.0000

66

67

68

MVC lent MVS Vent to MAWT Hg

to PVVS Vacuum Pump to MFT if

$.0000 \quad .0000$

$.6258 \mathrm{E}-11 \quad .0000$

.0000

$.7757 \mathrm{E}-12 \quad .0000$

$.8466 \mathrm{E}-06$

$.4310 \mathrm{E}-07$

$.6506 \mathrm{E}-25$

.0000

.0000

$.8615 E-20$

$.6898 \mathrm{E}-18$

$.6368 \mathrm{E}-14$

.0000

22.61

VAPOR FLOH, CEN

.01

5.13

.00

LIQUID FLOW, GPM

DESIG. FLOH.

DENSITI, LBS/FT3

TEMPERATLRE, DEG C

PIEESSURE, ATM

PRESSURE, PSIG

PRESSURE, MM IIG

PIINSE

E.TTIALPY, PCU/IIR

774.7558

88.00

1.00

.00

.0735

15.00

.97

$-.43$

737.58

LIQUID

VAPOR

.02

$-1353.03$

.0000
88.00
.02
-14.42
14.37
VAPOR
.00

775.8329

88.00

.99

$-.07$

756.20

LIQUID

2.52 
DPSP $80-1033$

MATERIAL BALANCE TABLES

SLUDG:-ONLY FEED

STREAM NUMBERS -

STREAM NAME

COMPONENT FLOHS, LB/HR

\begin{tabular}{|c|c|c|c|}
\hline 1 & $\mathrm{H} 2 \mathrm{O}$ & .2548 & .2218 \\
\hline 45 & Ag & $.1929 E-03$ & .0000 \\
\hline 116 & Ag20 & .0000 & .0000 \\
\hline 134 & AgN03 & $.1724 \mathrm{E}-02$ & .0000 \\
\hline 51 & $\mathrm{AgOH}$ & $.4228 \mathrm{E}-08$ & .0000 \\
\hline 74 & $\mathrm{Al}(\mathrm{OH}) \mathrm{S}$ & $.1190 E-05$ & .000 \\
\hline 77 & A 1203 & .0000 & .000 \\
\hline 75 & A $100 \mathrm{H}$ & .0000 & .000 \\
\hline 106 & B203 & . 1557E-07 & .000 \\
\hline 9 & $\mathrm{Ba}(\mathrm{NOB}) 2$ & $.1563 E-13$ & .000 \\
\hline 95 & $\mathrm{BnCl}$ & .0000 & .0000 \\
\hline 15 & $\mathrm{BaO}$ & .0000 & .0000 \\
\hline 24 & $\mathrm{BaSO4}$ & $.1112 E-07$ & .0000 \\
\hline 66 & CO & .0000 & .0000 \\
\hline 87 & $\mathrm{CO2}$ & $.1446 E-14$ & .0000 \\
\hline 142 & $\operatorname{co2}(\mathrm{C14})$ & $.6016 E-83$ & .000 \\
\hline 63 & $\mathrm{Ca}(\mathrm{z} 0 \mathrm{OII}) 2$ & . 4899E-06 & .000 \\
\hline 120 & $\mathrm{Ca}(\mathrm{OH}) 2$ & $.8659 E-19$ & .000 \\
\hline 113 & $\mathrm{Cn} 3(\mathrm{PO}) 2$ & $.8519 E-07$ & .000 \\
\hline 20 & $\mathrm{CaC204}$ & $.3806 E-07$ & .000 \\
\hline 18 & $\mathrm{CaCO3}$ & .0000 & .000 \\
\hline 78 & Caf2 & $.9516 \mathrm{E}-08$ & .000 \\
\hline 41 & $\mathrm{CaO}$ & .0000 & .000 \\
\hline 19 & $\mathrm{CaSO4}$ & $.4471 E-07$ & .000 \\
\hline 29 & Carbon & $.9516 \mathrm{E}-08$ & .000 \\
\hline 26 & $\mathrm{Co}(\mathrm{COOH}) 2$ & $.7735 E-08$ & .000 \\
\hline 121 & $\mathrm{Co}(\mathrm{OH}) 2$ & $.6329 \mathrm{E}-21$ & .000 \\
\hline 53 & $\mathrm{Co}(\mathrm{OH}) \mathrm{s}$ & .0000 & .0000 \\
\hline 69 & $\mathrm{CoO}$ & .0000 & .0000 \\
\hline 99 & $\mathrm{Cr}(\mathrm{OH}) 8$ & $.8617 \mathrm{E}-07$ & .0000 \\
\hline 98 & Cr203 & .0000 & .0000 \\
\hline 42 & Cs20 & $.1426 E-12$ & .000 \\
\hline 137 & Cs20 Semi Vol & .0000 & .000 \\
\hline 90 & $\mathrm{CsCOOH}$ & .0000 & .000 \\
\hline 96 & $\mathrm{CsCl}$ & $.9175 \mathrm{E}-13$ & .000 \\
\hline 136 & Cscl Semi Vol & .0000 & .000 \\
\hline & CsNO3 & $.1002 E-08$ & .000 \\
\hline 88 & CsResin & .0000 & .000 \\
\hline 122 & $\mathrm{Cu}(\mathrm{COOH}) 2$ & $.1652 \mathrm{E}-07$ & .000 \\
\hline 52 & $\mathrm{Cu}(\mathrm{OH}) 2$ & $.1377 E-20$ & .000 \\
\hline 58 & Cu20 & .0000 & .000 \\
\hline 64 & $\mathrm{CuCOOH}$ & .0000 & .000 \\
\hline 180 & $\mathrm{CuO}$ & .0000 & .000 \\
\hline 18 & $\mathrm{Fe}(\mathrm{OH}) 8$ & $.2879 \mathrm{E}-05$ & .000 \\
\hline 80 & & .0000 & .000 \\
\hline
\end{tabular}

69

Hg Feed to MASC

\section{.2548}

.0000

4228E-08

$.1190 \mathrm{E}-05$

.0000

.0000

1557E-07

1563E- 13

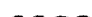

$.1112 \mathrm{E}-07$

$.1446 \mathrm{E}-14$

0000

.0000

0000

0000

0000

0000

0000

0000

0000

0000

0000

0000

0000

0000

0000

0000

0000

0000

.0000

.0000

.0000

0000

0000

0000

0000

0000

.0000
Appendix

Tiable 21-15

Page 070 of 173

Date $09 / 30 / 82$ Rev 09
72

INO3 Hash

from MASC

.4755

.0000

.0000

.2018E-02

$.4218 E-03$

$.1187 E-05$

.0000

.0000

$.1553 \mathrm{E}-07$

$.1559 \mathrm{E}-13$

.0000

.0000

$.1409 E-07$

.0000

$.1442 \mathrm{E}-14$

.6002E-33

$.4887 \mathrm{E}-00$

$.8650 E-19$

. $3511 \mathrm{E}-07$

$.3797 \mathrm{E}-07$

.0000

$.9493 E-08$

.0000

.4460E-07

$.9493 E-08$

$.7717 \mathrm{E}-08$

$.6314 \mathrm{E}-21$

.0000

.0000

$.3609 E-07$

.0000

$.1422 \mathrm{E}-12$

.0000

.0000

$.9152 \mathrm{E}-13$

.0000

$.9995 \mathrm{E}-09$

.0000

$.1648 \mathrm{E}-07$

$.1373 E-20$

.0000

.0000

.0000

$.2872 E-05$

.0000
73

Niall to

$S ! T$

$.86895-01$

.0000

.0000

.0000

.0000

.0000

.0000

.0000

.0000

.0000

.0000

.0000

.0000

.0000

.0000

.0000

.0000

.0000

.0000

.0000

.0000

.0000

.0000

.0000

.0000

.0000

.0000

.0000

.0000

.0000

.0000

.0000

.0000

.0000

.0000

.0000

.0000

.0000

.0000

.0000

.0000

.0000

.0000

.0000

.0000 . 
DPSP $80-1033$

Material balaACE TABLES

\section{SLUDGE-ONLY FETD}

\section{STREAMS ( CONT'D)-}

STREAM NAME

101 Feo
126 Group A Sem! Vo

102 GroupA

103 GroupB

$25 \mathrm{H2}$

133 H2C204

9111202

84 HCOOII

$43 \mathrm{HCl}$

$85 \mathrm{IIF}$

40 HNO3

86 UResin

$36 \mathrm{llg}$

$135 \mathrm{Hg} i 032$

$21 \mathrm{HgO}$

$97 \quad 12$

$39 \mathrm{k} 20$

$151 \mathrm{KMnO4}$

$118 \mathrm{KNOS}$

$105 \operatorname{Ln} 203$

108 Li20

$65 \mathrm{Mg}(\mathrm{COOH}) 2$

$55 \mathrm{Mg}(\mathrm{OlH}) 2$

$33 \mathrm{MgO}$

$60 \mathrm{Mn}(\mathrm{COOII}) 2$

$132 \mathrm{Mn}(\mathrm{N03}) 2$

$129 \mathrm{Mn}(\mathrm{OII}) 2$

$56 \mathrm{MnO}$

$14 \mathrm{MnO2}$

81 N2

143 N $12 \mathrm{CO}_{03}(\mathrm{C} 14)$

35 No

$84 \mathrm{NO2}$

$70 \mathrm{Nn}\left(\mathrm{H}_{\mathrm{E}} \mathrm{O}(\mathrm{OHI})\right)$

94 in $2 B 407$

109 in 2 C204

$5 \mathrm{Nin} 2 \mathrm{CO3}$

32 Nin 20

$71 \mathrm{Na}_{2} \mathrm{P}_{\mathrm{u}} 02$ (OII) 4

$73 \mathrm{Nis} 2 \mathrm{RhO4}^{2}$

$72 \mathrm{Nin} 2 \mathrm{RuO4}$

$6 \mathrm{Ni} 2 \mathrm{SO4}$

$68 \mathrm{NiA} 102$

$114 \mathrm{inBO2}$

1.10 NinBO2 Semi Vol

$50 \mathrm{NaCOOH}$
69

Hg Feed to HNO3 Wash

MASC

.0000

.0000

.2650E-07

$.8458 \mathrm{E}-07$

$.4854 \mathrm{E}-38$

.0000

.0000

.0000

.0000

.0000

.3493E-03

.0000

1.645

$.1074 \mathrm{E}-05$

$.1504 \mathrm{E}-08$

.0000

.0000

.0000

$.7774 E-10$

.2983E-09

. 6018E-08

.932GE-07

$.6240 \mathrm{E}-20$

$.1796 \mathrm{E}-08$

$.8314 \mathrm{E}-06$

.0000

.6592E-18

.0000

.0000

$.6010 \mathrm{E}-05$

.0000

$.3536 \mathrm{E}-28$

$.6605 \mathrm{E}-05$

.5965E- 10

$.3420 \mathrm{E}-10$

$.3119 E-10$

.0000

.2201E-07

.2419E-14

$.4973 \mathrm{E}-12$

$.4853 \mathrm{E}-11$

$.9841 \mathrm{E}-08$

.2419E-07

.0000

.0000

$.6328 \mathrm{E}-0 \mathrm{G}$
Appendix $\mathrm{H}$

Table 21-15

Page 071 of 178

Date 09/30/82 Rev 09 
DPSP 80-1033

MATERIAL BALANCE THBLES

SLUDGE-ONLY FEED STREAMS (CONT'D)STREAM NAME

$7 \mathrm{NaCl}$

$138 \mathrm{NaCl}$ Semi Vol

$69 \mathrm{NeF}$

$139 \mathrm{NaF}$ Semi Vol

12 NaI

$125 \mathrm{NaI}$ Semi Vol

$8 \mathrm{NaNO2}$

$2 \mathrm{NaNO3}$

$4 \mathrm{NaOH}$

87 NaResin

$61 \mathrm{~N} 1(\mathrm{COOH}) 2$

$17 \mathrm{Ni}(\mathrm{OH}) 2$

$40 \mathrm{~N} 10$

8202

$67 \mathrm{PbO}$

$28 \mathrm{PbS} 04$

$124 \mathrm{Pd}$

$123 \mathrm{Pd}(\mathrm{OII}) 2$

112 PdNO32

110 PdO

$117 \mathrm{Pu}(\mathrm{COOH}) 4$

$76 \mathrm{Pu} 02$

$22 \mathrm{Rh}_{2} 02$

$79 \mathrm{Ru} 02$

23 Ru02 Semi Vol

$83 \mathrm{Ru} 04$

$88 \mathrm{SO2}$

1115102

115 Silics Gol

$48 \mathrm{Sr}(\mathrm{COOH}) 2$

$10 \mathrm{Sr}(\mathrm{NO3}) 2$

$127 \mathrm{Sr}(\mathrm{OH}) 2$

$80 \mathrm{SrCO3}$

46 Sro

89 SrRESIN

141 Surfactant

$92 \mathrm{ThO2}$

$107 \mathrm{riO}$

119 Tritium

$93 \mathrm{VO2}$

$62 \mathrm{VO} 2(\mathrm{COOH}) 2$

$16 \mathrm{VO2}(\mathrm{OH}) 2$

$27 \mathrm{Y}(\mathrm{COOH}) \mathrm{S}$

$11 Y(N 03) 8$

$128 Y(\mathrm{OH}) 8$

$81 Y 2(\mathrm{COS}) \mathrm{S}$
60

Hg Foed to MASC

$.9811 E-03$

.0000

$.513 i E-1 J$

.0000

$.9501 E-03$

.0000

.0000

$.8443 E-06$

.0000

.0000

.2932E-06

.2397E-19

.0000

$.8528 E-05$

.0000

$.1329 \mathrm{E}-07$

.0000

.0000

.0000

.0000

.0000

.3459E-08

.1322E-03

$.6474 \mathrm{E}-03$

.0000

.0000

.0000

$.6167 E-00$

.0000

$.1190 \mathrm{E}-07$

$.1394 \mathrm{E}-13$

$.1069 \mathrm{E}-20$

.0000

.0000

.0000

.0000

$.5422 E-07$

.5773E-09

$.6060 \mathrm{E}-16$

.0000

.3792E-00

$.4199 \mathrm{E}-19$

$.8158 \mathrm{E}-03$

$.9901 \mathrm{E}-14$

$.6684 \mathrm{E}-21$

.0000
71

HNO3 Wash to MASC

.0000

.0000

.0000

.0000

.0000

.0000

.0000

.0000

.0000

.0000

.0000

.0000

.0000

.0000

.0000

.0000

.0000

.0000

.0000

.0000

.0000

.0000

.0000

.0000

.0000

.0000

.0000

.0000

.0000

.0000

. .0000

.0000

.0000

.0000

.0000

.0000

.0000

.0000

.0000

.0000

.0000

.0000

.0000

.0000

.0000

.0000
Appendix $H$

Table 21-15

Page 072 of 173

Date 09/80/82 Rev 00

$\begin{array}{lc}72 & 7 i \\ \text { HNO3 Hash } & \text { NaOH to } \\ \text { from MASC } & \text { SHT } \\ .0787 E-03 & .0000 \\ .0000 & .0000 \\ .5119 \mathrm{E}-10 & .0000 \\ .0000 & .0000 \\ .9478 \mathrm{E}-09 & .0000 \\ .0000 & .0000 \\ .0000 & .0000 \\ .8434 \mathrm{E}-00 & .0000 \\ .0000 & .8659 \mathrm{E}-01 \\ .0000 & .0000 \\ .2925 \mathrm{E}-06 & .0000 \\ .2391 \mathrm{E}-19 & .0000 \\ .0000 & .0000 \\ .3520 \mathrm{E}-05 & .00 \mathrm{C} 0 \\ .0000 & .0000 \\ .1326 \mathrm{E}-07 & .0000\end{array}$

.0000

.0000

.0000

.0000

.0000

$.3450 \mathrm{E}-08$

$.1318 \mathrm{E}-08$

$.6458 \mathrm{E}-03$

.0000

.0000

.0000

$.6152 E-06$

.0000

$.1188 \mathrm{E}-07$

$.1391 \mathrm{E}-13$

$.1066 \mathrm{E}-20$

.0000

.0000

.0000

.0000

$.5409 \mathrm{E}-07$

$.5759 \mathrm{E}-09$

$.6045 \mathrm{E}-16$

.0000

$.3783 E-06$

$.4189 \mathrm{E}-19$

$.8138 \mathrm{E}-08$

$.9877 \mathrm{E}-14$

$.6668 \mathrm{E}-21$

.0000
.0000

.0000

.0000

.0000

.0000

.0000

.0000

.0000

.0000

.0000

.0000

.0000

.0000

.0000

.0000

.0000

.0000

.0000

.0000

.0000

.0000

.0000

.0000

.0000

.0000

.0000

.0000

.0000

.0000

.0000 
MATERIAL BALANCE TABLES

Date 09/80/82 Rev 09

\section{SLCDGE-ONLY FEED}

STREAMS (CONT'D)-

STREAM NAME

47 Y203

100 Zeolite

$44 \mathrm{Zn}(\mathrm{COOH}) 2$

$54 \mathrm{Zn}(\mathrm{OH}) 2$

$57 \mathrm{ZnO}$

$104 \mathrm{Zr} 02$

TOTAL FL.OH, LB/IIR

VAPOR FLOW, CFM

LIQUID FLOH, GPM

DESIG. FLOH,

DE.ISISY, LBS/FTS

TIMPERATLRE, DEG C

PRESSURE, ATM

PRESSLIRE, PSIG

PRESSIRE, IM HG

PHASE

EXTHALIY, PCU/HR
69

Iig Feed to MASC

.0000

$.3466 \mathrm{E}-06$

. 4310E-07

$.8615 \mathrm{E}-20$

.0000

.2ก83E-09

1.90

.00

315.0483

88.00

2.36

19.99

LIQUID

11.93
71

HNO3 Wash

to MASC

.0000

.0000

.0000

.0000

.0000

.0000

.25

.00

65.0373

25.00

1.34

5.00

LIQUID

5.84
72

HNO3 Vinsh

from MASC

.0000

. 3458E-06

$.4300 \mathrm{E}-07$

$.8606 \mathrm{E}-20$

.0000

$.2975 \mathrm{E}-09$

.51

.00

63.9048

88.00

1.00

.00

LIQUID

18.73
73

$\mathrm{NaOH}$ to

SWT

.0000

.0000

.0000

.0000

.0000

.0000

.17

.00

84.9613

25.00

1.00

.00

LIQUED

2.91 
DPSP $80-1033$

MATERIAL BALANCE TABLES

SLUDGL-ONLY FEED

STREAM NUMBERS -

STREAM NAME

COMPONENT FLOHS, LB/HR

$\begin{array}{rl}1 & H 20 \\ 45 & \mathrm{Ag} \\ 116 & \mathrm{Ag} 20 \\ 134 & \mathrm{Ag} N\end{array}$

$51 \mathrm{AgOH}$

74 Al $(\mathrm{OH}) \mathrm{S}$

77 A 1203

$75 \mathrm{AlOOH}$

$106 \mathrm{~B} 203$

$9 \mathrm{Ba}(\mathrm{NO3}) 2$

$95 \mathrm{BaCl} 2$

$15 \mathrm{BaO}$

$24 \mathrm{BaSO} 4$

$66 \mathrm{CO}$

$87 \mathrm{CO2}$

$142 \mathrm{CO2}(\mathrm{C} 14)$

$63 \mathrm{Ca}(\mathrm{COOH}) 2$

$120 \mathrm{Ca}(\mathrm{OH}) 2$

$113 \mathrm{Ca} 3(\mathrm{PO} 4) 2$

$20 \mathrm{CaC2O4}$

$18 \mathrm{CaCO} 3$

$78 \mathrm{CaF} 2$

$41 \mathrm{CaO}$

$19 \mathrm{CaSO4}$

29 Carbon

$26 \mathrm{Co}(\mathrm{COOH}) 2$

$121 \mathrm{Co}(\mathrm{OH}) 2$

$53 \mathrm{Co}(\mathrm{OH}) 3$

$69 \mathrm{CoO}$

$99 \mathrm{Cr}(\mathrm{OH}) 3$

98 Cr203

$42 \mathrm{Cs} 20$

137 Cs20 Semi Vol

$90 \mathrm{CsCOOH}$

$96 \mathrm{CsCl}$

$186 \mathrm{CsCl}$ Semi Vol

8 CsN03

88 CsResin

$122 \mathrm{Cu}(\mathrm{COOH}) 2$

$52 \mathrm{Cu}(\mathrm{OH}) 2$

58 Cu20

$64 \mathrm{CuCOOH}$

$180 \mathrm{CuO}$

$13 \mathrm{Fe}(\mathrm{OH}) \mathrm{s}$

$80 \mathrm{Fe} 203$
74

Neut Hg Wiash to SME

1.357

.0000

.0000

.0000

$.2233 E-01$

.2063E-04

.0000

.0000

$.2699 \mathrm{E}-\mathrm{CS}$

$.2710 \mathrm{E}-12$

.0000

.0000

.2449E-06

.0000

$.2084 \mathrm{E}-13$

$.8691 E-32$

$.8496 \mathrm{E}-05$

$.6345 \mathrm{E}-18$

$.6103 E-0 G$

$.6601 E-0 S$

.0000

$.1650 \mathrm{E}-06$

.0000

$.7754 \mathrm{E}-0 \mathrm{~S}$

$.1650 \mathrm{E}-0 \mathrm{G}$

.1342E-0S

. 1098E-19

.0000

.0000

$.6274 \mathrm{E}-06$

.0000

$.2473 E-11$

.0000

.0000

$.1591 \mathrm{E}-11$

.0000

$.1788 \mathrm{E}-07$

.0000

$.2866 \mathrm{E}-03$

.2388E-19

.0000

.0000

.0000

$.4994 \mathrm{E}-04$

.0000
Appendix II

Table 21-15

Page 074 of 173

Date 09/30/82 Rev 09
75

Wisshed $\mathrm{Hg}$

from MASC

.1159E-02

$.1929 \mathrm{E}-05$

.0000

$.4921 \mathrm{E}-05$

.1029E-10

$.2894 \mathrm{E}-08$

.0000

.0000

$.3786 \mathrm{E}-10$

$.8801 \mathrm{E}-16$

.0000

.0000

$.3435 E-10$

.0000

$.3516 \mathrm{E}-17$

$.1463 \mathrm{E}-35$

$.1192 \mathrm{E}-08$

$.8900 \mathrm{E}-22$

$.8561 E-10$

$.9259 \mathrm{E}-10$

.0000

$.2315 \mathrm{E}-10$

.0000

$.1088 \mathrm{E}-09$

$.2315 E-10$

$.1882 \mathrm{E}-10$

$.1540 E-28$

.0000

.0000

$.8800 \mathrm{E}-10$

.0000

$.3468 \mathrm{E}-15$

.0000

.0000

$.2232 E-15$

.0000

$.2438 \mathrm{E}-11$

.0000

$.4019 \mathrm{E}-10$

$.3349 E-23$

.0000

.0000

.0000

$.7004 \mathrm{E}-08$

.0000

76

Hg Feed

to MNTIC 
MATERIAL BALANCE TABLES

Date 09/30/82 Rev 09

\section{SLIDGE-0:ILY FEED}

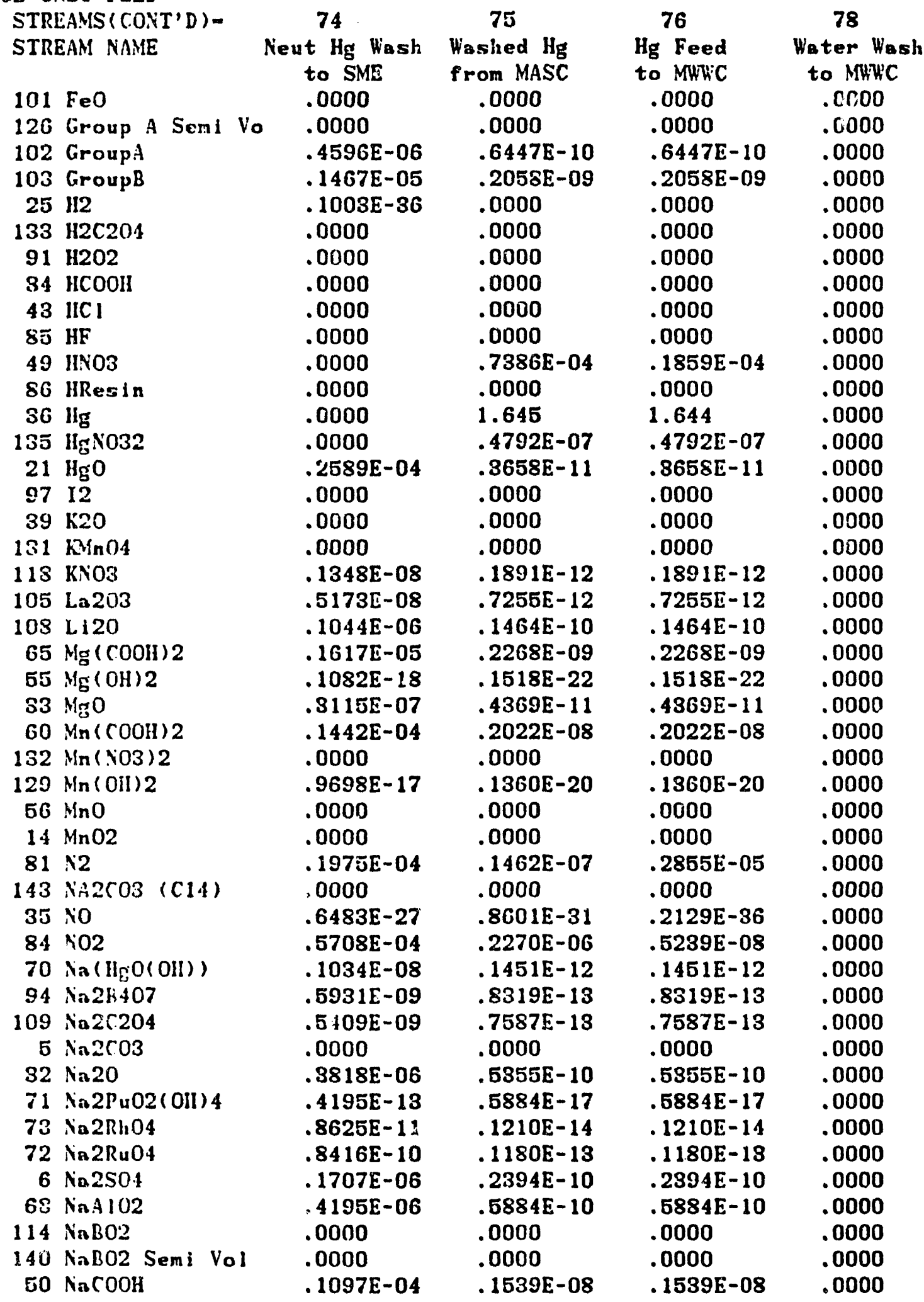


DPSP $80-1033$

Material baLANCE TABLES

SLLIDGE-ONLY FEED

STREAMS (CONT'D)STREAM NAME

$7 \mathrm{NaCl}$

$188 \mathrm{NnCl}$ Semi Vol

$69 \mathrm{NaF}$

139 NinF Semi Vol

$12 \mathrm{Ni} I$

$125 \mathrm{NaI}$ Semi Vol

$8 \mathrm{NaNO2}$

$2 \mathrm{NaN03}$

$4 \mathrm{NaOH}$

87 NaResin

$61 \mathrm{Ni}(\mathrm{COOH}) 2$

$17 \mathrm{Ni}(\mathrm{OII}) 2$

40 NiO

8202

$67 \mathrm{PbO}$

$28 \mathrm{PbSO4}$

$124 \mathrm{Pd}$

$123 \mathrm{Pd}(\mathrm{OH}) 2$

112 PdNO32

$110 \mathrm{PdO}$

$117 \mathrm{Pu}(\mathrm{COOH}) 4$

$76 \mathrm{Pu} 02$

$22 \mathrm{RhO2}$

79 Ru02

23 Ru02 Semi Vol

$83 \mathrm{RuO4}$

$88 \mathrm{SO2}$

$111 \mathrm{SiO2}$

115 Silica Gel

$48 \mathrm{Sr}$ (COOII) 2

$10 \mathrm{Sr}(\mathrm{NO3}) 2$

$127 \mathrm{Sr}(\mathrm{OH}) 2$

$80 \mathrm{SrCO3}$

$46 \mathrm{Sr} 0$

89 SrRESIN

141 Surfactant

$92 \mathrm{Th} 02$

$107 \mathrm{ri02}$

119 Tritium

93 v02

$62 \mathrm{V02}(\mathrm{COOH}) 2$

$16 \mathrm{VO} 2(\mathrm{OH}) 2$

$27 \mathrm{Y}(\mathrm{COOH}) \mathrm{S}$

$11 \mathrm{Y}(\mathrm{NOS}) 3$

$128 \mathrm{Y}(\mathrm{OH}) 8$

81 Y2(C.03)3
74

Neut Hg Wash

to SME

$.1701 \mathrm{E}-06$

.0000

$.8899 \mathrm{E}-09$

.0000

$.1648 \mathrm{E}-07$

.0000

.0000

$.7842 \mathrm{E}-01$

$.4999 \mathrm{E}-01$

.0000

$.5084 \mathrm{E}-05$

$.4157 \mathrm{E}-18$

.0000

$.1160 \mathrm{E}-04$

.0000

.2305E-06

.0000

.0000

.0000

.0000

.0000

.5999E-07

.2292E-07

. 1123E-00

.0000

.0000

$.2861 E-36$

$.1070 \mathrm{E}-04$

.0000

.2065E-06

$.2418 \mathrm{E}-12$

$.1854 \mathrm{E}-19$

.0000

.0000

.0000

.0000

$.9404 \mathrm{E}-06$

$.1001 \mathrm{E}-07$

$.3285 \mathrm{E}-15$

.0000

$.6576 \mathrm{E}-05$

$.7283 \mathrm{E}-18$

$.1415 \mathrm{E}-06$

$.1717 E-12$

$.1159 \mathrm{E}-19$

.0000
Appendix 11

Table 21-15

Page 076 of 173

Date 09/30/82 Rev 09

75

Viashed $\mathrm{Hg}$

from MASC

$.2386 \mathrm{E}-10$

.0000

$.1248 \mathrm{E}-12$

.0000

$.2311 E-11$

.0000

.0000

$.8374 \mathrm{E}-09$

.0000

.0000

$.7132 \mathrm{E}-09$

$.5830 \mathrm{E}-22$

.0000

$.8582 \mathrm{E}-08$

.0000

$.8233 \mathrm{E}-10$

.0000

.0000

.0000

.0000

.0000

$.8414 \mathrm{E}-11$

$.3215 \mathrm{E}-11$

$.1575 E-10$

.0000

.0000

.0000

$.1500 \mathrm{E}-08$

.0000

$.2896 \mathrm{E}-10$

$.8392 \mathrm{E}-16$

.2600E-23

.0000

.0000

.0000

.0000

$.1319 \mathrm{E}-09$

$.1404 \mathrm{E}-11$

$.1474 E-18$

.0000

.9224 E-09

$.1021 \mathrm{E}-21$

$.1984 \mathrm{E}-10$

$.2408 \mathrm{E}-16$

$.1626 \mathrm{E}-23$

.0000
76

78

Hg Feed

to $\mathrm{MIHTC}$

$.2386 \mathrm{E}-10$

.0000

$.1248 E-12$

.0000

$.2311 E-11$

.0000

.0000

$.8374 \mathrm{E}-09$

.0000

.0000

$.7132 \mathrm{E}-\mathrm{n} 9$

$.5830 \mathrm{E}-22$

.0000

$.1676 E-05$

.0000

$.3233 E-10$

.0000

.0000

.0000

.0000

.0000

$.8414 \mathrm{E}-11$

$.3215 E-11$

$.1575 \mathrm{E}-10$

.0000

.0000

.0000

$.1500 \mathrm{E}-08$

.0000

$.2896 E-10$

. $3392 E-16$

$.2600 E-23$

.0000

.0000

.0000

.0000

$.1319 \mathrm{E}-09$

$.1404 \mathrm{E}-11$

$.7404 \mathrm{E}-19$

.0000

$.0224 \mathrm{E}-09$

$.1021 \mathrm{E}-21$

$.1984 \mathrm{E}-10$

$.2108 \mathrm{E}-16$

$.1626 E-23$

.0000
Hinter Hasia

to MHiC

. joco

.0000

.0000

.0000

.0000

.0000

.0000

.0000

.0000

.0000

.0000

.0000

.0000

.0000

.0000

.0000

.0000

.0000

.0000

.0000

.0000

.0000

.0000

.0000

.0000

.0000

.0000

.0000

.0000

.0000

.0000

.0000

.0000

.0000

.0000

.0000

.0000

.0000

.0000

.0000

.0000

.0000

.0000

.0000

.8000

.0000 
MATER I. Bal. BANC tables

\section{SLUDGE-ONLY FEED}

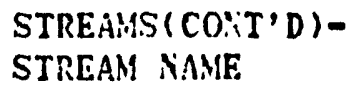

$47 Y 203$

100 Zeolite

$44 \mathrm{Zn}($ COOII $) 2$

$54 \mathrm{Zn}$ (Oli) 2

$57 \mathrm{ZnO}$

$104 \mathrm{ZrO2}$

TOTAL FLOW, LB/HR

VAPOR FLOH', CFM

LIQUID FLOH, GPM

DESIGN FLOH,

DENSITY, LBS/FT3

TEYPERITURE, DEG C

PRESSURE, ATM

PRESSURE, PSIG

PIESSIRE, IDI IIG

PIIASE

EXIIIALYY, PCL/HR
74

Neut Hg Wash to SME

.0000

$.6012 E-05$

$.7475 E-06$

$.6269 \mathrm{E}-19$

.0000

$.5173 E-08$

1.51

.00

66.3062

$\mathbf{8 8 . 0 0}$

.99

$-.07$

756.20

LIQUID

54.50
75

Washed Hg

from MASC

.0000

$.8432 E-09$

$.1048 \mathrm{E}-09$

$.8793 \mathrm{E}-28$

.0000

$.7255 \mathrm{E}-12$

1.65

.00

837.9657

38.00

1.00

.00

LIQUID

2.10
76

Hg Feed

to MuWC

.0000

$.8432 \mathrm{E}-09$

$.1048 \mathrm{E}-09$

$.8793 \mathrm{E}-23$

.0000

$.7255 \mathrm{E}-12$

1.68

.00

658.3542

38.00

2.36

19.99

LIQUID

3.53
78

Water Wash to MUW'C

.0000

.0000

.0000

.0000

.0000

.0000

.24

.00

62.4300

25.00

1.84

6.00

LIQUID

6.13 
DPSP $80-1038$

MATERIAL BALANCE TABLES

SLUDCE-ONLY FEED

STREAM NUMBERS -

STREAM NAME

COMPONENT FLOHS, LB/HR

11120

$45 \mathrm{Ag}$

116 Ag20

134 AgNO3

$61 \mathrm{AgOH}$

74 Al(OH) 3

77 A 1203

75 AlOOH

106 B203

$9 \mathrm{Ba}(\mathrm{N} 03) 2$

$95 \mathrm{BaCl} 2$

$15 \mathrm{BaO}$

$24 \mathrm{BaSO} 04$

$66 \mathrm{CO}$

$37 \mathrm{CO2}$

$142 \mathrm{CO}$ ( $\mathrm{C} 14$ )

$63 \mathrm{Ca}(\mathrm{COOH}) 2$

$120 \mathrm{Ca}(\mathrm{OH}) 2$

$113 \mathrm{Ca} 3(\mathrm{PO} 4) 2$

$20 \mathrm{CaC2O4}$

$18 \mathrm{CaCO3}$

$78 \mathrm{CaF2}$

$41 \mathrm{CaO}$

$19 \mathrm{CaSO}$

29 Carbon

$26 \mathrm{Co}(\mathrm{COOII}) 2$

$121 \mathrm{Co}(\mathrm{OH}) 2$

$53 \mathrm{Co}(\mathrm{OH}) 3$

$59 \mathrm{CoO}$

$99 \mathrm{Cr}(\mathrm{OH}) 3$

$98 \mathrm{Cr} 203$

42 Cs 20

187 Cs20 Semi Vol

$90 \mathrm{CsCOOH}$

$96 \mathrm{CsCl}$

$136 \mathrm{CsCl}$ Semi Vol

$8 \mathrm{CsNO3}$

88 CsResin

$122 \mathrm{Cu}(\mathrm{COOH}) 2$

$52 \mathrm{Cu}(\mathrm{OH}) 2$

$58 \mathrm{Cu} 20$

$64 \mathrm{CuCOOH}$

$180 \mathrm{Cu} 0$

$13 \mathrm{Fe}(\mathrm{OH}) 3$

$80 \mathrm{Fe} 203$
79

Water Wash

from MWWC

.2789

.0000

.0000

$.4900 \mathrm{E}-05$

$.1024 \mathrm{E}-10$

$.2881 E-08$

.0000

.0000

$.8770 \mathrm{E}-10$

$.8785 E-16$

.0000

.0000

$.3420 \mathrm{E}-10$

.0000

$.1108 \mathrm{E}-21$

.0000

$.1187 \mathrm{E}-08$

$.8862 \mathrm{E}-22$

$.8524 E-10$

$.9219 \mathrm{E}-10$

.0000

$.2305 E-10$

.0000

$.1083 \mathrm{E}-09$

$.2305 E-10$

$.1874 \mathrm{E}-10$

$.1533 \mathrm{E}-23$

.0000

.0000

$.8762 \mathrm{E}-10$

.0000

$.8453 E-15$

.0000

.0000

$.2222 \mathrm{E}-15$

.0000

$.2427 E-11$

.0000

$.4002 E-10$

$.8334 E-23$

.0000

.0000

.0000

$.6974 E-08$

.0000
Appendix H

Table 21-15

Page 078 of 173

Date $02 / 30 / 82$ Rev 09
80

Washed $\mathrm{Hg}_{\mathrm{g}}$

from MHLC

$.1210 \mathrm{E}-02$

$.1929 \mathrm{E}-05$

.0000

$.2125 \mathrm{E}-07$

$.4442 E-13$

$.1250 \mathrm{E}-10$

.0000

.0000

$.1635 E-12$

$.1642 \mathrm{E}-18$

.0000

.0000

$.1484 \mathrm{E}-12$

.0000

$.4805 \mathrm{E}-24$

.0000

$.5147 \mathrm{E}-11$

$.3844 E-24$

$.3697 \mathrm{E}-12$

.3999E-12

.0000

$.9997 \mathrm{E}-13$

.0000

$.4697 \mathrm{E}-12$

$.9997 \mathrm{E}-13$

$.8127 \mathrm{E}-13$

$.6649 \mathrm{E}-26$

.0000

.0000

$.3800 \mathrm{E}-12$

.0000

$.1498 \mathrm{E}-17$

.0000

.0000

$.9638 \mathrm{E}-18$

.0000

. 1053E- 13

.0000

. 1736E-12.

$.1446 \mathrm{E}-25$

.0000

.0000

.0000

.3025E- 10

.0000
81

Washed $\mathrm{Hg}$ Purified $\mathrm{H}_{3}$ to MV'S

\begin{tabular}{|c|c|}
\hline $.1210 \mathrm{E}-02$ & $.12135-02$ \\
\hline . 1929E-05 & $.1920 E-03$ \\
\hline .0000 & .0000 \\
\hline $.2125 \mathrm{E}-07$ & $.2125 E-10$ \\
\hline $.4442 \mathrm{E}-13$ & $.4442 E-16$ \\
\hline $.1250 \mathrm{E}-10$ & . $1250 E-13$ \\
\hline .0000 & .0000 \\
\hline .0000 & .0000 \\
\hline . 1685E-12 & $.1635 E-15$ \\
\hline $.1642 \mathrm{E}-18$ & $.1642 E-21$ \\
\hline .0000 & .0000 \\
\hline .0000 & .0000 \\
\hline $.1484 \mathrm{E}-12$ & $.1484 E-15$ \\
\hline .0000 & .0000 \\
\hline . 4805E-24 & $.4805 \mathrm{E}-2$ \\
\hline .0000 & .0000 \\
\hline $.5147 \mathrm{E}-11$ & $.5147 E-11$ \\
\hline $.3844 \mathrm{E}-24$ & $.3844 E-27$ \\
\hline $.3697 E-12$ & $.3697 E-15$ \\
\hline $.3999 E-12$ & .3999E-15 \\
\hline .0000 & .0000 \\
\hline $.9997 E-13$ & $.9997 E-16$ \\
\hline .0000 & .0000 \\
\hline . 4697E-12 & $.4697 E-15$ \\
\hline $.9997 E-13$ & $.9997 E-16$ \\
\hline $.8127 \mathrm{E}-13$ & $.8127 \mathrm{E}-16$ \\
\hline $.6649 E-26$ & $.6649 E-29$ \\
\hline .0000 & .0000 \\
\hline .0000 & .0000 \\
\hline $.3800 E-12$ & $.8800 E-15$ \\
\hline .0000 & .0000 \\
\hline $.1498 \mathrm{E}-17$ & $.1498 \mathrm{E}-20$ \\
\hline .0000 & .0000 \\
\hline .0000 & .0000 \\
\hline $.9638 \mathrm{E}-18$ & $.9638 E-21$ \\
\hline .0000 & .0000 \\
\hline . $1053 E-13$ & $.1053 E-16$ \\
\hline .0000 & .0000 \\
\hline $.1736 \mathrm{E}-12$ & $.1736 \mathrm{E}-15$ \\
\hline $.1446 \mathrm{E}-25$ & $.1446 E-28$ \\
\hline .0000 & .0000 \\
\hline .0000 & .0000 \\
\hline .0000 & .0000 \\
\hline . 8025E-10 & $.3025 E-13$ \\
\hline .0000 & .0000 \\
\hline
\end{tabular}


DPSP $80-1033$

MATERIAL. BALANCE TABLES

\section{SLUDGE-ONLY FEED}

STREANS (CONT'D)-

STREAM NAME

$\begin{array}{ll}101 & \text { FcO } \\ 120 & \text { Group A Semi } V_{0} \\ 102 & \text { GroupA } \\ 103 & \text { Group B } \\ 25 & \mathrm{H} 2 \\ 133 & 112 \mathrm{C2O} \\ 91 & \mathrm{H} 202 \\ 84 & \mathrm{HCOOH} \\ 43 \mathrm{HCl} \\ 85 \mathrm{HF} \\ 49 \mathrm{HNO3} \\ 86 \mathrm{IRes} \text { in }\end{array}$

$36 \mathrm{Hg}$

$135 \mathrm{HgNO} 2$

$21 \mathrm{HgO}$

$97 \quad 12$

39 K20

$131 \mathrm{KMnO4}$

$118 \mathrm{KNO3}$

105 La203

103 Li 20

$65 \mathrm{Mg}(\mathrm{COOH}) 2$

$55 \mathrm{Mg}(\mathrm{OII}) 2$

33 MgO

$60 \mathrm{Min}(\mathrm{COOH}) 2$

$132 \mathrm{Mn}(\mathrm{NO3}) 2$

$129 \mathrm{Mn}(\mathrm{OH}) 2$

$56 \mathrm{MnO}$

$14 \mathrm{MnO2}$

81 N2

143 NA2COB (C14)

35 NO

$84 \mathrm{NO2}$

$70 \mathrm{Na}(\mathrm{ligO}(\mathrm{OH}))$

$94 \quad \mathrm{Na} 23407$

$109 \mathrm{Na2C204}$

$5 \mathrm{Na} 2 \mathrm{CO3}$

$32 \quad \mathrm{Na} 20$

71 Na2Pu02(OII) 4

$73 \mathrm{Na} 2 \mathrm{Rh}_{04}$

$72 \mathrm{Na} 2 \mathrm{RuO4}$

$6 \mathrm{Na} 2 \mathrm{SO} 4$

$68 \mathrm{NaAlO2}$

$114 \mathrm{NaBO2}$

140 NaBO2 Semi Vol

$50 \mathrm{NaCOOH}$
Appendix H

Tablo 21-i5

Page 079 of 173

Date 09/30/82 Rev 09

\begin{tabular}{|c|c|c|c|}
\hline $\begin{array}{l}79 \\
\text { Water Wash } \\
\text { from MUW'C }\end{array}$ & $\begin{array}{l}80 \\
\text { Washed Hg } \\
\text { from MUWC }\end{array}$ & $\begin{array}{l}81 \\
\text { Washed Ilg } \\
\text { to MVS }\end{array}$ & $\begin{array}{l}82 \\
\text { Purifled } \mathrm{Hg}\end{array}$ \\
\hline .0000 & .0000 & .0000 & .0000 \\
\hline .0000 & .0000 & .0000 & .0000 \\
\hline $.6419 E-10$ & $.2784 E-12$ & $.2784 E-12$ & $.2784 E-15$ \\
\hline .2049E-09 & $.8886 E-12$ & $.8886 \mathrm{E}-12$ & $.8886 E-15$ \\
\hline .0000 & .0000 & .0000 & .0000 \\
\hline .0000 & .0000 & .0000 & .0000 \\
\hline .0000 & .0000 & .0000 & .0000 \\
\hline .0000 & .0000 & .0000 & .0000 \\
\hline .0000 & .0000 & .0000 & .0000 \\
\hline .0000 & .0000 & .0000 & .0000 \\
\hline $.1851 E-04$ & $.8027 E-07$ & $.8027 E-07$ & $.8027 E-07$ \\
\hline .0000 & .0000 & .0000 & .0000 \\
\hline .0000 & 1.644 & 1.644 & 1.631 \\
\hline . 4772E-07 & .2070E-09 & $.2070 \mathrm{E}-09$ & $.2070 E-12$ \\
\hline $.3642 E-11$ & . 1580E-13 & $.1580 \mathrm{E}-13$ & $.1580 \mathrm{E}-16$ \\
\hline .0000 & .0000 & .0000 & .0000 \\
\hline .0000 & .0000 & .0000 & .0000 \\
\hline .0000 & .0000 & .0000 & .0000 \\
\hline . $1883 E-12$ & $.8167 E-15$ & $.8167 E-15$ & $.8167 \mathrm{E}-18$ \\
\hline $.7224 \mathrm{E}-12$ & $3 E-14$ & $.3133 E-14$ & $38 E-17$ \\
\hline $.1458 \mathrm{E}-10$ & $.6322 E-13$ & $.6322 \mathrm{E}-13$ & $.6322 E-16$ \\
\hline .2259E-09 & $.9797 E-12$ & $.9797 E-12$ & $.9797 E-15$ \\
\hline $.1511 E-22$ & $.6555 \mathrm{E}-25$ & $.6555 \mathrm{E}-25$ & $.6555 E-28$ \\
\hline . 4350E-11 & $.1887 E-18$ & $.1887 E-13$ & $.1887 E-16$ \\
\hline .2014E-08 & $.8734 E-11$ & $.8734 \mathrm{E}-11$ & $.8784 \mathrm{E}-14$ \\
\hline .0000 & .0000 & .0000 & .0000 \\
\hline $.1354 \mathrm{E}-20$ & $.6875 E-23$ & $.5875 E-23$ & $.5875 E-26$ \\
\hline .0000 & & .0000 & \\
\hline .0000 & .000 & .0000 & \\
\hline . 2843E-05 & $3 E-07$ & . 1283E-07 & $3 E-07$ \\
\hline .000 & & .00 & .0000 \\
\hline . 2129E-36 & .0000 & .0000 & .0000 \\
\hline $.5216 E-08$ & $.2262 \mathrm{E}-10$ & $.2262 \mathrm{E}-10$ & $.2262 E-10$ \\
\hline $1445 \mathrm{E}-12$ & $.6266 \mathrm{E}-15$ & $.6266 \mathrm{E}-15$ & $.6266 \mathrm{E}-18$ \\
\hline $.8283 E-13$ & $.8593 E-15$ & .3593E-15 & $.8593 E-18$ \\
\hline $.7555 E-13$ & $.3277 E-15$ & $.3277 E-15$ & $.8277 E-18$ \\
\hline .0000 & .0000 & .0000 & .0000 \\
\hline $.5332 E-10$ & $.2313 E-12$ & $.2313 E-12$ & $.2313 E-15$ \\
\hline$E-17$ & $41 E-19$ & $.2541 E-19$ & $.2541 \mathrm{E}-22$ \\
\hline $.1205 E-14$ & $.5225 E-17$ & $.5225 E-17$ & . $6225 \mathrm{E}-20$ \\
\hline $.1175 E-13$ & $.5098 E-16$ & $.5098 E-16$ & $.5098 E-19$ \\
\hline $.2384 \mathrm{E}-10$ & $.1034 \mathrm{E}-12$ & $.1034 \mathrm{E}-12$ & $.1034 \mathrm{E}-15$ \\
\hline . 5859E-10 & $.2541 \mathrm{E}-12$ & $.2541 E-12$ & $.2541 \mathrm{E}-15$ \\
\hline .0000 & .0000 & .0000 & .0000 \\
\hline .0000 & .0000 & .0000 & .0000 \\
\hline 15325 & $.6648 \mathrm{E}$ & $.6648 \mathrm{E}-11$ & $.6648 \mathrm{E}$ \\
\hline
\end{tabular}


DPSP $80-1033$

MATERIAL BALANCE TABLES

SLLDGE-ONLX FEED

STREAMS (CONT'D)-

STREAM NAME

$7 \mathrm{NaCl}$

$138 \mathrm{NaCl}$ Semi Vol

$69 \mathrm{NaF}$

139 NaF Semi Vol

$12 \mathrm{NaI}$

$125 \mathrm{NaI}$ Semi Vol

$8 \mathrm{NaNO2}$

$2 \mathrm{NaNO3}$

$4 \mathrm{NaOH}$

87 NaResin

$61 \mathrm{Ni}(\mathrm{COOHI}) 2$

$17 \mathrm{Ni}(\mathrm{OHI}) 2$

$40 \mathrm{NiO}$

8202

$67 \mathrm{PbO}$

$28 \mathrm{PbS04}$

$124 \mathrm{Pd}$

$123 \mathrm{Pd}(\mathrm{OH}) 2$

112 PdNO32

$110 \mathrm{PdO}$

$117 \mathrm{Pu}(\mathrm{COOH}) 4$

$76 \mathrm{PuO2}^{2}$

$22 \mathrm{RhO2}$

$79 \mathrm{Ru} 02$

23 Ru02 Semi Vol

$83 \mathrm{Ru} 04$

$88 \mathrm{SO2}$

$111 \mathrm{SiO} 2$

115 Silica Gel

$48 \mathrm{Sr}(\mathrm{COOHI}) 2$

$10 \mathrm{Sr}(\mathrm{NO3}) 2$

$127 \mathrm{Sr}(\mathrm{OH}) 2$

$80 \mathrm{SrCO}$

$46 \mathrm{SrO}$

89 SrRESIN

141 Surfactant

$92 \mathrm{ThO2}$

107 TiO2

119 Tritium

$98 \mathrm{VO2}$

$62 \mathrm{VO} 2(\mathrm{COOH}) 2$

$16 \mathrm{VO} 2(\mathrm{OH}) 2$

$27 \mathrm{Y}(\mathrm{COOH}) 3$

$11 Y(N 03) 8$

$128 Y(\mathrm{OH}) \mathrm{S}$

$81 \mathrm{Y} 2(\mathrm{CO} 3) 3$
Appendix H

Table 21-15

Puge 080 of 173

Date 09/30/82 Rev 09 $\begin{array}{cccr}79 & 80 & 81 & 82\end{array}$

from MNHIC from MWiC

$.2376 E-10$

.0000

$.1243 E-12$

.0000

$.2301 \mathrm{E}-11$

.0000

.0000

$.8338 \mathrm{E}-09$

.0000

.0000

$.7101 \mathrm{E}-09$

$.5805 \mathrm{E}-22$

.0000

$.1669 \mathrm{E}-05$

.0000

$.3219 \mathrm{E}-10$

.0000

.0000

.0000

.0000

.0000

$.8377 \mathrm{E}-11$

$.3201 \mathrm{E}-11$

$.1568 \mathrm{E}-10$

.0000

.0000

.0000

$.1494 \mathrm{E}-08$

.0000

$.2883 \mathrm{E}-10$

.3377E-16

$.2589 E-23$

.0000

.0000

.0000

.0000

.1313E-09

$.1398 E-11$

$.7372 E-19$

.0000

$.9184 \mathrm{E}-09$

$.1017 \mathrm{E}-21$

$.1976 E-10$

$.2398 E-16$

$.1619 E-23$

.0000
.1031E- 12

.0000

$.5391 E-15$

.0000

$.9982 E-14$

.0000

.0000

.3617 F-11

.0000

.0000

.8080E-11

$.2518 \mathrm{E}-24$

.0000

$.7240 \mathrm{E}-08$

.0000

$.1896 \mathrm{E}-12$

.0000

.0000

.0000

.0000

.0000

$.8634 \mathrm{E}-13$

$.1388 \mathrm{E}-13$

$.6801 E-13$

.0000

.0000

.0000

$.6479 E-11$

.0000

$.1251 \mathrm{E}-12$

$.1465 \mathrm{E}-18$

$.1123 E-25$

.0000

.0000

.0000

.0000

$.5697 \mathrm{E}-12$

$.6065 E-14$

$.3198 E-21$

.0000

$.3984 \mathrm{E}-11$

$.4412 E-24$

$.8570 \mathrm{E}-13$

$.1040 \mathrm{E}-18$

$.7022 E-26$

.0000
Vashed Hg Purified II to MVS

$.1031 E-12.10315-15$

$.0000 \quad .0000$

$.5391 \mathrm{E}-15 \quad .5391 \mathrm{E}-18$

$.0000 \quad .0000$

$.9982 \mathrm{E}-14 \quad .9982 \mathrm{E}-\mathrm{i} 7$

$.0000 \quad .0000$

$.0000 \quad .0000$

$.3617 E-11 \quad .3617 E-14$

$.0000 \quad .0000$

$.0000 \quad .0000$

$.3080 \mathrm{E}-11 \quad .3080 \mathrm{E}-14$

$.2518 \mathrm{E}-24 \quad .2518 \mathrm{E}-27$

$.0000 \quad .0000$

$.7240 \mathrm{E}-08$.7240E-08

$.0000 \quad .0000$

$.1396 \mathrm{E}-12 \quad .1396 \mathrm{E}-15$

$.0000 \quad .0000$

$.0000 \quad .0000$

$.0000 \quad .0000$

$.0000 \quad .0000$

$.0000 \quad .0000$

$.3634 \mathrm{E}-13 \quad .3634 \mathrm{E}-16$

$.1388 \mathrm{E}-13 \quad .1388 \mathrm{E}-16$

$.6801 \mathrm{E}-13 \quad .6801 \mathrm{E}-16$

$.0000 \quad .0000$

$.0000 \quad .0000$

$.0000 \quad .0000$

$.6479 \mathrm{E}-11 \quad .6479 \mathrm{E}-14$

$.0000 \quad .0000$

$.1251 \mathrm{E}-12$.1251E-15

$.1465 E-18$.1465E-21

$.1123 \mathrm{E}-25 \quad .1123 \mathrm{E}-28$

.0000

.0000

.0000

.0000

$.5697 E-12$

$.6065 \mathrm{E}-14$

$.3198 E-21$

.0000

$.3984 \mathrm{E}-11$

$.4412 \mathrm{E}-24$

$.8570 E-13$

$.1040 E-18$

$.7022 E-26$

.0000
.0000

.0000

.0000

.0000

$.5697 E-15$

$.6065 E-17$

$.3198 E-21$

.0000

$.3984 E-14$

$.4412 E-27$

$.8570 \mathrm{E}-16$

$.1040 \mathrm{E}-21$

$.7022 E-29$

.0000 
MATERIAL BALANCE TABLES

Date 09/30/82 Rev 09

SLUDGE-ONLY FEED

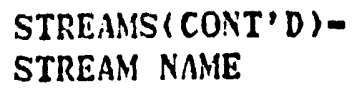

47 Y203

100 Zeollte

$44 \mathrm{Zn}(\mathrm{COOH}) 2$

$54 \mathrm{Zn}(\mathrm{OII}) 2$

$57 \mathrm{ZnO}$

$104 \mathrm{ZrO2}$

TOTAL FLOW, LB/HR

VAPOR FLOW, CFM

LIQUID FLOH, GPM

DESIGN FLOW',

DE:SSITY, LBS/FT3

TLYPERATURE, DEG C

PRESSURE, ATM

PRESSURE, PSIG

PRESSURE, MM HG

PIIASE

ENTHALPY, PCV/IIR

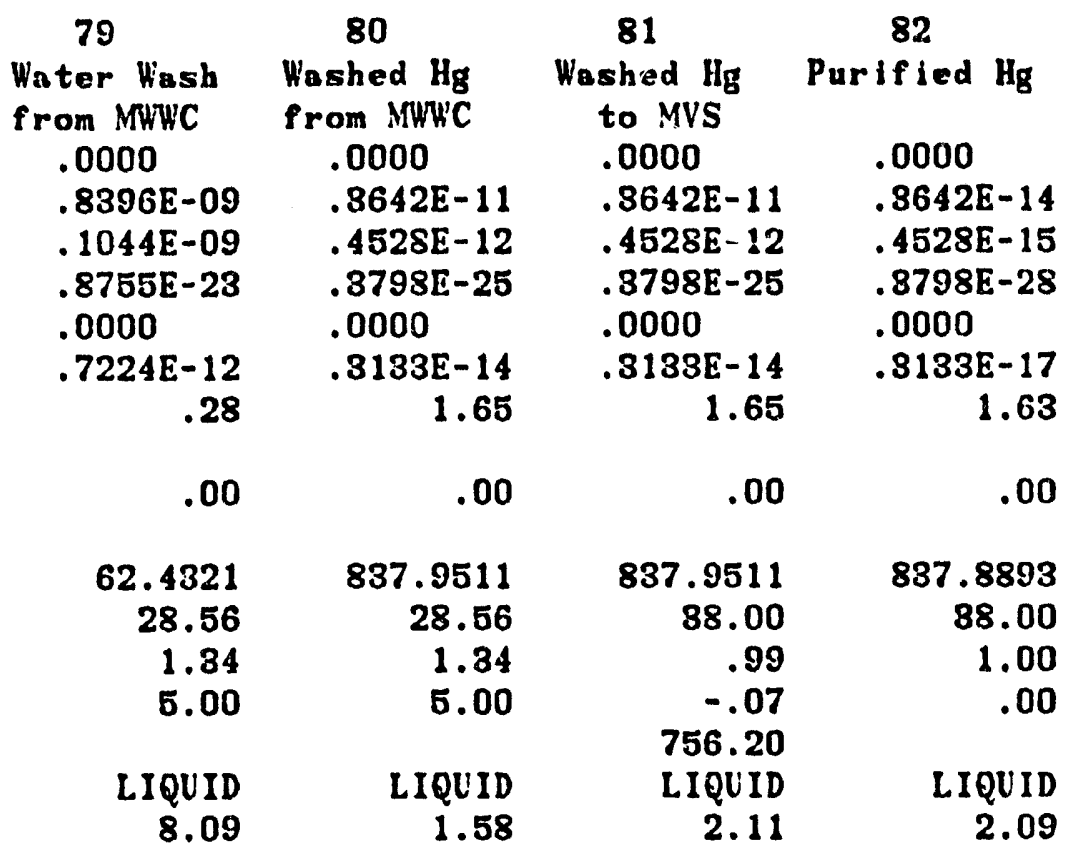


DPSP $80-1033$

MATERIAL BALANCE TABLES

SLUDCE-ONLY FEED

STREAM NLMBERS -

STREAM NAME

COMPONENT FLOWS, LB/HR

1 H2O

$45 \mathrm{Ag}$

116 Ag20

134 AgNO3

51 AgOlI

74 All (Oll) 3

77 A 1203

75 A $100 \mathrm{H}$

106 B203

$9 \mathrm{Ba}(\mathrm{NO3}) 2$

$95 \mathrm{BaCl} 2$

$15 \mathrm{BaO}$

$24 \mathrm{BaSO} 4$

$66 \mathrm{CO}$

$87 \mathrm{CO} 2$

$142 \mathrm{CO}$ ( $\mathrm{C} 14)$

$63 \mathrm{Ca}(\mathrm{COOH}) 2$

$120 \mathrm{Ca}(\mathrm{OHI}) 2$

$113 \mathrm{Ca3}(\mathrm{PO}) 2$

$20 \mathrm{CaC2O4}$

$18 \mathrm{CaCO3}$

$78 \mathrm{CaF2}$

$41 \mathrm{CaO}$

$19 \mathrm{CaSO4}$

29 Carbon

$26 \mathrm{Co}(\mathrm{COOHI}) 2$

$121 \mathrm{Co}(\mathrm{OH}) 2$

$53 \mathrm{Co}(\mathrm{OHI}) \mathrm{3}$

$59 \mathrm{CoO}$

$99 \mathrm{Cr}(\mathrm{Oll}) \mathrm{s}$

98 Cr203

42 Cs20

187 Cs20 Semi Vol

$90 \mathrm{CsCOOH}$

$96 \mathrm{CsCl}$

$136 \mathrm{CsCl}$ Semi Vol

8 CsNO3

88 CsResin

$122 \mathrm{Cu}(\mathrm{COOH}) 2$

$52 \mathrm{Cu}(\mathrm{OH}) 2$

$58 \mathrm{Cu} 20$

$64 \mathrm{CuCOOH}$

$180 \mathrm{CuO}$

$13 \mathrm{Fe}(\mathrm{OH}) 3$

$80 \mathrm{Fe} 203$
83

Purlfied Hg

$.1210 \mathrm{E}-02$

. 1929E-08

.0000

$.2125 E-10$

$.4442 E-16$

$.1250 E-13$

.0000

.0000

$.1635 \mathrm{E}-15$

$.1642 E-21$

.0000

.0000

$.1484 \mathrm{E}-15$

.0000

$.4805 E-24$

.0000

$.5147 E-14$

$.3844 E-27$

.8697E- 15

$.3999 E-15$

.0000

$.9997 \mathrm{E}-16$

.0000

$.4697 \mathrm{E}-15$

$.9997 \mathrm{E}-16$

$.8127 E-16$

$.6649 \mathrm{E}-29$

.0000

.0000

$.3800 E-15$

.0000

$.1498 \mathrm{E}-20$

.0000

.0000

$.9638 \mathrm{E}-21$

.0000

. 1053E- 16

.0000

$.1786 E-15$

$.1446 \mathrm{E}-28$

.0000

.0000

.0000

$.3025 \mathrm{E}-13$

.0000
Appendix H

Iitble 21-15

Page $0 S 2$ of 173

Date 09/30/82 Rev 09
$84 \quad 85$

PVVF Exhaust Sand Filter

to Ex Tunnel Condensate

24.99

$.1547 \mathrm{E}-10$

.0000

$.2539 \mathrm{E}-10$

$.4848 \mathrm{E}-11$

$.5799 E-09$

.0000

.0000

$.2201 \mathrm{E}-08$

$.7609 \mathrm{E}-17$

.0000

.0000

$.6877 \mathrm{E}-11$

$.4639 \mathrm{E}-04$

10.94

$.1072 \mathrm{E}-09$

$.2383 \mathrm{E}-09$

$.1600 \mathrm{E}-12$

$.1714 \mathrm{E}-10$

$.1854 E-10$

.0000

$.4634 E-11$

.0000

$.2177 \mathrm{E}-10$

$.4634 \mathrm{E}-11$

$.8763 \mathrm{E}-08$

$.2768 \mathrm{E}-14$

.0000

.0000

$.1762 \mathrm{E}-10$

.0000

$.9015 E-16$

.0000

.0000

.2919E- 14

.0000

$.4881 \mathrm{E}-12$

.0000

$.8037 \mathrm{E}-11$

$.6022 \mathrm{E}-14$

.0000

.0000

.0000

$.1404 \mathrm{E}-08$

.0000
15.80

.0000

.0000

.0000

.0000

.0000

.0000

.0000

.0000

.0000

.0000

.0000

.0000

.0000

.0000

.0000

.0000

.0000

.0000

.0000

.0000

.0000

.0000

.0000

.0000

.0000

.0000

.0000

.0000

.0000

.0000

.0000

.0000

.0000

.0000

.0000

.0000

.0000

.0000

.0000

.0000

.0000

.0000

.0000

.0000
86

Fan llous:

Condensate

13.80

.0000

.0000

.0000

.0000

.0000

.0000

.0000

.0000

.0000

.0000

.0000

.0000

.0000

.0000

.0000

.0000

.0000

.0000

.0000

.0000

.0000

.0000

.0000

.0000

.0000

.0000

.0000

.0000

.0000

.0000

.0000

.0000

.0000

.0000

.0000

.0000

.0000

.0000

.0000

.0000

.0000

.0000

.0000

.0000 
MITERIAL BALANCE TABLES

\section{SLUDCE-ONLY FEED}

STREAMS (CONT'D)STREAM NAME

$101 \mathrm{FeO}$

126 Group A Semi Vo

102 GroupA

103 GroupB

$25 \mathrm{HI} 2$

133 II2C204

9111202

$84 \mathrm{HCOOH}$

$43 \mathrm{IICl}$

$85 \mathrm{HF}$

49 HNO3

SC llkesin

$86 \mathrm{Hg}$

$135 \mathrm{Hg}_{\mathrm{g}} \mathrm{O} 32$

$21 \mathrm{HgO}$

97 I2

89 К20

$131 \mathrm{KMnO4}$

$118 \mathrm{KNO}$

$105 \mathrm{La} 203$

$108 \mathrm{Li} 20$

$65 \mathrm{Mg}(\mathrm{COOH}) 2$

$55 \mathrm{Mg}(\mathrm{OH}) 2$

83 YgO

$60 \mathrm{Mn}(\mathrm{COOH}) 2$

$132 \mathrm{Mn}(\mathrm{NO3}) 2$

$129 \mathrm{Mn}(\mathrm{OII}) 2$

$56 \mathrm{MnO}$

$14 \mathrm{MnO2}$

$81 \quad \mathrm{~N} 2$

$143 . \mathrm{NA2CO3}(\mathrm{Cl} 14)$

35 i0

$84 \mathrm{N02}$

$70 \mathrm{Na}(\mathrm{HgO}(\mathrm{OII}))$

$94 \quad \mathrm{Na} 2 \mathrm{~B} 407$

$109 \mathrm{Na} 2 \mathrm{C} 204$

$5 \mathrm{~N} 22 \mathrm{CO}$

$32 \mathrm{~N} 20$

$71 \mathrm{Na} 2 \mathrm{Pu}_{\mathrm{u}} 02(\mathrm{OII}) 4$

$73 \mathrm{Na} 2 \mathrm{RhO4}$

$72 \mathrm{Na}_{2} \mathrm{RuO4}_{4}$

$6 \mathrm{Nin} 2 \mathrm{SO4}$

$68 \mathrm{Nan} 102$

$114 \mathrm{NaEO2}$

140 NoBU2 Semi Vol

$50 \mathrm{NaCOOII}$
83

Purlfied $\mathrm{Hg}$

.0000

.0000

$.2784 \mathrm{E}-15$

$.8886 \mathrm{E}-15$

.0000

.0000

.0000

.0000

.0000

.0000

.8027 E- 07

.0000

1.631

.207CE-12

$.1580 \mathrm{E}-16$

.0000

.0000

.0000

$.8167 E-18$

$.3133 \mathrm{E}-17$

$.6322 \mathrm{E}-16$

$.9797 E-15$

$.6555 \mathrm{E}-28$

$.1887 \mathrm{E}-16$

$.8734 \mathrm{E}-14$

.0000

$.5875 \mathrm{E}-26$

.0000

.0000

. 1233E-07

.0000

.0000

.2262E-10

$.6266 \mathrm{E}-18$

.3593E- 18

$.8277 \mathrm{E}-18$

.0000

.2313E- 15

.254 1E-22

.5225E-20

.5098E-19

$.1034 \mathrm{E}-15$

$.2541 E-15$

.0000

.0000

$.6648 E-14$
84

PVVF Exhaust Sand Filter

to Ex Tunnel

.0000

.0000

$.1300 \mathrm{E}-10$

$.4119 E-10$

$.8156 \mathrm{E}-05$

.0000

.0000

$.6663 \mathrm{E}-01$

.0000

.0000

.0000

.0000

.3797E-03

$.1589 \mathrm{E}-18$

$.1312 \mathrm{E}-12$

.0000

.0000

.0000

$.7204 E-11$

$.7472 E-10$

$.8584 \mathrm{E}-09$

$.4536 E-10$

$.2729 \mathrm{E}-13$

$.2993 E-09$

$.4044 \mathrm{E}-09$

.0000

$.6598 \mathrm{E}-11$

.0000

.0000

1292.

.0000

1.259

$.1835 E-01$

$.2905 E-13$

$.1088 \mathrm{E}-11$

$.2891 E-11$

.0000

.2652E-08

$.1178 \mathrm{E}-17$

$.2422 E-15$

.2363E-14

$.4792 E-11$

$.1178 \mathrm{E}-10$

.0000

.0000

. 3803E-09

\section{Condensate} .0000

.0000

.0000

.0000

.0000

.0000

.0000

.0000

.0000

.0000

.0000

.0000

.0000

.0000

.0000

.0000

.0000

.0000

.0000

.0000

.0000

.0000

.0000

.0000

.0000

.0000

.0000

.0000

.0000

.0000

.0000

.0000

.0000

.0000

.0000

.0000

.0000

.0000

.0000

.0000

.0000

.0000

.0000

.0000

.0000

.0000
86

Fan House

Condensate .0000

.0000

.0000

.0000

.0000

.0000

.0000

.0000

.0000

.0000

.0000

.0000

.0000

.0000

.0000

.0000

.0000

.0000

.0000

.0000

.0000

.0000

.0000

.0000

.0000

.0000

.0000

.0000

.0000

.0000

.0000

.0000

.0000

.0000

.0000

.0000

.0000

.0000

.0000

.0000

.0000

.0000

.0000

.0000

.0000

.0000 
DPSP $80-1083$

MATERIAL BALANCE TABLES

SLUDGE-ONLY FEED STREAMS (CONT'D)STREAM NAME

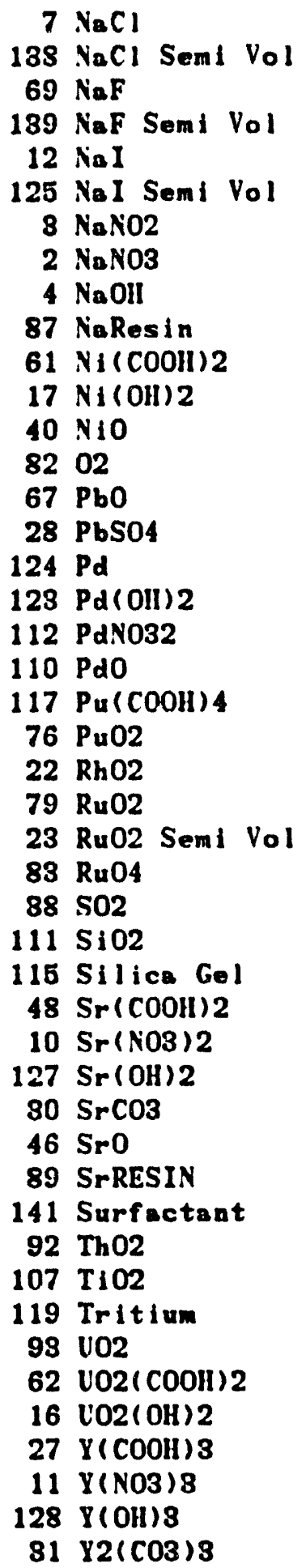

88

Purified $\mathrm{Hg}$

$.1031 \mathrm{E}-15$

.0000

$.6391 E-18$

.0000

$.9982 E-17$

.0000

.0000

$.8617 E-14$

.0000

.0000

$.8080 \mathrm{E}-14$

$.2518 \mathrm{E}-27$

.0000

$.7240 \mathrm{E}-08$

.0000

$.1396 \mathrm{E}-15$

.0000

.0000

.0000

$.000^{n}$

.0000

$.8634 \mathrm{E}-16$

$.1388 \mathrm{E}-16$

$.6801 \mathrm{E}-16$

.0000

.0000

.0000

$.6479 E-14$

.0000

$.1251 \mathrm{E}-15$

$.1465 \mathrm{E}-21$

$.1123 E-28$

.0000

.0000

.0000

.0000

$.5697 \mathrm{E}-15$

$.6065 \mathrm{E}-17$

$.8198 \mathrm{E}-21$

.0000

$.8984 \mathrm{E}-14$

$.4412 E-27$

$.8570 \mathrm{E}-16$

$.1040 \mathrm{E}-21$

$.7022 E-29$

.0000
Append Ix II

Table 21-15

Page 084 of 173

Dato 09/30/82 Rev 09
84

PVVF Exhaust Sand Filter

to Ex Tunnel Condensate $.5872 E-11$

.0000

$.1030 \mathrm{E}-11$

.0000

$.5338 \mathrm{E}-12$

.0000

.0000

$.3032 E-09$

$.1200 E-12$

.0000

$.1426 \mathrm{E}-09$

$.1048 E-12$

.0000

390.8

.0000

$.6473 \mathrm{E}-11$

.0000

.0000

.0000

.0000

.0000

$.1684 E-11$

$.6436 E-12$

$.8188 E-11$

.0000

.0000

.8969E-05

$.8940 \mathrm{E}-08$

.0000

$.5791 E-11$

$.6790 \mathrm{E}-17$

$.4676 \mathrm{E}-14$

.0000

.0000

.0000

.0000

$.2641 \mathrm{E}-10$

$.1494 E-09$

. $5190 E-10$

.0000

. 1845E-09

$.1837 E-12$

$.8968 \mathrm{E}-11$

$.4822 E-17$

$.2924 \mathrm{E}-14$

.0000
.0000

.0000

.0000

.0000

.0000

.0000

.0000

.0000

.0000

.0000

.0000

.0000

.0000

.0000

.0000

.0000

.0000

.0000

.0000

.0000

.0000

.0000

.0000

.0000

.0000

.0000

.0000

.0000

.0000

.0000

.0000

.0000

.0000

.0000

.0000

.0000

.0000

.0000

.0000

.0000

.0000

.0000

.0000

.0000

.0000

.0000
86

Inn llouse

Condensisto

.0000

.0000

.0000

.0000

.0000

.0000

.0000

.0000

.0000

.0000

.0000

.0000

.0000

.0000

.0000

.0000

.0000

.0000

.00100

.0000

.0000

.0000

.0000

.0000

.0000

.0000

.0000

.0000

.0000

.0000

.0000

.0000

.0000

.0000

.0000

.0000

.0000

.0000

.0000

.0000

.0000

.0000

.0000

.0000

.0000

.0000 
MATERIAL PALANCE TABLES

Date 09/80/82 Rev 09

\section{SLLDGE-0:ILY FEED}

STREABS (CONT'D) -

STREAM NAME

$\begin{array}{rl}47 & \text { Y203 } \\ 100 & \mathrm{Zeol} 1 \text { te } \\ 44 & \mathrm{Zn}(\mathrm{COOHI}) 2 \\ 54 & \mathrm{Zn}(011) 2 \\ 57 & \mathrm{Zn} 0\end{array}$

$104 \mathrm{ZrO2}$

TOTAL FLOH, LB/IIR

VAPOR FI.ON, CFM

LIQLIID FLOW, GPM

DESIGN FLOW,

DENSITX, LBS/ET3

TEMPERATURE, DEG C

PRESSURE, ATM

PRESSLRE, PSIG

PRESSLRE, MAI IIG

PIIASE

EYTHALPY, PCU/IR

83

Purlfied Hg

.0000

$.8642 \mathrm{E}-14$

$.4028 \mathrm{E}-15$

$.8798 \mathrm{E}-28$

.0000

$.8133 \mathrm{E}-17$

1.68

.00

837.8898

88.00

1.00

.00

LIQUID

2.09
84

PVVF Exhaust Snnd Filter

to Ex Tunnol

.0000

$.1688 \mathrm{E}-09$

$.2096 \mathrm{E}-10$

$.1581 \mathrm{E}-13$

.0000

$.7472 E-10$

1719.69

413.12

.0694

89.04

.99

$-.11$

754.53

VAPOR

$-87979.66$
Condensate

.0000

.0000

.0000

.0000

.0000

.0000

13.80

.03

62.4300

25.00

1.00

.00

LIQUID

$\mathbf{8 4 9 . 8 4}$
86

Fan House

Condensate

.0000

.0000

.0000

.0000

.0000

.0000

13.80

.03

62.4300

25.00

1.00

.00

LIQLID

$\mathbf{8 4 9 . 8 4}$ 
DPSP 80-1038

MATERIAL BALANCE TABLES

SLLDGE-ONLY FEED

STREAM NUMBERS -

STREAM NAME

COMPONENT FLOHS, LB/HR

$1 \mathrm{H} 20$

$46 \mathrm{Ag}$

116 Ag20

184 AgNO8

$51 \mathrm{AgOH}$

74 Al(ON) 3

77 A 1203

75 A $100 \mathrm{H}$

106 B203

$9 \mathrm{Ba}(\mathrm{N} 03) 2$

95 $\mathrm{BaCl} 2$

$15 \mathrm{BaO}$

$24 \mathrm{BaSO} 4$

$66 \mathrm{CO}$

$87 \mathrm{CO} 2$

$142 \mathrm{CO2}$ (C.14)

$63 \mathrm{Ca}(\mathrm{COOH}) 2$

$120 \mathrm{Cn}(\mathrm{OH}) 2$

$113 \mathrm{Ca} 3(\mathrm{PO}) 2$

$20 \mathrm{CaC204}$

$18 \mathrm{CaCO3}$

$78 \mathrm{CaF} 2$

$41 \mathrm{CaO}$

$19 \mathrm{CaSO} 4$

29 Carbon

$26 \mathrm{Co}(\mathrm{COOH}) 2$

$121 \mathrm{Co}(\mathrm{OH}) 2$

$53 \mathrm{Co}(\mathrm{OH}) 3$

$59 \mathrm{CoO}$

$99 \mathrm{Cr}(\mathrm{OH}) 3$

98 Cr203

$42 \mathrm{C}=20$

137 Cs20 Semi Vol

$90 \mathrm{CsCOOH}$

$96 \mathrm{CsCl}$

$136 \mathrm{CsCl}$ Semi Vol

8 CsNO3

88 CsResin

$122 \mathrm{Cu}(\mathrm{COOH}) 2$

$62 \mathrm{Cu}(\mathrm{OII}) 2$

$58 \mathrm{Cu} 20$

$64 \mathrm{CuCOOH}$

$180 \mathrm{CuO}$

$13 \mathrm{Fe}(\mathrm{OH}) 3$

$80 \mathrm{Fe} 203$
87

Decon Waste to DHTI

812.0

.0000

.0000

.0000

.0000

.0000

.0000

.0000

.0000

.0000

.0000

.0000

.0000

.0000

.0000

.0000

.0000

.0000

.0000

.0000

.0000

.0000

.0000

.0000

.0000

.0000

.0000

.0000

.0000

.0000

.0000

.0000

.0000

.0000

.0000

.0000

.0000

.0000

.0000

.0000

.0000

.0000

.0000

.0000

.0000
Appendix H

Table 21-15

Page 086 of 173

Dute 09/80/82 Ruv 03 
MATERIAL BALANCE TABLES

Date 09/30/82 Rev 09

\section{SLUDGE-OKLY FEED \\ STREAMS (CONT'D)- STREAM NAME}

$101 \mathrm{FeO}$

126 Group A Semi Vo

102 GroupA

103 GroupB

$25 \mathrm{H} 2$

133 HIC2O4

$91 \mathrm{H2O2}$

$34 \mathrm{HCOOH}$

$43 \mathrm{HCl}$

$85 \mathrm{IIF}$

49 HNO3

86 IIResin

$86 \mathrm{Hg}$

$125 \mathrm{HgN032}$

$21 \mathrm{HgO}$

$97 \quad 12$

$39 \quad 120$

$131 \mathrm{KMin01}$

$118 \mathrm{KNO}$

$105 \operatorname{Ln} 203$

$108 \mathrm{Li} 20$

$65 \mathrm{Mg}(\mathrm{COOH}) 2$

$55 \mathrm{Mg}(\mathrm{OII}) 2$

$33 \mathrm{MgO}$

$60 \mathrm{Mn}(\mathrm{COOHI}) 2$

$132 \mathrm{Mn}(\mathrm{NO} 03) 2$

$129 \mathrm{Mn}(\mathrm{OH}) 2$

$66 \mathrm{MnO}$

$14 \mathrm{MnO2}$

81 N2

$143 \mathrm{NA2CO3}$ ( $\mathrm{C}_{14}$ )

35 NO

$84 \mathrm{NO} 2$

$70 \mathrm{Ni}\left(1 \mathrm{~g}_{\mathrm{g}} \mathrm{O}(\mathrm{Oll})\right)$

$94 \mathrm{Na} 2 \mathrm{~B} 407$

$109 \mathrm{Na} 2 \mathrm{C}_{204}$

$5 \mathrm{Na} 2 \mathrm{CO} 3$

$82 \operatorname{Nin} 20$

71 in 2pu02(OII) 4

$73 \mathrm{Na2Rh04}$

$72 \mathrm{Na2RuO4}$

$6 \mathrm{Na}_{2 \mathrm{SO}}$

$68 \mathrm{Na}_{\mathrm{N}} \mathrm{HO2}$

$114 \mathrm{NaBO2}$

$140 \mathrm{NaBO2}$ Semi Vol

50 $\mathrm{NaCOOH}$
87

Decon Wasto to DWTI

.0000

.0000

.0000

.0000

.0000

5. 750

.0000

.0000

.0000

.0000

4.930

.0000

.0000

.0000

.0000

.0000

.0000

.3080

.0000

.0000

.0000

.0000

.0000

.0000

.0000

.0000

.0000

.0000

.0000

.0000

.0000

.0000

.0000

.0000

.0000

.0000

.0000

.0000

.0000

.0000

.0000

.0000

.0000

.0000

.0000

.0000
88

MIIIT Vent

to MVC

.0000

.0000

$.1216 \mathrm{E}-17$

$.3880 E-17$

.0000

.0000

.0000

.0000

.0000

.0000

.35U5E- 12

.0000

$.7180 \mathrm{E}-05$

$.9037 E-15$

$.6898 E-19$

.0000

.0000

.0000

.3566E-20

. 1368E-19

. 2760E- 18

$.4278 \mathrm{E}-17$

. 2862E-30

$.8238 E-19$

$.8814 E-16$

.0000

$.2565 E-28$

.0000

.0000

8.418

.0000

.0000

$.9878 E-16$

.2736E-20

1569E-20

.1431E-20

.0000

$.1010 \mathrm{E}-17$

$.1110 \mathrm{E}-24$

.2281E-22

.2226E-21

$.4514 E-18$

$.1110 \mathrm{E}-17$

.0000

.0000

.2903E-16
89

Misc Sumps

to RCT

.0000

.0000

.0000

.0000

.0000

.0000

.0000

.0000

.0000

.0000

.0000

.0000

.0000

.0000

.0000

.0000

.0000

.0000

.0000

.0000

.0000

.0000

.0000

.0000

.0000

.0000

.0000

.0000

.0000

.0000

.0000

.0000

.0000

.0000

.0000

.0000

.0000

.0000

.0000

.0000

.0000

.0000

.0000

.0000

.0000

.0000
90

60 Ht $\%$

$\mathrm{NaOH}$ to RCT

.0000

.0000

.0000

.0000

.0000

.0000

.0000

.0000

.0000

.0000

.0000

.0000

.0000

.0000

.0000

.0000

.0000

.0000

.0000

.0000

.0000

.0000

.0000

.0000

.0000

.0000

.0000

.0000

.0000

.0000

.0000

.0000

.0000

.0000

.0000

.0000

.0000

.0000

.0000

.0000

.0000

.0000

.0000

.0000

.0000

.0000 
DPSP $30-1033$

MATERIAL BALANCE TABLES

SLLDGE-ONLY FEED

STREAMS (CONT'D)-

STREAM NAME

$7 \mathrm{NaCl}$

$188 \mathrm{NaCl}$ Semi Vol

$69 \mathrm{NaF}$

189 NaF Semi Vol

$12 \mathrm{NaI}$

$125 \mathrm{Nin}$ Semi Vol

$8 \mathrm{NaNO2}$

$2 \mathrm{NaNO3}$

$4 \mathrm{NaOH}$

87 NinResin

$61 \mathrm{Ni}(\mathrm{COOH}) 2$

$17 \mathrm{Ni}(\mathrm{OH}) 2$

$40 \mathrm{NiO}$

8202

$67 \mathrm{PbO}$

$28 \mathrm{PbSO} 4$

$124 \mathrm{Pd}$

$123 \mathrm{Pd}(\mathrm{OH}) 2$

112 PdNO32

$110 \mathrm{PdO}$

$117 \mathrm{Pu}(\mathrm{COOII}) 4$

$76 \mathrm{Pu} 02$

$22 \mathrm{RhO2}$

$79 \mathrm{Ru} 02$

23 Ru02 Semi Vol

$83 \mathrm{Ru} 04$

$88 \mathrm{SO2}$

$111 \mathrm{SiO}$

115 Silica Gel

$48 \mathrm{Sr}(\mathrm{COOH}) 2$

$10 \mathrm{Sr}(\mathrm{NO}) 2$

$127 \mathrm{Sr}(\mathrm{OH}) 2$

$30 \mathrm{SrCO3}$

$46 \mathrm{Sr} 0$

89 SrRESIN

141 Surfactant

92 Th02

$107 \mathrm{Ti02}$

119 Tritium

$93 \mathrm{VO2}$

$62 \mathrm{VO} 2(\mathrm{COOH}) 2$

$16 \mathrm{VO2}(\mathrm{OH}) 2$

$27 \mathrm{Y}(\mathrm{COOH}) \mathrm{S}$

$11 \mathrm{Y}(\mathrm{NOB}) 3$

$128 \mathrm{Y}(\mathrm{OH}) \mathrm{B}$

$31 \mathrm{Y} 2(\mathrm{CO}) 3$

87
Decon Waste
to DHTT
.0000
.0000
.0000
.0000
.0000
.0000
.0000
.0000
.0000
.0000
.0000
.0000
.0000
.0000
.0000
.0000
.0000
.0000
.0000
.0000
.0000
.0000
.0000
.0000
.0000
.0000
.0000
.0000
.0000
.0000
.0000
.0000
.0000
.0000
.0000
.0000
.0000
.0000
.0000
.0000
.0000
.0000
.0000
.0000
.0000
.0000

88

MHT Vent Misc Sumps

to MVC

$.4500 E-18$

.0000

$.2354 \mathrm{E}-20$

.0000

$.4358 \mathrm{E}-19$

.0000

.0000

$.1579 \mathrm{E}-16$

.0000

.0000

.1345 E-16

. 1099E-29

.0000

1.083

.0000

$.6097 E-18$

.0000

.0000

.0000

.0000

.0000

. 1587E-18

$.6062 \mathrm{E}-19$

$.2969 E-18$

.0000

.0000

.0000

$.2829 \mathrm{E}-16$

.0000

$.6461 \mathrm{E}-18$

$.6396 \mathrm{E}-24$

. 4904E-31

.0000

.0000

.0000

.0000

$.2487 E-17$

. 2648E- 19

.1396E-26

.0000

. 1739E- 16

$.1926 \mathrm{E}-29$

Appendix II

Inble 2!-15

Pnge 088 of 173

Date 09/30/82 Rev 09

$.3742 E-18$

$.4542 E-24$

$.3066 \mathrm{E}-31$

.0000
90

$50 \mathrm{flt} \%$

$\mathrm{NaOl!}$ to RC.

$.0000 \quad .0000$

$.0000 \quad .0000$

$.0000 \quad .0000$

$.0000 \quad .0000$

$.0060 \quad .0000$

$.0000 \quad .0000$

$.0000 \quad .0000$

$.0000 \quad .0000$

$.0000 \quad 3.307$

$.0000 \quad .0000$

$.0000 \quad .0000$

$.0000 \quad .0000$

$.0000 \quad .0000$

$.0000 \quad .0000$

$.0000 \quad .0000$

$.0000 \quad .0000$

$.0000 \quad .0000$

$.0000 \quad .0000$

$.0000 \quad .0000$

$.0000 \quad .0000$

$.0000 \quad .0000$

$.0000 \quad .0000$

$.0000 \quad .0000$

$.0000 \quad .0000$

$.0000 \quad .0000$

$.0000 \quad .0000$

$.0000 \quad .0000$

$.0000 \quad .0000$

$.0000 \quad .0000$

$.0000 \quad .0000$

$.0000 \quad .0000$

$.0000 \quad .0000$

$.0000 \quad .0000$

$.0000 \quad .0000$

$.0000 \quad .0000$

$.0000 \quad .0000$

$.0000 \quad .0000$

$.0000 \quad .0000$

$.0000 \quad .0000$

$.0000 \quad .0000$

$.0000 \quad .0000$

$.0000 \quad .0000$

$.0000 \quad .0000$

$.0000 \quad .0000$

$.0000 \quad .0000$

$.0000 \quad .0000$ 
MTtRIAL BaLAiICE TABLES

SLCDGE-0YiX FEED

STREAMS (CONT'D)-

STREAM NAME

$47 \quad 1203$

100 Zeolite

$44 \mathrm{Zn}(\mathrm{COOII}) 2$

$54 \mathrm{Zn}(\mathrm{Oll}) 2$

$57 \mathrm{Zn} 0$

$104 \mathrm{ZrO} 2$

TOTAL FLOH, LB/IIR

VAPOR FLOW, CFY

LIQUYID FLOH, GPM DESIGN FLOW,

DEXSITY, LBS/FT3

TEYPERATURE, DEG C

PRESSURE, ATM

PRESSURE, PSIG

PRESSURE, MM HG

PHASE

E.TTHALPY, PCU/HR

87
Decon Waste
to DHIT
.0000
.0000
.0000
.0000
.0000
.0000
322.99
.64

63.2852
25.00
1.00
.00

LIQU1D
7084.71

88

MHT Vent

to MVC

.0000

. 1590E- 16

. 1977E-17

$.1658 \mathrm{E}-30$

.0000

. 1368E-19

4.53

1.07

64

3.2852

1.00

00

7984.71

$-.07$

756.20

VAPOR

$-233.05$

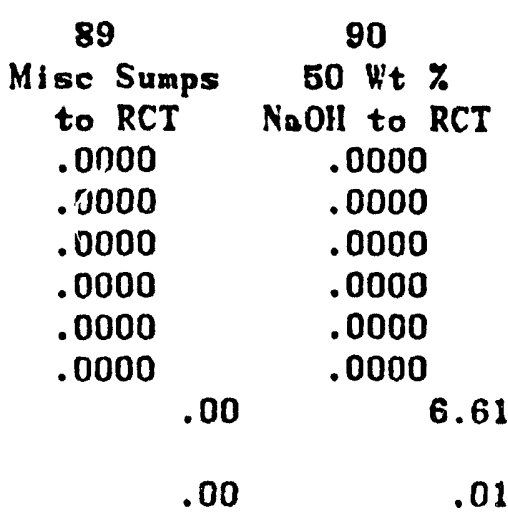

.0000

85.00

1.00

.00

84.9613

25.00

1.00

.00

LIQUID

.00

LIQUID

110.69 
DPSP $80-1033$

MATERIAL BALANCE TALLES

SLUDGE-ONLY FEED

STREAM NUMBERS -

STREAM NAME

COMPONENT FLOWS, LB/HR

$1 \mathrm{H} 2 \mathrm{O}$

$45 \mathrm{Ag}$

$116 \operatorname{Ag} 20$

184 AgNO3

$51 \mathrm{AgOH}$

74 Al(OH)B

77 A 1203

$75 \mathrm{~A} 100 \mathrm{H}$

106 B203

$9 \mathrm{Ba}(\mathrm{N} 03) 2$

$95 \mathrm{BaCl} 2$

$15 \mathrm{BaO}$

$24 \mathrm{BaSO4}$

$66 \mathrm{CO}$

$37 \mathrm{CO} 2$

$142 \mathrm{CO}$ ( $\mathrm{C14}$ )

$63 \mathrm{Ca}(\mathrm{COOH}) 2$

$120 \mathrm{Ca}(\mathrm{OH}) 2$

$113 \mathrm{Ca3}(\mathrm{PO} 4) 2$

$20 \mathrm{CaC2O4}_{2}$

$18 \mathrm{CaCO}$

$78 \mathrm{CaF} 2$

$41 \mathrm{CaO}$

$19 \mathrm{CaSO}_{\mathrm{a}}$

29 Carbon

$26 \mathrm{Co}(\mathrm{COOH}) 2$

$121 \mathrm{Co}(\mathrm{OH}) 2$

$53 \mathrm{Co}(\mathrm{Oll}) \mathrm{s}$

$59 \mathrm{CoO}$

$99 \mathrm{Cr}(\mathrm{OH}) 3$

98 Cr203

42 Cs20

137 Cs20 Semi Vol

$90 \mathrm{CsCOOH}$

$96 \mathrm{CsCl}$

$186 \mathrm{CsCl}$ Semi Vol

8 CsNO3

88 CsResin

$122 \mathrm{Cu}(\mathrm{COOH}) 2$

$52 \mathrm{Cu}(\mathrm{OII}) 2$

$58 \mathrm{Cu} 20$

$64 \mathrm{CuCOOH}$

$130 \mathrm{Cu} 0$

$13 \mathrm{Fe}(\mathrm{OH}) 3$

$80 \mathrm{Fe} 203$
91

92

Noutr Haste SISE Condensr

to Tank Farm Vent to FAVC

1078.

.0000

.0000

.0000

$.1005 \mathrm{E}-03$

.1081

.0000

.0000

.1860

$.8538 \mathrm{E}-09$

.0000

.0000

$.7704 \mathrm{E}-03$

$.4442 E-08$

.3492E-04

$.2695 E-19$

.0000

$.1522 \mathrm{E}-01$

$.1920 \mathrm{E}-02$

$.2076 \mathrm{E}-02$

.0000

$.5191 E-03$

.0000

$.2439 E-02$

$.5191 \mathrm{E}-03$

.0000

$.2633 \mathrm{E}-03$

.0000

.0000

$.1973 \mathrm{E}-02$

.0000

$.1497 E-05$

.0000

.0000

$.2634 \mathrm{E}-03$

.0000

$.5476 E-04$

.0000

.0000

$.5727 \mathrm{E}-03$

.0000

.0000

.0000

.2618

.0000

.0000
Appendix $\mathrm{H}$

Table 21-15

Page 090 of 173

Date 09/30/82 Rev 09
93

SU'T Vent to MVC

.1944

.0000

.0000

.0000

$.8419 \mathrm{E}-0 \mathrm{~S}$

$.7777 \mathrm{E}-11$

.0000

.0000

$.1018 \mathrm{E}-12$

$.1022 \mathrm{E}-18$

.0000

.0000

$.9233 \mathrm{E}-13$

$.8259 \mathrm{E}-33$

$.9521 \mathrm{E}-10$

$.3971 \mathrm{E}-28$

$.3203 E-11$

.2392E-24

$.2301 \mathrm{E}-12$

$.2488 \mathrm{E}-12$

.0000

$.6221 \mathrm{E}-13$

.0000

$.2923 \mathrm{E}-12$

$.62215-13$

. 5057E-13

$.4138 \mathrm{E}-26$

.0000

.0000

$.2365 \mathrm{E}-12$

.0000

$.9322 \mathrm{E}-18$

.0000

.0000

$.5998 \mathrm{E}-18$

.0000

$.6552 \mathrm{E}-14$

.0000

$.1080 \mathrm{E}-12$

$.9000 E-26$

.0000

.0000

.0000

$.1882 \mathrm{E}-10$

.0000
94

Mrill Vent

to MC

.1190

.2740E-00

.0000

.2440E-03

$.6006 \mathrm{E}-14$

$.1600 E-11$

.0000

.0000

.2211E- 13

$.2220 E-10$

.0000

.0000

.2006E- 13

$.1363 \mathrm{E}-33$

$.2171 E-10$

$.9034 \mathrm{E}-29$

$.6959 E-12$

$.5197 E-25$

$.4999 \mathrm{E}-13$

$.5407 E-13$

.0000

$.1352 E-13$

.0000

$.6351 \mathrm{E}-13$

$.1352 \mathrm{E}-13$

$.1090 E-13$

$.8991 \mathrm{E}-27$

.0000

.0000

$.5139 E-13$

.0000

$.2026 \mathrm{E}-18$

.0000

.0000

. $303 \mathrm{E}-18$

.0000

.1424 E- 14

.0000

$.2347 E-13$

$.1956 E-26$

.0000

.0000

.0000

$.4090 \mathrm{E}-11$

.0000 
MATERIAL BALANCE TABLES

Date 09/80/82 Rev 09

\section{SLCUGE-ONLY FEED}

STREAMS (CONT'D)-

STREAM NAME

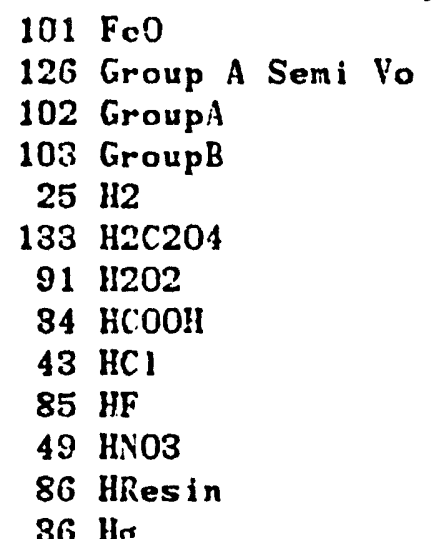

$135 \mathrm{HgN032}$

$21 \mathrm{HgO}$

$97 \quad 12$

39 K20

$131 \mathrm{KMnO4}$

$118 \mathrm{KNO}$

105 La203

108 Li20

$65 \mathrm{Mg}(\mathrm{COOH}) 2$

$55 \mathrm{Mg}(\mathrm{OII}) 2$

$33 \mathrm{MgO}$

$60 \mathrm{Mn}(\mathrm{COOH}) 2$

$132 \mathrm{Mn}(\mathrm{NO}) 2$

$129 \mathrm{Mn}(\mathrm{OIH}) 2$

$56 \mathrm{MnO}$

$14 \mathrm{MnO2}$

$81 \mathrm{~N} 2$

$143 \mathrm{NA2CO3}$ (C14)

35 No

$84 \quad 102$

$70 \mathrm{Na}(\mathrm{HgO}(\mathrm{OHI}))$

94 Nin2B 407

$109 \mathrm{Na} 2 \mathrm{C} 204$

$5 \mathrm{Na} 2 \mathrm{CO} 3$

$32 \mathrm{Na} 20$

$71 \mathrm{Na} 2 \mathrm{Pu} 02(\mathrm{OII}) 4$

$73 \mathrm{Na} 2 \mathrm{Rh} 04$

$72 \mathrm{Na} 2 \mathrm{RuO}_{4}$

$6 \mathrm{Nin} 2 \mathrm{SO}_{4}$

$68 \mathrm{NaAl} 102$

$114 \mathrm{NaBO} 2$

$140 \mathrm{NaBO2}$ Semi Vol

$50 \mathrm{NaCOOH}$
91

Neutr Hasto SME Condensr

to Tank Farm Vent to FAVC

.0000

.0000

$.1020 \mathrm{E}-01$

$.4614 \mathrm{E}-02$

$.8113 E-09$

.0000

.0000

.0000

.0000

.0000

.0000

.0000

.0000

.0000

$.8501 \mathrm{E}-02$

.0000

.0000

.0000

.1970

$.3784 \mathrm{E}-02$

$.7195 \mathrm{E}-01$

.0000

.2596E-02

.2220E-01

.0000

.0000

.2012

.0000

.0000

$.1285 \mathrm{E}-01$

.0000

$.6610 \mathrm{E}-07$

$.8332 \mathrm{E}-02$

$.3259 E-05$

$.9913 \mathrm{E}-01$

$.7906 E-01$

.0000

.2650

. 1822E-09

$.2717 E-07$

$.2652 E-06$

$.5377 E-03$

$.1322 \mathrm{E}-02$

.0000

.0000

2.951
.0000

.0000

$.4823 E-08$

$.1589 \mathrm{E}-07$

$.6250 \mathrm{E}-19$

.0000

.0000

.1337

.0000

.0000

.0000

.0000

.2588E-06

.0000

.0000

.0000

.0000

.0000

$.1415 \mathrm{E}-10$

$.1262 \mathrm{E}-07$

. 1444E-06

$.1697 \mathrm{E}-07$

.0000

. 5060E-07

.1513E-06

.0000

.0000

.0000

.0000

47.85

.0000

$.4970 \mathrm{E}-10$

.2700E-07

$.1085 \mathrm{E}-10$

$.6223 \mathrm{E}-11$

$.5676 \mathrm{E}-11$

.0000

$.4489 \mathrm{E}-06$

$.4402 \mathrm{E}-15$

$.9050 \mathrm{E}-13$

$.8831 E-12$

$.1791 \mathrm{E}-08$

$.4402 E-08$

.0000

.0000

$.1152 E-0 E$
93

SWI Vent

to MVC

.0000

.0000

$.1733 \mathrm{E}-12$

$.5530 \mathrm{E}-12$

$.1434 E-31$

.0000

.0000

.0000

.0000

.0000

.0000

.0000

.0000

.0000

$.9759 \mathrm{E}-11$

.0000

.0000

.0000

$.5082 \mathrm{E}-15$

$.1950 E-14$

$.3934 E-13$

$.6097 \mathrm{E}-12$

$.4079 \mathrm{E}-25$

$.1174 E-18$

$.5435 E-11$

.0000

$.8656 \mathrm{E}-23$

.0000

.0000

8.418

.0000

.3785E-22

.3494E-03

$.3900 \mathrm{E}-15$

$.2236 \mathrm{E}-15$

.2039E-15

.0000

$.1439 E-12$

$.1581 \mathrm{E}-19$

$.3251 \mathrm{E}-17$

$.3173 E-16$

$.6434 \mathrm{E}-13$

$.1581 E-12$

.0000

.0000

$.4137 \mathrm{E}-11$
94

MITI1 Vent

to MVC

.0000

.0000

$.3765 \mathrm{E}-13$

$.1202 \mathrm{E}-12$

$.2282 E-32$

.0000

.0000

.0000

.0000

.0000

$.4934 \mathrm{E}-03$

.0000

. 1070E-03

$.1526 \mathrm{E}-11$

.2136E-14

.0000

.0000

.0000

$.1104 \mathrm{E}-15$

$.4237 \mathrm{E}-15$

$.8549 \mathrm{E}-14$

$.1325 E-12$

$.8863 \mathrm{E}-26$

$.2551 \mathrm{E}-14$

$.1181 \mathrm{E}-11$

.0000

$.7944 \mathrm{E}-24$

.0000

.0000

3.418

.0000

$.6786 \mathrm{E}-23$

$.1329 E-03$

$.8473 E-16$

$.4858 \mathrm{E}-16$

$.4431 E-16$

.0000

.3127E-13

$.3436 \mathrm{E}-20$

$.7065 E-18$

$.6894 \mathrm{E}-17$

$.1398 E-13$

$.3486 \mathrm{E}-13$

.0000

.0000

$.8989 E-12$ 
DPSP $80-1033$

MATERIAL BALANCE TABLES SLLDGE-ONLY FEED

STREAMS (CONT'D) STREAM NAME

$7 \mathrm{NaCl}$

$138 \mathrm{NaCl}$ Semi Vol

$69 \mathrm{NaF}$

189 NaF Semi Vol

$12 \mathrm{NaI}$

$125 \mathrm{NaI}$ Semi Vol

$8 \mathrm{NaNO2}$

$2 \mathrm{NaNO3}$

$4 \mathrm{NeOH}$

87 NaResin

$61 \mathrm{Ni}(\mathrm{COOH}) 2$

$17 \mathrm{Ni}(\mathrm{OH}) 2$

$40 \mathrm{NiO}$

8202

$67 \mathrm{PbO}$

$28 \mathrm{PbSO} 4$

$124 \mathrm{Pd}$

$123 \mathrm{Pd}(\mathrm{OH}) 2$

112 PdNO32

$110 \mathrm{PdO}$

$117 \mathrm{Pu}(\mathrm{COOH}) 4$

$76 \mathrm{Pu} 02$

$22 \mathrm{RhO2}$

$79 \mathrm{Ru} 02$

23 Ru02 Semi Vol

$83 \mathrm{Ru} 04$

$88 \mathrm{SO2}$

1115102

115 Silica Gel

$48 \mathrm{Sr}(\mathrm{COOH}) 2$

$10 \mathrm{Sr}(\mathrm{NO3}) 2$

$127 \mathrm{Sr}(\mathrm{OHI}) 2$

$80 \mathrm{SrCO}$

$46 \mathrm{SrO}$

89 SrRESIN

141 Surfactant

$92 \mathrm{ThO2}$

$107 \mathrm{TiO}$

119 Tritium

$98 \mathrm{VO2}$

$62 \mathrm{VO} 2(\mathrm{COOH}) 2$

$16 \mathrm{VO} 2(\mathrm{OH}) 2$

$27 \mathrm{I}(\mathrm{COOH}) 3$

$11 \mathrm{Y}(\mathrm{NOS}) \mathrm{3}$

$128 \mathrm{Y}(\mathrm{OHI}) \mathrm{B}$

$81 Y 2(\cos ) 3$
91

92

Neutr Waste SME Condensr

to Tank Farm Vent to FAVC

$.9466 \mathrm{E}-01 \quad .1785 \mathrm{E}-08$

.0000

.0000

$.8792 E-01$

.0000

$.6395 \mathrm{E}-02$

.0000

.0000

3.192

1.607

.0000

.0000

$.9970 \mathrm{E}-02$

.0000

$.7412 E-02$

.0000

$.7251 E-03$

.0000

.0000

.0000

.0000

.0000

. 1887E-03

$.7210 E-04$

.8737E-02

.0000

.0000

.2565E-03

.7832

.0000

.0000

$.7618 \mathrm{E}-09$

$.4447 E-03$

.0000

.0000

.0000

.0000

. 2958E-02

. 7366E-02

$.4625 \mathrm{E}-09$

.0000

.0000

.1747 E- 01

.0000

$.5410 \mathrm{E}-09$

.2780E-08

.0000
$.9338 E-11$

.0000

$.1729 \mathrm{E}-09$

.0000

.0000

$.5632 E-07$

.0000

.0000

$.5335 \mathrm{E}-07$

.0000

.0000

14.45

.0000

$.2419 E-08$

.0000

.0000

.0000

.0000

.0000

$.6294 \mathrm{E}-09$

.2405E-09

$.1178 \mathrm{E}-08$

.0000

.0000

$.9123 \mathrm{E}-20$

$.1568 \mathrm{E}-05$

.0000

.2166E-08

.2537E-14

.0000

.0000

.0000

.0000

.0000

$.9868 \mathrm{E}-08$

$.2524 \mathrm{E}-07$

.2442E-10

.0000

$.6901 \mathrm{E}-07$

.0000

$.1484 \mathrm{E}-08$

$.1802 \mathrm{E}-14$

.0000

.0000
Appendix $\mathrm{H}$

Table 21-15

Page 092 of 173

Date 09/30/82 Rev 09
93

SHT Vent Mrill Vent

to MYC

$.6414 \mathrm{E}-13$

.0000

$.3355 E-15$

.0000

$.6212 \mathrm{E}-14$

.0000

.0000

$.2956[-07$

$.1884 \mathrm{E}-07$

.0000

$.1917 \mathrm{E}-11$

$.1567 E-24$

.0000

1.033

.0000

$.8690 \mathrm{E}-13$

.0000

.0000

.0000

.0000

.0000

$.2261 \mathrm{E}-13$

$.8640 \mathrm{E}-14$

$.4232 \mathrm{E}-13$

.0000

.0000

$.1037 \mathrm{E}-31$

$.4032 E-11$

.0000

$.7783 \mathrm{E}-13$

$.9115 E-19$

$.6989 \mathrm{E}-26$

.0000

.0000

.0000

.0000

$.8545 \mathrm{E}-12$

$.3774 \mathrm{E}-14$

$.4705 \mathrm{E}-16$

.0000

$.2479 E-11$

$.2745 \mathrm{E}-24$

.5333E- 13

$.6473 E-19$

$.4370 \mathrm{E}-26$

.0000
1: $\mathrm{MIC}$

.1394 E- -13

.0000

$.7289 E-10$

.0000

$.1350 \mathrm{E}-14$

.0000

.0000

$.4890 E-12$

.0000

.0000

$.4165 \mathrm{E}-12$

$.3405 E-25$

.0000

1.033

.0000

$.1885 \mathrm{E}-13$

.0000

.0000

.0000

.0000

.0000

$.4913 \mathrm{E}-14$

. 1877E- 14

$.9196 \mathrm{E}-14$

.0000

.0000

$.1936 \mathrm{E}-32$

$.8761 E-12$

.0000

$.1691 \mathrm{E}-13$

$.1981 E-19$

$.1519 \mathrm{E}-26$

.0000

.0000

.0000

.0000

$.7703 E-13$

$.8200 \mathrm{E}-15$

$.2852 E-16$

.0000

$.5387 \mathrm{E}-12$

$.5965 E-25$

$.1159 \mathrm{E}-13$

$.1407 \mathrm{E}-19$

$.9495 E-27$

.0000 . 
MitenIAL BALANCE TABLES

Date 09/80/82 Rev 09

SLUDGE-ONLY FEED

STREAMS ( CONT'D)STREAM NANE

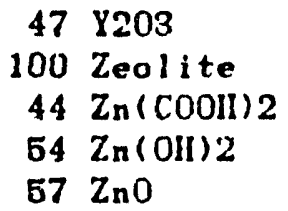

$47 \times 203$

100 Zeolite

$44 \mathrm{Zn}(\mathrm{COOII}) 2$

$54 \mathrm{Zn}(\mathrm{OII}) 2$

$57 \mathrm{Zn} 0$

$104 \mathrm{ZrO2}$

TOTAL FLOH', LE/HR

VAPOR FI.OH, CFM

LIQUID FLOH, GPM

DESIGN FLOV!,

DENSITY, LBS/FT3

TEMPERATURE, DEG C

PRESSURE, ATM

PRESSURE, PSIG

PRESSURE, MM HG

PHASE

ENTHALPY, PCI/HR

\section{1}

Neutr Waste SME Condensr

to Tank Farm Vent to FAVC

.0000

$.1891 E-01$

.0000

$.1504 \mathrm{E}-02$

.0000

$.3784 \mathrm{E}-02$

1088.71

2.16

$$
\begin{array}{r}
62.7502 \\
50.00 \\
.97 \\
-.51 \\
733.86 \\
\text { LIQUID } \\
55262.62
\end{array}
$$

$$
.0000
$$

$.6808 \mathrm{E}-07$

$.7843 \mathrm{E}-08$

.0000

.0000

$.1262 E-07$

84.72

24.82

.0569

50.00

.97

$-.51$

733.86

VAPOR

10146.68

$\begin{array}{cc}98 & 94 \\ \text { SWT Vent } & \text { MFTI1 Vent } \\ \text { to MVC } & \text { to MVC } \\ .0000 & .0000 \\ .2266 E-11 & .4924 E-12 \\ .2818 E-12 & .6123 E-13 \\ .2363 E-25 & .5135 E-26 \\ .0000 & .0000 \\ .1950 E-14 & .4237 E-15 \\ 4.65 & 4.57 \\ 1.13 & 1.10\end{array}$

.0685

37.99

.99

$-.07$

756.20

VAPOR

$-156.32$
.0691

37.99

.99

$-.07$

756.20

VAPOR

$-201.99$ 
DPSP $80-1033$

MATERIAL BALANCE TABLES

SLUDGE-ONLY FEED

STREAM NUMBERS -

STREAM NAME

COMPONENT FLOHS, LB/HR

$\begin{array}{rl}1 & 1120 \\ 45 & \mathrm{Ag} \\ 116 & \mathrm{Ag} 20 \\ 134 & \mathrm{AgNO3}\end{array}$

$51 \mathrm{AgOH}$

74 Al(OH) 3

77 A 1203

$75 \mathrm{~A} 10 \mathrm{OH}$

106 B203

$9 \mathrm{Ba}(\mathrm{N} 03) 2$

$95 \mathrm{BaCl} 2$

$15 \mathrm{BnO}$

$24 \mathrm{BaSO4}$

$66 \mathrm{CO}$

$37 \mathrm{CO} 2$

$142 \mathrm{CO2}$ (C14)

$63 \mathrm{Ca}(\mathrm{COOH}) 2$

$120 \mathrm{Ca}(\mathrm{OH}) 2$

$113 \mathrm{Ca} 3(\mathrm{PO}) 2$

$20 \mathrm{CnC2}_{2} \mathrm{C}$

$18 \mathrm{CaCO}$

$78 \mathrm{CaF} 2$

$41 \mathrm{CaO}$

$19 \mathrm{CaSO} 4$

29 Carbon

$26 \mathrm{Co}(\mathrm{COOH}) 2$

$121 \mathrm{Co}(\mathrm{OHI}) 2$

$63 \mathrm{Co}(\mathrm{OH}) 3$

$59 \mathrm{CoO}$

$99 \mathrm{Cr}(\mathrm{OH}) 3$

98 Cr203

$42 \mathrm{Cs} 20$

187 Cs20 Semi Vol

$90 \mathrm{CsCOOH}$

$96 \mathrm{CsCl}$

$136 \mathrm{CsCl}$ Semi Vol

$8 \mathrm{CsNO3}$

88 CsResin

$122 \mathrm{Cu}(\mathrm{COOH}) 2$

$52 \mathrm{Cu}(\mathrm{OH}) 2$

$58 \mathrm{Cu} 20$

$64 \mathrm{CuCOOH}$

$180 \mathrm{CuO}$

$13 \mathrm{Fo}(\mathrm{OH}) \mathrm{s}$

$80 \mathrm{Fe} 203$
.8779E-01

$.6472 \mathrm{E}-11$

.0000

$.1651 \mathrm{E}-10$

$.8451 \mathrm{E}-16$

$.9709 E-14$

.0000

.0000

$.1270 \mathrm{E}-15$

$.1275 \mathrm{E}-21$

.0000

.0000

$.1153 \mathrm{E}-15$

.0000

$.8516 \mathrm{E}-17$

$.1463 E-35$

$.3998 E-14$

.2986E-27

$.2872 E-15$

$.8106 \mathrm{E}-15$

.0000

$.7766 \mathrm{E}-16$

.0000

$.8649 \mathrm{E}-15$

$.7766 \mathrm{E}-16$

$.6313 \mathrm{E}-16$

$.5165 \mathrm{E}-29$

.0000

.0000

$.2952 E-15$

.0000

$.1164 \mathrm{E}-20$

.0000

.0000

$.7487 \mathrm{E}-21$

.0000

$.8180 \mathrm{E}-17$

.0000

$.1348 \mathrm{E}-15$

$.1124 \mathrm{E}-28$

.0000

.0000

.0000

.2850 E- 13

.0000
Appendix II

Table 21-15

Page 094 of 173

Date 09/50/82 Rev 09 
DPSP $20-1033$

MTERIAL BALANCE TABLES SLCDGE-OXILY FEED

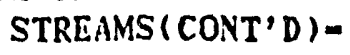

101 Fe0

126 Group A Semi Vo

102 Groupt

103 Group B

25 II 2

$133112 C_{204}$

9111202

34 licooll

$43 \mathrm{IICl}$

$85 \mathrm{IIF}$

49 HNO3

86 Illesin

$36 \mathrm{Hg}$

1.35 IIg.N032

$21 \mathrm{Hg} 0$

$97 \quad 12$

$39 \mathrm{k2O}$

$131 \mathrm{KMnO4}$

$118 \mathrm{KNO3}$

$105 \quad 1.2203$

108 Li 20

$65 \mathrm{Mg}(\mathrm{COOH}) 2$

$55 \mathrm{Mg}(\mathrm{OH}) 2$

$33 \mathrm{MgO}$

$60 \mathrm{Mn}(\mathrm{COOHI}) 2$

$132 \mathrm{Mn}(\mathrm{NO3}) 2$

$129 \mathrm{Mn}(\mathrm{OII}) 2$

$56 \mathrm{MnO}$

$14 \mathrm{MnO2}$

$81 \mathrm{~N} 2$

143 NA2CO3 (C14)

35 NO

$84 \mathrm{NO2}$

$\left.70 \mathrm{Na}\left(\mathrm{HgO}_{\mathrm{g}} \mathrm{Oll}\right)\right)$

$94 \mathrm{Na} 2 \mathrm{~B} 407$

$109 \mathrm{ia} 2 C_{204}$

$5 \mathrm{Na} 2 \mathrm{CO3}$

32 Na20

$71 \mathrm{Na} 2 \mathrm{Pu} 02$ (OII) 4

$73 \mathrm{Na} 2 \mathrm{Rh}_{\mathrm{O}} \mathrm{O}$

$72 \mathrm{Na} 2 \mathrm{Ru} 04$

$6 \mathrm{Na} 2 \mathrm{SO} 4$

$68 \mathrm{NaA} 102$

$114 \mathrm{NaBO2}$

140 NaB02 Semi Vol

$50 \mathrm{NaCOOH}$
Append ix $\mathrm{H}$

Table 21-15

Page 095 of 173

Drte 09/30/82 Rev 09
96

MFTI2 Vent Inlet Vapor

to MVC

.0000

.0000

$.2163 E-15$

$.6903 \mathrm{E}-15$

.0000

.0000

.0000

.0000

.0000

.0000

.6527E-04

.0000

.2257 E-03

. 1608E-12

$.1227 \mathrm{E}-16$

.0000

.0000

.0000

$.6344 \mathrm{E}-18$

$.2434 \mathrm{E}-17$

$.4911 \mathrm{E}-16$

$.7611 \mathrm{E}-15$

.6092E-28

$.1466 \mathrm{E}-16$

$.6785 \mathrm{E}-14$

.0000

$.4564 \mathrm{E}-26$

.0000

.0000

3.418

.0000

$.8601 E-31$

$.2218 E-06$

$.4868 \mathrm{E}-18$

$.2791 \mathrm{E}-18$

$.2546 \mathrm{E}-18$

.0000

$.1796 \mathrm{E}-15$

$.1974 E-22$

$.4059 \mathrm{E}-20$

$.8961 E-19$

$.8031 E-16$

$.1974 \mathrm{E}-15$

.0000

.0000

$.5165 E-14$ to MVC

.0000

.0000

$.9539 \mathrm{E}-12$

$.3044 \mathrm{E}-11$

$.8403 \mathrm{E}-26$

.0000

.0000

.0000

.0000

.0000

$.5339 \mathrm{E}-02$

.0000

$.4654 \mathrm{E}-03$

$.3179 E-10$

$.9803 \mathrm{E}-11$

.0000

.0000

.0000

$.2798 E-14$

.1074 E- 13

$.2166 \mathrm{E}-12$

$.3357 E-11$

.2246E-24

$.6464 \mathrm{E}-13$

.2092E-10

.0000

$.2013 \mathrm{E}-22$

.0000

.0000

17.16

.0000

$.9053 E-17$

$.8305 \mathrm{E}-02$

$.2147 E-14$

$.1231 \mathrm{E}-14$

$.1123 \mathrm{E}-14$

.0000

$.7923 E-12$

$.8707 E-19$

$.1790 \mathrm{E}-16$

$.1747 \mathrm{E}-15$

$.3542 E-12$

$.8707 E-12$

.0000

.0000

$.2278 E-10$

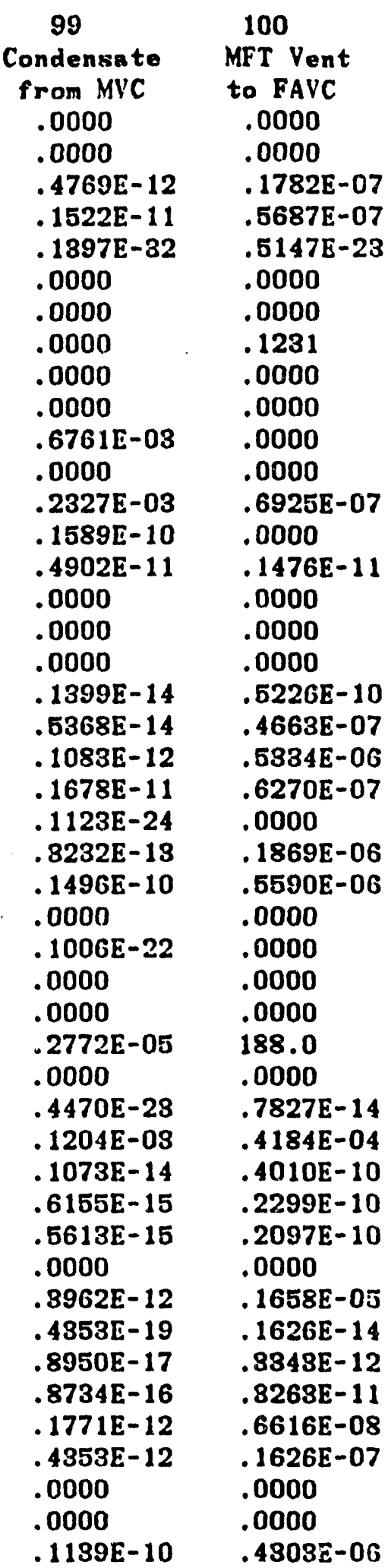


DPSP $80-1033$

MATERIAL BALANCE TABLES

SLUDGE-ONLY FEED

STREAMS (CONT'D)STREAM NAME

\section{$7 \mathrm{NaCl}$}

$188 \mathrm{NaCl}$ Semi Vol

$69 \mathrm{NaF}$

139 Naf Semi Vol

$12 \mathrm{NaI}$

$125 \mathrm{NaI}$ Semi Vol

$8 \mathrm{NaNO2}$

$2 \mathrm{NaNO}$

$4 \mathrm{NaOH}$

87 NaResin

$61 \mathrm{Ni}(\mathrm{COOH}) 2$

$17 \mathrm{Ni}(\mathrm{Oll}) 2$

$40 \mathrm{NiO}$

8202

$67 \mathrm{PbO}$

$28 \mathrm{PbS} 04$

$124 \mathrm{Pd}$

$123 \mathrm{Pd}(\mathrm{OH}) 2$

$112 \mathrm{PdNO} 2$

$110 \mathrm{PdO}$

$117 \mathrm{Pu}(\mathrm{COOHI}) 4$

$76 \mathrm{Pu} 02$

$22 \mathrm{RhO2}$

$79 \mathrm{Ru} 02$

23 Ru02 Semi Vol

$83 \mathrm{Ru} 04$

$38 \mathrm{SO2}$

$111 \mathrm{SiO}$

115 Silica Gel

$48 \mathrm{Sr}(\mathrm{COOH}) 2$

$10 \mathrm{Sr}(\mathrm{NO3}) 2$

$127 \mathrm{Sr}(\mathrm{OH}) 2$

$80 \mathrm{SrCO}$

$46 \mathrm{Sr} 0$

89 SrRESIN

141 Surfactant

$92 \mathrm{ThO2}$

$107 \mathrm{TiO}$

119 Tritium

98 U02

$62 \mathrm{VO2}(\mathrm{COOH}) 2$

$16 \mathrm{VO2}(\mathrm{OH}) 2$

$27 \mathrm{Y}(\mathrm{COOH}) \mathrm{S}$

$11 \mathrm{Y}(\mathrm{NO3}) 3$

$128 Y(011) 8$

$81 \times 2(\mathrm{COB}) 8$

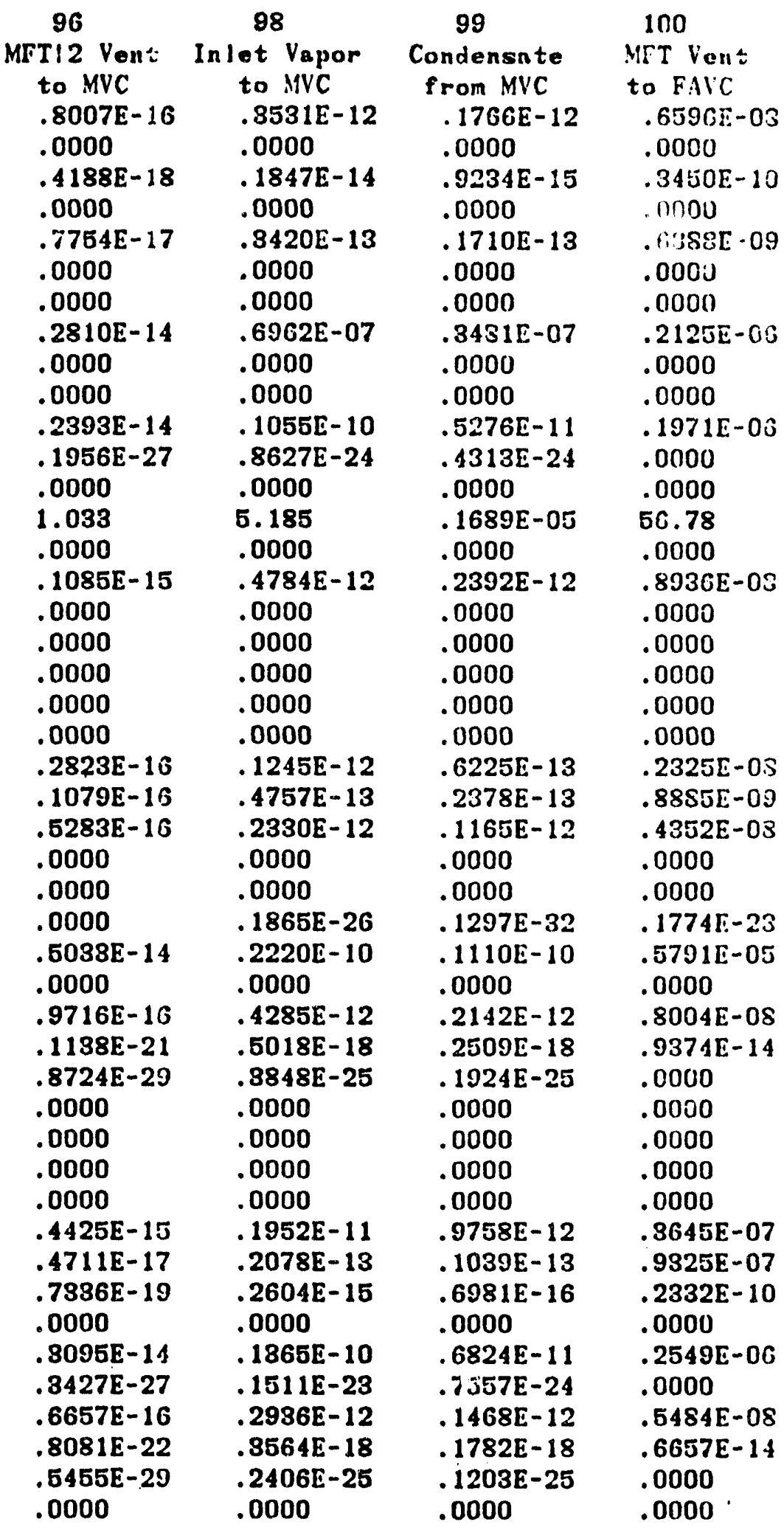

Appendix $H$

Table 21-15

Page 096 of 173

Date 09/30/82 Rev 09 
MATRRIAL BALANCE TABLES

Date 09/30/82 Rev 09

\section{SLLDGE-OYLY FEED}

STREAMS ( CONT'D)STREAM NAME

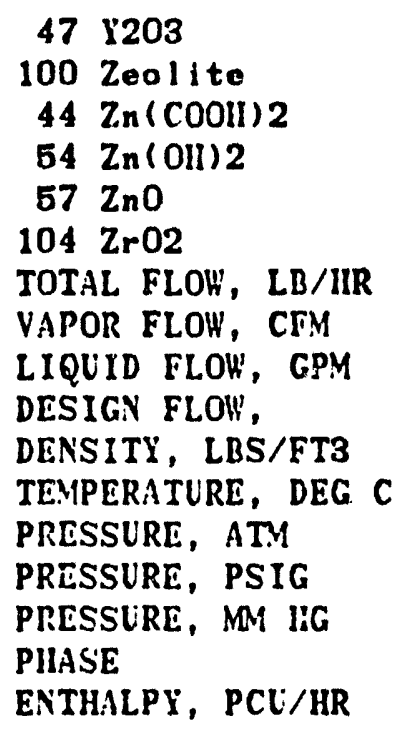

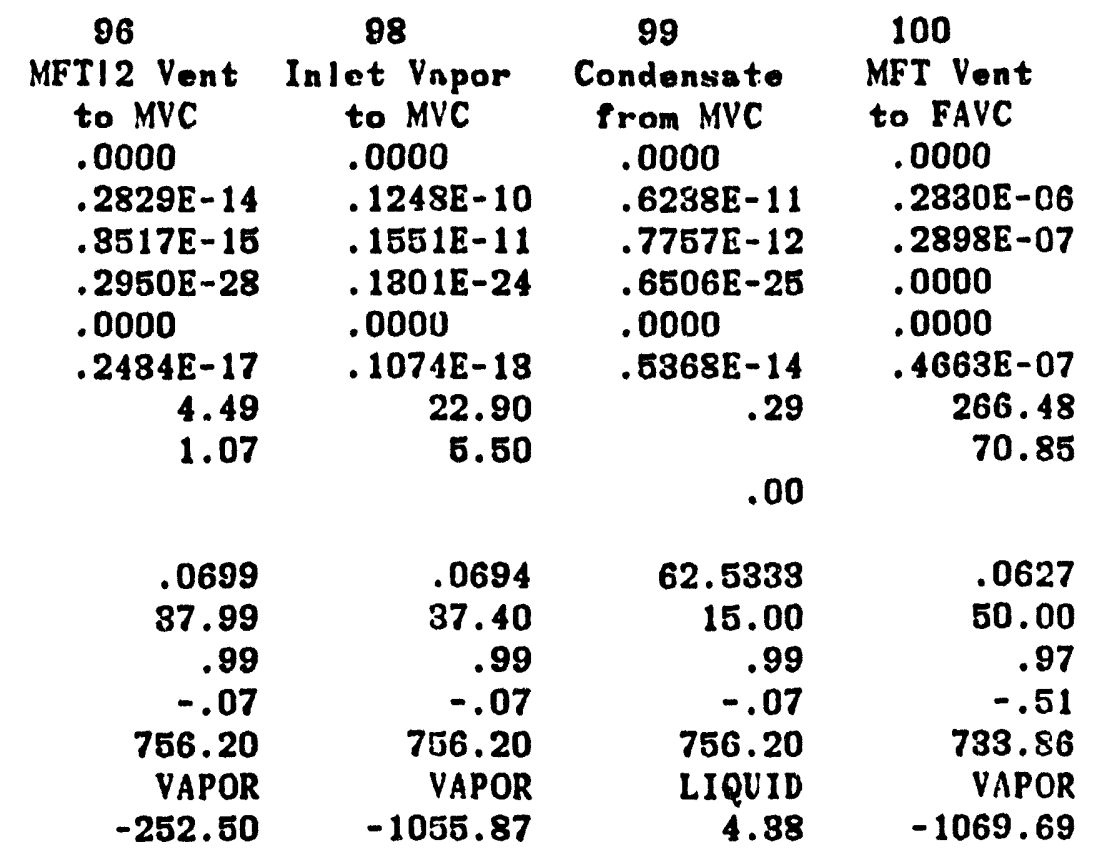


DPSP 80-1083

MATERIAL BALANCE TABLES

SLUDGE-ONLY FEED

STREAM NUMBERS -

STREAM NAME

COMPONENT FLOU'S, LB/HR

\begin{tabular}{|c|c|c|}
\hline & $\mathrm{H} 2 \mathrm{O}$ & .0000 \\
\hline 45 & $A g$ & .0000 \\
\hline 116 & $\operatorname{Ag} 20$ & .0000 \\
\hline 184 & AgNO3 & .0000 \\
\hline 51 & AgOll & .0000 \\
\hline 74 & Ail (OII) 3 & .0000 \\
\hline 77 & A1203 & .0000 \\
\hline 75 & A $100 \mathrm{H}$ & .0000 \\
\hline 106 & B203 & .0000 \\
\hline 9 & $\mathrm{Ba}(\mathrm{NO3}) 2$ & .0000 \\
\hline 95 & $\mathrm{BaCl2}$ & .0000 \\
\hline 15 & $\mathrm{BaO}$ & .0000 \\
\hline 24 & BaS04 & .0000 \\
\hline 66 & $\mathrm{CO}$ & .0000 \\
\hline 87 & $\mathrm{CO2}$ & .0000 \\
\hline 142 & $\operatorname{co2}(\mathrm{C} 14)$ & .0000 \\
\hline 63 & $\mathrm{Ca}(\mathrm{COOII}) 2$ & .0000 \\
\hline 120 & $\mathrm{Ca}(\mathrm{OH}) 2$ & .0000 \\
\hline 113 & $\mathrm{Ca3}(\mathrm{PO} 4) 2$ & .0000 \\
\hline 20 & $\mathrm{CaC204}$ & .0000 \\
\hline 18 & $\mathrm{CaCO3}$ & .0000 \\
\hline 78 & $\mathrm{CaF2}$ & .0000 \\
\hline 41 & $\mathrm{CaO}$ & .0000 \\
\hline 19 & CaS04 & .0000 \\
\hline 29 & Carbon & .0000 \\
\hline 26 & $\mathrm{Co}(\mathrm{COOH}) 2$ & .0000 \\
\hline 121 & $\mathrm{Co}(\mathrm{OH}) 2$ & .0000 \\
\hline 53 & $\mathrm{Co}(\mathrm{OH}) 3$ & .0000 \\
\hline 59 & $\mathrm{CoO}$ & .0000 \\
\hline 99 & $\mathrm{Cr}(\mathrm{OH}) \mathrm{3}$ & .0000 \\
\hline 98 & Cr203 & .0000 \\
\hline 42 & $\operatorname{cs} 20$ & .0000 \\
\hline 137 & Cs20 Semi Vol & .0000 \\
\hline 90 & $\mathrm{CsCOOH}$ & .0000 \\
\hline 96 & $\mathrm{CsCl}$ & .0000 \\
\hline 136 & Cscl Semi Vol & .0000 \\
\hline 8 & CsNO3 & .0000 \\
\hline 88 & CsResin & .0000 \\
\hline 122 & $\mathrm{Cu}(\mathrm{COOH}) 2$ & .0000 \\
\hline 52 & $\mathrm{Cu}(\mathrm{OH}) 2$ & .0000 \\
\hline 58 & Cu20 & .0000 \\
\hline 64 & $\mathrm{CuCOOH}$ & .0000 \\
\hline 130 & $\mathrm{CuO}$ & .0000 \\
\hline 13 & $\mathrm{Fe}(\mathrm{OH}) 3$ & .0000 \\
\hline & Fe203 & .0000 \\
\hline
\end{tabular}

Appendix $\mathrm{H}$

Table 21-15

Page 098 of 178

Date 09/30/82 Rev 09

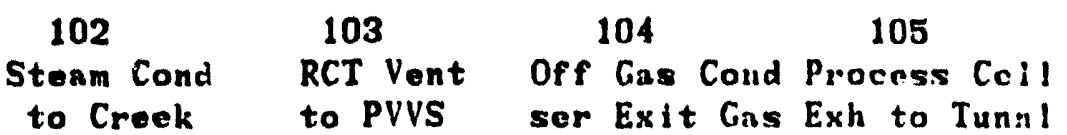

19.68

.0000

.0000

.0000

$.2484 E-11$

$.2672 E-08$

.0000

.0000

$.4596 \mathrm{E}-08$

$.2110 E-16$

.0000

.0000

$.1904 \mathrm{E}-10$

$.4668 \mathrm{E}-04$

$.1459 E-01$

$.1126 \mathrm{E}-16$

.0000

.3761E-09

$.4744 \mathrm{E}-10$

$.5131 \mathrm{E}-10$

.0000

$.1283 \mathrm{E}-10$

.0000

$.6027 \mathrm{E}-10$

$.1283 \mathrm{E}-10$

.0000

$.6506 \mathrm{E}-11$

.0000

.0000

$.4876 \mathrm{E}-10$

.0000

.8699E-13

.0000

.0000

$.6508 \mathrm{E}-11$

.0000

$.1353 E-11$

.0000

.0000

$.1415 E-10$

.0000

.0000

.0000

$.6468 \mathrm{E}-08$

.0000
50.04

.0000

.0000

$.1862 E-09$

$.1170 \mathrm{E}-06$

.0000

.0000

.2012E-06

$.1536 \mathrm{E}-14$

.0000

.0000

. 1389E-08

5.598

13.09

$.2189 \mathrm{E}-23$

$.4817 \mathrm{E}-07$

.0000

.3460E-08

$.3742 E-08$

.0000

$.9356 \mathrm{E}-09$

.0000

$.4396 \mathrm{E}-08$

$.9356 \mathrm{E}-09$

.0000

.0000

.0000

.0000

.3557E-08

.0000

$.1402 \mathrm{E}-13$

.0000

.0000

$.5066 \mathrm{E}-07$

.0000

$.9855 \mathrm{E}-10$

.0000

$.1625 \mathrm{E}-08$

.0000

.0000

.0000

.0000

.2831E-06

.0000
.0000
9570.

$.3480 \mathrm{E}-10$

.0000

$.5713 E-10$

$.1091 \mathrm{E}-10$

$.1305 E-0 S$

.0000

.0000

$.4952 \mathrm{E}-08$

. $1712 E-16$

.0000

.0000

$.1047 \mathrm{E}-10$

.0000

.0000

. 2412E-00

.5362E-09

$.3601 E-12$

$.8856 \mathrm{E}-10$

$.4171 \mathrm{E}-10$

.0000

$.1043 \mathrm{E}-10$

.0000

$.4899 \mathrm{E}-10$

$.1043 E-10$

$.8466 \mathrm{E}-08$

$.6220 \mathrm{E}-14$

.0000

.0000

$.8964 \mathrm{E}-10$

.0000

$.2028 E-15$

.0000

.0000

$.6569 \mathrm{E}-14$

.0000

$.1098 \mathrm{E}-11$

.0000

$.1808 \mathrm{E}-10$

$.1855 E-13$

.0000

.0000

.0000

$.3158 E-03$ .0000 . 
DPSP $80-1088$

MATERIAL BALANCE TABLES

SLUDGE-ONLY FEED

STREAMS (CONT'D)-

STREAM NAME

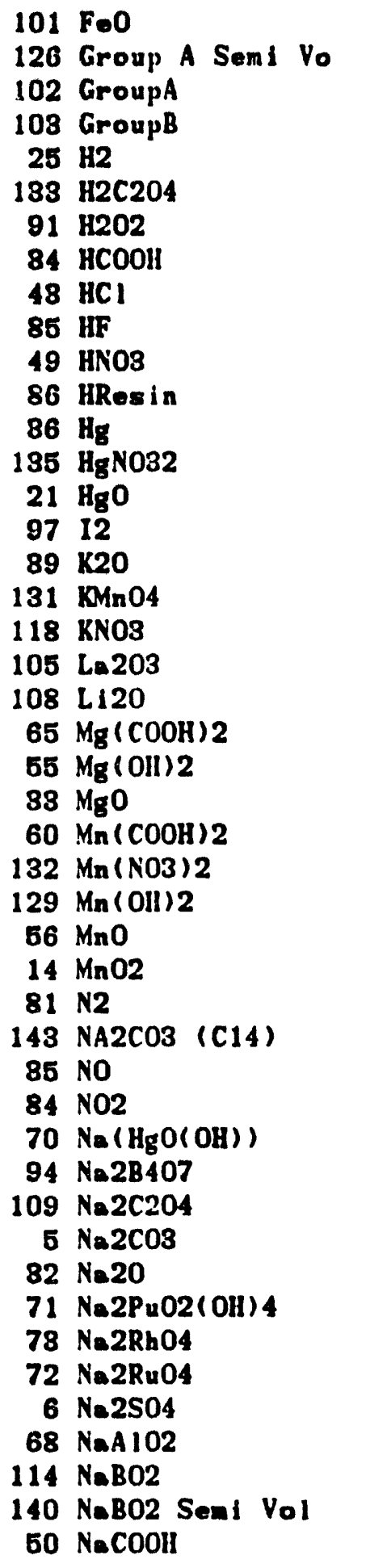

Appond 1x H

Table 21-15

Page 099 of 173

Date 09/80/52 Rev 09

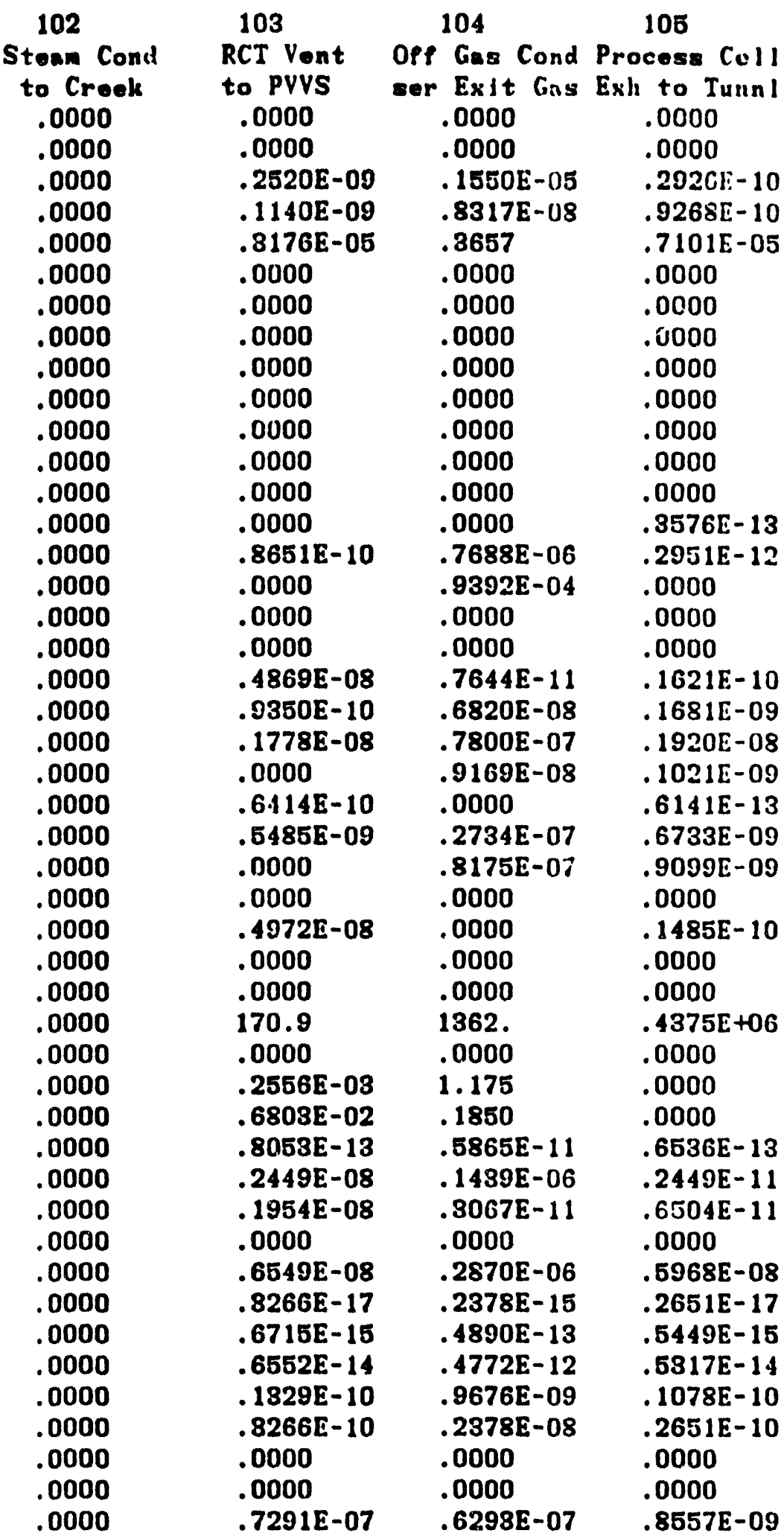


DPSP $80-1033$

MATERIAL BALANCE TABLES

SLUDGE-ONLY FEED

STREAMS (CONT'D) -

SIREAM NAME

$7 \mathrm{NaCl}$

$138 \mathrm{NaCl}$ Seml Vol

$60 \mathrm{NaF}$

$109 \mathrm{NaF}$ Semi Vol

$12 \mathrm{NnI}$

$125 \mathrm{Nal}$ Semi Vol

$8 \mathrm{Na}$. 02

$2 \mathrm{NaNO}$

$4 \mathrm{NaOll}$

87 NaRes in

G1 Nil(COCH)2

$17 \mathrm{Ni}(\mathrm{Oll}) 2$

$40 \mathrm{NiO}$

8202

$67 \mathrm{PbO}$

$29 \mathrm{PbSO}$

$124 \mathrm{Pd}$

$123 \mathrm{Pd}(\mathrm{Oll}) 2$

112 PdN03?

11) $\mathrm{PdO}$

$117 \mathrm{Pu}(\mathrm{COCH}) 4$

$76 \mathrm{Pu} 02$

$22 \mathrm{Rh02}$

$7 . \mathrm{Ru}_{\mathrm{u}} \mathrm{2}$

23 Ru02 Semi Vol

$83 \mathrm{Ru} 04$

8 S $\mathrm{SO2}$

$111 \mathrm{SiO}$

$11 !$ Sillic: Gel

$4 \because \operatorname{Sr}(\mathrm{CO}: 1) 2$

10 $\mathrm{Sr}(\mathrm{NOC}) 2$

12: $\mathrm{Sr}(\mathrm{OII}) 2$

3C. $\mathrm{SrCO} 3$

$40 \mathrm{SrO}$

8?' SrRESIN

141 Surfactant

92 Th02

107 T102

115 Tritiun

G? 102

.2 V02(COU) $) 2$

16 V02(Oll) 2

$27 \mathrm{Y}(\mathrm{COOH}) 3$

$11 Y(\mathrm{NOS}) \mathrm{s}$

$128 Y($ OII) 3

$31 \mathrm{Y} 2(\mathrm{CO}) 3$
102

Stoun Cond

to Creok

.0000

.0000

.0000

.0000

.0000

.0000

.0000

.0000

.0000

.0000

.0000

.0000

.0000

.0000

.0000

.0000

.0000

.0000

.0000

.0000

.0000

.0000

.0000

.0000

.0000

.0000

.0000

.0000

.0000

.0000

.0000

.0000

.0000

.0000

.0000

.0000

.0000

.0000

.0000

.0000

.0000

.0000

.0000

.0000

.0000

.0000
Appondix

Table 21-15

Page 100 of 173

Dnto 09/80/82 Res 09

103

RCT Vent to PVVS

.2389E-08

.0000

$.2172 \mathrm{E}-08$

.0000

$.1580 \mathrm{E}-09$

.0000

.0000

$.7887 E-07$

$.8972 E-07$

.0000

.0000

.2464E-09

.0000

51.63

.0000

$.1792 \mathrm{E}-10$

.0000

.0003

.0000

.0000

.0000

$.4663 \mathrm{E}-11$

$.1782 \mathrm{E}-11$

$.923 .1 \mathrm{E}-10$

.0000

.0000

$.9028 \mathrm{E}-05$

$.1935 E-07$

.0000

.0000

$.1882 E-16$

$.1099 \mathrm{E}-10$

.0000

.0000

.0000

.0000

$.7309 \mathrm{E}-10$

$.1820 \mathrm{E}-09$

$.8440 \mathrm{~L}-11$

.0000

.0000

$.4316 \mathrm{E}-09$

.0000

$.1337 \mathrm{E}-16$

$.6870 \mathrm{E}-11$

.0000
104

off Gas Cend Process Cell

sor Exit Gas Exh to Tunnl

$.1144 E-04 \quad .1821 E-10$

$.0000 \quad .000$ i

$.9035 \mathrm{~L}-03 \quad .231: 5-11$

.0000

$.1098 \mathrm{E}-0 \mathrm{E}$

.0000

.0000

$.8108 \mathrm{~L}-07$

.0000

.0000

.2883E-07

.0000

.0000

411.4

.0000

$.1807 \mathrm{E}-08$

.0000

.0000

.0000

.0000

.0000

.8401 !:-n9

$.1290 \mathrm{E}-119$

$.7568 \mathrm{E}-(166$

.0000

.0000

.8755

.8470 : -06

.0000

$.11711:-08$

$.1371 \mathrm{E}-14$

.0000

.0000

.0000

.0000

.0000

.5332E-08

. 1864E-07

$.7856 \mathrm{E}-11$

.0000

$.8729 E-07$

.0000

$.8021 E-09$

$.9735 \mathrm{E}-15$

.0000

.0000
.000 :

$.1201:-11$

.1000

.3000

$.6822:-09$

$.2701 \div-12$

.000 ?

$.320: \div-09$

.235 : -12

.00011

$.132:$ Et+Co

.000 :

$.145(: \because-10$

.00011

.00011

.000 !

.00011

.00011

$.3790 "=11$

$.1448 i-11$

$.7173 \mathrm{E}-11$

.0000

.0000

.0000

.2011:-07

.0000

$.1308:-10$

. $152 \varepsilon !:-16$

. $1052 \mathrm{E}-13$

.0000

.0000

.0000

.0000

$.5941 \mathrm{E}-10$

.3362E-09

$.1168 \mathrm{E}-09$

.0000

$.4160 \mathrm{E}-09$

$.4183 E-12$

$.8928 \mathrm{~F}-11$

$.1085 \mathrm{E}-16$

$.6578 \mathrm{E}-14$

.0000 . 
MATERIAL BALANCE TABLES

Date 09/30/82 Rev 09

SLUDSE-OYLL FEED

STREAMS (CONT'D)-

STREAM IAAME

$\begin{array}{rl}47 & Y 203 \\ 100 & \mathrm{Zeull} \\ 44 & \mathrm{Zn}(\mathrm{c} \text { (0) } \\ 54 & \mathrm{Zn}(011) 2 \\ 57 & \mathrm{ZnO} \\ 104 & \mathrm{Zr} 02\end{array}$

TOTAL FLOH, LB/IIR

VAPOR FLOH, CFM

LIOYID TIOH, GPY DESIGN FLOH,

DEXSITY, LBS/FT3

TEMPERATURE, DEG C

PRESSLRE, ATY

PRESSLRE, PSIG

PRESSLRE, MO HG

PIIASE

E.TTIALPY, PCU/IIR

102
Steam Cond
to Creek
.0000
.0000
.0000
.0000
.0000
.0000
.00

.0000

85.00

1.00

.00

$N / A$

.00
103

RCT Vent

to PVVS

.0000

$.4673 E-09$

.0000

$.3716 \mathrm{E}-10$

.0000

$.9350 \mathrm{E}-10$

212.22

64.41

.0627

50.00

.97

$-.51$

733.86

VAPOR

$-961.48$

$\begin{array}{cc}104 & 105 \\ \text { off Gas Cond Process Coll } \\ \text { ser Exit Gas Exh to Tunn } \\ .0000 & .0000 \\ .8408 E-07 & .8798 E-C 9 \\ .4238 E-08 & .4717 E-10 \\ .0000 & .3558 E-13 \\ .0000 & .0090 \\ .6820 E-08 & .1681 E-09 \\ 1844.37 & 579240.71 \\ 486.81 & 137810.79\end{array}$

.0632

27.99

.88

$-1.75$

669.56

VAPOR

$-82844.09-29829812.75$ 
DPSP $80-1033$

MATERIAL BALANCE TABLES

SLUDGE-ONLY FEED

STREAM NUMBERS -

STREAM NAME

COMPONENT FLOHS, LB/IIR

\begin{tabular}{|c|c|c|c|c|c|}
\hline 1 & H2O & 8.778 & .0000 & .0000 & .2073 \\
\hline 45 & $\mathrm{Ag}$ & .0000 & .0000 & .0000 & S000' \\
\hline 116 & Ag20 & .0000 & .0000 & .0000 & .0000 \\
\hline 134 & AgNO3 & .0000 & .0000 & .0000 & .0000 \\
\hline 51 & AgOll & $.1005 \mathrm{E}-03$ & $.9308 E-10$ & $.4654 E-10$ & . CT2SE-0S \\
\hline 74 & All(OII) 3 & .1081 & $.6848 \mathrm{E}-07$ & $.202 .1 E-07$ & $.3532 E-43$ \\
\hline 77 & A1203 & .0000 & .0000 & .0000 & .0000 \\
\hline 75 & AlOOH & .0000 & .0000 & .0000 & .0000 \\
\hline 106 & B203 & .1860 & $.1006 \mathrm{E}-00$ & $.5029 E-07$ & $.4687 \mathrm{E}-05$ \\
\hline 9 & $\mathrm{Ba}(\mathrm{XO3}) 2$ & $.4213 E-11$ & $.7682 E-15$ & $.3841 E-15$ & $.4705 E-11$ \\
\hline 95 & $\mathrm{BaC} 12$ & .0000 & .0000 & .0000 & .0000 \\
\hline 15 & $\mathrm{BaO}$ & .0000 & .0000 & .0000 & .0000 \\
\hline 24 & $\mathrm{BaSO4}$ & $.7704 \mathrm{E}-03$ & $.6943 E-00$ & $.3471 E-09$ & $.4253 E-05$ \\
\hline 66 & $\mathrm{CO}$ & $.2192 E-10$ & .0000 & .0000 & $.8414 E-2 \hat{U}$ \\
\hline 37 & $\mathrm{CO} 2$ & $.1723 E-06$ & .0000 & .0000 & $.6456 E-12$ \\
\hline 142 & $\operatorname{CO2}(\mathrm{C14})$ & .0000 & .0000 & .0000 & $.1290 \mathrm{E}-22$ \\
\hline 63 & $\mathrm{Ca}(\mathrm{COOH}) 2$ & .0000 & $.2409 E-07$ & $.1204 \mathrm{E}-07$ & $.1475 E-03$ \\
\hline 120 & $\mathrm{Ca}(\mathrm{OH}) 2$ & $.1522 E-01$ & .0000 & .0000 & $.1102 E-10$ \\
\hline 113 & $\mathrm{Ca} 3(\mathrm{P} 04) 2$ & $.1920 \mathrm{E}-02$ & $.1730 E-08$ & $.8651 E-03$ & $.10601 .-04$ \\
\hline 20 & $\mathrm{CaC204}$ & $.2076 \mathrm{E}-02$ & $.1871 \mathrm{E}-08$ & $.9356 E-09$ & $.11465-04$ \\
\hline 18 & $\mathrm{Ca}_{2} \mathrm{CO} 3$ & .0000 & .0000 & .0000 & .0000 \\
\hline 78 & CaF2 & $.5191 E-03$ & $.4678 \mathrm{E}-03$ & $.2339 E-00$ & $.2865 E-05$ \\
\hline 41 & $\mathrm{CaO}_{2}$ & .0000 & .0000 & .0000 & .0000 \\
\hline 19 & $\mathrm{CaSO4}$ & $.2439 E-02$ & $.2198 E-08$ & $.1099 E-0 \Omega$ & $.1346 E-04$ \\
\hline 29 & Carbon & $.5191 E-03$ & . 4678E-09 & $.2339 E-09$ & $.2865 E-05$ \\
\hline 26 & Col(COOII) 2 & .0000 & .0000 & .0000 & $.23295-05$ \\
\hline 121 & $\mathrm{Co}(\mathrm{OH}) 2$ & $.2633 \mathrm{E}-03$ & .0000 & .0000 & $.1006 E-18$ \\
\hline 53 & $\mathrm{Co}(\mathrm{OH}) 3$ & .0000 & .0000 & .0000 & .0000 \\
\hline 59 & $\mathrm{CoO}$ & .0000 & .0000 & .0000 & .0000 \\
\hline 99 & $\mathrm{Cr}(\mathrm{OH}) 3$ & $.1973 E-02$ & . 1778E-08 & $.8892 E-03$ & $.1089 E-04$ \\
\hline 98 & C.r203 & .0000 & .0000 & .0000 & .0000 \\
\hline 42 & Cs20 & $.1497 E-05$ & $.7010 E-14$ & $.3505 E-14$ & $.4294 E-10$ \\
\hline 137 & Cs20 Semi Vol & .0000 & .0000 & .0000 & .0000 \\
\hline 90 & $\mathrm{CsCOOH}$ & .0000 & .0000 & .0000 & .0000 \\
\hline 96 & $\mathrm{CsCl}$ & $.1800 \mathrm{E}-05$ & $.2533 E-07$ & $.1266 E-07$ & $.2763 E-10$ \\
\hline 136 & Cscl Semi Vol & .0000 & .0000 & .0000 & .0000 \\
\hline 8 & CsNO3 & $.2703 E-06$ & $.4927 E-10$ & $.2464 E-10$ & $.3018 E-0 G$ \\
\hline 88 & CsResin & .0000 & .0000 & .0000 & .0000 \\
\hline 122 & $\mathrm{Cu}(\mathrm{COOH}) 2$ & .0000 & $.8123 E-09$ & $.4062 E-09$ & $.4976 E-05$ \\
\hline 52 & $\mathrm{Cu}(\mathrm{OH}) 2$ & $.5727 E-03$ & .0000 & .0000 & $.4146 \mathrm{E}-18$ \\
\hline 58 & Cu20 & .0000 & .0000 & .0000 & .0000 \\
\hline 64 & $\mathrm{CuCOOH}$ & .0000 & .0000 & .0000 & .0000 \\
\hline 130 & $\mathrm{CuO}$ & .0000 & .0000 & .0000 & .0000 \\
\hline 18 & Fe $(\mathrm{OH}) 3$ & .2618 & $.1416 E-06$ & $.7078 E-07$ & $.8671 \mathrm{E}-03$ \\
\hline 80 & Fe203 & .0000 & .0000 & .0000 & $.0000^{\circ}$ \\
\hline
\end{tabular}

Appendix H

Toblo 21-15

Pnge 102 of 173

Date 09/30/S2 Rev 30 $\begin{array}{llll}106 & 107 & 109 & 109\end{array}$

Recycle fron Ru Absorber I2 Absorber Spent linsh

Tank Farm Accumulation Accumulation Mini $[$ t: Sli:T

\begin{tabular}{|c|c|c|c|}
\hline 3.778 & .0000 & .0000 & .2073 \\
\hline .0000 & .0000 & .0000 & נ.000' \\
\hline .0000 & .0000 & .0000 & .0000 \\
\hline .0000 & .0000 & .0000 & .0000 \\
\hline $1005 E-03$ & $.9308 E-10$ & $.4654 E-10$ & . ET2SE-0S \\
\hline 1081 & . 5848E-07 & $.2024 E-07$ & $.35325-43$ \\
\hline .0000 & .0000 & .0000 & .0000 \\
\hline .0000 & .0000 & .0000 & .0000 \\
\hline .1860 & $.1006 \mathrm{E}-00$ & $.5029 E-07$ & $.4687 \mathrm{E}-05$ \\
\hline $4213 E-11$ & $.7682 E-15$ & $.3841 E-15$ & $.4705 E-11$ \\
\hline .0000 & .0000 & .0000 & .0000 \\
\hline .0000 & .0000 & .0000 & .0000 \\
\hline $.7704 E-03$ & .6943E-00 & $.3471 E-09$ & $.4253 E-05$ \\
\hline $.2192 E-10$ & .0000 & .0000 & $.8414 E-20$ \\
\hline $.1723 E-06$ & .0000 & .0000 & $.6456 E-12$ \\
\hline .0000 & .0000 & .0000 & $.1290 \mathrm{E}-22$ \\
\hline .0000 & $.2409 E-07$ & $.1204 \mathrm{E}-07$ & $.1475 E-03$ \\
\hline $1522 \mathrm{E}-01$ & .0000 & .0000 & $.1102 E-16$ \\
\hline $1920 \mathrm{E}-02$ & $.1730 E-08$ & $.8651 E-03$ & $.10605-04$ \\
\hline $.2076 \mathrm{E}-02$ & . 1871E-08 & $.9356 E-09$ & $.11465-04$ \\
\hline .0000 & .0000 & .0000 & .0000 \\
\hline $.5191 E-03$ & $.4678 \mathrm{E}-09$ & $.2339 E-00$ & $.2865 E-05$ \\
\hline .0000 & .0000 & .0000 & .0000 \\
\hline .2439E-02 & $.2198 \mathrm{E}-08$ & $.1099 \mathrm{E}-0 \Omega$ & $.1346 E-04$ \\
\hline $.5191 E-03$ & . 4678E-09 & $.2339 E-09$ & $.2865 E-05$ \\
\hline .0000 & .0000 & .0000 & $.2329 \sqrt{-}-05$ \\
\hline 2633E-03 & .0000 & .0000 & $.1006 E-18$ \\
\hline .0000 & .0000 & .0000 & .0000 \\
\hline .0000 & .0000 & .0000 & .0000 \\
\hline . 1973E-02 & . 1778E-08 & $.8892 E-03$ & $.1089 E-04$ \\
\hline .0000 & .0000 & .0000 & .0000 \\
\hline . 1497E-05 & $.7010 \mathrm{E}-14$ & $.3505 E-14$ & $.4294 E-10$ \\
\hline .0000 & .0000 & .0000 & .0000 \\
\hline .0000 & .0000 & .0000 & .0000 \\
\hline $1800 \mathrm{E}-05$ & . 2533E-07 & $.1266 E-07$ & $.2763 E-10$ \\
\hline 0000 & .0000 & .0000 & .0000 \\
\hline $2703 E-06$ & . 4927E-10 & $.2464 E-10$ & $.3018 E-0 G$ \\
\hline .0000 & .0000 & .0000 & .0000 \\
\hline .0000 & $.8123 E-09$ & $.4062 E-09$ & $.4976 \mathrm{E}-05$ \\
\hline .5727E-03 & .0000 & .0000 & $.4146 \mathrm{E}-18$ \\
\hline .0000 & .0000 & .0000 & .0000 \\
\hline .0000 & .0000 & .0000 & .0000 \\
\hline .0000 & .0000 & .0000 & .0000 \\
\hline 2618 & $.1416 E-06$ & $.7078 E-07$ & $.8671 \mathrm{E}-03$ \\
\hline .0000 & .0000 & .0000 & $.0000^{\circ}$ \\
\hline
\end{tabular}


BATER IAL BALANCE TABLES

Date $09 / 30 / 82$ Rev 09

\section{SLLDGE-ONLY FEED}

STREAWS(CONT'D)-

STREAII NAME

100

107

108

109

Recycle from Ru Absorber I2 Absorber Spent Wish

$101 \mathrm{FeO}$

Tank Farm

Accunulation Accumulation MHWT to SRAT

126 Grouis A Semi Vo

.0000

.0000

.0000

.0000

.0000

102 Groupl:

$.1020 \mathrm{E}-01$

.0000

.0000

.0000

103 Gro:sp B

25112

$133 \mathrm{H} 2 \mathrm{C} 204$

9111202

34 IICOOH

$43 \mathrm{HCl}$

$85 \mathrm{IIF}$

49 IINO3

86 HIResin

$36 \mathrm{Hg}$

135 Hg:.03?

$.4614 \mathrm{E}-02$

.7749E-06

$.3875 \mathrm{E}-06$

$.7981 \mathrm{E}-05$

$.8113 E-09$

.0000

$.4158 \mathrm{E}-08$

$.2079 \mathrm{E}-08$

.2547E-04

.0000

.0000

.0000

$.1459 E-24$

.0000

.0000

.0000

.0000

.0000

.0000

.0000

.0000

.0000

.0000

.0000

$.3236 \mathrm{E}-04$

.0000

.0000

.0000

.0000

.0000

.0000

.0000

.0000

.0000

.0000

.0000

.0000

.0000

.0000

.0000

.0000

.0000

$.3501 \mathrm{E}-02$

.0000

.0000

.0000

$.3844 \mathrm{E}-06$

5712

$39 \mathrm{~K} 20$

$131 \mathrm{kMnO} 04$

118 K.N03

$105 \mathrm{La} 203$

108 Li 20

$65 \mathrm{Mg}(\mathrm{COOH}) 2$

.0000

.0000

.0000

$.1922 \mathrm{E}-06$

.0000

.0000

.0000

$.9299 \mathrm{E}-04$

$.451 .4 E-06$

.0000

$.3822 \mathrm{E}-11$

.0000

.0000

$.0724 \mathrm{E}-03$

$.3410 \mathrm{E}-08$

$.8784 \mathrm{E}-02$

$.3900 E-07$

$.4585 \mathrm{E}-08$

.0000

$55 \mathrm{Mg}(\mathrm{OH}) 2$

$33 \mathrm{MigO}$

$60 \mathrm{Mn}(\mathrm{COOH}) 2$

$132 \operatorname{Mn}\left(\mathrm{X}_{03}\right) 2$

$129 \mathrm{Min}(\mathrm{Ol:}) 2$

$56 \mathrm{MnO}$

$14 \mathrm{MnO2}$

$\begin{array}{lll}\varepsilon 1 & \wedge 2\end{array}$

143 N:2(CO3 (C14)

35 . 0

$84 \quad 102$

$70 \mathrm{Na}$ (HgO(OII))

$94 \mathrm{~N} 2 \mathrm{~B} 4 \mathrm{OT}$

$109 \mathrm{Na} 2 \mathrm{C} 204$

$5 \mathrm{Na} 2 \mathrm{CO3}$

32 ia20

$71 \mathrm{Na} 2 \mathrm{Pu} 02$ (Oll) 4

$73 \mathrm{Na} 2 \mathrm{~h} 04$

$72 \mathrm{Na} 2 \mathrm{RuO}_{4}$

$6 \mathrm{Na} 2 \mathrm{SO} 4$

$63 \mathrm{NaAlO2}$

$114 \mathrm{NaBO2}$

140 NaEO2 Semi Vol

$50 \mathrm{NaCOOll}$

$.2596 \mathrm{E}-02$

.2220E-01

.0000

.0000

.2012

.0000

.0000

$.6340 \mathrm{E}-04$

.0000

.0000

. 1367E-07

$.4087 \mathrm{E}-07$

.0000

.0000

.0000

.0000

.0000

.0000

$.1911 \mathrm{E}-11$

.0000

.1705E-08

.234 1E-07

$.1950 \mathrm{E}-07$

.2292E-08

.0000

$8982 \mathrm{E}-07$

$.1812 \mathrm{E}-05$

.2808E-04

$.6835 \mathrm{E}-08$

$.1879 \mathrm{E}-17$

.2044E-07

.0000

.0000

.0000

.0000

.0000

.0000

.0000

.0000

.0000

$.5408 \mathrm{E}-06$

$.2504 \mathrm{E}-03$

.0000

$.1684 E-15$

.0000

.0000

.2769E-09

.0000

$.1466 \mathrm{E}-11$

$.1608 \mathrm{E}-07$

.0000

$.3598 E-07$

$.7195 \mathrm{E}-07$

$.7667 E-12$

.0000

$.4353 \mathrm{E}-05$

.0000

$.1572 E-15$

$.8721 \mathrm{E}-12$

$.4892 E-03$

$.1533 E-11$

.0000

.2650

.0000

$.1435 \mathrm{E}-06$

$.7174 \mathrm{E}-07$

$.1796 \mathrm{E}-07$

$.1030 E-07$

$.9393 E-08$

.0000

$.6523 E-12$

$.1189 \mathrm{E}-15$

. 5946E- 16

$.6629 \mathrm{E}-05$

. $1341 \mathrm{E}-09$

.1222E-13

$.7284 \mathrm{E}-12$

.2445E-13

$.1193 E-12$

$.1498 \mathrm{E}-09$

1309E-08

$.2386 \mathrm{E}-12$

$.2419 \mathrm{E}-09$

$1461 \mathrm{E}-0 \mathrm{~S}$

$.4838 \mathrm{E}-09$

$.1189 \mathrm{E}-08$

.5946E-09

2963E-05

$.6523 \mathrm{E}-05$

.0000

.0000

$.7284 \mathrm{E}-05$

.0000

.0000

.0000

.0000

.0000

$.1456 \mathrm{E}-01$

. 3146E-07

. 1573E-07

.1906E-03 
DPSP $80-1033$

MATERIAL BALANCE TARLES SLUDGE-ONLY FEED

STREAMS (CONT'D) -

STREAM NAME

$7 \mathrm{NaCl}$

$138 \mathrm{NaCl}$ Semi Vol

$69 \mathrm{NaF}$

$139 \mathrm{NaF}$ Semi Vol

$12 \mathrm{NaI}$

$125 \mathrm{NaI}$ Semi Vol

$8 \mathrm{NaNO}$

$2 \mathrm{NaNO3}$

$4 \mathrm{NaOHI}$

87 NaResin

$61 \mathrm{Ni}(\mathrm{COOH}) 2$

$17 \mathrm{Ni}(\mathrm{Oll}) 2$

$40 \mathrm{NiO}$

8202

$67 \mathrm{PbO}$

$28 \mathrm{PbSO} 04$

$124 \mathrm{Pd}$

$123 \mathrm{Pd}(\mathrm{OH}) 2$

$112 \mathrm{PdNO} 032$

$110 \mathrm{PdO}$

$117 \mathrm{Pu}(\mathrm{COOH}) 4$

$76 \mathrm{Pu}^{02}$

$22 \mathrm{RhO}_{2}$

$79 \mathrm{Ru} 02$

23 Ru02 Semi Vol

$83 \mathrm{RuO4}$

$38 \mathrm{S02}$

$111 \mathrm{Si02}$

115 Silica Gel

$48 \mathrm{Sr}$ (COOHI) 2

$10 \mathrm{Sr}(\mathrm{N} 03) 2$

$127 \mathrm{Sr}$ (OH) 2

$30 \mathrm{SrCO}$

$46 \mathrm{SrO}$

89 SrRESIN

141 Surfactant

92 Th02

$107 \mathrm{TiO2}$

119 Tritium

93 V02

$62 \mathrm{V02}(\mathrm{COOH}) 2$

$16 \mathrm{VO} 2(\mathrm{OH}) 2$

$27 \mathrm{Y}(\mathrm{COOH}) \mathrm{S}$

$11 \mathrm{Y}(\mathrm{NO3}) 3$

$128 \mathrm{Y}(\mathrm{OII}) 3$

$31 \times 2(\mathrm{CO}) 3$
106

107

109

109

Recycle from Ru Absorber I2 Absorber Spent Hasia

Tank Farm

$.4672 \mathrm{E}-03$

.0000

$.4339 \mathrm{E}-03$

.0000

$.3156 \mathrm{E}-04$

.0000

.0000

$.1575 \mathrm{E}-01$

$.7933 E-02$

.0000

.0000

$.9970 \mathrm{E}-02$

.0000

$.3658 \mathrm{E}-04$

.0000

$.7251 \mathrm{E}-03$

.0000

.0000

.0000

.0000

.0000

$.1887 \mathrm{E}-03$

$.7210 E-04$

$.8737 E-02$

.0000

.0000

$.1266 \mathrm{E}-10$

.7832

.0000

.0000

$.8760 \mathrm{E}-11$

. 4447E-03

.0000

.0000

.0000

.0000

$.2958 \mathrm{E}-02$

$.7366 \mathrm{E}-02$

$.3765 \mathrm{E}-11$

.0000

.0000

$.1747 E-01$

.0000

$.2670 E-11$

$.2780 E-03$

.0000 Accumulation Accumulation Mitiz to Silir
$.5720 \mathrm{E}-05$

.0000

$.4518 \mathrm{E}-05$

.0000

$.5492 E-06$

.0000

.0000

$.1554 \mathrm{E}-07$

.0000

.0000

$.1441 E-07$

.0000

.0000

.0000

.0000

$.6534 \mathrm{E}-09$

.0000

.0000

.0000

.0000

.0000

$.1700 \mathrm{E}-09$

$.6497 \mathrm{E}-10$

$.3784 \mathrm{E}-06$

.0000

.0000

.0000

$.4235 \mathrm{E}-00$

.0000

$.5853 \mathrm{E}-09$

$.6855 \mathrm{E}-15$

.0000

.0000

.0000

.0000

.0000

$.2666 \mathrm{E}-08$

$.6819 \mathrm{E}-08$

.0000

.0000

$.1864 \mathrm{E}-07$

.0000

$.4010 \mathrm{E}-09$

$.4868 \mathrm{E}-15$

.0000

.0000
$.2860 \mathrm{E}-0 \mathrm{~J}$

.0000

$.2259 E-05$

.0000

$.2746 E-06$

.0000

.0000

$.77705-08$

.0000

.0000

.7207E-03

.0000

.0000

.0000

.0000

.3267E-09

.0000

.0000

.0000

.0000

.0000

$.8502 \mathrm{E}-10$

$.3240 \mathrm{E}-10$

. 1892E-06

.0000

.0000

.0000

.2117E-06

.0000

$.2926 \mathrm{E}-09$

$.3427 \mathrm{E}-15$

.0000

.0000

.0000

.0000

.0000

$.1333 \mathrm{E}-08$

$.3409 \mathrm{E}-08$

.0000

.0000

$.9321 \mathrm{E}-08$

.0000

.2005E-09

$.2434 \mathrm{E}-15$

.0000

.0000
.295i6i-C.J

.0000

$.1 \overline{0} \cdot 15 \mathrm{E}-37$

.0000

.2S01E-OS

.0000

.0000

$.9319 \mathrm{E}-0.1$

.0000

.0000

$.8828 \mathrm{E}-04$

$.7217 \mathrm{E}-17$

.0000

$.2511 E-05$

.0000

$.4003 E-03$

.0000

.0000

.0000

.0000

.0000

$.1042 E-05$

.3980E-06

$.1949 \mathrm{E}-05$

.0000

.0000

$.3239 E-25$

$.1857 \mathrm{E}-03$

.0000

$.3585 E-05$

$.4199 \mathrm{E}-11$

$.3219 E-18$

.0000

.0000

.0000

.0000

$.1633 \mathrm{E}-0.4$

$.1738 E-06$

$.9014 \mathrm{E}-14$

.0000

$.11425-03$

$.1265 \mathrm{E}-16$

$.2456 E-05$

$.2982 E-11$

$.2013 \mathrm{E}-18$

$.0000^{\circ}$
Appendix II

Inble 21-15

Page 104 of 173

Date $09 / 30 / 82$ Rev 09 
MATERIAL BALANCE TABLES

SLLDGE-OKLY FEED

STPRAMS(CONT'D)STREAM NAME

\section{$47 Y 203$ \\ 103 Zeolite \\ $44 \mathrm{Zn}(\mathrm{COOH}) 2$ \\ $54 \mathrm{Zn}(0 ! 1) 2$ \\ $57 \mathrm{ZnO}$ \\ 10.) $\mathrm{Zr} 02$}

TOI'AL FLOH, LB/IIS VAPOR FLOIi, CFM LIOUID FLON, GPY DFSIGY FLOH, DEISITY, LBS/FT3 TEYPERATURE, DEG C PRESSLRE, ATM PiIESSURE, PSIG PHESSLRE, MIIIG PIIASE

ENTHALPY, PCV/HR

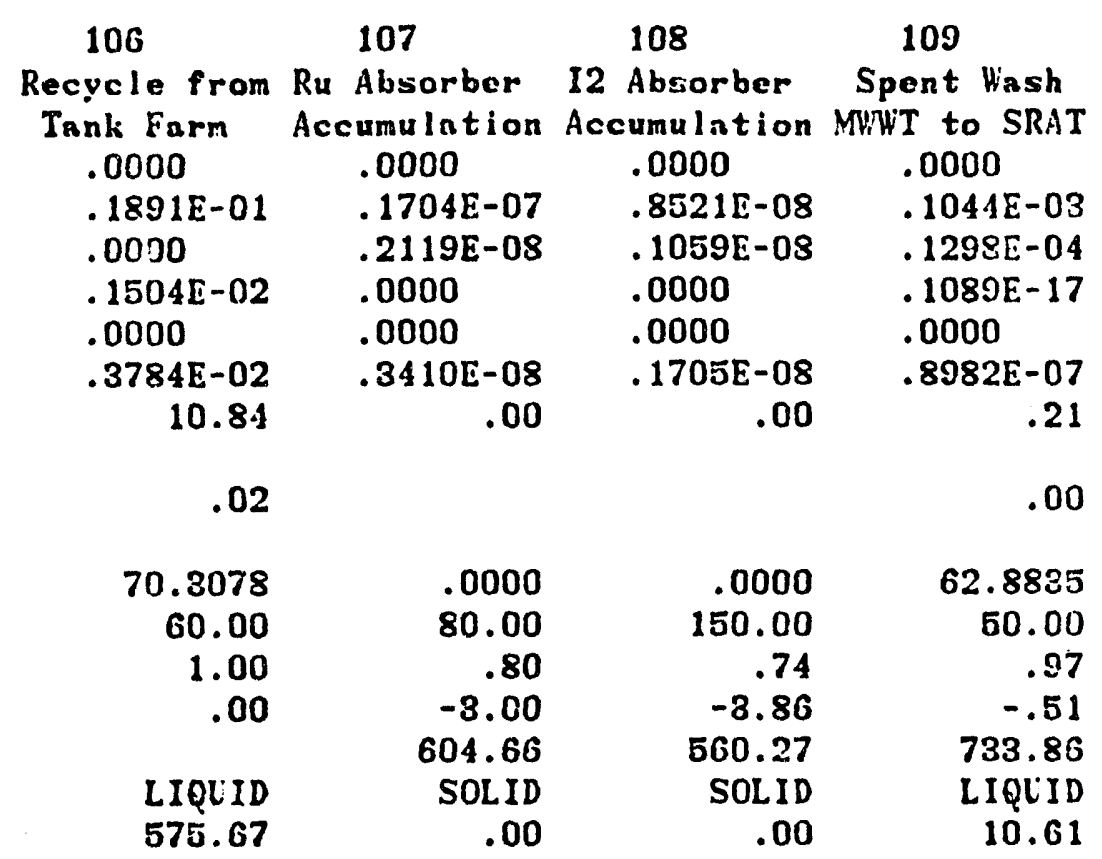


MATCRIAL BALANCE TABLES

SLUDGE-ONLY FEED

STREAM NUMBERS -

STREAM NAME

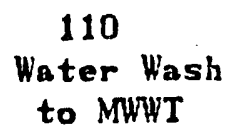

110

Water Wash to MWWT

COMPONENT FLOHS, LB/HR

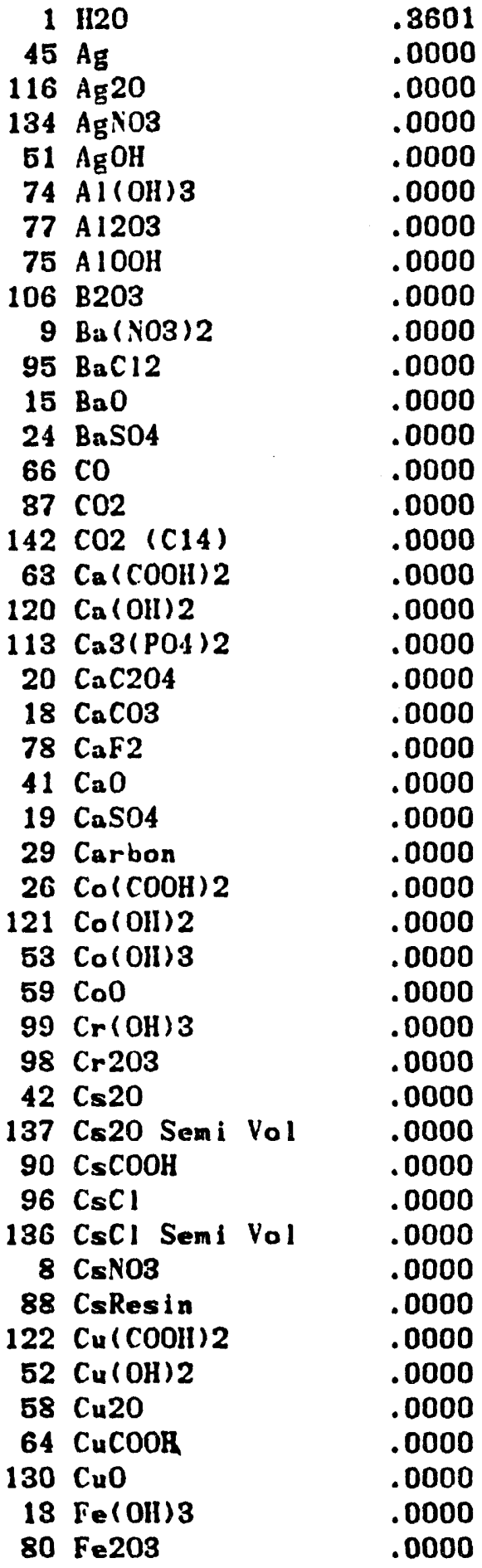

$111 \quad 112$

MUT:T Vent If from Birvis

to FAVC

$$
\text { to MAllI }
$$

$\begin{array}{lll}.2280 & .1194 \mathrm{E}-01 & .1600 \mathrm{E}-\mathrm{i} 2 \\ .3014 \mathrm{E}-07 & .1020 \mathrm{E}-01 & .0000 \\ .0000 & .0000 & .0000 \\ .0000 & .0000 & .0000 \\ .9463 \mathrm{E}-14 & .3299 \mathrm{E}-03 & .0000 \\ .5918 \mathrm{E}-09 & .2063 \mathrm{E}-04 & .0000 \\ .0000 & .0000 & .0000 \\ .0000 & .0000 & .0000 \\ .7744 \mathrm{E}-11 & .2699 \mathrm{E}-0.3 & .0000 \\ .7774 \mathrm{E}-17 & .2710 \mathrm{E}-12 & .0000 \\ .0000 & .0000 & .0000 \\ .0000 & .0000 & .0000\end{array}$

\section{$.7026 E-11$}

$.5332 \mathrm{E}-20$

$.1627 \mathrm{E}-07$

$.3252 E-18$

$.2437 \mathrm{E}-09$

.1820E-22

$.1751 \mathrm{E}-10$

$.1894 \mathrm{E}-10$

.0000

$.4734 \mathrm{E}-11$

.0000

$.2224 \mathrm{E}-10$

$.4734 E-11$

$.3848 \mathrm{E}-11$

$.3149 \mathrm{E}-24$

.0000

.0000

$.1800 \mathrm{E}-10$

.0000

$.7094 \mathrm{E}-16$

.0000

.0000

$.4564 \mathrm{E}-16$

.0000

$.4986 \mathrm{E}-12$

.0000

$.8220 \mathrm{E}-11$

$.6849 E-24$

.0000

.0000

.0000

$.1432 E-08$

.0000
$.2449 E-00$

$.4846 \mathrm{E}-27$

$.3718 E-13$

$.7431 E-24$

$.8496 E-05$

$.6345 \mathrm{E}-18$

.6103E-06

.6601 E-0G

.0000

.1650 E-06

.0000

$.7754 \mathrm{E}-0 \mathrm{G}$

. 1650E-06

. 1342E-06

$.1098 \mathrm{E}-19$

.0000

.0000

$.6274 \mathrm{E}-0 \mathrm{C}$

.0000

.2473E- 11

.0000

.0000

$.1591 E-11$

.0000

$.1738 \mathrm{E}-07$

.0000

.2866 E-06

.2388E-19

.0000

.0000

.0000

$.4994 \mathrm{E}-04$

.0000
113

Air Spirre?

to MHT

.0000

.0000

.0000

.0000

.0000

.0000

.0000

.0000

.0000

.0000

.0000

.0000

.0000

.0000

.0000

.0000

.0000

.0000

.0000

.0000

.0000

.0000

.0000

.0000

.0000

.0000

.0000

.0000

.0000

.0000

.0000

.0000

.0000 
MATERIAL BALANCE TABLES

Date 09/30/82 Rev 09

\section{S!.RDG!:-CNLY FEED}

STREAMS (CONT'D) -

STREAM NAME

$101 \mathrm{FuO}$

110

111

Niater Wash

to MHWT

126 Group A Serni Vo

.0000

102 Group:

.0000

103 Group B

25112

133 II2C201

Q1 11202

34 IICOOII

$43 \mathrm{HCl}$

$85 \mathrm{IIF}$

49 HNO3

86 IIResin

$30 \mathrm{Hg}$

135 IIGNO32

$21 \mathrm{HgO}$

$\begin{array}{ll}97 & 12\end{array}$

$39 \quad \mathrm{k} 20$

$131 \mathrm{kMnO4}^{2}$

118 KNO3

$105 \quad 20203$

108 Li20

$65 \mathrm{M}_{\mathrm{E}}(\mathrm{COOII}) 2$

.0000

.0000

.0000

.0000

.0000

.0000

.0000

.0000

.0000

.0000

.0000

.0000

.0000

.0000

.0000

.0000

.0000

.0000

.0000

.0000

$55 \mathrm{Mg}(\mathrm{O} ! 1) 2$

33 M $\mathrm{M}_{\mathrm{g}} \mathrm{O}$

$60 \mathrm{Mn}(\mathrm{COOH}) 2$

.0000

.0000

.0000

.0000

$132 \mathrm{Mn}(.03) 2$

$129 \mathrm{Mn}(\mathrm{OH}) 2$

$50 \mathrm{MnO}$

$14 \mathrm{Nin02}$

$81 \mathrm{~N} 2$

$143 \mathrm{~N}: 2 \mathrm{CO}$ (C14)

$35 \mathrm{NO}$

$84 \quad \mathrm{N02}$

$70 \mathrm{Na}(\mathrm{Hg} \mathrm{O}(\mathrm{OH}))$

94 Va2B407

$109 \mathrm{Na} 2 \mathrm{C} 204$

$5 \mathrm{ra} 2 \mathrm{CO} 3$

32 ia 20

$71 \mathrm{Na} 2 \mathrm{Pu} 02$ (OII) 4

$73 \mathrm{Na}_{2} \mathrm{RhO}_{4}$

$72 \mathrm{Na}_{2 \mathrm{Ru} 04}$

$6 \mathrm{Na} 2 \mathrm{SO}$

$68 \mathrm{NaA} 102$

.0000

.0000

.0000

.0000

.0000

.0000

.0000

.0000

.0000

.0000

.0000

.0000

.0000

.0000

.0000

.0000

.0000

.0000

$114 \mathrm{NaBO2}$

$110 \mathrm{NaBO2}$ Semi Vol

.0000

$50 \mathrm{NaCOOH}$

.0000

MUVIT Vent

to FAVC

.0000

.0000

$.1318 \mathrm{E}-10$

$.4208 \mathrm{E}-10$

$.8976 \mathrm{E}-19$

.0000

.0000

.3326E-04

.0000

.0000

.0000

.0000

$.2936 \mathrm{E}-03$

.0000

$.7457 \mathrm{E}-12$

.0000

.0000

.0000

$.8868 \mathrm{E}-13$

$.1484 \mathrm{E}-12$

$.2994 \mathrm{E}-11$

$.4640 \mathrm{E}-10$

.3104E-23

$.8935 \mathrm{E}-12$

$.4136 \mathrm{E}-09$

.0000

$.2782 E-21$

.0000

.0000

3.492

.0000

$.4317 \mathrm{E}-10$

$.4293 \mathrm{E}-10$

$.2968 \mathrm{E}-13$

. 1701E-13

$.1552 \mathrm{E}-13$

.0000

. 1095E-10

$.1203 E-17$

$.2474 E-15$

$.2414 \mathrm{E}-14$

$.4896 \mathrm{E}-11$

. 1203E- 10

.0000

.0000

.3148E-09
Hg from MHTT

to MAVIT

.0000

.0000

.4596 E-06

.1467E-05

$.8403 E-26$

.0000

.0000

$.1864 \mathrm{E}-05$

.0000

.0000

.0000

.0000

1.631

.0000

$.2599 \mathrm{E}-07$

.0000

.0000

.0000

.1848E-08

$.5173 \mathrm{E}-08$

$.1044 \mathrm{E}-06$

$.1617 \mathrm{E}-05$

$.1082 \mathrm{E}-18$

$.8115 \mathrm{E}-07$

$.1442 E-04$

.0000

$.9698 \mathrm{E}-17$

.0000

.0000

.2507E-06

.0000

$.9053 \mathrm{E}-17$

$.5023 \mathrm{E}-13$

$.1034 E-08$

.5931E-09

$.5409 E-09$

.0000

$.3818 \mathrm{E}-06$

$.4195 \mathrm{E}-13$

$.8625 \mathrm{E}-11$

$.8416 \mathrm{E}-10$

$.1707 E-06$

$.4195 \mathrm{E}-06$

.0000

.0000

$.1097 E-04$
113

Air Sparge

to MAWT

.0000

.0000

.0000

.0000

.0000

.0000

.0000

.0000

.0000

.0000

.0000

.0000

.0000

.0000

.0000

.0000

.0000

.0000

.0000

.0000

.0000

.0000

.0000

.0000

.0000

.0000

.0000

.0000

.0000

. 7357E-01

.0000

.0000

.0000

.0000

.0000

.0000

.0000

.0000

.0000

.0000

.0000

.0000

.0000

.0000

.0000

.0000 
DPSP $80-1033$

MATERIAL BALANCE TABLES

SLLDGE-ONLY FEED

STREAMS (CONT'D)-

STREAM NAME

$\begin{array}{rl}7 & \mathrm{NaCl} \\ 138 & \mathrm{NaCl} \text { Semi } \mathrm{Vol} \\ 69 & \mathrm{NaF} \\ 139 & \mathrm{NaF} \text { Semi } \mathrm{Vol} \\ 12 & \mathrm{NaI} \\ 125 & \mathrm{NaI} \text { Semi } \mathrm{Vol} \\ 8 & \mathrm{NaNO} \\ 2 & \mathrm{NaNO3} \\ 4 & \mathrm{NaOH} \\ 87 & \mathrm{NaResin} \\ 61 & \mathrm{Ni}(\mathrm{COOH}) 2 \\ 17 & \mathrm{Ni}(\mathrm{Oll}) 2 \\ 40 & \mathrm{NiO} \\ 82 & 02 \\ 67 & \mathrm{PbO} \\ 28 & \mathrm{PbSO}\end{array}$

$124 \mathrm{Pd}$

$123 \mathrm{Pd}(\mathrm{OH}) 2$

112 PdNO32

$110 \mathrm{PdO}$

$117 \mathrm{Pu}(\mathrm{COOH}) 4$

$76 \mathrm{Pu} 02$

$22 \mathrm{RhO2}$

$79 \mathrm{Ru} 02$

23 Ru02 Semi Vol

$83 \mathrm{Ru} 04$

$38 \mathrm{SO} 2$

$111 \mathrm{SiO} 2$

$115 \mathrm{Silica} \mathrm{Gel}$

$48 \mathrm{Sr}(\mathrm{COOH}) 2$

$10 \mathrm{Sr}(\mathrm{YO} 03) 2$

$127 \mathrm{Sr}(\mathrm{OH}) 2$

$30 \mathrm{SrCO}$

$46 \mathrm{Sr} 0$

89 SrRESIN

141 Surfactant

92 Th02

$107 \mathrm{TiO} 2$

119 Tritium

$93 \mathrm{V02}$

$62 \mathrm{VO2}(\mathrm{COOH}) 2$

$16 \mathrm{VO}(\mathrm{OH}) 2$

$27 \mathrm{Y}(\mathrm{COOH}) \mathrm{s}$

$11 \mathrm{Y}(\mathrm{NO3}) 3$

$128 \mathrm{Y}(\mathrm{OH}) 3$

$81 Y_{2}(\mathrm{CO}) 3$
110

Water Wash to MHTH'T

.0000

.0000

.0000

.0000

.0000

.0000

.0000

.0000

.0000

.0000

.0000

.0000

.0000

.0000

.0000

.0000

.0000

.0000

.0000

.0000

.0000

.0000

.0000

.0000

.0000

.0000

.0000

.0000

.0000

.0000

.0000

.0000

.0000

.0000

.0000

.0000

.0000

.0000

.0000

.0000

.0000

.0000

.0000

.0000

.0000

.0000
Appendix $\mathrm{H}$

Table 21-15

Page 108 of 173

Date 09/30/82 Rev 09 
DPSP $80-1033$

Material BALANCE TASLES SLCDGE-GILY FEED STREANS (CONT'D)STREAM NAME

$\begin{array}{rl}47 & y 203 \\ 100 & \mathrm{Zeolite} \\ 44 & \mathrm{Zn}(\mathrm{COOHI}) 2 \\ 54 & \mathrm{Zn}(0 \mathrm{ll}) 2 \\ 57 & \mathrm{Zn} 0 \\ 10.1 & \mathrm{Zr} 02\end{array}$

TOTIL FLO", LB/IIR VAPOR FLOVI, CFY LIQUID FLOW, GPM DESIGN FLOW, DEYSITY, LBS/FT3 TEMPERITLRE, DEG C PRESSURE, ATM PRESSURE, PSIG PRESSIRE, MOS HG PIIASE

E.TIIILPY, PCV/IIR
Appendix H

Tnble 21-15

Page 109 of 173

Date 09/80/82 Rev 09

\begin{tabular}{|c|c|c|c|}
\hline 110 & 111 & 112 & 113 \\
\hline iater Kash & MUH'T Vent & Hg from MNIIT & Air Sparge \\
\hline to MHWT & to FAl'C & to MAHT & to MAWT \\
\hline .0000 & .0000 & .0000 & .0000 \\
\hline .0000 & . $1725 E-09$ & $.6012 E-05$ & .0000 \\
\hline .0000 & $.2144 E-10$ & $.7475 E-06$ & .0000 \\
\hline .0000 & - 1798E-23 & $.6269 E-19$ & .0000 \\
\hline .0000 & .0000 & .0000 & .0000 \\
\hline .0000 & $.1484 E-12$ & $.5173 E-08$ & .0000 \\
\hline .36 & 4.77 & 1.66 & .10 \\
\hline & 1.25 & & .02 \\
\hline .00 & & .00 & \\
\hline 62.4300 & .0638 & 773.1063 & .0706 \\
\hline 25.00 & 49.99 & 50.00 & 35.00 \\
\hline 1.00 & .97 & .97 & 1.00 \\
\hline .00 & -.51 & -.51 & .00 \\
\hline & 733.86 & 733.86 & \\
\hline LIQUID & VAPOR & LIQUID & VAPOR \\
\hline 9.18 & -127.48 & 3.37 & -6.02 \\
\hline
\end{tabular}


DPSP SO-1033

MATERIAL BALANCE TABLES

SLLDGE-ONLI FEED

STREAY NUMBERS -

STREAM NAME

COMPONEYT FLOHS, LB/HR

$\begin{array}{rl}1 & \mathrm{H} 20 \\ 45 & \mathrm{Ag} \\ 116 & \mathrm{Ag} 20 \\ 134 & \mathrm{AgNO3}\end{array}$

$51 \mathrm{AgOH}$

74 Al (0!I) 3

77 A1203

75 AlOOH

106 B2.03

$9 \mathrm{Ba}(\mathrm{NOS}) 2$

$95 \mathrm{BaCl} 2$

$15 \mathrm{BaO}$

$24 \mathrm{BaS04}$

$66 \mathrm{CO}$

$87 \mathrm{CO} 2$

$142 \mathrm{CO}$ ( $\mathrm{C} 14)$

$63 \mathrm{Ca}(\mathrm{COOII}) 2$

$120 \mathrm{Ca}(\mathrm{OH}) 2$

$113 \mathrm{Ca} 3(\mathrm{PO} 4) 2$

$20 \mathrm{CaC204}$

$18 \mathrm{CaCO3}$

$78 \mathrm{CaF2}$

$41 \mathrm{CaO}$

19 CaSO4

29 Carbon

$26 \mathrm{Co}(\mathrm{COOH}) 2$

$121 \mathrm{Co}(\mathrm{OHI}) 2$

$53 \mathrm{Co}(\mathrm{OH}) 3$

$59 \mathrm{CoO}$

$99 \mathrm{Cr}(\mathrm{OH}) 3$

$98 \mathrm{Cr} 203$

$42 \mathrm{Cs} 20$

137 Cs20 Semi Vol

$90 \mathrm{CsCOOH}$

$96 \mathrm{CsCl}$

136 CsCl Semi Vol

$8 \mathrm{CsNO3}$

88 CsResin

$122 \mathrm{Cu}(\mathrm{COOH}) 2$

$52 \mathrm{Cu}(\mathrm{OH}) 2$

$58 \mathrm{Cu} 20$

$64 \mathrm{CuCOOH}$

$130 \mathrm{CuO}$

$13 \mathrm{Fe}(\mathrm{OH}) 3$

$80 \mathrm{Fe} 203$
114

MaHT Vent to MVC

.1109

$.3118 \mathrm{E}-09$

.0000

$.4832 \mathrm{E}-07$

$.6331 \mathrm{E}-15$

$.3334 E-10$

.0000

.0000

$.4362 E-12$

$.4379 \mathrm{E}-18$

.0000

.0000

$.3958 \mathrm{E}-12$

$.4846 \mathrm{E}-27$

$.1782 E-05$

$.7431 E-24$

. 1373E- 10

$.1025 E-23$

$.9863 E-12$

. 1067E- 11

.0000

.2667E-12

.0000

$.1253 \mathrm{E}-11$

$.2667 \mathrm{E}-12$

. 2168E-12

$.1774 \mathrm{E}-25$

.0000

.0000

$.1014 \mathrm{E}-11$

.0000

.3996E- 17

.0000

.0000

$.2571 E-17$

.0000

.2809E-13

.0000

$.4631 \mathrm{E}-12$

$.3858 E-25$

.0000

.0000

.0000

$.8070 \mathrm{E}-10$

.0000
115

HYO3 WASH

from MAHT

.1891

.0000

.0000

$.2817 \mathrm{E}-01$

$.3109 \mathrm{E}-09$

$.1944 \mathrm{E}-04$

.0000

.0000

.2544E-06

$.2554 \mathrm{E}-12$

.0000

.0000

$.2308 E-06$

$.8259 \mathrm{E}-33$

$.9523 \mathrm{E}-10$

$.3971 \mathrm{E}-28$

$.8007 \mathrm{E}-05$

$.5979 E-18$

$.5751 \mathrm{E}-06$

.6220E-06

.0000

$.1555 \mathrm{E}-0 \hat{0}$

.0000

$.7307 E-06$

$.1555 \mathrm{E}-06$

. 1264E-06

$.1034 \mathrm{E}-19$

.0000

.0000

$.5912 \mathrm{E}-06$

.0000

$.2330 \mathrm{E}-11$

.0000

.0000

.1499E- 11

.0000

$.1638 \mathrm{E}-07$

.0000

.2700E-06

$.2250 \mathrm{E}-19$

.0000

.0000

.0000

$.4706 \mathrm{E}-04$

.0000
Appendix II

Table 21-15

Page 110 of 173

Date $09 / 30 / E 2$ Rev 09
$117 \quad 118$

dir Sparge Steam to

to SWE

.8735

.0000

.0000

.0000

0000

.0000

.0000

.0000

.0000

.0000

.0000

.0000

.0000

.0000

.0000

.0000

.0000

.0000

.0000

.0000

.0000

.0000

.0000

.0000

.0000

.0000

.0000

.0000

.0000

.0000

.0000

.0000

.0000

.0000

.0000

.0000

.0000

.0000

.0000

.0000

.0000

.0000

.0000

.0000

.0000
S. Coil

.0000

.0000

.0000

.000 is

.11000

.0000

.0000

.0000

.0000

.0000

.0000

.0000

.0000

.0000

.0000

.0000

.0000

.0000

.0000

.0000

.0000

.0000

.0000

.0000

.0000

.0000

.0000

.0000

.0000

.0000

.0000

.0000

.0000

.0000

.0000

.0000

.0000

.0000

.0000

.0000

.0000

.0000

.0000

.0000

.0000 
DPSP $80-1033$

MATERIAL BALANCE TABLES

SLUDGE-ONLY FEED

STREIYS (CONT'D)-

STREAM TAME

$101 \mathrm{FeO}$

126 Group A Seni Vo

102 GroupA

103 GroupB

25112

133 II2C204

9111202

81 IICOOII

$43 \mathrm{IICl}$

85 IIF

49 IINO3

86 UlResin

$36 \mathrm{Hg}$

$135 \mathrm{HgNO}_{\mathrm{G}} \mathrm{Na}$

$21 \mathrm{Hg} \mathrm{O}$

2712

$30 \mathrm{~K} 20$

$131 \mathrm{kMn} 01$

$118 \mathrm{KNO3}$

$105 \operatorname{La} 203$

$108 \mathrm{Li} 20$

Gi) $\mathrm{Mg}(\mathrm{COOH}) 2$

$55 \mathrm{Mg}(011) 2$

$33 \mathrm{M} \mathrm{O}$

$60 \mathrm{Mn}(\mathrm{COOH}) 2$

$132 \mathrm{Mn}(\mathrm{N} 03) 2$

$129 \mathrm{Mn}(\mathrm{OHI}) 2$

$56 \mathrm{MnO}$

$14 \mathrm{MnO2}$

$81 \mathrm{~N} 2$

$143 \mathrm{~N} 12 \mathrm{CO}$ (C11)

$35 \mathrm{NO}$

84 i02

$70 \mathrm{Na}(\mathrm{HgO}(\mathrm{OHI}))$

$94 \mathrm{Na} 2 \mathrm{~B} 407$

$109 \quad \mathrm{Na} 2 \mathrm{C2O4}$

5 in $2 \mathrm{CO}$

32 in 20

$71 \mathrm{Na} 2 \mathrm{Pu}_{4} 02(011) 4$

$73 \mathrm{Na} 2 \mathrm{RhO}_{4}$

$72 \mathrm{Na} 2 \mathrm{KuO}_{4}$

$6 \mathrm{Na} 2 \mathrm{SO} 4$

$68 \mathrm{NaNl} 102$

$114 \mathrm{NaBO2}$

140 NaBO2 Semi Vol

$50 \mathrm{NaCOOII}$
$114 \quad 115$

MAK'T Vent

to MVC

.0000

.0000

$.7428 E-12$

$.2371 \mathrm{E}-11$

$.8403 E-26$

.0000

.0000

.0000

.0000

.0000

$.4790 \mathrm{E}-02$

.0000

$.1255 \mathrm{E}-03$

.3010E-10

$.4201 \mathrm{E}-13$

.0000

.0000

.0000

$.2179 \mathrm{E}-14$

$.8359 \mathrm{E}-14$

$.1687 \mathrm{E}-12$

.2614E-11

$.1749 \mathrm{E}-24$

.5033E-13

. 2330E-10

.0000

$.1567 \mathrm{E}-22$

.0000

.0000

8.492

.0000

$.9053 E-17$

$.7823 \mathrm{E}-02$

$.1672 E-14$

$.9585 E-15$

$.8742 E-15$

.0000

$.61 \mathrm{GPE}-12$

$.6780 \mathrm{E}-19$

$.1894 \mathrm{E}-16$

$.1360 \mathrm{E}-15$

$.2758 \mathrm{E}-12$

$.6780 \mathrm{E}-12$

.0000

.0000

$.1774 \mathrm{E}-10$
HNO3 WASII

from MAWT

.0000

.0000

$.4331 E-06$

$.1382 E-05$

$.1434 E-31$

.0000

.0000

.0000

.0000

.0000

.2721E-02

.0000

.0000

$.1755 \mathrm{E}-04$

.2450E-07

.0000

.0000

.0000

.1270E-08

$.4874 \mathrm{E}-08$

$.9835 \mathrm{E}-07$

$.1524 E-05$

$.1020 E-18$

.2935E-07

. 1359E-04

.0000

$.9139 \mathrm{E}-17$

.0000

.0000

$.4927 \mathrm{E}-05$

.0000

$.3786 \mathrm{E}-22$

$.3121 \mathrm{E}-03$

$.974 S E-09$

$.5589 \mathrm{E}-09$

.5097E-09

.0000

.3597E-06

.3953E-13

$.8127 \mathrm{E}-11$

$.7931 E-10$

$.1608 E-06$

.8953E-06

.0000

.0000

$.1034 \mathrm{E}-04$
Appendix $\mathrm{H}$

Table 21-15

Page 111 of 173

Date 09/30/82 Rev 09

$117 \quad 118$

Air Sparge Steam to

to SME SME Coll

.0000

.0000

.0000

.0000

.0000

.0000

.0000

.0000

.0000

.0000

.0000

.0000

.0000

.0000

.0000

.0000

.0000

.0000

.0000

.0000

.0000

.0000

.0000

.0000

.0000

.0000

.0000

.0000

.0000

.0000

.0000

.0000

.0000

.0000

.0000

.0000

.0000

.0000

.0000

.0000

.0000

.0000

.0000

.0000

.0000

.0000

.0000

.0000 
DPSP $80-1033$

MATERIAL BALANCE TABLES SLUDGE-ONLY FEED STREAMS (CONT'D)STREAM NAME

$7 \mathrm{NaCl}$

$138 \mathrm{NaCl}$ Semi Vol

$69 \mathrm{NaF}$

139 Naf Seml Vol

$12 \mathrm{NaI}$

$125 \mathrm{NaI}$ Semi Vol

$8 \mathrm{NaNO} 2$

$2 \mathrm{NaNO3}$

$4 \mathrm{NnOH}$

87 NaResin

$61 \mathrm{Ni}(\mathrm{COOH}) 2$

$17 \mathrm{Ni}(\mathrm{OH}) 2$

$40 \mathrm{NiO}$

8202

$67 \mathrm{PbO}$

$28 \mathrm{PbSO} 4$

$124 \mathrm{Pd}$

$123 \mathrm{Pd}(\mathrm{OH}) 2$

112 PdN032

$110 \mathrm{PdO}$

$117 \mathrm{Pu}(\mathrm{COOH}) 4$

$76 \mathrm{Pu} 02$

$22 \mathrm{RhO2}$

$79 \mathrm{RuO2}^{2}$

23 Ru02 Semi Vol

$83 \mathrm{Ru} 04$

$38 \mathrm{SO2}$

$111 \mathrm{SiO}$

115 Sillica Gel

$48 \mathrm{Sr}(\mathrm{COOH}) 2$

$10 \mathrm{Sr}(\mathrm{NO3}) 2$

$127 \mathrm{Sr}(\mathrm{OH}) 2$

$80 \mathrm{SrCO}$

$16 \mathrm{SrO}$

89 SrRESIN

141 Surfactant

$92 \mathrm{ThO} 2$

107 T!02

119 Iritium

$93 \mathrm{V02}$

$62 \mathrm{VO} 2(\mathrm{COOH}) 2$

$16 \mathrm{VO2}$ (OlI) 2

$27 \mathrm{Y}(\mathrm{COOH}) 3$

$11 \mathrm{Y}(\mathrm{NO3}) 3$

$128 Y(0 l l) 8$

$31 Y 2(\mathrm{CO}) 3$
114

MAWT Vent

to IIVC

$.2750 \mathrm{E}-12$

.0000

$.1438 \mathrm{E}-14$

.0000

.2663E-13

.0000

.0000

$.8673 E-11$

.0000

.0000

$.8217 \mathrm{E}-11$

$.6717 \mathrm{E}-24$

.0000

1.055

.0000

$.8725 \mathrm{E}-12$

.0000

.0000

.0000

.0000

.0000

$.9694 \mathrm{E}-13$

$.8704 \mathrm{E}-13$

$.1814 \mathrm{E}-12$

.0000

.0000

$.1865 \mathrm{E}-20$

$.1728 \mathrm{E}-10$

.0000

$.8337 \mathrm{E}-12$

$.8908 \mathrm{E}-1 \mathrm{~S}$

$.2996 \mathrm{E}-25$

.0000

.0000

.0000

.0000

$.1520 \mathrm{E}-11$

$.1618 \mathrm{E}-13$

$.1848 \mathrm{E}-15$

.0000

$.1063 \mathrm{E}-10$

$.1177 \mathrm{E}-23$

$.2286 \mathrm{E}-12$

$.2775 E-18$

$.1873 E-25$

.0000
Appendix II

Table 21-15

Pago 112 of 173

Date $09 / 30 / 82$ Rev 0 ? 
DPSP $80-1033$

MATEHIAL RALAiCt TABLES SLUDGT-ONLY FEED STREAMS (CONT'D)STREAM NANE

$47 \times 203$

100 zeolite

$44 \mathrm{Zn}(\mathrm{COOH}) 2$

$54 \mathrm{Zn}(\mathrm{OII}) 2$

$57 \mathrm{ZnO}$

$10.4 \mathrm{Zr} 02$

TOTAL FLOH', LB/HR

$\checkmark A P O R$ FLOH, CFM

LIQUID FLOW, GPM DESIGN FLOH, DEISITY, LDS/FT3

TEMPERITLRE, DEG C PRESSLRE, ATS PRESSURE, PSIG PRESSURE, MI HG PIIASE

E:TTHILPY, PCC/IIR

114
MAK' Vent
to MVC
.0000
$.9715 E-11$
$.1208 E-11$
$.1013 E-24$
.0000
$.8359 E-14$
4.67
1.12

.0693
37.99
.99
-.07
756.20
VAPOR
-212.02

115

HNO3 W'ASH

from MAKT

.0000

$.6665 E-05$

.7044E-06

$.5908 \mathrm{E}-19$

.0000

$.4874 \mathrm{E}-08$

.22

.00

69.6294

38.00

.09

$-.07$

756.20

LIQUID

7.54
Appendix H

Tablo 21-16

Page 113 of 173

Date 09/30/82 Rev 09 
DPSP S0-1033

MATER IAL BALANCE TABLES

SLLDGË-ONLY FEED

STREAM NLMBERS -

STREAM NAME

COMPONENT FLONS, LE/IIR

1 H2O

$45 \mathrm{Ag}$

116 Ag20

134 AgNO3

$51 \mathrm{Ag}$ OII

74 Al(OII) 3

77 A 1203

$75 \mathrm{AlOOH}$

$106 \mathrm{B203}$

$9 \mathrm{Ba}(\mathrm{NO3}) 2$

$95 \mathrm{BaCl} 2$

$15 \mathrm{BaO}$

$24 \mathrm{BaSO4}$

$66 \mathrm{CO}$

$87 \mathrm{CO} 2$

$142 \mathrm{CO}$ ( $\mathrm{C14})$

$63 \mathrm{Ca}(\mathrm{COOII}) 2$

$120 \mathrm{Ca}(\mathrm{Oll}) 2$

$113 \mathrm{Ca} 3(\mathrm{PO}) 2$

$20 \mathrm{CaC}_{\mathrm{a}} \mathrm{O} 4$

$18 \mathrm{CaCO3}$

$78 \mathrm{CaF2}$

$11 \mathrm{CaO}$

$19 \mathrm{CaSO4}$

29 Carbon

$26 \mathrm{Co}(\mathrm{COOH}) 2$

$121 \mathrm{Co}(\mathrm{OH}) 2$

$53 \mathrm{Co}(\mathrm{OH}) \mathrm{3}$

$59 \mathrm{CoO}$

$99 \mathrm{Cr}(\mathrm{OH}) 3$

98 Cr203

$42 \operatorname{Cs} 20$

137 Cs20 Semi Vol

$90 \mathrm{CsCOOH}$

$96 \mathrm{CsCl}$

$136 \mathrm{CsCl}$ Semi Vol

8 CsNO3

88 CsResin

$122 \mathrm{Cu}(\mathrm{COOH}) 2$

$52 \mathrm{Cu}(\mathrm{OH}) 2$

$58 \mathrm{Cu} 20$

$64 \mathrm{CuCOOH}$

$130 \mathrm{CuO}$

$13 \mathrm{Fe}(\mathrm{OH}) \mathrm{s}$

$80 \mathrm{Fe} 208$
119

Steam Conden Steam to snte fr SME SRIT Coll ante

.0000

.0000

.0000

.0000

.0000

.0000

.0000

.0000

.0000

.0000

.0000

.0000

.0000

.0000

.0000

.0000

.0000

.0000

.0000

.0000

.0000

.0000

.0000

.0000

.0000

.0000

.0000

.0000

.0000

.0000

.0000

.0000

.0000

.0000

.0000

.0000

.0000

.0000

.0000

.0000

.0000

.0000

.0000

.0000

.0000
Appendis $\mathrm{H}$

Tnble 21-15

Page 114 of 173

Date 09/30/82 Rev 09

$121 \quad 122$

Stenm Conden dir Sparggo

sate Fr SRA? to Sillt

$\begin{array}{ll}.0000 & .3735 \\ .0000 & .0000 \\ .0000 & .0000 \\ .0000 & .0400 \\ .0000 & .0000 \\ .0000 & .0000 \\ .0000 & .0000 \\ .0000 & .0000 \\ .0000 & .0000 \\ .0000 & .0000 \\ .0000 & .0000 \\ .0000 & .0000 \\ .0000 & .0000 \\ .0000 & .0000 \\ .0000 & .0000 \\ .0000 & .0000 \\ .0000 & .0000 \\ .0000 & .0000 \\ .0000 & .0000 \\ .0000 & .0000 \\ .0000 & .0000 \\ .0000 & .0000 \\ .0000 & .0000 \\ .0000 & .0000 \\ .0000 & .0000 \\ .0000 & .0000 \\ .0000 & .0000 \\ .0000 & .0000 \\ .0000 & .0000 \\ .0000 & .0000 \\ .0000 & .0000 \\ .0000 & .0000 \\ .0000 & .0000 \\ .0000 & .0 \\ .0000 & .1 \\ .0000 & .0000 \\ .0000 & .0000 \\ .0000 & .0000 \\ .0000 & .0000 \\ .0000 & .0000 \\ .0000 & .0000 \\ .0000 & .0000 \\ .0000 & .0000 \\ .0000 & .0000 \\ .0000 & .0000 \\ & \end{array}$


DPSP $80-1033$

MTERIAL BALANCE TAELES

SLLDGE-ONLY FEED

STREAMS (CONT'D)-

STREAM NAME

$101 \mathrm{FeO}$

126 Group a Sent Vo

102 Groupd

103 GroupB

$25 \mathrm{H2}$

$133112 \mathrm{C} 204$

9111202

84 IICOOII

$43 \mathrm{HCl}$

$85 \mathrm{HF}$

49 IIN03

86 HResin

$36 \mathrm{Hg}$

$135 \mathrm{Hg}_{\mathbb{E}} \mathrm{NO} 2$

$21 \mathrm{HgO}$

$97 \quad 12$

$39 \mathrm{~K} 20$

$131 \mathrm{KMnO} 04$

lis KNO3

$105 \operatorname{Ln} 203$

108 Li20

$65 \mathrm{Mg}(\mathrm{COCII}) 2$

$55 \mathrm{Mg}(\mathrm{Oll}) 2$

$33 \mathrm{MgO}$

$60 \mathrm{Mn}(\mathrm{COOH}) 2$

$122 \mathrm{Mn}(\mathrm{N} 03) 2$

$129 \mathrm{Mn}(\mathrm{OII}) 2$

$56 \mathrm{MnO}$

$14 \mathrm{MnO2}$

$81 \mathrm{N2}$

$143 \mathrm{~N}, 2 \mathrm{CO}$ ( $\mathrm{Cl} 4)$

$85 \mathrm{NO}$

$84 \quad 102$

$70 \mathrm{Na}\left(\mathrm{Hg}_{\mathrm{g}} \mathrm{O}(\mathrm{OH})\right)$

$94 \mathrm{Na} 2 \mathrm{~b} 407$

$109 \mathrm{Na} 2 \mathrm{C2O4}$

$5 \mathrm{Na} 2 \mathrm{CO3}$

$32 \quad \mathrm{Na}_{2} \mathrm{O}$

$71 \mathrm{Ni} 2 \mathrm{Pu}_{4} 02(\mathrm{OHI}) 4$

$73 \mathrm{Na} 2 \mathrm{Rh}_{0.4}$

$72 \mathrm{Na}_{2 \mathrm{Ru}} 04$

$6 \mathrm{Na} 2 \mathrm{SO} 4$

GS NaAlo2

$114 \mathrm{NaBO2}$

140 NaB02 Semi Vol

$50 \mathrm{NaCOOH}$
119

Stenm Conden Steam to

sute fr SME

.0000

.0000

.0000

.0000

.0000

.0000

.0000

.0000

.0000

.0000

.0000

.0000

.0000

.0000

.0000

.0000

.0000

.0000

.0000

.0000

.0000

.0000

.0000

.0000

.0000

.0000

.0000

.0000

.0000

.0000

.0000

.0000

.0000

.0000

.0000

.0000

.0000

.0000

.0000

.0000

.0000

.0000

.0000

.0000

.0000

.0000
Appendis II

Table 21-15

Page 116 of 173

Date 09/30/82 Rev 09 
DPSP $80-1033$

MATERIAL BALANCE TABLES SLLDGT-ONLY FEED

STREAMS (CONT'D)STREAM NAME

$7 \mathrm{NaCl}$

$138 \mathrm{NaCl}$ Semi Vol

$69 \mathrm{NaF}$

189 NaF Seml Vol

$12 \mathrm{NaI}$

125 NaI Semi vol

$3 \mathrm{NaNO2}$

$2 \mathrm{NaNO3}$

$4 \mathrm{NaOH}$

$87 \mathrm{NaRes}$ in

$61 \mathrm{Ni}(\mathrm{COOH}) 2$

$17 \mathrm{Ni}(\mathrm{OH}) 2$

$40 \mathrm{NiO}$

8202

$67 \mathrm{PbO}$

$28 \mathrm{PbSO4}$

$124 \mathrm{Pd}$

$123 \mathrm{Pd}(\mathrm{OH}) 2$

112 PdNO32

110 PdO

$117 \mathrm{Pu}(\mathrm{COOH}) 4$

$76 \mathrm{Pu} 02$

$22 \mathrm{RhO2}$

$79 \mathrm{Ru} 02$

28 Ru02 Semi Vol

$83 \mathrm{RuO4}$

$88 \mathrm{SO} 2$

$111 \mathrm{Si} 02$

115 Silica Gel

$48 \mathrm{Sr}(\mathrm{COOH}) 2$

$10 \mathrm{Sr}(\mathrm{NOS}) 2$

$127 \mathrm{Sr}(\mathrm{OH}) 2$

$30 \mathrm{SrCO3}$

$46 \mathrm{Sr} 0$

89 SrRESIN

141 Surfactant

92 Th02

$107 \mathrm{TiO}$

119 Tritium

$93 \mathrm{V02}$

$62 \mathrm{v02}(\mathrm{COOII}) 2$

$16 \mathrm{VO} 2(\mathrm{OH}) 2$

$27 x(\mathrm{COOH}) \mathrm{s}$

$11 \mathrm{Y}(\mathrm{NO3}) \mathrm{B}$

$128 \mathrm{Y}(\mathrm{OH}) \mathrm{S}$

$81 Y 2(\operatorname{COS}) 3$
119

Steam Conden Steam to

sate fr SME

.0000

.0000

.0000

.0000

.0000

.0000

.0000

.0000

.0000

.0000

.0000

.0000

.0000

.0000

.0000

.0000

.0000

.0000

.0000

.0000

.0000

.0000

.0000

.0000

.0000

.0000

.0000

.0000

.0000

.0000

.0000

.0000

.0000

.0000

.0000

.0000

.0000

.0000

.0000

.0000

.0000

.0000

.0000

.0000

.0000

.0000

120

SRAT Coll

.0000

.0000

.0000

.0000

.0000

.0000

.0000

.0000

.0000

.0000

.0000

.0000

.0000

.0000

.0000

.0000

.0000

.0000

.0000

.0000

.0000

.0000

.0000

.0000

.0000

.0000

.0000

.0000

.0000

.0000

.0000

.0000

.0000

.0000

.0000

.0000

.0000

.0000

.0000

.0000

.0000

.0000

.0000

.0000

.0000
Appendix II

Table 21-15

Page 116 of 173

Date $0 . / 30 / 32$ Rev 03

.0000
121

Stean Conde: Al: Sparge

sate Fr SR:iT to SR.IT

.0000

.0000

.0000

.0000

.0000

.0000

.0000

.0000

.0000

.0000

.0000

.0000

.0000

.0000

.0000

.0000

.0000

.0000

.0000

.0000

.0000

.0000

.0000

.0000

.0000

.0000

.0000

.0000

.0000

.0000

.0000

.0000

.0000

.0000

.0000

.0000

.0000

.0000

.0000

.0000

.0000

.0000

.0000

.0000

.0000

.0000
.0000

.0003

.0000

.0000

.0000

.0000

.0000

.0000

.0000

.0000

.0000

.0000

.0000

5. 158

.0000

.0000

.0000

.0000

.0000

.0500

.0000

.0000

.0000

.0000

.0000

.0000

.0000

.0000

.0000

.0000

.0000

.0000

.0000

.0000

.0000

.0000

.0000

.0000

.0000

.0000

.0000

.0000

.0000

.0000

.0000 
Miterial BaLANCE TABLES Date 09/S0/82 Rev 09

SLUDGE-ONLY FEED STPIANSS (CONT'D)STREAM NAME

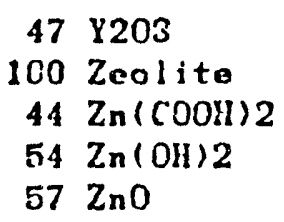

ENTHALPI, PCL/IIR

\begin{tabular}{|c|c|c|c|}
\hline 119 & 120 & 121 & 122 \\
\hline $\begin{array}{l}\text { Stenn Conden } \\
\text { sate fr SME }\end{array}$ & $\begin{array}{l}\text { Stenm to } \\
\text { SRAT Coll }\end{array}$ & $\begin{array}{l}\text { Steam Conden } \\
\text { sate Fr SRAT }\end{array}$ & $\begin{array}{c}\text { A ir Sparge } \\
\text { to SRAT }\end{array}$ \\
\hline .0000 & .0000 & .0000 & .0000 \\
\hline .0000 & .0000 & .0000 & .0000 \\
\hline .0000 & .0000 & .0000 & .0000 \\
\hline .0000 & .0000 & .0000 & .0000 \\
\hline .0000 & .0000 & .0000 & .0000 \\
\hline .0000 & .0000 & .0000 & .0000 \\
\hline .00 & .00 & .00 & $\begin{array}{r}22.61 \\
5.84\end{array}$ \\
\hline .0000 & .0000 & .0000 & .0706 \\
\hline 60.00 & 160.00 & 60.00 & 35.00 \\
\hline 1.00 & 6.10 & 1.00 & 1.00 \\
\hline .00 & 74.99 & .00 & .00 \\
\hline N/A & $N / A$ & N/A & VAPOR \\
\hline .00 & .00 & .00 & -1164.14 \\
\hline
\end{tabular}


DPSP 80-1088

MATERIAL BALANCE TABLES

SLUDGE-ONLY FEED

STREAM NUMBERS -

STREAM NAME

COMPONENT FLOHS, LB/HR

$1 \mathrm{H} 2 \mathrm{O}$
$45 \mathrm{Ag}$

116 Ag20

134 AgNO3

$51 \mathrm{AgOH}$

74 Al $(\mathrm{OH}) \mathrm{S}$

77 A 1208

75 AlOOH

106 B203

$9 \mathrm{Ba}(\mathrm{NO3}) 2$

$95 \mathrm{BaCl} 2$

$15 \mathrm{BaO}$

$24 \mathrm{BaSO} 04$

$66 \mathrm{CO}$

$37 \mathrm{CO2}$

$142 \mathrm{CO}$ ( $\mathrm{C} 14)$

$63 \mathrm{Ca}(\mathrm{COOH}) 2$

$120 \mathrm{Ca}(\mathrm{OH}) 2$

$113 \mathrm{Ca} 3(\mathrm{PO} 4) 2$

$20 \mathrm{CaC2O4}$

$18 \mathrm{CaCO}$

$78 \mathrm{CaF2}$

$41 \mathrm{CaO}$

$19 \mathrm{CaSO} 4$

29 Carbon

$26 \mathrm{Co}(\mathrm{COOH}) 2$

$121 \mathrm{Co}(\mathrm{OH}) 2$

$53 \mathrm{Co}(\mathrm{OH}) 3$

$59 \mathrm{CoO}$

$99 \mathrm{Cr}$ (Oll) 3

$98 \mathrm{Cr} 203$

$42 \mathrm{Cs} 20$

187 Cs20 Semi Vol

$90 \mathrm{CsCOOH}$

$96 \mathrm{CsCl}$

$136 \mathrm{CsCl}$ Semi Vol

$8 \mathrm{CsNOS}$

88 CsResin

$122 \mathrm{Cu}(\mathrm{COOH}) 2$

$52 \mathrm{Cu}(\mathrm{OH}) 2$

$58 \mathrm{Cu} 20$

$64 \mathrm{CuCOOH}$

$130 \mathrm{CuO}$

$13 \mathrm{Fe}(\mathrm{OH}) \mathrm{S}$

$80 \mathrm{Fe} 203$
123

Inlet Vapor

to FAVC

114.1

$.8034 E-07$

.0000

.0000

$.1277 E-08$

$.1160 \mathrm{E}-05$

.0000

.0000

$.4402 E-05$

$.1522 \mathrm{E}-13$

.0000

.0000

$.1375 \mathrm{E}-07$

$.4639 \mathrm{E}-04$

5.383

$.1072 \mathrm{E}-09$

$.4766 \mathrm{E}-06$

$.3201 \mathrm{E}-09$

$.3428 \mathrm{E}-07$

$.3707 \mathrm{E}-07$

.0000

$.9268 \mathrm{E}-08$

.0000

$.4354 \mathrm{E}-07$

$.9268 \mathrm{E}-08$

$.7525 \mathrm{E}-08$

$.5537 \mathrm{E}-11$

.0000

.0000

$.3523 E-07$

.0000

$.1803 \mathrm{E}-12$

.0000

.0000

$.5839 \mathrm{E}-11$

.0000

$.9761 \mathrm{E}-09$

.0000

$.1607 \mathrm{E}-07$

$.1204 \mathrm{E}-10$

.0000

.0000

.0000

.2807E-05

.0000
Appendix $H$

Table 21-15

Page 118 of 173

Date 09/30/:2 Rev 00 $\begin{array}{ccc}124 & 125 & 126 \\ \text { FAVC } & \text { Air Sparge } & \text { Dump Crn Air } \\ \text { Condensate } & \text { to MTT } & \text { Inleiliage }\end{array}$

$95.54 \quad .3735 \quad .665$.

$\begin{array}{lll}.1517 E-07 & .0500 & .0000\end{array}$

$.0000 \quad .0000 \quad .0000$

$.0000 \quad .0000 \quad .0000$

$\begin{array}{lll}.6886 \mathrm{E}-09 & .0000 \quad .0000\end{array}$

$.6799 E-06 \quad .0000 \quad .0000$

$.0000 \quad .0000 \quad .0000$

$.0000 \quad .0000 \quad .0000$

$\begin{array}{lll}.2201 E-05 & .0000 \quad .0000\end{array}$

$.7609 \mathrm{E}-14 \quad .0000 \quad .0000$

$\begin{array}{lll}.0000 & .0000 & .0000\end{array}$

$\begin{array}{lll}.0000 & .0000 & .0000\end{array}$

$\begin{array}{lll}.6877 E-08 & .0000 \quad .0000\end{array}$

$\begin{array}{lll}.3651 \mathrm{E}-10 \quad .0000 & .0000\end{array}$

$\begin{array}{lll}.2135 E-03 & .0000 & .0000\end{array}$

$\begin{array}{lll}.4252 \mathrm{E}-14 & .0000 \quad .0000\end{array}$

$.2383 \mathrm{E}-06 \quad .0000 \quad .0000$

$\begin{array}{lll}.1600 \mathrm{E}-09 & .0000 \quad .0000\end{array}$

$\begin{array}{lll}.1714 \mathrm{E}-07 & .0000 \quad .0000\end{array}$

$.1854 \mathrm{E}-07 \quad .0000 \quad .0000$

$\begin{array}{lll}.0000 & .0000 & .0000\end{array}$

$\begin{array}{lll}.4634 E-08 & .0000 \quad .0000\end{array}$

$.0000 \quad .0000 \quad .0000$

$\begin{array}{lll}.2177 E-07 & .0000 & .0000\end{array}$

$.4634 \mathrm{E}-08 \quad .0000 \quad .0000$

$\begin{array}{lll}.3762 \mathrm{E}-08 & .0000 \quad .0000\end{array}$

$.2768 \mathrm{E}-11 \quad .0000 \quad .0000$

$.0000 \quad .0000 \quad .0000$

$\begin{array}{lll}.0000 & .0000 & .0000\end{array}$

$\begin{array}{lll}.1762 E-07 & .0000 & .0000\end{array}$

$\begin{array}{lll}.0000 & .0000 & .0000\end{array}$

$\begin{array}{lll}.9015 \mathrm{E}-13 \quad .0000 & .0000\end{array}$

$\begin{array}{lll}.0000 & .0000 & .0000\end{array}$

$\begin{array}{lll}.0000 & .0000 & .0000\end{array}$

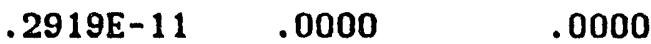

$\begin{array}{lll}.0000 & .0000 & .0000\end{array}$

$.4881 \mathrm{E}-09 \quad .0000 \quad .0000$

$.0000 \quad .0000 \quad .0000$

$\begin{array}{lll}.8037 E-08 & .0000 & .0000\end{array}$

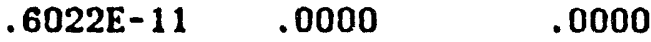

$\begin{array}{lll}.0000 & .0000 & .0000\end{array}$

$.0000 \quad .0000 \quad .0000$

$.0000 \quad .0000 \quad .0000$

$\begin{array}{lll}.1404 E-05 & .0000 \quad .0000\end{array}$

$\begin{array}{lll}.0000 & .0000 & .0000^{\circ}\end{array}$ 
MATEIIAL BALANCE TABLES

Date 09/30/82 Rev 09

SLCDGE-OKILY FEED

\begin{tabular}{|c|c|c|c|c|c|}
\hline \multicolumn{2}{|c|}{$\begin{array}{l}\text { STREAMS (CONT'D)- } \\
\text { STREAM NAME }\end{array}$} & $\begin{array}{c}123 \\
\text { Inlet Vapor }\end{array}$ & $\begin{array}{l}124 \\
\text { FAVC }\end{array}$ & $\begin{array}{l}125 \\
\text { Air Sparge }\end{array}$ & ${ }^{126}$ Dump Can Air \\
\hline 101 & $\mathrm{FeO}$ & .0000 & .0000 & .0000 & .0000 \\
\hline 126 & Group A Semi lo & .0000 & .0000 & .0000 & .0000 \\
\hline 102 & Groupd & $.2601 E-07$ & $.1300 E-07$ & .0000 & .0000 \\
\hline 103 & Group B & $.8288 E-07$ & $.4119 \mathrm{E}-07$ & .0000 & .0000 \\
\hline 25 & II2 & $.3156 \mathrm{E}-05$ & $.2342 E-11$ & .0000 & .0000 \\
\hline 133 & $112 C 204$ & .0000 & .0000 & .0000 & .0000 \\
\hline 91 & $\mathrm{H} 202$ & .0000 & .0000 & .0000 & .0000 \\
\hline 34 & $\mathrm{HCOOH}$ & .4563 & .8880 & .0000 & .0000 \\
\hline 43 & $\mathrm{IICl}$ & .0000 & .0000 & .0000 & .0000 \\
\hline 85 & $\mathrm{HF}$ & .0000 & .0000 & .0000 & .0000 \\
\hline 49 & IIN03 & .0000 & .0000 & .0000 & .0000 \\
\hline 86 & HRes in & .0000 & .0000 & .0000 & .0000 \\
\hline 36 & $\mathrm{Hg}_{\mathrm{g}}$ & $.2940 E-03$ & $.1470 \mathrm{E}-03$ & .0000 & .0000 \\
\hline 135 & $\mathrm{H}_{\mathrm{E}} \mathrm{NO} 2 \mathrm{3} 2$ & .0000 & .0000 & .0000 & .0000 \\
\hline 21 & $\mathrm{HgO}$ & $.2526 \mathrm{E}-09$ & $.1263 E-09$ & .0000 & .0000 \\
\hline 97 & 12 & .0000 & .0000 & .0000 & .0000 \\
\hline 33 & $\mathrm{~K} 20$ & .0000 & .0000 & .0000 & .0000 \\
\hline 151 & $\mathrm{KMnO4}$ & .0000 & .0000 & .0000 & .0000 \\
\hline 118 & KNO3 & $.4947 E-08$ & $.2474 E-08$ & .0000 & .0000 \\
\hline 105 & Li203 & $.1494 E-06$ & $.7472 E-07$ & .0000 & .0000 \\
\hline 108 & Li 20 & $.1707 \mathrm{E}-05$ & $.8534 E-06$ & .0000 & .0000 \\
\hline 65 & $\mathrm{Mg}(\mathrm{CCOH}) 2$ & $.9072 E-07$ & $.4536 \mathrm{E}-07$ & .0000 & .0000 \\
\hline 55 & $\mathrm{Mg}(\mathrm{O} I 1) 2$ & $.5458 \mathrm{E}-10$ & $.2729 E-10$ & .0000 & .0000 \\
\hline 83 & MgO & $.5985 \mathrm{E}-06$ & $.2993 \mathrm{E}-06$ & .0000 & .0000 \\
\hline 60 & $\operatorname{Mn}(\mathrm{COOHI}) 2$ & $.8088 \mathrm{E}-06$ & $.4044 E-06$ & .0000 & .0000 \\
\hline 132 & $\operatorname{Mn}(\mathrm{M} O \mathrm{~N}) 2$ & .0000 & .0000 & .0000 & .0000 \\
\hline 129 & $\operatorname{Nin}(0) 12$ & $.4872 E-08$ & $.2436 E-08$ & .0000 & .0000 \\
\hline 506 & $\mathrm{MnO}$ & .0000 & .0000 & .0000 & .0000 \\
\hline 14 & $\mathrm{~N} \ln 02$ & .0000 & .0000 & .0000 & .0000 \\
\hline 81 & $N_{2}$ & 1227. & $.8842 E-08$ & 17.07 & 80.42 \\
\hline 1.13 & $\mathrm{NA2COS}(\mathrm{Cl} H)$ & .0000 & .0000 & .0000 & .0000 \\
\hline 35 & yo & $.9042 E-01$ & . 1993E-06 & .0000 & .0000 \\
\hline 84 & $\mathrm{~N} 02$ & $.7186 \mathrm{E}-02$ & $.4224 E-03$ & .0000 & .0000 \\
\hline 70 & $\operatorname{Na}\left(H_{g}()(O H)\right)$ & $.5809 E-10$ & $.2905 E-10$ & .0000 & .0000 \\
\hline $9 \cdot 1$ & $\operatorname{Vin} 2 B \cdot 107$ & $.2176 \mathrm{E}-08$ & $.1088 \mathrm{E}-08$ & .0000 & .0000 \\
\hline 109 & $\therefore: 2 C 204$ & $.1985 E-08$ & $.9925 E-09$ & .0000 & .0000 \\
\hline 5 & $\mathrm{~N}_{\mathrm{a} 2 \mathrm{2CO} 3}$ & .0000 & .0000 & .0000 & .0000 \\
\hline 82 & $\operatorname{Nin} 20$ & $.5304 \mathrm{E}-05$ & $.2652 E-05$ & .0000 & .0000 \\
\hline 71 & $\operatorname{Nn} 2 P_{u} 02(\mathrm{OH}) 4$ & $.2356 \mathrm{E}-14$ & $.1178 \mathrm{E}-14$ & .0000 & .0000 \\
\hline 73 & $\mathrm{Na} 2 \mathrm{RhO}_{4}$ & $.4844 \mathrm{E}-12$ & $.2422 E-12$ & .0000 & .0000 \\
\hline 72 & $\mathrm{Nin} 2 \mathrm{RuO} 4$ & $.4726 \mathrm{E}-11$ & $.2363 E-11$ & .0000 & .0000 \\
\hline 6 & $\mathrm{Na} 2 \mathrm{SO} 4$ & $.9585 E-08$ & $.4792 E-08$ & .0000 & .0000 \\
\hline 68 & $\mathrm{Nand} 102$ & $.2356 E-07$ & $.1178 \mathrm{E}-07$ & .0000 & .0000 \\
\hline 114 & $\mathrm{NaBO} 2$ & .0000 & .0000 & .0000 & .0000 \\
\hline 140 & NaBO2 Semi Vol & .0000 & .0000 & .0000 & .0000 \\
\hline 50 & $\mathrm{NaCOOH}$ & $.7606 \mathrm{E}-06$ & $.3803 E-06$ & .0000 & .0000 \\
\hline
\end{tabular}


DPSP $80-1033$

MÁTERIAL BALANCE TABLES

SLUDGE-ONLY FEED

STREAMS (CONT'D)-

STREAM NAME

$7 \mathrm{NaCl}$

$188 \mathrm{NaCl}$ Semi Vol

$69 \mathrm{NaF}$

139 NaF Semi Voi

$12 \mathrm{NaI}$

$125 \mathrm{NaI}$ Semi Vol

$8 \mathrm{NaNO2}$

$2 \mathrm{NinO}$

$4 \mathrm{NnOH}$

$87 \mathrm{NaResin}$

$61 \mathrm{Ni}(\mathrm{COOH}) 2$

$17 \mathrm{Ni}(\mathrm{OH}) 2$

$40 \mathrm{NiO}$

8202

$67 \mathrm{PbO}$

$28 \mathrm{PbS04}$

$124 \mathrm{Pd}$

$123 \mathrm{Pd}(\mathrm{OH}) 2$

112 PdNOS2

$110 \mathrm{PdO}$

$117 \mathrm{Pu}(\mathrm{COOH}) 4$

$76 \quad \mathrm{Pu} 02$

$22 \mathrm{RhO}_{2}$

$79 \mathrm{Ru} 02$

28 Ru02 Semi Vol

$83 \mathrm{RuO}_{4}$

$38 \mathrm{S02}$

$111 \mathrm{SiO2}$

115 Silica Gel

$48 \mathrm{Sr}(\mathrm{COOH}) 2$

$10 \mathrm{Sr}(\mathrm{N} 03) 2$

$127 \mathrm{Sr}(\mathrm{OHI}) 2$

$80 \mathrm{SrCO}$

$46 \mathrm{Sr} 0$

89 SrRESIN

141 Surfactant

$92 \mathrm{ThO}_{2}$

$107 \mathrm{TiO} 2$

119 Tritium

93 v02

62 Vo2(COOH) 2

$16 \mathrm{VO} 2(\mathrm{OH}) 2$

$27 \mathrm{Y}(\mathrm{COOH}) 3$

$11 \mathrm{Y}(\mathrm{NOB}) \mathrm{S}$

$128 \mathrm{Y}(\mathrm{OH}) 3$

$31 Y 2(\cos ) 3$
Appendix II

Table 21-15

Page 120 of 173

Date 09/30/32 Rev 09

\begin{tabular}{|c|c|c|c|}
\hline 123 & 124 & 125 & 126 \\
\hline Inlet Vapor & FAVC & Air Sparge & Dump Can tir \\
\hline $\begin{array}{l}\text { to FAVC } \\
.1174 E-07\end{array}$ & $\begin{array}{l}\text { Condensate } \\
.5872 E-08\end{array}$ & $\begin{array}{l}\text { to } 1 / \mathrm{TT} \\
.0000\end{array}$ & $\begin{array}{c}\text { Inlealinge } \\
.0000\end{array}$ \\
\hline .0000 & .0000 & .0000 & .0000 \\
\hline $.2060 \mathrm{E}-08$ & $.1030 \mathrm{E}-08$ & .0000 & .0000 \\
\hline .0000 & .0000 & .0000 & .0000 \\
\hline $.1068 \mathrm{E}-08$ & $.5388 E-09$ & .0000 & .0000 \\
\hline .0000 & .0000 & .0000 & .0000 \\
\hline .0000 & .0000 & .0000 & .0000 \\
\hline $.8844 E-06$ & $.1922 \mathrm{E}-06$ & .0000 & .0000 \\
\hline .0000 & .0000 & .0000 & .0000 \\
\hline .0000 & .0000 & .0000 & .0000 \\
\hline $.2852 E-06$ & $.1426 \mathrm{E}-06$ & .0000 & .0000 \\
\hline $.2097 \mathrm{E}-09$ & $.1048 \mathrm{E}-09$ & .0000 & .0000 \\
\hline .0000 & .0000 & .0000 & .0000 \\
\hline 870.7 & $.5389 \mathrm{E}-03$ & 5.158 & $9.1 \varepsilon 9$ \\
\hline .0000 & .0000 & .0000 & .0000 \\
\hline . 1295E-07 & $.6473 E-08$ & .0000 & .0000 \\
\hline .0000 & .0000 & .0000 & .0000 \\
\hline .0000 & .0000 & .0000 & .0000 \\
\hline .0000 & .0000 & .0000 & .0000 \\
\hline .0000 & .0000 & .0000 & .0000 \\
\hline .0000 & .0000 & .0000 & .0000 \\
\hline $.3369 E-08$ & $.1684 \mathrm{E}-08$ & .0000 & .0000 \\
\hline $.1287 \mathrm{E}-08$ & $.6436 \mathrm{E}-09$ & .0000 & .0000 \\
\hline $.6375 \mathrm{E}-08$ & $.3188 E-08$ & .0000 & .0000 \\
\hline .0000 & .0000 & .0000 & .0000 \\
\hline .0000 & .0000 & .0000 & .0000 \\
\hline $.8969 E-05$ & $.2783 E-10$ & .0000 & .0000 \\
\hline $.1788 E-04$ & $.8940 E-05$ & .0000 & .0000 \\
\hline .0000 & .0000 & .0000 & .0000 \\
\hline $.1158 \mathrm{E}-07$ & $.5790 \mathrm{E}-08$ & .0000 & .0000 \\
\hline $.1358 \mathrm{E}-13$ & $.6790 E-14$ & .0000 & .0000 \\
\hline $.9352 E-11$ & $.4676 \mathrm{E}-11$ & .0000 & .0000 \\
\hline .0000 & .0000 & .0000 & .0000 \\
\hline .0000 & .0000 & .0000 & .0000 \\
\hline .0000 & .0000 & .0000 & .0000 \\
\hline .0000 & .0000 & .0000 & .0000 \\
\hline $.5281 E-07$ & $.2641 E-07$ & .0000 & .0000 \\
\hline $.2988 \mathrm{E}-06$ & $.1494 \mathrm{E}-06$ & .0000 & .0000 \\
\hline $.8931 E-10$ & $.3740 E-10$ & .0000 & .0000 \\
\hline .0000 & .0000 & .0000 & .0000 \\
\hline $.8689 E-06$ & $.1844 E-06$ & .0000 & .0000 \\
\hline $.8674 E-09$ & . 1837E-09 & .0000 & .0000 \\
\hline $.7935 E-08$ & $.3968 E-08$ & .0000 & .0000 \\
\hline $.9643 \mathrm{E}-14$ & $.4822 E-14$ & .0000 & .0000 \\
\hline $.5847 \mathrm{E}-11$ & $.2924 E-11$ & .0000 & .0000 \\
\hline .0000 & .0000 & .0000 & .0000 \\
\hline
\end{tabular}


DRSP $80-1033$

Material BALANCE TABLES

SLUDGE-ONLY FEED

STREAMS (CONT'D)STREIM NAME

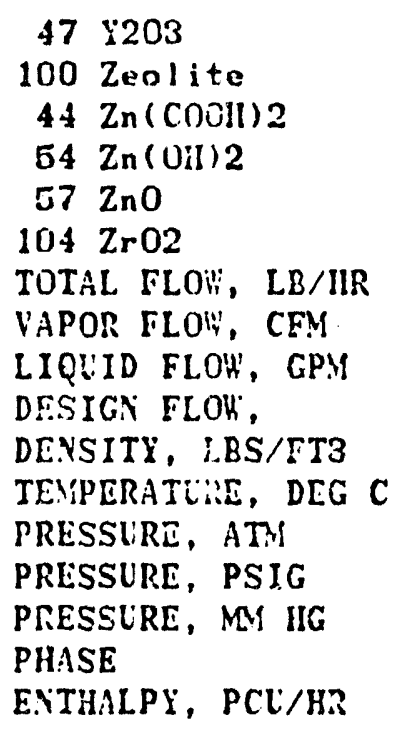

123
Inlet Vnpor
to FAVC
.0000
$.3376 \mathrm{E}-06$
$.4193 \mathrm{E}-07$
$.3162 \mathrm{E}-10$
.0000
$.1494 \mathrm{E}-06$
1717.66
454.96

124

FAVC

Condensnte

.0000

$.1685 \mathrm{E}-06$

$.2096 E-07$

$.1581 \mathrm{E}-10$

.0000

$.7472 \mathrm{E}-07$

95.93

.19
.0629
50.00
.96
$-.58$
730.13
VAPOR
$-26967.07$

Appendix $\mathrm{H}$

Inble 21-15

Page 121 of 173

Dnte 09/30/82 Rev 09

$\begin{array}{cc}125 & 126 \\ \text { Air Sparge } & \begin{array}{c}\text { Dump Con Air } \\ \text { to MFT }\end{array} \\ .0000 & .0000 \\ .0000 & .0000 \\ .0000 & .0000 \\ .0000 & .0000 \\ .0000 & .0000 \\ .0000 & .0000 \\ 22.61 & 40.29 \\ 5.84 & 9.88 \\ & \\ & \\ .0706 & .0680 \\ 85.00 & 35.00 \\ 1.00 & .96 \\ .00 & -.54 \\ & 732.03 \\ \text { VAPOR } & \text { VAPOR } \\ -1164.14 & -2074.10\end{array}$


DPSP $80-1053$

MATERIAL BALANCE TABLES

SLCDGI:-ONLY FEED

STREAM NUMBERS -

STREAM NAME

CONPONENT FLOHS, LE/IIR

\begin{tabular}{|c|c|c|c|c|c|}
\hline 1 & H2O & .0000 & .0000 & .0000 & 6.222 \\
\hline 45 & Ag & .0000 & .0000 & .0000 & .0000 \\
\hline 116 & $\mathrm{Ag} 20$ & .0000 & .0000 & .0000 & .0000 \\
\hline 134 & AgN03 & .0000 & .0000 & .0000 & .0000 \\
\hline 51 & AgOll & .0000 & .0000 & .0000 & .0000 \\
\hline 74 & $\mathrm{Al}(\mathrm{OH}) 3$ & .0000 & .0000 & .0000 & .0000 \\
\hline 77 & A1203 & .0000 & .0000 & .0000 & $.0: 000$ \\
\hline 75 & AloOH & .0000 & .0000 & .0000 & .0000 \\
\hline 106 & B203 & .0000 & .0000 & .0000 & .0000 \\
\hline 9 & $\mathrm{Ba}(\mathrm{NO3}) 2$ & .0000 & .0000 & .0000 & .0000 \\
\hline 95 & $\mathrm{BaC} 12$ & .0000 & .0000 & .0000 & .0000 \\
\hline 15 & $\mathrm{BaO}$ & .0000 & .0000 & .0000 & .0000 \\
\hline 24 & BaSO4 & .0000 & .0000 & .0000 & .0000 \\
\hline 66 & CO & .0000 & .0000 & .0000 & .0000 \\
\hline 37 & $\mathrm{CO2}$ & .0000 & .0000 & .0000 & 5.558 \\
\hline 142 & $\operatorname{CO2}(\mathrm{C14})$ & .0000 & .0000 & .0000 & .0000 \\
\hline 63 & $\mathrm{Ca}(\mathrm{COOH}) 2$ & .0000 & .0000 & .0000 & .0000 \\
\hline 120 & $\mathrm{Ca}(\mathrm{OII}) 2$ & .0000 & .0000 & .0000 & .0000 \\
\hline 113 & $\mathrm{Ca} 3(\mathrm{PO} 04) 2$ & .0000 & .0000 & .0000 & .0000 \\
\hline 20 & $\mathrm{CaC204}$ & .0000 & .0000 & .0000 & .0000 \\
\hline 18 & $\mathrm{CaCO3}$ & .0000 & .0000 & .0000 & .0000 \\
\hline 78 & CaF2 & .0000 & .0000 & .0000 & .0000 \\
\hline 41 & $\mathrm{CaO}$ & .0000 & .0000 & .0000 & .0000 \\
\hline 19 & $\mathrm{CaSO} 4$ & .0000 & .0000 & .0000 & .0000 \\
\hline 29 & Carbon & .0000 & .0000 & .0000 & .0000 \\
\hline 26 & $\mathrm{Co}(\mathrm{COOH}) 2$ & .0000 & .0000 & .0000 & .0000 \\
\hline 121 & $\mathrm{Co}(\mathrm{OH}) 2$ & .0000 & .0000 & .0000 & .0000 \\
\hline 53 & $\mathrm{CO}(\mathrm{OH}) 3$ & .0000 & .0000 & .0000 & .0000 \\
\hline 59 & $\mathrm{CoO}$ & .0000 & .0000 & .0000 & .0000 \\
\hline 99 & $\mathrm{Cr}(\mathrm{OH}) 3$ & .0000 & .0000 & .0000 & .0000 \\
\hline 98 & Cr203 & .0000 & .0000 & .0000 & .0000 \\
\hline 42 & Cs20 & .0000 & .0000 & .0000 & .0000 \\
\hline 137 & Cs20 Semi Vol & .0000 & .0000 & .0000 & .0000 \\
\hline 90 & $\mathrm{CsCOOH}$ & .0000 & .0000 & .0000 & .0000 \\
\hline 96 & CsCl & .0000 & .0000 & .0000 & .0000 \\
\hline 186 & Cscl Semi Vol & .0000 & .0000 & .0000 & .0000 \\
\hline 8 & CsNO3 & .0000 & .0000 & .0000 & .0000 \\
\hline 88 & CsResin & .0000 & .0000 & .0000 & .0000 \\
\hline 122 & $\mathrm{Cu}(\mathrm{COOH}) 2$ & .0000 & .0000 & .0000 & .0000 \\
\hline 52 & $\mathrm{Cu}(\mathrm{OH}) 2$ & .0000 & .0000 & .0000 & .0000 \\
\hline 58 & Cu2O & .0000 & .0000 & .0000 & .0000 \\
\hline 64 & $\mathrm{CuCOOH}$ & .0000 & .0000 & .0000 & .0000 \\
\hline 180 & $\mathrm{CuO}$ & .0000 & .0000 & .0000 & .0000 \\
\hline 13 & Fe(OH) 3 & .0000 & .0000 & .0000 & .0000 \\
\hline 80 & Fe203 & .0000 & .0000 & .0000 & .0000 \\
\hline
\end{tabular}

Appendix il

Tuble 21-15

Page 122 of 173

Date 09/30/S: Rrs oj 
MitrRial BALANCE TALLES

Date 09/30/82 Rev 09

\section{SLCDAT-0RILY TEED \\ STPEAYS (CONT'D)- STREAM NAME}

$101 \mathrm{FeO}$

126 Group A Semi Vo

102 Group.1

103 Group B

$25 \quad 112$

$123 \mathrm{H} 2 \mathrm{C} 2 \mathrm{O} \cdot 1$

$91 \mathrm{H202}$

34 ICOOH

43 IICI

$85 \mathrm{IIF}$

49 INNOZ

86 HResin

$80 \mathrm{Hg}$

135 Hg.032

$21 \mathrm{HgO}$

$97 \mathrm{I} 2$

59 $\times 20$

$131 \mathrm{KMnO} 01$

$119 \mathrm{KNO} 03$

1CJ L:IOO3

103 Li20

$65 \mathrm{Mg}(\mathrm{COOHI}) 2$

$55 \mathrm{Mg}(\mathrm{Oil}) 2$

$23 \mathrm{MgO}$

$60 \mathrm{Mn}(\mathrm{COOH}) 2$

$122 \mathrm{Mn}(\mathrm{NO}) 2$

$129 \mathrm{Mn}(011) 2$

$56 \mathrm{MnO}$

$14 \mathrm{MnO2}$

$81 \times 2$

$1.33 \mathrm{in2CO3} \mathrm{(C1:4)}$

35 No

8. 102

$70 \mathrm{Na}\left(\mathrm{II}_{\mathrm{g}} \mathrm{N}(\mathrm{OH})\right)$

$94 \mathrm{Na} 2 \mathrm{~B} 407$

$109 \mathrm{Na} 2 \mathrm{C} 204$

$5 \mathrm{Na2CO3}$

$82 \sin 20$

i1 $\mathrm{N}$ 2 $2 \mathrm{Pu}_{\mathrm{u}} 02(0.1) 4$

$73 \mathrm{Na}_{2} \mathrm{RH}_{1} 04$

$72 \mathrm{Na} 2 \mathrm{RuO4}$

$6 \mathrm{Na} 2 \mathrm{SO}$

68 NaA102

114 Naß02

140 NaBO2 Semi Vol

$50 \mathrm{NaCOOH}$
127

Control Alr Surfactant

to Ejector .0000

.0000

.0000

.0000

.0000

.0000

.0000

.0000

.0000

.0000

.0000

.0000

.0000

.0000

.0000

.0000

.0000

.0000

.0000

.0000

.0000

.0000

.0000

.0000

.0000

.0000

.0000

.0000

.0000

.0000

.0000

.0000

.0000

.0000

.0000

.0000

.0000

.0000

.0000

.0000

.0000

.0000

.0000

.0000

.0000

.0000
129

Surfactant

to FPT

.0000

.0000

.0000

.0000

.0000

.0000

.0000

.0000

.0000

.0000

.0000

.0000

.0000

.0000

.0000

.0000

.0000

.0000

.0000

.0000

.0000

.0000

.0000

.0000

.0000

.0000

.0000

.0000

.0000

.0000

.0000

.0000

.0000

.0000

.0000

.0000

.0000

.0000

.0000

.0000

.0000

.0000

.0000

.0000

.0000

.0000
130

DHIT Vont

to PVVS

.0000

.0000

.0000

.0000

.0000

.0000

.0000

.0000

.0000

.0000

.0000

.0000

.0000

.0000

.0000

.0000

.0000

.0000

$.4731 \mathrm{E}-03$

.0000

.0000

.0000

.0000

.0000

.0000

.0000

$.4162 E-0 S$

.0000

.0000

47.85

.0000

1.168

.0000

.0000

.0000

$.1898 \mathrm{E}-03$

.0000

.0000

.0000

.0000

.0000

.0000

.0000

.0000

.0000

.0000 
DPSP $80-1023$

MATERIAL BALANCE TARLES

SLIDGE-ONLY FEED

STREANS $(C O N T$ 'D) -

STREAM NAME

$7 \mathrm{NaCl}$

$138 \mathrm{NaCl}$ Semi Vol

$69 \mathrm{NaF}$

139 NaF Semi Vol

$12 \mathrm{NaI}$

$125 \mathrm{NaI}$ Semi Vol

$3 \mathrm{NaNO2}$

2 NinOS

$4 \mathrm{NaOH}$

87 NaResin

$61 \mathrm{Ni}(\mathrm{COOH}) 2$

$17 \mathrm{Ni}(\mathrm{OH}) 2$

$40 \mathrm{NiO}$

8202

$67 \mathrm{PbO}$

$28 \mathrm{PbS04}$

$124 \mathrm{Pd}$

$123 \mathrm{Pd}(\mathrm{OH}) 2$

112 Pdí032

$110 \mathrm{PdO}$

$117 \mathrm{Pu}(\mathrm{COOH}) 4$

$76 \mathrm{Pu} 02$

$22 \mathrm{RhO2}$

$79 \mathrm{Ru} 02$

23 RuO2 Semi Vol

$83 \mathrm{Ru} 04$

$38 \mathrm{SO2}$

$111 \mathrm{SiO}$

115 Silica Gel

$48 \mathrm{Sr}(\mathrm{COOH}) 2$

$10 \mathrm{Sr}(\mathrm{NOO}) 2$

$127 \mathrm{Sr}(\mathrm{OH}) 2$

$30 \mathrm{SrCO}$

$46 \mathrm{SrO}$

89 SrRESIN

141 Surfactant

92 ThO2

$107 \mathrm{TiO}$

119 Tritium

93 V02

$62 \mathrm{VO} 2(\mathrm{COOH}) 2$

$16 \mathrm{VO2}(\mathrm{OII}) 2$

$27 \mathrm{Y}(\mathrm{COOH}) \mathrm{3}$

$11 \mathrm{X}(\mathrm{NO3}) \mathrm{3}$

$128 \mathrm{Y}(\mathrm{OH}) 3$

$81 Y 2(\mathrm{COB}) 3$
127
Control Air
to Ejector
.0000
.0000
.0000

.0000

.0000

.0000

.0000

.0000

.0000

.0000

.0000

.0000

.0000

.0000

.0000

.0000

.0000

.0000

.0000

.0000

.0000

.0000

.0000

.0000

.0000

.0000

.0000

.0000

.0000

.0000

.0000

.0000

.0000

.0000

.0000

.0000

.0000

.0000

.0000

.0000

.0000

.0000

.0000

.0000

.0000

.0000
Appendix II

Tisble 21-15

Page 124 of 173

Date 09/30/52 Rew 09
$129 \quad 130$

Surfactant DHTT lient

to FPT to PITS

$.0000 \quad .0030$

$.0000 \quad .0000$

$.0000 \quad .0000$

$.0000 \quad .0000$

$.0000 \quad .0000$

$.0000 \quad .0000$

$.0000 \quad .0000$

.0000

.0000

.0000

.0000

.0000

.0000

.0000

.0000

.0000

.0000

.0000

.0000

.0000

.0000

.0000

.0000

.0000

.0000

.0000

.0000

.0000

.0000

.0000

.0000

.0000

.0000

.0000

.0000

$.1038 \mathrm{E}-02$

.0000

.0000

.0000

.0000

.0000

.0000

.0000

.0000

.0000

.0000
$.7622 \mathrm{E}-0 \mathrm{~B}$

$.1200 E-0: 3$

.0000

.0000

.0000

.0000

14.45

.0000

.0000

.0000

.0000

.0000

.0000

.0000

.0000

.0000

.0000

.0000

.0000

.0000

.0000

.0000

.0000

.0000

.0000

.0000

.0000

.0000

.0000

.0000

.0000

.0000

.0000

.0000

.0000

.0000

.0000

.0000

$.0000^{\circ}$ 
M:TERIAL BALANCE TABLES Date 09/30/82 Rev 09

SI.CDCE-ONLY FEED

STREMYS (CONT'D)STREAM NAYE

$47 \quad 1203$

100 Zeolite

$44 \mathrm{Zn}(\mathrm{CCOII}) 2$

$54 \mathrm{Zn}(\mathrm{Oill}) 2$

$57 \mathrm{ZnO}$

$104 \mathrm{Zr} 02$

TOTAL FLO'I, LB/HIR

VAPOR FLOH, CFM

LIQUID FLOH, GPM DESIGN FLOH,

DEYSITY, LBS/FT3

TEYPERATLRE, DEG C PRESSLRE, ATMI

PRESSLRE, PSIG

PRESSLPE, MY IIG

PIIASE

ENTHALPY, PCV/HR
127

Control Air

to Ejector

.0000

.0000

.0000

.0000

.0000

.0000

.00

.00

.0000

85.00

1.00

.00

VAPOR

.00
128

Surfactant to OGCT

.0000

.0000

.0000

.0000

.0000

.0000

.00

.00

66.8000

25.00

1.00

.00

LIỌCID

.08
129

Surfactant to FPT

.0000

.0000

.0000

.0000

.0000

.0000

.00

.03

66.8000

25.00

1.00

.00

LIQUID

.03
180

DHIT Vent

to PVVS

.0000

.0000

.0000

.0000

.0000

.0000

75.25

20.85

.0616

50.00

.93

$-1.08$

703.99

VAPOR

272.00 
MATERIAL BALANCE TABLES

SLUDGE:-ONLY FEED

STREAM NUMBERS -

STREAM NAME

181

132

133

134 CONPONEYT FLOYS, LB/HR

Inlet Gas to Sand Filter Fan Exhaust Stacl.
Sand Filter Exinaust to Stacl

\begin{tabular}{|c|c|}
\hline & H2O \\
\hline 45 & $5 \mathrm{Ag}$ \\
\hline 116 & $A g 20$ \\
\hline 184 & AgYOS \\
\hline 51 & I AgOll \\
\hline 74 & All(OH) 3 \\
\hline 77 & A1203 \\
\hline 75 & AlOOH \\
\hline 100 & B203 \\
\hline 9 & $\mathrm{Ba}(\mathrm{N} 03) 2$ \\
\hline 95 & $\mathrm{BaCl} 2$ \\
\hline 15 & $\mathrm{BnO}$ \\
\hline 24 & $\mathrm{BaSO4}$ \\
\hline 66 & $\mathrm{co}$ \\
\hline 87 & C02 \\
\hline 142 & $=\cos \left(C_{1} 1\right)$ \\
\hline 63 & $3 \mathrm{Ca}(\mathrm{COOH}) 2$ \\
\hline 120 & $\mathrm{Ca}(\mathrm{OHI}) 2$ \\
\hline 113 & $3 \mathrm{Ca} 3(\mathrm{PO} 4) 2$ \\
\hline 20 & $\mathrm{CaC2O4}$ \\
\hline 18 & $3 \mathrm{CaCO}$ \\
\hline 78 & $\mathrm{CaF2}$ \\
\hline 41 & $\mathrm{Ca} 0$ \\
\hline 19 & $\mathrm{CaSO4}_{\mathrm{aS}}$ \\
\hline 29 & Carbon \\
\hline 26 & ; $\mathrm{Co}(\mathrm{COOH}) 2$ \\
\hline 121 & $\mathrm{Co}(\mathrm{OH}) 2$ \\
\hline 53 & $3 \mathrm{Co}(\mathrm{OH}) 3$ \\
\hline 59 & $\mathrm{CoO}$ \\
\hline 99 & $\mathrm{Cr}(011) 3$ \\
\hline 98 & Cr203 \\
\hline 42 & $\mathrm{Cs} 20$ \\
\hline 137 & Cs20 Semi \\
\hline 90 & $\mathrm{CsCOOH}$ \\
\hline 96 & $\mathrm{CsCl}$ \\
\hline 136 & C CsCl Semi \\
\hline 8 & CsNO3 \\
\hline 88 & CsResin \\
\hline 122 & $\mathrm{Cu}_{\mathrm{u}}(\mathrm{COOH}) 2$ \\
\hline 52 & $\mathrm{Cu}_{\mathrm{u}}(\mathrm{OH}) 2$ \\
\hline 58 & 3 Cu20 \\
\hline 130 & Cu 0 \\
\hline 18 & $\mathrm{Fe}(\mathrm{OH}) 3$ \\
\hline 80 & $\mathrm{Fe} 203$ \\
\hline
\end{tabular}

9645.

$.5027 \mathrm{E}-10$

.0000

9645.

$.8252 \pi-10$

$.5027 \mathrm{E}-13$

.0000

96.15.

9045.

$.1580 \mathrm{E}-10$

$.8252 \mathrm{~F}-13$

.5027E-13

$.0 \mathrm{COO}$

$.5027 \mathrm{E}-13$

$.8252 \mathrm{E}-13$

.0000

$.1580 \mathrm{E}-13$

$.1580 \mathrm{E}-13$

$.52625-13$

$.1914 \mathrm{E}-08$

$.1914 \mathrm{E}-11$

.0000

.0000

$.1914 \mathrm{E}-11$

$.15805-i 3$

.0000

$.7204 \mathrm{E}-08$

.0000

.0000

$.101 \cdot$ E-11

$.7204 \mathrm{E}-11$

.0000

.0000

$.7204 E-11$

.0000

.2511E-19

$\begin{array}{ll}.2511 \mathrm{E}-16 & .0000 \\ .0000 & .0000\end{array}$

.0000

.0000

.2270E-10

5.598

$.2270 \mathrm{E}-13$

5.598

24.03

24.03

.3484E-09

.3484E-09

$.7865 \mathrm{E}-03$

$.7865 \mathrm{E}-12$

.2511E-19

$.7204 \mathrm{~F}-11$

.0000

$.25111-10$

.0000

.0000

$.2270 \mathrm{E}-13$

5.598

.0000

.2270 E- 13

24.03

5.598

24.03

$.3484 \mathrm{E}-03$

. 34S4E-00

$.5201 \mathrm{E}-12$

. $5201 E-15$

$.7865 \mathrm{E}-12$

$.7865 \mathrm{E}-12$

. $6656 \mathrm{E}-10$

$.5201 \mathrm{E}-15$

$.5201 \mathrm{E}-15$

$.6118 \mathrm{E}-10$

. $5656 \mathrm{E}-13$

$.5656 \mathrm{E}-13$

. $655 C E-13$

.0000

$.6118 \mathrm{E}-13$

$.6118 \mathrm{E}-13$

$.6118 \mathrm{E}-13$

$.1529 \mathrm{E}-10$

.0000

.0000

.0000

.0000

$.1529 \mathrm{E}-13$

$.1529 E-13$

.0000

.0000

.0000

$.7186 \mathrm{E}-10$

$.7186 \mathrm{E}-13$

$.7186 \mathrm{E}-13$

$.7156 \mathrm{E}-13$

$.1529 \mathrm{E}-10$

. 1529E-13

$.1529 E-13$

. 1520l:-18

. 1223E-07

. 1223E-07

. 1223E-07

$.1220 \mathrm{E}-07$

$.8997 \mathrm{E}-14$

.0000

.0000

$.8997 E-17$

$.8997 E-17$

$.8997 \mathrm{E}-17$

.0000

.0000

.0000

.0000

$.5814 \mathrm{E}-10$

$.5814 \mathrm{E}-13$

.0000

.0000

.0000

$.5814 \mathrm{E}-13$

$.5814 \mathrm{E}-13$

$.2965 \mathrm{E}-15$

.0000

.0000

.0000

$.1267 \mathrm{E}-10$

.2965E- 18

.0000

.0000

$.2965 \mathrm{E}-18$

$.2965 \mathrm{E}-1 \mathrm{~S}$

.0000

.0000

.0000

.0000

.0000

.0000

$.1267 \mathrm{E}-13$

. 1267E- 13

$.1267 \mathrm{E}-13$

.0000

.0000

.0000

.0000

$.1611 \mathrm{E}-11$

$.1011 E-14$

$.1011 E-14$

.0000

.0000

.0000

.0000

.2653E-10

$.2653 \mathrm{E}-13$

$.2653 \mathrm{E}-13$

$.2653 \mathrm{E}-13$

$.1957 E-13$

. 1957E-16

. 1957E-16

. 1957E-16

.0000

.0000

.0000

.0000

.0000

.0000

.0000

.0000

0000

.0000

.0000

.0000

$.4632 \mathrm{E}-0 \mathrm{~S}$

$.4632 \mathrm{E}-11$

$.46325-11$

.0000

.0000

.0000 . 
MATERIIL BALANCE TIBLES

Dnte 09/30/82 Rev 09

\section{SLLDCE-ONLY FEED STREAMS (CONT'D) - STREAM YAME}

$101 \mathrm{FeO}$

126 Croup A Seni Vo

102 GroupA

103 GroupB

$25 \mathrm{H} 2$

$133 \mathrm{HI} 2 \mathrm{C2O4}$

9111202

8.1 HCOOH

$43 \mathrm{IICl}$

$85 \mathrm{HF}$

49 IINO3

86 HRes in

$36 \mathrm{Hg}$

$135 \mathrm{H}_{\varepsilon} \cdot \mathrm{HO} 22$

$21 \mathrm{H}$.

$97 \quad 12$

$39 \mathrm{~K} 20$

$131 \mathrm{KMnO4}$

$118 \mathrm{KNO}$

$105 \operatorname{Ln} 203$

108 L 120

$65 \mathrm{Mg}(\mathrm{COOH}) 2$

$55 \mathrm{Mg}(\mathrm{OII}) 2$

$33 \mathrm{MgO}$

$60 \cdot \mathrm{Mn}(\mathrm{COOHI}) 2$

$182 \operatorname{Mn}(\mathrm{N} 03) 2$

$129 \mathrm{Mn}(\mathrm{O}: 1) 2$

$56 \operatorname{Mn} 0$

$14 \mathrm{MnO2}$

$81 \mathrm{N2}$

$143 \mathrm{NA2COB}\left(\mathrm{Cl}_{4}\right)$

$85 N O$

$84 \mathrm{NO2}$

$70 \mathrm{Nin}(\mathrm{HgO}(\mathrm{OH}))$

94 in 2B407

100 Nu2C204

$5 \mathrm{Ni} 2 \mathrm{CO} 3$

$32 \mathrm{Nn} 20$

$71 \mathrm{Na} 2 \mathrm{P}_{402}(\mathrm{OH}) 4$

$73 \mathrm{Nn} 2 \mathrm{RhO}$

$72 \mathrm{Na} 2 \mathrm{RuO4}$

$6 \mathrm{Na} 2 \mathrm{SO} 4$

$68 \mathrm{NaAlO2}$

$114 \mathrm{NnBO2}$

$140 \mathrm{NaBO2}$ Semi Vol 50 NinCOOII
181

Inlet Can to Sand Filter

Sand Filter

.0000

.0000

$.4297 \mathrm{E}-09$

$.1359 E-09$

.3658

.0000

.0000

$.6663 \mathrm{E}-01$

.0000

.0000

.0000

.0000

.3797E-08

$.5166 \mathrm{E}-13$

. 1926E-09

$.9392 E-09$

.0000

.0000

$.2842 E-10$

$.2445 E-09$

.2793E-08

. 1497E-09

$.8870 E-13$

$.9794 E-09$

. 1335E-08

.0000

$.2144 E-10$

.0000

.0000

$.44022+06$

.0000

2.439

.2034

$.9587 \mathrm{E}-18$

$.8951 E-10$

$.9395 \mathrm{E}-11$

.0000

$.8692 E-08$

$.8888 E-17$

$.7993 E-15$

$.7800 \mathrm{E}-14$

. 1582E- 10

$.8888 E-10$

.0000

.0000

. 1252E-08
183

Fon Exhnust to Stack

.0000

.0000

$.4297 \mathrm{E}-12$

$.1859 \mathrm{E}-12$

.8658

.0000

.0000

$.6668 \mathrm{E}-01$

.0000

.0000

.0000

.0000

$.8797 E-03$

.516GE-16

. 1926E- 12

$.9992 E-09$

.0000

.0000

.2342E-13

.2445E- 12

$.2793 \mathrm{E}-11$

$.1497 \mathrm{E}-12$

$.8870 E-16$

$.9794 E-12$

$.1835 E-11$

.0000

$.2144 E-13$

.0000

.0000

$.4402 E+06$

.0000

2.433

.2034

$.9587 E-16$

$.3951 \mathrm{E}-13$

$.9395 E-14$

.0000

$.8692 \mathrm{E}-11$

$.3888 \mathrm{E}-20$

$.7993 \mathrm{E}-18$

$.7800 \mathrm{E}-17$

$.1582 \mathrm{E}-13$

$.8888 E-13$

.0000

.0000

$.1252 E-11$
184

Stnck

Exhaust

.0000

.0000

$.4297 \mathrm{E}-12$

. 1359E- 12

.8658

.0000

.0000

.6663E-01

.0000

.0000

.0000

.0000

. 3797E-03

$.5166 \mathrm{E}-16$

. 1926E- 12

$.9392 E-09$

.0000

.0000

$.2342 E-13$

$.2445 \mathrm{E}-12$

.2793E- 11

$.1497 \mathrm{E}-12$

$.8870 \mathrm{E}-16$

$.9794 \mathrm{E}-12$

. 1835E- 11

.0000

$.2144 E-13$

.0000

.0000

.4402EitOS

.0000

2.433

.2034

$.9587 \mathrm{E}-16$

$.3951 \mathrm{E}-13$

$.9395 \mathrm{E}-14$

.0000

$.8692 \mathrm{E}-11$

$.3888 \mathrm{E}-20$

$.7993 \mathrm{E}-18$

$.7800 \mathrm{E}-17$

$.1582 \mathrm{E}-13$

$.8888 E-13$

.0000

.0000

$.1252 E-11$ 
DPSP $80-1038$

MITE!IAL BALANCE TABLES

SLURGI-ONLY FEED

STREAMIS ( CORIT' D) -

STREAY NAME

$7 \mathrm{NaCl}$

$188 \mathrm{NaCl}$ Seml Vol

$69 \mathrm{~N}$ F

189 Ninf Seni Vol

$12 \mathrm{NaI}$

$125 \mathrm{NaI}$ Seml Vol

$8 \mathrm{NaNO} 2$

$2 \mathrm{Nn. \textrm {NOS }}$

$4 \mathrm{inOll}$

87 . NaResin

$61 \mathrm{Ni}(\mathrm{COOH}) 2$

$17 \mathrm{Ni}(\mathrm{OH}) 2$

40 . $i 0$

8202

$67 \mathrm{PbO}$

$28 \mathrm{PbSO4}$

$124 \mathrm{Pd}$

$123 \mathrm{Pd}(\mathrm{OH}) 2$

112 PdNO32

$110 \mathrm{PdO}$

$117 \mathrm{Pu}(\mathrm{COOH}) 4$

$76 \mathrm{Pu} 02$

$22 \mathrm{Rh} 02$

$79 \mathrm{Ru} 02$

23 Ru02 Semi Vol

$83 \mathrm{Ru} 04$

$38 \mathrm{SO2}$

$111 \mathrm{Si02}$

115 Silica Gel

$48 \mathrm{Sr}(\mathrm{COOHI}) 2$

$10 \mathrm{Sr}(\mathrm{N} 03) 2$

$127 \mathrm{Sr}(\mathrm{OII}) 2$

$30 \mathrm{SrCO}$

$46 \mathrm{SrO}$

89 SrRESIN

141 Surfactant

92 ThO2

107 T102

119 Tritium

$93 \mathrm{VO2}$

$62 \mathrm{VO2}(\mathrm{COOH}) 2$

$16 \mathrm{VO} 2(\mathrm{OH}) 2$

$27 \mathrm{Y}(\mathrm{COOH}) 3$

$11 \mathrm{Y}(\mathrm{NOS}) \mathrm{S}$

$128 \times(\mathrm{OH}) 3$

$81 \times 2(\mathrm{CO}) 3$
Appendix II

Table 21-15

Page 128 of 173

Dato 0S/SU/S2 ReV 00

\begin{tabular}{|c|c|c|c|}
\hline 131 & 132 & 133 & 134 \\
\hline let Cas to & Sand Filter & Fnn Kxhaust & Stncl: \\
\hline $\begin{array}{l}\text { and Filter } \\
2879 E-08\end{array}$ & $\begin{array}{l}\text { Exhaust } \\
.2879 E-11\end{array}$ & $\begin{array}{l}\text { to Strick } \\
\text { 2879E- } 11\end{array}$ & $\begin{array}{l}\text { E::haust } \\
\text {.2S700- i }\end{array}$ \\
\hline .0000 & .0000 & .0000 & .0000 \\
\hline $.2262 E-08$ & $.2262[-11$ & $.2262 E-11$ & $.2202 E-11$ \\
\hline .0000 & .0000 & .0400 & .0000 \\
\hline $.2763 E-09$ & $.2763 E-12$ & $.2763 E-12$ & $.27030-12$ \\
\hline .0000 & .0000 & .0000 & .0000 \\
\hline .0000 & .0000 & .0000 & .0000 \\
\hline $.9932 E-09$ & $.9932 E-12$ & $.9032 E-12$ & $.99025-12$ \\
\hline $.8901 E-12$ & $.3901 E-15$ & $.3901 E-1 \bar{J}$ & $.3901 E-13$ \\
\hline .0000 & .0000 & .0000 & .0000 \\
\hline $.4707 E-09$ & $.4707 E-12$ & $.4707 E-12$ & $.4707 E-1$ \\
\hline $.3407 E-12$ & $.3407 E-15$ & $.3407 E-15$ & $.3407 E-1$ \\
\hline .0000 & .0000 & .0000 & .0000 \\
\hline . 1330E+0G & . 1330区 \pm 06 & $.1330 \mathrm{E}+00$ & $.1330 E+0$ \\
\hline .0000 & .0000 & .0000 & .0000 \\
\hline $.2136 \mathrm{E}-10$ & $.2136 E-13$ & $.2136 E-13$ & $.213 G E-13$ \\
\hline .0000 & .0000 & .0000 & .0000 \\
\hline .0000 & .0000 & .0000 & .0000 \\
\hline .0000 & .0000 & .0000 & .0000 \\
\hline .0000 & .0000 & .0000 & .0000 \\
\hline .0000 & .0000 & .0000 & .0000 \\
\hline $.5559 E-11$ & $.5559 E-14$ & $.5559 \mathrm{E}-14$ & $.5559 E-11$ \\
\hline $.2124 E-11$ & $.2124 \mathrm{E}-14$ & $.2124 E-14$ & $.2124 E-14$ \\
\hline $.1996 \mathrm{E}-09$ & $.1996 \mathrm{E}-12$ & $.1996 E-12$ & $.1996 \mathrm{E}-1$ \\
\hline .0000 & .0000 & .0000 & .0000 \\
\hline .0000 & .0000 & .0000 & .0000 \\
\hline .3755 & .3755 & .8755 & .8755 \\
\hline $.2927 E-07$ & $.2927 E-10$ & $.2027 E-10$ & $.2927 E-10$ \\
\hline .0000 & .0000 & .0000 & .0000 \\
\hline $.1911 \mathrm{E}-10$ & $.1911 \mathrm{E}-13$ & $.1911 E-13$ & $.1011 \mathrm{E}-13$ \\
\hline $.2241 E-16$ & $.2241 \mathrm{E}-19$ & $.2241 \mathrm{E}-19$ & $.2241 E-19$ \\
\hline $.1520 E-13$ & $.1520 \mathrm{E}-16$ & $.1520 \mathrm{E}-16$ & $.1520 \mathrm{E}-10$ \\
\hline .0000 & .0000 & .0000 & .0000 \\
\hline .0000 & .0000 & .0000 & .0000 \\
\hline .0000 & .0000 & .0000 & .0000 \\
\hline .0000 & .0000 & .0000 & .0000 \\
\hline $.8715 E-10$ & $.8715 E-13$ & $.8715 E-13$ & $.8715 E-13$ \\
\hline $.4890 \mathrm{E}-09$ & $.4890 E-12$ & $.4890 E-12$ & .4890ri-12 \\
\hline $.1765 \mathrm{E}-09$ & $.1765 E-09$ & $.1765 E-09$ & $.1765 \mathrm{E}-09$ \\
\hline .0000 & .0000 & .0000 & .0000 \\
\hline $.6088 \mathrm{E}-09$ & $.6088 \mathrm{E}-12$ & $.6088 E-12$ & $.6088 \mathrm{E}-12$ \\
\hline $.6970 \mathrm{E}-12$ & $.5970 E-15$ & $.5970 E-15$ & $.5970 E-15$ \\
\hline $.1310 E-10$ & $.1310 \mathrm{E}-13$ & $.1310 \mathrm{E}-13$ & $.1310 \mathrm{E}-13$ \\
\hline $.1591 \mathrm{E}-16$ & . $1591 E-19$ & $.1591 E-19$ & $.1591 E-19$ \\
\hline $.9502 E-14$ & $.9502 E-17$ & $.9502 f-17$ & $.9502 \mathrm{E}-17$ \\
\hline .0000 & .0000 & .0000 & $.0000^{\circ}$ \\
\hline
\end{tabular}


MATERIAL BALANCE TABLES

Date 09/80/82 Rev 09

\section{SLUDCE:-ONLY FEED} STREAMS ( CONT'D)STREIM NAME

$\begin{array}{rl}47 & Y 203 \\ 100 \mathrm{Zeol} \text { ite } \\ 44 \mathrm{Zn}(\mathrm{COOHI}) 2 \\ 5.1 \mathrm{Zn}(0 \mathrm{HI}) 2 \\ 57 \mathrm{ZnO}\end{array}$

$104 \mathrm{ZrO2}$

TOTAL FLO:, LB/IIR

VAPOR FL.O?, CFM

LIQUID FLOW, GPM DESIGN FLOK,

DEISITY, I.BS/FT3

TEYPERATL:?E, DEG C PRESSURE, ATM PRESSLRE, PSIG PRESSLRE, MI HG PIIASE

131

182

Inlet Gas to Sand Filter

Sand Filter

.0000

$.5571 E-09$

$.6919 \mathrm{E}-10$

$.5139 \mathrm{E}-13$

.0000

.2445E-09

582804.67

188778.96

Exhnust

.0000

$.6571 E-12$

$.6919 \mathrm{E}-13$

$.6139 E-16$

.0000

$.2445 \mathrm{E}-12$

682804.66

142291.08

$$
.0700
$$

85.17

.99

$-.11$

754.88

VAPOR

EXTIHLPY, PCV/IIR

\section{8}

Fan Exhnust

to Stack

.0000

$.5571 \mathrm{E}-12$

$.6919 \mathrm{E}-13$

$.5189 \mathrm{E}-16$

.0000

$.2445 \mathrm{E}-12$

582804.66

189719.90
184

Stack

Exhaust .0000

$.5571 E-12$

$.6919 \mathrm{E}-13$

$.5139 E-16$

.0000

.2445E-12

682804.66

139719.90

$\begin{array}{llll}-29973031.75 & -29975321.50 & -29860552.50 & -29360552.50\end{array}$ 
Appendis $H$

Table 21-15

Page 130 of 173

Date $09 / 30 / 52$ Rév 09

MATERIAL BALANCE TABLES

SLLDCE-ONLY FEED

STREAM NUMBERS -

STREAM NAME

185

$50 \mathrm{H} t \%$ NaOll DVIT Liquid

to DUTiT

COMPONENT FLOKSS, LB/IIR

11120

$45 \mathrm{Ag}$

116 Ag20

134 AgNO3

51 AgOII

74 Al( OHI) 3

77 A 1203

75 A 10011

106 B203

$9 \mathrm{Ba}(\mathrm{NO3}) 2$

$95 \mathrm{BaCl} 2$

$15 \mathrm{BaO}$

$24 \mathrm{BaSO4}$

$66 \mathrm{CO}$

$37 \quad \mathrm{CO} 2$

$142 \mathrm{CO}$ ( $\mathrm{C} 14)$

$63 \mathrm{Ca}(\mathrm{COOH}) 2$

$120 \mathrm{Ca}(\mathrm{OII}) 2$

$113 \mathrm{Ca} 3(\mathrm{PO}) 2$

$20 \mathrm{CaC}_{2} 204$

$18 \mathrm{CaCO3}$

$78 \mathrm{CaF2}$

$41 \mathrm{CaO}$

$19 \mathrm{CaSO}_{4}$

29 Carbon

$26 \mathrm{Co}(\mathrm{COOH}) 2$

$121 \mathrm{Co}(\mathrm{OH}) 2$

$53 \mathrm{Co}(\mathrm{OHI}) \mathrm{3}$

$59 \mathrm{CoO}$

$99 \mathrm{Cr}(\mathrm{OH}) 3$

98 Cr203

42 Cs20

137 Cs20 Semi Vol

$90 \mathrm{CsCOOH}$

$96 \mathrm{CsCl}$

$186 \mathrm{CsCl}$ Semi Vol

$8 \mathrm{CsNO3}$

88 CsResin

$122 \mathrm{Cu}(\mathrm{COOH}) 2$

$62 \mathrm{Cu}(\mathrm{OH}) 2$

$58 \mathrm{Cu} 20$

$64 \mathrm{CuCOOH}$

$180 \mathrm{CuO}$

$13 \mathrm{Fe}(\mathrm{OH}) \mathrm{S}$

$80 \mathrm{~F} \cdot 203$
1.546

.0000

.0000

.0000

.0000

.0000

.0000

.0000

.0000

.0000

.0000

.0000

.0000

.0000

.0000

.0000

.0000

.0000

.0000

.0000

.0000

.0000

.0000

.0000

.0000

.0000

.0000

.0000

.0000

.0000

.0000

.0000

.0000

.0000

.0000

.0000

.0000

.0000

.0000

.0000

.0000

.0000

.0000

.0000

.0000 to RCT

310.5

.0000

.0000

.0000

.0000

.0000

.0000

.0000

.0000

.0000

.0000

.0000

.0000

.0000

$.1211 \mathrm{E}-01$

.0000

.0000

.0000

.0000

.0000

.0000

.0000

.0000

.0000

.0000

.0000

.0000

.0000

.0000

.0000

.0000

.0000

.0000

.0000

.0000

.0000

.0000

.0000

.0000

.0000

.0000

.0000

.0000

.0000

.0000
137

Stcam to DH'Tr Coll

.0000

.0000

.0000

.0000

.0000

. 50

.1 1

.1

. $\mathrm{C}$,

.0 suo

.0000

.0000

.0000

.0000

.0000

.0000

.0000

.0000

.0000

.0000

.0000

.0000

.0000

.0000

.0000

.0000

.0000

.0000

.0000

.0000

.0000

.0000

.0000

.0000

.0000

.0000

.0000

.0000

.0000

.0000

.0000

.0000

.0000

.0000

.0000
138

Steam Conden sate fr biali

.0000

.0000

.0000

.0000

.0000

.0000

.0000

.0000

.0000

.0000

.0000

.0000

.0000

.0000

.0000

.0000

.0000

.0000

.0000

.0000

.0000

.0000

.0000

.0000

.0000

.0000

.0000

.0000

.0000

.0000

.0000

.0000

.0000

.0000

.0000

.0000

.0000

.0000

.0000

.0000

.0000

.0000

.0000

.0000

$.0000^{\circ}$ 
MITESIAL BALANCE TALLES

Date 09/30/82 Rev 09

SL.UDGE-ONLY FEED

STREAMS (CONT'D) .. STREAM SIAME

$101 \mathrm{Fel}$

126 Group A Semi Vo

102 GroupA

103 GroupB

25 II2

$183 \mathrm{H2C} 204$

9111202

$84 \mathrm{HCOCH}$

43 IICI

85 IIF

49 HNO3

86 IIResin

$30 \mathrm{lIg}$

$135 H_{g} \times 032$

$21 \mathrm{Hg} \mathrm{O}$

$97 \quad 12$

$39 \mathrm{~K} 2 \mathrm{O}$

$181 \mathrm{KMnO4}$

$118 \mathrm{KNO}$

$105 \quad \mathrm{~L}=203$

108 Li 20

$65 \mathrm{M} / \mathrm{g}(\mathrm{COOH}) 2$

$55 \mathrm{Mg}(\mathrm{Oil}) 2$

$83 \mathrm{MgO}$

$60 \mathrm{Nn}(\mathrm{COOH}) 2$

$152 \mathrm{Mn}(\mathrm{NO}) 2$

$129 \ln (0 \mathrm{Oi}) 2$

$56 \mathrm{MnO}$

$14 \mathrm{MnO2}$

$81 \mathrm{N2}$

143 NA2CO3 (C.14)

$85 \mathrm{NO}$

$84 \quad \mathrm{N02}$

$70 \mathrm{Na}_{\mathrm{a}}\left(\mathrm{H}_{\mathrm{S}} \mathrm{O}(\mathrm{OH})\right)$

$94 \quad \mathrm{Na} 2 \mathrm{~B} 407$

$109 \mathrm{Na} 2 \mathrm{C} 204$

6 $\mathrm{Na} 2 \mathrm{CO3}$

$32 \mathrm{Na} 20$

$71 \mathrm{Na} 2 \mathrm{Pu} 02(\mathrm{OH}) 4$

$73 \mathrm{Na} 2 \mathrm{lhO} 04$

$72 \mathrm{Na} 2 \mathrm{Ru} 04$

$6 \mathrm{Na} 2 \mathrm{SO}$

$68 \mathrm{NaAl} 02$

$114 \mathrm{NaBO} 2$

140 NaBO2 Semi Vol

$50 \mathrm{NaCOOH}$
185

$50 \mathrm{~K} t \% \mathrm{NaOH}$ DVTT Liquid to DWWT

.0000

.0000

.0000

.0000

.0000

.0000

.0000

.0000

.0000

.0000

.0000

.0000

.0000

.0000

.0000

.0000

.0000

.0000

.0000

.0000

.0000

.0000

.0000

.0000

.0000

.0000

.0000

.0000

.0000

.0000

.0000

.0000

.0000

.0000

.0000

.0000

.0000

.0000

.0000

.0000

.0000

.0000

.0000

.0000

.0000

.0000 to RCT

.0000

.0000

.0000

.0000

.0000

.0000

.0000

.0000

.0000

.0000

.0000

.0000

.0000

.0000

.0000

.0000

.0000

.0000

.1970

.0000

.0000

.0000

.0000

.0000

.0000

.0000

.1734

.0000

.0000

$.8276 \mathrm{E}-02$

.0000

.2336E-08

.0000

.0000

.0000

$.7906 \mathrm{E}-01$

.0000

.0000

.0000

.0000

.0000

.0000

.0000

.0000

.0000

.0000
187

Steam to

DWTT Coil

.0000

.0000

.0000

.0000

.0000

.0000

.0000

.0000

.0000

.0000

.0000

.0000

.0000

.0000

.0000

.0000

.0000

.0000

.0000

.0000

.0000

.0000

.0000

.0000

.0000

.0000

.0000

.0000

.0000

.0000

.0000

.0000

.0000

.0000

.0000

.0000

.0000

.0000

.0000

.0000

.0000

.0000

.0000

.0000

.0000

.0000
188

Sterm Conden

sate fr DHTT

.0000

.0000

.0000

.0000

.0000

.0000

.0000

.0000

.0000

.0000

.0000

.0000

.0000

.0000

.0000

.0000

.0000

.0000

.0000

.0000

.0000

.0000

.0000

.0000

.0000

.0000

.0000

.0000

.0000

.0000

.0000

.0000

.0000

.0000

.0000

.0000

.0000

.0000

.0000

.0000

.0000

.0000

.0000

.0000

.0000

.0000 
DPSP $\$ 0-1033$

MATERIAL BALANCE TABLES

\section{SLUDGE-ONLY FEED}

STREAMS (CONT'D)STREAM NAME

\section{$7 \mathrm{NaCl}$}

$188 \mathrm{NaCl}$ Semi Vol

$69 \mathrm{NaF}$

$189 \mathrm{NaF}$ Semi Vol

$12 \mathrm{NaI}$

125 ial Semi Vol

$8 \mathrm{NaN02}$

$2 \mathrm{NaNO3}$

$4 \mathrm{NaOH}$

87 NaResin

$61 \mathrm{Ni}(\mathrm{COOH}) 2$

$17 \mathrm{Ni}(\mathrm{OH}) 2$

$40 \mathrm{NiO}$

8202

$67 \mathrm{PbO}$

$28 \mathrm{PbS04}$

$124 \mathrm{Pd}$

$123 \mathrm{Pd}(\mathrm{Oll}) 2$

112 PdNO32

110 PdO

$117 \mathrm{Pu}(\mathrm{COOH}) 4$

$76 \mathrm{Pu} 02$

$22 \mathrm{Rh02}$

$79 \mathrm{Ru} 02$

23 Ru02 Semi Vol

83 Ru04

$85 \mathrm{SO2}$

$111 \mathrm{Si} 02$

115 Silica Gel

$48 \mathrm{Sr}(\mathrm{COOH}) 2$

$10 \mathrm{Sr}(\mathrm{NOS}) 2$

$127 \mathrm{Sr}(\mathrm{OH}) 2$

$80 \mathrm{SrCO3}$

$46 \mathrm{Sr} 0$

89 SrRESIN

141 Surfactant

92 ThO2

$107 \mathrm{Ti} 02$

119 Tritium

93 v02

$62 \mathrm{VO} 2(\mathrm{COOH}) 2$

$16 \mathrm{VO} 2(\mathrm{Oll}) 2$

$27 \mathrm{Y}(\mathrm{COOHI}) \mathrm{S}$

$11 \mathrm{Y}(\mathrm{NO}) \mathrm{S}$

$128 \mathrm{Y}(\mathrm{OH}) 3$

31 Y $2(\mathrm{CO}) 3$
135

50 Wt\% NaOll DliTT Liquid

to DWW'T

.0000

.0000

.0000

.0000

.0000

.0000

.0000

.0000

1.546

.0000

.0000

.0000

.0000

.0000

.0000

.0000

.0000

.0000

.0000

.0000

.0000

.0000

.0000

.0000

.0000

.0000

.0000

.0000

.0000

.0000

.0000

.0000

.0000

.0000

.0000

.0000

.0000

.0000

.0000

.0000

.0000

.0000

.0000

.0000

.0000

.0000
Appendix II

Table 21-15

Page 132 of 173

Date $09 / 30$ /52 Rev 00 
MIATERIAL BALAACE TABLES

Date 09/30/82 Rev 09 SIIDDE-ONLY FETD

STREAMS (CONT'D) STREAM NAME

$17 \quad 1203$

100 Zeolite

$44 \mathrm{Zn}(\mathrm{COOH}) 2$

$64 \mathrm{Zn}(\mathrm{OH}) 2$

$57 \mathrm{ZnO}$

10. $\mathrm{Zr} \cdot 02$

TOTAL FLOH, LB/IIR

VAPOR FLOH, CFM

IIOUID FLOV', GPM DESIGN FLOH,

DENSITY, LBS/ET3

TEMPERATURE, DEG C

PRESSLRE, ATM

PRESSURE, PSIG

PRESSL?E, MAI IIG

FIASE

EITIIALY, PCU/HR
185

50 Wt\% NaOH DHTT Liquid

to DWWT

.0000

.0000

.0000

.0000

.0000

.0000

8. 09

.00
84.9613
25.00
1.00
.00
LIQUID
51.74

136

.0000

.0000

.0000

.0000

.0000

.0000

814.19

.62
62.8380
50.00
.93
$-1.08$
708.99
LIQUID
15940.75

to RCT
187

Steam to DW'TT Coil

.0000

.0000

.0000

.0000

.0000

.0000

.00

188

Steam Conden sate fr DWTT .0000

.0000

.0000

.0000

.0000

.0000

.00
.0000

160.00

6.10

74.99

$N / A$

.00
.0000

60.00

1.00

.00

$N / A$

.00 
DPSP $80-1033$

MiTERIAL BALANCE TABLES

\section{SI.CDGE-ONLY FEED}

STREAM NUMBERS -

STREAM NAME

COMPONENT FLOHS, LB/HR

$\begin{array}{rl}1 & \mathrm{ll} 20 \\ 45 & \mathrm{Ag} \\ 116 & \mathrm{Ag} 20 \\ 134 & \mathrm{AgNO} \\ 51 \mathrm{AgOH} & \\ 74 & \mathrm{Al}(\mathrm{OH}) 3\end{array}$

77 A 1203

$75 \mathrm{~A} 100 \mathrm{H}$

$106 \mathrm{B203}$

$9 \mathrm{Ba}(\mathrm{N} 03) 2$

$95 \mathrm{BaCl} 12$

$15 \mathrm{BaO}$

$24 \mathrm{BnSO4}$

$66 \mathrm{CO}$

$37 \mathrm{CO} 2$

$142 \mathrm{CO}(\mathrm{C14})$

$63 \mathrm{Ca}(\mathrm{COOH}) 2$

$120 \mathrm{Ca}(\mathrm{OH}) 2$

$113 \mathrm{Ca} 3(\mathrm{P04}) 2$

$20 \mathrm{CaC} 204$

$18 \mathrm{CaCO} 3$

$78 \mathrm{CaF2}$

$41 \mathrm{CaO}$

$19 \mathrm{CaSO4}$

29 Carbon

$26 \mathrm{Co}(\mathrm{COOH}) 2$

$121 \mathrm{Co}(\mathrm{OH}) 2$

$53 \mathrm{Co}(\mathrm{Oll}) \mathrm{3}$

$59 \mathrm{CoO}$

$99 \mathrm{Cr}$ (OH) 3

$98 \mathrm{Cr} 203$

$42 \mathrm{Cs} 20$

187 Cs20 Sem $\mathrm{i}$ Vol

$90 \mathrm{CsCOOH}$

$96 \mathrm{CsCl}$

$136 \mathrm{CsCl}$ Semi Vol

$8 \mathrm{CsNO3}$

88 CsResin

$122 \mathrm{Cu}(\mathrm{COOH}) 2$

$52 \mathrm{Cu}(\mathrm{OH}) 2$

$58 \mathrm{Cu} 20$

$64 \mathrm{CuCOOII}$

$180 \mathrm{Cu} 0$

$13 \mathrm{Fe}(\mathrm{Olll}) \mathrm{s}$

$80 \mathrm{Fe} 203$
Appendix H

Iable 21-15

Page 134 of 173

Date $09 / 30 / \$ 2$ Rev 00

Air Sparge

Air Sparge

to SEHT

.8735

.0000

.0000

.0000

.0000

.0000

.0000

.0000

.0000

.0000

.0000

.0000

.0000

.0000

.0000

.0000

.0000

.0000

.0000

.0000

.0000

.0000

.0000

.0000

.0000

.0000

.0000

.0000

.0000

.0000

.0000

.0000

.0000

.0000

.0000

.0000

.0000

.0000

.0000

.0000

.0000

.0000

.0000

.0000

.0000
140

to FCT

141

Hros Hash Frit Slurry to MAH"i to Sill?

\section{.7463}

.0000

.0000

.0000

.0000

.0000

.0000

.0000

.0000

.0000

.0000

.0000

.0000

.0000

.0000

.0000

.0000

.0000

.0000

.0000

.0000

.0000

.0000

.0000

.0000

.0000

.0000

.0000

.0000

.0000

.0000

.0000

.0000

.0000

.0000

.0000

.0000

.0000

.0000

.0000

.0000

.0000

.0000

.0000

.0000

$\begin{array}{ll}.2201 & 151.1 \\ .0000 & .0000 \\ .0000 & .0000 \\ .0000 & .0000 \\ .0000 & .0000 \\ .0000 & .0000 \\ .0000 & .0000 \\ .0000 & .0000 \\ .0000 & 6.010 \\ .0000 & .0000 \\ .0000 & .0000 \\ .0000 & .0000 \\ .0000 & .0000 \\ .0000 & .0000 \\ .0000 & .0000 \\ .0000 & .0000 \\ .0000 & .0000 \\ .0000 & .0000 \\ .0000 & .0000 \\ .0000 & .0000 \\ .0000 & .0000 \\ .0000 & .0000 \\ .0000 & .0000 \\ .0000 & .0000 \\ .0000 & .0000 \\ .0000 & .0000 \\ .0000 & .0000 \\ .0000 & .0000 \\ .0000 & .0000 \\ .0000 & .0000 \\ .0000 & .0000 \\ .0000 & .0000 \\ .0000 & .0000 \\ .0000 & .0000 \\ .0000 & .0000 \\ .0000 & .0000 \\ .0000 & .0000 \\ .0000 & .0000 \\ .0000 & .0000 \\ .0000 & .0000 \\ .0000 & .0000 \\ .0000 & .0000 \\ .0000 & .0000 \\ .0000 & .0000 \\ .0000 & .0000 \\ & \end{array}$

181.1

0 0no

0000

.0000

voco

0000

0000

0000

0000

0000

0000

0000

0000

0000

0000

0000

0000

0000

4000

0000

0000

0000

0000

0000

00u0

ccoo

0000

0000

0000

0000

0000

0000

0000

0000

.0000 
MATERIAL BALANCE TAELES

Date 09/30/82 Rev 09

\section{SLLUCE-ONLY FEED}

STREAMS (COIT'D)-

STREAM NAME

$101 \mathrm{Fe} 0$

126 Group A Semi Vo

102 GroupA

103 GroupB

25112

133 112C204

9111202

84 IICOOII

45 IIC I

85 IIF

49 HNOO3

86 HResin

$36 \mathrm{Hg}$

$135 \mathrm{HgN032}$

21 IIgO

9712

39 K20

$131 \mathrm{hN} / \mathrm{n} 04$

$113 \mathrm{KNO3}$

105 La203

108 Li20

$65 \mathrm{Mg}(\mathrm{COOH}) 2$

$55 \mathrm{Mg}(\mathrm{OII}) 2$

$83 \mathrm{MgO}$

$60 \mathrm{Mn}(\mathrm{COOH}) 2$

$132 \mathrm{Mn}(\mathrm{NO3}) 2$

$129 \mathrm{Mn}(\mathrm{Oll}) 2$

$56 \mathrm{MnO}$

$14 \mathrm{MnO} 2$

$81 \mathrm{N2}$

$143 \mathrm{NA2CO3} \mathrm{(C14)}$

$35 \mathrm{NO}$

$84 \quad \mathrm{NO2}$

$70 \mathrm{Na}(\mathrm{HgO}(\mathrm{OIJ}))$

$94 \quad \mathrm{~N}$ 2B 407

$109 \mathrm{Na} 2 \mathrm{C2O4}$

$5 \mathrm{Na}_{2} \mathrm{CO} 3$

$82 \mathrm{Na} 20$

$71 \mathrm{Na} 2 \mathrm{PuO}^{2}(\mathrm{OHI}) 4$

$73 \mathrm{Na} 2 \mathrm{Rh} 04$

$72 \mathrm{Na2Ru04}$

$6 \mathrm{Na} 2 \mathrm{SO4}$

$68 \mathrm{NaAl} 102$

$114 \mathrm{NaBO2}$

140 NaBO2 Semi Vol $50 \mathrm{NaCOOH}$
139

Air Sparge
to SFHT

.0000

.0000

.0000

.0000

.0000

.0000

.0000

.0000

.0000

.0000

.0000

.0000

.0000

.0000

.0000

.0000

.0000

.0000

.0000

.0000

.0000

.0000

.0000

.0000

.0000

.0000

.0000

.0000

.0000

17.07

.0000

.0000

.0000

.0000

.0000

.0000

.0000

.0000

.0000

.0000

.0000

.0000

.0000

.0000

.0000

.0000
140

Air Sparge

to FCT

.0000

.0000

.0000

.0000

.0000

.0000

.0000

.0000

.0000

.0000

.0000

.0000

.0000

.0000

.0000

.0000

.0000

.0000

.0000

.0000

.0000

.0000

.0000

.0000

.0000

.0000

.0000

.0000

.0000

84.12

.0000

.0000

.0000

.0000

.0000

.0000

.0000

.0000

.0000

.0000

.0000

.0000

.0000

.0000

.0000

.0000
141

IINO3 Hash

to MAWT

.0000

.0000

.0000

.0000

.0000

.0000

.0000

.0000

.0000

.0000

$.8001 \mathrm{E}-01$

.0000

.0000

.0000

.0000

.0000

.0000

.0000

.0000

.0000

.0000

.0000

.0000

.0000

.0000

.0000

.0000

.0000

.0000

.0000

.0000

.0000

.0000

.0000

.0000

.0000

.0000

.0000

.0000

.0000

.0000

.0000

.0000

.0000

.0000

.0000
142

Frit Slurry

to SFHT

.0000

.0000

.0000

.0000

.0000

.0000

.0000

.4206

.0000

.0000

.0000

.0000

.0000

.0000

.0000

.0000

.0000

.0000

.0000

.2250

2.566

.0000

.0000

.9002

.0000

.0000

.0000

.0000

.0000

$.2825 \mathrm{E}-02$

.0000

.0000

.0000

.0000

.0000

.0000

.0000

7.967

.0000

.0000

.0000

.0000

.0000

.0000

.0000

.0000 
DOSP $80-1033$

YATERIAL BALANCE TABLES SLLDGE-ONLY FEED STREAMS (CONT'D)STREAM NAME

$\begin{array}{rl}7 & \mathrm{NaCl} \\ 138 & \mathrm{NaCl} \text { Semi Vol } \\ 69 & \mathrm{NaF} \\ 139 & \mathrm{NaF} \text { Semi Vol } \\ 12 & \mathrm{NaI}\end{array}$

$125 \mathrm{NaI}$ Semi Vol

$8 \mathrm{NaNO} 2$

$2 \mathrm{NaNO}^{2}$

$4 \mathrm{NaOH}$

87 NaResin

$61 \mathrm{Ni}(\mathrm{COOH}) 2$

$17 \mathrm{Ni}(\mathrm{OH}) 2$

$40 \mathrm{NiO}$

8202

$67 \mathrm{PbO}$

$28 \mathrm{PbS04}$

$124 \mathrm{Pd}$

$123 \mathrm{Pd}(\mathrm{OII}) 2$

112 PdNO32

$110 \mathrm{PdO}$

$117 \mathrm{Pu}(\mathrm{COOH}) 4$

$76 \mathrm{Pu} 02$

$22 \mathrm{RhO}_{2}$

79 Ru02

23 Ru02 Semi Vol

$83 \mathrm{Ru} 04$

$38 \mathrm{SO2}$

$111 \mathrm{SiO} 2$

115 Silien Gel

$48 \mathrm{Sr}(\mathrm{COOH}) 2$

$10 \mathrm{Sr}(\mathrm{YO} O 3) 2$

$127 \mathrm{Sr}(\mathrm{OH}) 2$

$80 \mathrm{SrCO3}$

$46 \mathrm{Sr} 0$

89 SrRESIN

141 Surfactant

$92 \mathrm{Th} 02$

$107 \mathrm{TiO}$

119 Tritium

93 V02

62 V02(C.OOH) 2

$16 \mathrm{VO} 2(\mathrm{OHI}) 2$

$27 \mathrm{Y}(\mathrm{COOH}) 3$

$11 Y(\mathrm{YOO}) \mathrm{S}$

$128 Y(\mathrm{OH}) \mathrm{S}$

81 Y2 (CO3) 3
139

Air Sparge
to SFIIT

.0000

.0000

.0000

.0000

.0000

.0000

.0000

.0000

.0000

.0000

.0000

.0000

.0000

Б. 158

.0000

.0000

.0000

.0000

.0000

.0000

.0000

.0000

.0000

.0000

.0000

.0000

.0000

.0000

.0000

.0000

.0000

.0000

.0000

.0000

.0000

.0000

.0000

.0000

.0000

.0000

.0000

.0000

.0000

.0000

.0000

.0000

Appendix 11

Table 21-15

Page 126 of 173

Date 09,30/5i2 Rev o3

140

Air Sparge

to $\mathrm{FCl}$

.0000

.0000

.0000

.0000

.0000

.0000

.0000

.0000

.0000

.0000

.0000

.0000

.0000

10.31

.0000

.0000

.0000

.0000

.0000

.0000

.0000

.0000

.0000

.0000

.0000

.0000

.0000

.0000

.0000

.0000

.0000

.0000

.0000

.0000

.0000

.0000

.0000

.0000

.0000

.0000

.0000

.0000

.0000

.0000

.0000

.0000
141

HNO3 Whash to MALT

.0600

.0000

.0000

.0000

.0000

.0000

.0000

.0000

.0000

.0000

.0000

.0000

.0000

.0000

.0000

.0000

.0000

.0000

.0000

.0000

.0000

.0000

.0000

.0000

.0000

.0000

.0000

.0000

.0000

.0000

.0000

.0000

.0000

.0000

.0000

.0000

.0000

.0000

.0000

.0000

.0000

.0000

.0000

.0000

.0000

.0000
$1: 2$

Frit Slurr:

to SFiil

.0000

.0000

.0000

.0000

.0000

.0000

.0000

.0000

.0000

.0000

.0000

.0000

.0000

$.1679 \mathrm{E}-02$

.0000

.0000

.0000

.0000

.0000

.0000

.0000

.0000

.0000

.0000

.0000

.0000

.0000

26.06

.0000

.0000

.0000

.0000

.0000

.0000

.0000

.0000

.0000

.4501

.0000

.0000

.0000

.0000

.0000

.0000

.0000

.0000 
Matstial baLANCE Tables

Date 09/30/82 Rev 09

SLUDGE-DNLY FEED

STREAMS (CONT'D)-

STREAM NAME

47 Y203

100 Zeolite

$44 \mathrm{Zn}(\mathrm{COOII}) 2$

$54 \mathrm{Zn}\left(0 \mathrm{II}^{\prime}\right) 2$

$57 \mathrm{ZnO}$

$104 \mathrm{ZrO}$

TOTAL FLOW', LB/IIR

VAPOR FLOH, CFM

LIQUID FLOW, GPM

DESIGN FLOW,

DENSITY, LBS/FT3

TEMPERATLRE, DEG C

PRESSURE, ATM

PRESSURE, PSIG

PRESSURE, MM HG

PHASE

ENTHALPY, PCU/IIR
139

Air Sparge

to SFHT

.0000

.0000

.0000

.0000

.0000

.0000

22.61

5.84

.0706

85.00

1.00

.00

VAPOR

$-1164.14$
140

Air Sparge

to FCT

.0000

.0000

.0000

.0000

.0000

.0000

45.17

10.67

.0706

85.00

1.00

.00

VAPOR

$-2326.09$
141

HNO3 Wash

to MAHT

.0000

.0000

.0000

.0000

.0000

.0000

.25

.00

65.0373

25.00

1.00

.00

LIQUID

5.79
.40

142

Frit Slurry

to SFHT

.0000

.0000

.0000

.0000

.0000

.2250

226.56

70.1600

80.00

.97

$-.51$

733.86

LIQUID

6021.94 
DPSP $80-1033$

MATERIAL BALANCE TABLES
SLUDG:-ONLY FEED

STREAM NLMEERS -

STREAY NAME

COMPONENT FLOHS, LB/HR
$45 \mathrm{Ag}$

116 Ag20

134 AgNO3

$51 \mathrm{AgOH}$

74 Al (OII) 3

77 A 1203

75 A 10011

106 B203

$9 \mathrm{Ba}(\mathrm{NOS}) 2$

$95 \mathrm{BaCl} 2$

$15 \mathrm{BaO}$

$24 \mathrm{BaSO4}$

$66 \mathrm{CO}$

$37 \mathrm{CO} 2$

$142 \mathrm{CO}$ ( $\mathrm{C14}$ )

$63 \mathrm{Ca}(\mathrm{COOII)}) 2$

$120 \mathrm{Ca}(\mathrm{Oll}) 2$

$113 \mathrm{Ca} 3(\mathrm{PO4}) 2$

$20 \mathrm{CaC2O4}$

$18 \mathrm{CaC03}$

$78 \mathrm{CaF2}$

$41 \mathrm{CaO}$

$19 \mathrm{CaSO} 4$

29 Carhon

$26 \mathrm{Co}(\mathrm{COOII}) 2$

$121 \mathrm{Co}(\mathrm{OH}) 2$

$53 \mathrm{Co}(\mathrm{Oll}) \mathrm{3}$

$59 \mathrm{CoO}$

$99 \mathrm{Cr}$ (OII) 3

$98 \mathrm{Cr} 203$

$42 \mathrm{Cs} 20$

137 Cs20 Semi Vol

$90 \mathrm{CsCOOH}$

$96 \mathrm{CsCl}$

$136 \mathrm{CsCl}$ Semi Vol

$8 \mathrm{CsNO3}$

88 CsResin

$122 \mathrm{Cu}(\mathrm{COOH}) 2$

$52 \mathrm{Cu}(\mathrm{OH}) 2$

$58 \mathrm{Cu} 20$

$64 \mathrm{CuCOOH}$

$130 \mathrm{CuO}$

$13 \mathrm{Fe}(\mathrm{Oli}) \mathrm{S}$

$80 \mathrm{Fe} 203$
143

FAVC Vent to PVUS

18.52

$.1517 \mathrm{E}-07$

.0000

.0000

$.6386 \mathrm{E}-09$

$.5799 \mathrm{E}-0 \mathrm{G}$

.0000

.0000

$.2201 \mathrm{E}-05$

.7609E-14

.0000

.0000

$.6877 \mathrm{E}-08$

$.4639 \mathrm{E}-04$

5.383

. 1072E-09

.2383E-06

$.1600 \mathrm{E}-09$

$.1714 \mathrm{E}-07$

$.1854 \mathrm{E}-07$

.0000

$.4634 \mathrm{E}-08$

.0000

.2177E-07

. 4684E-0S

.8762E-08

.2768E-11

.0000

.0000

$.1762 \mathrm{E}-07$

.0000

$.9015 \mathrm{E}-13$

.0000

.0000

.2919E-11

.0000

$.4881 \mathrm{E}-09$

.0000

.8037E-08

$.6022 \mathrm{E}-11$

.0000

.0000

.0000

$.1404 \mathrm{E}-05$

.0000
144

Air Sparge

to NHTH

$$
\begin{aligned}
& .1610 E-02 \\
& .0000 \\
& .0000
\end{aligned}
$$

.0000

.0000

.0000

.0000

.0000

.0000

.0000

.0000

.0000

.0000

.0000

.0000

.0000

.0000

.0000

.0000

.0000

.0000

.0000

.0000

.0000

.0000

.0000

.0000

.0000

.0000

.0000

.0000

.0000

.0000

.0000

.0000

.0000

.0000

.0000

.0000

.0000

.0000

.0000

.0000

.0000

.0000
Appendix $H$

Table 21-15

Page 138 of 173

Ditte $09 / 80, \leqslant 2$ Rev 00 
DPSP $80-1033$

MATREIAL BALANCE TABLES SEUDET-OILY FEED

STREMMS (CONT'D)-

STIREAM NAME

$101 \mathrm{FeO}$

126 Group A Semi Vo

102 GroupA

103 GroupB

$25 \mathrm{HI} 2$

$133 \mathrm{H} 2 \mathrm{C} 204$

$91 \mathrm{H} 2 \mathrm{C2}$

34 HCOOII

43 HC. 1

$85 \mathrm{HF}$

$49 \mathrm{HNO}$

86 HKesin

$36 \mathrm{Hg}$

$135 \mathrm{HgNO} 2$

$21 \mathrm{HgO}$

$97 \quad 12$

$39 \mathrm{~K} 20$

$131 \mathrm{kMnO} 4$

113 KNO3

$105 \operatorname{Ln} 203$

103 Li20

$65 \mathrm{Mg}(\mathrm{COOH}) 2$

$55 \mathrm{Mg}(\mathrm{Oll}) 2$

$33 \mathrm{MgO}$

$60 \mathrm{Mn}(\mathrm{COOH}) 2$

$132 \mathrm{Mn}(\mathrm{NO}) 2$

$129 \mathrm{Mn}(\mathrm{Oll}) 2$

$56 \mathrm{MnO}$

$14 \mathrm{MnO2}$

$81 \mathrm{~N} 2$

$143 \mathrm{NA2CO3}$ (C14)

$35 \mathrm{NO}$

84 N02

$70 \mathrm{Na}(\mathrm{HgO}(\mathrm{OH}))$

94 $\operatorname{Ni2B407}$

$109 \mathrm{Na2C204}$

$5 \mathrm{Na} 2 \mathrm{CO3}$

$32 \mathrm{~N}$ 20

$71 \mathrm{Na} 2 \mathrm{Pu} 02(\mathrm{Oll}) 4$

$73 \mathrm{Na} 2 \mathrm{RhO4}$

$72 \mathrm{Na2RuO4}$

$6 \mathrm{Na} 2 \mathrm{SO} 4$

$68 \mathrm{NaAlO} 2$

$114 \mathrm{NaCO2}$

$140 \mathrm{NiBO2}$ Semi Vol $50 \mathrm{NnCOOH}$

Append Ix H

Table 21-15

Page 189 of 173

Date 09/90/82 Rev 09

143

FAVC Vent

to PVVS

.0000

.0000

. 1300E-07

$.4119 \mathrm{E}-07$

$.3156 \mathrm{E}-05$

.0000

.0000

$.6833 E-01$

.0000

.0000

.0000

.0000

$.1470 \mathrm{E}-03$

.0000

$.1263 \mathrm{E}-09$

.0000

.0000

.0000

$.2474 E-08$

$.7472 E-07$

$.8534 \mathrm{E}-06$

. 4536E-07

.2729E-10

.2993E-06

.4044E-06

.0000

$.2436 \mathrm{E}-08$

.0000

.0000

1227.

.0000

$.9042 E-01$

$.6763 \mathrm{E}-02$

$.2905 E-10$

$.1088 \mathrm{E}-08$

$.9925 \mathrm{E}-09$

.0000

$.2652 E-05$

$.1178 \mathrm{E}-14$

$.2422 \mathrm{E}-12$

.2363E-11

$.4792 \mathrm{E}-08$

$.1178 \mathrm{E}-07$

.0000

.0000

.3803E-06
144

Air Sparge

to MHiT T

.0000

.0000

.0000

.0000

.0000

.0000

.0000

.0000

.0000

.0000

.0000

.0000

.0000

.0000

.0000

.0000

.0000

.0000

.0000

.0000

.0000

.0000

.0000

.0000

.0000

.0000

.0000

.0000

.0000

.7358E-01

.0000

.0000

.0000

.0000

.0000

.0000

.0000

.0000

.0000

.0000

.0000

.0000

.0000

.0000

.0000

.0000
145

HNOB Sumps

to DHTT

.0000

.0000

.0000

.0000

.0000

.0000

.0000

.0000

.0000

.0000

.0000

.0000

.0000

.0000

.0000

.0000

.0000

.0000

.0000

.0000

.0000

.0000

.0000

.0000

.0000

.0000

.0000

.0000

.0000

.0000

.0000

.0000

.0000

.0000

.0000

.0000

.0000

.0000

.0000

.0000

.0000

.0000

.0000

.0000

.0000

.0000
146

Liquid Spray to PWDBF\#1

.0000

$.4281 \mathrm{E}-01$

.6916E-02

.2225E-01

. 1552E-04

.0000

.0000

.0000

.0000

.0000

.0000

.0000

.0000

.0000

$.1710 \mathrm{E}-01$

.0000

.0000

.0000

$.1526 \mathrm{E}-04$

$.1824 \mathrm{E}-01$

.8487

$.2453 E-01$

.0000

.1075

.2188

.0000

.0000

.0000

.0000

$.2144 \mathrm{E}-01$

.0000

$.1077 \mathrm{E}-08$

$.7389 \mathrm{E}-01$

$.1571 \mathrm{E}-04$

.4842

$.6121 \mathrm{E}-05$

.0000

1.286

$.6373 E-09$

.1310E-06

. 1278E-05

.2593E-02

$.6378 E-02$

.0000

.0000

.2550 
[PSP SO-1033

FITERIAL BALANCE TABLES SEUDGE-ONLY FEED STREAMSS (CONT'D)STREAM NAME

\section{$7 \mathrm{NaCl}$}

$138 \mathrm{NaCl}$ Semi Yol

$69 \mathrm{NaF}$

$139 \mathrm{NaF}$ Semi Vol

$12 \mathrm{NaI}$

125 NaI Semi Vol

$8 \mathrm{NaN02}$

$2 \mathrm{NaNO3}$

$4 \mathrm{NaOH}$

87 NaResin

$61 \mathrm{Ni}(\mathrm{COOH}) 2$

$17 \mathrm{~N} 1(\mathrm{OH}) 2$

$40 \times 10$

8202

$67 \mathrm{PbO}$

$28 \mathrm{PbSO4}$

$124 \mathrm{Pd}$

$123 \mathrm{Pd}(\mathrm{OH}) 2$

112 Pd.Y032

$110 \mathrm{PdO}$

$117 \mathrm{Pu}(\mathrm{COOH}) 4$

$76 \mathrm{Pu} 02$

$22 \mathrm{Rh} 02$

$79 \mathrm{Ru} 02$

23 Ru02 Semi Vol

$83 \mathrm{RuO4}$

$88 \mathrm{SO2}$

$111 \mathrm{SiO}$

115 Silica Gel

$48 \mathrm{Sr}(\mathrm{COOH}) 2$

$10 \mathrm{Sr}(\mathrm{NO}) 2$

$127 \mathrm{Sr}$ (OII) 2

$30 \mathrm{SrCO}$

$46 \mathrm{SrO}$

89 SrRESIN

141 Surfactant

$92 \mathrm{ThO}$

$107 \mathrm{Ti} 02$

119 Tritium

98 v02

$62 \mathrm{VO2}(\mathrm{COOH}) 2$

$16 \mathrm{VO2}(\mathrm{OH}) 2$

$27 \mathrm{Y}(\mathrm{COOH}) 3$

$11 \mathrm{Y}(\mathrm{NO3}) 3$

$128 \mathrm{Y}(\mathrm{OH}) \mathrm{3}$

81 Y2( $(\mathrm{CO}) 3$
143

Fave Vent to PVVS

.5872E-08

.0000

$.1030 \mathrm{E}-08$

.0000

. 53SSE-0S

.0000

.0000

. 1922E-06

.0000

.0000

$.1426 \mathrm{E}-06$

$.1048 E-09$

.0000

370.7

.0000

$.6473 \mathrm{E}-08$

.0000

.0000

.0000

.0000

.0000

$.1684 \mathrm{E}-08$

$.6436 \mathrm{E}-09$

$.3188 E-08$

.0000

.0000

$.8969 E-05$

$.8940 E-05$

.0000

$.5790 \mathrm{E}-08$

$.6790 \mathrm{E}-14$

$.4676 \mathrm{E}-11$

.0000

.0000

.0000

.0000

.2641E-07

$.1494 \mathrm{E}-06$

$.5190 \mathrm{E}-10$

.0000

$.1844 \mathrm{E}-06$

$.1837 \mathrm{E}-09$

.3968E-08

$.4822 E-14$

.2924E-11

.0000
Appendis II

Table 21-15

Page 140 of 173

Date 09/30/8. Rev 0.J
144

Air Sparge

to MUTT

.0000

.0000

.0000

.0000

.0000

.0000

.0000

.0000

.0000

.0000

.0000

.0000

.0000

.2223E-01

.0000

.0000

.0000

.0000

.0000

.0000

.0000

.0000

.0000

.0000

.0000

.0000

.0000

.0000

.0000

.0000

.0000

.0000

.0000

.0000

.0000

.0000

.0000

.0000

.0000

.0000

.0000

.0000

.0000

.0000

.0000

.0000
145

IIN03 Sumps Liçtid Sprong

to D!:TT

.0000

.0000

.0000

.0000

.0000

.0000

.0000

.0000

.0000

.0000

.0000

.0000

.0000

.0000

.0000

.0000

.0000

.0000

.0000

.0000

.0000

.0000

.0000

.0000

.0000

.0000

.0000

.0000

.0000

.0000

.0000

.0000

.0000

.0000

.0000

.0000

.0000

.0000

.0000

.0000

.0000

.0000

.0000

.0000

.0000

.0000
$1 ! 6$

to $P \| D 3 F: 1$

$.2503 E-02$

$.459 \mathrm{~S}$

. $65+5 !-01$

.5310

.25011-03

$.30995-01$

.0000

$.8325 \mathrm{E}-\mathrm{O} \mathrm{i}$

.0000

.0000

$.7711 \mathrm{E}-01$

.0000

.0000

$.1228 \mathrm{E}-01$

.0000

. 3496E-02

. Oc000

.0000

.0000

.0000

.0000

$.9095 E-03$

$.3 .176 \mathrm{E}-03$

. 16765:-62

$.1656 \mathrm{E}-01$

.0000

$.4411 E-04$

3.796

.0000

. $3131 \mathrm{E}-02$

.3673E-0S

.0000

.0000

.0000

.0000

.0000

$.1426 \mathrm{E}-01$

. 3550E-01

.7893E-03

.0000

$.9974 \ddot{\mathrm{E}}-01$

.0000

$.2146 \mathrm{E}-02$

.2608E-08

.0000

.0000 ' 
DPSP $80-1033$

MATERIAL BALANCE TABLES SLUDGE-ONLY FEED STREAMS ( CONT'D)STREAM NAME

$\begin{array}{rl}47 & \mathrm{Y} 203 \\ 100 & \mathrm{Zcol} \text { ite } \\ 44 & \mathrm{Zn}(\mathrm{COOH}) 2 \\ 54 & \mathrm{Zn}(0 \mathrm{ll}) 2 \\ 57 & \mathrm{ZnO}\end{array}$

$104 \mathrm{Zr} 02$

TOTAL FI.OW, LB/IIR

VAPOR FLOW, CFM

LIQUID FLOW, GPM

DESIGN FLOW,

DENSITY, LBS/FT3

TEMPERATURE, DEG C

PRESSURE, ATM

PRESSURE, PSIG

PRESSURE, HG

PIIASE

ENTHALPY, PCU/HR
143

FAVC Vent

to PVVS

.0000

$.1688 \mathrm{E}-06$

$.2096 \mathrm{E}-07$

$.1581 E-10$

.0000

$.7472 E-07$

1621.73

885.11

.0702

15.00

.93

$-1.08$

703.99

VAPOR

$-96059.06$
Appendix H

Tablo 21-15

Page 141 of 178

Date 09/30/82 Rev 09

144

Air Sparge

to MWWT

.0000

.0000

.0000

.0000

.0000

.0000

.10

.02

145

HNO3 Sumps

to DHTT

.0000

.0000

.0000

.0000

.0000

.0000

.00

.00

146

Liquid Spray

to PNDBF\#1

.0000

$.9117 \mathrm{E}-01$

$.1184 \mathrm{E}-01$

.0000

.0000

. 1824E-01

2010.07

0000

85.00

1.00

.00

4.00

62.6253

65.00

9.18

82.04

VAPOR

$-5.02$
LIQUID

LIQUID

.00

112708.92 
Appencile $\mathrm{H}$

Tntle 21-15

Page 142 of 173

Das te 00/30/8is Rev UD

MITARIAL BALANCE TABLES

SL.UDGE-ONLY FEED

STREAM NUMBERS -

STREAM NAME

147

148

149

150

COMPONENT FLOHS, LB/HR

Liquid Spray PH'DBF \#2 PHDBF \#2 PHOLF 11

\begin{tabular}{|c|c|c|c|c|c|}
\hline 1 & 1120 & 1999. & 1090. & 2.698 & 114.5 \\
\hline 45 & Ag & .0000 & .0000 & .0000 & .0000 \\
\hline 116 & Ag20 & .0000 & .0000 & $.000)^{3}$ & .0000 \\
\hline 134 & AgN03 & .0000 & .0000 & .0000 & .0000 \\
\hline 51 & $\mathrm{AgOH}$ & $.4911 E-03$ & $.4968 \mathrm{E}-03$ & .0000 & $.5886 E-05$ \\
\hline 74 & $\mathrm{~A} I(\mathrm{OH}) 3$ & .5241 & .5277 & .0000 & $.3 G 98 E-62$ \\
\hline 77 & $A 1203$ & .0000 & .0000 & .0000 & .0000 \\
\hline 75 & $\mathrm{AlOOH}$ & .0000 & .0000 & .0000 & .0000 \\
\hline 106 & B203 & .9015 & .9077 & .0000 & $.6360 \mathrm{E}-02$ \\
\hline 9 & $\mathrm{Ba}(\mathrm{YOS}) 2$ & $.4117 E-08$ & $.4164 \mathrm{E}-08$ & .0000 & $.4857 E-10$ \\
\hline 95 & $\mathrm{BaCl2}$ & .0000 & .0000 & .0000 & .0000 \\
\hline 16 & $\mathrm{BaO}$ & .0000 & .0000 & .0000 & .0000 \\
\hline 24 & $\mathrm{BaSO4}$ & $.8715 E-02$ & $.3757 E-02$ & .0000 & $.4390 \mathrm{E}-04$ \\
\hline 66 & CO & $.2281 \mathrm{E}-03$ & $.1708 \mathrm{E}-03$ & .0000 & 5.596 \\
\hline 37 & $\mathrm{CO} 2$ & $.1228 \mathrm{E}-01$ & $.9614 \mathrm{E}-02$ & .0000 & 13.09 \\
\hline 142 & $\operatorname{CO2}\left(C_{14}\right)$ & $.2054 \mathrm{E}-26$ & $.1608 \mathrm{E}-26$ & .0000 & $.2188 E-23$ \\
\hline 63 & $\mathrm{Ca}(\mathrm{COOH}) 2$ & .1289 & .1303 & .0000 & . 1523E-02 \\
\hline 120 & $\mathrm{Ca}(\mathrm{OH}) 2$ & .0000 & .0000 & .0000 & .0000 \\
\hline 113 & $C_{23} 8(P 04) 2$ & $.9256 \mathrm{E}-02$ & $.9362 E-02$ & .0000 & . 109.1E- -03 \\
\hline 20 & $\mathrm{CaC2O4}$ & $.1001 E-01$ & $.1013 E-01$ & .0000 & $.11 S 3 E-03$ \\
\hline 18 & $\mathrm{CaCO3}$ & .0000 & .0000 & .0000 & .0000 \\
\hline 78 & $\mathrm{CaF} 2$ & $.2503 E-02$ & $.2531 \mathrm{E}-02$ & .0000 & $.2058 E-0.4$ \\
\hline 41 & $\mathrm{CaO}$ & .0000 & .0000 & .0000 & .0000 \\
\hline 19 & $\mathrm{CaSO4}$ & $.1176 E-01$ & $.1189 \mathrm{E}-01$ & .0000 & . 1390E-03 \\
\hline 29 & Carbon & $.2503 E-02$ & $.2531 \mathrm{E}-02$ & .0000 & . 295SE-04 \\
\hline 26 & $\mathrm{Co}(\mathrm{COOII}) 2$ & $.2035 \mathrm{E}-02$ & $.2058 \mathrm{E}-02$ & .0000 & $.2405 E-04$ \\
\hline 121 & $\mathrm{Co}(\mathrm{OHI}) 2$ & .0000 & .0000 & .0000 & .0000 \\
\hline 53 & $\mathrm{Co}(\mathrm{OH}) 3$ & .0000 & .0000 & .0000 & . \\
\hline 59 & $\mathrm{CoO}$ & .0000 & .0000 & .0000 & .0000 \\
\hline 99 & $\mathrm{Cr}(011) 8$ & $.9515 \mathrm{E}-02$ & $.9624 \mathrm{E}-02$ & .0000 & $.1124 \mathrm{E}-03$ \\
\hline 98 & Cr203 & .0000 & .0000 & .0000 & .0000 \\
\hline 42 & $\operatorname{Cs} 20$ & $.8791 E-07$ & $.3834 E-07$ & .0000 & $.4432 E-00$ \\
\hline 137 & Cs20 Semt Vol & $.7274 E-05$ & $.7274 E-05$ & .0000 & .0000 \\
\hline 90 & $\mathrm{Cs} \mathrm{COOH}$ & .0000 & .0000 & .0000 & .0000 \\
\hline 96 & $\mathrm{CsCl}$ & $.1418 \mathrm{E}-07$ & $.1446 E-07$ & .0000 & $.2852 \mathrm{E}-09$ \\
\hline 136 & CsCl Semi Vol & $.1297 \mathrm{E}-02$ & $.1332 E-02$ & .0000 & $.5066 \mathrm{E}-04$ \\
\hline 8 & Cs:N03 & $.2640 \mathrm{E}-03$ & $.2671 E-03$ & .0000 & $.8115 E-05$ \\
\hline 88 & CsResin & .0000 & .0000 & .0000 & .0000 \\
\hline 122 & $\mathrm{Cu}(\mathrm{COOH}) 2$ & $.4346 \mathrm{E}-02$ & $.4396 \mathrm{E}-02$ & .0000 & $.5136 E-04$ \\
\hline 52 & $\mathrm{Cu}(\mathrm{OH}) 2$ & .0000 & .0000 & .0000 & .0000 \\
\hline 58 & Cu2O & .0000 & .0000 & .0000 & .0000 \\
\hline 64 & $\mathrm{CuCOOH}$ & .0000 & .0000 & .0000 & .0000 \\
\hline 130 & $\mathrm{CuO}$ & .0000 & .0000 & .0000 & .0000 \\
\hline 13 & $F e(0 H) 3$ & 1.269 & 1.277 & .0000 & .8950 E-02 \\
\hline 80 & Fe203 & .0000 & .0000 & .0000 & .0000 \\
\hline
\end{tabular}


MATERIAL BALANCE TABLES

Date 09/80/82 Rev 09

\section{SLUDGE-ONLY FEED}

\section{STREAMS (CONT'D)-} STREAM NAME

$101 \mathrm{FeO}$

126 Group A Semi Vo

102 GroupA

103 GroupB

25112

133 H2C2O4

9111202

$84 \mathrm{HCOOH}$

$43 \mathrm{IICl}$

$85 \mathrm{HF}$

49 IINO3

86 HRes in

$36 \mathrm{Hg}$

135 IIg:032

$21 \mathrm{Hg} O$

$97 \quad 12$

$39 \times 20$

$131 \mathrm{kMn} 04$

$118 \mathrm{KNO3}$

105 Lo203

108 Li20

$65 \mathrm{Mg}(\mathrm{COOHI}) 2$

$65 \mathrm{Mg}$ (OH) 2

$83 \mathrm{MgO}$

$60 \mathrm{Mn}(\mathrm{COOH}) 2$

$132 \operatorname{Mn}(\mathrm{NO3}) 2$

$129 \mathrm{Mn}(\mathrm{OII}) 2$

$56 \mathrm{MnO}$

$14 \mathrm{MnO2}$

81 i2

$143 \mathrm{NA2CO3}(\mathrm{C} 14)$

85 No

84 N02

$70 \mathrm{Na}(\mathrm{HgO}(\mathrm{OH}))$

$94 \quad \mathrm{Na} 2 \mathrm{~B} 407$

$109 \mathrm{Na}_{2} \mathrm{C} 204$

$5 \mathrm{Na} 2 \mathrm{CO}$

$32 \mathrm{Na} 20$

$71 \mathrm{Na} 2 \mathrm{Pu} 02(\mathrm{OH}) 4$

$73 \mathrm{Na}_{2} \mathrm{Rl}_{3} \mathrm{O}_{4}$

$72 \mathrm{Na} 2 \mathrm{Ru}_{\mathrm{O}} 4$

$6 \mathrm{Na} 2 \mathrm{SO} 04$

$68 \mathrm{NaAlO2}$

$114 \mathrm{NaBO} 2$

140 NaBO2 Semi Vol

$50 \mathrm{NaCOOH}$
147

Liquid Spray

to PWDBF\#2

.0000

$.4281 \mathrm{E}-01$

$.6916 \mathrm{E}-02$

.2225E-01

. 1552E-04

.0000

.0000

.0000

.0000

.0000

.0000

.0000

.0000

.0000

$.1710 \mathrm{E}-01$

.0000

.0000

.0000

. 1526E-04

$.1824 \mathrm{E}-01$

.3487

$.2453 \mathrm{E}-01$

.0000

.1075

.2188

.0000

.0000

.0000

.0000

$.2144 \mathrm{E}-01$

.0000

.1077 E-03

.7339E-01

. 1571E-04

.4842

$.6121 E-05$

.0000

1.286

$.6373 E-09$

.1310E-06

. 1278E-05

.2593E-02

.6373E-02

.0000

.0000

.2550
148

PWDBF \#2

Exit Liquid .0000

$.4420 \mathrm{E}-01$

.6996E-02

.2250E-01

. 1156E-04

.0000

.0000

.0000

.0000

.0000

.0000

.0000

.0000

.0000

$.1779 E-01$

.0000

.0000

.0000

. 1549E-04

$.1845 \mathrm{E}-01$

.8511

.2481E-01

.0000

.1088

.2214

.0000

.0000

.0000

.0000

.2208E-01

.0000

$.8167 E-04$

$.6584 \mathrm{E}-01$

. 1589E-04

.4886

$.6215 \mathrm{E}-05$

.0000

1.295

$.6445 \mathrm{E}-09$

. 1325E-06

1293E-05

.2622E-02

$.6445 \mathrm{E}-02$

.0000

.0000

.2569
149

PWDBF \#2

Atomzg Air

.0000

.0000

.0000

.0000

.0000

.0000

.0000

.0000

.0000

.0000

.0000

.0000

.0000

.0000

.0000

.0000

.0000

.0000

.0000

.0000

.0000

.0000

.0000

.0000

.0000

.0000

.0000

.0000

.0000

123.1

.0000

.0000

.0000

.0000

.0000

.0000

.0000

.0000

.0000

.0000

.0000

.0000

.0000

.0000

.0000

.0000
150

PK'DBF \#1

Exit Gas

.0000

.1647 E-02

$.8238 E-04$

.2629E-03

.8657

.0000

.0000

.0000

.0000

.0000

.0000

.0000

.0000

.0000

$.7688 \mathrm{E}-03$

$.9892 \mathrm{E}-04$

.0000

.0000

.2416E-06

.2156E-03

.2466E-02

.2899E-03

.0000

$.8643 \mathrm{E}-03$

.2584E-02

.0000

.0000

.0000

.0000

801.6

.0000

1.175

.1810

$.1854 \mathrm{E}-06$

. 4549E-02

$.9696 \mathrm{E}-07$

.0000

.9072E-02

.7519E-11

. 1546E-08

. 1609E-07

.8059E-04

.7519E-04

.0000

.0000

. 1989E-02 
DPSP 80-1033

Appendix $H$

Table 21-15

Page 144 of 173

Date $09 / 50 / \varepsilon 2$ Re: 09

MATERIAL BALANCE TABLES

SLLDCII-ONLY FEED STREAYS (CONT'D)STREAM NAME

$7 \mathrm{NaCl}$

$188 \mathrm{NaCl}$ Semi Vol

$69 \mathrm{NoF}$

139 NaF Semi Vol

$12 \mathrm{NaI}$

$125 \mathrm{NaI}$ Semi Vol

$8 \mathrm{NaNO} 2$

$2 \mathrm{NaN08}$

$4 \mathrm{NaOH}$

87 NaResin

$61 \mathrm{Ni}(\mathrm{COOH}) 2$

$17 \mathrm{Ni}(\mathrm{OH}) 2$

$40 \mathrm{NiO}$

8202

$67 \mathrm{PbO}$

$28 \mathrm{PbSO} 04$

$124 \mathrm{Pd}$

$123 \mathrm{Pd}(\mathrm{OII}) 2$

112 PdN032

$110 \mathrm{PdO}$

$117 \mathrm{Pu}(\mathrm{COOH}) 4$

$76 \mathrm{Pu} 02$

$22 \mathrm{Rh} 02$

$79 \mathrm{Ru} 02$

23 Ru02 Semi Vol

$83 \mathrm{Ru} 04$

$88 \mathrm{SO2}$

$111 \mathrm{SiO}$

115 Silica Gol

$48 \mathrm{Sr}(\mathrm{COOH}) 2$

$10 \mathrm{Sr}(\mathrm{Y} 03) 2$

$127 \mathrm{Sr}(\mathrm{OH}) 2$

$80 \mathrm{SrCO}$

$46 \mathrm{SrO}$

89 SrRESIN

141 Surfactant

92 Th02

$107 \mathrm{TiO}$

119 Tritium

$93 \mathrm{v} 02$

$62 \mathrm{~V} 02$ (c.0OH) 2

$16 \mathrm{VO2}(\mathrm{OH}) 2$

$27 \mathrm{Y}(\mathrm{COOH}) 3$

$11 \mathrm{Y}(\mathrm{NOS}) 3$

$128 \mathrm{Y}(\mathrm{OH}) \mathrm{S}$

$81 Y 2(\mathrm{CO}) 3$

\begin{tabular}{|c|c|c|c|}
\hline 147 & 148 & 140 & 150 \\
\hline quid Spray & PHDBF \#2 & PKDCF \#2 & PIDBF \#1 \\
\hline $\begin{array}{l}\text { to PWDBF\#2 } \\
.2583 E-02\end{array}$ & $\begin{array}{l}\text { Exit Liquid } \\
.2613 E-02\end{array}$ & $\begin{array}{c}\text { Atomz: Air } \\
.0000\end{array}$ & $\begin{array}{l}\text { Exit Cons } \\
.30505-0 i\end{array}$ \\
\hline .4598 & .4701 & .0000 & $.11445-01$ \\
\hline $.6845 E-01$ & $.6922 \mathrm{E}-01$ & .0000 & $.7917 \mathrm{E}-03$ \\
\hline .8610 & .3691 & .0000 & $.00101:-02$ \\
\hline $.2501 E-03$ & $.2529 \mathrm{E}-03$ & .0000 & $.2253 \mathrm{E}-0=$ \\
\hline $.8099 E-01$ & $.8197 E-01$ & .0000 & $.1098 E-\dot{2} 2$ \\
\hline .0000 & .0000 & .0000 & .0000 \\
\hline $.8325 E-01$ & $.8420 E-01$ & .0000 & $.9826 \mathrm{E}-03$ \\
\hline .0000 & .0000 & .0000 & .0000 \\
\hline .0000 & .0000 & .0000 & .0000 \\
\hline $.7711 \mathrm{E}-01$ & $.7799 E-01$ & .0000 & $.9113 E-03$ \\
\hline .0000 & .0000 & .0000 & .0000 \\
\hline .0000 & .0000 & .0000 & .0000 \\
\hline . 1228E-01 & $.1269 \mathrm{E}-01$ & 37.19 & 242.1 \\
\hline .0000 & .0000 & .0000 & .0000 \\
\hline $.8496 \mathrm{E}-02$ & $.3536 E-02$ & .0000 & $.4132 \mathrm{E}-04$ \\
\hline .0000 & .0000 & .0000 & .0000 \\
\hline .0000 & .0000 & .0000 & .0000 \\
\hline .0000 & .0000 & .0000 & .0000 \\
\hline .0000 & .0000 & .0000 & .0000 \\
\hline .0000 & .0000 & .0000 & .0000 \\
\hline $.9098 E-03$ & $.9202 E-03$ & .0000 & $.1075 E-014$ \\
\hline $.3476 \mathrm{E}-03$ & $.8516 \mathrm{E}-03$ & .0000 & $.4108 \mathrm{E}-05$ \\
\hline $.1676 \mathrm{E}-02$ & . 1695E-02 & .0000 & $.2012 \pi-04$ \\
\hline $.1656 \mathrm{E}-01$ & $.1724 \mathrm{E}-01$ & .0000 & $.7563 E-03$ \\
\hline .0000 & .0000 & .0000 & .0000 \\
\hline $.4411 \mathrm{E}-04$ & $.3362 \mathrm{E}-04$ & .0000 & .3755 \\
\hline 8.796 & S.822 & .0000 & $.2078 E-01$ \\
\hline .0000 & .0000 & .0000 & .0000 \\
\hline $.8131 E-02$ & $.3167 E-02$ & .0000 & $.3701 \mathrm{E}-04$ \\
\hline $.3673 E-08$ & $.3715 E-08$ & .0000 & $.4334 E-10$ \\
\hline .0000 & .0000 & .0000 & .0000 \\
\hline .0000 & .0000 & .0000 & .0000 \\
\hline .0000 & .0000 & .0000 & .0000 \\
\hline .0000 & .0000 & .0000 & .0000 \\
\hline .0000 & .0000 & .0000 & .0000 \\
\hline $.1426 \mathrm{E}-01$ & $.1448 \mathrm{E}-01$ & .0000 & $.1686 \mathrm{E}-03$ \\
\hline $.8550 \mathrm{E}-01$ & . 3592E-01 & .0000 & $.4312 E-03$ \\
\hline . 7893E-09 & $.7847 E-09$ & .0000 & $.4515 E-10$ \\
\hline .0000 & .0000 & .0000 & .0000 \\
\hline $.9974 \mathrm{E}-01$ & .1009 & .0000 & $.1179 \mathrm{E}-02$ \\
\hline .0000 & .0000 & .0000 & .0000 \\
\hline $.2146 \mathrm{E}-02$ & $.2170 \mathrm{E}-02$ & .0000 & $.253 G E-04$ \\
\hline $.2608 \mathrm{E}-08$ & $.2638 E-08$ & .0000 & $.3078 \mathrm{E}-10$ \\
\hline .0000 & .0000 & .0000 & .0000 \\
\hline .0000 & .0000 & .0000 & $.0000^{\circ}$ \\
\hline
\end{tabular}



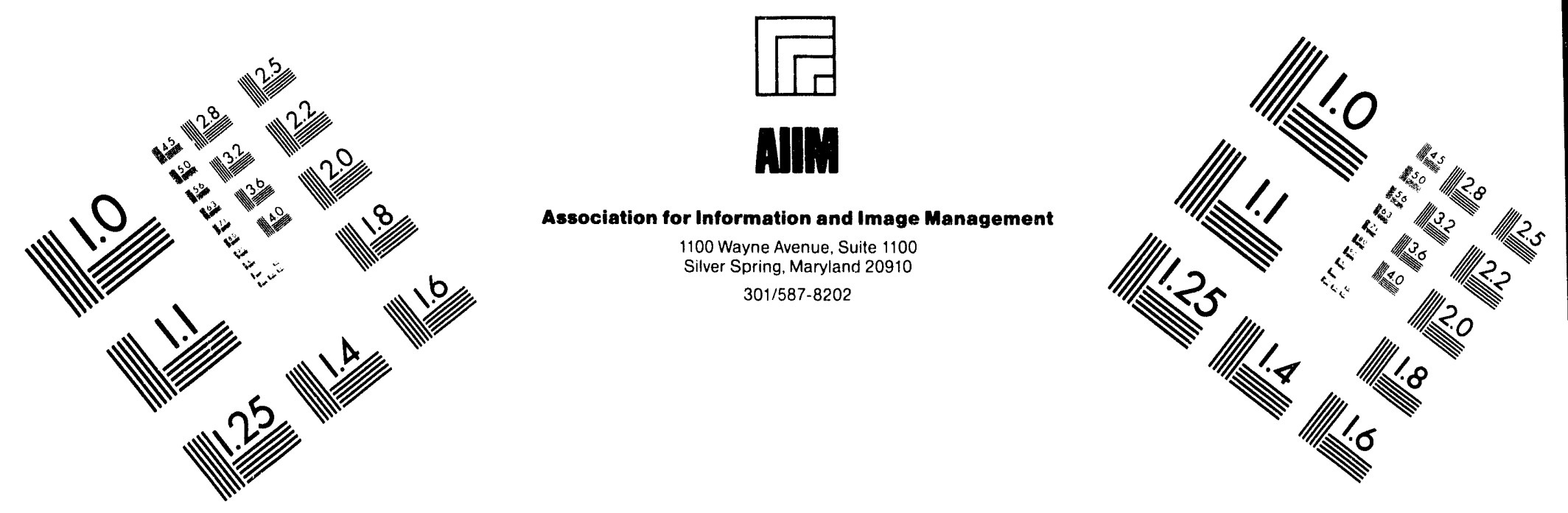

\section{Centimeter}

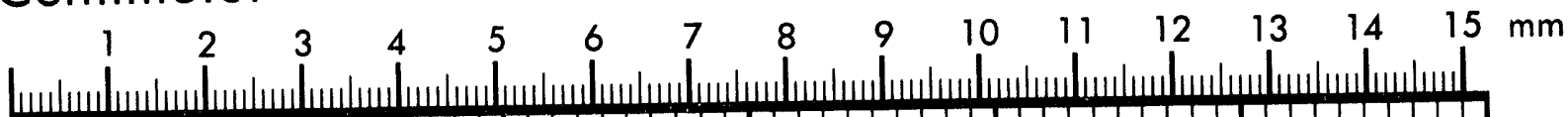
111 Inches
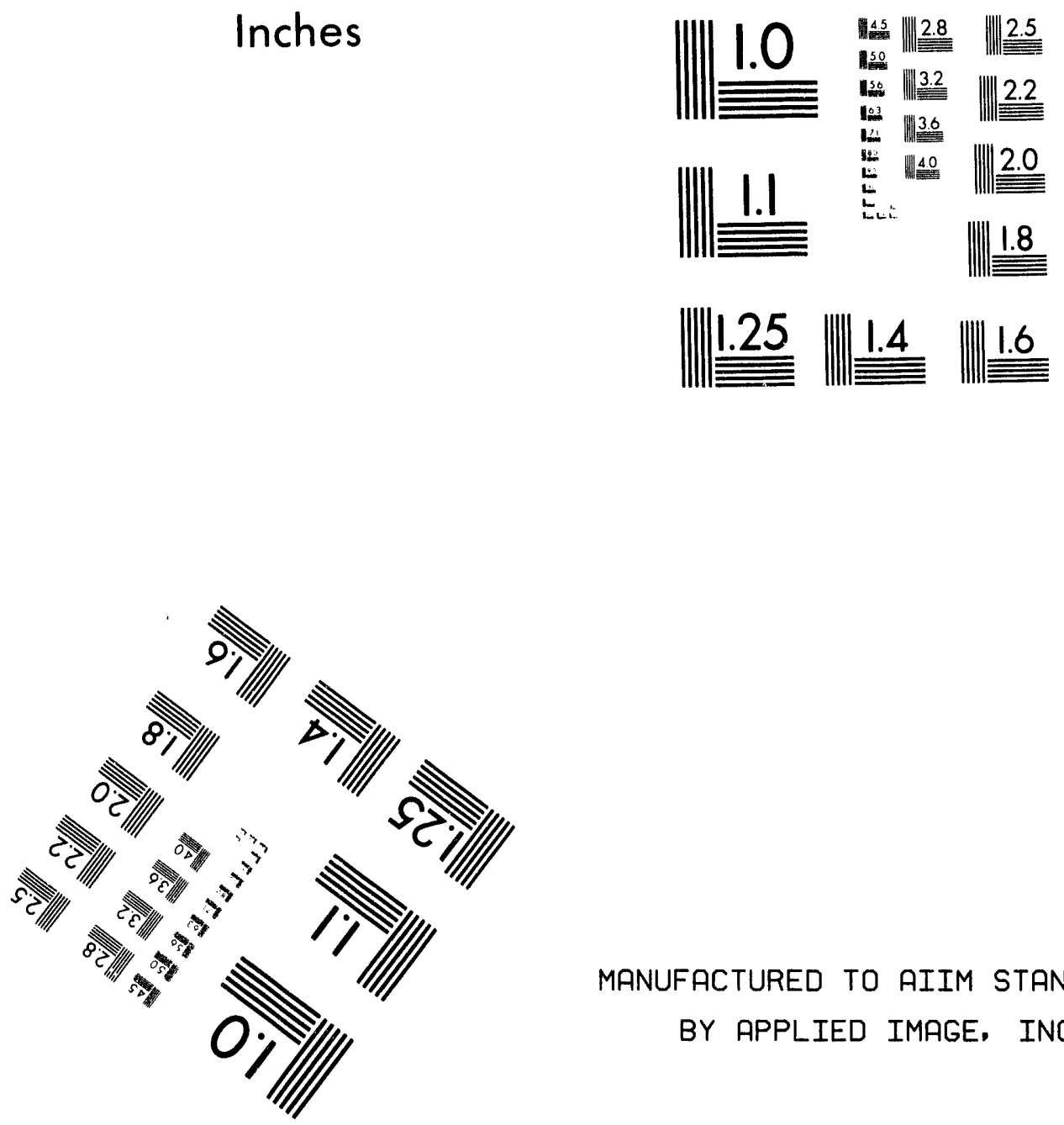

MANUFACTURED TO AIIM STANDARDS BY APPLIED IMAGE, INC.

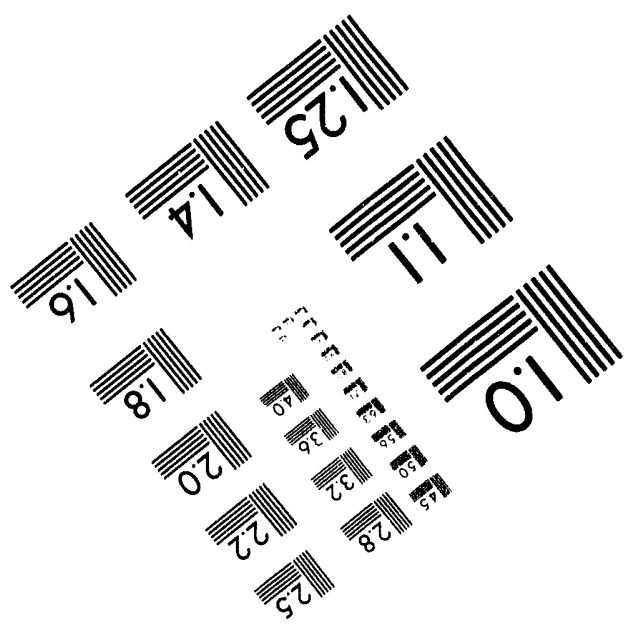



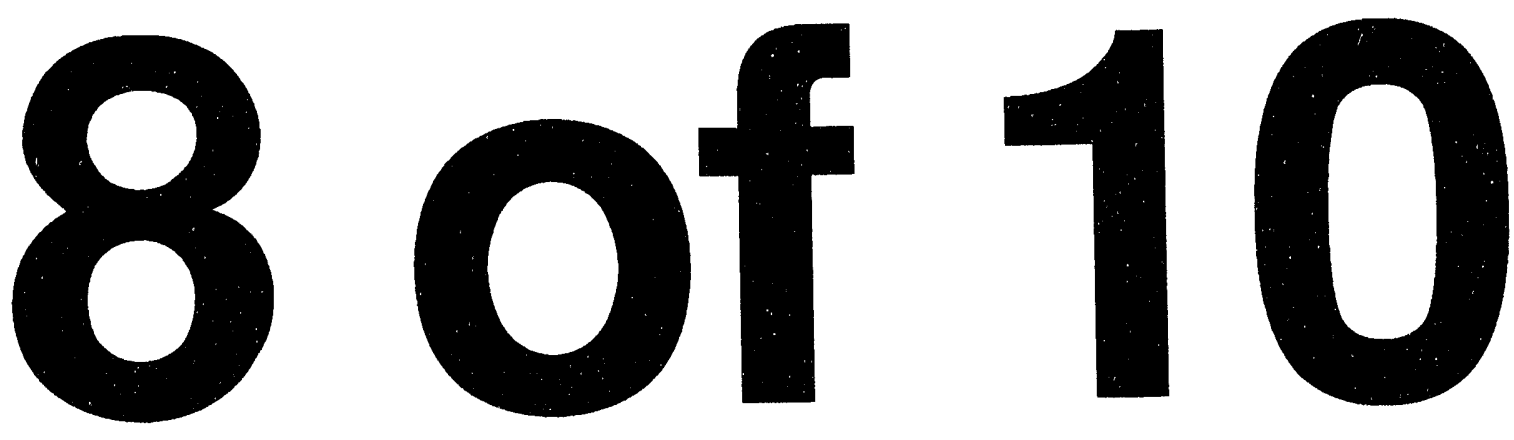
Material baLA.TCE TABLES

Date 09/80/82 Rev 09

SLUDGi-OKLY FEED

STREAMS (CONT'D)-

STREMI NAME

47 Y203

100 Zeolite

$44 \mathrm{Zn}(\mathrm{COOHI}) 2$

54 $\mathrm{Zn}(\mathrm{OHI}) 2$

$67 \mathrm{ZnO}$

$104 \mathrm{ZrO2}$

TOTAL FLOW, LB/HR

VAPOR FLOH, CFM

LIQUID FLOW, GPM

DESIGN FLOH,

DENSITY, LBS/FT3

TEYPERATURE, DEG C

PRESSURE, ATM

PRESSURE, PSIG

PRESSURE, MM HG

PIIASE

EXTHALPY, PCU/IIR

\begin{tabular}{|c|c|c|c|}
\hline 147 & 148 & 149 & 150 \\
\hline $\begin{array}{c}\text { Liquid Spray } \\
\text { to PUDBF\#2 }\end{array}$ & $\begin{array}{c}\text { PWDBF \#2 } \\
\text { Exit Liquid }\end{array}$ & PWDBF \#2 & PWDBF \#1 \\
\hline .0000 & .0000 & $\begin{array}{l}.0000 \\
\text { Atomzg }\end{array}$ & $\begin{array}{l}.0000 \\
.0010\end{array}$ \\
\hline $.9117 E-01$ & $.9222 \mathrm{E}-01$ & .0000 & $.1078 \mathrm{E}-02$ \\
\hline $.1134 \mathrm{E}-01$ & $.1147 E-01$ & .0000 & $.1840 \mathrm{E}-03$ \\
\hline .0000 & .0000 & .0000 & .0000 \\
\hline .0000 & .0000 & .0000 & .0000 \\
\hline . 1824E-01 & $.1845 E-01$ & .0000 & $.2156 \mathrm{E}-03$ \\
\hline 2010.07 & 2001.10 & 162.98 & 1179.04 \\
\hline 4.00 & 8.98 & & \\
\hline 626 & n & & \\
\hline 55 & & & 53.46 \\
\hline 818 & 95 & 8.72 & .96 \\
\hline 32.04 & -.69 & 89.97 & -.54 \\
\hline & 724.51 & & 732.11 \\
\hline LIQUI & LIQUID & VAPOR & VAPOR \\
\hline 112708. & 106912.98 & -8198.74 & 11131.37 \\
\hline
\end{tabular}


DPSP $80-1033$

MATERIAL BALANCE TABLES

SLIDGE-ONLY FEED

STREAM NUMBERS -

STREAN NAYE

COMPONEYT FLOHS, LB/HR

$1 \mathrm{H} 20$

$45 \mathrm{Ag}$

$116 \mathrm{Ag} 20$

134 AgN03

$51 \mathrm{AgOH}$

74 Al $(\mathrm{OH}) 3$

77 A1203

$75 \mathrm{AlOOH}$

106 B203

$9 \mathrm{Ba}(\mathrm{NO3}) 2$

$95 \mathrm{BaCl} 2$

$15 \mathrm{BaO}$

$24 \mathrm{BaSO4}$

$66 \mathrm{CO}$

$87 \mathrm{CO2}$

$142 \mathrm{CO}$ ( $\mathrm{C14})$

$63 \mathrm{Ca}(\mathrm{COOH}) 2$

$120 \mathrm{Ca}(\mathrm{OH}) 2$

$118 \mathrm{Ca} 3(\mathrm{PO} 4) 2$

$20 \mathrm{CaC}_{\mathrm{B}} \mathrm{CO}$

$18 \mathrm{CaCO3}$

$78 \mathrm{CaF} 2$

$41 \mathrm{C}_{2} \mathrm{O}$

$19 \mathrm{CaSO4}$

29 Carbon

$26 \mathrm{Co}(\mathrm{COOH}) 2$

$121 \mathrm{Co}(\mathrm{OH}) 2$

$53 \mathrm{Co}(\mathrm{OH}) 3$

$59 \mathrm{CoO}$

$99 \mathrm{Cr}(\mathrm{OH}) 3$

$98 \mathrm{Cr} 203$

42 Cs20

137 Cs20 Semi Vol

$90 \mathrm{Cs} \mathrm{COOH}$

$96 \mathrm{CsCl}$

$136 \mathrm{CsCl}$ Semi Vol

8 CsNO3

88 CsResin

$122 \mathrm{Cu}(\mathrm{COOH}) 2$

$52 \mathrm{Cu}(\mathrm{OH}) 2$

$58 \mathrm{Cu} 20$

$64 \mathrm{CuCOOH}$

$130 \mathrm{Cu} 0$

$13 \mathrm{Fe}(\mathrm{OH}) 3$

$80 \mathrm{Fe} 203$
Appendix $\mathrm{H}$

Táble 21-15

Page 146 of 173

Date $09 / 30 / 82$ Rev 09
151

Exit Gas

from HEPA

$$
\text { IRR }
$$

50.0

.0000

.0000

.0000

$.4654 \mathrm{E}-13$

$.2924 \mathrm{E}-10$

.0000

.0000

$.5029 E-10$

$.3841 E-18$

.0000

.0000

.3471E-12

5.598

13.09

$.2189 \mathrm{E}-23$

$.1204 E-10$

.0000

$.8651 \mathrm{E}-12$

$.9356 \mathrm{E}-12$

.0000

$.2339 \mathrm{E}-12$

.0000

$.1099 \mathrm{E}-11$

.2339E-12

.0000

.0000

.0000

.0000

$.8892 E-12$

.0000

$.8505 \mathrm{E}-17$

.0000

.0000

$.1266 \mathrm{E}-10$

.0000

$.2464 \mathrm{E}-18$

.0000

$.4062 \mathrm{E}-12$

.0000

.0000

.0000

.0000

$.7078 \mathrm{E}-10$

.0000
152

HEPA

Accumulation

.0000

.0000

.0000

.0000

$.4650 \mathrm{E}-10$

.2921E-07

.0000

.0000

$.5024 \mathrm{E}-07$

$.3837 E-15$

.0000

.0000

. 3468E-09

.0000

.0000

.0000

$.1203 \mathrm{E}-07$

.0000

$.8642 \mathrm{E}-09$

$.9347 \mathrm{E}-09$

.0000

.2337E-09

.0000

$.1098 \mathrm{E}-08$

.2337E-09

.0000

.0000

.0000

.0000

$.8883 E-09$

.0000

$.3501 \mathrm{E}-14$

.0000

.0000

$.1265 \mathrm{E}-07$

.0000

$.2461 \mathrm{E}-10$

.0000

$.4058 \mathrm{E}-09$

.0000

.0000

.0000

.0000

$.7071 \mathrm{E}-07$

.0000
153

Liq to SHDE Sand Filter

Nozzles Accumulation

$5 \$ 24$.

.0000

.0000

.0000

$.5022 \mathrm{E}-10$

.0000

$.7342 \mathrm{E}-05$

$.4725 \mathrm{E}-02$

.0000

.0000

$.8127 \mathrm{E}-02$

$.6210 \mathrm{E}-10$

.0000

.0000

$.5601 \mathrm{E}-04$

$.3771 \mathrm{E}-03$

$.2358 \mathrm{E}-01$

$.3942 E-20$

$.1943 \mathrm{E}-02$

.0000

$.1396 \mathrm{E}-03$

$.1510 \mathrm{E}-03$

.0000

$.3774 \mathrm{E}-04$

.0000

$.1773 E-03$

$.3774 \mathrm{E}-0$

.3071E-04

.0000

.0000

.0000

$.1435 \mathrm{E}-03$

.0000

.5197E-09

.0000

.0000

$.1754 \mathrm{E}-09$

.2025E-03

.3983E-05

.0000

$.6553 \mathrm{E}-04$

.0000

.0000

.0000

.0000

$.1144 \mathrm{E}-01$

.0000
.0000

$.8244 \mathrm{E}-10$

. 1579E-10

$.1912 E-03$

.0000

.0000

$.7196 \mathrm{E}-03$

$.2509 E-16$

.0000

.0000

$.2268 E-10$

.6000

.0000

.0000

$.7857 \mathrm{E}-0$ ?

$.5196 \mathrm{E}-12$

$.5651 E-10$

$.6112 \mathrm{E}-10$

.0000

$.1528 E-10$

.0000

$.7179 E-10$

$.1528 \mathrm{E}-10$

.0000

$.8988 \mathrm{E}-14$

.0000

.0000

$.5808 \mathrm{E}-10$

.0000

$.2962 E-15$

.0000

.0000

$.1266 \mathrm{E}-10$

.0000

$.1609 \mathrm{E}-11$

.0000

$.2650 \mathrm{E}-10$

$.1955 \mathrm{E}-13$

.0000

.0000

.0000

$.4628 \mathrm{E}$ - US

$.0000^{\circ}$ 
DPSP \&ง-1033

Miterial BALANCE TALLES

\section{SLUDGE-ONLY FEED}

STREAMS (CONT'D)-
STREAM NAME

$101 \mathrm{FeO}$

126 Groun A Semi Vo

102 GroupA

103 GroupB

25 II2

$135112 \mathrm{C204}$

9111202

34 HCOOH

$43 \mathrm{HCl}$

85 IIF

49 HNO3

86 llResin

$36 \mathrm{Hg}$

135 IIgNOS2

$21 \mathrm{HgO}$

$97 \quad 12$

$89 \mathrm{~K} 20$

$131 \mathrm{KM} / \mathrm{O} 04$

$118 \mathrm{KNOB}$

105 La203

$108 \mathrm{Li} 20$

$65 \mathrm{Mg}(\mathrm{COOH}) 2$

$55 \mathrm{Mg}(\mathrm{Oll}) 2$

$83 \mathrm{MgO}$

$60 \mathrm{Mn}(\mathrm{COOH}) 2$

$132 \mathrm{Mn}(\mathrm{NO3}) 2$

$129 \mathrm{Mn}(\mathrm{OII}) 2$

$56 \mathrm{MnO}$

$14 \mathrm{MnO}_{\mathrm{n}}$

81 N2

$143 \mathrm{NA2CO3}$ (C14)

85 NO

$84 \mathrm{NO2}$

$70 \mathrm{Na}$ ( $\mathrm{HgO}(\mathrm{OII})$ )

$94 \quad \mathrm{Na} 2 \mathrm{~B} 407$

$109 \mathrm{Na} 2 \mathrm{C2O4}$

$5 \mathrm{Na} 2 \mathrm{CO3}$

$82 \mathrm{Na} 20$

$71 \mathrm{Na} 2 \mathrm{PuO}$ (OH) 4

$73 \mathrm{Na} 2 \mathrm{RhO} 4$

$72 \mathrm{Na} 2 \mathrm{RuO}_{4}$

$6 \mathrm{Na} 2 \mathrm{SO} 4$

$68 \mathrm{NaAl} 02$

$114 \mathrm{NaBO2}$

$140 \mathrm{NaBO2}$ Semi Vol

$50 \mathrm{NaCOOH}$

Appendix H

Table 21-15

Pige 147 of 173

Date $05 / 30 / 82$ Rev 09

151

Exit Gas

from HEPA

.0000

.0000

$.3875 \mathrm{E}-09$

.2079E-11

.3657

.0000

.0000

.0000

.0000

.0000

.0000

.0000

.0000

.0000

$.1922 \mathrm{E}-09$

.9392E-09

.0000

.0000

$.1911 \mathrm{E}-14$

$.1705 \mathrm{E}-11$

$.1950 \mathrm{E}-10$

.2292E-11

.0000

$.6835 \mathrm{E}-11$

$.2044 \mathrm{E}-10$

.0000

.0000

.0000

.0000

1362.

.0000

1.175

.1850

$.1466 \mathrm{E}-14$

$.8598 \mathrm{E}-10$

$.7667 \mathrm{E}-15$

.0000

$.7174 \mathrm{E}-10$

$.5946 \mathrm{E}-19$

$.1222 \mathrm{E}-16$

$.1193 \mathrm{E}-15$

$.2419 E-12$

$.5946 \mathrm{E}-12$

.0000

.0000

$.1573 \mathrm{E}-10$
152

HEPA

Accumulation

.0000

.0000

$.3871 \mathrm{E}-0 \mathrm{C}$

.2077E-0S

.0000

.0000

.0000

.0000

.0000

.0000

.0000

.0000

.0000

.0000

. 1920E-06

$.9383 E-06$

.0000

.0000

$.1009 \mathrm{E}-11$

. 1703E-08

$.1948 \mathrm{E}-07$

.2290E-08

.0000

$.6828 \mathrm{E}-08$

.2042E-07

.0000

.0000

.0000

.0000

.0000

.0000

.0000

.0000

$.1465 E-11$

. $3594 \mathrm{E}-07$

$.7659 \mathrm{E}-12$

.0000

$.7167 \mathrm{E}-07$

$.5940 E-16$

$.1221 \mathrm{E}-13$

$.1192 \mathrm{E}-12$

.2417E-09

.5940E-09

.0000

.0000

$.1572 \mathrm{E}-07$
153

Liq to SHDEE Sand Filter

Nozzles Accusulation

.0000

.0000

$.6113 \mathrm{E}-\mathrm{C}: 2$

$.1040 \pi-03$

$.3355 \mathrm{E}-03$

$.25185-01$

.0000

.0000

.0000

.0000

.0000

.0000

.0000

.0000

.0000

$.3071 \mathrm{E}-02$

.0000

.0000

.0000

$.1989 E-06$

$.2751 \mathrm{E}-03$

.3145E-02

$.8699 \mathrm{E}-03$

.0000

$.1102 E-02$

.3302E-02

.0000

.0000

.0000

.0000

$.6836 \mathrm{E}-01$

.0000

$.1856 \mathrm{E}-03$

.1968

$.2370 \mathrm{E}-06$

$.5814 \mathrm{E}-0$ ?

$.7980 E-07$

.0000

$.1159 E-01$

$.9613 E-1$ :

$.1976 \mathrm{E}-08$

$.1929 E-07$

.3911E-04

$.9613 \mathrm{E}-04$

.0000

.0000

.2540 E- 02
.0000

$.42035-6 ?$

. 155SE-:D

.0000

.0000

.0000

.0000

.0000

.0000

.0000

.0000

.0000

$.5161 E-13$

$.1924 E-09$

.0000

.0000

.0000

$.2339 \mathrm{E}-10$

.2443L-03

$.2790 \mathrm{E}-0 \mathrm{i}$

$.1490 \mathrm{E}-03$

$.8 S 01 E-13$

$.9784 \mathrm{E}-09$

$.1333 E-08$

.0000

$.2142 \mathrm{E}-10$

.0000

.0000

.0000

.0000

.0000

.0000

$.9578 \mathrm{E}-13$

$.3947 \mathrm{E}-10$

$.9386 \mathrm{E}-11$

.0000

$.8683 \mathrm{E}-08$

$.8884 E-17$

$.7985 \mathrm{E}-15$

$.7792 E-14$

$.1580 \mathrm{E}-10$

$.3884 \mathrm{E}-10$

.0000

.0000

$.1250 \mathrm{E}-08$ 
LPSP SO-1033

MATIRIAL PALANCE TABLES

SLLDGE-0:ILY FEED

STREAMS (COYT'D)-

STREAII NAME

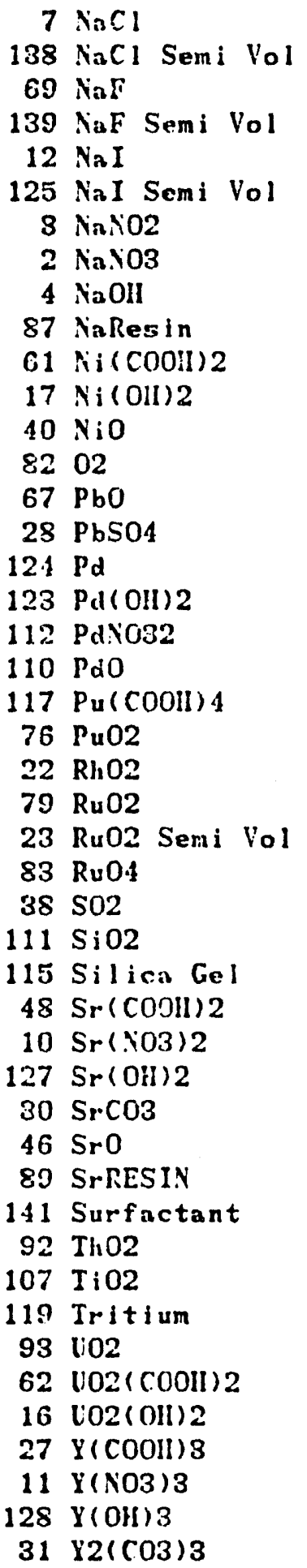

Append Ix II

Table 21-15

Pnge 148 of 173

Date 09/30/82 Rev 09

\begin{tabular}{|c|c|c|c|}
\hline 151 & 152 & 153 & 154 \\
\hline Exit Gas & HEPA & Liq to SHDBF & Sand Filter \\
\hline rom HEPA & Accumulation & Nozzles & Accumulation \\
\hline $.2860 E-08$ & $.2857 \mathrm{E}-05$ & $.3898 E-04$ & $.2876 E-08$ \\
\hline .0000 & .0000 & $.4569 E-01$ & .0000 \\
\hline $.2259 E-08$ & $.2257 E-05$ & $.1009 E-02$ & $.2260 E-08$ \\
\hline .0000 & .0000 & $.3592 E-01$ & .0000 \\
\hline $.2746 E-09$ & $.2743 E-06$ & $.3772 E-05$ & $.2761 \mathrm{E}-09$ \\
\hline .0000 & .0000 & $.4389 E-02$ & .0000 \\
\hline .0000 & .0000 & .0000 & .0000 \\
\hline $.7770 E-11$ & $.7763 E-08$ & $.1255 E-02$ & $.9922 \mathrm{E}-09$ \\
\hline .0000 & .0000 & .0000 & $.3897 E-12$ \\
\hline .0000 & .0000 & .0000 & .0000 \\
\hline $.7207 E-11$ & $.7199 E-08$ & $.1163 E-02$ & $.4702 \mathrm{E}-09$ \\
\hline .0000 & .0000 & .0000 & $.3404 E-12$ \\
\hline .0000 & .0000 & .0000 & .0000 \\
\hline 411.4 & .0000 & $.3963 E-01$ & .0000 \\
\hline .0000 & .0000 & .0000 & .0000 \\
\hline $.3267 E-12$ & $.8264 E-09$ & $.5272 E-04$ & $.2134 E-10$ \\
\hline .0000 & .0000 & .0000 & .0000 \\
\hline .0000 & .0000 & .0000 & .0000 \\
\hline .0000 & .0000 & .0000 & .0000 \\
\hline .0000 & .0000 & .0000 & .0000 \\
\hline .0000 & .0000 & .0000 & .0000 \\
\hline $.8502 E-13$ & $.8494 E-10$ & $.1872 E-04$ & $.5554 E-11$ \\
\hline $.3249 E-13$ & $.8245 E-10$ & $.5242 \mathrm{E}-05$ & $.2122 \mathrm{E}-11$ \\
\hline . 1892E-09 & $.1890 E-06$ & $.2517 E-04$ & $.1994 E-09$ \\
\hline .0000 & .0000 & . 2960E-02 & .0000 \\
\hline .0000 & .0000 & .0000 & .0000 \\
\hline .3755 & .0000 & $.7738 \mathrm{E}-04$ & .0000 \\
\hline $.2117 E-09$ & $.2115 E-06$ & $.3422 E-01$ & $.2924 E-07$ \\
\hline .0000 & .0000 & .0000 & .0000 \\
\hline $.2926 E-12$ & . 2923E-09 & $.4721 E-04$ & $.1909 E-10$ \\
\hline $.3427 E-18$ & $.3424 E-15$ & $.5541 E-10$ & $.2239 E-16$ \\
\hline .0000 & .0000 & .0000 & $.1518 \mathrm{E}-13$ \\
\hline .0000 & .0000 & .0000 & .0000 \\
\hline .0000 & .0000 & .0000 & .0000 \\
\hline .0000 & .0000 & .0000 & .0000 \\
\hline .0000 & .0000 & .0000 & .0000 \\
\hline $.1333 E-11$ & $.1332 E-08$ & $.2151 \mathrm{E}-03$ & $.8707 E-10$ \\
\hline $.3409 E-11$ & $.3406 E-08$ & $.5501 E-03$ & . $4885 E-09$ \\
\hline $.7856 \mathrm{E}-11$ & .0000 & $.9131 E-09$ & .0000 \\
\hline .0000 & .0000 & .0000 & .0000 \\
\hline $.9321 E-11$ & $.9312 E-08$ & $.1504 E-02$ & $.6082 E-09$ \\
\hline .0000 & .0000 & .0000 & $.5964 E-12$ \\
\hline $.2005 E-12$ & $.2003 E-09$ & $.3235 E-04$ & $.1308 E-10$ \\
\hline $.2434 E-18$ & $.2431 E-15$ & $.3935 E-10$ & . 1590E-16 \\
\hline .0000 & .0000 & .0000 & $.9492 E-14$ \\
\hline .0000 & .0000 & .0000 & $.0000^{\circ}$ \\
\hline
\end{tabular}


Appendix II

Tnble 21-15

Page 149 of 173

SATERIAL BALANCE TARLES

Date 09/30/52 Rev 09

SLUDGE-ONLY FEED

STREAMS (CONT'D) -

STREAM NAME

$47 \Upsilon 203$

100 Zoolite

$44 \mathrm{Zn}($ coOll $) 2$

$54 \mathrm{Zn}(\mathrm{Oll}) 2$

$57 \mathrm{ZnO}$

$104 \mathrm{ZrO2}$

TOTAL FLOW, LB/HR

VAPOR FLOH, CFM

LIQUID FLOW, GPM

DESIGN FLOW,

DENSITY, LBS/FT3

TEMPERATURE, DEG C

PRESSURE, ATM

PRESSURE, PSIG

PRESSURE, M HG

PHASE

ENTHILPY, PCU/IIR
151

Exit Gas

from HEPA

.0000

$.8521 E-11$

$.1059 \mathrm{E}-11$

.0000

.0000

$.1705 \mathrm{E}-11$

1844.37

657.75

.0467

50.00

.70

$-4.42$

531.32

VAPOR

$-73041.30$
153

HE'A

Accumulation

.0000

$.8512 E-08$

$.1058 \mathrm{E}-08$

.0000

.0000

$.1703 E-08$

.00

.00

.1031

50.00

.70

$-4.42$

531.32

VAPOR

.00
Liq to Slider Sand Filter

vozzles

.0000

$.1375 \mathrm{E}-22$

$.1709 E-C 3$

.0000

.0000

$.2751 \mathrm{E}-03$

5824.41

11.63

62.4318

46.47

3.18

32.04

LIQIID

276188.86
Aeculaul at ical .0000

$.55 i j 5-03$

$.6912 \mathrm{E}-10$

$.5134 \mathrm{E}-13$

.0000

$.2443 E-0$ ?

.010

.0000

35.17

.99

$-.11$

754.35

SOL.ID

.00 
DFSP $80-1033$

MATERIAL BALAYCE TABLES

SLLDGE-ONIY FEED

STREAM NUMBERS -

STREAMI NAME

COMPONENT FLOHS, LB/HR

\begin{tabular}{|c|c|c|c|}
\hline 1 & 1120 & .0000 & $1.04 \%$ \\
\hline 45 & $\mathrm{Ag}$ & $.1545 E-07$ & .0000 \\
\hline 116 & Ag20 & .0000 & .0000 \\
\hline 34 & AgrNo3 & $.2537 \mathrm{E}-07$ & .0000 \\
\hline 51 & AgOll & $.4843 E-08$ & .0000 \\
\hline 74 & Al $(0 \mathrm{H}) 3$ & $.5793 E-06$ & .0000 \\
\hline 77 & A1203 & .0000 & .0000 \\
\hline 75 & 410011 & .0000 & .0000 \\
\hline 06 & B203 & $.2199 E-05$ & .0000 \\
\hline 9 & $\mathrm{Ea}(\mathrm{X} 03) 2$ & $.7602 E-14$ & .0000 \\
\hline 95 & $\mathrm{BaC} 12$ & .0000 & .0000 \\
\hline 15 & $\mathrm{BaO}$ & .0000 & .0000 \\
\hline 24 & BaSO4 & $.6871 \mathrm{E}-08$ & .0000 \\
\hline 66 & $\mathrm{co}$ & .0000 & .0000 \\
\hline 37 & $\mathrm{CO} 2$ & .0000 & .0000 \\
\hline 142 & $\mathrm{CO2}(\mathrm{C14})$ & .0000 & .0000 \\
\hline 63 & $\mathrm{Ca}(\mathrm{COOH}) 2$ & $.2881 \mathrm{E}-06$ & .0000 \\
\hline 120 & $\mathrm{Ca}(\mathrm{OII}) 2$ & $.1599 \mathrm{E}-09$ & .0000 \\
\hline 13 & $\mathrm{Ca} 3(\mathrm{PO4}) 2$ & $.1712 E-07$ & .0000 \\
\hline 20 & $\mathrm{CaC2O4}$ & $.1852 E-07$ & .0000 \\
\hline 18 & $\mathrm{CaCO3}$ & .0000 & .0000 \\
\hline 78 & $\mathrm{CaF} 2$ & $.4629 \mathrm{E}-08$ & .0000 \\
\hline 41 & $\mathrm{CaO}$ & .0000 & .0000 \\
\hline 19 & $\mathrm{CaSO4}$ & $.2175 E-07$ & .0000 \\
\hline 23 & Canebon & $.4629 E-08$ & .0000 \\
\hline 26 & $\mathrm{Co}(\mathrm{COOH}) 2$ & .0000 & .0000 \\
\hline 121 & $\mathrm{Co}(\mathrm{OH}) 2$ & $.2766 E-11$ & .0000 \\
\hline 53 & Co(Oli) 3 & .0000 & .0000 \\
\hline 59 & $\mathrm{CoO}$ & .0000 & .0000 \\
\hline 99 & $\mathrm{Cr}(\mathrm{OH}) \mathrm{s}$ & $.1760 \mathrm{E}-07$ & .0000 \\
\hline 98 & Cr203 & .0000 & .0000 \\
\hline 42 & Cs20 & $.9006 \mathrm{E}-13$ & .0000 \\
\hline 137 & Cs20 Semi Vol & .0000 & .0000 \\
\hline 90 & Csr.ooll & .0000 & .0000 \\
\hline 96 & $\mathrm{CsCl}$ & $.2916 \mathrm{E}-11$ & .0000 \\
\hline 136 & CsCl Semi Vol & .0000 & .0000 \\
\hline 8 & CsNO3 & $.4876 E-09$ & .0000 \\
\hline 88 & CsResin & .0000 & .0000 \\
\hline 122 & $\mathrm{Cu}(\mathrm{COOH}) 2$ & $.8029 E-08$ & .0000 \\
\hline 52 & $\mathrm{Cu}(\mathrm{OH}) 2$ & $.6016 \mathrm{E}-11$ & .0000 \\
\hline 58 & Cu20 & .0000 & .0000 \\
\hline 64 & Cucooll & .0000 & .0000 \\
\hline 130 & $\mathrm{CuO}$ & .0000 & .0000 \\
\hline 18 & Fe $(011) 3$ & $.1402 E-05$ & .0000 \\
\hline 80 & Fe203 & .0000 & .0000 \\
\hline
\end{tabular}

Append IX H

Table 21-15

Page 150 of 173

Date 09/80/82 Rev 09

\section{5 \\ PVVF \\ SRAT Air \\ SME Air}

156

In leakago

$1.04 \%$

0000

.0000

0000

0000

0000

0000

0000

0000

0000

0000

0000

0000

0000

0000

0000

0000

0000

0000

0000

0000

0000

0000

0000

0000

0000

0000

0000

0000

0000

.0000
157

Inleakage

1.047

.0000

.0000

.0000

.0000

.0000

.0000

.0000

.0000

.0000

.0000

.0000

.0000

.0000

.0000

.0000

.0000

.0000

.0000

.0000

.0000

.0000

.0000

.0000

.0000

.0000

.0000

.0000

.0000

.0000

.0000

.0000

.0000

.0000

.0000

.0000

.0000

.0000

.0000

.0000

.0000

.0000

.0000

.0000

.0000
158

SHECT Air

Purge

3.738

.0000

.0000

.0000

.0000

.0000

.0000

.0000

.0000

.0000

.0000

.0000

.0000

.0000

.0000

.0000

.0000

.0000

.0000

.0000

.0000

.0000

.0000

.0000

.0000

.0000

.0000

.0000

.0000

.0000

.0000

.0000

.0000

.0000

.0000

.0000

.0000

.0000

.0000

.0000

.0000

.0000

.0000

.0000

.0000 
DPSP 80 1038

MATERIAL BALANCE TABLES

SLUDGE-ONLY FEED

STREAMS (CONT'D) -

STREAM NAMIE

$101 \mathrm{FeO}$

126 Group A Semi Vo

102 GroupA

103 Group B

$25 \mathrm{H} 2$

$133 \mathrm{H} 2 \mathrm{C} 2 \mathrm{O} 4$

$91 \mathrm{H2O2}$

$84 \mathrm{HCCOH}$

$48 \mathrm{HCl}$

$85 \mathrm{HF}$

49 HNO3

86 HResin

$36 \mathrm{Hg}$

135 Hg.VO32

$21 \mathrm{IIg} 0$

9712

$89 \mathrm{~K} 20$

$131 \mathrm{kMnO4}$

118 KNO3

$105 \quad$ La203

108 Li20

$65 \mathrm{Mg}(\mathrm{COOH}) 2$

$55 \mathrm{Mg}(\mathrm{OII}) 2$

83 MgO

$60 \mathrm{Mn}(\mathrm{COOH}) 2$

$132 \mathrm{Mn}(\mathrm{N} 03) 2$

$129 \mathrm{Mn}(\mathrm{OH}) 2$

$56 \mathrm{MnO}$

$14 \mathrm{MnO2}$

81 N2

143 NA2CO3 (C14)

35 NO

$84 \mathrm{NO2}$

$70 \mathrm{Na}(\mathrm{HgO}(\mathrm{OH}))$

$94 \mathrm{Na} 2 \mathrm{~B} 407$

$109 \mathrm{Na} 2 \mathrm{C}_{204}$

$5 \mathrm{Na} 2 \mathrm{CO} 3$

$32 \mathrm{Na} 20$

$71 \mathrm{Na} 2 \mathrm{Pu} 02$ ( 011$) 4$

$73 \mathrm{Na} 2 \mathrm{RhO} 04$

$72 \mathrm{Na} 2 \mathrm{RuO}_{4}$

$6 \mathrm{Na} 2 \mathrm{SO}_{4}$

$68 \mathrm{NaAl} 102$

$114 \mathrm{NaBO2}$

$140 \mathrm{NaBO2}$ Semi Vol

$50 \mathrm{NaCOOH}$
155

PVVF

Accumulation

.0000

.0000

$.1290 \mathrm{E}-07$

$.4115 \mathrm{E}-07$

.0000

.0000

.0000

.0000

.0000

.0000

.0000

.0000

.0000

$.1588 \mathrm{E}-10$

.1310E-09

.0000

.0000

.0000

$.7197 \mathrm{E}-08$

$.7464 \mathrm{E}-07$

$.8526 \mathrm{E}-06$

$.4532 \mathrm{E}-07$

$.2726 \mathrm{E}-10$

$.2990 \mathrm{E}-06$

$.4040 \mathrm{E}-06$

.0000

$.6592 \mathrm{E}-08$

.0000

.0000

.0000

.0000

.0000

.0000

$.2902 E-10$

$.1087 \mathrm{E}-08$

$.2888 E-08$

.0000

.2650E-05

$.1177 E-14$

$.2419 \mathrm{E}-12$

$.2361 E-11$

$.4788 \mathrm{E}-08$

$.1177 \mathrm{E}-07$

.0000

.0000

$.8799 \mathrm{E}-06$
Appendix $\mathrm{H}$

Table 21-15

Page 151 of 173

Date 00/30/S2 Rev 09 
DPSP $80-1033$

UIIERIAL BALANCE TABLES

SI.UDGE-ONLY FEED

STREAMS (CONT'D)-

STREAM NAME

$7 \mathrm{NaCl}$

$138 \mathrm{NaCl}$ Seni Vol

$69 \mathrm{NaF}$

$139 \mathrm{NaF}$ Semi Vol

$12 \mathrm{NaI}$

125 NaI Seml Vol

$8 \mathrm{NatO}$

$2 \mathrm{NaNO3}$

$4 \mathrm{NaOII}$

87 NaResin

$61 \mathrm{Ni}(\mathrm{COOH}) 2$

$17 \mathrm{Ni}(\mathrm{O} ! 1) 2$

$40 \mathrm{NiO}$

8202

$67 \mathrm{PbO}$

$28 \mathrm{PbSO} 4$

$124 \mathrm{Pd}$

$123 \mathrm{Pd}(\mathrm{OII}) 2$

112 PdN032

$110 \mathrm{PdO}$

$117 \mathrm{Pu}(\mathrm{COOH}) 4$

76 Pu02

$22 \mathrm{Rh} 02$

$79 \mathrm{Ru} 02$

23 Ru02 Semi Vol

$83 \mathrm{Ru} 04$

$88 \mathrm{SO2}$

$111 \mathrm{SiO} 2$

115 Silica Gel

$48 \mathrm{Sr}(\mathrm{COOH}) 2$

$10 \mathrm{Sr}(\mathrm{N} 03) 2$

$127 \mathrm{Sr}(0 ! 1) 2$

$30 \mathrm{SrCO3}$

46 Sro

89 SrRESIN

141 Surfactant

$92 \mathrm{Th} 02$

$107 \mathrm{TiO} 2$

119 Tritium

$93 \mathrm{l02}$

62 l.02(cooll) 2

16 V02(OII) 2

27 I $(\mathrm{COOII}) 3$

$11 \mathrm{Y}(\mathrm{NO} 03) 3$

$128 \mathrm{Y}(\mathrm{OH}) 3$

$31 \times 2(\cos ) 3$
155

PVVF

Accumulation

.5866E-08

.0000

$.1029 \mathrm{E}-08$

.0000

$.5333 \mathrm{E}-09$

.0000

.0000

$.3029 \mathrm{E}-06$

$.1199 \mathrm{E}-09$

.0000

$.1425 E-06$

$.1047 \mathrm{E}-09$

.0000

.0000

.0000

$.6466 \mathrm{E}-08$

.0000

.0000

.0000

.0000

.0000

. 1683E-08

$.6430 \mathrm{E}-09$

$.3185 E-08$

.0000

.0000

.0000

$.8931 E-05$

.0000

$.5785 \mathrm{E}-08$

$.6783 \mathrm{E}-14$

$.4671 \mathrm{E}-11$

.0000

.0000

.0000

.0000

$.2638 \mathrm{E}-07$

$.1493 \mathrm{E}-06$

.0000

.0000

$.1843 E \cdot 06$

. 1835E-09

$.8964 \mathrm{E}-08$

$.4817 \mathrm{E}-14$

. 2921E-11

.0000
Appendix H

Table 21-15

Page 152 of 173

Date 09/30/82 Rev 09 
DPSP $80-1033$

MATERIAL BALANCE TABLES

SLUDGE-ONLY FEED

STREAMS (CONT'D)STREAM NAME

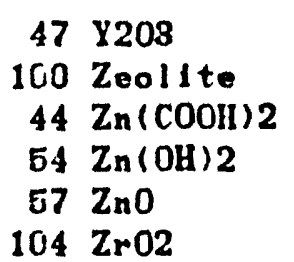

TOTAL FLOH', LB/HR

VAPOR FLOII, CFM

LIQUID FLOW, GPM DESIGN FLOW, DENSITY, LBS/FTB TEMPERATURE, DEG C PRESSURE, ATM PRESSURE, PSIG PRESSURE, MM HG PHASE

EITHALPY, PCU/HR
Appendix $H$

Table 21-15

Page 153 of 173

Date 09/30/S2 Rev 03

\begin{tabular}{|c|c|c|c|}
\hline 155 & 156 & 157 & 153 \\
\hline PVVF & SRAT Air & SNE Air & SUIET Air \\
\hline $\begin{array}{l}\text { Accumulation } \\
.0000\end{array}$ & $\begin{array}{c}\text { Inleakage } \\
.0000\end{array}$ & $\begin{array}{c}\text { Inleaknge } \\
.0000\end{array}$ & $\begin{array}{l}\text { Purge } \\
.0000\end{array}$ \\
\hline $.1686 E-0 G$ & .0000 & .0000 & .0000 \\
\hline $.2094 E-07$ & .0000 & .0000 & .0000 \\
\hline $.1580 \mathrm{E}-10$ & .0000 & .0000 & .0000 \\
\hline .0000 & .0000 & .0000 & .0000 \\
\hline $.7464 \mathrm{E}-07$ & .0000 & .0000 & .0000 \\
\hline .00 & $\begin{array}{l}63.35 \\
14.97\end{array}$ & $\begin{array}{l}63.85 \\
14.97\end{array}$ & $\begin{array}{r}220.27 \\
53.45\end{array}$ \\
\hline .0000 & .0706 & .0706 & .0706 \\
\hline 26.63 & 85.00 & 35.00 & 35.00 \\
\hline .92 & 1.00 & 1.00 & 1.00 \\
\hline-1.23 & .00 & .00 & .00 \\
\hline 696.54 & & & \\
\hline SOLID & VAPOR & VAPOR & VAPOR \\
\hline .00 & -3262.64 & -3262.64 & -11652.27 \\
\hline
\end{tabular}


Appendix H

Table 21-15

Page 154 of 173

MATERIAL BALANCE TABLES

Date 09/30/82 Rev 09

SLUI)GE-ONLY FEED

STREAM NUMBERS -

STREAM NAME

COMPONENT FLOY:S, LB/IIR
159
MFT Air
Purge

$1 \mathrm{H} 2 \mathrm{O}$

$45 \mathrm{Ag}$

116 Ag20

$134 \mathrm{AgNO3}$

$51 \mathrm{AgOH}$

74 Al $(\mathrm{OH}) 3$

77 A 1203

75 AlOOH

$106 \mathrm{~B} 203$

$9 \mathrm{Ba}(\mathrm{NO}) 2$

$95 \mathrm{BaCl} 2$

$15 \mathrm{BaO}$

$24 \mathrm{BaSO4}$

$66 \mathrm{CO}$

$37 \mathrm{CO} 2$

$142 \mathrm{CO}$ ( $\mathrm{C} 14)$

$63 \mathrm{Ca}(\mathrm{COOH}) 2$

$120 \mathrm{Ca}(\mathrm{OH}) 2$

$113 \mathrm{Ca} 3(\mathrm{PO} 4) 2$

$20 \mathrm{CaC2O4}$

$18 \mathrm{CaCO3}$

$78 \mathrm{CaF} 2$

$41 \mathrm{CaO}$

$19 \mathrm{CaSO} 4$

29 Curbon

$26 \mathrm{Co}(\mathrm{COOH}) 2$

$121 \mathrm{Co}(\mathrm{OH}) 2$

$53 \mathrm{Co}(\mathrm{Oll}) \mathrm{3}$

$59 \mathrm{CoO}$

$99 \mathrm{Cr}(\mathrm{OII}) 3$

$98 \mathrm{Cr} \cdot 203$

$42 \operatorname{Cs} 20$

137 Cs20 Semi Vol

$90 \mathrm{CsCOOH}$

$96 \mathrm{CsCl}$

$136 \mathrm{CsCl}$ Semi Vol

$8 \mathrm{CsNO3}$

88 CsResin

$122 \mathrm{Cu}(\mathrm{COOH}) 2$

$52 \mathrm{Cu}(\mathrm{Oll}) 2$

58 Cu20

$64 \mathrm{CuCOOH}$

$130 \mathrm{CuO}$

$13 \mathrm{Fe}(\mathrm{OH}) 3$

$80 \mathrm{Fe} 203$
8.738

.0000

.0000

.0000

.0000

.0000

.0000

.0000

.0000

.0000

.0000

.0000

.0000

.0000

.0000

.0000

.0000

.0000

.0000

.0000

.0000

.0000

.0000

.0000

.0000

.0000

.0000

.0000

.0000

.0000

.0000

.0000

.0000

.0000

.0000

.0000

.0000

.0000

.0000

.0000

.0000

.0000

.0000

.0000

.0000
160
OúCT Air
Inleakage

1.742

.0000

.0000

.0000

.0000

.0000

.0000

.0000

.0000

.1000

.0000

.0000

.1000

.0000

.0000

.0000

.0000

.0000

.1000

.6000

.0000

.0000

.0000

.0000

.0000

.0300

.0300

.0300

.0300

.0100

.0100

.01100

.01100

. $01: 00$

$.0 r 00$

. 0100

.01 .00

.0100

. OC 00

. 0100

.0000

. OC 00

$.0 C 00$

.0030

.0000
161

FPT Air

Inleakage

\subsection{2}

.0000

.0000

.0000

.0000

.0000

.0000

.0000

.0000

.0000

.0000

.0000

.0000

.0000

.0000

.0000

.0000

.0000

.0000

.0000

.0000

.0000

.0000

.0000

.0000

.0000

.0000

.0000

.0000

.0000

.0000

.0000

.0000

.0000

.0000

.0000

.0000

.0000

.0000

.0000

.0000

.0000

.0000

.0000

.0000
162

MWIT Air

Purge

\section{$.7477 E-01$}

.0000

.0000

.0000

.0000

.0000

.0000

.0000

.0000

.0000

.0000

.0000

.0000

.0000

.0000

.0000

.0000

.0000

.0000

.0000

.0000

.0000

.0000

.0000

.0000

.0000

.0000

.0000

.0000

.0000

.0000

.0000

.0000

.0000

.0000

.0000

.0000

.0000

.0000

.0000

.0000

.0000

.0000

.0000

.0000 
DPSP $80-1038$

MATERIAL BALANCE TABLES

SLUDGE-ONLY FEED

STREAMS (CONT'D)-

STREAM NAME

$101 \mathrm{Fe} 0$

126 Group A Semi Vo

102 GroupA

103 GroupB

$25 \mathrm{H} 2$

$133 \mathrm{H} 2 \mathrm{C} 204$

$91 \mathrm{H2O2}$

$84 \mathrm{HCOOH}$

$43 \mathrm{HCl}$

$85 \mathrm{HF}$

49 HNO3

86 HResin

$86 \mathrm{Hg}$

$135 \mathrm{HgNO} 2$

$21 \mathrm{HgO}$

97 I2

$89 \mathrm{~K} 20$

$131 \mathrm{kMnO4}$

$118 \mathrm{KNO3}$

105 La203

108 L 120

$65 \mathrm{Mg}(\mathrm{COOH}) 2$

$65 \mathrm{Mg}(\mathrm{OH}) 2$

$83 \mathrm{MgO}$

$60 \mathrm{Mn}(\mathrm{COOH}) 2$

$132 \mathrm{Mn}(\mathrm{NO}) 2$

$129 \mathrm{Mn}(\mathrm{OH}) 2$

$56 \mathrm{Mn} 0$

$14 \mathrm{MnO2}$

$81 \mathrm{~N} 2$

143 NA2CO3 (C14)

85 NO

$84 \mathrm{NO2}$

$70 \mathrm{Na}(\mathrm{HgO}(\mathrm{OH}))$

$94 \mathrm{Na} 2 \mathrm{~B} 407$

$109 \mathrm{Na}_{2} \mathrm{C}_{204}$

$5 \mathrm{Na} 2 \mathrm{CO}$

$82 \mathrm{Na} 20$

$71 \mathrm{Ne} 2 \mathrm{Pu} 02(\mathrm{OH}) 4$

$73 \mathrm{Na} 2 \mathrm{RhO} 04$

$72 \mathrm{Ne} 2 \mathrm{Ru} 04$

$6 \mathrm{Na} 2 \mathrm{SO} 4$

$68 \mathrm{NaAlO2}$

$114 \mathrm{NaBO} 2$

$140 \mathrm{NaBO2}$ Seni Vol $50 \mathrm{NaCOOH}$
159

MF'A Air

Purge

.0000

.0000

.0000

.0000

.0000

.0000

.0000

.0000

.0000

.0000

.0000

.0000

.0000

.0000

.0000

.0000

.0000

.0000

.0000

.0000

.0000

.0000

.0000

.0000

.0000

.0000

.0000

.0000

.0000

170.9

.0000

.0000

.0000

.0000

.0000

.0000

.0000

.0000

.0000

.0000

.0000

.0000

.0000

.0000

.0000

.0000
Appendix H

Table 21-15

Page 155 of 173

Date 09/30/82 Rev 09

160
OGCT Air
In lenksge
.0000
.0000
.0000
.0000
.0000
.0000
.0000
.0000
.0000
.0000
.0000
.0000
.0000
.0000

.0000

.0000

.0000

.0000

.0000

.0000

.0000

.0000

.0000

.0000

.0000

.0000

.0000

.0000

.0000

79.64

.0000

.0000

.0000

.0000

.0000

.0000

.0000

.0000

.0000

.0000

.0000

.0000

.0000

.0000

.0000

.0000
161

FPT Air

Inleakage

.0000

.0000

.0000

.0000

.0000

.0000

.0000

.0000

.0000

.0000

.0000

.0000

.0000

.0000

.0000

.0000

.0000

.0000

.0000

.0000

.0000

.0000

.0000

.0000

.0000

.0000

.0000

.0000

.0000

79.64

.0000

.0000

.0000

.0000

.0000

.0000

.0000

.0000

.0000

.0000

.0000

.0000

.0000

.0000

.0000

.0000
162

MHT.T Air

Purge

.0000

.0000

.0000

.0000

.0000

.0000

.0000

.0000

.0000

.0000

.0000

.0000

.0000

.0000

.0000

.0000

.0000

.0000

.0000

.0000

.0000

.0000

.0000

.0000

.0000

.0000

.0000

.0000

.0000

3.418

.0000

.0000

.0000

.0000

.0000

.0000

.0000

.0000

.0000

.0000

.0000

.0000

.0000

.0000

.0000

.0000 
DPSP $80-1033$

Mate:ial balaNCE TABLES

SLLDGE-0:ILY FEED

STREAMS (CONT'D)-

STRLAM NANE

$7 \mathrm{NaCl}$

$138 \mathrm{NaCl}$ Semi Vol

$60 \mathrm{NaF}$

139 NafF Semi Vol

$12 \mathrm{NaI}$

$125 \mathrm{NaI}$ Semi Vol

$3 \mathrm{Na \textrm {NO } 2}$

2 ia:

$4 \mathrm{NiOH}$

87 NaResin

$61 \mathrm{Ni}(\mathrm{COOH}) 2$

$17 \mathrm{Ni}(\mathrm{OH}) 2$

$40 \mathrm{NiO}$

8202

$67 \mathrm{PbO}$

$28 \mathrm{PbSO} 4$

$124 \mathrm{Pd}$

$123 \mathrm{Pd}(\mathrm{OH}) 2$

112 PdíO32

$110 \mathrm{PdO}$

$117 \mathrm{Pu}(\mathrm{COOH}) 4$

$76 \quad \mathrm{Pu} 02$

$22 \mathrm{PhO}_{2}$

$79 \mathrm{RuO2}$

23 Ru02 Semi Vol

$83 \mathrm{Ru} 01$

$38 \mathrm{SO2}$

111 SiO2

115 Siliea Gel

$48 \mathrm{Sr}(\mathrm{COOHI}) 2$

$10 \mathrm{Sr}(\mathrm{.103}) 2$

$127 \mathrm{Sr}(\mathrm{OII}) 2$

$30 \mathrm{SrCO3}$

$46 \mathrm{Sr} 0$

89 SRRESIN

141 Surfactant

92 ThO2

$107 \mathrm{TiO}$

119 Tritium

$93 \mathrm{VO} 2$

$62 \mathrm{VO} 2(\mathrm{COOH}) 2$

$16 \mathrm{l} 02(\mathrm{OII}) 2$

$27 \mathrm{Y}(\mathrm{COOH}) 3$

$11 \mathrm{Y}(\mathrm{NO} 03) 3$

$128 \mathrm{Y}(\mathrm{OH}) 3$

$31 \times 2(\mathrm{CO}) 3$
159

MFT Air

Purge

.0000

.0000

.0000

.0000

.0000

.0000

.0000

.0000

.0000

.0000

.0000

.0000

.0000

51.63

.0000

.0000

.0000

.0000

.0000

.0000

.0000

.0000

.0000

.0000

.0000

.0000

.0000

.0000

.0000

.0000

.0000

.0000

.0000

.0000

.0000

.0000

.0000

.0000

.0000

.0000

.0000

.0000

.0000

.0000

.0000

.0000
Append $1 \mathrm{x} \mathrm{H}$

Table 21-15

Page 156 of 173

Date 09/30/82 Rev 09

\section{0 \\ OGCT Air \\ In leakage \\ .0000}

.0000

.0000

.0000

.0000

.0000

.0000

.0000

.0000

.0000

.0000

.0000

.0000

24.06

.0000

.0000

.0000

.0000

.0000

.0000

.0000

.0000

.0000

.0000

.0000

.0000

.0000

.0000

.0000

.0000

.0000

.0000

.0000

.0000

.0000

.0000

.0000

.0000

.0000

.0000

.0000

.0000

.0000

.0000

.0000

.0000
161

FPT Air

Inleaknge

.0000

.0000

.0000

.0000

.0000

.0000

.0000

.0000

.0000

.0000

.0000

.0000

.0000

24.06

.0000

.0000

.0000

.0000

.0000

.0000

.0000

.0000

.0000

.0000

.0000

.0000

.0000

.0000

.0000

.0000

.0000

.0000

.0000

.0000

.0000

.0000

.0000

.0000

.0000

.0000

.0000

.0000

.0000

.0000

.0000

.0000
162

MUTT Air

Purge

.0000

.0000

.0000

.0000

.0000

.0000

.0000

.0000

.0000

.0000

.0000

.0000

.000 \&

1.033

.0000

.0000

.0000

.0000

.0000

.0000

.0000

.0000

.0000

.0000

.0000

.0000

.0000

.0000

.0000

.0000

.0000

.0000

.0000

.0000

.0000

.0000

.0000

.0000

.0000

.0000

.0000

.0000

.0000

.0000

.0000

.0000 
MATERIAL BALAYCE TABLES

Dato 09/30/82 Rov 09

SI.CDGE-ONLY FEED

STREAMS (CONT'D)-

STREAM NAME

$\begin{array}{rl}47 & Y 203 \\ 100 & \mathrm{Zeol} \text { ite } \\ 44 & \mathrm{Zn}(\mathrm{COOHI}) 2 \\ 54 & \mathrm{Zn}(\mathrm{OII}) 2 \\ 57 & \mathrm{Zn} 0 \\ 104 & \mathrm{Zr02}\end{array}$

TOTAL FLOH', LB/HR

VAPOR FLOW, CFM

LIQUID FI.OW, GPM

DESIGN FLOW,

DENSITY, LBS/FT3

TEMPERATURE, DEG C

PRESSURE, ATM

PRESSURE, PSIG

PRESSLRE, MM HG

PHASE

159

MFT Air

Purge

.0000

.0000

.0000

.0000

.0000

.0000

226.27

53.45

160
OGCT AIr
In leakage
.0000
.0000
.0000
.0000
.0000
.0000

105.44

24.91

161
FPT Air
Inleakage
.0000
.0000
.0000
.0000
.0000
.0000

105.44

24.91

162

MHWT Air

Purge

.0000

.0000

.0000

.0000

.0000

.0000

.0706

35.00

1.00

.00

.0706

85.00

.0706

85.00

1.00

.00

.00

4.53

1.07

ENTHALPY, PCU/HR

VAPOR

VAPOR

VAPOR

.0706

85.00

1.00

.00

$-11652.27$

$-5429.96$

$-5429.96$

VAPOR

$-233.05$ 
DPSP $80-1083$

MATERIAL BALANCE TABLES

SLUDGE-ONLY FEED

STREAM NUMBERS -

STREAM NAME

COMPONENT FLOHS, LB/HR

\section{$1 \mathrm{H} 2 \mathrm{O}$}

$45 \mathrm{Ag}$

116 Ag20

184 AgNO3

$51 \mathrm{AgOH}$

74 Al (OH) 8

77 A 1208

$75 \mathrm{AlOOH}$

106 B203

$9 \mathrm{Ba}(\mathrm{NO}) 2$

$95 \mathrm{BaCl} 12$

$15 \mathrm{BaO}$

$24 \mathrm{BaSO4}$

$66 \mathrm{CO}$

$87 \mathrm{CO2}$

$142 \mathrm{CO}(\mathrm{Cl} 14)$

$63 \mathrm{Ca}(\mathrm{COOH}) 2$

$120 \mathrm{Ca}(\mathrm{OH}) 2$

$113 \mathrm{Ca} 3(\mathrm{PO}))_{2}$

$20 \mathrm{CaC}_{\mathrm{C}} \mathrm{O} 4$

$18 \mathrm{CaCO}$

$78 \mathrm{CaF} 2$

$41 \mathrm{CaO}$

$19 \mathrm{CaSO} 4$

29 Carbon

$26 \mathrm{Co}(\mathrm{COOH}) 2$

$121 \mathrm{Co}(\mathrm{OH}) 2$

$53 \mathrm{Co}(\mathrm{OH}) 3$

$59 \mathrm{CoO}$

$99 \mathrm{Cr}(\mathrm{OH}) 3$

$98 \mathrm{Cr} 203$

$42 \mathrm{Cs} 20$

137 Cs20 Semi Vol

$90 \mathrm{CsCOOH}$

$96 \mathrm{CsCl}$

$136 \mathrm{CsCl} \mathrm{Sem} 1 \mathrm{Vol}$

8 CsNO3

88 CsResin

$122 \mathrm{Cu}(\mathrm{COOH}) 2$

$52 \mathrm{Cu}(\mathrm{OH}) 2$

$58 \mathrm{Cu} 20$

$64 \mathrm{CuCOOH}$

$130 \mathrm{CuO}$

$13 \mathrm{Fe}(\mathrm{OH}) 3$

$80 \mathrm{Fe} 203$
168

MALT AIr

Purgo

$.7477 E-01$

.0000

.0000

.0000

.0000

.0000

.0000

.0000

.0000

.0000

.0000

.0000

.0000

.0000

.0000

.0000

.0000

.0000

.0000

.0000

.0000

.0000

.0000

.0000

.0000

.0000

.0000

.0000

.0000

.0000

.0000

.0000

.0000

.0000

.0000

.0000

.0000

.0000

.0000

.0000

.0000

.0000

.0000

.0000

.0000
Appendix II

Table 21-15

Page 158 of 173

Date 09/30/82 Rev 09 
DPSP 80-1033

MATERIAL BALANCE TABLES

\section{SLUDGE-OXLY FEED}

STREAMS (CONT'D)-

STREAM NAME

$101 \mathrm{FeO}$

126 Group A Semi Vo

102 Grouph

103 Group B

$25 \mathrm{H} 2$

133 II2C204

9111202

$34 \mathrm{HCOOH}$

$43 \mathrm{HCl}$

$85 \mathrm{HF}$

49 HNO3

86 HResin

$36 \mathrm{Hg}$

135 HgNO32

$21 \mathrm{HgO}$

$97 \quad 12$

$39 \mathrm{k} 20$

$131 \mathrm{kM} / \mathrm{n} 04$

$118 \mathrm{KNO} 3$

105 La203

108 Li 20

$65 \mathrm{Mg}(\mathrm{COOH}) 2$

$55 \mathrm{Mg}(\mathrm{Oll}) 2$

$83 \mathrm{MgO}$

$60 \mathrm{Mn}(\mathrm{COOH}) 2$

$132 \mathrm{Mn}(\mathrm{N} 03) 2$

$129 \mathrm{Mn}(\mathrm{OII}) 2$

$56 \mathrm{MnO}$

$14 \mathrm{MnO} 2$

$81 \mathrm{N2}$

$143 \mathrm{NA2CO3} \mathrm{(C14)}$

$35 \mathrm{NO}$

$84 \mathrm{NO2}$

$70 \mathrm{Na}(\mathrm{HgO}(\mathrm{Oii}))$

$94 \mathrm{Na} 2 \mathrm{~B} 407$

$109 \mathrm{Na2C204}$

$5 \mathrm{Na} 2 \mathrm{CO3}$

$32 \mathrm{Na} 20$

$71 \mathrm{~N}_{3} 2 \mathrm{PuO}_{\mathrm{u}} \mathrm{O}$ (OH) 4

$73 \mathrm{Na} 2 \mathrm{RhO} 4$

$72 \mathrm{Na} 2 \mathrm{Ru} 04$

$6 \mathrm{Na} 2 \mathrm{SO} 4$

$68 \mathrm{NaAl} 102$

$114 \mathrm{NaBO2}$

$140 \mathrm{NaBO2}$ Semi Vol

$50 \mathrm{NaCOOH}$

\section{3 \\ MALT Air \\ Purge \\ 165 \\ MFT1 Air \\ Purge}

.0000

.0000

.0000

.0000

.0000

.0000

.0000

.0000

.0000

.0000

.0000

.0000

.0000

.0000

.0000

.0000

.0000

.0000

.0000

.0000

.0000

.0000

.0000

.0000

.0000

.0000

.0000

.0000

.0000

3.418

.0000

.0000

.0000

.0000

.0000

.0000

.0000

.0000

.0000

.0000

.0000

.0000

.0000

.0000

.0000

.0000
.0000

.0000

.0000

.0000

.0000

.0000

.0000

.0000

.0000

.0000

.0000

.0000

.0000

.0000

.0000

.0000

.0000

.0000

.0000

.0000

.0000

.0000

.0000

.0000

.0000

.0000

.0000

.0000

.0000

3.418

.0000

.0000

.0000

.0000

.0000

.0000

.0000

.0000

.0000

.0000

.0000

.0000

.0000

.0000

.0000

.0000
Append $\mathrm{ix} H$

Table 21-15

Page 159 of 173

Date 09/30/82 Rev 09

$\begin{array}{cc}167 & 168 \\ \text { MFT2 Air } & \text { MiT Air } \\ \text { Purge } & \text { Purge } \\ .0000 & .0000 \\ .0000 & .0000 \\ .0000 & .0000 \\ .0000 & .0000 \\ .0000 & .0000 \\ .0000 & .0000 \\ .0000 & .0000 \\ .0000 & .0000 \\ .0000 & .0000 \\ .0000 & .0000 \\ .0000 & .0000 \\ .0000 & .0000 \\ .0000 & .0000 \\ .0000 & .0000 \\ .0000 & .0000 \\ .0000 & .0000 \\ .0000 & .0000 \\ .0000 & .0000 \\ .0000 & .0000 \\ .0000 & .0000 \\ .0000 & .0000 \\ .0000 & .0000 \\ .0000 & .0000 \\ .0000 & .0000 \\ .0000 & .0000 \\ .0000 & .0000 \\ .0000 & .0000 \\ .0000 & .0000 \\ .0000 & .0000 \\ \mathbf{8 . 4 1 8} & \mathbf{8 . 4 1 8} \\ .0000 & .0000 \\ .0000 & .0000 \\ .0000 & .0000 \\ .0000 & .0000 \\ .0000 & .0000 \\ .0000 & .0000 \\ .0000 & .0000 \\ .0000 & .0000 \\ .0000 & .0000 \\ .0000 & .0000 \\ .0000 & .0000 \\ .0000 & .0000 \\ .0000 & .0000 \\ .0000 & .0000 \\ .0000 & .0000 \\ .0000 & .0000\end{array}$


DPSP 80-1033

MATERIAL BALANCE TABLES

SLUDGE-ONLY FEED

STREAMS $\left(C O N T^{\prime} D\right)=$

STREAM NAME

$7 \mathrm{NaCl}$

$188 \mathrm{NaCl} S e n l \mathrm{Vol}$

$69 \mathrm{NaF}$

139 NaF Sem 1 Vol

$12 \mathrm{NaI}$

$125 \mathrm{NaI}$ Semi Vol

$8 \mathrm{NaN02}$

$2 \mathrm{NaNO3}$

$4 \mathrm{NaOH}$

87 NaResin

$61 \mathrm{Ni}(\mathrm{COOH}) 2$

$17 \mathrm{Ni}(\mathrm{OH}) 2$

40 N10

8202

$67 \mathrm{PbO}$

$28 \mathrm{PbSO} 4$

$124 \mathrm{Pd}$

$123 \mathrm{Pd}(\mathrm{OH}) 2$

112 PdNO32

$110 \mathrm{PdO}$

$117 \mathrm{Pu}(\mathrm{COOH}) 4$

$76 \mathrm{Pu} 02$

$22 \mathrm{RhO2}$

$79 \mathrm{Ru} 02$

23 Ru02 Seni Vol

$83 \mathrm{Ru} 04$

$88 \mathrm{SO2}$

1115102

115 Silica Gel

$48 \mathrm{Sr}(\mathrm{COOH}) 2$

$10 \mathrm{Sr}(\mathrm{N} 03) 2$

$127 \mathrm{Sr}(\mathrm{Oll}) 2$

$30 \mathrm{SrCOB}$

$46 \mathrm{Sr} 0$

89 SrRESIN

141 Surfactant

92 Th02

$107 \mathrm{Ti02}$

119 Tritium.

98 U02

$62 \mathrm{VO} 2(\mathrm{COOII}) 2$

$16 \mathrm{VO2}(\mathrm{OH}) 2$

$27 \mathrm{Y}(\mathrm{COOH}) 3$

$11 \mathrm{Y}(\mathrm{NOS}) \mathrm{B}$

$128 Y(\mathrm{OH}) 3$

$81 Y 2(\mathrm{COB}) 3$
Appendix H

Table 21-15

Page 160 of 173

Date 09/30/82 Rev 03

\begin{tabular}{|c|c|c|c|}
\hline 163 & 165 & 167 & 168 \\
\hline MAWT Air & MFT1 Air & MFT2 Air & MHT Air \\
\hline Purge & Purge & Purge & Purge \\
\hline .0000 & .0000 & .0000 & .0000 \\
\hline .0000 & .0000 & .0000 & .0000 \\
\hline .0000 & .0000 & .0000 & .0000 \\
\hline .0000 & .0000 & .0000 & .0000 \\
\hline .0000 & .0000 & .0000 & .0000 \\
\hline .0000 & .0000 & .0000 & .0000 \\
\hline .0000 & .0000 & .0000 & .0000 \\
\hline 0000 & .0000 & .0000 & .0000 \\
\hline .0000 & .0000 & .0000 & .0000 \\
\hline .0000 & .0000 & .0000 & .0000 \\
\hline .0000 & .0000 & .0000 & .0000 \\
\hline .0000 & .0000 & .0000 & .0000 \\
\hline .0000 & .0000 & .0000 & .0000 \\
\hline 1.033 & 1.033 & 1.033 & 1.033 \\
\hline .0000 & .0000 & .0000 & .0000 \\
\hline .0000 & .0000 & .0000 & .0000 \\
\hline .0000 & .0000 & .0000 & .0000 \\
\hline .0000 & .0000 & .0000 & .0000 \\
\hline .0000 & .0000 & .0000 & .0000 \\
\hline .0000 & .0000 & .0000 & .0000 \\
\hline .0000 & .0000 & .0000 & .0000 \\
\hline .0000 & .0000 & .0000 & .0000 \\
\hline .0000 & .0000 & .0000 & .0000 \\
\hline .0000 & .0000 & .0000 & .0000 \\
\hline .0000 & .0000 & .0000 & .0000 \\
\hline .0000 & .0000 & .0000 & .0000 \\
\hline .0000 & .0000 & .0000 & .0000 \\
\hline .0000 & .0000 & .0000 & .0000 \\
\hline .0000 & .0000 & .0000 & .0000 \\
\hline .0000 & .0000 & .0000 & .0000 \\
\hline .0000 & .0000 & .0000 & .0000 \\
\hline .0000 & $.0000^{\circ}$ & .0000 & .0000 \\
\hline .0000 & .0000 & .0000 & .0000 \\
\hline .0000 & .0000 & .0000 & .0000 \\
\hline .0000 & .0000 & .0000 & .0000 \\
\hline .0000 & .0000 & .0000 & .0000 \\
\hline .0000 & $.000 n$ & .0000 & .0000 \\
\hline .0000 & .0000 & .0000 & .0000 \\
\hline .0000 & .0000 & .0000 & .0000 \\
\hline .0000 & .0000 & .0000 & .0000 \\
\hline .0000 & $.0000^{\circ}$ & .0000 & .0000 \\
\hline .0000 & $.0000^{\circ}$ & .0000 & .0000 \\
\hline .0000 & .0000 & .0000 & .0000 \\
\hline .0000 & .0000 & .0000 & .0000 \\
\hline .0000 & .0000 & .0000 & .0000 \\
\hline .0000 & $.0000^{\circ}$ & $.0000^{\circ}$ & .0000 \\
\hline
\end{tabular}


DPSP $80-1033$

MATERIAL BALANCE TABLES

\section{SLUDGE-ONLY FEED}

STREAMS (CONT'D) -

STREAM RAME

47 Y203

100 Zeolite

$44 \mathrm{Zn}(\mathrm{COOII}) 2$

$54 \mathrm{Zn}_{\mathrm{n}}(\mathrm{OII}) 2$

$57 \mathrm{ZnO}$

$104 \mathrm{Zr} 02$

TOTAL FLOW, LB/HR

VAPOR FLOK, CFM

LIQUID FLOW, GPM

DESIG.Y FLOW,

DENSITY, LBS/FT3

TEMPERATURE, DEG C

PRESSURE, ATM

PRESSURE, PSIG

PRESSURE, MM HG

PHASE

EYTHALPY, PCU/IIR
Appendix $H$

Table 21-15

Page 161 of 173

Date 09/30/82 Rev 09

\begin{tabular}{|c|c|c|c|}
\hline $\begin{array}{l}163 \\
\text { MAWT AIr }\end{array}$ & $\begin{array}{l}165 \\
\text { MFT1 A ir }\end{array}$ & $\begin{array}{l}167 \\
\text { MFT2 Air }\end{array}$ & $\begin{array}{l}168 \\
\text { MHT Air }\end{array}$ \\
\hline $\begin{array}{l}\text { MAHI AIr } \\
\text { Purge } \\
.0000\end{array}$ & $\begin{array}{l}\text { Purge } \\
.0000\end{array}$ & $\begin{array}{l}\text { Purge } \\
.0000\end{array}$ & $\begin{array}{l}\text { Purge } \\
.0000\end{array}$ \\
\hline .0000 & .0000 & .0000 & .0000 \\
\hline .0000 & .0000 & .0000 & .0000 \\
\hline .0000 & .0000 & .0000 & .0000 \\
\hline .0000 & .0000 & .0000 & .0000 \\
\hline .0000 & .0000 & .0000 & .0000 \\
\hline $\begin{array}{l}4.53 \\
1.07\end{array}$ & $\begin{array}{l}4.53 \\
1.07\end{array}$ & $\begin{array}{l}4.53 \\
1.07\end{array}$ & $\begin{array}{l}4.53 \\
1.07\end{array}$ \\
\hline 0706 & 0706 & .0706 & .0706 \\
\hline 100 & 100 & 1.00 & 1.00 \\
\hline .00 & .00 & .00 & .00 \\
\hline VAPOR & VAPOR & VAPOR & VAPOR \\
\hline-233.05 & -233.05 & -233.05 & -233.05 \\
\hline
\end{tabular}


DPSP $80-1033$

MATERIAL BALANCE TABLES

SLUDGE-ONLY FEED

STREAM NUMBERS -

STREAM NAME

COMPONENT FLOHS, LB/HR

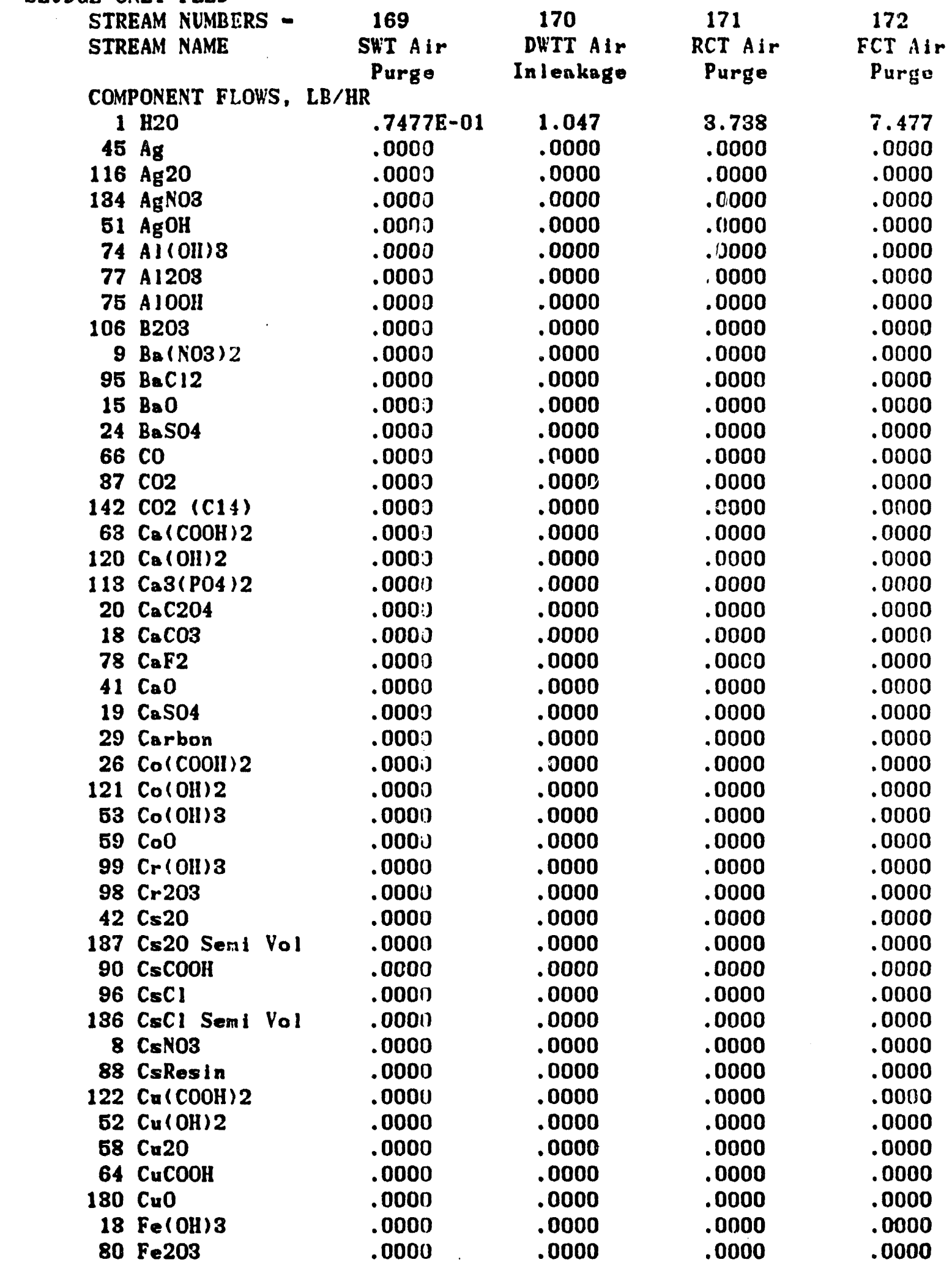

Appendix $H$

Table 21-15

Page 162 of 173

Date $09 / 30 / 82$ Rev 09 
DPSP 80-1033

MATERIAL BALAMCE TABLES

SLLDGE-ONLY FEED

STREAMS ( CONT'D)-

STREAM NAME

$101 \mathrm{FeO}$

126 Group A Semi Vo

102 GroupA

103 GroupB

$25 \mathrm{H} 2$

133 H2C2O4

9111202

84 ICOOH

$43 \mathrm{HCl}$

85 IIF

49 HNO3

86 llResin

$36 \mathrm{Hg}$

$135 \mathrm{HgN032}$

$21 \mathrm{HgO}$

9712

$39 \mathrm{~K} 20$

$131 \mathrm{kMn} 04$

$118 \mathrm{KNOO}$

$105 \mathrm{La} 203$

108 Li20

$65 \mathrm{Mg}(\mathrm{COOH}) 2$

$55 \mathrm{Mg}(\mathrm{Oill}) 2$

$33 \mathrm{MgO}$

$60 \mathrm{Mn}(\mathrm{COOH}) 2$

$132 \mathrm{Mn}(\mathrm{NO3}) 2$

$129 \mathrm{Mn}(\mathrm{OH}) 2$

$56 \mathrm{MnO}$

$14 \mathrm{MnO2}$

$81 \wedge 2$

$143 \mathrm{NA2CO3} \mathrm{(C14)}$

35 NO

84 N02

$70 \mathrm{Na}(\mathrm{HgO}(\mathrm{OH}))$

$94 \mathrm{Na} 2 \mathrm{~B} 407$

$109 \mathrm{Na} 2 \mathrm{C} 204$

$5 \mathrm{rin} 2 \mathrm{CO} 3$

32 Na20

$71 \mathrm{Na} 2 \mathrm{Pu} 02$ ( Oll) 4

$73 \mathrm{Na} 2 \mathrm{Rh} 04$

72 lia2Ru04

$6 \mathrm{Na} 2 \mathrm{SO}_{4}$

$68 \mathrm{NaAl} 102$

$114 \mathrm{NaBO2}$

$140 \mathrm{NaBO2}$ Semi Vol $50 \mathrm{NaCOOH}$
Append Ix H

Table 21-15

Page 168 of 173

Date 09/80/82 llov 09 $\begin{array}{llll}169 & 170 & 171 & 172\end{array}$

SWT AIr

Purge

.0000

.0000

.0000

.0000

.0000

.0000

.0000

.0000

.0000

.0000

.0000

.0000

.0000

.0000

.0000

.0000

.0000

.0000

.0000

.0000

.0000

.0000

.0000

.0000

.0000

.0000

.0000

.0000

.0000

3.418

.0000

.0000

.0000

.0000

.0000

.0000

.0000

.0000

.0000

.0000

.0000

.0000

.0000

.0000

.0000

.0000
DWTT Alr

In leakage

.0000

.0000

.0000

.0000

.0000

.0000

.0000

.0000

.0000

.0000

.0000

.0000

.0000

.0000

.0000

.0000

.0000

.0000

.0000

.0000

.0000

.0000

.0000

.0000

.0000

.0000

.0000

.0000

.0000

47.85

.0000

.0000

.0000

.0000

.0000

.0000

.0000

.0000

.0000

.0000

.0000

.0000

.0000

.0000

.0000

.0000
RCT Air

Purge

.0000

.0000

.0000

.0000

.0000

.0000

.0000

.0000

.0000

.0000

.0000

.0000

.0000

.0000

.0000

.0000

.0000

.0000

.0000

.0000

.0000

.0000

.0000

.0000

.0000

.0000

.0000

.0000

.0000

170.9

.0000

.0000

.0000

.0000

.0000

.0000

.0000

.0000

.0000

.0000

.0000

.0000

.0000

.0000

.0000

.0000
FCT Air

Purge .0000

.0000

.0000

.0000

.0000

.0000

.0000

.0000

.0000

.0000

.0000

.0000

.0000

.0000

.0000

.0000

.0000

.0000

.0000

.0000

.0000

.0000

.0000

.0000

.0000

.0000

.0000

.0000

.0000

$\mathbf{8 4 1 . 8}$

.0000

.0000

.0000

.0000

.0000

.0000

.0000

.0000

.0000

.0000

.0000

.0000

.0000

.0000

.0000

.0000 
DPSP $80-1033$

MATERIAL BALANCE TABLES

SLUDGE-ONLY FEED

STREAMS (CONT'D)STREAM NAME

$7 \mathrm{NaCl}$

$138 \mathrm{NaCl}$ Semi Vol

$69 \mathrm{NaF}$

139 NaF Semi Vol

$12 \mathrm{NaI}$

$125 \mathrm{NaI}$ Semi Vol

$8 \mathrm{NaNO2}$

$2 \mathrm{NaNO}$

$4 \mathrm{NaOH}$

87 NaResin

$61 \mathrm{Ni}(\mathrm{COOH}) 2$

$17 \mathrm{Ni}(\mathrm{OHI}) 2$

40 Nito

8202

$67 \mathrm{PbO}$

$28 \mathrm{PbSO} 4$

$124 \mathrm{Pd}$

$123 \mathrm{Pd}(\mathrm{OH}) 2$

112 PdNO32

$110 \mathrm{PdO}$

$117 \mathrm{Pu}(\mathrm{COOH}) 4$

$\begin{array}{lll}76 & \mathrm{Pu} 02\end{array}$

$22 \mathrm{RhO2}$

$79 \mathrm{Ru} 02$

23 Ru02 Senl Vol

83 Ru04

$38 \mathrm{SO} 2$

$111 \mathrm{SiO}$

115 Silica Gel

$48 \mathrm{Sr}(\mathrm{COOH}) 2$

$10 \mathrm{Sr}(\mathrm{NO3}) 2$

$127 \mathrm{Sr}(\mathrm{OHI}) 2$

$30 \mathrm{SrCO}$

46 Sro

89 SRRESIN

141 Surfactant

$92 \mathrm{ThO2}$

107 T102

119 Tritium

93 V02

$62 \mathrm{VO2}(\mathrm{COOH}) 2$

$16 \mathrm{VO2}(\mathrm{OH}) 2$

$27 \mathrm{Y}(\mathrm{COOH}) \mathrm{s}$

$11 \mathrm{Y}(\mathrm{N} 03) 8$

$128 Y(\mathrm{OH}) 8$

$81 \mathrm{Y} 2(\mathrm{CO}) 3$
169

SWT AIr

Purgo

.0003

.0003

.0003

$.000)$

.000 J

.0003

$.000 J$

.0000

$.000 \mathrm{~J}$

.0003

.000 J

$.000 \mathrm{~J}$

$.000 J$

1.033

$.000 \mathrm{~J}$

.0003

.0003

$.000 J$

$.000 \mathrm{~J}$

.000 J

.0003

.0001

.0003

.0001

.0003

.0001

.00011

.000 !)

.00010

.0000

.0000

.000 !

.0000

.0000

.0000

.0000

.0000

.0000

.0000

.0000

.0000

$.000(1)$

.0000

.0000

.0000

.0000
Appendix II

Table 21-15

Page 164 of 173

Date 09/30/82 Rev 09 
MATERIAL BALANCE TABLES

\section{SLLDGE-ONLY FEED}

STREAMS (CONT'D) STREAM NAME

$47 \lcm{1203}$

$100 \mathrm{Zeol} 1 \mathrm{t}$

$44 \mathrm{Zn}(\mathrm{COOH}) 2$

$54 \mathrm{Zn}(\mathrm{Oll}) 2$

$57 \mathrm{ZnO}$

$104 \mathrm{Zr} 02$

TOTAL FLOW, LB/IIR

VAPOR FLOH, CFM

LIQUID FLOH, GPM

DESIGN FLOH,

DENSITY, LBS/FT3

TEYPERATURE, DEG C

PRESSURE, ATM

PRESSURE, PSIG

PRESSURE, MA HG

PIIASE

ENTIIALPY, PCU/HR
169

SWI Air

Purge

.0000

.0000

.0000

.0000

.0000

.0000

4.53

1.07

.0706

85.00

1.00

.00

VAPOR

$-233.05$

\section{0}

DU'TT Alr

Inlenkage

.0000

.0000

.0000

.0000

.0000

.0000

63.85

14.97
.0703
85.0 '
1.00
.00

VAPO:

$-3262.64$
171

RCT Alr

Purge

.0000

.0000

.0000

.0000

.0000

.0000

226.27

53.46

.0706
85.00

1.00

.00

VAPOR

$-11652.27$
172

FCT Air

Purge

.0000

.0000

.0000

.0000

.0000

.0000

452.53

106.90

.0706

85.00

1.00

.00

VAPOR

$-23304.54$ 
DPSP $80-1033$

MATERIAL BALANCE TABLES

\section{SLUDGE-ONLY FEED}

STREAM NUMBERS -

STREAM NAME

COMPONENT FLOHS, LB/IIR

$1 \mathrm{H} 2 \mathrm{O}$

$45 \mathrm{Ag}$

116 Ag20

134 AgNO3

$51 \mathrm{AgOH}$

$74 \mathrm{Al}(\mathrm{OH}) 3$

77 A1203

75 Al0011

$106 \mathrm{~B} 203$

$9 \mathrm{Br}(\mathrm{N03}) 2$

$95 \mathrm{BaCl} 12$

$15 \mathrm{BaO}$

$24 \mathrm{BnS04}$

$66 \mathrm{CO}$

$37 \mathrm{CO2}$

$142 \operatorname{CO2}(\mathrm{C11})$

$63 \mathrm{Ca}_{\mathrm{B}}(\mathrm{COOH}) 2$

$120 \mathrm{CA}_{\mathrm{B}}(\mathrm{OH}) 2$

$113 \mathrm{Ca} 3(\mathrm{PO}) 2$

$20 \mathrm{CaC2O4}_{2}$

$18 \mathrm{CaCO}_{\mathrm{C}}$

$78 \mathrm{CaF2}$

$41 \mathrm{CaO}$

$19 \mathrm{CaSO4}$

29 Carbon

$26 \mathrm{Co}(\mathrm{COOH}) 2$

$121 \mathrm{Co}(\mathrm{OH}) 2$

$63 \mathrm{Co}(\mathrm{OH}) 3$

$59 \mathrm{CoO}$

$99 \mathrm{Cr}(\mathrm{OH}) 3$

98 Cr203

42 Cs20

137 Cs20 Seml Vol

$90 \mathrm{CsCOOH}$

$96 \mathrm{CsCl}$

$136 \mathrm{CsCl}$ Semi Vol

8 CsNO3

88 CsResin

$122 \mathrm{Cu}(\mathrm{COOH}) 2$

$52 \mathrm{Cu}(\mathrm{OH}) 2$

$58 \mathrm{Cu} 20$

$64 \mathrm{CuCOON}$

$180 \mathrm{CuO}$

$18 \mathrm{Fe}(\mathrm{OH}) \mathrm{s}$

80 Fe203
178

SFIIT Air Purgo

8.739

.0000

.0000

.0000

.0000

.0000

.0000

.0000

.0000

.0000

.0000

.0000

.0000

.0000

.0000

.0000

.0000

.0000

.0000

.0000

.0000

.0000

.0000

.0000

.0000

.0000

.0000

.0000

.0000

.0000

.0000

.0000

.0000

.0000

.0000

.0000

.0000

.0000

.0000

.0000

.0000

.0000

.0000

.0000

.0000
Appendix H

Table 21-15

Page 166 of 173

Dato 09/30/82 Rev 03

174

Off-Gas to SWDBF

175

176

FPT Cndnser

DUPF Sludre

Condensate

Slurry Feed

128.0

.0000

.0000

.0000

$.1861 E-06$

$.1169 \mathrm{E}-03$

.0000

.0000

$.2011 E-03$

$.1536 E-11$

.0000

.0000

$.1388 \mathrm{E}-05$

5.598

13.09

$.2189 \mathrm{E}-23$

$.4816 \mathrm{E}-04$

.0000

$.8460 \mathrm{E}-05$

$.3742 E-05$

.0000

$.9355 \mathrm{E}-06$

.0000

$.4395 \mathrm{E}-05$

$.9355 \mathrm{E}-06$

$.7604 \mathrm{E}-06$

.0000

.0000

.0000

$.8556 \mathrm{E}-05$

.0000

$.1402 \mathrm{E}-10$

.0000

.0000

84.06

.0000

300.6

.0000

.0000

.0000

.0000

.0000

.1862E-21

.1170E-18

$.2244 \mathrm{E}-01$

.0000

.0000

14.03

.0000

.0000

$.2012 E-18 \quad .1748$

$.1536 \mathrm{E}-26$

$.1843 E-06$

.0000

.0000

.0000

.0000

$.1389 \mathrm{E}-20$

.1666

$.5738 \mathrm{E}-05$

.2053E- 10

$.5125 E-03$

16:?2E-U0

$.8570 \mathrm{E}-28$

.0000

$.4817 \mathrm{E}-19$

.0000

.0000

$.3460 \mathrm{E}-20$

. 1295E-01

$.3742 E-20$

.0000

$.9356 \mathrm{E}-21$

.0000

.4151

.4490

4.428

.1122

.0000

$.4396 \mathrm{E}-20$

.5274

$.935 G \mathrm{E}-21$

.1122

.7606E-09

.0000

.0000

.0000

.0000

$.2239 E-03$

$.6708 \mathrm{E}-01$

.0000

.4267

.0000

.0000

$.1402 \mathrm{E}-25$

. 1682E-05

.0000

.0000

$.9019 \mathrm{E}-11$

$.5066 \mathrm{E}-05$

.0000

$.1082 E-05$

$.9021 E-26$

.0000

$.9853 \mathrm{E}-07$

.0000

$.5066 \mathrm{E}-10$

$.9855 \mathrm{E}-22$

$.1182 \mathrm{E}-01$

.0000

$.1625 \mathrm{E}-20$

.0000

.0000

.0000

.0000

.0000

1288

.0000

.0000

.0000

.0000

.2831E-18

.0000

83.96

.0000 . 
DPSP $80-1033$

MATERIAL BALANCE TABLES SLLDGE-ONLY FEED STIREAMS (CONT'D):STREAM NAME

101 Feo
126 Group A Semi Vo

102 GroupA

103 Group B

$25 \mathrm{H} 2$

$133 \mathrm{H} 2 \mathrm{C} 204$

9111202

34 HCOOII

$43 \mathrm{HCl}$

$85 \mathrm{HF}$

49 IINO3

86 llResin

$36 \mathrm{Hg}$

$135 \mathrm{Hg}$. 032

$21 \mathrm{HgO}$

$97 \quad 12$

39 K20

$131 \mathrm{KMnO4}$

118 KNO3

$105 \operatorname{La} 203$

108 Li20

$65 \mathrm{Mg}(\mathrm{COOH}) 2$

$55 \mathrm{Mg}(\mathrm{Oll}) 2$

$33 \mathrm{MgO}$

$60 \mathrm{Mn}(\mathrm{COOH}) 2$

$132 \mathrm{Mn}(\mathrm{NO3}) 2$

$120 \mathrm{Mn}(\mathrm{OHI}) 2$

$56 \mathrm{MnO}$

$14 \mathrm{MnO2}$

81 N2

$143 \mathrm{NA2CO3} \mathrm{(C14)}$

85 No

$84 \mathrm{~N} 02$

$70 \mathrm{NB}\left(\mathrm{Hg}_{\mathrm{O}} \mathrm{O}(\mathrm{OII})\right)$

$94 \mathrm{Nin} 2 \mathrm{~B} 407$

$109 \mathrm{Nn} 2 \mathrm{C} 204$

$5 \mathrm{in} 2 \mathrm{CO3}$

32 in 20

$71 \mathrm{Ni2PuO2(OH)4}$

$73 \mathrm{Nn} 2 \mathrm{Rl}_{1} \mathrm{O4}$

$72 \mathrm{Na} 2 \mathrm{RuO}_{4}$

$6 \mathrm{Nn} 2 \mathrm{SOA}$

$68 \mathrm{NaA} 102$

$114 \mathrm{NnBO2}$

140 NnB02 Semi Vol

$50 \mathrm{NaCOOH}$
178

SFIIT Air

Purge

.0000

.0000

.0000

.0000

.0000

.0000

.0000

.0000

.0000

.0000

.0000

.0000

.0000

.0000

.0000

.0000

.0000

.0000

.0000

.0000

.0000

.0000

.0000

.0000

.0000

.0000

.0000

.0000

.0000

170.9

.0000

.0000

.0000

.0000

.0000

.0000

.0000

.0000

.0000

.0000

.0000

.0000

.0000

.0000

.0000

.0000
Appendix II

Table 21-15

Page 167 of 173

Date 09/30/82 Rev 09

174

Off-Gas

to SWDBF

.0000

$.1547 E-03$

$.2605 E-05$

$.8315 \mathrm{E}-05$

.8657

.0000

.0000

.0000

.0000

.0000

.0000

.0000

.0000

.0000

$.7688 E-0$ !

$.9392 E-0.4$

.0000

.0000

$.7642 E-03$

$.6819 \mathrm{E}-03$

$.7799 \mathrm{E}-0.4$

$.9168 \mathrm{E}-05$

.0000

$.2733 E-04$

$.8178 E-0.4$

.0000

.0000

.0000

.0000

1004.

.0000

1.175

.1886

$.5864 \mathrm{E}-08$

$.1439 E-0 E$

.3066E-0E

.0000

. 2869E-0

. 2378E-12

$.4889 E-10$

$.4771 E-05$

$.9675 E-0 G$

. 2378E-05

.0000

.0000

$.6292 E-04$
175

FPT Cndnser

Condensa to

.0000

. 1547E- 17

.2606E-20

$.8317 E-20$

.3662E-06

.0000

.0000

.0000

.0000

.0000

.0000

.0000

.0000

.0000

$.7688 \mathrm{E}-18$

.0000

.0000

.0000

$.7644 \mathrm{E}-23$

$.6820 \mathrm{E}-20$

.7800E-13

$.9169 \mathrm{E}-20$

.0000

$.2734 \mathrm{E}-19$

$.8175 E-19$

.0000

.0000

.0000

.0000

. 1205E-02

.0000

.3121E-05

$.7579 \mathrm{E}-02$

$.5865 \mathrm{E}-23$

$.1439 \mathrm{E}-18$

$.3067 E-23$

.0000

.2870E-18

.2378E-27

$.4890 \mathrm{E}-25$

$.4772 E-24$

$.9676 \mathrm{E}-21$

.2378E-20

.0000

.0000

$.6293 \mathrm{E}-19$
176

DWPF Sludge

Slurry Foed

.0000

.0000

.3126

.9977

.3091E-09

.0000

.0000

.0000

.0000

.0000

.0000

.0000

.0000

.0000

1.769

.0000

.0000

.0000

$.9170 \mathrm{E}-03$

.3219E-02

$.6757 \mathrm{E}-01$

.0000

.5612

. 1998E-01

.0000

.0000

.1971

.0000

5.688

.5976E-04

.2517E-09

.2608E-09

$.8871 E-04$

$.7036 \mathrm{E}-03$

$.4034 \mathrm{E}-03$

$.8679 \mathrm{E}-03$

.8666E-01

.2490

. 2853E-07

$.6866 \mathrm{E}-05$

.5724E-04

.1161

.2858

.0000

.0000

. 1867E-01 
DPSP 80-1033

MATERIAL BALANCE TABLES

SLUDGE-ONLY FEED

STREAMS (CONT'D)-

STREAM NAME

$7 \mathrm{NaCl}$

$188 \mathrm{NaCl}$ Semi $\mathrm{Vol}$

$69 \mathrm{NaF}$

139 NaF Semi Vol

$12 \mathrm{NaI}$

$125 \mathrm{NaI}$ Semi Vol

$8 \mathrm{NaNO2}$

$2 \mathrm{NnNO3}$

$4 \mathrm{NaOH}$

87 NaResin

$61 \mathrm{Ni}(\mathrm{COOH}) 2$

$17 \mathrm{Ni}(\mathrm{OH}) 2$

$40 \mathrm{~N} 10$

8202

$67 \mathrm{PbO}$

$28 \mathrm{PbSO} 04$

$124 \mathrm{Pd}$

$123 \mathrm{Pd}(\mathrm{OHI}) 2$

112 PdNO32

$110 \mathrm{PdJ}$

$117 \mathrm{Pu}(\mathrm{COOH}) 4$

$76 \mathrm{Pu} 02$

$22 \mathrm{RhO2}$

$79 \mathrm{RuO2}$

23 RuO2 Seml Vol

83 Ru04

$88 \mathrm{SO2}$

$111 \mathrm{SiO2}$

115 Silica Gel

$48 \mathrm{Sr}(\mathrm{COOH}) 2$

$10 \mathrm{Sr}(\mathrm{NOB}) 2$

$127 \mathrm{Sr}(\mathrm{OH}) 2$

$30 \mathrm{SrCO} 3$

$46 \mathrm{Sr} 0$

89 SrRESIN

141 Surfactant

92 Th02

$107 \mathrm{TiO}$

119 Tritium

$93 \mathrm{VO2}$

$62 \mathrm{VO2}(\mathrm{COOH}) 2$

$16 \mathrm{VO2}(\mathrm{OH}) 2$

$27 \mathrm{Y}(\mathrm{COOH}) 3$

$11 \mathrm{Y}(\mathrm{NO3}) 3$

$128 \mathrm{Y}(\mathrm{OH}) 3$

$81 Y_{2}(\mathrm{CO}) 3$
173

SFIIT Air

Purgo

.0000

.0000

.0000

.0000

.0000

.0000

.0000

.0000

.0000

.0000

.0000

.0000

.0000

51.63

. 0 no?

.0000

.0003

.0003

.0000

.0003

.0003

$.000 \mathrm{~J}$

.0003

.0000

.000 .

.0003

.0003

.0000

.0000

.0000

.0000

.0003

.0000

.0000

.0000

.0000

.0000

.0000

.0000

.0000

.0000

.0000

.0000

.0000

.0000

.0000
Appendix $\mathrm{H}$

Table 21-15

Page 168 of 173

Date 09/30/82 Rev CO

174

off-Gns

to SWDBF

$.9645 \mathrm{E}-06$

. 1144E-02

$.2504 E-04$

$.9010 \mathrm{E}-03$

$.9340 \mathrm{E}-07$

$.1098 \mathrm{E}-03$

.0000

$.3108 E-04$

.0000

.0000

$.2882 E-04$

.0000

.0000

803.8

.0000

$.1307 E-05$

.0000

.0000

.0000

.0000

.0000

$.3400 E-06$

$.1299 \mathrm{E}-06$

$.6364 \mathrm{E}-06$

$.7568 \mathrm{E}-04$

.0000

.3755

$.8468 \mathrm{E}-03$

.0000

$.1170 \mathrm{E}-05$

$.1371 \mathrm{E}-11$

.0000

.0000

.0000

.0000

.0000

. 5331E-05

$.1864 \mathrm{E}-04$

$.4978 E-10$

.0000

$.8728 \mathrm{E}-04$

.0000

$.8019 E-06$

$.9734 E-12$

.0000

.0000
175

FPT Cndnser

Condensate

$.9646 \mathrm{E}-21$

$.1144 \mathrm{E}-16$

$.2504 E-19$

$.9010 \mathrm{E}-17$

$.9342 \mathrm{E}-22$

$.1098 \mathrm{E}-17$

.0000

$.3108 E-10$

.0000

.0000

.2883 E- 19

.0000

.0000

$.7186 \mathrm{E}-03$

.0000

. 1307E-20

.0000

.0000

.0000

.0000

.0000

.3401E-21

. 1299E-21

$.6365 \mathrm{E}-21$

$.7563 \mathrm{E}-18$

.0000

$.1358 \mathrm{E}-05$

$.8470 \mathrm{E}-18$

.0000

$.1171 \mathrm{E}-20$

$.1371 \mathrm{E}-26$

.0000

.0000

.0000

.0000

.0000

.5332E-20

$.1364 \mathrm{E}-19$

$.1320 \mathrm{E}-10$

.0000

$.3729 \mathrm{E}-19$

.0000

$.8021 E-21$

$.9735 \mathrm{E}-27$

.0000

.0000
176

DWPE Sludge

Slurry Feed

.1157

.0000

$.6052 E-03$

.0000

$.1121 \mathrm{E}-01$

.0000

.2073

8.650

4.197

.0000

.0000

2.156

.0000

.3447E-0.4

.0000

.1568

.0000

.0000

.0000

.0000

.0000

$.4080 \mathrm{E}-01$

. 1559E-01

$.7636 \mathrm{E}-01$

.0000

.0000

$.1185 \mathrm{E}-10$

7.240

.0000

.0000

$.1645 \mathrm{E}-06$

$.8783 E-03$

.1162

.0000

.0000

.0000

.6396

$.6210 \mathrm{E}-02$

.7334E-09

.0000

.0000

8.777

.0000

$.1168 \mathrm{E}-06$

$.2365 \mathrm{E}-03$

$.7657 \mathrm{E}-01$ 
DPSP $80-1033$

MATERIAL BALANCE TABLES SL.CDGE-OKLY FEED STRIAMS (CONT'D)STREAM NAME

$\begin{array}{rl}47 & Y 203 \\ 100 & \mathrm{Zcol} \text { ite } \\ 44 & \mathrm{Zn}(\text { COOII) } 2 \\ 54 & \mathrm{Zn}(0 \mathrm{OI}) 2 \\ 57 & \mathrm{ZnO} \\ 104 & \mathrm{Zr} 02\end{array}$

TOTAL FIOH, LB/HR VAPOR FLOH', CFM LIQUID FLOW, GPY DESIGN FLOW, DENSITY, LBS/FT3 TEMPERITLRE, DEG C PRESSLIRE, ATM PRESSURE, PSIG PRESSURE, MII HG PIIISE

ENTHALPY, PCU/IIR

\begin{tabular}{|c|c|c|c|}
\hline 173 & 174 & 175 & 176 \\
\hline SFIIT Air & Off-Gas & FPT Cndnser & DWPF Sludge \\
\hline Purge & to SHDBF & Condensa to & Slurry Feed \\
\hline .0000 & .0000 & .0000 & .0000 \\
\hline .0000 & $.8408 E-04$ & $.8408 E-19$ & 4.089 \\
\hline .0000 & $.4237 E-05$ & $.4238 E-20$ & .0000 \\
\hline .0000 & .0000 & .0000 & .8251 \\
\hline .0000 & .0000 & .0000 & .0000 \\
\hline .0000 & $.6819 \mathrm{E}-05$ & $.6820 \mathrm{E}-20$ & $.3219 E-02$ \\
\hline \multirow{3}{*}{$\begin{array}{r}226.27 \\
53.45\end{array}$} & 1456.43 & 84.07 & 485.87 \\
\hline & 896.81 & & \\
\hline & & .17 & .85 \\
\hline .0706 & .0612 & 62.4316 & 71.0612 \\
\hline 85.00 & 51.29 & 28.00 & 60.00 \\
\hline 1.00 & .95 & .88 & 1.00 \\
\hline \multirow[t]{2}{*}{.00} & -.74 & -1.75 & .00 \\
\hline & 721.85 & 669.56 & \\
\hline VAPOR & VAPOR & LIQUID & LIQUID \\
\hline-11652.27 & 8296.12 & 2888.96 & 25051.29 \\
\hline
\end{tabular}

Appendix H

Table 21-15

Page 169 of 178

Date 09/30/82 Rev 09 
DPSP $80-1033$

MATERIAL BALANCE TABLES

SLUDGE-ONLY FEED

STREAM NUMBERS -

STREAM NAME
Appendix H

Table 21-15

Page 170 of 175

Date $09 / 80 / 82$ Rev 09

COMPONENT FLOHS, LB/HR

\begin{tabular}{|c|c|c|}
\hline 1 & & nח \\
\hline 45 & $\mathrm{Ag}$ & - volu \\
\hline 116 & Ag20 & .0000 \\
\hline 134 & AgNO3 & .0000 \\
\hline 51 & $\mathrm{AgOH}$ & .0000 \\
\hline 74 & All(OH) 3 & .0000 \\
\hline 77 & A1203 & .0000 \\
\hline 75 & AlOOH & .0000 \\
\hline 106 & B203 & .0000 \\
\hline 9 & $\mathrm{Ba}(\mathrm{NO3}) 2$ & .0000 \\
\hline 95 & $\mathrm{BaCl2}$ & .0000 \\
\hline 15 & $\mathrm{BaO}$ & .0000 \\
\hline 24 & $\mathrm{BaSO4}$ & .0000 \\
\hline 66 & CO & .0000 \\
\hline 37 & $\mathrm{CO} 2$ & .0000 \\
\hline 142 & $\operatorname{co2}(C 14)$ & .0000 \\
\hline 68 & $\mathrm{Ca}(\mathrm{COOH}) 2$ & .0000 \\
\hline 120 & $\mathrm{Ca}(\mathrm{OH}) 2$ & .0000 \\
\hline 118 & Са3(P04)2 & .0000 \\
\hline 20 & CaC204 & .0000 \\
\hline 18 & $\mathrm{CaCOB}$ & .0000 \\
\hline 78 & CaF2 & .0000 \\
\hline 41 & $\mathrm{CaO}$ & .0000 \\
\hline 19 & $\mathrm{CaSO4}$ & .0000 \\
\hline 29 & Carbon & .0000 \\
\hline 26 & $\mathrm{Co}(\mathrm{COOH}) 2$ & .0000 \\
\hline 121 & $\mathrm{Co}(\mathrm{OH}) 2$ & .0000 \\
\hline 53 & $\mathrm{Co}(\mathrm{OlI}) 3$ & .0000 \\
\hline 59 & $\mathrm{CoO}$ & .0000 \\
\hline 99 & $\mathrm{Cr}(\mathrm{OH}) 3$ & .0000 \\
\hline 98 & Cr203 & .0000 \\
\hline 42 & $\operatorname{Cs} 20$ & .0000 \\
\hline 187 & Cs20 Semi Vol & .0000 \\
\hline 90 & $\mathrm{CsCOOH}$ & .0000 \\
\hline 96 & $\mathrm{CsCl}$ & .0000 \\
\hline 186 & CsCl Semi Vol & .0000 \\
\hline & CsNO3 & .0000 \\
\hline 88 & CsResin & .0000 \\
\hline 122 & $\mathrm{Cu}(\mathrm{COOH}) 2$ & .0000 \\
\hline 62 & $\mathrm{Cu}(\mathrm{OII}) 2$ & .0000 \\
\hline 58 & Cu20 & .0000 \\
\hline 64 & $\mathrm{CuCOOH}$ & .0000 \\
\hline 130 & $\mathrm{CuO}$ & .0090 \\
\hline 13 & Fe(OHI) 8 & - UUUU \\
\hline & Fe203 & .0000 \\
\hline
\end{tabular}

177

MVS Vac Pump

Exhalist

0000

OOCO

.0000

.0000

0000

.0000

.0000

0000

0000

0000

0000

.0000

0000

0000

0000

.0000

0000

0000

0000

0000

0000

0000

0090

0000 
MATERIAL BALANCE TABLES

SLLDGE-ONLY FEED

STREAMS (CONT'D)-

STREAM NAME

177

MVS Vac Pump

$101 \mathrm{Fe} 0$

Exhaust

126 Group A Semi Vo

.0000

102 GroupA

103 Group B

$25 \mathrm{H} 2$

$133 \mathrm{H} 2 \mathrm{C} 204$

0000

.0000

.0000

.0000

.0000

$91 \mathrm{H2O2}$

.0000

34 HCOOII

.0000

$43 \mathrm{HCl}$

$85 \mathrm{IIF}$

.0000

49 HNO3

S6 HResin

.0000

.0000

.0000

$86 \mathrm{Hg}$

135 hg.Y032

.0000

.0000

$21 \mathrm{HgO}$

.0000

$\begin{array}{lll}97 & 12\end{array}$

39 K20

.0000

.0000

$131 \mathrm{KMnO4}$

.0000

$118 \mathrm{KNO3}$

.0000

105 La203

.0000

108 Li20

.0000

$65 \mathrm{M}_{5}(\mathrm{COOH}) 2$

.0000

$55 \mathrm{Mg}(\mathrm{OII}) 2$

$83 \mathrm{MgO}$

.0000

.0000

$60 \mathrm{Mn}(\mathrm{COOH}) 2$

.0000

$132 \mathrm{Mn}(\mathrm{NO}) 2$

.0000

$120 \mathrm{Mn}(\mathrm{OII}) 2$

.0000

$56 \mathrm{MnO}$

$14 \mathrm{MnO2}$

.0000

81 N2

.0000

$143 \mathrm{NA2CO3} \mathrm{(C14)}$

.0000

.0000

35 Nũ

.0000

84 N02

.0000

$70 \mathrm{Na}$ ( $\mathrm{HgO}(\mathrm{OII})$ )

.0000

$94 \mathrm{Na} 2 \mathrm{~B} 407$

.0000

$109 \mathrm{Na2C204}$

.0000

$5 \mathrm{Nin} 2 \mathrm{CO}$

.0000

$32 \quad \mathrm{~N} 20$

.0000

$71 \mathrm{Na} 2 \mathrm{Pu}_{02}(\mathrm{OH}) 4 \quad .0000$

$73 \mathrm{Na2Rh04}$

.0000

$72 \mathrm{Na} 2 \mathrm{RuO} 04$

.0000

$6 \mathrm{Nin} 2 \mathrm{SO4}$

.0000

$68 \mathrm{NaAlO2}$

.0000

$114 \mathrm{NaBO2}$

.0000

$140 \mathrm{NaBO2}$ Semi Vol

.0000

$50 \mathrm{NaCOOII}$

.0000 
MATERIAL BALANCE TABLES

\section{SLUDGE-ONLY FEED}

STREAMS ( CONT'D)-

STREAM NAME

177

MVS Vac Pump

$7 \mathrm{NaCl}$

Exhaust

$.00 C 0$

$138 \mathrm{NaCl}$ Seni Vol .00Co

$69 \mathrm{NaF} \quad .0000$

139 NaF Semi Vol $\quad .0000$

$12 \mathrm{NaI} \quad .0000$

$125 \mathrm{NaI}$ Semi Vol $\quad .0000$

$8 \mathrm{NaNO2} \quad .0000$

$2 \mathrm{NaNO3} \quad .0000$

$4 \mathrm{NaOH} \quad .0000$

87 NaResin $\quad .0000$

$61 \mathrm{Ni}(\mathrm{COOH}) 2 \quad .0000$

$17 \mathrm{Ni}(\mathrm{OH}) 2 \quad .0000$

$40 \mathrm{NiO} \quad .0000$

$8202 \quad .0000$

$67 \mathrm{PbO} \quad .0000$

$28 \mathrm{PbSO4} \quad .0000$

$124 \mathrm{Pd} \quad .0000$

$123 \mathrm{Pd}(\mathrm{OH}) 2 \quad .0000$

112 PdNO32 .0000

$110 \mathrm{PdO} \quad .0000$

$117 \mathrm{Pu}(\mathrm{COOH}) 4 \quad .0000$

$76 \mathrm{Pu} 02 \quad .0000$

$22 \mathrm{Rh} 02 \quad .0000$

79 Ru02 $\quad 0000$

23 Ru02 Semi Vol $\quad .0000$

$83 \mathrm{Ru} 04 \quad 0000$

$38502 \quad .0000$

$1115102 \quad .0000$

115 Silica Gel $\quad 0000$

$48 \mathrm{Sr}$ (COOH)2 $\quad .0000$

$10 \mathrm{Sr}(\mathrm{NO3}) 2 \quad .0000$

$127 \mathrm{Sr}(011) 2 \quad .0000$

$30 \mathrm{SrC03} \quad .0000$

$46 \mathrm{Sr} 0 \quad .0000$

89 SrRESIN $\quad .0000$

141 Surfactant $\quad .0000$

$92 \mathrm{Th02} \quad .0000$

$107 \mathrm{TiO2} \quad .0000$

119 Tritium $\quad .0000$

$93 \mathrm{U02} \quad .0000$

62 U02(COOIl) $2 \quad .0000$

$16 \mathrm{VO2}(\mathrm{OH}) 2 \quad .0000$

$27 \mathrm{Y}(\mathrm{COOH}) 3 \quad .0000$

$11 Y(\mathrm{NO3}) 3 \quad \quad .0000$

$128 \mathrm{Y}(\mathrm{OH}) 3 \quad .0000$

$81 \mathrm{Y} 2(\mathrm{COB}) 3 \quad .0000$ 
DPSP 80-1033 5

MiTERIAL BALANCE TABLES

SI.LDGE-ONLY FIED

STREAMS (CONT'D)-

STREAM NAME

$47 Y 203$

100 Zeolite

$44 \mathrm{Zn}(\mathrm{COOH}) 2$

$54 \mathrm{Zn}(\mathrm{OII}) 2$

$57 \mathrm{ZnO}$

$104 \mathrm{Zr} 02$

TOTAL FLOH, LB/HR

VAPOR FLOH, CFM

LIOLID FLOW, GPM

DESIGN FLOW,

DENSITY, LES/FT3

TEMPERATURE, DEG C

PRESSURE, ATM

PRESSURE, PSIG

PRESSURE, MM HG

PHASE

ENTHALPY, PCU/HR
Appendix $\mathrm{H}$

Table 21-15

Page 173 of 17:3

Date 09/30/82 Rev 09
177

MVS Vac Pump

Exhaust

.0000

.0000

.0000

.0000

.0000

.0000

.00

.00

.0000

88.00

.99

$-.07$

756.20

VAPOR

.00 


\author{
DPSP 80-1033 \\ MATERIAL BALANCE TABLES \\ SLUDGE-SUPERNATE FEED \\ STREAMS
}

Append IX H

Table 21-16

Page 1 of 173

Date 09/30/82 Rev 09

DESCRIPTION

PAGE

\begin{tabular}{|c|c|c|c|c|c|c|c|c|c|c|c|c|c|c|c|c|c|}
\hline $\begin{array}{l}\text { STREAM } \\
\text { STREAM }\end{array}$ & $\begin{array}{l}\text { NUMBERS } \\
\text { NUMBERS }\end{array}$ & 5, & $\begin{array}{l}2, \\
6,\end{array}$ & $\because$ & 8 & - & - & $\bullet$ & - & $\dot{\circ}$ & - & $\bullet$ & - & • & - & . & 6 \\
\hline $\begin{array}{l}\text { STREAM } \\
\text { STREAM }\end{array}$ & NUMBERS & 9. & 10, & & 12 & - & - & - & - & • & • & • & • & - & • & - & 10 \\
\hline $\begin{array}{l}\text { TREAM } \\
\text { IREAM }\end{array}$ & NUMBERS & 13, & 14, & & 16 & - & - & - & - & • & - & • & • & • & - & • & \\
\hline $\begin{array}{l}\text { TREAM } \\
\text { TREAM }\end{array}$ & NUMBERS & 17. & 18. & & 24 & & - & • & • & • & • & - & • & • & • & • & \\
\hline $\begin{array}{l}\text { TREAM } \\
\text { IREAM }\end{array}$ & $\begin{array}{l}\text { NUMBERS } \\
\text { NUMBERS }\end{array}$ & $\begin{array}{l}21, \\
25\end{array}$ & $\begin{array}{l}22, \\
26 .\end{array}$ & 28, & $\begin{array}{l}24 \\
28\end{array}$ & • & . & • & • & • & - & • & • & & • & • & \\
\hline STREAM & $\begin{array}{l}\text { NUMBERS } \\
\text { NUMBERS }\end{array}$ & $\begin{array}{l}25 \text {, } \\
29,\end{array}$ & $\begin{array}{l}26, \\
30\end{array}$ & & 82 & & • & - & - & - & • & • & - & - & • & - & 4 \\
\hline $\begin{array}{l}\text { TREAM } \\
\text { TREAM } \\
\text { TREAM }\end{array}$ & $\begin{array}{l}\text { NUMBERS } \\
\text { NUMBERS }\end{array}$ & 83 , & 84, & & 86 & - & $\bullet$ & - & - & . & . & - & - & . & & & $0=$ \\
\hline $\begin{array}{l}\text { IREAM } \\
\text { IREAM }\end{array}$ & NUMBERS & 87, & 88, & 39, & 40 & - & 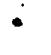 & • & - & & - & • & - & & & & 88 \\
\hline $\begin{array}{l}\text { REAM } \\
\text { 2EAM }\end{array}$ & NUMBERS & 41, & 42, & 43, & 4 & • & - & - & - & - & • & • & - & - & • & - & \\
\hline $\begin{array}{l}\text { EAM } \\
\text { EAM }\end{array}$ & NUMBERS & 45, & 46, & 47, & 48 & • & - & & - & - & • & - & - & - & • & & \\
\hline $\begin{array}{l}A M \\
\text { AM }\end{array}$ & NUMBERS & 49. & 50, & E1, & $\begin{array}{l}52 \\
56\end{array}$ & • & - & & - & - & $\bullet$ & • & • & - & - & & \\
\hline & NUMBERS & 63, & 54, & 55, & 56 & & 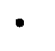 & • & • & - & - & • & - & - & • & - & \\
\hline & ABERS & 57. & 58 , & 69, & 60 & & - & - & • & • & - & - & • & - & - & - & \\
\hline & NUMBERS & 61. & 62 , & 63, & 6 & & - & • & $\bullet$ & • & - & • & • & - & • & - & \\
\hline & 1BERS & 65, & 66, & 67, & 78 & & - & - & - & • & • & • & • & - & & & \\
\hline & NU:1BERS & 69, & 71, & 72, & 78 & - & - & - & $\bullet$ & • & $\cdot$ & • & • & • & & & \\
\hline & NUMBERS & 74. & 75, & 76, & $\begin{array}{l}78 \\
82\end{array}$ & - & • & & - & • & • & • & • & • & - & & \\
\hline $\begin{array}{l}\text { EEAM } \\
\text { REAM }\end{array}$ & NUMBERS & 79, & 80. & 81. & 82 & $\bullet$ & - & - & - & • & $\bullet$ & - & • & - & - & & \\
\hline $\begin{array}{l}\text { REAM } \\
\text { REAM }\end{array}$ & NUMBERS & 83, & 84. & 85 & 86 & - & $\dot{.}$ & $\cdot \cdot$ & • & • & $\bullet$ & - & - & - & • & & \\
\hline $\begin{array}{l}\text { REAM } \\
\text { REAM }\end{array}$ & MBERS & 87. & 88 & 89 & & . & $\dot{\bullet}$ & • & - & - & • & - & - & - & • & & \\
\hline $\begin{array}{l}\text { STREAM } \\
\text { STREAM }\end{array}$ & KBERS & 91. & 92, & 93 & & . & . & : & • & - & $\bullet$ & - & - & • & - & & \\
\hline $\begin{array}{l}\text { STREAM } \\
\text { STREAM }\end{array}$ & MBERS & 96. & 98, & 99 & & - & . & : & - & - & - & - & - & • & • & & \\
\hline $\begin{array}{l}\text { STREAM } \\
\text { STREAM }\end{array}$ & ABERS & 102. & 103, & & & • & • & • & 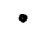 & - & - & - & - & • & • & & \\
\hline $\begin{array}{l}\text { STREAM } \\
\text { STREAM }\end{array}$ & NO & 106, & 107. & & 113 & - & • & . & - & • & - & - & - & - & • & & \\
\hline $\begin{array}{l}\text { STREAM } \\
\text { STREAM }\end{array}$ & N & 110, & 111, & & $\begin{array}{l}118 \\
118\end{array}$ & - & - & - & • & - & - & - & • & - & • & & \\
\hline$A M$ & NU & 114, & 11 & & $\begin{array}{l}118 \\
122\end{array}$ & • & . & . . & & • & - & • & • & - & • & • & \\
\hline$A x$ & NUMBERS & 119, & & & 126 & - & - & - & 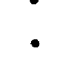 & . & • & $\bullet$ & • & - & • & • & \\
\hline$A M M$ & NUMBERS & 123, & & & 130 & • & . & • & & & • & - & • & • & • & & \\
\hline 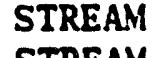 & NUMBERS & 127 & 12 & & 134 & - & - & - & & & - & - & • & - & • & - & \\
\hline STRE & NUMBERS & 131, & 13 & 13 & 138 & & • & - & & & & - & • & - & - & 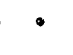 & \\
\hline STREAM & NUMBERS & 135 & & 14 & 142 & & & & & & & - & - & - & - & & \\
\hline$P F+2$ & NUMBERS & 189 & & & 146 & & & & & & • & • & - & - & - & & \\
\hline TPF & NUMBERS & 145 & & $\begin{array}{l}14 \\
14\end{array}$ & 150 & & & & & & - & - & - & • & - & & \\
\hline & NUMBERS & & & & 154 & & & & & & • & - & - & - & - & & \\
\hline & NUMBERS & 151, & & & 158 & & & & & & • & - & - & - & - & - & \\
\hline & MBERS & 155 , & & & 162 & & & & & & • & & - & & - & • & \\
\hline & MBERS & 15 & & & 168 & & & & & & & & - & - & • & • & \\
\hline & MBERS & 16 & & & 172 & & 烈 & 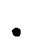 & & & & & & & $\cdot$ & - & \\
\hline & DERT & 16 & & & 176 & & & & & & & & & & ? & • & \\
\hline & 8ER: & 17 & & & & & & & & & & & & & • & - & \\
\hline & IUMBERS & 17 & & & & & & & & & & & - & & & & \\
\hline
\end{tabular}


DPSP $80 \cdot 1033$

Material balayce tablas

SLUDGE-SUPERNATE FEED

STREAM NLMLERS -

STIEAM NAME
Appendix II

Table 21-16

Page 002 of 173

Date 09/30/82 Rev 09

COMPONEAT FLOHS, LB/HR

$\begin{array}{lccc}1 & 2 & 3 & 4 \\ \text { Hished Sludge } & 90^{2} \text { wt\% } & \text { Supenate } & \text { Hg From } \\ \text { fr Tank Farm Formic Acid } & \text { Concentrate } & \text { SME }\end{array}$

\begin{tabular}{|c|c|c|c|c|c|}
\hline 1 & $\mathrm{H} 2 \mathrm{O}$ & 817.9 & 1.332 & 73.05 & $.8013 E-05$ \\
\hline 45 & $A g$ & .0000 & .0000 & .0000 & $.8004 E-04$ \\
\hline 116 & Ag20 & .0000 & .0000 & .0000 & .0000 \\
\hline 134 & AgNO3 & .0000 & .0000 & .0000 & .0000 \\
\hline 61 & $\mathrm{AgOH}$ & $.1845 \mathrm{E}-01$ & .0000 & .0000 & .0000 \\
\hline 74 & Ail $(\mathrm{OH}) 3$ & 11.49 & .0000 & .0000 & $.9341 E-07$ \\
\hline 77 & $A 1203$ & .0000 & .0000 & .0000 & .0000 \\
\hline 75 & A 10011 & .0000 & .0000 & .0000 & .0000 \\
\hline 106 & B203 & .0000 & .0000 & .0000 & $.1979 \mathrm{E}-06$ \\
\hline 9 & $\mathrm{Ba}(\mathrm{NO3}) 2$ & $.1521 \mathrm{E}-06$ & .0000 & .0000 & $.1228 \mathrm{E}-14$ \\
\hline 95 & $\mathrm{BaCl} 12$ & .0000 & .0000 & .0000 & .0000 \\
\hline 15 & $\mathrm{~B} \approx 0$ & .0000 & .0000 & .0000 & .0000 \\
\hline 24 & $\mathrm{BaSO}$ & .1369 & .0000 & .0000 & $.1110 \mathrm{E}-08$ \\
\hline 66 & $\mathrm{CO}$ & .0000 & .0000 & .0000 & . 1898E-32 \\
\hline 37 & $\mathrm{CO} 2$ & .0000 & .0000 & .0000 & $.6759 E-17$ \\
\hline 142 & $\mathrm{CO2}(\mathrm{C} 14)$ & .0000 & .0000 & .0000 & $.1930 \mathrm{E}-28$ \\
\hline 63 & $\mathrm{Ca}(\mathrm{COOH}) 2$ & .0000 & .0000 & .0000 & $.3851 E-07$ \\
\hline 120 & $\mathrm{Ca}(\mathrm{OH}) 2$ & .0000 & .0000 & .0000 & .0000 \\
\hline 113 & $\mathrm{Cn} 3(\mathrm{PO4}) 2$ & .3412 & .0000 & .0000 & $.2766 \mathrm{E}-08$ \\
\hline 20 & $\mathrm{CaC2O4}$ & .8690 & .0000 & .0000 & $.2992 E-08$ \\
\hline 18 & $\mathrm{CaCO3}$ & 8.653 & .0000 & .0000 & .0000 \\
\hline 78 & CaF2 & $.9224 E-01$ & .0000 & .0000 & $.7480 \mathrm{E}-09$ \\
\hline 41 & $\mathrm{CaO}$ & $.000 n$ & .0000 & .0000 & .0000 \\
\hline 19 & $\mathrm{CaSO}_{4}$ & .4334 & .0000 & .0000 & $.8514 E-08$ \\
\hline 29 & Carbon & $.9224 E-01$ & .0000 & .0000 & $.2598 \mathrm{E}-08$ \\
\hline 26 & $\mathrm{Co}(\mathrm{COOHI}) 2$ & .0000 & .0000 & .0000 & $.6080 \mathrm{E}-09$ \\
\hline 121 & $\mathrm{Co}(\mathrm{OH}) 2$ & .0000 & .0000 & .0000 & .0000 \\
\hline 53 & $\mathrm{Co}(\mathrm{OH}) \mathrm{3}$ & $.5585 E-01$ & .0000 & .0000 & .0000 \\
\hline 59 & $\mathrm{CoO}$ & .0000 & .0000 & .0000 & .0000 \\
\hline 99 & $\mathrm{Cr}(\mathrm{OH}) 3$ & .8507 & .0000 & .0000 & $.2843 E-08$ \\
\hline 98 & Cr203 & .0000 & .0000 & .0000 & .0000 \\
\hline 42 & Cs20 & .0000 & .0000 & .0000 & $.1679 \mathrm{E}-18$ \\
\hline 137 & Cs20 Semi Vol & .0000 & .0000 & .0000 & .0000 \\
\hline 90 & $\mathrm{CsCOOH}$ & .0000 & .0000 & .2139 & $.1727 \mathrm{E}-08$ \\
\hline 96 & CsCl & .0000 & .0000 & .0000 & $.1798 E-12$ \\
\hline 136 & Cscl Semi Vol & .0000 & .0000 & .0000 & .0000 \\
\hline 8 & CsNO3 & $.9754 \mathrm{E}-02$ & .0000 & .0000 & $.7874 E-10$ \\
\hline 88 & CsResin & .0000 & .0000 & .0000 & .0000 \\
\hline 122 & $\mathrm{Cu}(\mathrm{COOH}) 2$ & .0000 & .0000 & .0000 & $.1299 E-08$ \\
\hline 52 & $\mathrm{Cu}(\mathrm{OH}) 2$ & .1018 & .0000 & .0000 & .0000 \\
\hline 58 & $\mathrm{Cu} 20$ & .0000 & .0000 & .0000 & .0000 \\
\hline 64 & $\mathrm{CuCOOH}$ & .0000 & .0000 & .0000 & .0000 \\
\hline 130 & $\mathrm{CuO}$ & .0000 & .0000 & .0000 & .0000 \\
\hline 13 & $\mathrm{Fe}(011) 3$ & 27.82 & .0000 & .0000 & $.2261 E-06$ \\
\hline 80 & $\mathrm{Fe} 203$ & .0000 & .0000 & .0000 & .0000 \\
\hline
\end{tabular}


MITERIAL BALANCE TABLES

SLUDGE-SUPERNATE FEED STREAMS (CONT'D) STREAM RAME

$101 \mathrm{FeO}$

120 Group A Seni Vo

102 GroupA

103 Group B

$25 \mathrm{H} 2$

$133 \mathrm{H} 2 \mathrm{C} 204$

$91 \mathrm{H2O2}$

34 HCOOH

$43 \mathrm{HCl}$

$85 \mathrm{IIF}$

49 HNO3

86 IIResin

$86 \mathrm{Hg}$

$135 \mathrm{HgNO} 2$

$21 \mathrm{H}_{5} \mathrm{O}$

9712

$39 \mathrm{~K} 2 \mathrm{O}$

$131 \mathrm{KM} / \mathrm{n} 04$

$118 \mathrm{KNO3}$

105 La203

$108 \mathrm{Li} 20$

$65 \mathrm{Mg}(\mathrm{COOII}) 2$

$55 \mathrm{Mg}(\mathrm{OII}) 2$

$33 \mathrm{MgO}$

$60 \mathrm{Mn}(\mathrm{COOH}) 2$

$132 \mathrm{Mn}(\mathrm{NO3}) 2$

$129 \mathrm{Mn}(\mathrm{OII}) 2$

$56 \mathrm{MnO}$

$14 \mathrm{MnO2}$

81 N2

$143 \mathrm{NA2CO3} \mathrm{(C14)}$

$35 \mathrm{NO}$

$84 \mathrm{N02}$

$70 \mathrm{Na}(\mathrm{HgO}(\mathrm{OII}))$

$94 \mathrm{Nin} 2 \mathrm{~B} 407$

$109 \mathrm{Na2C204}$

$5 \mathrm{Na} 2 \mathrm{CO3}$

$32 \mathrm{Na} 20$

$71 \mathrm{Na} 2 \mathrm{Pu}_{4} 02(\mathrm{OH}) 4$

73 Na2Rh04

$72 \mathrm{Na2Ru04}$

$6 \mathrm{Nin} 2 \mathrm{SO4}$

$68 \mathrm{NaA} 102$

$114 \mathrm{NaBO2}$

140 NaBO2 Semi Vol $50 \mathrm{NaCOOH}$

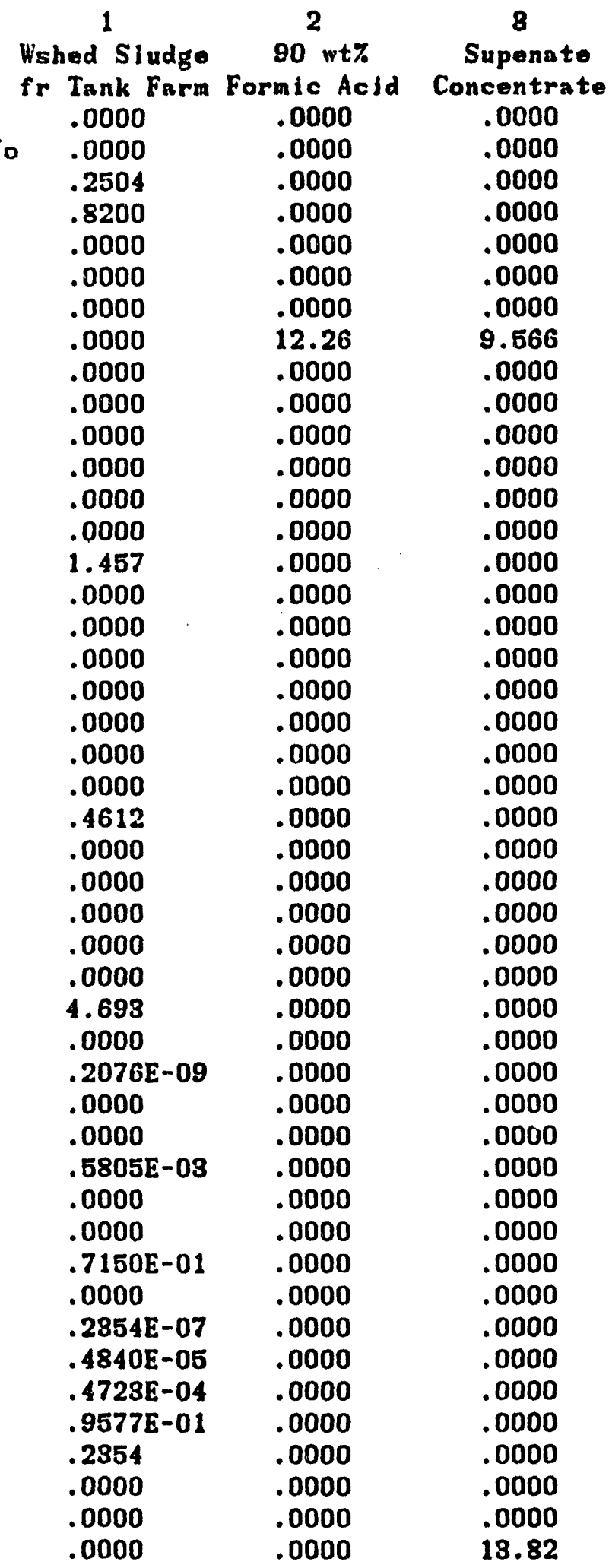

4
Hg From
SME
.0000
.0000
$.2096 E-08$
$.6649 E-08$
$.4580 E-31$
.0000
.0000
$.1228 E-07$
.0000
.0000
.0000
.0000
$.5407 E-02$
.0000
.0000
.0000
.0000
.0000
$.7531 E-11$
$.6715 E-08$
$.7672 E-07$
$.7330 E-08$
.0000
$.2691 E-07$
$.6575 E-07$
.0000
.0000
.0000
.0000
$.2145 E-10$
.0000
$.4931 E-22$
$.5046 E-16$
$.4686 E-11$
$.8911 E-11$
$.3022 E-11$
.0000
$.2385 E-06$
$.1900 E-15$
$.3907 E-13$
$.8812 E-12$
$.7731 E-09$
$.1900 E-08$
.0000
.0000
$.1746 E-06$

.00


DPSP $80-1038$

MATERIAL BALANCE TABLES SLUDGE-SUPERNATE FEED STREAMS (CONT'D)STREAM NAME

\begin{tabular}{|c|c|c|c|c|c|}
\hline $\begin{array}{l}\text { STR } \\
\text { STR }\end{array}$ & $\begin{array}{l}\text { EAMS }\left(C O N T^{\prime} D\right)- \\
\text { EAM NAME }\end{array}$ & $\begin{array}{l}1 \\
\text { Wshed Sludge } \\
\text { fr Tank Farm } \\
.951 .4 E-01\end{array}$ & $\begin{array}{c}2 \\
90^{2} w t \% \\
\text { Formic Acld } \\
.0000\end{array}$ & $\begin{array}{c}8 \\
\text { Supenate } \\
\text { Concentrate } \\
.0000\end{array}$ & $\begin{array}{l}4 \\
H_{g} \text { From } \\
\text { SUE } \\
.7706 E-09\end{array}$ \\
\hline 138 & NaCl Seni Vol & .0000 & .0000 & .0000 &. nooo \\
\hline 69 & NaF & $.1872 E-n 3$ & .0000 & .0000 &.$\{07 G E-11$ \\
\hline 139 & NaF Semi Vol & .0000 & .0000 & .0000 & .0000 \\
\hline 12 & $\mathrm{NaI}$ & $.9225 \mathrm{E}-\mathrm{C} 2$ & .0000 & .0000 & $.7469 E-10$ \\
\hline 125 & NaI Semi Vol & .0000 & .0000 & .0000 & .0000 \\
\hline 8 & $\mathrm{NaNO} 2$ & .1711 & .0000 & .0000 & .0000 \\
\hline 2 & $\mathrm{NaNO3}$ & 8.000 & .0000 & .0000 & $.2433 E-07$ \\
\hline 4 & $\mathrm{NaOH}$ & 8.456 & .0000 & .0000 & .0000 \\
\hline 87 & NoResin & .0000 & .0000 & .0000 & .0000 \\
\hline 61 & $\mathrm{Ni}(\mathrm{COOH}) 2$ & .0000 & .0000 & .0000 & $.2301 \mathrm{E}-07$ \\
\hline 17 & $\mathrm{~N}(1 \mathrm{OH}) 2$ & 1.772 & .0000 & .0000 & .0000 \\
\hline 40 & NiO & .0000 & .0000 & .0000 & .0000 \\
\hline 82 & 02 & .0000 & .0000 & .0000 & $.1200 E-10$ \\
\hline 67 & PbO & .0000 & .0000 & .0000 & .0000 \\
\hline 28 & PbSO4 & .1288 & .0000 & .0000 & $.1045 \mathrm{E}-08$ \\
\hline 124 & $P_{d}$ & .0000 & .0000 & .0000 & .0000 \\
\hline 123 & $\mathrm{Pd}(\mathrm{OH}) 2$ & .0000 & .0000 & .0000 & .0000 \\
\hline 112 & PdNO32 & .0000 & .0000 & .0000 & .0000 \\
\hline 110 & PdO & .0000 & .0000 & .0000 & .0000 \\
\hline 117 & $\mathrm{Pu}_{\mathrm{u}}(\mathrm{COOH}) 4$ & .0000 & .0000 & $.1327 \mathrm{E}-03$ & $.1071 E-11$ \\
\hline 76 & $\mathrm{Pu} 02$ & $.3353 E-01$ & .0000 & .0000 & $.2719 E-09$ \\
\hline 22 & $\mathrm{RhO}_{2}$ & $.1281 \mathrm{E}-01$ & .0000 & .0000 & $.1039 E-09$ \\
\hline 79 & $\mathrm{RuO2}$ & $.6040 E-C 1$ & .0000 & .0000 & $.5121 E-09$ \\
\hline 28 & Ru02 Seni Vol & .0000 & .0000 & .0000 & .0000 \\
\hline 83 & Ru04 & .0000 & .0000 & .0000 & .0000 \\
\hline 88 & S02 & .0000 & .0000 & .0000 & $.8307 E-32$ \\
\hline 111 & SiO2 & 5.366 & .0000 & .0000 & $.8382 E-06$ \\
\hline 115 & Sillica Gel & .0000 & .0000 & .0000 & .0000 \\
\hline 48 & $\mathrm{Sr}(\mathrm{COOH}) 2$ & .0000 & .0000 & $.2675 E-03$ & $.9379 E-09$ \\
\hline 10 & $\mathrm{Sr}(\mathrm{NO3}) 2$ & $.1857 \mathrm{E}-06$ & .0000 & .0000 & $.1095 E-14$ \\
\hline 127 & $\mathrm{Sr}(\mathrm{OH}) 2$ & .0000 & .0000 & .0000 & .0000 \\
\hline 80 & SrCO3 & $.9590 E-01$ & .0000 & .0000 & .0000 \\
\hline 46 & Sro & .0000 & .0000 & .0000 & .0000 \\
\hline 89 & SrRESIN & .0000 & .0000 & .0000 & .0000 \\
\hline 141 & Surfactint & .0000 & .0000 & .0000 & .0000 \\
\hline 92 & Th02 & .5256 & .0000 & .0000 & $.4262 E-03$ \\
\hline 107 & $\mathrm{Ti02}$ & .0000 & .0000 & .0000 & $.1343 E-07$ \\
\hline 119 & Tritiux & $.6028 E-09$ & .0000 & $.1464 E-09$ & $.3248 E-17$ \\
\hline 93 & U02 & .0000 & .0000 & .0000 & .0000 \\
\hline 62 & U02(c00II) 2 & .0000 & .0000 & .0000 & $.2981 E-07$ \\
\hline 16 & U02(Oli)2 & 8.104 & .0000 & .0000 & .0000 \\
\hline 27 & $Y(\mathrm{COOH}) 3$ & .0000 & .0000 & .0000 & $.6412 E-09$ \\
\hline 11 & $Y(N 03) 8$ & $.9686 E-07$ & .0000 & .0000 & $.7778 E-15$ \\
\hline 128 & Y(OH) 8 & .0000 & .0000 & .0000 & .0000 \\
\hline 81 & $\mathrm{Y} 2(\mathrm{COB}) 3$ & $.6318 \mathrm{E}-01$ & .0000 & .0000 & .0000 \\
\hline
\end{tabular}

\begin{tabular}{|c|c|c|c|c|c|}
\hline $\begin{array}{l}\text { STR } \\
\text { STR }\end{array}$ & $\begin{array}{l}\text { EAMS }\left(C O N T^{\prime} D\right)- \\
\text { EAM NAME }\end{array}$ & $\begin{array}{l}1 \\
\text { Wshed Sludge } \\
\text { fr Tank Farm } \\
.951 .4 E-01\end{array}$ & $\begin{array}{c}2 \\
90^{2} w t \% \\
\text { Formic Acld } \\
.0000\end{array}$ & $\begin{array}{c}8 \\
\text { Supenate } \\
\text { Concentrate } \\
.0000\end{array}$ & $\begin{array}{l}4 \\
H_{g} \text { From } \\
\text { SUE } \\
.7706 E-09\end{array}$ \\
\hline 138 & NaCl Seni Vol & .0000 & .0000 & .0000 &. nooo \\
\hline 69 & NaF & $.1872 E-n 3$ & .0000 & .0000 &.$\{07 G E-11$ \\
\hline 139 & NaF Semi Vol & .0000 & .0000 & .0000 & .0000 \\
\hline 12 & $\mathrm{NaI}$ & $.9225 \mathrm{E}-\mathrm{C} 2$ & .0000 & .0000 & $.7469 E-10$ \\
\hline 125 & NaI Semi Vol & .0000 & .0000 & .0000 & .0000 \\
\hline 8 & $\mathrm{NaNO} 2$ & .1711 & .0000 & .0000 & .0000 \\
\hline 2 & $\mathrm{NaNO3}$ & 8.000 & .0000 & .0000 & $.2433 E-07$ \\
\hline 4 & $\mathrm{NaOH}$ & 8.456 & .0000 & .0000 & .0000 \\
\hline 87 & NoResin & .0000 & .0000 & .0000 & .0000 \\
\hline 61 & $\mathrm{Ni}(\mathrm{COOH}) 2$ & .0000 & .0000 & .0000 & $.2301 \mathrm{E}-07$ \\
\hline 17 & $\mathrm{~N}(1 \mathrm{OH}) 2$ & 1.772 & .0000 & .0000 & .0000 \\
\hline 40 & NiO & .0000 & .0000 & .0000 & .0000 \\
\hline 82 & 02 & .0000 & .0000 & .0000 & $.1200 E-10$ \\
\hline 67 & PbO & .0000 & .0000 & .0000 & .0000 \\
\hline 28 & PbSO4 & .1288 & .0000 & .0000 & $.1045 \mathrm{E}-08$ \\
\hline 124 & $P_{d}$ & .0000 & .0000 & .0000 & .0000 \\
\hline 123 & $\mathrm{Pd}(\mathrm{OH}) 2$ & .0000 & .0000 & .0000 & .0000 \\
\hline 112 & PdNO32 & .0000 & .0000 & .0000 & .0000 \\
\hline 110 & PdO & .0000 & .0000 & .0000 & .0000 \\
\hline 117 & $\mathrm{Pu}_{\mathrm{u}}(\mathrm{COOH}) 4$ & .0000 & .0000 & $.1327 \mathrm{E}-03$ & $.1071 E-11$ \\
\hline 76 & $\mathrm{Pu} 02$ & $.3353 E-01$ & .0000 & .0000 & $.2719 E-09$ \\
\hline 22 & $\mathrm{RhO}_{2}$ & $.1281 \mathrm{E}-01$ & .0000 & .0000 & $.1039 E-09$ \\
\hline 79 & $\mathrm{RuO2}$ & $.6040 E-C 1$ & .0000 & .0000 & $.5121 E-09$ \\
\hline 28 & Ru02 Seni Vol & .0000 & .0000 & .0000 & .0000 \\
\hline 83 & Ru04 & .0000 & .0000 & .0000 & .0000 \\
\hline 88 & S02 & .0000 & .0000 & .0000 & $.8307 E-32$ \\
\hline 111 & SiO2 & 5.366 & .0000 & .0000 & $.8382 E-06$ \\
\hline 115 & Sillica Gel & .0000 & .0000 & .0000 & .0000 \\
\hline 48 & $\mathrm{Sr}(\mathrm{COOH}) 2$ & .0000 & .0000 & $.2675 E-03$ & $.9379 E-09$ \\
\hline 10 & $\mathrm{Sr}(\mathrm{NO3}) 2$ & $.1857 \mathrm{E}-06$ & .0000 & .0000 & $.1095 E-14$ \\
\hline 127 & $\mathrm{Sr}(\mathrm{OH}) 2$ & .0000 & .0000 & .0000 & .0000 \\
\hline 80 & SrCO3 & $.9590 E-01$ & .0000 & .0000 & .0000 \\
\hline 46 & Sro & .0000 & .0000 & .0000 & .0000 \\
\hline 89 & SrRESIN & .0000 & .0000 & .0000 & .0000 \\
\hline 141 & Surfactint & .0000 & .0000 & .0000 & .0000 \\
\hline 92 & Th02 & .5256 & .0000 & .0000 & $.4262 E-03$ \\
\hline 107 & $\mathrm{Ti02}$ & .0000 & .0000 & .0000 & $.1343 E-07$ \\
\hline 119 & Tritiux & $.6028 E-09$ & .0000 & $.1464 E-09$ & $.3248 E-17$ \\
\hline 93 & U02 & .0000 & .0000 & .0000 & .0000 \\
\hline 62 & U02(c00II) 2 & .0000 & .0000 & .0000 & $.2981 E-07$ \\
\hline 16 & U02(Oli)2 & 8.104 & .0000 & .0000 & .0000 \\
\hline 27 & $Y(\mathrm{COOH}) 3$ & .0000 & .0000 & .0000 & $.6412 E-09$ \\
\hline 11 & $Y(N 03) 8$ & $.9686 E-07$ & .0000 & .0000 & $.7778 E-15$ \\
\hline 128 & Y(OH) 8 & .0000 & .0000 & .0000 & .0000 \\
\hline 81 & $\mathrm{Y} 2(\mathrm{COB}) 3$ & $.6318 \mathrm{E}-01$ & .0000 & .0000 & .0000 \\
\hline
\end{tabular}

Append ix $\mathrm{H}$

Table 21-16

Page 004 of 173

Date 09/30/S2 Rov 09 
MITERIAL BALANCE TABLES

\section{SLLDCE-SLPERIATE FEED} STIEAMS (CONT'D)STREAM NAME

$\begin{array}{rl}47 & y 203 \\ 100 & Z e o l \text { ite } \\ 44 & \operatorname{Zn}(\text { COOH) } 2 \\ 54 & \operatorname{Zn}(011) 2 \\ 57 & \operatorname{Zn} 0\end{array}$

$104 \quad 2 r 02$ TOTAL FLOW, LB/HR VAPOR FLON, CFM LIQUID FLON, GPM DESIGN FLON, DEXSITY, LBS 'FT3 TEYPERATURE, DEG C PRESSURE, ATM PRESSURE, PSIG PRESSURE, IM HG PHASE EXTHALPY, PCU/HR

\begin{tabular}{|c|c|c|c|}
\hline 1 & 2 & 8 & 4 \\
\hline $\begin{array}{l}\text { Wished Sludge } \\
\text { fr Tank Farm }\end{array}$ & $\begin{array}{c}90 \text { wt\% } \\
\text { Formic Acid }\end{array}$ & $\begin{array}{c}\text { Supenate } \\
\text { Concentrate }\end{array}$ & $\begin{array}{l}\text { Hg From } \\
\text { SME }\end{array}$ \\
\hline .0000 & .0000 & .0000 & .0000 \\
\hline 3.360 & .0000 & .0000 & $.2725 E-07$ \\
\hline .0000 & .0000 & .0000 & $.8388 E-08$ \\
\hline .2672 & .0000 & .0000 & .0000 \\
\hline .0000 & .0000 & .0000 & .0000 \\
\hline .0000 & .0000 & .0000 & $.6715 E-08$ \\
\hline 892.49 & 13.69 & 96.65 & .01 \\
\hline .69 & .02 & .18 & .00 \\
\hline 71.0773 & 74.5439 & 68.4865 & 834.7486 \\
\hline 60.00 & 25.00 & 88.50 & 50.00 \\
\hline 1.00 & 1.00 & 1.00 & .97 \\
\hline .00 & .00 & .00 & -.51 \\
\hline LIQUID & LIOUID & LIQUID & LIQIID \\
\hline 20223.71 & 190.98 & 8191.08 & .01 \\
\hline
\end{tabular}


MATERIAL BALANCE TABLES

SLUDGE-SUPERNATE FEED

STREAM NUMBERS -

STREAM NAME

5

SRAT to MUNIT Vent to FAVC

COMPONENT FLOIIS, LB/IIR

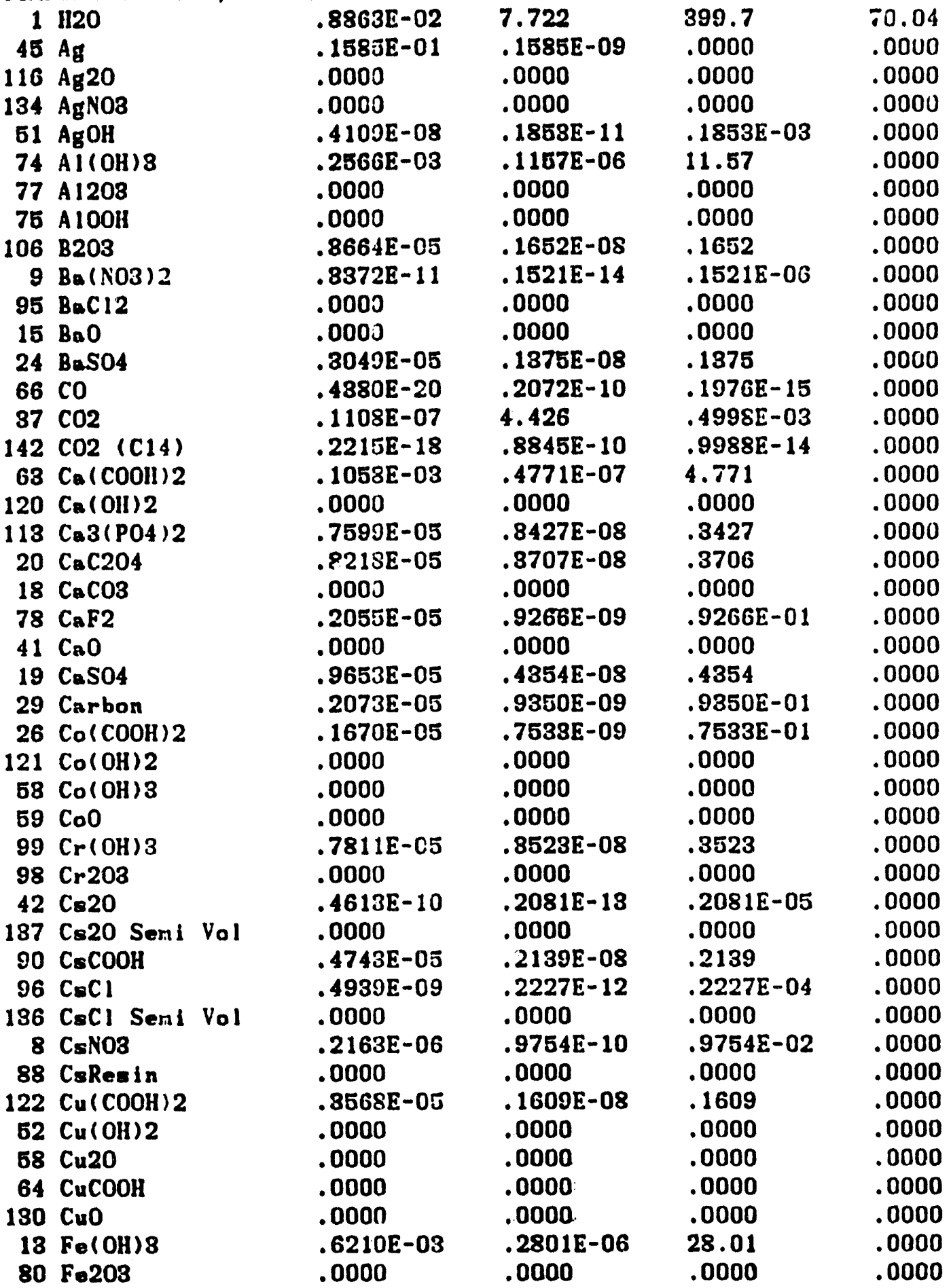


MITERIAL BALANCE T.IBLES

Date 09/80/82 Rev 09

SLUDGE-SUPI:RIATE FETD STREAMS ( CONT'D)STREAM NAME

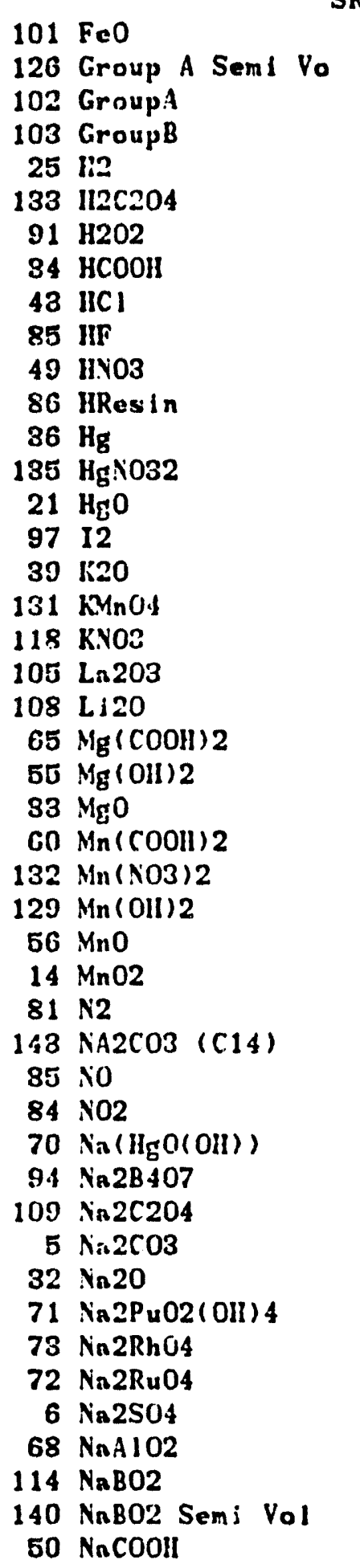

IIg from SRAT Cond

SRAT to MWHT Vont to FAVC .0000

.0000

$.5758 \mathrm{E}-05$

$.1826 \mathrm{E}-04$

$.8615 E-19$

.0000

.0000

$.4978 E-04$

.0000

.0000

.0000

.0000

1.388

.0000

$.3237 E-06$

.0000

.0000

.0000

.2069E-07

$.8304 E-07$

$.1418 \mathrm{E}-05$

.2014E-04

.0000

.4740E-06

$.1806 \mathrm{E}-03$

.0000

.0000

.0000

.0000

.2430E-08

.0000

$.2941 E-10$

.2140E-10

. 1287E-07

$.1074 \mathrm{E}-07$

.8300 E- 08

.0000

$.5246 \mathrm{E}-05$

$.5220 \mathrm{E}-12$

. 1073E-09

$.1047 E-08$

.2124E-05

$.5220 \mathrm{E}-05$

.0000

.0000

.4430 E-03
.0000

.0000

.2597E-08

$.8237 E-08$

$.8594 E-09$

.0000

.0000

$.8897 E-01$

.0000

.0000

.0000

.0000

. 1512E-07

.0000

$.1460 \mathrm{E}-09$

.0000

.0000

.0000

$.9330 \mathrm{E}-11$

$.8745 \mathrm{E}-10$

$.6393 \mathrm{E}-09$

$.9081 E-08$

.0000

.2138E-09

$.8146 \mathrm{E}-07$

.0000

.0000

.0000

.0000

64.93

.0000

$.7439 E-01$

$.2564 E-04$

$.5805 E-11$

$.4845 \mathrm{E}-11$

$.3743 E-11$

.0000

$.2366 \mathrm{E}-03$

$.2354 E-15$

$.4840 \mathrm{E}-13$

$.4723 E-12$

$.9578 \mathrm{E}-09$

$.2354 E-08$

.0000

.0000

$.1998 E-06$
7

SRAT Trans

por to SME

.0000

.0000

.2597

.8287

$.8886 \mathrm{E}-14$

.0000

.0000

2.245

.0000

.0000

.0000

.0000

.0500

.0000

$.1460 \mathrm{E}-01$

.0000

.0000

.0000

$.0329 \mathrm{E}-03$

$.3745 \mathrm{E}-02$

$.6393 \mathrm{E}-01$

.9081

.0000

.2188E-01

8.146

.0000

.0000

.0000

.0000

$.1096 \mathrm{E}-03$

.0000

. 1326E-05

$.9658 \mathrm{E}-06$

$.5805 \mathrm{E}-03$

$.4845 \mathrm{E}-03$

$.3743 \mathrm{E}-03$

.0000

.2366

$.2354 \mathrm{E}-07$

$.4840 \mathrm{E}-05$

$.4723 \mathrm{E}-04$

$.9578 \mathrm{E}-01$

.2854

.0000

.0000

19.98
8

Rinse Water

to Can Decon

.0000

.0000

.0000

.0000

.0000

.0000

.0000

.0000

.0000

.0000

.0000

.0000

.0000

.0000

.0000

.0000

.0000

.0000

.0000

.0000

.0000

.0000

.0000

.0000

.0000

.0000

.0000

.0000

.0000

.0000

.0000

.0000

.0000

.0000

.0000

.0000

.0000

.0000

.0000

.0000

.0000

.0000

.0000

.0000

.0000

.0000 
DPSP $80-1038$

MATERIAL BALANCE TABLES SLUDGE-SUPERNATE FEED STREAMS (CONT'D) STREAM NAME

$\begin{array}{rl}7 & \mathrm{NaCl} \\ 188 & \mathrm{NaCl} \text { Seml } \mathrm{Vol} \\ 69 & \mathrm{NaF} \\ 189 & \mathrm{NaF} \text { Semi } \mathrm{Vol} \\ 12 & \mathrm{NaI} \\ 125 & \mathrm{NaI} \text { Semi } \mathrm{Vol} \\ 8 & \mathrm{NaNO2} \\ 2 & \mathrm{NaNO3} \\ 4 & \mathrm{NaOH} \\ 87 & \mathrm{NaRes} \text { in } \\ 61 & \mathrm{Ni}(\mathrm{COOH}) 2 \\ 17 & \mathrm{Ni}(\mathrm{OH}) 2 \\ 40 & \mathrm{NiO} \\ 82 & 02 \\ 67 & \mathrm{PbO} \\ 28 \mathrm{PbSO} & \\ 124 & \mathrm{Pd}\end{array}$

$124 \mathrm{Pd}$

$128 \mathrm{Pd}(\mathrm{OH}) 2$

112 PdNO32

$110 \mathrm{PdO}$

$117 \mathrm{Pu}(\mathrm{COOH}) 4$

$76 \mathrm{Pu} 02$

$22 \mathrm{RhO2}$

$79 \mathrm{Ru} 02$

23 Ru02 Seni Vol

$83 \mathrm{Ru} 04$

$88 \mathrm{SO2}$

$1115 i 02$

115 Sillea Gel

$48 \mathrm{Sr}(\mathrm{COOH}) 2$

$10 \mathrm{Sr}(\mathrm{N} 03) 2$

$127 \mathrm{Sr}(\mathrm{OH}) 2$

$80 \mathrm{SrCO}$

$16 \mathrm{Sr} 0$

89 SrRESIN

141 Surfactant

$92 \mathrm{ThO2}$

107 Ti02

119 Tritiun

$93 \mathrm{VO2}$

$62 \mathrm{U02}(\mathrm{COOII}) 2$

$16 \mathrm{U} 02(\mathrm{OH}) 2$

$27 \mathrm{Y}(\mathrm{COOH}) 3$

$11 \mathrm{Y}(\mathrm{NOS}) 3$

$128 \mathrm{Y}(\mathrm{OH}) \mathrm{8}$

$81 Y 2(\mathrm{CO}) 3$
Append Ix H

Inblo 21-16

Page 008 of 173

Date 03/30/82 Rev 00 iti SRAT to MWNI Vent to FAVC

.2117E-05

.0000

$.1120 E-07$

.0000

.2052E-06

.0000

.0000

$.6684 \mathrm{E}-04$

.0000

.0000

$.6330 \mathrm{E}-04$

.0000

.0000

$.1821 \mathrm{E} \cdot 08$

.0000

.2870E-05

.0000

.0000

.0000

.0000

$.2942 E-08$

$.7468 E-06$

$.2854 E-06$

$.1407 E-05$

.0000

.0000

$.8397 E-20$

$.1845 \mathrm{E}-03$

.0000

$.2576 E-05$

$.8000 E-11$

.0000

.0000

.0000

.0000

.0000

$.1171 \mathrm{E}-04$

$.1661 E-06$

$.1685 E-13$

.0000

$.8188 E-04$

.0000

$.1761 \mathrm{E}-05$

$.2187 E-11$

.0000

.0000
$.9547 \mathrm{E}-09$

.0000

$.6049 E-11$

.0000

$.9258 \mathrm{E}-10$

.0000

.0000

$.8015 E-07$

.0000

.0000

.2855E-07

.0000

.0000

19.61

.0000

$.1294 \mathrm{E}-08$

.0000

.0000

.0000

.0000

$.1327 \mathrm{E}-11$

.3368E-09

. 1287E-09

$.6344 E-09$

.0000

.0000

$.7275 E-11$

$.6066 \mathrm{E}-07$

.0000

$.1162 E-08$

$.1357 E-14$

.0000

.0000

.0000

.0000

.0000

. $5280 \mathrm{E}-08$

$.7490 E-10$

$.1422 E-10$

.0000

$.8698 E-07$

.0000

.7944E-09

$.9686 \mathrm{E}-15$

.0000

.0000
SRAT

or to SMIE

$.9547 E-01$

.0000

.5049E-03

.0000

$.9253 \mathrm{E}-02$

.0000

.0000

8.015

.0000

.0000

2.855

.0000

.0000

.5958E-04

.0000

.1294

.0000

.0000

.0000

.0000

$.1327 \mathrm{E}-03$

$.3368 \mathrm{E}-01$

$.1287 \mathrm{E}-01$

$.6344 \mathrm{E}-01$

.0000

.0000

. 1532E-15

6.066

.0000

.1162

.1357 E-06

.0000

.0000

.0000

.0000

.0000

.6280

.7400E-02

$.7875 E-09$

.0000

$\mathbf{3 . 6 9 3}$

.0000

$.7944 \mathrm{E}-01$

$.9686 E-07$

.0000

.0000

\section{8}

Rinse Wnter

to Can Deco:

.0000

.0000

.0000

.0000

.0000

.0000

.0000

.0000

.0000

.0000

.0000

.0000

.0000

.0000

.0000

.0000

.0000

.0000

.0000

.0000

.0000

.0000

.0000

.0000

.0000

.0000

.0000

.0000

.0000

.0000

.0000

.0000

.0000

.0000

.0000

.0000

.0000

.0000

.0000

.0000

.0000

.0000

.0000

.0000

.0000

.0000 


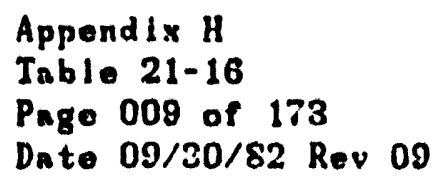

MITISIAL BALAYCE TABLES SLUDGE-SLPERNATE FEED STPEAMS (CONT'D)STREAM NAME

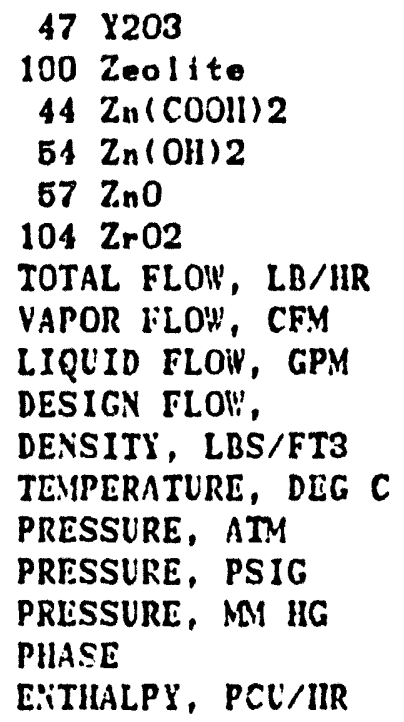

$\begin{array}{cc}7 & 8 \\ \text { SRAT Trans } & \text { Rinse Wnter } \\ \text { for to SNE } & \text { to Crn Decon } \\ .0000 & .0000 \\ 8.376 & .0000 \\ .4197 & .0000 \\ .0000 & .0000 \\ .0000 & .0000 \\ .8745 E-02 & .0000 \\ 500.08 & 70.04 \\ & \\ .89 & .14 \\ & \\ 70.8035 & 62.4300 \\ 50.00 & 80.00 \\ 1.00 & 137.09 \\ .00 & 1999.98 \\ & \\ \text { L1QUID } & \text { LIQUID } \\ 21293.16 & 2133.73\end{array}$


DPSP $80-1088$

MATERIAL BALANCE TABLES

SLLDGE-SUPER.VATE FEED

STREAM NUMBERS -

STREAM NAME

COMPONENT FLOHS, LB/HR

$1 \mathrm{H} 20$

$45 \mathrm{Ag}$

$116 \mathrm{Ag} 20$

184 AgNO3

$51 \mathrm{AgOH}$

74 Al (OII) 8

77 A 1208

$75 \mathrm{AlOOH}$

106 B203

$9 \mathrm{Ba}(\mathrm{NOS}) 2$

$95 \mathrm{BaCl} 2$

$15 \mathrm{BaO}$

$24 \mathrm{BaSO} 4$

$66 \mathrm{CO}$

$87 \mathrm{CO} 2$

$142 \mathrm{CO}$ (C14)

$63 \mathrm{Ca}(\mathrm{COOH}) 2$

$120 \mathrm{C}_{\mathrm{B}}(\mathrm{OH}) 2$

$113 \mathrm{Cas}(\mathrm{PO}) 2$

$20 \mathrm{CaC204}$

$18 \mathrm{CaCO} 3$

$78 \mathrm{CaF2}$

$41 \mathrm{CaO}$

$19 \mathrm{CnSO4}^{2}$

29 Carbon

$26 \mathrm{Co}(\mathrm{COOH}) 2$

$121 \mathrm{Co}(\mathrm{OHI}) 2$

$53 \mathrm{Co}(\mathrm{OH}) \mathrm{3}$

$59 \mathrm{CoO}$

$99 \mathrm{Cr}(\mathrm{Oll}) \mathrm{s}$

$98 \mathrm{Cr} 203$

$42 \mathrm{Cs} 20$

137 Cs20 Semi Vol

$90 \mathrm{CsCOOH}$

$96 \mathrm{CsCl}$

$136 \mathrm{CsCl}$ Seml Vol

8 CsNO3

88 CsResin

$122 \mathrm{Cu}(\mathrm{COOH}) 2$

$52 \mathrm{Cu}(\mathrm{OH}) 2$

$58 \mathrm{Cu} 20$

$64 \mathrm{CuCOOH}$

$130 \mathrm{CuO}$

$13 \mathrm{Fe}(\mathrm{OH}) \mathrm{S}$

$80 \mathrm{Fe} 203$
116.8

.0000

.0000

.0000

.0000

.0000

.0000

.0000

6.616

.0000

.0000

.0000

.0000

.0000

.0000

.0000

.0000

.0000

.0000

.0000

.0000

.0000

.0000

.0000

.0000

.0000

.0000

.0000

.0000

.0000

.0000

.0000

.0000

.0000

.0000

.0000

.0000

.0000

.0000

.0000

.0000

.0000

.0000

.0000

.0000
Appendix II

Table 21-16

Page 010 of 173

Dinte 0.9/30/82 Rev 00
10

FCT Vent to FAVC

18.93

.0000

.0000

.0000

.0000

.0000

.0000

.0000

$.1757 \mathrm{E}-05$

.0000

.0000

.0000

.0000

.0000

.0000

.0000

.0000

.0000

.0000

.0000

.0000

.0000

.0000

.0000

.0000

.0000

.0000

.0000

.0000

.0000

.0000

.0000

.0000

.0000

.0000

.0000

.0000

.0000

.0000

.0000

.0000

.0000

.0000

.0000

.0000
11

SFliT Vent

to FAVC

6.867

.0000

.0000

.0000

.0000

.0000

$.00 \cup 0$

.0000

$.8911 \mathrm{E}-06$

.0000

.0000

.0000

.0000

.0000

.0000

.0000

.0000

.0000

.0000

.0000

.0000

.0000

.0000

.0000

.0000

.0000

.0000

.0000

.0000

.0000

.0000

.0000

.0000

.0000

.0000

.0000

.0000

.0000

.0000

.0000

.0000

.0000

.0000

.0000

.0000
12

Decun Frit

Sirry to S!r:

178.2

.0000

.0000

.0000

.0000

.0000

.0000

.0000

0.616

.0000

.0000

.0000

.0000

.0000

.0000

.0000

.0000

.0000

.0000

.0000

.5000

.0000

.0000

.0000

.0000

.0000

.0000

.0000

.0000

.0000

.0000

.0000

.0000

.0000

.0000

.0000

.0000

.0000

.0000

.0000

.0000

.0000

.0000

.0000

.0000 
DPSP $80-1033$

MITERIII RALHNCE TAELES

SI.UDGE-SL:ERTATE FEED STREAMS (CONT'D)STRE:.Y NAME

$101 \mathrm{FeJ}$

126 Group A Semi Vo

102 Grouph

103 Groupi

$25 \mathrm{H} 2$

133 II2C2O:

$91 \mathrm{H} 202$

$84 \mathrm{HCOOH}$

$43 \mathrm{HCl}$

$85 \mathrm{HF}$

49 HNO3

86 llResin

$56 \mathrm{Hg}$

$135 \mathrm{HgN032}$

$21 \mathrm{H}=\mathrm{O}$

$97 \quad 12$

39 K20

$131 \mathrm{kM} / \mathrm{nO4}$

118 KNOZ

$105 \mathrm{La} 203$

$108 \angle 120$

$65 \mathrm{Mg}(\mathrm{COOH}) 2$

$55 \mathrm{Mg}$ (OH) 2

$33 \mathrm{MEO}$

$60 \mathrm{Mn}(\mathrm{COOII}) 2$

$182 \ln (.903) 2$

$129 \mathrm{Mn}(\mathrm{Oll}) 2$

$50 \mathrm{MnO}$

$14 \mathrm{Min} 02$

$81 \wedge 2$

$143 \mathrm{NA2CO3} \mathrm{(C14)}$

35 NO

$84 N 02$

$70 \mathrm{Na}(\mathrm{HgO}(\mathrm{OH}))$

$94 \mathrm{Na} 2 \mathrm{~B} \cdot 407$

$109 \mathrm{Na} 2 \mathrm{C} 204$

$5 \mathrm{ria} 2 \mathrm{CO}$

$32 \mathrm{~N}_{\mathrm{s}} 2 \mathrm{O}$

$71 \mathrm{Na} 2 \mathrm{Pu}_{\mathrm{u}} \mathrm{2}$ (OII) 4

$73 \mathrm{Na} 2 \mathrm{RhO}_{1}$

$72 \mathrm{Na} 2 \mathrm{Ru}_{\mathrm{O}} 4$

$6 \mathrm{Na} 2 \mathrm{SO} 4$

$68 \mathrm{NaAl} 02$

$114 \mathrm{NaB02}$

$140 \mathrm{NaB02}$ Semi Vol

$50 \mathrm{NaCOOH}$

$\begin{array}{cl} & 9 \\ \text { Frit Slurry } & \\ \text { to Can Decon } & \\ .0000 \\ .0000 \\ .0000 \\ .0000 \\ .0000\end{array}$

.0000

.0000

.4504

.0000

.0000

.0000

.0000

.0000

.0000

.0000

.0000

.0000

.0000

.0000

.2250

$2.56 \%$

.0000

.0000

.9002

.0000

.0000

.0000

.0000

.0000

.0000

.0000

.0000

.0000

.0000

.0000

.0000

.0000

7.967

.0000

.0000

.0000

.0000

.0000

.0000

.0000

.0000
Appendix II

Table 21-16

Page 011 of 173

Date 09/30/82 Rev 09

10

FCT Vent

to FAVC

.0000

.0000

.0000

.0000

.0000

.0000

.0000

.2977 E- 01

.0000

.0000

.0000

.0000

.0000

.0000

.0000

.0000

.0000

.0000

.0000

$.6976 E-07$

$.6812 \mathrm{E}-05$

.0000

.0000

$.2390 \mathrm{E}-0 \mathrm{~S}$

.0000

.0000

.0000

.0000

.0000

$\mathbf{8 7 5 . 9}$

.0000

.0000

.0000

.0000

.0000

.0000

.0000

$.2115 \mathrm{k}-05$

.0000

.0000

.0000

.0000

.0000

.0000

.0000

.0000
11 SFHT Vent Decon Frit te FAVC

.0000

.0000

.0000

.0000

.0000

.0000

.0000

$.1460 \mathrm{E}-01$

.0000

.0000

.0000

.0000

.0000

.0000

.0000

.0000

.0000

.0000

.0000

.8031E-07

$.8455 E-06$

.0000

.0000

$.1212 \mathrm{E}-00 \mathrm{O}$

.0000

.0000

.0000

.0000

.0000

188.0

.0000

.0000

.0000

.0000

.0000

.0000

.0000

$.1073 E-05$

.0000

.0000

.0000

.0000

.0000

.0000

.0000

.0000
SIrry to SME .0000

.0000

.0000

.0000

.0000

.0000

.0000

.4060

.0000

.0000

.0000

.0000

.0000

.0000

.0000

.0000

.0000

.0000

.0000

.2250

2.566

.0000

.0000

.9002

.0000

.0000

.0000

.0000

.0000

$.2780 \mathrm{E}-02$

.0000

.0000

.0000

.0000

.0000

.0000

.0000

7.967

.0000

.0000

.0000

.0000

.0000

.0000

.0000

.0000 
DPSP $80-1033$

MATERIAL BALANCE TABLES

SLUDGE-SUPERNATE FEED STREAMS (CONT'D)STREAM NAME

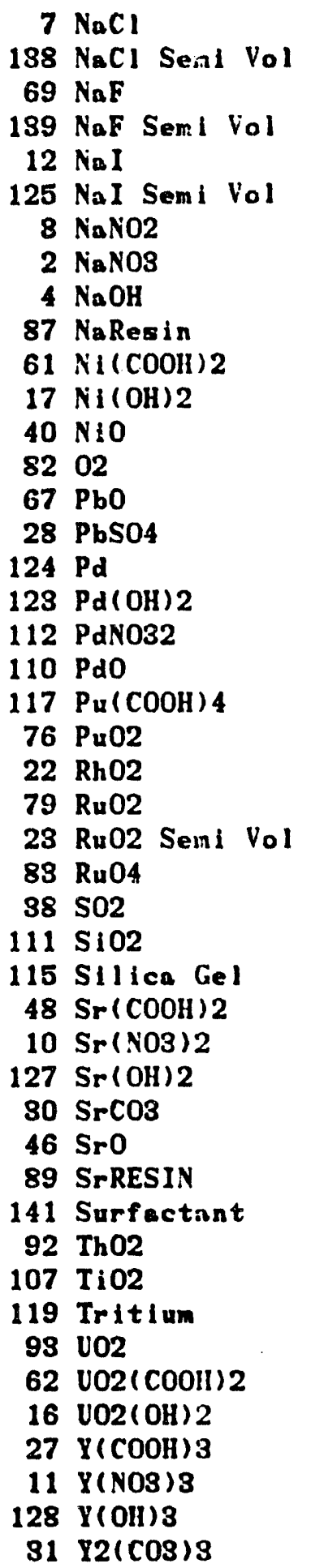

9
Frit S1urry
to Can Decion
.0000
.0000
.0000
.0000
.0000
.0000
.0000
.0000
.0000
.0000
.0000
.0000
.0000
.0000
.0000
.0000
.0000
.0000
.0000
.0000
.0000
.0000
.0000
.0000
.0000
.0000
.0000
26.06
.0000
.0000
.0000
.0000
.0000
.0000
.0000
.0000
.0000
.4501
.0000
.0000
.0000
.0000
.0000
.0000
.0000
.0000

10

FCT Vent

to FAVC

.0000

.0000

.0000

.0000

.0000

.0000

.0000

.0000

.0000

.0000

.0000

.0000

.0000

113.6

.0000

.0000

.0000

.0000

.0000

.0000

.0000

.0000

.0000

.0000

.0000

.0000

.0000

$.6920 \mathrm{E}-05$

.0000

.0000

.0000

.0000

.0000

.0000

.0000

.0000

.0000

$.1195 \mathrm{E}-06$

.0000

.0000

.0000

.0000

.0000

.0000

.0000

.0000
Appendix $\mathrm{H}$

Table 21-16

Page 012 of 173

Date 09/30/82 kes 09 
DPSP SO-1033

M:TER.JAL BALAKCE TAELES

SLUDGE-SUPERNATE FEED

STREAMS (CONT'D)-

STREAM NAME

47 Y203

105 Zeolite

$44 \mathrm{Zn}(\mathrm{COOHI}) 2$

$54 \mathrm{Zn}(\mathrm{OII}) 2$

$57 \mathrm{ZnO}$

$104 \mathrm{ZrO} 2$

TOTAL FLO'I, LB/HR

VAPOR FLOW, CFM

LIQUID FLOH: GPM DESIGN FI.OH,

DENSITY, LBS/FT3

TEMPERATURE, DEG C

PRESSUPE, ATM

PRESSURE, PSIG

PRESSURE, MA HG

PHASE

ENTHILPY, PCU/HR

\begin{tabular}{cc}
\multicolumn{1}{c}{9} & 10 \\
Frit Slurry & FCT Vent \\
to Can Decon & to FAVC \\
.0000 & .0000 \\
.0000 & .0000 \\
.0000 & .0000 \\
.0000 & .0000 \\
.0000 & .0000 \\
.2250 & $.5976 \mathrm{E}-07$ \\
162.25 & 503.44 \\
& 121.94 \\
.27 &
\end{tabular}

73.7839

80.00

5.08

59.96

LIQUID

604.57
Appendix H

Table 21-16

Page 013 of 17:3

Date 09/30/82 Rev 09

\begin{tabular}{|c|c|}
\hline 11 & 12 \\
\hline SFIIT Vent & Decon Frit \\
\hline to FAVC & SIrry to SHEE \\
\hline .0000 & .0000 \\
\hline .0000 & .0000 \\
\hline .0000 & .0000 \\
\hline .0000 & .0000 \\
\hline .0000 & .0000 \\
\hline $.8031 \mathrm{E}-07$ & .2250 \\
\hline 251.74 & 223.69 \\
\hline & .40 \\
\hline .0688 & 70.2707 \\
\hline 29.99 & 80.00 \\
\hline .97 & .97 \\
\hline-.51 & -.51 \\
\hline 733.86 & 783.86 \\
\hline VAPOR & LIQUID \\
\hline-11368.04 & 5934.74 \\
\hline
\end{tabular}


DPSP 80-1033

MATERIAL BALANCE TABLES

SLLDGE-SUPERNATE FEED STREAM NUMBERS STREAM NAME

COMPONENT FLOHS, LE/HR $1 \mathrm{H} 20$

$45 \mathrm{Ag}$

116 Ag20

134 AgN03

$51 \mathrm{AgOH}$

$74 \mathrm{Al}(\mathrm{OH}) 3$

77 A 1208

$75 \mathrm{~A} 100 \mathrm{H}$

106 B203

$9 \mathrm{Ba}(\mathrm{N} 03) 2$

$95 \mathrm{BaCl} 2$

$15 \mathrm{BnO}$

$24 \mathrm{BaSO} 0$

$66 \mathrm{CO}$

$37 \mathrm{CO} 2$

$142 \mathrm{CO}$ ( $\mathrm{C} 1 \mathrm{t})$

$63 \mathrm{Ca}(\mathrm{COOH}) 2$

$120 \mathrm{Cn}(\mathrm{OH}) 2$

$113 \mathrm{Ca}(\mathrm{PO4}) 2$

$20 \mathrm{CaC2O4}$

$18 \mathrm{CaCO3}$

$78 \mathrm{CaF2}$

$41 \mathrm{CaO}$

$19 \mathrm{CaSO}_{4}$

29 Carbon

$26 \mathrm{Co}(\mathrm{COOH}) 2$

$121 \mathrm{Co}(\mathrm{OH}) 2$

$53 \mathrm{Co}(\mathrm{OH}) 3$

$59 \mathrm{CoO}$

$99 \mathrm{Cr}(\mathrm{OH}) \mathrm{3}$

$98 \mathrm{Cr} 203$

$42 \mathrm{Cs} 20$

137 Cs20 Seini Vol

$90 \mathrm{CsCOOH}$

$96 \mathrm{CsCl}$

$186 \mathrm{CsCl}$ Semil Vol

8 CsNOS

88 CsResin

$122 \mathrm{Ca}(\mathrm{COOH}) 2$

$62 \mathrm{Cu}(\mathrm{OH}) 2$

$58 \mathrm{Cu} 20$

$64 \mathrm{CuCOOH}$

$130 \mathrm{CaO}$

$13 \mathrm{Fe}(\mathrm{OH}) 3$

$80 \mathrm{Fe} 203$
13

Waste Sand
Appendix H

Table 21-16

Page 014 of 173

Date 09/30/82 Rev 09
22.93

.0000

.0000

.0000

.0000

.0000

.0000

.0000

.0000

.0000

.0000

.0000

.0000

.0000

.0000

.0000

.0000

.0000

.0000

.0000

.0000

.0000

.0000

.0000

.2284

.0000

.0000

.0000

.0000

.0000

.0000

.0000

.0000

.0000

.0000

.0000

.0000

.0000

.0000

.0000

.0000

.0000

.0000

.0000

.0000
14

15

16

Fresh Frit SME Condens SME Cndnsite Sirry to SME ate to SMECT to RCI

80.45
.0000
.0000
.0000
.0000
.0000
.0000
.0000
17.73
.0000
.0000
.0000
.0000
.0000
.0000
.0000
.0000
.0000
.0000
.0000
.0000
.0000
.0000
.0000
.0000
.0000
.0000
.0000
.0000
.0000
.0000
.0000
.0000
.0000
.0000
.0000
.0000
.0000
.0000
.0000
.0000
.0000
.0000
.0000
.0000

257.8

$1020 \mathrm{E}-07$

.0000

.0000

.0000

$.7372 E-03$

.0000

.0000

$.1561 \mathrm{E}-02$

$.9688 \mathrm{E}-11$

.0000

.0000

$.8761 \mathrm{E}-05$

$.1976 \mathrm{E}-15$

$.3498 E-02$

$.9986 \mathrm{E}-14$

$.3039 \mathrm{E}-03$

.0000

.2183E-04

.2361E-0.1

.0000

$.5903 \mathrm{E}-05$

.0000

.2773E-04

.2051E-04

$.4799 \mathrm{E}-05$

.0000

.0000

.0000

.2244E-04

.0000

$.1825 \mathrm{E}-09$

.0000

.1363E-04

.1419E-08

.0000

$.6214 \mathrm{E}-06$

.0000

. 1025E-04

.0000

.0000

.0000

.0000

$.1784 \mathrm{E}-02$

.0000
865.3
$.003 n$

.0000

.0000

$.5190 \mathrm{E}-03$

$.7377 \mathrm{E}-03$

.0000

.0000

$.1564 \mathrm{E}-02$

$.9694 E-11$

.0000

.0000

$.8766 \mathrm{E}-05$

. 1SOSE- 14

$.2710 \mathrm{E}-05$

$.9964 E-17$

. 30+1E-03

$.1689 E-09$

$.2185 \mathrm{E}-04$

.2363E-04

.0000

.5907E-05

.0000

.2775E-0.4

. 2052E-04

.4802E-05

.2922E-11

.0000

.0000

.2245E-0.4

.0000

. 1327E-09

.0000

$.1364 \mathrm{E}-0.4$

. 1485E-08

.0000

$.6218 \mathrm{E}-06$

.0000

. 1026E-04

.6355E-11

.0000

.0000

.0000

$.1785 \mathrm{E}-02$

.0000 
DPSP 80-1033

MATERIAL BALANCE TARLES

SLUDGE-SUPERIATE FEED STREAMS (CONT'D)STREAM NAME

\begin{tabular}{|c|c|c|}
\hline 101 & Feo & .0000 \\
\hline 126 & Group A Semi Vo & .0000 \\
\hline 102 & GroupA & .0000 \\
\hline 103 & GroupB & .0000 \\
\hline 25 & $\mathrm{H} 2$ & .0000 \\
\hline 133 & $112 C 204$ & .0000 \\
\hline 91 & H2O2 & .0000 \\
\hline 8.1 & $\mathrm{IICOOH}$ & .0000 \\
\hline 43 & $\mathrm{HCl}$ & .0000 \\
\hline 85 & IIF & .0000 \\
\hline 49 & HNO3 & .0000 \\
\hline 86 & liResin & .0000 \\
\hline 36 & $\mathrm{Hg}$ & .0000 \\
\hline 135 & 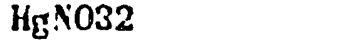 & .0000 \\
\hline 21 & $\mathrm{HgO}$ & .0000 \\
\hline 97 & 12 & .0000 \\
\hline 39 & K20 & .0000 \\
\hline 131 & $\mathrm{KMnO4}$ & .0000 \\
\hline 118 & KNO3 & .0000 \\
\hline 105 & $\operatorname{La} 203$ & .0000 \\
\hline 108 & Li20 & .0000 \\
\hline 65 & $\mathrm{Mg}(\mathrm{COOH}) 2$ & .0000 \\
\hline 55 & $\mathrm{Mg}(\mathrm{OII}) 2$ & .0000 \\
\hline 33 & $\mathrm{MgO}$ & .0000 \\
\hline 60 & $\operatorname{Mn}(\mathrm{COOH}) 2$ & .0000 \\
\hline 132 & $M_{n}(. .03) 2$ & .0000 \\
\hline 129 & $\mathrm{Mn}(\mathrm{OH}) 2$ & .0000 \\
\hline 56 & $\mathrm{MnO}$ & .0000 \\
\hline 14 & $\mathrm{MnO2}$ & .0000 \\
\hline 81 & N2 & .0000 \\
\hline 1.13 & $\mathrm{v} \wedge 2 \mathrm{CO3}(\mathrm{C} 1 \mathrm{~A})$ & .0000 \\
\hline 85 & No & .0000 \\
\hline 84 & $\mathrm{~N} 02$ & .0000 \\
\hline 70 & $\mathrm{Na}(\mathrm{HgO}(\mathrm{OH}))$ & .0000 \\
\hline 94 & $\mathrm{Na2B} 407$ & .0000 \\
\hline 109 & $\mathrm{Nin} 2 \mathrm{C2O4}$ & .0000 \\
\hline 5 & $\mathrm{Na2CO3}$ & .0000 \\
\hline 32 & $\mathrm{Na} 20$ & .0000 \\
\hline 71 & $\mathrm{Na} 2 \mathrm{P}_{4} 02(\mathrm{OH}) 4$ & .0000 \\
\hline 73 & $\mathrm{Na} 2 \mathrm{RhO4}$ & .0000 \\
\hline 72 & $\mathrm{Na} 2 \mathrm{Ru} 04$ & .0000 \\
\hline 6 & $\mathrm{Na2S04}$ & .0000 \\
\hline 68 & $\mathrm{NaA102}$ & .0000 \\
\hline 114 & $\mathrm{NaBO} 2$ & .0000 \\
\hline 140 & NaB02 Semi Vol & .0000 \\
\hline & iacoon & .0000 \\
\hline
\end{tabular}

Waste Sand
Append ix $\mathrm{H}$

Table 21-16

Page 015 of 173

Date 09/80/82 Rev 09

Fresh

1415

16

Sirry to SME ate to SMECT

.0000

.0000

.0000

.0000

.0000

.0000

.0000

1.207

.0000

.0000

.0000

.0000

.0000

.0000

.0000

.0000

.0000

.0000

.0000

.6081

6.875

.0000

.0000

2.412

.0000

.0000

.0000

.0000

.0000

.0000

.0000

.0000

.0000

.0000

.0000

.0000

.0000

21.35

.0000

.0000

.0000

.0000

.0000

.0000

.0000

.0000
.0000

.0000

$.1654 \mathrm{E}-04$

.6247E-04

.8885E-14

.0000

.0000

1.128

.0000

.0000

.0000

.0000

.2704E-02

.0000

.0000

.0000

.0000

.0000

.6943E-07

. 5299E-04

.6055E-03

.5785E-04

.0000

.2124E-03

$.5189 E-03$

.0000

.0000

.0000

.0000

17.08

.0000

$.1326 E-05$

$.9406 E-06$

$.8698 \mathrm{E}-07$

$.8086 \mathrm{E}-07$

.2385E-07

.0000

. 1883E-02

$.1500 \mathrm{E}-11$

.8083E-09

$.8009 E-08$

$.6101 \mathrm{E}-05$

. 1500E-04

.0000

.0000

. 1378E-02
Cndnsate

to RCT

.0000

.0000

. 1655E-04

.5250E-04

$.1014 E-1 \bar{J}$

.0000

.0000

1.828

.0000

.0000

.0000

.0000

.0000

.0000

$.1184 \mathrm{E}-09$

.0000

.0000

.0000

$.6165 \mathrm{E}-07$

.5307E-04

$.6063 \mathrm{E}-03$

.5789E-04

. 2880E- 10

.2127E-03

$.5192 E-03$

.0000

.2223E-08

.0000

.0000

$.4359 \mathrm{E}-02$

.0000

. 1010E-09

$.8172 E-04$

.3700E-07

.3231E-07

.2474E-07

.0000

. 1885E-02

.1501E-11

.3085E-09

.3011E-08

$.6105 \mathrm{E}-05$

. 1501 E-04

.0000

.0000

. 1379E-02 
DPSP $80-1033$

MATERIAL BALANCE TABLES

SLLDGE-SUPERNATE FEED

STREAMS (CONT'D)STREAM NAME

$7 \mathrm{NaCl}$

$188 \mathrm{NaCl}$ Seni Vol

$69 \mathrm{NaF}$

139 NळF Semi Vol

$12 \mathrm{NaI}$

$125 \mathrm{NaI}$ Semi Vol

$8 \mathrm{NaNO} 2$

$2 \mathrm{NaNO3}$

$4 \mathrm{NaOH}$

87 NaResin

$61 \mathrm{Ni}(\mathrm{COOH}) 2$

$17 \mathrm{Ni}(\mathrm{OH}) 2$

$40 \mathrm{NiO}$

8202

$67 \mathrm{PbO}$

$28 \mathrm{PbSO} 04$

$124 \mathrm{Pd}$

$123 \mathrm{Pd}(\mathrm{OH}) 2$

112 PdN032

$110 \mathrm{PdO}$

$117 \mathrm{Pu}(\mathrm{COOH}) 4$

$76 \mathrm{Pu} 02$

$22 \mathrm{RhO2}$

$79 \mathrm{Ru} 02$

23 Ru02 Seni Val

$83 \mathrm{Ru} 04$

$88 \mathrm{S02}$

$111 \mathrm{SiO} 2$

115 Silica Gel

$48 \mathrm{Sr}(\mathrm{COOH}) 2$

$10 \mathrm{Sr}(\mathrm{N} 03) 2$

$127 \mathrm{Sr}(\mathrm{OH}) 2$

$80 \mathrm{SrCO}$

$46 \mathrm{SrO}$

89 SrRESIN

141 Surfactant

$92 \mathrm{Th} 02$

107 Ti02

119 Tritium

$93 \mathrm{VO2}$

$62 \mathrm{VO} 2(\mathrm{COOH}) 2$

$16 \mathrm{UO2(OH)2}$

$27 \mathrm{Y}(\mathrm{COOH}) 3$

$11 Y(N O S) 8$

$128 \mathrm{Y}(\mathrm{OH}) \mathrm{S}$

$31 Y 2(\cos ) 3$
13

Waste Sand

.0000

.0000

.0000

.0000

.0000

.0000

.0000

.0000

.9712

.0000

.0000

.0000

.0000

.0000

.0000

.0000

.0000

.0000

.0000

.0000

.0000

.0000

.0000

.0000

.0000

.0000

.0000

1.882

.0000

.0000

.0000

.0000

.0000

.0000

.0000

.0000

.0000

.0000

.0000

.0000

.0000

.0000

.0000

.0000

.0000

.0000
Append ix II

Table 21-16

Page 016 of 173

Date 09/30/S2 Rev 09 
MATERIAL BALAKCE TABLES

SLLDGE-SLPERNATE FEED

STREAYS (CONT'D)-

STREAM NAME

\section{Y203 \\ 100 Zeolito \\ $44 \mathrm{Zn}(\mathrm{COOH}) 2$ \\ $54 \mathrm{Zn}(\mathrm{OII}) 2$ \\ $57 \mathrm{ZnO}$ \\ $104 \mathrm{Zr} 02$}

TOTAL FLOH, LB/IIR VAPOR FLOH, CFM LIQVID FLOH, GPM DESIGN FLOH', DEXSITY, LBS/FT3 TEMPERATURE, DEG $C$ PRESSURE, ATM PRESSURE, PSIG PRESSURE, IM HG PHASE

E.NTHLLPY, PCU/IIR
13

Waste Sand

.0000

.0000

.0000

.0000

.0000

.0000

26.01

.05

66.8118

88.00

1.00

.00

LIQUID

924.87
14

Fresh Frit SME Condens SME Cndnsate SIrry to SIEE ate to SMECT .0000 .0000 .0000 .0000 .0000 .6031

202.27

.27

$$
\begin{array}{r}
.0000 \\
.2150 E-03 \\
.2674 E-04 \\
.0000 \\
.0000 \\
.5299 E-04 \\
810.74 \\
.68
\end{array}
$$

$$
\begin{array}{r}
98.2861 \\
80.00 \\
1.84 \\
\mathbf{5 . 0 0}
\end{array}
$$

LIQUID 3803.02
61.7883

50.00

.97

$-.51$

733.86

LIQUID

16124.85 to RCI

.0000

.2152E-03

.2675E-04

$.1669 \mathrm{E}-10$

.0000

.5307E-04

866.69

.73

62.4728

50.00

.97

$-.51$

738.86

LIQUID

18699.16 
MATERIAL BALANCE TABLES

Date 09/80/82 Rov 09

\section{SLUDGE-SUPERNATE FEED}

STREAM NUMBERS -

STREAM NAME

$\begin{array}{cccc}17 & 18 & 19 & 20 \\ \text { SMECT Hg } & \text { SME Concent } & \text { Molter } & \text { Melter Sual } \\ \text { to MHiT } & \text { rate to NFT } & \text { Feed } & \text { Pot Purge }\end{array}$

COMPONENT FLOHS, LB/HR

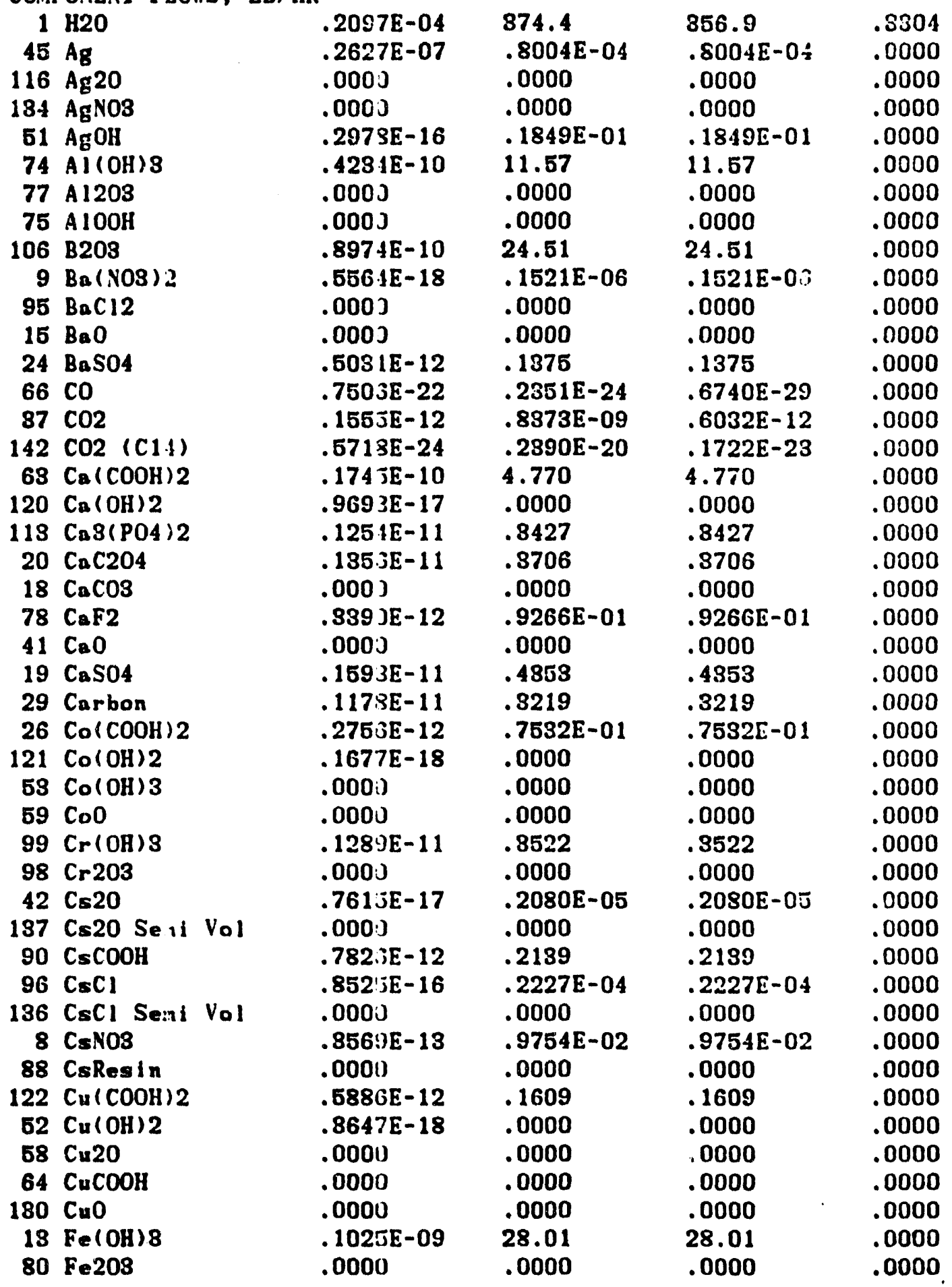


MATERIAL BALANCE TABLES

Date 09/30/82 Rev 09

SLCDGE-SLPERNATE FEED

\begin{tabular}{|c|c|c|c|c|c|}
\hline \multicolumn{2}{|c|}{$\begin{array}{l}\text { STREAMS }(\text { CONT'D) = } \\
\text { STREAMI TAME }\end{array}$} & $\begin{array}{l}17 \\
\text { SMECT } \mathrm{Hg}_{8} \\
\text { to MWWT }\end{array}$ & $\begin{array}{l}18 \\
\text { SME Concent } \\
\text { rate to MFT }\end{array}$ & $\begin{array}{l}19 \\
\text { Melter } \\
\text { Feed }\end{array}$ & $\begin{array}{l}20 \\
\text { Molter Seal } \\
\text { Pot Purge }\end{array}$ \\
\hline 101 & $\mathrm{FeO}$ & .0000 & .0000 & .0000 & $.0000^{\circ}$ \\
\hline 126 & Group A Sem I Vo & .0000 & .0000 & .0000 & .0000 \\
\hline 102 & GroupA & $.9501 E-12$ & .2597 & .2597 & .0000 \\
\hline 103 & GroupB & $.8013 E-11$ & .8286 & .8286 & .0000 \\
\hline 25 & $\mathrm{H2}$ & $.6819 E-23$ & $.5674 E-23$ & $.1676 E-27$ & .0000 \\
\hline 138 & $112 C 204$ & .0000 & .0000 & .0000 & .0000 \\
\hline 91 & H2O2 & .0000 & .0000 & .0000 & .0000 \\
\hline 34 & IICOOH & $.7620 \mathrm{E}-07$ & 1.464 & 1.886 & .0000 \\
\hline 48 & $\mathrm{IICI}$ & .0000 & .0000 & .0000 & .0000 \\
\hline 85 & HF & .0000 & .0000 & .0000 & .0000 \\
\hline 40 & Н.Nо3 & .0000 & .0000 & .0000 & .0000 \\
\hline 86 & llRes in & .0000 & .0000 & .0000 & .0000 \\
\hline 36 & ilg & $.2859 \mathrm{E}-02$ & $.5407 E-02$ & $.6407 E-02$ & .0000 \\
\hline 135 & $H_{E}, Y 032$ & .0000 & .0000 & .0000 & .0000 \\
\hline 21 & $\mathrm{HgO}$ & $.6510 \mathrm{E}-17$ & $.2141 E-04$ & $.2141 \mathrm{E}-04$ & .0000 \\
\hline 97 & 12 & .0000 & .0000 & .0000 & .0000 \\
\hline 39 & K20 & .0000 & .0000 & .0000 & .0000 \\
\hline 131 & $\mathrm{KMnO4}$ & .0000 & .0000 & .0000 & .0000 \\
\hline 118 & KNO3 & $.8538 E-14$ & $.9329 \mathrm{E}-03$ & $.9329 E-03$ & .0000 \\
\hline 105 & La203 & $.3046 E-11$ & .8318 & .8318 & .0000 \\
\hline 103 & $L 120$ & $.8480 E-10$ & 9.504 & $\mathbf{9 . 5 0 4}$ & .0000 \\
\hline 65 & $\mathrm{Mg}(\mathrm{COOH}) 2$ & $.3322 \mathrm{E}-11$ & .9081 & .9081 & .0000 \\
\hline 55 & $\mathrm{Mg}(\mathrm{OH}) 2$ & $.1653 E-17$ & .0000 & .0000 & .0000 \\
\hline s3 & $\mathrm{MgO}$ & $.1221 \mathrm{E}-10$ & 8.834 & $\mathbf{8 . 3 8 4}$ & .0000 \\
\hline 60 & $\operatorname{Mn}(\mathrm{COOH}) 2$ & $.2980 \mathrm{E}-10$ & 8.145 & 8.145 & .0000 \\
\hline 132 & $\operatorname{Mn}\left(\mathrm{N}_{03}\right) 2$ & .0000 & .0000 & .0000 & .0000 \\
\hline 129 & $\operatorname{Mn}(\mathrm{OH}) 2$ & $.1276 \mathrm{E}-15$ & .0000 & .0000 & .0000 \\
\hline 56 & $\mathrm{MnO}$ & .0000 & .0000 & .0000 & .0000 \\
\hline 14 & $\mathrm{MnO2}$ & .0000 & .0000 & .0000 & .0000 \\
\hline 81 & $\mathrm{~N} 2$ & $.2501 E-09$ & $.2674 E-02$ & $.4258 E-02$ & 16.11 \\
\hline 143 & $\mathrm{NA2CO3}(\mathrm{C} 14)$ & .0000 & .0000 & .0000 & .0000 \\
\hline 35 & NO & $.5796 \mathrm{E}-17$ & $.6108 E-14$ & $.4040 E-18$ & .0000 \\
\hline 84 & $\mathrm{NO2}$ & $.4690 \mathrm{E}-11$ & .8537 E-04 & $.9533 E-05$ & .0000 \\
\hline 70 & $\mathrm{Nn}(\mathrm{HgO}(\mathrm{OH}))$ & $.2124 E-14$ & $.5805 E-03$ & $.6805 \mathrm{E}-03$ & .0000 \\
\hline 94 & $\mathrm{Na2B} 407$ & $.1854 E-14$ & $.4844 \mathrm{E}-03$ & $.4844 E-03$ & .0000 \\
\hline 109 & $\mathrm{Na} 2 \mathrm{C}_{2} \mathrm{O} 4$ & $.1420 \mathrm{E}-14$ & $.3743 E-03$ & $.8743 E-08$ & .0000 \\
\hline $\mathbf{5}$ & $\mathrm{Nin} 2 \mathrm{CO3}$ & .0000 & .0000 & .0000 & .0000 \\
\hline 32 & $\operatorname{Sin} 20$ & $.1082 \mathrm{E}-09$ & 29.55 & 29.55 & .0000 \\
\hline 71 & $\mathrm{~T}_{2} 2 \mathrm{P}_{u} 02(0 \mathrm{II}) 4$ & $.8613 E-19$ & $.2354 E-07$ & $.2354 E-07$ & .0000 \\
\hline 78 & $\mathrm{No} 2 \mathrm{PhO}_{4}$ & $.1771 E-16$ & $.4840 \mathrm{E}-05$ & $.4840 \mathrm{E}-05$ & .0000 \\
\hline 72 & $\mathrm{Na} 2 \mathrm{Ru} 04$ & $.1728 \mathrm{E}-15$ & $.4723 \mathrm{E}-04$ & $.4723 E-04$ & .0000 \\
\hline 6 & $\mathrm{Na} 2 \mathrm{~S} 04$ & $.8504 E-12$ & $.9577 E-01$ & $.9577 E-01$ & .0000 \\
\hline 68 & $\mathrm{NaA} 102$ & $.8618 E-12$ & .2354 & .2854 & .0000 \\
\hline 114 & $\mathrm{NaBO2}$ & .0000 & .0000 & .0000 & .0000 \\
\hline 140 & NaB02 Semi Vol & .0000 & .0000 & .0000 & .0000 \\
\hline 50 & $\mathrm{NinCOOH}$ & $.7914 E-10$ & 21.72 & 21.72 & .0000 \\
\hline
\end{tabular}


DPSP $80-1033$

MATERIAL BALANCE TABIES SLUDGE-SLPERNATE FEED

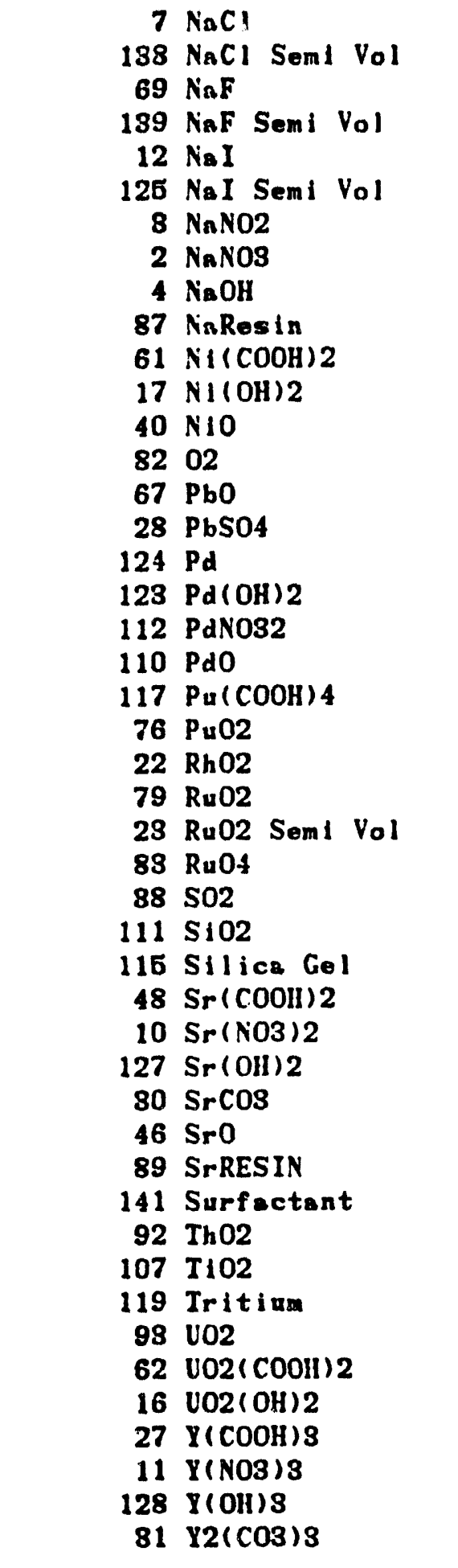

\section{STREAMS ( CONT'D)- STREAM NAME$$
\text { STREAM NAME }
$$

Appeudix II

Tnble 21-16

Pnge 020 of 173

Date 09/80/82 Rev CO

\begin{tabular}{|c|c|}
\hline 19 & 20 \\
\hline Melter & Moltur Seal \\
\hline $\begin{array}{l}\text { Feed } \\
.9546 r-01\end{array}$ & $\begin{array}{c}\text { Pot Pי:1.a : } \\
\text {.0000 }\end{array}$ \\
\hline .0000 & .0000 \\
\hline $.5049 E-03$ & .0500 \\
\hline .0000 & .0600 \\
\hline $.9252 E-02$ & .0000 \\
\hline .0000 & .0060 \\
\hline .0000 & .0000 \\
\hline S.079 & .0000 \\
\hline .0000 & .0000 \\
\hline .0000 & .0000 \\
\hline 2.855 & .0000 \\
\hline .0000 & .0000 \\
\hline .0000 & .0000 \\
\hline $.2466 E-02$ & 4.563 \\
\hline .0000 & .0000 \\
\hline .1294 & .0000 \\
\hline .0000 & .0000 \\
\hline .0000 & .0000 \\
\hline .0000 & .0000 \\
\hline .0000 & .0000 \\
\hline $.1327 E-03$ & .11000 \\
\hline $.3368 E-01$ & .0000 \\
\hline $.1287 E-01$ & .0000 \\
\hline $.6343 E-01$ & .0000 \\
\hline .0000 & .0000 \\
\hline .0000 & .0000 \\
\hline $.8810 E-28$ & .0000 \\
\hline 103.8 & .0000 \\
\hline .0000 & .0000 \\
\hline .1162 & .0000 \\
\hline $.1357 E-06$ & .0000 \\
\hline .0000 & .0000 \\
\hline .0000 & .0000 \\
\hline .0000 & .0000 \\
\hline .0000 & .0000 \\
\hline .0000 & .0000 \\
\hline .5280 & .0000 \\
\hline 1.664 & .0000 \\
\hline $.8794 E-09$ & .0000 \\
\hline .0000 & .0000 \\
\hline 8. 692 & .0000 \\
\hline .0000 & .0000 \\
\hline $.7943 E-01$ & .0000 \\
\hline $.9636[-07$ & .0000 \\
\hline .0000 & .0000 \\
\hline .0000 & .0000 \\
\hline
\end{tabular}


DPSP 80-1033

MATERIAL BALANCE TABLES SLUDGE-SEPERNATE FEED STREAMS (CONT'D)STREAM NAME

17 Y203

100 Zeolite

$44 \mathrm{Zn}(\mathrm{COOH}) 2$

$64 \mathrm{Zn}(\mathrm{OH}) 2$

$57 \mathrm{ZnO}$

$104 \mathrm{ZrO}$

TOTAL FLOH, LB/IIR VIPOR FLOH', CFM LINUID FLOW, GPM DESIGI FLOW, DENSITY, LBS/FT8 TENPERATURE, DEG C PRESSURL, ATI PRESSURE, PSIG PRESSURE, HG PIIISE

ENTHALPY, PCU/HR
Append Ix H

Table 21-16

Page 021 of 178

Date 09/80/82 Rev 09

17

SMECT Hg SME Concent

to MWViT

.0000

rate to MFT

.0000

$.1235 \mathrm{E}-10$

.1586E- 11

$.9577 E-18$

.0000

8.376

.4197

.0000

.0000

$.8046 \mathrm{E}-11$

.00

.8318

648.47

.00

.99

19

Melter

Food

.0000

8.875

.4197

.0000

.0000

.8318

625.89

20
Molter Seal
Pot Purge
.0000
.0000
.0000
.0000
.0000
.0000
20.00
4.72

.95

774.6994

50.00

.97

$-.51$

783.86

LIQUID

.01

$\begin{array}{rr}82.0182 & .0700 \\ 50.00 & 85.00 \\ .97 & 1.00 \\ -.51 & .00 \\ 783.86 & \\ \text { LIQUID } & \text { VAPOR } \\ 22190.85 & -1029.96\end{array}$


DPSP $80-1093$

MATERIAL BALANCE TABLES

SLUDGE-SLPER.YATE FEED

STREAM NUMBERS -

STREAM NAME

COMPONENT E-OWS, LB/HR

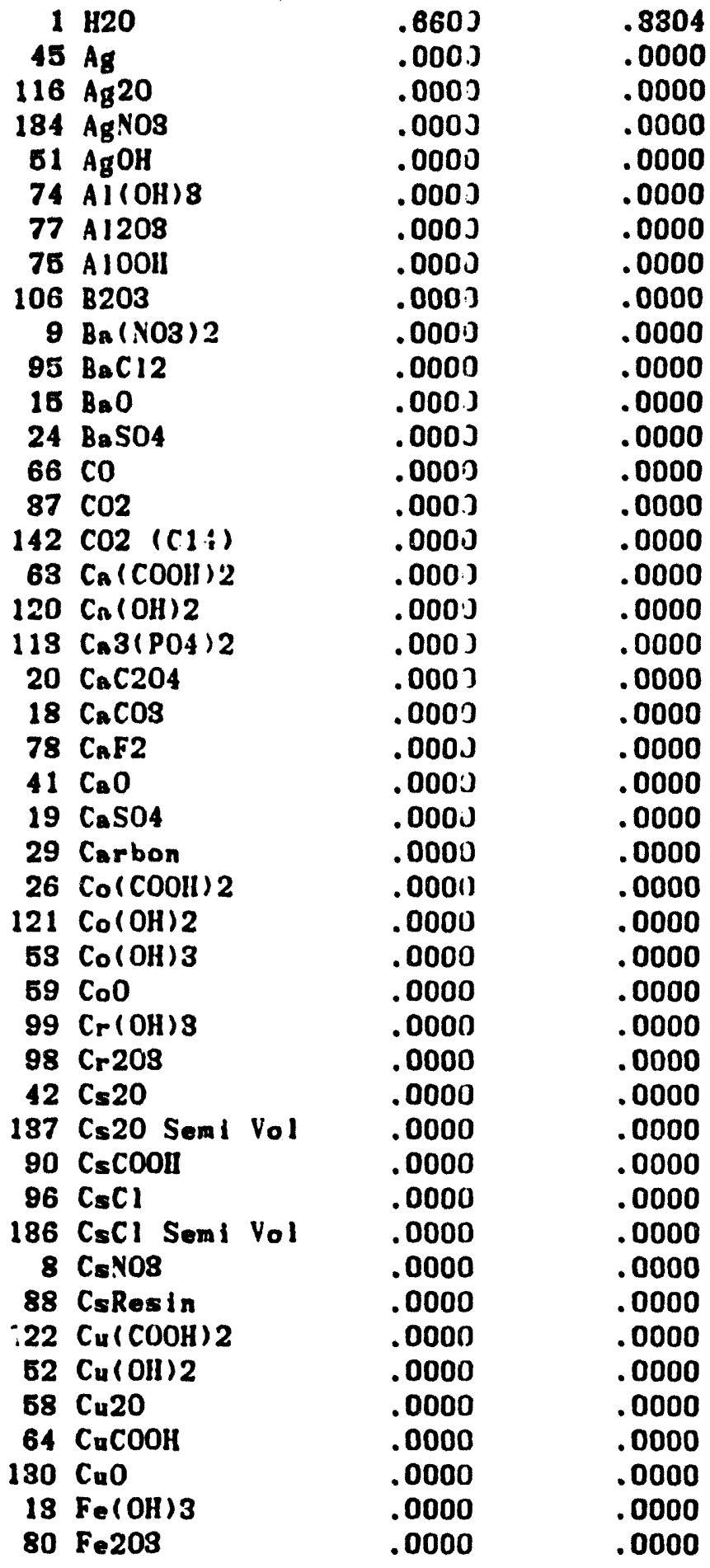

Molter ECTV Melter Air

In Lenkage

8304

.0000

.0000

.0000

0000

0000

.0000

0000

.0000

0000

0000

0000

.0000

0000

0000

0000

0000

0000

0000

.0000

- toon

0000

.0000

.0000
Appondix 11

Table 21-16

Pago 022 of 173

Date 09/30/82 Rev 00
23

Nelter

Off-Gas

869.9

.0000

.0000

.0000

$.1849 \mathrm{E}-03$

.1157

.0000

.0000

.2451

$.1521 \mathrm{E}-08$

.0000

.0000

$.1875 \mathrm{E}-02$

7.614

16.57

. 1722E-23

$.4770 E-01$

.0000

.3427E-02

.3706E-02

.0000

$.9266 \mathrm{E}-03$

.0000

. 4353E-02

$.3219 \mathrm{E}-02$

.7532E-03

.0000

.0000

.0000

$.8522 \mathrm{E}-02$

.0000

.2080E-07

.0000

.2139E-02

.2227E-06

$.1046 E-01$

.9754 E-04

.0000

. 1609E-02

.0000

.0000

.0000

.0000

.2801

.0000
21

Histe

Clases

.0000

.0000

.1707 E-01

.0000

.0000

.0000

7.632

.0000

2.1 .14

.0000

.0000

$.8044 E-01$

.0000

.0000

.0000

.0000

.0000

.0000

.3393

.0000

.0000

.0000

2.489

.0000

.0000

.0000

.0000

.0000

$.3751 E-01$

.0000

.2566

.1659

.0000

.0000

.0000

.0000

.0000

.0000

.0000

.0000

.0000

.0000

.8251 E-01

.0000

13.88 
MATERIAL BALANCE TABLES

SILDGE-SUPERNATE FEED

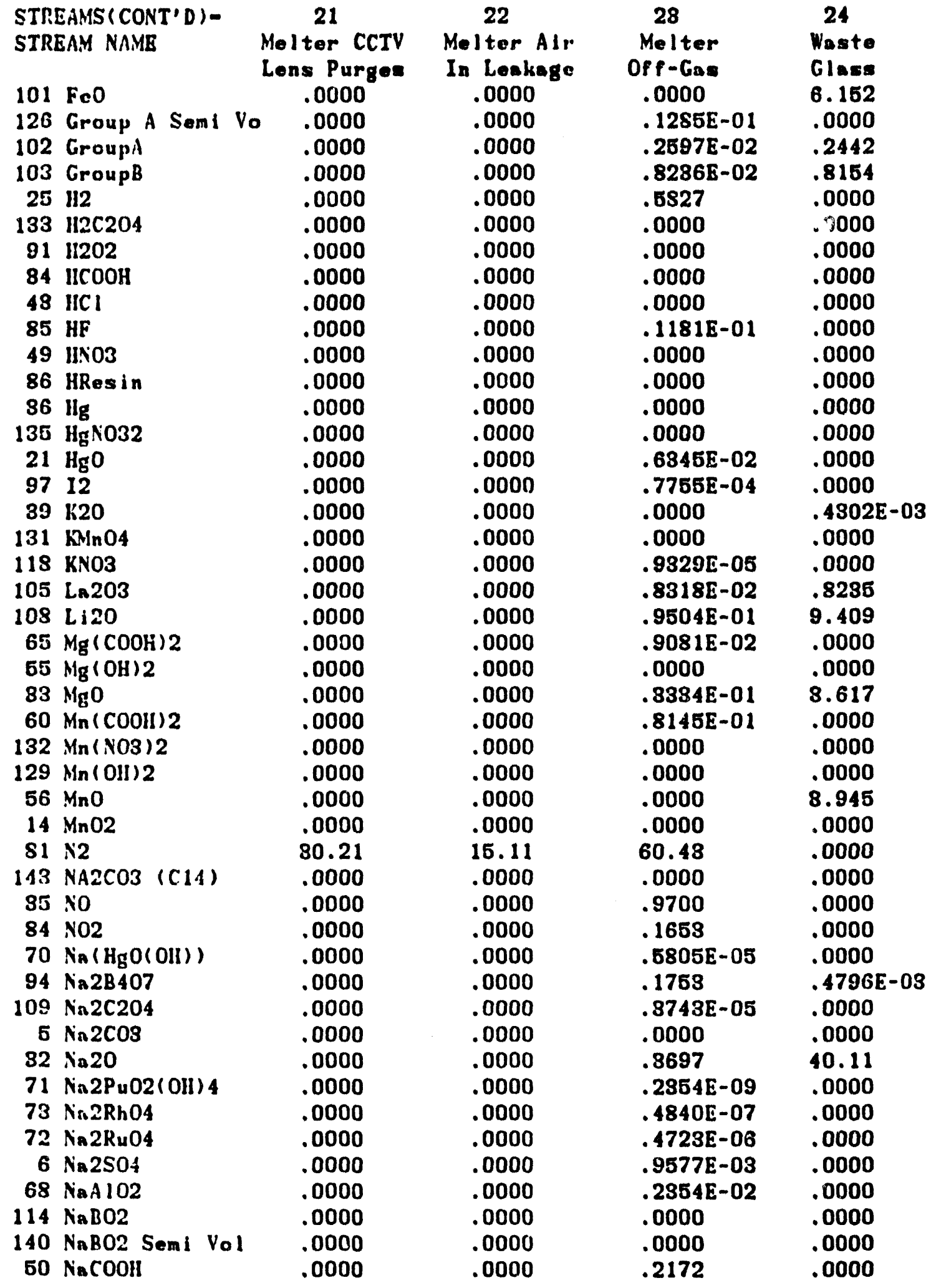


DPSP $80-1088$

MATERIAL BALANCE TABLES SLUDGE-SLPERNATE FEED STREAMS (CONT'D)STREAM NAME

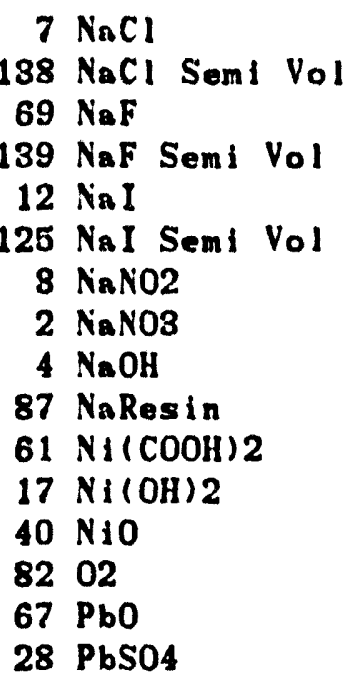

$124 \mathrm{Pd}$

$123 \mathrm{Pd}(\mathrm{OH}) 2$

112 PdNO32

$110 \mathrm{PdO}$

$117 \mathrm{Pu}(\mathrm{COOH}) 4$

$76 \mathrm{Pu} 02$

22 Rh02

79 Ru02

23 Ru02 Semi Vol

$83 \mathrm{Ru} 04$

$88 \mathrm{~S} 02$

$111 \mathrm{Si} 02$

115 Sillca Gel

$48 \mathrm{Sr}(\mathrm{COOH}) 2$

$10 \mathrm{Sr}(\mathrm{NO3}) 2$

$127 \mathrm{Sr}(\mathrm{OH}) 2$

$80 \mathrm{SrCO3}$

$46 \mathrm{SrO}$

89 SrRESIN

141 Surfactant

92 Th02

107 Ti02

119 Tritium

$93 \mathrm{U} 02$

$62 \mathrm{VO}(\mathrm{COOH}) 2$

$16 \mathrm{VO2}(\mathrm{OH}) 2$

$27 \mathrm{Y}(\mathrm{COOH}) \mathrm{S}$

$11 \mathrm{Y}(\mathrm{NOS}) \mathrm{S}$

$128 \mathrm{Y}(\mathrm{OH}) 8$

$81 Y 2(\cos ) \mathrm{s}$

\begin{tabular}{|c|c|}
\hline 21 & 22 \\
\hline $\begin{array}{c}\text { Melter JCTV } \\
\text { Lens } \mathrm{P}_{\mathrm{u}} \cdot \mathrm{ges} \\
.00 \mathrm{~J}\end{array}$ & $\begin{array}{c}\text { Melter Air } \\
\text { In Leakage } \\
.0000\end{array}$ \\
\hline .000$)$ & .0000 \\
\hline נ.000. & .0000 \\
\hline .000$\}$ & .0000 \\
\hline .0001 & .0000 \\
\hline נ.000. & .0000 \\
\hline .000$\}$ & .0000 \\
\hline .000$\}$ & .0000 \\
\hline .0001 & .0000 \\
\hline .0001 & .0000 \\
\hline .000$)$ & .0000 \\
\hline ) & .0000 \\
\hline .0003 & .0000 \\
\hline 9.127 & 4.663 \\
\hline J000了. & .0000 \\
\hline .000$)$ & .0000 \\
\hline .0003 & .0000 \\
\hline J000נ. & .0000 \\
\hline .000 .3 & .0000 \\
\hline .0001 & .0000 \\
\hline I.000 & .0000 \\
\hline I.000) & .0000 \\
\hline ).000) & .0000 \\
\hline J & .0000 \\
\hline .000 .1 & .0000 \\
\hline ).000. & .0000 \\
\hline ני000. & .0000 \\
\hline $\left..000_{i}\right)$ & .0000 \\
\hline .00011 & .0000 \\
\hline .000 & .0000 \\
\hline .000: & .0000 \\
\hline ).000. & .0000 \\
\hline .00011 & .0000 \\
\hline (000'. & .0000 \\
\hline .000 .1 & .0000 \\
\hline .0000 & .0000 \\
\hline .0000 & .0000 \\
\hline .0000 & .0000 \\
\hline .0000 & .0000 \\
\hline .0000 & .0000 \\
\hline .0000 & .0000 \\
\hline .0000 & .0000 \\
\hline .0000 & .0000 \\
\hline .0000 & .0000 \\
\hline .0000 & .0000 \\
\hline .0000 & .0000 \\
\hline
\end{tabular}

Appendix $\mathbf{H}$

Tnble 21-16

Page 024 of 173

Date 09/30/82 Rev 09

\begin{tabular}{|c|c|}
\hline 23 & 24 \\
\hline Melter & Haste \\
\hline Off - Gas & GInss \\
\hline $.9546 \mathrm{E}-03$ & $.00 \div 30$ \\
\hline . 9088E-01 & .0000 \\
\hline $.50 \cdot 9 E-05$ & .0000 \\
\hline $.7439 E-01$ & .0000 \\
\hline $.9252 \pi-04$ & .0000 \\
\hline $.9068 \mathrm{E}-02$ & .0000 \\
\hline .0000 & .0000 \\
\hline $.3079 E-01$ & .0000 \\
\hline .0000 & .0000 \\
\hline .0000 & .0000 \\
\hline $.2855 E-01$ & .0000 \\
\hline .0000 & .0000 \\
\hline .0000 & 1.419 \\
\hline 18.20 & .0000 \\
\hline .0000 & $.9430 \mathrm{E}-01$ \\
\hline $.1294 \mathrm{E}-02$ & .0000 \\
\hline .0000 & .0000 \\
\hline .0000 & .0000 \\
\hline .0000 & .0000 \\
\hline .0000 & .0000 \\
\hline . 1327E-05 & .0000 \\
\hline $.3368 \mathrm{E}-03$ & $.3343 E-01$ \\
\hline $.1287 E-03$ & $.1274 E-01$ \\
\hline $.6343 E-03$ & $.5654 \mathrm{E}-0 !$ \\
\hline $.6283 E-02$ & .0000 \\
\hline .0000 & .0000 \\
\hline .8100 & .0000 \\
\hline 1.088 & 102.8 \\
\hline .0000 & .0000 \\
\hline $.1162 \mathrm{E}-02$ & .0000 \\
\hline . 1857E-08 & .0000 \\
\hline .0000 & .0000 \\
\hline .0000 & .0000 \\
\hline .0000 & $.6710 \mathrm{E}-01$ \\
\hline .0000 & .0000 \\
\hline .0000 & .0000 \\
\hline $.5280 \mathrm{E}-02$ & .5227 \\
\hline $.1664 \mathrm{E}-01$ & 1.647 \\
\hline .3794E-09 & .0000 \\
\hline .0000 & 2.742 \\
\hline $.8692 E-01$ & .0000 \\
\hline .0000 & .0000 \\
\hline .7943E-03 & .0000 \\
\hline $.9686 E-09$ & .0000 \\
\hline .0000 & .0000 \\
\hline .0000 & $.0000^{\circ}$ \\
\hline
\end{tabular}


MATERIAL BALANCE TABLES

Date 09/80/82 Rev 09

SLUDGE-SUPERNATE FEED

STREAYS (CONT'D)-

STREAM NAME

$47 \quad 1203$

100 Zeolite

$44 \mathrm{Zn}(\mathrm{COOH}) 2$

$54 \mathrm{Zn}_{\mathrm{n}}(\mathrm{Oll}) 2$

$57 \mathrm{Zn}_{\mathrm{n}}$

$104 \mathrm{Zr} 02$

TOTAL FLOH', LB/HR

VAPOR FLOW, CFM

LIQUID FLOH, GPM

DESIGN FLOH,

DENSITY, LBS/FT3

TEVPERATURE, DEG C

PRESSURE, ATM

PRESSLIRE, PSIG

PRESSURE, MM HG

PIIASE

ENTHALPY, PCU/IIR

\begin{tabular}{|c|c|c|c|}
\hline $\begin{array}{l}21 \\
\text { Melter CCTV } \\
\text { Lens Purges }\end{array}$ & $\begin{array}{l}22 \\
\text { Melter Air } \\
\text { In Leakage }\end{array}$ & $\begin{array}{c}28 \\
\text { Melter } \\
\text { Off-Gas }\end{array}$ & $\begin{array}{l}24 \\
\text { Waste } \\
\text { Glass }\end{array}$ \\
\hline $.0000^{\circ}$ & .0000 & .0000 & $.8964 \mathrm{E}-\mathrm{C} 1$ \\
\hline .0000 & .0000 & $.3875 E-01$ & 8.842 \\
\hline .0000 & .0000 & $.4197 \mathrm{E}-02$ & .0000 \\
\hline .0000 & .0000 & .0000 & .0000 \\
\hline .0000 & .0000 & .0000 & .2176 \\
\hline $\begin{array}{r}.0000 \\
40.00 \\
9.45\end{array}$ & $\begin{array}{r}.0000 \\
20.00 \\
4.72\end{array}$ & $\begin{array}{r}.8318 \mathrm{E}-02 \\
477.88 \\
426.80\end{array}$ & $\begin{array}{c}.8235 \\
228.0\end{array}$ \\
\hline .0706 & .0706 & .0187 & 150.3417 \\
\hline 85.00 & 85.00 & 520.00 & 1050.0 \\
\hline 1.00 & 1.00 & .99 & .9 \\
\hline .00 & .00 & $\begin{array}{r}-.18 \\
750.88\end{array}$ & $\begin{array}{r}-.18 \\
750.88\end{array}$ \\
\hline $\begin{array}{r}\text { VAPOR } \\
-2059.93\end{array}$ & $\begin{array}{r}\text { VAPOR } \\
-1029.96\end{array}$ & $\begin{array}{r}\text { VAPOR } \\
\mathbf{3 2 9 9 1 7 . 6 2}\end{array}$ & $\begin{array}{r}\text { LIQUID } \\
78800.89\end{array}$ \\
\hline
\end{tabular}


DPSP $80-1033$

MATERIAL BALANCE TABLES

SLUDGE-SUPERNATE FEED

STREAM NUNBERS -

STREAM NAME

COMPONENT FLOH'S, LB/HR

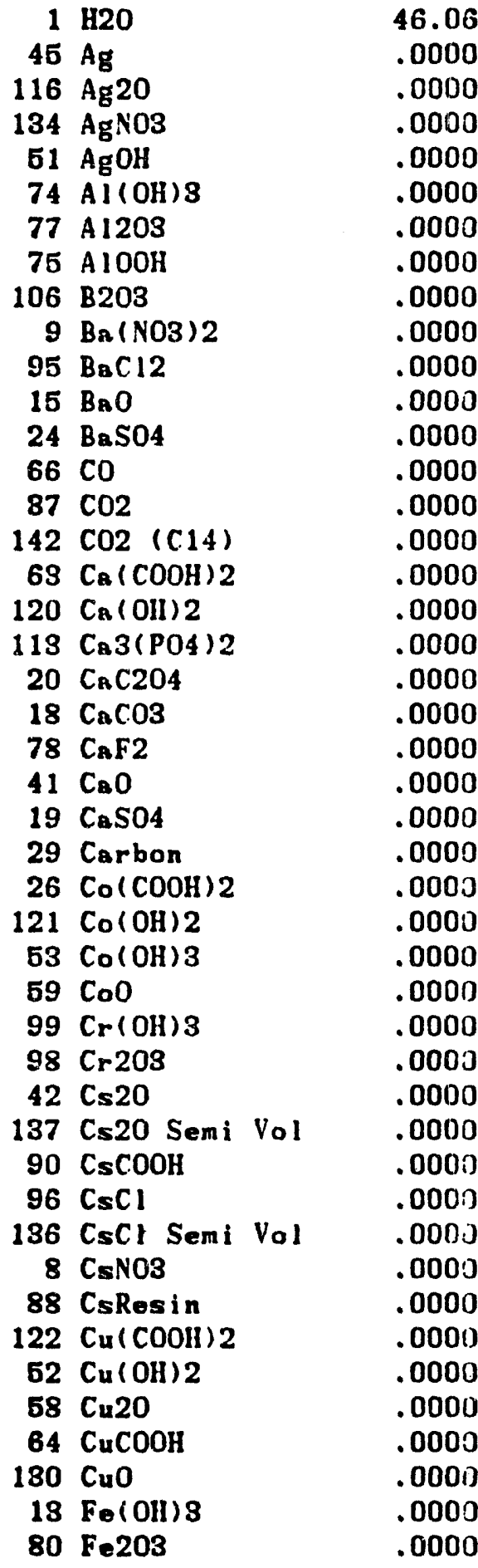

Appendix H

Table 21-16

Pnge 020 of 173

Date 09/30/82 Rev 09 
Material BALANCE TABLES

SLUDGE-SLPERNATE FELD

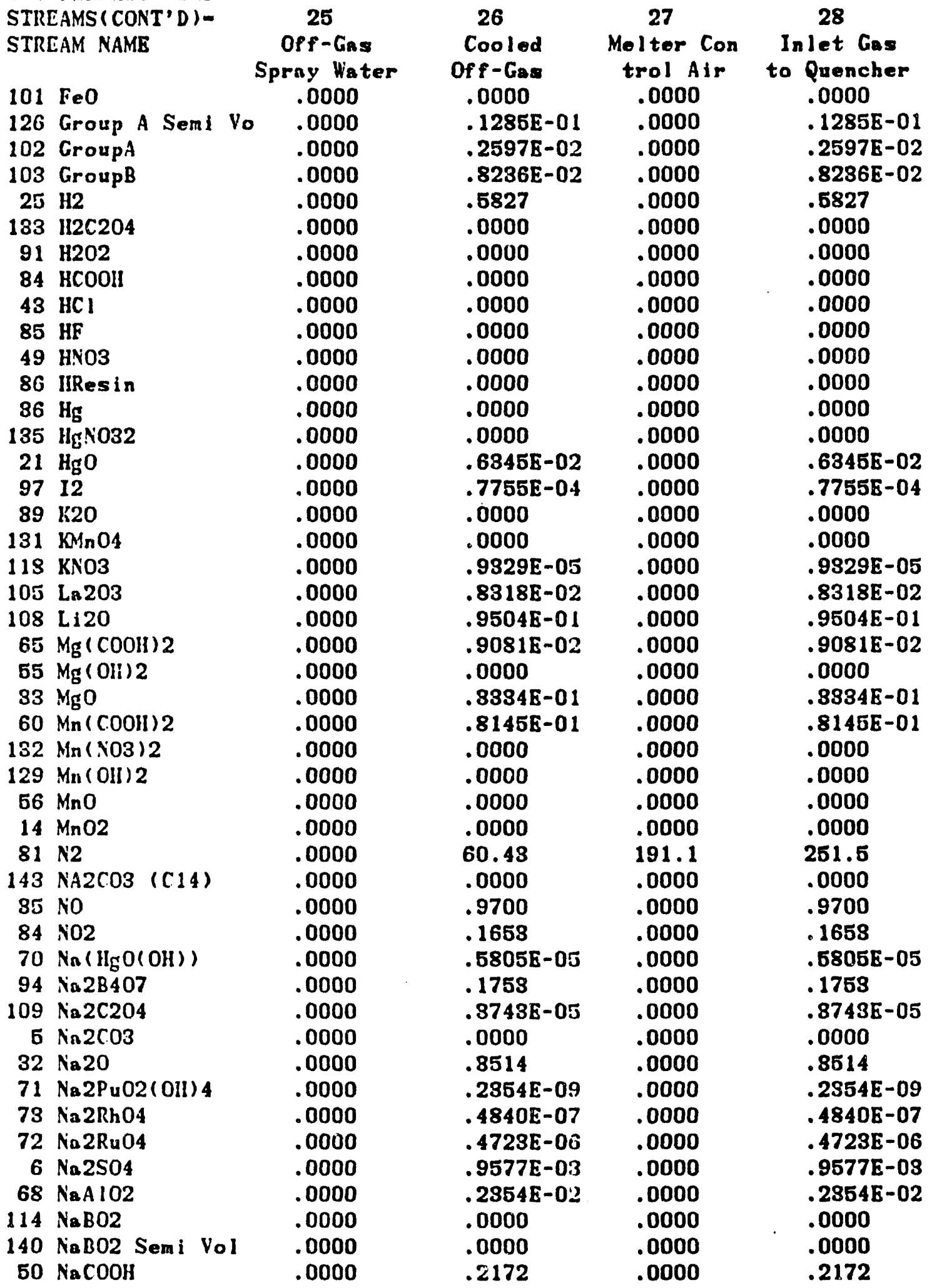


DPSP 80-1083

MATERIAL BALANCE TABLES

SLUDGE-SUPERNATE FEED

STREAMS (CONT'D)-

STREAM NAME

$7 \mathrm{NaCl}$

$138 \mathrm{NaCl}$ Seni Vol

$69 \mathrm{NaF}$

139 NaF Semi Vol

$12 \mathrm{NaI}$

$125 \mathrm{NaI}$ Semi Vol

$8 \mathrm{NaNO}_{2}$

$2 \mathrm{NaNO3}$

$4 \mathrm{NaOH}$

87 NaResin

$61 \mathrm{Ni}(\mathrm{COOH}) 2$

$17 \mathrm{Ni}(\mathrm{OH}) 2$

$40 \mathrm{NiO}$

8202

$67 \mathrm{PbO}$

$28 \mathrm{PbS} 04$

$124 \mathrm{Pd}$

$123 \mathrm{Pd}(\mathrm{OH}) 2$

112 PdNO32

$110 \mathrm{PdO}$

$117 \mathrm{Pu}(\mathrm{COOH}) 4$

$76 \mathrm{Pu} 02$

$22 \mathrm{RhO2}$

$79 \mathrm{Ru} 02$

23 Ru02 Seni Vol

$83 \mathrm{Ru} 04$

$88 \mathrm{SO2}$

$111 \mathrm{SiO} 2$

115 Silics Gel

$48 \mathrm{Sr}(\mathrm{COOH}) 2$

$10 \mathrm{Sr}(\mathrm{NO3}) 2$

$127 \mathrm{Sr}(\mathrm{OH}) 2$

$80 \mathrm{SrCO3}$

$46 \mathrm{Sr} 0$

89 SrRESIN

141 Surfactant

$92 \mathrm{ThO2}$

107 Ti02

119 Tritium

$98 \mathrm{VO2}$

$62 \mathrm{VO}(\mathrm{COOII}) 2$

$16 \mathrm{VO2}(\mathrm{OH}) 2$

$27 \mathrm{Y}(\mathrm{COOH}) 3$

$11 \mathrm{Y}(\mathrm{NOS}) \mathrm{8}$

$128 \mathrm{Y}(\mathrm{OH}) \mathrm{S}$

$81 Y 2(\cos ) 8$

25
Off-Cas
Sprey Hater
.0000
.0000
.0000
.0000
.0003
.0003
$.000 J$
.0000
.0005
.0005
.0000
.0000
.0000
.0000
.0000
.0000
.0000
.0003
.0000
.0000
.0000
.0000
.0000
.0000
.0000
.0000
.0000
.0000
.0000
.0000
.0000
.0000
.0000
.0000
.0000
.0000
.0000
.0000
.0000
.0000
.0000
.0000
.0000
.0000
.0000
.0000

Appendix H

Table 21-15

Page 028 of 173

Date $09 / 30 / \varepsilon 2$ Rev 09

\begin{tabular}{|c|c|c|}
\hline 26 & 27 & 28 \\
\hline $\begin{array}{l}\text { Cooled } \\
\text { off-Gas }\end{array}$ & $\begin{array}{l}\text { Melter Con } \\
\text { trol Air }\end{array}$ & $\begin{array}{l}\text { Inlut Gas } \\
\text { to Ouericher }\end{array}$ \\
\hline $.9546 \mathrm{E}-03$ & .0000 & $.9546 \mathrm{E}-03$ \\
\hline $.9088 \mathrm{E}-01$ & .0000 & $.00885-01$ \\
\hline $.2480 E-01$ & .0000 & $.2480 \mathrm{E}-01$ \\
\hline $.7439 E-01$ & .0000 & $.74395-01$ \\
\hline $.9252 \mathrm{E}-04$ & .0000 & $.9252 E-04$ \\
\hline $.9068 \mathrm{E}-02$ & .0000 & $.90655-02$ \\
\hline .0000 & .0000 & .0000 \\
\hline $.8079 E-01$ & .0000 & $.30702-01$ \\
\hline .0000 & .0000 & .0000 \\
\hline .0000 & .0000 & .0000 \\
\hline $.2855 E-01$ & .0000 & $.2855 E-01$ \\
\hline .0000 & .0000 & . \\
\hline .0000 & .0000 & .0000 \\
\hline 18.20 & 67.73 & 75.93 \\
\hline .0000 & .0000 & .0000 \\
\hline $.1294 E-02$ & .0000 & $.1294 \mathrm{E}-02$ \\
\hline .0000 & .0000 & .0000 \\
\hline .0000 & .0000 & .0000 \\
\hline .0000 & .0000 & .0000 \\
\hline .0000 & .0000 & .0000 \\
\hline . 1327E-05 & .0000 & ت \\
\hline $.8368 \mathrm{E}-03$ & .0000 & $.3368 E-03$ \\
\hline $.1287 E-03$ & .0000 & $.1287 \mathrm{E}-\mathrm{C3}$ \\
\hline $.6343 \mathrm{E}-03$ & .0000 & $.6843 E-03$ \\
\hline $.6283 \mathrm{E}-02$ & .0000 & $.6283 E-02$ \\
\hline .0000 & .0000 & .0000 \\
\hline .3100 & .0000 & .3100 \\
\hline 1.038 & .0000 & 1.038 \\
\hline .0000 & .0000 & .0000 \\
\hline $.1162 \mathrm{E}-02$ & .0000 & $.1162 E-02$ \\
\hline .1857 E-08 & .0000 & $.1857 E-08$ \\
\hline .0000 & .0000 & .0000 \\
\hline .0000 & .0000 & .0000 \\
\hline .0000 & .0000 & .0000 \\
\hline .0000 & .0000 & .0000 \\
\hline .0000 & .0000 & .0000 \\
\hline $.6280 E-02$ & .0000 & $.5280 \mathrm{E}-02$ \\
\hline $.1664 E-01$ & .0000 & $.1664 \llbracket-01$ \\
\hline $.3794 E-09$ & .0000 & $.8794 E-09$ \\
\hline .0000 & .0000 & .0000 \\
\hline $.3692 E-01$ & .0000 & $.3692 E-01$ \\
\hline .0000 & .0000 & .0000 \\
\hline $.7943 E-03$ & .0000 & $.7943 E-03$ \\
\hline $.9686 E-09$ & .0000 & $.9636 E-09$ \\
\hline .0000 & .0000 & .0000 \\
\hline .0000 & .0000 & .0000 \\
\hline
\end{tabular}


MATER.IAL BALANCE TABLES

Deto 09/30/82 Rev 09

SLUDGE-SIPERNATE FEED STREAMS (CONT'D)STREAM NAME

$47 \times 203$

100 Zeolite

$44 \mathrm{Zn}(\mathrm{COOH}) 2$

$54 \mathrm{Zn}(\mathrm{OH}) 2$

$57 \mathrm{Zn} 0$

$104 \mathrm{Zr} 02$

TOTAL FLOH, LB/HR

VAPOR FLOW, CFM

LIQUID FLOW, GPM DESIGN FLOW, DENSITY, LBS/FT3 TEMPERATURE, DEG C PRESSURE, ATM PRESSURE, PSIG PRESSURE, MM HG PHASE

ENTHALPY, PCU/HR

\begin{tabular}{|c|c|c|c|}
\hline & & & \\
\hline 25 & 26 & 27 & 28 \\
\hline $\begin{array}{l}\text { Off-Gas } \\
\text { Spray Water }\end{array}$ & $\begin{array}{l}\text { Cooled } \\
\text { Off-Gas }\end{array}$ & $\begin{array}{l}\text { Melter Con } \\
\text { trol Air }\end{array}$ & $\begin{array}{l}\text { Inlet Gas } \\
\text { to Quencher }\end{array}$ \\
\hline $\begin{array}{l}.0000 \\
.0000\end{array}$ & $\begin{array}{l}.0000 \\
.8875 E-01\end{array}$ & $\begin{array}{l}.0000 \\
.0000\end{array}$ & $\begin{array}{l}.0000 \\
.8375 E-01\end{array}$ \\
\hline .0000 & $.4197 \mathrm{E}-02$ & .0000 & $.4197 \mathrm{E}-02$ \\
\hline .0000 & .0000 & .0000 & .0000 \\
\hline .0000 & .0000 & .0000 & .0000 \\
\hline .0000 & $.8318 E-02$ & .0000 & $.8318 \mathrm{E}-02$ \\
\hline 46.06 & $\begin{array}{l}523.93 \\
887.06\end{array}$ & $\begin{array}{r}253.01 \\
59.77\end{array}$ & $\begin{array}{l}776.95 \\
464.61\end{array}$ \\
\hline .09 & & & \\
\hline 62.4300 & .0226 & .0706 & .0279 \\
\hline 40.00 & 375.00 & 35. & 808.63 \\
\hline 1.34 & .98 & 1.00 & .98 \\
\hline 5.00 & -.26 & .00 & -.84 \\
\hline & 746.55 & & 742.44 \\
\hline LIQUID & VAPOR & VAPOR & VAPOR \\
\hline 1876 & 832576.94 & -18029.66 & 319547.29 \\
\hline
\end{tabular}


DPSP 80-1033

MATERIAL BALANCE TABLES

SLUDGE-SUPERNATE FEED

STREAM NUMEERS -

STREAM NAME

COMPONENT FLOHS, LB/HR

$1 \mathrm{H} 2 \mathrm{O}$

$45 \mathrm{Ag}$

116 Ag20

134 AgNO3

$51 \mathrm{AgOH}$

74 Al $(\mathrm{OH}) \mathrm{S}$

77 A1203

$75 \mathrm{~A} 100 \mathrm{H}$

106 B203

$9 \mathrm{Ba}(\mathrm{NO3}) 2$

$95 \mathrm{BaCl} 2$

$15 \mathrm{Ba} O$

$24 \mathrm{BaSO}$

$66 \mathrm{CO}$

$87 \mathrm{CO2}$

$142 \mathrm{CO}$ ( $\mathrm{C} 14)$

$63 \mathrm{Ca}(\mathrm{COOH}) 2$

$120 \mathrm{Ca}(\mathrm{OH}) 2$

$113 \mathrm{Ca} 3(\mathrm{PO}) 2$

$20 \mathrm{CaC2O4}$

$18 \mathrm{CaCO3}$

$78 \mathrm{CaF2}$

$41 \mathrm{CaO}$

$19 \mathrm{CaSO4}$

29 Carbon

$26 \mathrm{Co}(\mathrm{COOH}) 2$

$121 \mathrm{Co}(\mathrm{OH}) 2$

$53 \mathrm{Co}(\mathrm{OH}) \mathrm{S}$

$59 \mathrm{CoO}$

$99 \mathrm{Cr}(\mathrm{OH}) \mathrm{S}$

$98 \mathrm{Cr} 203$

$42 \mathrm{Cs} 20$

137 Cs20 Semi Vol

$90 \mathrm{CsCOOH}$

$96 \mathrm{CsCl}$

$186 \mathrm{CsCl}$ Semi Vol

$8 \mathrm{CsNO3}$

88 CsResin

$122 \mathrm{Cu}(\mathrm{COOH}) 2$

$52 \mathrm{Cu}(\mathrm{OH}) 2$

58 Cu2O

$64 \mathrm{CuCOOH}$

$130 \mathrm{CuO}$

$13 \mathrm{Fe}(\mathrm{OH}) \mathrm{S}$

$80 \mathrm{Fe} 203$

$\begin{array}{cc}29 & 80 \\ \text { Liquid to } & \text { Dilution } \\ \text { Quencher } & \text { Air }\end{array}$

$.2760 E \& 05$

.0000

.0000

.0000

$.6401 E-02$

5.660

.0000

.0000

11.97

$.5193 E-07$

.0000

.0000

$.4688 \mathrm{E}-01$

$.8020 E-02$

.1514

$.1574 \mathrm{E}-25$

1.626

.0000

.1168

.1264

.0000

$.3150 E-01$

.0000

.1484

$.9297 \mathrm{E}-01$

.2568E-01

.0000

.0000

.0000

.1201

.0000

$.7627 E-06$

$.1239 E-03$

$.7261 \mathrm{E}-01$

$.4858 \mathrm{E}-05$

.3596

$.8831 E-02$

.0000

$.5485 E-01$

.0000

.0000

.0000

.0000

13.70

.0000
Appendix II

Table 21-16

Page 030 of 173

Date 09/30/82 Rev 09 
DPSP 80-1033

MATERIAL BALANCE TABLES

SLIDCE-SUPERNATE FEED

STREAMS (CONT'D) -

STREAM NAME

$101 \mathrm{FeO}$

126 Group A Semi Vo

102 GroupA

103 Group B

$25 \mathrm{H} 2$

$133 \mathrm{H} 2 \mathrm{C2O4}$

9111202

$84 \mathrm{HCOOH}$

$43 \mathrm{HCl}$

$85 \mathrm{HF}$

49 HNO3

86 IIRes in

$86 \mathrm{Hg}$

$135 \mathrm{HgN032}$

$21 \mathrm{HgO}$

9712

$39 \times 20$

$131 \mathrm{KMnO4}$

118 KNO3

$105 \operatorname{La} 203$

$108 \mathrm{Li} 20$

$65 \mathrm{Mg}(\mathrm{COOH}) 2$

$65 \mathrm{Mg}(\mathrm{OHI}) 2$

$33 \mathrm{MgO}$

$60 \mathrm{Mn}(\mathrm{COOH}) 2$

$132 \mathrm{Mn}(\mathrm{NOS}) 2$

$129 \mathrm{Mn}(\mathrm{OII}) 2$

$56 \mathrm{MnO}$

$14 \mathrm{MnO2}$

81 N2

$142 \mathrm{NA2CO3}$ (C14)

$85 \mathrm{NO}$

$84 \mathrm{NO2}$

$70 \mathrm{Na}(\mathrm{HgO}(\mathrm{OH}))$

$94 \mathrm{Na} 2 \mathrm{~B} 407$

$109 \mathrm{Na} 2 \mathrm{C2O4}$

$5 \mathrm{Na} 2 \mathrm{CO} 3$

$32 \mathrm{Na} 20$

$71 \mathrm{Nn} 2 \mathrm{Pu} 02(\mathrm{OH}) 4$

$73 \mathrm{Na} 2 \mathrm{RhO} 04$

$72 \mathrm{Na} 2 \mathrm{Ru} 04$

$6 \mathrm{Na} 2 \mathrm{SO} 4$

$68 \mathrm{NaAlO2}$

$114 \mathrm{NaBO2}$

$140 \mathrm{NaBO2}$ Semi Vol

$50 \mathrm{NaCOOH}$

$\begin{array}{lc}29 & 80 \\ \text { Liquid to } & \text { Dilution } \\ \text { Quencher } & \text { Air } \\ .0000 & .0000 \\ .5836 & .0000 \\ .8784 \mathrm{E}-01 & .0000 \\ .2808 & .0000 \\ .2408 \mathrm{E}-03 & .0000 \\ .0000 & .0000 \\ .0000 & .0000 \\ .0000 & .0000 \\ .0000 & .0000 \\ .0000 & .0000 \\ .0000 & .0000 \\ .0000 & .0000 \\ .0000 & .0000 \\ .0000 & .0000 \\ .2177 & .0000 \\ .0000 & .0000 \\ .0000 & .0000 \\ .0000 & .0000 \\ .2176 \mathrm{E}-03 & .0000 \\ .2833 & .0000 \\ 4.636 & .0000 \\ .3096 & .0000 \\ .0000 & .0000 \\ 1.570 & .0000 \\ 2.780 & .0000 \\ .0000 & .0000 \\ .0000 & .0000 \\ .0000 & .0000 \\ .0000 & .0000 \\ .2970 & 573.8 \\ .0000 & .0000 \\ .8665 E-08 & .0000 \\ .6041 & .0000 \\ .1982 \mathrm{E}-08 & .0000 \\ 7.608 & .0000 \\ .8730 \mathrm{E}-04 & .0000 \\ .0000 & .0000 \\ 17.17 & .0000 \\ .8039 \mathrm{E}-08 & .0000 \\ .1653 \mathrm{E}-05 & .0000 \\ .1613 \mathrm{E}-04 & .0000 \\ .8271 \mathrm{E}-01 & .0000 \\ .8039 \mathrm{E}-01 & .0000 \\ .0000 & .0000 \\ .0000 & .0000 \\ 9.169 & .0000 \\ & \end{array}$

Append IX H

Table 21-16

Page 081 of 173

Dato 09/80/82 Rev 09

\begin{tabular}{ll}
81 & \multicolumn{1}{|c}{82} \\
Quencher & Off-Gas to \\
Exit & PWDBF \\
.0000 & .0000 \\
.5826 & $.1285 E-01$ \\
$.8798 E-01$ & $.2164 E-02$ \\
.2812 & $.6868 E-02$ \\
.5829 & .5827 \\
.0000 & .0000 \\
.0000 & .0000 \\
.0000 & .0000 \\
.0000 & .0000 \\
.0000 & .0000 \\
.0000 & .0000 \\
.0000 & .0000 \\
.0000 & .0000 \\
.0000 & .0000 \\
.2170 & $.6345 E-02$ \\
.0000 & $.7755 E-04$ \\
.0000 & .0000 \\
.0000 & .0000 \\
$.2177 E-03$ & $.7774 E-05$ \\
.2837 & $.6982 E-02$ \\
4.646 & $.7920 E-01$ \\
.8101 & $.7567 E-02$ \\
.0000 & .0000 \\
1.573 & $.2778 E-01$ \\
2.784 & $.6788 E-01$ \\
.0000 & .0000 \\
.0000 & .0000 \\
.0000 & .0000 \\
.0000 & .0000 \\
251.8 & 965.8 \\
.0000 & .0000 \\
.9709 & .9700 \\
.7698 & .1498 \\
$.1985 E-03$ & $.4837 E-05$ \\
7.622 & .1461 \\
$.8786 E-04$ & $.8119 E-05$ \\
.0000 & .0000 \\
17.21 & .2929 \\
$.8052 E-08$ & $.1962 E-09$ \\
$.1655 E-05$ & $.4038 E-07$ \\
$.1615 E-04$ & $.8986 E-06$ \\
$.8276 E-01$ & $.7981 E-03$ \\
$.8052 E-01$ & $.1962 E-02$ \\
.0000 & .0000 \\
.0000 & .0000 \\
9.186 & .1810 \\
& \\
\hline &
\end{tabular}


DPSP $80-1033$

MATERIAL BALANCE TABLES SLUDGE-SUPERNATE FEED STREAMS (CONT'D) STREAM NAME

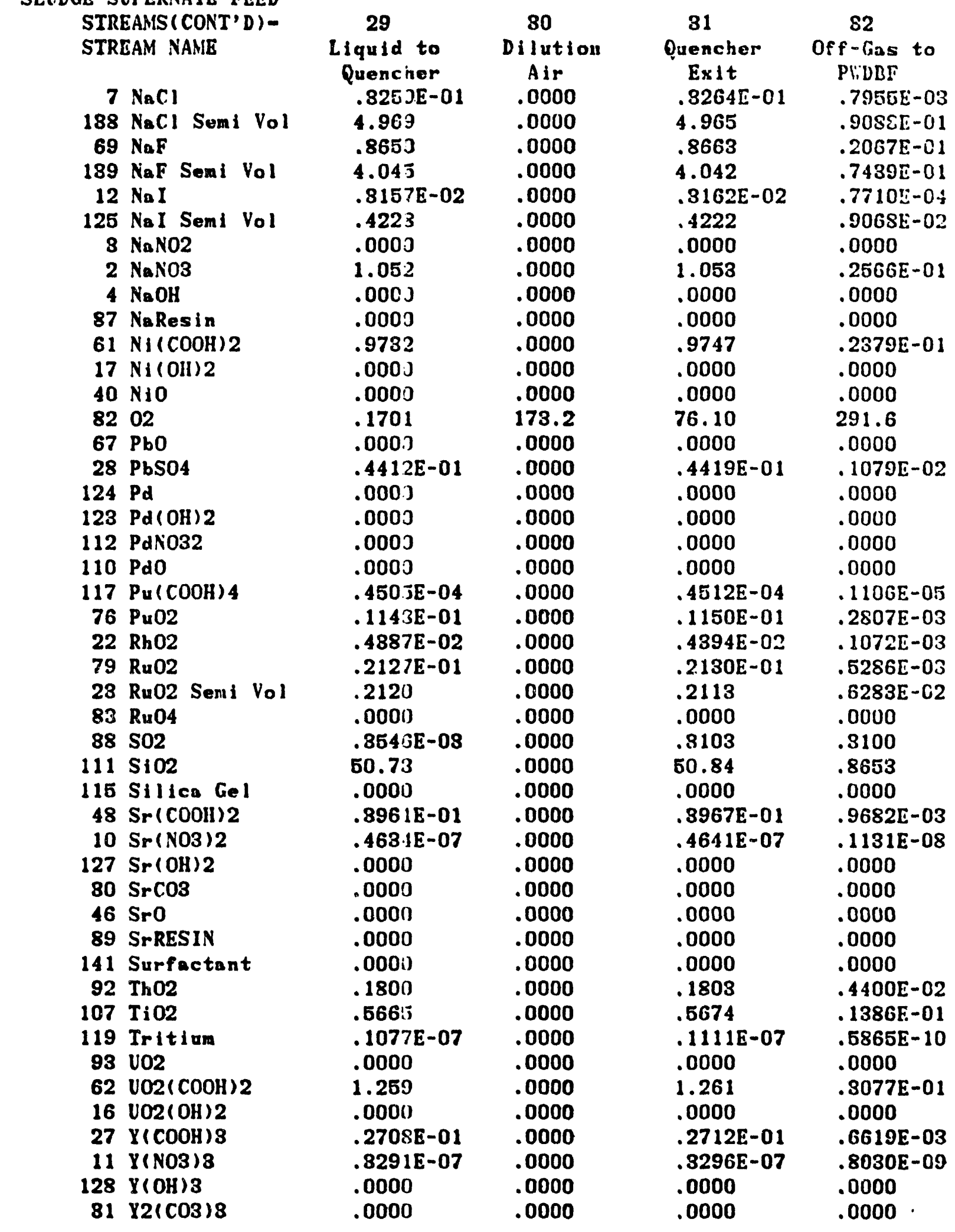

Appendix $\mathrm{H}$

Table 21-16

Page 032 of 173

Date 09/30/82 Rev 09 
DPSP $80-1033$

MATERIAL BALANCE TABLES SLUDGE-SUPERNATE FEED STREAMS (CONT'D)STREAM NAME

47 Y2O3
$100 \mathrm{ZCO} /$ ite
$44 \mathrm{Zn}(\mathrm{COOH}) 2$
$54 \mathrm{Zn}(\mathrm{OH}) 2$
$57 \mathrm{ZnO}$
$104 \mathrm{ZrO2}$
TOTAL FLOW, LB/HR
VAPOR FLOH, CEM
LIOUID FLOW, GPM
DESIGN FLOW,
DENSITY, LBS/FT3
TEYPERATURE, DEG C
PRESSURE, ATM
PRESSURE, PSIG
PRESSURE, AM HG
PHASE
ENTHALPY, PCU/HR

\begin{tabular}{|c|c|c|c|}
\hline 29 & 80 & 81 & 82 \\
\hline $\begin{array}{l}\text { Liquid to } \\
\text { Quencher } \\
.0000\end{array}$ & $\begin{array}{l}\text { Dilution } \\
\text { Air } \\
.0000\end{array}$ & $\begin{array}{l}\text { Quencher } \\
\text { Exit } \\
.0000\end{array}$ & $\begin{array}{l}\text { Orf-Gos to } \\
\text { PWDBF } \\
.0000\end{array}$ \\
\hline 1.151 & .0000 & 1.153 & $.2813 E-01$ \\
\hline .1431 & .0000 & .1483 & $.8497 E-02$ \\
\hline .0000 & .0000 & .0000 & .0000 \\
\hline .0000 & .0000 & .0000 & .0000 \\
\hline .2833 & .0000 & .2837 & $.6982 E-02$ \\
\hline 27811.62 & $\begin{array}{l}759.04 \\
179.80\end{array}$ & 28585.74 & $\begin{array}{r}1486.29 \\
885.06\end{array}$ \\
\hline 65. 38 & & 67.04 & \\
\hline 02.6167 & .0706 & 62.4843 & .0622 \\
\hline 8.72 & 1.00 & .89 & .99 \\
\hline 89.97 & .00 & $\begin{array}{r}-.14 \\
752.78\end{array}$ & $\begin{array}{r}-.21 \\
748.90\end{array}$ \\
\hline LIQU & VAPOR & LIQUID & VAPOR \\
\hline 1559709 & -89088.97 & 1878711.92 & 22427.22 \\
\hline
\end{tabular}

Append Ix H

Table 21-16

Page 083 of 173

Date 09/30/82 Rev 09 
DPSP $80-1033$

MATERIAL BALANCE TABLES

SLUDGE-SUPERNATE FEED STREAM NUMBERS STREAM NAME

COMPONENT FLOWS, LB/HR

$\begin{array}{rl}1 & \mathrm{H} 2 \mathrm{O} \\ 45 & \mathrm{Ag} \\ 116 & \mathrm{Ag} 20 \\ 34 & \mathrm{AgNO3} \\ 51 & \mathrm{AgOH} \\ 74 & \mathrm{Al}(\mathrm{OH}) 8 \\ 77 & \mathrm{~A} 1203 \\ 75 & \mathrm{Al} 100 \mathrm{H} \\ 106 & \mathrm{~B} 203\end{array}$

$9 \mathrm{Ba}(\mathrm{NO3}) 2$

$95 \mathrm{BaCl} 2$

$15 \mathrm{BaO}$

$24 \mathrm{BaSO4}$

$66 \mathrm{CO}$

$87 \mathrm{CO2}$

$142 \mathrm{CO2}(\mathrm{C.14})$

$63 \mathrm{Ca}(\mathrm{COOH}) 2$

$120 \mathrm{Ca}(\mathrm{OH}) 2$

$113 \mathrm{Ca} 3(\mathrm{PO} 4) 2$

$20 \mathrm{CaC2O4}$

$18 \mathrm{CaC} .3$

$78 \mathrm{CaF2}$

$41 \mathrm{CaO}$

19 CaSO4

29 Carbon

$26 \mathrm{Co}(\mathrm{COOIII)} 2$

$121 \mathrm{Co}(\mathrm{OH}) 2$

$63 \mathrm{Co}(\mathrm{OH}) 8$

$69 \mathrm{CoO}$

$99 \mathrm{Cr}(\mathrm{OH}) \mathrm{s}$

$98 \mathrm{Cr} 203$

$42 \operatorname{Cs} 20$

187 Cs20 Semi Vol

$90 \mathrm{CsCOOH}$

$96 \mathrm{CsCl}$

$136 \mathrm{CsCl}$ Semi Vol

8 CsNO3

88 CsResin

$122 \mathrm{Cu}(\mathrm{COOH}) 2$

$52 \mathrm{Cu}(\mathrm{OH}) 2$

$58 \mathrm{Cu} 20$

$64 \mathrm{CuCOOH}$

$180 \mathrm{CuO}$

$18 \mathrm{Fe}(\mathrm{OH}) 8$

$80 \mathrm{Fe} 203$
88

Liq to PWDBF Nozzles

5659.

.0003

$.000 J$

.0003

$.1303 \mathrm{E}-02$

1.153

.0003

.0003

2.443

$.1062 \mathrm{E}-07$

.0003

.0003

$.9583 \mathrm{E}-02$

$.617 .3 \mathrm{E}-03$

$.8097 \mathrm{E}-01$

$.8213 E-26$

.8327

$.000 \mathrm{~J}$

.239JE-01

.258.JE-01

$.000 \mathrm{~J}$

$.6461 \mathrm{E}-02$

.000 i)

.803 BE-01

. 190'2E-01

.525:3E-02

.0000

.0000

.0000

$.2456 \mathrm{E}-01$

.0000

$.1540 \mathrm{E}-06$

$.2535 \mathrm{E}-04$

$.1485 \mathrm{E}-01$

$.8913 E-06$

$.7856 \mathrm{E}-01$

$.6813 E-03$

.0000

$.1122 \mathrm{E}-01$

.0000

.0000

.0000

.0000

2.803

.0000
Appendix H

Iable 21-16

Page 034 of 173

Date 09/30/:2 Rev 09

\section{4 \\ 85 \\ 86}

PH:DBF \#1

Atomzg Air Exit Liquid

8.811

.0000

.0000

.0000

.0000

.0000

.0000

.0000

.0000

.0000

.0000

.0000

.0000

.0000

.0000

.0000

.0000

.0000

.0000

.0000

.0000

.0000

.0000

.0000

.0000

.0000

.0000

.0000

.0000

.0000

.0000

.0000

.0000

.0000

.0000

.0000

.0000

.0000

.0000

.0000

.0000

.0000

.0000

.0000

.0000
2821.

.0000

.0000

.0000

$.8039 \mathrm{E}-03$

.6723

.0000

.0000

1.423

$.6538 \mathrm{E}-03$

.0000

.0000

.5904E-02

$.2673 \mathrm{E}-03$

. 1376E-01

$.1430 \mathrm{E}-20$

.2048

.0000

$.1471 \mathrm{E}-01$

. 1591E-01

.0000

.8978E-02

.0000

. 1869E-01

$.1211 \mathrm{E}-01$

$.8234 E-02$

.0000

.0000

.0000

.1512E-01

.0000

.9377 E-07

. 1267E-04

.9152E-02

.6254E-06

$.4619 E-01$

$.4194 E-03$

.0000

.6908E-02

.0000

.0000

.0000

.0000

1.627

.0000
PYDLF $\# 2$

Euit Gas

179.1

.0000

.0000

.0000

$.1541 E-06$

$.8044 \mathrm{E}-0.4$

.0000

.0000

.2043E-C3

. 1267E-11

.0000

.0000

$.1146 E-05$

7.614

16.57

$.1722 E-23$

$.3976 \mathrm{E}-04$

.0000

.285GE-0'S

. 3OSSE-0J

.0000

$.77235-06$

.0000

$.3628 E-05$

.2683E-05

$.6278 \mathrm{~L}-05$

.0000

.0000

.0000

$.2936 E-05$

.0000

$.1734 \mathrm{E}-10$

.0000

$.1783 E-05$

$.1856 \mathrm{E}-09$

$.1046 \mathrm{E}-03$

$.8129 \mathrm{E}-07$

.0000

$.1341 \mathrm{E}-05$

.0000

.0000

.0000

.0000

.2834E-03

.0000 
DPSP 80-1033

MATERIAL BALANCE TABLES

SLLDGE-SUPERNATE FEED STREAMS (CONT'D)STREAM NAME

101 FeO

126 Groulp A Seml Vo

102 GroupA

103 GroupB

$25 \mathrm{II} 2$

$133 \mathrm{H} 2 \mathrm{C2OA}$

$91 \mathrm{II202}$

84 HCOOH

$43 \mathrm{HCl}$

$85 \mathrm{HF}$

49 HNO3

86 HResin

$36 \mathrm{Hg}$

135 HgN032

$21 \mathrm{HgO}$

9712

39 K20

$131 \mathrm{KMnO4}$

$118 \mathrm{KNO3}$

105 La203

$108 L 120$

$65 \mathrm{Mg}(\mathrm{COOH}) 2$

56 $\mathrm{Mg}(\mathrm{OHI}) 2$

$33 \mathrm{MgO}$

$60 \mathrm{Mn}(\mathrm{COOH}) 2$

$132 \mathrm{Mn}(\mathrm{NO3}) 2$

$129 \operatorname{Min}(011) 2$

$56 \mathrm{MnO}$

$14 \mathrm{MnO2}$

81 N2

$143 \mathrm{NA2CO3}$ (C14)

$35 \mathrm{NO}$

$84 \mathrm{NO2}$

$70 \mathrm{Na}(\mathrm{HgO}(\mathrm{OH}))$

94 Na2B 407

$109 \mathrm{Na} 2 \mathrm{C}_{204}$

$5 \mathrm{Na} 2 \mathrm{CO} 3$

$32 \mathrm{Na} 20$

$71 \mathrm{Na} 2 \mathrm{Pu} 02(\mathrm{OH}) 4$

$73 \mathrm{Na} 2 \mathrm{Rh} 04$

$72 \mathrm{Na} 2 \mathrm{RuO4}_{4}$

$6 \mathrm{Na} 2 \mathrm{SO4}$

$68 \mathrm{NaA} 102$

$114 \mathrm{NaBO2}$

$140 \mathrm{NaBO2}$ Semi Vol $50 \mathrm{NaCOOH}$
88

Liq to PWDBF

Nozzles

.0000

.1194

$.1707 \mathrm{E}-01$

$.5743 E-01$

$.4925 \mathrm{E}-04$

.0000

.0000

.0000

.0000

.0000

.0000

.0000

.0000

.0000

$.4458 E-01$

.0000

.0000

.0000

$.4450 \mathrm{E}-04$

$.6794 \mathrm{E}-01$

.9483

$.6332 \mathrm{E}-01$

.0000

.8211

.5686

.0000

.0000

.0000

.0000

$.6076 \mathrm{E}-01$

.0000

$.1772 E-03$

.1236

$.4055 E-04$

1.556

$.1786 \mathrm{E}-04$

.0000

8.518

$.1644 \mathrm{E}-08$

$.8381 \mathrm{E}-06$

$.8299 \mathrm{E}-05$

$.6690 \mathrm{E}-02$

$.1644 \mathrm{E}-01$

.0000

.0000

1.875
Append $1 \times$ H

Toble 21-16

Page 085 of 178

Date 09/80/82 Rev 09

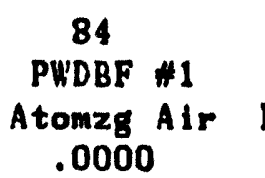

.0000

.0000

.0000

.0000

.0000

.0000

.0000

.0000

.0000

.0000

.0000

.0000

.0000

.0000

.0000

.0000

.0000

.0000

.0000

.0000

.0000

.0000

.0000

.0000

.0000

.0000

.0000

.0000

174.2

.0000

.0000

.0000

.0000

.0000

.0000

.0000

.0000

.0000

.0000

.0000

.0000

.0000

.0000

.0000

.0000
85

PWDBF 1

Exit Liquid

.0000

.7125E-01

$.1108 E-01$

.8586E-01

$.2123 E-04$

.0000

.0000

.0000

.0000

.0000

.0000

.0000

.0000

.0000

.2797E-01

.0000

.0000

.0000

$.2978 E-04$

.8568E-01

.5508

.8899E-01

.0000

.1875

.8500

.0000

.0000

.0000

.0000

$.8120 E-01$

.0000

.7724E-04

. 5864E-01

$.2496 E-04$

.9196

$.1195 E-04$

.0000

2.040

$.1012 E-08$

.2081E-06

.2081E-05

$.4118 E-02$

$.1012 E-01$

.0000

.0000

1.118
86

PWDBF *2

Exit Gas

.0000

$.1285 E-08$

.2164E-05

$.6865 \mathrm{E}-05$

.6827

.0000

.0000

.0000

.0000

.0000

.0000

.0000

.0000

.0000

$.6345 \mathrm{E}-04$

$.7755 \mathrm{E}-04$

.0000

.0000

$.7775 E-08$

$.6933 \mathrm{E}-05$

$.7921 \mathrm{E}-04$

$.7568 \mathrm{E}-05$

.0000

$.2779 \mathrm{E}-04$

$.6789 \mathrm{E}-04$

.0000

.0000

.0000

.0000

1314.

.0000

.9700

.1598

$.4888 \mathrm{E}-08$

$.1461 \mathrm{E}-03$

.3120 E-08

.0000

.2929E-03

$.1962 \mathrm{E}-12$

$.4034 \mathrm{E}-10$

$.8986 \mathrm{E}-09$

$.7982 \mathrm{E}-06$

.1962E-05

.0000

.0000

.1810 E-03 
DPSP 80-1033

MATERIAL BALANCE TABLES

SLUDCE-SUPERNATE FEED

STREAMS ( CONT'D) -

STREAM NAME

$7 \mathrm{NaCl}$

$188 \mathrm{NaCl}$ Seml Vol

$69 \mathrm{NaF}$

$189 \mathrm{NaF}$ Semi Vol

$12 \mathrm{NaI}$

$125 \mathrm{NaI}$ Semi Vol

$8 \mathrm{NaNO2}$

$2 \mathrm{NaNO3}$

$4 \mathrm{NaOlI}$

87 NeResin

$61 \mathrm{Ni}(\mathrm{COOII}) 2$

$17 \mathrm{Ni}(\mathrm{OH} / 2$

$40 \times 10$

8202

$67 \mathrm{PbO}$

$28 \mathrm{PbSO4}$

$124 \mathrm{Pd}$

$123 \mathrm{Pd}(\mathrm{OH}) 2$

112 PdNO32

$110 \mathrm{PdO}$

$117 \mathrm{Pu}(\mathrm{COOH}) 4$

$76 \mathrm{Pu} 02$

$22 \mathrm{RhO2}$

$79 \mathrm{Ru} 02$

23 Ru02 Semi Vol

$83 \mathrm{Ru} 04$

$88 \mathrm{~S} 02$

1115102

115 Silica Gel

$48 \mathrm{Sr}(\mathrm{COOII}) 2$

$10 \mathrm{Sr}(\mathrm{N03}) 2$

$127 \mathrm{Sr}(\mathrm{OH}) 2$

$80 \mathrm{SrCO}$

$46 \mathrm{Sr} 0$

89 SrRESIN

141 Surfactint

$92 \mathrm{Th} 02$

$107 \mathrm{TiO2}$

119 Tritium

$98 \mathrm{VO2}$

$62 \mathrm{VO}(\mathrm{COOII}) 2$

$16 \mathrm{VO2}$ (OII) 2

27 Y (COOII) 3

$11 \mathrm{Y}(\mathrm{NOS}) 3$

$128 Y(\mathrm{OH}) 8$

81 Y2(CO3):
88

Liq to PWDBF

Nozzles

$.666 \mathrm{JE}-02$

1.013

.1763

.8275

$.6457 \mathrm{E}-03$

$.8649 \mathrm{E}-01$

.0000

.2151

.0000

.0000

.1991

.0000

.0000

$.8480 E-01$

.0000

$.9025 E-02$

.0000

.0000

.0000

.0000

$.9214 \mathrm{E}-05$

$.2349 \mathrm{E}-02$

$.8974 \mathrm{E}-03$

$.4851 \mathrm{E}-02$

$.4837 E-01$

.0000

$.7254 \mathrm{E}-04$

10.38

.0000

$.8102 E-02$

$.9478 \mathrm{E}-08$

.0000

.0000

.0000

.0000

.0000

$.8682 \mathrm{E}-01$

.1159

$.2204 \mathrm{E}-08$

.0000

.2576

.0000

.6539E-02

$.6731 \mathrm{E}-08$

.0000

.0000
Appendix H

Table 21-16

Page 026 of 173

Date 09/30/82 Rev 00
84

PWDBF \#1

Atonzg AI

.0000

.0000

.0000

.0000

.0000

.0000

.0000

.0000

.0000

.0000

.0000

.0000

.0000

ธ2. 63

.0000

.0000

.0000

.0000

.0000

.0000

.0000

.0000

.0000

.0000

.0000

.0000

.0000

.0000

.0000

.0000

.0000

.0000

.0000

.0000

.0000

.0000

.0000

.0000

.0000

.0000

.0000

.0000

.0000

.0000

.0000

.0000
85

PUDBF \#1

Exit Liquid

. 4103z-02

.6900

.1085

.4807

$.3975 t-03$

$.5141 \mathrm{E}-01$

.0000

.1824

.0000

.0000

.1226

.0000

.0000

.1791 E-01

.0000

$.5557 E-02$

.0000

.0000

.0000

.0000

$.5678 E-05$

$.1446 \mathrm{E}-02$

$.5526 E-03$

.2687E-02

.2734E-01

.0000

.3172E-04

6.026

.0000

.4989E-02

.5884 E-08

.0000

.0000

.0000

.0000

.0000

.2267 E-01

$.7137 \mathrm{E}-01$

$.1097 E-08$

.0000

.1585

.0000

$.3411 E-02$

$.4143 E-08$

.0000

.0000
86

PHDEF \#2

Exit Gas

.7956E-06̈

.90S8E-0i

. 20G7E-0.

$.7439 E-03$

$.7712 \mathrm{E}-\mathrm{U}$

$.9065 E-0.1$

.0000

.256GE-04

.0000

.0000

.2370 Г: -0.1

.0000

.0000

396.8

.0000

. 1079E-05

.0000

.0000

.0000

.0000

.110GE-03

$.2807 E-06$

$.1073 E-06$

$.5287 E-06$

$.6283 E-04$

.0000

.8100

$.8655 E-03$

.0000

$.9684 \mathrm{E}-06$

$.1131 \mathrm{E}-11$

.0000

.0000

.0000

.0000

.0000

$.4401 E-05$

$.1387 \mathrm{E}-04$

$.6965 \mathrm{E}-10$

.0000

.3078E-04

.0000

.6620E-0R

.8031E- 12

.0000

.0000 ' 
MATERIIL BALANCE TARLES SiLDGE-SUPERNATE FEED STREAMS (CONT'D)STILAM NAMB

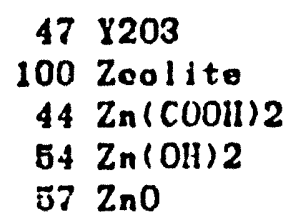

E.TTHALPY, PCV/IIR

\begin{tabular}{|c|c|c|c|}
\hline Liq 83 to PWDBF & $\begin{array}{c}84 \\
\text { PKDDE \#1 }\end{array}$ & $\begin{array}{c}85 \\
\text { PWDBF }\end{array}$ & $\begin{array}{c}86 \\
\text { PWDBF \#2 }\end{array}$ \\
\hline Nozzlos & Atomzg Air & Exit Liquid & Exit Cas \\
\hline $\begin{array}{l}.0000 \\
.2854\end{array}$ & $\begin{array}{l}.0000 \\
.0000\end{array}$ & $\begin{array}{l}.0000 \\
.1449\end{array}$ & $\begin{array}{l}.0000 \\
.2813 E-04\end{array}$ \\
\hline $.2927 \mathrm{E}-01$ & .0000 & $.1802 E-01$ & $.3498 \mathrm{E}-05$ \\
\hline .0000 & .0000 & .0000 & .0000 \\
\hline .0000 & .0000 & .0000 & .0000 \\
\hline $.5794 E-01$ & .0000 & $.8568 \mathrm{E}-01$ & $.6933 E-05$ \\
\hline 6688.86 & $\begin{array}{r}230.66 \\
14.89\end{array}$ & 2838.83 & $\begin{array}{r}1916.84 \\
625.25\end{array}$ \\
\hline 11.8 & & 5.65 & \\
\hline 62.61 & .2688 & 62.649 & .0608 \\
\hline 65. 0 & 40.00 & 53.46 & 52.45 \\
\hline 8.18 & 8.72 & .97 & .95 \\
\hline 82.04 & 89.97 & -.51 & -.72 \\
\hline & & 783. & 722.76 \\
\hline LIQU & VAPOR & LIQUID & VAPOR \\
\hline 19037. & -11603 & 154562.97 & 12229.78 \\
\hline
\end{tabular}


DPSP $80-1033$

MATERIAL BALANCE TABLES

SLUDGE-SUPERNATE FEED

STREAM NUMEERS -

STREAM NAME

COMPONENT FLOWS, LB/HR

$1 \mathrm{H} 2 \mathrm{O}$

$45 \mathrm{Ag}$

$116 \mathrm{Ag} 20$

184 AgNO3

$51 \mathrm{AgOH}$

74 Al(OII) 8

77 A 1203

75 A100H

106 B203

$9 \mathrm{Ba}(\mathrm{NO} 3) 2$

$95 \mathrm{BnCl} 2$

$15 \mathrm{BaO}$

$24 \mathrm{BaS04}$

$66 \mathrm{CO}$

$87 \mathrm{CO2}$

$142 \mathrm{CO}$ ( C14)

$63 \mathrm{Ca}(\mathrm{COOH}) 2$

$120 \mathrm{Cn}(\mathrm{OH}) 2$

$113 \mathrm{Ca} 3(\mathrm{PO} 4) 2$

$20 \mathrm{CaC2O4}^{2}$

$18 \mathrm{CnCO3}$

$78 \mathrm{CnF2}$

$41 \mathrm{CnO}$

$19 \mathrm{CaSO} 4$

29 Carbon

$26 \mathrm{Co}(\mathrm{COO} I 1) 2$

$121 \mathrm{Co}(\mathrm{Olll}) 2$

$53 \mathrm{Co}(\mathrm{OH}) 3$

$59 \mathrm{CoO}$

$99 \mathrm{Cr}(\mathrm{Oll}) \mathrm{3}$

$98 \mathrm{Cr} 203$

42 Cs20

137 Cs20 Semi Vol

$90 \mathrm{CsCOOH}$

$96 \mathrm{CsCl}$

$136 \mathrm{CsCl}$ Semi Vol

$8 \mathrm{CsNO3}$

88 CsResin

$122 \mathrm{Cu}(\mathrm{COOH}) 2$

$52 \mathrm{Cu}(\mathrm{Oll}) 2$

$58 \mathrm{Cu} 20$

$64 \mathrm{Cu}$ COOII

$180 \mathrm{CuO}$

$13 \mathrm{Fe}(\mathrm{OH}) \mathrm{S}$

$80 \mathrm{Fe} 203$
37

FPT Liquid Canister Air Inlet Air to OCET

140.4

.0000

.0000

.0003

$.1082 \mathrm{E}-06$

$.6633 \mathrm{E}-04$

.0000

.0003

$.1402 E-03$

$.8703 \mathrm{E}-12$

.0003

.0000

$.7857 \mathrm{E}-06$

$.887 \mathrm{JE}-05$

$.5137 \mathrm{E}-03$

$.5339 E-28$

$.2723 E-04$

.0000

$.1953 E-05$

$.2113 E-05$

$.000 \mathrm{~J}$

$.5291 E-06$

.0000

$.2487 E-05$

.182SE-05

$.4303 E-06$

.0000

.0000

.0000

$.2013 \mathrm{E}-05$

.0000

$.1236 \mathrm{E}-10$

.0000

$.1214 \mathrm{E}-05$

$.6965 \mathrm{E}-10$

$.7035 \mathrm{E}-04$

$.6584 \mathrm{E}-07$

.0000

$.9192 \mathrm{E}-06$

.0000

.0000

.0000

.0000

$.160 G E-03$

.0000
Appendix $H$

Table 21-10

Page 038 of 173

Dnto 09/30/82 Rey DJ 
MATERIAL BALANCE TABLES

Date 09/30/82 Rev 09

SLIDGE-SLPERNATE FEED

STREAMS (CONT'D)-

STREAM NAME

$101 \mathrm{FeO}$

126 Group A Semi Vo

102 GroupA

103 Group B

25112

$133 \mathrm{H2C2O4}$

9111202

$34 \mathrm{HCOOH}$

$43 \mathrm{IICl}$

$85 \mathrm{HF}$

$49 \mathrm{HNO3}$

80 lltesin

$36 \mathrm{Hg}$

135 HIgN032

$21 \mathrm{Hg} \mathrm{O}$

$97 \mathrm{I2}$

$39 \mathrm{~K} 20$

$131 \mathrm{kMnO4}$

$118 \mathrm{KNO3}$

$105 \mathrm{La} 203$

1081.120

$65 \mathrm{Mg}(\mathrm{COOH}) 2$

$55 \mathrm{Mg}(\mathrm{OH}) 2$

$33 \mathrm{MgO}$

$60 \mathrm{Mn}(\mathrm{COOH}) 2$

$132 \mathrm{Mn}(\mathrm{NO}) 2$

$129 \mathrm{Mn}$ (Olli?

$56 \mathrm{MnO}$

$14 \mathrm{MnO2}$

$81 \mathrm{N2}$

$143 \mathrm{NA2CO3}$ (C14)

$35 \mathrm{NO}$

$84 \quad 102$

$70 \mathrm{Na}$ (HgO(OII))

94 ia 2B407

109 Na2C204

$5 \mathrm{Na} 2 \mathrm{CO}$

$32 \mathrm{Na} 20$

71 . 2 2PuO2(OH) 4

$73 \mathrm{Na}_{2} \mathrm{Rh}_{1} \mathrm{O}$

$72 \mathrm{Na} 2 \mathrm{Ru} 04$

$6 \mathrm{Na} 2 \mathrm{SO} 04$

$68 \mathrm{NaAl} 02$

$114 \mathrm{NaBO2}$

$140 \mathrm{NaBO2}$ Semi Vol $50 \mathrm{NaCOOII}$
87

FPT Liquid Canister Air to OGCT

.0000

$.8629 \mathrm{E}-04$

$.1469 \mathrm{E}-05$

$.4706 E-05$

$.6944 \mathrm{E}-06$

.0000

.0000

.0000

.0000

.0000

.0000

.0000

.0000

.0000

$.4300 \mathrm{E}-04$

.0000

.0000

.0000

$.8197 \mathrm{E}-08$

$.4745 E-05$

$.5418 \mathrm{E}-04$

$.5188 \mathrm{E}-05$

.0000

$.1900 E-04$

$.4661 \mathrm{E}-04$

.0000

.0000

.0000

.0000

$.1643 \mathrm{E}-02$

.0000

$.2648 \mathrm{E}-05$

$.2841 \mathrm{E}-02$

$.3323 \mathrm{E}-08$

$.1003 \mathrm{E}-03$

$.1283 E-08$

.0000

$.2010 \mathrm{E}-03$

.1348E-12

$.2771 \mathrm{E}-10$

$.2704 \mathrm{E}-09$

$.5483 E-06$

$.1348 \mathrm{E}-05$

.0000

.0000

$.1235 \mathrm{E}-03$
89

40

Inlet Air Liquid Feed

to Ejector to Ejector

.0000

.0000

.0000

.0000

.0000

.0000

.0000

.0000

.0000

.0000

.0000

.0000

.0000

.0000

.0000

.0000

.0000

.0000

.0000

.0000

.0000

.0000

.0000

.0000

.0000

.0000

.0000

.0000

.0000

60.84

.0000

.0000

.0000

.0000

.0000

.0000

.0000

.0000

.0000

.0000

.0000

.0000

.0000

.0000

.0000

.0000
.0000

1.866

.2809

.8979

$.7699 \mathrm{E}-03$

.0000

.0000

.0000

.0000

.0000

.0000

.0000

.0000

.0000

.6962

.0000

.0000

.0000

$.6958 \mathrm{E}-03$

.9058

14.82

.9900

.0000

5.020

8.889

.0000

.0000

.0000

.0000

.9498

.0000

.2771E-02

1.932

$.6339 \mathrm{E}-03$

24.83

.2792E-03

.0000

64.92

. 2571E-07

. 5285E-05

.5158E-04

.1046

.2571

.0000

.0000

29.82 
DPSP SO-1033

MATERIAL BALANCE TABLES SLUDGE-SUPERNATE FEED STREAMS (CONT'D)STREAM NAME

\begin{tabular}{|c|c|}
\hline $\begin{array}{r}7 \\
138 \\
69\end{array}$ & $\begin{array}{l}\mathrm{NaCl} \\
\mathrm{NaCl} \text { Semi } \mathrm{Vol}\end{array}$ \\
\hline 189 & NaF Semi Vol \\
\hline 12 & $\mathrm{NaI}$ \\
\hline 125 & NaI Semi Vol \\
\hline $\mathbf{8}$ & $\mathrm{NaN02}$ \\
\hline 2 & $\mathrm{NaNO3}$ \\
\hline 4 & $\mathrm{NaOH}$ \\
\hline 87 & NaResin \\
\hline 61 & $\mathrm{Ni}(\mathrm{COOH}) 2$ \\
\hline 17 & $\mathrm{Ni}(\mathrm{OH}) 2$ \\
\hline 40 & NiO \\
\hline 82 & 02 \\
\hline 67 & $\mathrm{PbO}$ \\
\hline 28 & PbSO4 \\
\hline 124 & Pd \\
\hline 123 & $\mathrm{Pd}(\mathrm{OH}) 2$ \\
\hline 112 & PdN032 \\
\hline 110 & PdO \\
\hline 117 & $\mathrm{Pu}(\mathrm{COOH}) 4$ \\
\hline 76 & $\mathrm{Pu} 02$ \\
\hline 22 & $\mathrm{RhO}_{2}$ \\
\hline 79 & Ru02 \\
\hline 23 & Ru02 Semi Vol \\
\hline 83 & $\mathrm{RuO4}$ \\
\hline 88 & S02 \\
\hline 111 & $\mathrm{SiO} 2$ \\
\hline 115 & Silica Gel \\
\hline 48 & Sr (COOHI) 2 \\
\hline 10 & $\operatorname{Sr}(\mathrm{N} 03) 2$ \\
\hline 127 & $\mathrm{Sr}(\mathrm{OH}) 2$ \\
\hline $\mathbf{8 0}$ & $\mathrm{SrCO}$ \\
\hline 46 & Sro \\
\hline 89 & SrRESIN \\
\hline 141 & Surfactant \\
\hline 92 & $\mathrm{Th}_{\mathrm{h}} \mathrm{O2}$ \\
\hline 107 & $\mathrm{TiO} 2$ \\
\hline 119 & Tritium \\
\hline 98 & v02 \\
\hline 62 & $\mathrm{U} 02(\mathrm{COOll}) 2$ \\
\hline 16 & U02(0Il) 2 \\
\hline 27 & $Y(\mathrm{COOH}) \mathrm{S}$ \\
\hline 11 & $Y(N 03) 3$ \\
\hline 128 & $Y(\mathrm{OH}) 3$ \\
\hline & Y2(CO3)3 \\
\hline
\end{tabular}

Append ix H

Table 21-16

Page 040 of 173

Date 09/30/82 Rev 09
87

FPT Li fuid Canister Air

to $O G=T$

$.54535-06$

$.616 ; E-03$

$.1413 E-04$

.503 JE-03

$.5292 E-07$

$.6153 \mathrm{E}-04$

.000 ?

$.1763 \mathrm{E}-04$

.0003

.0003

$.1631 \mathrm{E}-04$

.0000

.0000

$.9521 \mathrm{E}-03$

$.000 \mathrm{~J}$

$.739: \mathrm{JE}-06$

.000 ]

.0000

.0000

.0000

$.7529 \mathrm{E}-09$

.192 JE-06

.7353E-07

. 3553E-06

$.417+E-04$

.0000

$.1103 \mathrm{E}-05$

.5938E-03

.0000

$.6638 E-06$

$.7763 E-12$

.0000

.0000

.0000

.0000

.0000

$.3017 E-05$

$.9489 E-05$

.202GE-10

.0000

$.2110 \mathrm{E}-04$

.0000

$.4588 \mathrm{E}-06$

$.5516 \mathrm{E}-12$

.0000

.0000
39

Inlet $A$ ir

to Ejector

.0000

.0000

.0000

.0000

.0000

.0000

.0000

.0000

.0000

.0000

.0000

.0000

.0000

18.38

.0000

.0000

.0000

.0000

.0000

.0000

.0000

.0000

.0000

.0000

.0000

.0000

.0000

.0000

.0000

.0000

.0000

.0000

.0000

.0000

.0000

.0000

.0000

.0000

.0000

.0000

.0000

.0000

.0000

.0000

.0000

.0000
40

Liquid Feed

to Ejector

.1042

15.89

2.766

12.94

$.1009 \mathrm{E}-\mathrm{CL}$

1.352

.0000

3.363

.0000

.0000

3.112

.0000

.0000

.5441

.0000

.1411

.0000

.0000

.0000

.0000

$.1410 \mathrm{E}-03$

$.3672 E-01$

. 1403E-01

$.6801 \mathrm{E}-01$

.6780

.0000

$.1134 \mathrm{E}-02$

162.2

.0000

.1267

.1482E-0G

.0000

.0000

.0000

.0000

.0000

.5756

1.812

$.3446 E-07$

.0000

4.026

.0000

$.8660 \mathrm{E}-01$

$.1052 \mathrm{E}-06$

.0000

.0000 
DPSP $80-1033$

MITERIAL BILANCE FARLES SLLDCE-SLP STNATE FEED STREAYS (CONT'D)STIEANY NAME

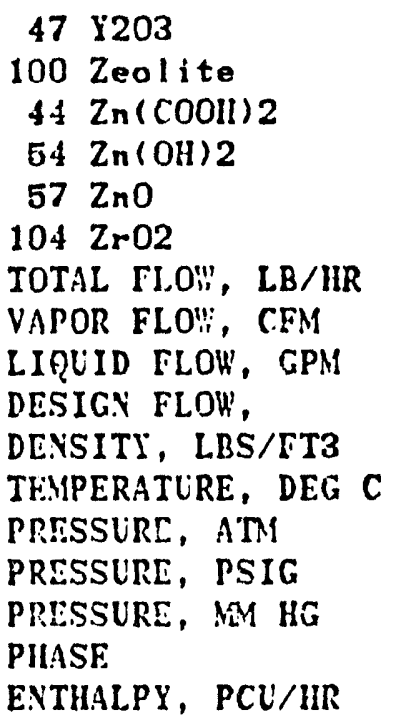

Append $\mathrm{Ix} H$

Table 21-16

Page 041 of 178

Date 09/30/82 Rev 09

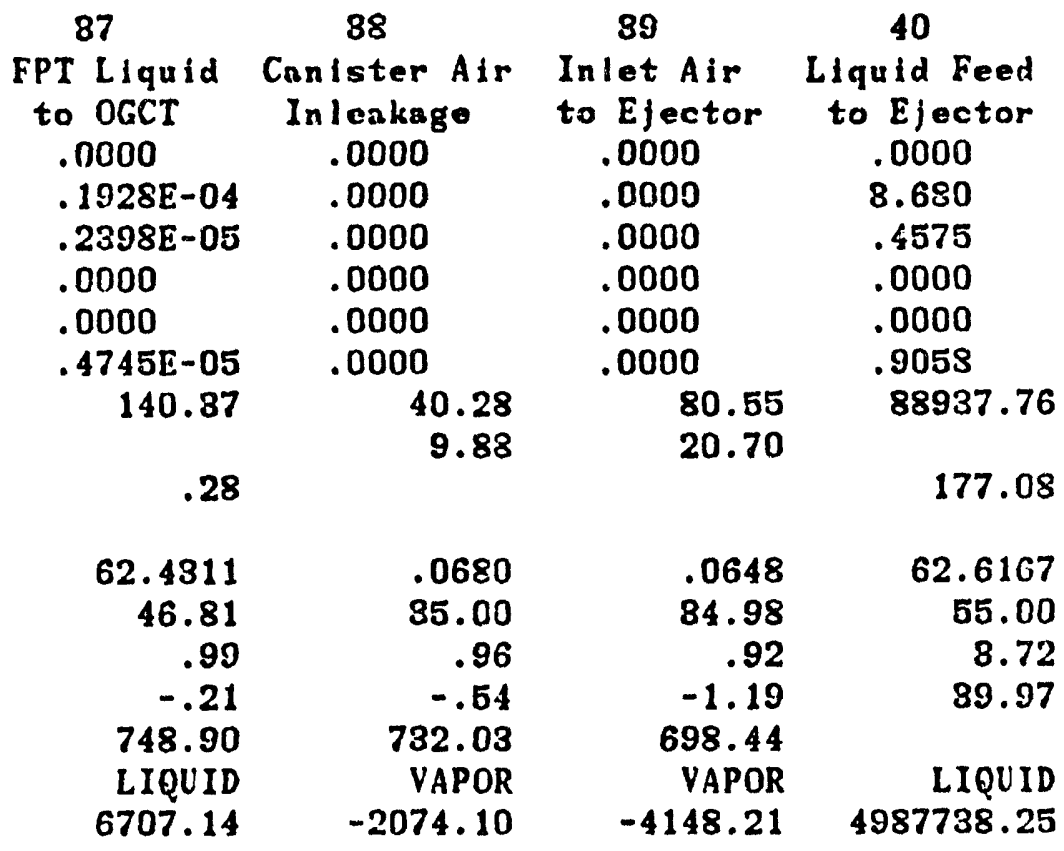


DPSP $80-1033$

MATERIAL BALANCE TABLES

SLUDGE-SUPERNATE FEED

STREAM NUMBERS -

STREAM NAME

COMPONENT FLOHS, LB/HR

\begin{tabular}{|c|c|c|c|c|c|}
\hline 1 & $\mathrm{H} 2 \mathrm{O}$ & 9.050 & $.8846 \mathrm{~B}+05$ & 4088. & 5.495 \\
\hline 45 & $\mathrm{Ag}$ & .0000 & .0000 & .0000 & .0000 \\
\hline 116 & Ag20 & .0000 & .0000 & .0000 & .0000 \\
\hline 184 & AgNO3 & .0000 & .0000 & .0000 & .0000 \\
\hline 51 & $\mathrm{AgOH}$ & .0000 & $.2040 E-01$ & $.8153 E-05$ & .0000 \\
\hline 74 & Al $(\mathrm{OH}) 8$ & .0000 & 18.08 & $.1932 E-02$ & .0000 \\
\hline 77 & A 1203 & .0000 & .0000 & .0000 & .0000 \\
\hline 75 & A IOOH & .0000 & .0000 & .0000 & .0000 \\
\hline 06 & B203 & .0000 & 88.24 & $.4083 E-02$ & .0000 \\
\hline 9 & $\mathrm{Ba}(\mathrm{NO3}) 2$ & .0000 & $.1655 \mathrm{E}-06$ & $.2536 E-10$ & .0000 \\
\hline 95 & $\mathrm{BaCl2}$ & .0000 & .0000 & .0000 & .0000 \\
\hline 15 & $\mathrm{BaO}$ & .0000 & .0000 & .0000 & .0000 \\
\hline 24 & BaS04 & .0000 & .1494 & $.2288 E-04$ & .0000 \\
\hline 66 & CO & $.9463 \mathrm{E}-02$ & . 1992E-03 & $.2584 E-03$ & .0000 \\
\hline 87 & $\mathrm{CO2}$ & .8259 & .1588 & $.1496 \mathrm{E}-01$ & .0000 \\
\hline 42 & $\mathrm{CO2}(\mathrm{C} 14)$ & $.8387 E-25$ & $.1646 E-25$ & $.1555 E-26$ & .0000 \\
\hline 63 & $\mathrm{Ca}(\mathrm{COOH}) 2$ & .0003 & 5. 183 & $.7939 E-03$ & .0000 \\
\hline 20 & $\mathrm{Ca}(\mathrm{OH}) 2$ & .0000 & .0000 & .0000 & .0000 \\
\hline 13 & $\mathrm{Ca} 3(\mathrm{P} 04) 2$ & .0000 & .3723 & $.5703 E-04$ & .0000 \\
\hline 20 & $\mathrm{CaC2O4}$ & .0003 & .4027 & $.6168 \mathrm{E}-04$ & .0000 \\
\hline 18 & $\mathrm{CaCO3}$ & .0000 & .0000 & .0000 & .0000 \\
\hline 78 & CAF2 & .0000 & .1007 & $.1542 E-04$ & .0000 \\
\hline 41 & $\mathrm{CaO}$ & .0000 & .0000 & .0000 & .0000 \\
\hline 19 & $\mathrm{CaSO} 04$ & .0009 & .4730 & $.7245 E-04$ & .0000 \\
\hline 29 & Carbon & .0000 & .2960 & $.5325 E-04$ & .0000 \\
\hline 26 & $\mathrm{Co}(\mathrm{COOH}) 2$ & .0000 & $.8184 E-01$ & $.1255 \mathrm{E}-04$ & .0000 \\
\hline 21 & $\mathrm{Co}(\mathrm{OH}) 2$ & .0000 & .0000 & .0000 & .0000 \\
\hline 53 & $\mathrm{Co}: \mathrm{OH}) 3$ & .0000 & .0000 & .0000 & .0000 \\
\hline 59 & $\mathrm{CoO}$ & .0000 & .0000 & .0000 & .0000 \\
\hline 99 & $\mathrm{Cr}(\mathrm{OH}) 8$ & .0000 & .8827 & $.5862 E-04$ & .0000 \\
\hline 98 & Cr203 & .0000 & .0000 & .0000 & .0000 \\
\hline 42 & Cs20 & .0000 & $.2400 E-05$ & $.3599 E-09$ & .0000 \\
\hline 87 & Cs20 Sent Vol & .0000 & $.3976 E-03$ & .0000 & .0000 \\
\hline 90 & $\mathrm{CsCOOH}$ & .0000 & .2314 & $.3585 E-04$ & .0000 \\
\hline 96 & $\mathrm{CsCl}$ & .0000 & $.1382 E-04$ & .2029E-08 & .0000 \\
\hline 86 & CsCl Semi Vol & .0000 & 1.146 & .2049E-02 & .0000 \\
\hline 8 & CsNO3 & .0000 & $.1062 E-01$ & $.1626 \mathrm{E}-05$ & .0000 \\
\hline 88 & CsResin & .0000 & .0000 & .0000 & .0000 \\
\hline 22 & $\mathrm{Cu}(\mathrm{COOH}) 2$ & .0000 & .1748 & $.2678 \mathrm{E}-04$ & .0000 \\
\hline 52 & $\mathrm{Cu}(\mathrm{OH}) 2$ & .0000 & .0000 & .0000 & .0000 \\
\hline 58 & Cu20 & .0000 & .0000 & .0000 & .0000 \\
\hline 64 & $\mathrm{CuCOOH}$ & .0000 & .0000 & .0000 & .0000 \\
\hline $\mathbf{8 0}$ & $\mathrm{CuO}$ & .0000 & .0000 & .0000 & .0000 \\
\hline 18 & $\mathrm{Fe}(\mathrm{OH}) 8$ & .0000 & 43.76 & . 4677E-02 & .0000 \\
\hline 80 & Fe203 & .0000 & .0000 & .0000 & .0000 \\
\hline
\end{tabular}

Append Ix II

Table 21-16

Page 042 of 173

Date $09 / 30 / 82$ Rev 09
$41442 \quad 43 \quad 44$

Ejector Ejector Liquid Spray Atonzg Air Exit Vapor Exit Liquid to SWDBE \#1 SnLbF $\# 1$

45 Ag

$51 \mathrm{AgOH}$

74 Al(OH)B

$75 \mathrm{AlOOH}$

$9 \mathrm{Ba}(\mathrm{NO3}) 2$

$66 \mathrm{CO}$

37. $\mathrm{CO} 2$

$142 \mathrm{CO} 2(\mathrm{C14})$

$63 \mathrm{Ca}(\mathrm{COOH}) 2$

$120 \mathrm{Ca}(\mathrm{OH}) 2$

$18 \mathrm{CaCO}_{2}$

$78 \mathrm{CaF2}$

$19 \mathrm{CaSO}^{2}$

$26 \mathrm{Co}(\mathrm{COOH}) 2$

\section{Colotis}

$99 \mathrm{Cr}(\mathrm{OH}) 8$

98 Cr203

137 Cs20 Semi Vol

$90 \mathrm{CsCOOH}$

$186 \mathrm{CsCl}$ Semi Vol

8 CsNo3

88 CsResin

$122 \mathrm{Cu}(\mathrm{COOH}) 2$

$62 \mathrm{Cu}(\mathrm{OH}) 2$

58 Cu2O

$64 \mathrm{CuCOOH}$

$18 \mathrm{Fe}(\mathrm{OH}) \mathrm{s}$

$80 \mathrm{Fe} 203$ 
MATFIRIAL BALANCE TABLES

Date $09 / 30 / 82$ Rev 09

SLUDGE-SUPERNATE FEED STREAMS (CONT'D) STREAM NAME

\section{$101 \mathrm{FeO}$ \\ 126 Group A Semi Vo \\ 102 GroupA \\ 103 GroupB \\ 25112}

$183 \mathrm{H} 2 \mathrm{C} 204$

$91 \mathrm{H} 202$

$84 \mathrm{HCOOII}$

$43 \mathrm{NCI}$

$85 \mathrm{HF}$

$49 \mathrm{HNO}$

86 HResin

$36 \mathrm{Hg}$

135 ligN032

$21 \mathrm{HgO}$

$97 \quad 12$

$39 \mathrm{~K} 20$

$131 \mathrm{KMn} 0.4$

$118 \mathrm{KNO3}$

$105 \operatorname{La} 203$

$108 \mathrm{Li} 20$

$65 \mathrm{Mg}(\mathrm{COOH}) 2$

$55 \mathrm{Mg}(\mathrm{OH}) 2$

$33 \mathrm{MgO}$

$60 \mathrm{Mn}(\mathrm{COOH}) 2$

$122 \mathrm{Mn}(\mathrm{NO}) 2$

$129 \mathrm{Mn}(\mathrm{OII}) 2$

$56 \mathrm{MnO}$

$14 \mathrm{MnO2}$

81 N2

143 NA2CO3 (C14)

$35 \mathrm{NO}$

$84 \mathrm{NO2}$

$70 \mathrm{Na}(\mathrm{HgO}(\mathrm{OH}))$

$94 \mathrm{Na} 2 \mathrm{~B} 407$

$109 \mathrm{Na} 2 \mathrm{C2O4}$

$5 \mathrm{Na} 2 \mathrm{CO} 3$

32 Na20

$71 \mathrm{Na} 2 \mathrm{PuO2}_{2}(\mathrm{OH}) 4$

$73 \mathrm{Na} 2 \mathrm{RhO}$

$72 \mathrm{Na} 2 \mathrm{RuO} 4$

$6 \mathrm{Na} 2 \mathrm{SO} 4$

$68 \mathrm{NaAlO2}$

$114 \mathrm{NaBO2}$

140 NaBO2 Semi Vol

$50 \mathrm{NaCOOII}$
41

Ejector

Exit Vapor

.0000

.0000

.0000

.0000

$.7534 \mathrm{E}-03$

.0000

.0000

.0000

.0000

.0000

.0000

.0000

.0000

.0000

.0000

.0000

.0000

.0000

.0000

.0000

.0000

.0000

.0000

.0000

.0000

.0000

.0000

.0000

.0000

60.80

.0000

.2645E-02

.8961E-02

.0000

.0000

.0000

.0000

.0000

.0000

.0000

.0000

.0000

.0000

.0000

.0000

.0000
43

Litiuid Spray Atomzg Air

Ejector

Exit Liquid

.0000

1.863

.2800

.8949

$.1652 \mathrm{E}-04$

.0000

.0000

.0000

.0000

.0000

.0000

.0000

.0000

.0000

.6939

.0000

.0000

.0000

$.6913 \mathrm{E}-03$

.9028

14.81

.9867

.0000

5.013

8.860

.0000

.0000

.0000

.0000

.9933

.0000

$.1255 \mathrm{E}-03$

1.923

$.6318 \mathrm{E}-03$

24.28

$.2774 \mathrm{E}-03$

.0000

54.85

.2562E-07

.5268E-05

$.5140 \mathrm{E}-04$

.1042

.2562

.0000

.0000

29.26 to SUDBF \#1

.0000

$.2513 E-02$

.4280E-04

. $1871 \mathrm{E}-03$

.2022E-04

.0000

.0000

.0000

.0000

.0000

.0000

.0000

.0000

.0000

.1252E-02

.0000

.0000

.0000

$.9311 \mathrm{E}-07$

$.1382 E-03$

$.1578 \mathrm{E}-02$

$.1511 \mathrm{E}-03$

.0000

. 5535E-03

. 1358E-02

.0000

.0000

.0000

.0000

$.4786 \mathrm{E}-01$

.0000

$.7713 \mathrm{E}-04$

$.8274 \mathrm{E}-01$

$.9680 \mathrm{E}-07$

$.2921 \mathrm{E}-02$

.3736E-07

.0000

$.5854 \mathrm{E}-02$

$.3926 \mathrm{E}-11$

$.8071 \mathrm{E}-09$

$.7875 \mathrm{E}-08$

. 1597E-04

.3926E-04

.0000

.0000

.8597 E-02
44

SWDBF \#1

.0000

.0000

.0000

.0000

.0000

.0000

.0000

.0000

.0000

.0000

.0000

.0000

.0000

.0000

.0000

.0000

.0000

.0000

.0000

.0000

.0000

.0000

.0000

.0000

.0000

.0000

.0000

.0000

.0000

251.2

.0000

.0000

.0000

.0000

.0000

.0000

.0000

.0000

.0000

.0000

.0000

.0000

.0000

.0000

.0000

.0000 
DPSP $80-1033$

MATERIAL BALANCE TABLES

SLUDGE-SUPERNATE FEED STREAMS (CONT'D)STREAM NAME



Append ix II

Table 21-16

Page 044 of 173

Date 09/30/82 Rev CJ 
MITERIAL BALAKCE TABLES

Date 09/30/82 Rev 09

SLLDGE-SUPERSIATE FEED SIREAMS (CONT'D)STRTAM NAME

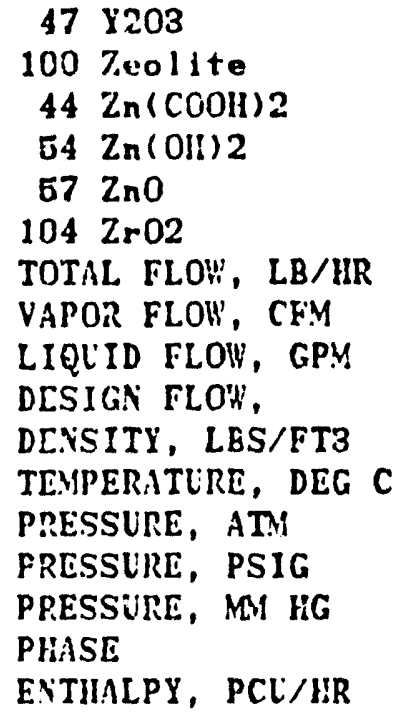

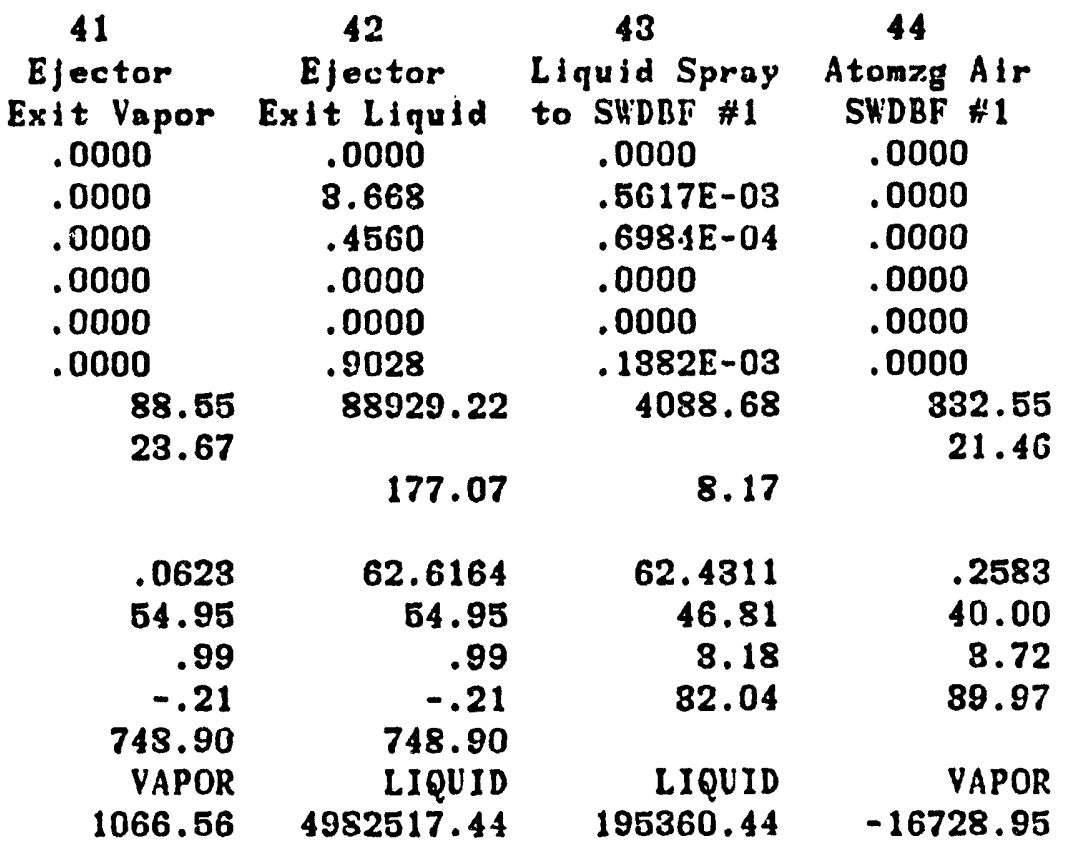


DPSP $80-1033$

MATERIAL BALANCE IABLES

SLCDGE-SUPERNATE FEED

STREAM NUMBERS -

STREAM NAME

COMPONENI FLOHS, LB/HR

\section{$1 \mathrm{H} 20$}

$45 \mathrm{Ag}$

116 Ag20

134 Ag.NO3

$51 \mathrm{AgOH}$

74 Al (OH) 8

77 A1203

$75 \mathrm{~A} 100 \mathrm{H}$

$106 \mathrm{~B} 203$

$9 \mathrm{Ba}(\mathrm{NO3}) 2$

$95 \mathrm{BaCl} 12$

$15 \mathrm{BaO}$

$24 \mathrm{BaSO}$

$66 \mathrm{CO}$

$37 \mathrm{CO2}$

$142 \mathrm{CO2}$ ( $\mathrm{C} 1:$ )

$63 \mathrm{Ca}(\mathrm{COOH}) 2$

$120 \mathrm{Ca}(\mathrm{OH}) 2$

$113 \mathrm{Ca} 3(\mathrm{PO} 04) 2$

$20 \mathrm{CaC204}$

$18 \mathrm{CaCO3}$

$78 \mathrm{CaF2}$

$41 \mathrm{CaO}$

$19 \mathrm{CaS04}$

29 Carbon

$26 \mathrm{Co}(\mathrm{COOH}) 2$

$121 \mathrm{Co}(\mathrm{OH}) 2$

$53 \mathrm{Co}(\mathrm{OH}) \mathrm{s}$

$59 \mathrm{CoO}$

$99 \mathrm{Cr}(\mathrm{OH}) 3$

$98 \mathrm{Cr} 203$

$42 \mathrm{Cs} 20$

187 Cs20 Semi Val

$90 \mathrm{CsCOOH}$

$96 \mathrm{CsCl}$

$136 \mathrm{CsCl}$ Semi Vol

8 CsN03

88 CsResin

$122 \mathrm{Cu}(\mathrm{COOH}) 2$

$62 \mathrm{Cu}(\mathrm{OH}) 2$

$58 \mathrm{Cu} 20$

$64 \mathrm{CuCOOH}$

$180 \mathrm{CuO}$

$13 \mathrm{Fe}(\mathrm{Oll}) 3$

$80 \mathrm{Fe} 203$
4095

.0003

.0000

.0003

$.8302 E-05$

$.2025 \mathrm{E}-02$

$.000 \mathrm{~J}$

.0000

$.4281 \mathrm{E}-02$

.2653E-10

.0000

.0000

.239:JE-04

$.2763 \mathrm{E}-03$

$.1563 E-01$

$.1680 \mathrm{E}-26$

$.832 \cdot \mathrm{E}-03$

.0000

.5979E-04

$.6467 \mathrm{E}-04$

.000 ?

$.1617 \mathrm{E}-04$

.0000

$.75903 \mathrm{E}-04$

.5585E-04

$.1315 \mathrm{E}-04$

.0000

.0000

.0000

$.6146 \mathrm{E}-04$

.0000

.3767 E-09

.0000

$.8708 \mathrm{E}-04$

.2203E-08

.2143E-02

$.1705 \mathrm{E}-05$

.0000

.2807E-04

.0000

.0000

.0000

.0000

$.4903 \mathrm{E}-02$

.0000
Appendix $H$

Table 21-16

Page 046 of 173

Date 09/30/82 Rev 00 
DPSP $8 U-1033$

MITERIAL BALANCE TABLES

SLUDLIE-SUPERNATE FETED STREAMS (CONT'D)STREAM NAME

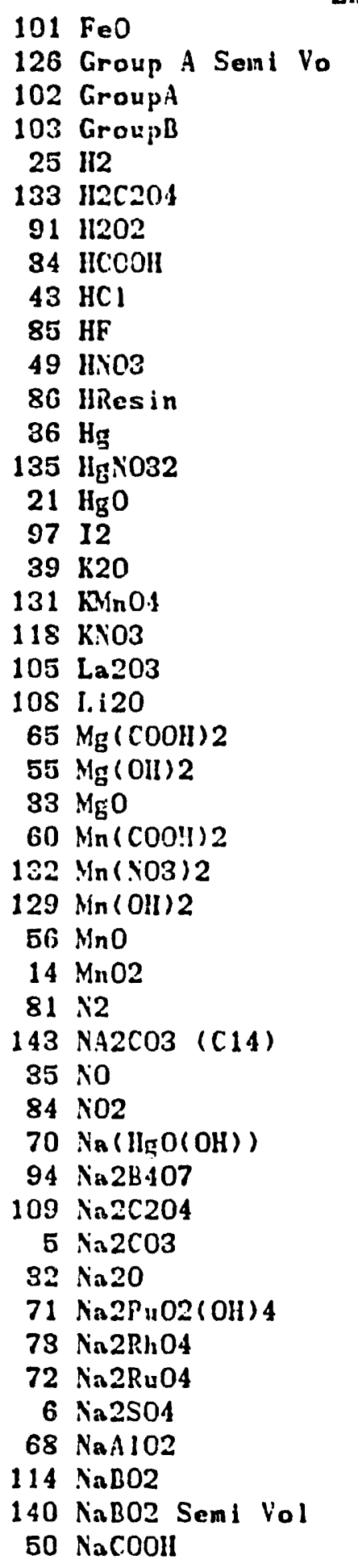

Appendix $H$

Table 21-16

Pnge 017 of 173

Date 09/30/82 Rev 09
45
SWDBF \#1

Exit Liquid .0000

.2629E-02

$.4490 E-04$

$.1437 \mathrm{E}-08$

$.2173 E-04$

.0000

.0000

.0000

.0000

.0000

.0000

.0000

.0000

.0000

$.1310 \mathrm{E}-02$

.0000

.0000

.0000

$.1006 \mathrm{E}-06$

$.1449 \mathrm{E}-03$

. 1655E-02

$.1584 \mathrm{E}-03$

.0000

$.5804 \mathrm{E}-03$

. 1423E-02

.0000

.0000

.0000

.0000

$.4759 \mathrm{E}-01$

.0000

$.8215 \mathrm{E}-04$

$.8215 \mathrm{E}-01$

$.1015 \mathrm{E}-06$

$.8062 E-02$

$.4038 \mathrm{E}-07$

.0000

$.6138 \mathrm{E}-02$

$.4116 E-11$

$.8461 E-09$

$.8257 \mathrm{E}-08$

$.1674 \mathrm{E}-04$

$.4116 E-04$

.0000

.0000

$.8772 E-02$
46

SWDDBF \#1

Exit Gas

.0000

. 1285E-04

$.6845 \mathrm{E}-07$

.2171E-06

.5927

.0000

.0000

.0000

.0000

.0000

.0000

.0000

.0000

.0000

$.6345 \mathrm{E}-05$

$.7755 \mathrm{E}-04$

.0000

.0000

.2159E-09

.2193E-06

.2505E-05

.2394E-0O

.0000

$.8787 \mathrm{E}-0 \mathrm{G}$

.2147E-05

.0000

.0000

.0000

.0000

1045.

.0000

.9700

.1598

. 1530E-00

$.4622 \mathrm{E}-05$

$.9866 \mathrm{E}-10$

.0000

$.9264 \mathrm{E}-0 \mathrm{~S}$

$.6205 \mathrm{E}-14$

. 1276E-11

. 1245E-10

$.2524 \mathrm{E}-07$

$.6205 E-07$

.0000

.0000

$.5724 \mathrm{E}-0 \mathrm{E}$
47

Liquid Spray to SWDBF \#2 .0000

$.2518 \mathrm{E}-02$

$.4280 \mathrm{E}-04$

$.1371 \mathrm{E}-03$

.2022E-04

.0000

.0000

.0000

.0000

.0000

.0000

.0000

.0000

.0000

$.1252 E-02$

.0000

.0000

.0070

.9311E-07

.1382E-03

$.1578 \mathrm{E}-02$

$.1511 \mathrm{E}-03$

.0000

. 5535E-03

. 1358E-02

.0000

.0000

.0000

.0000

$.4786 \mathrm{E}-01$

.0000

$.7713 E-04$

$.8274 \mathrm{E}-01$

$.9680 \mathrm{E}-07$

.2921E-02

$.8736 E-07$

.0000

.5854E-02

$.8926 \mathrm{E}-11$

$.8071 E-09$

$.7875 \mathrm{E}-08$

$.1597 \mathrm{E}-04$

.8926E-04

.0000

.0000

$.8597 E-02$
48

SWDBF \#2

Atomzg Air

.0000

.0000

.0000

.0000

.0000

.0000

.0000

.0000

.0000

.0000

.0000

.0000

.0000

.0000

.0000

.0000

.0000

.0000

.0000

.0000

.0000

.0000

.0000

.0000

.0000

.0000

.0000

.0000

.0000

251.2

.0000

.0000

.0000

.0000

.0000

.0000

.0000

.0000

.0000

.0000

.0000

.0000

.0000

.0000

.0000

.0000 
DPSP $80-1088$

MATERIAL BALANCE TABLES SLLDGE-SUPERNATE FEED STREAMS (CONT'D) STREAM NAME

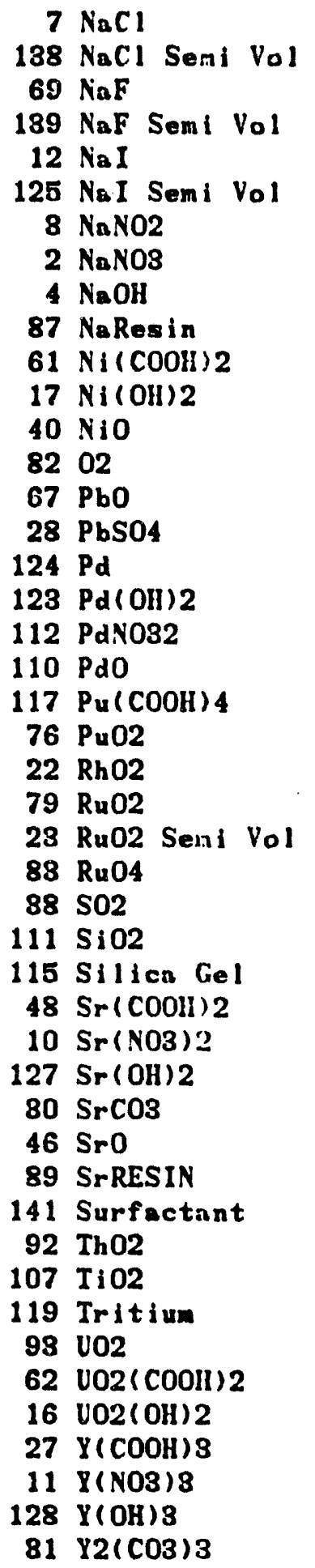

Appendix $H$

Table 21-10

Pago 048 of 178

Date $09 / 30 / 82$ Rev 03
45

SWDBE \#1

Exit Liquid

$.16 c 7 E-04$

$.1878 E-01$

$.4322 E-03$

$.1531 E-01$

$.161 \mathrm{OE}-05$

$.187+E-02$

.0000

$.6382 \mathrm{E}-03$

.0003

.0003

$.4981 \mathrm{E}-03$

$.000 J$

$.000 J$

$.2752 E-01$

$.000 \mathrm{~J}$

$.2253 \mathrm{E}-04$

.0000

.0000

.0003

.0000

.230:JE-07

$.5877 E-05$

$.224 J E-05$

. 1083E-04

.1272E-02

.0000

$.8412 E-04$

$.1813 \mathrm{E}-01$

.0000

.2027E-04

.2872E-10

.0000

.0000

.0000

.0000

.0000

$.9213 E-04$

.2898E-03

$.6321 \mathrm{E}-09$

.0000

$.6443 \mathrm{E}-03$

.0000

$.1386 \mathrm{E}-04$

$.1685 \mathrm{E}-10$

.0000

.0000
46

SHDBF \#1

Exit Gas

.2516E-07

$.9088 \mathrm{E}-04$

$.6537 \mathrm{E}-0 \mathrm{G}$

$.7439 E-04$

$.2439 E-08$

$.9068 E-05$

.0000

$.8116 E-06$

.0000

.0000

$.7525 E-06$

.0000

.0000

496.7

.0000

$.8412 E-07$

.0000

.0000

.0000

.0000

$.3498 \mathrm{E}-10$

$.8878 \mathrm{E}-08$

$.8392 E-08$

. 1672E-07

$.6283 \mathrm{E}-05$

.0000

.8100

.2737 E-04

.0000

$.3063 \mathrm{E}-07$

$.8577 \mathrm{E}-13$

.0000

.0000

.0000

.0000

.0000

$.1392 \mathrm{E}-06$

$.4385 \mathrm{E}-06$

$.2768 \mathrm{E}-10$

.0000

$.9733 \mathrm{E}-06$

.0000

$.2094 \mathrm{E}-07$

$.2540 \mathrm{E}-13$

.0000

.0000
47

Liquid Spar.y to SH'DBF t:? .15902-04

. 17961-01

$.41225-C .3$

$.1467 E-01$

$.1541 \mathrm{E}-05$

.1792E-02

.0000

$.5133 E-03$

.0000

.0000

$.4751 \mathrm{E}-03$

.0000

.0000

$.2773 E-01$

.0000

.2154 E-04

.0000

.0000

.0000

.0000

.2193E-07

$.5605 E-05$

.2142E-05

. 1035E-04

.1216E-02

.0000

$.3212 E-04$

$.1730 \mathrm{E}-01$

.0000

$.1934 \mathrm{E}-04$

$.2263 E-10$

.0000

.0000

.0000

.0000

.0000

$.8787 E-04$

$.2764 \mathrm{E}-03$

.5901E-09

.0000

$.6145 \mathrm{E}-03$

.0000

$.1322 E-04$

.1607E- 10

.0000

.0000
48

StioBf $\# 2$

Atonize $\mathrm{dir}$

.0000

.0000

.0000

.0000

.0000

.0000

.0000

.0000

.0000

.0000

.0000

.0000

.0000

75.89

.0000

.0000

.0000

.0000

.0000

.0000

.0000

.0000

.0000

.0000

.0000

.0000

.0000

.0000

.0000

.0000

.0000

.0000

.0000

.0000

.0000

.0000

.0000

.0000

.0000

.0000

.0000

.0000

.0000

.0000

.0000

.0000 
Date 09/30/82 Rev 09

MIIERIAL BALANCE TARLES SLLDGI:-SLPERNATE FEED STRTAMS (CONT'D)STRIAY NAME

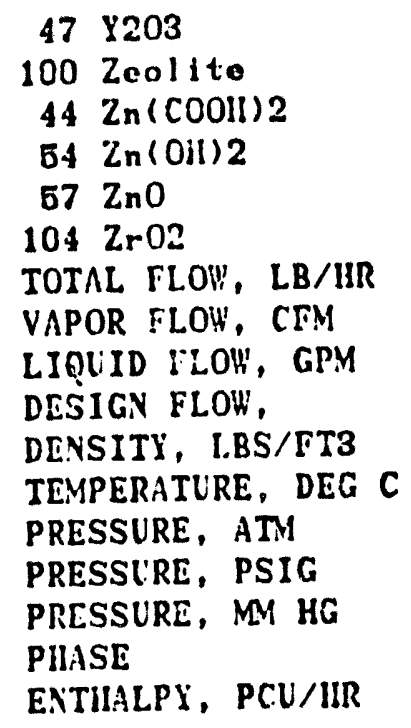

45
SWDBF \#1
Exit Liquid
.0000
$.5890 E-03$
$.7323 E-04$
.0000
.0000
$.1449 E-03$
4095.62

8.18

62.4811
48.03
.98
-1.01
707.56
$L 1 Q U 1 D$
C
200847.45

46

SWDBF \#1

Exit Gas

.0000

$.8897 E-06$

$.1106 \mathrm{E}-06$

.0000

.0000

$.2193 E-06$

2346.89

644.55

47

Liquid Spray

to SWDBF \#2

.0000

. 5617E-03

$.6984 \mathrm{E}-04$

.0000

.0000

$.1382 \mathrm{E}-03$

4088. 68

48

SWDUF \#2

Atomzg Air

.0000

.0000

.0000

.0000

.0000

.0000

832.55

21.46

8.17
.0607
48.05
.93
$-1.06$
705.05
VAPOR
$-15419.49$
62.4311
46.81
8.18
82.04
.2583
40.00
8.72
89.97
LIOUID
VAPOR
195360.44
$-16728.95$


DPSP $80-1038$

MATERIAL BALANCE TABLES

SLLDGE-SUPERNATE FEED

STREAM NUMBERS -

STREAM NAME

COMPONENT FLOWS, LB/HR

$1 \mathrm{H} 20$

$45 \mathrm{Ag}$

$116 \mathrm{Ag} 20$

134 AgNO3

$51 \mathrm{AgOH}$

74 Al $(\mathrm{OH}) 3$

77 Al203

75 A $100 \mathrm{H}$

$106 \mathrm{~B} 203$

$9 \mathrm{Ba}(\mathrm{NO3}) 2$

$95 \mathrm{BaCl} 2$

$15 \mathrm{BaO}$

$24 \mathrm{BaSO} 04$

$66 \mathrm{CO}$

$87 \mathrm{CO} 2$

$142 \mathrm{CO}$ ( $\mathrm{Cl} 14)$

$63 \mathrm{Ca}(\mathrm{COOH}) 2$

$120 \mathrm{Ca}(\mathrm{OH}) 2$

$113 \mathrm{Cn} 3(\mathrm{PO} 4) 2$

$20 \mathrm{CaC2O4}$

$18 \mathrm{CaCO3}$

$78 \mathrm{CaF2}$

$41 \mathrm{CnO}$

$19 \mathrm{CaSO}_{4}$

29 Carbon

$26 \mathrm{Co}(\mathrm{COOH}) 2$

$121 \mathrm{Co}(\mathrm{OH}) 2$

$53 \mathrm{Co}(\mathrm{OH}) 3$

$59 \mathrm{CoO}$

$99 \mathrm{Cr}(\mathrm{OH}) 3$

$98 \mathrm{Cr} 203$

$42 \operatorname{Cs} 20$

137 Cs20 Semi Vol

$90 \mathrm{CsCOOH}$

$96 \mathrm{CsCl}$

$186 \mathrm{CsCl}$ Semi Vol

8 CsNO3

88 CsResin

$122 \mathrm{Cu}(\mathrm{COOH}) 2$

$62 \mathrm{Cu}(\mathrm{OH}) 2$

68 Cu20

$64 \mathrm{CuCOOH}$

$130 \mathrm{CuO}$

$18 \mathrm{Fe}(\mathrm{OH}) 3$

$80 \mathrm{Fe} 203$
48

SWDBF \#2

Exit Liruid

4084.

.0000

.0000

.0000

.8167E-05

$.1985 \mathrm{E}-02$

.0000

.0000

$.4089 \mathrm{E}-02$

.2540E-10

.0000

.0000

.2292E-04

.2408E-03

$.1408 \mathrm{E}-01$

$.1464 \mathrm{E}-26$

$.7951 \mathrm{E}-03$

.0000

$.6712 \mathrm{E}-04$

$.6177 \mathrm{E}-04$

.0000

$.1044 \mathrm{E}-04$

.0000

$.7256 \mathrm{E}-04$

. $5333 \mathrm{E}-04$

. 1257E-04

.0000

.0000

.0000

$.5871 E-04$

.0000

$.8604 \mathrm{E}-09$

.0000

$.3541 E-04$

.2034E-08

.2058E-02

$.1629 E-05$

.0000

.2682E-04

.0000

.0000

.0000

.0000

.4684 E-02

.0000
Append IX H

Tnble 21-16

Pnge 050 of 173

Date 09/30/E2 Rev 03

50

51

52

SWDBF \#2 Ru Adsorber I2 Adsorber

Exit Gas

Gas Feed Prchter Feed

189.7
.0000
.0000
.0000
$.1541 E-09$
$.9646 E-07$
.0000
.0000
$.2048 E-06$
$.1268 E-14$
.0000

69.63

69.63

.0000

.0000

.0000

.0000

.0000

$.1541 \mathrm{E}-09$

.0000

.964 GE-07

$.7707 \mathrm{E}-10$

$.4823 E-07$

.0000

.0000

.0000

.0000

$.2043 E-06$

$.1022 \mathrm{E}-00$

.1268E-14

.0000

.0000

$.6338 \mathrm{E}-15$

.0000

.0000

$.1146 \mathrm{E}-08$

7.614

16.07

.1722E-23

.3977E-07

.0000

.2857E-08

.3090E-08

.0000

$.7724 \mathrm{E}-09$

.0000

$.8629 \mathrm{E}-08$

$.2683 \mathrm{E}-08$

$.6279 \mathrm{E}-09$

.0000

.0000

.0000

.2936E-08

.0000

$.1146 E-08$

7.614

16.57

$.1722 \mathrm{E}-23$

$.8977 \mathrm{E}-07$

.0000

.2857E-08

.3090E-08

.0000

.7724 E-09

.0000

$.3629 \mathrm{E}-08$

$.2683 E-08$

.0000

.0000

.0000

.0000

.2936 E- 08

.0000

$.1734 E-13$

.0000

$.1783 \mathrm{E}-08$

$.1046 E-05$

.0000

$.8131 \mathrm{E}-10$

.0000

$.1341 \mathrm{E}-08$

.0000

.0000

.0000

.0000

.2335E-06

.0000
.5732E-09

7.614

16.57

$.1722 E-23$

.1988 E-07

.0000

$.112 S E-08$

$.1545 \mathrm{E}-08$

.0000

.3862E-09

.0000

. 1815E-OS

$.1342 E-08$

.0000

.0000

.0000

.0000

$.1468 \mathrm{E}-08$

.0000

$.8672 E-14$

.0000

$.8915 \mathrm{E}-09$

. 5229E-06

.0000

$.4065 \mathrm{E}-10$

.0000

$.6706 \mathrm{E}-09$

.0000

.0000

.0000

.0000

$.1167 E-00$ .0000
.2335E-06

.0000 
MMIENIIL BALANCE TABLES

Date 09/30/82 Rev 09

SLLEGE-S!PERNATE FIEDD

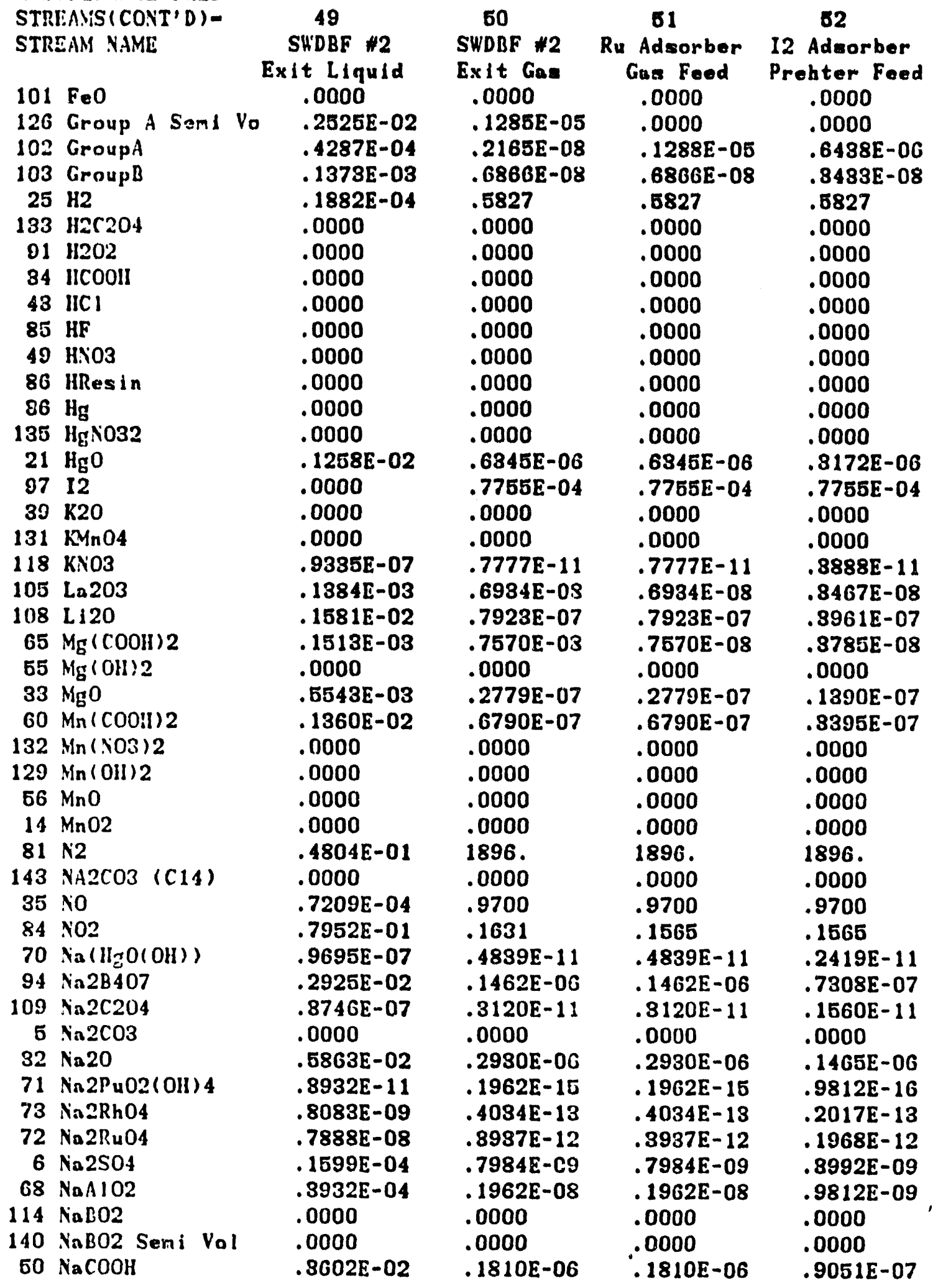


DPSP $80-1038$

MATERIAL BALANCE TABLES

SLUDGE-SUPERNATE FEED

STREAMS ( CONT' D)-

STREAM NAME

$7 \mathrm{NaCl}$

$188 \mathrm{NaCl}$ Seml Vol

$69 \mathrm{NaF}$

$189 \mathrm{NaF}$ Semi Vol

$12 \mathrm{NaI}$

125 Nol Seml Vol

$8 \mathrm{NaNO2}$

$2 \mathrm{NaNO3}$

$4 \mathrm{NaOH}$

87 NaResin

$61 \mathrm{Ni}(\mathrm{COOH}) 2$

$17 \mathrm{Ni}(\mathrm{OH}) 2$

40 N10

8202

$67 \mathrm{PbO}$

$28 \mathrm{PbSO} 4$

$124 \mathrm{Pd}$

$123 \mathrm{Pd}(\mathrm{OH}) 2$

112 PdNO32

110 PdO

$117 \mathrm{Pu}(\mathrm{COOH}) 4$

$76 \mathrm{Pu} 02$

$22 \mathrm{RhO2}$

$79 \mathrm{Ru} 02$

23 Ru02 Seini Vol

$88 \mathrm{Ru} 04$

$88 \mathrm{SO2}$

$111 \mathrm{SiO2}$

115 Silica Gel

$48 \mathrm{Sr}(\mathrm{COOH}) 2$

$10 \mathrm{Sr}(\mathrm{NO3}) 2$

$127 \mathrm{Sr}(\mathrm{OH}) 2$

$80 \mathrm{SrCO}$

$46 \mathrm{SrO}$

89 SrRESIN

141 Surfactant

92 Th02

107 T102

119 Tritiun

$93 \mathrm{~V} 02$

$62 \mathrm{VO} 2(\mathrm{COOH}) 2$

$16 \mathrm{VO} 2(\mathrm{OH}) 2$

$27 \mathrm{Y}(\mathrm{COOH}) 3$

$11 \mathrm{Y}(\mathrm{NOS}) \mathrm{S}$

$128 Y(\mathrm{OH}) \mathrm{B}$

$81 Y 2(\mathrm{CO}) 3$
Appendix $\mathrm{H}$

Table 21-16

Pnge 052 of 173

Date 09/30/32 Rev 09

50

SUIDBF \#2

E::it Gaa

.7958E-09

$.9088 \mathrm{E}-05$

.2007E-07

$.7439 E-05$

$.7713 \mathrm{E}-10$

$.9068 \mathrm{E}-06$

.0000

.2567E-07

.0000

.0000

.2380E-07

.0000

.0000

572.6

.0000

$.1079 E-08$

.0000

.0000

.0000

.0000

$.1106 \mathrm{E}-11$

.2808E-09

$.1073 E-09$

.5288E-09

$.6283 E-06$

.0000

.3100

$.8656 \mathrm{E}-06$

.0000

$.9686 \mathrm{E}-09$

$.1181 E-14$

.0000

.0000

.0000

.0000

.0000

$.4401 \mathrm{E}-08$

$.1387 E-07$

$.2743 \mathrm{E}-10$

.0000

$.8078 \mathrm{E}-07$

.0000

$.6622 \mathrm{E}-09$

$.8032 E-15$

.0000

.0000
51

Ru Adsorber

Gins Feed

.9089 E-05

.0000

$.7459 E-05$

.0000

$.9060 \mathrm{E}-0 \mathrm{G}$

.0000

.0000

.2567 E-07

.0000

.0000

$.2380 \mathrm{E}-07$

.0000

.0000

572.6

.0000

. 1079E-OS

.0000

.0000

.0000

.0000

$.1106 \mathrm{E}-11$

.2808E-09

. 1073E-09

$.6288 \mathrm{E}-06$

.0000

.0000

.8100

$.8656 \mathrm{E}-06$

.0000

$.9686 \mathrm{E}-09$

$.1131 \mathrm{E}-14$

.0000

.0000

.0000

.0000

.0000

$.4401 E-08$

$.1387 \mathrm{E}-07$

$.1007 \mathrm{E}-10$

.0000

.8078E-07

.0000

$.6622 \mathrm{E}-09$

$.8032 E-15$

.0000

.0000
E2

I2 Adso:-ber Prehter Foed $.4545 \mathrm{E}-05$ .0000

.3730E-05

.0000

$.4535 \mathrm{~F}-06$

.0000

.0000

$.1283 \mathrm{E}-07$

.0000

.0000

$.1190 E-07$

.0000

.0000

572.6

.0000

.5395E-09

.0000

.0000

.0000

.0000

$.5531 E-12$

$.1404 \mathrm{E}-09$

$.5364 E-10$

$.3144 E-06$

.0000

.0000

.3100

$.4328 E-06$

.0000

$.4843 E-09$

$.56566 .-15$

.0000

.0000

.0000

.0000

.0000

$.2201 \mathrm{E}-08$

$.6934 \mathrm{E}-08$

$.1007 \mathrm{E}-10$

.0000

$.1539 \mathrm{E}-07$

.0000

$.3311 E-09$

$.4016 \mathrm{E}-15$

.0000

$.0000^{\circ}$ 
MATERIAL BALANCE TABLES

Date 09/30/82 Rev 09

SLUDGE-SUPERNATT FIED

STREAMS (CONT'D)STREAM NAME

47 Y2O3
$100 \mathrm{ZeOlite}$
$44 \mathrm{Zn}($ COOH) 2
$54 \mathrm{Zn}(0 \mathrm{H}) 2$
$57 \mathrm{ZnO}$
$104 \mathrm{ZrO2}$
TOTAL FLOW, LB/HR
VAPOR FLOW, CFM
LIQUID FLOW, GPM
DESIGN FLOW,
DENSITY, LBS/FT3
TEMPERATURE, DEG C
PRESSURE, ATM
PRESSURE, PSIG
PRESSURE, AM HIG
PHASE
ENTHALPY, PCU/IIR

49

SYDBF \#2

Exit Liquid

.0000

$.5626 \mathrm{E}-03$

$.6995 E-04$

.0000

.0000

$.1384 \mathrm{E}-03$

4083.80

8.16

62.4311

46.29

.92

$-1.21$

697.45

LIQUID

192903.54
50

SHDBF \#2

Esit Gas

.0000

$.2814 \mathrm{E}-07$

.3499E-08

.0000

.0000

$.6934 \mathrm{E}-08$

2684.82

740.59

.0604

46.27

.82

$-1.24$

695.70

VAPOR

$-29.695 .83$
51

Ru Adsorber

Gas Feed

.0000

.2814E-07

$.8499 \mathrm{E}-08$

.0000

.0000

$.6934 \mathrm{E}-08$

2564.20

800.09

I2 Adso:ber

Prehter Feed

.0000

$.1407 \mathrm{E}-07$

$.1749 \mathrm{E}-08$

.0000

.0000

.3467E-08

2564.20

878.73

.0534
80.00
.87
-1.85
664.09
VAPOR
-82953.74

.0486

80.00

.80

$-8.00$

604.66

VAPOR

$-82953.74$ 
DPSP $80-1033$

MATERIAL BALANCE TABLES SLUDGE-SUPERNATE FEED STREAM NUMLERS STREAM NAME

COMPONENT FLOHS, LB/HR

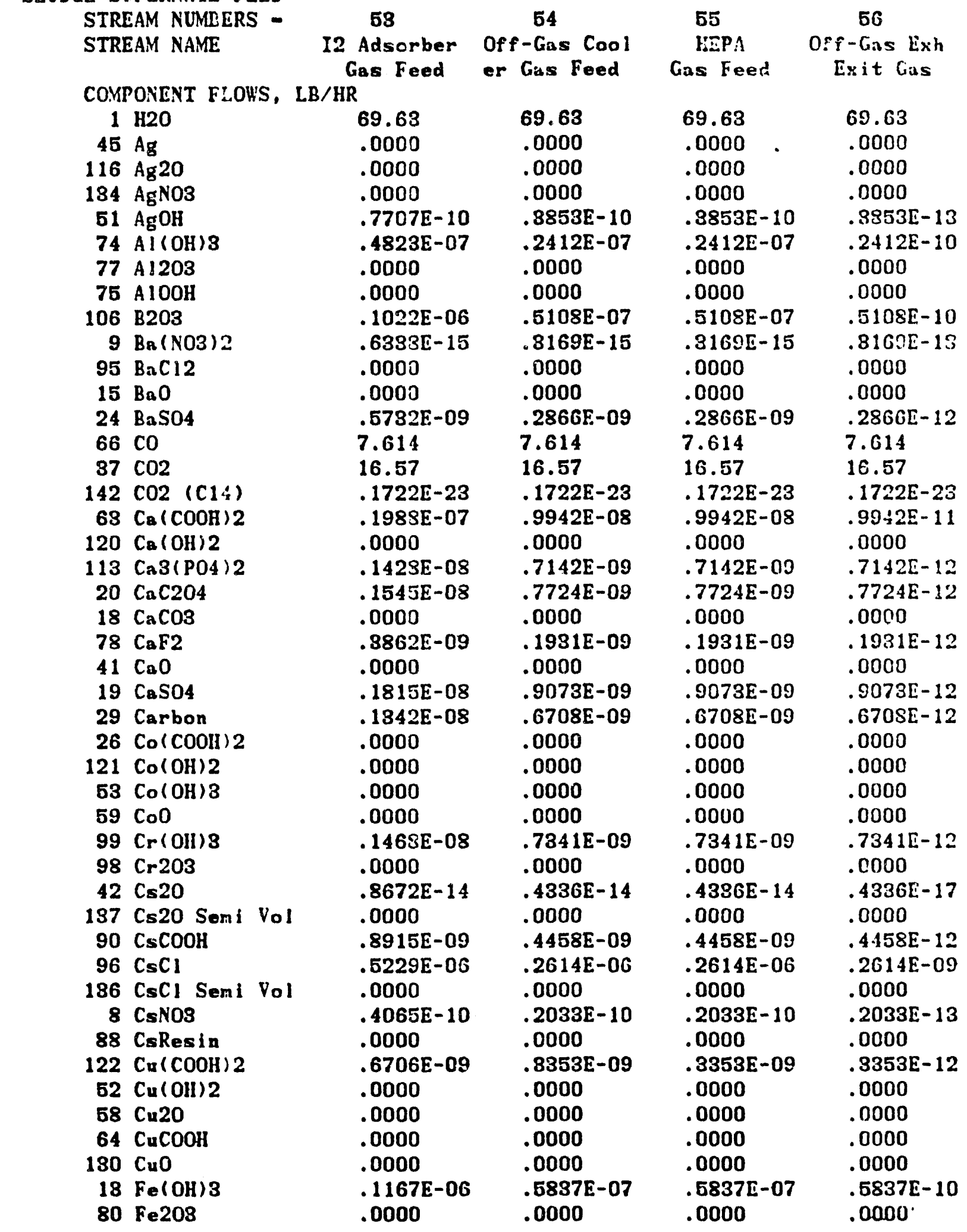

Appendix $\mathrm{H}$

Table 21-16

Page 054 of 173

Date 09/30/82 Rev 09 
DPSP $80-1033$

MITLAIAL BALANCE TABLES

SLI'DGE-SLPERYATE FEED STREAMS (CONT'D)STREAM NAME

$101 \mathrm{FeO}$

126 Group A Semi Vo

102 GroupA

103 GroupB

$25 \mathrm{HI} 2$

183 II2C204

$91 \mathrm{HI2O2}$

$84 \mathrm{HCOOH}$

$43 \mathrm{HCl}$

$85 \mathrm{HF}$

49 HNO3

86 HResin

$86 \mathrm{Hg}$

$135 \mathrm{Hg} \mathrm{Y} 032$

$21 \mathrm{HrO}$

9712

39 K20

$131 \mathrm{KM} \ln 04$

$118 \mathrm{KNO3}$

$105 \operatorname{La} 203$

103 Li20

$65 \mathrm{Mg}(\mathrm{COOH}) 2$

$55 \mathrm{Mg}(\mathrm{OII}) 2$

$33 \mathrm{MgO}$

$60 \mathrm{Mn}(\mathrm{COOH}) 2$

$132 \mathrm{Mn}(\mathrm{NO3}) 2$

$129 \mathrm{Mn}(\mathrm{OII}) 2$

$56 \mathrm{MnO}$

$14 \mathrm{MnO2}$

81 N2

143 NA2CO3 (C14)

35 NO

$84 \mathrm{NO2}$

$70 \mathrm{Nn}(\mathrm{HgO}(\mathrm{Oil}))$

$94 \mathrm{Na2B} 407$

$109 \mathrm{Na} 2 \mathrm{C} 204$

$5 \mathrm{Na} 2 \mathrm{CO}$

$32 \mathrm{Na} 20$

$71 \mathrm{Na}_{2} \mathrm{Pu}_{\mathrm{O}} \mathrm{O}(\mathrm{OH}) 4$

$73 \mathrm{Na} 2 \mathrm{RhO4}$

72 Na2Ru04

$6 \mathrm{Na} 2 \mathrm{SO} 4$

$68 \mathrm{NaAlO2}$

$114 \mathrm{NaBO2}$

$140 \mathrm{NaBO2}$ Semi Vol

$50 \mathrm{NaCOOH}$
Appendix H

Tnble 21-16

Page 055 of 173

Date 09/30/82 Rev 09

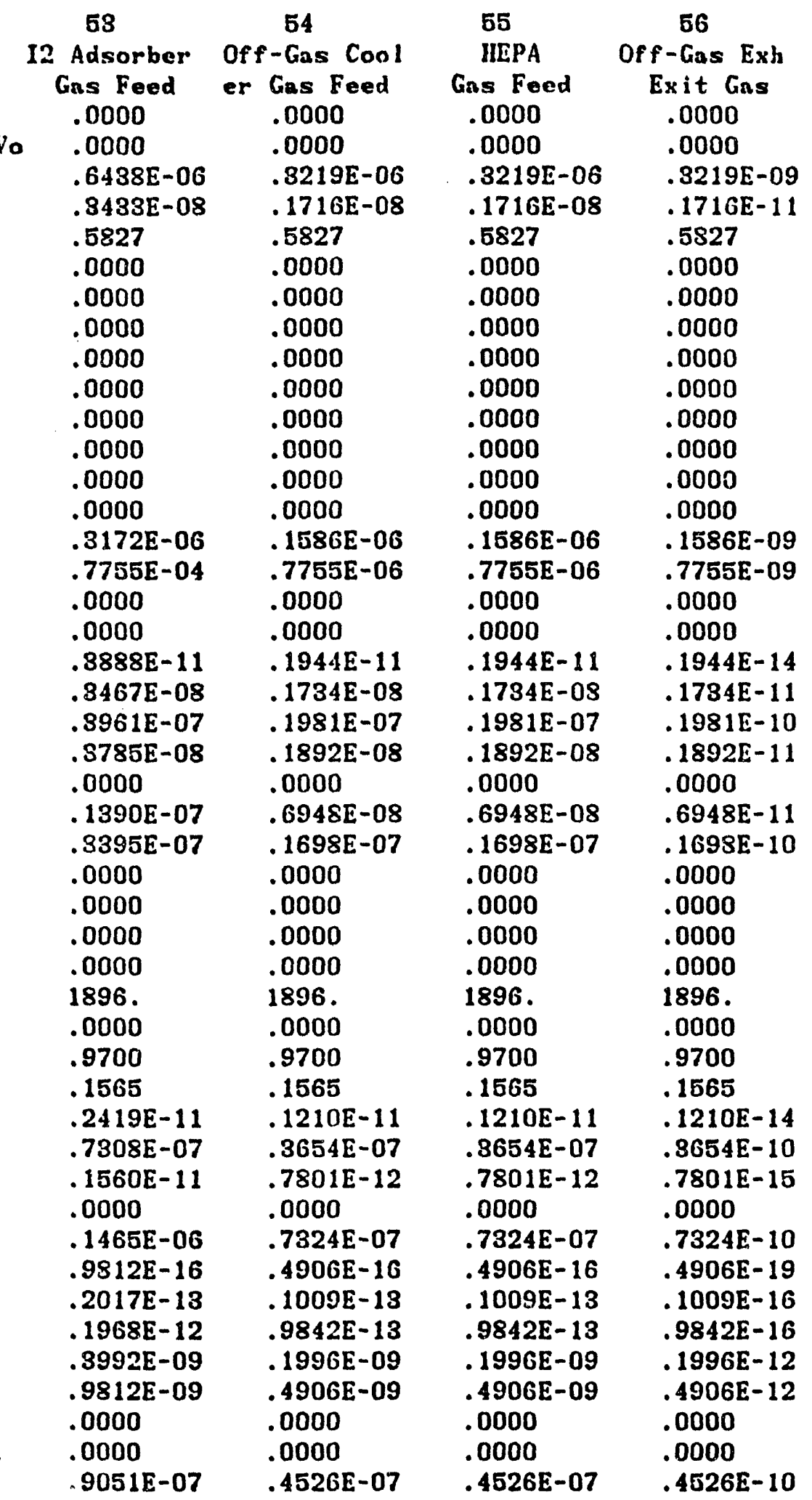


DPSP $80-1033$

MATERIAL BALANCE TABLES

SLUDGE-SUPERNATE FEED

STREAMS (CONT'D)-

STREAM NAME

$7 \mathrm{NaCl}$

$138 \mathrm{NaCl}$ Semi Vol

$69 \mathrm{NaF}$

139 NaF Semi Vol

$12 \mathrm{NaI}$

$125 \mathrm{NaI}$ Semi Vol

$8 \mathrm{NaN02}$

$2 \mathrm{NaNO}$

$4 \mathrm{NaOH}$

87 NaResin

$61 \mathrm{Ni}(\mathrm{COOH}) 2$

$17 \mathrm{Ni}(\mathrm{OH}) 2$

$40 \mathrm{NiO}$

8202

$67 \mathrm{PbO}$

$28 \mathrm{PbSO} 4$

$124 \mathrm{Pd}$

$123 \mathrm{Pd}(\mathrm{OH}) 2$

112 PdNO32

$110 \mathrm{PdO}$

$117 \mathrm{Pu}(\mathrm{COOH}) 4$

$76 \mathrm{Pu} 02$

$22 \mathrm{RhO2}^{2}$

$79 \mathrm{Ru} 02$

28 Ru02 Semi Vol

$83 R_{4} 04$

$88 \mathrm{SO2}$

$111 \mathrm{SiO}$

115 Silica Gel

$48 \mathrm{Sr}(\mathrm{COOH}) 2$

$10 \mathrm{Sr}(\mathrm{NOO})$ ?

$127 \mathrm{Sr}(\mathrm{OH}) 2$

$80 \mathrm{SrCO}$

$46 \mathrm{SrO}$

89 SrRESIN

141 Surfactant

$92 \mathrm{ThO} 2$

$107 \mathrm{TiO2}$

119 Tritium

93 U02

$62 \mathrm{UO2}(\mathrm{COOH}) 2$

$16 \mathrm{VO} 2(\mathrm{OH}) 2$

$27 \mathrm{Y}(\mathrm{COOH}) 3$

$11 \mathrm{Y}(\mathrm{NO3}) 3$

$128 \mathrm{Y}(\mathrm{OH}) 3$

$81 \mathrm{Y2}(\mathrm{CO}) 3$
Appendix $\mathrm{H}$

Table 21-10

Page 056 of 173

Date 09/30/82 Rev 09

\begin{tabular}{|c|c|c|c|}
\hline 58 & 54 & 55 & 56 \\
\hline I2 Adsorber & Off-Gas Cool & HEPA & Off-Gas Exh \\
\hline $\begin{array}{l}\text { Gas Feed } \\
.4545 \mathrm{~J}-05\end{array}$ & $\begin{array}{l}\text { er Gas Feed } \\
.2272 \mathrm{E}-05\end{array}$ & $\begin{array}{l}\text { Gas Feed } \\
.2273 . E-05\end{array}$ & $\begin{array}{l}\text { Exit Gas } \\
.2272 E-C 3\end{array}$ \\
\hline .0000 & .0000 & .0000 & .0000 \\
\hline $.87 \varepsilon 0 \mathrm{E}-05$ & $.1865 E-05$ & $.1865 E-05$ & $.1865 \mathrm{E}-03$ \\
\hline .0000 & .0000 & .0000 & .0000 \\
\hline $.4585 \mathrm{E}-06$ & $.2267 E-06$ & $.2267 \mathrm{E}-06$ & $.2267 \mathrm{E}-00$ \\
\hline .0000 & .0000 & .0000 & .0000 \\
\hline .0000 & .0000 & .0000 & .0000 \\
\hline $.1283 E-07$ & $.6417 E-08$ & $.6417 \mathrm{E}-08$ & $.6417 \mathrm{E}-11$ \\
\hline .0000 & .0000 & .0000 & .0000 \\
\hline .0000 & .0000 & .0000 & .0000 \\
\hline $.1190 \mathrm{E}-07$ & . 5949E-08 & $.5949 E-08$ & $.5949 E-11$ \\
\hline .0000 & .0000 & .0000 & .0000 \\
\hline .0000 & .0000 & .0000 & .0000 \\
\hline 572.6 & 572.6 & 572.6 & 572.6 \\
\hline .0000 & .0000 & .0000 & .0000 \\
\hline $.539 J E-09$ & $.2697 E-09$ & $.2697 \mathrm{E}-09$ & $.2697 \mathrm{E}-12$ \\
\hline .0000 & .0000 & .0000 & .0000 \\
\hline .0000 & .0000 & .0000 & .0000 \\
\hline .0000 & .0000 & .0000 & .0000 \\
\hline .0000 & .0000 & .0000 & .0000 \\
\hline $.5531 E-12$ & $.2765 E-12$ & $.2765 E-12$ & $.2765 \mathrm{E}-15$ \\
\hline $.1404 E-09$ & $.7019 E-10$ & $.7019 E-10$ & $.7019 \mathrm{E}-13$ \\
\hline $.5364 E-10$ & $.2682 E-10$ & $.2682 E-10$ & $.26 S 2 E-13$ \\
\hline $.3144 E-06$ & . 1572E-06 & $.1572 E-06$ & $.1572 E-0.3$ \\
\hline .0000 & .0000 & .0000 & .0000 \\
\hline .0000 & .0000 & .0000 & .0000 \\
\hline .8100 & .8100 & .3100 & .8100 \\
\hline $.4323 \mathrm{E}-06$ & $.2164 E-06$ & $.2164 E-06$ & $.2164 \mathrm{E}-03$ \\
\hline .0000 & .0000 & .0000 & .0000 \\
\hline $.4843 E-09$ & $.2421 E-09$ & $.2421 E-09$ & $.2421 E-12$ \\
\hline $.5650 E-15$ & $.2828 \mathrm{E}-15$ & $.2828 E-15$ & $.2828 \mathrm{E}-18$ \\
\hline .0000 & .0000 & .0000 & .0000 \\
\hline .0000 & .0000 & .0000 & .0000 \\
\hline .0000 & .0000 & .0000 & .0000 \\
\hline .0000 & .0000 & .0000 & .0000 \\
\hline .0000 & .0000 & .0000 & .0000 \\
\hline $.2201 E-08$ & $.1100 \mathrm{E}-08$ & $.1100 \mathrm{E}-08$ & $.1100 \mathrm{E}-11$ \\
\hline $.6934 \mathrm{E}-08$ & $.8467 E-08$ & $.3467 E-08$ & $.8467 E-11$ \\
\hline . 1007E-10 & $.1007 E-10$ & . 1007E-10 & $.1007 \mathrm{E}-10$ \\
\hline .0000 & .0000 & .0000 & .0000 \\
\hline $.1539 E-07$ & $.7695 \mathrm{E}-08$ & $.7695 \mathrm{E}-08$ & $.7695 \mathrm{E}-11$ \\
\hline .0000 & .0000 & .0000 & .0000 \\
\hline $.8311 E-09$ & $.1655 E-09$ & . 1655E-09 & $.1655 \mathrm{E}-12$ \\
\hline $.4016 E-15$ & $.2008 \mathrm{E}-15$ & $.2008 E-15$ & $.2008 \mathrm{E}-18$ \\
\hline .0000 & .0000 & .0000 & .0000 \\
\hline .0000 & .0000 & .0000 & .0000 \\
\hline
\end{tabular}


M:TERIAI. BALANCE TADLES

Date 09/30/82 Rev 09

SLCDGE-SUPERNATE FEED STREAMS (CONT'D)STREAM NAME

$\begin{array}{rl}47 & \text { Y203 } \\ 100 & \mathrm{Zeol} \text { ite } \\ 44 \mathrm{Zn}(\mathrm{COOII}) 2 & \\ 54 \mathrm{Zn}(\mathrm{OH}) 2 \\ 57 \mathrm{ZnO} \\ 104 \mathrm{Zr} 02 \\ \text { TOTAL FLO!, LB }\end{array}$
TOTAL FLO', LB/HR VAPOR FLOW, CFM LIQCID FLON, GPM DESIGN FLOH, DENSITY, LBS/TTB TEMIPERATURE, DEG C PRESSURE, ATM PRESSLRE, PSIG PRESSURE, M HG FIIASE

$\begin{array}{cccc}53 & 54 & 55 & 56 \\ \text { 12. Adsorber } & \text { Off-Gas Cool } & \begin{array}{c}\text { HEPA } \\ \text { Gas Feed }\end{array} & \begin{array}{c}5 \text { er Gas Feed } \\ \text { Gas Feed } \\ \text { Exit Gas }\end{array} \\ .0000 & .0000 & .0000 & .0000 \\ .1407 E-07 & .7034 E-08 & .7034 E-08 & .7034 \mathrm{E}-11 \\ .1749 \mathrm{E}-08 & .8746 \mathrm{E}-09 & .8746 \mathrm{E}-09 & .8746 \mathrm{E}-12 \\ .0000 & .0000 & .0000 & .0000 \\ .0000 & .0000 & .0000 & .0000 \\ .3467 \mathrm{E}-08 & .1734 \mathrm{E}-08 & .1734 \mathrm{E}-08 & .1734 \mathrm{E}-11 \\ 2564.20 & 2564.20 & 2564.20 & 2564.20 \\ 1061.44 & 1136.31 & 901.41 & 723.73\end{array}$

ENTHALPY, PCU/HR

.0403
150.00
.79
-3.10
599.79
VAPOR
-39081.13

.0376
150.00
.74
-3.86
560.27
VAPOR
-39081.13

.0474
50.00
.71
-4.27
539.37
VAPOR
618.11

.0591 89.80 .99 $-.11$ 754.53 VAPOR $-76833.60$ 
DPSP $80-1033$

MATERIAL BALANCE TABLES

SLUDGE-SUPERNATE FEED

STREAM NUMBERS -

STREAM NAME

COMPONENT FLOHS, LB/HR

$\begin{array}{rl}1 & \mathrm{H} 20 \\ 45 & \mathrm{Ag} \\ 116 & \mathrm{Ag} 20\end{array}$

134 AgNO3

$51 \mathrm{AgOH}$

74 Al $(\mathrm{OH}) 3$

77 A 1203

$75 \mathrm{AlOOH}$

106 B203

$9 \mathrm{Ba}(\mathrm{N} 03) 2$

$95 \mathrm{BaCl} 2$

$15 \mathrm{BaO}$

$24 \mathrm{BaSO4}$

$66 \mathrm{CO}$

$87 \mathrm{CO} 2$

$142 \mathrm{CO}$ ( $\mathrm{C} 1 \mathrm{t})$

$63 \mathrm{Ca}(\mathrm{COOH}) 2$

$120 \mathrm{Ca}(\mathrm{OH}) 2$

$113 \mathrm{Ca}$ (P04) 2

$20 \mathrm{CaC2O4}$

$18 \mathrm{CaCO3}$

$78 \mathrm{CaF2}$

$41 \mathrm{CaO}$

19 CaSO4

29 Carbon

$26 \mathrm{Co}(\mathrm{COOH}) 2$

$121 \mathrm{Co}(\mathrm{OII}) 2$

$53 \mathrm{Co}(\mathrm{OH}) 3$

$59 \mathrm{CoO}$

$99 \mathrm{Cr}(\mathrm{OH}) 3$

$98 \mathrm{Cr} 203$

$42 \mathrm{Cs} 20$

137 Cs20 Semi Vol

$90 \mathrm{Cs} \mathrm{COOH}$

$96 \mathrm{CsCl}$

$136 \mathrm{CsCl}$ Semi Vol

8 CsNO3

88 CsResin

$122 \mathrm{Cu}(\mathrm{COOH}) 2$

$52 \mathrm{Cu}(\mathrm{OH}) 2$

$58 \mathrm{Cu} 20$

$64 \mathrm{CuCOOH}$

$130 \mathrm{CuO}$

$13 \mathrm{Fe}(\mathrm{OH}) 3$

$80 \mathrm{Fe} 203$
67

DGCT Liquid to RCT

404.8

.0000

.0000

.0000

$.9367 \mathrm{E}-04$

$.8282 \mathrm{E}-01$

.0000

.0000

.1752

$.7598 \mathrm{E}-09$

.0000

.0000

$.6860 \mathrm{E}-03$

$.4420 \mathrm{E}-04$

$.2216 \mathrm{E}-02$

$.2303 E-27$

.2880E-01

.0000

$.1709 \mathrm{E}-02$

$.1849 \mathrm{E}-02$

.0000

$.4622 \mathrm{E}-03$

.0000

$.2172 \mathrm{E}-02$

.1360E-02

.3757E-03

.0000

.0000

.0000

$.1757 \mathrm{E}-02$

.0000

$.1101 E-07$

$.1813 E-05$

$.1062 \mathrm{E}-02$

$.6376 \mathrm{E}-07$

$.5262 \mathrm{E}-02$

$.4874 \mathrm{E}-04$

.0000

$.8026 \mathrm{E}-03$

.0000

.0000

.0000

.0000

.2005

.0000
Appendix $\mathrm{H}$

Table 21-16

Page 058 of 173

Drte 09/30/82 Rev 09

58

SMECI Vent to FAVC

59

60

Total Vessel PVVII Exit

Vent to PVVII Gas

$$
\begin{aligned}
& 21.61 \\
& .1919 E-14 \\
& .0000 \\
& .0000 \\
& .3791 E-16 \\
& .6388 E-10 \\
& .0000
\end{aligned}
$$

.0000

$.1142 \mathrm{E}-09$

$.7080 \mathrm{E}-18$

.0000

.0000

$.6403 \mathrm{E}-12$

$.4457 \mathrm{E}-10$

$.3672 \mathrm{E}-02$

$.1350 \mathrm{E}-18$

$.2221 \mathrm{E}-10$

. 1234E-16

24.99

$.1688 E-07$

.0000

$.2571 \mathrm{E}-07$

$.4613 \mathrm{E}-08$

$.4721 E-00$

.0000

.0000

$.2202 E-05$

$.6200 \mathrm{E}-14$

.0000

.0000

.5607E-08

. 4493E-04

10.00

$.8846 \mathrm{E}-10$

. 1943E-06

. 1479E-09

. 1397E-07

$.1596 \mathrm{E}-11$

$.1511 E-07$

.0000

.3778E-08

.0000

$.1775 \mathrm{E}-07$

$.1197 E-07$

. 3067E-08

.2559E-11

.0000

.0000

. 1436E-07

.0000

.1099E-12

.0000

$.8721 \mathrm{E}-08$

$.5772 \mathrm{E}-10$

.0000

.3977E-09

.0000

$.6552 \mathrm{E}-08$

$.5566 \mathrm{E}-11$

.0000

.0000

.0000

$.1143 \mathrm{E}-05$

.0000
24.89

$.1638 E-07$

.0000

$.2571 E-07$

$.4613 \mathrm{E}-08$

$.4721 \mathrm{E}-06$

.0000

.0000

$.22025:-05$

$.6200[-14$

.0000

.0000

$.5607 \mathrm{E}-08$

$.4493 \mathrm{E}-04$

10.00

$.8846 E-10$

$.1943 E-06$

$.1479 \mathrm{E}-09$

$.1397 \mathrm{E}-07$

$.1511 \mathrm{E}-07$

.0000

$.3778 E-08$

.0000

$.1775 \mathrm{E}-07$

$.1197 \mathrm{E}-07$

. 3067E-08

.2559E-11

.0000

.0000

$.1436 E-07$

.0000

$.1099 \mathrm{E}-12$

.0000

$.8721 \mathrm{E}-08$

$.5772 \mathrm{E}-10$

.0000

.3977 E-09

.0000

$.6552 \mathrm{E}-09$

.5566E-11

.0000

.0000

.0000

$.1143 E-05$

.0000 . 
DPSP $80-1033$

MATERIAL BALANCE TAFLES

SLUDGE-SUPERNATE FEED

STREAMS ( CONT'D)STREAM NAME

$\begin{array}{rl}101 & \text { FeO } \\ 126 & \text { Group A Semi Vo } \\ 102 & \text { Groupd } \\ 103 & \text { GroupB } \\ 25 & \mathrm{H} 2 \\ 133 & \mathrm{H} 2 \mathrm{C} 204 \\ 91 & \mathrm{H} 202 \\ 34 \mathrm{HCOOH} \\ 43 \mathrm{HCl} \\ 85 \mathrm{HF} \\ 49 \mathrm{HNO} \\ 86 \mathrm{HRes} \text { in } \\ 36 \mathrm{Hg}\end{array}$

135 HgN032

$21 \mathrm{HgO}$

$97 \quad 12$

$39 \mathrm{k} 20$

$131 \mathrm{KMnO4}$

118 KNO3

105 La203

$10 B L 120$

$65 \mathrm{Mg}(\mathrm{COOH}) 2$

$55 \mathrm{Mg}$ (Oll) 2

$33 \mathrm{MgO}$

$60 \mathrm{Mn}(\mathrm{COOH}) 2$

$132 \mathrm{Mn}(\mathrm{NO3}) 2$

$129 \mathrm{Mn}(\mathrm{OH}) 2$

56 $\mathrm{MnO}$

$14 \mathrm{MnO2}$

81 N2

143 NA2CO3 (C14)

35 NO

$84 \mathrm{N02}$

$70 \mathrm{Na}$ ( $\mathrm{HgO}(\mathrm{OHI}))$

$94 \mathrm{ia} 2 \mathrm{~B} 407$

$109 \mathrm{Na} 2 \mathrm{C} 204$

$5 \mathrm{Na} 2 \mathrm{CO}$

$32 \mathrm{Na} 2 \mathrm{O}$

71 in $2 \mathrm{Pu} 02(\mathrm{OII}) 4$

$73 \mathrm{Na} 2 \mathrm{RhO}_{4}$

$72 \mathrm{Na} 2 \mathrm{Ru}_{\mathrm{O}} 04$

$6 \mathrm{Na} 2 \mathrm{SO} 04$

$68 \mathrm{NaA} 102$

$114 \mathrm{NaBO} 2$

140 NaBO2 Semi Vol

$50 \mathrm{NaCOOH}$
57

OGCT Liquid

to RCT

.0000

$.8539 \mathrm{E}-02$

$.1285 \mathrm{E}-02$

$.4109 \mathrm{E}-02$

$.3523 E-05$

.0000

.0000

.0000

.0000

.0000

.0000

.0000

.0000

.0000

$.3185 \mathrm{E}-02$

.0000

.0000

.0000

$.3184 \mathrm{E}-05$

$.4145 \mathrm{E}-02$

$.6783 \mathrm{E}-01$

$.4530 \mathrm{E}-02$

.0000

$.2297 \mathrm{E}-01$

$.4067 \mathrm{E}-01$

.0000

.0000

.0000

.0000

$.4346 \mathrm{E}-02$

.0000

$.1268 \mathrm{E}-04$

$.8839 \mathrm{E}-02$

$.2901 \mathrm{E}-05$

.1113

$.1277 E-05$

.0000

.2518

$.1176 \mathrm{E}-09$

$.2418 \mathrm{E}-07$

$.2360 \mathrm{E}-06$

$.4786 \mathrm{E}-03$

$.1176 \mathrm{E}-02$

.0000

.0000

.1342

Appendix $\mathrm{H}$

Table 21-16

Page 059 of 173

Date 09/30/82 Rev 09

58

SMECT Vent

to FAVC

.0000

.0000

$.1209 \mathrm{E}-11$

$.3835 \mathrm{E}-11$

$.3354 \mathrm{E}-11$

.0000

.0000

$.7388 \mathrm{E}-01$

.0000

.0000

.0000

.0000

.2921E-07

.0000

$.8284 \mathrm{E}-17$

.0000

.0000

.0000

$.4503 \mathrm{E}-14$

$.3876 \mathrm{E}-11$

$.4429 \mathrm{E}-10$

$.4228 \mathrm{E}-11$

$.2104 \mathrm{E}-17$

$.1553 \mathrm{E}-10$

$.3793 E-10$

.0000

$.1624 \mathrm{E}-15$

.0000

.0000

188.0

.0000

$.1491 \mathrm{E}-05$

$.2163 E-03$

$.2703 \mathrm{E}-14$

.2360E-14

.1807E-14

.0000

. 1377E-09

$.1096 \mathrm{E}-18$

.2253E-10

$.2199 E-15$

$.4459 \mathrm{E}-12$

$.1096 \mathrm{E}-11$

.0000

0000

.1007 E-09
69

Total Vessel

Vent to PVVH

.0000

.0000

$.1069 \mathrm{E}-07$

$.3358 E-07$

$.3583 E-05$

.0000

.0000

$.4669 \mathrm{E}-01$

.0000

.0000

.0000

.0000

.3793E-03

$.1608 \mathrm{E}-10$

$.1180 \mathrm{E}-09$

.0000

.0000

.0000

$.7148 \mathrm{E}-08$

$.7479 E-07$

$.8587 E-06$

$.8698 \mathrm{E}-07$

$.2523 E-10$

.2995E-06

.3317E-06

.0000

$.6528 \mathrm{E}-08$

.0000

.0000

1292.

.0000

1.243

. 1382E-01

.2367E- 10

$.1256 \mathrm{E}-08$

.2868E-08

.0000

. 2653E-05

$.9599 E-15$

$.1973 E-12$

$.1926 \mathrm{E}-11$

$.8905 \mathrm{E}-08$

$.9599 \mathrm{E}-08$

.0000

.0000

$.9346 \mathrm{E}-06$
60

PVVH Exit

Gns

.0000

.0000

$.1069 \mathrm{E}-07$

$.8358 \mathrm{E}-07$

$.3583 \mathrm{E}-05$

.0000

.0000

$.4669 \mathrm{E}-01$

.0000

.0000

.0000

.0000

$.8793 E-03$

$.1608 \mathrm{E}-10$

$.1130 \mathrm{E}-09$

.0000

.0000

.0000

$.7148 \mathrm{E}-08$

$.7479 \mathrm{E}-07$

$.8537 E-06$

. 8698E-07

. 2523E-10

.2995E-06

.8317E-06

.0000

$.6528 \mathrm{E}-08$

.0000

.0000

1292.

.0000

1.243

. 1382E-01

.2367E-10

. 1256E-08

.2868E-08

.0000

.2653E-05

$.9599 E-15$

. 1973E- 12

$.1926 \mathrm{E}-11$

.3905E-08

$.9599 E-08$

.0000

.0000

$.9846 \mathrm{E}-06$ 
DPSP $80-1033$

MATERIAL BALANCE TABLES SLUDGE-SUPERNATE FEED STREAMS (CONI'D)STREAM NAME

$7 \mathrm{NaCl}$

$138 \mathrm{NaCl}$ Senl Vol

$69 \mathrm{NaF}$

$139 \mathrm{NaF}$ Sem i Vol

$12 \mathrm{NaI}$

$125 \mathrm{NaI}$ Semi Vol

$3 \mathrm{NaNO} 2$

$2 \mathrm{NaNO3}$

$4 \mathrm{NaOH}$

87 NaResin

$61 \mathrm{Ni}(\mathrm{COOlI}) 2$

$17 \mathrm{Ni}(\mathrm{OH}) 2$

$40 \mathrm{NiO}$

8202

$67 \mathrm{PbO}$

$28 \mathrm{PbSO} 4$

$124 \mathrm{Pd}$

$123 \mathrm{Pd}(\mathrm{OH}) 2$

$112 \mathrm{PdNO} 2$

$110 \mathrm{PdO}$

$117 \mathrm{Pu}(\mathrm{COOH}) 4$

$76 \mathrm{Pu} 02$

$22 \mathrm{RhO2}$

$79 \mathrm{Ru} 02$

23 Ru02 Semi Vol

$83 \mathrm{Ru} 04$

$88 \mathrm{SO2}$

$111 \mathrm{SiO2}$

115 Silica Gel

$48 \mathrm{Sr}(\mathrm{COOH}) 2$

$10 \mathrm{Sr}(\mathrm{N} 03) 2$

$127 \mathrm{Sr}(\mathrm{OH}) 2$

$80 \mathrm{SrCO}$

$46 \mathrm{SrO}$

89 SrRESIN

141 Surfactant

92 ThO2

$107 \mathrm{TiO} 2$

119 Tritium

$93 \mathrm{v02}$

$62 \mathrm{VO2}(\mathrm{COOII}) 2$

$16 \mathrm{VO2}(\mathrm{OHI}) 2$

$27 \mathrm{Y}(\mathrm{COOH}) 3$

$11 Y(N 03) 8$

$128 \mathrm{Y}(\mathrm{OH}) 3$

$81 Y 2(\mathrm{CO} 3) 3$
57

OGCT Liquid to RCT

$.4768 \mathrm{E}-03$

$.7271 \mathrm{E}-01$

$.1266 \mathrm{E}-01$

.5919E-01

$.461 \mathrm{FE}-04$

$.6187 \mathrm{E}-02$

.0000

$.1539 E-01$

.0000

.0000

$.1424 E-01$

.0000

.0000

.2490 E-02

.0000

$.6453 \mathrm{E}-03$

.0000

.0000

.0000

.0000

$.6591 \mathrm{E}-06$

. 1680E-03

$.6420 \mathrm{E}-04$

. 3112E-03

. 3102E-02

.0000

$.5180 \mathrm{E}-05$

.7423

.0000

.5790́E-03

$.6780 \mathrm{E}-09$

.0000

.0000

.0000

.0000

.0000

. 263.1E-02

$.8290 \mathrm{E}-02$

. 1577E-09

.0000

$.1842 \mathrm{E}-01$

.0000

.8962E-03

$.4815 \mathrm{E}-09$

.0000

.0000
58

SMECT Vent Total Vessel to FAVC Vent to PVVII

.4445 - 12

.0000

$.2419 \mathrm{E}-14$

.0000

$.4309 \mathrm{E}-13$

.0000

.0000

$.1404 \mathrm{E}-10$

.0000

.0000

$.1329 E-10$

$.8081 \mathrm{E}-17$

.0000

56.78

.0000

$.6026 \mathrm{E}-12$

.0000

.0000

.0000

.0000

$.6178 \mathrm{E}-15$

$.1568 \mathrm{E}-12$

$.5992 E-13$

$.2954 \mathrm{E}-12$

.0000

.0000

$.2064 \mathrm{E}-10$

$.4838 \mathrm{E}-09$

.0000

$.5410 \mathrm{E}-12$

$.6318 \mathrm{E}-18$

$.3613 E-18$

.0000

.0000

.0000

.0000

$.2458 \mathrm{E}-11$

$.7752 E-11$

$.1944 \mathrm{E}-10$

.0000

$.1719 E-10$

$.1416 E-16$

$.3698 \mathrm{E}-12$

$.4486 E-18$

$.2254 \mathrm{E}-18$

.0000

$.1162 \mathrm{E}-06$

Appendix $\mathrm{H}$

Table 21-16

Page 060 of 173

Date 09/50/82 Rev 09

5960

$\begin{array}{ll} & \text { Gas } \\ 4723 E-08 & 4720\end{array}$ $.0000 \quad .0000$

$.8311 E-09$

.0000

$.4489 \mathrm{E}-09$

.0000

.0000

$.2771 E-03$

. 1200E-09

.0000

$.9690 \mathrm{E}-10$

.0000

890.3

.0000

.5277E-08

.0000

.0000

.0000

.0000

$.5403 E-11$

$.1373 \mathrm{E}-08$

.5247E-09

.2620E-08

.0000

.0000

$.5283 \mathrm{E}-05$

$.8960 \mathrm{E}-05$

.0000

$.4731 E-08$

$.5533 E-14$

$.4332 E-11$

.0000

.0000

.0000

.0000

.2153E-07

.1496E-06

$.5189 E-10$

.0000

$.1504 E-06$

$.1698 \mathrm{E}-09$

$.8234 \mathrm{E}-08$

$.3929 \mathrm{E}-14$

$.2702 E-11$

.0000
$.8311 \mathrm{E}-49$

.0000

$.1489 E-03$

.0000

.0000

.2771E-0G

$.1200 E-0 J$

.0000

$.1162 E-06$

$.9690 E-10$

.0000

390.3

.0000

$.5277 \mathrm{E}-08$

.0000

.0000

.0000

.0000

$.5403 E-11$

$.1373 E-0 S$

$.5247 E-C 9$

.2020E-0S

.0000

.0000

$.5283 E-05$

.8960E-05

.0000

$.4731 E-08$

$.5533 E-14$

$.4332 E-11$

.0000

.0000

.0000

.0000

$.2153 E-07$

1496E-06

$.5189 E-10$

.0000

$.1504 \mathrm{E}-06$

$.1698 \mathrm{E}-09$

.3234E-08

$.3929 \mathrm{E}-14$

$.2702 E-11$

$.0000^{\circ}$ 
MATERIAI. BALANCE TABLES

\section{SL:DGE-SLPERNATE FEED \\ STREAMS (CONT' D) - \\ STREAM NAME}

47 Y203

100 Zeolite

$44 \mathrm{Zn}(\mathrm{COOH}) 2$

$64 \mathrm{Zn}(\mathrm{OH}) 2$

$57 \mathrm{ZnO}$

$104 \mathrm{Zr} 02$

TOTAL FLOH, LB/IIR

VAPOR FLOH, CFM

LIQUID FLOW, GPM

DESIGN FLOW,

DENSITY, LBS/FT3

TEMPERATLRE, DEG C

PRESSURE, ATM

PRESSURE, PSIG

PIEESSURE, M HG

PIIASE

EITHALPY, PCU/IIR
57

O\&CT Liquid to RCT

.0000

$.1684 \mathrm{E}-01$

$.2094 E-02$

.0000

.0000

$.4145 \mathrm{E}-02$

406.95

.81

62.6167

55.00

.97

$-.51$

733.40

LIQUID

22822.05
58

SMECI Vont to FAVC

.0000

$.1572 E-10$

$.1954 \mathrm{E}-11$

$.1219 \mathrm{E}-17$

.0000

$.3876 \mathrm{E}-11$

266.45

70.85

.0627

50.00

.97

$-.51$

733.86

VAPOR

$-1065.56$
59

Total Vessel

Vent to PVVH .0000

$.1276 \mathrm{E}-06$

$.1709 \mathrm{E}-07$

$.1462 E-10$

.0000

$.7479 \mathrm{E}-07$

1718.58

413.02

.0694

16.63

.92

$-1.16$

700.26

VAPOR

$-97201.42$
60

PVVH ExIt

Gas .0000

$.1376 \mathrm{E}-06$

$.1709 E-07$

$.1462 E-10$

.0000

$.7479 \mathrm{E}-07$

1718.58

429.56

.0667

26.63

.92

$-1.23$

696.54

VAPOR

$-93118.86$ 
DPSP $80-1033$

MATERIAL BALANCE TABLES

SLUDGE-SUPERNATE FEED

STREAM NUNBERS -

STREAM NAME

COMPONENT FLOWS, LB/HR

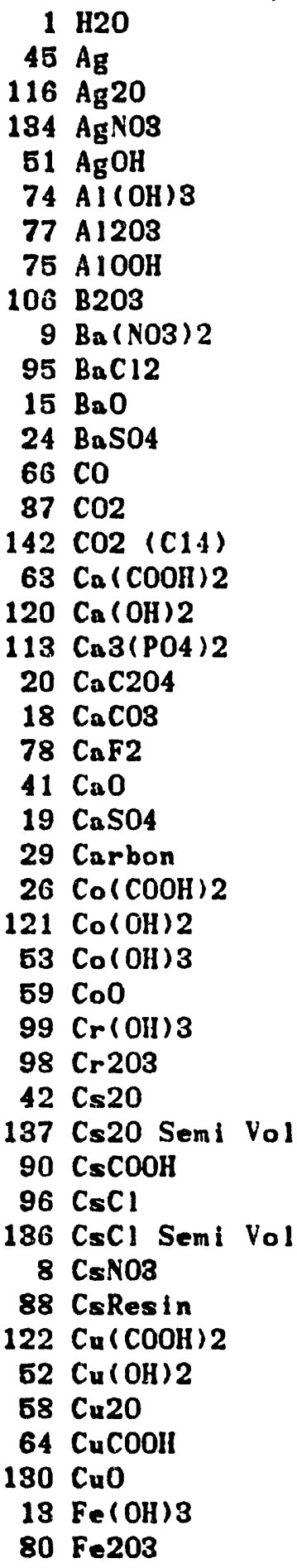

$616263 \quad 64$ PVVF Exit HNO3 Rinse Hiter Rinse MIS Rinses

Gas to MVS

to Sili

24.99

$.1638 \mathrm{E}-10$

.0000

$.2571 E-10$

$.4613 E-11$

$.4721 E-09$

.0000

.0000

.2202E-08

$.6200 \mathrm{E}-17$

.0000

.0000

$.5607 \mathrm{E}-11$

.4493E-04

10.00

$.8846 \mathrm{E}-10$

$.1943 \mathrm{E}-09$

$.1479 \mathrm{E}-12$

$.1397 E-10$

$.1511 \mathrm{E}-10$

.0000

$.8778 E-11$

.0000

$.1775 \mathrm{E}-10$

$.1197 \mathrm{E}-10$

.8067E-08

$.2559 \mathrm{E}-14$

.0000

.0000

$.1436 \mathrm{E}-10$

.0000

$.1099 \mathrm{E}-15$

.0000

$.8721 \mathrm{E}-11$

$.5772 E-13$

.0000

$.3977 E-12$

.0000

$.6552 \mathrm{E}-11$

$.5566 \mathrm{E}-14$

.0000

.0000

.0000

$.1143 \mathrm{E}-08$

.0000 to MVS

$.8866 E-01$
.0000
.0000
.0000
.0000

.2738
.0000
.0000
.0000
.0000
.0000
.0000
.0000
.0000
.0000
.0000
.0000
.0000

.0000

.0000

.0000

.0000

.0000

.0000

.0000

.0000

.0000

.0000

.0000

.0000

.0000

.0000

.0000

.0000

.0000

.0000

.0000

.0000

.0000

.0000

.0000

.0000

.0000

.0000

.0000

.0000

.0000

.0000

.0000

.0000
.8573

.0000

.0000

$.2482 \mathrm{~T}-05$

$.3841 \mathrm{E}-13$

$.8515 \mathrm{E}-11$

.0000

.0000

. 1281E- 12

$.1119 E-18$

.0000

.0000

. $1012 \mathrm{E}-12$

.0000

$.1380 \mathrm{E}-32$

.0000

. $3510 \mathrm{E}-11$

.3216E-24

. 2522E- 12

$.2727 \mathrm{E}-12$

.0000

$.6818 \mathrm{E}-13$

.0600

$.3204 E-12$

$.6386 \mathrm{E}-13$

. 5543E- 13

$.5563 \mathrm{E}-26$

.0000

.0000

. $25 \div 2 \mathrm{E}-12$

.0000

$.1531 \mathrm{E}-17$

.0000

$.1574 E-12$

. $1639 \mathrm{E}-16$

.0000

.7177E-14

.0000

. 1184E-12

$.1210 \mathrm{E}-25$

.0000

.0000

.0000

$.2061 E-10$

.0000
Appendix H

Table 21-16

Page 062 of 173

Date 09/30/82 Rev 03 
MATERIAL BALANCE TABIES

SI.UDGE-SUPERNATE FEED STREAMS (CONT'D)STREAM NAME

61

\section{PVVF Exit}

\section{Gas}

$101 \mathrm{FeO}$

126 Group A Semi Vo

102 GroupA

103 GroupB

$25 \mathrm{H} 2$

$133 \mathrm{H} 2 \mathrm{C} 204$

$91 \mathrm{H2O2}$

$84 \mathrm{HCOOH}$

$43 \mathrm{HCl}$

$85 \mathrm{HF}$

$49 \mathrm{HNO3}$

86 HResin

$36 \mathrm{Hg}$

$135 \mathrm{Hg}: 032$

$21 \mathrm{HgO}$

9712

$39 \mathrm{k} 20$

$131 \mathrm{KMnO4}$

118 KNO3

105 La 203

108 L 120

$65 \mathrm{Mg}(\mathrm{COOH}) 2$

$55 \mathrm{Mg}(\mathrm{OII}) 2$

$33 \mathrm{MgO}$

$60 \mathrm{Mn}(\mathrm{COOH}) 2$

$132 \mathrm{Mn}(\mathrm{NOS}) 2$

$129 \mathrm{Mn}(\mathrm{OHI}) 2$

$56 \mathrm{MnO}$

$14 \mathrm{MnO2}$

$81 \mathrm{~N} 2$

143 NA2CO3 (C14)

$35 \mathrm{NO}$

84 NO2

$70 \mathrm{Na}(\mathrm{HgO}(\mathrm{OH}))$

$94 \hat{\mathrm{a}} 2 \mathrm{~B} 407$

$109 \mathrm{Na} 2 \mathrm{C204}$

$5 \mathrm{Na} 2 \mathrm{CO3}$

$32 \mathrm{Na} 20$

$71 \mathrm{Na} 2 \mathrm{P}_{u} 02(\mathrm{OII}) 4$

$73 \mathrm{Na} 2 \mathrm{RhO}$

$72 \mathrm{Na} 2 \mathrm{Ru} 04$

$6 \mathrm{Na} 2 \mathrm{SO} 4$

$68 \mathrm{NaAl} 02$

$114 \mathrm{NaBO2}$

$140 \mathrm{NaBO2}$ Semi Vol

$50 \mathrm{NaCOOH}$
.0000

.0000

$.1069 \mathrm{E}-10$

$.3358 \mathrm{E}-10$

$.8588 \mathrm{E}-05$

.0000

.0000

$.4669 \mathrm{E}-01$

.0000

.0000

.0000

.0000

$.8793 E-08$

$.1608 \mathrm{E}-18$

$.1130 \mathrm{E}-12$

.0000

.0000

.0000

$.7148 \mathrm{E}-11$

$.7479 \mathrm{E}-10$

$.8537 \mathrm{E}-09$

$.3698 \mathrm{E}-10$

.2523E-13

.2995E-09

.3317E-09

.0000

$.6528 \mathrm{E}-11$

.0000

.0000

1292.

.0000

1.248

. 1382E-01

.2367E-13

$.1256 \mathrm{E}-11$

. 2868E-11

.0000

. 2653E-08

$.9599 \mathrm{E}-18$

$.1973 \mathrm{E}-16$

$.1926 \mathrm{E}-14$

$.8905 \mathrm{E}-11$

$.9599 \mathrm{E}-11$

.0000

.0000

$.9846 \mathrm{E}-09$
62

HNO3 Rinse Water Rinse

to MVS

.0000

.0000

.0000

.0000

.0000

.0000

.0000

.0000

.0000

.0000

$.1141 \mathrm{E}-01$

.0000

.0000

.0000

.0000

.0000

.0000

.0000

.0000

.0000

.0000

.0000

.0000

.0000

.0000

.0000

.0000

.0000

.0000

.0000

.0000

.0000

.0000

.0000

.0000

.0000

.0000

.0000

.0000

.0000

.0000

.0000

.0000

.0000

.0000

.0000
63

to MVS

.0000

.0000

.0000

.0000

.0000

.0000

.0000

.0000

.0000

.0000

.0000

.0000

.0000

.0000

.0000

.0000

.0000

.0000

.0000

.0000

.0000

.0000

.0000

.0000

.0000

.0000

.0000

.0000

.0000

.0000

.0000

.0000

.0000

.0000

.0000

.0000

.0000

.0000

.0000

.0000

.0000

.0000

.0000

.0000

.0000

.0000
64

MVS Rinses

to SWT

.0000

.0000

.1911E-12

$.6061 \mathrm{E}-12$

.0000

.0000

.0000

.0000

.0000

.0000

$.1140 \mathrm{E}-01$

.0000

.0000

$.1288 \mathrm{E}-05$

$.1078 E-18$

.0000

.0000

.0000

$.6865 \mathrm{E}-15$

.2978E-14

$.4957 \mathrm{E}-13$

$.6682 \mathrm{E}-12$

.5484E-25

$.1662 E-13$

$.5994 E-11$

.0000

$.4233 \mathrm{E}-23$

.0000

.0000

$.7651 \mathrm{E}-17$

.0000

.0000

.1023E-05

$.4272 E-15$

$.8565 \mathrm{E}-15$

$.2754 \mathrm{E}-15$

.0000

$.1820 \mathrm{E}-12$

$.1732 \mathrm{E}-19$

$.8561 \mathrm{E}-17$

$.8475 E-16$

$.7047 \mathrm{E}-13$

$.1732 E-12$

.0000

.0000

. 1470E-10 
DPSP $80-1033$

MATERIAL BALANCE TABLES

SLUDGE-SUPERNATE FEED

STREAMS (CONI'D)-

STREAM NAME

$7 \mathrm{NaCl}$

$188 \mathrm{NaCl}$ Semi $\mathrm{Vol}$

$69 \mathrm{NaF}$

$189 \mathrm{NaF}$ Semi Vol

$12 \mathrm{NaI}$

$125 \mathrm{NaI}$ Semi Vol

$8 \mathrm{NaNO} 2$

$2 \mathrm{NaNOB}$

$4 \mathrm{NaOH}$

87 NaResin

$61 \mathrm{~N} 1(\mathrm{COOH}) 2$

$17 \mathrm{Ni}(\mathrm{OH}) 2$

$40 \mathrm{NiO}$

8202

$67 \mathrm{PbO}$

$28 \mathrm{PbS04}$

$124 \mathrm{Pd}$

$123 \mathrm{Pd}(\mathrm{OH}) 2$

112 PdN032

$110 \mathrm{PdO}$

$117 \mathrm{Pu}(\mathrm{COOH}) 4$

$76 \mathrm{Pu} 02$

$22 \mathrm{RhO2}$

$79 \mathrm{Ru} 02$

28 Ru02 Semi Vol

$83 \mathrm{Ru} 04$

$88 \mathrm{SO2}$

1115102

$115 \mathrm{Silica} \mathrm{Gel}$

$48 \mathrm{Sr}(\mathrm{COOH}) 2$

$10 \mathrm{Sr}(\mathrm{NOS}) 2$

$127 \mathrm{Sr}(\mathrm{OH}) 2$

$80 \mathrm{SrCO}$

$46 \mathrm{Sr} 0$

89 SrRESIN

141 Surfactant

$92 \mathrm{ThO}$

$107 \mathrm{TiO}$

119 Tritium

$93 \mathrm{~V} 02$

$62 \mathrm{VO} 2(\mathrm{COOH}) 2$

$16 \mathrm{VO2}(\mathrm{OH}) 2$

$27 \mathrm{Y}(\mathrm{COOH}) 8$

$11 \mathrm{Y}(\mathrm{NOS}) \mathrm{3}$

$128 \mathrm{Y}(\mathrm{OH}) 8$

$81 \mathrm{Y} 2(\mathrm{CO}) 3$
61

PVVF Exit

Gas

$.4723 \mathrm{E}-11$

.0000

$.83118-12$

.0000

$.4489 \mathrm{E}-12$

.0000

.0000

.2771E-09

$.1200 \mathrm{E}-12$

.0000

. 1162E-09

$.969 .0 \mathrm{E}-13$

.0000

890.3

.0000

$.5277 E-11$

.0000

.0000

.0000

.0000

$.5403 E-14$

. 1373E-11

.5247E-12

.2620E-11

.0000

.0000

$.6283 E-05$

.8960E-08

.0000

$.4731 E-11$

$.5533 E-17$

$.4332 \mathrm{E}-14$

.0000

.0000

.0000

.0000

$.2153 E-10$

$.1496 \mathrm{E}-09$

. 5189E-10

.0000

$.1504 \mathrm{E}-09$

$.1698 \mathrm{E}-12$

$.3234 E-11$

$.8929 \mathrm{E}-17$

$.2702 E-14$

.0000
Append Ix H

Table 21-16

Page 064 of 173

Date 09/30/82 Rev 09 
Append ix $\mathrm{H}$

Table 21-16

Page 065 of 178

Date 09/80/82 Rev 09

METERTAL BALINCE TALLES

SILDG:̈-SUPERYITE FEED

STREAYS(CONT'D)-

STRLiM NAME

$\begin{array}{rl}47 & 12 C 3 \\ 100 & \mathrm{Znol} \text { ite } \\ 44 \mathrm{Zn}(\mathrm{COOII}) 2 & \\ 51 \mathrm{Zn}(0 \mathrm{I}) 2 \\ 57 \mathrm{ZnO}\end{array}$

104 7r0?

TOTAL FLO"', LB/IIR

VAPOR FLO"', CFM

LIOUID FLOW, GPM

DESIGN FLOW,

DFYSITY, LBS/FT3

TEMPERITURE, DEG C

PRESSLRE, ATM

PRESSURE, PSIG

PRESSLRE, M HG

PIIISE

EXTHALPY, PCV/HR
61

PVVF Exit

Gas

.0000

$.1376 \mathrm{E}-09$

$.1709 \mathrm{E}-10$

$.1462 E-13$

.0000

$.7479 \mathrm{E}-10$

1718.58

436.50

.0656

26.63

.90

$-1.44$

685.37

VAPOR

$-93118.86$
62

HNOS Rinse to MVS

.0000

.0000

.0000

.0000

.0000

.0000

.10

.00

65.0373

25.00

1.00

.00

LIOUID

2.20
63

Water Rinse to MVS

.0000

.0000

.0000

.0000

.0000

.0000

.27

.00

62.4300

25.00

1.00

.00

LIQUID

6.94
64

MVS Rinses

to SVIT

.0000

$.2484 E-11$

$.3088 \mathrm{E}-12$

$.8177 E-25$

.0000

.2078E- 14

.87

.00

63.0822

88.00

1.00

.00

LIOUID

13.94 
DPSP $80-1038$

MATERIAL BALANCE TABLES

SLUDGE-SUPERNATE FEED

STREAM NUMBERS -

STREAM NAME

COMPONENT FLOHS, LB/HR

$45 \mathrm{Ag}$

116 Ag20

$134 \mathrm{AgNO}$

51 AgOH

74 Al (OH) 8

77 A1203

75 A $100 \mathrm{H}$

106 B203

$9 \mathrm{Ba}(\mathrm{NO3}) 2$

$95 \mathrm{BaCl} 2$

$15 \mathrm{BaO}$

$24 \mathrm{BaS04}$

$66 \mathrm{CO}$

$87 \mathrm{CO2}$

$142 \mathrm{CO2}$ (C14)

$63 \mathrm{Ca}(\mathrm{COOH}) 2$

$120 \mathrm{Ca}(\mathrm{OH}) 2$

$113 \mathrm{Ca} 3(\mathrm{PO} 4) 2$

$20 \mathrm{CaC2O}_{\mathrm{a}}$

$18 \mathrm{CaCO3}$

$78 \mathrm{CaF2}$

$41 \mathrm{CaO}$

$19 \mathrm{CaSO4}$

29 Carbon

$26 \mathrm{Co}(\mathrm{COOH}) 2$

$121 \mathrm{Co}(\mathrm{OH}) 2$

$53 \mathrm{Co}(\mathrm{OH}) 3$

$59 \mathrm{CoO}$

$99 \mathrm{Cr}(\mathrm{OH}) 3$

$98 \mathrm{Cr} 203$

$42 \mathrm{Cs} 20$

187 Cs20 Semi Vol

$90 \mathrm{CsCOOH}$

$96 \mathrm{CsCl}$

$186 \mathrm{CsCl}$ Semi Vol

$8 \mathrm{CsNO3}$

88 CsResin

$122 \mathrm{Cu}(\mathrm{COOH}) 2$

$52 \mathrm{Cu}(\mathrm{OH}) 2$

$58 \mathrm{Cu} 20$

$64 \mathrm{CuCOOH}$

$130 \mathrm{CuO}$

$13 \mathrm{Fe}(\mathrm{OH}) \mathrm{s}$

$80 \mathrm{Fe} 203$
65

MVS Bottoms

to MitHT

.7876E-04

$.15 \subseteq 1 E-07$

.0000

.54TOE-09

$.84 C 5 E-17$

$.1877 \mathrm{E}-14$

.0000

.0000

$.2824 E-16$

.2466E-22

.0000

.0000

$.2230 \mathrm{E}-16$

.0000

$.8042 E-36$

.0000

$.7737 E-15$

$.7088 \mathrm{E}-28$

$.5553 \mathrm{E}-16$

$.6011 \mathrm{E}-16$

.0000

$.1503 \mathrm{E}-16$

.0000

.706 E- 16

$.1513 \mathrm{E}-16$

$.1222 E-16$

$.1226 \mathrm{E}-29$

.0000

.0000

$.5713 E-16$

.0000

$.3375 \mathrm{E}-21$

.0000

$.8469 \mathrm{E}-16$

$.3612 \mathrm{E}-20$

.0000

$.1582 \mathrm{E}-17$

.0000

$.2610 \mathrm{E}-16$

.2667E-29

.0000

.0000

.0000

$.4543 E-14$

.0000
Appondix H

Tuble 21-16

Page 060 of 173

Date 09/30/82 Rev 09

66

MVC Vent

to PVVS

.2493

$.2862 \mathrm{E}-09$

.0000

$.2571 \mathrm{E}-07$

$.4092 \mathrm{E}-08$

$.1942 E-10$

.0000

.0000

$.2921 E-12$

$.2551 E-18$

.0000

.0000

$.2307 \mathrm{E}-12$

$.8498 \mathrm{E}-27$

$.1276 \mathrm{E}-05$

$.4372 \mathrm{E}-24$

$.8004 \mathrm{E}-11$

$.7332 \mathrm{E}-24$

$.5750 E-12$

$.6219 \mathrm{E}-12$

.0000

$.1555 \mathrm{E}-12$

.0000

$.7305 \mathrm{E}-12$

$.1570 \mathrm{E}-12$

$.1264 \mathrm{E}-12$

$.1268 \mathrm{E}-25$

.0000

.0000

$.5910 \mathrm{E}-12$

.0000

$.8491 \mathrm{E}-17$

.0000

$.3589 \mathrm{E}-12$

$.8737 E-16$

.0000

$.1637 \mathrm{E}-13$

.0000

$.2700 \mathrm{E}-12$

$.2759 \mathrm{E}-25$

.0000

.0000

.0000

$.4699 \mathrm{E}-10$

.0000
67

MVS Vent to MALT Hg

Vacusm Pump to MET $\not 1$

.0000

.0000

.0000

.0000

.0000

.0000

.0000

.0000

.0000

.0000

.0000

.0000

.0000

.0000

.0000

.0000

.0000

.0000

.0000

.0000

.0000

.0000

.0000

.0000

.0000

.0000

.0000

.0000

.0000

.0000

.0000

.0000

.0000

.0000

.0000

.0000

.0000

.0000

.0000

.0000

.0000

.0000

.0000

.0000

.0000
$.9553 \mathrm{~L}-\mathrm{C2}$

. 15932-03

.0000

$.1464 \mathrm{E}-02$

$.1459 E-10$

$.9113 E-0 C$

.0000

.0000

$.1571 E-07$

$.119 S E-13$

.0000

.0000

$.1083 \mathrm{E}-07$

.3060E-34

.3501E-11

. 1199E-29

$.3757 \mathrm{E}-06$

$.3441 \mathrm{E}-19$

.2699E-07

.29191-07

.0000

$.7297 E-0 S$

.0000

$.3428 E-07$

.7369E-08

.5932E-08

$.5953 \mathrm{E}-21$

.0000

.0000

$.2774 E-07$

.0000

$.1638 E-12$

.0000

. 1684E-07

$.1754 \mathrm{E}-11$

.0000

$.7681 E-09$

.0000

. 1267E-07

$.1295 E-20$

.0000

.0000

.0000

.2206E-05

$.0000^{\circ}$ 

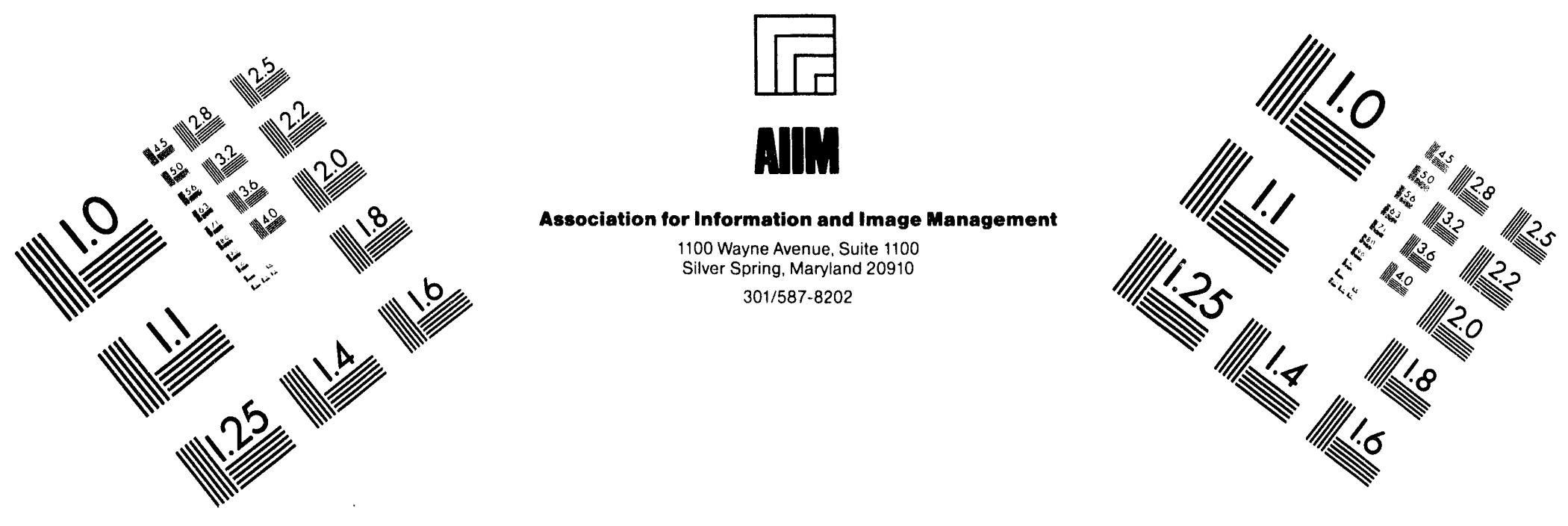

\section{Centimeter}

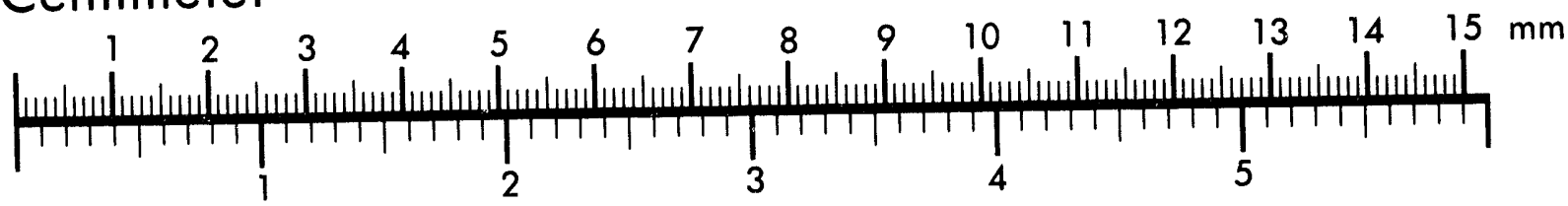
Inches

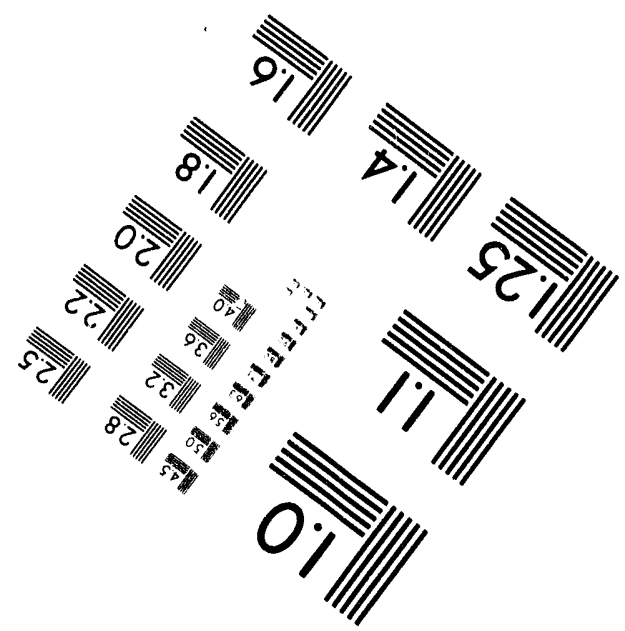

MANUFACTURED TO AIIM STANDARDS

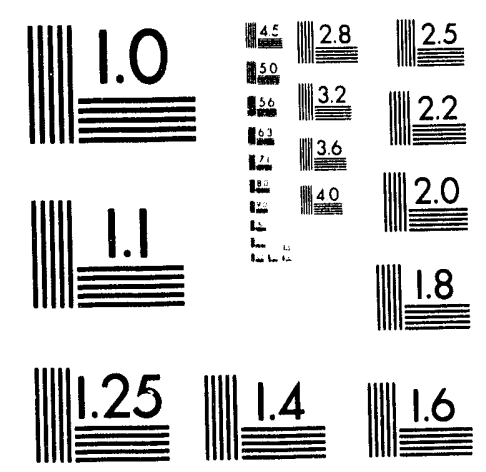

BY APPLIED IMAGE, INC.

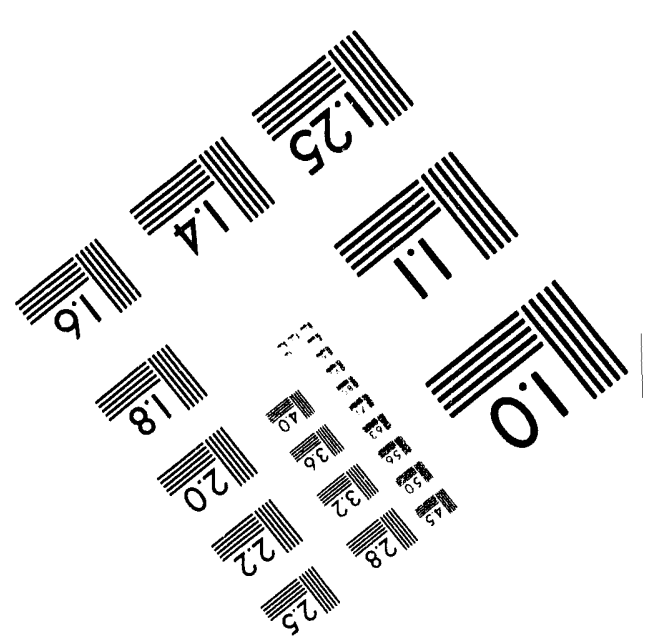



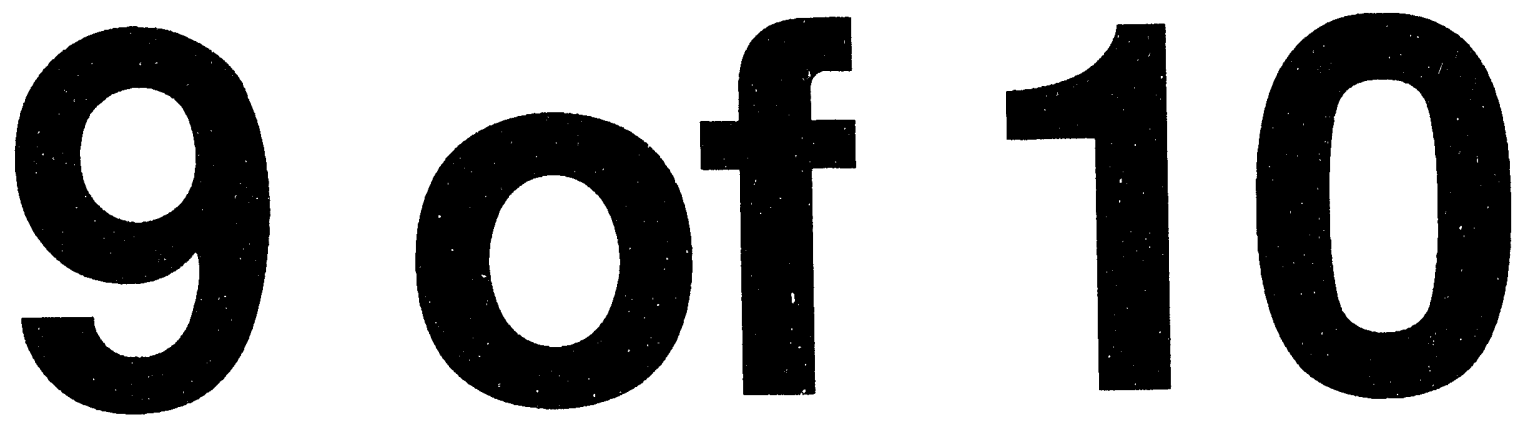
MiTERIAL BALANCE TABLES

Date 09/30/82 Rev 09

SLCDGE-SUPERNATE FEED

STREAMS (CONT'D)STIIEAM NAME

65

MUS Bottoms to MAWIT

$101 \mathrm{FeO}$

126 Group A Semi Vo

102 Grotipt

103 GroupB

$25 \mathrm{H} 2$

$133 \mathrm{H} 2 \mathrm{C} 2 \mathrm{O} 4$

9111202

84 HCOOH

$43 \mathrm{HCl}$

85 IIF

49 HNO3

86 t!Resin

$36 \mathrm{Hg}$

$135 \mathrm{HgN032}$

$21 \mathrm{IIg} 0$

$\begin{array}{lll}97 & 12\end{array}$

$39 \mathrm{~K} 20$

$131 \mathrm{kM} / \mathrm{n} 04$

$118 \mathrm{KNOS}$

105 La203

108 Li 20

$65 \mathrm{Mg}(\mathrm{COOH}) 2$

$55 \mathrm{Mg}(\mathrm{OII}) 2$

$33 \mathrm{MgO}$

$60 \mathrm{Mn}(\mathrm{COOII}) 2$

$132 \mathrm{Mn}(\mathrm{NO3}) 2$

$129 \mathrm{Mn}(\mathrm{OII}) 2$

$56 \mathrm{MnO}$

$14 \mathrm{MnO2}$

$81 \mathrm{~N} 2$

$143 \mathrm{NA} 2 \mathrm{CO}$ ( $\mathrm{Cl} 4)$

$85 \mathrm{NO}$

84 NO2

$70 \mathrm{Na}(\mathrm{HgO}(\mathrm{OII}))$

$94 \mathrm{Na} 2 \mathrm{~B} 407$

$109 \mathrm{Na2C204}$

$5 \mathrm{Na} 2 \mathrm{CO3}$

$32 \mathrm{Na} 20$

$71 \mathrm{Na} 2 \mathrm{Pu} 02(\mathrm{OH}) 4$

$73 \mathrm{~N}: 2 \mathrm{RhO} \mathrm{O}$

$72 \mathrm{Na} 2 \mathrm{RuO4}$

$6 \mathrm{Na} 2 \mathrm{SO}$

$68 \mathrm{NaAlO} 2$

$114 \mathrm{NaBO}$

140 NaBO2 Semi Vol

$50 \mathrm{NaCOOH}$
.0000

.0000

$.4212 E-16$

$.1336 \mathrm{E}-15$

.0000

.0000

.0000

.0000

.0000

.0000

.2513E-05

.0000

. 1093E-01

.2729E-09

$.2376 E-17$

.0000

.0000

.0000

$.1513 \mathrm{E}-18$

$.6563 \mathrm{E}-18$

$.1093 E-16$

$.1473 \mathrm{E}-15$

$.1209 E-28$

$.8663 \mathrm{E}-17$

$.1821 \mathrm{E}-14$

.0000

.9330 E-27

.0000

.0000

$.1686 \mathrm{E}-20$

.0000

.0000

.2254E-09

$.9415 \mathrm{E}-19$

$.7858 \mathrm{E}-19$

$.6071 \mathrm{E}-19$

.0000

$.4011 \mathrm{E}-16$

$.3818 \mathrm{E}-23$

$.7850 \mathrm{E}-21$

$.7660 \mathrm{E}-20$

$.1553 \mathrm{E}-16$

$.8818 \mathrm{E}-16$

.0000

.0000

$.3241 E-14$
66

MVC Vent to PVVS

.0000

.0000

$.4357 \mathrm{E}-12$

$.1382 E-11$

$.6968 \mathrm{E}-26$

.0000

.0000

.0000

.0000

.0000

$.4115 \mathrm{E}-02$

.0000

$.2250 \mathrm{E}-03$

. 1608E-10

$.4761 E-11$

.0000

.0000

.0000

$.1565 \mathrm{E}-14$

$.6790 \mathrm{E}-14$

$.1130 \mathrm{E}-12$

$.1524 \mathrm{E}-11$

$.1250 E-24$

$.3789 E-13$

$.1367 E-10$

.0000

$.9652 \mathrm{E}-23$

.0000

.0000

17.15

.0000

$.5327 E-17$

$.6770 \mathrm{E}-02$

$.9740 E-15$

$.8129 \mathrm{E}-15$

$.6280 \mathrm{E}-15$

.0000

$.4149 \mathrm{E}-12$

$.8950 \mathrm{E}-19$

$.8121 E-17$

$.7924 \mathrm{E}-16$

$.1607 E-12$

$.3950 \mathrm{E}-12$

.0000

.0000

$.3352 E-10$
67

MVS Vent to

Vacuum Pump

.0000

.0000

.0000

.0000

.0000

.0000

.0000

.0000

.0000

.0000

.0000

.0000

.0000

.0000

.0000

.0000

.0000

.0000

.0000

.0000

.0000

.0000

.0000

.0000

.0000

.0000

.0000

.0000

.0000

.0000

.0000

.0000

.0000

.0000

.0000

.0000

.0000

.0000

.0000

.0000

.0000

.0000

.0000

.0000

.0000

.0000
68

MAVI $\mathrm{Hg}$

to MrT \#1

.0000

.0000

.2045E-07

$.6486 \mathrm{E}-07$

$.6105 \mathrm{E}-33$

.0000

.0000

.0000

.0000

.0000

.1237 E-03

.0000

1.357

$.9116 \mathrm{E}-06$

$.1149 \mathrm{E}-08$

.0000

.0000

.0000

$.7347 \mathrm{E}-10$

.8187E-09

$.5305 E-08$

$.7151 \mathrm{E}-07$

$.5869 E-20$

$.1778 \mathrm{E}-08$

$.6415 E-06$

.0000

$.4530 \mathrm{E}-18$

.0000

.0000

.2520E-06

.0000

. 1143E-23

. 1332E-04

$.4571 \mathrm{E}-10$

$.3815 \mathrm{E}-10$

.2948E-10

.0000

$.1947 \mathrm{E}-07$

$.1854 \mathrm{E}-14$

$.8811 \mathrm{E}-12$

$.3719 \mathrm{E}-11$

$.7542 \mathrm{E}-08$

. 1854E-07

.0000

.0000

$.1573 E-05$ 
DPSP 80-1033

MATERIAL BALANCE TABLES

SLUDGE-SUPERNATE FEED STREAMS (CONT'D)STREAM NAME

$7 \mathrm{NaCl}$

$188 \mathrm{NaCl}$ Semi Vol

$69 \mathrm{NaF}$

$139 \mathrm{NaF}$ Semi Vol

$12 \mathrm{NaI}$

$125 \mathrm{NaI}$ Semi Vol

8. $\mathrm{NaNO2}$

$2 \mathrm{NaNO3}$

$4 \mathrm{NaOH}$

87 NaResin

$61 \mathrm{Ni}(\mathrm{COOH}) 2$

$17 \mathrm{Ni}(\mathrm{OlI}) 2$

$40 \mathrm{NiO}$

8202

$67 \mathrm{PbO}$

$28 \mathrm{PbSO4}$

$124 \mathrm{Pd}$

$123 \mathrm{Pd}(\mathrm{OH}) 2$

112 PdNOB2

$110 \mathrm{PdO}$

$117 \mathrm{Pu}(\mathrm{COOH}) 4$

$76 \mathrm{PuO}_{\mathrm{H}}$

$22 \mathrm{RhO2}$

$79 \mathrm{Ru} 02$

28 Ru02 Semi Vol

$83 \mathrm{Ru}^{04}$

$88 \mathrm{SO2}$

$1115 i 02$

115 Silica Gel

$48 \mathrm{Sr}(\mathrm{COOH}) 2$

$10 \mathrm{Sr}(\mathrm{N} 03) 2$

$127 \mathrm{Sr}(\mathrm{OH}) 2$

$80 \mathrm{SrCO}$

$46 \mathrm{SrO}$

89 SrRESIN

141 Surfactant

$92 \mathrm{ThO}$

$107 \mathrm{TiO}$

119 Tritium

93 U02

$62 \mathrm{VO} 2(\mathrm{COOH}) 2$

$16 \mathrm{UO2}(\mathrm{OH}) 2$

$27 \mathrm{Y}(\mathrm{COOH}) 3$

$11 \mathrm{Y}(\mathrm{NOS}) 3$

$128 \times(\mathrm{OH}) \mathrm{S}$

$81 \mathrm{Y} 2(\mathrm{CO}) 3$
Append ix $\mathrm{H}$

Trble 21-16

Page 068 of 173

Date 09/30/82 Rev 0 ?

\begin{tabular}{|c|c|c|c|}
\hline 65 & 66 & $\begin{array}{l}67 \\
\end{array}$ & 68 \\
\hline $\begin{array}{l}\text { MVS Bottoms } \\
\text { to MAKT }\end{array}$ & $\begin{array}{l}\text { MVC Vent } \\
\text { to PVVs }\end{array}$ & $\begin{array}{l}\text { MVS Vent to } \\
\text { Vncuum Pump }\end{array}$ & $\begin{array}{l}\text { MAHT Hg } \\
\text { to MET if } 1\end{array}$ \\
\hline $.1548 \mathrm{E}-16$ & $.1602 E-12$ & .0000 & $.7518 \mathrm{E}-08$ \\
\hline .0003 & .0000 & .0000 & .0000 \\
\hline $.8183 E-19$ & $.8472 E-15$ & .0000 & $.3976 E-10$ \\
\hline .0000 & .0000 & .0000 & .0000 \\
\hline $.1501 E-17$ & $.1552 E-18$ & .0000 & $.7257 E-09$ \\
\hline .0000 & .0000 & .0000 & .0000 \\
\hline .0000 & .0000 & .0000 & .0000 \\
\hline $.5663 E-15$ & $.3786 E-07$ & .0000 & $.2374 E-00$ \\
\hline .0000 & .0000 & .0000 & .0000 \\
\hline .0003 & .0000 & .0000 & .0000 \\
\hline .463$] E-15$ & $.4790 E-11$ & .0000 & $.2248 E-06$ \\
\hline $.4643 \mathrm{E}-28$ & $.4803 E-24$ & .0000 & $.2254 E-19$ \\
\hline .000 .3 & .0000 & .0000 & .0000 \\
\hline $.1644 E-20$ & 5.181 & .0000 & $.1479 E-06$ \\
\hline .0000 & .0000 & .0000 & .0000 \\
\hline $.2099 \mathrm{E}-16$ & $.2172 \mathrm{E}-12$ & .0000 & $.1019 \mathrm{E}-07$ \\
\hline .0000 & .0000 & .0000 & .0060 \\
\hline .0000 & .0000 & .0000 & .0000 \\
\hline .0000 & .0000 & .0000 & .0000 \\
\hline .0000 & .0000 & .0000 & .0000 \\
\hline $.2152 E-19$ & $.2226 \mathrm{E}-15$ & .0000 & $.1045 \mathrm{E}-\mathrm{1} 0$ \\
\hline $.5463 E-17$ & $.5651 E-13$ & .0000 & $.2652 E-08$ \\
\hline $.2087 \mathrm{E}-17$ & $.2159 \mathrm{E}-13$ & .0000 & $.1013 E-08$ \\
\hline $.1029 \mathrm{E}-16$ & $.1064 \mathrm{E}-12$ & .0000 & $.4995 \mathrm{E}-08$ \\
\hline .0000 & .0000 & .0000 & .0000 \\
\hline .0000 & .0000 & .0000 & .0000 \\
\hline .0000 & $.8208 E-27$ & .0000 & $.2342 \mathrm{E}-33$ \\
\hline $.9896 E-15$ & $.1024 \mathrm{E}-10$ & .0000 & $.4805 E-06$ \\
\hline .0000 & .0000 & .0000 & .0000 \\
\hline $.1885 \mathrm{E}-16$ & $.1950 \mathrm{E}-12$ & .0000 & $.9150 \mathrm{E}-08$ \\
\hline $.2201 \mathrm{E}-22$ & $.2277 \mathrm{E}-18$ & .0000 & $.1069 \mathrm{E}-13$ \\
\hline $.2076 \mathrm{E}-29$ & $.2147 E-25$ & .0000 & $.1008 \mathrm{E}-20$ \\
\hline .0000 & .0000 & .0000 & .0000 \\
\hline .0000 & .0000 & .0000 & .0000 \\
\hline .0000 & .0000 & .0000 & .0000 \\
\hline .0000 & .0000 & .0000 & .0000 \\
\hline $.8564 E-16$ & $.8859 E-12$ & .0000 & $.4158 E-07$ \\
\hline $.1313 E-17$ & . 1358E-13 & .0000 & $.6373 \mathrm{E}-09$ \\
\hline $.4751 E-30$ & $.1741 E-15$ & .0000 & $.1491 \mathrm{E}-16$ \\
\hline .0000 & .0000 & .0000 & .0000 \\
\hline $.6989 E-15$ & $.6196 \mathrm{E}-11$ & .0000 & $.2908 \mathrm{E}-06$ \\
\hline $.8135 E-28$ & $.8415 E-24$ & .0000 & $.3950 E-19$ \\
\hline $.1288 \mathrm{E}-16$ & . $1333 E-12$ & .0000 & $.6255 \mathrm{E}-08$ \\
\hline . 1563E-22 & $.1617 E-18$ & .0000 & $.7588 \mathrm{E}-14$ \\
\hline . $1295 \mathrm{E}-29$ & . 1339E-25 & .0000 & $.6287 \mathrm{E}-21$ \\
\hline .0000 & .0000 & $\therefore \therefore D$ & .0000 \\
\hline
\end{tabular}


Material Balaice tables

Date 09/30/82 Rev 09

SLUDGE-SUPESNATE FEED STREAMS (CONT'D) STREAM NAME

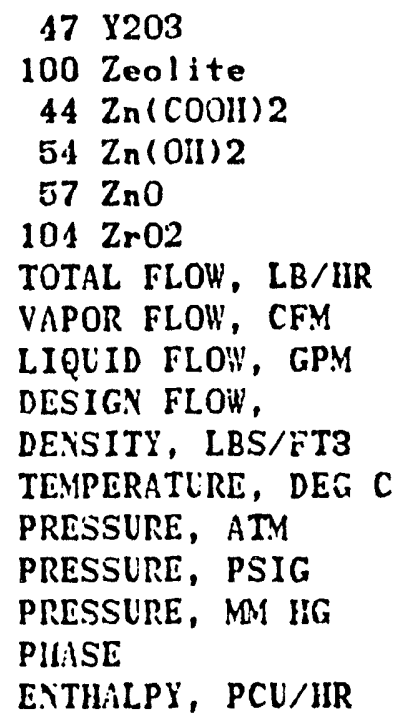

65

MVS Bottons to MAWT

.0000

$.5475 \mathrm{E}-15$

$.6507 \mathrm{E}-16$

$.7003 E-29$

.0000

$.6563 \mathrm{E}-18$

.01

.00

774.7558

38.00

1.00

.00

LIQUID

.02
66

MVC Vent

to PVVS

.0000

$.5664 \mathrm{E}-11$

.7042E-12

$.7244 \mathrm{E}-25$

.0000

$.6790 E-14$

22.69

5.12

.0785

15.00

.97

$-.43$

737.58

VAPOR

$-1852.22$
67

MVS Vent to

Vacuum Pump

.0000

.0000

.0000

.0000

.0000

.0000

.00

.00

.0000

88.00

.02

$-14.42$

14.37

VAPOR

.00
68

MAWT $\mathrm{Hg}$

to MET \#1

.0000

$.2658 \mathrm{E}-06$

$.8305 E-07$

.3400E-20

.0000

.3187E-09

1.37

.00

775.3479

88.00

.99

$-.07$

756.20

LIQUID

2.08 
DPSP $80-1083$

MATERIAL BALANCE TABLES

SLUDGE-SUPERNATE FEED

STREAM NUMBERS -

STREAM NAME

COMPONENT FLOHS, LB/HR

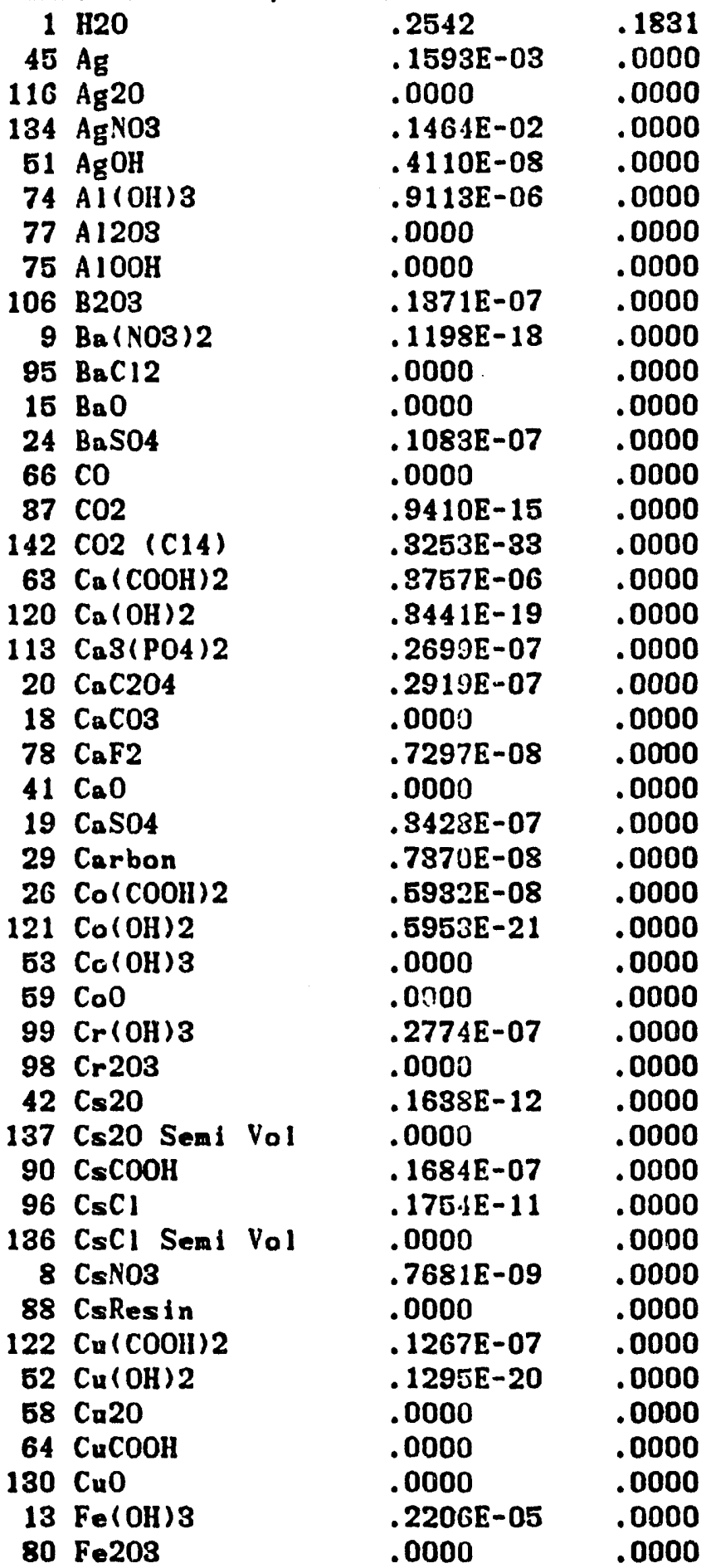

Appendix H

Table 21-16

Page 070 of 173

Date $09 / 30 / 82$ Rev 09

$69 \quad 71 \quad 72$

Hg Feed to HNO3 Wash MASC to MASC

HNO3 Wash

from MASC

73

Nioll to

SWIT

$\begin{array}{ll}.4363 & .8027 E-01 \\ .0000 & .0000 \\ .0000 & .0000\end{array}$

$.1707 E-02 \quad .0000$

$.4101 E-08 \quad .0000$

$.9093 E-06 \quad .0000$

$.0000 \quad .0000$

$.0000 \quad .0000$

$.1368 \mathrm{E}-07 \quad .0000$

$.1195 \mathrm{E}-13 \quad .0000$

$.0000 \quad .0000$

$.0000 \quad .0000$

$.1081 E-07 \quad .0000$

$.0000 \quad .0000$

$.9389 E-15 \quad .0000$

$.3245 \mathrm{E}-33 \quad .0000$

$.3749 \mathrm{E}-0 \mathrm{0} \quad .0000$

$.3434 \mathrm{E}-19 \quad .0000$

.2693E-07 .0000

$.2912 \mathrm{E}-07 \quad .0000$

$.0000 \quad .0000$

$.7281 \mathrm{E}-08 \quad .0000$

$.0000 \quad .0000$

$.8421 \mathrm{E}-07 \quad .0000$

$.7353 \mathrm{E}-08 \quad .0000$

$.5919 E-08 \quad .0000$

$.5940 E-21 \quad .0000$

$.0000 \quad .0000$

$.0000 \quad .0000$

$.2768 \mathrm{E}-07 \quad .0000$

$.0000 \quad .0000$

$.1635 \mathrm{E}-12 \quad .0000$

$.0000 \quad .0000$

$.1681 \mathrm{E}-07 \quad .0000$

$.1750 \mathrm{E}-11 \quad .0000$

$.0000 \quad .0000$

$.7665 E-09 \quad .0000$

$.0000 \quad .0000$

$.1264 E-07 \quad .0000$

$.1292 \mathrm{E}-20 \quad .0000$

$.0000 \quad .0000$

$.0000 \quad .0000$

$.0000 \quad .0000$

.2201E-05 .0000

$.0000 \quad .0000$ 
DPSP $80-1033$

MATERIAL BALANCE TAELES

SLCDGE-SLPEPNATE FEED

STIREMS (CONT'D)STREAM NAME

$101 \mathrm{FeO}$

126 Group A Sen! Vo

102 GroupA

103 GroupB

$25 \mathrm{H} 2$

133 I2C204

9111202

34 HCOOH

$43 \mathrm{IICl}$

85 IIF

49 HNOS

86 HResin

$35 \mathrm{~kg}$

$135 \mathrm{HgNO} 2$

$21 \mathrm{Hg} O$

$37 \quad 12$

$39 \mathrm{~K} 20$

$131 \mathrm{KMinO4}$

$118 \mathrm{KNO}$

$105 \mathrm{La} 203$

$108 \mathrm{Li} 20$

$65 \mathrm{Mg}(\mathrm{COOH}) 2$

$55 \mathrm{Mg}(\mathrm{OH}) 2$

$83 \mathrm{MgO}$

$60 \mathrm{Mn}(\mathrm{COOH}) 2$

$132 \mathrm{Mn}(\mathrm{NO}) 2$

$129 \mathrm{Mn}(\mathrm{OII}) 2$

$56 \mathrm{MnO}$

$14 \mathrm{MnO2}$

81 N2

$143 \mathrm{NA2CO3}$ (C14)

$35 \mathrm{NO}$

$84 \mathrm{NO2}$

$70 \mathrm{Na}(\mathrm{HgO}(\mathrm{OII}))$

$94 \mathrm{Na} 2 \mathrm{~B} 407$

$109 \mathrm{Na} 2 \mathrm{C} 204$

$5 \mathrm{Na} 2 \mathrm{CO}$

$32 \operatorname{Nin} 20$

$71 \mathrm{Na}_{2} \mathrm{P}_{11} 02(\mathrm{Oll}) 4$

$73 \mathrm{Nin}_{2} \mathrm{Rh}_{\mathrm{O}} \mathrm{O}$

$72 \mathrm{Na}_{2} \mathrm{Ru}_{\mathrm{O}} 04$

$6 \mathrm{Ni}_{2} 2 \mathrm{SO} 4$

$68 \mathrm{NaAl} 102$

$114 \mathrm{NaBO2}$

140 NaB02 Semi Vol

$50 \mathrm{NaCOOH}$
69

$\mathrm{Hg}$ Feed to

MASC

.0?00

.0000

$.2045 \mathrm{E}-07$

$.6486 \mathrm{E}-07$

$.4490 \mathrm{E}-38$

.0000

.0000

.0000

.0000

.0000

$.2933 \mathrm{E}-03$

.0000

1.857

$.9116 \mathrm{E}-06$

$.1154 \mathrm{E}-08$

.0000

.0000

.0000

$.7847 \mathrm{E}-10$

$.3187 \mathrm{E}-09$

$.5305 \mathrm{E}-08$

$.7151 \mathrm{E}-07$

. 5869E-20

$.1778 \mathrm{E}-08$

$.6415 \mathrm{E}-06$

.0000

$.4530 \mathrm{E}-18$

.0000

.0000

$.5600 \mathrm{E}-05$

.0000

$.1884 \mathrm{E}-28$

$.5162 E-05$

$.4571 E-10$

$.3815 \mathrm{E}-10$

$.2948 E-10$

.0000

$.1947 \mathrm{E}-07$

$.1854 \mathrm{E}-14$

$.3811 E-12$

$.3719 \mathrm{E}-11$

$.7542 \mathrm{E}-08$

$.1854 \mathrm{E}-07$

.0000

.0000

$.1573 \mathrm{E}-05$
Appendix $\mathrm{H}$

Table 21-16

Page 071 of 173

Date 09/30/82 Rev 09 
DPSP $80-1033$

MATERIAL BALANCE TABL.ES

SLUDGE-SUPERNATE FEED

STREAMS ( CONT'D) -

STREAM NAME

\begin{tabular}{|c|c|}
\hline \multicolumn{2}{|c|}{$7 \mathrm{NaCl}$} \\
\hline $138 \mathrm{~N}$ & $\mathrm{NaCl}$ Semi Vo \\
\hline $139 \mathrm{~N}$ & NaF Semi Vol \\
\hline $12 \mathrm{~N}$ & $\mathrm{NaI}$ \\
\hline $125 \mathrm{~N}$ & NaI Semi Vo \\
\hline $8 \mathrm{~N}$ & $\mathrm{NaNO2}$ \\
\hline $2 N$ & $\mathrm{NaNO3}$ \\
\hline $4 N$ & $\mathrm{NaOH}$ \\
\hline $87 N$ & NaResin \\
\hline $61 \mathrm{~N}$ & $\mathrm{Ni}(\mathrm{COOH}) 2$ \\
\hline $17 \mathrm{~N}$ & $\mathrm{Ni}(\mathrm{OH}) 2$ \\
\hline $40 N$ & NiO \\
\hline 820 & 02 \\
\hline $67 \mathrm{P}$ & $\mathrm{PbO}$ \\
\hline $28 \mathrm{Pl}$ & \\
\hline
\end{tabular}

$124 \mathrm{Pd}$

$123 \mathrm{Pd}(\mathrm{OH}) 2$

112 PdNO32

110 PdO

$117 \mathrm{Pu}(\mathrm{COOH}) 4$

$76 \mathrm{Pu} 02$

$22 \mathrm{RhO2}$

79 Ru02

23 Ru02 Semi Vol

$83 \mathrm{RuO4}$

$38 \mathrm{~S} 02$

$111 \mathrm{SiO2}$

115 Silica Gel

$48 \mathrm{Sr}(\mathrm{COOH}) 2$

$10 \mathrm{Sr}(\mathrm{NO}) 2$

$127 \mathrm{Sr}(\mathrm{OH}) 2$

$80 \mathrm{SrCO}$

$46 \mathrm{Sr} 0$

89 SrRESIN

141 Surfactant

92 Th02

107 Ti02

119 Tritium

$93 \mathrm{U} 02$

$62 \mathrm{VO2}(\mathrm{COOH}) 2$

$16 \mathrm{VO2}(\mathrm{OH}) 2$

$27 \mathrm{Y}(\mathrm{COOH}) \mathrm{s}$

$11 \mathrm{Y}(\mathrm{NO3}) 3$

$128 Y(\mathrm{OH}) 8$

$81 Y 2(\mathrm{CO} 3) 8$
69

Hg Feed to HNO3 Hiash

MASC

$.7518 \mathrm{E}-08$

.0000

$.8976 \mathrm{E}-10$

.0000

$.7287 \mathrm{E}-09$

.0000

.0000

$.2752 \mathrm{E}-06$

.0000

.0000

.2248E-06

$.2254 \mathrm{E}-19$

.0000

$.3287 \mathrm{E}-05$

.0000

$.1019 \mathrm{E}-07$

.0000

.0000

.0000

.0000

$.1045 \mathrm{E}-10$

$.2652 E-08$

$.1013 \mathrm{E}-08$

$.4996 \mathrm{E}-08$

.0000

.0000

.0000

$.4805 \mathrm{E}-06$

.0000

$.9150 \mathrm{E}-08$

$.1069 \mathrm{E}-13$

$.1008 \mathrm{E}-20$

.0000

.0000

.0000

.0000

$.4158 \mathrm{E}-07$

$.6373 \mathrm{E}-09$

$.5824 E-16$

.0000

$.2908 \mathrm{E}-06$

$.8950 \mathrm{E}-19$

$.6256 \mathrm{E}-08$

$.7588 \mathrm{E}-14$

$.6287 \mathrm{E}-21$

.0000
Appendix H

Iable 21-16

Page 072 of 173

Date 09/30/\$2 Rev 09 
DPSP $80-1033$

MiTIRIAL BALANCE TABLES

SLCUGE-SUPERNATE FEED

STREAMIS (CONT'D)-

STREAM NAME

47 Y203

100 Zeolite

$44 \mathrm{Zn}(\mathrm{COOII}) 2$

$54 \mathrm{Zn}(\mathrm{Oil}) 2$

$57 \mathrm{Zn} 0$

$104 \mathrm{ZrO2}$

TOTAL FLOH, LB/HR

VAPOR FLOW, CFM

LIQUID FLON, GPM DESIGN FLOK, DENSITY, LBS/FT3

TEMPERATURE, DEG C PRESSURE, ATM

PRESSURE, PSIG

PRESSURE, MM HG

PHASE

ENTIIALPY, PCU/IIR
Appendix H

Table 21-16

Page 073 of 173

Date 09/30/82 Rev 09

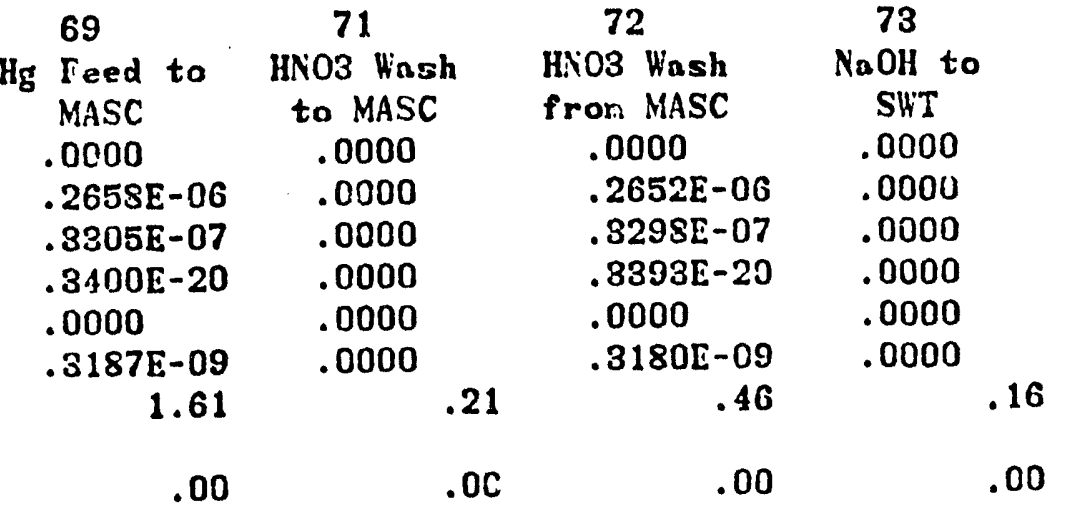

283.7800

65.0373

25.00

88.00
2.36

19.99

1.34

5.00

63.7668

88.00

1.00

.00

84.9613

25.00

1.00

LIQUID

LIQUID

4.82

LIQUID

17.16

LIQUID

2.69 
DPSP $80-1033$

MATERIAL BALANCE TABLES

SLCDGE-SUPERNATE FEED

COMPONENT FLOHS, LB/HR

\begin{tabular}{|c|c|c|c|c|c|}
\hline 1 & H2O & 1.150 & $.9609 E-03$ & $.34 S 0 E-01$ & .1997 \\
\hline 45 & $\mathrm{Ag}$ & .0000 & . 1593E-05 & $.1592 \pi-05$ & .0000 \\
\hline 116 & $\mathrm{Ag} 20$ & .0000 & .0000 & .0900 & .0000 \\
\hline 184 & Ag.Y03 & .0000 & $.8759 E-05$ & $.3759 E-05$ & .0030 \\
\hline 51 & $\mathrm{AgOII}$ & $.1844 E-01$ & $.9031 E-11$ & $.9031 E-11$ & .0000 \\
\hline 74 & Al $(011) 8$ & $.1557 E-04$ & $.2002 E-08$ & $.2002 E-08$ & .0000 \\
\hline 77 & A1203 & .0000 & .0000 & .0000 & .0000 \\
\hline 75 & AlOOH & .0000 & .0000 & .0000 & .0000 \\
\hline 106 & B203 & $.2312 E-06$ & $.3013 E-10$ & $.8013 E-10$ & .0000 \\
\hline 9 & $\mathrm{Ba}(\mathrm{NO}) 2$ & $.2020 \mathrm{E}-12$ & $.2631 E-16$ & $.2631 E-16$ & .0000 \\
\hline 95 & $\mathrm{BaCl}$ & .0000 & .0000 & .0000 & .0000 \\
\hline 15 & $\mathrm{BaO}$ & .0000 & .0000 & .0000 & .0000 \\
\hline 24 & BaS04 & $.1820 \mathrm{E}-06$ & . $2380 E-10$ & $.2380 E-10$ & .0000 \\
\hline 66 & co & .0000 & .0000 & .0000 & .0000 \\
\hline 87 & $\mathrm{CO} 2$ & $.1030 \mathrm{E}-13$ & $.2068 \mathrm{E}-17$ & $.5511 E-22$ & .0000 \\
\hline 142 & $\operatorname{co2}(\mathrm{C} 14)$ & $.3530 E-32$ & $.7147 E-36$ & .0000 & .0000 \\
\hline 63 & $\mathrm{CA}_{\mathrm{A}}(\mathrm{COOH}) 2$ & $.6386 \mathrm{E}-05$ & $.8255 \mathrm{E}-09$ & $.8255 E-09$ & .0000 \\
\hline 120 & $\mathrm{Ca}(\mathrm{OH}) 2$ & $.580 .1 E-18$ & . $7562 E-22$ & $.7562 \mathrm{E}-22$ & .0000 \\
\hline 113 & $\mathrm{Cn} 3(\mathrm{PO4}) 2$ & $.4551 \mathrm{E}-06$ & $.5930 E-10$ & $.5930 E-10$ & .0000 \\
\hline 20 & $\mathrm{CaC2O4}$ & $.4922 E-06$ & $.6414 E-10$ & $.6413 E-10$ & .0000 \\
\hline 18 & $\mathrm{CaCO3}$ & .0000 & .0000 & .0000 & .0000 \\
\hline 78 & CaF2 & $.1231 E-06$ & . $1603 E-10$ & $.1603 E-10$ & .0000 \\
\hline 41 & $\mathrm{CnO}$ & .0000 & .0000 & .0000 & .0000 \\
\hline 19 & CaS04 & $.5782 E-06$ & . $7533 \mathrm{E}-10$ & $.7533 E-10$ & .0000 \\
\hline 29 & Carbon & $.1243 E-06$ & . 1619E-10 & . $1619 \mathrm{E}-10$ & .0000 \\
\hline 26 & $\mathrm{Co}(\mathrm{COOH}) 2$ & . 1000E-06 & . $1303 E-10$ & . $1303 E-10$ & .0000 \\
\hline 121 & $\mathrm{Co}(\mathrm{OH}) 2$ & $.1004 E-19$ & . $1308 \mathrm{E}-23$ & . $1308 \mathrm{E}-23$ & .0000 \\
\hline 53 & $\mathrm{Co}(011) \mathrm{s}$ & .0000 & .0000 & .0000 & .0000 \\
\hline 59 & $\mathrm{CoO}$ & .0000 & .0000 & .0000 & .0000 \\
\hline 99 & $\mathrm{Cr}(\mathrm{OH}) \mathrm{s}$ & $.4678 \mathrm{E}-06$ & $.6095 E-10$ & $.6095 E-10$ & .0000 \\
\hline 98 & $C_{r 203}$ & .0000 & .0000 & .0000 & .0000 \\
\hline 42 & $\mathrm{Cs} 20$ & $.2763 E-11$ & $.3600 E-15$ & $.8600 E-15$ & .0000 \\
\hline 137 & Cs20 Semi & .0000 & .0000 & .0000 & .0000 \\
\hline 90 & $\mathrm{CsCOOH}$ & $.2841 \mathrm{E}-06$ & $.8701 E-10$ & $.8701 E-10$ & .0000 \\
\hline 96 & $\mathrm{CsCl}$ & $.2958 \mathrm{E}-10$ & $.8854 E-14$ & $.3854 E-14$ & .0000 \\
\hline 136 & Cscl Semi Vol & .0000 & .0000 & .0000 & .0000 \\
\hline 8 & Cs.i03 & . 1295E-07 & $.1688 E-11$ & $.1688 \mathrm{E}-11$ & .0000 \\
\hline 88 & CsRes in & .0000 & .0000 & .0000 & .0000 \\
\hline 122 & $\mathrm{Cu}(\mathrm{COOH}) 2$ & $.2137 \mathrm{E}-06$ & $.2784 E-10$ & $.2784 E-10$ & .0000 \\
\hline $\mathbf{5 2}$ & $\mathrm{Cu}(\mathrm{OH}) 2$ & $.2184 E-19$ & $.2845 \mathrm{E}-23$ & $.2845 E-23$ & .0000 \\
\hline 58 & Cu20 & .0000 & .0000 & .0000 & .0000 \\
\hline 64 & CuCoOII & .0000 & .0000 & .0000 & .0000 \\
\hline 180 & CuO & .0000 & .01100 & .0000 & .0000 \\
\hline 18 & Fe $(0 \mathrm{H}) \mathrm{B}$ & $.8720 E-04$ & $.4817 \mathrm{E}-08$ & $.4846 E-08$ & .0000 \\
\hline 80 & Fe203 & .0000 & .0000 & .0000 & .0000 \\
\hline
\end{tabular}

Append ix $H$

Pago 074 of 173

Date 09/80/82 Rev (1)
Table 21-1G STREAM NAME

\section{STREAM NUMBERS -}

75

Washed Hg

from MASC
76

Ho Feed to $\mathrm{NRH}+\mathrm{C}$
79

Kirte: Hinsh to Mnit:
1.

.0000

$.1844 \mathrm{E}-01$

. 1557E-04

.0000

.0000

.2312E-06

0000

$.1820 \mathrm{E}-06$

.0000

.3530E-32

$.6386 \mathrm{E}-05$

.4922E-06

.0000

.0000

. 5782E-06

. 1243E-00

. 1000E-00

$.1004 \mathrm{E}-19$

0000

$.4678 \mathrm{E}-06$

.0000

.0000

. 2841E-06

.2958E - 10

.0000

.0000

.2137E-06

(184E-19

.0000

.0000

.3720E-04

.0000 
DPSP 80-1033

MATERIAL BALANCE TABLES

SLLDGE-SLPERNATE FEED

STREAMS ( CONT' Di-

STREAM NANE

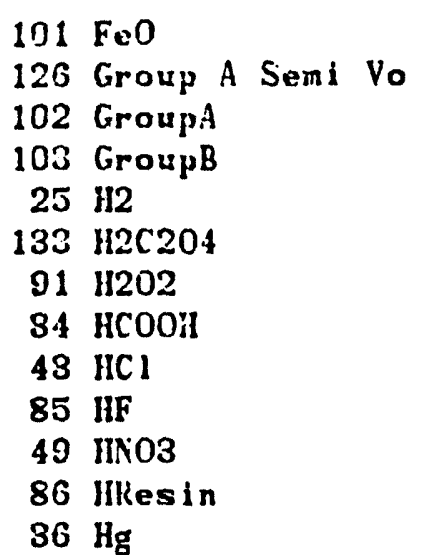

135 IIgN032

$21 \mathrm{HgO}$

9712

$39 \mathrm{~K} 20$

$131 \mathrm{KMnO4}$

$115 \mathrm{KNO}$

$105 \operatorname{La} 203$

108 Li 20

$65 \mathrm{Mg}(\mathrm{COOII}) 2$

$55 \mathrm{Mg}(\mathrm{OII}) 2$

$33 \mathrm{MgO}$

$60 \mathrm{Mn}(\mathrm{COOH}) 2$

$132 \mathrm{Mn}(\mathrm{N} 03) 2$

$129 \mathrm{Mn}(\mathrm{OH}) 2$

$56 \mathrm{MnO}$

$14 \mathrm{MnO} 2$

S1 N2

143 NA2CO3 (C14)

35 NO

84 NO2

$70 \mathrm{Na}(\mathrm{llg} \mathrm{O}(\mathrm{OII}))$

$94 \mathrm{Na} 2 \mathrm{~B} 407$

109 Va2C204

$5 \mathrm{Na} 2 \mathrm{CO3}$

$32 \mathrm{Na} 20$

$71 \mathrm{Na} 2 \mathrm{P}_{\mathrm{u}} 02(\mathrm{O} !:) 4$

$73 \mathrm{Na} 2 \mathrm{RhO4}$

$72 \mathrm{Na}_{2} 2 \mathrm{RuO}_{4}$

$6 \mathrm{Na} 2 \mathrm{SO} 4$

$68 \mathrm{NaAlO2}$

$114 \mathrm{NaBO} 2$

$140 \mathrm{NaBO2}$ Semi Vol

$50 \mathrm{NaCOOH}$
Append ix $\mathrm{H}$

Table 21-16

Page 075 of 173

Date 09/80/82 Rev 09

7475

Neut Hg Wash

to SME

.0000

.0000

$.3449 \mathrm{E}-06$

$.1094 \mathrm{E}-05$

$.5740 E-37$

.0000

.0000

.0000

.0000

.0000

.0000

.0000

.0000

.0000

.2136E-04

.0000

.0000

.0000

. 1239E-08

.5374E-08

$.8947 E-07$

. 1206E-05

$.9897 \mathrm{E}-19$

. 2999E-07

. 1082E-04

.0000

$.7640 \mathrm{E}-17$

.0000

.0000

$.1675 \mathrm{E}-04$

.0000

.2633E-27

$.8516 \mathrm{E}-04$

.7709E-09

$.6434 \mathrm{E}-09$

. 4971E-09

.0000

$.3284 E-06$

$.8127 \mathrm{E}-13$

$.6428 \mathrm{E}-11$

$.6272 \mathrm{E}-10$

.1272E-06

$.3127 \mathrm{E}-06$

.0000

.0000

.2654 E-04
76

Hg Foed

to MHWC

.0000

.0000

$.4494 \mathrm{E}-1 \mathrm{D}$

. 1425E-09

.0000

.0000

.0000

.0000

.0000

.0000

$.1216 \mathrm{E}-04$

.0000

1.857

. 857SE-07

.2535E- 11

.0000

.0000

.0000

$.1614 \mathrm{E}-12$

.7002E- 12

$.1166 \mathrm{E}-10$

. 1571E-09

$.1290 \mathrm{E}-22$

$.3908 \mathrm{E}-11$

$.1410 \mathrm{E}-08$

.0000

$.9954 \mathrm{E}-21$

.0000

.0000

$.2405 \mathrm{E}-05$

.0000

$.8631 \mathrm{E}-37$

$.8291 \mathrm{E}-08$

$.1004 \mathrm{E}-12$

$.8383 \mathrm{E}-13$

$.6477 \mathrm{E}-13$

.0000

$.4279 \mathrm{E}-10$

$.4074 \mathrm{E}-17$

$.8375 \mathrm{E}-15$

$.8172 E-14$

$.1657 \mathrm{E}-10$

$.4074 E-10$

.0000

.0000

$.3457 E-08$
78

Water Wash

to MuivC

.0000

.0000

.0000

.0000

.0000

.0000

.0000

.0000

.0000

.0000

.0000

.0000

.0000

.0000

.0000

.0000

.0000

.0000

.0000

.0000

.0000

.0000

.0000

.0000

.0000

.0000

.0000

.0000

.0000

.0000

.0000

.0000

.0000

.0000

.0000

.0000

.0000

.0000

.0000

.0000

.0000

.0000

.0000

.0000

.0000

.0000 
DPSP $80-1033$

MATERIAL BALANCE TABLES

SLUDGE-SUPERNATE FEED

STREAMS (CONT'D)STREAM NAME

$7 \mathrm{NaCl}$

$188 \mathrm{NaCl}$ Semi Vol

$69 \mathrm{NaF}$

$189 \mathrm{NaF}$ Semi Vol

$12 \mathrm{NaI}$

$125 \mathrm{NaI}$ Semi Vol

$8 \mathrm{NaNO2}$

$2 \mathrm{NaNO3}$

$4 \mathrm{NaOH}$

87 NaResin

$61 \mathrm{Ni}(\mathrm{COOH}) 2$

$17 \mathrm{Ni}(\mathrm{OH}) 2$

$40 \mathrm{NiO}$

8202

$67 \mathrm{PbO}$

$28 \mathrm{PbS04}$

$124 \mathrm{Pd}$

$123 \mathrm{Pd}(\mathrm{OH}) 2$

$112 \mathrm{PdNO32}$

$110 \mathrm{PdO}$

$117 \mathrm{Pu}(\mathrm{COOH}) 4$

$76 \mathrm{Pu} 02$

$22 \mathrm{RhO2}$

$79 \mathrm{Ru} 02$

23 Ru02 Semi Vol

$83 \mathrm{Ru} 04$

$38 \mathrm{SO2}$

1115102

115 Silica Gel

$48 \mathrm{Sr}(\mathrm{COOH}) 2$

$10 \mathrm{Sr}(\mathrm{NO3}) 2$

$127 \mathrm{Sr}(\mathrm{OII}) 2$

$30 \mathrm{SrCO}$

46 Sro

89 SrRESIN

141 Surfactant

92 Th02

$107 \mathrm{TiO2}$

119 Tritium

98 v02

$62 \mathrm{VO2}(\mathrm{COOH}) 2$

$16 \mathrm{VO2}(\mathrm{OH}) 2$

$27 \mathrm{Y}(\mathrm{COOHI}) \mathrm{S}$

$11 Y(N 03) 8$

$128 Y(\mathrm{OH}) 3$

$31 \mathrm{Y} 2(\mathrm{CO} 3) 3$

\begin{tabular}{|c|c|c|c|}
\hline 74 & 75 & 76 & 78 \\
\hline $\begin{array}{c}\text { Neut } H_{\bar{S}} H_{\text {iash }} \\
\text { to } S \mathrm{ME}\end{array}$ & $\begin{array}{l}\text { Nashed } \mathrm{Hg} \\
\text { from MASC }\end{array}$ & $\begin{array}{l}\text { Hg Feed } \\
\text { to MHitic }\end{array}$ & $\begin{array}{c}\text { Water Wiash } \\
\text { to Intye }\end{array}$ \\
\hline $.1263 E-06$ & $.1652 E-10$ & $.1652 E-10$ & .0000 \\
\hline .0003 & .0000 & .0000 & .0000 \\
\hline $.6703 \mathrm{E}-09$ & $.8737 E-13$ & $.8737 E-13$ & .0000 \\
\hline .0003 & .0000 & .0000 & .0000 \\
\hline . 1229E-07 & $.1601 E-11$ & $.1601 \mathrm{E}-11$ & .0000 \\
\hline $.000 \mathrm{~J}$ & .0000 & .0000 & .0000 \\
\hline J000 & .0000 & .0000 & .0000 \\
\hline $.643 \mathrm{JE}-01$ & $.6047 \mathrm{E}-09$ & $.6047 \mathrm{E}-09$ & .0000 \\
\hline . 499 ЭE-01 & .0000 & .0000 & .0000 \\
\hline .0000 & .0000 & .0000 & .0000 \\
\hline $.3791 E-05$ & . 4940E-09 & $.4940 E-09$ & .0000 \\
\hline $.8802 E-18$ & . 4954E-22 & $4954 \mathrm{E}-22$ & .0000 \\
\hline $.000 \mathrm{~J}$ & .0000 & .0000 & .0000 \\
\hline $.9830 \mathrm{E}-05$ & $.7228 E-08$ & $.1412 E-05$ & .0000 \\
\hline .000 : & .0000 & .0000 & .0000 \\
\hline . 171)E-06 & $.2240 \mathrm{E}-10$ & $.2240 \mathrm{E}-10$ & .0000 \\
\hline .000 & .0000 & .0000 & .0000 \\
\hline $.000 u$ & .0000 & .0000 & .0000 \\
\hline .0000 & .0000 & .0000 & .0000 \\
\hline .000 .3 & .0000 & .0000 & .0000 \\
\hline . 176:2E-09 & $.2296 \mathrm{E}-18$ & $.2290 \mathrm{E}-13$ & .0000 \\
\hline $.4473 E-07$ & $.5828 E-11$ & $.5828 E-11$ & .0000 \\
\hline . 170JE-07 & $.2227 \mathrm{E}-11$ & $.2227 \mathrm{E}-11$ & .0000 \\
\hline $.8425 \mathrm{JE}-07$ & . $1098 \mathrm{E}-10$ & $.1098 \mathrm{E}-10$ & .0000 \\
\hline .0000 & .0000 & .0000 & .0000 \\
\hline $.000 !)$ & .0000 & .0000 & .0000 \\
\hline .0000 & .0000 & .0000 & .0000 \\
\hline $.810 \div E-05$ & . 1056E-08 & $.1056 \mathrm{E}-03$ & .0000 \\
\hline .0000 & .0000 & .0000 & .0000 \\
\hline . 1543E-06 & $.2011 E-10$ & $.2011 E-10$ & .0000 \\
\hline . 180:2E-12 & . 2348E-16 & $.2348 \mathrm{E}-16$ & .0000 \\
\hline $.1700 E-19$ & $.2215 E-23$ & $.2214 \mathrm{E}-23$ & .0000 \\
\hline .0000 & .0000 & .0000 & .0000 \\
\hline .0000 & .0000 & .0000 & .0000 \\
\hline .0000 & .0000 & .0000 & .0000 \\
\hline .0000 & .0000 & .0000 & .0000 \\
\hline $.7012 E-06$ & $.9137 \mathrm{E}-10$ & $.9137 \mathrm{E}-10$ & .0000 \\
\hline . 1075E-07 & $.1400 \mathrm{E}-11$ & $.1400 \mathrm{E}-11$ & .0000 \\
\hline $.2479 E-15$ & $.1170 \mathrm{E}-18$ & $.5376 \mathrm{E}-19$ & .0000 \\
\hline .0000 & .0000 & .0000 & .0000 \\
\hline $.4904 E-05$ & $.6890 \mathrm{E}-09$ & $.6390 \mathrm{E}-09$ & .0000 \\
\hline $.6661 E-18$ & $.8679 E-22$ & $.8679 E-22$ & .0000 \\
\hline . 105:IE-06 & . 1375E-10 & . $1875 E-10$ & .0000 \\
\hline $.1280 E-12$ & . 1667E-16 & $.1667 \mathrm{E}-16$ & .0000 \\
\hline . 1060E-19 & . $1381 E-23$ & $.1381 \mathrm{E}-23$ & .0000 \\
\hline .0000 & .0000 & .0000 & $.0000^{\circ}$ \\
\hline
\end{tabular}

Appendi:: II

Table 21-16

Page 076 of 173

Dnte 09/30/82 Rev 00 
MATERIAL BALINCE TABLES

Date 09/80/82 Rev 09

SLUDGE-SUPERNATE FEED STREAMS (CONT'D) STREAM NAME

$47 \times 203$

100 Zeolite

$44 \mathrm{Zn}(\mathrm{COOH}) 2$

$54 \mathrm{Zn}(\mathrm{OII}) 2$

$57 \mathrm{ZnO}$

$104 \mathrm{Zr} 02$

TOTAL FLON, LB/WR

VAPOR FLOW, CFM

LIQLID FLOW, GPYI DESIGN FLOW,

DENSITY, LBS/FT3

TIMPERATURE, DEG C

74

Nieut Hg Hash

to SME

.0000

$.4483 \mathrm{E}-05$

$.5574 E-06$

$.5734 E-19$

.0000

$.5374 \mathrm{E}-08$

66.4258

PRESSURE, PSIC

PRESSURE, MM HG

PHASE

ENTHALPY, PCU/HR
1.28

.00

88.00

.99

$-.07$

75

Washed $\mathrm{Hg}$

from MASC

.0000

$.5841 \mathrm{E}-09$

$.7262 \mathrm{E}-1 \mathrm{~J}$

$.7471 E-23$

.0000

$.7002 E-12$

1.83

.00

887.9642

88.0

1.00

.05

756.20

LIQUID

45.25

LIQUID

1.74
76

Hg Feed

to MUWC

.0000

$.5841 E-09$

$.7262 \mathrm{E}-10$

$.7471 \mathrm{E}-28$

.0000

$.7002 \mathrm{E}-12$

1.39

.00

643.6918

88.00

2.86

19.99
LIQUID

3.05
78

Water Wish

to MUtic

.0000

.0000

.0000

.0000

.0000

.0000

.20

.00

62.4300

25.00

1.34

5. 00

LIQUID

ธ. 06 
DPSP $80-1033$

MATERIAL BALANCE TABLES

SLUDGE-SUPERNATE FEED

STREAM NUMBERS -

STREAM NAME

COMPONENT FLOHS, LB/HR

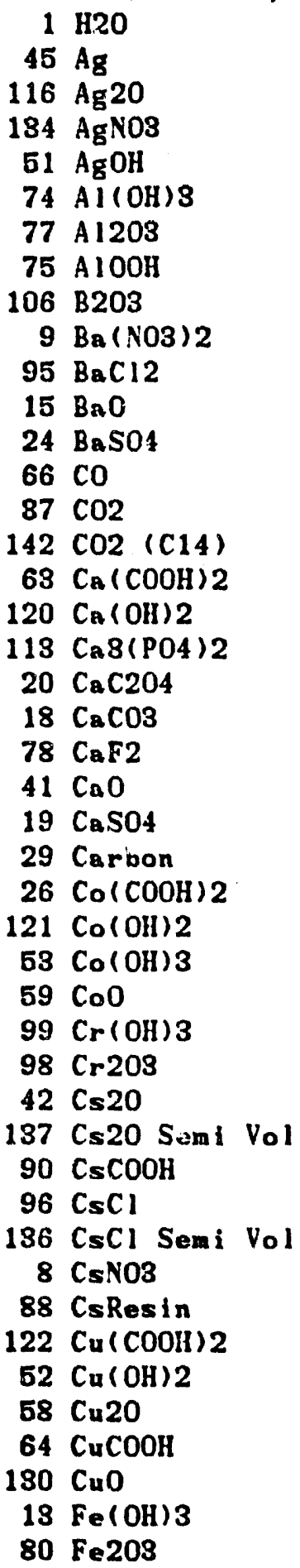

79

Water Hash Wiashed $\mathrm{Hg}$

from MiNWC from MirliC

.2385

.0003

$.000]$

$.3743 \mathrm{E}-05$

$.8993 \mathrm{E}-11$

$.1994 \mathrm{E}-08$

.0003

.0003

$.3003 \mathrm{E}-10$

$.2620 \mathrm{E}-16$

.000 )

$.000 \mathrm{~J}$

$.2869 \mathrm{E}-10$

.000 : J

$.5487 \mathrm{E}-22$

.000 J

$.822 \mathrm{aE}-09$

$.758 \mathrm{JE}-22$

. $690 \mathrm{SE}-10$

. 638: $\mathrm{BE}-10$

.0000

. 1597E-10

.0000

$.7501 \mathrm{E}-10$

.1612E-10

$.1293 \mathrm{E}-10$

$.1303 E-23$

.000 J

.0000

$.6069 E-10$

.0000

$.3585 \mathrm{E}-15$

.0000

$.3686 \mathrm{E}-10$

$.3838 E-14$

.0000

$.1681 \mathrm{E}-11$

.0000

.2772E-10

. 288SE-23

.0000

.0000

.0000

$.4826 \mathrm{E}-08$

.0000

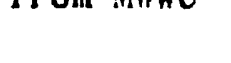

Appendix H

Table 21-16

Page 078 of 170

Date 09/30/82 Rev 09

\section{1}

Hashed Hg Purified IIg to MVS

$$
\begin{aligned}
& .9983 E-03 \quad .9983 E-03 \\
& .1593 E-05 \quad .1593 E-08 \\
& .0000 \quad .0000 \\
& .1600 \mathrm{E}-07 \quad .1600 \mathrm{E}-10 \\
& .3845 \mathrm{E}-13 \quad .3845 \mathrm{E}-16 \\
& .8525 E-11 \quad .8525 E-14 \\
& .0000 \quad .0000 \\
& .0000 \quad .0000 \\
& .1283 E-12 \quad .1288 E-15 \\
& .1120 E-18 \quad .1120 E-21 \\
& .0000 \quad .0000 \\
& .0000 \quad .0000 \\
& .1013 \mathrm{E}-12 \quad .1013 \mathrm{E}-15 \\
& .0000 \quad .0000 \\
& .2346 \mathrm{E}-24 \quad .2346 \mathrm{E}-24 \\
& .0000 \quad .0000 \\
& .3515 \mathrm{E}-11 \quad .3515 \mathrm{E}-14 \\
& .3220 \mathrm{E}-24 \text {.8220E-27 } \\
& .2525 \mathrm{E}-12 \text {.2525E-i5 } \\
& .2731 \mathrm{E}-12 \quad .2731 \mathrm{E}-15 \\
& .0000 \quad .0000 \\
& .6827 \mathrm{E}-13 \quad .6827 \mathrm{E}-16 \\
& .0000 \quad .0000 \\
& .3207 \mathrm{E}-12 \quad .3207 \mathrm{E}-1 \mathrm{5} \\
& .6894 \mathrm{E}-13 \quad .6894 \mathrm{E}-16 \\
& .5549 \mathrm{E}-1 \mathrm{~S} \quad .5549 \mathrm{E}-16 \\
& .5569 \mathrm{E}-26 \quad .5569 \mathrm{E}-29 \\
& .0000 \quad .0000 \\
& .0000 \quad .0000 \\
& .2595 E-12 \quad .2595 E-15 \\
& .0000 \quad .0000 \\
& .1533 E-17 \quad .1533 E-20 \\
& .0000 \quad .0000 \\
& .1576 \mathrm{E}-12 \quad .1576 \mathrm{E}-15 \\
& .1641 \mathrm{E}-16 \quad .1641 \mathrm{E}-19 \\
& .0000 \quad .0000 \\
& .7186 \mathrm{E}-14 \quad .7186 \mathrm{E}-17 \\
& .0000 \quad .0000 \\
& .1185 \mathrm{E}-12 \text {.1185E-15 } \\
& .1211 \mathrm{E}-25 \quad .1211 \mathrm{E}-28 \\
& .0000 \quad .0000 \\
& .0000 \quad .0000 \\
& .0000 \quad .0000 \\
& .2063 E-10 \quad .2063 E-13 \\
& .0000
\end{aligned}
$$


DPSP $80-1033$

MATERIAL BALINCE TABLIS

SLIDẼ-SUPERNATE FEED

STREAMS (CONT'D)-

STREAM NAME

$101 \mathrm{FeO}$

126 Group A Semi Vo

102 GroupA

103 GroupB

25 H2

$133 \mathrm{H} 2 \mathrm{C} 204$

$91 \mathrm{H} 202$

84 HCOOH

43 IIC I

$85 \mathrm{HF}$

49 HNOB

86 HResin

$86 \mathrm{Hg}$

$135 \mathrm{HgNO} 032$

$21 \mathrm{HgO}$

$97 \quad 12$

$89 \mathrm{~K} 20$

$131 \mathrm{KMnO4}$

118 KN03

$105 \operatorname{La} 203$

$108 \mathrm{Li} 20$

$65 \mathrm{Mg}(\mathrm{COOH}) 2$

$55 \mathrm{Mg}(\mathrm{OlI}) 2$

$83 \mathrm{MgO}$

$60 \mathrm{Mn}(\mathrm{COOH}) 2$

$132 \mathrm{Mn}(\mathrm{N03}) 2$

$129 \mathrm{Mn}(\mathrm{OHI}) 2$

$56 \mathrm{MnO}$

$14 \mathrm{MnO2}$

81 N2

$143 \mathrm{NA} 2 \mathrm{CO} \quad(\mathrm{C} 14)$

$85 \mathrm{NO}$

$84 \mathrm{NO} 2$

$70 \mathrm{Na}(\mathrm{HgO}(\mathrm{OH}))$

$94 \quad \mathrm{Na} 2 \mathrm{~B} 107$

$109 \mathrm{Na2C204}$

$5 \mathrm{Na} 2 \mathrm{CO} 3$

$82 \mathrm{Na} 20$

71 in $2 \mathrm{Pu} 02$ (OII) 4

$78 \mathrm{Na} 2 \mathrm{RhO}$

$72 \mathrm{~N}_{3} 2 \mathrm{RuO4}$

$6 \mathrm{Na} 2 \mathrm{SO}_{4}$

$68 \mathrm{NaAlO} 2$

$114 \mathrm{NaBO} 2$

140 NaB02 Semi Vol

$50 \mathrm{NaCOOH}$
Append Ix H

Table 21-16

Page 079 of 173

Date 09/30/82 Rev 09

\begin{tabular}{|c|c|c|c|}
\hline $\begin{array}{l}79 \\
\text { ter Wash } \\
\text { rom MWWC }\end{array}$ & $\begin{array}{l}80 \\
\text { Washed Hg } \\
\text { from MWUiC }\end{array}$ & $\begin{array}{l}81 \\
\text { Washed Hg } \\
\text { to MVS }\end{array}$ & $\begin{array}{l}82 \\
\text { Purif ied Hg }\end{array}$ \\
\hline .0000 & .0000 & .0000 & .0000 \\
\hline .0000 & .0000 & .0000 & .0000 \\
\hline $.4474 E-10$ & . $1913 E-12$ & $.1918 E-12$ & $.1913 \mathrm{E}-15$ \\
\hline . 1419E-09 & $.6068 \mathrm{E}-12$ & $.6068 \mathrm{E}-12$ & $.6068 \mathrm{E}-15$ \\
\hline .0000 & .0000 & .0000 & .0000 \\
\hline .0000 & .0000 & .0000 & .0000 \\
\hline .0000 & .0000 & .0000 & .0000 \\
\hline .0000 & .0000 & .0000 & .0000 \\
\hline .0000 & .0000 & .0000 & .0000 \\
\hline .0000 & .0000 & .0000 & .0000 \\
\hline $.1210 \mathrm{E}-04$ & $.5176 E-07$ & $.5176 \mathrm{E}-07$ & $.5176 \mathrm{E}-07$ \\
\hline .0000 & .0000 & .0000 & .0000 \\
\hline .0000 & 1.357 & 1.857 & 1.846 \\
\hline . 8563E-07 & . 15235-09 & . 1523E-09 & $.1523 E-12$ \\
\hline $2524 \mathrm{E}-11$ & $.1079 \mathrm{E}-13$ & $.1079 E-13$ & . 1079E-16 \\
\hline .0000 & .0000 & .0000 & .0000 \\
\hline .0000 & .0000 & .0000 & .0000 \\
\hline .0000 & .0000 & .0000 & .0000 \\
\hline $.1607 E-12$ & $.6873 E-15$ & .6873E-15 & $.6873 E-18$ \\
\hline $.6972 E-12$ & $.2981 \mathrm{E}-14$ & $.2981 E-14$ & $.2981 \mathrm{E}-17$ \\
\hline $.1161 \mathrm{E}-10$ & $.4963 E-13$ & $.4963 E-13$ & $.4963 E-16$ \\
\hline . 1565E-09 & $.6690 \mathrm{E}-12$ & $.6690 \mathrm{E}-12$ & $.6690 \mathrm{E}-15$ \\
\hline . $1284 \mathrm{E}-22$ & $.5490 \pi-25$ & $.5490 E-25$ & $.5490 \mathrm{E}-28$ \\
\hline . $8891 E-11$ & $.1664 \mathrm{E}-13$ & $.1664 \mathrm{E}-13$ & $.1664 \mathrm{E}-16$ \\
\hline . $1404 \mathrm{E}-08$ & $.6001 E-11$ & $.6001 E-11$ & $.6001 \mathrm{E}-14$ \\
\hline .0000 & .0000 & .0000 & .0000 \\
\hline $.9912 \mathrm{E}-21$ & . $4238 \mathrm{E}-23$ & $\cdot 4238 E-23$ & - 4238E-26 \\
\hline $\begin{array}{l}.0000 \\
.0000\end{array}$ & .0000 & .0000 & .0000 \\
\hline $\begin{array}{l}.0000 \\
.2395 E-05\end{array}$ & .0000 & .0000 & .0000 \\
\hline $\begin{array}{l}.2395 \mathrm{E}-05 \\
.0000\end{array}$ & $.1024 \mathrm{E}-07$ & $.1024 \mathrm{E}-07$ & . $1024 E-07$ \\
\hline $\begin{array}{l}.0000 \\
.8631 E-37\end{array}$ & .0000 & .0000 & .0000 \\
\hline $\begin{array}{l}.8631 \mathrm{E}-37 \\
.3277 \mathrm{E}-08\end{array}$ & .0000 & $1401 \mathrm{E}-10$ & $.00001 \mathrm{E}-10$ \\
\hline $.1000 E-12$ & $4277 E-15$ & $.4277 E-15$ & $.4277 E-18$ \\
\hline $.8347 \mathrm{E}-$ & $.3569 \mathrm{E}-15$ & $.8569 E-15$ & $.8569 \mathrm{E}-18$ \\
\hline $.6449 E-13$ & $.2758 \mathrm{E}-1 \mathrm{~J}$ & $.2758 \mathrm{E}-15$ & $.2758 E-18$ \\
\hline .0000 & .0000 & .0000 & .0000 \\
\hline $.4261 \mathrm{E}-10$ & $.1822 \mathrm{E}-12$ & . $1822 E-12$ & . 1822E-15 \\
\hline $.4056 E-17$ & $.1734 \mathrm{E}-19$ & $.1734 E-19$ & $.1734 E-22$ \\
\hline $.8339 E-15$ & $.8566 \mathrm{E}-17$ & $.3566 \mathrm{E}-17$ & $.3566 \mathrm{E}-20$ \\
\hline $.8138 \mathrm{E}-14$ & $.8480 E-115$ & $.8480 E-16$ & $.3480 E-19$ \\
\hline $.1650 \mathrm{E}-10$ & $.7056 \mathrm{E}-1: 3$ & $.7056 \mathrm{E}-13$ & $.7056 \mathrm{E}-16$ \\
\hline $.4056 \mathrm{E}-10$ & $.1734 \mathrm{E}-12$ & $.1734 \mathrm{E}-12$ & $.1784 E-15$ \\
\hline .000 & .0000 & .0000 & .0000 \\
\hline .0000 & .0000 & .0000 & .0000 \\
\hline & $.1472 E-10$ & $.1472 \mathrm{E}-10$ & $.1472 \mathrm{E}-13$ \\
\hline
\end{tabular}


DPSP $80-1038$

MATERIAL BALANCE TABLES

SLUDGE-SUPERNATE FEED STREAMS (CONT'D)STREAM NAME

$7 \mathrm{NaCl}$

$188 \mathrm{NaCl}$ Seni Vol

$69 \mathrm{NaF}$

$139 \mathrm{NaF}$ Semi Vol

$12 \mathrm{NaI}$

$125 \mathrm{NaI}$ Semi Vol

$8 \mathrm{NaNO2}$

2 NaNO3

$4 \mathrm{NaOH}$

87 NaResin

$61 \mathrm{Ni}(\mathrm{COOH}) 2$

$17 \mathrm{Ni}(\mathrm{OH}) 2$

40 N10

8202

$67 \mathrm{PbO}$

$28 \mathrm{PbSO4}$

$124 \mathrm{Pd}$

$123 \mathrm{Pd}(\mathrm{OH}) 2$

112 PdNO32

$110 \mathrm{PdO}$

$117 \mathrm{Pu}(\mathrm{COOH}) 4$

$76 \mathrm{Pu} 02$

$22 \mathrm{RhO2}$

$79 \mathrm{Ru} 02$

23 Ru02 Semi Vol

$83 \mathrm{Ru} 04$

$88 \mathrm{SO2}$

$111 \mathrm{SiO2}$

115 Silica Gel

$48 \mathrm{Sr}(\mathrm{COOlI}) 2$

$10 \mathrm{Sr}(\mathrm{NO3}) 2$

$127 \mathrm{Sr}(\mathrm{OH}) 2$

$80 \mathrm{SrCO}$

$46 \mathrm{Sr} 0$

89 SrRESIN

141 Surfactant

$92 \mathrm{Th} 02$

$107 \mathrm{~T} 102$

119 Tritium

$93 \mathrm{VO2}$

$62 \mathrm{VO} 2(\mathrm{COOH}) 2$

$16 \mathrm{VO2}(\mathrm{Oll}) 2$

$27 \mathrm{Y}(\mathrm{COOH}) 3$

$11 \mathrm{Y}(\mathrm{NOS}) \mathrm{S}$

$128 \mathrm{Y}(\mathrm{OHI}) 3$

$31 \mathrm{Y} 2(\mathrm{CO} 3) 3$
Appendix II

Tisble 21-16

Page 080 of 173

Date 09/30/82 Rev 09
79

Ninter Wash from NWTC

$.1645 \mathrm{E}-10$

.0000

$.8700 \mathrm{E}-13$

.0000

$.1594 \mathrm{E}-11$

.0000

.0000

.6022 E-09

.0000

.0003

$.4919 \mathrm{E}-09$

$.4932 \mathrm{E}-22$

.0000

$.1406 \mathrm{E}-05$

.0000

$.2230 \mathrm{E}-10$

.0000

.0000

.0000

.0000

$.2280 \mathrm{E}-13$

$.6803 E-11$

$.2217 E-11$

$.1093 \mathrm{E}-10$

.0000

.0000

.0000

$.1051 \mathrm{E}-08$

.0000

$.2002 E-10$

.2338E-16

.2205E-23

.0000

.0000

.0000

.0000

$.9099 \mathrm{E}-10$

$.1394 \mathrm{E}-11$

$.5853 E-19$

.0000

$.6362 \mathrm{E}-09$

$.8642 \mathrm{E}-22$

$.1869 \mathrm{E}-10$

$.1660 \mathrm{E}-16$

$.1376 \mathrm{E}-23$

.0000
80

Washed Hg

fron MUTHC

.7033E- 18

.0000

$.8720 E-15$

.0000

$.6817 \mathrm{E}-14$

.0000

.0000

$.2575 \mathrm{E}-11$

.0000

.0000

.2103E-11

.2109E-24

.0000

$.6012 \mathrm{E}-08$

.0000

$.9536 \mathrm{E}-13$

.0000

.0000

.0000

.0000

$.9776 \mathrm{E}-16$

$.2481 E-13$

$.9481 \mathrm{E}-14$

$.4674 \mathrm{E}-18$

.0000

.0000

.0000

$.4495 \mathrm{E}-11$

.0000

$.8560 \mathrm{E}-18$

$.9997 \mathrm{E}-19$

$.9429 \mathrm{E}-26$

.0000

.0000

.0000

.0000

$.3890 \mathrm{E}-12$

.5963E-14

.2289E-21

.0000

. 2720E-11

$.3695 \mathrm{E}-24$

$.6852 \mathrm{E}-13$

$.7099 \mathrm{E}-19$

.5882E-26

.0000
81

Vished $\mathrm{Hg}$ Purified $\mathrm{Hg}_{\mathrm{G}}$ to MVS

$.7033 E-13 \quad .7033 E-16$

$.0000 \quad .0000$

. .8720E-15 .3720E-19

$.0000 \quad .0000$

$.6817 \mathrm{E}-14 \quad .6817 \mathrm{E}-17$

$.0000 \quad .0000$

$.0000 \quad .0000$

$.2575 E-11 \quad .2575 E-14$

$.0000 \quad .0000$

$.0000 \quad .0000$

$.2103 E-11$.2103E-14

$.2109 \mathrm{E}-24 \quad .2109 \mathrm{E}-27$

$.0000 \quad .0000$

$.6012 \mathrm{E}-08 \quad .6012 \mathrm{E}-08$

$.0000 \quad .0000$

$.9536 \mathrm{E}-13 \quad .9536 \mathrm{E}-\mathrm{i}$ Oि

$.0000 \quad .0000$

$.0000 \quad .0000$

$.0000 \quad .0000$

$.0000 \quad .0000$

$.9776 \mathrm{E}-10 \quad .9776 \mathrm{E}-10$

$.2481 E-13 \quad .2481 E-16$

$.9481 E-14 \quad .9481 E-17$

$.4674 \mathrm{E}-18 \quad .4674 \mathrm{E}-16$

$.0000 \quad .0000$

$.0000 \quad .0000$

$.0000 \quad .0000$

$.4495 E-11 \quad .4495 E-14$

$.0000 \quad .0000$

$.8560 \mathrm{E}-13 \quad .8560 \mathrm{E}-1 \mathrm{~S}$

$.9997 \mathrm{E}-19 \quad .9997 \mathrm{E}-22$

$.9429 \mathrm{E}-26 \quad .9429 \mathrm{E}-29$

$.0000 \quad .0000$

$.0000 \quad .0000$

$.0000 \quad .0000$

$.0000 \quad .0000$

$.8890 \mathrm{E}-12 \quad .3890 \mathrm{E}-15$

$.5963 E-14 \quad .5963 E-17$

$.2289 E-21 \quad .2289 E-21$

$.0000 \quad .0000$

$.2720 \mathrm{E}-11 \quad .2720 \mathrm{E}-14$

$.3695 \mathrm{E}-24 \quad .3695 \mathrm{E}-27$

$.5852 E-13 \quad .5852 E-16$

$.7099 E-19 \quad .7099 E-22$

$.6882 E-26 \quad .5882 E-29$

.0000

.0000 
DPSP $80-1033$

MATERIAL BALANCE TABLES

SLIDGE-SLPERNATE FEED

STREAYS (CONT'D)-

STREAM NAME

$47 \times 203$

100 Zcolite

$44 \mathrm{Zn}(\mathrm{COOH}) 2$

$54 \mathrm{Zn}(\mathrm{OHI}) 2$

$57 \mathrm{ZnO}$

104 $\mathrm{ZrO2}$

TOTAL ILOH, LB/HR

VAPOR FLOW, CFM

LIQUID FLOH, GPM

DESIGY FLOW,

DENSITY, LBS/ET3

TEMPERATURE, DEG C

PRESSURE, ATM

PRESSURE, PSIG

PRESSURE, MU HG

PHASE

EYTHALPY, PCU/HR

Append ix H

Table 21-16

Page 081 of 178

Date 09/30/82 Rev 09

79

Water Wash

from MWWC

.0000

$.5816 E-09$

$.7231 \mathrm{E}-10$

$.7439 E-23$

.0000

$.6972 E-12$

.23

.00

62.4318

28.68

1.84

5.00

LIOUID

6.80
80

Hashed Hg

.0000

$.2487 \mathrm{E}-11$

$.8092 \mathrm{E}-12$

$.3181 \mathrm{E}-25$

.0000

$.2981 E-14$

1.86

.00

837.9511

28.68

1.84

5.00

LIQUID

1.81
81

Washed $\mathrm{Hg}$ Purified $\mathrm{Hg}$ to MVS

.0000

.2487E-11

$.3092 \mathrm{E}-12$

$.3181 \mathrm{E}-25$

.0000

$.2981 E-14$

1.36

.00

837.9511

38.00

.99

$-.07$

756.20

LIQUID

1.74
.0000

.2487 E- 14

$.3092 \mathrm{E}-15$

$.3181 E-28$

.0000

$.2981 E-17$

1.85

.00

837.8893

88.00

1.00

.00

LIQUID

1.72 
JPSP $80-1088$

MATERIAL BALANCE TABLES SLUDGE-SUPERNATE FEED STREAM NUMBERS STREAM NAME

83 Purifled $\mathrm{Hg}$

COMPONENT FLOHS, LB/HR

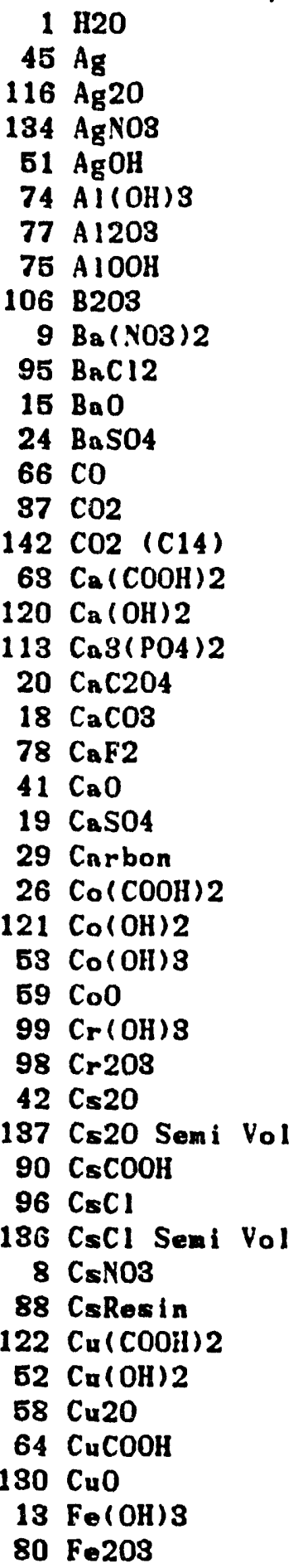

$.9983 E-03$

$.1593 E-08$

.0003

$.160 \mathrm{JE}-10$

$.884 .5 \mathrm{E}-16$

$.8525 \mathrm{E}-14$

.0003

$.000]$

$.1283 \mathrm{E}-15$

$.112 J E-21$

.0000

.0003

$.1013 E-15$

$.000 J$

$.284 \mathrm{SE}-24$

$.000 \mathrm{~J}$

$.851 J E-14$

$.822 \mathrm{JE}-27$

$.252 J E-15$

$.2731 E-15$

.000 ]

$.6827 \mathrm{E}-16$

.000 !

$.3207 \mathrm{E}-15$

$.689 .1 E-16$

$.554 . \mathrm{E}-16$

.556.)E-29

.0003

.0000

$.259 ! j E-15$

.0000

$.153: 3 E-20$

$.0001)$

.157 IE -15

.164 IE-19

.0000

$.718: \mathrm{E}-17$

.0000

$.118 \mathrm{IE}-15$

$.121: E-28$

.0000

.0000

.0000

.206?E-13

.0000
Appendix $\mathrm{H}$

Tuble 21-16

Page 082 of 173

Date 09/30/82 Rev 09
84

pVVF Exhaust Sand Filter.

to Ex Tunnel Condensate

\subsection{9}

$.1638 \mathrm{E}-10$

.0000

$.2571 E-10$

$.4613 \mathrm{E}-11$

$.4721 \mathrm{E}-09$

.0000

.0000

$.2202 \mathrm{E}-08$

$.6200 \mathrm{E}-17$

.0000

.0000

$.5607 \mathrm{E}-11$

$.4493 \mathrm{E}-04$

10.00

$.8846 \mathrm{E}-10$

$.1943 E-09$

$.1479 \mathrm{E}-12$

$.1397 \mathrm{E}-10$

$.1511 \mathrm{E}-10$

.0000

$.3778 \mathrm{E}-11$

.0000

$.1775 \mathrm{E}-10$

$.1197 \mathrm{E}-10$

$.8067 E-08$

.2559E-14

.0000

.0000

$.1436 \mathrm{E}-10$

.0000

$.1099 \mathrm{E}-15$

.0000

.8721E-11

.5772E-13

.0000

$.8977 E-12$

.0000

$.6552 \mathrm{E}-11$

.5566E- 14

.0000

.0000

.0000

. 1143E-08

.0000
13.80

.0000

.0000

.0000

.0000

.0000

.0000

.0000

.0000

.0000

.0000

.0000

.0000

.0000

.0000

.0000

.0000

.0000

.0000

.0000

.0000

.0000

.0000

.0000

.0000

.0000

.0000

.0000

.0000

.0000

.0000

.0000

.0000

.0000

.0000

.0000

.0000

.0000

.0000

.0000

.0000

.0000

.0000

.0000
.0000
86

Far. Hicuse

Concteasate

13.80

.0030

.0000

.0000

.0000

.0000

.0000

.0000

.0000

.0000

.0000

.0000

.0000

.0000

.0000

.0000

.0000

.0000

.0000

.0000

.0000

.0000

.0000

.0000

.0000

.0000

.0000

.0000

.0000

.0000

.0000

.0000

.0000

.0000

.0000

.0000

.0000

.0000

.0000

.0000

.0000

.0000

.0000

.0000

.0000 
MATE!IIL BALANCE TABLES

SLLDGE-SLPERNATE FEED STREAMS (CONT'D)STREAM NANE

83

84

85

Purified Hz PVVF Exhaust Sand Filter

to Ex Tunnel Condensate .0000

.0000

$.1069 \mathrm{E}-10$

$.3358 \mathrm{E}-10$

$.3583 E-05$

.0000

.0000

$.4669 \mathrm{E}-01$

.0000

.0000

.0000

.0000

$.87938-03$

$.1608 E-13$

$.1130 \mathrm{E}-12$

.0000

.0000

.0000

$131 \mathrm{KMnO4}$

$118 \mathrm{KNO3}$

105 La203

108 Li20

$65 \mathrm{Mg}(\mathrm{COOH}) 2$

$55 \mathrm{Mg}(\mathrm{OH}) 2$

$33 \mathrm{M} \mathrm{EO}$

$60 \mathrm{Mn}(\mathrm{COOH}) 2$

$132 \mathrm{Mn}(\mathrm{NO} 03) 2$

$129 \operatorname{Mn}(\mathrm{OH}) 2$

$56 \mathrm{MnO}$

$14 \mathrm{MnO2}$

81 N2

$143 \times A 2 C 03$ (C14)

$35 \mathrm{NO}$

84 NO2

$70 \mathrm{Na}(\mathrm{HgO}(\mathrm{OH}))$

$94 \quad \mathrm{Na} 2 \mathrm{~B} 407$

$109 \mathrm{Na} 2 \mathrm{C2O4}$

$5 \mathrm{Na} 2 \mathrm{CO3}$

32 Nin20

$71 \mathrm{Na2Pu02(OII)4}$

$73 \mathrm{Nn} 2 \mathrm{RhO} 0$

$72 \mathrm{Na}_{2 \mathrm{RuO}}$

$6 \mathrm{Na} 2 \mathrm{SO}_{1}$

$68 \mathrm{NaAlO2}$

$114 \mathrm{NaBO} 2$

140 NaBO2 Semi Vol $50 \mathrm{NaCOOH}$
1.846

. 1523E- 12

$.1079 E-16$

.0000

.0000

.0000

$.6873 E-18$

$.2981 \mathrm{E}-17$

$.4963 \mathrm{E}-16$

$.6690 \mathrm{E}-15$

.5490E-28

$.1664 \mathrm{E}-16$

$.6001 E-14$

.0000

$.4238 \mathrm{E}-26$

.0000

.0000

$.1024 \mathrm{E}-07$

.0000

.0000

$.1401 E-10$

$.4277 E-18$

$.3569 \mathrm{E}-18$

$.2758 \mathrm{E}-18$

.0000

$.1822 \mathrm{E}-15$

$.1784 \mathrm{E}-22$

$.8566 \mathrm{E}-20$

$.8480 \mathrm{E}-19$

$.7056 \mathrm{E}-16$

$.1734 \mathrm{~F}-15$

.0000

.0000

$.1472 E-13$
$.7148 \mathrm{E}-11$

$.7479 \mathrm{E}-10$

$.8537 \mathrm{E}-09$

. 3698E-10

.2523E- 13

.2995E-09

.8317E-09

.0000

$.6528 \mathrm{E}-11$

.0000

.0000

1292.

.0000

1.243

. 1382E-01

$.2367 E-13$

$.1256 \mathrm{E}-11$

$.2868 \mathrm{E}-11$

.0000

$.2653 E-0.3$

.9599E-13

$.1973 E-15$

$.1926 \mathrm{E}-1.1$

$.3905 E-11$

$.9599 \mathrm{E}-11$

.0000

.0000

$.9346 \mathrm{E}-0$

\section{.0000}

.0000

.0000

.0000

.0000

.0000

.0000

.0000

.0000

.0000

.0000

.0000

.0000

.0000

.0000

.0000

.0000

.0000

.0000

.0000

.0000

.0000

.0000

.0000

.0000

.0000

.0000

.0000

.0000

.0000

.0000

.0000

.0000

.0000

.0000

.0000

.0000

.0000

.0000

.0000

.0000

.0000

.0000

.0000

.0000
.0000
86

Fan House

Condensa to

.0000

.0000

.0000

.0000

.0000

.0000

.0000

.0000

.0000

.0000

.0000

.0000

.0000

.0000

.0000

.0000

.0000

.0000

.0000

.0000

.0000

.0000

.0000

.0060

.0000

.0000

.0000

.0000

.0000

.0000

.0000

.0000

.0000

.0000

.0000

.0000

.0000

.0000

.0000

.0000

.0000

.0000

.0000

.0000

.0000

.0000 
DPSP $80-1033$

MATERIAL BALANCE TABLES SLUDGE-SUPERNATE FEED

STREAMS (CONT'D)STREAM NAME

$7 \mathrm{NaCl}$

$138 \mathrm{NaCl}$ Seml Vol

$69 \mathrm{NaF}$

$139 \mathrm{NaF}$ Semi Vol

$12 \mathrm{NBI}$

$125 \mathrm{NaI}$ Semi Vol

$8 \mathrm{NaNO2}$

$2 \mathrm{NaNO3}$

$4 \mathrm{NaOH}$

87 NaResin

$61 \mathrm{Ni}(\mathrm{COOH}) 2$

$17 \mathrm{Ni}(\mathrm{OH}) 2$

$40 \mathrm{NiO}$

8202

$67 \mathrm{PbO}$

$28 \mathrm{PbSO} 4$

$124 \mathrm{Pd}$

$123 \mathrm{Pd}(\mathrm{OH}) 2$

112 PdNO32

$110 \mathrm{PdO}$

$117 \mathrm{Pu}(\mathrm{COOH}) 4$

$76 \mathrm{Pu} 02$

$22 \mathrm{RhO2}$

$79 \mathrm{Ru} 02$

23 Ru02 Semi Vol

$83 \mathrm{Ru} 04$

$38 \mathrm{SO2}$

1115102

115 Silica Gel

$48 \mathrm{Sr}(\mathrm{COOH}) 2$

$10 \mathrm{Sr}(\mathrm{NO3}) 2$

$127 \mathrm{Sr}(\mathrm{OH}) 2$

$80 \mathrm{SrCO}$

46 Sro

89 SrRESIN

141 Surfectant

$92 \mathrm{ThO} 2$

107 Ti02

119 Tritium

98 VO2

$62 \mathrm{VO} 2(\mathrm{COOH}) 2$

$16 \mathrm{VO}(\mathrm{OH}) 2$

$27 \mathrm{Y}(\mathrm{COOH}) 3$

$11 \mathrm{Y}(\mathrm{NO3}) 3$

$128 \mathrm{Y}(\mathrm{OH}) 3$

$31 \mathrm{Y} 2(\mathrm{CO} 03) 3$
Appendix H

Table 21-16

Page 084 of 173

Date 09/30/S2 Rev 09

88

84

85

86

Purified Hg PVyF Exhaust Sand Filtur

to Ex Tunnel Condensate $.4723 E-11 \quad .0000$

$.0000 \quad .0000$

$.8311 \mathrm{E}-12 \quad .0000$

$.0000 \quad .0000$

$.4489 \mathrm{E}-12 \quad .0000$

$.0000 \quad .0000$

$.0000 \quad .0000$

$.2771 \mathrm{E}-09$

.0000

.0000

.0000

.0000

.0000

.0000

.0000

.0000

.0000

.0000

.0000

.0000

.0000

.0000

.0000

.0000

.0000

.0000

.0000

.0000

.0000

.0000

.0000

.0000

.0000

.0000

.0000

.0000

.0000

.0000

.0000

.0000

.0000

.0000

.0000

.0000

.0000

.0000

.0000
Fan House

Conciensiate

.0000

.0000

.0000

.0000

.0000

.0000

.0000

.0000

.0000

.0000

.0000

.0000

.0000

.0000

.0000

.0000

.0000

.0000

.0000

.0000

.0000

.0000

.0000

.0000

.0000

.0000

.0000

.0000

.0000

.0000

.0000

.0000

.0000

.0000

.0000

.0000

.0000

.0000

.0000

.0000

.0000

.0000

.0000

.0000

.0000

.0000 
MITERIAL BALANCE TABLES

Date 09/30/82 Rev 09

SLUDCE-SUPERNATE FEED

STREAMIS (CONT'D) STREAM NAME

$\begin{array}{rl}47 & y 203 \\ 100 & \mathrm{Zeol} \text { ite } \\ 44 & \mathrm{Zn}(\mathrm{COOH}) 2 \\ 51 & \mathrm{Zn}(0 \mathrm{OH}) 2 \\ 57 & \mathrm{Zn} 0\end{array}$

$104 \mathrm{ZrO}$

TOTAL FLON, LB/IIR

VAPOR FLOH', CFM

LIQUID FLO"', GPM

DESIGN FLOW,

DENSIIY, LBS/FTS

TEYPERATLRE, DEG C

PRESSURE, ATM

PRESSURE, PSIG

PRESSURE, MA IIG

PHASE

EXTIIALPY, PCU/IIR
83

Purified Hg

.0000

$.2487 \mathrm{E}-14$

$.3092 \mathrm{E}-15$

$.3181 \mathrm{E}-28$

.0000

$.2981 \mathrm{E}-17$

1.85

.00

837.8893

88.00

1.00

.00

LIQUID

1.72
84

PVVF Exhaust Sand Filter

to Ex Tunnel Condensato .0000

$.1376 \mathrm{E}-09$

$.1709 \mathrm{E}-10$

$.1462 \mathrm{E}-13$

.0000

$.7479 \mathrm{E}-10$

1718.58

412.97

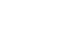

.0000

.0000

.0000

.0000

.0000

.0000
13.80

.08

62.4300

25.00

1.00

.00

754.53

VAPOR

$-88043.79$

LIQUID

$\mathbf{8 4 9 . 8 4}$
.03

86

Fan House

Condensate .0000 .0000 .0000 .0000 .0000 .0000

13.80

62.4800

25.00

1.00

.00

LIQUID

849.84 
DPSP $80-1033$

MATERIAL BALANCE TABLES SLUDGE-SUPERNATE FEED

COMPONENT FLONS, LB/HR

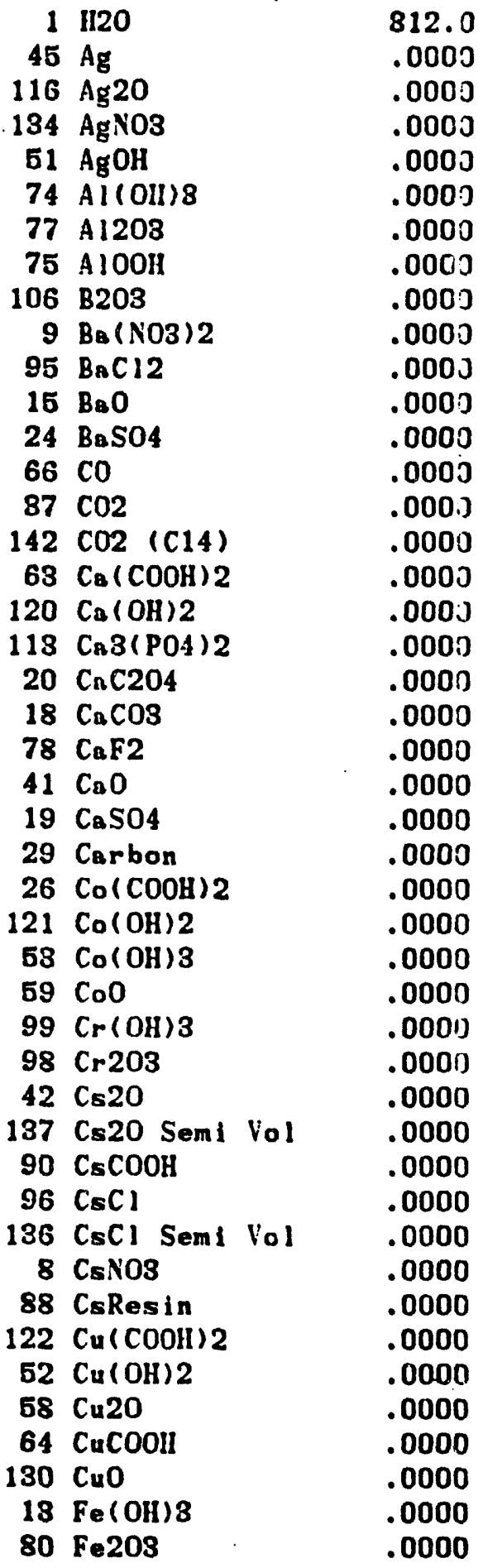

STREAM NUMBERS STREAM NAME

c

CC

Appendix $\mathrm{H}$

Table 21-16

Page 086 of 173

Date $03 / 50 / 82$ Rev 09

$\begin{array}{cccc}87 & 88 & 89 & 90 \\ \text { Cecon Haste } & \text { MHT Vent } & \text { Mise Sumps } & 59 \text { Hit } \% \\ \text { to DKIT } & \text { to MVC } & \text { to RCT } & \text { NaOil to IC: }\end{array}$

\begin{tabular}{|c|c|c|}
\hline $.7477 E-01$ & .0000 & 2.827 \\
\hline $.8427 E-11$ & .0000 & .0000 \\
\hline .0000 & .0000 & .0000 \\
\hline $.8467 \mathrm{E}-13$ & .0000 & .0000 \\
\hline $.2034 E-18$ & .0000 & .0000 \\
\hline $.4510 E-16$ & .0000 & .0000 \\
\hline .0000 & .0000 & .0000 \\
\hline .0000 & .0000 & .0000 \\
\hline $.6786 E-18$ & .0000 & .0000 \\
\hline . 5927E-24 & .0000 & .0000 \\
\hline .0000 & .0000 & .0000 \\
\hline .0000 & .0000 & .0000 \\
\hline .6360 E-18 & .0000 & .0000 \\
\hline .0000 & .0000 & .0000 \\
\hline $.1241 E-29$ & .0000 & .0000 \\
\hline .0000 & .0000 & .0000 \\
\hline . $1859 E-16$ & .0000 & .0000 \\
\hline $.1703 E-29$ & .0000 & .0000 \\
\hline $.1336 E-17$ & .0000 & .0000 \\
\hline $.1445 E-17$ & .0000 & .0000 \\
\hline .0000 & .0000 & .0000 \\
\hline $.8612 E-18$ & .0000 & .0000 \\
\hline .0000 & .0000 & .0000 \\
\hline $.1697 E-17$ & .0000 & .0000 \\
\hline $.3648 E-18$ & .0000 & .0000 \\
\hline $.2936 E-18$ & .0000 & .0000 \\
\hline $.2947 E-31$ & .0000 & .0000 \\
\hline .0000 & .0000 & .0000 \\
\hline .0000 & .0000 & .0000 \\
\hline $1373 E-17$ & .0000 & .0000 \\
\hline .0000 & .0000 & .0000 \\
\hline $.8110 E-23$ & .0000 & .0000 \\
\hline .0000 & .0000 & .0000 \\
\hline $.8337 E-18$ & .0000 & .0000 \\
\hline $.8682 E-22$ & .0000 & .0000 \\
\hline .0000 & .0000 & .0000 \\
\hline . 3802E-19 & .0000 & .0000 \\
\hline .0000 & .0000 & .0000 \\
\hline $6271 E-18$ & .0000 & .0000 \\
\hline .6409E-31 & .0000 & .0000 \\
\hline .0000 & .0000 & .0000 \\
\hline .0000 & .0000 & .0000 \\
\hline .0000 & .0000 & .0000 \\
\hline $.1092 E-15$ & .0000 & .0000 \\
\hline .0000 & .0000 & .0000 \\
\hline
\end{tabular}


YiTERIAL BALANCE TABLES

SLCUGE-SUPER.NATE FEED

STREAMS ( CONT' D)-

STREAM NAME

$101 \mathrm{FeO}$

(1)

126 Group A Seni Vo

102 GroupA

103 Group B

25112

$13312 \mathrm{l} 2204$

9111202

84 HCOOII

$43 \mathrm{HCl}$

85 IIF

49 HNO3

80 liResin

$36 \mathrm{Hg}$

$135 \mathrm{HgNO} 2$

$21 \mathrm{Hg} 0$

$97 \quad 12$

$39 \mathrm{~K} 20$

$131 \mathrm{KMnO4}$

118 KNO:

$105 \mathrm{La} 203$

108 Li20

$65 \mathrm{Mg}(\mathrm{COOHI}) 2$

55 $\mathrm{M}_{\mathrm{E}}(\mathrm{OII}) 2$

$83 \mathrm{MgO}$

$60 \mathrm{Mn}(\mathrm{COOII}) 2$

$132 \mathrm{Mn}(\mathrm{NO}) 2$

$129 \mathrm{Mn}(\mathrm{Oli}) 2$

$66 \mathrm{MnO}$

$14 \mathrm{MnO}_{2}$

$81 \mathrm{~N} 2$

143 NA2CO3 (C14)

35 NO

$84 N 02$

$70 \mathrm{Na}(\mathrm{HgO}(\mathrm{OII}))$

$94 \mathrm{Na} 2 \mathrm{~B} 407$

87

Decon Waste

to DWTT

.0000

.0000

.0000

.0000

.0000

5.750

.0000

.0000

.0000

.0000

4.930

.0000

.0000

.0000

.0000

.0000

.0000

.8080

.0000

.0000

.0000

.0000

.0000

.0000

.0000

.0000

.0000

.0000

.0000

.0000

.0000

.0000

.0000

.0000

.0000

.0000

109 Na2C204

.0000

$5 \mathrm{Na2CO3}$

$82 \mathrm{Na} 20$

.0000

$71 \mathrm{Na} 2 \mathrm{Pu} 02$ (OH) 4

.0000

$73 \mathrm{Na} 2 \mathrm{RhO4}$

.0000

$72 \mathrm{Na} 2 \mathrm{Ru} 04$

$6 \mathrm{Na} 2 \mathrm{SO}_{4}$

.0000

.0000

.0000

$68 \mathrm{NaAlO2}$

$114 \mathrm{NaBO} 2$

.0000

$140 \mathrm{NaBO2}$ Semi Vol

.0000

$50 \mathrm{NaCOOH}$

.0000

MIIT

to MVC

.0000

.0000

$.1012 \mathrm{E}-17$

$.8210 \mathrm{E}-17$

.0000

.0000

.0000

.0000

.0000

.0000

$.2788 \mathrm{E}-12$

.0000

$.7180 \mathrm{E}-05$

$.8060 \mathrm{E}-15$

$.5711 E-19$

.0000

.0000

.0000

$.8636 \mathrm{E}-20$

$.1577 \mathrm{E}-10$

$.2626 E-18$

$.8540 \mathrm{E}-17$

$.2905 E-30$

$.8802 E-19$

$.8175 \mathrm{E}-16$

.0000

$.2242 E-28$

.0000

.0000

3.418

.0000

.0000

$.7412 E-16$

.2263E-20

. 1888E-20

$.1459 \mathrm{E}-20$

.0000

$.9688 \mathrm{E}-18$

$.9176 \mathrm{E}-25$

. 1886E-22

.1841E-21

$.8733 E-18$

$.9176 E-18$

.0000

.0000

$.7788 \mathrm{E}-16$
89

Misc Sumps

to RCT

.0000

.0000

.0000

.0000

.0000

.0000

.0000

.0000

.0000

.0000

.0000

.0000

.0000

.0000

.0000

.0000

.0000

.0000

.0000

.0000

.0000

.0000

.0000

.0000

.0000

.0000

.0000

.0000

.0000

.0000

.0000

.0000

.0000

.0000

.0000

.0000

.0000

.0000

.0000

.0000

.0000

.0000

.0000

.0000

.0000

.0000
90

50 Wt \%

$\mathrm{NaOH}$ to $\mathrm{RCT}$

.0000

.0000

.0000

.0000

.0000

.0000

.0000

.0000

$.000 \mathrm{C}$

.0000

.0000

.0000

.0000

.0000

.0000

.0000

.0000

.0000

.0000

.0000

.0000

.0000

.0000

.0000

.0000

.0000

.0000

.0000

.0000

.0000

.0000

.0000

.0000

.0000

.0000

.0000

.0000

.0000

.0000

.0000

.0000

.0000

.0000

.0000

.0000

.0000 
DPSP 80-1083

MATERIAL BALANCE TABLES

SLUDGE-SUPERNATE FFED STREAMS ( CONT'D)STREAM NAME

\section{$7 \mathrm{NaCl}$}

$188 \mathrm{~N}_{2} \mathrm{Cl}$ Semi Vol

$69 \mathrm{NaF}$

$189 \mathrm{NaF}$ Semi Vol

$12 \mathrm{NaI}$

125 NaI Semi Vol

$8 \mathrm{NaNO2}$

$2 \mathrm{NaNO3}$

$4 \mathrm{NaOH}$

87 NaResin

$61 \mathrm{Ni}(\mathrm{COOH}) 2$

$17 \mathrm{Ni}(\mathrm{OH}) 2$

$40 \mathrm{NiO}$

8202

$67 \mathrm{PbO}$

$28 \mathrm{PbSO} 4$

$124 \mathrm{Pd}$

$123 \mathrm{Pd}(\mathrm{OH}) 2$

112 PdNO82

$110 \mathrm{PdO}$

$117 \mathrm{Pu}(\mathrm{COOH}) 4$

$76 \mathrm{Pu} 02$

$22 \mathrm{RhO2}$

79 Ru02

28 Ru02 Semi Vol

83 Ru04

$88 \mathrm{SO2}$

$111 \mathrm{Si} 02$

115 Sillicn Gel

$48 \mathrm{Sr}(\mathrm{COOH}) 2$

$10 \mathrm{Sr}(\mathrm{N} 03) 2$

$127 \mathrm{Sr}(\mathrm{OH}) 2$

$80 \mathrm{SrCO3}$

$46 \mathrm{Sr} 0$

89 SrRESIN

141 Surfactant

92 Th02

$107 \mathrm{Ti} 02$

119 Tritium

$93 \mathrm{~V} 02$

$62 \mathrm{VO2}(\mathrm{COOH}) 2$

$16 \mathrm{VO}(\mathrm{OH}) 2$

$27 \mathrm{Y}(\mathrm{COOH}) \mathrm{S}$

$11 \mathrm{Y}(\mathrm{NOS}) 3$

$128 \mathrm{Y}(\mathrm{OH}) \mathrm{S}$

$81 Y 2(\mathrm{CO}) 3$
87

Decon Kaste to DKITT

.0003

.0000

.0000

.0000

.0000

.0000

.0003

.0003

.0000

.0000

.0003

$.000 J$

.0000

$.000 \mathrm{~J}$

.0000

$.000 \mathrm{~J}$

.0003

$.000 \mathrm{~J}$

.0003

.0000

.0000

.000 J

.000 )

.0000

.0000

.0003

.0003

.0000

.0003

.0001

.000 !

.0003

.000 !)

.0000

.0000

.0000

.000 !

.0000

.0000

.0000

.0000

.0000

.0000

.0000

.0000

.0000
Appendis $\mathrm{H}$

Table 21-16

Page 088 of 173

Date 09/30/82 Rev CO 
MATERIAL BALANCE TABLES

STREAMS ( CONT' U)-

STREAM VANE

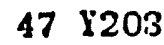

100 Zeollte

$44 \mathrm{Zn}(\mathrm{COOII}) 2$

$54 \mathrm{Zn}(\mathrm{OII}) 2$

$57 \mathrm{ZnO}$

$104 \mathrm{ZrO}$

87

Decon Waste

to DK'IT

.0000

.0000

.0000

.0000

.0003

.0000

322.99

VAPOR FLOH, CFY

LIGLIID FLOI, GPM

DESIG. FLON",

DEXSITY, LBS/FT3

IEMPERATLRE, DEG C

PRESSURE, ATY

PRESSURE, PSIG

PRESSURE, MM HG

PHASE

EXTiAhLPY, PCU/IIR
822.99
.64

63.2352

25.00

.00

LIQUID

7984.71
1.00

88
MilT Vent
to MVC
.0000
$.1316 \mathrm{E}-16$
$.1636 \mathrm{E}-17$
$.1683 \mathrm{E}-80$
.0000
$.1577 \mathrm{E}-19$
4.53
1.07

.0702

34.93

.99

$-.07$

756.20

VAPO?

$-233.05$

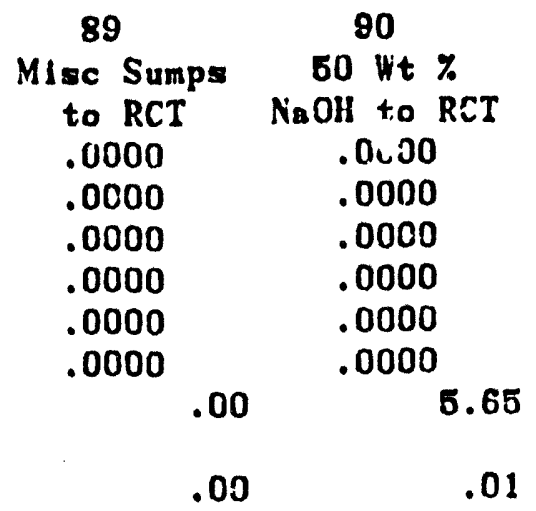

.0000

85.00

1.00

.00

LIQUID

.00
84.9613

25.00

1.00

.00

LIQUID

94.64 
DPSP $80-1083$

MATERIAL BALANCE TABLES

SLUDGE-SUPER.VATE FEED

STREAM NUMBERS -

STREAM NAME

COMPONENT FLOHS, LB/HR

$1 \mathrm{H} 2 \mathrm{O}$

$45 \mathrm{Ag}$

$116 \mathrm{Ag} 20$

184 AgNO3

$61 \mathrm{AgOH}$

74 Al(OH)S

77 A 1203

$75 \mathrm{AlOOH}$

$106 \mathrm{B203}$

$9 \mathrm{Ba}(\mathrm{NO3}) 2$

$95 \mathrm{BaC} 12$

$15 \mathrm{BrO}$

$24 \mathrm{BaS04}$

$66 \mathrm{CO}$

$87 \mathrm{CO} 2$

$142 \mathrm{CO}$ (C14)

$63 \mathrm{Ca}(\mathrm{COOH}) 2$

$120 \mathrm{Ca}(\mathrm{OH}) 2$

$113 \mathrm{Ca} 3(\mathrm{PO} 4) 2$

$20 \mathrm{CaC} 204$

$18 \mathrm{CaCO}$

$78 \mathrm{CaF} 2$

$41 \mathrm{CaO}$

$19 \mathrm{CaSO} 4$

29 Carbon

$26 \mathrm{Co}(\mathrm{COOH}) 2$

$121 \mathrm{Co}(\mathrm{Oll}) 2$

$53 \mathrm{Co}(\mathrm{Oll}) \mathrm{3}$

$59 \mathrm{CoO}$

$99 \mathrm{Cr}(\mathrm{OH}) 3$

$98 \mathrm{Cr} 203$

$42 \operatorname{Cs} 20$

137 Cs20 Semi Vol

$90 \mathrm{CsCOOH}$

$96 \mathrm{CsCl}$

$186 \mathrm{CsCl}$ Semi Vol

8 CsNO3

88 CsResin

$122 \mathrm{Cu}(\mathrm{COOH}) 2$

$52 \mathrm{Cu}(\mathrm{OH}) 2$

$68 \mathrm{Cu} 20$

$64 \mathrm{CuCOOH}$

$180 \mathrm{CuO}$

$13 \mathrm{Fe}(\mathrm{OH}) 3$

80 Fe208
91

92

Neutr Viste SME Condensr

to Tanl: Farm Vent to FAVC

1096.

.0000

.0000

.0000

$.9367 \mathrm{E}-04$

$.8353 \mathrm{E}-01$

.0000

.0000

.1768

$.7695 \mathrm{E}-09$

$.000 J$

.0000

$.6947 \mathrm{E}-03$

$.4272 \mathrm{E}-08$

.847 1E-04

$.2413 \mathrm{E}-19$

.0003

$.1372 \mathrm{E}-01$

$.1731 \mathrm{E}-02$

.187 ?E-02

$.000)$

$.4681 \mathrm{E}-03$

$.000 \mathrm{~J}$

.219 JE-02

.1881E-02

.0001

.237 IE-03

.0001

.000 :

$.178 . J E-02$

.000 !)

.182 IE-05

.0000

$.107 . j E-02$

.526:2E-02

.000 :

$.493 \cdot 3 E-04$

$.000: 3$

$.0001)$

$.516 \cdot \mid \mathrm{E}-03$

.0000

.0000

$.000(1)$

.2023

.00011
Appendix H

Table 21-16

Page 090 of 173

Date 09/50/82 Rev 09 
MAERIAL BALANCE TABLES

SLUDGE-SUPERVATE FEED STREAMS (CONT'D)STKEAM NAME

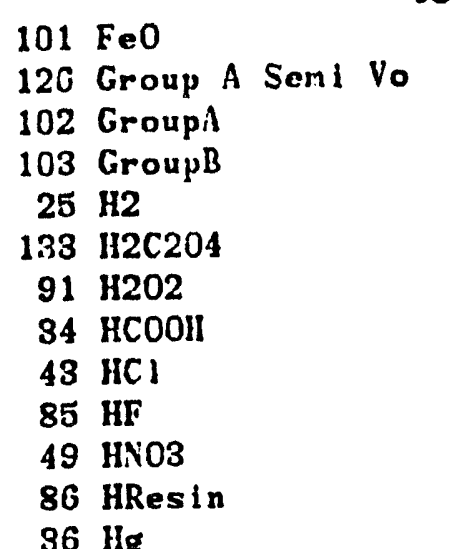

$\begin{array}{ll}91 & 92 \\ & \text { SHE Condensr }\end{array}$

93 SWT Vent to MVC .0000

.0000

$.1581 E-12$

. 4855E- 12

$.9685 \mathrm{E}-32$

.0000

.0000

.0000

.0000

.0000

.0000

.0000

.0000

.0000

$.9481 \mathrm{E}-11$

.0000

.0000

.0000

. 5499E-15

.2385E-14

$.3971 \mathrm{E}-18$

. 5352E-12

.4392E-25

. 1331E-13

$.4801 E-11$

.0000

$.8391 \mathrm{E}-23$

.0000

.0000

8.418

.0000

$.1814 \mathrm{E}-22$

.2539E-03

$.8421 \mathrm{E}-15$

$.2855 \mathrm{E}-15$

$.2206 E-15$

.0000

$.1457 \mathrm{E}-12$

$.1388 \mathrm{E}-19$

$.2853 E-17$

$.2784 E-16$

$.5645 \mathrm{E}-13$

$.1888 E-12$

.0000

.0000 $.1178 \mathrm{E}-10$
94

MFT\#1 Vent

to MVC

.0000

.0000

$.3084 \mathrm{E}-13$

$.9782 \mathrm{E}-18$

$.2266 \mathrm{E}-32$

.0000

.0000

.0000

.0000

.0000

$.4448 \mathrm{E}-03$

.0000

$.9473 E-04$

$.1375 E-11$

$.1740 E-14$

.0000

.0000

.0000

$.1108 E-15$

$.4806 \mathrm{E}-15$

$.8001 E-14$

.1079E- 12

$.8851 E-26$

$.2682 E-14$

$.9674 \mathrm{E}-12$

.0000

$.6832 \mathrm{E}-24$

.0000

.0000

8.418

.0000

$.8880 \mathrm{E}-23$

$.1114 \mathrm{E}-03$

$.6894 \mathrm{E}-16$

$.5754 E-16$

$.4446 E-16$

.0000

.2937E- 18

$.2796 E-20$

$.5748 E-18$

$.6609 E-17$

$.1137 \mathrm{E}-13$

.2796E-18

.0000

.0000

$.2373 E-11$ 
DPSP $80-1033$

MATERIAL BALANCE TABLES SLUDGE-SUPERNATE FEED

STREAMS (CONT'D) STREAM NAME

$7 \mathrm{NaCl}$

$138 \mathrm{NaCl}$ Semi Vol

$69 \mathrm{NaF}$

139 NaF Semi Vol

$12 \mathrm{NaI}$

$125 \mathrm{NaI}$ Semi Vol

$8 \mathrm{NaNO} 2$

$2 \mathrm{NaNO3}$

$4 \mathrm{NaOH}$

87 NaResin

$61 \mathrm{Ni}(\mathrm{COOH}) 2$

$17 \mathrm{Ni}(\mathrm{OH}) 2$

$40 \mathrm{NiO}$

3202

$67 \mathrm{PbO}$

$28 \mathrm{PbSO} 4$

$124 \mathrm{Pd}$

$123 \mathrm{Pd}(\mathrm{OH}) 2$

112 PdNO32

$110 \mathrm{PdO}$

$117 \mathrm{Pu}(\mathrm{COOH}) 4$

$\begin{array}{ll}76 & \mathrm{Pu} 02\end{array}$

$22 \mathrm{RhO2}$

$79 \mathrm{RuO2}$

23 Ru02 Semi Vol

$83 \mathrm{Ru} 04$

$38 \mathrm{SO2}$

$111 \mathrm{SiO2}$

115 Silica Gel

$48 \mathrm{Sr}(\mathrm{COOH}) 2$

$10 \mathrm{Sr}(\mathrm{N} 03) 2$

$127 \mathrm{Sr}$ (OH) 2

$80 \mathrm{SrCOS}$

$46 \mathrm{SrO}$

89 SRRESIN

141 Surfactant

$92 \mathrm{ThO}$

$107 \mathrm{TiO}$

119 Tritium

98 U02

$62 \mathrm{VO}(\mathrm{COOH}) 2$

$16 \mathrm{V02}$ (OII) 2

$27 \mathrm{Y}(\mathrm{COOH}) \mathrm{S}$

$11 \mathrm{Y}(\mathrm{NOS}) 3$

$128 \mathrm{Y}(\mathrm{OH}) \mathrm{S}$

$31 \mathrm{Y2}(\mathrm{CO3}) 3$
91

Neutr Waste SME Condensr

to Tank Farm Vent to FAVC

.7319E-01 .1452E-08

.0000

$.7185 \mathrm{E}-01$

.0000

$.623 . \mathrm{E}-02$

.0000

.0000

8.190

1.624

.0000

.0000

$.899\lfloor E-02$

.0000

$.7529 E-02$

.0000

$.6539 \mathrm{E}-03$

.0000

.0000

.0001

.0000

.0000

$.1700 \mathrm{E}-03$

$.6502 \mathrm{E}-04$

$.8413 E-02$

.0000

.0000

$.1497 \mathrm{E}-08$

.7489

.0000

.0000

$.6867 \mathrm{E}-09$

$.4019 \mathrm{E}-03$

.0000

.0000

.0000

.0000

.2668E-02

$.8396 \mathrm{E}-02$

$.4776 E-09$

.0000

.0000

$.1575 E-01$

.0000

$.4876 \mathrm{E}-09$

.2507E-03

.0000
.0000

$.7678 \mathrm{E}-11$

.0000

.1407 E-09

.0000

.0000

$.4584 \mathrm{E}-07$

.0000

.0000

$.4341 \mathrm{E}-07$

.0000

.0000

14.45

.0000

$.1968 E-08$

.0000

.0000

.0000

.0000

.2018E-11

.5122E-09

. 1957E-09

$.9647 E-09$

.0000

.0000

$.5278 E-20$

$.1579 E-05$

.0000

$.1767 \mathrm{E}-08$

.2064E-14

.0000

.0000

.0000

.0000

.0000

$.8030 \mathrm{E}-08$

.2530E-07

.2448E-10

.0000

$.6615 \mathrm{E}-07$

.0000

$.1208 \mathrm{E}-08$

$.1465 E-14$

.0000

.0000
Appendix $\mathrm{H}$

Table 21-16

Page 092 of 173

Date 09/30/82 Rev 09
93

Si:T Vent

to MVC

$.5627 \mathrm{E}-13$

.0000

$.2976 \mathrm{E}-15$

.0000

$.5454 \mathrm{E}-14$

.0000

.0000

.2856E-07

$.2219 \mathrm{E}-\mathrm{C} 7$

.0000

$.1683 \mathrm{E}-11$

.1687 E-24

.0000

1.033

.0000

$.7629 \mathrm{E}-13$

.0000

.0000

.0000

.0000

$.7821 \mathrm{E}-16$

$.1985 \mathrm{E}-13$

$.7585 \mathrm{E}-14$

$.3739 E-13$

.0000

.0000

$.3715 E-32$

.3596E-11

.0000

$.6849 \mathrm{E}-13$

$.7998 \mathrm{E}-19$

.7543E-26

.0000

.0000

.0000

.0000

$.3112 E-12$

$.4770 \mathrm{E}-14$

.4187 E-16

.0000

.2176E-11

$.2956 \mathrm{E}-24$

$.4682 \mathrm{E}-13$

.5679E-19

.4705E-26

.0000
94

MFT:i l Vent

to MVC

$.11346-13$

.0000

$.5907 E-15$

.0000

$.10908-14$

.0000

.0000

$.4151 E-12$

.0000

.0000

$.3391 \mathrm{E}-12$

$.3400 E-25$

.0000

1.033

.0000

$.1537 E-13$

.0000

.0000

.0000

.0000

$.1576 \mathrm{E}-16$

$.4000 \mathrm{E}-14$

$.152 S E-14$

$.7534 \mathrm{E}-14$

.0000

.0000

$.1191 E-52$

$.7247 E-12$

.0000

$.1380 \mathrm{E}-13$

. 1612E-19

$.1520 \mathrm{E}-26$

.0000

.0000

.0000

.0000

$.6271 \mathrm{E}-13$

$.9612 E-15$

$.2690 \mathrm{E}-16$

.0000

$.4386 \mathrm{E}-12$

$.5957 E-25$

$.9434 E-14$

$.1144 \mathrm{E}-19$

$.9481 E-27$

.0000 . 
MITERIAL BALANCE TABLES

SLUDGE-SUPERNATE FEED

STREAMS (CONT'D)-

STREAM IAME

$\begin{array}{rl}47 & \text { Y203 } \\ 100 & \mathrm{Zeol} \text { ite } \\ 44 & \mathrm{Zn}(\text { COOII) } 2 \\ 54 & \mathrm{Zn}(011) 2 \\ 57 & \mathrm{ZnO}\end{array}$

$104 \mathrm{ZrO2}$

TOTAL FLON, LB/HR

VAPOR FLON, CFM

LIUUID FLOH, GPM

DESIGN FLOW,

DENSITY, LBS/FT3

TEMPERATURE, DEG C

PRESSURE, ATM

PRESSURE, PSIG

PRESSURE, MM IIG

PHISE

EXTHALPY, PCU/HR
91

Neutr Wasto SME Condensr

to Tank Farm Vent to FAVC .0000

$.1705 \mathrm{E}-01 \quad .5133 \mathrm{E}-07$

$.0000 \quad .6382 \mathrm{E}-08$

$.1356 \mathrm{E}-02$

.0000

$.4198 \mathrm{E}-02$

1105.12

2.20

62.7190

50.00

.97

$-.51$

783.86

LIQUID

56136.54
.0000

.0000

$.1265 \mathrm{E}-07$

85.10

24.98

.0568

60.00

.97

$-.51$

783.86

VAPOR

10400.91
93

S:T Vent MFT\#1 Vent to MVC to MVC

.0000

$.1990 \mathrm{E}-11$

$.2474 E-12$

$.2545 \mathrm{E}-25$

.0000

.2385E- 14

4.65

1.13

.0685

87.99

.99

$-.07$

756.20

VAPOR

$-156.34$
.0000

$.4009 \mathrm{E}-12$

$.4985 \mathrm{E}-13$

$.5128 \mathrm{E}-26$

.0000

$.4806 \mathrm{E}-15$

4.58

1.11

.0691

87.99

.99

$-.07$

756.20

VAPOR

$-196.78$ 
DPSP $80-1033$

MATERIAL BALANCE TABLES

SLUDGE-SUPERNATE FEED

STREAM NUMBERS -

STREAM NAME

COMPONENT FLOHS, LB/HR

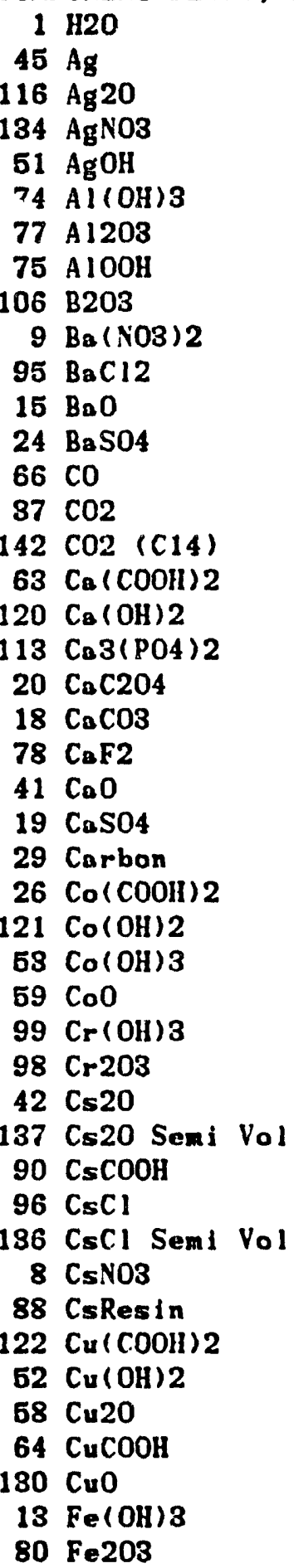

$96 \quad 98$

MFT\#2 "ont Inlot Vapor to M!:C

4093E-01

$.631 \mathrm{GE}-11$

.0000

$.1491 \mathrm{E}-10$

$.8581 E-16$

$.7940 \mathrm{E}-14$

.0000

.0000

$.1195 \mathrm{E}-15$

$.1045 E-21$

.0000

.0000

$.9436 \mathrm{E}-16$

.0000

$.2068 \mathrm{E}-17$

$.7147 E-86$

$.3273 E-14$

$.2998 E-27$

$.2351 E-15$

$.2543 \mathrm{E}-15$

.0000

$.6358 \mathrm{E}-16$

.0000

$.2987 E-15$

$.6421 \mathrm{E}-16$

.516รE-16

$.5187 \mathrm{E}-29$

.0000

.0000

$.2417 \mathrm{E}-15$

.0000

. 1428E-20

.0000

$.1468 \mathrm{E}-15$

$.1528 \mathrm{E}-19$

.0000

$.6693 \mathrm{E}-17$

.0000

$.1104 \mathrm{E}-15$

$.1128 \mathrm{E}-28$

.0000

.0000

.0000

$.1922 \mathrm{E}-13$

.0000
Appendix $H$

Table 21-10

Page 094 of 173

Date 09/30/82 Rev 09 $\begin{array}{cl}99 & 100 \\ \text { Condensate } & \text { MFT Vent } \\ \text { from MVC } & \text { to FAlC }\end{array}$

\section{.2983 \\ 21.61}

.2862E-09

.0000

$.2571 \mathrm{E}-07$

$.4092 \mathrm{E}-08$

$.1942 \mathrm{E}-10$

.0000

.0000

$.2921 \mathrm{E}-12$

$.2551 \mathrm{E}-18$

.0000

.0000

$.2307 \mathrm{E}-12$

$.6387 \mathrm{E}-34$

$.1174 \mathrm{E}-10$

$.4023 \mathrm{E}-20$

$.8004 \mathrm{E}-11$

$.7332 \mathrm{E}-24$

$.5750 \mathrm{E}-12$

$.6219 \mathrm{E}-12$

.0000

$.1555 \mathrm{E}-12$

.0000

$.7305 \mathrm{E}-12$

$.1570 \mathrm{E}-12$

$.1264 \mathrm{E}-12$

$.1268 \mathrm{E}-25$

.0000

.0000

$.5910 \mathrm{E}-12$

.0000

$.3491 E-17$

.0000

$.8589 \mathrm{E}-12$

.3737E- 16

.0000

.1637E-13

.0000

$.2700 \mathrm{E}-12$

$.2759 \mathrm{E}-25$

.0000

.0000

.0000

$.4699 \mathrm{E}-10$

.0000
$.4496 \mathrm{E}-11$

.0010

.0000

. 1039E-08

$.6501 \mathrm{E}-06$

.0000

.0000

$.1377 \mathrm{E}-05$

$.8543 E-14$

.0000

.0000

$.7725 \mathrm{E}-08$

$.2351 \mathrm{E}-24$

$.8367 \mathrm{E}-03$

$.2389 \mathrm{E}-20$

.2680E-0E

.0000

$.1925 \mathrm{E}-07$

. 20\$2E-07

.0000

$.5205 \mathrm{E}-08$

.0000

.2446E-07

. 1808E-07

$.4232 \mathrm{E}-08$

.0000

.0000

.0000

. 1979E-07

.0000

$.1169 E-12$

.0000

. 1202E-07

$.1251 \mathrm{E}-11$

.0000

$.6480 \mathrm{E}-09$

.0000

$.9039 \mathrm{E}-08$

.0000

.0000

.0000

.0000

$.1573 \mathrm{E}-05$ $.0000^{\circ}$ 
DPSP $80-1033$

MITERIAL BALANCE TABLES

SLUDGE-SUPERNATE FEED

STREAMS (CONT'D) -

STREAM NAME

101 FeO
126 Group A Senl Vo
102 GroupA
103 GroupB
25 H2

$133 \mathrm{HI} C 2 \mathrm{CH}$

9111202

84 IICOOHI

$43 \mathrm{IICl}$

$85 \mathrm{HF}$

49 HNO3

86 HResin

$36 \mathrm{Hg}$

$135 \mathrm{HgNO} 2$

$21 \mathrm{HgO}$

$97 \quad 12$

$39 \mathrm{~K} 2 \mathrm{O}$

$131 \mathrm{KMnO4}^{2}$

$118 \mathrm{KNO3}$

105 La203

108 L 120

$65 \mathrm{Mg}(\mathrm{COOH}) 2$

$55 \mathrm{Mg}(\mathrm{OHI}) 2$

$33 \mathrm{MgO}$

$60 \mathrm{Mn}(\mathrm{COOH}) 2$

$132 \operatorname{Mn}\left(\mathrm{NO}_{03}\right) 2$

$129 \mathrm{Mn}(\mathrm{OHI}) 2$

$56 \mathrm{MnO}$

$14 \mathrm{MnO2}$

81 N2

$143 \mathrm{NA} 2 \mathrm{CO}$ (C14)

35 NO

$84 \mathrm{NO2}$

$70 \mathrm{Nn}(\mathrm{HgO}(\mathrm{OH}))$

$94 \mathrm{Na} 2 \mathrm{~B} 407$

$109 \mathrm{Na} 2 \mathrm{C} 204$

$5 \mathrm{Na} 2 \mathrm{CO} 3$

$32 \mathrm{~N} 20$

$71 \mathrm{Na} 2 \mathrm{PuO}_{2}$ (OH) 4

$73 \mathrm{Na} 2 \mathrm{Rh} 04$

$72 \mathrm{Nu} 2 \mathrm{Ru}_{\mathrm{O}} \mathrm{4}$

$6 \mathrm{No} 2 \mathrm{SO}_{4}$

$68 \mathrm{NaAl} 02$

$114 \mathrm{NaBO2}$

$140 \mathrm{NaBO2}$ Semi Vol

$60 \mathrm{NaCOOH}$
Appendix H

Table 21-16

Page 095 of 178

Date 09/80/82 Rov 09

\begin{tabular}{|c|c|c|c|}
\hline 96 & 98 & 99 & 100 \\
\hline $\begin{array}{l}\text { MFT\#2 Vent } \\
\text { to MVC } \\
.0000\end{array}$ & $\begin{array}{c}\text { Inlet Vapor } \\
\text { to MVC } \\
.0000\end{array}$ & $\begin{array}{l}\text { Condensato } \\
\text { from MVC } \\
.0000\end{array}$ & $\begin{array}{l}\text { MFT Vent } \\
\text { to FAVC } \\
.0000\end{array}$ \\
\hline .0000 & .0000 & .0000 & .0000 \\
\hline $.1782 E-15$ & $.8714 \mathrm{E}-12$ & $.4357 E-12$ & . 1459E-07 \\
\hline $.5651 E-15$ & $.2764 E-11$ & $.1882 E-11$ & $.4627 \mathrm{E}-07$ \\
\hline .0000 & $.6968 \mathrm{E}-26$ & $.1200 \mathrm{E}-32$ & $.5673 E-23$ \\
\hline .0000 & .0000 & .0000 & .0000 \\
\hline .0000 & .0000 & .0000 & .0000 \\
\hline .0000 & .0000 & .0000 & $.7839 E-01$ \\
\hline .0000 & .0000 & .0000 & .0000 \\
\hline .0000 & .0000 & .0000 & .0000 \\
\hline $.4291 \mathrm{E}-04$ & $.4730 \mathrm{E}-02$ & $.6146 \mathrm{E}-08$ & .0000 \\
\hline .0000 & .0000 & .0000 & .0000 \\
\hline $.2211 E-03$ & $.4500 E-03$ & $.2250 E-03$ & $.5646 \mathrm{E}-07$ \\
\hline $.1419 E-12$ & $.3216 \mathrm{E}-10$ & $.1608 \mathrm{E}-10$ & .0000 \\
\hline $.1005 E-16$ & $.9521 \mathrm{E}-11$ & $.4761 \mathrm{E}-11$ & $.1203 \mathrm{E}-11$ \\
\hline .0000 & .0000 & .0000 & .0000 \\
\hline .0000 & .0000 & .0000 & .0000 \\
\hline .0000 & .0000 & .0000 & .0000 \\
\hline $.6401 E-18$ & $.8131 E-14$ & $.1565 E-14$ & $.5241 E-10$ \\
\hline $.2777 E-17$ & $.1358 \mathrm{E}-13$ & $.6790 E-14$ & $.4673 E-07$ \\
\hline $.4623 E-16$ & $.2261 E-12$ & $.1130 \mathrm{E}-12$ & $.5389 \mathrm{E}-06$ \\
\hline $.6231 E-15$ & $.8047 E-11$ & $.1524 E-11$ & $.5101 \mathrm{E}-07$ \\
\hline $.5118 E-28$ & $.2501 E-24$ & $.1250 E-24$ & .0000 \\
\hline $.1549 E-16$ & $.7578 E-13$ & $.3789 E-13$ & $.1873 E-06$ \\
\hline $.5589 E-14$ & $.2733 E-10$ & $.1367 E-10$ & $.4576 E-06$ \\
\hline .0000 & .0000 & .0000 & .0000 \\
\hline $.8947 E-26$ & $.1930 \mathrm{E}-22$ & $.9652 \mathrm{E}-23$ & .0000 \\
\hline .0000 & .0000 & .0000 & .0000 \\
\hline .0000 & .0000 & .0000 & 100 \\
\hline 8.418 & & .28 & 188.0 \\
\hline .0000 & .0000 & .0000 & .0000 \\
\hline $.4139 E-31$ & $.5327 \mathrm{E}-17$ & $.2723 E-23$ & $.6108 E-14$ \\
\hline $.1654 \mathrm{E}-06$ & $.6878 E-02$ & $.1030 E-03$ & $.2583 E-04$ \\
\hline $.3983 E-18$ & $.1948 \mathrm{E}-1$. & $.9740 E-15$ & $.3261 E-10$ \\
\hline $.3324 E-18$ & $.1626 \mathrm{E}-1.4$ & $.8129 E-15$ & $.2722 E-10$ \\
\hline $.2568 E-18$ & $.1256 \mathrm{E}-11$ & $.6280 \mathrm{E}-15$ & $.2103 E-10$ \\
\hline .0000 & .0000 & .0000 & .0000 \\
\hline $.1697 E-15$ & $.8298 E-12$ & $.4149 \mathrm{E}-12$ & $.1660 \mathrm{E}-05$ \\
\hline $.1615 E-22$ & $.7900 \mathrm{E}-10$ & $.8950 \mathrm{E}-19$ & $.1322 E-14$ \\
\hline $.8321 E-20$ & $.1624 E-10$ & $.8121 \mathrm{E}-17$ & $.2719 E-12$ \\
\hline $.8241 E-19$ & $.1585 E-1 j$ & $.7924 E-16$ & $.2653 E-11$ \\
\hline $.6572 E-16$ & $.3214 E-12$ & $.1607 \mathrm{E}-12$ & $.6380 \mathrm{E}-08$ \\
\hline $.1615 E-15$ & $.7900 \mathrm{E}-12$ & $.8950 \mathrm{E}-12$ & . 1822E-07 \\
\hline .0000 & .0000 & .0000 & .0000 \\
\hline .0000 & .0000 & .0000 & .0000 \\
\hline $.1371 E-13$ & $.6705 E-10$ & $.3352 E-10$ & . 1220E-05 \\
\hline
\end{tabular}


DPSP $80-1038$

MATERIAL BALANCE TABLES SLUDGE-SUPERNATE FEED STREAMS (CONT'D)STREAM NAME

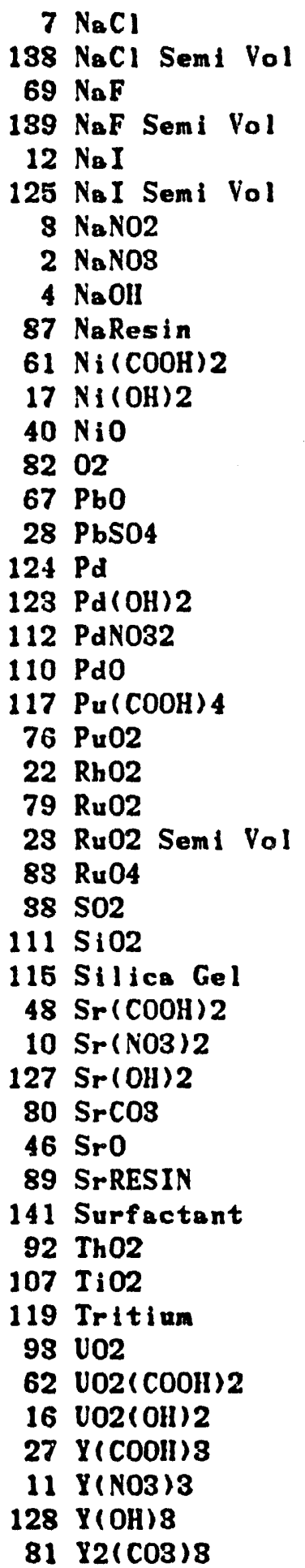

Appendix $H$

Iable 21-16

Page 096 of 173

Date 09/30/82 Rev C9
96

MFT\#2 Vent Inlet Vapor to MVC

$.655 \mathrm{OE}-16$

.0000

$.846 J E-18$

.0003

$.6349 \mathrm{E}-17$

.0003

.0003

$.2393 E-14$

$.000 \mathrm{~J}$

$.000 \mathrm{~J}$

$.1953 \mathrm{E}-14$

$.1961 E-27$

.0003

1.033

$.000 \mathrm{~J}$

$.8881 E-16$

$.000 \mathrm{~J}$

.0000

.000 !

.0000

$.9105 \mathrm{E}-19$

$.2311 E-16$

$.8830 \mathrm{E}-17$

$.4853 E-16$

.0000

.0000

.0000

$.4187 \mathrm{E}-14$

.0000

$.7973 E-16$

$.9311 E-22$

$.8781 E-29$

.0000

.0000

.0000

.0000

$.8623 E-15$

$.5553 \mathrm{E}-17$

$.6323 \mathrm{E}-19$

.0000

$.2584 \mathrm{E}-14$

$.8441 E-27$

$.5450 E-16$

$.6612 \mathrm{E}-22$

. 547SE-29

.0000
99

Condensate

from MVC

$.1602 \mathrm{E}-12$

.0000

$.8472 E-15$

.0000

$.1552 \mathrm{E}-13$

.0000

.0000

$.8786 \mathrm{E}-07$

.0000

.0000

$.4790 \mathrm{E}-11$

$.4803 \mathrm{E}-24$

.0000

$.1747 \mathrm{E}-05$

.0000

$.2172 \mathrm{E}-12$

.0000

.0000

.0000

.0000

$.2226 \mathrm{E}-15$

$.5651 \mathrm{E}-13$

$.2159 \mathrm{E}-13$

$.1064 \mathrm{E}-12$

.0000

.0000

. $5909 \mathrm{E}-33$

$.1024 \mathrm{E}-10$

.0000

$.1950 \mathrm{E}-12$

$.2277 E-18$

$.2147 \mathrm{E}-25$

.0000

.0000

.0000

.0000

$.8859 \mathrm{E}-12$

$.1358 \mathrm{E}-13$

$.6516 \mathrm{E}-16$

.0000

$.6196 E-11$

$.8415 E-24$

$.1333 \mathrm{E}-12$

$.1617 \mathrm{E}-18$

1339E-25

.0000
100

MrT Vent

to FAlC

$.5363 E-08$

.0000

$.28365-10$

.0000

.5198E-09

.0000

.0000

$.1730 E-06$

.0000

.0000

.1604 E-OG

.0000

.0000

56.78

.0000

$.7271 \mathrm{E}-08$

.0000

.0000

.0000

.0000

$.7455 \mathrm{E}-11$

$.1892 \mathrm{E}-08$

$.7230 \mathrm{E}-09$

$.3564 \mathrm{E}-08$

.0000

.0000

$.1029 \mathrm{E}-23$

$.5834 \mathrm{E}-05$

.0000

$.6527 \mathrm{E}-08$

$.7623 E-14$

.0000

.0000

.0000

.0000

.0000

.2966E-07

$.9346 \mathrm{E}-07$

$.2298 \mathrm{E}-10$

.0000

.2074E-06

.0000

$.4462 E-08$

$.5413 E-14$

.0000

.0000 . 
MATERIAL BALANCE TABLES

SLUDGE-SUPERNATE FEED STREAMS (CONT'D)STREAM NAME

47 Y2O3
$100 \mathrm{Zcol} 1$ te
$44 \mathrm{Zn}(\mathrm{COOH}) 2$
$54 \mathrm{Zn}(0 \mathrm{II}) 2$
$57 \mathrm{ZnO}$
$104 \mathrm{ZrO2}$
TOTAL FLOH, LB/HR
VAPOR FLOW, CFM
LIQUID FLOW, GPM
DESIGN FLOW,
DENSITY, LBS/FT3
TEMPERATURE, DEG C
PRESSURE, ATM
PRESSURE, PSIG
PRESSURE, MM HG
PHASE
ENTHALPY, PCU/HR

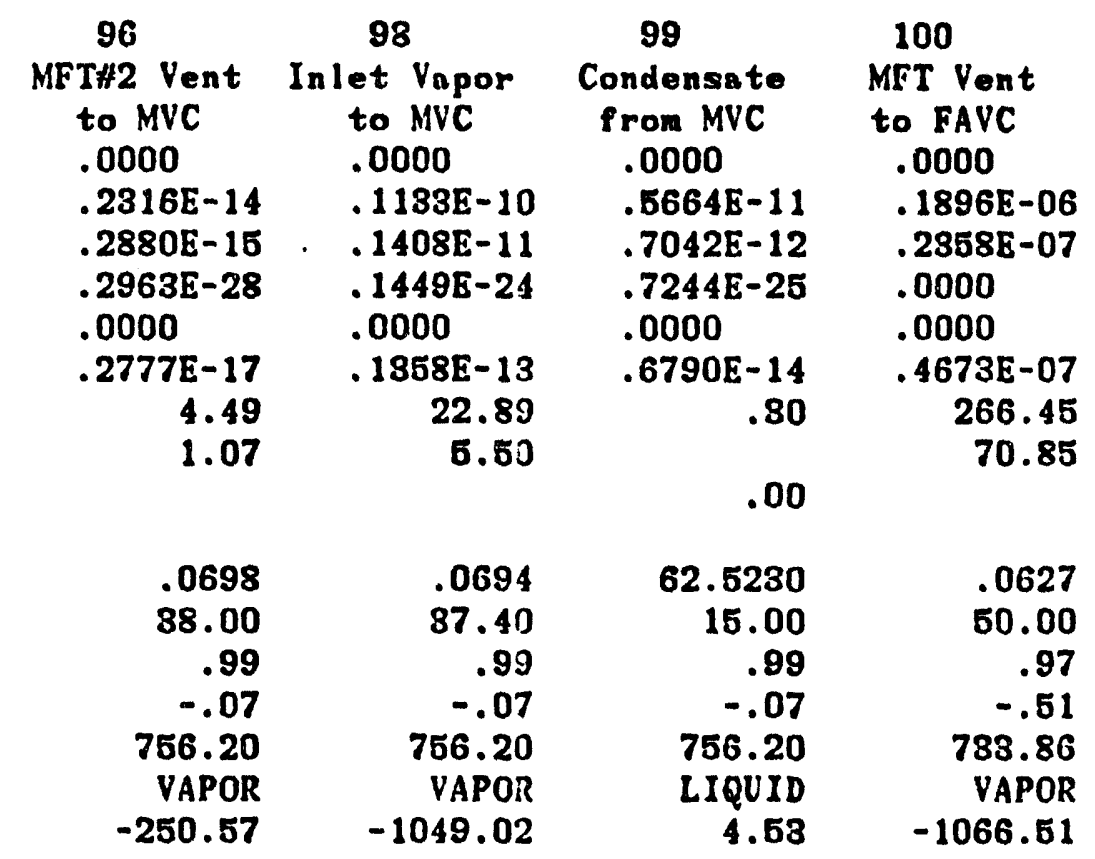


DPSP $80-1033$

MATERIAL BALANCE TABLES SLUDGE-SUPERNATE FEED STREAM NUMBERS STREAM NAME

COMPONENT FLOIIS, LB/IIR



Appendix $\mathrm{H}$

Table 21-16

Page 098 of 173

Date 09/30/82 Rev C9 
MITERIAL BALANCE TABLES

Date 09/80/82 Rev 09

\section{SLUDGE-SUPERNATE FEED}

STRLAMS (CONT'D)-

STREAM NAME

101 Fco
126 Group A Seni Vo
102 GroupA
103 Group $B$
25 II

$133 \mathrm{H} 2 \mathrm{C2O4}$

$91 \mathrm{H202}$

34 HCOO!I

43 IICI

$85 \mathrm{HF}$

49 INO3

86 IIResin

$36 \mathrm{Hg}$

135 HgN032

$21 \mathrm{HgO}$

$97 \quad 12$

$39 \mathrm{~K} 20$

$131 \mathrm{KMnO4}$

$118 \mathrm{KNO3}$

$105 \mathrm{~L} .203$

108 Li20

$65 \mathrm{Mg}(\mathrm{COOH}) 2$

$55 \mathrm{Mg}(\mathrm{OII}) 2$

$33 \mathrm{MgO}$

$60 \mathrm{Mn}(\mathrm{COOH}) 2$

$132 \mathrm{Mn}(\mathrm{NO}) 2$

$129 \mathrm{Mn}(\mathrm{OII}) 2$

$56 \mathrm{MnO}$

$14 \mathrm{MnO2}$

$81 \mathrm{~N} 2$

$143 \mathrm{NA2CO3}$ (C14)

$85 N 0$

$84 \mathrm{NO2}$

$70 \mathrm{Na}(\mathrm{HgO}(\mathrm{OH}))$

$94 \mathrm{Na} 2 \mathrm{~B} 407$

$109 \mathrm{Na} 2 \mathrm{C2O} 4$

$5 \mathrm{Na} 2 \mathrm{CO}$

$32 \mathrm{Na} 20$

$71 \mathrm{Na} 2 \mathrm{Pu} 02$ (OII) 4

$73 \mathrm{Na} 2 \mathrm{RhO4}$

$72 \mathrm{Na} 2 \mathrm{RuO}_{4}$

$6 \mathrm{Na} 2 \mathrm{SO}$

$68 \mathrm{NaA} 102$

$114 \mathrm{NaBO2}$

$140 \mathrm{NaBO2}$ Semi Vol

$50 \mathrm{NaCOOH}$
102

Steam Cond

to Creok

.0000

.0000

.0000

.0000

.0000

.0000

.0000

.0000

.0000

.0000

.0000

.0000

.0000

.0000

.0000

.0000

.0000

.0000

.0000

.0000

.0000

.0000

.0000

.0000

.0000

.0000

.0000

.0000

.0000

.0000

.0000

.0000

.0000

.0000

.0000

.0000

.0000

.0000

.0000

.0000

.0000

.0000

.0000

.0000

.0000

.0000
103

RCT Vent

to PVVS

.0000

.0000

.2394a-09

$.1012 \pi-09$

.8528 -05

.0000

.0000

.0000

.0000

.0000

.0000

.0000

.0000

.0000

$.7750:-10$

.0000

.0000

.0000

$.4794 \mathrm{Z}-08$

. $1021 \mathrm{i}-09$

$.1665 \mathrm{I}-08$

.0000

$.5695:-10$

.5641:-09

.0000

.0000

$.48331:-08$

.0000

.0000

170.9

.0000

$.2462 \mathrm{i}:-03$

$.8975 !:-02$

$.7147 !:-13$

$.27081:-08$

.1924 T:-08

.0000

$.6160 \mathrm{r}:-08$

$.2899 !:-17$

$.69591:-15$

$.58151:-14$

$.11791:-10$

$.28991:-10$

.0000

.0000

$.5329[-07$
104

Off Gas Cond Process Coll

eor Exit Gas Exh to Tunn!

.0000

.0000

. 1288E-05

$.6866 \mathrm{E}-08$

.5827

.0000

.0000

.0000

.0000

.0000

.0000

.0000

.0000

.0000

$.6845 \mathrm{E}-06$

.7755E-04

.0000

.0000

$.7777 E-11$

$.6934 \mathrm{E}-08$

.7923E-07

.7570E-08

.0000

.2779E-07

$.6790 E-07$

.0000

.0000

.0000

.0000

1896.

.0000

.9700

.1565

$.4839 \mathrm{E}-11$

$.1462 E-06$

$.8120 E-11$

.0000

.2930E-06

. 1962E- 15

$.4034 E-18$

$.3937 \mathrm{E}-12$

.7984E-09

. 1962E-08

.0000

.0000

$.1810 \mathrm{E}-06$
.0000

.0000

$.2404 E-10$

$.7556 \mathrm{E}-10$

$.8062 E-05$

.0000

.0000

.0000

.0000

.0000

.0000

.0000

.0000

$.8618 \mathrm{E}-13$

.2543E- 12

.0000

.0000

.0000

$.1608 \mathrm{E}-10$

. 1683E-09

$.1921 \mathrm{E}-08$

$.8320 \mathrm{E}-10$

$.6676 \mathrm{E}-13$

$.6739 E-09$

.7463E-09

.0000

$.1469 \mathrm{E}-10$

.0000

.0000

.4375Et:06

.0000

.0000

.0000

$.5325 \mathrm{E}-13$

.2825E-11

$.6458 \mathrm{E}-11$

.0000

.5969E-08

.2160E-17

$.4440 \mathrm{E}-15$

$.4833 E-14$

$.8786 \mathrm{E}-11$

$.2160 \mathrm{E}-10$

.0000

.0000

.2108E-08 
DPSP $80-1083$

MATERIAL BALANCE TABLES

SLUDGE-SLPERNATE FEED

STREAMS ( CONT'D) -

STREAM NAME

$7 \mathrm{NaCl}$

$138 \mathrm{NaCl}$ Semi $\mathrm{Val}$

$69 \mathrm{NaF}$

$139 \mathrm{NaF} \mathrm{Semi} \mathrm{Vol}$

$12 \mathrm{NaI}$

$125 \mathrm{NaI}$ Semi Vol

$8 \mathrm{NaNO2}$

2 NaNOS

$4 \mathrm{NaOll}$

87 NaResin

$61 \mathrm{Ni}(\mathrm{COOH}) 2$

$17 \mathrm{Ni}$ (OII) 2

$40 \mathrm{NiO}$

8202

$67 \mathrm{PbO}$

$28 \mathrm{PbS} 04$

$124 \mathrm{Pd}$

$123 \mathrm{Pd}(\mathrm{OII}) 2$

112 PdNOS2

$110 \mathrm{PdO}$

$117 \mathrm{Pu}(\mathrm{COOH}) 4$

$76 \mathrm{Pu} 02$

$22 \mathrm{Rh} 02$

$79 \mathrm{Ru} 02$

23 Ru02 Semi Vol

$83 \mathrm{Ru} 04$

$38 \quad 502$

$111 \mathrm{Si} 02$

115 Silica Gel

$48 \mathrm{Sr}(\mathrm{COOII}) 2$

$10 \mathrm{Sr}(\mathrm{N} 03) 2$

$127 \mathrm{Sr}(\mathrm{OII}) 2$

$80 \mathrm{SrCO3}$

46 Sro

89 SrRESIN

141 Surfostant

$92 \mathrm{ThO}$

$107 \mathrm{Ti} 02$

119 Tritium

98 V02

$62 \mathrm{VO2}(\mathrm{COOII}) 2$

$16 \mathrm{VO}(\mathrm{OH}) 2$

$27 \mathrm{Y}(\mathrm{COOH}) 3$

$11 \mathrm{Y}(\mathrm{NOS}) 3$

$128 \mathrm{Y}(\mathrm{OH}) 3$

$81 Y 2(\mathrm{COS}) 3$

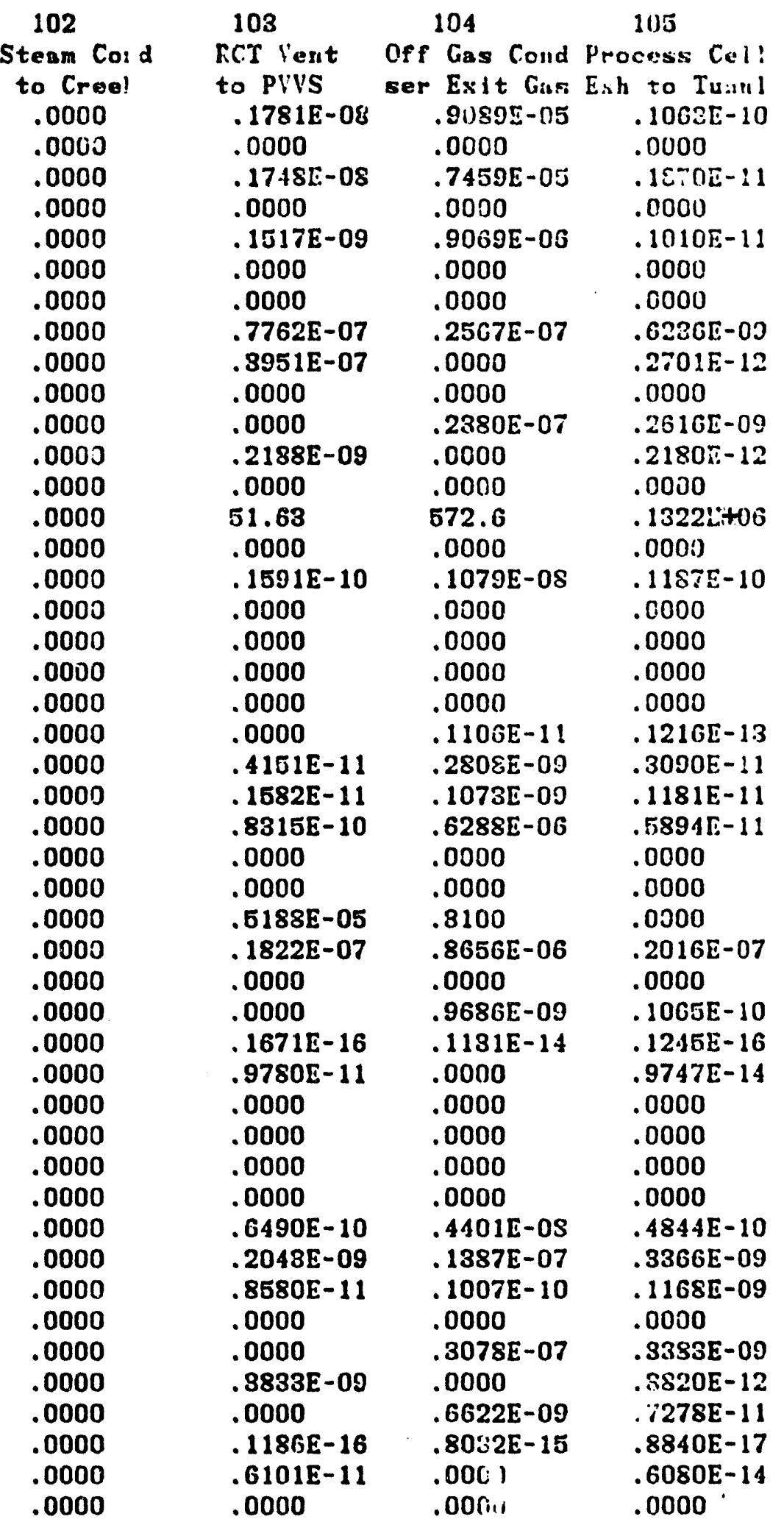

appendix II

Tabie 21-10

Page 100 of $17 \%$

Date 03/30/Sa R. 19 
Disp $80-1033$

MATERIAL BaLANCE TABLISS SL.VDGE-SUPLRNATE FEED STREAMIS (CONT'D)STREAM NAME

47 Y2.03

100 Zeolite

$44 \mathrm{Zn}($ CCOII) 2

$5.1 \mathrm{Zn}(\mathrm{OHi}) 2$

$57 \mathrm{ZnO}$

$104 \mathrm{ZrO2}$

TOTAL FLOW, LB/HR

VAPOR FLOK, CFM

LIQUID FLOH, GPM DESIGY FLOH, DENSITY, LBS/FTB TEMPERITURE, DEG C PRESSIRE, ATM PRESSURE, PSIG PIESSURE, MA HG PHASE

ERTILALPY, PCU/HR
Appendix H

Table 21-16

Page 101 of 178

Date 09/80/82 Rev 09

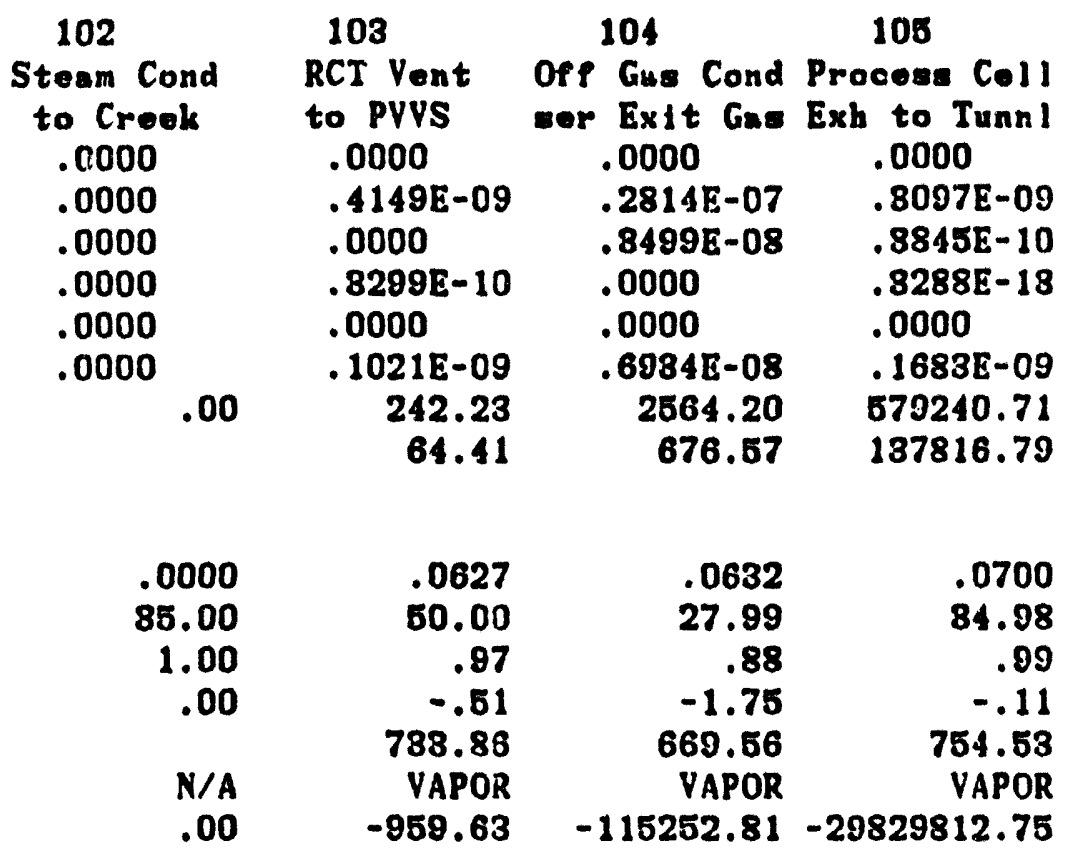


DPSP $80-1038$

MATERIAL BALANCE TABLES

SLUDGE-SUPERNATE FEED

STREAM NUMBERS -

STREAM NAME COMPONENT FLOWS, LB/IIR

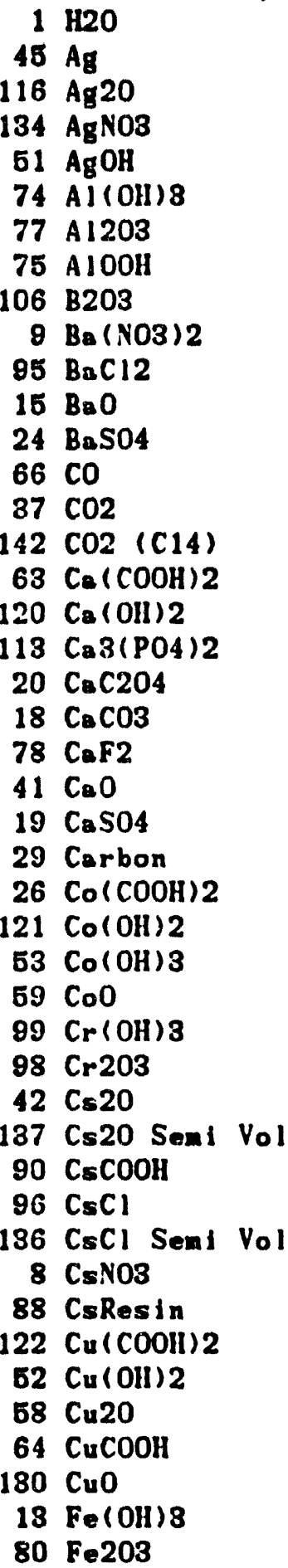

106

Appendix II

Table 21-16

Page 102 of 178

Date $09 / 30 / 82$ Rev 09

yele from Ru Absorber I2 Absorber Spent Hish Tank Farm Accumulation Accunulation Mifit to SHiT

\begin{tabular}{|c|c|c|c|}
\hline 8.121 & .0000 & .0000 & .1546 \\
\hline .0000 & .0000 & .0000 & .0000 \\
\hline .0000 & .0000 & .0000 & .0000 \\
\hline .0000 & .0000 & .0000 & .0000 \\
\hline $.9367 \mathrm{E}-04$ & $.7707 E-10$ & $.3853 E-10$ & $.386 \Omega E-03$ \\
\hline $.8856 \mathrm{E}-01$ & $.4823 E-07$ & $.2412 E-07$ & . $2.413 i-03$ \\
\hline .0000 & .0000 & .0000 & .0000 \\
\hline .0000 & .0000 & .0000 & .0000 \\
\hline .1768 & . 1022E-06 & . $108 \mathrm{E}-07$ & 3630E-05 \\
\hline $.8869 \mathrm{E}-11$ & $.6388 \mathrm{E}-15$ & $.3169 \mathrm{E}-15$ & $.3171 E-11$ \\
\hline .0000 & .0000 & .0000 & .0000 \\
\hline .0000 & .0000 & .0000 & .0000 \\
\hline $.6947 \mathrm{E}-03$ & $.5732 \mathrm{E}-09$ & $.2866 \mathrm{E}-09$ & $.2868 \mathrm{E}-05$ \\
\hline $.2148 E-10$ & .0000 & .0000 & $.5493 E-26$ \\
\hline $.1747 \mathrm{E}-06$ & .0000 & .0000 & $.3435 E-12$ \\
\hline .0000 & .0000 & .0000 & $.6865 E-23$ \\
\hline .0000 & . 1988E-07 & $.9942 E-08$ & $.9948 E-04$ \\
\hline $.1372 E-01$ & .0000 & .0000 & $.9113 i-17$ \\
\hline $.1781 \mathrm{E}-02$ & $.1428 \mathrm{E}-08$ & $.7142 \mathrm{E}-03$ & $.71102-05$ \\
\hline . $1872 \mathrm{E}-112$ & $.1545 E-08$ & $.7724 E-09$ & $.7729 E-0 J$ \\
\hline .0000 & .0000 & .0000 & .0000 \\
\hline $.4681 \mathrm{E}-03$ & $.8862 E-09$ & . 1931E-09 & . 1932E-0J \\
\hline .0000 & .0000 & .0000 & .0000 \\
\hline $.2199 \mathrm{E}-02$ & $.1815 \mathrm{E}-08$ & $.9073 E-00$ & $.9078 E-05$ \\
\hline $.1881 E-02$ & . 1342E-08 & $.6708 \mathrm{E}-09$ & . $1051 E-05$ \\
\hline .0000 & .0000 & .0000 & . 1571F-05 \\
\hline $.287 \cdot 4 E-03$ & .0000 & .0000 & $.1576 E-18$ \\
\hline .000() & .0000 & .0000 & .0000 \\
\hline .0000 & .0000 & .0000 & .0000 \\
\hline $.1780 E-02$ & $.1468 E-08$ & $.7341 \mathrm{E}-09$ & $.7346 E-05$ \\
\hline .0000 & .0000 & .0000 & .0000 \\
\hline $.1824 \mathrm{E}-05$ & $.8672 E-14$ & $.4336 E-14$ & $.4339 \mathrm{E}-10$ \\
\hline .0000 & .0000 & .0000 & .0000 \\
\hline $.6411 \mathrm{E}-05$ & $.8915 E-09$ & . 4458E-09 & $.4460 \Sigma-05$ \\
\hline $.2646 \mathrm{E}-04$ & $.5229 E-0 G$ & $.2614 \mathrm{E}-06$ & $.4645 E-09$ \\
\hline .0000 & .0000 & .0000 & .0000 \\
\hline .2482E-06 & $.4065 E-10$ & $.2033 E-10$ & $.2034 E-06$ \\
\hline .0000 & .0000 & .0000 & .0000 \\
\hline .00011 & $.670 G E-09$ & .3358E-09 & $.8355 E-05$ \\
\hline $.516 \cdot 1 \mathrm{E}-03$ & .0000 & .0000 & $.8429 G-1 \delta$ \\
\hline .0000 & .0000 & .0000 & .0000 \\
\hline .0000 & .0000 & .0000 & .0000 \\
\hline .0000 & .0000 & .0000 & .0000 \\
\hline .2023 & . 1167E-06 & .5837E-07 & $.5841 E-03$ \\
\hline .0000 & .0000 & .0000 & $.0000^{\circ}$ \\
\hline
\end{tabular}


MATERIAL BALANCE TABLES

Dete 09/80/82 Rov 09 SLUDGE-SUPERNATE FEED STREAMS ( CONT'D)STREAM NAME

101 Foo
126 Group A Semi Vo
102 GroupA
103 Group B
25 H2

$\begin{array}{llll}106 & 107 & 108 & 109\end{array}$

Rocycle Prom Ru Absorber 12 Abeorber Spent Wash

Tank Form Accumulation Accumulation MWWT to SRAT $\begin{array}{llll}.0000 & .0000 & .0000 & .0000\end{array}$

$\begin{array}{llll}.0000 & .0000 & .0000 & .0000\end{array}$

$.0841 E-02 \quad .6438 E-06 \quad .8219 E-06 \quad .0416 E-05$

$.4161 \mathrm{E}-02 \quad .8488 \mathrm{E}-08 \quad .1716 \mathrm{E}-08 \quad .1718 \mathrm{E}-04$

$\begin{array}{llll}.8507 \mathrm{E}-09 & .0000 & .0000 & .1094 \mathrm{E}-24\end{array}$

$\begin{array}{llll}.0000 & .0000 & .0000 & .0000\end{array}$

$\begin{array}{llll}.0000 & .0000 & .0000 & .0000\end{array}$

9111202

84 нCOOH

$48 \mathrm{HCl}$

$85 \mathrm{HF}$

49 IIN03

86 liResin

$86 \mathrm{Hg}$

$135 \mathrm{HgNO} 2$

$21 \mathrm{HgO}$

9712

$39 \mathrm{~K} 20$

$131 \mathrm{KM} 04$

$118 \mathrm{KNO3}$

105 La203

$108 \mathrm{~L} 120$

$65 \mathrm{Mg}(\mathrm{COOH}) 2$

.0000

.0000

.0000

.0000

.0000

.0000

$.0000 \quad .0000$

$.0000 \quad .0000$

.0000

.0000

.0000

.0000

$.8185 E-02$

.0000

$.8172 E-06$

.0000

$.0000 \quad .0000$

.0000

.0000

$.9908 \mathrm{E}-08$

$.4198 \mathrm{E}-02$

$.8888 \mathrm{E}-11$

$.8467 E-08$

$.6844 \mathrm{E}-01$

$.8961 E-07$

.0000

$55 \mathrm{Mg}(\mathrm{Oll}) 2$

$33 \mathrm{MgO}$

$60 \mathrm{Mn}(\mathrm{COOH}) 2$

.2841E-02

$.8785 E-08$

.0000

$.2096 \mathrm{E}-04$

.0000

.0000

.0000

.0000

.0000

.0000

.0000

.0000

.0000

.0000

.0000

.0000

. 1686E-06

$.8048 \mathrm{E}-06$

$.7677 E-04$

.0000

.0000

.0000

.0000

.0000

$.1944 E-11$

$.1946 \mathrm{E}-07$

.1734E-08

$.8488 \mathrm{E}-07$

.1981E-07

$.1405 \mathrm{E}-05$

.1892E-08

$.1894 E-04$

.2318E-01

.0000

.0000

.1986

$129 \mathrm{Mn}(\mathrm{OHI}) 2$

$56 \mathrm{MnO}$

$14 \mathrm{MnO} 2$

81 N2

143 NA2CO3 (C14)

$85 \mathrm{NO}$

$81 \mathrm{NO2}$

$70 \mathrm{Na}(\mathrm{HgO}(\mathrm{Oll}))$

.0000

.0000

$.1554 E-17$

$.1390 \mathrm{E}-07 \quad .6948 \mathrm{E}-08 \quad .4709 \mathrm{E}-06$

$.8395 E-07$

.0000

. 1698E-07

$.1699 \mathrm{E}-08$

.0000

.0000

.0000

.0000

.0000

.0000

$.1200 E-15$

.0000

.0000

$.6563 \mathrm{E}-04$

.0000

.0000

.0000

.0000

.0000

.0000

.0000

.0000

.0000

$.8889 \mathrm{E}-05$

.2761E-09

.0000

$.2487 \mathrm{E}-04$

.0000

.0000

.0000

$.1477 \mathrm{E}-07$

$.2410 E-11$

.0000

$.8865 \mathrm{E}-16$

$.6597 E-08$

$.1210 E-11$

$.4072 \mathrm{E}-12$

$.7808 E-07$

$.8654 E-07$

$.1211 E-07$

$.8975 E-03$

$.1560 \mathrm{E}-11$

$.7801 \mathrm{E}-12$

$.1010 \mathrm{E}-07$

.0000

.2532

.0000

.0000

$82 \mathrm{Na} 20$

71 Na2Pu02(OH) 4

$.6990 \mathrm{E}-12$

$.1465 \mathrm{E}-06$

$.7824 E-07$

.7806E-08

.0000

$.9812 \mathrm{E}-16$

$.4906 \mathrm{E}-16$

$.5156 E-05$

. 1232E-09

$.2017 E-13$

$.1009 \mathrm{E}-13$

$.4909 \mathrm{E}-12$

$72 \mathrm{Na} 2 \mathrm{RuO4}$

$.1968 \mathrm{E}-12$

$.9842 E-13$

$.1009 E-09$

. 1202E-08

$.8992 E-09$

$.9840 \mathrm{E}-09$

.2437E-05

. 1996E-09

$.9812 \mathrm{E}-09$

$.4906 E-09$

. 1997E-05

.6990E-05

.0000

.0000

$.4909 \mathrm{E}-05$

$114 \mathrm{NaBO2}$

.0000

.0000

.0000

.0000

.0000

$50 \mathrm{NaCOOH}$

$.1101 E-01$

$.9051 \mathrm{E}-07$

$.4626 E-07$

$.4167 E-08$ 
DPSP $80-1033$

MATERIAL BALANCE TABLES

SL.UDGE-SUPERNATE FEED

STREAMS (CONT'D)-

STREAM NAME

$7 \mathrm{NaCl}$

$188 \mathrm{NaCl}$ Soml Vol

$69 \mathrm{NaF}$

$189 \mathrm{NaF}$ Semt Vol

$12 \mathrm{NaI}$

$125 \mathrm{NaI}$ Semi Vol

$8 \mathrm{NaNO2}$

2 NaNO3

$4 \mathrm{NaOH}$

87 NaResin

$61 \mathrm{Ni}(\mathrm{COOH}) 2$

$17 \mathrm{Ni}(\mathrm{OH}) 2$

$40 \mathrm{NiO}$

8202

$67 \mathrm{PbO}$

$28 \mathrm{PbS} 04$

$124 \mathrm{Pd}$

$123 \mathrm{Pd}(\mathrm{OH}) 2$

$112 \mathrm{PdNO} 02$

$110 \mathrm{PdO}$

$117 \mathrm{Pu}(\mathrm{COOH}) 4$

$76 \mathrm{Pu} 02$

$22 \mathrm{RhO}^{2}$

$79 \mathrm{RuO2}$

23 Ru02 Semi Vol

$88 \mathrm{Ru} 04$

$88 \mathrm{SO2}$

$1115 i 02$

115 Sillca Gel

$48 \mathrm{Sr}(\mathrm{COOII}) 2$

$10 \mathrm{Sr}(\mathrm{NOB}) 2$

$127 \mathrm{Sr}(\mathrm{OH}) 2$

$80 \mathrm{SrCO}$

$46 \mathrm{Sr} 0$

89 SrRESIN

141 Surfactant

92 Th02

107 Ti02

119 Tritium

$98 \mathrm{U} 02$

$62 \mathrm{VO2}(\mathrm{COOH}) 2$

$16 \mathrm{~V} 02(\mathrm{OH}) 2$

$27 \mathrm{Y}(\mathrm{COOH}) 8$

$11 Y(\mathrm{~N} 08) 8$

$128 Y(\mathrm{OH}) 8$

$81 Y 2(\cos ) 8$
Appendix H

Tablo 21-16

Page 104 of 173

Date 03/30/82 Rev 09

$\begin{array}{llll}106 & 107 & 108 & 109\end{array}$

Recycle from Ru Absorber I2 Absorber Spent linsh

Tank Farm Accumulation Accunulation MhTi to SR:T .8680E-03 .4545E-05 .2272E-05 .1901E-05

$\begin{array}{llll}.0000 & .0000 & .0000 & .0000\end{array}$

$.8613 \mathrm{E}-03 \quad .8730 \mathrm{E}-05 \quad .1865 \mathrm{E}-05 \quad .1053 \mathrm{E}-07$

.0003

$.8131 E-04$

.0003

.0003

$.1601 \mathrm{E}-01$

$.8163 E-02$

.0003

.0003

$.8991 \mathrm{E}-02$

$.000 \mathrm{~J}$

.878 UE-04

.0000

.658 JE-03

.000 J

.0003

.0003

.0000

.0000

. 170JE-03

.6502E-04

$.8413 E-02$

.0000

.0000

$.7520 \mathrm{E}-11$

.7481

.0000

.0000

$.8453 E-11$

$.4010 \mathrm{E}-03$

.0000

.0000

.0000

.0000

. 266UE-02

.8896E-02

$.8540 E-11$

.0000

.0000

.1575E-01

.0000

.2452E-11

.2507E-03

.0000

$.4535 \mathrm{E}-06$

.0000

.0000

$.1283 E-07$

.0000

.0000

$.1190 \mathrm{E}-07$

.0000

.0000

.0000

.0000

$.5395 \mathrm{E}-09$

.0000

.0000

.0000

.0000

.0000

.0000

$.2267 E-06$

.1920 E-06

.0000

.0000

.0000

.0000

$.6417 \mathrm{E}-08$

$.6286 \mathrm{E}-04$

.0000

.0000

$.0000 \quad .0000$

$.5949 E-08$

.0000

.0000

$.5953 \mathrm{E}-04$

.5970E- 17

.0000

.0000

.0000 .

$.1955 \mathrm{E}-05$

.2697E-09

.0000

.2699E-05

.0000

.0000

.0000

.0000

.0000

.0000

.0000

$.5531 \mathrm{E}-12$

$.2765 \mathrm{E}-12$

.0000

$.1404 E-09$

$.7019 \mathrm{E}-10$

$.2707 E-08$

$.5364 \mathrm{E}-10$

.2682E-10

$.7024 E-06$

.8144E-06

.0000

.0000

.0000

$.4328 \mathrm{E}-06$

.0000

$.4848 E-09$

.1572E-06

.0000

.0000

.0000

.2164E-06

.0000

$.2684 \mathrm{E}-06$

$.1323 \mathrm{E}-05$

.0000

.0000

$.1289 E-25$

$.1272 E-03$

.0000

$.2421 E-09$.2423E-05

$.5656 \mathrm{E}-15$

.0000

.0000

.0000

.0000

.0000

.2201E-08

$.2828 E-15$

$.2830 \mathrm{E}-11$

.0000

.0000

.0000

.0000

.0000

.2609E- 18

.0000

.0000

.0000

.0000

$.1100 \mathrm{E}-08$

$.1101 E-04$

$.6934 \mathrm{E}-08$

.0000

.0000

.8467E-08

.0000

.0000

. 1688E-06

$.6624 \mathrm{E}-14$

$.1539 \mathrm{E}-07$

$.7695 \mathrm{E}-08$

.0000

.0000

.0000

$.7700 E-04$

$.8311 \mathrm{E}-09$

$.1655 \mathrm{E}-09$

$.1046 \mathrm{E}-16$

$.4016 \mathrm{E}-15$

$.2008 \mathrm{E}-15$

$.1656 \mathrm{E}-05$

.0000

.0000

.0000

$.1665 \mathrm{E}-18$

.0000

.0000 
SiTERIAI. BALANCE TABLES

Date 09/30/82 Rev 09 SLUDGE-SUPERNATE FEED STREAMS ( CONT'D)STREAM NAME

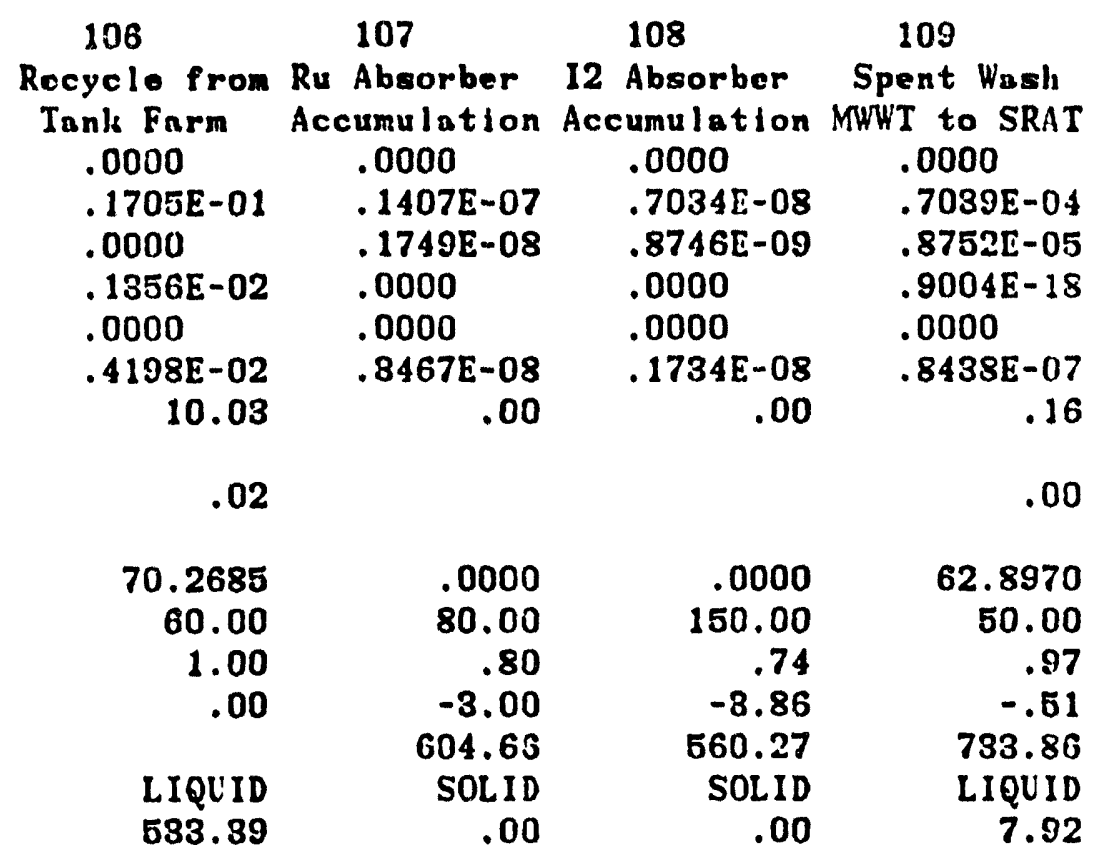

$47 \quad 1203$

100 Zeolite

$44 \mathrm{Zn}($ cooll $) 2$

$54 \mathrm{Zn}(\mathrm{Oli}) 2$

$57 \mathrm{ZnO}$

$104 \mathrm{Zr} 02$

TOTAL FLOW, LB/HR

VAPOR FLOI:, CFM

LIQUID FLOW', GPM

DESIGK FLOW,

DENSITi, LBS/ET3

TEMPERITLRE, DEG C

PRESSURE, ATM

PRESSUIE, PSIG

PRESSURE, MAI IIG

PIIASE

583.89

.00

7.92 
DPSP $80-1038$

MATERIAL BALANCE TARLES

SLUDGE-SUPERNATE FEED

STREAM NUMBERS -

STREAM NAME

COMPONENT FLOWS, LB/HR

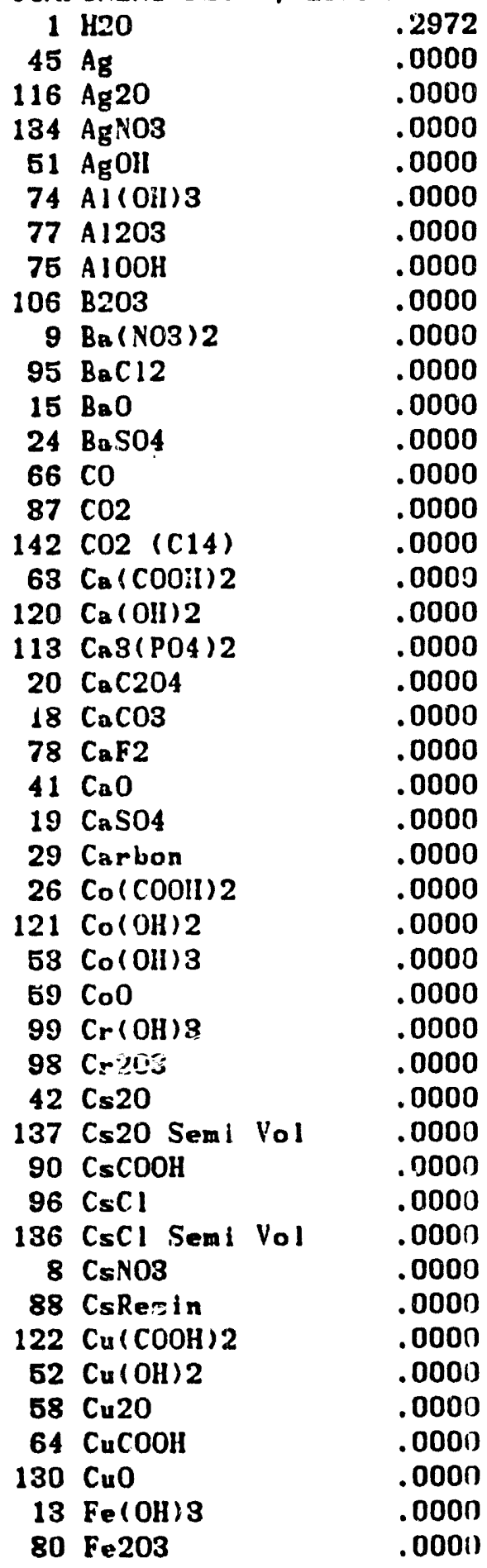

Appendix II

Table 21-10

Pnge 106 of 173

Date $09 / 80 / 82$ Rev 09 $\begin{array}{lccc}110 & 111 & 112 & 113 \\ \text { Water Wash } & \text { MHir Vent } & \text { Hg from MUNi.T A A S Sparge } \\ \text { to MUWT } & \text { to FAVC } & \text { to MAHT } & \text { to MIVI }\end{array}$

$\begin{array}{lll}.2177 & .9847 E-02 & .1325 E-02 \\ .8201 E-07 & .1593 E-01 & .0000 \\ .0000 & .0000 & .0000 \\ .0000 & .0000 & .0000\end{array}$

$.8259 E-14 \quad .2160 E-09 \quad .000$ C

$.5159 \mathrm{E}-09 \quad .1537 \mathrm{E}-0.4 \quad .00 \mathrm{~J} J 0$

$.0000 \quad .0000 \quad .0000$

$.0000 \quad .0000 \quad .0000$

$.7761 \mathrm{E}-11 \quad .2512 \mathrm{E}-00 \quad .0000$

$.6779 E-17 \quad .2020 E-12 \quad .0000$

$\begin{array}{lll}.0000 & .0000 & .0000\end{array}$

$\begin{array}{lll}.0000 & .0000 & .0000\end{array}$

$.6131 \mathrm{E}-11 \quad .1826 \mathrm{E}-06 \quad .0000$

$\begin{array}{lll}.4455 E-20 & .8498 E-27 & .0000\end{array}$

$\begin{array}{lll}.1108 \mathrm{E}-07 & .2188 \mathrm{E}-13 \quad .0000\end{array}$

$.2214 \mathrm{E}-18 \quad .4372 \mathrm{E}-24 \quad .0000$

$.2127 \mathrm{E}-09 \quad .6336 \mathrm{E}-05 \quad .0000$

$.1948 \mathrm{E}-22 \quad .5804 \mathrm{E}-18 \quad .0000$

$.1528 \mathrm{E}-10 \quad .4551 \mathrm{E}-06 \quad .0000$

$.1652 \mathrm{E}-10 \quad .4922 \mathrm{E}-0 \mathrm{G} \quad .0000$

$\begin{array}{lll}.0000 & .0000 & .0000\end{array}$

$.4131 \mathrm{E}-11 \quad .1231 \mathrm{E}-06 \quad .0000$

$\begin{array}{lll}.0000 & .0000 & .0000\end{array}$

$.1941 \mathrm{E}-10 \quad .5782 \mathrm{E}-0 \mathrm{G} \quad .0000$

$.4172 E-11 \quad .1243 E-05 \quad .0000$

$.3358 \mathrm{E}-11 \quad .1000 \mathrm{E}-06 \quad .0000$

$.3370 \mathrm{E}-24 \quad .1004 \mathrm{E}-10 \quad .0000$

$\begin{array}{lll}.0000 & .0000 & .0000\end{array}$

$\begin{array}{lll}.0000 & .0000 & .0000\end{array}$

$.1570 \mathrm{E}-10 \quad .4678 \mathrm{E}-06 \quad .0050$

$\begin{array}{lll}.0000 & .0000 & .0000\end{array}$

$.9275 E-16 \quad .2763 E-11 \quad .0000$

$\begin{array}{lll}.0000 & .0000 & .0000\end{array}$

$\begin{array}{lll}.9536 \mathrm{E}-11 & .2841 \mathrm{E}-06 \quad .0000\end{array}$

$.9929 E-15 \quad .2958 E-10 \quad .0000$

$\begin{array}{lll}.0000 & .0000 & .0000\end{array}$

$.4348 E-12 \quad .1295 E-07 \quad .0000$

$\begin{array}{lll}.0000 & .0000 & .0000\end{array}$

$.7173 E-11 \quad .2137 E-06 \quad .0000$

$.7330 \mathrm{E}-24 \quad .2184 \mathrm{E}-10 \quad .0000$

$\begin{array}{lll}.0000 & .0000 & .0000\end{array}$

$.0000 \quad .0000 \quad .0000$

$\begin{array}{lll}.0000 & .0000 & .0000\end{array}$

$.1249 \mathrm{E}-08 \quad .3720 \mathrm{E}-04 \quad .0000$

$.0000 \quad .0000 \quad .0000$. 
DISP SO-1033

MATEPIAL BALANCE TABLES

SLUDGE-SUPERNATE FEED

STREAYS (CONT'D)-

STREAM NAME

$101 \mathrm{Fe} 0$

126 Group A Semi Vo

102 GroupA

103 Group B

$25 \mathrm{H2}$

133 112C2O4

9111202

$34 \mathrm{ICOOH}$

$43 \mathrm{HCl}$

$85 \mathrm{HF}$

49 HNO3

80 HRes in

$36 \mathrm{Hg}$

135 Hg:032

$21 \mathrm{HIgO}$

97 I2

$39 \mathrm{~K} 20$

$131 \mathrm{kMn} 04$

$118 \mathrm{KNOO}$

$105 \quad \mathbf{L} 203$

108 Li20

$65 \mathrm{Mg}(\mathrm{COOHI}) 2$

$55 \mathrm{Mg}(\mathrm{OII}) 2$

$33 \mathrm{MgO}$

$60 \mathrm{Nin}(\mathrm{COOH}) 2$

$1 \mathrm{~s} 2 \mathrm{Mn}(: 03) 2$

$129 \mathrm{Mn}(\mathrm{Oli}) 2$

$56 \mathrm{MnO}$

$14 \mathrm{MnO2}$

$81 \mathrm{N2}$

$143 \quad N 12 C 03$ (C14)

$35 \mathrm{NO}$

$84 \mathrm{N02}$

$70 \mathrm{Na}\left(\mathrm{Hg}_{\mathrm{G}} \mathrm{O}(\mathrm{OH})\right)$

$94 \mathrm{Na} 2 \mathrm{~B} 407$

$100 \mathrm{~N} 2 \mathrm{C2O4}$

$5 \mathrm{Na} 2 \mathrm{CO} 3$

$32 \mathrm{Na} 20$

$71 \mathrm{Na}_{2} \mathrm{Pu}_{\mathrm{O}} 02(\mathrm{OH}) 4$

$73 \mathrm{Na}_{2} \mathrm{RhO4}_{1}$

72 Na2Ru0.1

$6 \mathrm{~N}$ 2 $2 \mathrm{SO} 01$

$68 \mathrm{NaA} 102$

$114 \mathrm{NaBO2}$

140 NaBO2 Semi Vol

$50 \mathrm{NaCOOII}$
110

Vinter Winsh

to MUT'T

.0000

.0000

.0000

.0000

.0000

.0000

.0000

.0000

.0000

.0000

.0000

.0000

.0000

.0000

.0000

.0000

.0000

.0000

.0000

.0000

.0000

.0000

.0000

.0000

.0000

.0000

.0000

.0000

.0000

.0000

.0000

.0000

.0000

.0000

.0000

.0000

.0000

.0000

.0000

.0000

.0000

.0000

.0000

.0000

.0000

.0000
Appendix $\mathrm{H}$

Table 21-16

Page 107 of 173

Date 09/30/82 Rev 09 
DPSP $80-1033$

MATERIAL BALANCE TABLES SLUDGE-SUPERNATE FEED STREAMS ( CONT'D) -

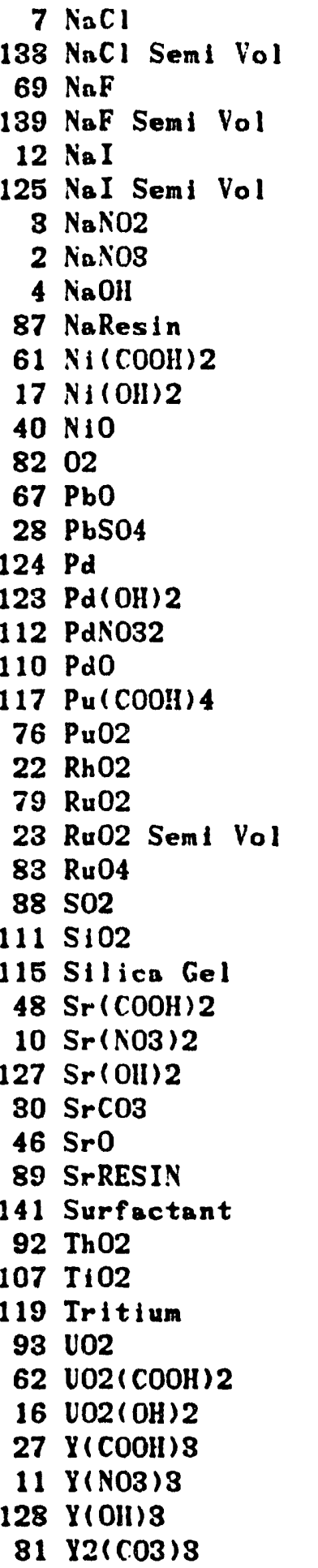

\section{STREAM NAME}

\section{STREAM NAME}

$138 \mathrm{NaCl}$ Seml Vol

$69 \mathrm{NaF}$
$12 \mathrm{NaI}$
$25 \mathrm{NaI}$ Semi Vol
$4 \mathrm{NaOH}$

$40 \mathrm{NiO}$

$67 \mathrm{PbO}$

$28 \mathrm{PbSO}$

112 PdNO32

$117 \mathrm{Pu}(\mathrm{COOH}) 4$

23 RuO2 Semi Vol

88502

1115102

115 Silica Gel

$10 \mathrm{Sr}(\mathrm{NO}) 2$

$30 \mathrm{SrCO3}$

$46 \mathrm{Sr} 0$

89 SrRESIN
92 Th02
$93 \mathrm{VO2}$
$62 \mathrm{VO} 2(\mathrm{COOH}) 2$
$16 \mathrm{VO2}(\mathrm{OH}) 2$
$11 \mathrm{Y}(\mathrm{NO3}) 3$
$81 \mathrm{x}(\mathrm{cos}) \mathrm{s}$

\begin{tabular}{|c|c|c|c|}
\hline \multirow{3}{*}{$\begin{array}{l}110 \\
\text { Water Wash }\end{array}$} & & \multicolumn{2}{|c|}{$\begin{array}{l}\text { Appendix } U \\
\text { Iable } 21-16 \\
\text { Page } 108 \text { of } 173 \\
\text { Date } 09 / 30 / \varepsilon \text { ? Rev 09 }\end{array}$} \\
\hline & 111 & 112 & 113 \\
\hline & MiriT Vent & $\mathrm{H}_{\mathrm{g}}$ from NWiT & Alr Sparf̧e \\
\hline to .0000 & $.4256 E-11$ & to .1268E-03 & .0000 \\
\hline .0000 & .0000 & .0000 & .0000 \\
\hline .0000 & $.2251 \mathrm{E}-13$ & $.6706 \mathrm{E}-\mathrm{CO}$ & .0000 \\
\hline .0000 & .0000 & .0000 & .0000 \\
\hline .0000 & $.4125 \mathrm{E}-12$ & $.1229 E-07$ & .0000 \\
\hline .0000 & .0000 & .0000 & .0000 \\
\hline .0000 & .0000 & .0000 & .0000 \\
\hline .0000 & $.1344 E-09$ & $.4004 E-05$ & .0000 \\
\hline .0000 & .0000 & .0000 & .0000 \\
\hline .0000 & .0000 & .0000 & .0000 \\
\hline .0000 & $.1273 E-09$ & $.3701 E-05$ & .0000 \\
\hline .0000 & $.1276 \mathrm{E}-22$ & $.3802 E-13$ & .0000 \\
\hline .0000 & .0000 & .0000 & .0000 \\
\hline .0000 & 1.051 & $.1245 E-05$ & $.1834 \mathrm{E}-01$ \\
\hline .0000 & .0000 & .0000 & .0000 \\
\hline .0000 & $.5770 E-11$ & $.1719 E-06$ & .0000 \\
\hline .0000 & .0000 & .0000 & .0000 \\
\hline .0000 & .0000 & .0000 & .0000 \\
\hline .0000 & .0000 & .0000 & .0000 \\
\hline .0000 & .0000 & .0000 & .0000 \\
\hline .0000 & $.5916 E-14$ & $.1762 E-09$ & .0000 \\
\hline .0000 & $.1502 E-11$ & $.4473 E-07$ & .0000 \\
\hline .0000 & $.5737 E-12$ & $.1709 E-07$ & .0000 \\
\hline .0000 & $.2828 E-11$ & $.8425 E-07$ & .0000 \\
\hline .0000 & .0000 & .0000 & .0000 \\
\hline .0000 & .0000 & .0000 & .0000 \\
\hline .0000 & $.8501 E-20$ & $.8208 \mathrm{E}-27$ & .0000 \\
\hline .0000 & $.2720 E-09$ & $.8104 E-05$ & .0000 \\
\hline .0000 & .0000 & .0000 & .0000 \\
\hline .0000 & $.5180 E-11$ & $.1543 E-06$ & .0000 \\
\hline .0000 & $.6049 E-17$ & $.1802 E-12$ & .0000 \\
\hline .0000 & $.5705 E-24$ & $.1700 E-19$ & .0000 \\
\hline .0000 & .0000 & .0000 & .0000 \\
\hline .0000 & .0000 & .0000 & .0000 \\
\hline .0000 & .0000 & .0000 & .0000 \\
\hline .0000 & .0000 & .0000 & .0000 \\
\hline .0000 & $.2354 \mathrm{E}-10$ & $.7012 E-06$ & .0000 \\
\hline .0000 & $.3608 E-12$ & $.1075 E-07$ & .0000 \\
\hline .0000 & $.9328 E-14$ & $.4219 E-15$ & .0000 \\
\hline .0000 & .0000 & .0000 & .0000 \\
\hline .0000 & $.1646 \mathrm{E}-09$ & $.4904 \mathrm{E}-05$ & .0000 \\
\hline .0000 & $.2236 \mathrm{E}-22$ & $.6661 \mathrm{E}-18$ & .0000 \\
\hline .0000 & $.8541 \mathrm{E}-11$ & $.1055 E-06$ & .0000 \\
\hline .0000 & $.4296 E-17$ & $.1280 E-12$ & .0000 \\
\hline .0000 & $.3559 E-24$ & $.1060 \mathrm{E}-10$ & .0000 \\
\hline .0000 & .0000 & .0000 & $.0000^{\circ}$ \\
\hline
\end{tabular}

Appendix

Table 21-16

Page 108 of 173

Date 09/30/82 Rev 09

$$
\text { a. } 54
$$


DISP $80-1033$

MATERIAL BALANCI TABLES SLEDGE-SUPERNATE FETD STRWAYS (CONT'D)ST:EAM YAME

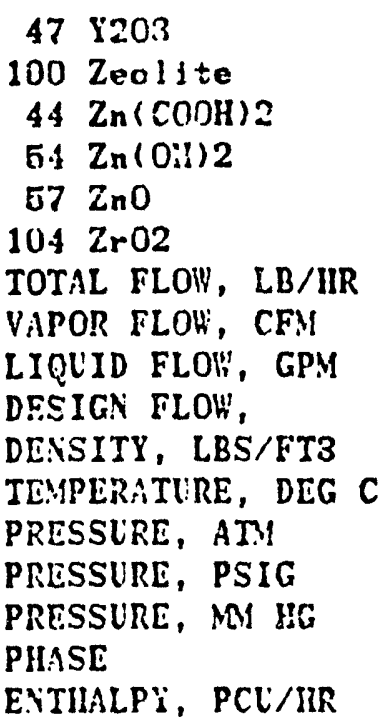

110

Water Wash

to MWWT

.0000

.0000

.0000

.0000

.0000

.0000

.80

.00

62.4300

25.00

1.00

.00

LIQUID

7.63
Append 1 X II

Table 21-16

Page 109 of 173

Date 03/80/82 Rev 09
111 Milit Vert to FAV : .0000 $.1505 \pi-09$ $.18715-10$ $.1925:-23$ .0000

$.1804 \mathrm{~T}-12$

4.75

1.24

.0639

49.99

.97

$-.51$

733.86

VIPOR

$-132.88$
112

Hg from MNWT to MAHT

.0000

$.4483 E-05$

$.5574 E-06$

$.6734 \mathrm{E}-19$

.0000

$.6874 \mathrm{E}-08$

1.37

.00

773.1066

50.00

.97

$-.51$

783.86

LIQUID

2.78
113

Air Spargo

to MAWT

.0000

.0000

.0000

.0000

.0000

.0000

.08

.02

$.0 \% 06$

85.00

1.00

.00

VAPOR

$-4.14$ 
DPSP $80-1038$

MATERIAL BALANCE TABLES

SLUDGT-SUPERNATE FEED

STREAM NUMBERS -

STREAM NAME

COMPONENT FLOHS, LB/HR

\begin{tabular}{|c|c|c|}
\hline \multirow{3}{*}{$\begin{array}{r}1 \\
45 \\
16\end{array}$} & \multirow{2}{*}{\multicolumn{2}{|c|}{1120}} \\
\hline & & \\
\hline & \\
\hline 34 & \multirow{2}{*}{\multicolumn{2}{|c|}{34 AgN03 }} \\
\hline 51 & & \\
\hline 74 & \multicolumn{2}{|l|}{ Al(OH) 3} \\
\hline 77 & \multicolumn{2}{|l|}{ Al203 } \\
\hline 75 & \multicolumn{2}{|l|}{ A100H } \\
\hline 06 & \multirow{2}{*}{\multicolumn{2}{|c|}{$\begin{array}{l}\mathrm{B} 203 \\
\mathrm{Ba}\left(\mathrm{NO}^{2}\right) 2\end{array}$}} \\
\hline & & \\
\hline 95 & \multicolumn{2}{|l|}{$\mathrm{BaCl} 2$} \\
\hline 15 & \multirow{2}{*}{\multicolumn{2}{|c|}{$\begin{array}{l}\mathrm{BaO} \\
\mathrm{BaS04}\end{array}$}} \\
\hline 24 & & \\
\hline 66 & \multirow{2}{*}{\multicolumn{2}{|c|}{$\begin{array}{l}\mathrm{CO} \\
\mathrm{CO} 2\end{array}$}} \\
\hline 87 & & \\
\hline 42 & \multicolumn{2}{|l|}{$\mathrm{CO} 2$ ( C14) } \\
\hline 63 & \multirow{4}{*}{\multicolumn{2}{|c|}{$\begin{array}{l}\mathrm{Ca}(\mathrm{COOH}) 2 \\
\mathrm{Ca}(\mathrm{OH}) 2 \\
\mathrm{Ca} 3(\mathrm{PO})_{2} 2 \\
\mathrm{CaC} 204\end{array}$}} \\
\hline 20 & & \\
\hline 13 & & \\
\hline 20 & & \\
\hline 18 & \multicolumn{2}{|l|}{$\mathrm{CaCO} 3$} \\
\hline 78 & \multicolumn{2}{|l|}{ CaF2 } \\
\hline 41 & \multicolumn{2}{|l|}{$\mathrm{CaO}$} \\
\hline 19 & \multicolumn{2}{|l|}{$\mathrm{CaS04}$} \\
\hline 29 & \multirow{2}{*}{\multicolumn{2}{|c|}{$\begin{array}{l}\text { Carbon } \\
\text { Co }(\mathrm{COOH}) 2\end{array}$}} \\
\hline 26 & & \\
\hline 21 & \multicolumn{2}{|l|}{$\mathrm{Co}(\mathrm{OHI}) 2$} \\
\hline Б3 & \multicolumn{2}{|l|}{$\mathrm{Co}(\mathrm{OHI}) 3$} \\
\hline 59 & $\mathrm{CoO}$ & \\
\hline 99 & $\mathrm{Cr}(\mathrm{OH}) 3$ & \\
\hline 98 & Cr203 & \\
\hline 42 & Cs2O & \\
\hline 87 & Cs20 Semi & Vol \\
\hline 90 & $\mathrm{CsCOOH}$ & \\
\hline 96 & $\mathrm{CsCl}$ & \\
\hline & CsCl Sem I & Vol \\
\hline & CsNO3 & \\
\hline 88 & CsResin & \\
\hline & $\mathrm{Cu}(\mathrm{COOH}) 2$ & \\
\hline 52 & $\mathrm{Cu}(\mathrm{OH}) 2$ & \\
\hline $\begin{array}{l}58 \\
64\end{array}$ & $\begin{array}{l}\mathrm{Cu} 20 \\
\mathrm{CuCOOH}\end{array}$ & \\
\hline & $\mathrm{CuO}$ & \\
\hline $\begin{array}{l}18 \\
80\end{array}$ & $\begin{array}{l}\mathrm{Fe}(\mathrm{OH}) 3 \\
\mathrm{Fe} 203\end{array}$ & \\
\hline
\end{tabular}

$114: 15$

MAVT Vent HNIS WASH

to NivC

.10

.1092

$.3175 \mathrm{E}-09$

$.000 J$

$.4920 \mathrm{E}-07$

$.4903 E-15$

$.3063 \mathrm{E}-10$

.0003

.0003

$.4603 E-12$

$.402 j E-18$

.0007

$.000 \mathrm{~J}$

$.364 \mathrm{JE}-12$

$.3498 E-27$

$.1276 \mathrm{E}-05$

$.4372 \mathrm{E}-24$

. 1263E- 10

$.1157 \mathrm{E}-23$

$.0071 E-12$

$.9810 \mathrm{E}-12$

.0000

.2453E- 12

.0000

.1152E- 11

$.2477 E-: 2$

$.1994 \mathrm{E}-12$

$.2001 E-25$

.0000

.0000

$.9324 \mathrm{E}-: 2$

.0000

$.6507 \mathrm{E}-17$

.0000

$.566 ? \mathrm{E}-12$

. 589!5E-16

.0000

.258?.?-13

.0000

$.4250 \mathrm{E}-12$

$.435:$ : -25

.00011

.00011

.0001

$.741: E-10$

.0000 from MALT

.1515

.0000

.0000

$.2322 E-01$

. 2314E-09

$.1446 \mathrm{E}-04$

.0000

.0000

$.2175 \mathrm{E}-06$

$.1900 \mathrm{E}-12$

.0000

.0000

$.1718 \mathrm{E}-06$

$.4855 \mathrm{E}-33$

. $5553 \mathrm{E}-10$

$.1903 \mathrm{E}-28$

$.5960 \mathrm{E}-05$

$.5460 \mathrm{E}-18$

$.4281 \mathrm{E}-06$

$.4631 E-06$

.0000

$.1158 \mathrm{E}-00$

.0000

$.5439 E-06$

$.1169 \mathrm{E}-06$

$.0411 E-07$

$.9444 \mathrm{E}-20$

.0000

.0000

$.4401 \mathrm{E}-06$

.0000

.2599E-11

.0000

$.2672 \mathrm{E}-06$

$.2783 \mathrm{E}-10$

.0000

.1219E-07

.0000

.2010E-06

.2054E-19

.0000

.0000

.0000

$.3499 \mathrm{E}-04$

.0000
Appendis $\mathrm{H}$

Table 21-16

Pnge 110 of 173

Date 09/30/32 Rev 0J
117

Alr Sparge

to SME

.3735

.0000

.0000

.0000

.0000

.0000

.0000

.0000

.0000

.0000

.0000

.0000

.0000

.0000

.0000

.0000

.0000

.0000

.0000

.0000

.0000

.0000

.0000

.0000

.0000

.0000

.0000

.0000

.0000

.0000

.0000

.0000

.0000

.0000

.0000

.0000

.0000

.0000

.0000

.0000

.0000

.0000

.0000

.0000

.0000
118

Steam to

S:IE Coil

.0005

.0000

.0000

.0000

.0000

.0000

.0000

.0000

.0000

.0000

.0000

.0000

.0000

.0000

.0000

.0000

.0000

.0000

.0000

.0000

.0000

.0000

.0000

.0000

.0000

.0000

.0000

.0000

.0000

.0000

.0000

.0000

.0000

.0000

.0000

.0000

.0000

.0000

.0000

.0000

.0000

.0000

.0000

.0000

.0000 
DPSP 80-1033

MATERIAI. BALANCE TABLES

SLLDCE-SUPER.YATE FEED STREAMS (CONT'D)STREAM NAME

$101 \mathrm{FeO}$

126 Group A Seril Vo

102 GroupA

103 GroupB

$25 \mathrm{H12}$

133 II2C204

$91 \mathrm{H2O}$

$84 \mathrm{HCOOH}$

$43 \mathrm{HCl}$

$85 \mathrm{HF}$

49 HNO3

86 HResin

$36 \mathrm{Hg}$

$135 \mathrm{Hg} N 032$

$21 \mathrm{HgO}$

$97 \mathrm{I2}$

39 K20

$131 \mathrm{KMinO4}$

$118 \mathrm{KNO3}$

$105 \mathrm{La} 203$

108 Li 20

$65 \mathrm{Mg}(\mathrm{COOH}) 2$

$55 \mathrm{Mg}(\mathrm{Oll}) 2$

$33 \mathrm{MgO}$

$60 \mathrm{Mn}(\mathrm{COOH}) 2$

$132 \mathrm{Mn}(\mathrm{NO}))_{2}$

$129 \mathrm{Mn}(\mathrm{Oll}) 2$

$56 \mathrm{MnO}$

$14 \mathrm{MnO2}$

$81 \mathrm{N2}$

$143 \mathrm{NA2CO3}$ (C14)

$35 \mathrm{NO}$

$84 \mathrm{NO2}$

$70 \mathrm{Na}(\mathrm{HgO}(\mathrm{OH}))$

$94 \mathrm{Na} 2 \mathrm{B4O}$

$108 \mathrm{Na2C204}$

$5 \mathrm{Na} 2 \mathrm{COS}$

$32 \mathrm{Na} 20$

$71 \mathrm{Na2Pu02(011)4}$

$73 \mathrm{Na} 2 \mathrm{RhO4}$

$72 \mathrm{Na} 2 \mathrm{Ru} 04$

$6 \mathrm{Na} 2 \mathrm{SO} 4$

$68 \mathrm{NaAlO} 2$

$114 \mathrm{NaBO2}$

140 NaB02 Semi Vol

$50 \mathrm{NiCOOH}$
114

MAll' Vont

to MVC

.0000

.0000

$.6874 \mathrm{E}-12$

$.2180 \mathrm{E}-11$

$.6968 \mathrm{E}-26$

.0000

.0000

.0000

.0000

.0000

$.4242 E-02$

.0000

$.1270 \mathrm{E}-03$

$.3064 \mathrm{E}-10$

.3862E-13

.0000

.0000

.0000

.2469E-14

$.1071 \mathrm{E}-13$

$.1783 \mathrm{E}-12$

$.2404 \mathrm{E}-11$

.1973E-24

.5977E-13

.2156E-10

.0000

$.1523 E-22$

.0000

.0000

8.479

.0000

.5327E-17

$.6508 \mathrm{E}-02$

$.1536 \mathrm{E}-14$

$.1282 E-14$

.9907 E- 15

.0000

$.6545 \mathrm{E}-12$

$.6231 \mathrm{E}-19$

$.1281 \mathrm{E}-16$

. 1250E-15

.2535E- 12

$.6231 \mathrm{E}-12$

.0000

.0000

$.6289 \mathrm{E}-10$
Appendix $H$

Table 21-16

Page 111 of 178

Date 09/30/82 Rev 09 
DPSP $80-1038$

MATERIAL BALANCE TABLES

SLUDGE-SUPERNATE FEED

STREAMS (CONT'D)-

STREAM NAME

$7 \mathrm{NeCl}$

$188 \mathrm{NaCl}$ Seml Vol

$69 \mathrm{NaF}$

189 NaF Semi Vol

$12 \mathrm{NeI}$

125 NaI Seml Vol

$8 \mathrm{NaNO2}$

$2 \mathrm{NaN03}$

$4 \mathrm{NaOH}$

87 NaResin

$61 \mathrm{Ni}(\mathrm{COOH}) 2$

$17 \mathrm{Ni}(\mathrm{OH}) 2$

$40 \mathrm{NiO}$

8202

$67 \mathrm{PbO}$

$28 \mathrm{PbSO} 04$

$124 \mathrm{Pd}$

$128 \mathrm{Pd}(\mathrm{OH}) 2$

$112 \mathrm{PdNOS2}$

$110 \mathrm{PdO}$

$117 \mathrm{Pu}(\mathrm{COOH}) 4$

$76 \mathrm{Pu} 02$

$22 \mathrm{RhO2}$

$79 \mathrm{Ru} 02$

23 Ru02 Semi Vol

$83 \mathrm{Ru} 04$

$38 \mathrm{SO2}$

111 Si02

115 Silice Gel

$48 \mathrm{Sr}(\mathrm{COOH}) 2$

$10 \mathrm{Sr}(\mathrm{N} 03) 2$

$127 \mathrm{Sr}(\mathrm{OH}) 2$

$80 \mathrm{SrCO}$

46 Sro

89 SrRESIN

141 Surfactant

92 ThO2

$107 \mathrm{TiO}$

119 Tritium

$93 \mathrm{~V} 02$

$62 \mathrm{VO2}(\mathrm{COOII}) 2$

$16 \mathrm{VO2}(\mathrm{OH}) 2$

$27 \mathrm{Y}(\mathrm{COOH}) \mathrm{S}$

$11 \mathrm{Y}(\mathrm{NO3}) 3$

$128 \mathrm{Y}(\mathrm{OH}) 8$

81 Y2(CO3)3
114

MaYT Vont

to MVC

$.2527 \mathrm{E}-12$

.0000

$.1836 \mathrm{E}-14$

.0000

$.2449 E-13$

.0000

.0000

$.7979 \mathrm{E}-11$

.0000

.0000

$.7556 \mathrm{E}-11$

$.7577 E-24$

.0000

1.051

.0000

$.8426 \mathrm{E}-12$

.0000

.0000

.0000

.0000

$.8512 E-15$

$.8915 \mathrm{E}-18$

$.8406 \mathrm{E}-18$

$.1679 E-12$

.0000

.0000

$.8208 \mathrm{E}-27$

$.1615 E-10$

.0000

$.8075 \mathrm{E}-12$

$.8592 E-18$

$.8387 E-25$

.0000

.0000

.0000

.0000

$.1898 \mathrm{E}-11$

$.2142 E-13$

$.1704 \mathrm{E}-15$

.0000

$.9774 \mathrm{E}-11$

$.1828 E-23$

$.2102 \mathrm{E}-\mathrm{i} 2$

$.2550 E-\div 8$

$.2113 E-25$

.0000
115

HNO3 WASH

from MAWT

$.1198 E-06$

.0000

$.6308 \mathrm{E}-09$

.0000

$.1156 \mathrm{E}-07$

.0000

.0000

$.3766 E-05$

.0000

.0000

. 3567E-05

$.8576 \mathrm{E}-18$

.0000

$.2846 \mathrm{E}-05$

.0000

. 1617E-06

.0000

.0000

.0000

.0000

. 1658E-09

$.4208 \mathrm{E}-07$

. 1608E-07

.7925E-07

.0000

.0000

$.3715 \mathrm{E}-82$

.7628E-05

.0000

$.1452 \mathrm{E}-06$

$.1695 \mathrm{E}-12$

$.1599 \mathrm{E}-19$

.0000

.0000

.0000

.0000

$.6597 E-06$

. 1011E-07

$.2366 \mathrm{E}-15$

.0000

$.4613 \mathrm{E}-05$

$.6266 \mathrm{E}-18$

$.9924 \mathrm{E}-07$

$.1204 E-12$

$.9974 E-20$

.0000
117

Air Sparge

to SME

.0000

.0000

.0000

.0000

.0000

.0000

.0000

.0000

.0000

.0000

.0000

.0000

.0000

5.158

.0000

.0000

.0000

.0000

.0000

.0000

.0000

.0000

.0000

.0000

.0000

.0000

.0000

.0000

.0000

.0000

.0000

.0000

.0000

.0000

.0000

.0000

.0000

.0000

.0000

.0000

.0000

.0000

.0000

.0000

.0000

.0000
118

Steam to

SME Coil

.0000

.0000

.0000

.0000

.0000

.0000

.0000

.0000

.0000

.0000

.0000

.0000

.0000

.0000

.0000

.0000

.0000

.0000

.0000

.0000

.0000

.0000

.0000

.0000

.0000

.0000

.0000

.0000

.0000

.0000

.0000

.0000

.0000

.0000

.0000

.0000

.0000

.0000

.0000

.0000

.0000

.0000

.0000

.0000

.0000

.0000 . 
DPSP $80-1033$

MATERIAL BALANCE TABLES

SLUDGL-SLPERNATE FEED STREAMS (CONT'D)STREAM NAME

$\begin{array}{rl}47 & \text { Y203 } \\ 100 & \mathrm{Zeol} \text { le } \\ 44 & \mathrm{Zn}(\mathrm{COOll}) 2 \\ 54 & \mathrm{Zn}(011) 2 \\ 57 & \mathrm{Zn} 0 \\ 104 & \mathrm{Zr} 02\end{array}$

TOTAL FLOW, LB/HR VAPOR FLON, CFM LIQUID FLOW, GPM DESIGN FLOH, DENSITY, LBS/FT3 TEMPERATURE, DEG C PRESSURE, ATM PRESSURE, PSIG PRESSURE, MM HG PHASE

ENTHALPY, PCU/HR

114
MAVIT Vent
to MVC
.0000
$.8934 \mathrm{E}-11$
$.1111 \mathrm{E}-11$
$.1143 \mathrm{E}-24$
.0000
$.1071 \mathrm{E}-18$
4.65
1.12

.0698
87.99
.99
-.07
756.20
VAPOR
-212.29

115

HNO3 WASB

from MAWT

.0000

$.4217 \mathrm{E}-05$

.524EE-06

.5394 E-19

.0000

.6056 ¿-08

.18

.00

69.7955

83.00

.99

$-.07$

75 ii. 20

LIQ̨UID

6.04
Appendix $\mathrm{H}$

Table 21-16

Page 118 of 178

Date 09/80/82 Rev 09

\begin{tabular}{rrr}
117 & 118 \\
A1r Spargo & \multicolumn{2}{c}{ Stoam to } \\
to SME & SME Coll \\
.0000 & .0000 \\
.0000 & .0000 & .0000 \\
.0000 & .000 \\
.0000 & .0000 & \\
.0000 & .0000 & \\
.0000 & .0000 & \\
22.61 & & .00 \\
5.84 & & \\
& & \\
& & \\
.0706 & .0000 \\
85.00 & 160.00 \\
1.00 & 6.10 \\
.00 & 74.99 \\
& \\
VAPOR & N/A \\
-1164.14 & .00
\end{tabular}


DPSP $80-1083$

MATERIAL BALANCE TABLES

SLUDGE-SUPERNATE FEED

STREAM NUMBERS -

STREAM NAME

COMPONENT FLOWS, LB/HR

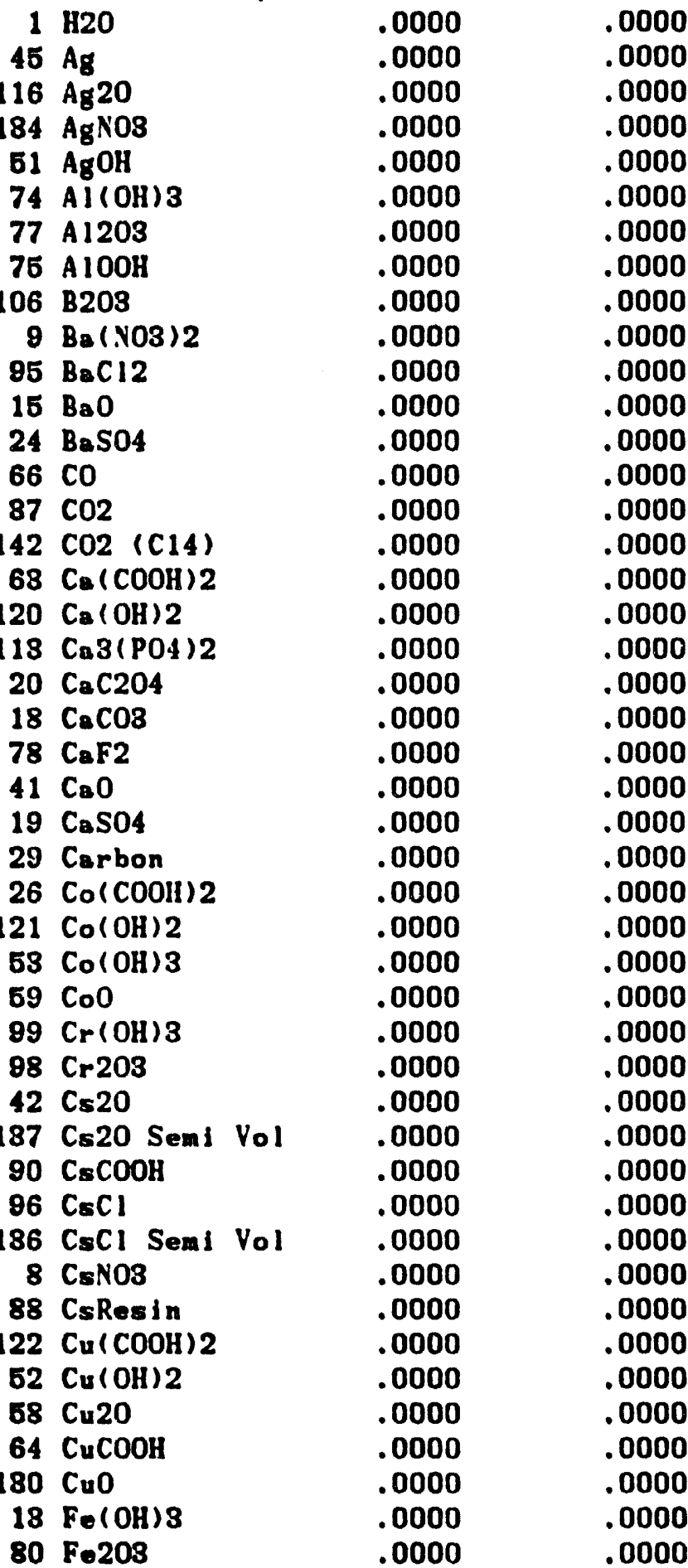

120

ate fr SNE

0000

0000

0000

0000

.0000

0000

0000

0000

.0000

0000

0000

0000

0000

0000

.0000

0000

0000

0000

0000

0000

.0000

0000

0000

0000

0000

0000

000

0000
Append ix H

Tablo 21-16

Page 114 of 173

Date 09/30/82 Rev 09

Steam Conden Stoam to
cate fr SNE SRriT Coll
121

Steam Conden Air Spargu

sato Fr SRAT to SRAT

$\begin{array}{ll}.0000 & .3735 \\ .0000 & .0000 \\ .0000 & .0000 \\ .0000 & .0000 \\ .0000 & .0000 \\ .0000 & .0000 \\ .0000 & .0000 \\ .0000 & .0000 \\ .0000 & .0000 \\ .0000 & .0000 \\ .0000 & .0000 \\ .0000 & .0000 \\ .0000 & .0000 \\ .0000 & .0000 \\ .0000 & .0000 \\ .0000 & .0000 \\ .0000 & .0000 \\ .0000 & .0000 \\ .0000 & .0000 \\ .0000 & .0000 \\ .0000 & .0000 \\ .0000 & .0000 \\ .0000 & .0000 \\ .0000 & .0000 \\ .0000 & .0000 \\ .0000 & .0000 \\ .0000 & .0000 \\ .0000 & .0000 \\ .0000 & .0000 \\ .0000 & .0000 \\ .0000 & .0000 \\ .0000 & .0000 \\ .0000 & .0000 \\ .0000 & .0000 \\ .0000 & .0000 \\ .0000 & .0000 \\ .0000 & .0000 \\ .0000 & .0000 \\ .0000 & .0000 \\ .0000 & .0000 \\ .0000 & .0000 \\ .0000 & .0000 \\ .0000 & .0000 \\ .0000 & .0000 \\ .0000 & .0000 \\ & \end{array}$


DPSP 80-1033

MATERIAL BALANCE TABLES

SLUDGE-SUPERNATE FEED

STREAMIS (CONT'D) -

STREAM NAME

$101 \mathrm{~F} \in \mathrm{O}$

126 Group A Semi Vo

102 GroupA

103 GroupB

$25 \mathrm{H} 2$

133 H2C2O4

9111202

$84 \mathrm{HCOOH}$

$43 \mathrm{HCl}$

85 HF

49 HNO3

86 HResin

$86 \mathrm{Hg}$

$185 \mathrm{HgNO} 2$

$21 \mathrm{HgO}$

9712

$89 \mathrm{~K} 20$

$131 \mathrm{KMn} 04$

118 KN03

105 La.203

$108 L_{120}$

$65 \mathrm{Mg}(\mathrm{COOHI}) 2$

$55 \mathrm{Mg}(\mathrm{OII}) 2$

$83 \mathrm{MgO}$

$60 \mathrm{Mn}(\mathrm{COOII}) 2$

$182 \mathrm{Mn}(\mathrm{NO3}) 2$

$129 \mathrm{Mn}(\mathrm{OHI}) 2$

$56 \mathrm{MnO}$

$14 \mathrm{MnO2}$

$81 \mathrm{N2}$

$143 \mathrm{NA2CO3}$ (C14)

85 NO

84 NO2

$70 \mathrm{Na}(\mathrm{HgO}(\mathrm{OH}))$

$94 \mathrm{Na} 2 \mathrm{~B} 407$

$109 \mathrm{Na} 2 \mathrm{C2O4}$

$5 \mathrm{Na} 2 \mathrm{CO3}$

$82 \mathrm{Na} 20$

$71 \mathrm{No} 2 \mathrm{Pu} 02$ (Oll) 4

$73 \mathrm{Na} 2 \mathrm{RhO} 04$

$72 \mathrm{Ne} 2 \mathrm{RuO}_{4}$

$6 \mathrm{Na}_{2} \mathrm{SO}_{4}$

$68 \mathrm{NaAlO2}$

$114 \mathrm{NaBO2}$

$140 \mathrm{NaBO2}$ Semi Vol

$50 \mathrm{NaCOOH}$
$119 \quad 120$

Steam Conden Stean to ua te Pr SME

.0000

.0000

.0000

.0000

.0000

.0000

.0000

.0000

.0000

.0000

.0000

.0000

.0000

.0000

.0000

.0000

.0000

.0000

.0000

.0000

.0000

.0000

.0000

.0000

.0000

.0000

.0000

.0000

.0000

.0000

.0000

.0000

.0000

.0000

.0000

.0000

.0000

.0000

.0000

.0000

.0000

.0000

.0000

.0000

.0000

.0000

.0000

.0000

.0000

.0000

.0000

.0000

.0000

.0000

.0000

.0000

.0000

.0000

.0000

.0000

.0000

.0000

.0000

.0000

.0000

.0000

.0000

.0000

.0000

.0000

.0000

.0000

.0000

.0000

.0000

.0000

.0000

.0000

.0000

.0000

.0000

.0000

.0000

.0000

.0000

.0000

.0000

.0000

.0000

.0000

.0000

.0000
Append Ix H

Table 21-16

Page 116 of 178

Dato 09/80/82 Rov 09

\section{SRAT COII}

121

Stoam Conden Alr Sparge

- to Fr SRAT

.0000

.0000

.0000

.0000

.0000

.0000

.0000

.0000

.0000

.0000

.0000

.0000

.0000

.0000

.0000

.0000

.0000

.0000

.0000

.0000

.0000

.0000

.0000

.0000

.0000

.0000

.0000

.0000

.0000

.0000

.0000

.0000

.0000

.0000

.0000

.0000

.0000

.0000

.0000

.0000

.0000

.0000

.0000

.0000

.0000

.0000 to SRAT

.0000

.0000

.0000

.0000

.0000

.0000

.0000

.0000

.0000

.0000

.0000

.0000

.0000

.0000

.0000

.0000

.0000

.0000

.0000

.0000

.0000

.0000

.0000

.0000

.0000

.0000

.0000

.0000

.0000

17.07

.0000

.0000

.0000

.0000

.0000

.0000

.0000

.0000

.0000

.0000

.0000

.0000

.0000

.0000

.0000

.0000 
DPSP $80-1088$

MATERIAL BALANCE TABLES

SLUDGE-SUPERNATB FEED

STREAMS (CONT'D)-

STREAM NAME

$7 \mathrm{NaCl}$

$188 \mathrm{NaCl}$ Sem I Vol

$69 \mathrm{NaF}$

189 NaF Seml Vol

$12 \mathrm{NaI}$

$125 \mathrm{NaI}$ Sem $\mathrm{Vol}$

8 NaN02

2 NaNO3

$4 \mathrm{NaOH}$

87 NaResin

$61 \mathrm{Ni}(\mathrm{COOH}) 2$

$17 \mathrm{Ni}(\mathrm{OII}) 2$

$40 \mathrm{~N} 10$

8202

$67 \mathrm{PbO}$

$28 \mathrm{PbSO} 4$

$124 \mathrm{Pd}$

$123 \mathrm{Pd}(\mathrm{OH}) 2$

112 PdNO32

110 PdO

$117 \mathrm{Pu}(\mathrm{COOH}) 4$

$76 \mathrm{Pu} 02$

$22 \mathrm{RhO2}$

79 RuO2

23 Ru02 Semi Vol

$88 \mathrm{Ru} 04$

$88 \mathrm{SO2}$

1115102

115 Silice Gel

$48 \mathrm{Sr}(\mathrm{COOH}) 2$

$10 \mathrm{Sr}(\mathrm{N} 03) 2$

$127 \mathrm{Sr}(\mathrm{OII}) 2$

$80 \mathrm{SrCO}$

$46 \mathrm{Sr} 0$

89 SrRESIN

141 Surfactant

92 Th02

107 Ti 02

119 Iritium

$93 \mathrm{VO2}$

$62 \mathrm{VO} 2(\mathrm{COOH}) 2$

$16 \mathrm{VO2}(\mathrm{OH}) 2$

$27 \mathrm{Y}(\mathrm{COOH}) 8$

$11 \mathrm{Y}(\mathrm{N} 03) \mathrm{3}$

$128 Y(\mathrm{OH}) \mathrm{S}$

$81 Y 2(\operatorname{COS}) 8$
119

Stcom Cond sn Steam to

ate ir SM?

.0000

.0000

.0000

.0000

.0000

.0000

.0000

.0000

.0000

.0000

.0000

.0000

.0000

.0000

.0000

.0000

.0000

.0000

.0000

.0000

.0000

.0000

.0000

.0000

.0000

.0000

.0000

.0000

.0000

.0000

.0000

.0000

.0000

.0000

.0000

.0000

.0000

.0000

.0000

.0000

.0000

.0000

.0000

.0000

.0000

.0000

SRA.T COII

.0000

.0000

.0000

.0000

.0000

.0000

.0000

.0000

.0000

.0000

.0000

.0000

.0000

.0000

.0000

.0000

.0000

.0000

.0000

.0000

.0000

.0000

.0000

.0000

.0000

.0000

.0000

.0000

.0000

.0000

.0000

.0000

.0000

.0000

.0000

.0000

.0000

.0000

.0000

.0000

.0000

.0000

.0000

.0000

.0000
Appendix $H$

Table 21-16

Page 116 of 173

Date 09/80/82 Rev 09

.0000
121

Steam Conden Alr Sparge

sate Fr SRAT to SRAT

.0000

.0000

.0000

.0000

.0000

.0000

.0000

.0000

.0000

.0000

.0000

.0000

.0000

.0000

.0000

.0000

.0000

.0000

.0000

.0000

.0000

.0000

.0000

.0000

.0000

.0000

.0000

.0000

.0000

.0000

.0000

.0000

.0000

.0000

.0000

.0000

.0000

.0000

.0000

.0000

.0000

.0000

.0000

.0000
.0000

.0000

.0000

.0000

.0000

.0000

.0000

. noor;

.0000

.0000

.0000

.0000

.0000

5. 168

.0000

.0000

.0000

.0000

.0000

.0000

.0000

.0000

.0000

.0000

.0000

.0000

.0000

.0000

.0000

.0000

.0000

.0000

.0000

.0000

.0000

.0000

.0000

.0000

.0000

.0000

.0000

.0000

.0000

.0000

.0000

.0000
.0000

.0000 
Date 09/80/82 Rev 09

MITERIIL BALANCE TABLISS SLLDC:-SLPERYATE FEED STREAMS (CONT'D)STREAM NAME

$47 Y 203$

100 Zeollte

$44 \mathrm{Zn}(\mathrm{COOHI}) 2$

$51 \mathrm{Zn}(\mathrm{OH}) 2$

$67 \mathrm{Zn} 0$

110

Steam Condon so to fr SME

.0000

.0000

.0000

.0000

.0000

.0000

TOTAL FLOW, LB/HR VAPOR FLOH', CFM LIQCID FLOH, GPM DESIGN FLOV: DEYSITY, LBS/FT3 TEMPERITURE, DEG C PRLSSURE, ATM PRESSURE, PSIG PRESSURE, HG PIHSE

E.THALPY, PCV/HR
.00

120

Steam to SRAT Coll

.0200

.0000

.0000

.0000

.0000

.0000

.00

.0000

60.00

1.00

.00

N/A

.00

.0000

160.00

6.10
121

Stoom Conden

wate Fr SRAT

.0000

.0000

.0000

.0000

.0000

.0000

74.99

N/A

.00
.00

122

Alr Sparge

to SRAT

.0000

.0000

.0000

.0000

.0000

.0000

22.61

5.84

.0000

.0706

35.00

60.00

1.00

.00

1.00

.00

N/A

VAPOR

$.00 \quad-1164.14$ 
DPSP 80-1038

MATERIAL BALANCE TABLES

SLUDGE-SLPERNATE FEED

STREAM NUMBERS -

STREAM NAME

COMPONENT FLOWS, LB/HR

11120

$48 \mathrm{Ag}$

116 Ag20

184 AgNO3

$61 \mathrm{AgOH}$

74 Al(OH) 3

77 A1203

$75 \mathrm{~A} 100 \mathrm{H}$

106 B203

$9 \mathrm{Bb}(\mathrm{N} 03) 2$

$95 \mathrm{BaCl} 2$

$16 \mathrm{BaO}$

$24 \mathrm{BaSO}$

$66 \mathrm{CO}$

$87 \mathrm{CO} 2$

$142 \mathrm{CO}$ (C14)

$68 \mathrm{Ca}(\mathrm{COOH}) 2$

$120 \mathrm{Ca}(\mathrm{OII}) 2$

$113 \mathrm{Ca} 3(\mathrm{PO} 4) 2$

$20 \mathrm{CaC} 204$

$18 \mathrm{CaCOS}$

$78 \mathrm{CaF2}$

$41 \mathrm{CaO}$

$19 \mathrm{CaSO4}$

29 Carbon

$26 \mathrm{Co}(\mathrm{COOIII)} 2$

$121 \mathrm{Co}(\mathrm{OH}) 2$

$53 \mathrm{Co}(\mathrm{OH}) \mathrm{S}$

$59 \mathrm{CoO}$

$99 \mathrm{Cr}(\mathrm{OH}) 8$

98 Cr208

$42 \mathrm{Cs} 20$

137 Cs20 Seml Vol

$90 \mathrm{Cs} \mathrm{COOH}$

$96 \mathrm{CsCl}$

$186 \mathrm{CsCl}$ Seml Vol

8 CsNO8

88 CsResin

$122 \mathrm{Cu}(\mathrm{COOH}) 2$

$52 \mathrm{Cu}(\mathrm{OH}) 2$

$58 \mathrm{Cu} 20$

$64 \mathrm{CuCOOH}$

180 CuO

$18 \mathrm{Fe}(\mathrm{OH}) 8$

$80 \mathrm{~F} \cdot 203$

\section{8 \\ Inlet Vapor to FAVC}

114.5

$.8218 E-07$

.0000

.0000

$.1043 \mathrm{E}-08$

$.9442 E-06$

.0000

.0000

$.4403 \mathrm{E}-05$

$.1240 \mathrm{E}-18$

.0000

.0000

$.1121 \mathrm{E}-07$

$.4493 E-04$

4.444

$.8846 \mathrm{E}-10$

$.8885 E-06$

$.2958 \mathrm{E}-() 9$

$.2794 \mathrm{E}-07$

$.8022 E-07$

.0000

$.7656 \mathrm{E}-08$

.0000

$.8550 \mathrm{E}-07$

$.2395 E-07$

$.6184 \mathrm{E}-08$

$.5118 \mathrm{E}-11$

.0000

.0000

.2872E-07

.0000

$.2197 \mathrm{E}-12$

.0000

$.1744 \mathrm{E}-07$

$.1154 \mathrm{E}-09$

.0000

$.7954 \mathrm{E}-09$

.0000

. 1810E-07

$.1113 \mathrm{E}-10$

.0000

.0000

.0000

.2285E-05

.0000
Appendix H

Table 21-10

Page 118 of 173

Date 00/30/32 Rev 09 $\begin{array}{ccc}124 & 125 & 126 \\ \text { FAVC } & \text { Air Spargo } & \text { Dump Can Air } \\ \text { Condensate } & \text { to MFT } & \text { Inlenkago }\end{array}$

85.93

$.1609 \mathrm{E}-07$

.0000

.0000

$.6213 \mathrm{E}-09$

$.4721 \mathrm{E}-06$

.0000

.0000

.2202E-05

$.6200 E-14$

.0000

.0000

$.5607 \mathrm{E}-08$

$.3551 E-10$

$.1770 \mathrm{E}-03$

$.3528 \mathrm{E}-14$

. 1942E-06

$.1479 \mathrm{E}-09$

$.1397 E-07$

. 1511E-07

.0000

$.3778 E-08$

.0000

$.1775 E-07$

$.1197 \mathrm{E}-07$

$.3067 \mathrm{E}-08$

$.2559 \mathrm{E}-11$

.0000

.0000

$.1436 \mathrm{E}-07$

.0000

. 1099E- 12

.0000

$.8721 E-08$

$.6772 E-10$

.0000

.3977E-09

.0000

. 6551E-08

.5566E- 11

.0000

.0000

.0000

$.1143 \mathrm{E}-05$

.0000
.8735

.0000

.0000

.0000

.0000

.0000

.0000

.0000

.0000

.0000

.0000

.0000

.0000

.0000

.0000

.0000

.0000

.0000

.0000

.0000

.0000

.0000

.0000

.0000

.0000

.0000

.0000

.0000

.0000

.0000

.0000

.0000

.0000

.0000

.0000

.0000

.0000

.0000

.0000

.0000

.0000

.0000

.0000

.0000

.0000
.6654

.0000

.000 ?

.0000

.0000

.0000

.0000

.0000

.0000

.0000

.0000

.0000

.0000

.0000

.0000

.0000

.0000

.0000

.0000

.0000

.0000

.0000

.0000

.0000

.0000

.0000

.0000

.0000

.0000

.0000

.0000

.0000

.0000

.0000

.0000

.0000

.0000

.0000

.0000

.0000

.0000

.0000

.0000

.0000

.0000 
DPSP $80-1083$

MATERIAL BALANCE TABLES SLUDGE-SUPERNATE FEED STREAMS (CONT'D)STREAM NAME

$101 \mathrm{FeO}$

126 Group A Semi Vo

102 GroupA

103 GroupB

$25 \mathrm{H} 2$

183 II2C204

$91 \mathrm{H2O2}$

$84 \mathrm{HCOOH}$

$43 \mathrm{HCl}$

$85 \mathrm{HF}$

49 HNO3

86 HResin

$86 \mathrm{Hg}$

$135 \mathrm{HgNO} 2$

$21 \mathrm{HgO}$

9712

89 K20

$181 \mathrm{KMnO4}$

$118 \mathrm{KNOB}$

105 La208

108 L120

$65 \mathrm{Mg}(\mathrm{COOH}) 2$

$65 \mathrm{Mg}(\mathrm{OH}) 2$

$83 \mathrm{MgO}$

$60 \mathrm{Mn}(\mathrm{COOH}) 2$

$182 \mathrm{Mn}(\mathrm{NO3}) 2$

$129 \mathrm{Mn}(\mathrm{OHI}) 2$

$56 \mathrm{MnO}$

$14 \mathrm{MnO2}$

81 N2

148 NA2COS (C14)

85 NO

$84 \mathrm{NO2}$

$70 \mathrm{Na}(\mathrm{HgO}(\mathrm{OH}))$

$94 \mathrm{Nn} 2 \mathrm{~B} 407$

$109 \mathrm{Na} 2 \mathrm{C2O4}$

$5 \mathrm{Nin} 2 \mathrm{CO}$

82 Nin 20

$71 \mathrm{Na} 2 \mathrm{Pu} 02$ (OH) 4

$73 \mathrm{Na2RhO4}$

$72 \mathrm{Na} 2 \mathrm{RuO}_{4}$

$6 \mathrm{Na} 2 \mathrm{SO4}$

$68 \mathrm{NaAlO2}$

$114 \mathrm{NaBO2}$

$140 \mathrm{NaBO2}$ Seml Vol

$50 \mathrm{NaCOOH}$

Append 1x II

Tablo 21-16

Page 119 of 173

Date $09 / 30 / 82$ Rev 09

128

Inlet Vnper

to FAVC

.0000

.0000

.2187E-07

$.6716 \mathrm{E}-07$

$.3583 \mathrm{E}-05$

.0000

.0000

.8280

.0000

.0000

.0000

.0000

$.8080 \mathrm{E}-03$

.0000

$.2166 E-09$

.0000

.0000

.0000

$.4885 \mathrm{E}-08$

$.1496 E-06$

$.1707 \varepsilon-05$

$.7895 E-07$

$.5045 \mathrm{E}-10$

. 5990E-06

$.6633 \mathrm{E}-06$

.0000

$.4782 E-08$

.0000

.0000

1227.

.0000

$.7464 \mathrm{E}-01$

$.4294 \mathrm{E}-02$

$.4784 \mathrm{E}-10$

$.2511 \mathrm{E}-08$

$.1940 E-08$

.0000

. 5806E-05

$.1920 \mathrm{E}-14$

$.8947 E-12$

$.8851 E-11$

$.7810 \mathrm{E}-08$

. 1920E-07

.0000

.0000

$.1869 \mathrm{E}-05$
$: 24$

FAVC

Condensate

.0000

.0000

$.1069 E-07$

.3358E-07

$.2670 \mathrm{E}-11$

.0000

.0000

.2748

.0000

.0000

.0000

.0000

$.1548 E-03$

.0000

.1083E-09

.0000

.0000

.0000

.2418E-08

$.7479 \mathrm{E}-07$

$.8537 E-06$

.3697E-07

.2523E- 10

. 2995E-06

$.3817 E-06$

.0000

$.2366 \mathrm{E}-08$

.0000

.0000

$.8878 E-03$

.0000

. 1651E-06

.2533E-03

. 2367E-10

$.1256 \mathrm{E}-08$

.9701E-09

.0000

.2653E-05

$.9598 \mathrm{E}-15$

$.1973 E-12$

$.1926 \mathrm{E}-11$

.8905E-08

$.9598 \mathrm{E}-08$

.0000

.0000

$.9346 E-06$
125

Alr Sparge

to MET

.0000

.0000

.0000

.0000

.0000

.0000

.0000

.0000

.0000

.0000

.0000

.0000

.0000

.0000

.0000

.0000

.0000

.0000

.0000

.0000

.0000

.0000

.0000

.0000

.0000

.0000

.0000

.0000

.0000

17.07

.0000

.0000

.0000

.0000

.0000

.0000

.0000

.0000

.0000

.0000

.0000

.0000

.0000

.0000

.0000

.0000
126

Dunp Can Air

Inleakiage

.0000

.0000

.0000

.0000

.0000

.0000

.0000

.0000

.0000

.0000

.0000

.0000

.0000

.0000

.0000

.0000

.0000

.0000

.0000

.0000

.0000

.0000

.0000

.0000

.0000

.0000

.0000

.0000

.0000

80.42

.0000

.0000

.0000

.0000

.0000

.0000

.0000

.0000

.0000

.0000

.0000

.0000

.0000

.0000

.0000

.0000 
DPSP $80-1033$

MATERIAL BALANCE TABLES

SLUDGT-SUPERN:ITE FEED

STREAMS (CONT'D)-

STREAM NAME

$7 \mathrm{NaCl}$

$138 \mathrm{NaCl}$ Semi Vol

$63 \mathrm{NaF}$

139 NaF Semi Vol

$12 \mathrm{NaI}$

125 Nal Semi Vol

$3 \mathrm{NaN02}$

$2 \mathrm{NaNO}$

$4 \mathrm{NaOll}$

87 NaResin

$61 \mathrm{Ni}(\mathrm{COOII}) 2$

$17 \mathrm{Ni}(\mathrm{OHI}) 2$

$40 \mathrm{NiO}$

8202

$67 \mathrm{PbO}$

$28 \mathrm{PbSO} 4$

$124 \mathrm{Pd}$

$123 \mathrm{Pd}(\mathrm{OH}) 2$

112 PdN032

$110 \mathrm{PdO}$

$117 \mathrm{Pu}(\mathrm{COOH}) 4$

$76 \mathrm{Pu} 02$

$22 \mathrm{Rh}_{\mathrm{H}} \mathrm{2}$

$79 \mathrm{Ru} 02$

23 Ru02 Semi Vol

$83 \mathrm{RuO}_{4}$

$38 \mathrm{SO} 2$

$111 \mathrm{Si} 02$

$115 \mathrm{Silica} \mathrm{Gel}$

$48 \mathrm{Sr}(\mathrm{COOH}) 2$

$10 \mathrm{Sr}(\mathrm{N} 03) 2$

$127 \mathrm{Sr}(\mathrm{OII}) 2$

$30 \mathrm{SrCO} 3$

$46 \mathrm{Sr} 0$

89 SrRESIN

141 Surfactant

$92 \mathrm{ThO}^{2}$

$107 \mathrm{TiO2}$

119 Tritium

$93 \mathrm{lO} 2$

$62 \mathrm{VO} 2(\mathrm{COOH}) 2$

$16 \mathrm{NO2}(\mathrm{OlH}) 2$

$27 \mathrm{Y}(\mathrm{COOH}) 3$

$11 \mathrm{Y}(\mathrm{NO} 03) 3$

$128 \mathrm{Y}(\mathrm{OII}) \mathrm{3}$

$31 \times 2(\mathrm{CO}) 3$
123

Inlet Vapor

to FAVC

$.9446 \mathrm{E}-08$

.0000

$.1662 \mathrm{E}-08$

.0000

$.8978 \mathrm{E}-09$

.0000

.0000

$.3261 \mathrm{E}-06$

.0000

.0000

$.2325 E-06$

$.1938 \mathrm{E}-09$

.0000

370.7

.0000

$.1055 \mathrm{E}-07$

.0000

.0000

.0000

.0000

$.1081 \mathrm{E}-10$

.2746E-08

. 1049E-08

.5239E-08

.0000

.0000

.5283E-05

.2792E-04

.0000

$.9462 \mathrm{E}-08$

$.1106 \mathrm{E}-18$

$.8664 \mathrm{E}-11$

.0000

.0000

.0000

.0000

$.4306 \mathrm{E}-07$

.2992E-06

$.8933 \mathrm{E}-10$

.0000

$.3007 \mathrm{E}-06$

$.8396 \mathrm{E}-09$

$.6469 \mathrm{E}-08$

$.7857 \mathrm{E}-14$

$.5405 \mathrm{E}-11$

.0000

Appendix $\mathrm{H}$

Table 21-16

Page 120 of 178

Date 09/80/82 Rev 09

$124 \quad 125$

FAVC

Condensite

$.4723 \mathrm{E}-08$

.0000

$.8311 E-09$

.0000

$.4489 E-09$

.0000

.0000

$.1631 E-06$

.0000

.0000

.1162E-06

$.9690 \mathrm{E}-10$

.0000

$.5411 \mathrm{E}-03$

.0000

$.5277 \mathrm{E}-08$

.0000

.0000

.0000

.0000

$.54035-11$

$.1373 E-08$

$.5247 E-09$

.2620E-08

.0000

.0000

$.1646 \mathrm{E}-10$

$.8960 \mathrm{E}-05$

.0000

$.4731 \mathrm{i}-08$

$.5532 \mathrm{E}-14$

.4332E-11

.0000

.0000

.0000

.0000

.2153E-07

. 1496E-06

$.3744 \mathrm{E}-10$

.0000

$.1504 \mathrm{E}-06$

.1698 E-09

. 3234E-08

.3929E- 14

.2702E-11

.0000
Air Sparge to MFT

.0000

.0000

.0000

.0000

.0000

.0000

.0000

.0000

.0000

.0000

.0000

.0000

.0000

5. 158

.0000

.0000

.0000

.0000

.0000

.0000

.0000

.0000

.0000

.0000

.0000

.0000

.0000

.0000

.0000

.0000

.0000

.0000

.0000

.0000

.0000

.0000

.0000

.0000

.0000

.0000

.0000

.0000

.0000

.0000

.0000

.0000
126

Dump Can A !r

In leakage

.0000

.0000

.0000

.0000

.0000

.0000

.0000

.0000

.0000

.0000

.0000

.0000

.0000

9.189

.0000

.0000

.0000

.0000

.0000

.0000

.0000

.0000

.0000

.0000

.0000

.0000

.0000

.0000

.0000

.0000

.0000

.0000

.0000

.0000

.0000

.0000

.0005

.0000

.0000

.0000

.0000

.0000

.0000

.0000

.0000

.0000 . 
DPSP $80-1033$

MATERIAL BALANCE TABLES SLUDGE-SUPERNATE FEED

STREAMS (CONT'D) STREAM NAIIE

$47 Y 203$

100 Zeolite

$44 \mathrm{Zn}(\mathrm{COOH}) 2$

$54 \mathrm{Zn}(\mathrm{OH}) 2$

$57 \mathrm{ZnO}$

$104 \mathrm{Zr} 02$

TOTAL FLON, LB/HR

VISPOR FLOW, CFM

LIQUID FLOH, GPM

DESIGN FLOW",

DENSITI, LBS/FT3

TEMPERATURE, DEG C

PRESSURE, ATM

PRESSLRE, PSIG

PRESSURE, MSI HG

PIIASE

E.TTIALPY, PCU/IR

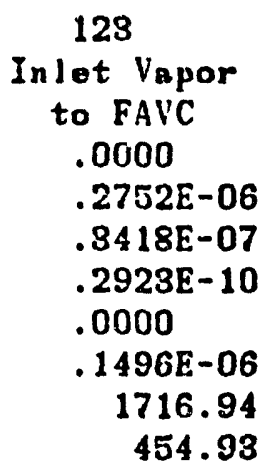

.0629

50.00

.96

$-.58$

730.13

VAPOR

$-26811.85$

Appendix II Table 21-16

Page 121 of 173

Date 09/30/82 Rev 09

124

FAVC

Condensate

.0000

$.1376 \vdots-06$

.1709 i-07

$.14623-10$

.0000

$.7479:-07$

93.21

.19

62. 1622

15.00

.96

$-.58$

$73 ! .18$

LITUID

$145 \% .63$
125

Air Sparge to MFT

.0000

.0000

.0000

.0000

.0000

.0000

22.61

5.34

.0706

85.00

1.00

.00

VAPOR

$-1164.14$
126

Dump Can Air

In leaknge

.0000

.0000

.0000

.0000

.0000

.0000

40.28

9.88

.0680

85.00

.96

$-.54$

732.03

VAPOR

$-2074.10$ 
DPSP $80-1038$

MATERIAL BALANCE TABLES

SLUDGE-SUPERNATE FEED
STREAM NUMBERS -

COMPONENT FLOWS, LB/HR

\begin{tabular}{|c|c|c|}
\hline 1 & H2O & .0000 \\
\hline 45 & $\mathrm{Ag}$ & .0000 \\
\hline 16 & Ag20 & .0000 \\
\hline 84 & AgNO3 & .0000 \\
\hline 51 & $\mathrm{AgOH}$ & .0600 \\
\hline 74 & Al $(\mathrm{OH}) 3$ & .0000 \\
\hline 77 & A1203 & .0000 \\
\hline 75 & A $100 \mathrm{H}$ & .0000 \\
\hline 06 & B203 & .0000 \\
\hline 9 & $\mathrm{Ba}(\mathrm{NO3}) 2$ & .0000 \\
\hline 95 & $\mathrm{BaCl} 2$ & .0000 \\
\hline 15 & $\mathrm{BaO}$ & .0000 \\
\hline 24 & BaS04 & .0000 \\
\hline 66 & co & .0000 \\
\hline 87 & $\mathrm{CO} 2$ & .0000 \\
\hline 142 & $\mathrm{CO} 2(\mathrm{C} 14)$ & .0000 \\
\hline 63 & $\mathrm{Ca}(\mathrm{COOH}) 2$ & .0000 \\
\hline 120 & $\mathrm{Ca}_{\mathrm{a}}(\mathrm{OII}) 2$ & .0000 \\
\hline 113 & Ca3 (P04) 2 & .0000 \\
\hline 20 & $\mathrm{CaC2}_{2}$ & .0000 \\
\hline $\begin{array}{l}18 \\
78\end{array}$ & $\begin{array}{l}\mathrm{CaCO} 3 \\
\mathrm{CaF}\end{array}$ & .0000 \\
\hline 41 & CaO & .0000 \\
\hline 19 & CaSO4 & .0000 \\
\hline 29 & Carbon & .0000 \\
\hline 26 & $\mathrm{Co}(\mathrm{COOH}) 2$ & .0000 \\
\hline 21 & Co(Oll) 2 & .0000 \\
\hline 53 & $\mathrm{Co}(\mathrm{OHI}) 3$ & .0000 \\
\hline 59 & $\mathrm{CoO}$ & .0000 \\
\hline 99 & $\mathrm{Cr}(\mathrm{OH}) 3$ & .0000 \\
\hline 98 & Cr203 & .0000 \\
\hline 42 & Cs20 & .0000 \\
\hline 87 & Cs20 Semi Vol & .0000 \\
\hline 90 & $\mathrm{CsCOOH}$ & .0000 \\
\hline 96 & $\mathrm{CsCl}$ & .0000 \\
\hline 186 & ; Cscl Semi Vol & .0000 \\
\hline 8 & CsNO3 & .0000 \\
\hline 88 & CsResin & .0000 \\
\hline 122 & 2 $\mathrm{Cu}(\mathrm{COOH}) 2$ & .0000 \\
\hline 52 & $\mathrm{Cu}(\mathrm{OH}) 2$ & .0000 \\
\hline 58 & $\mathrm{Cu} 20$ & .0000 \\
\hline 64 & $\mathrm{CuCOOH}$ & .0000 \\
\hline 130 & $\mathrm{CuO}$ & .0000 \\
\hline 13 & $3 \mathrm{Fe}(\mathrm{OH}) 3$ & .0000 \\
\hline & e203 & .0000 \\
\hline
\end{tabular}

SLUDGE-SUPERNATE FEED
STREAM NUMBERS STREAM NAME
Appendix H

Inble 21-16

Page 122 of 173

Date 09/30/82 Rev 09

\author{
127 \\ Control Air Surfactant
to Ejectcr to OGCT
}

.0000

.0000

.0000

.0000

.0000

.0000

.0000

.0000

.0000

.0000

.0000

.0000

.0000

.0000

.0000

.0000

.0000

.0000

.0000

.0000

.0000

.0000

.0000

.0000

.0000

.0000

.0000

.0000

.0000

.0000

.0000

.0000

.0000

.0000

.0000

.0000

.0000

.0000

.0000

.0000

.0000

.0000

.0000

.0000

.0000 $\begin{array}{cc}129 & 130 \\ \text { urfactant } & \text { Di:TS Vent } \\ \text { to FPI } & \text { to PVVS }\end{array}$

$\begin{array}{ll}.0000 & 6.222 \\ .0000 & .0000 \\ .0000 & .0000 \\ .0000 & .0000 \\ .0000 & .0000 \\ .0000 & .0000 \\ .0000 & .0000 \\ .0000 & .0000 \\ .0000 & .0000 \\ .0000 & .0000 \\ .0000 & .0000 \\ .0000 & .0000 \\ .0000 & .0000 \\ .0000 & .0000 \\ .0000 & 5.558 \\ .0000 & .0000 \\ .0000 & .0000 \\ .0300 & .0000 \\ .0000 & .0000 \\ .0000 & .0000 \\ .0000 & .0000 \\ .0000 & .0000 \\ .0000 & .0000 \\ .0000 & .0000 \\ .0000 & .0000 \\ .0000 & .0000 \\ .0000 & .0000 \\ .0000 & .0000 \\ .0000 & .0000 \\ .0000 & .0000 \\ .0000 & .0000 \\ .0000 & .0000 \\ .0000 & .0000 \\ .0000 & .0000 \\ .0000 & .0000 \\ .0000 & .0000 \\ .0000 & .0000 \\ .0000 & .0000 \\ .0000 & .0000 \\ .0000 & .0000 \\ .0000 & .0000 \\ .0000 & .0000 \\ .0000 & .0000 \\ .0000 & .0000 \\ .0000 & .0000 \\ & \end{array}$


DPSP 80-1033

MATERIAL BALANCE TABLES

SLCDGE-SUPERNATE FEED

STRTAMS (CONT'D)-

STRLAM NAME

$101 \mathrm{FeO}$

126 Group A Semi Vo

102 GroupA

103 Group B

$25 \mathrm{H} 2$

$133 \mathrm{H} 2 \mathrm{C} 2 \mathrm{O4}$

$9 1 \longdiv { \mathrm { H } 2 0 2 }$

34 HCOOII

$43 \mathrm{HCl}$

$85 \mathrm{HF}$

49 HNO3

86 HResin

$36 \mathrm{Hg}$

$125 \mathrm{Hg} .032$

$21 \mathrm{Hg} 0$

9712

39 K20

$131 \mathrm{kMnO4}$

$118 \mathrm{KNO}$

$105 \operatorname{Ln} 203$

108 L 120

$65 \mathrm{Mg}(\mathrm{COOH}) 2$

$55 \mathrm{Mg}(\mathrm{OII}) 2$

$33 \mathrm{Mg} O$

$60 \mathrm{Mn}(\mathrm{COOH}) 2$

$132 \mathrm{Mn}(\mathrm{NO3}) 2$

$129 \mathrm{Mn}(\mathrm{OII}) 2$

$56 \operatorname{Mn} 0$

$14 \mathrm{MnO2}$

81 N2

$1+3 \quad \mathrm{~N} 12 \mathrm{CO} \quad(\mathrm{C} 14)$

35 No

$84 \mathrm{NO2}$

$70 \mathrm{Na}\left(\mathrm{H}_{\mathrm{B}} \mathrm{O}(\mathrm{OII})\right)$

$94 \mathrm{~N} 2 \mathrm{~B} 407$

109 ia2C204

$5 \mathrm{Na} 2 \mathrm{CO}$

$82 \mathrm{Na} 20$

$71 \mathrm{Na} 2 \mathrm{PuO}_{\mathrm{u}}(\mathrm{OII}) 4$

$73 \mathrm{Na2RhO4}$

$72 \mathrm{Na} 2 \mathrm{RuO4}$

$6 \mathrm{Nin} 2 \mathrm{SO4}$

$68 \mathrm{NaAl} 02$

$114 \mathrm{NaBO} 2$

140 NaBO2 Semi Vol

$50 \mathrm{NaCOOH}$

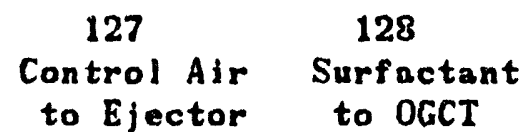

.0000

.0000

.0000

.0000

.0000

.0000

.0000

.0000

.0000

.0000

.0000

.0000

.0000

.0000

.0000

.0000

.0000

.0000

.0000

.0000

.0000

.0000

.0000

.0000

.0000

.0000

.0000

.0000

.0000

.0000

.0000

.0000

.0000

.0000

.0000

.0000

.0000

.0000

.0000

.0000

.0000

.0000

.0000

.0000

.0000

.0000

.0000

.0000

.0000

.0000

.0000

.0000

.0000

.0000

.0000

.0000

.0000

.0000

.0000

.0000

.0000

.0000

.0000

.0000

.0000

.0000

.0000

.0000

.0000

.0000

.0000

.0000

.0000

.0000

.0000

.0000

.0000

.0000

.0000

.0000

.0000

.0000

.0000

.0000

.0000

.0000

.0000

.0000

.0000

.0000

.0000

.0000
Appond Ix H

Table 21-16

Page 123 of 178
Date $09 / 80 / 82$ Rev 09

Page 123 of 178
Dete 09/80/82 Rev 09

$\begin{array}{cc}129 & 130 \\ \text { Surfoctant } & \text { DU'TT }\end{array}$

to FPT

.0000

Vent
.0000

.0000

.0000

.0000

.0000

.0000

.0000

.0000

.0000

.0000

.0000

.0000

.0000

.0000

.0000

.0000

.0000

.0000

.0000

.0000

.0000

.0000

.0000

.0000

.0000

.0000

.0000

.0000

.0000

.0000

.0000

.0000

.0000

.0000

.0000

.0000

.0000

.0000

.0000

.0000

.0000

.0000

.0000

.0000

.0000 to PVVS

.0000

.0000

.0000

.0000

.0000

.0000

.0000

.0000

.0000

.0000

.0000

.0000

.0000

.0000

.0000

.0000

.0000

.0000

$.4731 E-08$

.0000

.0000

.0000

.0000

.0000

.0000

.0000

$.4162 \mathrm{E}-08$

.0000

.0000

47.85

.0000

1.168

.0000

.0000

.0000

. 1898E-08

.0000

.0000

.0000

.0000

.0000

.0000

.0000

.0000

.0000

.0000 
DPSP $80-1033$

MATERIAL BALANCE TABLES

SLUDGE-SUPERNATE FEED

STREAMS (CONT'D)-

STREAM NAME

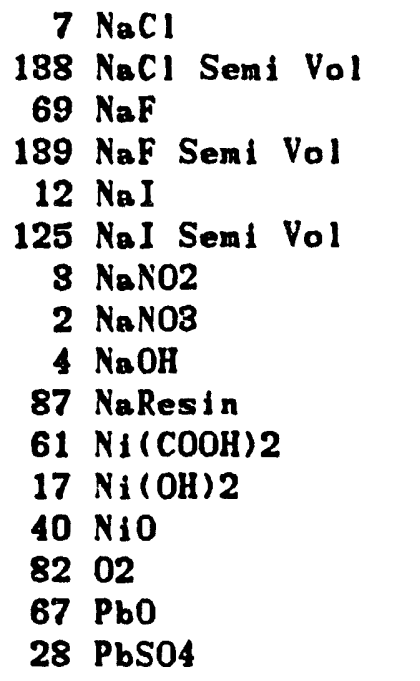

$124 \mathrm{Pd}$

$123 \mathrm{Pd}(\mathrm{OH}) 2$

112 PdNO32

$110 \mathrm{PdO}$

$117 \mathrm{Pu}(\mathrm{COOH}) 4$

$76 \mathrm{Pu} 02$

$22 \mathrm{Rh} 02$

$79 \mathrm{Ru} 02$

28 Ru02 Semi Vol

$83 \mathrm{Ru} 04$

$88 \mathrm{SO} 2$

1115102

115 Silica Gel

$48 \mathrm{Sr}(\mathrm{COOH}) 2$

$10 \mathrm{Sr}(\mathrm{NO3}) 2$

$127 \mathrm{Sr}(\mathrm{OH}) 2$

$80 \mathrm{SrCO3}$

$46 \mathrm{Sr} 0$

89 SrRESIN

141 Surfactant

92 Th02

107 T 102

119 Tritium

$93 \mathrm{VO2}$

$62 \mathrm{VO2}(\mathrm{COOH}) 2$

$16 \mathrm{VO}(\mathrm{OH}) 2$

$27 \mathrm{Y}(\mathrm{COOH}) \mathrm{3}$

$11 \mathrm{Y}(\mathrm{N} 03) \mathrm{S}$

$128 \mathrm{Y}(\mathrm{OH}) 3$

$81 \mathrm{Y} 2(\mathrm{CO}) \mathrm{s}$
127

Control Air to Ejectur .0000

.0000

.0000

.0000

.0000

.0000

.0000

.0000

.0000

.0000

.0000

.0000

.0000

.0000

.0000

.0000

.0000

.0000

.0000

.0000

.0000

.0000

.0000

.0000

.0000

.0000

.0000

.0000

.0000

.0000

.0000

.0000

.0000

.0000

.0000

.0000

.0000

.0000

.0000

.0000

.0000

.0000

.0000

.0000

.0000

.0000
Appendix II

Table 21-16

Page 124 of 173

Date 09/30/\&2 Rev 09 


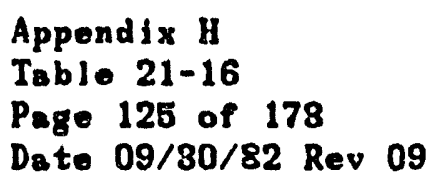

MATERIAL BALANCE TABLES

SLLDGE-SUPERNATE FEED STREAMSO (CONI'D)STRFAM NAME

47 y203
$100 \mathrm{ZeOlite}$
$44 \mathrm{Zn}(\mathrm{COOH}) 2$
$54 \mathrm{Zn}(\mathrm{OII}) 2$
$57 \mathrm{ZnO}$
$104 \mathrm{ZrO2}$
TOTAL FLOW, LB/HR
VAPOR FLOH, CFM
LIOUID FLOW, GPM
DESIGN FI.OW,
DENSITY, LBS/FT3
TEMPERATURE, DEG
PRESSURE, ATM
PRESSURE, PSIG
PIESSURE, MMI HG
PHASE
ENTHALPY, PCU/HR

128
Surfactant
to 0GCT
.0000
.0000
.0000
.0000
.0000
.0000
.00
.00

66.8000

25.00

1.00

.00

LIQUID

.07
129

Surfactant

to FPT

.0000

.0000

.0000

.0000

.0000

.0000

.00

.00

66.8000

25.00

1.00

.00

LIQUID

.04
180

DWTI Vent

to PVVS

.0000

.0000

.0000

.0000

.0000

.0000

75.25

20.85

.0616

50.00

.93

$-1.08$

703.99

VAPOR

272.00 
DPSP $80-1033$

YATERIAL BALANCE TABLES

SLUDGE-SUPERNATE FEED

STREAM NAME

COMPONENT FLOWS, LB/HR

$1 \mathrm{H} 2 \mathrm{O}$

116 Ag20

184 AgNO3

$51 \mathrm{AgOH}$

74 Al( OHI) 3

77 Al203

75 A $100 \mathrm{H}$

106 B203

$9 \mathrm{Ba}(\mathrm{NO3}) 2$

$95 \mathrm{BaCl} 12$

$15 \mathrm{Ba} 0$

$24 \mathrm{BaSO} 4$

$66 \mathrm{CO}$

$37 \mathrm{CO} 2$

$142 \mathrm{CO}$ ( $\mathrm{C} 14)$

$63 \mathrm{Ca}(\mathrm{COOH}) 2$

$120 \mathrm{Ca}(\mathrm{OH}) 2$

$113 \mathrm{Ca} 3(\mathrm{PO} 4) 2$

$20 \mathrm{C}_{\mathrm{B}} \mathrm{C204}$

$18 \mathrm{CaCO}$

$78 \mathrm{CaF2}$

$41 \mathrm{CaO}$

$19 \mathrm{CaSO}_{\mathrm{a}}$

29 Carbon

$26 \mathrm{Co}(\mathrm{COOHI}) 2$

$121 \mathrm{Co}(\mathrm{OH}) 2$

$53 \mathrm{Co}(\mathrm{OH}) 3$

$59 \mathrm{CoO}$

$99 \mathrm{Cr}(\mathrm{OH}) 3$

98 Cr203

$42 \operatorname{Cs} 20$

137 Cs20 Semi Vol

$90 \mathrm{Cs} \mathrm{COOH}$

$96 \mathrm{CsCl}$

$136 \mathrm{CsCl}$ Semi Vol

$8 \mathrm{CsNO3}$

88 CsResin

$122 \mathrm{Cu}(\mathrm{COOII}) 2$

$52 \mathrm{Cu}(\mathrm{OH}) 2$

$58 \mathrm{Cu} 20$

$64 \mathrm{CuCOOH}$

$180 \mathrm{Cu} 0$

$13 \mathrm{Fe}(\mathrm{OH}) \mathrm{8}$

$80 \mathrm{Fe} 203$
181

132

Inlet Gas to Sane Filter

Sand Filter Exhaust

9665.

. 5822E-10

.0000

$.8356 \mathrm{E}-10$

$.1503 \mathrm{E}-10$

$.1559 \mathrm{E}-08$

.0000

.0000

$.7207 \mathrm{E}-08$

.2047E-16

.0000

.0000

$.1851 \mathrm{E}-10$

7.614

26.57

$.2875 \mathrm{E}-09$

$.6413 \mathrm{E}-09$

$.4808 \mathrm{E}-12$

$.4613 E-10$

$.4989 \mathrm{E}-10$

.0000

$.1247 \mathrm{E}-10$

.0000

$.6860 \mathrm{E}-10$

$.3959 \mathrm{E}-10$

$.9968 \mathrm{E}-08$

$.8316 E-14$

.0000

.0000

$.4741 \mathrm{E}-10$

.0000

$.8614 \mathrm{E}-15$

.0000

$.2879 E-10$

$.2616 E-09$

.0000

$.1313 \mathrm{E}-11$

.0000

$.2163 E-10$

$.1809 \mathrm{E}-13$

.0000

.0000

.0000

$.8772 E-08$

.0000
Appendix H

Table 21-16

Page 126 of 173

Date 09/30/82 Rev 09

S665. 9665.9665 .

$.5322 E-13 \quad .5322 E-13 \quad .5322 E-13$

$\begin{array}{lll}.0000 & .0000 \quad .0000\end{array}$

$.8356 \mathrm{E}-13 \quad .8356 \mathrm{E}-13 \quad .8356 \mathrm{E}-13$

$.1503 E-13 \quad .1503 E-13 \quad .1503 E-13$

$.1559 E-11 \quad .1559 E-11 \quad .1559 E-11$

$.0000 \quad .0000 \quad .0000$

$\begin{array}{lll}.0000 & .0000 & .0000\end{array}$

$.7207 E-11 \quad .7207 E-11 \quad .7207 E-11$

$.2047 E-19 \quad .2047 E-19 \quad .2047 E-19$

$.0000 \quad .0000 \quad .0000$

$\begin{array}{lll}.0000 & .0000 & .0000\end{array}$

$.1851 E-13 \quad .1851 E-13 \quad .1851 E-13$

$\begin{array}{lll}7.614 & 7.614 & 7.614\end{array}$

$26.57 \quad 26.57 \quad 26.57$

$.2875 \mathrm{E}-09 \quad .2875 \mathrm{E}-09 \quad .2875 \mathrm{E}-09$

$.6413 \mathrm{E}-12 \quad .6413 \mathrm{E}-12 \quad .6413 \mathrm{E}-12$

$.4808 \mathrm{E}-15 \quad .4808 \mathrm{E}-15 \quad .4808 \mathrm{E}-15$

$.4613 \mathrm{E}-13 \quad .4613 \mathrm{E}-13 \quad .4613 \mathrm{E}-13$

$.4989 E-13 \quad .4989 E-13 \quad .4089 E-13$

$.0000 \quad .0000 \quad .0000$

$.1247 E-18 \quad .1247 E-13 \quad .1247 E-13$

$\begin{array}{lll}.0000 & .0000 & .0000\end{array}$

$.5860 \mathrm{E}-13 \quad .5860 \mathrm{E}-13 \quad .5860 \mathrm{E}-13$

$.3959 \mathrm{E}-13 \quad .3959 \mathrm{E}-13 \quad .3959 \mathrm{E}-13$

$.9968 E-08 \quad .9968 E-08 \quad .9968 E-08$

$.8316 \mathrm{E}-17 \quad .8316 \mathrm{E}-17 \quad .8316 \mathrm{E}-17$

$.0000 \quad .0000 \quad .0000$

$\begin{array}{lll}.0000 & .0000 & .0000\end{array}$

$.4741 \mathrm{E}-13 \quad .4741 \mathrm{E}-13 \quad .4741 \mathrm{E}-13$

$\begin{array}{lll}.0000 & .0000 & .0000\end{array}$

$.3614 \mathrm{E}-18 \quad .8614 \mathrm{E}-18 \quad .3614 \mathrm{E}-18$

$\begin{array}{lll}.0000 & .0000 \quad .0000\end{array}$

$.2879 \mathrm{E}-13 \quad .2879 \mathrm{E}-13 \quad .2879 \mathrm{E}-13$

$.2616 \mathrm{E}-12 \quad .2616 \mathrm{E}-12 \quad .2616 \mathrm{E}-12$

$.0000 \quad .0000 \quad .0000$

$.1313 E-14 \quad .1313 E-14 \quad .1313 E-14$

$\begin{array}{lll}.0000 & .0000 & .0000\end{array}$

$.2163 E-13 \quad .2163 E-13 \quad .2163 E-13$

$.1809 E-16 \quad .1809 E-16 \quad .1809 E-16$

$.0000 \quad .0000 \quad .0000$

$.0000 \quad .0000 \quad .0000$

$\begin{array}{lll}.0000 & .0000 & .0000\end{array}$

$.3772 E-11 \quad .3772 E-11 \quad .3772 E-11$

$\begin{array}{lll}.0000 & .0000 & .0000^{\circ}\end{array}$ 
DFSP $80-1032$

SHATRRIAL BALANCE TABLES SLUUGE-SLPERIATE FEED STREAMS (CONT'D)= STREAM NAME

101 FeO
126 Group A Semi Vo
102 GroupA
103 GroupB
$\because \mathrm{H} 2$
$133 \mathrm{H} 2 \mathrm{C} 204$
$91 \mathrm{H} 202$
$34 \mathrm{HCOOH}$
$43 \mathrm{HCl}$
$85 \mathrm{HF}$
$49 \mathrm{HNO}$
$86 \mathrm{HRes}$ in
36 Hg

135 higN032

$21 \mathrm{HEO}$

$97 \quad 12$

$39 \mathrm{~K} 20$

$131 \mathrm{KMn} 04$

118 KNO3

105 La 203

108 Li 20

$65 \mathrm{Mg}(\mathrm{COOH}) 2$

$65 \mathrm{Mg}(\mathrm{OII}) 2$

$33 \mathrm{MgO}$

$60 \mathrm{Mn}(\mathrm{COOH}) 2$

$132 \mathrm{Mn}(\mathrm{YO} 03) 2$

$129 \mathrm{Mn}(\mathrm{Oll}) 2$

$56 \mathrm{MnO}$

$14 \mathrm{MnO} 2$

81 N2

$143 \quad \mathrm{~N} 12 \mathrm{CO} \quad$ (C14)

35 NO

$84 \mathrm{NO2}$

$70 \mathrm{Na}(\mathrm{HgO}(\mathrm{Oll}))$

$94 \mathrm{Na} 2 \mathrm{~B} 407$

109 Na2C204

5 $\mathrm{Na2} 2 \mathrm{CO}$

32 Na20

71 Na2Pu02(OII) 4

$73 \mathrm{Na} 2 \mathrm{RhO}$

$72 \mathrm{Na}_{2 \mathrm{RuO}}$

$6 \mathrm{Na} 2 \mathrm{SO} 4$

$68 \mathrm{~N}_{\mathrm{A} A 102}$

$114 \mathrm{NaBO2}$

$140 \mathrm{NaBO2}$ Seml Vol $50 \mathrm{NaCOOH}$
Appendix H

Tablo 21-16

Page 127 of 173

Dato 09/80/82 Rev 09

181

132

Inlet Gas to Sand Filter

Sand Filter

Exhoust

.0000

.0000

.0000

.0000

$.3566 \mathrm{E}-09$

$.8566 \mathrm{~K}-12$

$.1109 \mathrm{E}-09$

$.1109 \mathrm{E}-12$

.5827

.5827

.0000

.0000

.0000

.0000

4669E-01

.0000

$.4669 \mathrm{E}-01$

.0000

.0000

.0000

.3793E-03

.0000

.0000

.0000

.0000

.3793E-03

.5225E-13

.5225E-16

. 1590E-09

$.1590 \mathrm{E}-12$

$.7755 \mathrm{E}-09$

.0000

$.7755 \mathrm{E}-09$

.0000

.0000

.2323E-10

.2448E-09

.2323E-13

.2448ז-12

.2794I-11

2794E-08

$.1221 \mathrm{E}-12$

$8199 E-13$

$.8199 \mathrm{E}-16$

$.9803 E-12$

$.1095 \mathrm{E}-11$

$.1095 \mathrm{E}-08$

.0000

.0000

$.2122 \mathrm{E}-13$

$.2122 \mathrm{E}-10$

.0000

.0000

.4407 Ed06

.0000

0000

.0000

$.4407 \mathrm{E}+06$

.0000

2.213

.1703

.1703

$.7813 E-16$

$.4062 \mathrm{E}-13$

$.7813 \mathrm{E}-13$

$.9322 \mathrm{E}-14$

.0000

.0000

$.8696 \mathrm{E}-11$

$.8169 \mathrm{E}-211$

$.6514 \mathrm{E}-18$

$.6357 \mathrm{E}-17$

$.1289 \mathrm{E}-13$

$.3169 \mathrm{E}-13$

.0000

.0000

.3083E-11
183

Fan Exhaust

so Stack

.0000

.0000

$.3566 \mathrm{E}-12$

. 1109E- 12

.5827

.0000

.0000

$.4669 \mathrm{E}-01$

.0000

.0000

.0000

.0000

. 8793E-03

.5225E-16

. 1590E-12

$.7755 \mathrm{E}-09$

.0000

.0000

.2323E- 13

.2448E-12.

$.2794 \mathrm{E}-11$

$.1221 E-12$

$.8199 E-16$

$.9803 \mathrm{E}-12$

$.1095 \mathrm{E}-11$

.0000

.2122E-13

.0000

.0000

$.4407 E 4.06$

.0000

2.213

.1703

$.7813 E-16$

$.4062 \mathrm{E}-13$

$.9322 E-14$

.0000

$.8696 \mathrm{E}-11$

$.8169 \mathrm{E}-20$

$.6514 \mathrm{E}-18$

$.6357 \mathrm{E}-17$

$.1289 \mathrm{E}-18$

$.8169 \mathrm{E}-13$

.0000

.0000

$.3083 E-11$
134

Stack

Exhaust

.0000

.0000

$.8566 \mathrm{E}-12$

. 1109E-12

.5827

.0000

.0000

$.4669 \mathrm{E}-01$

.0000

.0000

.0000

.0000

$.3793 \mathrm{E}-03$

. 5225E-16

. 1590E- 12

$.7755 \mathrm{E}-09$

.0000

.0000

.2323E- 13

.2448E-12

$.2794 \mathrm{E}-11$

$.1221 E-12$

$.8199 \mathrm{E}-16$

$.9803 \mathrm{E}-12$

$.1095 \mathrm{E}-11$

.0000

.2122E-13

.0000

.0000

$.4407 \mathrm{E}+06$

.0000

2.213

.1703

$.7813 \mathrm{E}-16$

.4062E-13

$.9322 \mathrm{E}-14$

.0000

$.8696 \mathrm{E}-11$

.3160E-20

$.6514 \mathrm{E}-18$

$.6357 \mathrm{E}-17$

$.1289 \mathrm{E}-13$

$.8169 E-13$

.0000

.0000

$.3088 \mathrm{E}-11$ 
DPSP $80-1088$

MATERIAL BALANCE TABLES SLUDGE-SUPERNATE FEED STREAMS (CONT'D)STREAM NAME

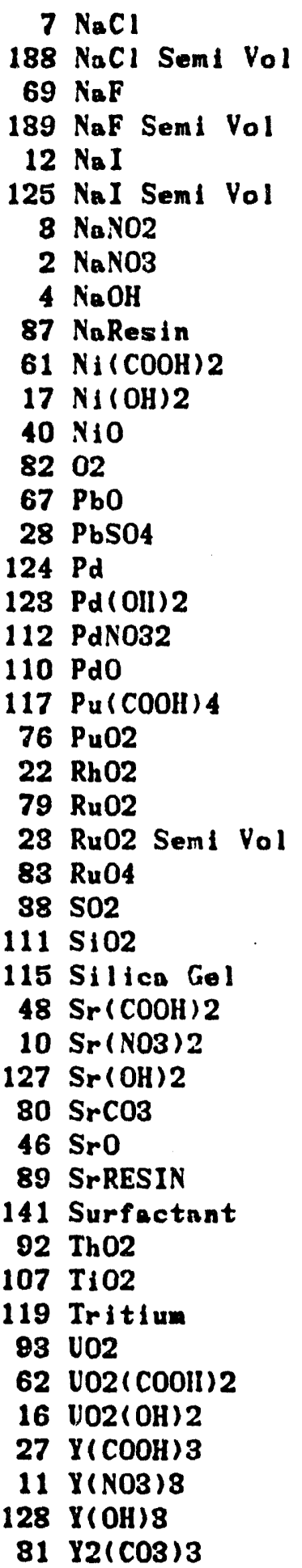

181

132

Inlet Gas to Sani Filter

Sand Filter .2283E-08

.0000

$.1863 \mathrm{E}-08$

.0000

2282E- 09

.0000

.0000

$.9071 \mathrm{E}-09$

$.8901 \mathrm{E}-12$

.0000

$.8837 \mathrm{E}-09$

$.3149 \mathrm{E}-12$

.0000

$.1331 E \pm 06$

.0000

$.1742 E-10$

.0000

.0000

.0000

.0000

$.1784 \mathrm{E}-13$

$.4533 E-11$

$.1782 E-11$

$.1657 \mathrm{E}-09$

.0000

.0000

.8100

.2984E-07

.0000

$.1562 \mathrm{E}-10$

$.1826 \mathrm{E}-16$

$.1408 \mathrm{E}-18$

.0000

.0000

.0000

.0000

$.7107 \mathrm{E}-10$

$.4896 E-09$

$.1787 \mathrm{E}-09$

.0000

$.4964 \mathrm{E}-09$

$.5518 \mathrm{E}-12$

$.1068 \mathrm{E}-10$

$.1297 \mathrm{E}-16$

$.8783 E-14$

.0000
Exinaust

.2288E-11

.0000

$.1868 \mathrm{E}-11$

.0000

$.2282 E-12$

.0000

.0000

$.9071 E-12$

$.3901 E-15$

.0000

$.3837 \mathrm{E}-12$

$.3149 \mathrm{E}-15$

.0000

$.1331 \mathrm{E}+06$

.0000

$.1742 \mathrm{E}-13$

.0000

.0000

.0000

.0000

$.1784 E-16$

$.4533 \mathrm{E}-14$

. 1732E-14

$.1657 \mathrm{E}-12$

.0000

.0000

.3100

$.2934 \mathrm{E}-10$

.0000

$.1562 \mathrm{E}-13$

$.1826 \mathrm{E}-19$

$.1408 \mathrm{E}-16$

.0000

.0000

.0000

.0000

$.7107 E-13$

$.4896 \mathrm{E}-12$

.1787 E-09

.0000

$.4964 \mathrm{E}-12$

$.5518 \mathrm{E}-15$

$.1068 \mathrm{E}-18$

$.1297 \mathrm{E}-19$

$.8783 \mathrm{E}-17$

.0000
Appendix II

Tablo 21-16

Page 128 of 173

Dato 09/30/82 Rev 09
133

Fan Exhaust

to Stack

.2288E-11

.0000

$.1868 \mathrm{E}-11$

.0000

.2282E-12

.0000

.0000

$.9071 \mathrm{E}-12$

$.3901 E-15$

.0000

$.8837 \mathrm{E}-12$

$.3149 \mathrm{q}-15$

.0000

$.1331 \mathrm{E}+06$

.0000

$.1742 \leftleftarrows-13$

.0000

.0000

.0000

.0000

$.1784 \mathrm{E}-16$

$.4533 \mathrm{E}-14$

$.1732 \mathrm{E}-14$

$.1657 \mathrm{E}-12$

.0000

.0000

.8100

.2984E-10

.0000

$.1562 \mathrm{E}-18$

$.1826 \mathrm{E}-19$

$.1408 \mathrm{E}-16$

.0000

.0000

.0000

.0000

$.7107 \mathrm{E}-13$

$.4896 \mathrm{E}-12$

.1787 E-09

.0000

$.4964 \mathrm{E}-12$

$.5518 \mathrm{E}-15$

$.1068 \mathrm{E}-13$

$.1297 \mathrm{E}-19$

$.8783 E-17$

.0000
134

Stack

Exhaust

.22885-11

.0000

. 1868E- 11

.0000

.2282E-12

.0000

.0000

$.9071 E-12$

$.3901 E-15$

.0000

$.8837 \mathrm{E}-12$

$.3149 \mathrm{E}-15$

.0000

. 1331E\$06

.0000

$.1742 E-13$

.0000

.0000

.0000

.0000

$.1784 \mathrm{E}-16$

$.4533 \mathrm{E}-14$

. 1732E-14

$.1657 \mathrm{E}-12$

.0000

.0000

.8100

.2934E-10

.0000

.1562 E- 13

$.1826 \mathrm{E}-19$

$.1408 E-16$

.0000

.0000

.0000

.0000

$.7107 E-13$

$.4896 E-12$

$.1787 E-09$

.0000

$.4964 \mathrm{E}-12$

$.5518 \mathrm{E}-15$

. 1068E-13

$.1297 E-10$

$.8783 E-17$

.0000 
MATEIRILL BALANCE TABLES

Din to 09/80/82 Rev 09

SLUDGE-SUPTRNATE FEED

STREAMS (CONT'D)-

STREAM NAME

$47 \curlyvee 203$

100 Zenlite

$44 \mathrm{Zn}(\mathrm{COOH}) 2$

$54 \mathrm{Zn}($ OII $) 2$

$57 \ln 0$

$104 \mathrm{Zr} 02$

TOTAL FLOW, LB/HR

VAPOR FLOW, CFM

LIUUID FLOW, GPM

DESIGN FLOW,

DENSITY, LBS/FT3

TEMPERATURE, DEG C

PRESSURE, ATM

PRESSURE, PSIG

PRESSURE, MI HG

PHASE

ENTHALPY, PCU/IIR
181

Inlet Gas to Sand Filtor

Sand Filter

.0000

$.4548 \mathrm{E}-09$

$.5612 E-10$

$.4750 \mathrm{E}-13$

.0000

$.2448 E-09$

683528.48

138982.53

.0700

85.24

.99

$-.11$

754.88

VAPOR
Exhaust

.0000

$.4548 E-12$

$.5642 E-13$

$.4750 \mathrm{D}-16$

.0000

$.2448 \Xi-12$

683523.48

142499.80

188
Fon Exhaust
to Stack
.0000
$.4548 \mathrm{E}-12$
$.6642 \mathrm{E}-13$
$.4750 \mathrm{E}-16$
.0000
$.2448 \mathrm{E}-12$
883528.48
189924.63

.0695

89.65

1.00

.00

735.76

VAPOR

$\begin{array}{rrr}\text { VAPOR } & \text { VAPOR } & \text { VAPOR } \\ -29997035.00 & -29381418.75 & -29381418.75\end{array}$
184

Stack

Exhaust

.0000

$.4543 \mathrm{E}-12$

. 6642E-13

$.4750 \mathrm{E}-16$

.0000

.2448E- 12

588528.48

189924.68

$-29994690.00-29997035.00-29381418.75 \quad-29381418.75$ 
DPSP $80-1033$

MATERIAL BALANCE TABLES

SLUDGE-SUPERNATE FEED

STREAM NUMBERS -

STREAM NAME

COMPONENT FLOWS, LB/HR

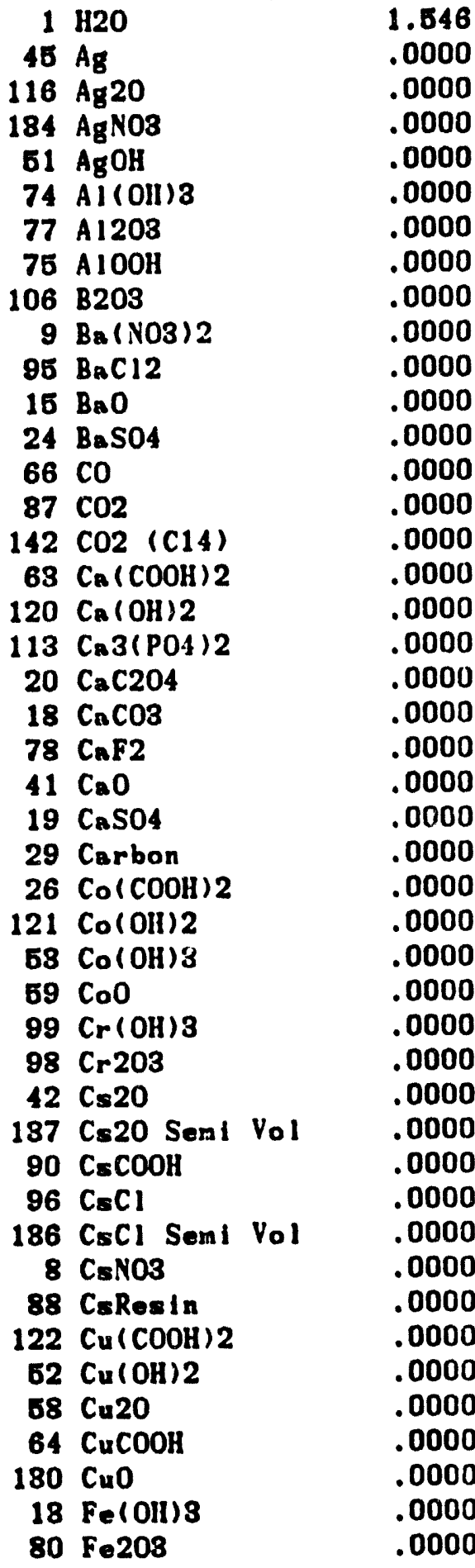

Appendix H

Tnble 21-16

Page 180 of 178

Date 09/80/82 Rev 09 $\begin{array}{llll}185 & 186 & 137 & 188\end{array}$

EO Wt\% NaCH DHTT Liquid Stenm to Steam Conden

to DWWT to RCT DHTT Coll snte fr DHIT
.0000

.0000

.0000

.0000

.0000

.0000

.0000

.0000

.0000

.0000

.0000

.0000

.0000

.0000

.0000

.0000

.0000

.0000

.0000

.0000

.0000

.0000

.0000

.0000

.0000

.0000

.0000

.0000

.0000

.0000

.0000

.0000

.0000

.0000

.0000

.0000

.0000

.0000

.0000

.0000

.0000

.0000

.0000

.0000

$.0000^{\circ}$ 
MATERIAL BALANCE TABLES

Date 09/80/82 Rev 09

\section{SLUDGE-SUPERNATE FEED}

STREAMS (CONT'D)-

STREAM NAME

$101 \mathrm{~F} \cdot 0$

126 Group A Seml Vo

102 GroupA

103 Group B

25112

$133 \mathrm{H} 2 \mathrm{C} 204$

$91 \mathrm{H} 202$

84 HCOOII

$43 \mathrm{HCl}$

$85 \mathrm{HF}$

49 HNOS

86 HResin

$86 \mathrm{Hg}$

$135 \mathrm{HgNO} 2$

$21 \mathrm{HgO}$

9712

$\begin{array}{lll}39 & 1.20\end{array}$

$131 \mathrm{KMnO4}$

$118 \mathrm{KNO3}$

105 La203

108 Li20

$65 \mathrm{Mg}(\mathrm{COOH}) 2$

$65 \mathrm{Mg}$ (OII) 2

$83 \mathrm{Mg} 0$

$60 \mathrm{Mn}(\mathrm{COOH}) 2$

$132 \mathrm{Mn}(\mathrm{NO}) 2$

$129 \mathrm{Mn}(\mathrm{Oll}) 2$

$56 \mathrm{MnO}$

$14 \mathrm{MnO2}$

81 N2

$143 \mathrm{NA2CO3}(\mathrm{C} 14)$

$85 \mathrm{NO}$

$84 \mathrm{NO2}$

$70 \mathrm{Nn}\left(\mathrm{Hg}_{\mathrm{g}} \mathrm{O}(\mathrm{OlI})\right)$

$94 \mathrm{Na} 2 \mathrm{~B} 407$

$109 \mathrm{Nin} 2 \mathrm{C204}$

$5 \mathrm{Nn} 2 \mathrm{CO3}$

$82 \mathrm{Na} 20$

$71 \mathrm{Na} 2 \mathrm{Pu} 02(\mathrm{OH}) 4$

$78 \mathrm{Nn} 2 \mathrm{RhO}^{2}$

$72 \mathrm{Nin} 2 \mathrm{RuO4}$

$6 \mathrm{Na} 2 \mathrm{SO} 4$

$68 \mathrm{NaA} 102$

$114 \mathrm{NaB02}$

$140 \mathrm{NaBO2}$ Semi Vol

$60 \mathrm{NaCOOH}$
188

60 Wt\% NaOH DIITT Liquid

to DWWT

.0000

.0000

.0000

.0000

.0000

.0000

.0000

.0000

.0000

.0000

.0000

.0000

.0000

.0000

.0000

.0000

.0000

.0000

.0000

.0000

.0000

.0000

.0000

.0000

.0000

.0000

.0000

.0000

.0000

.0000

.0000

.0000

.0000

.0000

.0000

.0000

.0000

.0000

.0000

.0000

.0000

.0000

.0000

.0000

.0000

.0000 to RCT

.0000

.0000

.0000

.0000

.0000

.0000

.0000

.0000

.0000

.0000

.0000

.0000

.0000

.0000

.0000

.0000

.0000

.0000

.1970

.0000

.0000

.0000

.0000

.0000

.0000

.0000

.1784

.0000

.0000

$.8276 E-02$

.0000

.2386E-03

.0000

.0000

.0000

.7906E-01

.0000

.0000

.0000

.0000

.0000

.0000

.0000

.0000

.0000

.0000
187

Stoon to

DWTT Coll

.0000

.0000

.0000

.0000

.0000

.0000

.0000

.0000

.0000

.0000

.0000

.0000

.0000

.0000

.0000

.0000

.0000

.0000

.0000

.0000

.0000

.0000

.0000

.0000

.0000

.0000

.0000

.0000

.0000

.0000

.0000

.0000

.0000

.0000

.0000

.0000

.0000

.0000

.0000

.0000

.0000

.0000

.0000

.0000

.0000

.0000
188

Stoan Conden

ut to Pr DUTT

.0000

.0000

.0000

.0000

.0000

.0000

.0000

.0000

.0000

.0000

.0000

.0000

.0000

.0000

.0000

.0000

.0000

.0000

.0000

.0000

.0000

.0000

.0000

.0000

.0000

.0000

.0000

.0000

.0000

.0000

.0000

.0000

.0000

.0000

.0000

.0000

.0000

.0000

.0000

.0000

.0000

.0000

.0000

.0000

.0000

.0000 
IATERIAL BALANCE TABLES

Date 09/80/82 Rov 09

\section{SLUDGE-SUPERNATE FEED}

STREAMS (CONT'D)-

STREAM NAME

$7 \mathrm{NaCl}$

188 NoCl Semt Vol

$69 \mathrm{NaF}$

189 NaF Seml Vol

$12 \mathrm{NaI}$

$125 \mathrm{NaI}$ Seml Vol

$8 \mathrm{NaNO} 2$

$2 \mathrm{NaNOB}$

$4 \mathrm{NaOH}$

87 NaResin

$61 \mathrm{Ni}(\mathrm{COOH}) 2$

$17 \mathrm{Ni}(\mathrm{OH}) 2$

$40 \mathrm{NiO}$

8202

$67 \mathrm{PbO}$

$28 \mathrm{PbSO} 4$

$124 \mathrm{Pd}$

$128 \mathrm{Pd}(\mathrm{OH}) 2$

112 PdNO32

$110 \mathrm{PdO}$

$117 \mathrm{Pu}(\mathrm{COOH}) 4$

$76 \mathrm{Pu} 02$

$22 \mathrm{RhO2}$

$79 \mathrm{RuO2}$

23 Ru02 Semi Vol

$83 \mathrm{Ru} 04^{2}$

$88 \mathrm{SO2}$

$111 \mathrm{SiO2}$

115 Silica Gel

$48 \mathrm{Sr}(\mathrm{COOH}) 2$

$10 \mathrm{Sr}(\mathrm{NOS}) 2$

$127 \mathrm{Sr}(\mathrm{OH}) 2$

$80 \mathrm{SrCOB}$

46 Sro

89 SRRESIN

141 Surfactant

$92 \mathrm{Th} 02$

107 T 102

119 Tritium

$98 \mathrm{VO2}$

$62 \mathrm{VO2}(\mathrm{COOH}) 2$

$16 \mathrm{VO2}(\mathrm{OH}) 2$

$27 \mathrm{Y}(\mathrm{COOH}) \mathrm{S}$

$11 \mathrm{Y}(\mathrm{NOS}) 3$

$128 \mathrm{Y}(\mathrm{OH}) 3$

$81 Y 2(\cos ) 8$
185

BO WtK NaOH DHT: Liquid

to DUWT

.0000

.0000

.0000

.0000

.0000

.0000

.0000

.0000

1.646

.0000

.0000

.0000

.0000

.0000

.0000

.0000

.0000

.0000

.0000

.0000

.0000

.0000

.0000

.0000

.0000

.0000

.0000

.0000

.0000

.0000

.0000

.0000

.0000

.0000

.0000

.0000

.0000

.0000

.0000

.0000

.0000

.0000

.0000

.0000

.0000

.0000 to RCT

.0000

.0000

.0000

.0000

.0000

.0000

.0000

8.175

$.5000 E-02$

.0000

.0000

.0000

.0000

. 1890E-02

.0000

.0000

.0000

.0000

.0000

.0000

.0000

.0000

.0000

.0000

.0000

.0000

.0000

.0000

.0000

.0000

.0000

.0000

.0000

.0000

.0000

.0000

.0000

.0000

.0000

.0000

.0000

.0000

.0000

.0000

.0000

.0000
137

Stoam to DUTT Coil .0000

.0000

.0000

.0000

.0000

.0000

.0000

.0000

.0000

.0000

.0000

.0000

.0000

.0000

.0000

.0000

.0000

.0000

.0000

.0000

.0000

.0000

.0000

.0000

.0000

.0000

.0000

.0000

.0000

.0000

.0000

.0000

.0000

.0000

.0000

.0000

.0000

.0000

.0000

.0000

.0000

.0000

.0000

.0000

.0000

.0000
138

Steam Conden

sate $\mathrm{fr}$ DUr $\mathrm{d}$

.0000

.0000

.0000

.0000

.0000

.0000

.0000

.0000

.0000

.0000

.0000

.0000

.0000

.0000

.0000

.0000

.0000

.0000

.0000

.0000

.0000

.0000

.0000

.0000

.0000

.0000

.0000

.0000

.0000

.0000

.0000

.0000

.0000

.0000

.0000

.0000

.0000

.0000

.0000

.0000

.0000

.0000

.0000

.0000

.0000

.0000 
MATERIAL BALANCE TABLES

Date 09/80/82 Rev 09

\section{SLUDGE-SUPERNATE FEED} STREAMS (CONT'D) STREAM NAME

$47 \times 203$

100 Zeolite

$41 \mathrm{Zn}(\mathrm{COOHI}) 2$

$54 \mathrm{Zn}(\mathrm{OHI}) 2$

$57 \mathrm{ZnO}$

$104 \mathrm{Zr} 02$

TOTAL FLOW, LB/HR

VAPOR FLOW, CFM LIQUID ILOH, GPM DESIGN FLOW, DEYSITY, LBS/FT3 TEYPERATURE, DEG C PRESSURE, ATM PRESSURE, PSIG PRESSURE, MM HG PIIASE

ENTIIALPY, PCV/IIR

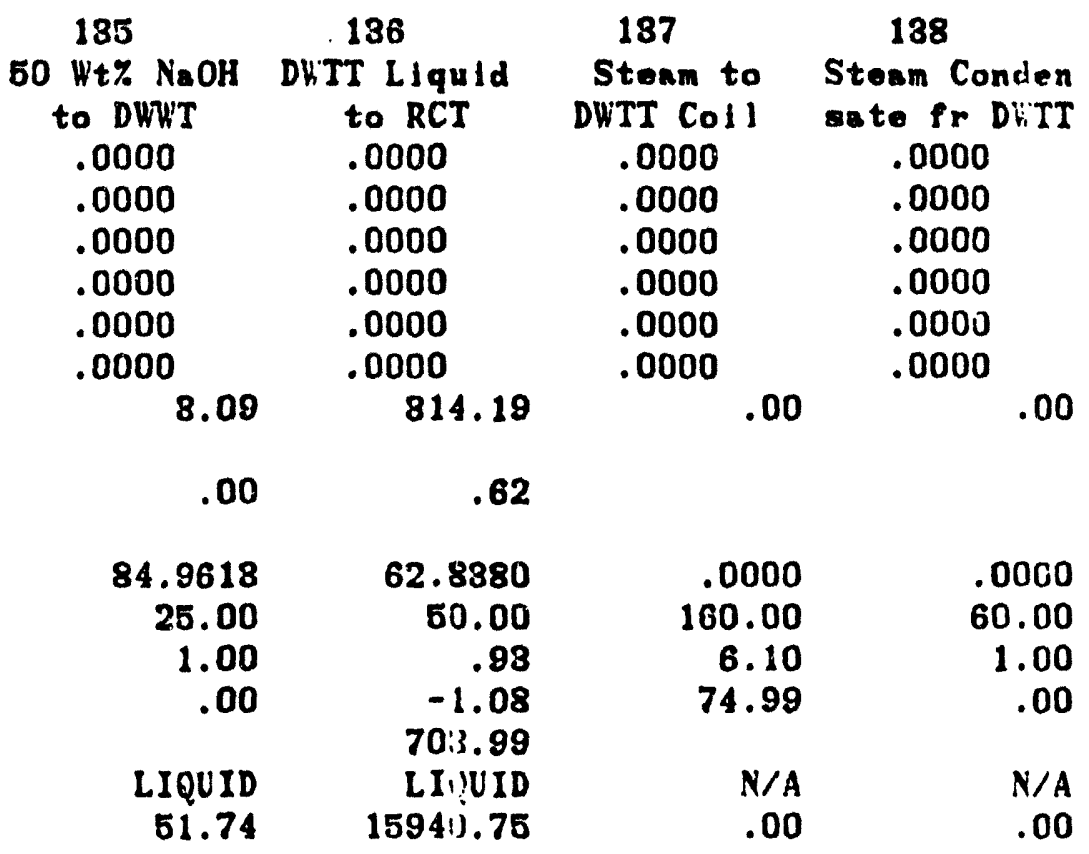


DPSP 80-1038

MATERIAL BALANCE TABLES

SLLDGE-SLPERNATE. FEED

STREAM NUMBERS -

STREAM NAME

COMPONENT FLOHS, LB/HR

\begin{tabular}{|c|c|c|c|c|c|}
\hline 1 & $\mathrm{H2O}$ & .3735 & .7463 & .1816 & 151.1 \\
\hline 45 & $\mathrm{Ag}$ & .0000 & .0000 & .0000 & .0000 \\
\hline 16 & Ag20 & .0000 & .0000 & .0000 & .0000 \\
\hline 84 & AgN03 & .0000 & .0000 & .0000 & .0000 \\
\hline 51 & $\mathrm{AgOH}$ & .0000 & .0000 & .0000 & .0000 \\
\hline 74 & Al (OH) 3 & .0000 & .0000 & .0000 & .0000 \\
\hline 77 & A1203 & .0000 & .0000 & .0000 & .0000 \\
\hline 75 & A $100 \mathrm{H}$ & .0000 & .0000 & .0000 & .0000 \\
\hline 06 & B203 & .0000 & .0000 & .0000 & 6.616 \\
\hline 9 & $\mathrm{Ba}(\mathrm{NO3}) 2$ & .0000 & .0000 & .0000 & .0000 \\
\hline 95 & $\mathrm{BaCl2}$ & .0000 & .0000 & .0000 & .0000 \\
\hline 15 & $\mathrm{BaO}$ & .0000 & .0000 & .0000 & .0000 \\
\hline 24 & $\mathrm{BnSO4}$ & .0000 & .0000 & .0000 & .0000 \\
\hline 66 & CO & .0000 & .0000 & .0000 & .0000 \\
\hline 87 & $\mathrm{CO} 2$ & .0000 & .0000 & .0000 & .0000 \\
\hline 42 & $\operatorname{Co2}(C 14)$ & .0000 & .0000 & .0000 & .0000 \\
\hline 63 & $C_{B}(\mathrm{COOH}) 2$ & .0000 & .0000 & .0000 & .0000 \\
\hline 20 & $\mathrm{Ca}_{\mathrm{a}}(\mathrm{OH}) 2$ & .0000 & .0000 & .0000 & .0000 \\
\hline 13 & $\mathrm{Ca} 3(\mathrm{PO} 04) 2$ & .0000 & .0000 & .0000 & .0000 \\
\hline 20 & $\mathrm{CaC204}$ & .0000 & .0000 & .0000 & .0000 \\
\hline 18 & $\mathrm{C}_{\mathrm{BCO}} \mathrm{CO}$ & .0000 & .0000 & .0000 & .0000 \\
\hline 78 & $\mathrm{CaF2}$ & .0000 & .0000 & .0000 & .0000 \\
\hline 41 & $\mathrm{CaO}$ & .0000 & .0000 & .0000 & .0000 \\
\hline 19 & CaSO. & .0000 & .0000 & .0000 & .0000 \\
\hline 29 & Carbon & .0000 & .0000 & .0000 & .0000 \\
\hline 26 & $\mathrm{Co}(\mathrm{COOH}) 2$ & .0000 & .0000 & .0000 & .0000 \\
\hline 21 & $\mathrm{Co}(\mathrm{OII}) 2$ & .0000 & .0000 & .0000 & .0000 \\
\hline 53 & $\mathrm{Co}(\mathrm{Oll}) 3$ & .0000 & .0000 & .0000 & .0000 \\
\hline 59 & $\mathrm{CoO}$ & .0000 & .0000 & .0000 & .0000 \\
\hline 99 & $\mathrm{Cr}(\mathrm{OH}) 3$ & .0000 & .0000 & .0000 & .0000 \\
\hline 98 & Cr203 & .0000 & .0000 & .0000 & .0000 \\
\hline 42 & Cs20 & .0000 & .0000 & .0000 & .0000 \\
\hline 37 & Cs20 Semi Vol & .0000 & .0000 & .0000 & .0000 \\
\hline 90 & $\mathrm{CsCOOH}$ & .0000 & .0000 & .0000 & .0000 \\
\hline 96 & $\mathrm{Cs} C \mathrm{Cl}$ & .0000 & .0000 & .0000 & .0000 \\
\hline 186 & Cscl Semi Vol & .0000 & .0000 & .0000 & .0000 \\
\hline 8 & CsNO3 & .0000 & .0000 & .0000 & .0000 \\
\hline 88 & CsResin & .0000 & .0000 & .0000 & .0000 \\
\hline & $\mathrm{Cu}(\mathrm{COOH}) 2$ & .0000 & .0000 & .0000 & .0000 \\
\hline 52 & $\mathrm{Cu}(\mathrm{OH}) 2$ & .0000 & .0000 & .0000 & .0000 \\
\hline 68 & Cu2O & .0000 & .0000 & .0000 & .0000 \\
\hline 64 & $\mathrm{CuCOOH}$ & .0000 & .0000 & .0000 & .0000 \\
\hline 130 & $\mathrm{CuO}$ & .0000 & .0000 & .0000 & .0000 \\
\hline 18 & Fe(OH)3 & .0000 & .0000 & .0000 & .0000 \\
\hline & Fe203 & .0000 & .0000 & .0000 & .0000 \\
\hline
\end{tabular}

Appendix H

Table 21-16

Date $09 / 30 / 82$ Rev 09

189

140

141

142

Air Sparege Air Sparge INGO3 Hish Frit Slurry to SFHT

to FCT

to MANT

to Siilir

31.1

0000

.0000

0000

0000

.616

0000

0000

0000

0000

0000

.0000

.0000

.0000

0000

.0000

0000

0000

0000

.

.0000

0000
Page 131 of 173 
DPSP $80-1033$

MATERIAL BAIANCE TALLES

SLUDGE-SLPERNATE FEED

STREAMS (CONT'D) STREAM NAME

101 Feo
126 Group A Semi Vo
102 GroupA
103 Group B
25 H2

$133 \mathrm{H} 2 \mathrm{C} 204$

$91 \mathrm{H2O2}$

34 HCOOII

$43 \mathrm{HCl}$

$85 \mathrm{HF}$

49 HNO3

86 HResin

$86 \mathrm{Hg}$

135 HgNO32

$21 \mathrm{HgO}$

$97 \quad 12$

$39 \mathrm{~K} 20$

$131 \mathrm{KMnO4}$

$118 \mathrm{KNO3}$

$105 \quad$ La203

$108 \lcm{120}$

$65 \mathrm{Mg}(\mathrm{COOHI}) 2$

$55 \mathrm{Mg}(\mathrm{OII}) 2$

$83 \mathrm{MgO}$

$60 \mathrm{Mn}(\mathrm{COOII}) 2$

$132 \mathrm{Mn}(\mathrm{YOS}) 2$

$129 \mathrm{Mn}(\mathrm{Oli}) 2$

$56 \mathrm{MnO}$

$14 \mathrm{MnO2}$

$81 \mathrm{~N} 2$

$143 \mathrm{NA2CO3} \mathrm{(C14)}$

$85 \mathrm{NO}$

$84 \mathrm{~N} 02$

$70 \mathrm{Ya}(\mathrm{HgO}(\mathrm{OlI}))$

$94 \quad \mathrm{Na} 2 \mathrm{~B} 107$

$109 \mathrm{Na}_{2} \mathrm{C2O4}$

$5 \mathrm{Na} 2 \mathrm{CO} 3$

32 Na 20

$71 \mathrm{Na} 2 \mathrm{Pu}_{\mathrm{U}} 02$ (OII) 4

$73 \mathrm{~N}$ 2Rh04

$72 \mathrm{Na} 2 \mathrm{RuO}_{4}$

$6 \mathrm{Na} 2 \mathrm{SO} 4$

68 NaAl02

$114 \mathrm{NaBO} 2$

$140 \mathrm{NaBO2}$ Semi Vol

$50 \mathrm{NaCOOH}$
139

Air Sparge
to SFHT

.0000

.0000

.0000

.0000

.0000

.0000

.0000

.0000

.0000

.0000

.0000

.0000

.0000

.0000

.0000

.0000

.0000

.0000

.0000

.0000

.0000

.0000

.0000

.0000

.0000

.0000

.0000

.0000

.0000

17.07

.0000

.0000

.0000

.0000

.0000

.0000

.0000

.0000

.0000

.0000

.0000

.0000

.0000

.0000

.0000

.0000
140

Air Spa:.ge

to FC?

.0000

.0000

.0000

.0000

.0000

.0000

.01000

.0000

.0000

.0000

.0000

.0000

.0000

.0000

.0000

.0000

.0000

.0000

.0000

.0000

.0000

.0000

.0000

.0000

.0000

.0000

.0000

.0000

.0000

84.12

.0000

.0000

.0000

.0000

.0000

.0000

.0000

.0000

.0000

.0000

.0000

.0000

.0000

.0000

.0000

.0000
Append IX HI

Inble 21-16

Page 185 of 173

Date 09/30/82 Rev 09 
DPSP $80-1038$

MATERIAL BALANCE TABLES

SLUDGE-SLPERNATE FEED

STREAMS (CONT'D)-

STREAM NAME:

$7 \mathrm{NaCl}$

$138 \mathrm{NaCl}$ Seml Vol

$69 \mathrm{NnF}$

$189 \mathrm{NnF}$ Semi Vol

$12 \mathrm{NaI}$

$125 \mathrm{NaI}$ Semi Vol

$8 \mathrm{NaNO2}$

$2 \mathrm{NaNO3}$

$4 \mathrm{NaOH}$

87 NinResin

$61 \mathrm{Ni}(\mathrm{COOII}) 2$

$17 \mathrm{Ni}(\mathrm{OH}) 2$

$40 \mathrm{NiO}$

8202

$67 \mathrm{PbO}$

$28 \mathrm{PbSO4}$

$124 \mathrm{Pd}$

$123 \mathrm{Pd}(\mathrm{OH}) 2$

112 PdNO32

110 PdO

$117 \mathrm{Pu}(\mathrm{COOH}) 4$

$76 \quad \mathrm{Pu} 02$

$22 \mathrm{Rh} 02$

79 Ru02

23 Ru02 Semi Vol

$83 \mathrm{Ru} 04$

$88 \mathrm{SO2}$

$111 \mathrm{Si02}$

115 Silica Gel

$48 \mathrm{Sr}$ (COOH) 2

$10 \mathrm{Sr}(\mathrm{NO3}) 2$

$127 \mathrm{Sr}(\mathrm{OH}) 2$

$80 \mathrm{SrCO} 3$

$46 \mathrm{Sr} 0$

89 SrRESIN

141 Surfactant

$92 \mathrm{Th} 02$

$107 \mathrm{TiO}$

119 Tritium

98 U02

$62 \mathrm{VO} 2(\mathrm{COOH}) 2$

$16 \mathrm{VO2}(\mathrm{OH}) 2$

$27 \mathrm{Y}(\mathrm{COOH}) 3$

$11 Y(N O 3) 3$

$128 \mathrm{Y}(\mathrm{OH}) 8$

31 Y2 $(\cos ) 3$
139

Air Spare

to SFHT

.0000

.0000

.0000

.0000

.0000

.0000

.0000

.0000

.0000

.0000

.0000

.0000

.0000

5. 158

.0000

.0000

.0000

.0000

.0000

.0000

.0000

.0000

.0000

.0000

.0000

.0000

.0000

.0000

.0000

.0000

.0000

.0000

.0000

.0000

.0000

.0000

.0000

.0000

.0000

.0000

.0000

.0000

.0000

.0000

.0000

.0000
Appendix H

Table 21-16

Paze 136 of 173

Date 09/30/82 Rev 09

140

Air Sparge

to FCI

.0000

.0000

.0000

.0000

.0000

.0000

.0000

.0000

.0000

.0000

.0000

.0000

.0000

10.31

.0000

.0000

.0000

.0000

.0000

.0000

.0000

.0000

.0000

.0000

.0000

.0000

.0000

.0000

.0000

.0000

.0000

.0000

.0000

.0000

.0000

.0000

.0000

.0000

.0000

.0000

.0000

.0000

.0000

.0000

.0000

.0000
141

HirO3 Wash

to MALT

.0000

.0000

.0000

.0000

.0000

.0000

.0000

.0000

.0000

.0000

.0000

.0000

.0000

.0000

.0000

.0000

.0000

.0000

.0000

.0000

.0000

.0000

.0000

.0000

.0000

.0000

.0000

.0000

.0000

.0000

.0000

.0000

.0000

.0000

.0000

.0000

.0000

.0000

.0000

.0000

.0000

.0000

.0000

.0000

.0000
.0000
142

Frit Slurry

to SFIIT

.0000

.0000

.0000

.0000

.0000

.0000

.0000

.0000

.0000

.0000

.0000

.0000

.0000

.1670E-02

.0000

.0000

.0000

.0000

.0000

.0000

.0000

.0000

.0000

.0000

.0000

.0000

.0000

26.06

.0000

.0000

.0000

.0000

.0000

.0000

.0000

.0000

.0000

.4501

.0000

.0000

.0000

.0000

.0000

.0000

.0000

.0000 
DPSP $80-1033$

MATERIAL BALANCE TABLES SLUDGE-SLPERNATE FEED STREAMS (CONT'D)STREAM NAME

$\begin{array}{rl}47 & \text { Y203 } \\ 100 & \mathrm{Zeolite} \\ 44 & \mathrm{Zn}(\mathrm{COOII}) 2 \\ 54 & \mathrm{Zn}(\mathrm{Oll}) 2 \\ 57 & \mathrm{Zn} 0 \\ 104 & \mathrm{Zr} 02\end{array}$

TOTAL FLON, LB/HR VAPOR FLOW, CFM LIOUID FLOW, GPM DESIGN FLOW, DENSITY, LES/FT3 TEMPERATURE, DEG C PRESSURE, ATM PRESSURE, PSIG PRESSURE, MM HG PHASE

ENTHALPY, PCU/IIR
139

Air Spargo

to SFIIT

.0000

.0000

.0000

.0000

.0000

.0000

22.61

5.84

.0706

85.00

1.00

.00

VAPOR

$-1164.14$

Appendix $H$

Table 21-16

Page 137 of 173

Date 09/80/82 Rev 09

140

Air Sparge

to FCI

.0000

.0000

.0000

.0000

.0000

.0000

45.17

10.67

.0706

85.00

1.00

.00

VAPOR

$-2320.09$
141

HNO3 Wash

to MAKT

.0000

.0000

.0000

.0000

.0000

.0000

.21

.00

65.0378

25.00

1.00

.00

LIQUID

4.78
.40

142

Frit Slurry

to SFIIT

.0000

.0000

.0000

.0000

.0000

.2250

226.56

70.1600

80.00

.97

$-.51$

733.86

LIQUID

6021.94 
DPSP $80-1033$

MATERIAL BALANCE IABLES

SLUDGE-SUPERNATE FEED

STREAM NUMBERS -

STREAM NAME

COMPONENT FLOHS, LB/HR

$1 \mathrm{H} 2 \mathrm{O}$

$45 \mathrm{Ag}$

116 Ag20

184 AgNO3

$51 \mathrm{AgOH}$

74 All OII) 3

77 A 1203

$75 \mathrm{AlOOH}$

$106 \mathrm{~B} 203$

$9 \mathrm{Ba}(\mathrm{N} 03) 2$

$95 \mathrm{BaCl} 2$

$15 \mathrm{BaO}$

$24 \mathrm{BnS04}$

$66 \mathrm{CO}$

$87 \mathrm{CO} 2$

$142 \mathrm{CO}$ ( $\mathrm{C} 14)$

$63 \mathrm{Ca}(\mathrm{COOH}) 2$

$120 \mathrm{Ca}(\mathrm{OH}) 2$

$113 \mathrm{Cn} 3(\mathrm{PO} 4) 2$

$20 \mathrm{CnC}_{2} \mathrm{O} 4$

$18 \mathrm{C}_{2} \mathrm{CO} 3$

$78 \mathrm{CaF2}$

$41 \mathrm{Ca} 0$

19 CaSO4

29 Carbon

$26 \mathrm{Co}(\mathrm{COOII}) 2$

$121 \mathrm{Co}(\mathrm{OH}) 2$

$53 \mathrm{Co}(\mathrm{OH}) 3$

$59 \mathrm{CoO}$

$99 \mathrm{Cr}(\mathrm{OH}) 3$

$98 \mathrm{Cr} 203$

42 Cs20

137 Cs20 Seml Vol

$90 \mathrm{CsCOOH}$

$96 \mathrm{CsCl}$

$136 \mathrm{CsCl}$ Semi Vol

8 CsNO3

88 CsResin

$122 \mathrm{Cu}(\mathrm{COOH}) 2$

$62 \mathrm{Cu}(\mathrm{OH}) 2$

$68 \mathrm{Cu} 20$

$64 \mathrm{CuCOOH}$

$180 \mathrm{CuO}$

$13 \mathrm{Fe}(\mathrm{OH}) \mathrm{8}$

$80 \mathrm{Fe} 203$
148

FavC Vent to PVVS

18.52

$.1609 \mathrm{E}-07$

.0000

.0000

. 5213E-00

$.4721 \mathrm{E}-06$

.0000

.0000

.2202E-05

$.6200 \mathrm{E}-14$

.0000

.0000

.5607E-08

$.4493 E-04$

4.443

$.8846 \mathrm{E}-10$

$.1942 E-06$

$.1479 E-09$

. 1397E-07

.1511E-07

.0000

$.3778 \mathrm{E}-08$

.0000

$.1775 \mathrm{E}-37$

$.1197 \mathrm{E}-07$

.8067E-08

$.2559 \mathrm{E}-11$

.0000

.0000

$.1436 \mathrm{E}-07$

.0000

$.1099 \mathrm{E}-12$

.0000

$.8721 \mathrm{E}-1) 8$

$.5772 E-10$

.0000

$.8977 E-09$

.0000

$.6551 E-08$

$.6566 \mathrm{E}-11$

.0000

.0000

.0000

$.1143 E-115$

.0000
144

Air. Sparge to MUNT

1328E-02

.0000

.0000

.0000

.0000

.0000

.0000

.0000

.0000

.0000

.0000

.0000

.0000

.0000

.0000

.0000

.0000

.0000

.0000

.0000

.0000

.0000

.0000

.0000

.0000

.0000

.0000

.0000

.0000

.0000

.0000

.0000

.0000

.0000

.0000

.0000

.0000

.0000

.0000

.0000

.0000

.0000

.0000

.0000

.0000
Appendix $H$

Table 21-16

Page 138 of 173

Date 09/30/82 Rev 09

145

146

HIN03 Sumps Liquid Sprny to DVITT to PIIDBF\#1

$.0000 \quad 2829$

$.0000 \quad .0000$

$.0000 \quad .0000$

$.0000 \quad .0000$

$.0000 \quad .6547 E-03$

$.0000 \quad .5789$

$.0000 \quad .0000$

$.0000 \quad .0000$

$.0000 \quad 1.225$

$.0000 \quad .5311 \mathrm{E}-08$

$.0000 \quad .0000$

$.0000 \quad .0000$

$.0000 \quad .4795 \mathrm{E}-02$

$.0000 \quad .3089 E-03$

$.0000 \quad .1549 \mathrm{E}-01$

$.0000 \quad .1610 \mathrm{E}-26$

.0000

.0000

.0000

.0000

.0000

.0000

.0000

.0000

.0000

.0000

.0000

.0000

.0000

.0000

.0000

.0000

.0000

.0000

.0000

.0000

.0000

.0000

.0000

.0000

.0000

.0000

.0000

.0000

.0000
.1663

.0000

$.1195 \mathrm{E}-01$

$.1202 E-01$

.0000

$.3231 \mathrm{E}-02$

.0000

$.1518 \mathrm{E}-01$

$.9509 E-02$

. 2626E-02

.0000

.0000

.0000

. 1228E-01

.0000

$.7699 E-07$

. 1267E-04

.7426E-02

$.4457 \mathrm{E}-06$

.3678E-01

.3407E-03

.0000

.5610E-02

.0000

.0000

.0000

.0000

1.401

.0000 
DPSP $80-1063$

MATERIAL BALANCE TABLES

SLUDGE-SUPERNATE FEED STREAMS (CONT'D)STREAM NAME

$101 \mathrm{FeO}$

126 Group A Semi Vo

102 GroupA

103 GroupB

$25 \mathrm{II} 2$

133 H2C2O4

Q1 11202

34 HCOOII

$43 \mathrm{HCl}$

$85 \mathrm{HF}$

49 HNO3

86 HResin

$86 \mathrm{llg}$

$125 \mathrm{HgN032}$

$21 \mathrm{HrO}$

$97 \quad 12$

$39 \mathrm{~K} 20$

$131 \mathrm{kMnO4}$

$118 \mathrm{KNO3}$

105 La203

$108 \mathrm{Li} 20$

$65 \mathrm{Mg}(\mathrm{COOH}) 2$

$55 \mathrm{Mg}(\mathrm{OHi}) 2$

$83 \mathrm{MgO}$

$60 \mathrm{Mn}(\mathrm{COOH}) 2$

$132 \operatorname{Mn}(\mathrm{NOS}) 2$

$129 \mathrm{Mn}(\mathrm{OH}) 2$

$56 \mathrm{M} \mathrm{n} 0$

$14 \mathrm{MnO2}$

$81 \mathrm{N2}$

$143 \mathrm{NA2CO3}(\mathrm{C} 14)$

35 io

$84 \mathrm{NO2}$

$70 \mathrm{Na}(\mathrm{HaO} \mathrm{OH})$ )

$94 \mathrm{Na} 2 \mathrm{~B} . \mathrm{O} 07$

$109 \mathrm{Na} 2 \mathrm{C204}$

$5 \mathrm{Na} 2 \mathrm{COS}$

$32 \mathrm{Ni \omega} 20$

$71 \mathrm{Na} 2 \mathrm{Pu}_{\mathrm{u}} \mathrm{O}(\mathrm{OH}) 4$

$73 \mathrm{Na} 2 \mathrm{RhOH}_{4}$

$72 \mathrm{Na} 2 \mathrm{RuO4}$

$6 \mathrm{Na} 2 \mathrm{SO}_{4}$

$68 \mathrm{NaAlO} 2$

$114 \mathrm{NaBO2}$

140 NaBO2 Semi Vol

$50 \mathrm{NaCOOII}$
143

FAVC Vent

to PVVS

.0000

.0000

$.1069 \mathrm{E}-07$

$.3358 \mathrm{E}-07$

$.3583 E-05$

.0000

.0000

$.4820 \mathrm{E}-01$

.0000

.0000

.0000

.0000

$.1543 \mathrm{E}-08$

.0000

. 1083E-09

.0000

.0000

.0000

$.2418 \mathrm{E}-08$

$.7479 \mathrm{E}-07$

$.8537 E-06$

$.3697 \mathrm{E}-07$

. 2523E- 10

.2995E-06

$.3317 E-06$

.0000

.2366E-08

.0000

.0000

1227.

.0000

$.7464 \mathrm{E}-01$

$.4041 \mathrm{E}-02$

.2367E- 10

. $1256 \mathrm{E}-08$

$.9701 \mathrm{E}-09$

.0000

.2653E-05

$.9598 \mathrm{E}-15$

$.1973 \mathrm{E}-12$

$.1926 \mathrm{E}-11$

$.8905 \mathrm{E}-08$

$.9598 \mathrm{E}-08$

.0000

.0000

$.9346 \mathrm{E}-06$

Appendix $H$

Table 21-16

Page 139 of 173

Date 09/80/82 Rev 09

144

Air Spa:ge

to MIW I

.0000

.0000

.0000

.0000

.0000

.0000

.0000

.0000

.0000

.0000

.0000

.0000

.0000

.0000

.0000

.0000

.0000

.0000

.0000

.0000

.0000

.0000

.0000

.0000

.0000

.0000

.0000

.0000

.0000

$.60731:-01$

.0000

.0000

.0000

.0000

.0000

.0000

.0000

.0000

.0000

.0000

.0000

.0000

.0000

.0000

.0000

.0000
145

HNO3 Sumps

to DWTT

.0000

.0000

.0000

.0000

.0000

.0000

.0000

.0000

.0000

.0000

.0000

.0000

.0000

.0000

.0000

.0000

.0000

.0000

.0000

.0000

.0000

.0000

.0000

.0000

.0000

.0000

.0000

.0000

.0000

.0000

.0000

.0000

.0000

.0000

.0000

.0000

.0000

.0000

.0000

.0000

.0000

.0000

.0000

.0000

.0000

.0000
146

Liquid Sprny

to PWDBF 1

.0000

$.6969 \mathrm{E}-01$

$.8984 \mathrm{E}-02$

.2872E-01

.2462E-04

.0000

.0000

.0000

.0000

.0000

.0000

.0000

.0000

.0000

.2226E-01

.0000

.0000

.0000

$.2225 \mathrm{E}-04$

.2897E-01

.4741

$.3166 \mathrm{E}-01$

.0000

.1606

.2843

.0000

.0000

.0000

.0000

.8038E-01

.0000

$.8862 \mathrm{E}-04$

$.6178 \mathrm{E}-01$

.2027E-04

.7781

$.8928 \mathrm{E}-05$

.0000

1.756

$.8222 \mathrm{E}-09$

. 1690E-0G

$.1649 E-05$

.8345E-02

$.8222 \mathrm{E}-02$

.0000

.0000

.9377 
DPSP 80-1038

MATERIAL BALANCE TABLES SLUDGE-SUPERNATE FEED STREAMS (CONT'D)STREAM NAME

$7 \mathrm{NnCl}$

$188 \mathrm{NaCl}$ Seml Vol

$69 \mathrm{NaF}$

139 NaF Semi Vol

$12 \mathrm{NaI}$

$125 \mathrm{NaI}$ Semi Vol

$8 \mathrm{NaNO2}$

$2 \mathrm{NaNO3}$

$4 \mathrm{NaOH}$

87 NaResin

$61 \mathrm{Ni}(\mathrm{COOH}) 2$

$17 \mathrm{Ni}(\mathrm{OH}) 2$

$40 \mathrm{NiO}$

8202

$67 \mathrm{PbO}$

$28 \mathrm{PbSO} 4$

$124 \mathrm{Pd}$

$123 \mathrm{Pd}(\mathrm{OH}) 2$

112 PdNO32

$110 \mathrm{PdO}$

$117 \mathrm{Pu}(\mathrm{COOH}) 4$

$76 \mathrm{Pu} 02$

$22 \mathrm{RhO2}$

$79 \mathrm{Ru} 02$

28 Ru02 Semi Vol

$83 \mathrm{Ru} 04$

$88 \mathrm{SO2}$

$111 \mathrm{SiO}$

115 Silica Gel

$48 \mathrm{Sr}(\mathrm{COOH}) 2$

$10 \mathrm{Sr}(\mathrm{NO3}) 2$

$127 \mathrm{Sr}(\mathrm{OH}) 2$

$30 \mathrm{SrCO}$

$46 \mathrm{Sr} 0$

89 SrRESIN

141 Surfactant

$92 \mathrm{ThO2}$

$107 \mathrm{Ti02}$

119 Tritium

$93 \mathrm{~V} 02$

$62 \mathrm{U} 02(\mathrm{COOH}) 2$

16 V02(OII) 2

$27 \mathrm{Y}(\mathrm{COOH}) 3$

$11 \mathrm{Y}(\mathrm{NO3}) 3$

$128 Y(\mathrm{OH}) \mathrm{B}$

$81 Y 2(\mathrm{CO}) 3$
148

FAVC Vent to PVVS

$.4723 E-08$

.0000

$.8311 \mathrm{E}-09$

.0000

$.4489 \mathrm{E}-09$

.0000

.0000

$.1631 E-06$

.0000

.0000

$.1162 \mathrm{E}-06$

$.9690 \mathrm{E}-10$

.0000

870.7

.0000

$.5277 \mathrm{E}-08$

.0000

.0000

.0000

.0000

.5403E- 11

. 1873E-08

$.5247 \mathrm{E}-09$

$.2620 \mathrm{E}-08$

.0000

.0000

.5283E-05

$.8960 \mathrm{E}-05$

.0000

$.4731 \mathrm{E}-08$

.5532E- 14

$.4832 E-11$

.0000

.0000

.0000

.0000

$.2153 E-37$

.1496E-J6

.5189E- 10

.0000

$.1604 \mathrm{E}-\mathrm{J} 6$

$.1698 \mathrm{E}-09$

$.3234 E-1) 8$

$.8929 E-14$

$.2702 E-11$

.0000
144

Al. Sparge

to MWWIT

.0000

.0000

.0000

.0000

.0000

.0000

.0000

.0000

.0000

.0000

.0000

.0000

.0000

$.1835 \mathrm{E}-01$

.0000

.0000

.0000

.0000

.0000

.0000

.0000

.0000

.0000

.0000

.0000

.0000

.0000

.0000

.0000

.0000

.0000

.0000

.0000

.0000

.0000

.0000

.0000

.0000

.0000

.0000

.0000

.0000

.0000

.0000

.0000

.0000

Appendix II

Table 21-16

Page 140 of 173

Dato ,09/30,'E2 Rev 09

145

HNO3 Sumps to DUTT

.0000

.0000

.0000

.0000

.0000

.0000

.0000

.0000

.0000

.0000

.0000

.0000

.0000

.0000

.0000

.0000

.0000

.0000

.0000

.0000

.0000

.0000

.0000

.0000

.0000

.0000

.0000

.0000

.0000

.0000

.0000

.0000

.0000

.0000

.0000

.0000

.0000

.0000

.0000

.0000

.0000

.0000

.0000

.0000

.0000

.0000
146

Liraid Spray to PUDBF it 1

.3333E-02

$.50 \$ 2$

.8846E-01

.4137

.3220r -03

$.4325 \mathrm{E}-01$

.0000

.1075

.0000

.0000

$.9954 \mathrm{E}-01$

.0000

.0000

$.1740 \mathrm{E}-01$

.0000

$.4513 \mathrm{E}-02$

.0000

.0000

.0000

.0000

$.4607 E-0 J$

. 1174E-02

$.4487 \mathrm{E}-03$

.2175E-02

.2168E-01

.0000

.3627E-04

5.189

.0000

$.4051 E-02$

$.4739 E-08$

.0000

.0000

.0000

.0000

.0000

$.1841 \mathrm{E}-01$

$.5794 E-01$

$.1102 \mathrm{E}-08$

.0000

.1287

.0000

$.2770 \mathrm{E}-02$

$.3365 \mathrm{E}-08$

.0000

$.0000^{\circ}$ 
DPSP $80-1033$

Material RALANCE TABLES

SLCDGE-SUPERNATE FEED

STREAMS (CONI'D)-

STREAM NAME

$47 \quad 1203$

100 Zeolite

$44 \mathrm{Zn}(\mathrm{COOH}) 2$

$54 \mathrm{Zn}(0 \mathrm{H}) 2$

$57 \mathrm{ZnO}$

$104 \mathrm{Zr} 02$

TOTAL FLOH, LB/HR

VAPOR FLOW, CFM

LIQUUID FLOH, GPM

DESIGN FLOW,

DENSITY, LBS/FT3

TEYPERATURE, DEG C

PRESSURE, ATM

PRESSURE, PSIG

PRESSURE, MA IIG

PHISE

ENTHALPY, PCU/HR
148

Fave Vent

to PVVS

.0000

$.1376 \mathrm{E}-06$

$.1709 \mathrm{E}-07$

$.1462 \mathrm{E}-10$

.0000

$.7479 \mathrm{E}-07$

1620.74

884.96

.0702

15.00

.93

$-1.08$

703.99

VAPOR

$-96121.20$
Appendix H

Table 21-16

Page 141 of 173

Date 09/30/82 Rev 09

144
AIr Spa go
to MUWI
.0000
.0000
.0000
.0000
.0000
.0000


.08
.02

\section{5}

HNO3 Sumps

to DHTT

.0000

.0000

.0000

.0000

.0000

.0000

1.00

.00

VAPOR

$-4.14$
.00

.00

.0000

35.00

1.00

.00

146

Liquid Spray

to PWDBF\#1

.0000

.1177

$.1463 \mathrm{E}-01$

.0000

.0000

.2897 E- 01

2844.43

5.66

62.6167

55.00

8.18

32.04

LIQUID

.00
LIQUID

159518.95 
DPSP $80-1033$

MATERIAL BALANCE TABLES

SLUDGE-SUPERNATE FEED

STREAM NUMBERS -

STREAM NAME

COMPONENT FLOWS, LB/IIR

$1 \mathrm{H} 20$

$45 \mathrm{Ag}$

116 Ag20

$184 \mathrm{AgNO3}$

$61 \mathrm{AgOH}$

74 Al (OH)S

77 A 1203

$75 \mathrm{~A} 100 \mathrm{H}$

106 B203

$9 \mathrm{Ba}(\mathrm{NO3}) 2$

$95 \mathrm{BaCl} 2$

$15 \mathrm{BaO}$

$24 \mathrm{BaSO} 4$

$66 \mathrm{CO}$

$87 \mathrm{CO} 2$

$142 \mathrm{CO}$ ( $\mathrm{C14})$

$63 \mathrm{Ca}(\mathrm{COOII}) 2$

$120 \mathrm{Ca}(\mathrm{OH}) 2$

$113 \mathrm{Ca} 3(\mathrm{PO}) 2$

$20 \mathrm{CaC2O4}$

$18 \mathrm{CaC03}$

$78 \mathrm{CaF2}$

$41 \mathrm{CaO}$

19 CaSO4

29 Carbon

$26 \mathrm{Co}(\mathrm{COOH}) 2$

$121 \mathrm{Co}(\mathrm{OH}) 2$

$53 \mathrm{Co}(\mathrm{OH}) 3$

59 Con

$99 \mathrm{Cr}(\mathrm{OH}) 3$

98 Cr203

$42 \operatorname{Cs} 20$

137 Cs20 Semi Vol

$90 \mathrm{CsCOOH}$

$96 \mathrm{CsCl}$

136 CsCl Semi Vol

8 CsNO3

88 CsResin

$122 \mathrm{Cu}(\mathrm{COOH}) 2$

$52 \mathrm{Cu}(\mathrm{OH}) 2$

$58 \mathrm{Cu} 20$

$64 \mathrm{CuCOOH}$

$180 \mathrm{CuO}$

$13 \mathrm{Fe}(\mathrm{OH}) \mathrm{S}$

$80 \mathrm{Fe} 203$
147

Liquid Spray PI:DBF \#2

to PWDBF:2 Exic Liquid

2829.

.0000

.0000

.0000

$.6547 \mathrm{E}-03$

.5789

.0000

.0000

1.225

$.5811 \mathrm{E}-08$

.0000

.0000

$.4795 \mathrm{E}-02$

.3089E-03

. 1549E-01

$.1610 \mathrm{E}-26$

.1663

.0000

$.1195 \mathrm{E}-01$

$.1292 E-01$

.0000

.3231E-02

.0000

$.1518 \mathrm{E}-\mathrm{J1}$

$.9509 \mathrm{E}-32$

.2626E-02

.0000

.0000

.0000

$.1228 \mathrm{E}-\mathrm{J} 1$

.0000

$.7699 \mathrm{E}-37$

$.1267 \mathrm{E}-04$

$.7426 \mathrm{E}-02$

$.4457 \mathrm{E}-06$

$.3678 \mathrm{E}-J 1$

.3407E-03

.0000

$.5610 \mathrm{E}-1] 2$

.0000

.0000

.0000

.0000

1.401

.0000
Appendix II

Tuble 21-16

Page 142 of 173

Date 09/80/E2 Rev 09 
DPSP $80-1033$

Material balance tables

SL!DGE-SUPERNATE FFICD

STREAMS ( CONT'D)-

STREAM NAME

101 FeO
126 Group A Senl Vo
102 GroupA
103 Groups
25112

133 H2C2O4

91 H202

$84 \mathrm{HCOOH}$

$43 \mathrm{HCl}$

85 IIF

49 HNO3

80 llResin

$36 \mathrm{Hg}$

$135 \mathrm{Hg}: \mathrm{NO} 2$

$21 \mathrm{HgO}$

9712

$39 \mathrm{~K} 20$

$131 \mathrm{KMnO4}^{2}$

$118 \mathrm{KYO3}$

$105 \operatorname{Ln} 203$

$108 \angle 120$

$65 \mathrm{Mg}(\mathrm{COOH}) 2$

$55 \mathrm{Mg}(\mathrm{Oll}) 2$

$33 \mathrm{MgO}$

$60 \operatorname{Mn}(\mathrm{COOH}) 2$

$132 \mathrm{Mn}(\mathrm{NOO}) 2$

$129 \mathrm{Mn}(\mathrm{OII}) 2$

$56 \mathrm{MnO}$

$14 \mathrm{MnO2}$

$81 \mathrm{~N} 2$

$143 \mathrm{~N} 12 \mathrm{CO}(\mathrm{C} 1.4)$

$35 \mathrm{NO}$

81 NO2

$70 \mathrm{Na}(\mathrm{HgO}(\mathrm{OH}))$

$94 \mathrm{Na} 2 \mathrm{~B} 407$

109 Nin 2 C204

$5 \mathrm{Na} 2 \mathrm{CO}$

$32 \mathrm{Nin} 20$

$71 \mathrm{Nn} 2 \mathrm{Pu}_{\mathrm{u}} 02(0 \mathrm{ll}) 4$

$73 \mathrm{Na} 2 \mathrm{RhO4}$

$72 \mathrm{Na} 2 \mathrm{RuO}_{4}$

$6 \mathrm{Na} 2 \mathrm{SO} 4$

$68 \mathrm{NaAlO2}$

$114 \mathrm{NaBO} 2$

140 NaBO2 Semi Vol

$50 \mathrm{NaCOOH}$

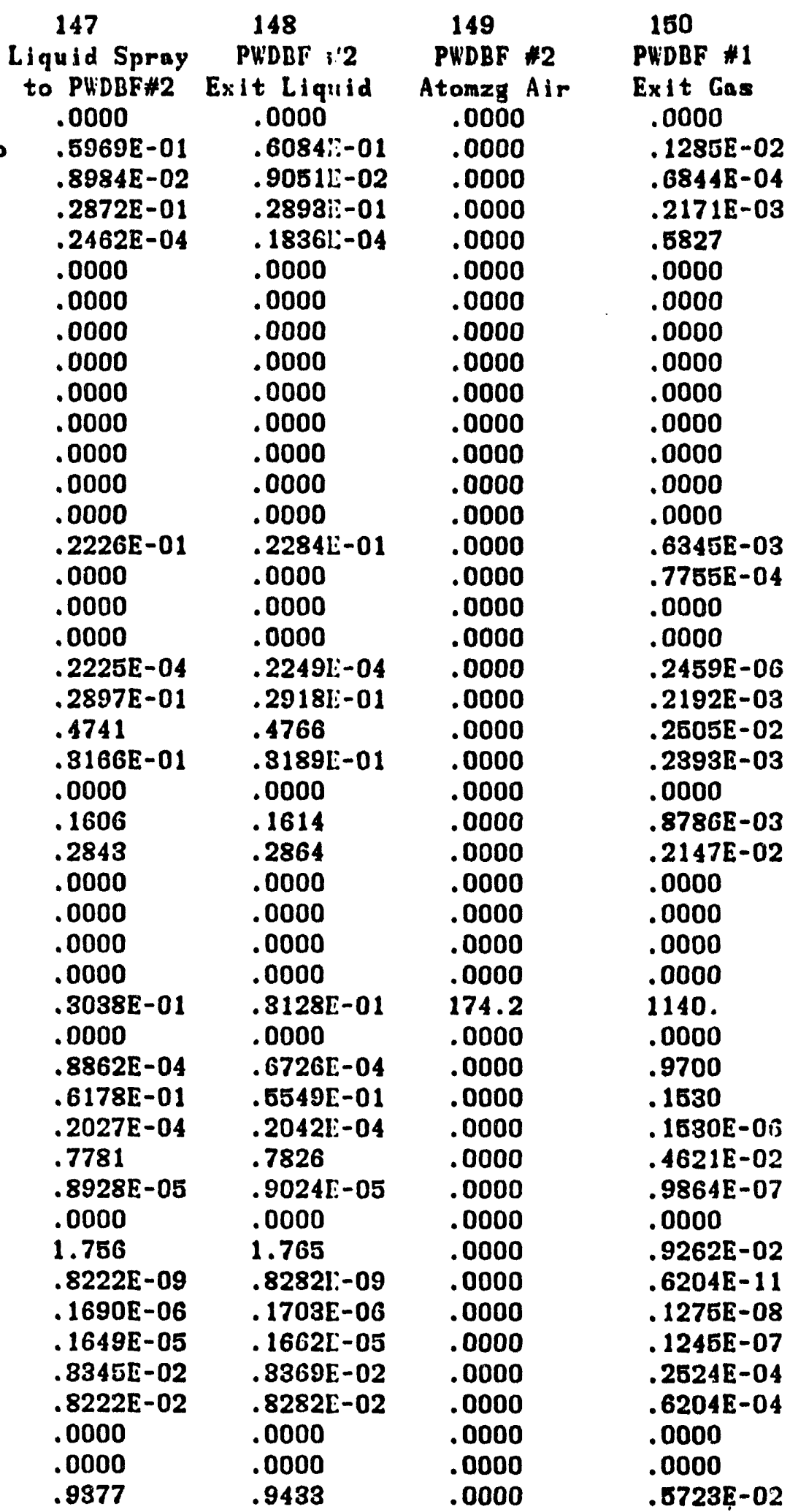

Appendix H

Table 21-16

Page 148 of 173

Date 09/30/82 Rev 09 
DPSP $80-1038$

MATERIAL BALANCE TABLES SLUDGE-SUPERNATE FEED STREAMS (CONT'D)STREAM NAME

$7 \mathrm{NaCl}$

$188 \mathrm{NaCl}$ Semi Vol

$69 \mathrm{NaF}$

189 NaF Semi Vol

$12 \mathrm{NaI}$

125 NaI Sonl Vol

$8 \mathrm{NaNO2}$

$2 \mathrm{NaN08}$

$4 \mathrm{NaOH}$

87 NaResin

$61 \mathrm{Ni}(\mathrm{COOH}) 2$

$17 \mathrm{Ni}(\mathrm{OH}) 2$

$40 \mathrm{NiO}$

8202

$67 \mathrm{PbO}$

$28 \mathrm{PbS} 04$

$124 \mathrm{Pd}$

$123 \mathrm{Pd}(\mathrm{OH}) 2$

112 PdNOS2

$110 \mathrm{PdO}$

$117 \mathrm{Pu}(\mathrm{COOH}) 4$

$76 \mathrm{Pu} 02$

$22 \mathrm{Rh} 02$

79 Ru02

23 Ru02 Seni Vol

$88 \mathrm{RuO4}$

88502

$111 \mathrm{SiO}$

115 Sillca Gel

$48 \mathrm{Sr}(\mathrm{COOH}) 2$

$10 \mathrm{Sr}(\mathrm{NO3}) 2$

$127 \mathrm{Sr}(\mathrm{OH}) 2$

$30 \mathrm{SrCO}$

$46 \mathrm{Sr} 0$

89 SrRESIN

141 Surfactant

92 Th02

$107 \mathrm{Ti} 02$

119 Tritium

$93 \mathrm{VO2}$

$62 \mathrm{VO2}(\mathrm{COOH}) 2$

$16 \mathrm{VO} 2(\mathrm{OH}) 2$

$27 \mathrm{Y}(\mathrm{COOH}) 3$

$11 Y(N 03) 3$

$128 \mathrm{Y}(\mathrm{OH}) 3$

$31 \mathrm{Y} 2(\mathrm{CO}) 3$

\begin{tabular}{|c|c|c|c|}
\hline 147 & 148 & 149 & 160 \\
\hline Liquid Spray & PHDBF \#2 & PVDBF 12 & PY:UBF \#1 \\
\hline to PWDBFEt 2 & Exit Liquid & Atomzg Ais & Exit Gins \\
\hline & & .0000 & . $2516 \mathrm{GE}-04$ \\
\hline $\begin{array}{l}.5082 \\
8846 \mathrm{E}-01\end{array}$ & $\begin{array}{l}.5164 \\
8910 E-01\end{array}$ & .0000 & $\begin{array}{l}-20385-02 \\
65365-03\end{array}$ \\
\hline & $\begin{array}{l}.8910 \mathrm{t}-01 \\
.4204\end{array}$ & .0000 & $.04301-0$ - \\
\hline $\begin{array}{l}.4187 \\
.3229 \mathrm{E}-03\end{array}$ & $.4204-.82528-03$ & .0000 & $2438 E-0 \overline{3}$ \\
\hline $\begin{array}{l}.3229 \mathrm{E}-08 \\
.4825 \mathrm{E}-01\end{array}$ & $\begin{array}{l}.8252 E-03 \\
.4406 E-01\end{array}$ & .0000 & $.30685-02$ \\
\hline & $\begin{array}{l}.4406 E-01 \\
.0000\end{array}$ & .0000 & .0000 \\
\hline .0000 & .083 & 0000 & $8114 E-03$ \\
\hline .1075 & .1083 & .0000 & .0000 \\
\hline .0000 & .0000 & .0000 & .0000 \\
\hline .0000 & .1008 & .0000 & $.7523 E-03$ \\
\hline $\begin{array}{l}.995+1 E-U 1 \\
.0000\end{array}$ & .0000 & .0000 & .0000 \\
\hline .0000 & .0000 & .0000 & .0000 \\
\hline $.1740 \mathrm{E}-01$ & . 1798E-01 & 52.63 & $3+1.2$ \\
\hline .0000 & .0000 & .0000 & .0000 \\
\hline $.4513 \mathrm{E}-02$ & . 4546E-02 & .0000 & $.3411 \mathrm{E}-0.4$ \\
\hline .0000 & .0000 & .0000 & .0000 \\
\hline .0000 & .0000 & .0000 & .0000 \\
\hline .0000 & .0000 & .0000 & .0000 \\
\hline .0000 & .0000 & .0000 & .0000 \\
\hline $.4607 \mathrm{E}-05$ & $.4641 E-05$ & .0000 & . 34975:-07 \\
\hline $.1174 E-02$ & . 1183E-02 & .0000 & .8876E-05 \\
\hline $.4487 \mathrm{E}-08$ & . 4620E-03 & .0000 & $.3392 E-05$ \\
\hline $.2175 \mathrm{E}-02$ & $.2191 \mathrm{E}-02$ & .0000 & . 1672E-04 \\
\hline $.2168 \mathrm{E}-01$ & $.2225 E-01$ & .0000 & $.6283 E-03$ \\
\hline .0000 & .0000 & .0000 & .0000 \\
\hline $.3627 E-04$ & . 2768E-04 & .0000 & .3100 \\
\hline Б.189 & Б.215 & .0000 & $.2737 E-01$ \\
\hline .0000 & .0000 & .0000 & .0000 \\
\hline $.4051 E-02$ & . 4081E-02 & .0000 & $.3062 E-04$ \\
\hline .4739E-08 & . 4774E-08 & .0000 & $.3576[-10$ \\
\hline .0000 & .0000 & .0000 & .0000 \\
\hline .0000 & .0000 & .0000 & .0000 \\
\hline .0000 & .0000 & .0000 & .0000 \\
\hline .0000 & .0000 & .0000 & .0000 \\
\hline .0000 & .0000 & .0000 & .0000 \\
\hline $.1841 \mathrm{E}-01$ & $.1854 E-01$ & .0000 & . 1392E-03 \\
\hline $.5794 E-01$ & $.5837 E-01$ & .0000 & $.4381 E-03$ \\
\hline $.1102 E-08$ & $.1096 \mathrm{E}-08$ & .0000 & $.6322 E-10$ \\
\hline .0000 & .0000 & .0000 & .0000 \\
\hline .1287 & .1297 & .0000 & $.9731 \mathrm{E}-03$ \\
\hline .0000 & .0000 & .0000 & .0000 \\
\hline $.2770 \mathrm{E}-02$ & $.2790 \mathrm{E}-02$ & .0000 & $.2093 E-04$ \\
\hline . 3365E-08 & . 8390E-08 & .0000 & $.2539 \mathrm{E}-10$ \\
\hline .0000 & .0000 & .0000 & .0000 \\
\hline .0000 & .0000 & .0000 & $.0000^{\circ}$ \\
\hline
\end{tabular}

Table 21-10

Pago 144 of 173

Date 09/30/82 Rev 09 
M.TERIAL BALANCE TABLES

Date 09/80/82 Rev 09

SLULCE-SUPERNATE FETD

STRTAMS (CONT'D)-

STREAM NAME.

$47 \times 203$

100 Zeollte

$44 \mathrm{Zn}(\mathrm{COOH}) 2$

54 $\mathrm{Zn}$ (OII) 2

$57 \mathrm{ZnO}$

$104 \mathrm{Zr} 02$

TOTAL FI.OU:, LB/HR

VAPOR FLOH, CFM

LIOLIIS FLOW, GPM

DESIGI FLOK,

DEISITY, LBS/FT3

TEYPERATURE, DEG C

PRESSURE, ATM

PRESSURE, PSIG

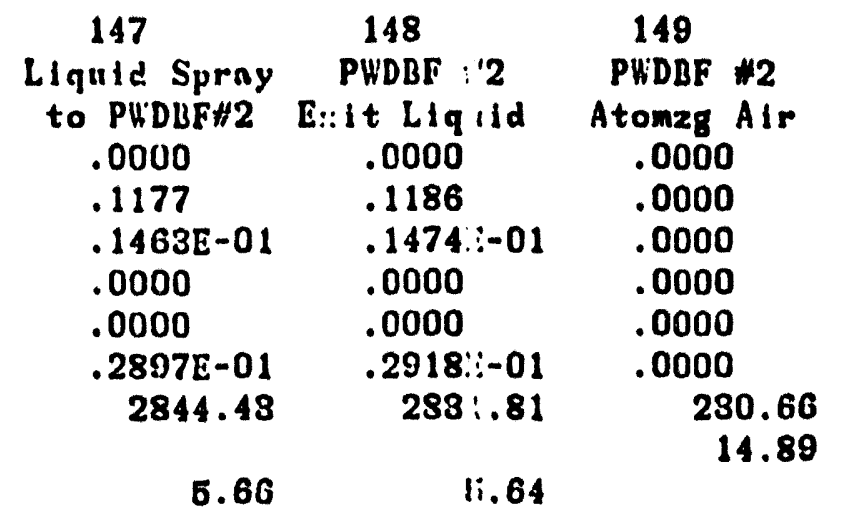

150

PHDBF \#1

Exit Gas

.0000

$.8896 \mathrm{E}-03$

. 1106E-03

.0000

.0000

.2192E-03

1672.55

455.06

PRESSURE, MM HIG

PIIISE

62.6167

65.00

8.18

62. $\{: 187$

.2583

.0613

82.04

6:!.48

.95

$\cdots .69$

72. 51

LIQUID

LIIUID

40.00

8.72

89.97

58. 46

.96

$-.54$

E.ITHALPY, PCU/IIR

159518.95

$15188: .99$

VAPOR

732.11

VAPOR

$-11603.65$

15706.64 
DPSP $80-1033$

MATERIAL BALANCE TABLES

SLLDCE-SUPERNATE FEED

STREAM NUMBERS STREAM NAYE

CONAPONENT FLOWS, LB/HR

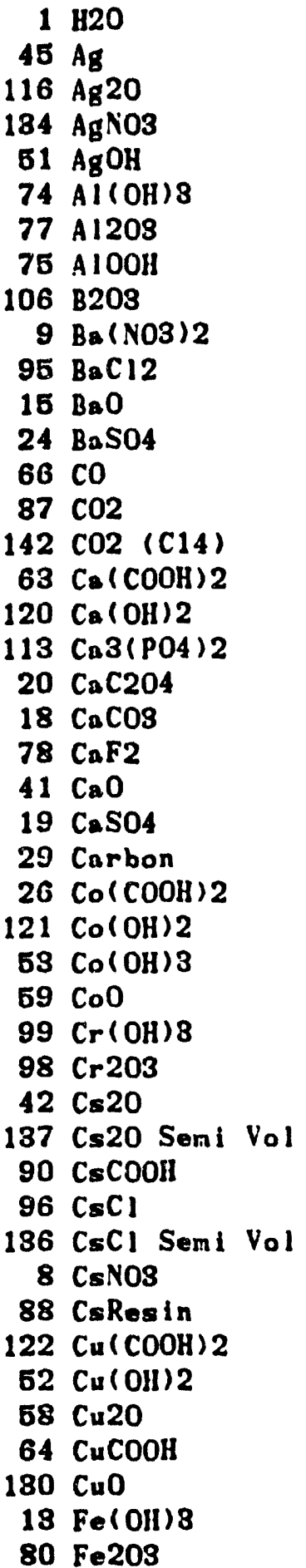

151

Ex/t Gas from HEPA

69.63

.0000

.0000

.0000

$.3853 \mathrm{E}-13$

$.2412 E-10$

.0000

.0000

$.5108 E-10$

$.8169 E-18$

.0000

.0000

$.2866 \mathrm{E}-12$

7.614

16.67

$.1722 E-23$

$.9942 E-11$

.0000

$.7142 \mathrm{E}-12$

$.7724 \mathrm{E}-12$

.0000

$.1931 E-12$

.0000

$.9073 E-12$

.670SE-12

.0000

.0000

.0000

.0000

$.7341 E-12$

.0000

$.4836 \mathrm{E}-17$

.0000

$.4458 \mathrm{E}-12$

. 2614E-09

.0000

.2033E-13

.0000

$.3858 E-12$

.0000

.0000

.0000

.0000

$.5837 \mathrm{E}-10$

.0000
Append Ix $\mathrm{H}$

Tnble 21-10

Page 140 of 173

Date 09/30/82 Rer 09 
DPSP S0-1033

Mite! ial baLANCE TABLES

SI.CDGE-SUPERNATE FEED STREAMS (CONT'D)STREAM NAME

$101 \mathrm{FeO}$

126 Group A Seral Vo

102 GroupA

103 GroupB

$25 \mathrm{H2}$

$133 \mathrm{H} 2 \mathrm{C} 204$

$91 \mathrm{H} 202$

$84 \mathrm{HCOOH}$

$43 \mathrm{HCl}$

85 IIF

49 HNO3

86 Hikes in

$86 \mathrm{Hg}$

135 HहNO32

$21 \mathrm{HgO}$

9712

39 K20

$131 \mathrm{KMnO4}$

$118 \mathrm{KNO3}$

$105 \quad L_{2} 203$

$108 \mathrm{~L} 120$

$65 \mathrm{Mg}(\mathrm{COOH}) 2$

55 $\mathrm{Mg}(\mathrm{OHI}) 2$

$83 \mathrm{MgO}$

$60 \mathrm{Mn}(\mathrm{COOH}) 2$

$132 \mathrm{Mn}(\mathrm{N} 03) 2$

$129 \mathrm{Mn}(\mathrm{Oll}) 2$

$56 \mathrm{Min} 0$

$14 \mathrm{MnO2}$

$81 \quad \mathrm{N2}$

$143 \mathrm{NA} 2 \mathrm{CO}$ (C14)

85 NO

$84 \mathrm{NO2}$

$70 \mathrm{ra}(\mathrm{HgO}(\mathrm{OHI}))$

94 Na2B.407

$109 \mathrm{Na}_{2} 2 \mathrm{C}_{204}$

$5 \mathrm{Na} 2 \mathrm{CO}$

$82 \mathrm{Na} 20$

$71 \mathrm{Na} 2 \mathrm{PuO2}(\mathrm{OH}) 4$

$73 \mathrm{Na} 2 \mathrm{RhO} 04$

$72 \mathrm{Na} 2 \mathrm{RuO4}^{2}$

$6 \mathrm{Na} 2 \mathrm{SO}_{4}$

$68 \mathrm{NaAlO2}$

$114 \mathrm{NaBO2}$

$140 \mathrm{NaBO2}$ Seni Vol

$50 \mathrm{NaCOOH}$
Append IX H

Tablo 21-16

Page 147 of 178

Date 09/80/82 Rev 09

151

Exit Gas

from IIEPA

.0000

.0000

$.3219 \mathrm{E}-09$

$.1716 \mathrm{E}-11$

.5827

.0000

.0000

.0000

.0000

.0000

.0000

.0000

.0000

.0000

. 1586E-09

$.7755 \mathrm{E}-09$

.0000

.0000

$.1944 \mathrm{E}-14$

$.1734 \mathrm{E}-11$

$.1981 \mathrm{E}-10$

$.1892 E-11$

.0000

$.6948 \mathrm{E}-11$

$.1698 \mathrm{E}-10$

.0000

.0000

.0000

.0000

1896.

.0000

.9700

.1565

$.1210 \mathrm{E}-14$

$.3654 \mathrm{E}-10$

$.7801 E-15$

.0000

$.7324 \mathrm{E}-10$

$.4906 \mathrm{E}-19$

$.1009 E-16$

$.9842 E-16$

$.1996 \mathrm{E}-12$

$.4906 \mathrm{E}-12$

.0000

.0000

$.4526 \mathrm{E}-10$
152

HEPA

Accumulation

.0000

.0000

$.8216 \mathrm{E}-06$

$.1715 \mathrm{E}-08$

.0000

.0000

.0000

.0000

.0000

.0000

.0000

.0000

.0000

.0000

. 1585E-06

$.7747 \mathrm{E}-06$

.0000

.0000

.1942E-11

$.1732 E-08$

$.1979 \mathrm{E}-07$

$.1891 E-08$

.0000

$.6941 E-08$

$.1696 \mathrm{E}-07$

.0000

.0000

.0000

.0000

.0000

.0000

.0000

.0000

. 1209E-11

$.8650 \mathrm{E}-07$

.7793E-12

.0000

$.7317 E-07$

$.4901 \mathrm{E}-16$

$.1008 \mathrm{E}-18$

$.9838 \mathrm{E}-13$

. 1994E-09

$.4901 E-09$

.0000

.0000

$.4521 E-07$
158

Liq to SWDBF Sand Filtor

Nozzles Accumulation

$.0000 \quad .0000$

$.5027 E-02 \quad .0000$

$.8560 \mathrm{E}-04$

$.2741 E-03$

$.4045 E-04$

.0000

.0000

.0000

.0000

.0000

.0000

.0000

.0000

.0000

$.2505 \mathrm{E}-02$

.0000

.0000

.0000

$.1862 \mathrm{E}-06$

$.2764 E-03$

$.8156 \mathrm{E}-02$

$.3022 \mathrm{E}-03$

.0000

$.1107 \mathrm{E}-02$

$.2716 \mathrm{E}-02$

.0000

.0000

.0000

.0000

$.95718-01$

.0000

. 1543E-03

.1655

. 1936E-06

. 5841E-02

.7472E-07

.0000

$.1171 \mathrm{E}-01$

$.7851 \mathrm{E}-11$

. 1614E-08

. 1575E-07

$.8194 E-04$

$.7851 \mathrm{E}-04$

.0000

.0000

.7193E-02
. 3563E-09

. 1107E-09

.0000

.0000

.0000

.0000

.0000

.0000

.0000

.0000

.0000

$.5220 \mathrm{E}-13$

. 1588E-09

.0000

.0000

.0000

$.2321 \mathrm{E}-10$

.2446E-09

.2792E-08

. 1219E-09

$.8190 \mathrm{E}-13$

$.9793 \mathrm{E}-09$

. 1094E-08

.0000

$.2120 \mathrm{E}-10$

.0000

.0000

.0000

.0000

.0000

.0000

$.7805 E-13$

$.4058 \mathrm{E}-10$

$.9813 E-11$

.0000

$.8687 \mathrm{E}-08$

$.8165 E-17$

$.6508 \mathrm{E}-15$

$.6351 \mathrm{E}-14$

. 1288E- 10

$.8165 \mathrm{E}-10$

.0000

.0000

$.3080 \mathrm{E}-08$ 
DPSP $80-1033$

MATERIAL BALANCE Tabres SLUDGE-SUPERNATE FEED STREAMS (CONT'D)STREAM NAME

\section{$7 \mathrm{NaCl}$}

$138 \mathrm{NaCl}$ Semi Vol

$69 \mathrm{NaF}$

189 NaF Semi Vol

$12 \mathrm{NaI}$

$125 \mathrm{NaI}$ Semi Vol

$8 \mathrm{NaNO2}$

$2 \mathrm{NaNO3}$

$4 \mathrm{NaOH}$

87 NaResin

$61 \mathrm{Ni}(\mathrm{COOH}) 2$

$17 \mathrm{Ni}(\mathrm{Oll}) 2$

$40 \mathrm{NiO}$

8202

$67 \mathrm{PbO}$

$28 \mathrm{PbSO} 4$

$124 \mathrm{Pd}$

$123 \mathrm{Pd}(\mathrm{OH}) 2$

112 PdNO32

$110 \mathrm{PdO}$

$117 \mathrm{P}_{\mathrm{u}}(\mathrm{COOH}) 4$

$76 \mathrm{Pu} 02$

$22 \mathrm{RhO2}$

$79 \mathrm{RuO2}$

23 Ru02 Semi Vol

$83 \mathrm{Ru} 04$

$88 \mathrm{S02}$

$111 \mathrm{SiO} 2$

115 Silica Gel

$48 \mathrm{Sr}(\mathrm{COOH}) 2$

$10 \mathrm{Sr}(\mathrm{NOS}) 2$

$127 \mathrm{Sr}(\mathrm{OH}) 2$

$80 \mathrm{SrCO}$

$46 \mathrm{Sr} 0$

89 SrRESIN

141 Surfactant

92 Th02

$107 \mathrm{TiO2}$

119 Tritium

93 V02

$62 \mathrm{VO} 2(\mathrm{COOH}) 2$

$16 \mathrm{VO} 2(\mathrm{OH}) 2$

$27 \mathrm{Y}(\mathrm{COOH}) \mathrm{S}$

$11 Y(\mathrm{NO}) 3$

$128 \times(011) 8$

$81 Y 2(\cos ) 8$
Appendix II

Table 21-16

Page 148 of 173

Date 09/90/82 Rev 09

$151 \quad 152 \quad 153 \quad 154$

Exit Gas HEPA Liq to SHDBF Sand Filter

from HEPA Accumulation iozzles Accumulation

.2272E-08 .2270E-05 .3180E-04 .2285E-03

$\begin{array}{llll}.0000 & .0000 & .8592 \mathrm{E}-21 & .0000\end{array}$

$.1865 E-08 \quad .1863 E-05$

$.0000 \quad .0000$

$.2267 \mathrm{E}-09 \quad .2265 \mathrm{E}-06$

.0000

.0000

$.6417 \mathrm{E}-11$

.0000

.0000

$.5949 \mathrm{E}-11$

.0000

.0000

572.6

.0000

$.2697 \mathrm{E}-12$

.0000

.0000

.0000

.0000

$.6410 E-08$

.0000

.0000

$.5943 \mathrm{E}-08$

.0000

.0000

.0000

.0000

.2695E-09

.0000

.0000

.0000

.0000

.0000

$.2768 \mathrm{E}-12$

$.7012 E-10$

$.2679 E-10$

. 1570E-06

.0000

.0000

.0000

.8100

$.216+E-09$

.0000

.2162E-06

.0000

.2421E- 12

.2419E-09

.2825E-15

.0000

.0000

.0000

.0000

.0000

$.8244 \mathrm{E}-03$

$.1860 \mathrm{E}-08$

$.2933 \mathrm{E}-01 \quad .0000$

.3083E-05 .2280E-09

$.3584 \mathrm{E}-02 \quad .0000$

$.0000 \quad .0000$

$.1027 E-02 \quad .0062 E-09$

.0000

.0000

$.8 S 97 \mathrm{E}-12$

.0000

$.9501 \mathrm{E}-03 \quad .3834 \mathrm{E}-03$

.0000

.0000

$.8146 \mathrm{E}-12$

.0000

$.5546 E-01 \quad .0000$

$.0000 \quad .0000$

$.4308 \mathrm{E}-04 \quad .1740 \mathrm{E}-10$

.0000

.0000

.0000

.0000

.0000

.0000

$.4386 \mathrm{E}-07$

.0000

$.1121 \mathrm{E}-04 \quad .4529 \mathrm{E}-11$

$.4283 E-05 \quad .1730 E-11$

.2070E-04 . 1655E-09

$.2432 E-02 \quad .0000$

.0000

$.6424 \mathrm{E}-04$

.0000

.0000

$.2031 E-07$

$.0000 \quad .0000$

$.3867 \mathrm{E}-04 \quad .1560 \mathrm{E}-10$

$.4525 \mathrm{E}-10 \quad .1825 \mathrm{E}-10$

.0000

.0000

.0000

.0000

.0000

$.1406 \mathrm{E}-13$

.0000

.0000

.0000

.0000

$.1100 \mathrm{E}-11 \quad .1099 \mathrm{E}-08$

$.1757 \mathrm{E}-03$

$.7100 \mathrm{E}-10$.

$.3464 \mathrm{E}-08$

.0000

.0000

$.5528 \mathrm{E}-03$

$.4891 \mathrm{E}-09$

.0000

.0000

$.7688 \mathrm{E}-08$

.0000

$.1180 \mathrm{E}-08$

.0000

4959E-09

$.5512 E-12$

.0000

. 1067E-10

$.1654 \mathrm{E}-09$

.2644E-04

$.1296 \mathrm{E}-16$

.0000

$.3214 \mathrm{E}-10$

$.8774 \mathrm{E}-14$

.0000 
DPSP $80-1033$

MATERAL BALANCE TABLES SLLUGE-SLPER.NATE FEED STREAMS (CONT'D)STREAM NAME

47 Y203

100 Zeolite

$44 \mathrm{Zn}(\mathrm{COOH}) 2$

$54 \mathrm{Zn}(\mathrm{OII}) 2$

$57 \mathrm{Zn} 0$

$10.4 \mathrm{Zr} 02$

TOTAL FLOH, LB/IIR

VAPOR FLOH, CFM

LIOUID FLOW, GPM

DESICN ILOW,

DEXSITY, LBS/FT3

TEMPERATURE, DEG C PRESSLIRE, ATM

PRESSLRE, PSIG

PRESSLRE, IMI IIG

PHASE

EYTIIALPY, PCU/IIR

$\begin{array}{cc}151 & 152 \\ \text { Exit Gas } & \text { IIEPA } \\ \text { from HEPA } & \text { Accumulation } \\ .0000 & .0000 \\ .7034 \mathrm{E}-11 & .7027 \mathrm{E}-08 \\ .8746 \mathrm{E}-12 & .8788 \mathrm{E}-09 \\ .0000 & .0000 \\ .0000 & .0000 \\ .1734 \mathrm{E}-11 & .1732 \mathrm{E}-08 \\ 2564.20 & .00 \\ 915.07 & .00\end{array}$

158

Liq to SWDBF Sand Filtor

Nozzles

.0000

$.1123 \mathrm{E}-02$

.13975-03

.0000

.0000

.2764 E-03

8177.37

$$
\begin{array}{r}
.0467 \\
50.00 \\
.70 \\
-4.42 \\
531.32 \\
\text { VAPOR } \\
-101618.11
\end{array}
$$

$$
\begin{array}{r}
.1060 \\
50.00 \\
.70 \\
-4.42 \\
581.82 \\
\text { VAPOR } \\
.00
\end{array}
$$

16.83

173

2 Rev 09

$\begin{array}{rr}2.4311 & .0000 \\ 46.81 & 85.24 \\ 8.18 & .99 \\ 32.04 & -.11 \\ & 754.38 \\ \text { LIQUID } & \text { SOLID } \\ 720.88 & .00\end{array}$


DPSP $80-1033$

MATERIAL BALANCE TABLES SLUDGE-SLPERNATE FEED STREAM NUMEERS STREAM NAME COMPONENT FLOHS, LD/IIR

\begin{tabular}{|c|c|}
\hline 11 & $\mathrm{H} 2 \mathrm{O}$ \\
\hline $45 A$ & Ag \\
\hline $16 \mathrm{~A}$ & Ag20 \\
\hline 134 & AgNOS \\
\hline $51 A$ & AgOH \\
\hline 74 & Al (0II) 8 \\
\hline 77 & A 1203 \\
\hline 75 & A $100 \mathrm{H}$ \\
\hline 1061 & B203 \\
\hline 9 & $\mathrm{Ba}(\mathrm{NO3}) 2$ \\
\hline 95 & $\mathrm{BaCl2}$ \\
\hline 24 & $\mathrm{BaSO} 4$ \\
\hline 66 & co \\
\hline 87 & $\mathrm{CO2}$ \\
\hline 142 & $\cos (C 14)$ \\
\hline 63 & $\mathrm{Ca}(\mathrm{COOH}) 2$ \\
\hline 120 & $\mathrm{Ca}(\mathrm{OH}) 2$ \\
\hline 13 & $\mathrm{Ca} 3(\mathrm{P} 04) 2$ \\
\hline 20 & $\mathrm{CaC2O4}$ \\
\hline 18 & $\mathrm{CaCO3}$ \\
\hline 78 & $\mathrm{CaF2}$ \\
\hline 41 & $\mathrm{CaO}$ \\
\hline $\begin{array}{l}19 \\
29\end{array}$ & $\begin{array}{l}\text { CaS04 } \\
\text { Carbon }\end{array}$ \\
\hline 26 & $\mathrm{Co}(\mathrm{COOH}) 2$ \\
\hline 121 & $\mathrm{Co}(\mathrm{OH}) 2$ \\
\hline 58 & $\mathrm{Co}(\mathrm{OH}) \mathrm{B}$ \\
\hline 69 & $\mathrm{CoO}$ \\
\hline 99 & $\mathrm{Cr}(\mathrm{OH}) 3$ \\
\hline 98 & Cr208 \\
\hline 42 & Cs20 \\
\hline 187 & Cs20 Sem i \\
\hline 90 & $\mathrm{Cs} \mathrm{COOH}$ \\
\hline 96 & $\mathrm{CsCl}$ \\
\hline 186 & CsCl Semi \\
\hline & $\begin{array}{l}\text { CsN03 } \\
\text { CsResin }\end{array}$ \\
\hline 122 & $\begin{array}{l}\text { Cskesin } \\
\mathrm{Cu}(\mathrm{COOH}) 2\end{array}$ \\
\hline 52 & $\mathrm{Cu}(\mathrm{OH}) 2$ \\
\hline 58 & Cu20 \\
\hline 64 & $\mathrm{CuCOOH}$ \\
\hline 130 & $\mathrm{CuO}$ \\
\hline $\begin{array}{l}18 \\
80\end{array}$ & $\begin{array}{l}\mathrm{Fe}(\mathrm{OH}) 3 \\
\mathrm{Fe} 203\end{array}$ \\
\hline
\end{tabular}

$$
.0000
$$

$.1686 \mathrm{E}-07$

.0000

.2569E-07

$.4609 E-08$

$.4717 \mathrm{E}-06$

.0000

.0000

.2200E-05

$.6194 \mathrm{E}-14$

.0000

.0000

$.5601 \mathrm{E}-08$

.0000

.0000

.0000

$.1941 \mathrm{E}-06$

$.1478 E-09$

$.1890 \mathrm{E}-07$

$.1510 \mathrm{E}-07$

.0000

$.8774 \mathrm{E}-08$

.0000

$.1773 E-07$

$.1196 \mathrm{E}-07$

.0000

$.2556 \mathrm{E}-11$

.0000

.0000

$.1435 \mathrm{E}-07$

.0000

$.1097 \mathrm{E}-12$

.0000

$.8713 \mathrm{E}-08$

$.5766 \mathrm{E}-10$

.0000

$.3973 \mathrm{E}-09$

.0000

$.6545 \mathrm{E}-08$

$.5560 \mathrm{E}-11$

.0000

.0000

.0000

$.1142 E-05$

.0000
Append ix $\mathrm{H}$

Table 21-10

Page 150 of 173

Date 00/30/82 Rev 09
157

SyE Air

Ir leakige

1.047

.0000

.0000

.0000

.0000

.0000

.0000

.0000

.0000

.0000

.0000

.0000

.0000

.0000

.0000

.0000

.0000

.0000

.0000

.0000

.0000

.0000

.0000

.0000

.0000

.0000

.0000

.0000

.0000

.0000

.0000

.0000

.0000

.0000

.0000

.0000

.0000

.0000

.0000

.0000

.0000

.0000

.0000

.0000

.0000
158

Sir:eT Air

Puragu

3.738

.0000

.0000

.0000

.0000

.0000

.0000

.0000

.0000

.0000

.0000

.0000

.0000

.0000

.0000

.0000

.0000

.0000

.0000

.0000

.0000

.0000

.0000

.0000

.0000

.0000

.0000

.0000

.0000

.0000

.0000

.0000

.0000

.0000

.0000

.0000

.0000

.0000

.0000

.0000

.0000

.0000

.0000

.0000

.0000 . 
DPSP 80-1033

MATERIAL BALANCE TABLES

SIUDGE-SUPERNATE FEED

STREAYS (CONT'D) -

STREAM NAME

$101 \mathrm{FeO}$

126 Group A Semi Vo

102 GroupA

103 GroupB

$25 \mathrm{HI}$

$133112 \mathrm{C} 204$

$9 1 \longdiv { 1 1 2 0 2 }$

$34 \mathrm{HCOOH}$

$43 \mathrm{IiCl}$

$85 \mathrm{HF}$

49 HNO3

86 HResin

$30 \mathrm{Hg}$

135 IIgNO32

$21 \mathrm{HgO}$

$97 \quad 12$

$39 k 20$

$131 \mathrm{KMn} 04$

$118 \mathrm{KNO3}$

$105 \quad \operatorname{Ln} 203$

108 Li 20

$65 \mathrm{Mg}(\mathrm{COOH}) 2$

$55 \mathrm{Mg}(\mathrm{OHH}) 2$

$33 \mathrm{Mg} 0$

$60 \mathrm{Mn}(\mathrm{COOH}) 2$

$132 \mathrm{Mn}(\mathrm{K} 03) 2$

$129 \mathrm{Mn}(\mathrm{OII}) 2$

$56 \mathrm{MnO}$

$14 \mathrm{MnO2}$

81 N2

$143 \mathrm{NA2CO3}$ (C14)

35 NO

84 NO2

$70 \mathrm{Na}$ ( $\mathrm{HgO}(\mathrm{OII}))$

$94 \mathrm{Na} 2 \mathrm{~B} 407$

$109 \mathrm{Nin} 2 \mathrm{C} 204$

$5 \mathrm{Nis} 2 \mathrm{CO} 3$

$32 \quad \mathrm{Na} 20$

$71 \mathrm{~N}_{\mathrm{ii}} 2 \mathrm{P}_{\mathrm{u}} \mathrm{O2}(\mathrm{OH}) 4$

$73 \mathrm{Na}_{2} \mathrm{R}_{2} \mathrm{O}$

$72 \mathrm{Nn} 2 \mathrm{Ru} 04$

$6 \mathrm{Na} 2 \mathrm{SO} 4$

$68 \mathrm{NaA} 102$

$114 \mathrm{NaBO2}$

$140 \mathrm{NaBO2}$ Semi Vol

$50 \mathrm{NaCOOH}$

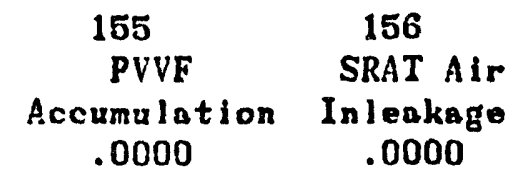

.0000

$.1068 \mathrm{E}-07$

$.3355 \mathrm{E}-07$

.0000

.0000

.0000

.0000

.0000

.0000

.0000

.0000

.0000

.1606E-10

$.1129 \mathrm{E}-09$

.0000

.0000

.0000

$.7111 \mathrm{E}-08$

$.7471 E-07$

$.8529 \mathrm{E}-06$

$.8694 \mathrm{E}-07$

.2520E-10

.2992E-06

.8313E-06

.0000

$.6522 \mathrm{E}-08$

.0000

.0000

.0000

.0000

.0000

.0000

$.2364 \mathrm{E}-10$

$.1254 \mathrm{E}-08$

$.2865 E-08$

.0000

$.2650 E-05$

$.9589 \mathrm{E}-15$

$.1971 \mathrm{E}-12$

$.1924 \mathrm{E}-11$

$.3901 \mathrm{E}-08$

$.9589 E-08$

.0000

.0000

.9237 E-06
Appendix H

Table 21-16

Page 151 of 173

Date 09/80/82 Rev 09
157

SME Air

In leakage

.0000

.0000

.0000

.0000

.0000

.0000

.0000

.0000

.0000

.0000

.0000

.0000

.0000

.0000

.0000

.0000

.0000

.0000

.0000

.0000

.0000

.0000

.0000

.0000

.0000

.0000

.0000

.0000

.0000

47.85

.0000

.0000

.0000

.0000

.0000

.0000

.0000

.0000

.0000

.0000

.0000

.0000

.0000

.0000

.0000

.0000
158

SMECT AIr

Purge

.0000

.0000

.0000

.0000

.0000

.0000

.0000

.0000

.0000

.0000

.0000

.0000

.0000

.0000

.0000

.0000

.0000

.0000

.0000

.0000

.0000

.0000

.0000

.0000

.0000

.0000

.0000

.0000

.0000

170.9

.0000

.0000

.0000

.0000

.0000

.0000

.0000

.0000

.0000

.0000

.0000

.0000

.0000

.0000

.0000

.0000 
DPSP $80-1033$

MATERIAL BALANCE TABLES SLUDGE-SUPERNATE FEED STREAMS (CONI'D)STREAM NAME

$\begin{array}{rl}7 & \mathrm{NaCl} \\ 138 & \mathrm{NaCl} \text { Semi } \mathrm{Vo} \\ 69 & \mathrm{NaF} \\ 139 & \mathrm{NaF} \text { Semi } \mathrm{Vol} \\ 12 & \mathrm{NaI} \\ 125 & \mathrm{NaI} \text { Semi } \mathrm{Vol} \\ 3 & \mathrm{NaNO2} \\ 2 & \mathrm{NaNO} \\ 4 & \mathrm{NaOH} \\ 87 & \mathrm{NaResin} \\ 61 & \mathrm{Ni}(\mathrm{COOH}) 2 \\ 17 & \mathrm{Ni}(\mathrm{OH}) 2 \\ 40 & \mathrm{NiO} \\ 82 & \mathrm{O} \\ 67 & \mathrm{PbO} \\ 28 \mathrm{PbSO} \\ 124 \mathrm{Pd} \\ 123 \mathrm{Pd}(\mathrm{OH}) 2 \\ 112 \mathrm{PdNO} 2 \\ 110 \mathrm{PdO}\end{array}$

$117 \mathrm{Pu}(\mathrm{COOH}) 4$

$76 \mathrm{Pu} 02$

$22 \mathrm{RhO2}$

$79 \mathrm{Ru} 02$

23 Ru02 Seni Vol

$83 \mathrm{Ru} 04$

$38 \mathrm{SO2}$

$111 \mathrm{SiO}$

115 Silica Gel

$48 \mathrm{Sr}(\mathrm{COOII}) 2$

$10 \mathrm{Sr}(\mathrm{NOS}) 2$

$127 \mathrm{Sr}(\mathrm{OH}) 2$

$80 \mathrm{SrCOS}$

$46 \mathrm{SrO}$

89 SrRESIN

141 Surfactant

$92 \mathrm{ThO} 2$

$107 \mathrm{TiO}$

119 Tritium

$93 \mathrm{VO2}$

$62 \mathrm{U} 02(\mathrm{COOH}) 2$

$16 \mathrm{VO} 2(\mathrm{OH}) 2$

$27 \mathrm{Y}(\mathrm{COOH}) \mathrm{3}$

$11 \mathrm{Y}(\mathrm{NOS}) 3$

$128 \mathrm{Y}(\mathrm{OH}) 3$

$31 Y 2(\cos ) 3$
Appendis 1

Table 21-10

Page 152 of 173

Date $09 / 30 / 82$ Rev 09

Acou

155

PVVF

Accumulation

$.4718 \mathrm{E}-08$

.0000

$.8303 \mathrm{E}-09$

.0000

$.4485 \mathrm{E}-09$

.0000

.0000

$.2769 \mathrm{E}-06$

$.1199 \mathrm{E}-09$

.0000

$.1161 \mathrm{E}-06$

$.9680 \mathrm{E}-10$

.0000

.0000

.0003

$.5272 \mathrm{E}-08$

$.000 \mathrm{~J}$

.0000

.0000

.0000

$.5398 \mathrm{E}-11$

.1372E-08

. $6242 E-09$

.2617E-08

.0000

.0000

.0000

$.8951 E-05$

.0000

$.4727 \mathrm{E}-08$

$.5527 \mathrm{E}-14$

$.4928 E-11$

.0000

.0000

.0000

.0000

$.2151 \mathrm{E}-07$

$.149 .1 \mathrm{E}-06$

.0000

.0000

$.1502 \mathrm{E}-06$

$.1696 \mathrm{E}-09$

$.3231 \mathrm{E}-08$

$.8925 E-14$

$.2700 E-11$

.0000
157

SYE Air

Inleakago

.0000

.0000

.0000

.0000

.0000

.0000

.0000

.0000

.0000

.0000

.0000

.0000

.0000

14.46

.0000

.0000

.0000

.0000

.0000

.0000

.0000

.0000

.0000

.0000

.0000

.0000

.0000

.0000

.0000

.0000

.0000

.0000

.0000

.0000

.0000

.0000

.0000

.0000

.0000

.0000

.0000

.0000

.0000

.0000

.0000

.0000
158

SYICT $A \mathrm{I}:$

Purre

.0000

.0000

.0000

.0000

.0000

.0000

.0000

.0000

.0000

.0000

.0000

.0000

.0000

51.63

.0000

.0000

.0000

.0003

.0000

.0000

.0000

.0000

.0000

.0000

.0000

.0000

.0000

.0000

.0000

.0000

.0000

.0000

.0000

.0000

.0000

.0000

.0000

.0000

.0000

.0000

.0000

.0000

.0000

.0000

.0000

$.0000^{\circ}$ 
MATERIAL BALANCE TABLES

Date 09/30/82 Rev 09

\section{SLLDGE-SUPERIIATE FEED}

STREAMS (CONT'D)STREAY NAME

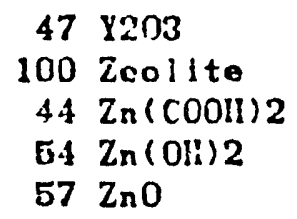

ENTHALPY, PCL/IIR

156

SRAT Air

Inlenkage

.0000

.0000

.0000

.0000

.0000

.0000

63.35

14.97

.0000

26.68

.92

$-1.23$

696.54

SOLID

.0706

85.00

1.00

.00

VAPOR
157

SME Air

Inlenkage

.0000

.0000

.0000

.0000

.0000

.0000

63.85

14.97

$-8262.61$

\section{.0706}

85.00

1.00

.00

VAPOR

$-8262.64$
158

SMECT AIr

Purge

.0000

.0000

.0000

.0000

.0000

.0000

226.27

58.45

.0706

85.00

1.00

.00

VAPOR

$-11652.27$ 
DPSP $80-1038$

MATERIAL BALANCE TABLES

SLLDGE-SUPERNATE FEED

STREAM NUMBERS -

STREAM NAME

COMPONENT FLO'HS, LB/HR

\begin{tabular}{|c|c|c|c|}
\hline 1 & $\mathrm{H} 2 \mathrm{O}$ & 8.783 & 1.742 \\
\hline 45 & $\mathrm{Ag}$ & .0000 & .0000 \\
\hline 16 & Ag20 & .0000 & .0000 \\
\hline 4 & AgN03 & .0000 & .0000 \\
\hline 51 & $\mathrm{AgOH}$ & .0000 & .0000 \\
\hline 74 & Al (OII) 3 & .0000 & .0000 \\
\hline 77 & A 1203 & .0000 & .0000 \\
\hline 75 & AlOOH & .0000 & .0000 \\
\hline & B203 & .0000 & .0000 \\
\hline 9 & $\mathrm{Ba}(\mathrm{N} 03) 2$ & .0000 & .0000 \\
\hline 95 & $\mathrm{BaCl} 2$ & .0000 & .0000 \\
\hline 15 & $\mathrm{BaO}$ & .0000 & .0000 \\
\hline & BaSO4 & .0003 & .0000 \\
\hline 6 & CO & .0000 & .0000 \\
\hline 7 & $\mathrm{CO2}$ & .0000 & .0000 \\
\hline & $\operatorname{co2}(\mathrm{Cl} 1)$ & .0000 & .0000 \\
\hline & $\mathrm{Ca}(\mathrm{COOII}) 2$ & .0003 & .0000 \\
\hline & $\mathrm{Ca}_{\mathrm{a}}(\mathrm{OH}) 2$ & ני000. & .0000 \\
\hline & $\mathrm{Ca3}(\mathrm{PO4}) 2$ & .0000 & .0000 \\
\hline 20 & $\mathrm{CaC2O4}$ & .0000 & .0000 \\
\hline 18 & $\mathrm{C}_{\mathrm{B}} \mathrm{CO}$ & .0000 & .0000 \\
\hline 78 & $\mathrm{CaF} 2$ & .0000 & .0000 \\
\hline 41 & $\mathrm{CnO}$ & $.000 \mathrm{~J}$ & .0000 \\
\hline 19 & $\mathrm{CaSO}$ & .0000 & .0000 \\
\hline 29 & Carbon & .0000 & .0000 \\
\hline 6 & $\mathrm{Co}(\mathrm{COOH}) 2$ & .0000 & .0000 \\
\hline & $\mathrm{Co}(\mathrm{OH}) 2$ & .0000 & .0000 \\
\hline 58 & $\mathrm{Co}(\mathrm{OH}) 3$ & .00010 & .0000 \\
\hline 59 & $\mathrm{CoO}$ & .0000 & .0000 \\
\hline 99 & $\mathrm{Cr}(\mathrm{OH}) 3$ & .0000 & .0000 \\
\hline 38 & Cr203 & .0000 & .0000 \\
\hline 12 & $\operatorname{Cs} 20$ & .0000 & .0000 \\
\hline & Cs20 Seni Vol & $.0001)$ & .0000 \\
\hline & CsCOOH & .0000 & .0000 \\
\hline 36 & $\mathrm{CsCl}$ & .0000 & .0000 \\
\hline & Cscl Semi Vol & .0000 & .0000 \\
\hline 8 & CsNO3 & $.000 !)$ & .0000 \\
\hline 88 & CsResin & .0000 & .0000 \\
\hline 2 & $\mathrm{Cu}(\mathrm{COOH}) 2$ & .0000 & .0000 \\
\hline 2 & $\mathrm{Cu}(\mathrm{OH}) 2$ & $.0001)$ & .0000 \\
\hline 8 & $\mathrm{Cu} 20$ & .0000 & .0000 \\
\hline & $\mathrm{CuCOOH}$ & .0000 & .0000 \\
\hline & $\mathrm{CuO}$ & .0000 & .0000 \\
\hline & $\mathrm{Fe}(\mathrm{Oll}) \mathrm{s}$ & .0000 & .6200 \\
\hline & $\mathrm{Fe} 203$ & .0000 & .0000 \\
\hline
\end{tabular}

Aprendix li

Table 21-10

Pago 15. of i73

Date $09 / 30 / 32 \mathrm{Rev} C \mathrm{C}$

$\begin{array}{ccc}160 & 161 & 162 \\ \text { OGCT Air } & \text { Fr Air } & \text { Mrit ir } \\ \text { Inleakage } & \text { Inleakige } & \text { Furge }\end{array}$

1.742

.0000

.0600

.0600

.0000

.0000

.0000

.0000

.0000

.0000

.0000

.0000

.0000

.0000

.0000

.0000

.0000

.0000

.0000

.0000

.0000

.0000

.0000

.0000

.0000

.0000

.0000

.0000

.0000

.0000

.0000

.0000

.0000

.0000

.0000

.0000

.0000

.0000

.0000

.0000

.0000

.0000

.0000

.0000

.0000
$.7477 \mathrm{E}-01$

.0000

.0000

.0000

.0000

.0000

.0000

.0000

.0000

.0000

.0000

.0000

.0000

.0000

.0000

.0000

.0000

.0000

.0000

.0000

.0000

.0000

.0000

.0100

.0000

.0000

.0000

.0000

.0000

.0000

.0000

.0000

.0000

.0000

.0000

.0000

.0000

.0000

.0000

.0000

.0000

.0000

.0000

.0000

.0000 . 
Appendix H

Table 21-16

Page 155 of 173

Date 09/30/82 Rev 09

MATRRIAL BALANCE TABLES

SLUDGE-SLPEPNATE FEED

STREAMS (CONT'D)-

STRE:IN NAME

$101 \mathrm{FeO}$

159

MFT Air

Purge

126 Group A Semi Vo

.0000

102 Grou:

.0000

103 GroupB

.0000

$25 \quad 112$

133 H2C2O4

9111202

$34 \mathrm{HCOOH}$

.0000

.0000

.0000

.0000

$43 \mathrm{IICl}$

.0000

$85 \mathrm{HF}$

43 HNO3

86 liResin

$36 \mathrm{IIg}$

$185 \mathrm{higN032}$

$21 \mathrm{HgO}$

$97 \quad 12$

$89 \mathrm{~K} 20$

$131 \mathrm{KMnO}$

$118 \mathrm{KNO3}$

105 La203

$10 S$ Li 20

$65 \mathrm{Mg}(\mathrm{COOH}) 2$

$55 \mathrm{Mg}(\mathrm{OH}) 2$

$33 \mathrm{MgO}$

$60 \mathrm{in}(\mathrm{COOH}) 2$

.0000

.0000

.0000

.0000

.0000

.0000

.0000

.0000

.0000

.0000

.0000

.0000

.0000

.0000

.0000

.0000

.0000

$132 \mathrm{Mn}(\mathrm{N} 03) 2$

$129 \mathrm{Mn}(0.1) 2$

5) $\mathrm{MnO}$

$14 \mathrm{MnO2}$

$81 \mathrm{~N} 2$

$143 \mathrm{NA} 2 \mathrm{CO}$ (C14)

.0000

.0000

.0000

.0000

170.9

.0000

35 NO

$84 \mathrm{NO2}$

$70 \mathrm{Na}$ (ligO(Oil))

.0000

.0000

.0000

$94 \mathrm{Na} 2 \mathrm{~B} 407$

.0000

$109 \mathrm{Na} 2 \mathrm{C} 204$

$5 \mathrm{Na} 2 \mathrm{CO}$

$32 \mathrm{Na} 20$

71 Ne2Pu02(OI1) 4

.0000

.0000

.0000

.0000

$73 \mathrm{Na} 2 \mathrm{RhO}_{\mathrm{O}}$

$72 \mathrm{No} 2 \mathrm{RuO}_{4}$

$6 \mathrm{Na} 2 \mathrm{SO} 4$

$68 \mathrm{NaAlO2}$

$114 \mathrm{NaBO2}$

.0000

.0000

.0000

.0000

.0000

$140 \mathrm{NaBO2}$ Semi Vol

.0000

$50 \mathrm{NaCOOH}$

.0000

160
$06 C T$ A r
In Jenkage
.0000
.0000
.0000
.0000
.0000
.0000
.0000
.0000
.0000
.0000
.0000
.0000
.0000
.0000
.0000
.0000
.0000
.0000
.0000
.0000
.0000
.0000
.0000
.0000
.0000
.0000
.0000
.0000
.0000
79.64
.0000
.0000
.0000
.0000
.0000
.0000
.0000
.0000
.0000
.0000
.0000
.0000
.0000
.0000
.0000
.0000

161

FPT Air

Inleakage

.0000

.0000

.0000

.0000

.0000

.0000

.0000

.0000

.0000

.0000

.0000

.0000

.0000

.0000

.0000

.0000

.0000

.0000

.0000

.0000

.0000

.0000

.0000

.0000

.0000

.0000

.0000

.0000

.0000

79.64

.0000

.0000

.0000

.0000

.0000

.0000

.0000

.0000

.0000

.0000

.0000

.0000

.0000

.0000

.0000

.0000
162

MUTT Air

Purgo

.0000

.0000

.0000

.0000

.0000

.0000

.0000

.0000

.0000

.0000

.0000

.0000

.0000

.0000

.0000

.0000

.0000

.0000

.0000

.0000

.0000

.0000

.0000

.0000

.0000

.0000

.0000

.0000

.0000

8.418

.0000

.0000

.0000

.0000

.0000

.0000

.0000

.0000

.0000

.0000

.0000

.0000

.0000

.0000

.0000

.0000 
DPSP $80-1033$

MATERIAL BALANCE TABLES SL.UDCE-SLPERNATE FEED STREAMS (CONT'D)STREAM NAME

$7 \mathrm{NaCl}$

$138 \mathrm{NaCl}$ Semi Vol

$69 \mathrm{NaF}$

$189 \mathrm{NaF}$ Semi Vol

$12 \mathrm{NaI}$

$125 \mathrm{NaI}$ Semi Vol

$8 \mathrm{NaNO} 2$

$2 \mathrm{NaNO}$

$4 \mathrm{NaOH}$

87 NaRes in

$61 \mathrm{Ni}(\mathrm{COOH}) 2$

$17 \mathrm{Ni}(\mathrm{OH}) 2$

$40 \mathrm{NiO}$

8202

$67 \mathrm{PbO}$

$28 \mathrm{PbSO4}$

$124 \mathrm{Pd}$

$123 \mathrm{Pd}(\mathrm{OH}) 2$

112 PdNO32

110 PdO

$117 \mathrm{Pu}(\mathrm{COOH}) 4$

$76 \mathrm{PuO}_{\mathrm{u}}$

$22 \mathrm{RhO2}$

$79 \mathrm{Ru} 02$

23 Ru02 SenI Vol

$83 \mathrm{RuO}_{4}$

$38 \mathrm{S02}$

$111 \mathrm{Si02}$

115 Silica Gel

$48 \mathrm{Sr}(\mathrm{COOH}) 2$

$10 \mathrm{Sr}(\mathrm{N} 03) 2$

$127 \mathrm{Sr}(\mathrm{OHI}) 2$

$30 \mathrm{SrCOS}$

$46 \mathrm{Sr} 0$

89 SrRESIN

141 Surfactant

92 Th02

$107 \mathrm{TiO}$

119 Tritium

93 v02

$62 \mathrm{UO2}(\mathrm{COOHI}) 2$

$16 \mathrm{VO} 2(\mathrm{OH}) 2$

$27 \mathrm{Y}(\mathrm{COOH}) 3$

$11 \mathrm{Y}(\mathrm{NOS}) \mathrm{S}$

$128 \mathrm{Y}(\mathrm{OH}) \mathrm{S}$

$81 \mathrm{Y} 2(\mathrm{CO}) \mathrm{B}$
159

MFT Air

Purge

.0000

.0000

.0000

.0000

.0000

.0000

.0000

.0000

.0000

.0000

.0000

.0000

.0003

51.63

.0000

.0000

.0000

$.000 \mathrm{~J}$

.000 .3

.0003

.0000

.0000

.0000

.000 ]

$.000 \mathrm{~J}$

.000 is

$.000 \mathrm{~J}$

.0000

.0000

.0000

.0000

.0000

.0000

.0000

.0000

.00013

.0000

.0000

.0000

.0000

.0000

.0000

.0000

.0000

.0000

.0000
Appendix II

Tnule 21-16

$\mathrm{Pa}_{\mathrm{S}} \mathrm{U} 1 \mathrm{56}$ of 178

Date 03/50/82 Rev DO
161

FPI Ai:

In leakage

.0000

.0000

.0000

.0000

.0000

.0000

.0000

.0000

.0000

.0000

.0000

.0000

.0000

24.06

.0000

.0000

.0000

.0000

.0000

.0000

.0000

.0000

.0000

.0000

.0000

.0000

.0000

.0000

.0000

.0000

.0000

.0000

.0000

.0000

.0000

.0000

.0000

.0000

.0000

.0000

.0000

.0000

.0000

.0000

.0000

.0000
152

MintiT Air

Purge

$.000 !$

$.00 r 0$

.0000

.0000

.0060

.0000

.0000

.0000

.0000

.0000

.0000

.0000

.0000

1.033

.0000

.0000

.0000

.0000

.0000

.0000

.0000

.0000

.0000

.0000

.0000

.0000

.0000

.0000

.0000

.0000

.0000

.0000

.0000

.0000

.0000

.0000

.0000

.0000

.0000

.0000

.0000

.0000

.0000

.0000

.0000

$.0000^{\circ}$ 
MATERIAL BALANCE TABLES

Date 09/80/82 Rev 09

SLUDCE-SUPERNATE FEED

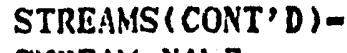

SCREAM NAME

$47 \times 203$

100 Zeolite

$44 \mathrm{Zn}(\mathrm{COOII)} 2$

$54 \mathrm{Zn}(\mathrm{OII}) 2$

$57 \mathrm{Zn} 0$

$104 \mathrm{ZrO2}$

TOTAL FLOW, LB/HR

VAPOR FLOH, CFM

LIQUID FLOW, GPM DESIGN FLOW, DENSITY, LBS/FT3

TEMPERATLRE, DEG C

PRESSURE, ATM

PRESSURE, PSIG

PRESSURE, MM HG

PHASE

EXIHALI\%, PCL/IIR

159
MFT A1r
Purge
.0000
.0000
.0000
.0000
.0000
.0000

226.27

58.45

.0706

85.00

1.00

.00

VAPOR

$-11652.27$
160
OGCT Air
In leakage
.0000
.0000
.0000
.0000
.0000
.0000

105.41

24.91

.0706

85.00

1.00

.00

VAPO?

-5429.9 ;
161

FPT Ais

In leakage

.0000

.0000

.0000

.0000

.0000

.0000

105.44

24.91

.0706

85.00

1.00

.00

VAPOR

$-5429.96$
162

MWWT Alr

Purge

.0000

.0000

.0000

.0000

.0000

.0000

4.53

1.07

.0706

85.00

1.00

.00

VAPOR

$-238.05$ 
DPSP $80-1038$

MITERIAL BALANCE TABLES

SLUDGE-SLPERNATE FEED

STREAM NUMBERS -

STREAM NAYE

COMPONENT FLOHS, LB/HR

$1 \mathrm{H} 2 \mathrm{O}$

45 Ag

116 Ag20

134 AgN03

$51 \mathrm{AgOH}$

$74 \mathrm{Al}(\mathrm{OH}) \mathrm{S}$

77 A1203

75 Alooll

106 B203

$9 \mathrm{Ba}(\mathrm{N03}) 2$

$95 \mathrm{BaCl} 2$

$15 \mathrm{BaO}$

$24 \mathrm{BaSO} 4$

$66 \mathrm{CO}$

$87 \mathrm{CO} 2$

$142 \mathrm{CO}$ (C14)

$63 \mathrm{Ca}(\mathrm{COOH}) 2$

$120 \mathrm{Ca}(\mathrm{OH}) 2$

$118 \mathrm{Ca} 3(\mathrm{PO4}) 2$

$20 \mathrm{CaC204}$

$18 \mathrm{CaCO3}$

$78 \mathrm{CaF2}$

$41 \mathrm{CaO}$

$19 \mathrm{raSO4}_{3}$

29 Carbon

$26 \mathrm{Co}(\mathrm{COOH}) 2$

$121 \mathrm{Co}(\mathrm{OII}) 2$

$53 \mathrm{Co}(\mathrm{OH}) 3$

$59 \mathrm{CoO}$

$99 \mathrm{Cr}(\mathrm{OH}) 3$

$98 \mathrm{Cr} 203$

42 Cs20

187 Cs20 Semi Vol

$90 \mathrm{Cs} \mathrm{COOH}$

$96 \mathrm{CsCl}$

$186 \mathrm{CsCl}$ Semi Vol

$8 \mathrm{Cs.YO3}$

88 CsResin

$122 \mathrm{Cu}(\mathrm{COOH}) 2$

$52 \mathrm{Cu}(\mathrm{OHI}) 2$

$58 \mathrm{Cu} 20$

$64 \mathrm{CuCOOH}$

$130 \mathrm{CuO}$

$13 \mathrm{Fe}(011) \mathrm{s}$

$80 \mathrm{Fe} 203$

$\begin{array}{cc}163 & 165 \\ \text { MALT A1r } & \text { MFT1 Air } \\ \text { Purgo } & \text { Purge }\end{array}$

$.7477 E-01$

$.00 \mathrm{CJ}$

.0003

.0000

.0003

.0003

$.000 J$

.0003

$.000 \mathrm{~J}$

.0003

$.000 \mathrm{~J}$

$.000 \mathrm{~J}$

.0003

.0003

$.000 J$

.0003

.0003

.0003

.000 )

.000 J

$.000 \mathrm{~J}$

$.000 \mathrm{~J}$

$.000 \mathrm{~J}$

$.000 \mathrm{~J}$

.0003

.0003

$.000 \mathrm{~J}$

$.000 \mathrm{~J}$

$.000 \mathrm{~J}$

.000 J

$.000 \mathrm{~J}$

.000

.0000

.000 i]

.000 is

.0000

.000 is

.0000

.0000

.0000

.0000

.0000

.0000

.0000

.0000

.0000

.0000

.0000

.0000

.0000

.0000

.0000

.0000

.0000

.0000

.0000

.0000

.0000

.0000

.0000

.0000

.0000

.0000

.0000

.0000

.0000

.0000

.0000

.0000

.0000

.0000

.0000

.0000

.0000

.0000

.0000

.0000

.0000

.0000

.0000
Append ix II

Table 21-10

Page 153 of 173

Date 09/30/82 Rrv CO

$\begin{array}{lll}.7477 E-01 & .7477 E-C 1 & .7477 E-01 \\ .0000 & .0000 & .0000 \\ .0000 & .0000 & .0000 \\ .0000 & .0000 & .0000 \\ .0000 & .0000 & .0000 \\ .0000 & .0000 & .01100 \\ .0000 & .0000 & .0000 \\ .0000 & .0000 & .0000 \\ .0000 & .0000 & .0000 \\ .0000 & .0000 & .0000\end{array}$

.0000

.0000

.0000

.0000

.0000

.0000

.0000

.0000

.0000

.0000

.0000

.0000

.0000

.0000

.0000

.0000

.0000

.0000

.0000

.0000

.0000

.0000

.0000

.0000

.0000

.0000

.0000

.0000

.0000

.0000

.0000

.0000

.0000

.0000

.0000

.0000

.0000

.0000

.0000

.0000

.0000

.0000

.0000

.0000

.0000

.0000

.0000

.0000

.0000

.0000

.0000

.0000

.0000

.0000

.0000

.0000

.0000

.0000

.0000

.0000

.0000

.0000

.0000

.0000

.0000

.0000

.0000

.0000 .

.0000

.0000 
DPSP $80-1083$

MATERIAL BALANCE TABLES

SLLDGE-SLPERNATE FEED

STREAMS (CONT'D)=

STRLAM NAME

$101 \mathrm{FeO}$

126 Group A Semi Vo

102 GroupA

103 Group B

$25 \mathrm{ll} 2$

$133112 C 204$

9111202

84 HCOOII

$43 \mathrm{IICl}$

$85 \mathrm{HF}$

49 HNO3

86 HResin

$36 \mathrm{lgg}$

135 lig $\mathrm{NO} 2$

$21 \mathrm{Hg} 0$

9712

89 K20

$131 \mathrm{KMnO4}$

$118 \mathrm{KNO}$

105 La203

$10 S$ L 120

$65 \mathrm{Mg}(\mathrm{COOHI}) 2$

$55 \mathrm{Mg}(\mathrm{Oll}) 2$

$83 \mathrm{MgO}$

$60 \mathrm{Mn}(\mathrm{COOII}) 2$

$132 \mathrm{Mn}(\mathrm{NO3}) 2$

$129 \mathrm{Mn}(\mathrm{OII}) 2$

$5 G \mathrm{MnO}$

$14 \mathrm{MnO2}$

81 N2

$143 \mathrm{NA2CO3} \mathrm{(C14)}$

$35 \mathrm{NO}$

$84 \mathrm{NO2}$

$70 \mathrm{Na}(\mathrm{HgO}(\mathrm{Oll}))$

$94 \quad \mathrm{Na} 2 \mathrm{~B} 407$

$109 \mathrm{Na} 2 \mathrm{C}_{204}$

$5 \mathrm{Na} 2 \mathrm{CO} 3$

$82 \mathrm{Na} 20$

$71 \mathrm{Na} 2 \mathrm{PuO}_{2}(\mathrm{OHI}) 4$

$73 \mathrm{Na} 2 \mathrm{RhO}_{4}$

$72 \mathrm{Na} 2 \mathrm{Ru} 04$

$6 \mathrm{Na} 2 \mathrm{SO} 4$

$68 \mathrm{NaAlO2}$

$114 \mathrm{NaBO} 2$

$140 \mathrm{NaBO2}$ Semi Vol

$50 \mathrm{NaCOOH}$
163

MAWT Air

Purge

.0000

.0000

.0000

.0000

.0000

.0000

.0000

.0000

.0000

.0000

.0000

.0000

.0000

.0000

.0000

.0000

.0000

.0000

.0000

.0000

.0000

.0000

.0000

.0000

.0000

.0000

.0000

.0000

.0000

3.418

.0000

.0000

.0000

.0000

.0000

.0000

.0000

.0000

.0000

.0000

.0000

.0000

.0000

.0000

.0000

.0000
Appendix H

Table 21-16

Page 159 of 178

Date 09/80/82 Rev 09

167

168

MFT2 Air

Purge

.0000

.0000

.0000

.0000

.0000

.0000

.0000

.0000

.0000

.0000

.0000

.0000

.0000

.0000

.0000

.0000

.0000

.0000

.0000

.0000

.0000

.0000

.0000

.0000

.0000

.0000

.0000

.0000

.0000

8.418

.0000

.0000

.0000

.0000

.0000

.0000

.0000

.0000

.0000

.0000

.0000

.0000

.0000

.0000

.0000

.0000
MHT AIr

Purge

.0000

.0000

.0000

.0000

.0000

.0000

.0000

.0000

.0000

.0000

.0000

.0000

.0000

.0000

.0000

.0000

.0000

.0000

.0000

.0000

.0000

.0000

.0000

.0000

.0000

.0000

.0000

.0000

.0000

8.418

.0000

.0000

.0000

.0000

.0000

.0000

.0000

.0000

.0000

.0000

.0000

.0000

.0000

.0000

.0000

.0000 
DPSP 80-1033

MATERIAL BALANCE TABLES

SLLDGE-SUPERNATE FEED STREAMS (CONT'D) -

STREAM NAME

\begin{tabular}{|c|c|c|}
\hline 7 & $\mathrm{NaCl}$ & $.000 \mathrm{~J}$ \\
\hline 188 & NaCl Se:il Vol & .0000 \\
\hline 69 & $\sin F$ & .0000 \\
\hline 189 & VaF Semi Vol & .0003 \\
\hline 12 & $\mathrm{NaI}$ & .0000 \\
\hline 125 & NaI Semi Vol & .0000 \\
\hline $\mathbf{8}$ & $\mathrm{NaN02}$ & .0000 \\
\hline 2 & $\mathrm{NaNOS}$ & .0000 \\
\hline 4 & $\mathrm{NnOH}$ & .0000 \\
\hline 87 & NaResin & .0000 \\
\hline 61 & $\mathrm{~N}_{1}(\mathrm{COOH}) 2$ & .0000 \\
\hline 17 & $\mathrm{Ni}(\mathrm{OH})_{2}$ & .0000 \\
\hline 40 & Nio & .0000 \\
\hline 82 & 02 & 1.033 \\
\hline 67 & PbO & .0003 \\
\hline 28 & PbS04 & .0000 \\
\hline 124 & $\mathbf{P d}$ & .0000 \\
\hline 123 & $\mathrm{Pd}(\mathrm{OII}) 2$ & .0000 \\
\hline 112 & PdA032 & .0000 \\
\hline 110 & PdO & .0000 \\
\hline 117 & $\mathrm{Pu}(\mathrm{COOH}) 4$ & .0000 \\
\hline 76 & $\mathrm{PuO2}$ & .0000 \\
\hline 22 & $\mathrm{RhO2}$ & .0000 \\
\hline 79 & $\mathrm{RuO2}$ & .0000 \\
\hline 23 & Ru02 Seni Vol & .0000 \\
\hline 83 & $\mathrm{RuO4}$ & .0000 \\
\hline 88 & S02 & .0000 \\
\hline 111 & SiO2 & .0000 \\
\hline 115 & ; Sillica Gel & .0000 \\
\hline 48 & $\mathrm{Sr}(\mathrm{COOH}) 2$ & .0000 \\
\hline 10 & Sr $\left(. \mathrm{NO}^{2}\right) 2$ & .0000 \\
\hline 127 & Sr $(\mathrm{OH}) 2$ & .0000 \\
\hline 80 & $\mathrm{SrCOB}$ & .0000 \\
\hline 46 & ; SrO & .0000 \\
\hline 89 & SrRESIN & .0000 \\
\hline 141 & Surfactant & .0000 \\
\hline 92 & $\mathrm{ThO}_{\mathrm{N}}$ & .0000 \\
\hline 107 & Ti02 & .0000 \\
\hline 119 & Tritium & .0000 \\
\hline 93 & $3 \mathrm{VO2}$ & .0000 \\
\hline 62 & $2 \mathrm{lO} 2(\mathrm{COOH}) 2$ & .0000 \\
\hline 16 & $6 \mathrm{VO2}(\mathrm{OH}) 2$ & .0000 \\
\hline 27 & $7 \mathrm{Y}(\mathrm{COOH}) 3$ & .0000 \\
\hline 11 & $1 \mathrm{Y}(\mathrm{N} 03) 3$ & .0000 \\
\hline $12 S$ & $8 \mathrm{Y}(\mathrm{OH}) 3$ & .0000 \\
\hline $\mathbf{3 1}$ & $1 Y 2(C 03) 3$ & .0000 \\
\hline
\end{tabular}

Appendis $\mathrm{H}$

Table 21-10

Page 160 of 173

Date 03/30/S2 Rev 09

\begin{tabular}{|c|c|c|c|}
\hline 163 & 165 & 167 & 168 \\
\hline MAVT tir & MET1 Air & MET2 Air & MriT Air \\
\hline $\begin{array}{l}\text { Purgo } \\
.000 \text { J }\end{array}$ & $\begin{array}{l}\text { Purge } \\
.0000\end{array}$ & $\begin{array}{l}\text { Purge } \\
.0000\end{array}$ & $\begin{array}{l}\text { PLrge } \\
.0000\end{array}$ \\
\hline $\begin{array}{l}.000 \mathrm{~J} \\
.0000\end{array}$ & .0000 & .0000 & .0000 \\
\hline $\begin{array}{l}.0000 \\
.0001\end{array}$ & .0000 & .0000 & $.00 \mathrm{co}$ \\
\hline .0003 & .0000 & .0000 & . nous \\
\hline .0000 & .0000 & .0000 & .0000 \\
\hline .0000 & .0000 & .0000 & .0000 \\
\hline .0000 & .0000 & .0000 & .0000 \\
\hline .0000 & .0000 & .0000 & .0000 \\
\hline .0000 & .0000 & .0000 & .0000 \\
\hline .0000 & .0000 & .0500 & .0000 \\
\hline .0000 & .0000 & .0000 & .0000 \\
\hline .0000 & .0000 & .0000 & .0000 \\
\hline .0000 & .0000 & .0000 & .0000 \\
\hline 1.033 & 1.038 & 1.033 & 1.033 \\
\hline $.000 J$ & .0000 & .0000 & .0000 \\
\hline .0000 & .0000 & .0000 & .0000 \\
\hline .0000 & .0000 & .0000 & .0000 \\
\hline .0000 & .0000 & .0000 & .0000 \\
\hline .0000 & .0000 & .0000 & .0000 \\
\hline .0000 & .0000 & .0000 & .0000 \\
\hline .0000 & .0000 & .0000 & .0000 \\
\hline .0000 & .0000 & .0000 & .0000 \\
\hline .0000 & .0000 & .0000 & .0000 \\
\hline .0000 & .0000 & .0000 & .0000 \\
\hline .0000 & .0000 & .0000 & .0000 \\
\hline .0000 & .0000 & .0000 & .0000 \\
\hline .0000 & .0000 & .0000 & .0000 \\
\hline .0000 & .0000 & .0000 & .0000 \\
\hline .0000 & .0000 & .0000 & .0000 \\
\hline .0000 & .0000 & .0000 & .0000 \\
\hline .0000 & .0000 & .0000 & .0000 \\
\hline .0000 & .0000 & .0000 & .0000 \\
\hline .0000 & .0000 & .0000 & .0000 \\
\hline .0000 & .0000 & .0000 & .0000 \\
\hline .0000 & .0000 & .0000 & .0000 \\
\hline .0000 & .0000 & .0000 & .0000 \\
\hline .0000 & .0000 & .0000 & .0000 \\
\hline .0000 & .0000 & .0000 & .0000 \\
\hline .0000 & .0000 & .0000 & .0000 \\
\hline .0000 & .0000 & .0000 & .0000 \\
\hline .0000 & .0000 & .0000 & .0000 \\
\hline .0000 & .0000 & .0000 & .0000 \\
\hline .0000 & .0000 & .0000 & .0000 \\
\hline .0000 & .0000 & .0000 & .0000 \\
\hline .0000 & .0000 & .0000 & .0000 \\
\hline nono & .0000 & .0000 & $.0000^{\circ}$ \\
\hline
\end{tabular}


DPSP $80-1033$

MATERIAI. BALANCE TABLES SLUDGE-SUPERNATE FEED STREAIS ( CONT'D)STREAM NAME

$\begin{array}{rl}47 & Y 203 \\ 100 & \mathrm{Zen} \text { (1) } \\ 44 & \mathrm{Zn}(\mathrm{COOII)}) \\ 54 & \mathrm{Zn}(\mathrm{OHI}) 2 \\ 57 & \mathrm{Zn} 0 \\ 104 & \mathrm{Zr} 02\end{array}$

TOTAL FLOW, LB/HR VAPOR FLOW, CFM LIQUID FLOH, GPM DESIGN FLO"I: DENSITY, LBS/FT3 TEMPERÁTURE, DEG C PRESSURE, ATM PRESSURE, PSIG PRESSURE, MM HG PHASE

ENTHALPY, PCU/HR
Append IX H

Table 21-16

Page 161 of 178

Date 09/80/82 Rev 09

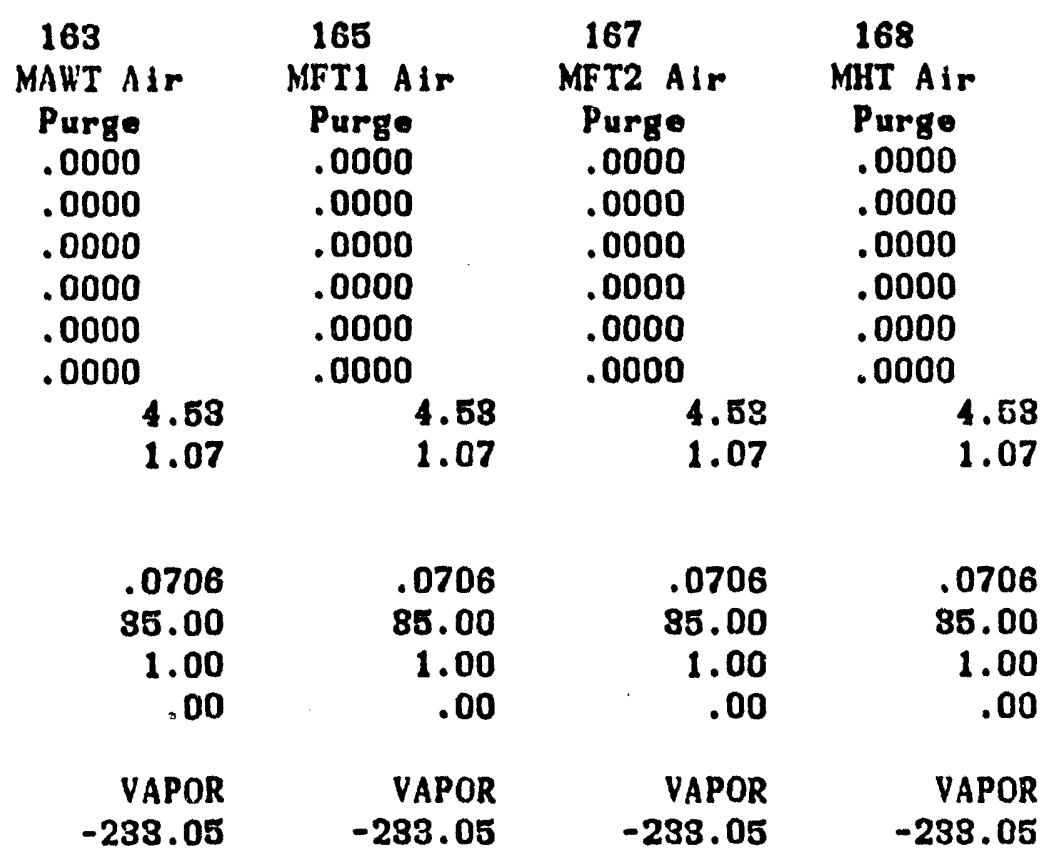



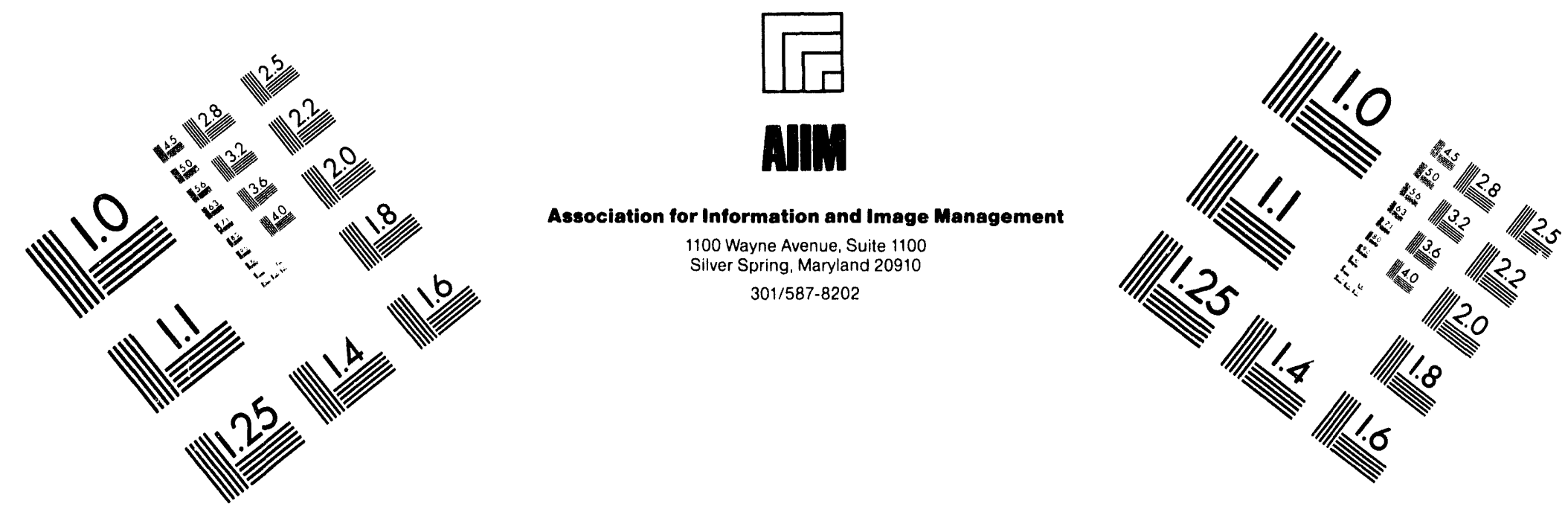

\section{Centimeter}

$\begin{array}{llllllllllllllll}1 & 2 & 3 & 4 & 5 & 6 & 7 & 8 & 9 & 10 & 11 & 12 & 13 & 14 & 15 & \mathrm{~mm}\end{array}$

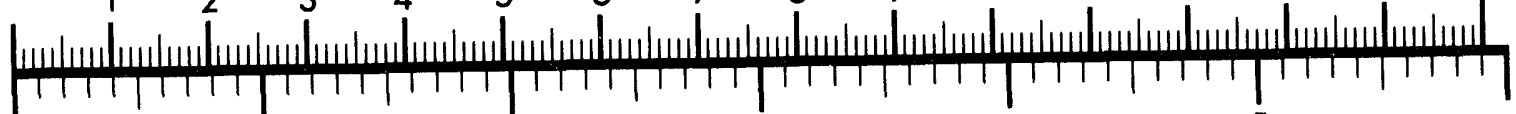

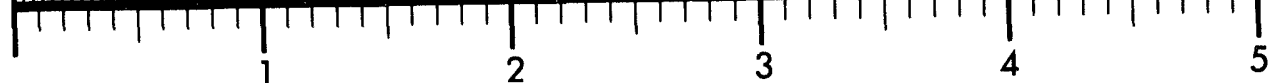
Inches
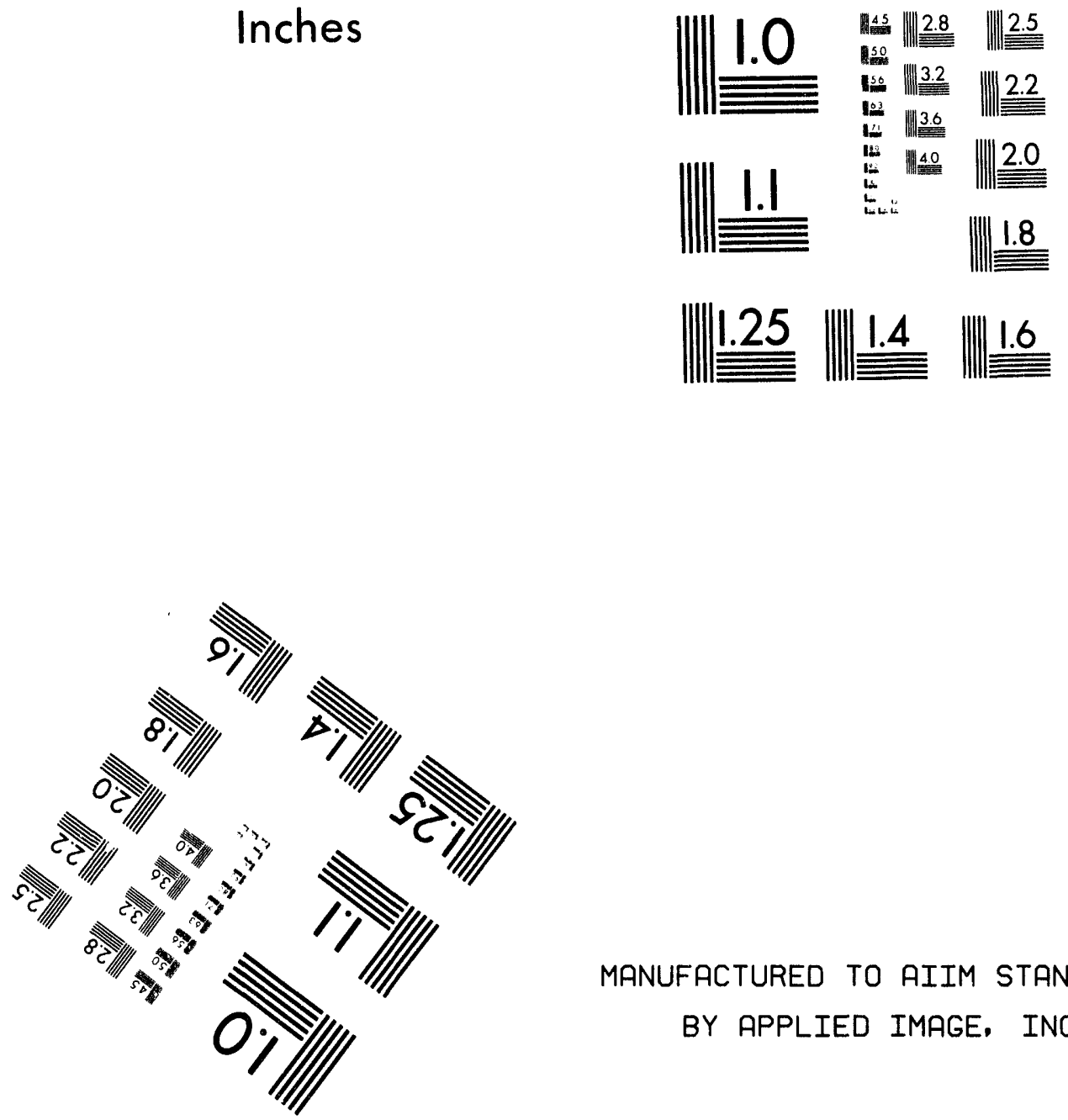

MANUFACTURED TO AIIM STANDARDS BY APPLIED IMAGE, INC.

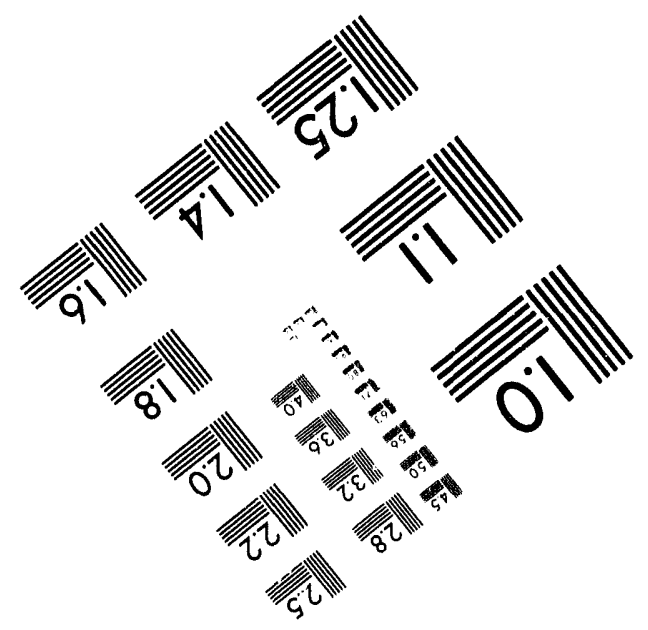



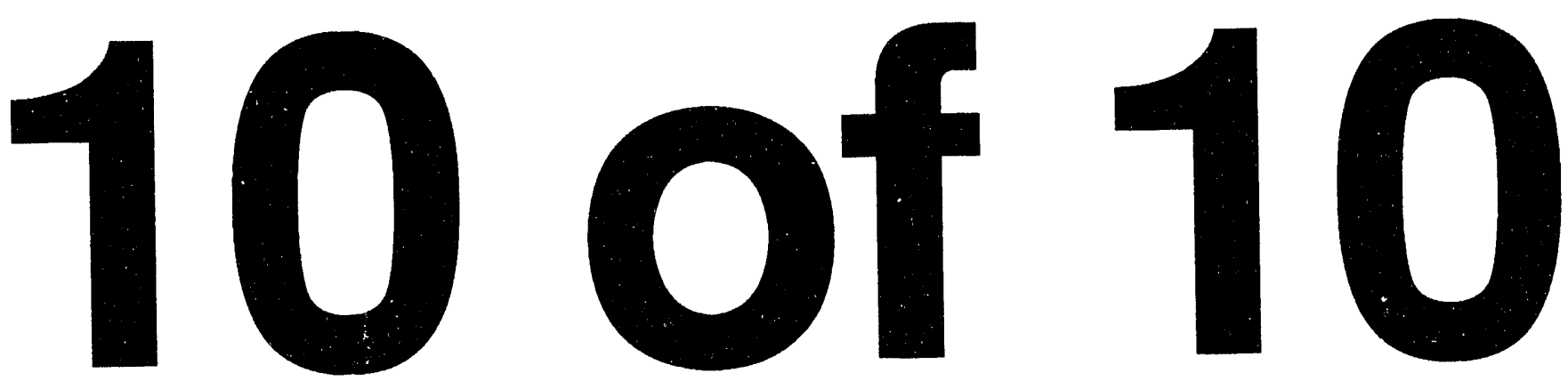
DPSP $80-1033$

MATERIAL BALANCE TABLES

SLLDGE-SUPERNATE FEED

STREAM NUMEERS -

STREAM NAME

COMPONENT FLOHS, LB/HR

$1 \mathrm{H} 2 \mathrm{O}$
$45 \mathrm{Ag}$

116 Ag20

$134 \mathrm{AgNO3}$

$51 \mathrm{AgOH}$

$74 \mathrm{Al}(\mathrm{OH}) \mathrm{S}$

77 A 1208

$75 \mathrm{~A} 100 \mathrm{H}$

106 B203

$9 \mathrm{Ba}(\mathrm{NO3}) 2$

$95 \mathrm{BaCl} 2$

$15 \mathrm{BaO}$

$24 \mathrm{BaSO} 4$

$66 \mathrm{CO}$

$37 \mathrm{CO} 2$

$142 \mathrm{CO}$ ( $\mathrm{C14})$

$63 \mathrm{Ca}(\mathrm{COOH}) 2$

$120 \mathrm{Ca}(\mathrm{OH}) 2$

$113 \mathrm{Ca} 3(\mathrm{PO} 4) 2$

$20 \mathrm{CaC204}$

$18 \mathrm{CaCO3}$

$78 \mathrm{CaF2}$

$41 \mathrm{CaO}$

$19 \mathrm{CaSO} 4$

29 Carbon

$26 \mathrm{Co}(\mathrm{COOH}) 2$

$121 \mathrm{Co}(\mathrm{OH}) 2$

$53 \mathrm{Co}(\mathrm{OH}) 3$

$59 \mathrm{CoO}$

$99 \mathrm{Cr}(\mathrm{OH}) 3$

$98 \mathrm{Cr} 203$

$42 \mathrm{Cs} 20$

137 Cs20 Seni Vol

$90 \mathrm{CsCOOH}$

$96 \mathrm{CsCl}$

$136 \mathrm{CsCl}$ Semi Vol

$8 \mathrm{CsNO3}$

88 CsResin

$122 \mathrm{Cu}(\mathrm{COOH}) 2$

$52 \mathrm{Cu}(\mathrm{OH}) 2$

$58 \mathrm{Cu} 20$

$64 \mathrm{CuCOOH}$

$130 \mathrm{CuO}$

$13 \mathrm{Fe}(\mathrm{OH}) 3$

$80 \mathrm{Fe} 203$
169

SWT Air

Purge

.7477E-01

.0000

.0000

.0000

.0000

.0000

.0000

.0000

.0000

.0000

.0000

.0000

.0000

.0000

.0000

.0000

.0000

.0003

.0000

.0000

.0000

.0000

.0000

.0000

.0000

.0000

.0000

.0000

.0000

.0000

.0000

.0000

.0000

.0000

.0000

.0000

.0000

.0000

.0000

.0000

.0000

.0000

.0000

.0000

.0000
Appendix $\|$

Table 21-16

Page 162 of 173

Date $09 / 80 / 82$ kev 09
171

RCt Air

Purgo

3.738

.0000

.0000

.0000

.0000

.0000

.0000

.0000

.0000

.0000

.0000

.0000

.0000

.0000

.0000

.0000

.0000

.0000

.0000

.0000

.0000

.0000

.0000

.0000

.0000

.0000

.0000

.0000

.0000

.0000

.0000

.0000

.0000

.0000

.0000

.0000

.0000

.0000

.0000

.0000

.0000

.0000

.0000

.0000

.0000
172

FCT Air

Purge

7.477

.0000

.0000

.0000

.0000

.0000

.0000

.0000

.0000

.0000

.0000

.0000

.0000

.0000

.0000

.0000

.0000

.0000

.0000

.11000

.0000

.6000

.0000

.0000

.0000

.0000

.0000

.0000

.0000

.0000

.0000

.0000

.0000

.0000

.0000

.0000

.0000

.0000

.0000

.0000

.0000

.0000

.0000

.0000

$.0000^{\circ}$ 
Date 09/30/82 Rev 09

M:ATCRIAL BALANCE TABLES

SLUDGE-SUPERNATE FEED

S:REAI!S (CONT'D) -

STREAM NAME

$101 \mathrm{FeO}$

126 Group A Seni Vo

102 Groupll

103 GroupB

$25 \mathrm{HI} 2$

1331126204

9111202

34 IICOOII

$43 \mathrm{HCl}$

$85 \mathrm{HF}$

49 HNO3

86 HResin

$30 \mathrm{Hg}$

135 HgN032

$21 \mathrm{HgO}$

$97 \quad 12$

39 K20

$131 \mathrm{kMn} 04$

$118 \mathrm{KNO3}$

$105 L_{\Omega} 203$

108 Li20

$65 \mathrm{Mg}(\mathrm{COOH}) 2$

$55 \mathrm{Mg}(\mathrm{OH}) 2$

83 Nigo

(i) $\sin (\mathrm{COOII)} 2$

$132 \mathrm{Mn}(\mathrm{N} 03) 2$

$129 \mathrm{Mn}(\mathrm{Oil}) 2$

$56 \mathrm{MnO}$

$14 \mathrm{MnO} 2$

81 N2

$142 \mathrm{NA2CO3} \mathrm{(C.14)}$

35 NO

84 N02

$70 \mathrm{Na}\left(\mathrm{II}_{\mathrm{g}} \mathrm{O}(\mathrm{OH})\right)$

$94 \mathrm{~N}$ 2B 407

$109 \mathrm{Na} 2 \mathrm{C204}$

$5 \mathrm{Ni} 2 \mathrm{CO3}$

$32 \mathrm{Na} 20$

$71 \mathrm{Ni2} 2 \mathrm{P} 02(\mathrm{OHI}) 4$

$73 \mathrm{Na}_{2} \mathrm{Rh}_{1} \mathrm{O}$

$72 \mathrm{Na} 2 \mathrm{RuO4}$

$6 \mathrm{Na} 2 \mathrm{SO}_{4}$

$68 \mathrm{NaAl} 102$

$114 \mathrm{NaBO} 2$

140 NaBO2 Semi Vol

$50 \mathrm{NaCOOH}$
169

SWT Air

.0000

.0000

.0000

.0000

.0000

.0000

.0000

.0000

.0000

.0000

.0000

.0000

.0000

.0000

.0000

.0000

.0000

.0000

.0000

.0000

.0000

.0000

.0000

.0000

.0000

.0000

.0000

.0000

.0000

3.418

.0000

.0000

.0000

.0000

.0000

.0000

.0000

.0000

.0000

.0000

.0000

.0000

.0000

.0000

.0000

.0000
170

DWTT Air

In leakage

.0000

.0000

.0000

.0000

.0000

.0000

.0000

.0000

.0000

.0000

.0000

.0000

.0000

.0000

.0000

.0000

.0000

.0000

.0000

.0000

.0000

.0000

.0000

.0000

.0000

.0000

.0000

.0000

.0000

47.85

.0000

.0000

.0000

.0000

.0000

.0000

.0000

.0000

.0000

.0000

.0000

.0000

.0000

.0000

.0000

.0000
171

RCT Air

Purge

.0000

.0000

.0000

.0000

.0000

.0000

.0000

.0000

.0000

.0000

.0000

.0000

.0000

.0000

.0000

.0000

.0000

.0000

.0000

.0000

.0000

.0000

.0000

.0000

.0000

.0000

.0000

.0000

.0000

170.9

.0000

.0000

.0000

.0000

.0000

.0000

.0000

.0000

.0000

.0000

.0000

.0000

.0000

.0000

.0000

.0000
172

FCT Air

Purge

.0000

.0000

.0000

.0000

.0000

.0000

.0000

.0000

.0000

.0000

.0000

.0000

.0000

.0000

.0000

.0000

.0000

.0000

.0000

.0000

.0000

.0000

.0000

.0000

.0000

.0000

.0000

.0000

.0000

841.8

.0000

.0000

.0000

.0000

.0000

.0000

.0000

.0000

.0000

.0000

.0000

.0000

.0000

.0000

.0000

.0000 
DPSP 80- 1083

MATERIAL BALANCE TABLES

SLLDGE-SUPERYATE FEED STREAMS (CONT'D)-

STREAM NAME

$7 \mathrm{NaCl}$

$138 \mathrm{NaCl}$ Semi Vol

$69 \mathrm{NaF}$

$139 \mathrm{NaF}$ Semi Vol

$12 \mathrm{NaI}$

$125 \mathrm{NaI}$ Semi Vol

$3 \mathrm{NaN02}$

$2 \mathrm{NaNO}^{2}$

$4 \mathrm{NaOH}$

87 NaResin

$61 \mathrm{Ni}(\mathrm{COOH}) 2$

$17 \mathrm{Ni}(\mathrm{OH}) 2$

$40 \mathrm{NiO}$

8202

$67 \mathrm{PbO}$

$28 \mathrm{PbS04}$

$124 \mathrm{Pd}$

$123 \mathrm{Pd}(\mathrm{OH}) 2$

112 PdNO32

$110 \mathrm{PdO}$

$117 \mathrm{Pu}(\mathrm{COOH}) 4$

$76 \mathrm{Pu} 02$

$22 \mathrm{Rh} 02$

$79 \mathrm{Ru} 02$

23 Ru02 Semi Vol

$83 \mathrm{Ru} 04$

$88 \mathrm{SO} 2$

$111 \mathrm{SiO2}$

115 Silica Gel

$48 \mathrm{Sr}(\mathrm{COOH}) 2$

$10 \mathrm{Sr}(\mathrm{NOS}) 2$

$127 \mathrm{Sr}$ (OH) 2

$80 \mathrm{SrCOS}$

$46 \mathrm{Sr} 0$

89 SrRESIN

141 Surfactant

92 Th02

$107 \mathrm{TiO2}$

119 Tritium

93 U02

$62 \mathrm{VO2}(\mathrm{COO} ! \mathrm{H}) 2$

$16 \mathrm{VO2}(\mathrm{OH}) 2$

$27 \mathrm{Y}(\mathrm{COOH}) 3$

$11 \mathrm{Y}(\mathrm{NO3}) 3$

$128 Y(\mathrm{OH}) 3$

$81 Y 2(\mathrm{COS}) 3$

\section{9}

SWT Air

Purge

.0000

.0000

.0000

.0000

.0000

.0000

.0000

.0000

.0000

.0000

.0000

.0000

.0000

1.033

.0000

.0000

.0000

.0000

.0000

.0000

.0000

.0000

.0000

.0000

.0000

.0000

.0000

.0000

.0000

.0000

.0000

.0000

.0000

.0000

.0000

.0000

.0000

.0000

.0000

.0000

.0000

.0000

.0000

.0000

.0000

.0000
Append ix H

Table 21-10

Page 164 of 173

Date 09/30/82 Rev 09 
DPSI' $30-1032$

VATERIAT, BALAYCE TANIIS SLCDGI-SUPER AATE FEID STIEAMS (CONT'D)STREAM NAME

$4 \%$ Y203

150 Zeolite

4: $\mathrm{Zn}($ COOH $) 2$

5.) $\mathrm{Zn}(\mathrm{Oil}) 2$

$57 \mathrm{ZnO}$

$10+\mathrm{ZrO2}$

TOML FLOW, LB/HR

VAPOR FLOM, CFY.

LIOUID FLOH, GPM

DE. IIGN FLOH,

DEXSITY, LBS/FT3

TEPEDATURE, DEG $\mathrm{C}$

PISLSSURE, ATM

PiESSURE, PSIG

PRI:SSURE, MI IRG

PII!SE

EYTIHALP", PCU/IIR
Appendix $H$

Table 21-16

Page 165 of 173

Date 03/30/82 Rev 09

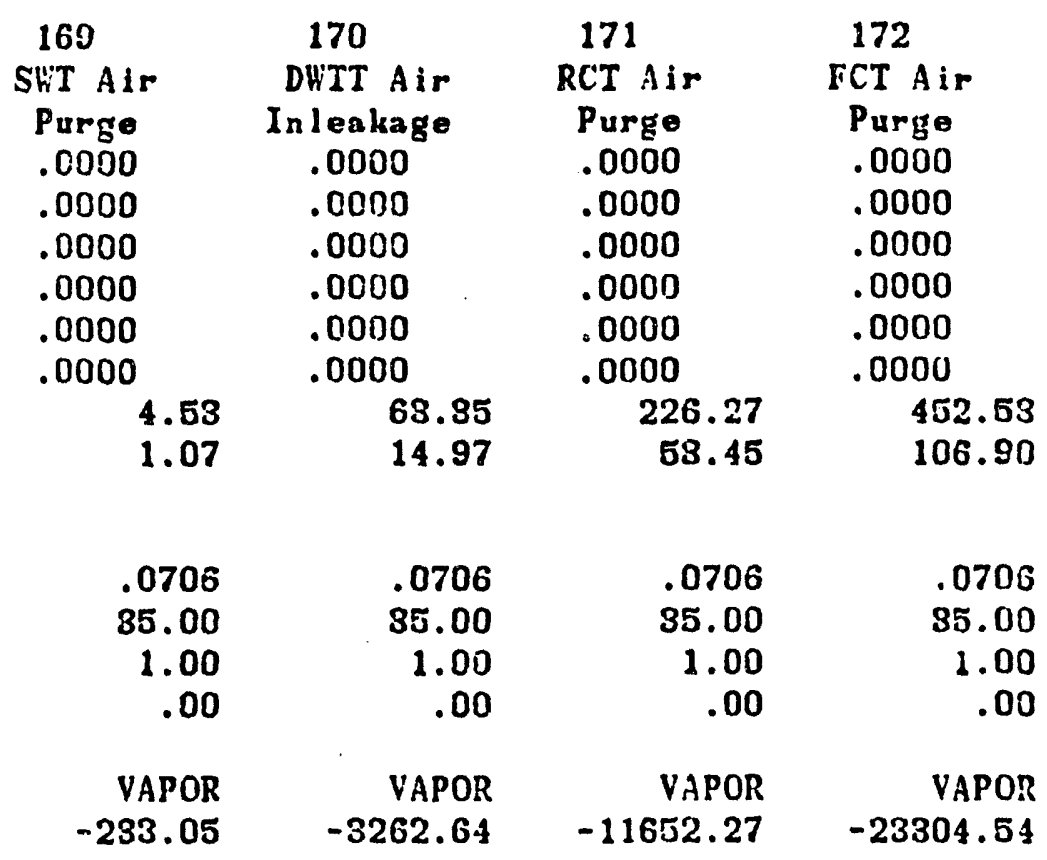


DPSP $80-1033$

MATIRIAL BALANCE TABLES

SLUDGE-SUPER.ATTE FEED

STREAM NUMBERS -

STREAM NAME

CONPONENT FLONS, LB/HR

\begin{tabular}{|c|c|c|}
\hline 1 & $\mathrm{H2O}$ & 8.733 \\
\hline 45 & Ag & .0000 \\
\hline 6 & Ag20 & .0000 \\
\hline & AgNO3 & .0000 \\
\hline 1 & $\mathrm{AgOH}$ & .00011 \\
\hline 4 & Al (OH) 3 & .0000 \\
\hline 7 & A 1203 & .0000 \\
\hline 75 & Alooll & .0000 \\
\hline & B203 & .0000 \\
\hline 9 & $\mathrm{Ba}(\mathrm{NO3}) 2$ & .0000 \\
\hline 05 & $\mathrm{BaCl} 2$ & .0000 \\
\hline 15 & $\mathrm{BaO}$ & .0000 \\
\hline 24 & BaS04 & .0000 \\
\hline 66 & CO & .0000 \\
\hline 37 & $\mathrm{CO} 2$ & .0000 \\
\hline 2 & $\mathrm{CO2}(\mathrm{C} 14)$ & .0000 \\
\hline 3 & $\mathrm{Ca}(\mathrm{COOH}) 2$ & .0000 \\
\hline & $\mathrm{Ca}(\mathrm{OH}) 2$ & .0000 \\
\hline & $\mathrm{Cn} 3(P 04) 2$ & .0000 \\
\hline & $\mathrm{CaC2O4}$ & .0000 \\
\hline & $\mathrm{CaC03}$ & .0000 \\
\hline & CaF2 & .0000 \\
\hline & $\mathrm{CaO}$ & .0000 \\
\hline & CaS04 & .0000 \\
\hline & Carbon & .0000 \\
\hline 6 & $\mathrm{Co}(\mathrm{COOH}) 2$ & .0000 \\
\hline & $\mathrm{Co}(\mathrm{OH}) 2$ & .0000 \\
\hline & $\mathrm{Co}(\mathrm{OH}) 3$ & .0000 \\
\hline & $\mathrm{CoO}$ & .0000 \\
\hline & $\mathrm{Cr}(\mathrm{OII}) 3$ & .0000 \\
\hline & Cr203 & .0000 \\
\hline 2 & Cs20 & .0000 \\
\hline & Cs20 Semi Vol & .0000 \\
\hline & Cscooll & .0000 \\
\hline & $\mathrm{CsCl}$ & .0000 \\
\hline & CsCl Semi Vol & .0000 \\
\hline 8 & Csin08 & .0000 \\
\hline & CsResin & .0000 \\
\hline & $\mathrm{Cu}(\mathrm{COOH}) 2$ & .0000 \\
\hline & $\mathrm{Cu}(\mathrm{OH}) 2$ & .0000 \\
\hline & Cu20 & .0000 \\
\hline & $\mathrm{CuCOOH}$ & .0000 \\
\hline & $\mathrm{Cu} 0$ & .0000 \\
\hline & $\mathrm{Fe}(\mathrm{OH}) 3$ & .0000 \\
\hline & Fe203 & .000 \\
\hline
\end{tabular}

Purgo

8.753
Appendix $\mathrm{H}$

Table 21-16

Page 166 of $: 73$

Date 09/80/82 Rev no

174

Orf-Gas

to SWDBF

SFHT lir

180.8

.0000

.0000

.0000

$.1541 \mathrm{E}-06$

$.9644 \mathrm{E}-04$

.0000

.0000

.2048E-03

$.1267 \mathrm{E}-11$

.0000

.0000

$.1146 \mathrm{E}-05$

7.614

16.57

$.1722 E-23$

$.8976 E-04$

.0000

$.2856 \mathrm{E}-05$

.3089E-05

.0000

$.7723 E-06$

.0000

$.3628 \mathrm{E}-05$

.2683E-0J

$.6278 \mathrm{E}-06$

.0000

.0000

.0000

.2936E-05

.0000

$.1734 E-10$

.0000

$.1783 E-05$

$.1856 \mathrm{E}-09$

$.1046 \mathrm{E}-03$

$.8129 \mathrm{E}-07$

.0000

.1341E-05

.0000

.0000

.0000

.0000

.2334 E-03

.0000
175

Fit Cndnser

Condensnte

120.1

.0000

.0000

.0000

$.1541 \mathrm{E}-21$

$.9646 E-19$

.0000

.0000

. 2043E- 18

. 126SE-20

.0000

.0000

$.1146 \mathrm{E}-20$

$.8014 E-05$

$.6601 \mathrm{E}-03$

$.6924 \mathrm{E}-28$

.3977E-10

.0000

.2857E-20

$.3090 \mathrm{E}-20$

.0000

$.7724 \mathrm{E}-21$

.0000

. $3629 \mathrm{E}-20$

. 26SSE-20

.6279E-09

.0000

.0000

.0000

$.2936 \leftleftarrows-20$

.0000

$.1784 \mathrm{E}-25$

.0000

$.1783 E-20$

$.1857 \mathrm{E}-24$

$.1046 \mathrm{E}-17$

$.8131 \mathrm{E}-22$

.0000

$.1341 \mathrm{E}-20$

.0000

.0000

.0000

.0000

$.2335 \mathrm{E}-18$

.0000
170

DHP Sludgo:

Slurry Fee:!

325.5

.0500

.0000

.0000

$.1853 \mathrm{E}-01$

11.57

.0000

.0000

.1652

$.1521 E-06$

.0000

.0000

.1375

$.2072 \mathrm{E}-10$

. 1662E-06

.0000

.6000

. 1225 E-01

.3427

.8706

8. 653

$.9206 E-01$

.0000

.4554

$.9350 \mathrm{E}-01$

.0000

. $2110 \mathrm{E}-03$

$.5535 E-D 1$

.0000

.8523

.0000

.20S1E-05

.0000

$.4541 \mathrm{E}-0 \mathrm{~J}$

$.2227 \mathrm{E}-\mathrm{C} 4$

.0000

$.9754 \mathrm{E}-02$

.0000

.0000

.1022

.0000

.0000

.0000

2s.01

.0000 
DPSP 80-1088

MatuRIAL BaLANCE TABLES

\section{SLLDGE-SLPERNATE FEED}

STREAMS (CONT' D) -

STREAM NAME

$101 \mathrm{FcO}$

126 Group A Semi Vo

102 GroupA

103 Group B

$25 \mathrm{H} 2$

133 H2C204

9111202

84 IICOO!

$43 \mathrm{HCl}$

$85 \mathrm{HF}$

49 JiN03

80 HResin

$36 \mathrm{Hg}$

135 IIgNOE2

$21 \mathrm{Hg} 0$

$\begin{array}{ll}97 & 12\end{array}$

$89 \mathrm{~K} 20$

$131 \mathrm{KMnO4}$

$118 \mathrm{KNO}$

$105 \mathrm{La} 203$

108 Li 20

$65 \mathrm{Mg}(\mathrm{COOH}) 2$

$65 \mathrm{Mg}(\mathrm{OH}) 2$

$38 \mathrm{MgO}$

$60 \mathrm{Mn}(\mathrm{COOH}) 2$

$1: 2 \mathrm{Mn}(\mathrm{NOO}) 2$

$129 \mathrm{Mn}(\mathrm{OH}) 2$

$56 \mathrm{MnO}$

$14 \mathrm{MnO2}$

$81 \mathrm{~N} 2$

$143 \mathrm{NA2C03}$ (C14)

35 NO

8. $\mathrm{NO2}$

$70 \mathrm{Na}$ ( ilgO(OII))

$94 \quad \mathrm{Na} 2 \mathrm{~B} 407$

$109 \mathrm{Na} 2 \mathrm{C} 204$

$5 \mathrm{Na} 2 \mathrm{CO} 3$

$32 \mathrm{Na} 20$

$71 \mathrm{Na} 2 \mathrm{Pu}_{4} 02(\mathrm{OH}) 4$

$73 \mathrm{Na} 2 \mathrm{RhO} 04$

$72 \mathrm{Na} 2 \mathrm{RuO4}$

$6 \mathrm{Na} 2 \mathrm{SO}_{4}$

$68 \mathrm{NaAlO2}$

114 NaBO?

$140 \mathrm{NaB02}$ Semi Vol

$50 \mathrm{NaCOOH}$
173

SFHI Air

Purge

.0000

.0000

.0000

.0000

.0000

.0000

.0000

.0000

.0000

.0000

.0000

.0000

.0000

.0000

.0000

.0000

.0000

.0000

.0000

.0000

.0000

.0000

.0000

.0000

.0000

.0000

.0000

.0000

.0000

170.9

.0000

.0000

.0000

.0000

.0000

.0000

.0000

.0000

.0000

.0000

.0000

.0000

.0000

.0000

.0000

.0000
174

Off-Gas

to SWDBF

.0000

$.1285 E \cdot 33$

.2164E-05

$.6865 \mathrm{E}-05$

.5827

.0000

.0000

.0000

.0000

.0000

.0000

.0000

.0000

.0000

.6345E-04

$.7755 \mathrm{E}-04$

.0000

.0000

$.7775 \mathrm{E}-08$

$.6938 \mathrm{E}-05$

$.7921 \mathrm{E}-04$

$.7568 \mathrm{E}-05$

.0000

.2779E-04

$.6789 \mathrm{E}-04$

.0000

.0000

.0000

.0000

1893.

.0000

.9700

.1593

$.4838 \mathrm{E}-08$

$.1461 \mathrm{E}-03$

.3120E-08

.0000

.2929E-03

. 1962E-12

$.4034 \mathrm{E}-10$

$.3996 \mathrm{E}-09$

$.7982 E-0 C$

$.1962 E-05$

.0000

.0000

$.1810 \mathrm{E}-08$
175

FPT Cndnser

Condensate

.0000

$.1285 E-17$

$.2165 \mathrm{E}-20$

$.6866 \mathrm{E}-20$

. 5990E-06

.0000

.0000

.0000

.0000

.0000

.0000

.0000

.0000

.0000

$.6845 \mathrm{E}-18$

.0000

.0000

.0000

$.7777 E-23$

$.6934 \mathrm{E}-20$

$.7923 \mathrm{E}-19$

$.7570 \mathrm{E}-20$

.0000

$.2779 E-19$

$.6790 \mathrm{E}-19$

.0000

.0000

.0000

.0000

. 1723E-02

.0000

$.2646 \mathrm{E}-05$

$.6581 \mathrm{E}-02$

$.4839 \mathrm{E}-28$

$.1462 E-18$

$.3120 \mathrm{E}-23$

.0000

$.2930 \mathrm{E}-18$

$.1962 E-27$

$.4034 \mathrm{E}-25$

$.8987 E-24$

$.7984 E-21$

$.1962 E-20$

.0000

.0000

$.1810 \mathrm{E}-18$
176

DWPF Sludge

Slarry Feed

.0000

.0000

.2597

.8237

$.8593 E-09$

.0000

.0000

.0000

.0000

.0000

.0000

.0000

.0000

.0000

1.460

.0000

.0000

.0000

$.9329 \mathrm{E}-03$

. 3745E-02

$.6393 \mathrm{E}-01$

.0000

.4638

.2188E-01

.0000

.0000

.1959

.0000

4.693

$.6225 E-04$

.2076E-09

.2621E-09

.2390E-04

. 5805E-03

$.4845 \mathrm{E}-03$

.3743E-03

$.7150 E-01$

.2866

.2354E-07

$.4840 \mathrm{E}-05$

$.4728 E-04$

$.9578 \mathrm{E}-01$

.2854

.0000

.0000

$.10285-01$ 
DPSP $80-1033$

MATERIAL BALANCE TABLES

\section{SLLDGE-SUPERNATE FEED}

STREAMS (CONT'D) -

STREAM NAME

$7 \mathrm{NaCl}$

$138 \mathrm{NaCl}$ Seml Vol

$69 \mathrm{NaF}$

$189 \mathrm{NaF}$ Semi Vol

$12 \mathrm{NaI}$

$125 \mathrm{NaI}$ Semi Vol

$3 \mathrm{NaNO} 2$

$2 \mathrm{NaNOS}$

$4 \mathrm{NaOHI}$

87 NaResin

$61 \mathrm{Ni}(\mathrm{COOH}) 2$

$17 \mathrm{Ni}(\mathrm{OH}) 2$

$40 \mathrm{NiO}$

8202

$67 \mathrm{PbO}$

$28 \mathrm{PbS04}$

$124 \mathrm{Pd}$

$123 \mathrm{Pd}$ (OH) 2

112 PdN032

$110 \mathrm{PdO}$

$117 \mathrm{Pu}(\mathrm{COOH}) 4$

$76 \mathrm{Pu} 02$

$22 \mathrm{RhO}_{2}$

79 Ru02

23 Ru02 Semi Vol

$83 \mathrm{Ru} 04$

$88 \mathrm{SO2}$

$111 \mathrm{SiO2}$

115 Silica Gel

$48 \mathrm{Sr}(\mathrm{COOH}) 2$

$10 \mathrm{Sr}(\mathrm{NO3}) 2$

$127 \mathrm{Sr}(\mathrm{OH}) 2$

$80 \mathrm{SrCO}$

$46 \mathrm{Sr} 0$

89 SrRESIN

141 Surfactant

92 Th02

$107 \mathrm{Ti} 02$

119 Tritium

$93 \mathrm{~V} 02$

$62 \mathrm{VO2}(\mathrm{COOH}) 2$

$16 \mathrm{VO}(\mathrm{OH}) 2$

$27 \mathrm{Y}(\mathrm{COOH}) \mathrm{S}$

$11 \mathrm{Y}(\mathrm{NOS}) 3$

$128 \mathrm{Y}(\mathrm{OH}) 3$

$81 Y 2(\mathrm{CO}) 3$
173

SFHT Air

Purga

.0000

.0000

.0000

.0000

.0000

.0000

.0000

.0000

.0000

.0000

.0000

.0000

.0000

51.63

.0000

.0000

.0000

.0000

.0000

.0000

.0000

.0000

.0000

.0000

.0000

.0000

.0000

.0000

.0000

.0000

.0000

.0000

.0000

.0000

.0000

.0000

.0000

.0000

.0000

.0000

.0000

.0000

.0000

.0000

.0000

.0000
Appendix $\mathrm{H}$

Table 21-16

Pnge 168 of 173

Date 09/30/82 Rev 09

174

off-Gis

to SWDBF

$.7956 \mathrm{E}-06$

$.9088 \mathrm{E}-03$

$.2067 \mathrm{E}-04$

.7439E-03

$.7712 E-07$

$.9068 E-04$

.0000

$.2566 \mathrm{E}-01$

.0000

.0000

$.2379 E-04$

.0000

.0000

420.9

.0000

$.1079 \mathrm{E}-05$

.0000

.0000

.0000

.0000

$.1106 \mathrm{E}-08$

$.2807 E-06$

. 1073E-06

. 5287E-06

$.6283 E-04$

.0000

.3100

$.8655 \mathrm{E}-03$

.0000

$.9684 \mathrm{E}-06$

$.1131 E-11$

.0000

.0000

.0000

.0000

.0000

$.4401 E-05$

$.1887 E-04$

$.6965 \mathrm{E}-10$

.0000

$.3078 \mathrm{E}-04$

.0000

$.6620 \mathrm{E}-06$

$.8081 \mathrm{E}-12$

.0000

.0000

$.9686 \mathrm{E}-21$
175

FPT Cndnser DUPE Slringe

Conciensate Slurry Feed

$.7958 E-21 \quad .9547 \mathrm{E}-01$

$.9088 \mathrm{E}-17 \quad .0000$

$.2067 E-19$.5010E-0

$.7439 \mathrm{~L}-17 \quad .0000$

$.7713 E-22 \quad .0253 E-02$

$.9068 \mathrm{E}-18 \quad .0000$

$.0000 \quad .1711$

$.2567 E-19 \quad 3.015$

$.0000 \quad 3.464$

$.0000 \quad .0000$

$.2380 E-19 \quad .0000$

$.0000 \quad 1.780$

$.0000 \quad .0000$

$.1027 E-02$

.0000

$.1079 \mathrm{E}-20$

.0000

.0000

.0000

.0000

$.1106 \mathrm{E}-23$

.2805E-21

$1073 E-21$

. $2288 \mathrm{E}-21$

$.6283 E-18$

.0000

$.1152 \mathrm{E}-05$

$.8656 \mathrm{E}-18$

.0000

$.1131 \mathrm{E}-26$

.0000

.0000

.0000

.0000

.0000

$.4401 \mathrm{E}-20$

$.1887 \mathrm{E}-19$

$.1736 E-10$

.0000

$.3078 E-19$

.0000

$.6622 \mathrm{E}-21$

$.8032 E-27$

.0000

.0000
$.3591 \mathrm{E}-0.1$

.0000

.1294

.0000

.0000

.0000

.0000

.0000

. 3365E-01

$.1287 \mathrm{E}-01$

$.6344 \mathrm{E}-01$

.0000

.0000

.7278E-11

6.065

.0000

.0000

$.1357 \mathrm{E}-0 \mathrm{G}$

$.3587 \mathrm{E}-03$

$.9590 \mathrm{E}-01$

.0000

.0000

.0000

.5280

.7490E-02

$.6055 \mathrm{E}-09$

.0000

.0000

3.118

.0000

$.9636 \mathrm{E}-07$

.2238E-03

$.6318 \mathrm{E}-01$ 
DPSP 80-1089

MATIRIAL BALANCE TABLES

SL.UDGE-SUPERNATE FEED

STREAMS (CONT'D) -

STREAM NAME

$47 \quad 1203$

100 Zeolite

$44 \mathrm{Zn}($ COOII) 2

$54 \mathrm{Zn}(\mathrm{OII}) 2$

$57 \mathrm{ZnO}$

$104 \mathrm{ZrO2}$

TOTAL FLON, LB/HR

VAPOR FLOH, CFM

LIQUID FLOW, GPM DESIGN FLOW,

DENSITY， LBS/FT3

TENPERATURE, DEG $C$

PRESSURE, ATM

PRESSURE, PSIG

PPESSURE, MM HG

PHASE

EXTHALPY, PCU/HR
Appendix H

Table 21-16

Page 169 of 173

Date 09/80/82 Rev 09

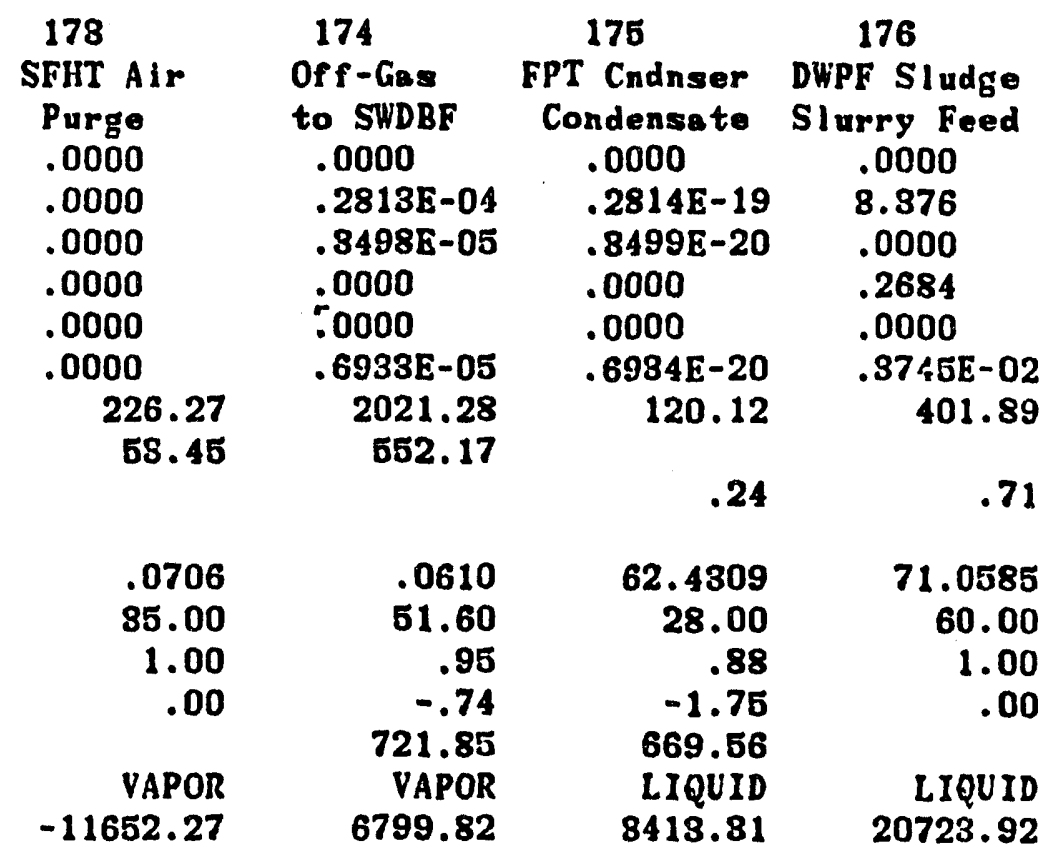


MATERIAL BALANCE TABLES

SLUDGE-SUPERNATE FEED

STREAM NUMBERS -

177

STREAM NAME

MVS Vac Pump

COMPONENT FLOHS, LB/HR

Exhaust

\begin{tabular}{|c|c|c|}
\hline 1 & $\mathrm{H} 2 \mathrm{O}$ & .0000 \\
\hline 45 & $\mathrm{Ag}$ & .0000 \\
\hline 116 & Ag20 & .0000 \\
\hline 184 & AgN03 & .0000 \\
\hline 51 & AgOll & .0000 \\
\hline 74 & AI $(\mathrm{OH}) 3$ & .0000 \\
\hline 77 & A1208 & .0000 \\
\hline 75 & A $100 \mathrm{H}$ & .0000 \\
\hline 106 & B203 & .0000 \\
\hline 9 & $\mathrm{Ba}(\mathrm{NOS}) 2$ & .0000 \\
\hline 95 & $\mathrm{BaC} 12$ & .0000 \\
\hline 15 & $\mathrm{BaO}$ & .0000 \\
\hline 24 & BaS04 & .0000 \\
\hline 66 & co & .0000 \\
\hline 87 & $\mathrm{CO2}$ & .0000 \\
\hline 142 & $\operatorname{co2}(\mathrm{C} 14)$ & .0000 \\
\hline 63 & $\mathrm{Ca}(\mathrm{COOH}) 2$ & .0000 \\
\hline 120 & $\mathrm{Cn}_{\mathrm{n}}(\mathrm{OHI}) 2$ & .0000 \\
\hline 118 & $\mathrm{Ca} 3(\mathrm{P04}) 2$ & .0000 \\
\hline 20 & $\mathrm{CaC204}$ & .0000 \\
\hline 18 & $\mathrm{CaCOS}$ & .0000 \\
\hline 78 & $\mathrm{CaF2}$ & .0000 \\
\hline 41 & $\mathrm{CaO}$ & .0000 \\
\hline 19 & CaSO4 & .0000 \\
\hline 29 & Carbon & .0000 \\
\hline 26 & $\mathrm{Co}(\mathrm{COOH}) 2$ & .0000 \\
\hline 121 & $\mathrm{Co}(\mathrm{OH}) 2$ & .0000 \\
\hline 58 & $\mathrm{Co}(\mathrm{OH}) 3$ & .0000 \\
\hline 59 & $\mathrm{CoO}$ & .0000 \\
\hline 99 & $\mathrm{Cr}(\mathrm{OH}) 3$ & .0000 \\
\hline 98 & Cr203 & .0000 \\
\hline 42 & Cs20 & .0000 \\
\hline 187 & Cs20 Semi Vol & .0000 \\
\hline 90 & $\mathrm{Cs} \mathrm{COOH}$ & .0000 \\
\hline 96 & $\mathrm{CsCl}$ & .0000 \\
\hline 186 & CsCl Semi Vol & .0000 \\
\hline 8 & CsNO3 & .0000 \\
\hline 88 & CsResin & .0000 \\
\hline 122 & $\mathrm{Cu}(\mathrm{COOII}) 2$ & .0000 \\
\hline 52 & $\mathrm{Cu}(\mathrm{OH}) 2$ & .0000 \\
\hline 58 & Cu20 & .0000 \\
\hline 64 & $\mathrm{CuCOOH}$ & .0000 \\
\hline 180 & $\mathrm{CuO}$ & .0000 \\
\hline 18 & $\mathrm{Fe}(\mathrm{OH}) 8$ & .0000 \\
\hline 80 & Fe203 & .0000 \\
\hline
\end{tabular}


DPSP 80-1038

MATERIAL BALANCE TABLES

SLUDGE-SUPERNATE FEED

STREAMS ( CONT'D)-

STREAM NAME

$101 \mathrm{FeO}$

126 Group A Semi Vo

102 Grouph

103 GroupB

$25 \mathrm{H} 2$

$133 \mathrm{H} 2 \mathrm{C} 204$

3111202

84 HCOOH

$43 \mathrm{HCl}$

$85 \mathrm{HF}$

49 IINO3

86 HResin

$36 \mathrm{Hg}$

135 HgNO32

$21 \mathrm{HgO}$

$97 \quad 12$

39 K20

$131 \mathrm{kMnO4}$

$118 \mathrm{KNO3}$

$105 \operatorname{Ln} 203$

$10 S$ Li 20

$65 \mathrm{Mg}(\mathrm{COOH}) 2$

$55 \mathrm{ME}(\mathrm{OII}) 2$

$83 \mathrm{MgO}$

$60 \mathrm{Mn}(\mathrm{COOH}) 2$

$132 \mathrm{Mn}(\mathrm{N} 03) 2$

$129 \mathrm{Mn}(\mathrm{Oll}) 2$

$56 \mathrm{MnO}$

$14 \mathrm{MnO} 2$

$81 \mathrm{~N} 2$

$143 \mathrm{NA2CO3}$ (C14)

$35 \mathrm{NO}$

$84 \mathrm{N02}$

$70 \mathrm{Na}(\mathrm{llgO}(\mathrm{OH})$ )

$94 \mathrm{Na2B} 407$

109 Na2C204

$5 \mathrm{Na} 2 \mathrm{CO3}$

32 Na20

$71 \mathrm{Na2PuO2(OH)4}$

$73 \mathrm{Nn} 2 \mathrm{RhO4}$

$72 \mathrm{Nn} 2 \mathrm{Ru} 04$

$6 \mathrm{Na} 2 \mathrm{SO4}$

$63 \mathrm{NaAlO2}$

$114 \mathrm{NaBO} 2$

$140 \mathrm{NaLO2}$ Semi Vol

$50 \mathrm{NaCOOH}$
Appendix $\mathrm{H}$

Table 21-16

Page 171 of 173

Date 09/80/82 Rev 09
177

MVS Vac Pump

Exhaust

.0000

.0000

.0000

.0000

.0000

.0000

.0000

.0000

.0000

.0000

.0000

.0000

.0000

.0000

.0000

.0000

.0000

.0000

.0000

.0000

.0000

.0000

.0000

.0000

.0000

.0000

.0000

.0000

.0000

.0000

.0000

.0000

.0000

.0000

.0000

.0000

.0000

.0000

.0000

.0000

.0000

.0000

.0000

.0000

.0000

.0000 
MATERIAL BALANCE TABLES

SLLDGE-SUPERNATE: FEED

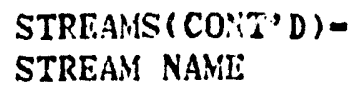

$7 \mathrm{NaCl}$

$188 \mathrm{NaCl}$ Semi Vol

$69 \mathrm{NaF}$

139 NaF Semi Vol

$12 \mathrm{NaI}$

125 NaI Semi Vol

3 NaN02

$2 \mathrm{NaNO3}$

$4 \mathrm{NaOH}$

87 NaRes in

$61 \mathrm{Ni}(\mathrm{COOHi}) 2$

$17 \mathrm{Ni}(\mathrm{OH}) 2$

$40 \mathrm{NiO}$

8202

$67 \mathrm{PbO}$

$28 \mathrm{PbSO} 4$

$124 \mathrm{Pd}$

$123 \mathrm{Pd}(\mathrm{OH}) 2$

112 PdNO32

$110 \mathrm{PdO}$

$117 \mathrm{Pu}(\mathrm{COOH}) 4$

$76 \mathrm{Pu} 02$

$22 \mathrm{RhO2}$

$79 \mathrm{RuO2}$

23 Ru02 Semi Vol

$83 \mathrm{RuO4}$

$38 \mathrm{S02}$

$111 \mathrm{SiO2}$

115 Silica Gel

$48 \mathrm{Sr}(\mathrm{COOH}) 2$

$10 \mathrm{Sr}(\mathrm{NO3}) 2$

$127 \mathrm{Sr}(\mathrm{OH}) 2$

$30 \mathrm{SrCO3}$

$46 \mathrm{SrO}$

89 SrRESIN

177

MVS Vac Pump

Exhaust

.0000

.0000

.0000

.0000

.0000

.0000

.0000

.0000

.0000

.0000

.0000

.0000

.0000

.0000

.0000

.0000

.0000

.0000

.0000

.0000

.0000

.0000

.0000

.0000

.0000

.0000

.0000

.0000

.0000

.0000

.0000

.0000

.0000

.0000

.0000

.0000

.0000

.0000

.0000

.0000

.0005

.0000

.0000

.0000

.0000

.0000 
MATERIAL BALANCE TABLES

Date 09/30/82 Kev 09

SLUVGE-SLPERNATE FEED

STREAMS (CONT'D)-

177

STREAM NAME

MVS Vac Pump

$47 \quad 1203$

Exhaust

100 Zeolite

$44 \mathrm{Zn}(\mathrm{COOII}) 2$

$54 \mathrm{Zn}(0: 1) 2$

$57 \mathrm{ZnO}$

$104 \mathrm{ZrO2}$

.0000

.0000

.0000

.0000

.0000

TOTAL FLOH, LB/HR

VAPOR FLOH, CEM

.0000

LIQUIID FLON, GPS

DESIG. FLOH',

DENSITY, LBS/FT3

TEYFERATURE, DEG C

FRESSLR:E, ATM

88.00

PRESSLRE, PSIG

PRESSURE, MM HG

PHISE

.00

.00

ESTIILPY, PCU/IIR

756.20

VAPOR

.00 
PAGE 1 of 1

DATE 9-82; Rev. 9

SLUDGE ONLY CURIE BALANCE

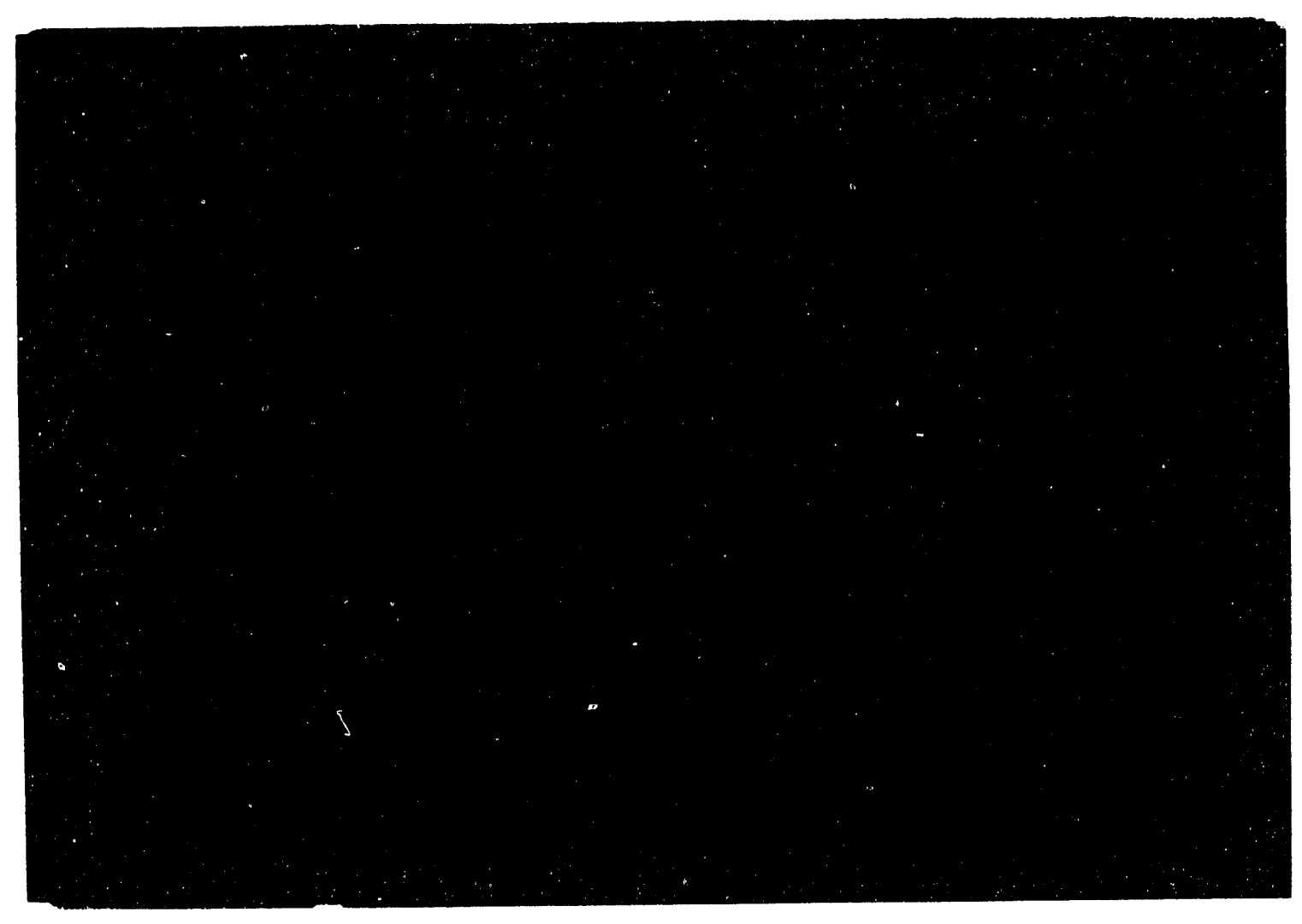

** NEW TABLE** 


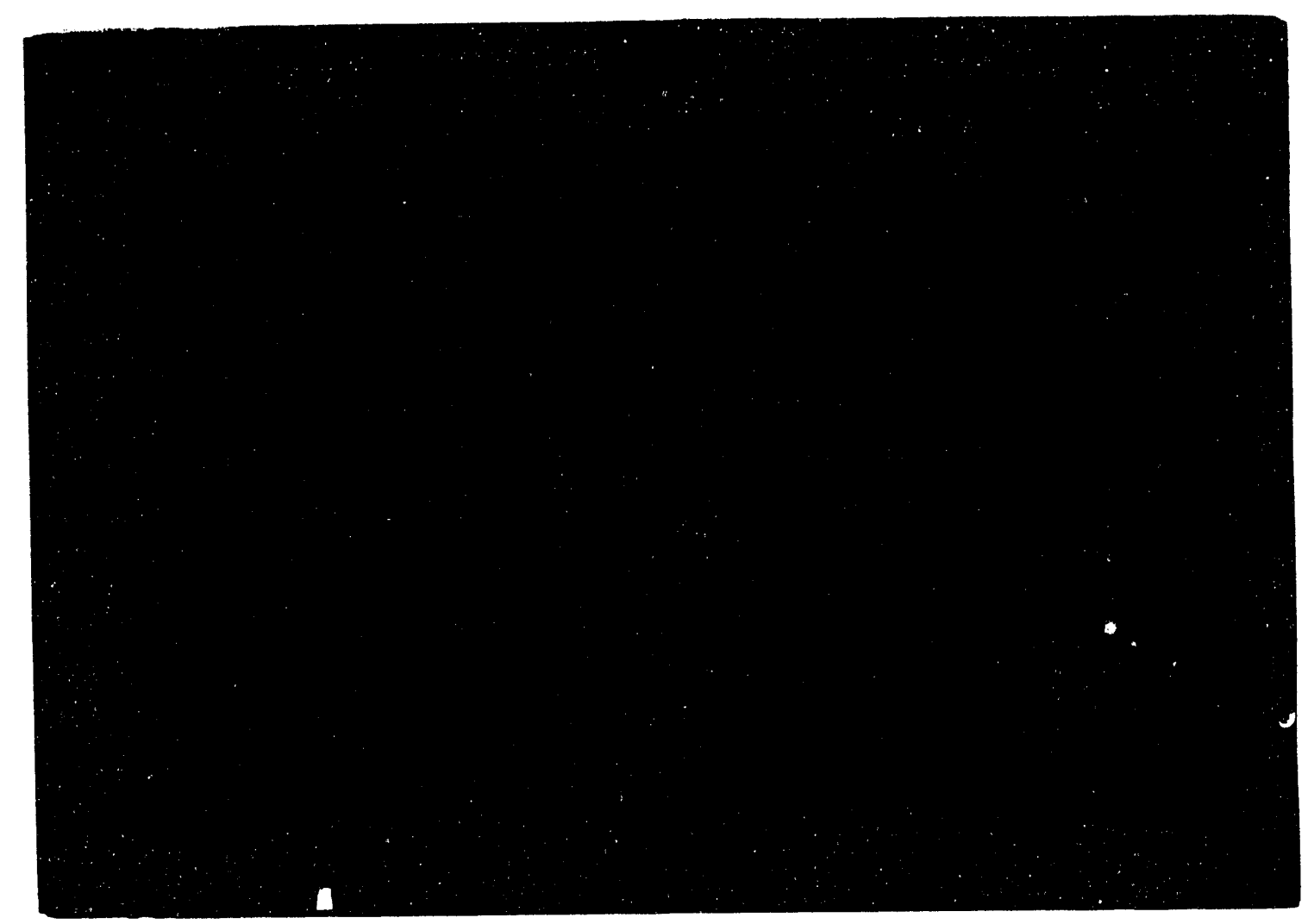




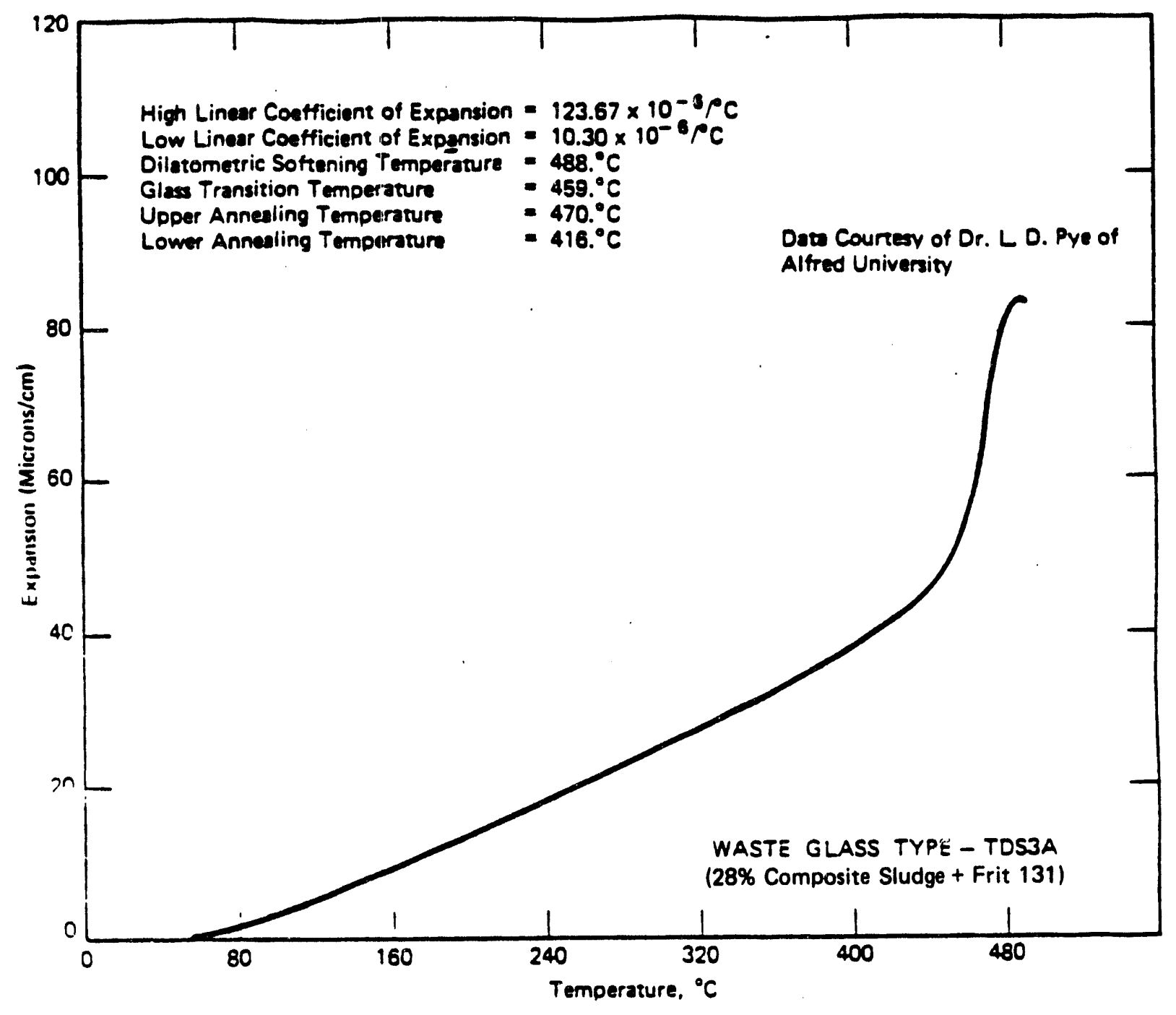

FIGURE 21-1. EXPERIMENTAL THERMAL EXPANSION DATA FOR SIMULATED SRP WASTE GLASS 


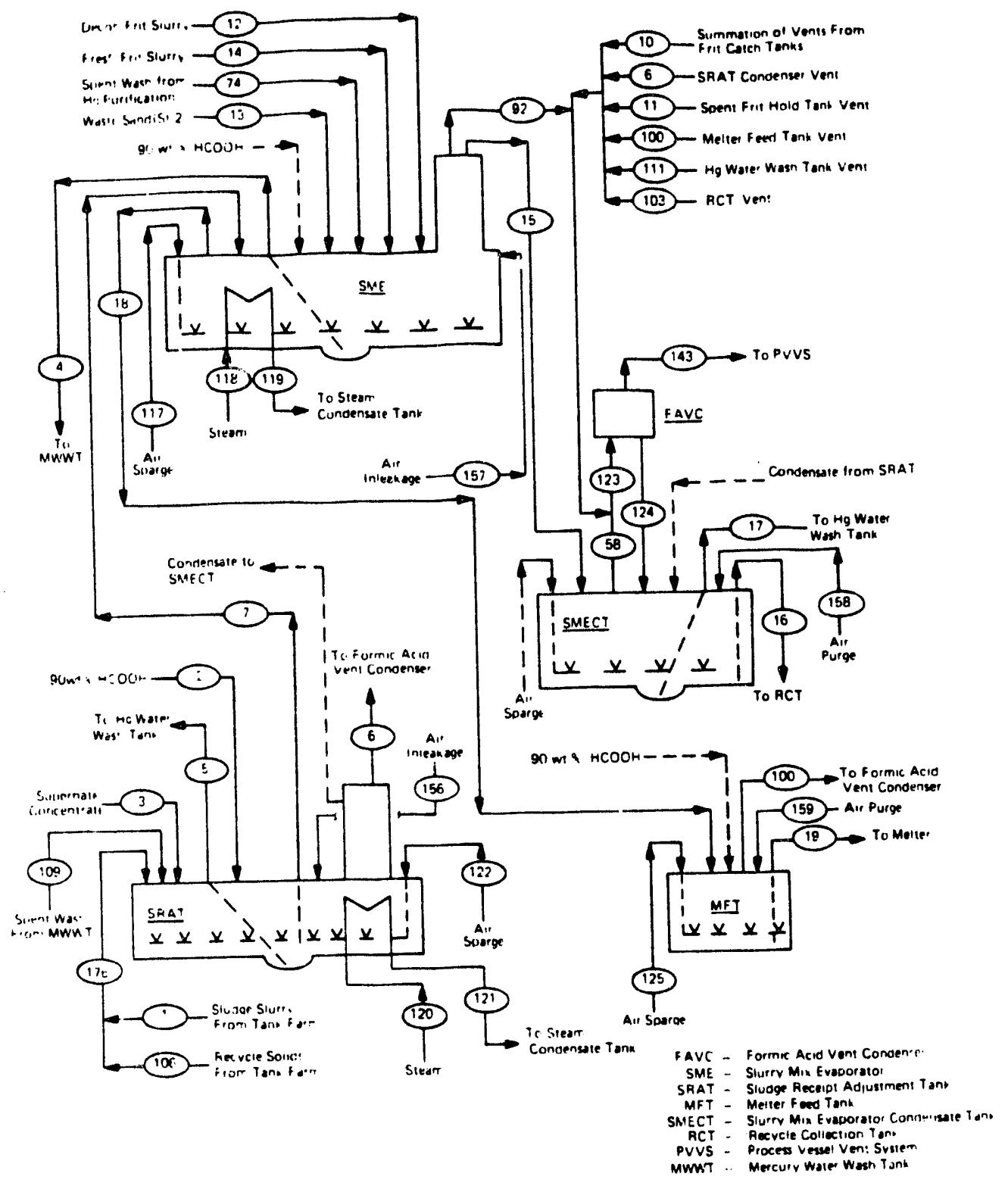

FIGURE 21-2. PROCESS SUMMARY DIAGRAM MELTER FEED PREPARATION 


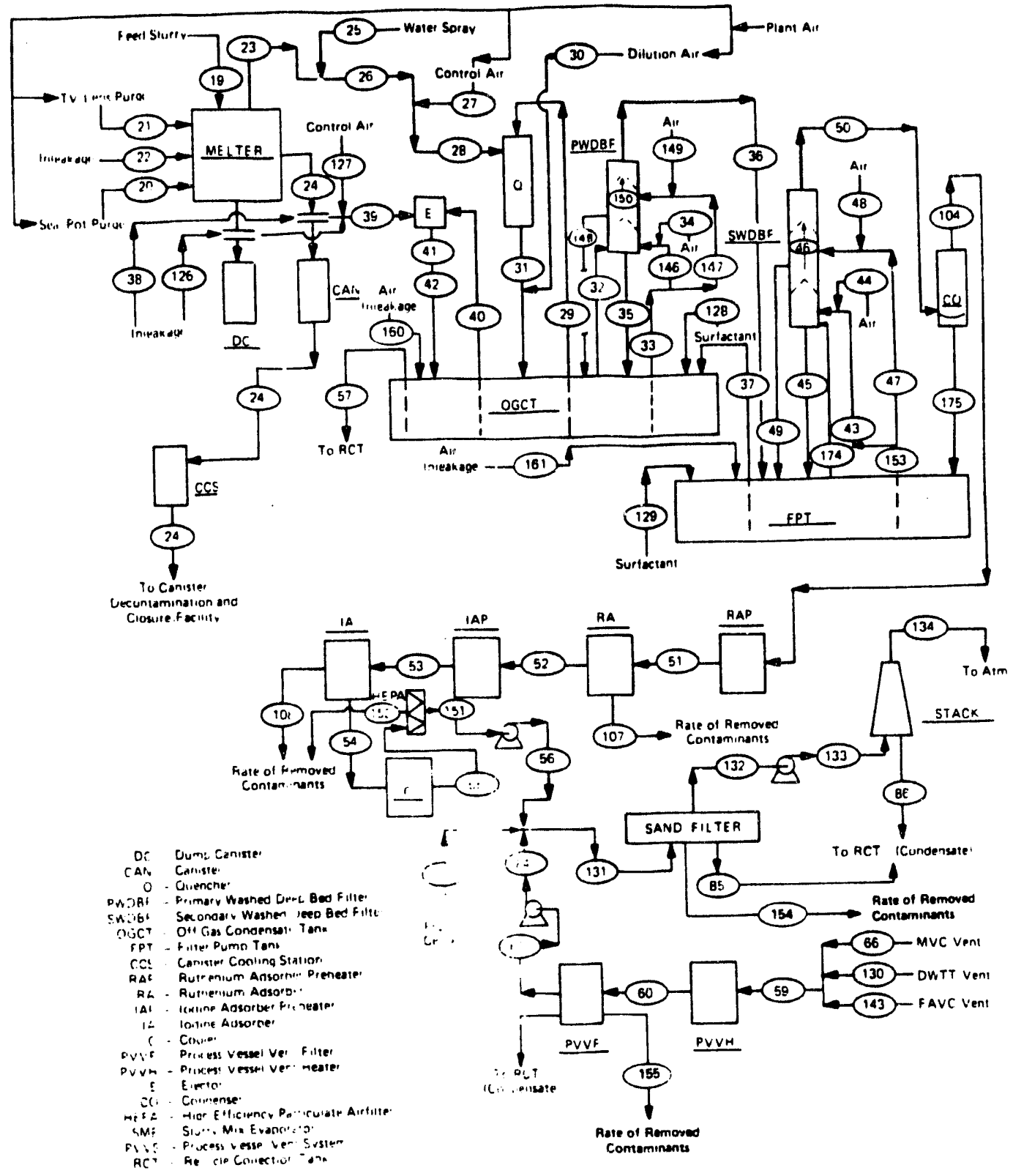




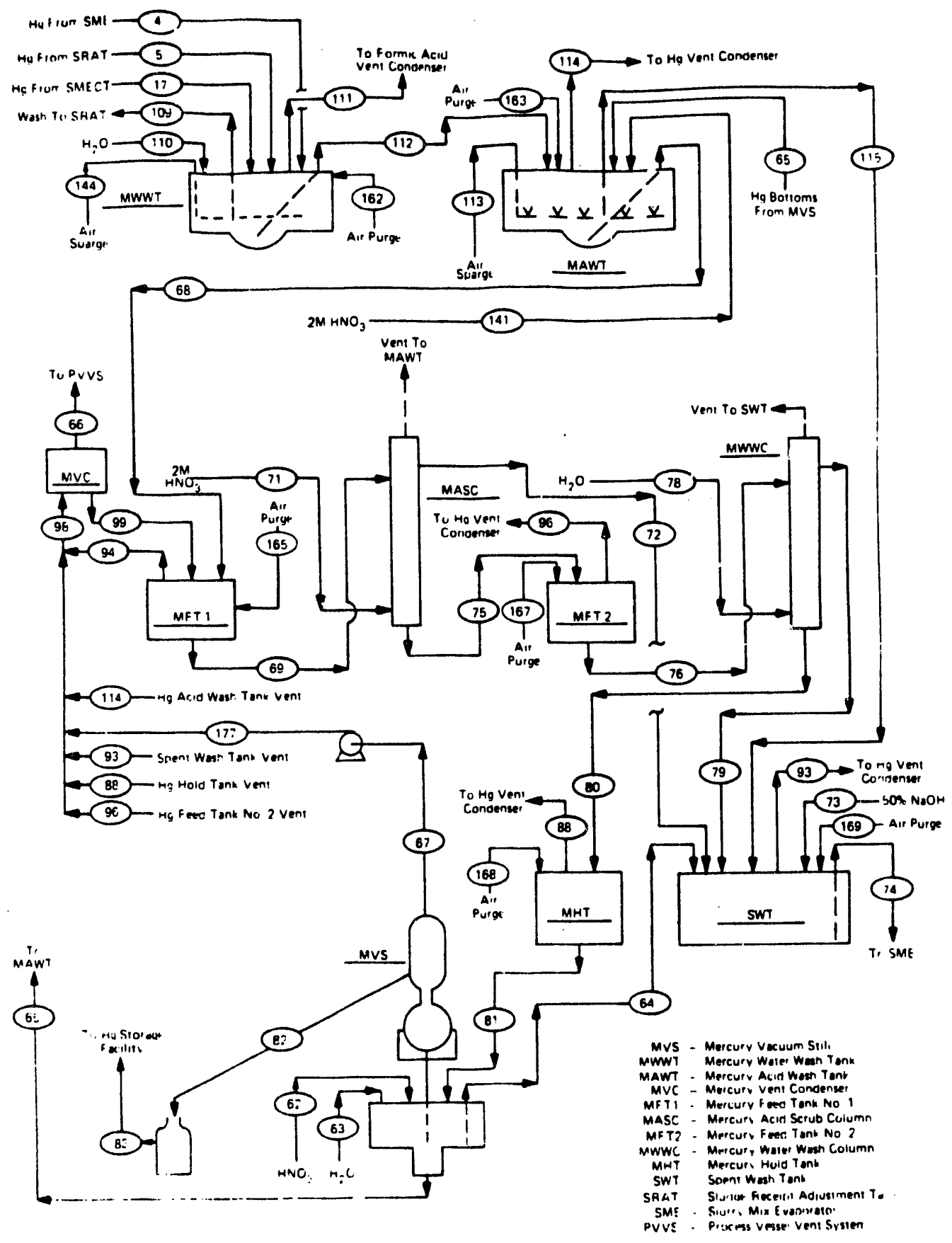

FIGURE 21-4. PROCESS SUMMARY DIAGRAM MERCURY PURIFICATION AND PACKAGING 


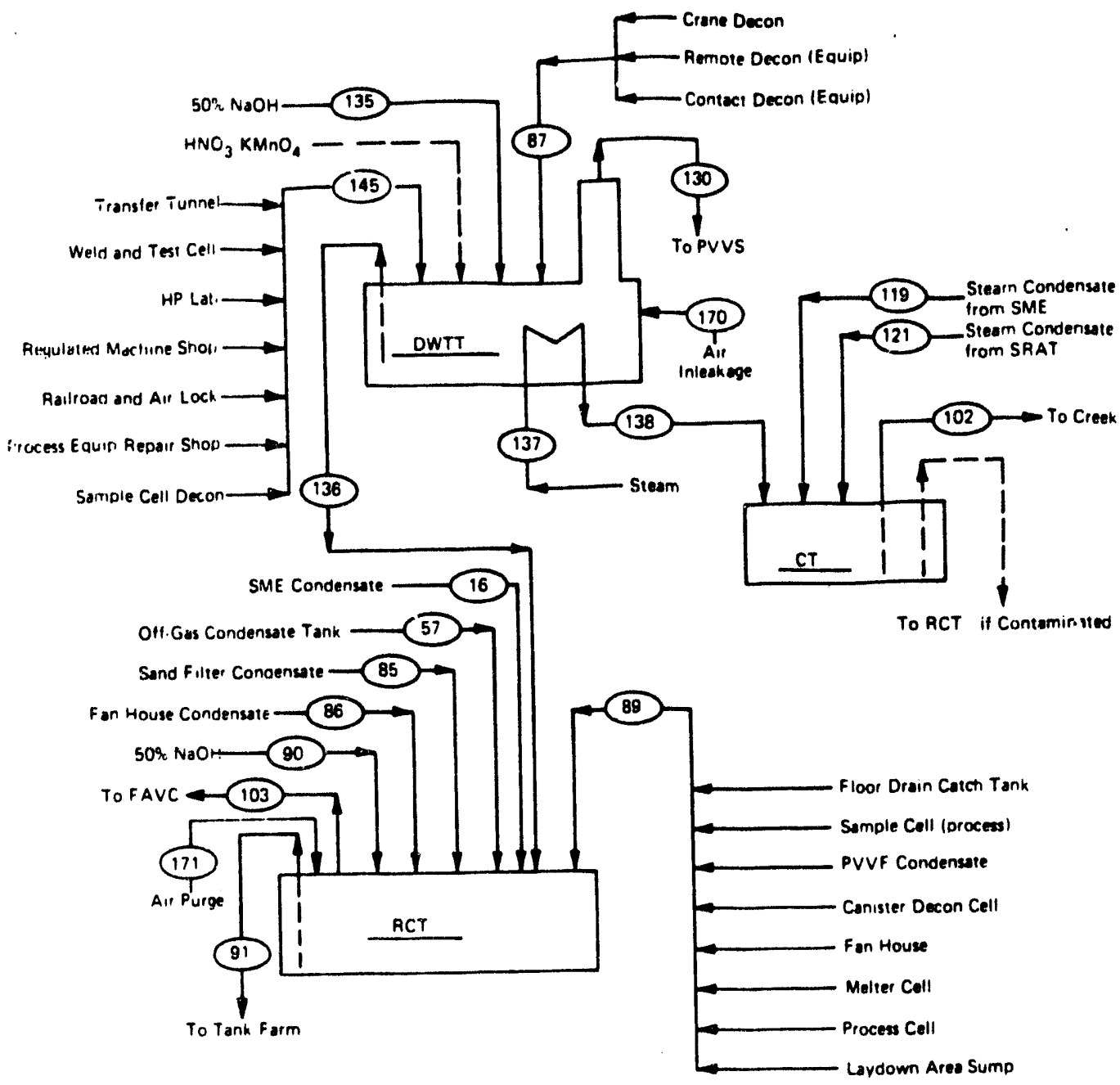

DWT . Decon Wase Treasment Tank

CT - Sieam Conoensate Tank

RCT - Rercle Collection, Tank

FAVC - Formic Acid Veni Conoenser

PVVS - Focess Vesse Vent System

SNE . Siurry Mix Evasorator

SAAT - Sludge Feceip: Adusiment Tank 


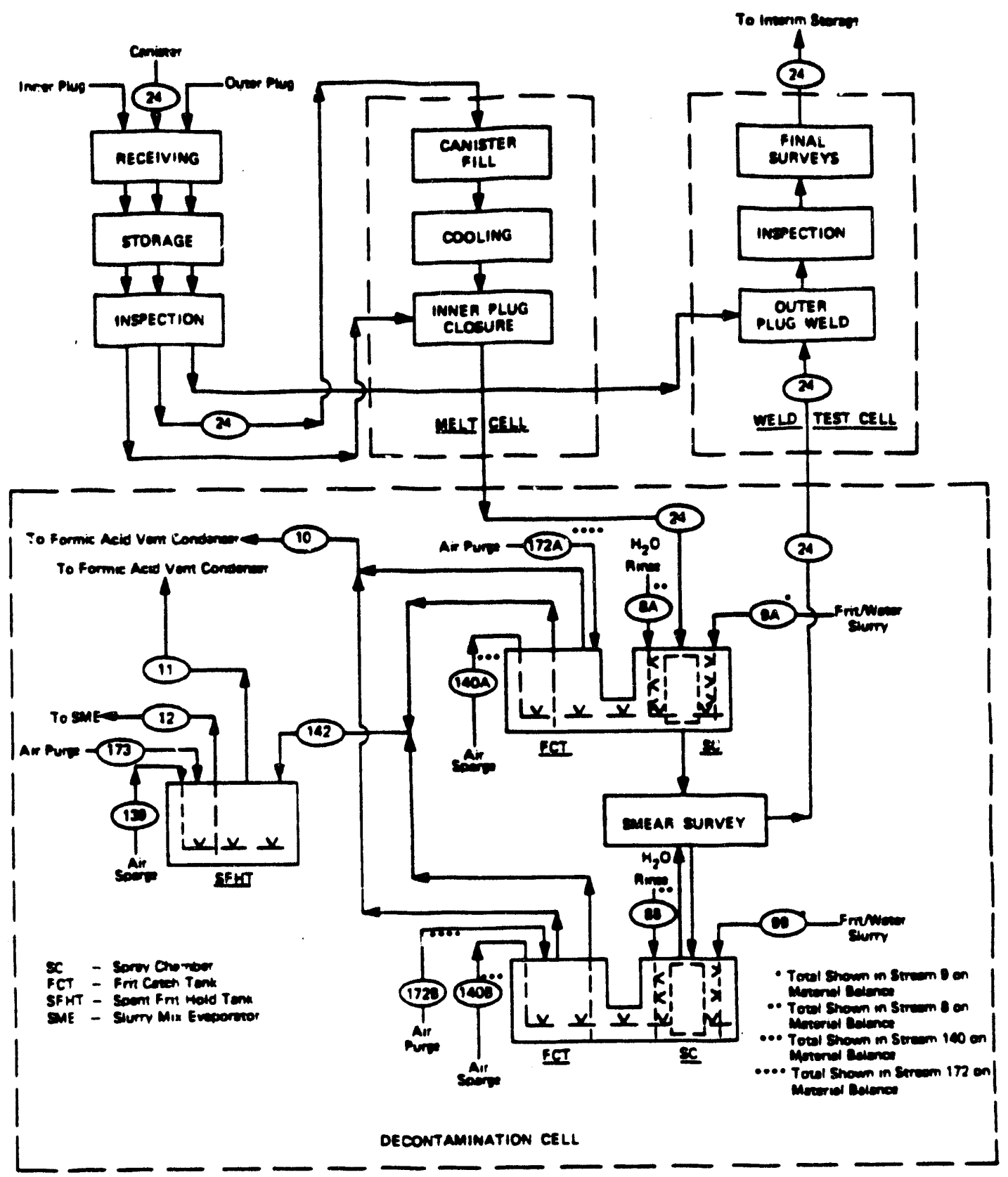

FIGURE 21-6. PROCESS SUMMARY DIAGRAM - CANISTER DECONTAMINATION, CLOSURE AND INSPECTION 


\section{Canister Decay Heat}

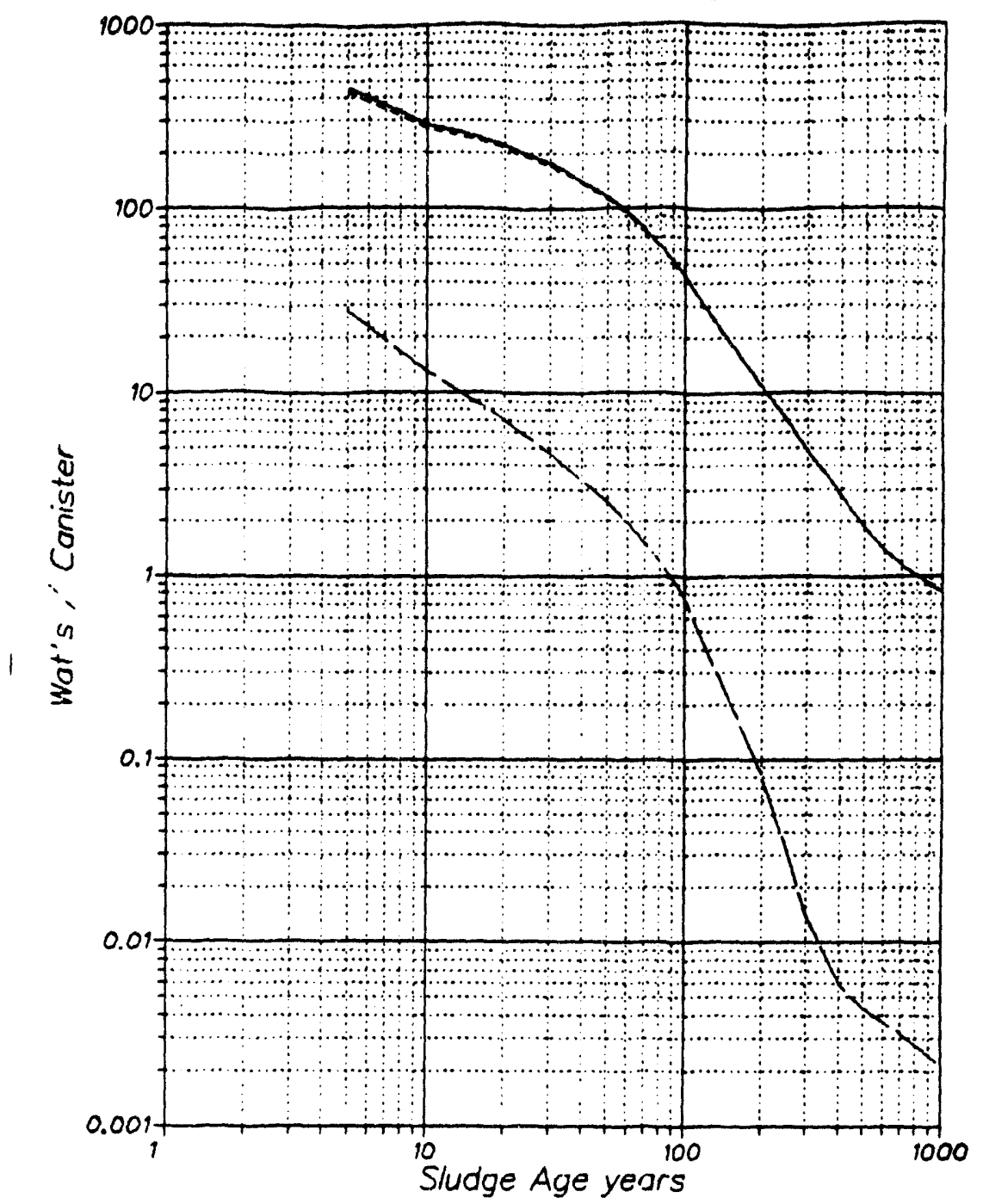




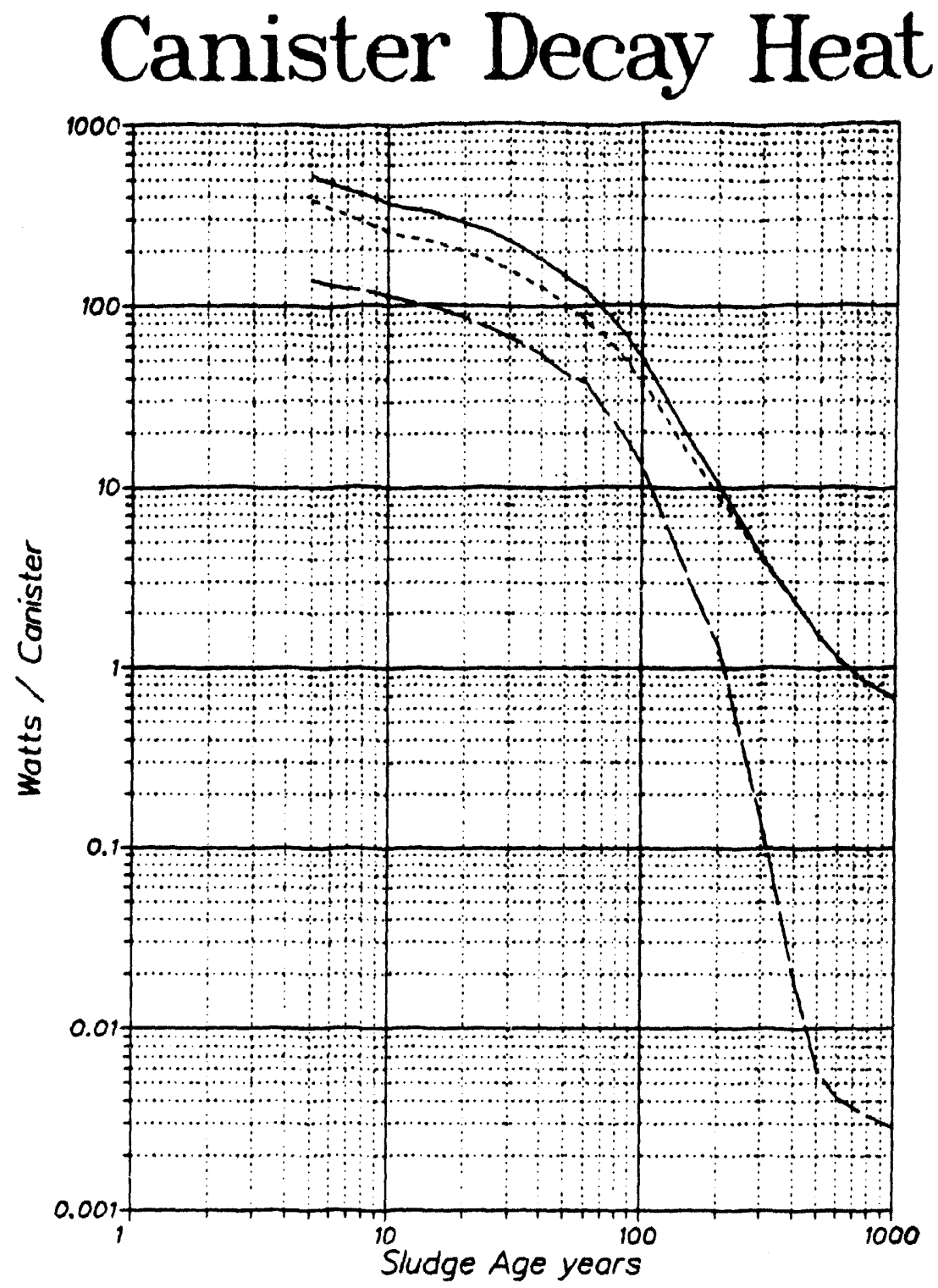

Legend Total

Alpho_ Beto Gammo

FIGURE 21-8. SLUDGE SUPERNATE GLASS CANISTER DECAY HEAT 
DPSP-80-1088

Isotopic Content of 5-your In-tank Waste

\author{
Append IX H \\ Toble 21-19 \\ Page 8 of 3 \\ Date 9-82, REV 9
}

\begin{tabular}{|c|c|c|c|c|c|}
\hline $\begin{array}{l}\text { ISOTOPE } \\
A=242 \\
A=242 M \\
A=248 \\
C=242 \\
C=243 \\
C=244\end{array}$ & $\begin{array}{l}\frac{G M / G A L}{1.99 E-12} \\
1.66 E-07 \\
3.25 E-06 \\
1.19 E-09 \\
1.21 E-08 \\
2.26 E-07\end{array}$ & $\begin{array}{l}\text { ISOTOPE } \\
\text { CI245 } \\
\text { Cw246 } \\
\text { C } 247 \\
C=248 \\
\text { Bk249 }\end{array}$ & $\begin{array}{l}\text { GM/GAL } \\
4.84 E-09 \\
1.94 E-10 \\
7.91 E-18 \\
1.81 E-14 \\
1.98 E-18\end{array}$ & $\begin{array}{l}\text { ISOTOPE } \\
\text { Cf249 } \\
\text { Cr250 } \\
\text { Cf251 } \\
\text { Cf } 252 \\
\text { Cr253 }\end{array}$ & $\begin{array}{l}\frac{G M / G A L}{1.09 E-16} \\
1.61 E-17 \\
1.67 E-18 \\
8.50 E-19 \\
8.26 E-52\end{array}$ \\
\hline
\end{tabular}


DPSP-80-1083

Isotopic Content of 5-year In-tank Waste

\begin{tabular}{|c|c|c|}
\hline \multicolumn{2}{|c|}{ ISOTOPE } & GM/GAL \\
\hline H & 8 & $4.26 E-07$ \\
\hline He & 8 & $2.82 \varepsilon-07$ \\
\hline C & 14 & 8.89E-08 \\
\hline$N$ & 14 & 2. $12 E-11$ \\
\hline v & 51 & $6.79 E-06$ \\
\hline$C_{5}$ & 51 & $1.14 E-25$ \\
\hline Co & 59 & 8.04E-08 \\
\hline Co & 60 & $1.70 \mathrm{E}-05$ \\
\hline $\mathbf{N i}$ & 59 & $1.93 \mathrm{E}-0 \mathrm{C}$ \\
\hline $\mathbf{N i}$ & 60 & $1.58 \mathrm{E}-05$ \\
\hline $\mathrm{Ni}$ & 63 & 6.52E-04 \\
\hline$C_{u}$ & 63 & $2.16 E-05$ \\
\hline Ge & 72 & $3.45 E-07$ \\
\hline Ge & 73 & $1.20 \mathrm{E}-06$ \\
\hline Ge & 74 & 8.00E-06 \\
\hline Ge & 76 & $2.00 E-05$ \\
\hline As & 75 & $6.91 E-06$ \\
\hline Se & 77 & $3.71 E-05$ \\
\hline Se & 78 & $9.35 E-05$ \\
\hline Se & 79 & $2.31 \mathrm{E}-04$ \\
\hline Se & 80 & 5.50E-04 \\
\hline Se & 82 & $1.11 \mathrm{E}-03$ \\
\hline $\mathrm{Br}$ & 81 & 9.84E-04 \\
\hline $\mathbf{K r}$ & 82 & 8.99E-44 \\
\hline Rb & 85 & $4.73 E-03$ \\
\hline Rb & 87 & $1.16 \mathrm{E}-02$ \\
\hline Sr & 88 & $1.68 \mathrm{E}-02$ \\
\hline Sr & 89 & $1.06 E-13$ \\
\hline Sr & 90 & $2.42 E-02$ \\
\hline $\mathbf{X}$ & 89 & $2.25 \mathrm{E}-02$ \\
\hline $\mathbf{Y}$ & 90 & $6.30 \mathrm{E}-06$ \\
\hline $\mathbf{Y}$ & 91 & $4.31 E-12$ \\
\hline $\mathbf{Z r}_{\mathbf{r}}$ & 90 & 8.56E-03 \\
\hline $\mathrm{Zr}$ & 91 & $2.83 E-02$ \\
\hline $\mathrm{Zr}$ & 92 & 2.90E-02 \\
\hline $\mathbf{Z r}$ & 93 & 5.04E-02 \\
\hline $\mathbf{Z r}$ & 94 & 3.22E-02 \\
\hline $\begin{array}{l}\mathrm{Zr} \\
\mathrm{Zr}\end{array}$ & $\begin{array}{l}95 \\
96\end{array}$ & $\begin{array}{l}5.31 E-11 \\
3.23 E-02\end{array}$ \\
\hline & & \\
\hline
\end{tabular}

Appendix H

Table 21-19

Page 1 of 8

Date 9-82, REV 9

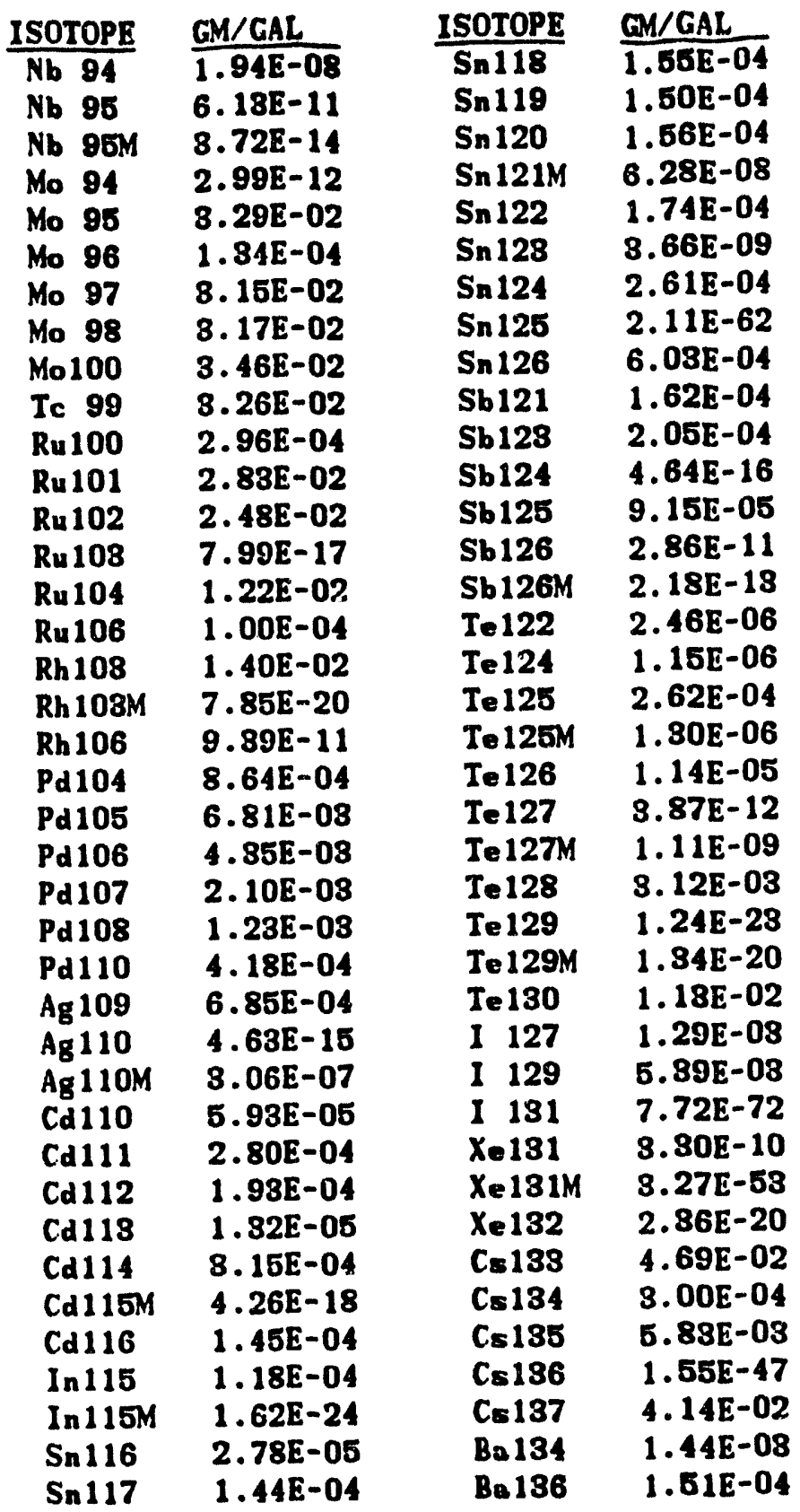


DPSP-80-1033

Isotopic Content of 5-year In-tank Waste

\begin{tabular}{|c|c|c|c|c|c|}
\hline ISOTOPE & GM/GAL & ISOTOPE & GM/GAL & ISOTOPE & GM/GAL \\
\hline $\mathrm{Ba} 186 \mathrm{M}$ & $1.36 E-54$ & Gd152 & 8.67E-07 & $\operatorname{Rn} 219$ & $6.16 \mathrm{E}-22$ \\
\hline $\mathrm{Ba} 137$ & $5.74 E-08$ & Gd 154 & $1.86 E-04$ & Rn220 & $3.75 E-16$ \\
\hline $\mathrm{Ba} 187 \mathrm{M}$ & $6.31 E-09$ & Gd156 & $1.81 E-04$ & Rn222 & $1.60 E-17$ \\
\hline $\mathrm{Ba} 138$ & $5.06 E-02$ & Gd156 & $6.50 E-04$ & Fr221 & $1.32 E-22$ \\
\hline $\mathrm{B}=140$ & $5.84 E-46$ & Gd157 & $4.88 E-06$ & Fr223 & $2.58 \mathrm{E}-20$ \\
\hline La 139 & $4.86 E-02$ & Gd158 & $1.59 E-04$ & $\operatorname{Ra} 223$ & $1.56 E-16$ \\
\hline$L_{2} 140$ & $8.81 E-47$ & Gd160 & $1.04 E-1) 5$ & $\operatorname{Ra} 224$ & $2.17 E-12$ \\
\hline Ce 140 & 4.79E-02 & Tb 159 & $2.32 E-05$ & $\operatorname{Ra} 225$ & $6.04 E-19$ \\
\hline Ce141 & $1.43 E-19$ & Tb 160 & $1.12 E-14$ & $\operatorname{Ra} 226$ & $2.50 E-12$ \\
\hline Ce 142 & $4.51 E-02$ & Dy 160 & $7.14 \mathrm{E}-07$ & $\operatorname{Ra} 228$ & $5.82 E-18$ \\
\hline Ce144 & 8.51E-04 & Dy 161 & $3.91 E-06$ & Ac225 & $4.04 E-19$ \\
\hline Pr141 & 4.49E-02 & Dy 162 & $2.33 E-06$ & Ac227 & $9.98 \mathrm{E}-14$ \\
\hline Pr143 & $2.02 E-48$ & T1206 & $2.46 E-30$ & Ac228 & $7.05 E-22$ \\
\hline $\operatorname{Pr} 144$ & $1.48 E-08$ & T1207 & $4.20 E-20$ & Th227 & $2.31 E-16$ \\
\hline $\operatorname{Pr} 144 M$ & $7.39 E-11$ & T1208 & $4.22 E-16$ & Th228 & $4.24 E-10$ \\
\hline Nd142 & $1.59 E-04$ & T1209 & $1.24 \mathrm{E}-24$ & Th229 & $1.13 E-13$ \\
\hline Nd 148 & $5.36 \mathrm{E}-02$ & Pb206 & $6.75 E-17$ & Th230 & $6.68 \mathrm{E}-08$ \\
\hline Nd144 & $4.61 E-02$ & Рb207 & $7.58 \mathrm{E}-15$ & Th231 & $1.12 E-14$ \\
\hline Nd145 & 2.96E-02 & Рb208 & $2.98 E-10$ & Th232 & $1.73 E-08$ \\
\hline Nd146 & $2.40 E-02$ & Рb209 & $5.08 E-21$ & Th,234 & $1.41 E-12$ \\
\hline Nd147 & $1.78 E-58$ & Pb210 & $2.14 E-15$ & $\mathrm{~Pa} 231$ & $1.10 \mathrm{E}-09$ \\
\hline Nd148 & $1.39 E-02$ & Pb211 & $8.24 E-19$ & $\mathrm{~Pa} 233$ & $4.78 E-11$ \\
\hline Nd150 & 5.57E-03 & Pb212 & $2.49 E-18$ & Pa234 & $3.27 E-14$ \\
\hline$P=147$ & 2.95E-03 & Pb214 & $7.52 E-20$ & U 232 & $2.68 E-08$ \\
\hline$P=148$ & $4.80 E-20$ & В 1209 & $1.61 \mathrm{E}-17$ & U 283 & $7.04 \mathrm{E}-09$ \\
\hline$P m 148 M$ & $5.35 E-18$ & B i210 & $1.29 E-18$ & U 284 & $2.88 E-04$ \\
\hline$S m 147$ & $9.51 E-03$ & Bi210M & $9.60 E-19$ & v 235 & $2.75 E-03$ \\
\hline$S=148$ & $2.11 E-03$ & Bi211 & $1.93 E-20$ & U 286 & $1.99 \mathrm{E}-03$ \\
\hline$S=149$ & 8.23E-04 & B 1212 & $2.86 E-14$ & v 288 & $9.74 E-02$ \\
\hline$S=150$ & $1.17 \mathrm{E}-02$ & Bi218 & $1.21 \mathrm{E}-21$ & Np236 & $1.48 \mathrm{E}-10$ \\
\hline$S=151$ & $1.05 E-08$ & Bi214 & $5.53 E-20$ & Np287 & $1.41 \mathrm{E}-03$ \\
\hline$S=152$ & $4.21 E-03$ & Po210 & $2.82 E-17$ & Pu236 & $1.32 E-08$ \\
\hline$S m 154$ & $7.48 E-04$ & Po212 & $1.23 E-24$ & Pu237 & $4.25 E-20$ \\
\hline Eu151 & $4.39 E-05$ & Po218 & $1.82 E-30$ & Pu238 & $4.91 E-03$ \\
\hline Eu 152 & $2.36 \mathrm{E}-06$ & Po214 & $7.66 \mathrm{E}-27$ & Pu239 & $1.28 E-02$ \\
\hline Eu 158 & $2.32 E-03$ & Po215 & $2.71 E-25$ & Pu240 & $2.21 \mathrm{E}-03$ \\
\hline Eu 154 & $2.60 \mathrm{E}-04$ & Po216 & $9.94 E-19$ & Pu241 & $9.37 E-04$ \\
\hline En155 & $1.15 E-04$ & Po218 & $8.72 E-21$ & Pu242 & $1.7 G E-04$ \\
\hline Eu 156 & $1.08 E-40$ & At217 & $1.46 \mathrm{E}-26$ & $A m 241$ & $3.54 E-04$ \\
\hline
\end{tabular}

Appendix $\mathrm{H}$

Table 21-19

Page 2 of 3

Date 9-82, REV 9 
DPSP-80-1083

Radionuclide Content of 5-year In-tank Waste
Append ix H

Table 21-20

Page 1 of 2

Date 9-82, REV 9

\begin{tabular}{|c|c|c|c|c|c|}
\hline$\frac{\text { ISOTOPE }}{3}$ & CI/GAL & $\frac{\text { ISOTOPE }}{T-129 M}$ & $\frac{\mathrm{Cl} / \mathrm{GAL}}{\mathrm{GF}-16}$ & $\frac{\text { ISOTOPE }}{\mathrm{Pb} 212}$ & $\frac{\mathrm{CI} / \mathrm{GAL}}{3.46 \mathrm{E}-07}$ \\
\hline $\begin{array}{rr}H & 3 \\
C & 14\end{array}$ & $\begin{array}{l}4.12 E-03 \\
1.73 E-07\end{array}$ & $\begin{array}{l}\text { Te129M } \\
\text { I } 129\end{array}$ & $\begin{array}{l}4.07 E-16 \\
9.42 E-07\end{array}$ & $\begin{array}{l}\text { Pb212 } \\
\text { Pb214 }\end{array}$ & $\begin{array}{l}3.46 E-07 \\
2.47 E-12\end{array}$ \\
\hline$C_{r} 51$ & $1.05 E-20$ & Xe131M & $2.72 E-48$ & Bi210 & $1.61 \mathrm{E}-13$ \\
\hline Co 60 & $1.93 \mathrm{E}-02$ & $\mathrm{Cs} 134$ & $3.89 E-01$ & B i210M & $5.37 E-22$ \\
\hline Ni 59 & $1.56 \mathrm{E}-04$ & $C s 135$ & $6.72 E-06$ & B 1211 & $7.99 \mathrm{E}-12$ \\
\hline Ni 63 & 3.85E-02 & $C=136$ & $1.15 \mathrm{E}-42$ & B 1212 & 3.46E-07 \\
\hline Se 79 & $1.61 E-05$ & $C s 187$ & $3.59 E+00$ & Bi218 & $2.34 E-14$ \\
\hline Rb 87 & $1.02 \mathrm{E}-09$ & $\mathrm{Bn} 186 \mathrm{M}$ & $3.68 E-48$ & Bi214 & $2.47 E-12$ \\
\hline Sr 89 & 3.07E-09 & $\mathrm{Ba} 137 \mathrm{M}$ & $3.40 E+00$ & Po210 & $1.27 E-13$ \\
\hline Sr 90 & $3.43 E+00$ & $\mathrm{Ba} 140$ & $4.26 \mathrm{E}-41$ & Po212 & $2.22 E-07$ \\
\hline 190 & $8.43 E+00$ & La 140 & $4.91 E-41$ & Po213 & $2.29 E-14$ \\
\hline Y 91 & $1.06 \mathrm{E}-07$ & Ce141 & $4.07 E-15$ & Po214 & $2.47 E-12$ \\
\hline Zr 93 & $1.27 \mathrm{E}-04$ & Ce142 & $1.08 \mathrm{E}-09$ & Po215 & $8.01 E-12$ \\
\hline Zr 95 & $1.12 \mathrm{E}-06$ & Ce144 & $1.12 E+00$ & Po216 & $3.46 E-07$ \\
\hline Nb 94 & 3.65E-09 & $\operatorname{Pr} 148$ & $1.86 \mathrm{E}-38$ & Po218 & $2.47 E-12$ \\
\hline Nb 95 & $2.40 \mathrm{E}-06$ & $\operatorname{Pr} 144$ & $1.12 E+00$ & At217 & $2.34 E-14$ \\
\hline $\mathrm{Nb}_{\mathrm{b}} 95 \mathrm{M}$ & $1.42 E-08$ & Pr144M & $1.34 E-02$ & $\operatorname{Rn} 219$ & $8.01 E-12$ \\
\hline Tc 99 & $5.53 E-04$ & Nd144 & $5.45 E-14$ & $\operatorname{Rn} 220$ & 3.46E-07 \\
\hline Ru 103 & $2.56 \mathrm{E}-12$ & Nd147 & $1.44 E-48$ & $\operatorname{Rn} 222$ & $2.47 E-12$ \\
\hline Ru 106 & 3.35E-01 & $P=147$ & $2.74 E+00$ & Fr221 & $2.34 E-14$ \\
\hline Rh 103M & $2.56 \mathrm{E}-12$ & $P_{m 148}$ & $7.88 E-15$ & Fr223 & $9.96 E-12$ \\
\hline Rh 106 & 3.34E-01 & $P=148 M$ & $1.14 \mathrm{E}-18$ & $\operatorname{Ra} 228$ & $8.01 E-12$ \\
\hline Pd107 & $1.08 E-06$ & $\operatorname{Sin} 147$ & $2.16 \mathrm{E}-10$ & $\operatorname{Ra224}$ & $3.46 E-07$ \\
\hline Ag 110 & $1.93 E-05$ & $S=148$ & $6.88 E-16$ & Ra225 & $2.37 E-14$ \\
\hline Ag $110 M$ & $1.45 E-03$ & $\operatorname{Sm} 149$ & $1.98 E-16$ & Ra226 & $2.48 E-12$ \\
\hline Cd115M & $1.08 E-18$ & $\operatorname{Sm} 151$ & 2.67E-02 & Ra228 & $1.58 E-15$ \\
\hline $\operatorname{In} 115$ & $7.34 E-16$ & Eu 152 & 4.27E-04 & Ac225 & $2.34 E-14$ \\
\hline $\operatorname{In} 115 M$ & $9.81 E-18$ & Eu154 & 7.02E-02 & Ac227 & $7.22 E-12$ \\
\hline Sn $121 M$ & $8.71 E-06$ & Eu 155 & $5.56 \mathrm{E}-02$ & Ac228 & $1.58 E-15$ \\
\hline Sn123 & 3.01E-05 & Eu 156 & $5.92 E-36$ & Th227 & $7.09 E-12$ \\
\hline $\operatorname{Sn} 126$ & $1.71 \mathrm{E}-05$ & Gd152 & $7.86 E-18$ & Th228 & $8.47 E-07$ \\
\hline Sb124 & 8. $12 E-12$ & Ib 160 & $1.27 \mathrm{E}-10$ & Th229 & $2.40 E-14$ \\
\hline Sb 125 & $9.60 \mathrm{E}-02$ & T1206 & $5.37 E-22$ & Th230 & $1.30 \mathrm{E}-09$ \\
\hline Sb 126 & $2.40 E-06$ & T1207 & $7.97 E-12$ & Th231 & $5.95 E-09$ \\
\hline Sb126M & $1.71 \mathrm{E}-05$ & T1208 & $1.24 \mathrm{E}-07$ & Th232 & $1.90 E-15$ \\
\hline Te125M & $2.34 E-02$ & T1209 & $5.06 E-16$ & Th284 & $3.27 E-08$ \\
\hline Te127 & $1.02 E-05$ & Pb20? & $2.34 E-14$ & Pa231 & $6.17 E-11$ \\
\hline Te127M & $1.04 \mathrm{E}-05$ & Pb210 & $1.64 \mathrm{E}-18$ & Pa233 & $9.91 E-07$ \\
\hline Te129 & $2.59 E-16$ & Pb211 & $7.99 \mathrm{E}-12$ & Pa234 & $6.54 E-08$ \\
\hline
\end{tabular}


DPSP-80-1033

\author{
Appendix H \\ Table 21-20 \\ Page 2 of 2 \\ Date 9-82, REV 9
}

\begin{tabular}{|c|c|c|c|c|c|}
\hline ISOTOPE & $\underline{\mathrm{CI} / \mathrm{GAL}}$ & ISOTOPE & $\mathrm{CI} / \mathrm{GAL}$ & ISOTOPE & $\mathrm{CI} / \mathrm{GAL}$ \\
\hline v 232 & $\overline{5.76 E-07}$ & $\overline{P u 239}$ & $\overline{7.96 E-04}$ & $C_{m 215}$ & $\overline{7.47 E-10}$ \\
\hline U 233 & $6.78 \mathrm{E}-11$ & Pu240 & 5.03E-04 & $\mathrm{Cm} 246$ & $5.97 E-11$ \\
\hline U 234 & $1.80 E-06$ & Pu241 & $9.45 E-02$ & $C_{m} 247$ & $7.33 E-17$ \\
\hline U 235 & $5.94 E-09$ & Pu242 & $6.70 \mathrm{E}-07$ & $C_{m} 248$ & $7.66 \mathrm{E}-17$ \\
\hline U 236 & $1.29 E-07$ & Am241 & $1.22 \mathrm{E}-03$ & Bk249 & $3.23 E-15$ \\
\hline U 238 & $3.27 E-08$ & $\operatorname{Am} 242$ & $1.61 E-06$ & Cf249 & 4. $46 \mathrm{E}-16$ \\
\hline Np236 & $1.95 \mathrm{E}-12$ & $A=242 M$ & $1.61 E-06$ & Cf 250 & $1.76 \mathrm{E}-15$ \\
\hline$N_{p 237}$ & $9.91 E-07$ & An243 & $6.49 E-07$ & Cf 251 & $7.41 \mathrm{E}-18$ \\
\hline Pu236 & $7.04 E-06$ & $\operatorname{Cm} 242$ & $3.94 E-06$ & Cf 252 & $1.88 E-16$ \\
\hline Pu237 & $5.14 \mathrm{E}-16$ & $\operatorname{cm} 243$ & $6.25 E-07$ & Cf 253 & $9.44 E-48$ \\
\hline Pu238 & $8.45 E-02$ & $\operatorname{Cm} 244$ & $1.83 \mathrm{E}-05$ & & \\
\hline & $\begin{array}{l}\text { Total } \\
\text { Decay }\end{array}$ & $\begin{array}{l}\text { Activity } \\
\text { Heat }\end{array}$ & $2.04 E+$ & $\mathrm{CI} / \mathrm{GAL}$ & \\
\hline & $\begin{array}{l}\text { To } \\
\text { To }\end{array}$ & $\begin{array}{l}\text { I Primary } \\
\text { al Gammas }\end{array}$ & $\begin{array}{l}4.29 \mathrm{E}-02 \\
1.75 \mathrm{E}-02\end{array}$ & $\begin{array}{l}\text { WATT/GAL } \\
\text { WATT/GAL }\end{array}$ & \\
\hline
\end{tabular}


DPSP-80-1033

\begin{tabular}{|c|c|c|c|c|c|c|}
\hline \multicolumn{2}{|c|}{ ISOTO?E } & G.U/GAL & ISOTOPE & GM/GAL & ISOTOPE & GM/GAL \\
\hline H & $\overline{3}$ & $\overline{6.61 \mathrm{E}-09}$ & Ru104 & $\overline{9.64 \mathrm{E}-02}$ & Te125M & $\overline{1.90 \mathrm{E}-05}$ \\
\hline c & 14 & $2.96 \mathrm{E}-10$ & Ru 106 & $8.03 E-04$ & Te 126 & $1.67 E-04$ \\
\hline$C_{r}$ & 51 & $1.66 \mathrm{E}-24$ & Rh 108 & $1.07 \mathrm{E}-01$ & Te 127 & 5. $66 \mathrm{E}-11$ \\
\hline Co & 60 & $2.60 \mathrm{E}-04$ & Rh108M & $6.03 E-19$ & Te $127 \mathrm{M}$ & $1.62 \mathrm{E}-08$ \\
\hline $\mathrm{Ni}$ & 59 & $2.96 \mathrm{E}-02$ & Rh106 & $7.42 E-10$ & Te128 & $4.56 \mathrm{E}-02$ \\
\hline $\mathrm{Ni}$ & 63 & $5.02 E-03$ & Pd104 & $1.26 \mathrm{E}-02$ & Te 129 & $1.81 E-22$ \\
\hline Se & 77 & $5.41 E-04$ & Pd105 & 9.90E-02 & Te129M & $1.96 E-19$ \\
\hline Se & 78 & $1.36 E-03$ & Pd106 & $6.32 \mathrm{E}-02$ & Te 130 & $1.65 E-01$ \\
\hline Se & 79 & $3.35 E-03$ & Pd107 & 8.06E-02 & I 127 & $1.66 \mathrm{E}-02$ \\
\hline Se & 80 & $7.99 E-03$ & Pd108 & $1.78 \mathrm{E}-02$ & I 129 & 7.03E-02 \\
\hline Se & 82 & $1.62 E-02$ & Pd110 & $6.08 \mathrm{E}-03$ & Cs 133 & $3.63 E-02$ \\
\hline Rb & 85 & $7.25 \mathrm{E}-02$ & Ag 109 & $1.02 E-02$ & Cs 134 & $2.34 E-04$ \\
\hline $\mathbf{R} \mathbf{b}$ & 87 & $1.78 \mathrm{E}-01$ & $\mathrm{Ag} 110 \mathrm{M}$ & $4.73 E-06$ & Cs185 & $4.68 E-03$ \\
\hline Sr & 88 & $2.57 \mathrm{E}-01$ & $\mathrm{Cd} 110$ & $8.59 E-04$ & Cs 137 & 3.30E-02 \\
\hline Sr & 89 & $3.13 E-12$ & Cd111 & $4.06 E-03$ & $\mathrm{Ba} 134$ & $2.15 E-02$ \\
\hline Sr & 90 & $3.78 \mathrm{E}-01$ & $\mathrm{Cd} 112$ & $2.80 \mathrm{E}-03$ & $\mathrm{Ba} 136$ & $2.28 \mathrm{E}-03$ \\
\hline $\mathbf{Y}$ & 80 & $3.45 E-01$ & $C d 113$ & $1.92 E-04$ & $\mathrm{Ba} 137$ & $8.73 E-02$ \\
\hline$Y$ & 90 & $9.76 \mathrm{E}-05$ & Cd114 & $4.56 E-03$ & Ba $137 \mathrm{M}$ & 5.03E-09 \\
\hline $\mathbf{Y}$ & 91 & $6.73 E-11$ & Cd115M & $6.18 E-17$ & $\mathrm{Ba} 138$ & $7.76 \mathrm{E}-01$ \\
\hline $\mathbf{Z r}$ & 90 & $5.44 \mathrm{E}-02$ & Cd116 & $2.11 E-03$ & La 139 & $7.36 \mathrm{E}-01$ \\
\hline $\mathrm{Zr}$ & 91 & $4.33 \mathrm{E}-01$ & Sn 116 & $4.21 \mathrm{E}-04$ & Ce 140 & $7.26 \mathrm{E}-01$ \\
\hline $\mathrm{Zr}$ & 92 & $4.43 E-01$ & Sn 117 & $2.18 \mathrm{E}-03$ & Ce141 & $2.17 E-18$ \\
\hline $\mathrm{Zr}$ & 93 & $7.72 E-01$ & $\operatorname{Sn} 118$ & $2.34 E-03$ & Ce 142 & $6.83 E-01$ \\
\hline $\mathbf{Z r}_{\mathbf{r}}$ & 94 & $4.93 \mathrm{E}-01$ & Sn 119 & $2.28 E-03$ & Ce 144 & $5.31 E-03$ \\
\hline $\mathrm{Zr}_{\mathbf{r}}$ & 95 & $8.12 \mathrm{E}-10$ & Sn 120 & $2.36 E-03$ & Pr141 & $6.80 E-01$ \\
\hline$Z_{r}$ & 96 & $4.95 E-01$ & Sn $121 M$ & $9.54 E-07$ & Pr 144 & $2.24 E-07$ \\
\hline Nb & 94 & $5.01 E-06$ & Sn 122 & $2.64 \mathrm{E}-03$ & $\operatorname{Pr} 144 \mathrm{M}$ & $1.13 E-09$ \\
\hline $\mathrm{Nb}$ & 95 & $9.35 E-10$ & Sn 123 & 5.53E-08 & Nd142 & $2.42 E-03$ \\
\hline $\mathrm{Nib}$ & $95 \mathrm{M}$ & $5.67 E-13$ & Sn 124 & 8.95E-03 & Nd143 & $8.12 E-01$ \\
\hline Mo & 95 & $5.05[-01$ & Sn 126 & $9.09 \mathrm{E}-03$ & Nd144 & $6.97 E-01$ \\
\hline Mo & 96 & $2.05 \mathrm{E}-03$ & Sb121 & $2.46 \mathrm{E}-03$ & Nd 145 & $4.49 E-01$ \\
\hline Mo & 97 & $4.83 E-01$ & $\mathrm{Sb} 123$ & 3.11E-03 & Nd146 & 3.64E-01 \\
\hline Mo & 98 & $4.88 E-01$ & Sb 124 & $7.03 E-15$ & Nd148 & $2.11 \mathrm{E}-01$ \\
\hline Mo & 100 & $5.33 \mathrm{E}-01$ & Sb125 & $1.39 \mathrm{E}-03$ & Nd150 & $8.44 \mathrm{E}-02$ \\
\hline Te & 99 & $2.51 \mathrm{E}-01$ & Sb126 & $4.85 E-11$ & Pm147 & 4. 47E-02 \\
\hline $\mathbf{R u}$ & 100 & $2.25 E-03$ & Sb126M & 3.30E-12 & Pm148 & $7.26 E-19$ \\
\hline & 101 & $2.17 E-01$ & Te122 & $8.60 E-05$ & $\operatorname{Pm} 148 \mathrm{M}$ & $8.10 E-17$ \\
\hline & 102 & $1.92 E-01$ & Te124 & $1.68 E-05$ & $\operatorname{Sm} 147$ & $1.45 E-01$ \\
\hline & 103 & $6.26 \mathrm{E}-16$ & Te125 & 8.82E-03 & $\operatorname{Sm} 148$ & $3.20 E-02$ \\
\hline
\end{tabular}

Appendix H

Table 21-21

Page 1 of 2

Date 9-82, REV 9

\section{Isotopic Content of Sludge Feed}


DPSP-80-1033

Isotopic Content of Sludje Feed

\begin{tabular}{|c|c|c|}
\hline ISOTOPE & GM/GAL & I SOTOPE \\
\hline $\operatorname{Sm} 149$ & $1.25 \mathrm{E}-02$ & T1208 \\
\hline Sm 150 & $1.77 \mathrm{E}-01$ & T1209 \\
\hline $\operatorname{Sin} 151$ & $1.59 \mathrm{E}-02$ & U 232 \\
\hline$S_{m} 152$ & $6.89 \mathrm{E}-02$ & U 283 \\
\hline $\operatorname{Sm} 151$ & 1. $13 \mathrm{E}-02$ & U 234 \\
\hline Eu151 & $6.70 E-04$ & U 285 \\
\hline Eu 152 & $3.61 E-05$ & V 236 \\
\hline Eu 153 & 8.55E-02 & V 288 \\
\hline Eu 154 & $3.97 \mathrm{E}-03$ & .ip236 \\
\hline Eu 155 & $1.76 \mathrm{E}-03$ & $N_{p} 237$ \\
\hline Tb159 & $3.52 E-04$ & Pu236 \\
\hline Tb 160 & $1.71 E-13$ & Pu237 \\
\hline T1206 & $3.57 \mathrm{E}-29$ & Pu238 \\
\hline T1207 & $8.81 E-19$ & pu239 \\
\hline
\end{tabular}

Appendis: it

Table 21-21

Page 2 of 2

Date 9-82, REI O

Total

GM/GAL

6.14E-15

$1.81 \mathrm{E}-23$

6.82E-06

$1.81 \mathrm{E}-06$

7.87E-02

7.09E-01

5.16E-01

2.54E+01

2.28E-09

2.16E-02

2. $00 \mathrm{E}-07$

$6.44 \mathrm{E}-19$

7.52E-02

$1.95 \mathrm{E}-01$
ISOTO?

Pu2:0

Pu241

Pu242

Am21 1

Am242

Am242:

Am243

$\mathrm{Cm}_{\mathrm{m}} 242$

$\mathrm{C}_{\mathrm{m} 243}$

$\mathrm{Cm}_{\mathrm{m} 244}$

$C_{m 245}$

$\mathrm{C}_{\mathrm{m} 246}$

$\mathrm{C}_{\mathrm{m} 247}$

Cm24S
$\frac{G y \cdot \operatorname{siti}}{3.35 i-02}$

1. $4 ! E-C 2$

2.71E-00

5.115-03

S. $0 . \mathrm{E}-11$

$2.515-06$

4.96E-05

1. $82 \mathrm{E}-08$

1. $85 \mathrm{E}-07$

3. $465:-06$

6. C3E-08

2. $96[-09$

1.21E-11

2.705: -13

4.14E+01 GM/GAL 
DPSP- $90-1033$

Appendix 11

Table 21-22

Page 1 of 1

Date 9-82, REV 9

Radionuclide Content of Sludge Feed

\begin{tabular}{|c|c|c|c|c|c|}
\hline ISOTOPE & CI/GAL & ISOTOPE & CI/GAL & ISOTOPE & CI/GAL \\
\hline H 3 & $6.81 E-05$ & $\mathrm{Sb} 124$ & $1.23 \mathrm{E}-10$ & Eu 155 & $8.21 E-01$ \\
\hline C 14 & $1.32 E-09$ & Sb125 & $1.48 E+00$ & Tb160 & $1.93 E-09$ \\
\hline Cr 51 & $1.53 E-19$ & Sb126 & $8.64 E-06$ & T 1208 & $1.81 E-06$ \\
\hline Co 60 & $2.94 E-01$ & Sb126M & $2.60 E-04$ & U 232 & $1.46 \mathrm{E}-04$ \\
\hline Ni 59 & 2.89E-03 & Te125M & $3.42 \mathrm{E}-01$ & v 233 & $1.74 E-08$ \\
\hline $\mathrm{Ni} 63$ & $2.97 E-01$ & Te127 & $1.49 E-04$ & U 234 & $4.60 E-04$ \\
\hline Se 79 & $2.34 E-04$ & Te127M & $1.53 E-04$ & U 285 & $1.53 E-06$ \\
\hline $\mathrm{Rb} 87$ & $1.56 \mathrm{E}-08$ & Te129 & $3.80 E-15$ & U 236 & $3.84 E-05$ \\
\hline Sr 89 & $9.09 \mathrm{E}-08$ & Te129M & $5.91 E-15$ & V 238 & 8.53E-06 \\
\hline Sr 90 & $5.17 \mathrm{E}+01$ & I 129 & $1.24 \mathrm{E}-05$ & Np236 & $3.00 E-11$ \\
\hline 90 & $5.32 E+01$ & Cs134 & 3.03E-01 & Np287 & $1.52 E-05$ \\
\hline 191 & $1.65 \mathrm{E}-06$ & Cs135 & $5.28 E-06$ & Pu236 & $1.06 \mathrm{E}-04$ \\
\hline Zr 93 & $1.94 \mathrm{E}-03$ & Cs 137 & $2.86 \mathrm{E}+00$ & Pu237 & $7.77 \mathrm{E}-15$ \\
\hline Zr $\$ 5$ & $1.74 E-05$ & $\mathrm{Ba} 137 \mathrm{M}$ & $2.70 E+00$ & Pu238 & $1.29 \mathrm{E}+00$ \\
\hline $\mathrm{Nb} 94$ & $9.40 E-07$ & Ce141 & $6.18 \mathrm{E}-14$ & Pu239 & $1.21 E-02$ \\
\hline Nb 95 & $3.67 E-05$ & Ce142 & $1.64 \mathrm{E}-08$ & Pu240 & $7.70 \mathrm{E}-03$ \\
\hline $\mathrm{Nb} 95 \mathrm{M}$ & $2.15 E-07$ & Cel 144 & $1.69 E+01$ & Pu241 & $1.45 E+00$ \\
\hline Te 99 & $4.26 E-03$ & $\operatorname{Pr} 144$ & $1.69 \mathrm{E}+01$ & Pu242 & $1.06 \mathrm{E}-05$ \\
\hline Ru 103 & $2.02 E-11$ & Pr144M & $2.04 E-01$ & Am241 & $1.86 E-02$ \\
\hline$R u 105$ & $2.69 \mathrm{E}+00$ & Nd144 & $8.28 E-18$ & Am242 & $2.45 \mathrm{E}-05$ \\
\hline Rh 103is & $1.96 E-11$ & $P_{m} 147$ & $4.15 E+01$ & Am242M & $2.47 E-05$ \\
\hline Rh 106 & $2.64 \mathrm{E}+00$ & $P_{m} 148$ & $1.19 \mathrm{E}-13$ & Am243 & $9.89 E-06$ \\
\hline Pd107 & $1.57 E-05$ & $P_{m} 148 M$ & $1.73 E-12$ & $C_{m} 242$ & 6.03E-05 \\
\hline Ag $110 \mathrm{M}$ & $2.25 E-02$ & $\sin 147$ & $3.37 E-09$ & $C_{m} 243$ & $9.53 \mathrm{E}-06$ \\
\hline Cd113 & $6.52 E-17$ & $\operatorname{Sm} 148$ & $9.77 E-15$ & $C_{m} 244$ & $2.80 \mathrm{E}-04$ \\
\hline Cd115M & $1.57 \mathrm{E}-12$ & $\operatorname{Sm} 149$ & $8.00 E-15$ & $C m 245$ & $1.14 \mathrm{E}-08$ \\
\hline $\operatorname{Sn} 121: i$ & E. 13E-05 & Sm151 & $4.19 \mathrm{E}-01$ & $C_{m} 246$ & $9.10 \mathrm{E}-10$ \\
\hline $\operatorname{Sn} 123$ & $4.55 \mathrm{E}-04$ & Eu 152 & $6.87 \mathrm{E}-03$ & Cm247 & $1.12 E-15$ \\
\hline $\operatorname{Sn} 126$ & $2.58 E-04$ & Eu 154 & $1.07 E+00$ & $C_{m} 248$ & $1.17 E-15$ \\
\hline
\end{tabular}

Total Activity Decay Hent

Total Primary

Total Gammas
1.99E+02 CI/GAL

5.74E-01 WATT/GAL 3.71E-02 WATT/GAL 


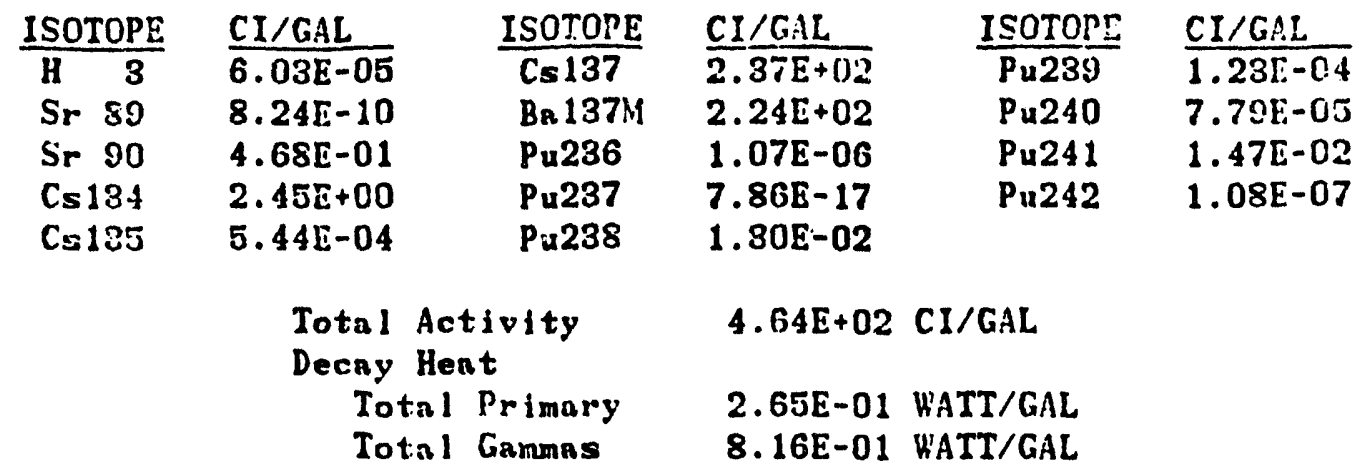


DPSP-80-1033

Radionuclide Content of Sludge-Only Glass

\begin{tabular}{|c|c|c|c|c|c|}
\hline ISOTOPE & CI/LB & ISOTOPE & CI/LB & ISOTOPE & $C I / L B$ \\
\hline Cr 51 & $\overline{3.34 E-20}$ & $5 b 125$ & $\overline{3.12 E-01}$ & $T b 160$ & $\overline{4.21 \mathrm{E}-10}$ \\
\hline Co 60 & $6.42 E-02$ & Sb126 & $7.98 E-07$ & T1208 & $3.95 E-07$ \\
\hline Ni 59 & E. $22 E-04$ & Sb126M & $5.66 \mathrm{E}-0 \mathrm{E}$ & U 232 & $3.19 \mathrm{E}-05$ \\
\hline Ni 63 & $6.48 E-02$ & Te125M & $7.27 E-02$ & U 233 & $3.80 E-09$ \\
\hline Se 79 & $4.97 E-05$ & Te 127 & $8.18 E-05$ & U 234 & $1.00 \mathrm{E}-04$ \\
\hline $\mathrm{Rb} 87$ & $3.31 E-09$ & $\mathrm{Te} 127 \mathrm{M}$ & $8.24 E-05$ & U 235 & $3.34 E-07$ \\
\hline Sr 89 & $1.98 \mathrm{E}-08$ & Te129 & $8.07 E-16$ & U 286 & $7.28 E-06$ \\
\hline Sr 90 & $1.13 E+01$ & Te129M & $1.26 \mathrm{E}-1 \mathrm{E}$ & U 238 & $1.86 E-06$ \\
\hline Y 90 & $1.16 E+01$ & Cs134 & $6.25 E-02$ & Np236 & $6.55 E-12$ \\
\hline $\begin{array}{l}Y \\
1\end{array}$ & $3.61 E-07$ & Cs185 & $1.09 \mathrm{E}-06$ & $N_{p 2} 237$ & 8.32E-06 \\
\hline Zr. 93 & $4.23 E-04$ & Cs137 & $5.90 E-01$ & Pu236 & $2.31 E-05$ \\
\hline Zr 95 & $3.80 E-06$ & $\mathrm{Ba} 137 \mathrm{M}$ & 5.58E-01 & Pu237 & $1.69 E-15$ \\
\hline $\mathrm{Nb} 94$ & $2.05 E-07$ & Ce141 & $1.85 E-14$ & Pu288 & $2.81 E-01$ \\
\hline No 95 & $8.00 E-06$ & Cel42 & $8.58 E-09$ & Pu239 & $2.64 E-03$ \\
\hline Nb 95M & $4.69 E-08$ & Ce144 & $3.70 E+00$ & Pu240 & $1.68 \mathrm{E}-03$ \\
\hline Tc 99 & $9.05 E-04$ & Pr 144 & $3.70 \mathrm{E}+00$ & Pu241 & 8.17E-01 \\
\hline Ru 103 & $4.13 E-12$ & $\operatorname{Pr} 144 M$ & $4.45 E-02$ & Pu242 & $2.32 E-06$ \\
\hline Ru106 & $5.48 E-01$ & Nd144 & $1.81 \mathrm{E}-13$ & Am241 & $4.05 E-03$ \\
\hline Rh103M & $4.29 E-12$ & $P_{m} 147$ & $9.05 E+00$ & Am242 & $5.35 \mathrm{E}-06$ \\
\hline $\mathrm{RL}_{2} 106$ & $5.765-01$ & $P_{m} 148$ & $2.60 E-14$ & $\operatorname{Am} 242 M$ & $5.38 E-06$ \\
\hline Pd107 & $3.43 E-06$ & $P_{m} 148 M$ & $8.78 E-13$ & Am243 & $2.16 \mathrm{E}-05$ \\
\hline $\mathrm{Ag} 110 \mathrm{M}$ & $4.90 \mathrm{E}-03$ & $\operatorname{Sm} 147$ & $7.35 E-10$ & $C_{m} 242$ & $1.31 \mathrm{E}-05$ \\
\hline Cd113 & $1.42 E-17$ & $S_{m} 148$ & $2.13 E-15$ & $C_{m} 243$ & $2.08 E-06$ \\
\hline Cd115:M & $3.44 E-13$ & $\operatorname{Sm} 149$ & $6.56 E-16$ & $C_{m} 244$ & $6.10 E-05$ \\
\hline$S n 121 M$ & $1.12 E-05$ & Sm151 & $9.15 E-02$ & Cm245 & $2.49 E-09$ \\
\hline $\operatorname{Sn} 123$ & $9.92 \mathrm{E}-05$ & Eu 152 & $1.39 E-03$ & $C_{m} 246$ & $1.99 E-10$ \\
\hline $\operatorname{Sn} 126$ & $5.63 E-05$ & Eu 154 & $2.34 E-01$ & $\mathrm{Cm} 247$ & $2.44 E-16$ \\
\hline \multirow[t]{3}{*}{ Sb 124} & $2.68 \mathrm{E}-11$ & Eu 155 & $1.79 E-01$ & $C_{m} 248$ & $2.55 E-16$ \\
\hline & \multicolumn{2}{|c|}{$\begin{array}{l}\text { Total Activity } \\
\text { Decay Heat }\end{array}$} & \multicolumn{2}{|c|}{$4.33 \mathrm{E}+01 \mathrm{CI} / \mathrm{LB}$} & \\
\hline & $\begin{array}{l}\text { To } \\
\text { To }\end{array}$ & $\begin{array}{l}\text { tal Primary } \\
\text { tal Ganmas }\end{array}$ & $\begin{array}{l}1.25 E-01 \\
7.96 E-03\end{array}$ & $\begin{array}{l}\text { WATTS/LB } \\
\text { WATTS/LB }\end{array}$ & \\
\hline
\end{tabular}

Appendix H

Table 21-24

Page 1 of 1

Date 9-32, REV 9 
DPSP-80-1033

Appendix $\mathrm{H}$

Toble 21-25

Page 1 of 1

Date 9-82, REV 9

Radionuclide Content of SIudge-Supernate Glass

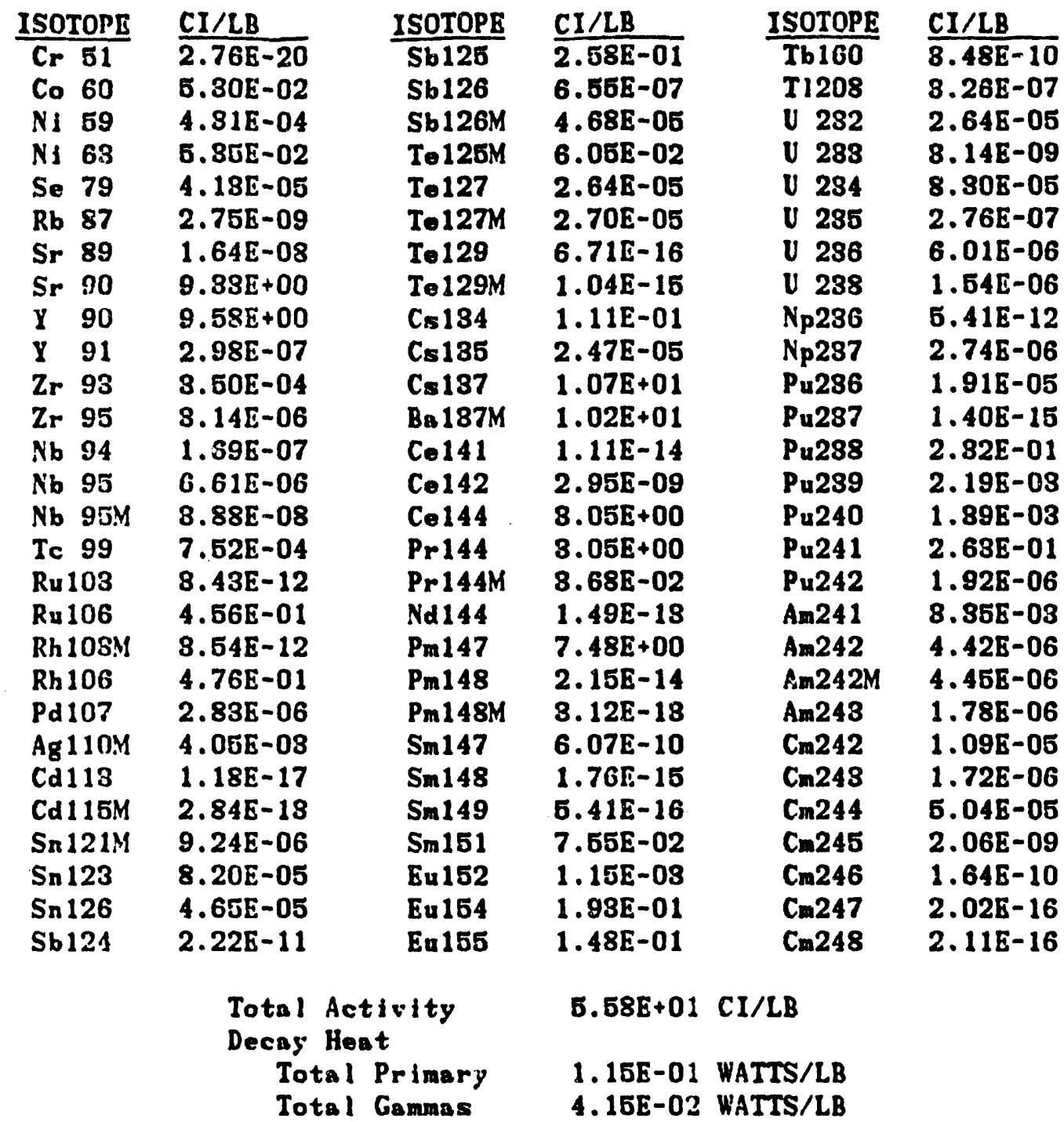


EST IMATED ATMOSPHERIC RELEASES, SLUDGE-ONLY OPERATION

\begin{tabular}{|c|c|c|c|c|c|}
\hline ISOTOPE & CUPTFS & ISOTOPR & CURIES & TSOTOPE & CURTES \\
\hline H 8 & $\overline{6.73 E+00}$ & Sb125 & $8.59 \mathrm{E}-08$ & U232 & $\overline{8.79 E-12}$ \\
\hline 14 & $1.88 \mathrm{E}-03$ & Sb126 & $2.18 E-18$ & U 283 & $1.05 E-15$ \\
\hline Co 60 & $1.76[-08$ & Sb126M & $1.56 E-11$ & 284 & $2.76 E-11$ \\
\hline$N_{i} 59$ & $1.43 E-10$ & Te125M & $2.18 E-07$ & 285 & $9.19 z-14$ \\
\hline Ni 63 & $1.78 E-08$ & To127. & $9.28 E-11$ & 286 & $2.00 E-12$ \\
\hline Se 79 & $1.45 E-10$ & To127M & $9.47 E-11$ & 288 & E. $12 E-13$ \\
\hline Rb 87 & $9.66 \mathrm{E}-15$ & I 129 & 6. $41 E-07$ & $N_{p} 286$ & $1.80 E-18$ \\
\hline Sr 89 & $5.45 E-15$ & Cs 184 & $1.83 E-07$ & Np287 & $9.14 E-13$ \\
\hline Sr 90 & 8.10E-06 & $C=185$ & $8.19 \mathrm{E}-12$ & Pu236 & $6.86 E-12$ \\
\hline 90 & $8.19 E-06$ & Cs137 & $1.78 \mathrm{E}-06$ & Pu288 & $7.72 E-08$ \\
\hline Y 91 & $9.92 E-14$ & $\mathrm{Ba} 187 \mathrm{M}$ & $1.68 E-\mathrm{CS}$ & Pu289 & $7.27 E-10$ \\
\hline Zr 93 & $1.17 E-10$ & Ce142 & $9.84 E-16$ & Pu240 & $4.62 E-10$ \\
\hline Zr 95 & $1.05 \mathrm{E}-12$ & Co144 & $1.02 E-06$ & Pu241 & $8.73 E-08$ \\
\hline Nb 94 & $5.64 E-14$ & $\operatorname{Pr} 144$ & $1.02 E-06$ & Pu242 & $6.38 E-13$ \\
\hline Nb 95 & $2.20 \mathrm{E}-12$ & $\operatorname{Pr} 144 M$ & $1.22 E-08$ & Am241 & $1.11 E-09$ \\
\hline Nb $95 \mathrm{M}$ & $1.29 E-14$ & Nd144 & $4.97 E-20$ & Am242 & $1.47 E-12$ \\
\hline Tc 99 & $2.64 E-09$ & $P_{m} 147$ & $2.49 E-06$ & $A m 242 M$ & $1.48 \mathrm{E}-12$ \\
\hline Ru103 & $2.42 E-17$ & $\operatorname{Sm} 147$ & $2.02 E-16$ & $A=243$ & $6.93 E-13$ \\
\hline Ru 106 & $8.21 E-06$ & $\operatorname{Sm} 148$ & $5.87 \mathrm{E}-22$ & $C_{m} 242$ & $3.61 E-12$ \\
\hline Rh 106 & $1.58 \mathrm{E}-07$ & $S m 149$ & $1.80 E-22$ & $\mathrm{Cm}_{\mathrm{m}} 248$ & $5.72 E-13$ \\
\hline$P d 107$ & $9.44 E-13$ & Sm151 & $2.52 E-08$ & $C_{m} 244$ & $1.68 E-11$ \\
\hline Ag $110 M$ & $2.48 E-09$ & Eu152 & $3.82 E-10$ & $C_{m} 245$ & $6.85 E-16$ \\
\hline Cd113 & $3.91 E-24$ & Eu154 & $6.43 E-08$ & $\operatorname{cm} 246$ & $5.46 E-17$ \\
\hline Sn121M & $3.08 E-12$ & Eu 155 & $4.93 E-08$ & $\mathrm{C}=247$ & $6.72 E-23$ \\
\hline Sn 123 & $2.73 E-11$ & Tb160 & $1.16 \mathrm{E}-16$ & $\operatorname{cm} 248$ & $7.01 E-23$ \\
\hline & (4) & & & & \\
\hline
\end{tabular}

Total Estimated Annual Releases

$\begin{array}{lll}\text { Tritium } & 6.73 E+00 & \text { CURIES } \\ \text { Fission Products } & 1.90 E-03 & \text { CURIES } \\ \text { Uranium } & 8.90 E-11 & \text { CURIES } \\ \text { Transuranics } & 1.67 E-07 & \text { CURIES }\end{array}$




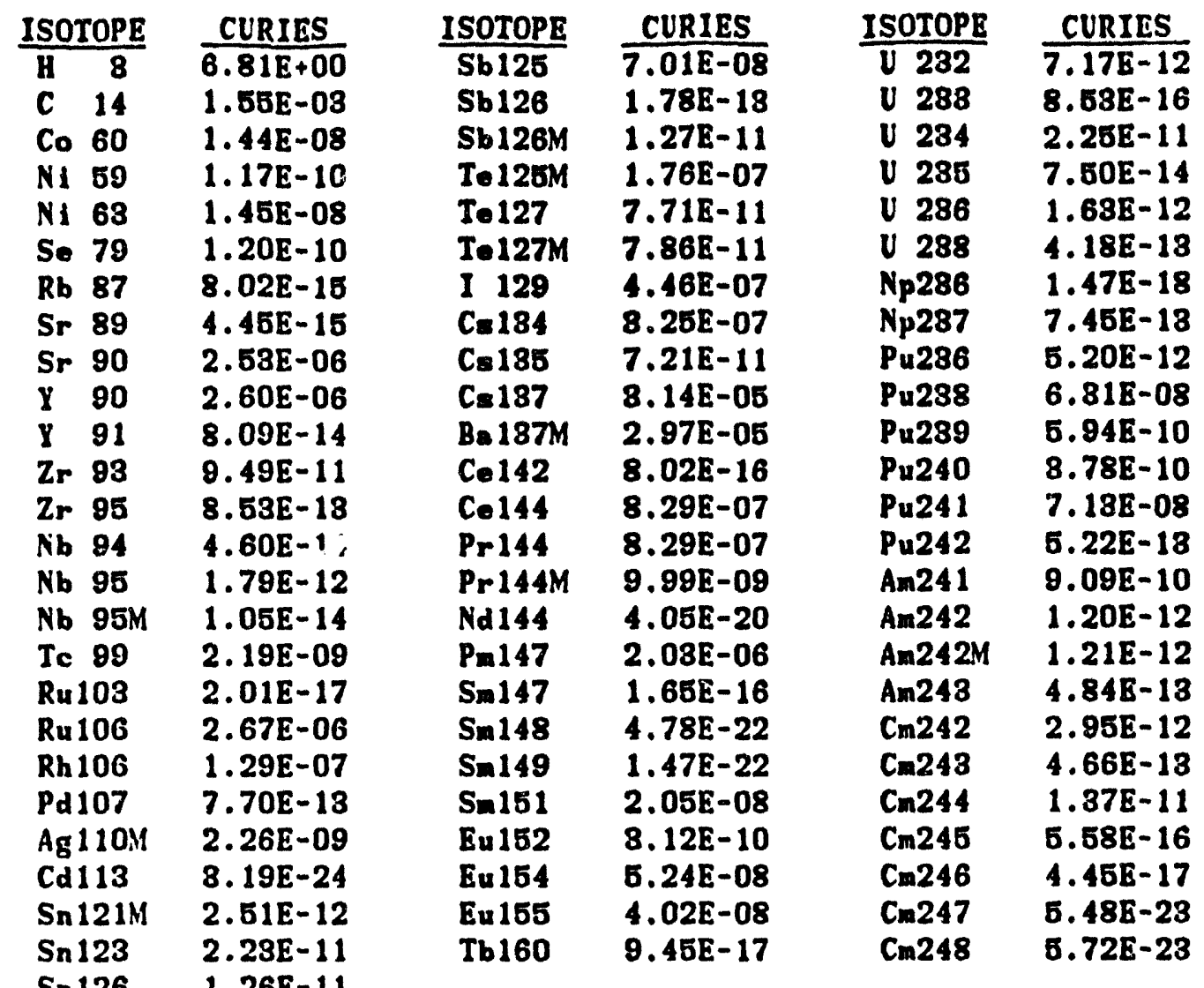

Total Estimated Annusl Releases

$\begin{array}{lll}\text { Tritium } & 6.81 E+00 & \text { CURIES } \\ \text { Fission Products } & 1.62 E-03 & \text { CURIES } \\ \text { Uranium } & 8.18 E-11 & \text { CURIES } \\ \text { Trnnsuranics } & 1.86 E-07 & \text { CURIES }\end{array}$



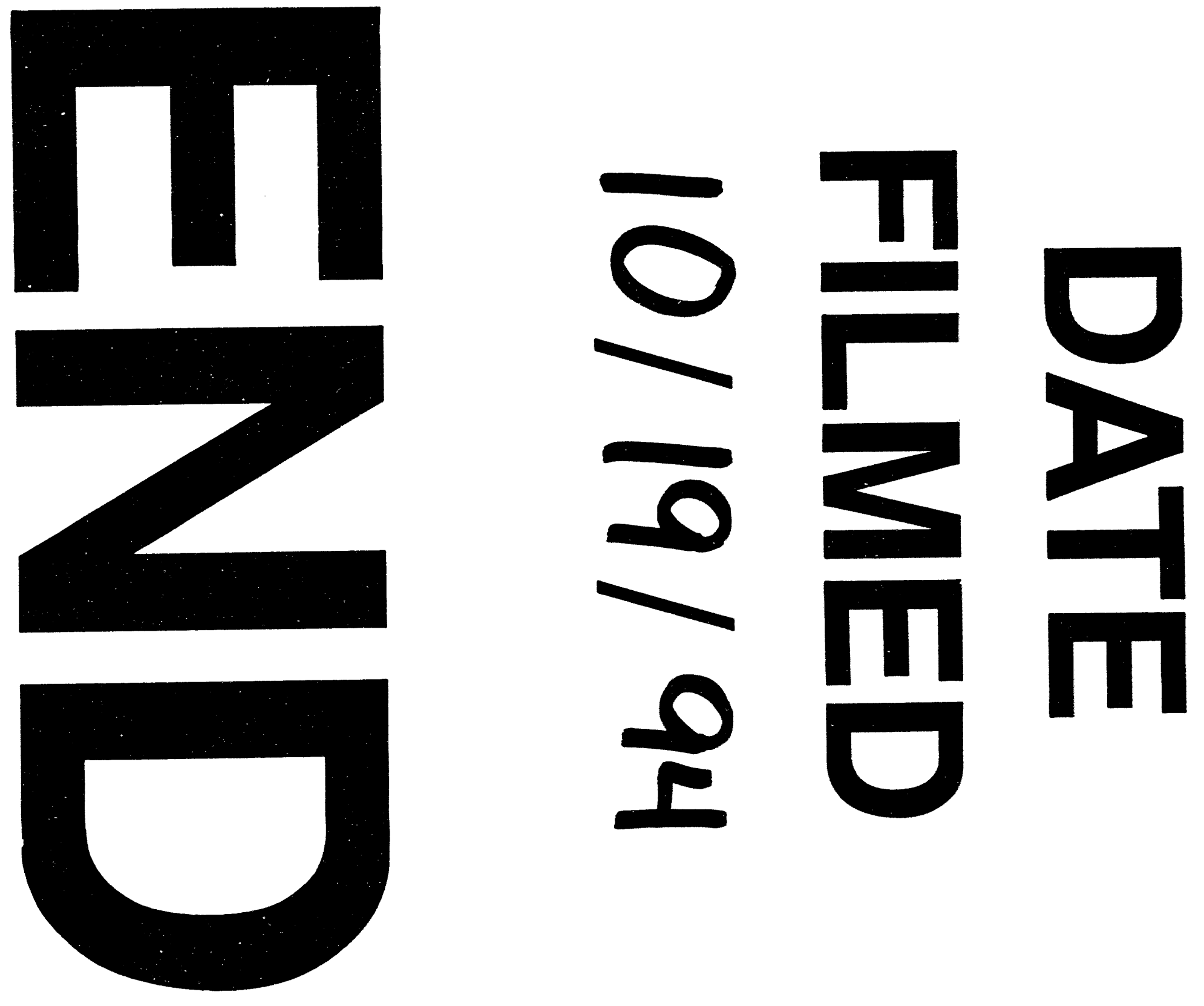


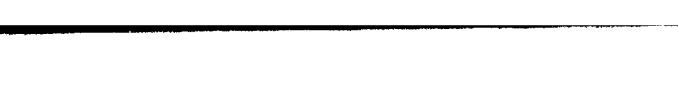

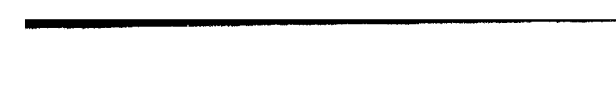

5





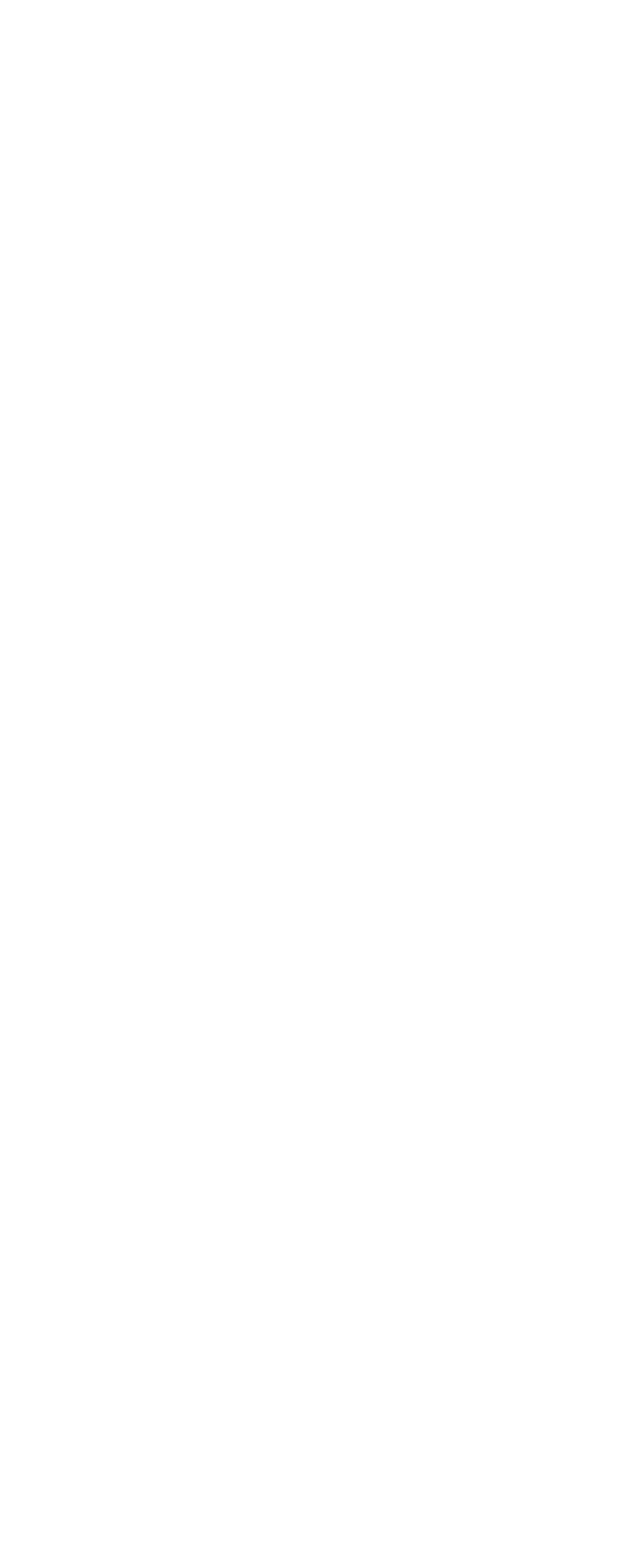

